\title{
Financial Statistics of Major U.S. Publicly Owned Electric Utilities 1993
}

\section{February 1995}

Energy Information Administration

Office of Coal, Nuclear, Electric and Alternate Fuels

U.S. Department of Energy

Washington, DC 20585 


\section{DISCLAIMER}

This report was prepared as an account of work sponsored by an agency of the United States Government. Neither the United States Government nor any agency thereof, nor any of their employees, make any warranty, express or implied, or assumes any legal liability or responsibility for the accuracy, completeness, or usefulness of any information, apparatus, product, or process disclosed, or represents that its use would not infringe privately owned rights. Reference herein to any specific commercial product, process, or service by trade name, trademark, manufacturer, or otherwise does not necessarily constitute or imply its endorsement, recommendation, or favoring by the United States Government or any agency thereof. The views and opinions of authors expressed herein do not necessarily state or reflect those of the United States Government or any agency thereof. 


\section{DISCLAIMER}

Portions of this document may be illegible in electronic image products. Images are produced from the best available original document. 


\section{Contacts}

The Financial Statistics of Major U.S. Publicly Owned Electric Utilities is prepared annually by the Survey Management Division; Office of Coal, Nuclear, Electric and Alternate Fuels (CNEAF); Energy Information Administration (EIA); U.S. Department of Energy (DOE).

General information regarding the contents of this publication may be obtained from the National Energy Information Center (202/586-8800). General information about the data appearing in this publica- tion may be obtained from Howard L. Walton (202/254-5500), Director of the Survey Management Division, or Fred Mayes (202/254-5300), Chief of the Renewable and Financial Data Systems and Outreach Branch.

Questions and comments should be referred to Roger L. Sacquety (202/254-5440), Financial Systems Team Leader. Specific information about data contained in the Form EIA-412 may be obtained from Charlene Harris-Russell (202/254-5437). 


\section{Contents}

Summary Statistics of Major U.S. Publicly Owned Electric Utilities

Detailed Statistics of Major U.S. Publicly Owned Electric Utilities

Appendices

A. Summary Statistics of U.S. Rural Electric Cooperative Borrowers

B. Major U.S. Publicly Owned Electric Utility Respondents

C. Major U.S. Generator/Nongenerator Respondents by June 30 and December 31 Fiscal Years and by All Respondents, 1989-1993

D. Regulation of U.S. Publicly Owned Electric Utilities

E. Technical Notes

F. Glossary 


\section{Tables}

Page

1. Selected Electric Utility Data by Ownership, $1993 \quad \ldots \ldots \ldots \ldots \ldots \ldots \ldots \ldots \ldots \ldots \ldots \ldots$

2. Selected Data for Major U.S. Publicly Owned and Federal Electric Utilities Compared to All U.S. Publicly Owned and Federal Electric Utilities, $1993 \quad \ldots \ldots \ldots \ldots \ldots \ldots \ldots \ldots \ldots \ldots \ldots \ldots \ldots$

3. Ten Largest U.S. Publicly Owned Generator Electric Utilities Ranked by Megawatthour Sales to Ultimate

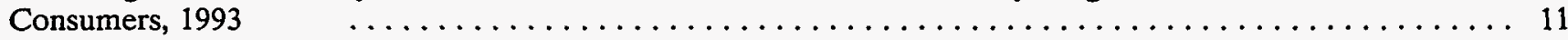

4. Ten Largest U.S. Publicly Owned Generator Electric Utilities Ranked by Megawatthour Sales for Resale, 1993

5. Composite Statement of Income for Major U.S. Publicly Owned Generator Electric Utilities, 1989-1993

6. Composite Balance Sheet for Major U.S. Publicly Owned Generator Electric Utilities at End of Period, 1989-1993

7. Composite Financial Indicators for Major U.S. Publicly Owned Generator Electric Utilities, 1989-1993

8. Electric Operation and Maintenance Expenses for Major U.S. Publicly Owned Generator Electric Utilities,

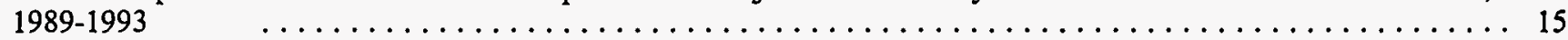

9. Electric Utility Plant for Major U.S. Publicly Owned Generator Electric Utilities at End of Period,

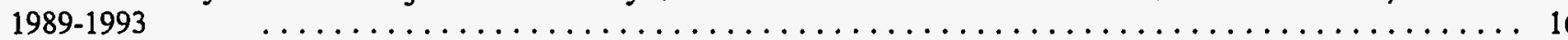

10. Number of Consumers, Sales, and Operating Revenue for Major U.S. Publicly Owned Generator Electric

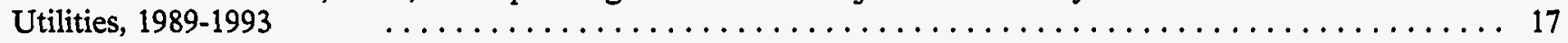

11. Electric Energy Account for Major U.S. Publicly Owned Generator Electric Utilities, 1989-1993 $\quad$.. 18

12. Ten Largest U.S. Publicly Owned Nongenerator Electric Utilities Ranked by Megawatthour Sales to

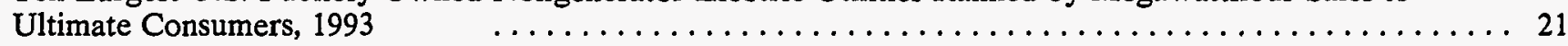

13. Ten Largest U.S. Publicly Owned Nongenerator Electric Utilities Ranked by Megawatthour Sales for

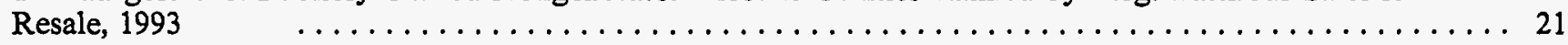

14. Composite Statement of Income for Major U.S. Publicly Owned Nongenerator Electric Utilities, 1989-1993 22

15. Composite Balance Sheet for Major U.S. Publicly Owned Nongenerator Electric Utilities at End of Period,

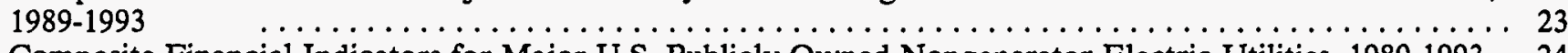

16. Composite Financial Indicators for Major U.S. Publicly Owned Nongenerator Electric Utilities, 1989-1993 24

17. Electric Operation and Maintenance Expenses for Major U.S. Publicly Owned Nongenerator Electric Utilities, 1989-1993

18. Electric Utility Plant for Major U.S. Publicly Owned Nongenerator Electric Utilities at End of Period,

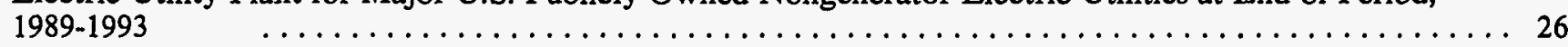

19. Number of Consumers, Sales, and Operating Revenue for Major U.S. Publicly Owned Nongenerator

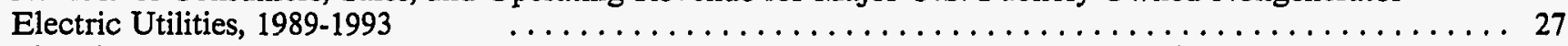

20. Electric Energy Account for Major U.S. Publicly Owned Nongenerator Electric Utilities, 1989-1993 28

21. Statement of Income by Major U.S. Publicly Owned Electric Utility Within State, $1993 \quad \ldots \ldots$

22. Balance Sheet by Major U.S. Publicly Owned Electric Utility Within State at End of Period, $1993 \quad 113$

23. Electric Operation and Maintenance Expenses by Major U.S. Publicly Owned Electric Utility Within

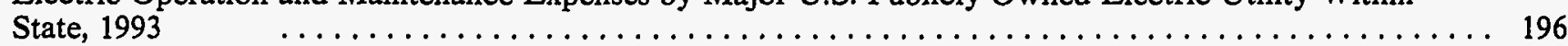

24. Electric Utility Plant by Major U.S. Publicly Owned Electric Utility Within State at End of Period, 1993

25. Number of Consumers, Sales, and Operating Revenue by Major U.S. Publicly Owned Electric Utility

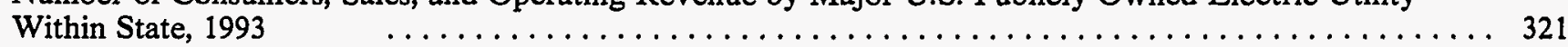

26. Electric Energy Account by Major U.S. Publicly Owned Electric Utility Within State, $1993 \quad \ldots \ldots 363$

27. Statement of Income by U.S. Federal Electric Utility, $1993 \quad \ldots \ldots \ldots \ldots \ldots \ldots \ldots \ldots \ldots \ldots . \ldots 45$

28. Balance Sheet by U.S. Federal Electric Utility on September 30, $1993 \quad \ldots \ldots \ldots \ldots \ldots \ldots \ldots 453$

29. Electric Operation and Maintenance Expenses by U.S. Federal Electric Utility, $1993 \ldots \ldots \ldots \ldots \ldots$

30. Electric Utility Plant by U.S. Federal Electric Utility on September 30, $1993 \quad \ldots \ldots \ldots \ldots \ldots \ldots 457$

31. Number of Consumers, Sales, and Operating Revenue by U.S. Federal Electric Utility, $1993 \quad$... 458

32. Electric Energy Account by U.S. Federal Electric Utility, $1993 \quad \ldots \ldots \ldots \ldots \ldots \ldots \ldots \ldots \ldots .459$

A1. Composite Statement of Income for the U.S. Cooperative Borrowers, 1989-1993 _. . . . . . . . . 464

A2. Composite Balance Sheet for the U.S. Cooperative Borrowers on December 31, 1989-1993 _ . ... 464

A3. Electric Operation and Maintenance Expenses for the U.S. Cooperative Borrowers, 1989-1993 $\quad \ldots \quad 465$

A4. Number of Consumers, Sales, and Operating Revenue for the U.S. Cooperative Distributor Borrowers,

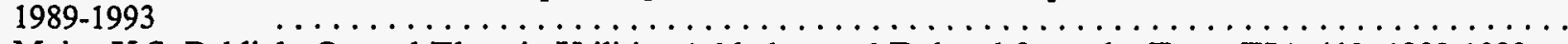

B1. Major U.S. Publicly Owned Electric Utilities Added to and Deleted from the Form EIA-412, 1989-1993

B2. Major U.S. Publicly Owned Electric Utilities by Fiscal Year and Generator/Nongenerator Status from

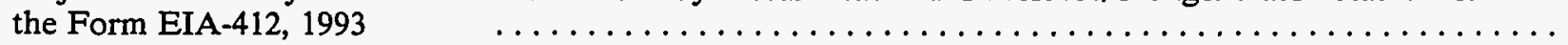


B3. Major U.S. Publicly Owned Electric Utilities That Submitted the Form EIA-412, 1993

C1. Ten Largest U.S. Publicly Owned Generator Electric Utilities Ranked by Megawatthour Sales to

Ultimate Consumers with Financial Year Ending on June 30, 1993

C2. Ten Largest U.S. Publicly Owned Generator Electric Utilities Ranked by Megawatthour Sales for Resale with Financial Year Ending on June 30, 1993

C3. Composite Statement of Income for Major U.S. Publicly Owned Generator Electric Utilities with

Financial Year Ending on June 30, 1989-1993

C4. Composite Balance Sheet for Major U.S. Publicly Owned Generator Electric Utilities with Financial Year Ending on June 30 at End of Period, 1989-1993

C5. Composite Financial Indicators for Major U.S. Publicly Owned Generator Electric Utilities with Financial Year Ending on June 30, 1989-1993

C6. Electric Operation and Maintenance Expenses for Major U.S. Publicly Owned Generator Electric Utilities with Financial Year Ending on June 30, 1989-1993

C7. Electric Utility Plant for Major U.S. Publicly Owned Generator Electric Utilities with Financial Year Ending on June 30 at End of Period, 1989-1993

C8. Number of Consumers, Sales, and Operating Revenue for Major U.S. Publicly Owned Generator Electric

Utilities with Financial Year Ending on June 30, $1989-1993 \quad \ldots \ldots \ldots \ldots \ldots \ldots \ldots \ldots \ldots \ldots$ C9. Electric Energy Account for Major U.S. Publicly Owned Generator Electric Utilities with Financial Year
Ending on June 30, $1989-1993 \quad \ldots \ldots \ldots \ldots \ldots \ldots \ldots \ldots \ldots \ldots \ldots \ldots \ldots \ldots \ldots \ldots \ldots \ldots \ldots \ldots \ldots \ldots \ldots \ldots$

C10. Ten Largest U.S. Publicly Owned Generator Electric Utilities Ranked by Megawatthour Sales to Ultimate Consumers with Financial Year Ending on December 31, $1993 \quad \ldots \ldots \ldots \ldots \ldots \ldots$

C11. Ten Largest U.S. Publicly Owned Generator Electric Utilities Ranked by Megawatthour Sales for Resale with Financial Year Ending on December 31, 1993

C12. Composite Statement of Income for Major U.S. Publicly Owned Generator Electric Utilities with Financial Year Ending on December 31, 1989-1993

C13. Composite Balance Sheet for Major U.S. Publicly Owned Generator Electric Utilities with Financial Year Ending on December 31 at End of Period, 1989-1993

C14. Composite Financial Indicators for Major U.S. Publicly Owned Generator Electric Utilities with Financial Year Ending on December 31, 1989-1993

C15. Electric Operation and Maintenance Expenses for Major U.S. Publicly Owned Generator Electric Utilities with Financial Year Ending on December 31, 1989-1993

C16. Electric Utility Plant for Major U.S. Publicly Owned Generator Electric Utilities with Financial Year
Ending on December 31 at End of Period, $1989-1993 \quad \ldots \ldots \ldots \ldots \ldots \ldots \ldots \ldots \ldots \ldots \ldots \ldots \ldots \ldots \ldots$

C16. Electric Utility Plant for Major U.S. Publicly Owned Generator Electric Utilities with Financial Year
Ending on December 31 at End of Period, $1989-1993 \quad \ldots \ldots \ldots \ldots \ldots \ldots \ldots \ldots \ldots \ldots \ldots \ldots \ldots \ldots$

C17. Number of Consumers, Sales, and Operating Revenue for Major U.S. Publicly Owned Generator Electric Utilities with Financial Year Ending on December 31, 1989-1993

C18. Electric Energy Account for Major U.S. Publicly Owned Generator Electric Utilities with Financial Year Ending on December 31, 1989-1993

C19. Ten Largest U.S. Publicly Owned Nongenerator Electric Utilities Ranked by Megawatthour Sales to Ultimate Consumers with Financial Year Ending on June 30, 1993

C20. U.S. Publicly Owned Nongenerator Electric Utilities Ranked by Megawatthour Sales for Resale with

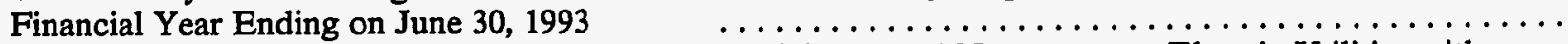

C21. Composite Statement of Income for Major U.S. Publicly Owned Nongenerator Electric Utilities with Financial Year Ending on June 30, 1989-1993

C22. Composite Balance Sheet for Major U.S. Publicly Owned Nongenerator Electric Utilities with Financial Year Ending on June 30 at End of Period, 1989-1993

C23. Composite Financial Indicators for Major U.S. Publicly Owned Nongenerator Electric Utilities with Financial Year Ending on June 30, 1989-1993

C24. Electric Operation and Maintenance Expenses for Major U.S. Publicly Owned Nongenerator Electric Utilities with Financial Year Ending on June 30, 1989-1993

C25. Electric Utility Plant for Major U.S. Publicly Owned Nongenerator Electric Utilities with Financial Year Ending on June 30 at End of Period, 1989-1993

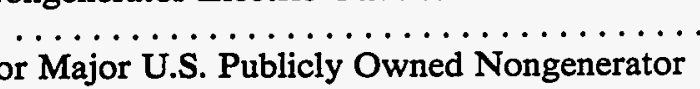

C26. Number of Consumers, Sales, and Operating Revenue for Major U.S. Publicly Owned Nongenerator Electric Utilities with Financial Year Ending on June 30, 1989-1993 $\quad \ldots \ldots \ldots \ldots \ldots \ldots \ldots$

C27. Electric Energy Account for Major U.S. Publicly Owned Nongenerator Electric Utilities with Financial Year Ending on June 30, 1989-1993

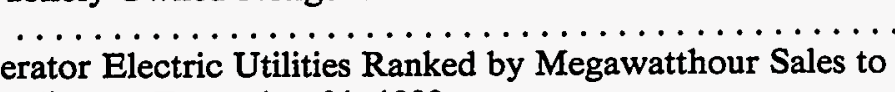

C28. Ten Largest U.S. Publicly Owned Nongenerator Electric Utilities Ranked by Megawatthour Sales to
Ultimate Consumers with Financial Year Ending on December 31, $1993 \quad \ldots \ldots \ldots \ldots \ldots . . . . . . .$.

C29. Ten Largest U.S. Publicly Owned Nongenerator Electric Utilities Ranked by Megawatthour Sales for Resale with Financial Year Ending on December 31, $1993 \quad \ldots \ldots \ldots \ldots \ldots \ldots \ldots \ldots \ldots$

C30. Composite Statement of Income for Major U.S. Publicly Owned Nongenerator Electric Utilities with Financial Year Ending on December 31, 1989-1993

C31. Composite Balance Sheet for Major U.S. Publicly Owned Nongenerator Electric Utilities with Financial Year Ending on December 31 at End of Period, 1989-1993

C32. Composite Financial Indicators for Major U.S. Publicly Owned Nongenerator Electric Utilities with Financial Year Ending on December 31, 1989-1993 
C33. Electric Operation and Maintenance Expenses for Major U.S. Publicly Owned Nongenerator Electric Utilities with Financial Year Ending on December 31, 1989-1993 .............................

C34. Electric Utility Plant for Major U.S. Publicly Owned Nongenerator Electric Utilities with Financial Year Ending on December 31 at End of Period, 1989-1993

C35. Number of Consumers, Sales, and Operating Revenue for Major U.S. Publicly Owned Nongenerator Electric Utilities with Financial Year Ending on December 31, 1989-1993

C36. Electric Energy Account for Major U.S. Publicly Owned Nongenerator Electric Utilities with Financial Year Ending on December 31, 1989-1993

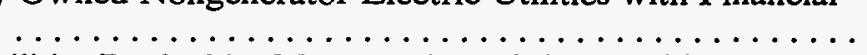

C37. Twenty Largest U.S. Publicly Owned Electric Utilities Ranked by Megawatthour Sales to Ultimate

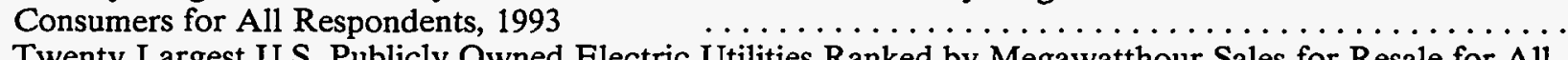

C38. Twenty Largest U.S. Publicly Owned Electric Utilities Ranked by Megawatthour Sales for Resale for All Respondents, 1993

C39. Twenty Largest U.S. Publicly Owned Electric Utilities Ranked by Electric Utility Revenues for All

C40. Twenty Largest U.S. Publicly Owned Electric Utilities Ranked by Purchase Power Expenses for All Respondents, 1993

C41. Twenty Largest U.S. Publicly Owned Electric Utilities Ranked by Electric Utility Plant for All Respondents, 1993

C42. Twenty Largest U.S. Publicly Owned Electric Utilities Ranked by Construction Work in Progress for All Respondents, 1993

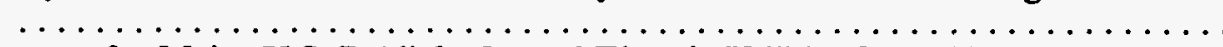

C43. Composite Statement of Income for Major U.S. Publicly Owned Electric Utilities for All Respondents, 1989-1993

C44. Composite Balance Sheet for Major U.S. Publicly Owned Electric Utilities for All Respondents at End of Period, 1989-1993

C45. Composite Financial Indicators for Major U.S. Publicly Owned Electric Utilities for All Respondents, 1989-1993

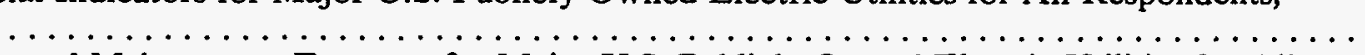

C46. Electric Operation and Maintenance Expenses for Major U.S. Publicly Owned Electric Utilities for All

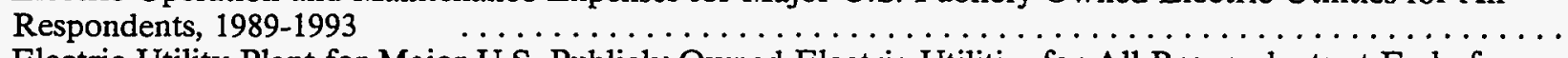

C47. Electric Utility Plant for Major U.S. Publicly Owned Electric Utilities for All Respondents at End of Period, 1989-1993

C48. Number of Consumers, Sales, and Operating Revenue for Major U.S. Publicly Owned Electric Utilities for All Respondents, 1989-1993

C49. Electric Energy Account for Major U.S. Publicly Owned Electric Utilities for All Respondents, 1989-1993

D1. State Agency Authority to Regulate Rate of U.S. Publicly Owned Electric Utilities, 1993

$\ldots \ldots \ldots$

\section{Illustrations}

1. Investment in Electric Utility Plant per Dollar of Revenue, 1989-1993

$\ldots \ldots \ldots \ldots \ldots \ldots \ldots \ldots$

B1. Principal Business Office of the Major U.S. Publicly Owned Electric Utilities, 1993 


\section{Introduction}

\section{About This Publication}

The 1993 edition of the Financial Statistics of Major U.S. Publicly Owned Electric Utilities publication presents 5 years (1989 through 1993) of summary financial data and current year detailed financial data on the major publicly owned electric utilities. The objective of the publication is to provide Federal and State governments, industry, and the general public with current and historical data that can be used for policymaking and decisionmaking purposes related to publicly owned electric utility issues.

Generator (Tables 3 through 11) and nongenerator (Tables 12 through 20) summaries are presented in this publication. Five years of summary financial data are provided (Tables 5 through 11 and 14 through 20). Summaries of generators for fiscal years ending June 30 and December 31, nongenerators for fiscal years ending June 30 and December 31, and summaries of all respondents are provided in Appendix $\mathbf{C}$.

The composite tables present aggregates of income statement and balance sheet data, as well as financial indicators. Composite tables also display electric operation and maintenance expenses, electric utility plant, number of consumers, sales of electricity, and operating revenue, and electric energy account data.

The primary source of publicly owned financial data is the Form EIA-412, "Annual Report of Public Electric Utilities." Public electric utilities file this survey on a fiscal year, rather than a calendar year basis, in conformance with their recordkeeping practices. In previous editions of this publication, data were aggregated by the two most commonly reported fiscal years, June 30 and December 31. This omitted approximately 20 percent of the respondents who operate on fiscal years ending in other months.

Accordingly, the EIA undertook a review of the Form EIA-412 submissions to determine if alternative classifications of publicly owned electric utilities would permit the inclusion of all respondents. The study also focused on understanding the differences in financial characteristics between electric utilities whose fiscal years end June 30 and December 31 . The review indicated that financial indicators differ most according to whether or not a publicly owned electric utility generates electricity. Therefore, the main body of the report provides summary information in generator/nongenerator classifications.

\section{History}

As the result of the Federal Power Act of 1935, the Federal Power Commission (FPC), which was the predecessor to the Federal Energy Regulatory Commission (FERC), began collecting financial statistics for investor-owned electric utilities in 1938. In 1946, the FPC started collecting financial statistics on publicly owned electric utilities. The Energy Information Administration (EIA) upon its establishment in October 1977 took over the responsibility of gathering and publishing the financial statistics from the FERC. In 1982, the EIA combined the contents of two publications containing financial statistics of investorowned (private) and publicly owned electric utilities into a single volume, the Financial Statistics of Selected Electric Utilities. The 1989 edition reverted to the two separate publications, the Financial Statistics of Selected Investor-Owned Electric Utilities and the Financial Statistics of Selected Publicly Owned Electric Utilities. In 1991, the publication titles were changed to the Financial Statistics of Major Investor-Owned Electric Utilities and the Financial Statistics of Major Publicly Owned Electric Utilities. In 1992, the publication titles were further changed to the Financial Statistics of Major U.S. Investor-Owned Electric Utilities and the Financial Statistics of Major U.S. Publicly Owned Electric Utilities .

Currently, the Financial Statistics of Major U.S. Publicly Owned Electric Utilities publication is prepared by the Renewable and Financial Data Systems and Outreach Branch; Survey Management Division; Office of Coal, Nuclear, Electric and Alternate Fuels; EIA; U.S. Department of Energy. The format was designed to be used by a variety of private, electric power industry, and government users. The publication contents and format have evolved over the years to better serve the needs and requirements of the targeted audience.

\section{About The Industry}

The U.S. electric power industry is a combination of electric utilities (investor-owned, publicly owned, Federal, and cooperatives) and nonutility power producers. Investor-owned electric utilities account for over three-fourths of the sales of electricity and revenue in the industry. Historically, the investorowned electric utilities serve the large consolidated markets and operate in all States except Nebraska. Hawaii is the only State in which all electricity is supplied by investor-owned electric utilities.

Publicly owned electric utilities are nonprofit operations that have been established to serve their communities and nearby consumers at cost. The publicly 
owned electric utilities in this publication include municipals, public power districts, State authorities, irrigation districts, and other State organizations. Publicly owned electric utilities are exempt from taxes and can obtain new financing at lower rates than investor-owned electric utilities.

The publicly owned electric utilities are divided into generators and nongenerators (In contrast, virtually all investor-owned electric utilities own and operate generating capacity). Generators are those electric utilities that own/operate generating capacity to supply some or all of their consumer needs. However, some generators supplement their demand by purchasing power. The nongenerators do not produce electric power for end use and rely exclusively on purchasing power. Their primary function is to transmit and distribute electricity to their consumers. The nongenerators comprise over half of the total number of major publicly owned electric utilities.

Federal electric utilities are also presented in this publication and include the five Federal power marketing administrations, the Tennessee Valley Authority, the U.S. Army Corps of Engineers, and the U.S. Bureau of Indian Affairs. The five Federal power marketing administrations are the Alaska Power Administration, the Bonneville Power Administration, the Southeastern Power Administration, the Southwestern Power Administration, and the Western Area Power Administration. Electric power produced by Federal electric utilities is generated primarily by water resources. This power, which is not produced for profit, is primarily wholesaled to other electric utilities rather than being distributed to ultimate consumers. As required by law, publicly owned and cooperative electric utilities are given preference in the purchase of this less expensive power produced by the Federal electric utilities.

Cooperative electric utilities are owned by their members and are established to provide electricity to those members. The Rural Electrification Administration, U.S. Department of Agriculture, was established under the Rural Electrification Act of 1936 with the purpose to extend electric service to small rural communities (usually under 1,500 consumers) and farms where it was more expensive to provide service. The National Rural Utilities Cooperative Finance Corporation, the Federal Financing Bank, and the Bank for Cooperatives are the most important sources of debt financing for cooperatives . Cooperative borrowers (904 of 941 total cooperatives) currently operate in 47 States. Financial data for the cooperative borrowers are found in the Statistical Report, Rural Electric Borrowers published by the Rural Electrification Administration of the U.S. Department of Agriculture. Summary tables for the cooperative borrowers are provided in Appendix A.

\section{Data Users}

The Financial Statistics of Major U.S. Publicly Owned Electric Utilities publication provides information about the financial results from operations of publicly owned electric utilities for use by government, industry, electric utilities, financial organizations and educational institutions in energy planning. In the private sector, the readers of this publication are researchers and analysts associated with the financial markets, the policymaking and decisionmaking members of electric utility companies, and economic development organizations. Other organizations that may be interested in the data presented in this publication include manufacturers of electric power equipment and marketing organizations. In the public sector, the readers of this publication include analysts, researchers, statisticians, and other professionals engaged in regulatory, policy, and program areas. These individuals are generally associated with the Congress, other legislative bodies, State public utility commissions, universities, and national strategic planning organizations.

\section{Sources and Coverage}

Publicly owned electric utilities are required to submit the Form EIA-412 when the generation, transmission, or distribution of electricity, for the two previous years, results in one of the following :

- 120,000 megawatthours of sales to ultimate consumers.

- 120,000 megawatthours of sales for resale.

These criteria are based on data reported on the Form EIA-861, "Annual Electric Utility Report." This survey is submitted by all electric utilities in the United States, the U.S. territories, and Puerto Rico. Appendix B contains a list of the major publicly owned electric utilities that submitted Form EIA-412 data for 1993.

Many of the publicly owned electric utilities are selfregulated while some fall under the jurisdiction of State public utility commissions as shown in Appendix $D$. Because of the absence of required reporting to a specific regulatory body, the accounting practices and policies of publicly owned electric utilities vary considerably. Many use the FERC Uniform System of Accounts or variations of this and other accounting systems. The composite statistics provided in this publication must be viewed with an appropriate degree of caution.

The Form EIA-412 is used to collect detailed annual accounting, financial, and other operating characteristics of publicly owned electric utilities for publication in EIA reports. In 1993, 495 major publicly owned electric utilities submitted data to the EIA. Although calender year reporting of data is preferred, electric utilities are given the option of reporting data on a fiscal year basis. This option is permitted in order to minimize respondent burden in preparing the data. When reporting by fiscal year, electric utilities must report operational data for a 12 -month period and 
show consistency in fiscal periods and accounting practices.

\section{Industry Profile}

Selected electric utility data for 1993 are compiled from the Form EIA-861 for the total universe of electric utilities. In 1993, there were 3,212 investorowned, publicly owned, Federal, and cooperative electric utilities (Table 1).

Key facts concerning sales and revenues in 1993 are as follows :

- The 254 investor-owned electric utilities $(7.9$ percent of all electric utilities) accounted for 79.0 percent of all revenues from sales of electricity to ultimate consumers and 42.6 percent of all revenues from sales for resale.

- The 2,007 publicly owned electric utilities $(62.5$ percent of all electric utilities) accounted for 12.5 percent of all revenues from sales to ultimate con- sumers and 18.2 percent of all revenues from sales for resale.

- The 10 Federal electric utilities accounted for 0.6 percent of all revenues from sales to ultimate consumers and 15.3 percent of all revenues from sales for resale.

- The 941 cooperative electric utilities (29.3 percent of all electric utilities) accounted for 7.8 percent of all revenues from sales to ultimate consumers and 23.9 percent of all revenues from sales for resale.

- The average ultimate consumers revenue per kilowatthour ranged from 2.8 to 7.2 cents depending on the type of electric utility. The overall average was 6.9 cents.

- The average sales for resale revenue per kilowatthour ranged from 3.3 to 4.1 cents, depending on the type of electric utility. The overall average was 3.6 cents.

Table 1. Selected Electric Utility Data by Ownership, 1993

\begin{tabular}{|c|c|c|c|c|c|}
\hline \multirow[b]{2}{*}{ Item } & \multicolumn{5}{|c|}{ Type of Electric Utility } \\
\hline & Investor-Owned & Publicly Owned & Federal & Cooperative & Total' \\
\hline 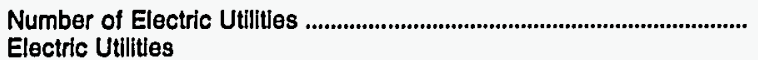 & 254 & 2,007 & 10 & 941 & 3,212 \\
\hline 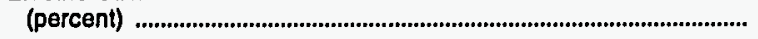 & 7.9 & 62.5 & * & 29.3 & 100.0 \\
\hline 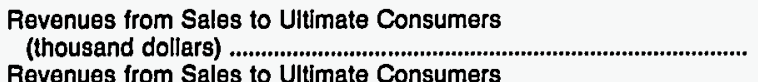 & $156,663,793$ & $24,781,611$ & $1,282,858$ & $15,475,499$ & $198,203,761$ \\
\hline $\begin{array}{l}\text { (percent) } \\
\text { Sales of Electricity to Ultimate Consumers }\end{array}$ & 79.0 & 12.5 & .6 & 7.8 & 100.0 \\
\hline $\begin{array}{l}\text { (thousand megawatthours) } \\
\text { Sales of Electricity to Ultimate Consumers }\end{array}$ & $2,186,888$ & 406,976 & 46,369 & 221,030 & $2,861,265$ \\
\hline $\begin{array}{l}\text { (percent) } \\
\text { Average Revenue per kWh for Ultimate Consumers }\end{array}$ & 76.4 & 14.2 & 1.6 & 7.7 & 100.0 \\
\hline 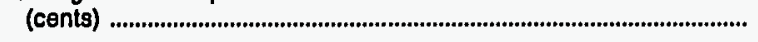 & 7.2 & 6.1 & 2.8 & 7.0 & 6.9 \\
\hline $\begin{array}{l}\text { Revenues from Sales for Resale } \\
\text { (thousand dollars) } \\
\text { Revenues from Sales for Resale }\end{array}$ & $18,452,517$ & $7,866,159$ & $6,649,342$ & $10,351,832$ & $43,319,850$ \\
\hline $\begin{array}{l}\text { (percent) } \\
\text { Sales of Electriclty Avallable for Resale }\end{array}$ & 42.6 & 18.2 & 15.3 & 23.9 & 100.0 \\
\hline $\begin{array}{l}\text { (thousand megawatthours) } \\
\text { Sales of Electriclty Avallable for Resale }\end{array}$ & 537,352 & 207,186 & 200,708 & 254,798 & $1,200,046$ \\
\hline $\begin{array}{l}\text { (percent) } \\
\text { Average Revenue per kWh for Sales for Resale }\end{array}$ & 44.8 & 17.3 & 16.7 & 21.2 & 100.0 \\
\hline (cents) & 3.4 & 3.8 & 3.3 & 4.1 & 3.6 \\
\hline
\end{tabular}

- Value less than 0.5 percent.

I Includes only those electric utilities in the United States and the District of Columbia.

Note: Totals may not equal sum of components because of independent rounding.

Source: Energy Information Administration, Form EIA-861, "Annual Electric Utility Report." Data are based on calendar year submissions. 
This publication will concentrate on selected operational data for 495 of the 2,007 publicly owned electric utilities and on 8 of the 10 Federal electric utilities in the United States. The Introduction compares them as a percent of the total value reported by publicly owned and Federal electric utilities on the Form EIA-861.

In 1993, the 495 major publicly owned electric utilities in this publication accounted for 87.7 percent of the revenues from sales to ultimate consumers and 99.7 percent of the revenues from sales for resale of all publicly owned electric utilities (Table 2). The eight Federal electric utilities in this publication cover the entire Federal segment.

This publication contains summary and detailed data for 495 major publicly owed electric utilities (Tables 3 through 26). Also, included are summary and detailed data for the eight Federal electric utilities (Tables 27 through 32).

Appendix A tables contain 5 years of summary statistics on U.S. rural electric cooperative borrowers (Tables A1 through A4).
Appendix B contains a list of the major U.S publicly owned electric utility respondents. The major U.S. publicly owned electric utilities added and deleted for 1989 through 1993 are listed (Table B1). The number of generator/nongenerator respondents for June 30, for December 31, and for the "other" fiscal years are provided (Table B2). The name, State, financial reporting date, and generating status of the respondents are also provided (Table B3).

Appendix $\mathrm{C}$ contains summary statistics for generating and nongenerating major U.S. publicly owned electric utilities for the fiscal year periods ending June 30 and December 31, as well as for all respondents (Tables C1 through C49).

Appendix $D$ contains a list of the State agencies which have regulatory oversight of publicly owned electric utilities.

Appendix E contains all Technical Notes for the publication. The key sections are Sources of Data, Quality of Data, Formulas and Calculations, and General Information.

The Glossary defines common terms used in the publication.

Table 2. Selected Data for Major U.S. Publicly Owned and Federal Electric Utilities Compared to All U.S. Publicly Owned and Federal Electric Utilities, 1993

\begin{tabular}{|c|c|c|}
\hline Item & Publicly Owned & Federal' \\
\hline $\begin{array}{l}\text { Number of Electric Utilities in This Report } \\
\text { Share of Electric Utilities Within Ownership Class }\end{array}$ & 495 & 8 \\
\hline (percent) & 24.7 & 80.0 \\
\hline \multicolumn{3}{|l|}{$\begin{array}{l}\text { Revenues from Sales to Ultimate Consumers } \\
\text { (thousand dollars) }\end{array}$} \\
\hline (thousand dollars) & $21,735,020$ & $1,282,858$ \\
\hline \multicolumn{3}{|l|}{ Share of Revenues from Sales to Ultimate Consumers } \\
\hline $\begin{array}{l}\text { (percent) } \\
\text { Sales of Electricity to Ultimate Consumers }\end{array}$ & 87.7 & 100.0 \\
\hline (thousand megawatthours) & 360,023 & 46,369 \\
\hline \multicolumn{3}{|l|}{ Share of Sales of Electricity to Ultimate Consumers } \\
\hline \multicolumn{3}{|l|}{ Revenues from Sales for Resale } \\
\hline 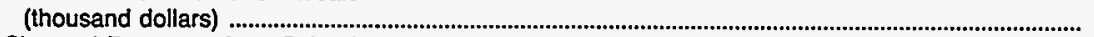 & $7,838,949$ & $6,649,342$ \\
\hline \multicolumn{3}{|l|}{ Share of Revenues from Sales for Resale } \\
\hline \multicolumn{3}{|l|}{ Sales of Electricity Available for Resale } \\
\hline (thousand megawatthours) & 206,078 & 200,708 \\
\hline \multicolumn{3}{|l|}{ Share of Sales of Electricity Available for Resale } \\
\hline (percent) & 99.5 & 100.0 \\
\hline
\end{tabular}

1 The Department of Interior-U.S. Bureau of Reclamation and the Department of State-International Water and Boundary Commission do not file the Form ElA-412; however, their energy is marketed and reported by the Bonneville Power Administration, the Southeastern Power Administration, the Southwestern Power Administration, and the Western Area Power Administration.

Source: Energy Information Administration, Form ElA-861, "Annual Electric Utility Report." Data are based on calendar year submissions. 


\section{Summary Statistics of Major U.S. Publicly Owned Electric Utilities}

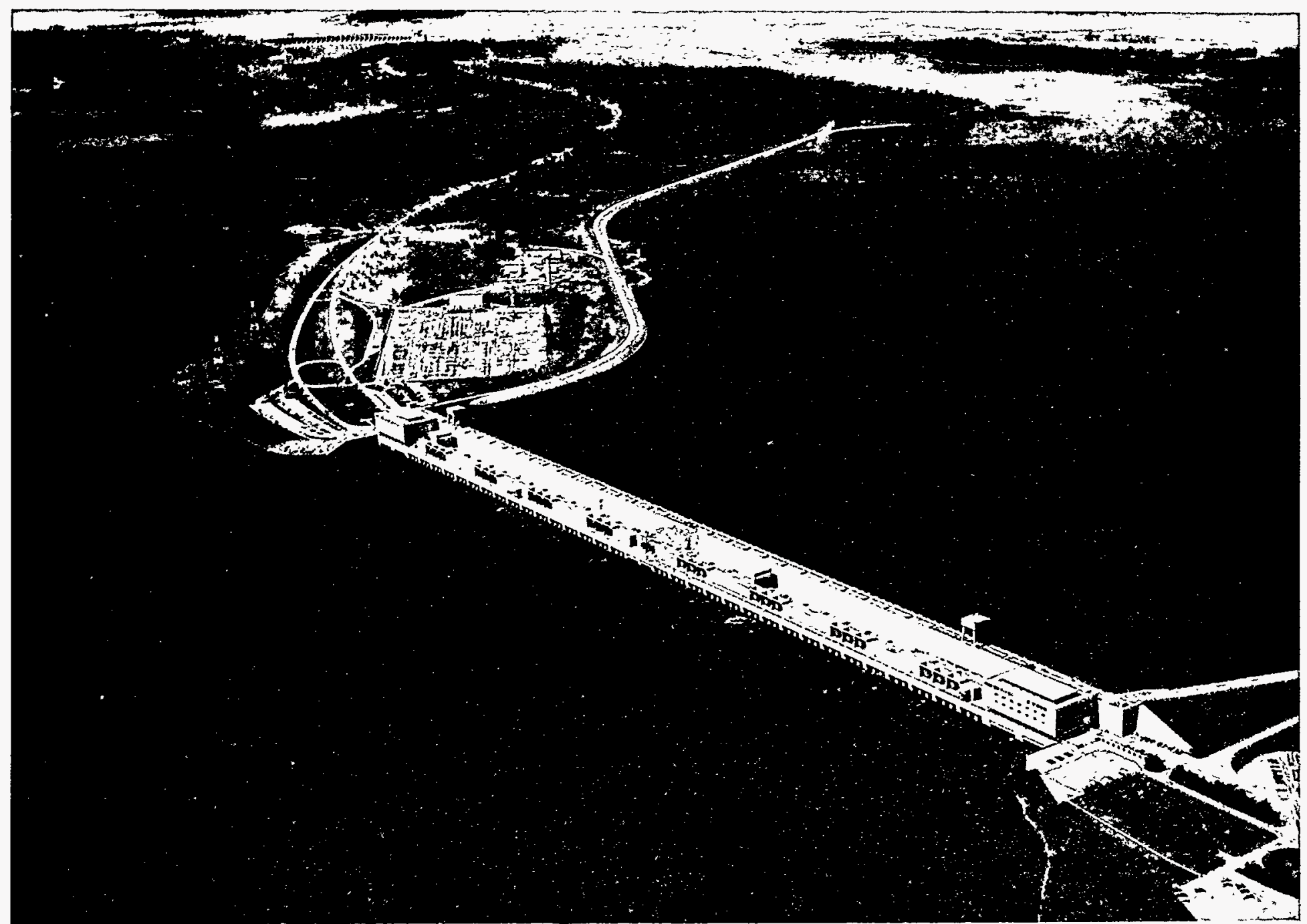

The Moses Power Dam, a hydroelectric plant, is located in St. Lawrence County, New York, and owned by the Power Authority of the State of New York. 


\section{Factors Affecting Major U.S. Publicly Owned Electric Utilities During 1993}

\section{Overview}

Summary financial statistics are provided for major U.S. publicly owned electric utilities. These statistics include data for 495 electric utilities for 1993; 483 electric utilities for 1992; 470 electric utilities for 1991; 467 electric utilities for 1990; and 454 electric utilities for 1989.

Economic Context. Despite several positive factors that emerged during 1993, growth in the U.S economy can only be characterized as slow for the better part of the year. While Real Gross Domestic Product (GDP) was up 3.0 percent, this included a fourth quarter 7.0-percent gain (on an annualized basis), the highest quarterly increase in 6 years. A major factor in the increased GDP was the 4.2-percent increase in industrial production. The increased industrial activity did stimulate industrial sales of electricity for the publicly owned electric utilities which showed a 3.1-percent increase for the year.

Weather. Floods in the Midwest and a drought in the Southeast reduced the output of the agricultural sectors in these regions. However, the cleanup and construction activity that followed countered the reduction in agricultural output, suggesting that the economic effects of these regional weather events cannot be definitively assessed.

The weather improved retail electricity sales for major publicly owned electric utilities, which were up 3.5 percent, the highest increase since the increase in 1990 (Table C49). The cold first quarter and hot third quarter increased heating degree days 12.3 percent and cooling degree days 23.1 percent from 1992, respectively.

Inflation and Interest Rates. Inflation continued under control in 1993, increasing a mere 2.5 percent for the year, measured in terms of the GDP implicit deflator. The 1993 deflator increase was the smallest increase in 30 years (since 1964). The Consumer Price Index of all items (CPI-U) increased a mere 2.7 percent, the lowest increase since 1986. A major factor holding down the CPI-U was the decline in oil prices during the year. Oil prices at the beginning of the year averaged $\$ 20$ per barrel, as benchmarked by West Texas Intermediate crude oil. The $\$ 20$ price continued through the first half of the year before falling in midOctober to $\$ 18.25$ per barrel and dropping to $\$ 14.25$ per barrel by year-end. The 28.8-percent decline in oil prices translated directly into lower inflation.

Lower inflation generally leads to lower interest rates. Short-term interest rates as measured by the 3-month
Treasury bills were the lowest in 30 years, averaging a mere 3.02 percent. Long-term interest rates were also at a 30-year low, averaging 6.59 percent for the year (yields based on the most actively traded issues adjusted to 10-year constant maturities by the Treasury Department). The low interest rates in 1993 resulted in the issuance and retirement of a record amount of long-term debt in the electric power industry.

\section{Generator Electric Utilities versus Nongenerator Electric Utilities}

The next section of the publication discusses generator and nongenerator electric utilities separately. The two groups are distinct because their financial profiles are significantly different, and aggregating generators and nongenerators obscures fundamental financial and operational differences between the two groups. For example, significant plant production expenses would not exist for nongenerator electric utilities. Existing production plant expenses are mainly maintenance costs for standby plants. It should be noted that both generator and nongenerator electric utilities report according to varying fiscal years.

Because nongenerator electric utilities purchase all their power needs, they have less plant investment than generator electric utilities do per dollar of revenue generated. In 1993, the generator electric utilities showed $\$ 3.92$ of electric utility plant per dollar of electric utility operating revenue, compared with $\$ 1.11$ for nongenerator electric utilities.

Operation and maintenance (O\&M) expenses represent very different costs between the two groups of electric utilities. Purchase power expenses, which comprise the majority of nongenerators' O\&M expenses, contain all the associated costs for the generating plants from which the power was purchased, including depreciation. This causes nongenerators' O\&M expenses to appear higher than generators' O\&M expenses on a mills per kilowatthour basis. In 1993, nongenerators' O\&M expenses were 88.1 percent of revenues and depreciation was only 3.4 percent. For generators, depreciation of plant is shown directly, since all or some of their generating needs are met by their own plants. Generators' O\&M expenses only represented 65.7 percent of revenues, but depreciation was 10.8 percent of revenues.

Financing is also different for the two groups. The generator electric utilities, with their larger plant investments per dollar of revenue, have more debt per dollar of revenue than the nongenerator electric utilities. The large amount of debt creates greater interest expense. Interest expense represented 19.7 percent of revenues in 1993 for the generators versus just 1.5 percent of revenues for the nongenerators (Tables 7 and 16). 
Figure 1. Investment in Electric Utility Plant per Dollar of Revenue, 1989-1993

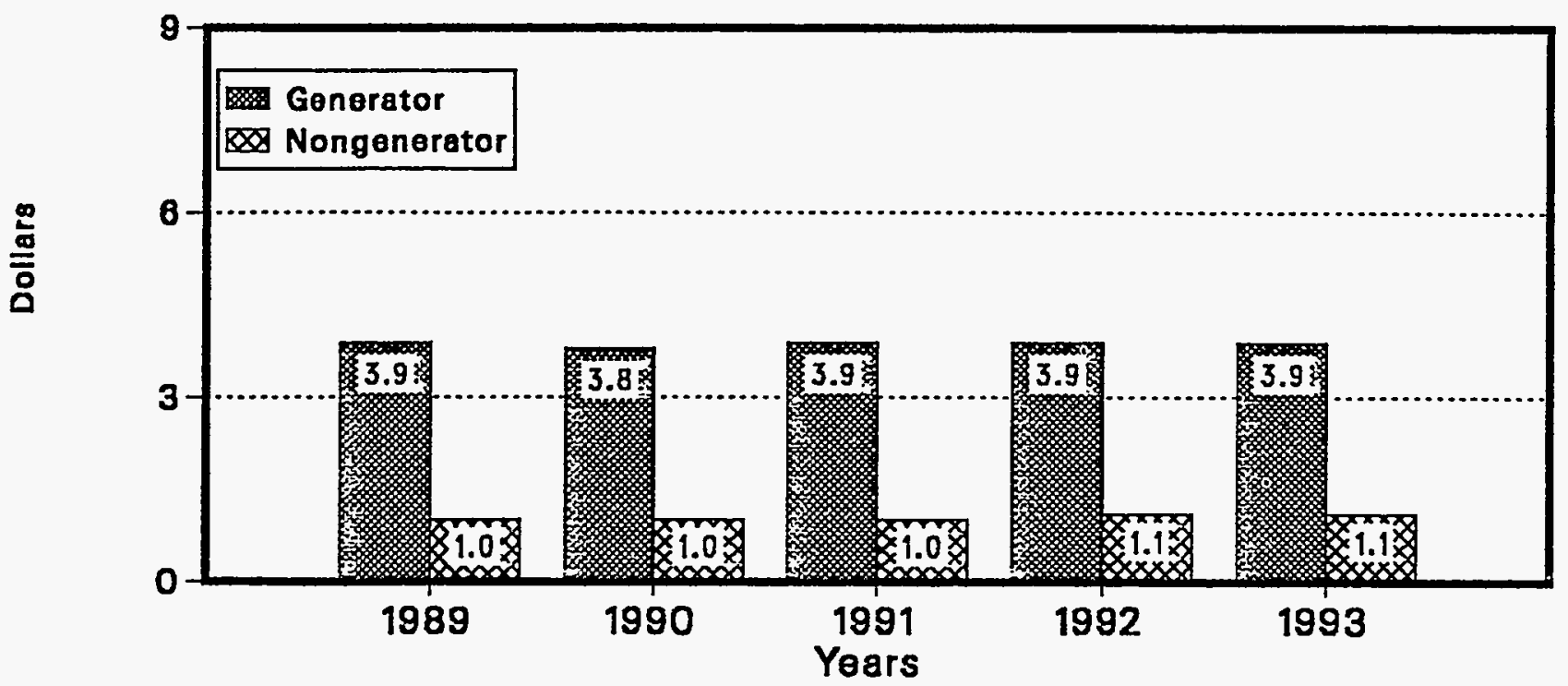

Note: Summary dato aro provided in Tables 7 and 10.

Source: Energy Information Administration. Form ElA-412, "Annual Report of Public Electric Utilitias." 


\section{Financial Performance for Generator Electric Utilities}

Summary financial statistics are provided for major publicly owned generator electric utilities. These statistics include 226 electric utilities for 1993; 225 electric utilities for 1992; 218 electric utilities for 1991; 216 electric utilities for 1990; and 214 electric utilities for 1989. The new respondents, as well as the electric utilities that are no longer reporting from the previous years, are listed in Appendix B.

\section{Highlights of Generator Financial Performance}

With total electric utility operating costs increasing faster than revenues and the contribution from extraordinary items contributing substantially less, the net income was off a substantial 30.5 percent. Key indicators of the generator electric utilities financial performance were:

- Net income was 3.0 percent of electric utility operating revenues, down from 4.5 percent in 1992.

- Total electric utility operating expenses were up 5.7 percent in 1993 from 1992.

- Other electric income was down 20.8 percent from the previous year.

- Electric utility generating revenues increased 3.9 percent in 1993.

- Long-term debt outstanding at the end of the year increased $\$ 4.2$ billion in 1993.

\section{Income Statement}

The Composite Statement of Income for major publicly owned generator electric utilities for the years 1989 to 1993 is presented (Table 5). Net income of $\$ 0.7$ billion for generator electric utilities was down a substantial 30.5 percent from the prior year. Extraordinary income was off 37.3 percent, contributing only \$0.1 billion, while extraordinary deductions were up 25.4 percent to $\$ 0.3$ billion. The net effect was to drive income before extraordinary items down 18.3 percent to \$0.9 billion in 1993.

Revenues. Generator electric utilities revenues were up 3.9 percent to $\$ 22.5$ billion in 1993 . Increased sales were a major contributing factor to the increased revenues. In 1993, wholesale sales and revenues grew even faster than retail sales and revenues.

Electric Utility Operating Expenses. Total electric utility operating expenses of $\$ 18.2$ billion were up 5.7 percent over the previous year. The largest increase in expenses was in operation expenses, up $\$ 0.7$ billion to $\$ 13.2$ billion in 1993. Operation expenses accounted for 72.9 percent of the total electric utility operating expenses. The second largest contributor was depreciation expense, which accounted for 13.4 percent of total electric utility operating expenses, and was up
$\$ 0.2$ billion or 6.8 percent over the prior year. Maintenance expenses represented the next most significant contribution to total electric utility operating expenses, accounting for 8.6 percent of the total, and were virtually unchanged from the prior year. Tax and tax equivalents were up 11.5 percent in 1993 from 1992. These tax expenses accounted for 4.2 percent the total electric utility operating expenses in 1993.

Production Expenses. Production expenses were up 4.7 percent over the prior year, accounting for $\$ 11.3$ billion of expense (Table 8). Fuel expenses were up 10.2 percent over the prior year and amounted to $\$ 3.4$ billion versus $\$ 3.1$ billion in 1992. Purchased power expenses were $\$ 5.4$ billion, up 2.4 percent, accounting for 36.1 percent of the total operation and maintenance expenses of the publicly owned generator electric utilities. Steam power generation production expenses were up 9.1 percent on a total dollar basis and up 4.1 percent to 9.5 mills per kilowatthour, versus 9.2 mills per kilowatthour in 1992 (Table 10). Total production expenses increased only a marginal 0.1 percent to 26.3 on a mills per kilowatthour sold basis in 1993.

Transmission and Distribution Expenses. Transmission expenses accounted for only 1.6 mills per kilowatthour sold, up a nominal 3.5 percent in 1993. However, on a total dollar basis, transmission expenses were up 8.4 percent to $\$ 0.7$ billion. Distribution expenses accounted for 1.9 mills per kilowatthour sold or \$0.8 billion dollars of operation and maintenance expenses. Distribution expenses were up 5.9 percent in dollar terms and 1.1 percent in terms of mills per kilowatthour sold in 1993.

Electric Utility Income. With revenues increasing 3.9 percent while total electric operating expenses increased 5.7 percent, net electric utility operating income was down 3.0 percent to $\$ 4.4$ billion in 1993 . Other electric income dropped $\$ 0.3$ billion in 1993, from $\$ 1.8$ billion in 1992 versus $\$ 1.5$ billion in 1993 . The three electric utilities contributing the most to this decline were the PUD No 1 of Benton County (WA), the PUD No 1 of Clark County (WA), and the Alabama Municipal Electric Authority (AL) with other electric deductions of $\$ 4.1$ million, $\$ 3.3$ million, and $\$ 2.7$ million, respectively. The combination of lower operating income and other electric income resulted in lower (total) electric utility income in 1993. The 1993 figure was $\$ 5.6$ billion versus $\$ 6.1$ billion in 1992 , off 8.9 percent.

Interest Expense. Despite the publicly owned generator electric utilities increasing their debt by $\$ 4.2$ billion for the year ending 1993, interest expenses went down, because of refinancing at lower interest rates. Interest expenses decreased from $\$ 4.8$ billion in 1992 to $\$ 4.4$ billion in 1993 , a decline of 6.8 percent.

Net Income. The lower interest expense helped moderate the negative (total) electric utility income. Still, income before extraordinary items suffered a substantial 18.3 percent decline to $\$ 0.9$ billion in 1993. The corresponding figure in 1992 was $\$ 1.1$ billion. 


\section{Balance Sheet}

The Composite Balance Sheet for publicly owned generator electric utilities revealed a 5.0-percent increase for the year (Table 6).

Assets and Other Debits. Increases in other property and investments, deferred debits, and electric utility plant contributed the most significant gains on the asset side of the balance sheet in 1993, increasing 12.4 percent, 16.4 percent, and 3.1 percent, respectively.

Electric Utility Plant. Electric utility plant in service increased 3.0 percent to $\$ 80.5$ billion in 1993 (Table 9). Including adjustments, utility plant increased to $\$ 82.0$ billion. The increase in steam production plant of $\$ 0.8$ billion was almost matched by the increase in distribution plant of $\$ 0.7$ billion. Together, increases in these two categories of plant accounted for almost two-thirds of the increase in electric plant in service. While essentially unchanged from the prior year, nuclear plant investments of $\$ 18.8$ billion accounted for 21.9 percent of the total electric utility plant revealing the fact that publicly owned generator electric utilities have significant nuclear plant investment exposure. Other changes in the asset accounts included:

- The single largest increase was in other property and investments, up 12.4 percent or $\$ 2.3$ billion to $\$ 20.5$ billion in 1993. Investments and special funds accounted for 80.3 percent of these assets or $\$ 16.4$ billion.

- Construction work in progress (CWIP) increased to $\$ 3.8$ billion in 1993 , up $\$ 0.2$ billion over the $\$ 3.5$ billion figure for 1992 (note difference does not add due to rounding). CWIP as a percent of total electric utility plant was 4.4 percent in 1993 , up from 4.3 percent in 1992.

- Accounts receivable accounted for $\$ 0.2$ billion of the $\$ 0.4$ billion increase in current and accrued assets in 1993. Cash working funds and investments accounted for $\$ 9.6$ billion or 62.3 percent of current and accrued assets.

- Deferred debits increased almost $\$ 2.0$ billion between 1992 and 1993, amounting to $\$ 14.0$ billion by year end.

Liabilities and Other Credits. Increases in long-term debt dominated the changes on the liabilities side of the balance sheet, accounting for 77.7 percent of the increase. Bonds outstanding at year-end increased from $\$ 72.4$ billion in 1992 to $\$ 75.2$ billion in 1993 , a 3.8 percent increase. While only $\$ 0.7$ billion, advances from the municipalities and other accounted for the greatest percent increase in a liability account at 27.4 percent. Other significant changes in liability and other credit accounts included:

- Proprietary capital increases of 3.1 percent did not keep pace with the increases in debt. The result was an increase in financial leverage for this segment of the industry.

- Increased notes payable and miscellaneous current and accrued liabilities accounted for most of the $\$ 0.5$ billion increase in current and accrued liabilities in 1993.

\section{Consumers, Sales, and Revenue}

The information in this section is based upon the Form EIA-861.

Sales Growth. Sales to ultimate consumers of the generator electric utilities grew 2.3 percent in 1993, a modest improvement over the 1.6 percent increase in sales between 1991 and 1992 (Table 10). The residential sector reversed the decline in sales of the previous year by increasing 4.1 percent during the year. Commercial and industrial sales increased at more modest rates of 2.4 percent and 1.2 percent, respectively. A colder first quarter combined with a warmer third quarter helped increase the weather-sensitive residential sales. The improved economy contributed to the increase in commercial sales. The variance in the growth rates across the sectors shifted the relative sector mix in sales to ultimate consumers.

Average Revenue (Revenues Divided by Sales). Commercial and industrial consumers saw the greatest increases, 2.6 percent in each instance. Residential consumers experienced a 1.6 percent increase in average revenue paid for electricity. Increases in consumption per customer combined with these increases in average revenue raised the average annual electric bill paid by 4.4 percent for both the residential and commercial consumers. On average, residential consumers paid $\$ 57.51$ per month while commercial consumers paid \$394.04 per month. Consumption per industrial consumer decreased 1.8 percent between 1992 and 1993, allowing the average monthly bill paid by these consumers to increase a modest 0.7 percent.

Resale sales increased a substantial 7.8 percent between 1992 and 1993. Sales for resale accounted for 46.1 percent of the total sales of electricity in 1993, up from 44.8 percent in 1992. Sales for resale revenues represented 34.4 percent of total revenues from the sales of electricity, unchanged from the prior year. Average revenues from sales for resale were 38.2 mills per kilowatthour in 1993, down 2.9 percent percent from the 39.3 mills per kilowatthour in 1992.

Total revenues were up 4.8 percent for the year according to Table 10. Virtually all of the increase ( 99.8 percent) in revenues in 1993 was driven by the increase in sales volume, as average revenues remained essentially unchanged at 51.2 mills per kilowatthour sold. 


\section{Generation and Purchased Power}

In 1993, total net energy generated and received increased 4.7 percent, a direct response to the corresponding increase in sales volume (Table 11). The increase in 1993 followed three straight years where the total net energy required remained essentially unchanged. Net generation as a percent of the total net energy required continued to decline in 1993, dropping to 66.9 percent of the total. The corresponding figures for 1992 and 1991 were 67.3 percent and 69.1 percent, respectively.

Conventional hydroelectric generation increased by 8.1 percent over the prior year, raising its proportion of total net generation to 23.5 percent. Steam generation increased a more modest 6.2 percent in 1993, accounting for 59.4 percent of the total. Nuclear generation continued to decline, off 7.6 percent from the prior year and shrinking to 16.1 percent of total generation. Nuclear generation has fallen 15.9 percent in the last two years.

Purchased power continues to play an ever increasing role in the supply mix of generator electric utilities. In 1993, purchased power represented 33.1 percent of the supply mix of these electric utilities. Purchases from electric utilities dominated the power purchases, accounting for 32.8 percent of the total supply. Nonutility purchases provided a relative insignificant 0.3 percent of total power supply. 
Table 3. Ten Largest U.S. Publicly Owned Generator Electric Utilities Ranked by Megawatthour Sales to Ultimate Consumers, 1993

\begin{tabular}{|c|c|c|c|}
\hline Publicly Owned Electric Utilities & State & Amount & Percent \\
\hline Los Angeles City of & California & $21,769,016$ & 9.36 \\
\hline Salt River Proj Ag I \& P Dist & Arizona & $15,575,686$ & 6.70 \\
\hline Power Authority of State of NY & New York & $13,385,987$ & 5.76 \\
\hline San Antonio City of & Texas & $12,369,214$ & 5.32 \\
\hline Seattle City of & Washington & $8,914,889$ & 3.83 \\
\hline Jacksonville Electric Auth & Florida & $8,599,683$ & 3.70 \\
\hline Sacramento Municipal Util Dist & California & $8,446,459$ & 3.63 \\
\hline South Carolina Pub Serv Auth & South Carolina & $7,370,739$ & 3.17 \\
\hline Austin City of & Texas & $6,967,280$ & 3.00 \\
\hline 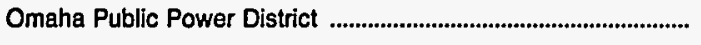 & Nebraska & $6,725,968$ & 2.89 \\
\hline Subtotal & & $110,124,921$ & 47.35 \\
\hline
\end{tabular}

Note: Percentage calculations are based on total generator electric utilities.

Source: Energy Information Administration, Form ElA-412, "Annual Report of Public Electric Utilities." Individual electric utilities report fiscal year data. Appendix $B$ shows the fiscal year for each electric utility.

Table 4. Ten Largest U.S. Publicly Owned Generator Electric Utilities Ranked by Megawatthour Sales for Resale, 1993

\begin{tabular}{|c|c|c|c|}
\hline Publlcly Owned Electric Utilities & State & Amount & Percent \\
\hline Power Authority of State of NY & New York & $25,134,370$ & 12.84 \\
\hline 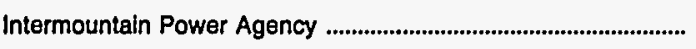 & Utah & $11,974,735$ & 6.12 \\
\hline 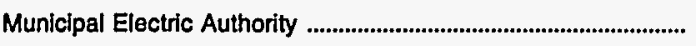 & Georgia & $10,265,581$ & 5.24 \\
\hline 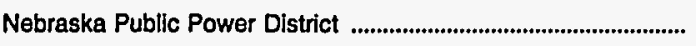 & Nebraska & $10,122,311$ & 5.17 \\
\hline 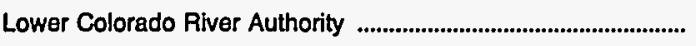 & Texas & $8,799,456$ & 4.49 \\
\hline 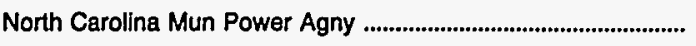 & North Carolina & $8,422,060$ & 4.30 \\
\hline 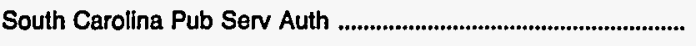 & South Carolina & $7,059,116$ & 3.61 \\
\hline 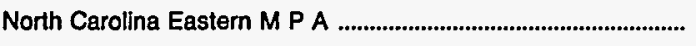 & North Carolina & $6,522,213$ & 3.33 \\
\hline 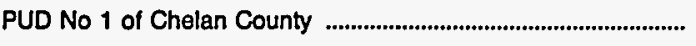 & Washington & $6,482,408$ & 3.31 \\
\hline 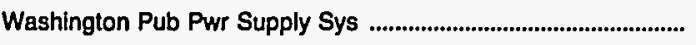 & Washington & $6,188,829$ & 3.16 \\
\hline 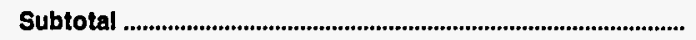 & & $100,971,079$ & 51.58 \\
\hline
\end{tabular}

Note: Percentage calculations are based on total generator electric utilities.

Source: Energy Information Administration, Form ElA-412, "Annual Report of Public Electric Utilities." Individual electric utilities report fiscal year data. Appendix $B$ shows the fiscal year for each electric utility. 
Table 5. Composite Statement of Income for Major U.S. Publicly Owned Generator Electric Utilities, 1989-1993

(Thousand Dollars)

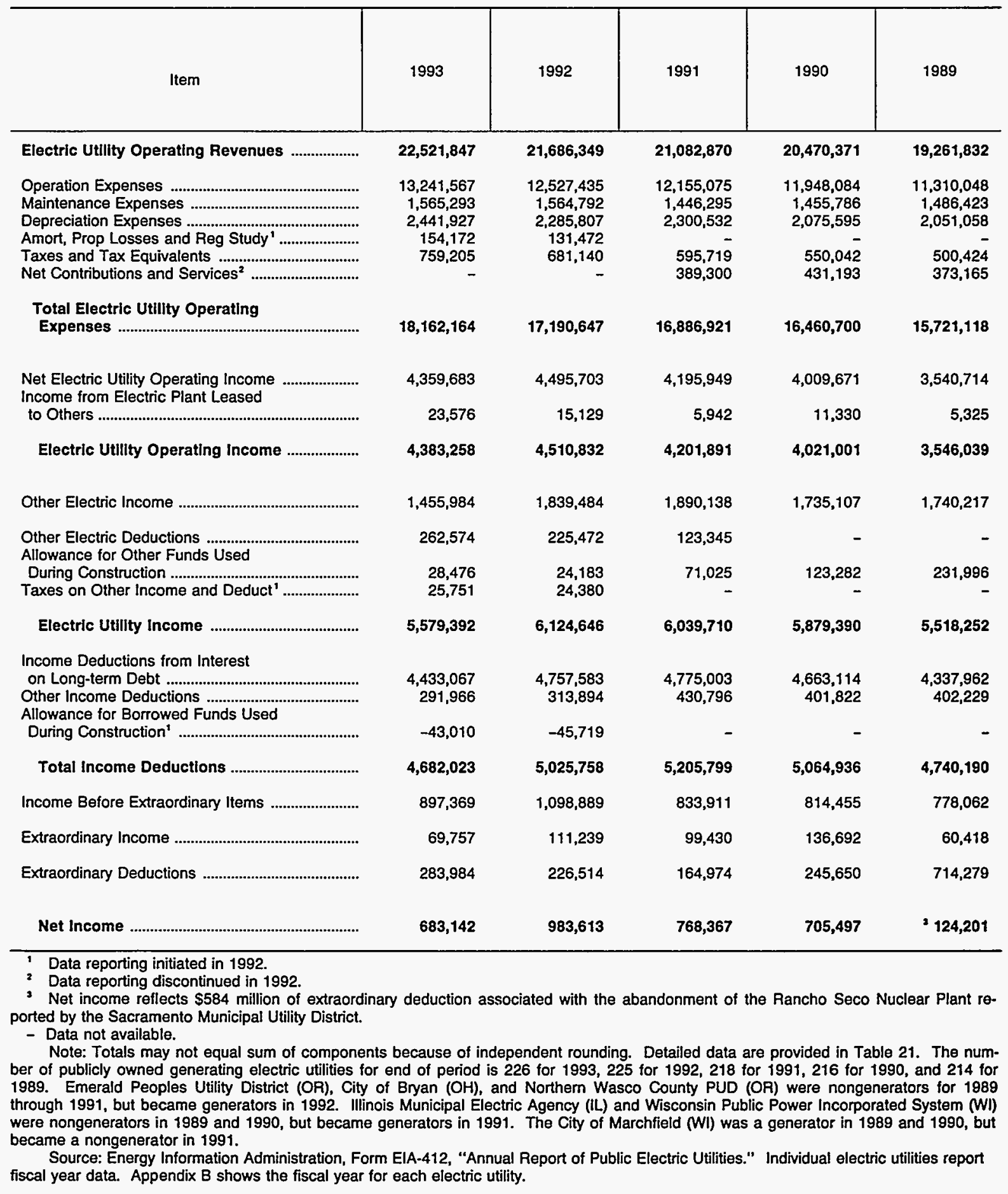


Table 6. Composite Balance Sheet for Major U.S. Publicly Owned Generator Electric Utilities at End of Period, 1989-1993

(Thousand Dollars)

\begin{tabular}{|c|c|c|c|c|c|}
\hline Item & 1993 & 1992 & 1991 & 1990 & 1989 \\
\hline \multicolumn{6}{|l|}{ Electric Utility Plant } \\
\hline Electric Utility Plant \& Adjust ...................................... & $81,995,168$ & $79,555,377$ & $81,535,543$ & $78,244,146$ & $74,665,136$ \\
\hline Const Work in Progress ............................................ & $3,777,408$ & $3,532,582$ & & & \\
\hline 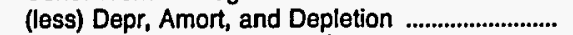 & $24,224,587$ & $22,301,093$ & $20,798,127$ & $18,647,693$ & $16,340,263$ \\
\hline Net Electric Utility Plant ${ }^{1}$.................................... & $61,547,988$ & $60,786,867$ & - & - & - \\
\hline 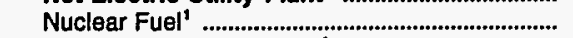 & $2,580,570$ & $2,271,919$ & - & - & - \\
\hline (less) Amort of Nucl Fuel' & $1,650,975$ & $1,348,032$ & - & - & \\
\hline Net Elec Plant Incl Nucl Fuel .................................... & $62,477,584$ & $61,710,753$ & $60,737,416$ & $59,596,453$ & $58,324,873$ \\
\hline \multicolumn{6}{|l|}{ Other Property \& Investments } \\
\hline Nonutility Property ......................................................... & $5,453,823$ & $5,000,781$ & $4,701,488$ & $4,226,501$ & $4,039,331$ \\
\hline (less) Accum Provisions for Depr \& Amort .......... & $1,763,781$ & $1,646,040$ & $1,530,242$ & $1,417,611$ & $1,353,972$ \\
\hline 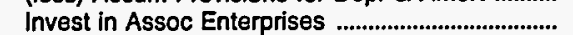 & 351,033 & 238,493 & 77,443 & 70,201 & 62,670 \\
\hline 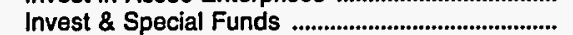 & $16,446,328$ & $14,618,703$ & $14,083,892$ & $12,922,220$ & $12,289,720$ \\
\hline Total Other Property \& Investments ............. & $20,487,402$ & $18,228,937$ & $17,332,581$ & $15,801,311$ & $15,037,749$ \\
\hline \multicolumn{6}{|l|}{ Current and Accrued Assets } \\
\hline Cash, Working Funds \& Investments ..................... & $9,563,657$ & $9,378,734$ & $9,325,031$ & $9,339,006$ & $8,519,708$ \\
\hline Notes \& Other Receivables ..................................... & 725,707 & 736,137 & $2,321,436$ & $2,491,339$ & $2,403,019$ \\
\hline Customer Accts Receivable ${ }^{1} \ldots$ & $1,999,590$ & $1,763,091$ & - & & - \\
\hline (less) Accum Prov for Uncollected Accts ............. & 106,485 & 99,830 & 93,358 & 85,334 & 82,222 \\
\hline Fuel Stock \& Exp Undistr' .......................................... & 496,149 & 544,131 & - & - & - \\
\hline Materials \& Supplies ......................................................... & $1,107,019$ & $1,163,156$ & $1,629,673$ & $1,452,816$ & $1,389,388$ \\
\hline Prepayments ............................................................. & 241,763 & 249,621 & 273,137 & 191,053 & 190,430 \\
\hline Accrued Utility Revenues' ........................................... & 303,140 & 258,068 & & & \\
\hline Miscellaneous Current \& Accrued Assets ............ & $1,026,573$ & 997,599 & 628,771 & 478,282 & 545,126 \\
\hline Total Current \& Accrued Assets ....................... & $15,357,112$ & $14,990,707$ & $14,084,691$ & $13,867,162$ & $12,965,449$ \\
\hline \multicolumn{6}{|l|}{ Deferred Debits } \\
\hline 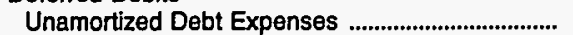 & $2,427,106$ & $2,200,298$ & $1,838,193$ & $1,766,253$ & $1,804,320$ \\
\hline Extraordinary Losses, Study Cost .................................. & 911,714 & 465,291 & 34,360 & 31,911 & 33,146 \\
\hline Misc Debt, R \& D Exp, Unamrt Losses ................ & $10,648,504$ & $9,351,452$ & $9,017,609$ & $8,128,531$ & $6,891,540$ \\
\hline 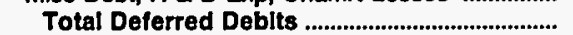 & $13,987,324$ & $12,017,041$ & $10,890,161$ & $9,926,695$ & $8,729,005$ \\
\hline 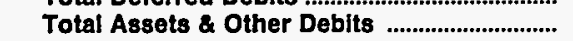 & $112,309,422$ & $106,947,439$ & $103,044,849$ & $99,191,621$ & $95,057,077$ \\
\hline \multicolumn{6}{|l|}{ Proprietary Capital } \\
\hline 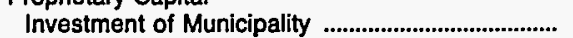 & $1,565,518$ & $1,601,685$ & $1,677,807$ & $1,481,272$ & $1,562,725$ \\
\hline Misc Capital ......................................................... & 205,855 & 92,311 & $-14,474$ & 48,920 & 255,914 \\
\hline Retained Earnings ................................................................. & $21,756,224$ & $21,129,231$ & $20,558,709$ & $20,150,936$ & $19,230,922$ \\
\hline 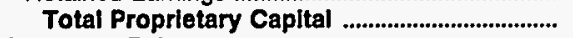 & $23,527,598$ & $22,823,226$ & $22,222,042$ & $21,681,128$ & $21,049,561$ \\
\hline \multicolumn{6}{|l|}{ Long-term Debt } \\
\hline 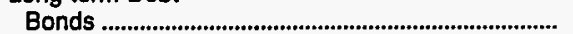 & $75,154,364$ & $72,372,625$ & $68,241,190$ & $65,443,518$ & $61,997,489$ \\
\hline 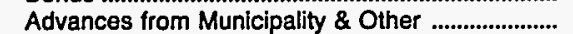 & $3,225,141$ & $2,531,683$ & $3,198,284$ & $3,505,229$ & $3,317,660$ \\
\hline 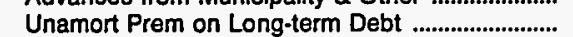 & 619,279 & 60,388 & 13,414 & -722 & 2,052 \\
\hline (less) Unamort Discount on Long-term Debt ....... & $2,830,002$ & $2,960,305$ & $2,581,371$ & $2,437,802$ & $2,215,744$ \\
\hline 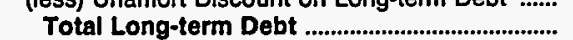 & $76,168,783$ & $72,004,391$ & $68,871,516$ & $66,510,223$ & $63,101,457$ \\
\hline \multicolumn{6}{|l|}{ Other Noncurrent Liabilities } \\
\hline Accum Operating Provisions ....... & 475,624 & 694,074 & 622,507 & 435,670 & 401,397 \\
\hline 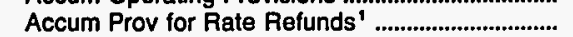 & 115,164 & 4,277 & & & \\
\hline 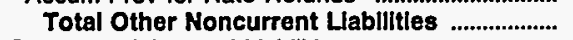 & 590,789 & 698,351 & 622,507 & 435,670 & 401,397 \\
\hline \multicolumn{6}{|l|}{ Current and Accrued Labilities } \\
\hline Notes Payable ................................ & $1,310,284$ & $1,117,110$ & $1,164,516$ & 990,061 & $1,085,469$ \\
\hline Accounts Payable ........................................................... & $2,056,839$ & $2,019,801$ & $1,845,315$ & $1,893,900$ & $1,753,283$ \\
\hline Payables to Assoc Enterprises ............................... & 304,054 & 284,324 & 240,228 & 229,580 & 196,156 \\
\hline 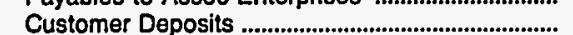 & 284,735 & 297,901 & 268,456 & 220,347 & 245,993 \\
\hline Taxes Accrued & 202,354 & 191,865 & 258,660 & 231,535 & 209,964 \\
\hline Interest Accrued ............................................................. & $1,472,136$ & $1,464,605$ & $1,509,266$ & $1,420,973$ & $1,316,281$ \\
\hline Misc Current \& Accrued Liabilities ....................... & $2,963,651$ & $2,705,171$ & $2,558,230$ & $2,297,082$ & $2,406,001$ \\
\hline 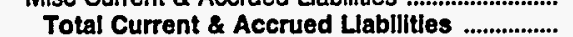 & $8,594,053$ & $8,080,777$ & $7,844,671$ & $7,283,479$ & $\mathbf{7 , 2 1 3 , 1 4 8}$ \\
\hline \multicolumn{6}{|l|}{ Deferred Credits } \\
\hline Customer Advances for Construction ....................... & 170,922 & 168,889 & 141,050 & 127,280 & 93,860 \\
\hline Other Deferred Credits ................................................. & $2,947,484$ & $2,787,138$ & $2,775,909$ & $2,729,381$ & $2,751,812$ \\
\hline Unamort Gain on Reacgr Debt ............................... & 309,794 & 384,667 & 567,153 & 424,459 & 445,841 \\
\hline Total Doferred Credlts ......................................... & $3,428,200$ & $3,340,694$ & $3,484,113$ & $3,281,121$ & $3,291,514$ \\
\hline 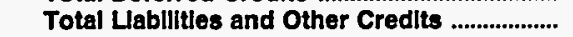 & $112,309,422$ & $106,947,439$ & $103,044,849$ & $99,191,621$ & $95,057,077$ \\
\hline
\end{tabular}

1 Data reporting initiated in 1992.

Note: Totals may not equal sum of components because of independent rounding. Detailed data are provided in Table 22. The number of publicly owned generating electric utilities for end of period is 226 for 1993, 225 for 1992, 218 for 1991, 216 for 1990, and 214 for 1989. Emerald Peoples Utility District (OR), City of Bryan (OH), and Northern Wasco County PUD (OR) were nongenerators for 1989 through 1991, but became generators in 1992. Illinois Municipal Electric Agency (IL) and Wisconsin Public Power Incorporated System (WI) were nongenerators in 1989 and 1990, but became generators in 1991. The City of Marshfield (WI) was a generator in 1989 and 1990, but became a nongenerator in 1991.

Source: Energy Information Administration, Form ElA-412, "Annual Report of Public Electric Utilities." Individual electric utilities report fiscal year data. Appendix $B$ shows the fiscal year for each electric utility. 
Table 7. Composite Financial Indicators for Major U.S. Publicly Owned Generator Electric Utilities, 1989-1993

\begin{tabular}{|c|c|c|c|c|c|}
\hline Item & 1993 & 1992 & 1991 & 1990 & 1989 \\
\hline Total Electric Utility Plant per Dollar of Revenue & 3.9 & 3.9 & 3.9 & 3.8 & 3.9 \\
\hline 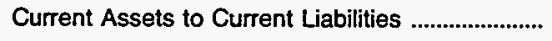 & 1.8 & 1.9 & 1.8 & 1.9 & 1.8 \\
\hline $\begin{array}{l}\text { Total Electric Utility Plant as a Percent of Total } \\
\text { Assets }\end{array}$ & 78.7 & 79.8 & 79.1 & 78.9 & 78.5 \\
\hline Net Electric Utility Plant as a Percent of Total & & & & & \\
\hline 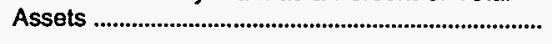 & 55.6 & 57.7 & 58.9 & 60.1 & 61.4 \\
\hline Debt as a Percent of Total Liabilities ..................... & 75.5 & 74.9 & 74.4 & 74.4 & 74.0 \\
\hline $\begin{array}{l}\text { Depreciation, Amortization and Depletion } \\
\text { as a Percent of Total Electric Utility Plant .......... }\end{array}$ & 29.3 & 27.7 & 25.5 & 23.8 & 21.9 \\
\hline $\begin{array}{l}\text { Electric Operation and Maintenance Expenses } \\
\text { as a Percent of } \\
\text { Electric Utility Operating Revenues ....................... }\end{array}$ & 65.7 & 65.0 & 64.5 & 65.5 & 66.4 \\
\hline $\begin{array}{l}\text { Electric Depreciation and Amortization } \\
\text { as a Percent of } \\
\text { Electric Utility Operating Revenues .......................... }\end{array}$ & 10.8 & 10.5 & 10.9 & 10.1 & 10.6 \\
\hline $\begin{array}{l}\text { Taxes and Tax Equivalents } \\
\text { as a Percent of } \\
\text { Electric Utility Operating Revenues ....................... }\end{array}$ & 3.4 & 3.1 & 2.8 & 2.7 & 2.6 \\
\hline $\begin{array}{l}\text { Interest on Long-term Debt } \\
\text { as a Percent of } \\
\text { Electric Utility Operating Revenues }\end{array}$ & 19.7 & 21.9 & 22.6 & 22.8 & 22.5 \\
\hline $\begin{array}{l}\text { Net Income as a Percent of Electric } \\
\text { Utility Operating Revenues }\end{array}$ & 3.0 & 4.5 & 3.6 & 3.4 & .6 \\
\hline Purchased Power Cents Per Kilowatthour ............ & 3.6 & 3.7 & 3.8 & 3.8 & 4.2 \\
\hline Generated Cents Per Kilowatthour ........................ & 1.9 & 1.9 & 1.8 & 1.8 & 1.6 \\
\hline $\begin{array}{l}\text { Total Power Supply Per } \\
\text { Kilowatthour Sold }\end{array}$ & 2.6 & 2.6 & 2.6 & 2.6 & 2.6 \\
\hline
\end{tabular}

Note: Totals may not equal sum of components because of independent rounding. The number of publicly owned generating electric utilities for end of period is 226 for 1993,225 for 1992, 218 for 1991, 216 for 1990, and 214 for 1989. Emerald Peoples Utility District (OR) City of Bryan (OH), and Northern Wasco County PUD (OR) were nongenerators for 1989 through 1991, but became generators in 1992. IIIinois Municipal Electric Agency (IL) and Wisconsin Public Power Incorporated System (WI) were nongenerators in 1989 and 1990 , but became generators in 1991. The City of Marshfield (WI) was a generator in 1989 and 1990, but became a nongenerator in 1991.

Source: Energy Information Administration, Form ElA-412, "Annual Report of Public Electric Utilities." Individual electric utilities report fiscal year data. Appendix $\mathrm{B}$ shows the fiscal year for each electric utility. 
Table 8. Electric Operation and Maintenance Expenses for Major U.S. Publicly Owned Generator Electric Utilities, 1989-1993

(Thousand Dollars)

\begin{tabular}{|c|c|c|c|c|c|}
\hline Item & 1993 & 1992 & 1991 & 1990 & 1989 \\
\hline \multicolumn{6}{|l|}{ Production Expenses } \\
\hline 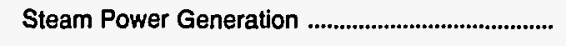 & $4,104,660$ & $3,761,983$ & $3,688,328$ & $3,741,339$ & $3,437,703$ \\
\hline 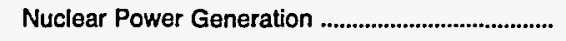 & $1,304,604$ & $1,318,443$ & $1,217,567$ & $1,133,495$ & $1,179,125$ \\
\hline 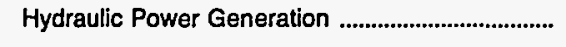 & 241,456 & 244,143 & 225,691 & 204,495 & 187,130 \\
\hline 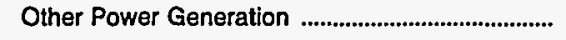 & 178,489 & 175,250 & 167,133 & 196,314 & 170,169 \\
\hline 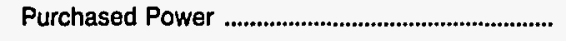 & $5,350,345$ & $5,225,943$ & $5,059,469$ & $5,108,259$ & $4,977,616$ \\
\hline 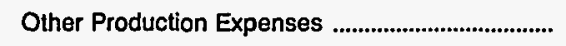 & 127,581 & 72,589 & 88,298 & 105,441 & 61,843 \\
\hline Total Production Expenses & $11,307,136$ & $10,798,351$ & $10,446,486$ & $10,489,344$ & $10,013,586$ \\
\hline Transmission Expenses & 687,949 & 634,583 & 608,062 & 566,408 & 520,387 \\
\hline 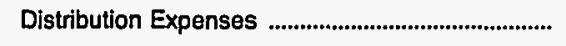 & 812,479 & 767,396 & 700,869 & 651,424 & 615,326 \\
\hline 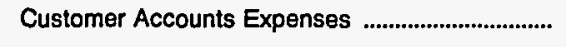 & 314,992 & 299,209 & 290,006 & 273,614 & 248,784 \\
\hline Customer Service and Information Expenses ..... & 94,089 & 82,731 & 73,913 & 60,587 & 63,978 \\
\hline 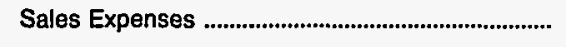 & 17,210 & 17,545 & 18,077 & 18,066 & 11,958 \\
\hline Administrative and General Expenses .................... & $1,573,005$ & $1,492,411$ & $1,463,958$ & $1,344,426$ & $1,322,452$ \\
\hline $\begin{array}{l}\text { Total Electric Operation } \\
\text { and Malntenance Expenses }\end{array}$ & $14,806,860$ & $14,092,227$ & $13,601,370$ & $13,403,870$ & $12,796,471$ \\
\hline \multicolumn{6}{|l|}{ Fuel Expenses in Operation } \\
\hline Steam Power Generation & $3,036,075$ & A $2,733,568$ & $2,634,840$ & $2,394,569$ & $2,142,836$ \\
\hline 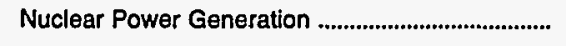 & 299,445 & ${ }^{\text {A }} 303,042$ & 345,206 & 242,283 & 351,899 \\
\hline 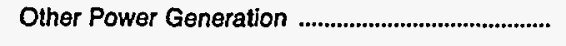 & 102,401 & ${ }^{\mathrm{n}} 82,823$ & 92,111 & 113,038 & 92,268 \\
\hline \multicolumn{6}{|l|}{ Number of Elec Dept Employees } \\
\hline Regular Full-time $e^{\prime}$ & 58,603 & 60,435 & - & - & - \\
\hline Part-time \& Temporary' & 2,610 & 2,812 & - & - & - \\
\hline Total Elec Dept Employees' .................................... & 61,211 & 63,244 & - & - & - \\
\hline
\end{tabular}

1 Data reporting initiated in 1992.

$\mathbf{R}=$ Revised data.

Note: Totals may not equal sum of components because of independent rounding. Detailed data are provided in Table 23. The number of publicly owned generating electric utilities for end of period is 226 for 1993, 225 for 1992, 218 for 1991,216 for 1990 , and 214 for 1989. Emerald Peoples Utility District (OR). City of Bryan (OH), and Northern Wasco County PUD (OR) were nongenerators for 1989 through 1991, but became generators in 1992. Illinois Municipal Electric Agency (IL) and Wisconsin Public Power Incorporated System (WI) were nongenerators in 1989 and 1990, but became generators in 1991. The City of Marshfield (WI) was a generator in 1989 and 1990, but became a nongenerator in 1991.

Source: Energy Information Administration, Form ElA-412, "Annual Report of Public Electric Utilities." Individual electric utilities report fiscal year data. Appendix $B$ shows the fiscal year for each electric utility. 
Table 9. Electric Utility Plant for Major U.S. Publicly Owned Generator Electric Utilities at End of Period, 1989-1993

(Thousand Dollars)

\begin{tabular}{|c|c|c|c|c|c|}
\hline Item & 1993 & 1992 & 1991 & 1990 & 1989 \\
\hline \multicolumn{6}{|l|}{ Electric Plant in Service } \\
\hline 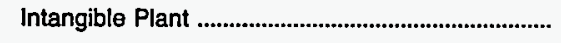 & 341,387 & 284,166 & 364,919 & 318,464 & 382,790 \\
\hline \multicolumn{6}{|l|}{ Production Plant } \\
\hline Steam & $24,169,408$ & $23,346,099$ & $22,488,350$ & $21,219,432$ & $19,120,267$ \\
\hline Nuclear & $18,814,910$ & $18,743,463$ & $19,440,482$ & $18,992,687$ & $18,313,109$ \\
\hline Hydraulic & $7,632,945$ & $7,491,451$ & $6,975,677$ & $6,837,541$ & $6,333,219$ \\
\hline Other & $1,816,249$ & $1,868,084$ & $1,557,135$ & $1,591,090$ & $1,470,073$ \\
\hline 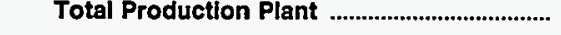 & $52,433,513$ & $51,449,097$ & $50,461,644$ & $48,640,749$ & $45,236,667$ \\
\hline 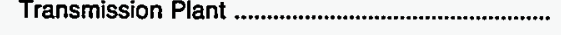 & $8,920,683$ & $8,743,222$ & $8,490,104$ & $7,847,445$ & $7,476,064$ \\
\hline 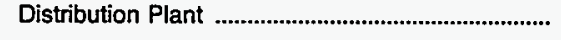 & $14,222,657$ & $13,492,083$ & $12,586,918$ & $11,675,396$ & $11,148,904$ \\
\hline General Plant & $4,573,592$ & $4,143,795$ & $4,073,586$ & $3,790,484$ & $3,258,961$ \\
\hline Total Electric Plant in Service ............................ & $80,491,832$ & $78,112,364$ & $75,977,171$ & $72,272,538$ & $67,503,386$ \\
\hline 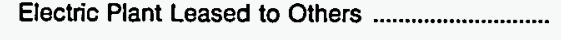 & 16,701 & 67,580 & 565,948 & 482,946 & 478,043 \\
\hline Construction Work in Progress - Electric ................ & $3,777,408$ & $3,532,582$ & $3,909,155$ & $3,938,231$ & $5,371,308$ \\
\hline Electric Plant Held for Future Use ............................ & 321,707 & 305,565 & 626,776 & 819,007 & 743,806 \\
\hline 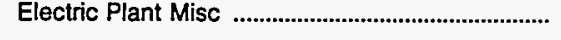 & $1,164,928$ & $1,069,868$ & 456,493 & 731,424 & 568,593 \\
\hline Total Electric Utility Plant ..................................... & $85,772,576$ & $83,087,959$ & $81,535,543$ & $78,244,146$ & $74,665,136$ \\
\hline 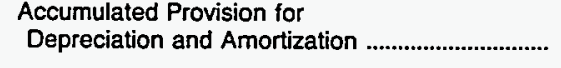 & $24,224,587$ & $22,301,093$ & $20,798,127$ & $18,647,693$ & $16,340,263$ \\
\hline Net Electric Utility Plant ........................................ & $61,547,988$ & $60,786,867$ & $60,737,416$ & $59,596,453$ & $58,324,873$ \\
\hline $\begin{array}{l}\text { Note: Totals may not equal sum of compone } \\
\text { ber of publicly owned generating electric utilities } \\
1989 \text {. Emerald Peoples Utility District (OR), City } \\
\text { through 1991, but became generators in } 1992 \text {. Illi } \\
\text { were nongenerators in } 1989 \text { and } 1990 \text {, but becam } \\
\text { became a nongenerator in } 1991 \text {. } \\
\text { Source: Energy Information Administration, F } \\
\text { fiscal year data. Appendix B shows the fiscal year }\end{array}$ & $\begin{array}{l}\text { decause of ir } \\
\text { Bryan (OH), } \\
\text { Municipal El } \\
\text { Ierators in } 1\end{array}$ & $\begin{array}{l}\text { dent round } \\
\text { for } 1993 \text {, } \\
\text { Northern W } \\
\text { Agency (IL) } \\
\text { The City of }\end{array}$ & $\begin{array}{l}\text { etailed data } \\
\text { I 1992, } 218 \\
\text { County PUD } \\
\text { Visconsin P } \\
\text { field (WI) we }\end{array}$ & $\begin{array}{l}\text { ovided in } T \\
91,216 \text { for } \\
\text { were nong } \\
\text { wer Incorp } \\
\text { inerator in }\end{array}$ & $\begin{array}{l}\text { 4. The num- } \\
\text { and } 214 \text { for } \\
\text { ors for } 1989 \\
\text { System (WI) } \\
\text { nd 1990, but } \\
\text { lities report }\end{array}$ \\
\hline
\end{tabular}


Table 10. Number of Consumers, Sales, and Operating Revenue for Major

U.S. Publicly Owned Generator Electric Utilities, 1989-1993

\begin{tabular}{|c|c|c|c|c|c|}
\hline Item & 1993 & 1992 & 1991 & 1990 & 1989 \\
\hline \multicolumn{6}{|l|}{ Number of Consumers } \\
\hline 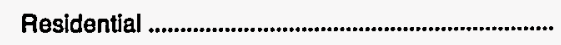 & $7,489,340$ & $7,399,653$ & $7,320,039$ & $7,155,754$ & $7,026,529$ \\
\hline Commercial or Smalt & 985,258 & 977,783 & 894,604 & 893,611 & 929,909 \\
\hline Industrial or Large & 51,989 & 50,465 & 45,202 & 50,829 & 49,864 \\
\hline Other & 92,891 & 158,098 & 162,871 & 164,051 & 137,416 \\
\hline 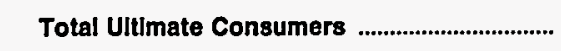 & $8,619,478$ & $8,585,999$ & $8,422,716$ & $8,264,245$ & $8,143,718$ \\
\hline \multicolumn{6}{|l|}{ Sales for the Year (megawatthours) } \\
\hline 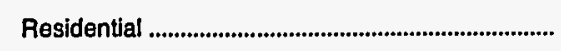 & $74,252,932$ & $71,313,263$ & $71,667,965$ & $70,078,774$ & $68,285,003$ \\
\hline Commercial or Small & $68,401,493$ & $66,801,045$ & $65,283,723$ & $65,302,667$ & $62,908,557$ \\
\hline Industrial or Large & $71,517,638$ & $70,698,216$ & $68,550,382$ & $67,376,604$ & $64,856,200$ \\
\hline Other & $17,804,844$ & $17,977,295$ & $17,643,031$ & $17,378,120$ & $15,418,212$ \\
\hline Total Sales to Ultimate Consumers ................... & $231,976,907$ & $226,789,819$ & $223,145,101$ & $220,136,165$ & $211,467,972$ \\
\hline Sales for Resale & $198,650,136$ & $184,259,846$ & $183,508,522$ & $184,836,059$ & $181,607,993$ \\
\hline 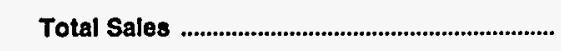 & $430,627,043$ & $411,049,665$ & $406,653,623$ & $404,972,224$ & $393,075,965$ \\
\hline \multicolumn{6}{|l|}{$\begin{array}{l}\text { Operating Revenues for the Year } \\
\text { (thousand dollars) }\end{array}$} \\
\hline 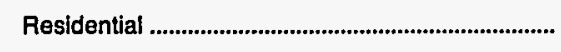 & $5,168,480$ & $4,885,087$ & $4,759,672$ & $4,673,479$ & $4,456,953$ \\
\hline Commercial or Small & $4,658,839$ & $4,434,108$ & $4,244,293$ & $4,296,416$ & $4,015,774$ \\
\hline 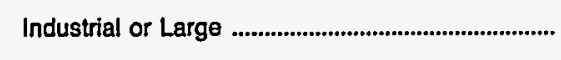 & $3,365,369$ & $3,243,937$ & $3,117,161$ & $3,014,459$ & $2,950,948$ \\
\hline Other & $1,279,902$ & $1,242,026$ & $1,105,045$ & $1,142,976$ & $1,008,679$ \\
\hline 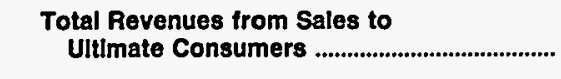 & $14,472,590$ & $13,805,158$ & $13,226,171$ & $13,127,330$ & $12,432,354$ \\
\hline Sales for Resale & $7,592,335$ & $7,246,170$ & $6,995,157$ & $7,051,730$ & $6,818,991$ \\
\hline $\begin{array}{l}\text { Total Revenues From Sales of } \\
\text { Electricity }\end{array}$ & $22,064,925$ & $21,051,328$ & $20,221,328$ & $20,179,060$ & $19,251,345$ \\
\hline
\end{tabular}

Note: Totals may not equal sum of components because of independent rounding. Detailed data are provided in Table 25. The number of publicly owned generating electric utilities for end of period is 226 for 1993, 225 for 1992, 218 for 1991, 216 for 1990, and 214 for 1989. Emerald Peoples Utility District (OR), City of Bryan (OH), and Northern Wasco County PUD (OR) were nongenerators for 1989 through 1991, but became generators in 1992. Illinois Municipal Electric Agency (IL) and Wisconsin Public Power Incorporated System (WI) were nongenerators in 1989 and 1990, but became generators in 1991. The City of Marshfield (WI) was a generator in 1989 and 1990, but became a nongenerator in 1991. sions.

Source: Energy Information Administration, Form ElA-861, "Annual Electric Utility Report." Data are based on calendar year submis- 
Table 11. Electric Energy Account for Major U.S. Publicly Owned Generator Electric Utilities, 1989-1993

(Megawatthours)

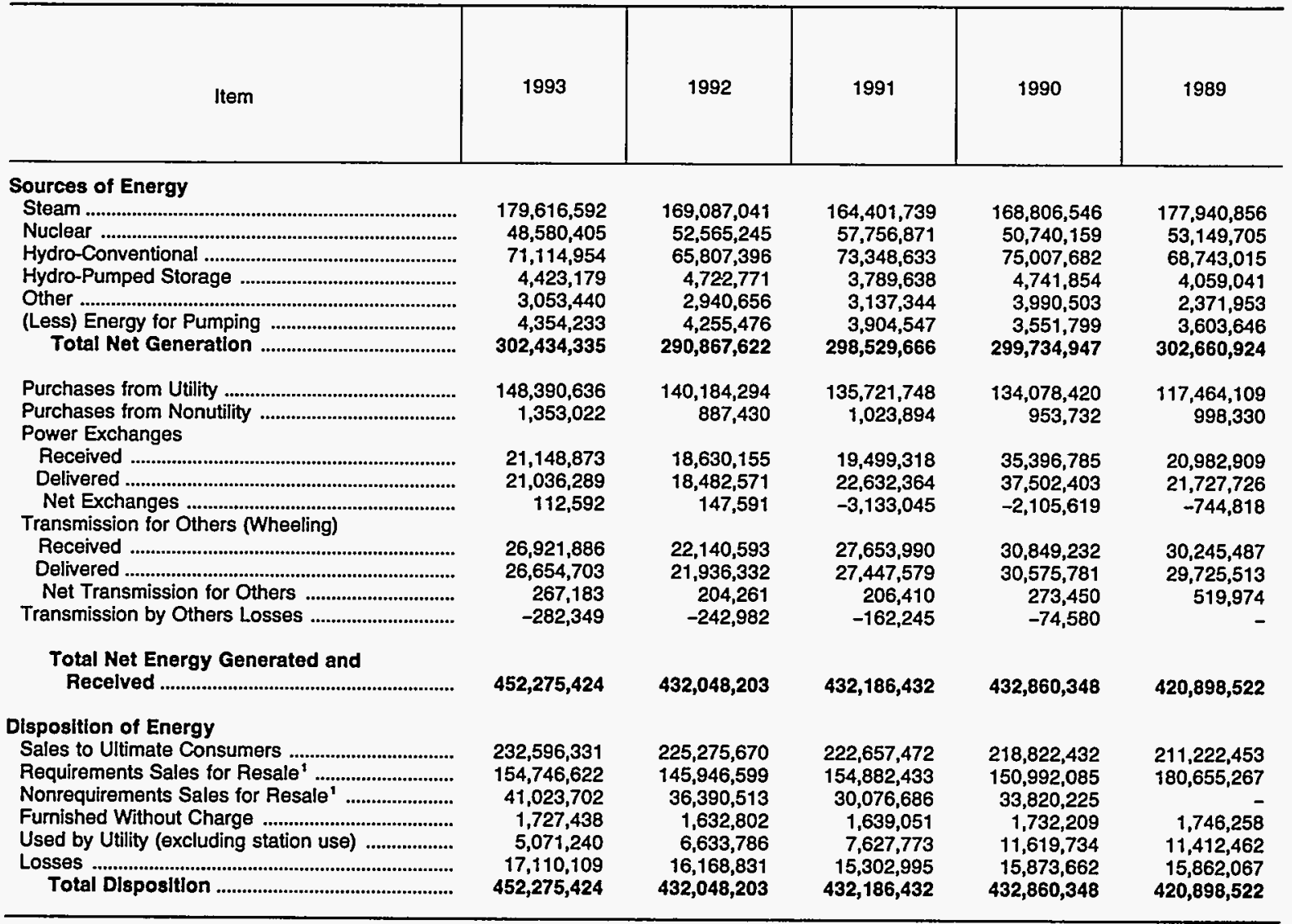

1 The 1989 data were reported as Sales for Resale (one entry) which is shown as Requirements Sales for Resale.

Note: Totals may not equal sum of components because of independent rounding. Detailed data are provided in Table 26. The number of publicly owned generating electric utilitios for end of period is 226 for 1993,225 for 1992,218 for 1991,216 for 1990 , and 214 for 1989. Emerald Peoples Utility District (OR), City of Bryan (OH), and Northern Wasco County PUD (OR) were nongenerators for 1989 through 1991, but became generators in 1992. Illinois Municipal Electric Agency (IL) and Wisconsin Public Power Incorporated System (WI) were nongenerators in 1989 and 1990, but became generators in 1991 . The City of Marshfield (WI) was a generator in 1989 and 1990 , but became a nongenerator in 1991. Double counting occurs in components of both sources and disposition of energy and thus neither provides a true total. Purchases from utilities, net exchanges, and net wheeling (except for imports) are included in net generation. Sales for resale is included in sales to ultimate consumers.

Source: Energy Information Administration, Form EIA-412, "Annual Report of Public Electric Utilities." Individual electric utilities report fiscal year data. Appendix B shows the fiscal year for each electric utility. 


\section{Financial Performance for Nongenerator Electric Utilities}

Summary financial statistics are provided for major publicly owned nongenerator electric utilities. These statistics include 269 electric utilities for 1993; 258 electric utilities for 1992; 252 electric utilities for 1991; 251 electric utilities for 1990; and 240 electric utilities for 1989. The new respondents, as well as the electric utilities that are no longer reporting from the previous years, are listed in Appendix B.

\section{Highlights of Nongenerator Financial Performance}

With total electric utility operating costs increasing slower than revenues in 1993, the nongenerator electric utilities net income was up 7.5 percent. Key indicators of the nongenerator electric utilities financial performance were:

- Income before extraordinary items was up 14.4 percent in 1993.

- Total electric operating expenses were up only 3.2 percent over the previous year.

- Interest expense increased 4.7 percent in 1993.

- Long-term debt outstanding at the end of the year increased $\$ 0.2$ billion in 1993.

\section{Income Statement}

The Composite Statement of Income for major publicly owned nongenerator electric utilities for the years 1989 to 1993 is presented (Table 14). Net income of $\$ 0.4$ billion for nongenerator electric utilities was up 7.5 percent over the prior year. Income before extraordinary items was up 14.4 percent to $\$ 0.4$ billion in 1993.

Revenues. Nongenerator electric utilities revenues were up 3.8 percent to $\$ 7.5$ billion in 1993. Increased sales were a major contributing factor to the increased revenues. Revenues from sales to ultimate consumers increased by $\$ 0.3$ billion in 1993.

Electric Utility Operating Expenses. Total electric utility operating expenses of $\$ 7.1$ billion were up 3.2 percent over the previous year. The largest dollar increase was in operation expenses, up 2.9 percent or $\$ 0.2$ billion in 1993. Operation expenses accounted for 91.0 percent of the total electric utility operating expenses. The second largest contributor is depreciation expense, which accounted for 3.6 percent of total electric utility operating expenses, was up 1.9 percent over the prior year. Maintenance expenses accounted for 2.9 percent of the total. Tax and tax equivalents were up 12.7 percent in 1993. These tax expenses accounted for 2.5 percent of the total electric utility operating expenses in 1993.

Production Expenses. Production expenses were up 2.6 percent over the prior year, accounting for $\$ 5.8$ billion of expenses (Table 17). Purchased power expenses represented virtually all ( 99.7 percent) of production expenses. These expenses were 42.5 on a mills per kilowatthour sold basis (Table 19).

Transmission and Distribution Expenses. Transmission expenses accounted for only 0.3 mills per kilowatthour sold, down 7.0 percent in 1993. However, on a total dollar basis, transmission expenses were down 3.2 percent (accounting for less than $\$ 0.1$ billion). Distribution expenses accounted for 2.9 mills per kilowatthour sold or $\$ 0.4$ billion dollars of operation and maintenance expenses. Distribution costs were up 8.1 percent in dollar terms and 3.7 percent in terms of mills per kilowatthour sold in 1993.

Electric Utility Income. With revenues increasing more than total electric operating expenses, net electric utility operating income was up 13.9 percent to $\$ 0.5$ billion in 1993. Other electric income contributed significantly less in 1993 to the bottom line for nongenerator electric utilities. Electric utility income was up 16.9 percent to $\$ 0.6$ billion in 1993, up from $\$ 0.5$ billion in 1992.

Interest Expense. The nongenerator electric utilities increased their debt by $\$ 0.2$ billion for the year ending 1993, while interest expenses went up 4.7 percent. Interest expenses amounted to $\$ 0.1$ billion in 1993.

Net Income. The higher interest expense reduced income before extraordinary items somewhat, but it still increased a substantial 14.4 percent to $\$ 0.4$ billion in 1993. The corresponding figure in 1992 was $\$ 0.3$ billion.

\section{Balance Sheet}

The Composite Balance Sheet for publicly owned nongenerator electric utilities revealed a healthy 7.6-percent increase for the year (Table 15).

Assets and Other Debits. Increases in electric utility plant, cash working funds and investments, and total deferred debits contributed the most significant gains on the asset side of the balance sheet in 1993, increasing 7.8 percent, 16.2 percent, and 9.7 percent, respectively. Total assets and other debits amounted to $\$ 10.1$ billion in 1993, up from $\$ 9.4$ billion in 1992.

Electric Utility Plant. Electric utility plant in service increased 7.8 percent to $\$ 8.0$ billion in 1993 (Table 18). Distribution plant investment was primarily responsible, increasing 10.6 percent from $\$ 5.4$ billion in 1992 to $\$ 5.9$ billion in 1993. In 1993, distribution plant represented 74.4 percent of total utility electric plant in service for the nongenerator electric utilities. Other significant changes in the asset accounts included:

- Other property and investment increased 1.1 percent, or 18.9 percent of total assets and other 
debits in 1993, as compared with 20.1 percent in 1992.

- Construction work in progress (CWIP) remained a relatively small $\$ 0.3$ billion in 1993. CWIP as a percent of total electric utility plant was 3.1 percent in 1993, down from 3.3 percent in 1992.

- Cash working funds and investments accounted for $\$ 1.3$ billion, or $\mathbf{5 3 . 2}$ percent of the current and accrued assets in 1993. This account increased $\$ 0.2$ billion, or 16.2 percent for the year, and now represents 13.1 percent of total assets and other debits, as compared with 12.2 percent in 1992.

- Deferred debits increased a healthy 9.7 percent between 1992 and 1993, but still represented a relatively insignificant 4.2 percent of total assets and other debits in 1993.

Liabilities and Other Credits. The most significant increase in liabilities and other credits was the 8.4 percent increase in total proprietary capital. This account represents the equity that the nongenerator electric utilities have in electric operations. In 1993, the equity fraction of total capitalization (assumed here to be defined as the sum of total proprietary capital and total long-term debt) increased to 67.3 percent, compared with 67.0 percent in 1992. This ratio represents one of the most distinguishing differences between the generator and nongenerator electric utilities. For the generator electric utilities, this equity ratio was 23.6 percent in 1993 . Other significant changes in the liabilities and other credits included:

- Long-term debt at year-end increased from $\$ 2.7$ billion in 1992 to $\$ 2.9$ billion in 1993, a 6.8-percent increase.

- Accounts payable increased $\$ 0.1$ billion, up 9.8 percent from the prior year. Accounts payable amounted to $\$ 0.7$ billion of the $\$ 1.0$ billion in total current and accrued liabilities.

\section{Consumers, Sales, and Revenue}

Sales Growth. Sales to ultimate consumers of the nongenerator electric utilities grew 4.5 percent in 1993, a significant improvement over the 0.7 percent sales growth between 1991 and 1992 (Table 19). Commercial sales increased at a more modest 1.4-percent rate, while industrial sales expanded 5.8 percent. A colder first quarter combined with a warmer third quarter helped increase the weather sensitive residential sales. The improved economy contributed to the increase in commercial sales and industrial sales.

The variance in the growth rates across the sectors slightly shifted the relative sector mix to ultimate con- sumers. This is another area where the nongenerator electric utilities varied significantly from their generator counterparts. The commercial share of total sales of nongenerator electric utilities to ultimate consumers accounted for only 17.2 percent. In the case of the generator electric utilities, commercial sales accounted for 29.5 percent of total sales (a figure more in line with that of the investor-owned segment of the electric power industry).

Average Revenue (Revenues Divided by Sales). Residential and commercial consumers increased, but the industrial consumers experienced a decrease. Industrial consumers saw a 1.1-percent decline in average revenue. Residential consumers experienced a 0.7 -percent increase in average revenue paid for electricity, averaging 60.6 mills per kilowatthour. Commercial consumers paid 65.5 mills per kilowatthour and industrial consumers paid 49.1 mills per kilowatthour.

In 1993, decreases in consumption per consumer in the residential and commercial sectors were 2.0 percent and 2.2 percent, respectively. Industrial consumption per consumer decreased 1.0 percent. The average monthly bill paid by residential, commercial and industrial consumers amounted to $\$ 64.33, \$ 233.23$, and $\$ 4,582.22$, respectively. The residential monthly bill increased 2.7 percent, while the commercial and industrial monthly bills declined 1.1 percent and 2.0 percent, respectively.

Resale sales decreased 1.1 percent between 1992 and 1993. Sales for resale accounted for 5.5 percent of the total nongenerator electric utility sales of electricity in 1993, essentially unchanged from its 5.8 percent share of sales in 1992. As one might expect, without any significant generating resources of their own, sales for resale in the nongenerator segment are not very significant to the overall sales and revenues of these entities. In 1993, sales for resale revenues accounted for $\$ 0.3$ billion dollars or 3.3 percent of total revenues from the sale of electricity.

Total revenues were up 4.7 percent for the year, as seen in Table 19. The increase in revenues in 1993 were driven in large part (90.4 percent) by the increase in sales volume. Average revenues remained unchanged at 55.4 mills per kilowatthour sold. In 1992, just 47.6 percent of the revenue increase was due to the increase in sales.

\section{Purchased Power}

In 1993, purchased power from electric utilities and nonutilities increased 3.8 percent to 141.3 million megawatthours. 
Table 12. Ten Largest U.S. Publicly Owned Nongenerator Electric Utilities Ranked by Megawatthour Sales to Ultimate Consumers, 1993

\begin{tabular}{|c|c|c|c|}
\hline Publlcly Owned Electric Utilitles & State & Amount & Percent \\
\hline Memphis City of & Tennessee & $11,075,238$ & 8.69 \\
\hline 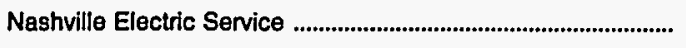 & Tennessee & $9,976,634$ & 7.83 \\
\hline Chattanooga City of & Tennessee & $5,262,184$ & 4.13 \\
\hline 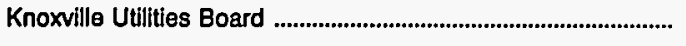 & Tennessee & $4,568,275$ & 3.59 \\
\hline Huntsville City of & Alabama & $3,544,599$ & 2.78 \\
\hline PUD No 1 of Clark County & Washington & $3,430,257$ & 2.69 \\
\hline 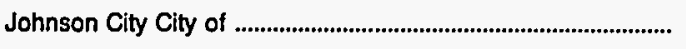 & Tennessee & $1,472,763$ & 1.16 \\
\hline Decatur City of & Alabama & $1,382,214$ & 1.09 \\
\hline PUD No 1 of Benton County & Washington & $1,360,014$ & 1.07 \\
\hline Central Lincoln Peoples Utt Dt & Oregon & $1,314,113$ & 1.03 \\
\hline 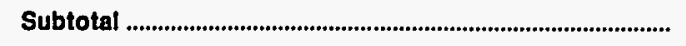 & & $43,386,291$ & 34.06 \\
\hline
\end{tabular}

Note: Percentage calculations are based on total nongenerator electric utilities.

Source: Energy Information Administration, Form EIA-412, "Annual Report of Public Electric Utilities." Individual electric utilities report fiscal year data. Appendix B shows the fiscal year for each electric utility.

Table 13. Ten Largest U.S. Publicly Owned Nongenerator Electric Utilities Ranked by Megawatthour Sales for Resale, 1993

\begin{tabular}{|c|c|c|c|}
\hline Publlcly Owned Electrlc UtIlities & State & Amount & Percent \\
\hline 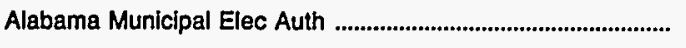 & Alabama & $2,272,157$ & 30.98 \\
\hline 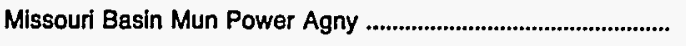 & South Dakota & $1,824,685$ & 24.88 \\
\hline 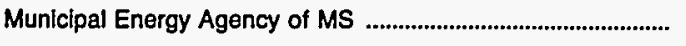 & Mississippi & 818,696 & 11.16 \\
\hline 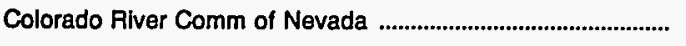 & Nevada & 768,468 & 10.48 \\
\hline Arizona Power Authority & Arizona & 612,863 & 8.36 \\
\hline 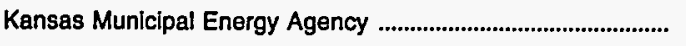 & Kansas & 323,038 & 4.40 \\
\hline 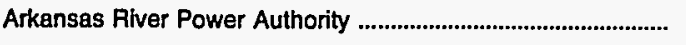 & Colorado & 274,109 & 3.74 \\
\hline 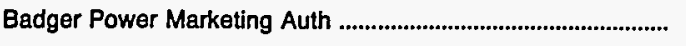 & Wisconsin & 249,200 & 3.40 \\
\hline Wilson City of & North Carolina & 58,814 & .80 \\
\hline Redding City of & California & 23,778 & .32 \\
\hline 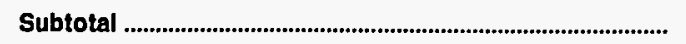 & & $7,225,808$ & 98.53 \\
\hline
\end{tabular}

Note: Percentage calculations are based on total nongenerator electric utilities.

Source: Energy Information Administration, Form EIA-412, "Annual Report of Public Electric Utilities." Individual electric utilities report fiscal year date. Appendix $B$ shows the fiscal year for each electric utility. 
Table 14. Composite Statement of Income for Major U.S. Publicly Owned Nongenerator Electric Utilities, 1989-1993

(Thousand Dollars)

\begin{tabular}{|c|c|c|c|c|c|}
\hline Item & 1993 & 1992 & 1991 & 1990 & 1989 \\
\hline Electrlc Utillty Operating Revenues .................. & $7,523,453$ & $7,247,407$ & $7,119,875$ & $6,978,752$ & $6,552,712$ \\
\hline 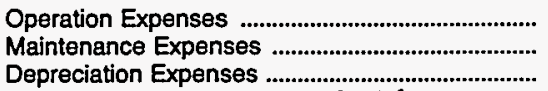 & $\begin{array}{r}6,424,798 \\
207,046 \\
252,850\end{array}$ & $\begin{array}{r}6,244,831 \\
192,635 \\
248,040\end{array}$ & $\begin{array}{r}6,119,385 \\
186,267 \\
246,594\end{array}$ & $\begin{array}{r}6,030,028 \\
191,621 \\
231,197\end{array}$ & $\begin{array}{r}5,693,914 \\
182,509 \\
200,580\end{array}$ \\
\hline Amort, Prop Losses and Reg Study ${ }^{\prime}$.......................... & 3,887 & 3,039 & - & - & - \\
\hline 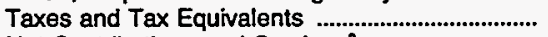 & 174,681 & 154,994 & 138,491 & 133,125 & 124,160 \\
\hline 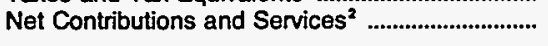 & - & - & 168,882 & 154,956 & 153,431 \\
\hline $\begin{array}{c}\text { Total Electric Utility Operating } \\
\text { Expenses }\end{array}$ & $7,063,260$ & $6,843,539$ & $6,859,619$ & $6,740,926$ & $6,354,593$ \\
\hline $\begin{array}{l}\text { Net Electric Utility Operating Income } \\
\text { Income from Electric Plant Leased }\end{array}$ & 460,193 & 403,868 & 260,255 & 237,826 & 198,118 \\
\hline to Others & 2,405 & 1.773 & 3,264 & 2,121 & 1,727 \\
\hline Electric Utillty Operating Income ..................... & 462,598 & 405,642 & 263,520 & 239,948 & 199,845 \\
\hline Other Electric Income & 172,569 & 172,938 & 147,117 & 154,240 & 169,518 \\
\hline $\begin{array}{l}\text { Other Electric Deductions } \\
\text { Allowance for Other Funds Used }\end{array}$ & 74,084 & 98,838 & 13,949 & - & - \\
\hline During Construction & 106 & 39 & 1,606 & -213 & -302 \\
\hline Taxes on Other Income and Deduct ' ${ }^{\prime}$..................... & 2,174 & 1,427 & - & - & - \\
\hline 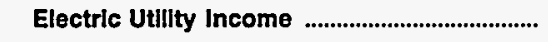 & 559,015 & 478,354 & 398,294 & 393,975 & 369,062 \\
\hline 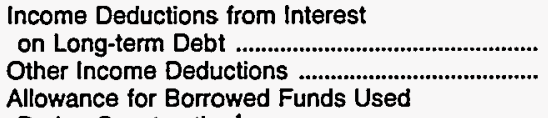 & $\begin{array}{r}114,527 \\
58,534\end{array}$ & $\begin{array}{r}109,378 \\
31,560\end{array}$ & $\begin{array}{r}112,031 \\
27,775\end{array}$ & $\begin{array}{r}109,972 \\
27,340\end{array}$ & $\begin{array}{r}101,469 \\
20,934\end{array}$ \\
\hline During Construction ${ }^{1}$ & -270 & -78 & - & - & - \\
\hline Total Income Deductions ................................. & 172,792 & 140,861 & 139,806 & 137,311 & 122,403 \\
\hline 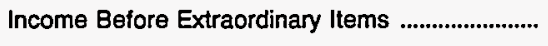 & 386,223 & 337,493 & 258,488 & 256,663 & 246,658 \\
\hline Extraordinary Income & 17,981 & 35,508 & 24,074 & 5,274 & 26,641 \\
\hline 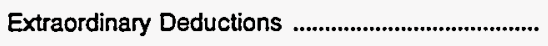 & 43,581 & 37,664 & 33,326 & 16,589 & 11,691 \\
\hline Net Income & 360,624 & 335,338 & 249,236 & 245,348 & 261,608 \\
\hline
\end{tabular}

Data reporting initiated in 1992.

2 Data reporting discontinued in 1992

- Data not available.

Note: Totals may not equal sum of components because of independent rounding. Detailed data are provided in Table 21 . The number of publicly owned nongenerating electric utilities for end of period is 269 for 1993, 258 for 1992, 252 for 1991,251 for 1990 , and 240 for 1989. Emerald Peoples Utility District (OR), City of Bryan (OH), and Northern Wasco County PUD (OR) were nongenerators for 1989 through 1991, but became generators in 1992. Illinois Municipal Electric Agency (IL) and Wisconsin Public Power Incorporated System (WI) were nongenerators in 1989 and 1990, but became generators in 1991. The City of Marshfield (WI) was a generator in 1989 and 1990, but became a nongenerator in 1991.

Source: Energy Information Administration, Form ElA-412, "Annual Report of Public Electric Utilities." Individual electric utilities report fiscal year data. Appendix B shows the fiscal year for each electric utility. 
Table 15. Composite Balance Sheet for Major U.S. Publicly Owned Nongenerator Electric Utilities at End of Period, 1989-1993

(Thousand Dollars)

\begin{tabular}{|c|c|c|c|c|c|}
\hline Item & 1993 & 1992 & 1991 & 1990 & 1989 \\
\hline \multicolumn{6}{|l|}{ Electric Utility Plant } \\
\hline 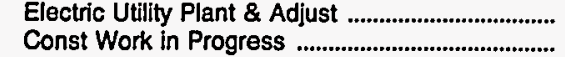 & $\begin{array}{r}8,055,891 \\
261,205\end{array}$ & $\begin{array}{r}7,474,793 \\
258,244\end{array}$ & $\begin{array}{r}7,318,688 \\
-\end{array}$ & $6,861,881$ & $6,344,572$ \\
\hline (less) Depr, Amort, and Depletion ............................. & $3,048,867$ & $2,852,034$ & $2,656,267$ & $2,454,302$ & $2,231,882$ \\
\hline 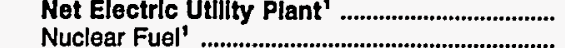 & $5,268,229$ & $4,881,003$ & - & - & - \\
\hline 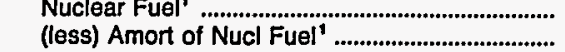 & $\begin{array}{l}- \\
-\end{array}$ & - & $\overline{-}$ & $\overline{-}$ & 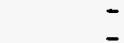 \\
\hline 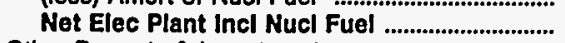 & $5,268,229$ & $4,881,003$ & $4,662,42 \overline{1}$ & $4,407,579$ & $4,112,690$ \\
\hline \multicolumn{6}{|l|}{ Other Property \& Investments } \\
\hline Nonutility Property & $1,503,937$ & $1,407,105$ & $1,368,349$ & $1,351,755$ & $1,296,434$ \\
\hline (less) Accum Provisions for Depr \& Amort ........... & 374,268 & 331,064 & 310,379 & 294,492 & 270,584 \\
\hline 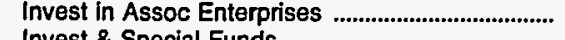 & 20,759 & 16,768 & 10,274 & 11,269 & $\mathbf{8 , 1 2 0}$ \\
\hline Invest \& Special Funds & 761,295 & 797,642 & 781,364 & 702,051 & 676,096 \\
\hline \multicolumn{2}{|l|}{ Current and Accrued Assets } & $1,890,451$ & $1,849,607$ & $1,770,583$ & $1,710,066$ \\
\hline Cash, Working Funds \& Investments ...................... & $1,327,201$ & $1,142,447$ & $1,103,512$ & 976,625 & 959,146 \\
\hline 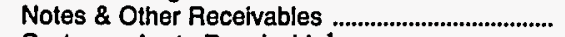 & 377,135 & 311,782 & 743,971 & 762,732 & 710,705 \\
\hline 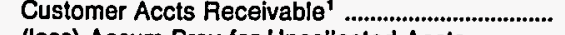 & 374,415 & 377,995 & & & \\
\hline (less) Accum Prov for Uncollected Accts ............... & 19.173 & 21,554 & 20,887 & 18,993 & 17,998 \\
\hline Fuel Stock \& Exp Undistr ${ }^{1}$ & 264 & 1,180 & & - & \\
\hline 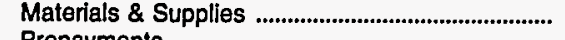 & 176,825 & 168,474 & 167,291 & 167,884 & 166,343 \\
\hline 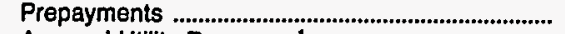 & 151,504 & 155,980 & 104,547 & 130,823 & 50,268 \\
\hline 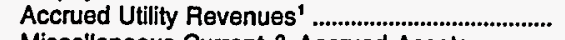 & 31,701 & 29,411 & & - & - \\
\hline Miscellaneous Current \& Accrued Assets ............ & 75,888 & 61,368 & 63,698 & 44,859 & 65,816 \\
\hline $\begin{array}{l}\text { Total Current \& Accrued Assets ........................ } \\
\text { Deferred Deblts }\end{array}$ & $2,495,760$ & $2,227,084$ & $2,162,131$ & $2,063,931$ & $1,934,281$ \\
\hline Unamortized Debt Expenses ............................................ & 109,026 & 91,016 & 70,967 & 64,706 & Delerreo Deblts \\
\hline 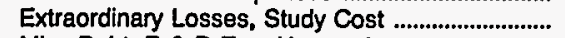 & 6,718 & 4,360 & & & $0,0<1$ \\
\hline Misc Debt, R \& D Exp, Unamrt Losses ................. & 308,163 & 290,887 & 253,473 & 206,745 & 197,007 \\
\hline Total Deferred Debits & 423,907 & 386,263 & 324,440 & 271,452 & 249,834 \\
\hline $\begin{array}{l}\text { Total Assets \& Other Deblts } \\
\text { Proprietary Capital }\end{array}$ & $10,099,620$ & $9,384,801$ & $8,998,600$ & $8,513,545$ & $8,006,871$ \\
\hline 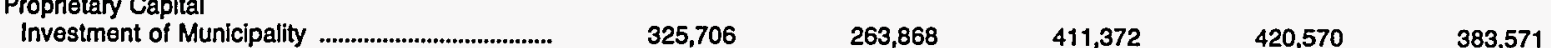 & 325,706 & 263,868 & 411,372 & 420,570 & 383,571 \\
\hline 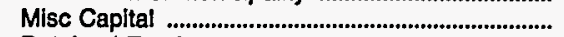 & 450,733 & 429,805 & 466,780 & 396,386 & 401,346 \\
\hline 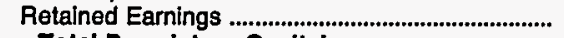 & $5,206,936$ & $4,828,568$ & $4,366,799$ & $4,177,166$ & $3,890,337$ \\
\hline $\begin{array}{l}\text { Total Proprletary Capltal ....................................... } \\
\text { Long-term Debt }\end{array}$ & $5,983,376$ & $5,522,242$ & $5,244,951$ & $4,994,123$ & $4,675,254$ \\
\hline 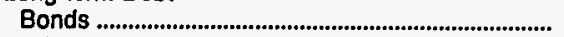 & $2,470,313$ & $2,277,558$ & $2,174,746$ & $1,989,076$ & $1,854,737$ \\
\hline Advances from Municipality \& Other ....................... & 442,009 & 440,938 & 383,340 & 374,749 & 383,084 \\
\hline Unamort Prem on Long-term Debt .......................... & 543 & 9,962 & 2,437 & 2,190 & 1,082 \\
\hline (less) Unamort Discount on Long-term Debt ....... & 14,048 & 14,736 & 18,088 & 17,340 & 22,004 \\
\hline 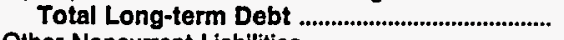 & $2,898,817$ & $2,713,721$ & $2,542,435$ & $2,348,676$ & $2,216,899$ \\
\hline \multicolumn{6}{|l|}{ Other Noncurrent Liabilities } \\
\hline 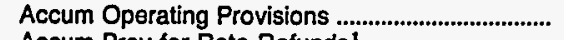 & 10,525 & 10,078 & 55,488 & 38,157 & 40,842 \\
\hline Accum Prov for Rate Refunds ${ }^{1}$ & 224 & 206 & - & - & \\
\hline $\begin{array}{l}\text { Total Other Noncurrent Llabilitles ..................... } \\
\text { Current and Accrued Liabilities }\end{array}$ & $10, \overline{749}$ & 10,284 & 55,488 & 38,157 & 40,842 \\
\hline 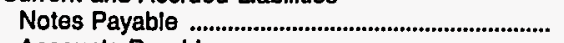 & 54,495 & 50,560 & 69,765 & 51,547 & 46,566 \\
\hline Accounts Payable & 667,104 & 607,825 & 592,275 & 611,501 & 576,639 \\
\hline 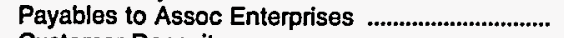 & 10,391 & 16,355 & 29,095 & 22,803 & 28,338 \\
\hline 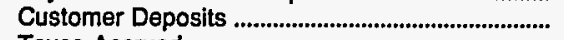 & 137,456 & 125,964 & 116,132 & 106,199 & 96,505 \\
\hline 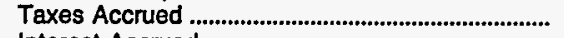 & 23,935 & 21,355 & 36,991 & 17,762 & 17,816 \\
\hline 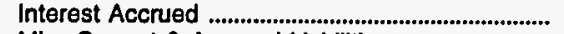 & 36,594 & 59,637 & 40,611 & 51,094 & 37,435 \\
\hline 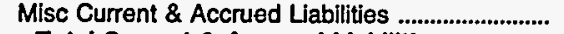 & 109,891 & 102,169 & 84,054 & 88,440 & 83,779 \\
\hline $\begin{array}{l}\text { Total Current \& Accrued Llabilitles } \\
\text { Defe.................. }\end{array}$ & $1,039,867$ & 982,587 & 968,924 & 949,345 & 887,078 \\
\hline Customer Advances for Construction ...................... & 57,474 & 48,058 & 48,299 & 43,976 & 38,156 \\
\hline 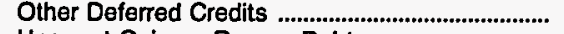 & 107,830 & 101,658 & 136,614 & 139,170 & 143,843 \\
\hline Unamort Gain on Reacqr Debt ......................................... & 1,508 & 4,973 & 1,890 & & 4,800 \\
\hline 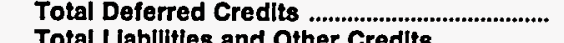 & 166,812 & 154,689 & 186,803 & 183,244 & 186,799 \\
\hline Total Llabllitles and Other Credits ..................... & $10,099,620$ & $9,384,801$ & $8,998,600$ & $8,513,545$ & $8,006,871$ \\
\hline
\end{tabular}

Data reporting initiated in 1992.

Note: Totals may not equal sum of components because of independent rounding. Detailed data are provided in Table 22 . The number of publicly owned nongenerating electric utilities for end of period is 269 for 1993,258 for 1992,252 for 1991,251 for 1990 , and 240 for 1989. Emerald Peoples Utility District (OR), City of Bryan (OH), and Northern Wasco County PUD (OR) were nongenerators for 1989 through 1991, but became generators in 1992. Illinois Municipal Electric Agency (IL) and Wisconsin Public Power Incorporated System (WI) were nongenerators in 1989 and 1990, but became generators in 1991. The City of Marshfield (WI) was a generator in 1989 and 1990, but became a nongenerator in 1991 .

Source: Energy Information Administration, Form EIA-412, "Annual Report of Public Electric Utilities." Individual electric utilities report fiscal year data. Appendix B shows the fiscal year for each electric utility. 
Table 16. Composite Financial Indicators for Major U.S. Publicly Owned Nongenerator Electric Utilities, 1989-1993

\begin{tabular}{|c|c|c|c|c|c|}
\hline Item & 1993 & 1992 & 1991 & 1990 & 1989 \\
\hline Total Electric Utility Plant per Dollar of Revenue & 1.1 & 1.1 & 1.0 & 1.0 & 1.0 \\
\hline Current Assets to Current Liabilities .......................... & 2.4 & 2.3 & 2.2 & 2.2 & 2.2 \\
\hline $\begin{array}{l}\text { Total Electric Utility Plant as a Percent of Total } \\
\text { Assets }\end{array}$ & 82.4 & 82.4 & 81.3 & 80.6 & 79.2 \\
\hline $\begin{array}{l}\text { Net Electric Utility Plant as a Percent of Total } \\
\text { Assets }\end{array}$ & 52.2 & 52.0 & 51.8 & 51.8 & 51.4 \\
\hline Debt as a Percent of Total Liabilities ..................... & 39.0 & 39.4 & 39.0 & 38.7 & 38.8 \\
\hline $\begin{array}{l}\text { Depreciation, Amortization and Depletion } \\
\text { as a Percent of Total Electric Utility Plant ........... }\end{array}$ & 36.7 & 36.9 & 36.3 & 35.8 & 35.2 \\
\hline $\begin{array}{l}\text { Electric Operation and Maintenance Expenses } \\
\text { as a Percent of } \\
\text { Electric Utility Operating Revenues ............................. }\end{array}$ & 88.1 & 88.8 & 88.6 & 89.2 & 89.7 \\
\hline $\begin{array}{l}\text { Electric Depreciation and Amortization } \\
\text { as a Percent of } \\
\text { Electric Utility Operating Revenues ......................... }\end{array}$ & 3.4 & 3.4 & 3.5 & 3.3 & 3.1 \\
\hline $\begin{array}{l}\text { Taxes and Tax Equivalents } \\
\text { as a Percent of } \\
\text { Electric Utility Operating Revenues ......................... }\end{array}$ & 2.3 & 2.1 & 1.9 & 1.9 & 1.9 \\
\hline $\begin{array}{l}\text { Interest on Long-term Debt } \\
\text { as a Percent of } \\
\text { Electric Utility Operating Revenues ........................ }\end{array}$ & 1.5 & 1.5 & 1.6 & 1.6 & 1.5 \\
\hline 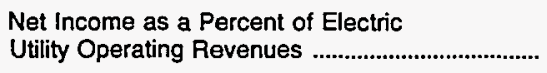 & 4.8 & 4.6 & 3.5 & 3.5 & 4.0 \\
\hline Purchased Power Cents Per Kilowatthour ............ & 4.1 & 4.1 & 4.1 & 4.0 & 4.0 \\
\hline
\end{tabular}

Note: Totals may not equal sum of components because of independent rounding. The number of publicly owned nongenerating electric utilities for end of period is 269 for 1993, 258 for 1992, 252 for 1991, 251 for 1990, and 240 for 1989 . Emerald Peoples Utility District (OR). City of Bryan (OH), and Northern Wasco County PUD (OR) were nongenerators for 1989 through 1991, but became generators in 1992. Illinois Municipal Electric Agency (IL) and Wisconsin Public Power Incorporated System (WI) were nongenerators in 1989 and 1990, but became generators in 1991. The City of Marshfield (WI) was a generator in 1989 and 1990, but became a nongenerator in 1991.

Source: Energy Information Administration, Form EIA-412, "Annual Report of Public Electric Utilities." Individual electric utilities report fiscal year data. Appendix $B$ shows the fiscal year for each electric utility. 
Table 17. Electric Operation and Maintenance Expenses for Major U.S. Publicly Owned Nongenerator Electric Utilities, 1989-1993 (Thousand Dollars)

\begin{tabular}{|c|c|c|c|c|c|}
\hline Item & 1993 & 1992 & 1991 & 1990 & 1989 \\
\hline \multicolumn{6}{|l|}{ Production Expenses } \\
\hline 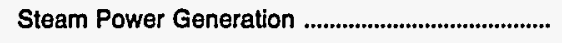 & 362 & 416 & 544 & 230 & 263 \\
\hline 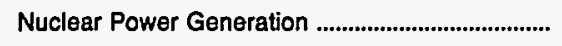 & - & - & - & - & - \\
\hline 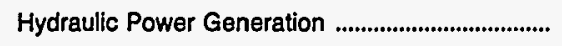 & 92 & 15 & 7 & 17 & 52 \\
\hline 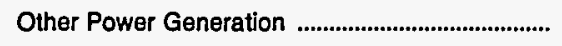 & 1,249 & 622 & 97 & 105 & 1,802 \\
\hline 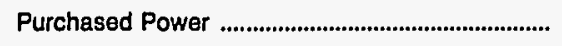 & $5,746,737$ & $5,608,871$ & $5,511,698$ & $5,433,716$ & $5,022,464$ \\
\hline 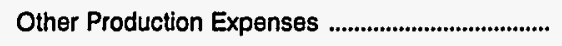 & 13,283 & 7,993 & 14,274 & 49,529 & 37,305 \\
\hline 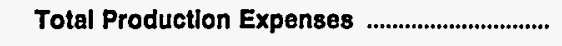 & $5,761,722$ & $5,617,918$ & $5,526,621$ & $5,483,597$ & $5,061,887$ \\
\hline Transmission Expenses & 41,796 & 43,128 & 37,107 & 37,609 & 31,930 \\
\hline Distribution Expenses & 386,932 & 357,995 & 326,810 & 298,847 & 373,048 \\
\hline 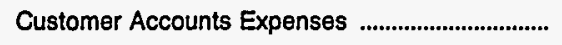 & 117,353 & 109,196 & 103,456 & 101,115 & 95,413 \\
\hline Customer Service and Information Expenses ...... & 17,166 & 15,629 & 15,743 & 14,123 & 13,993 \\
\hline Sales Expenses & 8,704 & 11,646 & 11,587 & 11,283 & 5,657 \\
\hline 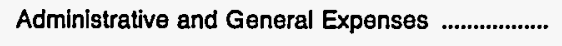 & 298,151 & 281,954 & 284,327 & 275,073 & 294,495 \\
\hline $\begin{array}{l}\text { Total Electric Operation } \\
\text { and Maintenance Expenses }\end{array}$ & $6,631,823$ & $6,437,466$ & $6,305,652$ & $6,221,649$ & $5,876,423$ \\
\hline
\end{tabular}

Fuel Expenses In Operation

Steam Power Generation

Nuclear Power Generation

Other Power Generation

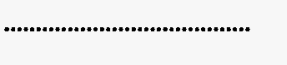

13
-
5

2

$\begin{array}{ll}-3 & - \\ - & - \\ 3 & -\end{array}$

Number of Elec Dept Employees

Regular Full-time'

Part-time \& Temporary'

14,458

1,031

1,054

Total Elec Dept Employees'

15,743

15,514

- Data reporting initiated in 1992.

Note: Totals may not equal sum of components because of independent rounding. Detailed data are provided in Table 23. The number of publlcly owned nongenerating electric utilities for end of period is 269 for 1993,258 for 1992, 252 for 1991, 251 for 1990, and 240 for 1989. Emerald Peoples Utility District (OR), City of Bryan (OH), and Northern Wasco County PUD (OR) were nongenerators for 1989 through 1991, but became generators in 1992. Illinois Municipal Electric Agency (IL) and Wisconsin Public Power Incorporated System (WI) were nongenerators in 1989 and 1990, but became generators in 1991. The City of Marshfield (WI) was a generator in 1989 and 1990, but became a nongenerator in 1991.

Source: Energy Information Administration, Form EIA-412, "Annual Report of Public Electric Utilities." Individual electric utilities report fiscal year data. Appendix $B$ shows the fiscal year for each electric utility. 
Table 18. Electric Utility Plant for Major U.S. Publicly Owned Nongenerator Electric Utilities at End of Period, 1989-1993

(Thousand Dollars)

\begin{tabular}{|c|c|c|c|c|c|}
\hline Item & 1993 & 1992 & 1991 & 1990 & 1989 \\
\hline \multicolumn{6}{|l|}{ Electric Plant in Servlce } \\
\hline 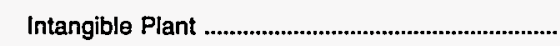 & 10,565 & 10,549 & 8,292 & 7,521 & 8,019 \\
\hline \multicolumn{6}{|l|}{ Production Plant } \\
\hline Steam & 69,761 & 69,727 & 68,062 & 27,215 & 71,049 \\
\hline Nuclear & - & - & - & - & - \\
\hline Hydraulic & 15,334 & 15,334 & 15,334 & 15,334 & 14,956 \\
\hline Other & 27,082 & 18,984 & 19,164 & 48,607 & 14,954 \\
\hline Total Production Plant & 112,177 & 104,045 & 102,560 & 91,156 & 100,959 \\
\hline Transmission Plant & 628,184 & 602,713 & 589,808 & 501,168 & 460,099 \\
\hline Distribution Plant & $5,923,094$ & $5,354,892$ & $5,192,372$ & $4,904,220$ & $4,537,394$ \\
\hline 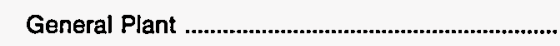 & $1,286,857$ & $1,312,183$ & $1,147,474$ & $1,076,942$ & 968,309 \\
\hline Total Electric Plant in Service & $7,960,877$ & $7,384,383$ & $7,040,506$ & $6,581,006$ & $6,074,779$ \\
\hline 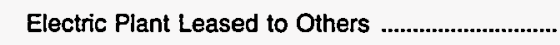 & 704 & 615 & 662 & 708 & 640 \\
\hline Construction Work in Progress - Electric .................. & 261,205 & 258,244 & 210,030 & 212,939 & 188,487 \\
\hline 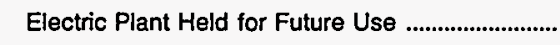 & 16,268 & 16,074 & 13,860 & 11,391 & 10,638 \\
\hline Electric Plant Misc & 78,042 & 73,722 & 53,630 & 55,837 & 70,028 \\
\hline 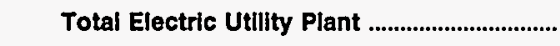 & $8,317,096$ & $7,733,037$ & $7,318,688$ & $6,861,881$ & $6,344,572$ \\
\hline 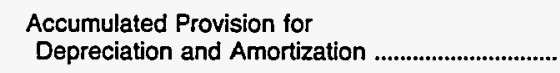 & $3,048,867$ & $2,852,034$ & $2,656,267$ & $2,454,302$ & $2,231,882$ \\
\hline Net Electric Utillty Plant & $5,268,229$ & $4,881,003$ & $4,662,421$ & $4,407,579$ & $4,112,690$ \\
\hline
\end{tabular}

Note: Totals may not equal sum of components because of independent rounding. Detailed data are provided in Table 24. The number of publicly owned nongenerating electric utilities for end of period is 269 for 1993, 258 for 1992, 252 for 1991, 251 for 1990, and 240 for 1989. Emerald Peoples Utility District (OR), City of Bryan (OH), and Northern Wasco County PUD (OR) were nongenerators for 1989 through 1991, but became generators in 1992. Illinois Municipal Electric Agency (IL) and Wisconsin Public Power Incorporated System (WI) were nongenerators in 1989 and 1990, but became generators in 1991. The City of Marshfield (WI) was a generator in 1989 and 1990, but became a nongenerator in 1991.

Source: Energy Information Administration, Form EIA-412, "Annual Report of Public Electric Utilities." Individual electric utilitles report fiscal year data. Appendix B shows the fiscal year for each electric utility. 
Table 19. Number of Consumers, Sales, and Operating Revenue for Major U.S. Publicly Owned Nongenerator Electric Utilities, 1989-1993

\begin{tabular}{|c|c|c|c|c|c|}
\hline Item & 1993 & 1992 & 1991 & 1990 & 1989 \\
\hline \multicolumn{6}{|l|}{ Number of Consumers } \\
\hline 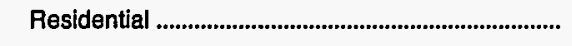 & $3,829,989$ & $3,705,525$ & $3,624,017$ & $3,556,400$ & $3,454,820$ \\
\hline Commercial or Small & 517,511 & 499,250 & 503,917 & 493,348 & 451,940 \\
\hline Industrial or Large & 48,650 & 45,537 & 30,629 & 31,854 & 35,684 \\
\hline Other & 68,043 & 87,037 & 103,377 & 99,949 & 94,973 \\
\hline 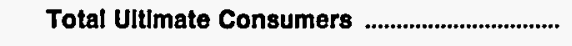 & $4,464,193$ & $4,337,349$ & $4,261,940$ & $4,181,551$ & $4,037,417$ \\
\hline \multicolumn{6}{|l|}{ Sales for the Year (megawatthours) } \\
\hline 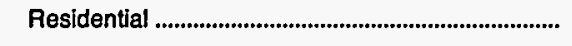 & $48,803,402$ & $46,306,852$ & $46,808,977$ & $45,347,843$ & $44,021,341$ \\
\hline Commercial or Small & $22,128,772$ & $21,815,955$ & $26,987,619$ & $25,768,440$ & $23,530,515$ \\
\hline Industrial or Large & $54,445,292$ & $51,453,636$ & $44,693,894$ & $43,948,454$ & $42,770,643$ \\
\hline Other & $2,669,498$ & $2,936,880$ & $3,146,985$ & $3,055,644$ & $2,987,372$ \\
\hline Total Sales to Ultimate Consumers ..................... & $128,046,964$ & $122,513,323$ & $121,637,475$ & $118,120,381$ & $113,309,871$ \\
\hline Sales for Resale & $7,428,071$ & $7,506,885$ & $7,288,781$ & $10,767,467$ & $8,041,747$ \\
\hline Total Sales & $135,475,035$ & $130,020,208$ & $128,926,256$ & $128,887,848$ & $121,351,618$ \\
\hline \multicolumn{6}{|l|}{$\begin{array}{l}\text { Operating Revenues for the Year } \\
\text { (thousand dollars) }\end{array}$} \\
\hline 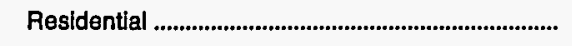 & $2,956,794$ & $2,785,966$ & $2,752,710$ & $2,659,845$ & $2,557,348$ \\
\hline Commercial or Small & $1,448,420$ & $1,412,309$ & $1,680,252$ & $1,596,862$ & $1,453,940$ \\
\hline Industrial or Large & $2,675,104$ & $2,553,929$ & $2,188,095$ & $2,150,794$ & $2,093,283$ \\
\hline Other & 182,112 & 189,783 & 198,756 & 190,987 & 183,333 \\
\hline $\begin{array}{l}\text { Total Revenues from Sales to } \\
\text { Ultimate Consumers }\end{array}$ & $7,262,430$ & $6,941,987$ & $6,819,813$ & $6,598,488$ & $6,287,904$ \\
\hline Sales for Resale & 246,614 & 232,879 & 226,388 & 345,818 & 256,140 \\
\hline $\begin{array}{l}\text { Total Revenues From Sales of } \\
\text { Electriclty }\end{array}$ & $7,509,044$ & $7,174,866$ & $7,046,201$ & $6,944,306$ & $6,544,044$ \\
\hline
\end{tabular}

Note: Totals may not equal sum of components because of independent rounding. Detailed data are provided in Table 25. The number of publicly owned nongenerating electric utilities for end of period is 269 for 1993,258 for 1992, 252 for 1991, 251 for 1990 , and 240 for 1989. Emerald Peoples Utility District (OR), City of Bryan (OH), and Northern Wasco County PUD (OR) were nongenerators for 1989 through 1991, but became generators in 1992. Illinois Municipal Electric Agency (IL) and Wisconsin Public Power Incorporated System (WI) were nongenerators in 1989 and 1990, but became generators in 1991. The City of Marshfield (WI) was a generator in 1989 and 1990, but became a nongenerator in 1991. sions.

Source: Energy Information Administration, Form EIA-861, "Annual Electric Utility Report." Data are based on calendar year submis- 
Table 20. Electric Energy Account for Major U.S. Publicly Owned Nongenerator Electric Utilities, 1989-1993

(Megawatthours)

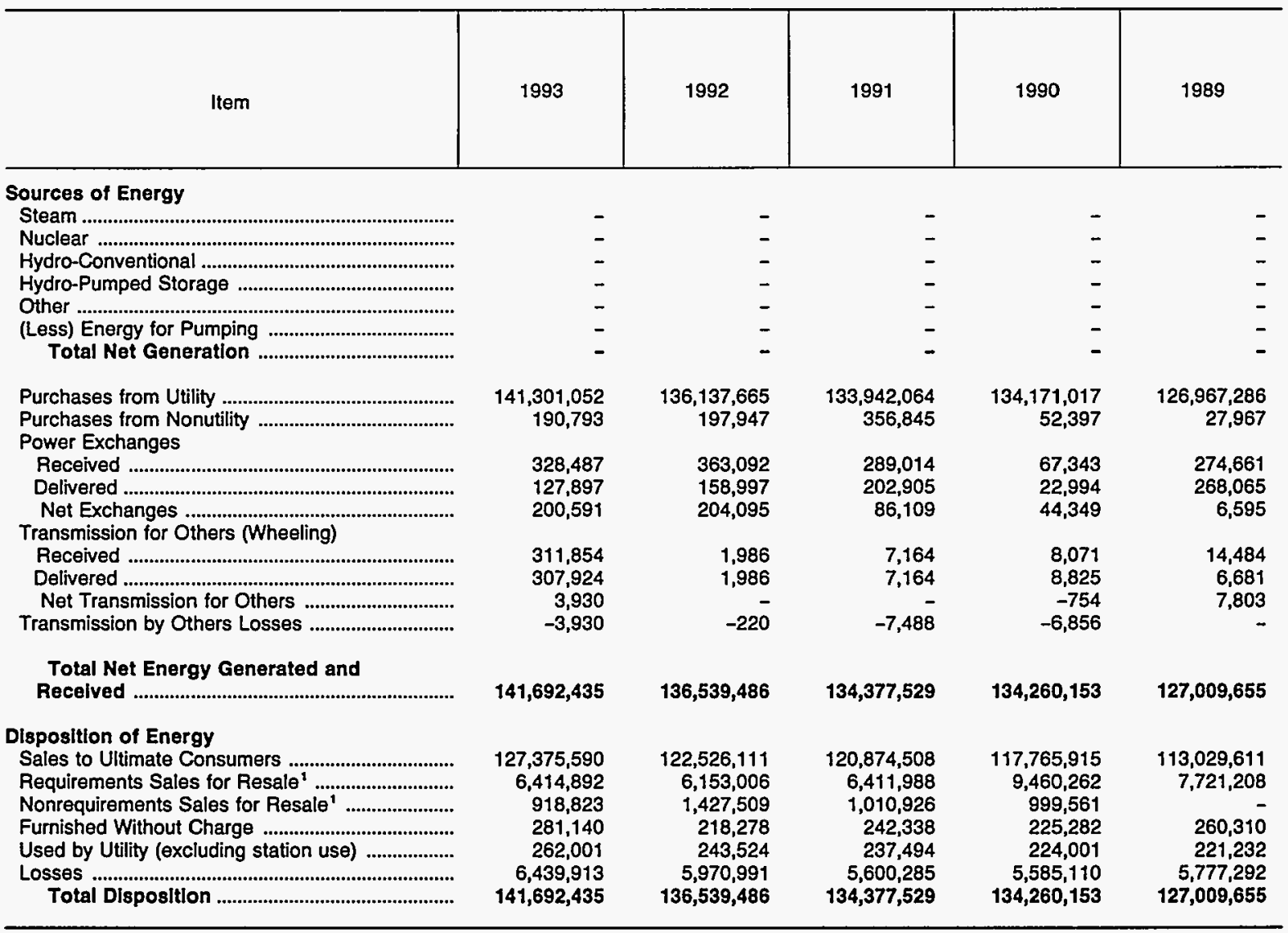

1 The 1989 data were reported as Sales for Resale (one entry) which is shown as Requirements Sales for Resale.

Note: Totals may not equal sum of components because of independent rounding. Detailed data are provided in Table 26. The number of publicly owned nongenerating electric utilities for end of period is 269 for 1993,258 for 1992,252 for 1991,251 for 1990 , and 240 for 1989. Emerald Peoples Utility District (OR), City of Bryan (OH), and Northern Wasco County PUD (OR) were nongenerators for 1989 through 1991, but became generators in 1992. Illinois Municipal Electric Agency (IL) and Wisconsin Public Power Incorporated System (WI) were nongenerators in 1989 and 1990, but became generators in 1991. The City of Marshfield (WI) was a generator in 1989 and 1990, but became a nongenerator in 1991. Double counting occurs in components of both sources and disposition of energy and thus neither provides a true total. Purchases from utilities, net exchanges, and net wheeling (except for imports) are included in net generation. Sales for resale is included in sales to ultimate consumers.

Source: Energy Information Administration, Form ElA-412, "Annual Report of Public Electric Utilities." Individual electric utilitles report fiscal year data. Appendix B shows the fiscal year for each electric utility. 


\section{Detailed Statistics of Major U.S. Publicly Owned Electric Utilities}

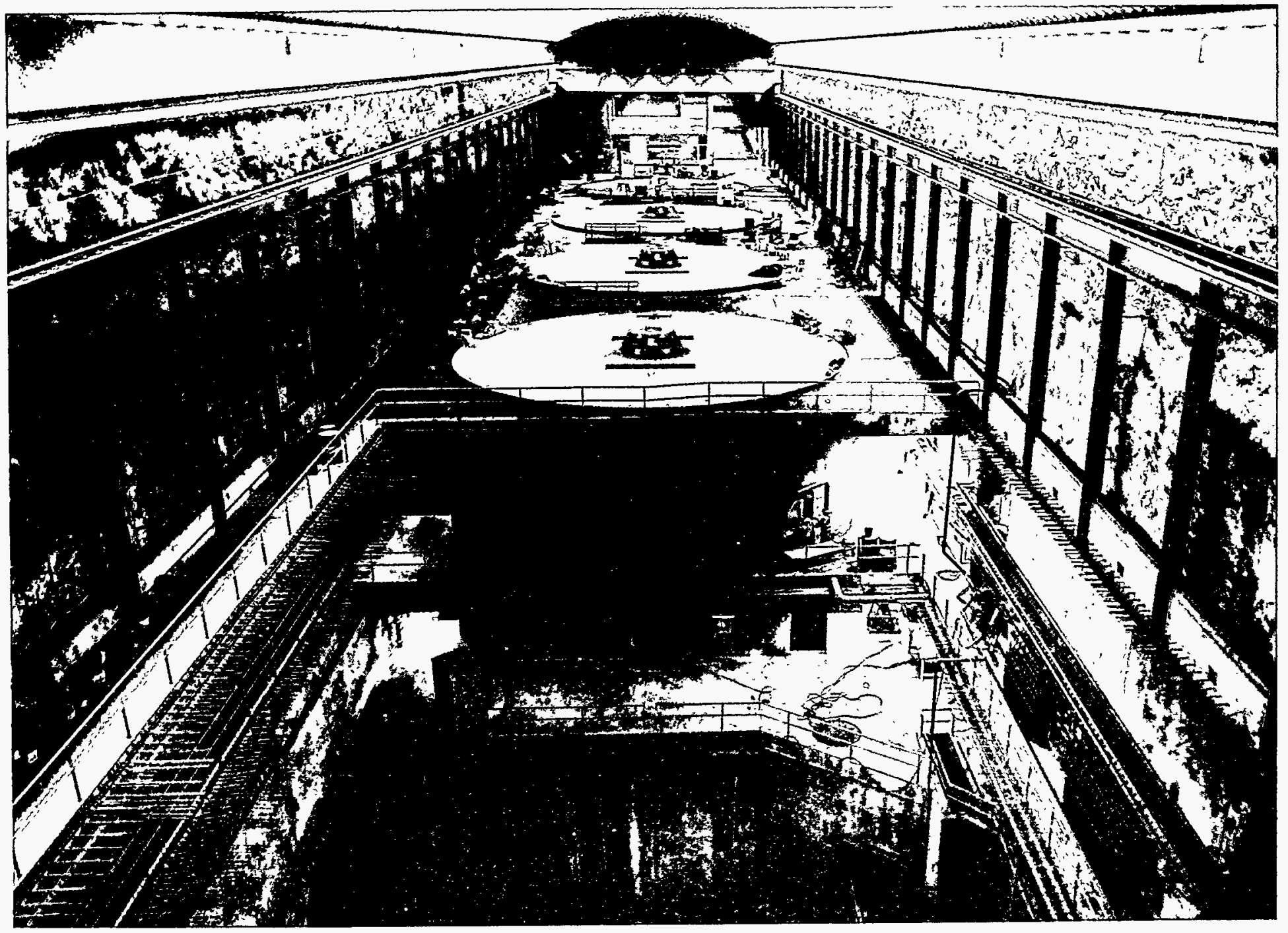

The underground powerhouse of Boundary Dam is located in Pend Oreille County, State of Washington, and owned by the City of Seattle. 
Table 21. Statement of Income by Major U.S. Publicly Owned Electric Utility Within State, 1993

(Thousand Dollars)

\begin{tabular}{|c|c|c|c|c|c|c|}
\hline Item & $\begin{array}{l}\text { Alabama } \\
\text { Alabama } \\
\text { Municipal } \\
\text { Elec Auth } \\
\text { September } 30\end{array}$ & $\begin{array}{l}\text { Alabama } \\
\text { Albertville } \\
\text { Municipal } \\
\text { Utils Bd } \\
\text { June } 30\end{array}$ & $\begin{array}{c}\text { Alabama } \\
\text { Andalusia } \\
\text { City of }\end{array}$ & $\begin{array}{l}\text { Alabama } \\
\text { Athens } \\
\text { City of }\end{array}$ & $\begin{array}{l}\text { Alabama } \\
\text { Bessemer } \\
\text { City of } \\
\text { June } 30\end{array}$ & $\begin{array}{l}\text { Alabama } \\
\text { Cullman } \\
\text { Power Board } \\
\text { June } 30\end{array}$ \\
\hline Electric Utility Operating Revenues ............. & 87,818 & 18,896 & 14,353 & 36,061 & 16,809 & 16,060 \\
\hline 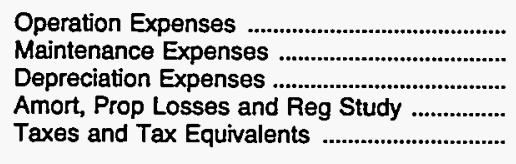 & $\begin{array}{r}66,084 \\
0 \\
20 \\
0 \\
915\end{array}$ & $\begin{array}{r}17,438 \\
484 \\
493 \\
0 \\
379\end{array}$ & $\begin{array}{r}11,895 \\
105 \\
315 \\
0 \\
1,364\end{array}$ & $\begin{array}{r}31,845 \\
784 \\
911 \\
0 \\
881\end{array}$ & $\begin{array}{r}15,397 \\
835 \\
545 \\
0 \\
814\end{array}$ & $\begin{array}{r}14,914 \\
318 \\
390 \\
0 \\
247\end{array}$ \\
\hline $\begin{array}{l}\text { Total Electric Utility Operating } \\
\text { Expenses }\end{array}$ & 67,018 & 18,794 & 13,678 & 34,421 & 17,592 & 15,869 \\
\hline $\begin{array}{l}\text { Net Electric Utility Operating Income } \\
\text { Income from Electric Plant Leased } \\
\text { to Others }\end{array}$ & $\begin{array}{r}20,800 \\
0\end{array}$ & 101 & 674 & 1,641 & $\begin{array}{r}-783 \\
0\end{array}$ & 192 \\
\hline Electric Utillty Operating Income ............. & 20,800 & 101 & 674 & 1,641 & -783 & 192 \\
\hline 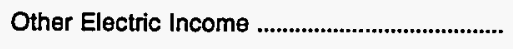 & 3,426 & 222 & 67 & 700 & 220 & 147 \\
\hline $\begin{array}{l}\text { Other Electric Deductions .................................. } \\
\text { Allowance for Other Funds Used }\end{array}$ & 11,892 & 7 & 0 & 0 & 0 & 1 \\
\hline 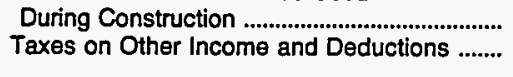 & $\begin{array}{l}0 \\
0\end{array}$ & $\begin{array}{l}0 \\
0\end{array}$ & $\begin{array}{l}0 \\
0\end{array}$ & $\begin{array}{l}0 \\
0\end{array}$ & $\begin{array}{l}0 \\
0\end{array}$ & $\begin{array}{l}0 \\
0\end{array}$ \\
\hline 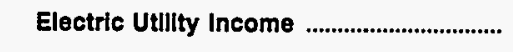 & 12,334 & 316 & 741 & 2,341 & -563 & 338 \\
\hline 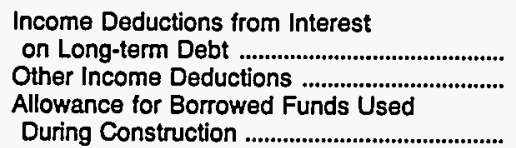 & $\begin{array}{r}12,283 \\
0\end{array}$ & $\begin{array}{l}0 \\
0\end{array}$ & $\begin{array}{l}0 \\
0\end{array}$ & $\begin{array}{r}1,005 \\
35\end{array}$ & $\begin{array}{r}155 \\
2\end{array}$ & $\begin{array}{r}98 \\
3\end{array}$ \\
\hline 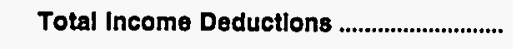 & 12,283 & 0 & 0 & 1,040 & 157 & 101 \\
\hline Income Before Extraordinary Items ................... & 51 & 316 & 741 & 1,301 & -721 & 237 \\
\hline Extraordinary income & $\mathbf{0}$ & 0 & 0 & 31 & 0 & 0 \\
\hline 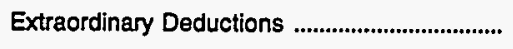 & 0 & 0 & 0 & 0 & 0 & 0 \\
\hline 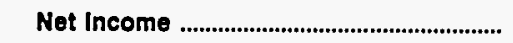 & 51 & 316 & 741 & 1,332 & -721 & 237 \\
\hline
\end{tabular}

Note: Totals may not equal sum of components because of independent rounding.

Source: Energy Information Administration, Form ElA-412, "Annual Report of Public Electric Utilities." 
Table 21. Statement of Income by Major U.S. Publicly Owned Electric Utility Within State, 1993 (Continued)

(Thousand Dollars)

\begin{tabular}{|c|c|c|c|c|c|c|}
\hline Item & $\begin{array}{l}\text { Alabama } \\
\text { Decatur } \\
\text { City of } \\
\text { June } 30\end{array}$ & $\begin{array}{l}\text { Alabama } \\
\text { Dothan } \\
\text { City of } \\
\text { September } 30\end{array}$ & $\begin{array}{l}\text { Alabama } \\
\text { Florence } \\
\text { City of } \\
\text { June } 30\end{array}$ & $\begin{array}{c}\text { Alabama } \\
\text { Foley } \\
\text { City of } \\
\text { (Riviera Utils) } \\
\text { December } 31\end{array}$ & $\begin{array}{c}\text { Alabama } \\
\text { Fort Payne } \\
\begin{array}{c}\text { Improvement } \\
\text { Auth }\end{array} \\
\text { June } 30\end{array}$ & $\begin{array}{l}\text { Alabama } \\
\text { Guntersville } \\
\text { Electric } \\
\text { Board } \\
\text { June } 30\end{array}$ \\
\hline Electric Utillty Operatlng Revenues ............. & 58,121 & 53,644 & 56,245 & 32,433 & 15,831 & 11,578 \\
\hline 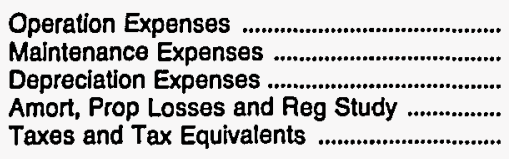 & $\begin{array}{r}54,271 \\
681 \\
1,229 \\
33 \\
999\end{array}$ & $\begin{array}{r}38,598 \\
1,204 \\
1,698 \\
0 \\
0\end{array}$ & $\begin{array}{r}50,633 \\
1,802 \\
2,168 \\
0 \\
1,960\end{array}$ & $\begin{array}{r}23,282 \\
579 \\
1,873 \\
0 \\
2,654\end{array}$ & $\begin{array}{r}14,199 \\
344 \\
327 \\
0 \\
279\end{array}$ & $\begin{array}{r}10,535 \\
261 \\
263 \\
0 \\
228\end{array}$ \\
\hline 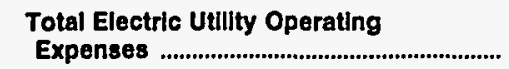 & 57,213 & 41,500 & 56,562 & 28,387 & 15,148 & 11,288 \\
\hline 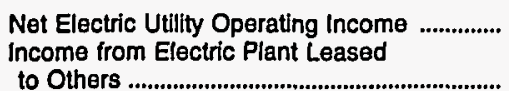 & 908 & 12,144 & -317 & 4,045 & 683 & 291 \\
\hline Electrle Utllity Operating Income ............. & 908 & 12,144 & -317 & 4,050 & 683 & 291 \\
\hline 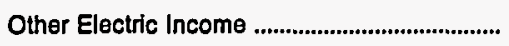 & 366 & 0 & 1,014 & 512 & 293 & 165 \\
\hline 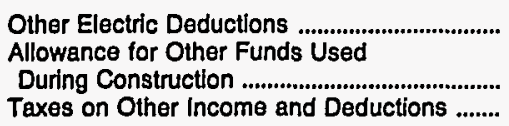 & $\begin{array}{l}0 \\
0\end{array}$ & $\begin{array}{l}0 \\
0\end{array}$ & $\begin{array}{l}0 \\
0\end{array}$ & $\begin{array}{l}0 \\
0\end{array}$ & $\begin{array}{l}0 \\
0\end{array}$ & $\begin{array}{l}0 \\
0\end{array}$ \\
\hline Electric Utillty Income & 1,274 & 12,144 & 697 & 4,562 & 976 & 455 \\
\hline 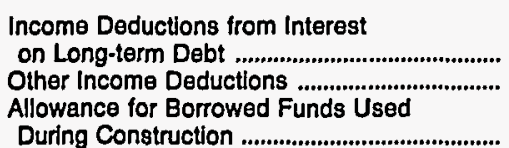 & $\begin{array}{l}0 \\
0\end{array}$ & $\begin{array}{l}0 \\
0\end{array}$ & $\begin{array}{l}317 \\
257\end{array}$ & $\begin{array}{r}832 \\
20\end{array}$ & $\begin{array}{r}325 \\
35\end{array}$ & $\begin{array}{r}25 \\
1\end{array}$ \\
\hline 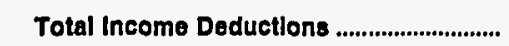 & 0 & 0 & 574 & 852 & 360 & 26 \\
\hline Income Before Extraordinary ltems .................. & 1,274 & 12,144 & 123 & 3,711 & 616 & 429 \\
\hline Extraordinary Income & 0 & 0 & 0 & 0 & 128 & 0 \\
\hline 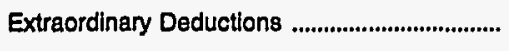 & 0 & 0 & 0 & 0 & 0 & 0 \\
\hline Not Income & 1,274 & 12,144 & 123 & 3,711 & 744 & 429 \\
\hline
\end{tabular}

Note: Totals may not equal sum of components because of independent rounding.

Source: Energy Information Administration, Form EIA-412, "Annual Report of Public Electric Utilities." 
Table 21. Statement of Income by Major U.S. Publicly Owned Electric Utility Within State, 1993 (Continued) (Thousand Dollars)

\begin{tabular}{|c|c|c|c|c|c|c|}
\hline Item & $\begin{array}{c}\text { Alabama } \\
\text { Huntsville } \\
\text { City of } \\
\text { September } 30\end{array}$ & $\begin{array}{l}\text { Alabama } \\
\text { Muscle } \\
\text { Shoals } \\
\text { City of } \\
\text { June } 30\end{array}$ & $\begin{array}{l}\text { Alabama } \\
\text { Opelika } \\
\text { City of } \\
\text { September } 30\end{array}$ & $\begin{array}{l}\text { Alabama } \\
\text { Scottsboro } \\
\text { City of } \\
\text { June } 30\end{array}$ & $\begin{array}{l}\text { Alabama } \\
\text { Sheffield } \\
\text { Utilities } \\
\text { June } 30\end{array}$ & $\begin{array}{c}\text { Alabama } \\
\text { Sylacauga } \\
\text { Utilities } \\
\text { Board } \\
\text { September } 30\end{array}$ \\
\hline Electric Utility Operating Revenues ............. & 183,179 & 10,690 & 16,283 & 15,997 & 23,542 & 11,178 \\
\hline 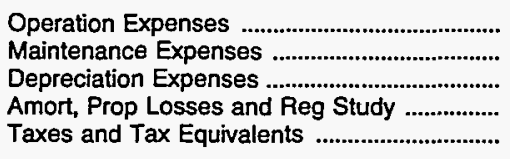 & $\begin{array}{r}168,116 \\
2,841 \\
4,812 \\
0 \\
4,965\end{array}$ & $\begin{array}{r}9,506 \\
285 \\
389 \\
0 \\
370\end{array}$ & $\begin{array}{r}13,193 \\
450 \\
578 \\
0 \\
0\end{array}$ & $\begin{array}{r}14,314 \\
546 \\
454 \\
0 \\
306\end{array}$ & $\begin{array}{r}20,538 \\
921 \\
994 \\
21 \\
677\end{array}$ & $\begin{array}{r}6,983 \\
195 \\
673 \\
0 \\
0\end{array}$ \\
\hline $\begin{array}{l}\text { Total Electric Utillty Operating } \\
\text { Expenses }\end{array}$ & 180,733 & 10,550 & 14,221 & 15,620 & 23,152 & 7,851 \\
\hline 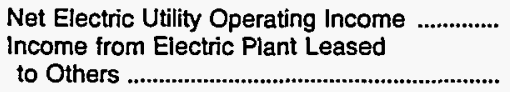 & 2,446 & 140 & 2,062 & 377 & 390 & 3,327 \\
\hline Electric Utility Operating Income .............. & 2,446 & 140 & 2,062 & 377 & 390 & 3,327 \\
\hline Other Electric Income & 4,505 & 149 & 247 & 220 & 543 & 0 \\
\hline $\begin{array}{l}\text { Other Electric Deductions } \\
\text { Allowance for Other Funds Used }\end{array}$ & 0 & 1 & 131 & 0 & 23 & 1,108 \\
\hline $\begin{array}{l}\text { During Construction ............................. } \\
\text { Taxes on Other Income and Deductions ...... }\end{array}$ & $\begin{array}{l}0 \\
0\end{array}$ & $\begin{array}{l}0 \\
0\end{array}$ & $\begin{array}{l}0 \\
0\end{array}$ & $\begin{array}{l}0 \\
0\end{array}$ & $\begin{array}{l}0 \\
0\end{array}$ & $\begin{array}{l}0 \\
0\end{array}$ \\
\hline 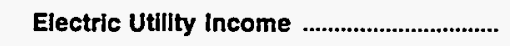 & 6,952 & 288 & 2,178 & 597 & 911 & 2,219 \\
\hline 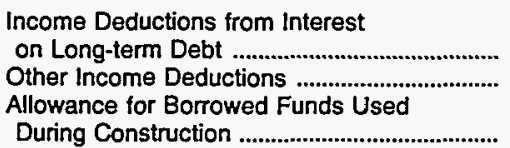 & $\begin{array}{l}494 \\
479\end{array}$ & $\begin{array}{r}62 \\
3\end{array}$ & $\begin{array}{r}187 \\
2,045\end{array}$ & $\begin{array}{r}294 \\
28\end{array}$ & $\begin{array}{r}133 \\
2\end{array}$ & $\begin{array}{r}447 \\
0\end{array}$ \\
\hline 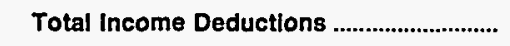 & 973 & 64 & 2,232 & 322 & 135 & 447 \\
\hline Income Before Extraordinary Items ................... & 5,979 & 224 & -55 & 275 & 775 & 1,772 \\
\hline Extraordinary Income & 0 & 0 & 0 & 0 & 0 & 0 \\
\hline 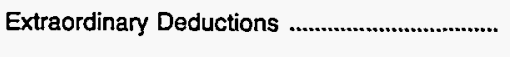 & 534 & 0 & 0 & 0 & 0 & 0 \\
\hline Net Income & 5,445 & 224 & -55 & 275 & 775 & 1,772 \\
\hline
\end{tabular}

Note: Totals may not equal sum of components because of independent rounding.

Source: Energy Information Administration, Form EIA-412, "Annual Report of Public Electric Utilities." 
Table 21. Statement of Income by Major U.S. Publicly Owned Electric Utility Within State, 1993 (Continued)

(Thousand Dollars)

\begin{tabular}{|c|c|c|c|c|c|c|}
\hline Item & $\begin{array}{c}\text { Alabama } \\
\text { Troy } \\
\text { City of } \\
\text { September } 30\end{array}$ & $\begin{array}{l}\text { Alabama } \\
\text { Tuskegee } \\
\text { City of } \\
\text { September } 30\end{array}$ & $\begin{array}{l}\text { Alaska } \\
\text { Alaska } \\
\text { Energy } \\
\text { Authority } \\
\text { June } 30\end{array}$ & $\begin{array}{c}\text { Alaska } \\
\text { Anchorage } \\
\text { City of } \\
\text { December } 31\end{array}$ & $\begin{array}{c}\text { Alaska } \\
\text { Fairbanks } \\
\text { City of } \\
\text { December } 31\end{array}$ & $\begin{array}{c}\text { Alaska } \\
\text { Ketchikan } \\
\text { City of } \\
\text { December } 31\end{array}$ \\
\hline Electric Uthlty Operating Revenues ............. & 12,252 & 8,458 & 27,682 & 68,205 & 15,006 & 10,565 \\
\hline 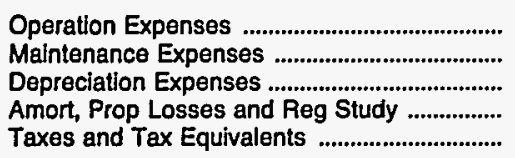 & $\begin{array}{r}8,869 \\
114 \\
0 \\
0 \\
3,561\end{array}$ & $\begin{array}{r}7,544 \\
30 \\
270 \\
0 \\
241\end{array}$ & $\begin{array}{r}4,683 \\
475 \\
22,714 \\
0 \\
0\end{array}$ & $\begin{array}{r}37,166 \\
4,714 \\
10,586 \\
511 \\
1,706\end{array}$ & $\begin{array}{r}11,458 \\
253 \\
1,814 \\
0 \\
912\end{array}$ & $\begin{array}{r}8,090 \\
1,029 \\
1,295 \\
0 \\
297\end{array}$ \\
\hline $\begin{array}{l}\text { Total Electric Utllity Operating } \\
\text { Expenses }\end{array}$ & 12,544 & 8,086 & 27,872 & 54,683 & 14,437 & 10,711 \\
\hline 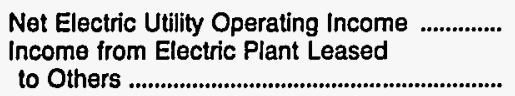 & $\begin{array}{r}-292 \\
0\end{array}$ & 373 & $\begin{array}{r}-190 \\
0\end{array}$ & 13,522 & 569 & -146 \\
\hline Electric Utility Operating Income ............. & -292 & 373 & -190 & 13,522 & 569 & -146 \\
\hline 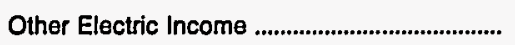 & 283 & 252 & 4,546 & 3,227 & 84 & 318 \\
\hline $\begin{array}{l}\text { Other Electric Deductions } \\
\text { Allowance for Other Funds Used } \\
\text { During Construction ................................................. } \\
\text { Taxes on Other Income and Deductions ........ }\end{array}$ & $\begin{array}{l}0 \\
0\end{array}$ & $\begin{array}{l}0 \\
0\end{array}$ & 561 & $\begin{array}{l}0 \\
0\end{array}$ & $\begin{array}{r}16 \\
0\end{array}$ & 0 \\
\hline Electrlc Utllity Income & -9 & 613 & 3,795 & 16,749 & 669 & 172 \\
\hline 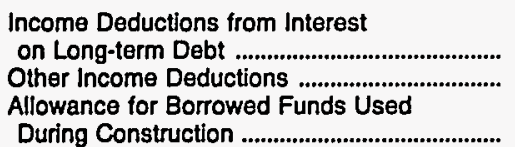 & $\begin{array}{l}511 \\
771\end{array}$ & $\begin{array}{r}616 \\
0\end{array}$ & $\begin{array}{r}21,505 \\
1,567\end{array}$ & $\begin{array}{r}12,210 \\
2,854\end{array}$ & $\begin{array}{r}1,335 \\
0\end{array}$ & $\begin{array}{r}401 \\
16\end{array}$ \\
\hline 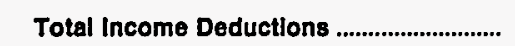 & 1,282 & 616 & 23,073 & 15,063 & 1,335 & 418 \\
\hline Income Before Extraordinary Items .................... & $-1,291$ & -3 & $-19,278$ & 1,685 & -666 & -245 \\
\hline 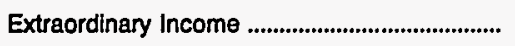 & 0 & 0 & 0 & 0 & 0 & 102 \\
\hline 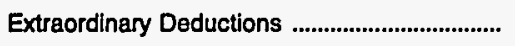 & 0 & 0 & 4,494 & 0 & 0 & 0 \\
\hline 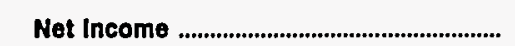 & $-1,291$ & -3 & $-23,772$ & 1,685 & -666 & -144 \\
\hline
\end{tabular}

Note: Totals may not equal sum of components because of independent rounding.

Source: Energy Information Administration, Form ElA-412, "Annual Report of Public Electric Utilities." 
Table 21. Statement of Income by Major U.S. Publicly Owned Electric Utility Within State, 1993 (Continued)

(Thousand Dollars)

\begin{tabular}{|c|c|c|c|c|c|c|}
\hline Item & $\begin{array}{l}\text { Arizona } \\
\text { Arizona } \\
\text { Power } \\
\text { Authority } \\
\text { June } 30\end{array}$ & $\begin{array}{c}\text { Arizona } \\
\text { Electrical } \\
\text { Dist } \\
\text { No2 } \\
\text { Pinal Cnty } \\
\text { December } 31\end{array}$ & $\begin{array}{l}\text { Arizona } \\
\text { Mesa } \\
\text { City of } \\
\text { June } 30\end{array}$ & $\begin{array}{l}\text { Arizona } \\
\text { Navajo } \\
\text { Tribal } \\
\text { Utility } \\
\text { Auth } \\
\text { December } 31\end{array}$ & $\begin{array}{l}\text { Arizona } \\
\text { Salt River } \\
\text { Proj Ag } \\
\text { I \& P Dist } \\
\text { Aprit } 30\end{array}$ & $\begin{array}{l}\text { Arizona } \\
\text { Tohono } \\
\text { OOdham } \\
\text { Utility Auth } \\
\text { December } 31\end{array}$ \\
\hline Electric Utillty Operating Revenues ............ & 17,105 & 7,145 & 20,946 & 33,899 & $1,295,671$ & 8,552 \\
\hline 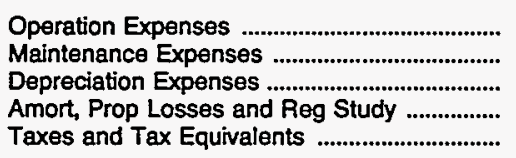 & $\begin{array}{r}16,156 \\
0 \\
79 \\
0 \\
0\end{array}$ & $\begin{array}{r}5,914 \\
247 \\
638 \\
0 \\
0\end{array}$ & $\begin{array}{r}15,719 \\
1,962 \\
1,254 \\
-2,799 \\
0\end{array}$ & $\begin{array}{r}26,798 \\
745 \\
3,600 \\
0 \\
0\end{array}$ & $\begin{array}{r}555,752 \\
101,813 \\
156,194 \\
6,926 \\
171,290\end{array}$ & $\begin{array}{r}7.746 \\
154 \\
282 \\
0 \\
0\end{array}$ \\
\hline $\begin{array}{l}\text { Total Electric Utility Operating } \\
\text { Expenses }\end{array}$ & 16,236 & 6,799 & 16,135 & 31,143 & 991,975 & 8,182 \\
\hline 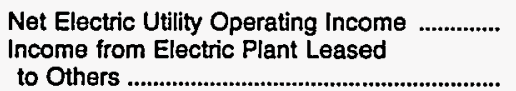 & 869 & 346 & $\begin{array}{r}4,811 \\
0\end{array}$ & 2,756 & $\begin{array}{r}303,696 \\
176\end{array}$ & 370 \\
\hline Electric Uttlity Operating Income .............. & 869 & 346 & 4,811 & 2,756 & 303,873 & 370 \\
\hline Other Electric Income & 6,506 & 104 & 233 & 496 & 24,786 & 61 \\
\hline 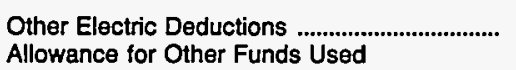 & 0 & 0 & 0 & 414 & 119 & 0 \\
\hline 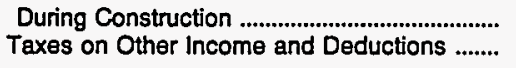 & $\begin{array}{l}0 \\
0\end{array}$ & $\begin{array}{l}0 \\
0\end{array}$ & $\begin{array}{l}0 \\
0\end{array}$ & $\begin{array}{l}0 \\
0\end{array}$ & $\begin{array}{l}0 \\
0\end{array}$ & $\begin{array}{l}0 \\
0\end{array}$ \\
\hline 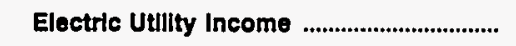 & 7,376 & 451 & 5,044 & 2,839 & 328,540 & 432 \\
\hline 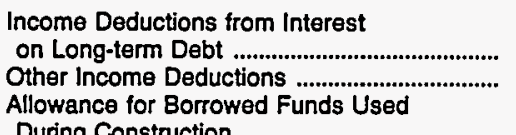 & $\begin{array}{r}6,261 \\
67\end{array}$ & $\begin{array}{l}0 \\
0\end{array}$ & $\begin{array}{r}158 \\
0\end{array}$ & $\begin{array}{r}1,132 \\
0\end{array}$ & $\begin{array}{r}230,396 \\
17,259\end{array}$ & $\begin{array}{r}216 \\
0\end{array}$ \\
\hline 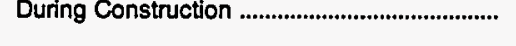 & 0 & 0 & 0 & -153 & $-7,364$ & 0 \\
\hline 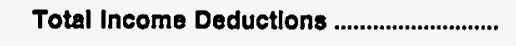 & 6,328 & o & 158 & 979 & 240,291 & 216 \\
\hline Income Before Extraordinary Items ................... & 1,048 & 451 & 4,885 & 1,860 & 88,249 & 215 \\
\hline Extraordinary Income & 0 & 362 & 0 & 0 & 0 & 0 \\
\hline 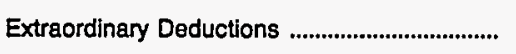 & 0 & 0 & 0 & 0 & 0 & 0 \\
\hline Net Income & 1,048 & 812 & 4,885 & 1,860 & 88,249 & 216 \\
\hline
\end{tabular}

Note: Totals may not equal sum of components because of independent rounding.

Source: Energy Information Administration, Form ElA-412, "Annual Report of Public Electric Utilities." 
Table 21. Statement of Income by Major U.S. Publicly Owned Electric Utility Within State, 1993 (Continued)

(Thousand Dollars)

\begin{tabular}{|c|c|c|c|c|c|c|}
\hline Item & $\begin{array}{l}\text { Arkansas } \\
\text { Benton } \\
\text { City of } \\
\text { December } 31\end{array}$ & $\begin{array}{l}\text { Arkansas } \\
\text { Bentonville } \\
\text { City of } \\
\text { December } 31\end{array}$ & $\begin{array}{l}\text { Arkansas } \\
\text { Clarksville } \\
\text { Light } \\
\& \\
\text { Water Co } \\
\text { September } 30\end{array}$ & $\begin{array}{l}\text { Arkansas } \\
\text { Conway } \\
\text { Corp } \\
\text { December } 31\end{array}$ & $\begin{array}{c}\text { Arkansas } \\
\text { Hope } \\
\text { City of } \\
\text { December } 31\end{array}$ & $\begin{array}{l}\text { Arkansas } \\
\text { Jonesboro } \\
\text { City of } \\
\text { December } 31\end{array}$ \\
\hline Electrlc UtIlity Operating Revenues ............. & 14,322 & 9,491 & 8,107 & 25,824 & 11,515 & 33,042 \\
\hline 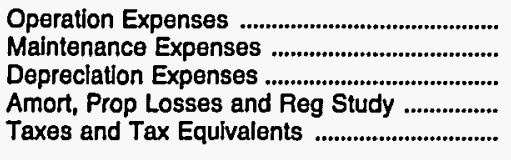 & $\begin{array}{r}9,386 \\
263 \\
254 \\
602 \\
602\end{array}$ & $\begin{array}{r}7,623 \\
150 \\
655 \\
0 \\
675\end{array}$ & $\begin{array}{r}5,661 \\
302 \\
402 \\
0 \\
616\end{array}$ & $\begin{array}{r}18,257 \\
1,170 \\
2,274 \\
0 \\
561\end{array}$ & $\begin{array}{r}7,956 \\
414 \\
374 \\
0 \\
34\end{array}$ & $\begin{array}{r}20,667 \\
1,277 \\
5,539 \\
0 \\
222\end{array}$ \\
\hline $\begin{array}{l}\text { Total Electric Utility Operating } \\
\text { Expenses }\end{array}$ & 11,108 & 9,103 & 6,980 & 22,262 & 8,779 & 27,704 \\
\hline 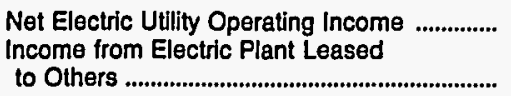 & $\begin{array}{r}3,214 \\
0\end{array}$ & $\begin{array}{r}388 \\
0\end{array}$ & $\begin{array}{r}1,127 \\
0\end{array}$ & $\begin{array}{r}3,562 \\
0\end{array}$ & $\begin{array}{r}2,737 \\
0\end{array}$ & 5,338 \\
\hline Electrlc UtIIty Operating Income ............. & 3,214 & 388 & 1,127 & 3,562 & 2,737 & 5,338 \\
\hline 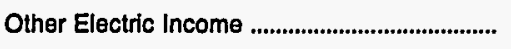 & 676 & 110 & 128 & 599 & 0 & 1,699 \\
\hline $\begin{array}{l}\text { Other Electric Deductions } \\
\text { Allowence for Other Funds Used }\end{array}$ & 0 & 149 & 243 & 400 & 523 & 0 \\
\hline $\begin{array}{l}\text { During Construction .................................. } \\
\text { Taxes on Other Income and Deductions ....... }\end{array}$ & $\begin{array}{l}0 \\
0\end{array}$ & $\begin{array}{l}0 \\
0\end{array}$ & $\begin{array}{l}0 \\
0\end{array}$ & $\begin{array}{l}0 \\
0\end{array}$ & $\begin{array}{l}0 \\
0\end{array}$ & $\begin{array}{r}15 \\
0\end{array}$ \\
\hline 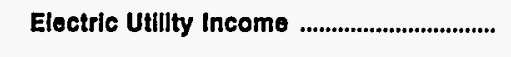 & 3,890 & 350 & 1,012 & 3,762 & 2,214 & 7,053 \\
\hline 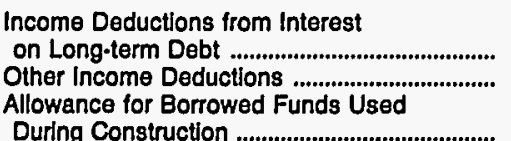 & $\begin{array}{l}0 \\
0\end{array}$ & $\begin{array}{r}117 \\
0\end{array}$ & $\begin{array}{r}83 \\
0\end{array}$ & $\begin{array}{r}1,656 \\
29\end{array}$ & $\begin{array}{r}0 \\
29\end{array}$ & $\begin{array}{r}3,373 \\
161\end{array}$ \\
\hline 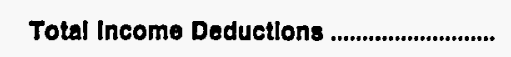 & 0 & 117 & 83 & 1,685 & 29 & 3,549 \\
\hline Income Before Extraordinary Items .................... & 3,890 & 232 & 928 & 2,076 & 2,185 & 3,503 \\
\hline Extraordinary Income & 0 & 0 & 0 & 0 & 0 & 0 \\
\hline 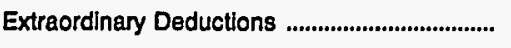 & 0 & 0 & 0 & 0 & 0 & 1,110 \\
\hline 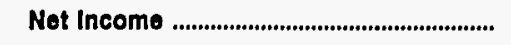 & 3,890 & 232 & 928 & 2,076 & 2,185 & 2,393 \\
\hline
\end{tabular}

Note: Totals may not equal sum of components because of independent rounding.

Source: Energy Informatlon Administration, Form EIA-412, "Annual Report of Public Electric Utilities." 
Table 21. Statement of Income by Major U.S. Publicly Owned Electric Utility Within State, 1993 (Continued)

(Thousand Dollars)

\begin{tabular}{|c|c|c|c|c|c|c|}
\hline Item & $\begin{array}{c}\text { Arkansas } \\
\text { North } \\
\text { Little } \\
\text { Rock } \\
\text { City of } \\
\text { December } 31\end{array}$ & $\begin{array}{l}\text { Arkansas } \\
\text { Osceola } \\
\text { City of } \\
\text { December } 31\end{array}$ & $\begin{array}{c}\text { Arkansas } \\
\text { Paragould } \\
\text { Light } \\
\& \\
\text { Water Comm } \\
\text { December } 31\end{array}$ & $\begin{array}{l}\text { Arkansas } \\
\text { Siloam } \\
\text { Springs } \\
\text { City of } \\
\text { December } 31\end{array}$ & $\begin{array}{c}\text { Arkansas } \\
\text { West } \\
\text { Memphis } \\
\text { City of } \\
\text { December } 31\end{array}$ & $\begin{array}{l}\text { California } \\
\text { Alameda } \\
\text { City of } \\
\text { June } 30\end{array}$ \\
\hline Electric Utillty Operating Revenues ........... & 64,928 & 9,348 & 11,722 & 9,348 & 18,408 & 43,591 \\
\hline 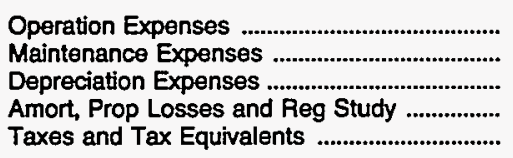 & $\begin{array}{r}40,215 \\
1,522 \\
3,773 \\
0 \\
544\end{array}$ & $\begin{array}{r}7,245 \\
132 \\
431 \\
0 \\
0\end{array}$ & $\begin{array}{r}8,298 \\
0 \\
846 \\
0 \\
0\end{array}$ & $\begin{array}{r}6,533 \\
167 \\
134 \\
0 \\
0\end{array}$ & $\begin{array}{r}13,143 \\
382 \\
2,004 \\
0 \\
773\end{array}$ & $\begin{array}{r}35,520 \\
460 \\
1,519 \\
0 \\
0\end{array}$ \\
\hline $\begin{array}{l}\text { Total Electric Utility Operating } \\
\text { Expenses ........................................................ }\end{array}$ & 46,053 & 7,808 & 9,144 & 6,835 & 16,301 & 37,500 \\
\hline 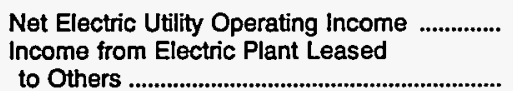 & $\begin{array}{r}18,875 \\
0\end{array}$ & $\begin{array}{r}1,540 \\
0\end{array}$ & $\begin{array}{r}2,579 \\
0\end{array}$ & $\begin{array}{r}2,513 \\
0\end{array}$ & 2,107 & 6,092 \\
\hline Electric Utllity Operating Income .............. & 18,875 & 1,540 & 2,579 & 2,513 & 2,107 & 6,092 \\
\hline Other Electric Income & 1,852 & 0 & 285 & $\mathbf{0}$ & 3,611 & 804 \\
\hline $\begin{array}{l}\text { Other Electric Deductions } \\
\text { Allowance for Other Funds Used }\end{array}$ & 9,564 & 0 & 0 & 1,600 & 3,637 & 0 \\
\hline 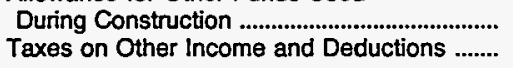 & $\begin{array}{l}0 \\
0\end{array}$ & $\begin{array}{l}0 \\
0\end{array}$ & $\begin{array}{l}0 \\
0\end{array}$ & $\begin{array}{l}\mathbf{0} \\
0\end{array}$ & $\begin{array}{l}0 \\
0\end{array}$ & $\begin{array}{l}\mathbf{0} \\
\mathbf{0}\end{array}$ \\
\hline Electric Utility Income & 11,164 & 1,540 & 2,863 & 913 & 2,081 & 6,895 \\
\hline 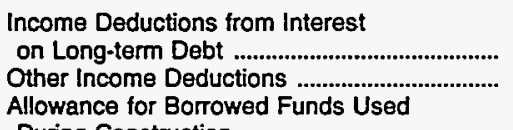 & $\begin{array}{r}10,117 \\
0\end{array}$ & $\begin{array}{r}331 \\
0\end{array}$ & $\begin{array}{l}568 \\
291\end{array}$ & $\begin{array}{l}1 \\
0\end{array}$ & $\begin{array}{r}1,364 \\
148\end{array}$ & $\begin{array}{r}603 \\
6\end{array}$ \\
\hline 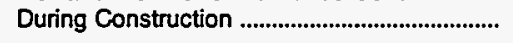 & 0 & 0 & 0 & 0 & 0 & $\mathbf{0}$ \\
\hline 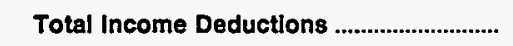 & 10,117 & 331 & 859 & 1 & 1,513 & 610 \\
\hline 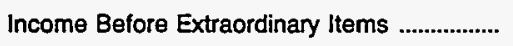 & 1,047 & 1,209 & 2,005 & 912 & 569 & 6,286 \\
\hline Extraordinary Income & 0 & 0 & 0 & 0 & 66 & 0 \\
\hline 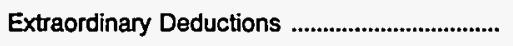 & 0 & 0 & 0 & 0 & 0 & 0 \\
\hline 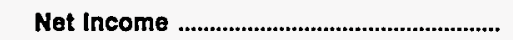 & 1,047 & 1,209 & 2,005 & 912 & 635 & 6,286 \\
\hline
\end{tabular}

Note: Totals may not equal sum of components because of independent rounding.

Source: Energy Information Administration, Form EIA-412, "Annual Report of Public Electric Utilities." 
Table 21. Statement of Income by Major U.S. Publicly Owned Electric Utility Within State, 1993 (Continued)

(Thousand Dollars)

\begin{tabular}{|c|c|c|c|c|c|c|}
\hline Item & $\begin{array}{l}\text { California } \\
\text { Anaheim } \\
\text { City of } \\
\text { June } 30\end{array}$ & $\begin{array}{l}\text { California } \\
\text { Azusa } \\
\text { City of } \\
\text { June } 30\end{array}$ & $\begin{array}{l}\text { California } \\
\text { Burbank } \\
\text { City of } \\
\text { June } 30\end{array}$ & $\begin{array}{l}\text { California } \\
\text { California } \\
\text { Dept } \\
\text { Wtr } \\
\text { Resources } \\
\text { June } 30\end{array}$ & $\begin{array}{l}\text { California } \\
\text { Colton } \\
\text { City of } \\
\text { June } 30\end{array}$ & $\begin{array}{l}\text { California } \\
\text { Glendale } \\
\text { City of } \\
\text { June } 30\end{array}$ \\
\hline Electrlc Utllity Operating Revenues ............. & 233,491 & 17,245 & 91,630 & 123,004 & 19,190 & 93,041 \\
\hline 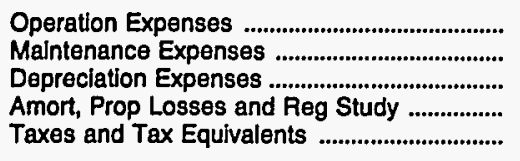 & $\begin{array}{r}161,572 \\
21,674 \\
12,534 \\
863 \\
0\end{array}$ & $\begin{array}{r}9,974 \\
1,605 \\
389 \\
0 \\
1,723\end{array}$ & $\begin{array}{r}72,694 \\
4,892 \\
4,481 \\
0 \\
5,832\end{array}$ & $\begin{array}{r}49,910 \\
-563 \\
23,856 \\
0 \\
1,289\end{array}$ & $\begin{array}{r}16,524 \\
79 \\
483 \\
0 \\
1.718\end{array}$ & $\begin{array}{r}65,241 \\
5,755 \\
8,043 \\
0 \\
0\end{array}$ \\
\hline 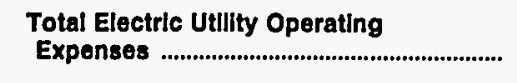 & 196,643 & 13,690 & 87,899 & 74,492 & 18,804 & 79,039 \\
\hline 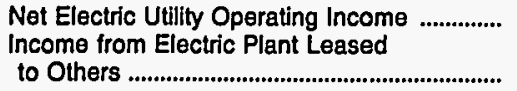 & $\begin{array}{r}36,848 \\
0\end{array}$ & $\begin{array}{r}3,555 \\
0\end{array}$ & 3,731 & $\begin{array}{r}48,512 \\
0\end{array}$ & 387 & 14,002 \\
\hline Electric Utllity Operating Income .............. & 36,848 & 3,555 & 3,731 & 48,512 & 387 & 14,002 \\
\hline 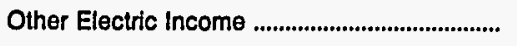 & 5,168 & 360 & 1,347 & 3,856 & 335 & 4.410 \\
\hline $\begin{array}{l}\text { Other Electric Deductions ............................... } \\
\text { Allowance for Other Funds Used } \\
\text { During Construction ........................................ } \\
\text { Taxes on Other Income and Deductions ........ }\end{array}$ & 4,618 & 3,196 & 1,929 & $\begin{array}{l}0 \\
0\end{array}$ & $\begin{array}{l}0 \\
0\end{array}$ & 9,890 \\
\hline 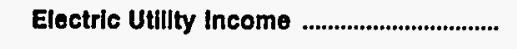 & 37,398 & 719 & 3,149 & 52,368 & 630 & 8,522 \\
\hline 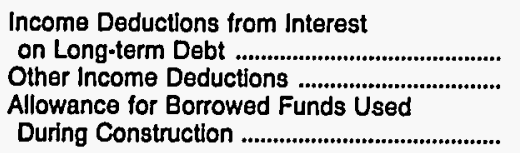 & $\begin{array}{r}20,737 \\
0\end{array}$ & $\begin{array}{l}0 \\
0\end{array}$ & $\begin{array}{r}2,290 \\
215\end{array}$ & $\begin{array}{r}62,564 \\
0\end{array}$ & $\begin{array}{r}46 \\
0\end{array}$ & $\begin{array}{r}1,571 \\
0\end{array}$ \\
\hline 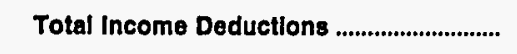 & 20,737 & 0 & 2,505 & 62,564 & 46 & 1,571 \\
\hline Income 8efore Extraordinary Items .................. & 16,661 & 719 & 644 & $-10,196$ & 585 & 6,951 \\
\hline 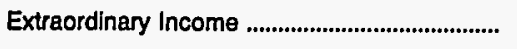 & 0 & 84 & 0 & 0 & 0 & 0 \\
\hline 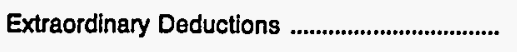 & 0 & 0 & 1,085 & 285 & 0 & 0 \\
\hline 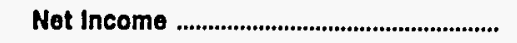 & 16,661 & 804 & -441 & $-10,481$ & 585 & 6,951 \\
\hline
\end{tabular}

Source: Energy Information Administration, Form EIA-412, "Annual Report of Public Electric Utilities." 
Table 21. Statement of Income by Major U.S. Publicly Owned Electric Utility Within State, 1993 (Continued)

(Thousand Dollars)

\begin{tabular}{|c|c|c|c|c|c|c|}
\hline Item & $\begin{array}{c}\text { California } \\
\text { Imperial } \\
\text { Irrigation } \\
\text { District } \\
\text { December } 31\end{array}$ & $\begin{array}{l}\text { California } \\
\text { Lassen } \\
\text { Municipal } \\
\text { Utility Dist } \\
\text { June } 30\end{array}$ & $\begin{array}{c}\text { California } \\
\text { Lodi } \\
\text { City of } \\
\text { June } 30\end{array}$ & $\begin{array}{l}\text { California } \\
\text { Los Angeles } \\
\text { City of } \\
\text { June } 30\end{array}$ & $\begin{array}{c}\text { California } \\
\text { Merced } \\
\text { Irrigation } \\
\text { District } \\
\text { December } 31\end{array}$ & $\begin{array}{l}\text { California } \\
\text { Metropolitan } \\
\text { Water } \\
\text { District } \\
\text { June } 30\end{array}$ \\
\hline Electric Utillty Operating Revenues ............ & 184,700 & 13,870 & 34,667 & $2,037,699$ & 4,630 & 13,454 \\
\hline 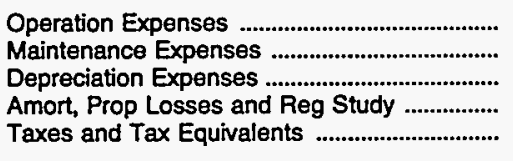 & $\begin{array}{r}125,786 \\
13,226 \\
16,702 \\
0 \\
360\end{array}$ & $\begin{array}{r}11,934 \\
499 \\
716 \\
0 \\
0\end{array}$ & $\begin{array}{r}28,500 \\
1,330 \\
467 \\
0 \\
0\end{array}$ & $\begin{array}{r}1,376,510 \\
150,927 \\
171,370 \\
0 \\
19,345\end{array}$ & $\begin{array}{r}1,675 \\
450 \\
655 \\
0 \\
641\end{array}$ & $\begin{array}{r}1,515 \\
0 \\
2,062 \\
0 \\
0\end{array}$ \\
\hline $\begin{array}{l}\text { Total Electric Utility Operating } \\
\text { Expenses }\end{array}$ & 156,073 & 13,149 & 30,297 & $1,718,152$ & 3,421 & 3,577 \\
\hline $\begin{array}{l}\text { Net Electric Utility Operating Income } \\
\text { Income from Electric Plant Lea.... }\end{array}$ & 28,627 & 722 & 4,370 & 319,546 & 1,209 & 9,877 \\
\hline 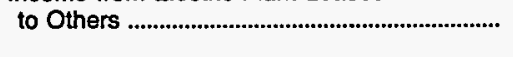 & 0 & 0 & 0 & 0 & 0 & 0 \\
\hline Electric Utility Operating Income ............. & 28,627 & 722 & 4,370 & 319,546 & 1,209 & 9,877 \\
\hline 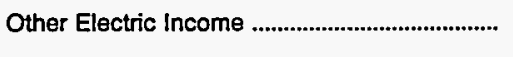 & 1,994 & 0 & 0 & 15,281 & 0 & 0 \\
\hline $\begin{array}{l}\text { Other Electric Deductions ................................... } \\
\text { Allowance for Other Funds Used }\end{array}$ & 0 & 0 & 2,758 & 0 & 163 & 0 \\
\hline $\begin{array}{l}\text { During Construction ................................. } \\
\text { Taxes on Other Income and Deductions ....... }\end{array}$ & $\begin{array}{l}0 \\
0\end{array}$ & $\begin{array}{l}0 \\
0\end{array}$ & $\begin{array}{l}0 \\
0\end{array}$ & $\begin{array}{l}0 \\
0\end{array}$ & $\begin{array}{l}0 \\
0\end{array}$ & $\begin{array}{l}0 \\
0\end{array}$ \\
\hline 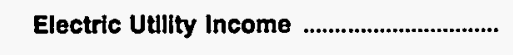 & 30,621 & 722 & 1,613 & 334,827 & 1,046 & 9,877 \\
\hline $\begin{array}{l}\text { Income Deductions from Interest } \\
\text { on Long-term Debt ............................................ } \\
\text { Other Income Deductions ......................... } \\
\text { Allowance for Borrowed Funds Used }\end{array}$ & $\begin{array}{r}7,053 \\
0\end{array}$ & $\begin{array}{r}2,008 \\
-486\end{array}$ & $\begin{array}{r}0 \\
1,042\end{array}$ & $\begin{array}{r}173,843 \\
0\end{array}$ & $\begin{array}{r}859 \\
0\end{array}$ & $\begin{array}{l}0 \\
0\end{array}$ \\
\hline 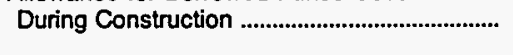 & 0 & 0 & 0 & $-15,152$ & 0 & 0 \\
\hline 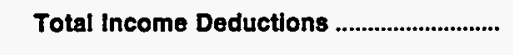 & 7,053 & 1,521 & 1,042 & 158,691 & 859 & $\mathbf{0}$ \\
\hline Income Before Extraordinary Items ................. & 23,569 & -800 & 570 & 176,136 & 187 & 9,877 \\
\hline 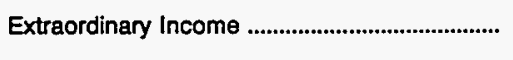 & 0 & 0 & 0 & 0 & 0 & 0 \\
\hline 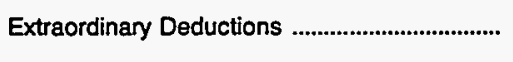 & 5,132 & 0 & 0 & 0 & 0 & 0 \\
\hline 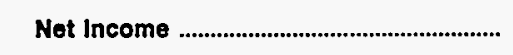 & 18,437 & -800 & 570 & 176,136 & 187 & 9,877 \\
\hline
\end{tabular}

Note: Totals may not equal sum of components because of independent rounding.

Source: Energy Information Administration, Form EIA-412, "Annual Report of Public Electric Utilities." 
Table 21. Statement of Income by Major U.S. Publicly Owned Electric Utility Within State, 1993 (Continued)

(Thousand Dollars)

\begin{tabular}{|c|c|c|c|c|c|c|}
\hline Item & $\begin{array}{c}\text { California } \\
\text { Modesto } \\
\text { Irrigation } \\
\text { District } \\
\text { December } 31\end{array}$ & $\begin{array}{c}\text { Califomia } \\
\text { MSR } \\
\text { Public } \\
\text { Power } \\
\text { Agency } \\
\text { December } 31\end{array}$ & $\begin{array}{c}\text { California } \\
\text { Northern } \\
\text { California } \\
\text { Power Agny } \\
\text { June } 30\end{array}$ & $\begin{array}{c}\text { California } \\
\text { Oakdale \& } \\
\text { South } \\
\text { San Joaquin } \\
\text { December } 31\end{array}$ & $\begin{array}{c}\text { California } \\
\text { Oroville } \\
\text { Wyandotte } \\
\text { Irrig Dist } \\
\text { December } 31\end{array}$ & $\begin{array}{l}\text { California } \\
\text { Palo Alto } \\
\text { City of } \\
\text { June } 30\end{array}$ \\
\hline Electric Utility Operating Revenues ............. & 128,393 & 61,934 & 171,635 & 5,593 & 8,828 & 63,307 \\
\hline 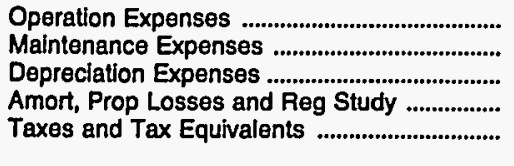 & $\begin{array}{r}88,557 \\
5,844 \\
7,042 \\
0 \\
0\end{array}$ & $\begin{array}{r}36,622 \\
2,937 \\
7,877 \\
0 \\
936\end{array}$ & $\begin{array}{r}76,412 \\
4,453 \\
30,796 \\
0 \\
0\end{array}$ & $\begin{array}{r}1,693 \\
255 \\
829 \\
0 \\
0\end{array}$ & $\begin{array}{r}8,111 \\
717 \\
1,315 \\
0 \\
0\end{array}$ & $\begin{array}{r}31,172 \\
5,765 \\
3,908 \\
0 \\
8,744\end{array}$ \\
\hline $\begin{array}{l}\text { Total Electrlc Utllity Operating } \\
\text { Expenses }\end{array}$ & 101,443 & 48,372 & 111,661 & 2,778 & 10,143 & 49,589 \\
\hline 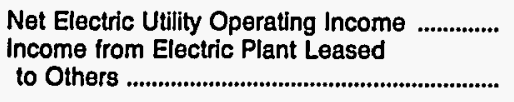 & 26,950 & $\begin{array}{r}13,562 \\
0\end{array}$ & $\begin{array}{r}59,974 \\
0\end{array}$ & 2,815 & $\begin{array}{r}-1,315 \\
0\end{array}$ & $\begin{array}{r}13,718 \\
0\end{array}$ \\
\hline Electrlc Ut!IIty Operating Income ............... & 26,950 & 13,562 & 59,974 & 2,815 & $-1,315$ & 13,718 \\
\hline Other Electric Income & $-1,275$ & 3,962 & 21,510 & 987 & 567 & 6,246 \\
\hline 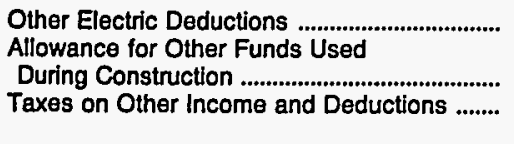 & 542 & $\begin{array}{l}0 \\
0\end{array}$ & $\begin{array}{l}0 \\
0\end{array}$ & 259 & $\begin{array}{l}0 \\
0\end{array}$ & 7,410 \\
\hline Electrlc Utillty Income & 25,134 & 17,524 & 81,484 & 3,544 & -747 & 12,554 \\
\hline 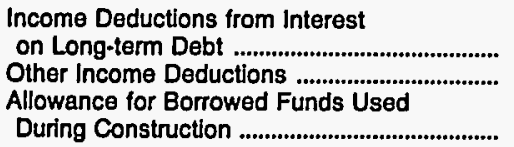 & $\begin{array}{r}14,102 \\
538\end{array}$ & $\begin{array}{r}35,244 \\
467\end{array}$ & $\begin{array}{r}63,908 \\
4,605\end{array}$ & $\begin{array}{l}0 \\
0\end{array}$ & $\begin{array}{r}3,311 \\
-193 \\
0\end{array}$ & $\begin{array}{l}0 \\
0\end{array}$ \\
\hline 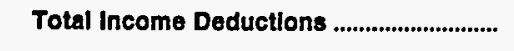 & 14,640 & 35,711 & 68,513 & 0 & 3,118 & $\mathbf{0}$ \\
\hline Income Before Extraordinary Items ................... & 10,494 & $-18,187$ & 12,971 & 3,544 & $-3,865$ & 12,554 \\
\hline Extraordinary Income & 0 & 0 & 0 & 0 & 4,761 & 0 \\
\hline 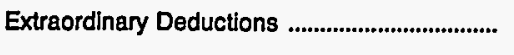 & 0 & 7,391 & 0 & 0 & 0 & 0 \\
\hline 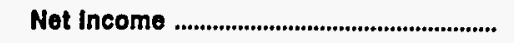 & 10,494 & $-25,578$ & 12,971 & 3,544 & 896 & 12,554 \\
\hline
\end{tabular}

Noto. Totals may not equal sum of components because of independent rounding

Source: Energy Information Administration, Form ElA-412, "Annual Report of Public Electric Utilities." 
Table 21. Statement of Income by Major U.S. Publicly Owned Electric Utility Within State, 1993 (Continued)

(Thousand Dollars)

\begin{tabular}{|c|c|c|c|c|c|c|}
\hline Item & $\begin{array}{l}\text { California } \\
\text { Pasadena } \\
\text { City of } \\
\text { June } 30\end{array}$ & $\begin{array}{c}\text { California } \\
\text { Placer } \\
\text { County } \\
\text { Water } \\
\text { Agency } \\
\text { December } 31\end{array}$ & $\begin{array}{l}\text { California } \\
\text { Redding } \\
\text { City of } \\
\text { June } 30\end{array}$ & $\begin{array}{l}\text { California } \\
\text { Riverside } \\
\text { City of } \\
\text { June } 30\end{array}$ & $\begin{array}{l}\text { California } \\
\text { Roseville } \\
\text { City of } \\
\text { June } 30\end{array}$ & $\begin{array}{l}\text { California } \\
\text { Sacramento } \\
\text { Municipal } \\
\text { Util Dist } \\
\text { December } 31\end{array}$ \\
\hline Electric Utility Operating Revenues ............ & 103,363 & 8,822 & 46,520 & 166,297 & 46,100 & 617,117 \\
\hline 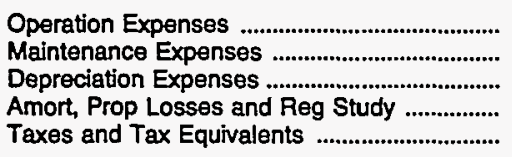 & $\begin{array}{r}82,772 \\
5,861 \\
6,028 \\
0 \\
0\end{array}$ & $\begin{array}{r}1,679 \\
1,818 \\
1,630 \\
0 \\
0\end{array}$ & $\begin{array}{r}36,022 \\
524 \\
4,792 \\
0 \\
0\end{array}$ & $\begin{array}{r}125,319 \\
5,032 \\
9,530 \\
0 \\
0\end{array}$ & $\begin{array}{r}29,770 \\
5,383 \\
2,105 \\
0 \\
2,328\end{array}$ & $\begin{array}{r}376,478 \\
24,161 \\
44,816 \\
55,146 \\
139\end{array}$ \\
\hline $\begin{array}{l}\text { Total Electric Utllity Operating } \\
\text { Expenses }\end{array}$ & 94,660 & 5,128 & 41,339 & 139,881 & 39,586 & 500,740 \\
\hline 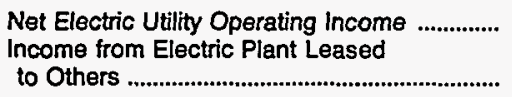 & 8,703 & 3,694 & 5,182 & 26,416 & 6,515 & 116,377 \\
\hline Electric Utility Operating Income ............. & 8,703 & 3,694 & 5,182 & 26,416 & 6,515 & 116,377 \\
\hline Other Electric Income & 3,503 & 324 & 1,058 & 10,181 & 767 & 36,154 \\
\hline $\begin{array}{l}\text { Other Electric Deductions .............................. } \\
\text { Allowance for Other Funds Used } \\
\text { During Construction ....................................... } \\
\text { Taxes on Other Income and Deductions ........ }\end{array}$ & $\begin{array}{r}0 \\
10\end{array}$ & $\begin{array}{l}0 \\
0\end{array}$ & 138 & 13,672 & $\begin{array}{l}0 \\
0\end{array}$ & $\begin{array}{r}110 \\
0\end{array}$ \\
\hline 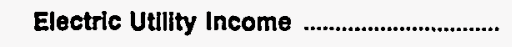 & 12,196 & 4,018 & 6,102 & 22,926 & 7,281 & 152,641 \\
\hline $\begin{array}{l}\text { Income Deductions from Interest } \\
\text { on Long-term Debt ......................................... } \\
\text { Other Income Deductions .................................. } \\
\text { Allowance for Borrowed Funds Used }\end{array}$ & $\begin{array}{r}4,837 \\
0\end{array}$ & $\begin{array}{r}2,517 \\
0\end{array}$ & $\begin{array}{r}3,964 \\
0\end{array}$ & $\begin{array}{r}12,914 \\
0\end{array}$ & $\begin{array}{r}671 \\
0\end{array}$ & $\begin{array}{r}141,429 \\
4,096\end{array}$ \\
\hline 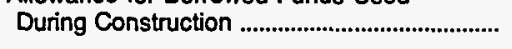 & 0 & 0 & 0 & 0 & 0 & $-1,237$ \\
\hline Total Income Deductlons ............................ & 4,837 & 2,517 & 3,964 & 12,914 & 671 & 144,288 \\
\hline Income Before Extraordinary Items .................. & 7,359 & 1,501 & 2,138 & 10,012 & 6,611 & 8,352 \\
\hline 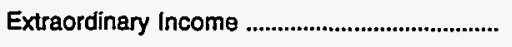 & 4,826 & 0 & 6,131 & 0 & 575 & 18,646 \\
\hline Extraordinary Deductions .................................... & 0 & 0 & 0 & 9,243 & 503 & 0 \\
\hline Net Income & 12,185 & 1,501 & 8,270 & 769 & 6,682 & 26,999 \\
\hline
\end{tabular}

Note: Totals may not equal sum of components because of independent rounding.

Source: Energy Information Administration, Form ElA-412, "Annual Report of Public Electric Utilities." 
Table 21. Statement of Income by Major U.S. Publicly Owned Electric Utility Within State, 1993 (Continued) (Thousand Dollars)

\begin{tabular}{|c|c|c|c|c|c|c|}
\hline Item & $\begin{array}{c}\text { California } \\
\text { San Francisco } \\
\text { City } \\
\& \\
\text { County of } \\
\text { June } 30\end{array}$ & $\begin{array}{l}\text { California } \\
\text { Santa } \\
\text { Clara } \\
\text { City of } \\
\\
\text { June } 30\end{array}$ & $\begin{array}{l}\text { California } \\
\text { Southem } \\
\text { California } \\
\text { P P } \\
\text { A } \\
\text { June } 30\end{array}$ & $\begin{array}{c}\text { California } \\
\text { Turlock } \\
\text { Irrigation } \\
\text { District } \\
\text { December } 31\end{array}$ & $\begin{array}{l}\text { California } \\
\text { Vernon } \\
\text { City of } \\
\text { June } \mathbf{3 0}\end{array}$ & $\begin{array}{l}\text { Califomia } \\
\text { Yuba } \\
\text { County } \\
\text { Water } \\
\text { Agency } \\
\text { June } 30\end{array}$ \\
\hline Electrlc UtIlity Operating Revenues ............ & 71,309 & 173,877 & 124,914 & 100,328 & 58,569 & 11,670 \\
\hline 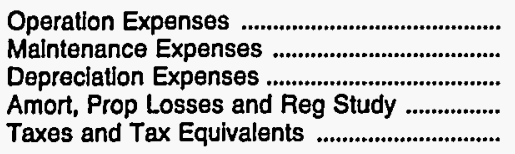 & $\begin{array}{r}41,809 \\
2,998 \\
8,953 \\
0 \\
940\end{array}$ & $\begin{array}{r}134,472 \\
2,275 \\
5,241 \\
0 \\
9,359\end{array}$ & $\begin{array}{r}49,610 \\
10,683 \\
51,181 \\
0 \\
11,287\end{array}$ & $\begin{array}{r}67,968 \\
5,919 \\
7,101 \\
0 \\
0\end{array}$ & $\begin{array}{r}45,990 \\
3,433 \\
2,647 \\
0 \\
1,682\end{array}$ & $\begin{array}{r}2,239 \\
841 \\
2,383 \\
107 \\
0\end{array}$ \\
\hline $\begin{array}{c}\text { Total Electrlc Utllity OperatIng } \\
\text { Expenses }\end{array}$ & 54,700 & 151,347 & 122,761 & 80,988 & 53,752 & 5,569 \\
\hline $\begin{array}{l}\text { Net Electric Utility Operating Income .............. } \\
\text { Income from Electric Plant Leased }\end{array}$ & 16,609 & 22,530 & 2,154 & 19,340 & 4,817 & 6,101 \\
\hline 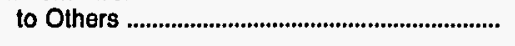 & 0 & 0 & 0 & 0 & 0 & 3 \\
\hline Electric Utility Operating Income ............... & 16,609 & 22,530 & 2,154 & 19,340 & 4,817 & 6,105 \\
\hline Other Electric Income ........................................... & 14,874 & 10,895 & 113,373 & $-2,526$ & 4,483 & 80 \\
\hline $\begin{array}{l}\text { Other Electric Deductions } \\
\text { Allowance for Other Funds Used }\end{array}$ & 4,590 & 9,907 & 0 & 0 & 264 & 0 \\
\hline $\begin{array}{l}\text { During Construction .......................................... } \\
\text { Taxes on Other Income and Deductions ....... }\end{array}$ & $\begin{array}{l}0 \\
0\end{array}$ & $\begin{array}{l}0 \\
0\end{array}$ & $\begin{array}{l}0 \\
0\end{array}$ & $\begin{array}{l}0 \\
0\end{array}$ & $\begin{array}{l}0 \\
0\end{array}$ & $\begin{array}{l}0 \\
0\end{array}$ \\
\hline Electric Utility Income .................................. & 26,894 & 23,518 & 115,526 & 16,813 & 9,037 & 6,184 \\
\hline 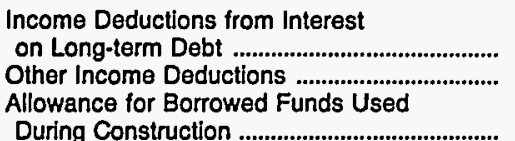 & $\begin{array}{r}17 \\
0\end{array}$ & $\begin{array}{r}7,846 \\
0\end{array}$ & $\begin{array}{r}155,437 \\
0\end{array}$ & $\begin{array}{r}9,621 \\
0\end{array}$ & $\begin{array}{r}0 \\
4,752\end{array}$ & $\begin{array}{r}4,407 \\
80\end{array}$ \\
\hline Total Income Deductions ............................. & 17 & 7,846 & 155,437 & 9,621 & 4,752 & 4,487 \\
\hline Income Before Extraordinary Items ................. & 26,876 & 15,672 & $-39,911$ & 7,192 & 4,285 & 1,697 \\
\hline Extraordinary Income & 2,347 & 0 & 0 & 0 & 0 & 1 \\
\hline 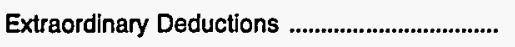 & 22,300 & 0 & 0 & 0 & $\mathbf{0}$ & 0 \\
\hline Net Income & 6,923 & 15,672 & $-39,911$ & 7,192 & 4,285 & 1,698 \\
\hline
\end{tabular}

Note: Totals may not equal sum of components because of independent rounding.

Source: Energy Information Administration, Form EIA-412, "Annual Report of Public Electric Utilities." 
Table 21. Statement of Income by Major U.S. Publicly Owned Electric Utility Within State, 1993 (Continued)

(Thousand Dollars)

\begin{tabular}{|c|c|c|c|c|c|c|}
\hline Item & $\begin{array}{c}\text { Colorado } \\
\text { Arkansas } \\
\text { River } \\
\text { Power } \\
\text { Authority } \\
\text { December } 31\end{array}$ & $\begin{array}{l}\text { Colorado } \\
\text { Colorado } \\
\text { Springs } \\
\text { City of } \\
\text { December } 31\end{array}$ & $\begin{array}{l}\text { Colorado } \\
\text { Fort Collins } \\
\text { City of } \\
\text { December } 31\end{array}$ & $\begin{array}{l}\text { Colorado } \\
\text { Fort Morgan } \\
\text { City of } \\
\text { December } 31\end{array}$ & $\begin{array}{l}\text { Colorado } \\
\text { Longmont } \\
\text { City of }\end{array}$ & $\begin{array}{l}\text { Colorado } \\
\text { Loveland } \\
\text { City of } \\
\text { December } 31\end{array}$ \\
\hline Electric Utility Operating Revenues ............. & 10,136 & 156,553 & 44,601 & 5,639 & 22,166 & 21,116 \\
\hline 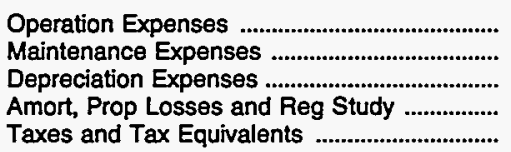 & $\begin{array}{r}9,818 \\
0 \\
83 \\
0 \\
0\end{array}$ & $\begin{array}{r}86,849 \\
13,598 \\
23,512 \\
0 \\
10,348\end{array}$ & $\begin{array}{r}38,163 \\
743 \\
3,555 \\
0 \\
2,676\end{array}$ & $\begin{array}{r}3,903 \\
219 \\
252 \\
0 \\
744\end{array}$ & $\begin{array}{r}20,356 \\
579 \\
1,234 \\
0 \\
1,583\end{array}$ & $\begin{array}{r}14,050 \\
639 \\
1,303 \\
0 \\
1,211\end{array}$ \\
\hline $\begin{array}{l}\text { Total Electric Utllity Operating } \\
\text { Expenses }\end{array}$ & 9,902 & 134,307 & 45,138 & 5,118 & 23,753 & 17,202 \\
\hline $\begin{array}{l}\text { Net Electric Utility Operating Income } \\
\text { Income from Electric Plant Leased } \\
\text { to Others }\end{array}$ & 235 & 22,247 & -537 & 522 & $-1,587$ & 3,914 \\
\hline Electric Utility Operating Income ............. & 235 & 22,247 & -537 & 522 & $-1,587$ & 3,914 \\
\hline Other Electric Income & 502 & 9,500 & 1,975 & 132 & 491 & 766 \\
\hline $\begin{array}{l}\text { Other Eiectric Deductions } \\
\text { Allowance for Other Funds Used }\end{array}$ & 0 & 0 & 0 & 0 & 0 & 1,462 \\
\hline $\begin{array}{l}\text { During Construction ................................ } \\
\text { Taxes on Other Income and Deductions ........ }\end{array}$ & $\begin{array}{l}0 \\
0\end{array}$ & $\begin{array}{r}611 \\
0\end{array}$ & $\begin{array}{l}0 \\
0\end{array}$ & $\begin{array}{l}0 \\
0\end{array}$ & $\begin{array}{l}0 \\
0\end{array}$ & $\begin{array}{l}0 \\
0\end{array}$ \\
\hline 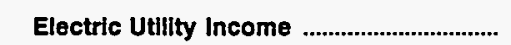 & 737 & 32,358 & 1,438 & 653 & $-1,096$ & 3,218 \\
\hline 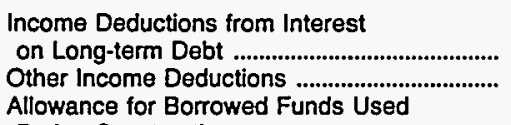 & $\begin{array}{l}0 \\
0\end{array}$ & $\begin{array}{r}27,485 \\
1,302\end{array}$ & $\begin{array}{l}0 \\
0\end{array}$ & $\begin{array}{l}0 \\
0\end{array}$ & $\begin{array}{l}0 \\
0\end{array}$ & $\begin{array}{r}506 \\
0\end{array}$ \\
\hline 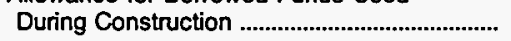 & 0 & -989 & 0 & 0 & 0 & 0 \\
\hline 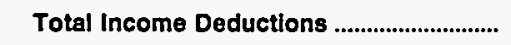 & 0 & 27,798 & $\mathbf{0}$ & 0 & 0 & 506 \\
\hline Income Before Extraordinary Items .................. & 737 & 4,560 & 1,438 & 653 & $-1,096$ & 2,712 \\
\hline 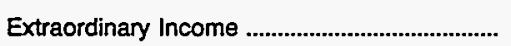 & 0 & 0 & 0 & 0 & 0 & 0 \\
\hline 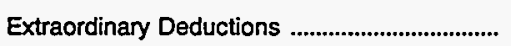 & 0 & 1,474 & 0 & 0 & 0 & 0 \\
\hline Net Income & 737 & 3,086 & 1,438 & 653 & $-1,096$ & 2,712 \\
\hline
\end{tabular}

Note: Totals may not equal sum of components because of independent rounding.

Source: Energy Information Administration, Form ElA-412, "Annual Report of Public Electric Utilities." 
Table 21. Statement of Income by Major U.S. Publicly Owned Electric Utility Within State, 1993 (Continued)

(Thousand Dollars)

\begin{tabular}{|c|c|c|c|c|c|c|}
\hline Item & $\begin{array}{l}\text { Colorado } \\
\text { Platte River } \\
\text { Power } \\
\text { Authority } \\
\text { December } 31\end{array}$ & $\begin{array}{c}\text { Connecticut } \\
\text { Connecticut } \\
\text { Mun } \\
\text { Elec } \\
\text { Engy Coop } \\
\text { December } 31\end{array}$ & $\begin{array}{l}\text { Connecticut } \\
\text { Groton } \\
\text { City of } \\
\text { June } 30\end{array}$ & $\begin{array}{l}\text { Connecticut } \\
\text { Norwich } \\
\text { City of } \\
\text { June } 30\end{array}$ & $\begin{array}{l}\text { Connecticut } \\
\text { Wallingford } \\
\text { Town of } \\
\text { June } 30\end{array}$ & $\begin{array}{l}\text { Delaware } \\
\text { Dover } \\
\text { City of } \\
\text { June } 30\end{array}$ \\
\hline Electrlc Utillty Operating Revenues ............. & 138,429 & 58,331 & 44,447 & 25,057 & 40,848 & 40,437 \\
\hline 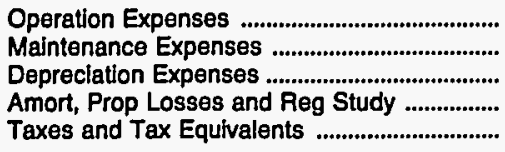 & $\begin{array}{r}58,983 \\
7,536 \\
21,715 \\
0 \\
0\end{array}$ & $\begin{array}{r}49,960 \\
765 \\
1,751 \\
37 \\
71\end{array}$ & $\begin{array}{r}38,945 \\
500 \\
1,266 \\
0 \\
2,254\end{array}$ & $\begin{array}{r}22,049 \\
802 \\
704 \\
0 \\
1,345\end{array}$ & $\begin{array}{r}36,083 \\
1,106 \\
1,280 \\
0 \\
1,930\end{array}$ & $\begin{array}{r}34,549 \\
0 \\
2,597 \\
0 \\
939\end{array}$ \\
\hline $\begin{array}{l}\text { Total Electric Utillty Operating } \\
\text { Expenses }\end{array}$ & 88,234 & 52,585 & 42,964 & 24,900 & 40,399 & 38,086 \\
\hline 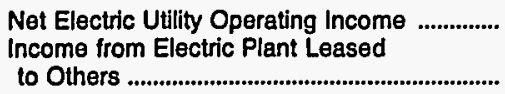 & 50,195 & 5,746 & 1,483 & 156 & 450 & 2,351 \\
\hline Electric Utllity Operatting Income ................. & 50,195 & 5,746 & $\mathbf{1 , 4 8 3}$ & 798 & 450 & 2,351 \\
\hline Other Electric Income & 18,797 & 4,356 & 256 & 49 & 621 & 630 \\
\hline $\begin{array}{l}\text { Other Electric Deductions ................................. } \\
\text { Allowance for Other Funds Used }\end{array}$ & 0 & 0 & 1,156 & 0 & 28 & 0 \\
\hline $\begin{array}{l}\text { During Construction } \\
\text { Taxes on Other Income and Deductions ....... }\end{array}$ & $\begin{array}{l}0 \\
0\end{array}$ & $\begin{array}{l}0 \\
0\end{array}$ & $\begin{array}{l}0 \\
0\end{array}$ & $\begin{array}{l}\mathbf{0} \\
0\end{array}$ & $\begin{array}{l}0 \\
0\end{array}$ & $\begin{array}{l}0 \\
0\end{array}$ \\
\hline 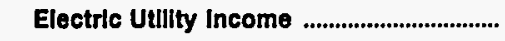 & 68,992 & 10,102 & 584 & 847 & 1,042 & 2,981 \\
\hline 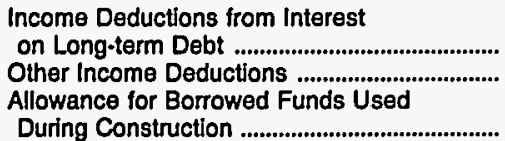 & $\begin{array}{l}49,195 \\
11,236\end{array}$ & $\begin{array}{r}9,115 \\
764\end{array}$ & $\begin{array}{r}404 \\
67\end{array}$ & $\begin{array}{r}225 \\
7\end{array}$ & $\begin{array}{r}49 \\
1,550\end{array}$ & $\begin{array}{r}2,009 \\
40\end{array}$ \\
\hline Total Income Deductions ............................... & 60,431 & 9,879 & 472 & 231 & 1,599 & 2,049 \\
\hline Income Before Extraordinary Items .................... & 8,561 & 223 & 112 & 616 & -556 & 931 \\
\hline 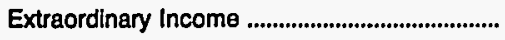 & 0 & 0 & 0 & 0 & 0 & 0 \\
\hline 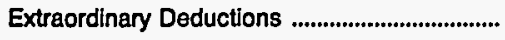 & 0 & 0 & 0 & 0 & 105 & 4,850 \\
\hline 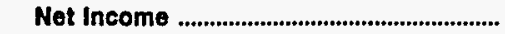 & 8,561 & 223 & 112 & 616 & -661 & $-3,919$ \\
\hline
\end{tabular}

Note: Totals may not equal sum of components because of independent rounding.

Source: Energy Information Administration, Form EIA-412, "Annual Report of Public Electric Utilities." 
Table 21. Statement of Income by Major U.S. Publicly Owned Electric Utility Within State, 1993 (Continued)

(Thousand Dollars)

\begin{tabular}{|c|c|c|c|c|c|c|}
\hline Item & $\begin{array}{c}\text { Delaware } \\
\text { Milford } \\
\text { City of } \\
\text { September } 30\end{array}$ & $\begin{array}{c}\text { Delaware } \\
\text { Newark } \\
\text { City of } \\
\text { December } 31\end{array}$ & $\begin{array}{l}\text { Florida } \\
\text { Bartow } \\
\text { City of } \\
\text { September } 30\end{array}$ & $\begin{array}{c}\text { Florida } \\
\text { Florida } \\
\text { Municipal } \\
\text { Power Agency } \\
\text { September } 30\end{array}$ & $\begin{array}{c}\text { Fiorida } \\
\text { Fort Pierce } \\
\text { Utilities } \\
\text { Auth } \\
\text { September } 30\end{array}$ & $\begin{array}{c}\text { Florida } \\
\text { Gainesville } \\
\text { Regional } \\
\text { Utilities } \\
\text { September } 30\end{array}$ \\
\hline Electric Utillty Operating Revenues ............ & 9,594 & 20,283 & 20,000 & 162,070 & 42,505 & 115,932 \\
\hline 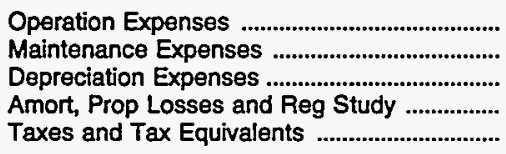 & $\begin{array}{r}6,896 \\
109 \\
277 \\
0 \\
14\end{array}$ & $\begin{array}{r}14,899 \\
318 \\
456 \\
0 \\
0\end{array}$ & $\begin{array}{r}14,470 \\
0 \\
315 \\
0 \\
0\end{array}$ & $\begin{array}{r}112,308 \\
5,212 \\
10,294 \\
0 \\
0\end{array}$ & $\begin{array}{r}30,162 \\
1,883 \\
3,782 \\
0 \\
988\end{array}$ & $\begin{array}{r}60,010 \\
8,176 \\
14,360 \\
0 \\
12,813\end{array}$ \\
\hline $\begin{array}{l}\text { Total Electric Utility Operating } \\
\text { Expenses }\end{array}$ & 7,297 & 15,672 & 14,785 & 127,814 & 36,815 & 95,358 \\
\hline 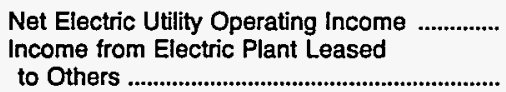 & 2,297 & 4,611 & 5,216 & 34,256 & $\begin{array}{r}5,690 \\
16\end{array}$ & 20,574 \\
\hline Electric UtIIIty Operating Income ............. & 2,297 & 4,611 & 5,216 & 34,256 & 5,706 & 20,574 \\
\hline 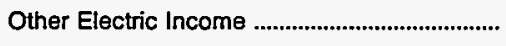 & 253 & 0 & 135 & 14,542 & 829 & 10,664 \\
\hline $\begin{array}{l}\text { Other Electric Deductions ............................ } \\
\text { Allowance for Other Funds Used } \\
\text { During Construction .................................. } \\
\text { Taxes on Other Income and Deductions ....... }\end{array}$ & $\begin{array}{l}0 \\
0\end{array}$ & $\begin{array}{l}0 \\
0\end{array}$ & $\begin{array}{l}0 \\
0\end{array}$ & $\begin{array}{l}0 \\
0\end{array}$ & $\begin{array}{l}0 \\
0\end{array}$ & $\begin{array}{l}0 \\
0\end{array}$ \\
\hline Electric Utility Income .................................. & 2,550 & 4,611 & 5,351 & 48,798 & 6,536 & 31,238 \\
\hline 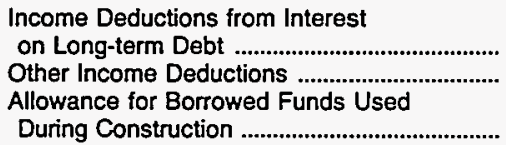 & $\begin{array}{r}39 \\
1,536\end{array}$ & $\begin{array}{l}0 \\
0\end{array}$ & $\begin{array}{l}0 \\
0\end{array}$ & $\begin{array}{l}37,110 \\
11,688\end{array}$ & $\begin{array}{l}2,997 \\
1,705\end{array}$ & $\begin{array}{r}25,374 \\
0\end{array}$ \\
\hline Total Income Deductions ............................. & 1,575 & $\mathbf{0}$ & 0 & 48,798 & 4,702 & 25,374 \\
\hline Income Before Extraordinary items ................. & 974 & 4,611 & 5,351 & 0 & 1,834 & 5,864 \\
\hline 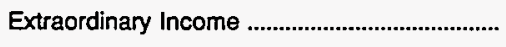 & 0 & 0 & 0 & 0 & 0 & 0 \\
\hline 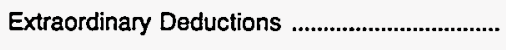 & 0 & 0 & 4,123 & 0 & 3,244 & 0 \\
\hline 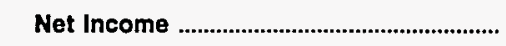 & 974 & 4,611 & 1,228 & $\mathbf{0}$ & $-1,410$ & 5,864 \\
\hline
\end{tabular}

Note: Totals may not equal sum of components because of independent rounding.

Source: Energy Information Administration, Form EIA-412, "Annual Report of Public Electric Utilities." 
Table 21. Statement of Income by Major U.S. Publicly Owned Electric Utility Within State, 1993 (Continued)

(Thousand Dollars)

\begin{tabular}{|c|c|c|c|c|c|c|}
\hline Item & $\begin{array}{c}\text { Florida } \\
\text { Homestead } \\
\text { City of } \\
\text { September } 30\end{array}$ & $\begin{array}{c}\text { Florida } \\
\text { Jacksonville } \\
\text { Beach } \\
\text { City of } \\
\text { September } 30\end{array}$ & $\begin{array}{c}\text { Florida } \\
\text { Jacksonville } \\
\text { Electric } \\
\text { Auth } \\
\text { September } 30\end{array}$ & $\begin{array}{c}\text { Florida } \\
\text { Key West } \\
\text { City of } \\
\text { September } 30\end{array}$ & $\begin{array}{c}\text { Florida } \\
\text { Kissimmee } \\
\text { Utility } \\
\text { Authority } \\
\text { September } 30\end{array}$ & $\begin{array}{l}\text { Florida } \\
\text { Lake Worth } \\
\text { City of }\end{array}$ \\
\hline Electrlc UtIllty Operating Revenues ............ & 16,259 & 38,292 & 681,878 & 49,277 & 61,264 & 32,652 \\
\hline 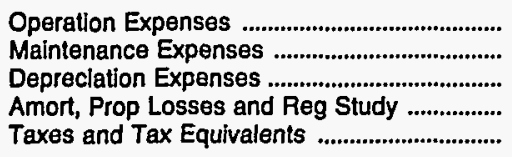 & $\begin{array}{r}19,758 \\
5,932 \\
1,431 \\
0 \\
1,449\end{array}$ & $\begin{array}{r}32,189 \\
417 \\
2,164 \\
0 \\
0\end{array}$ & $\begin{array}{r}373,484 \\
43,023 \\
80,038 \\
0 \\
15,199\end{array}$ & $\begin{array}{r}31,341 \\
3,507 \\
5,172 \\
0 \\
1,239\end{array}$ & $\begin{array}{r}39,546 \\
3,948 \\
6,875 \\
-2,257 \\
10\end{array}$ & $\begin{array}{r}21,627 \\
1,555 \\
2,318 \\
0 \\
4,263\end{array}$ \\
\hline $\begin{array}{c}\text { Total Electrlc UtIIIty Operating } \\
\text { Expenses }\end{array}$ & 28,570 & 34,769 & 511,744 & 41,259 & 48,123 & 29,762 \\
\hline 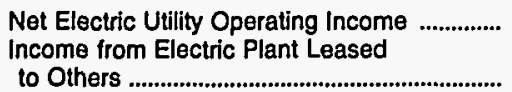 & $-12,311$ & 3,523 & 170,134 & 8,018 & 13,140 & 2,889 \\
\hline Electrlc Utllity Operating Income ............. & $-12,311$ & 3,523 & 170,134 & 8,018 & 13,140 & 2,889 \\
\hline Other Electric Income & 16,301 & 2,003 & 97,173 & 1,099 & 3,064 & 1,576 \\
\hline $\begin{array}{l}\text { Other Electric Deductions ............................ } \\
\text { Allowance for Other Funds Used } \\
\text { During Construction ..................................... } \\
\text { Taxes on Other Income and Deductions ....... }\end{array}$ & $\begin{array}{l}0 \\
0\end{array}$ & $\begin{array}{r}0 \\
335\end{array}$ & 66,942 & $\begin{array}{l}0 \\
0\end{array}$ & 5,797 & $\begin{array}{l}0 \\
0\end{array}$ \\
\hline Electric Utllity Income & 3,991 & 2,740 & 200,365 & 9,117 & 10,408 & 4,466 \\
\hline 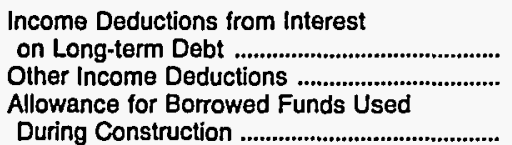 & $\begin{array}{r}359 \\
0\end{array}$ & $\begin{array}{r}3,997 \\
0\end{array}$ & $\begin{array}{r}170,534 \\
31,244 \\
-1,704\end{array}$ & $\begin{array}{r}8,149 \\
334\end{array}$ & $\begin{array}{l}8,092 \\
1,135\end{array}$ & $\begin{array}{r}1,991 \\
0\end{array}$ \\
\hline Total Income Deductlons ............................ & 359 & 3,997 & 200,073 & 8,483 & 9,227 & 1,991 \\
\hline Income Before Extraordinary Items .................. & 3,631 & $-1,257$ & 292 & 634 & 1,181 & 2,474 \\
\hline 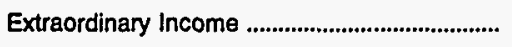 & 0 & 0 & $\mathbf{0}$ & 0 & 0 & 0 \\
\hline Extraordinary Deductions ........................................ & 0 & 0 & 0 & 0 & 0 & 0 \\
\hline 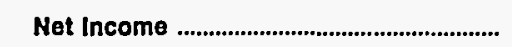 & 3,631 & $-1,257$ & 292 & 634 & 1,181 & 2,474 \\
\hline
\end{tabular}

Note: Totals may not equal sum of components because of independent rounding.

Source: Energy Information Administration, Form EIA-412, "Annual Report of Public Electric Utilities." 
Table 21. Statement of Income by Major U.S. Publicly Owned Electric Utility Within State, 1993 (Continued)

(Thousand Dollars)

\begin{tabular}{|c|c|c|c|c|c|c|}
\hline Item & $\begin{array}{l}\text { Florida } \\
\text { Lakeland } \\
\text { City of } \\
\text { September } 30\end{array}$ & $\begin{array}{c}\text { Florida } \\
\text { Leesburg } \\
\text { City of } \\
\text { September } 30\end{array}$ & $\begin{array}{c}\text { Florida } \\
\text { New Smyrna } \\
\text { Beach } \\
\text { Utils Comm } \\
\text { September } 30\end{array}$ & $\begin{array}{c}\text { Florida } \\
\text { Ocala } \\
\text { City of } \\
\text { September } 30\end{array}$ & $\begin{array}{l}\text { Florida } \\
\text { Orlando } \\
\text { Utilities } \\
\text { Comm } \\
\text { September } 30\end{array}$ & $\begin{array}{c}\text { Florida } \\
\text { Quincy } \\
\text { City of } \\
\text { September } 30\end{array}$ \\
\hline Electric Utillty Operating Revenues ............ & 149,442 & 26,853 & 24,880 & 71,649 & 303,150 & 9,092 \\
\hline 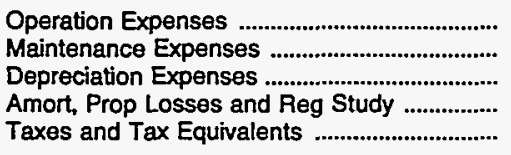 & $\begin{array}{r}79,707 \\
16,162 \\
16,743 \\
0 \\
0\end{array}$ & $\begin{array}{r}17,784 \\
1,687 \\
1,857 \\
138 \\
657\end{array}$ & $\begin{array}{r}18,931 \\
679 \\
1,642 \\
99 \\
1,480\end{array}$ & $\begin{array}{r}47,028 \\
2,454 \\
2,758 \\
508 \\
1,844\end{array}$ & $\begin{array}{r}149,973 \\
26,004 \\
35,125 \\
16 \\
16,207\end{array}$ & $\begin{array}{r}5,714 \\
350 \\
186 \\
0 \\
127\end{array}$ \\
\hline $\begin{array}{l}\text { Total Electric Utillty Operating } \\
\text { Expenses }\end{array}$ & 112,612 & 22,122 & 22,830 & 54,592 & 227,326 & 6,377 \\
\hline 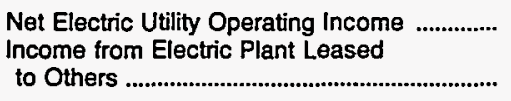 & $\begin{array}{r}36,830 \\
676\end{array}$ & 4,731 & 2,050 & $\begin{array}{r}17,056 \\
0\end{array}$ & 75,825 & 2,715 \\
\hline Electric Utility Operating Income ............. & 37,506 & 4,731 & 2,050 & 17,056 & 75,825 & 2,715 \\
\hline 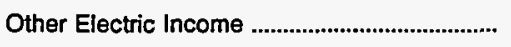 & 21,491 & 1,071 & 392 & 1,764 & 26,040 & 164 \\
\hline 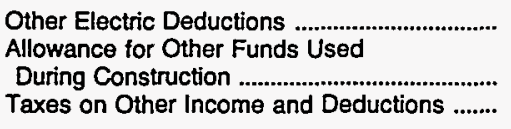 & 11,231 & 3,234 & $\begin{array}{l}0 \\
0\end{array}$ & 259 & 14,493 & $\begin{array}{l}0 \\
0\end{array}$ \\
\hline 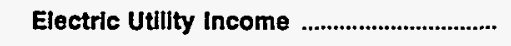 & 47,766 & 2,568 & 2,397 & 18,561 & 87,371 & 2,860 \\
\hline 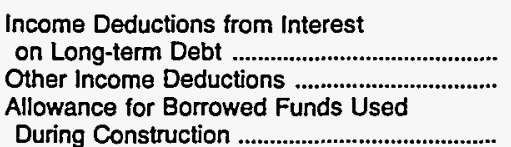 & $\begin{array}{r}22,075 \\
1,477\end{array}$ & $\begin{array}{r}1,130 \\
0\end{array}$ & $\begin{array}{r}1,573 \\
109\end{array}$ & $\begin{array}{r}1,071 \\
0\end{array}$ & $\begin{array}{r}70,512 \\
8,583\end{array}$ & $\begin{array}{l}0 \\
0\end{array}$ \\
\hline 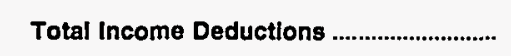 & 23,552 & 1,130 & 1,682 & 1,071 & 79,096 & $\mathbf{0}$ \\
\hline Income Before Extraordinary Items ................. & 24,214 & 1,438 & 715 & 17,490 & 8,276 & 2,860 \\
\hline 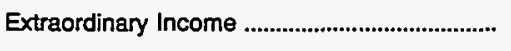 & 0 & 0 & -287 & 0 & 0 & 0 \\
\hline 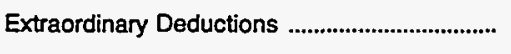 & 6,345 & 0 & 1,360 & 0 & 0 & 0 \\
\hline Net Income & 17,869 & 1,438 & -932 & 17,490 & 8,276 & 2,860 \\
\hline
\end{tabular}

Note: Totals may not equal sum of components because of independent rounding.

Source: Energy Information Administration, Form ElA-412, "Annual Report of Public Electric Utilities." 
Table 21. Statement of Income by Major U.S. Publicly Owned Electric Utility Within State, 1993 (Continued)

(Thousand Dollars)

\begin{tabular}{|c|c|c|c|c|c|c|}
\hline Item & $\begin{array}{c}\text { Florida } \\
\text { Reedy Creek } \\
\text { Improvement } \\
\text { Dist }\end{array}$ & $\begin{array}{l}\text { Florida } \\
\text { St Cloud } \\
\text { City of } \\
\text { September } 30\end{array}$ & $\begin{array}{c}\text { Florida } \\
\begin{array}{c}\text { Tallahassee } \\
\text { City of }\end{array} \\
\text { September } 30\end{array}$ & $\begin{array}{c}\text { Florida } \\
\text { Vero } \\
\text { Beach } \\
\text { City of } \\
\text { September } 30\end{array}$ & $\begin{array}{l}\text { Georgia } \\
\text { Albany Water } \\
\text { Gas \& Light } \\
\text { Comm } \\
\text { June } 30\end{array}$ & $\begin{array}{l}\text { Georgia } \\
\text { Calhoun } \\
\text { City of } \\
\text { June } 30\end{array}$ \\
\hline Electric Utllity Operating Revenues ............. & 54,299 & 20,383 & 168,039 & 41,592 & 56,223 & 18,749 \\
\hline 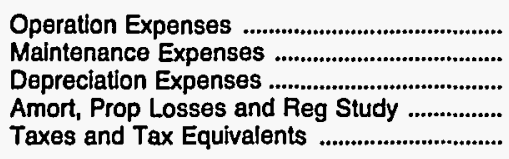 & $\begin{array}{r}36,484 \\
3,808 \\
0 \\
0 \\
1,911\end{array}$ & $\begin{array}{r}14,067 \\
258 \\
1,943 \\
0 \\
496\end{array}$ & $\begin{array}{r}100,093 \\
2,896 \\
12,583 \\
215 \\
0\end{array}$ & $\begin{array}{r}29,392 \\
2,743 \\
3,670 \\
0 \\
142\end{array}$ & $\begin{array}{r}47,399 \\
1,579 \\
1,205 \\
0 \\
0\end{array}$ & $\begin{array}{r}15,207 \\
125 \\
280 \\
0 \\
0\end{array}$ \\
\hline $\begin{array}{l}\text { Total Electrlc Utllity Operatlng } \\
\text { Expenses }\end{array}$ & 42,203 & 16,765 & 115,788 & 35,947 & 50,183 & 15,611 \\
\hline 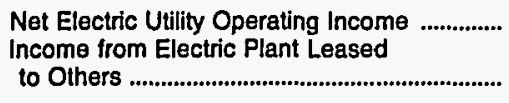 & 12,096 & 3,618 & 52,251 & 5,644 & 6,040 & 3,137 \\
\hline Electric Utility Operating Income .............. & 12,096 & 3,618 & 52,251 & 5,644 & 6,040 & 3,137 \\
\hline 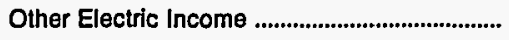 & 0 & 197 & 6,215 & 1,930 & 1,655 & 19 \\
\hline $\begin{array}{l}\text { Other Electric Deductions } \\
\text { Allowance for Other Funds Used }\end{array}$ & $\mathbf{0}$ & 0 & 3,124 & 0 & 0 & 0 \\
\hline $\begin{array}{l}\text { During Construction } \\
\text { Taxes on Other Income and Deductions ......... }\end{array}$ & $\begin{array}{l}0 \\
0\end{array}$ & $\begin{array}{l}0 \\
0\end{array}$ & $\begin{array}{l}0 \\
0\end{array}$ & $\begin{array}{l}0 \\
0\end{array}$ & $\begin{array}{l}0 \\
0\end{array}$ & $\begin{array}{l}0 \\
0\end{array}$ \\
\hline Electric Utillty Income & 12,096 & 3,815 & 55,343 & 7,574 & 7,695 & 3,157 \\
\hline 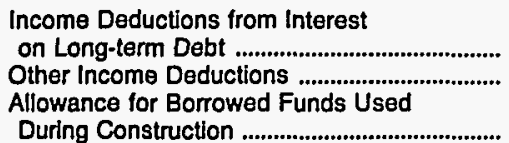 & $\begin{array}{r}9,332 \\
0\end{array}$ & $\begin{array}{r}1,678 \\
0\end{array}$ & $\begin{array}{r}7,967 \\
39,673\end{array}$ & $\begin{array}{l}4,953 \\
3,196\end{array}$ & $\begin{array}{r}0 \\
17\end{array}$ & $\begin{array}{r}442 \\
2,572\end{array}$ \\
\hline 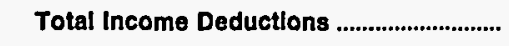 & 9,332 & 1,678 & 41,846 & 8,149 & 17 & 3,014 \\
\hline Income Before Extraordinary Items ...................... & 2,764 & 2,137 & 13,496 & -574 & 7,678 & 143 \\
\hline Extraordinary Income & 0 & 0 & 0 & 0 & 0 & 6,881 \\
\hline 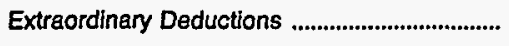 & 0 & 0 & 12,784 & 6,020 & 0 & 5,504 \\
\hline 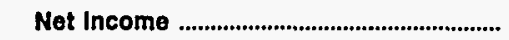 & 2,764 & 2,137 & 712 & $-6,595$ & 7,678 & 1,519 \\
\hline
\end{tabular}

Note: Totals may not equal sum of components because of independent rounding.

Source: Energy Information Administration, Form EIA-412, "Annual Report of Public Electric Utilities." 
Table 21. Statement of Income by Major U.S. Publicly Owned Electric Utility Within State, 1993 (Continued)

(Thousand Dollars)

\begin{tabular}{|c|c|c|c|c|c|c|}
\hline Item & $\begin{array}{l}\text { Georgia } \\
\text { Cartersville } \\
\text { City of } \\
\text { June } 30\end{array}$ & $\begin{array}{c}\text { Georgia } \\
\text { College } \\
\text { Park City of } \\
\text { June } 30\end{array}$ & $\begin{array}{l}\text { Georgia } \\
\text { Covington } \\
\text { City of } \\
\text { December } 31\end{array}$ & $\begin{array}{c}\text { Georgia } \\
\text { Crisp } \\
\text { County } \\
\text { Power } \\
\text { Comm } \\
\text { December } 31\end{array}$ & $\begin{array}{l}\text { Georgia } \\
\text { Dalton } \\
\text { City of } \\
\text { November } 30\end{array}$ & $\begin{array}{l}\text { Georgia } \\
\text { Douglas } \\
\text { City of } \\
\text { June } 30\end{array}$ \\
\hline Electric Utility Operating Revenues ............ & 22,842 & 15,028 & 16,078 & 17,430 & 50,174 & 13,413 \\
\hline 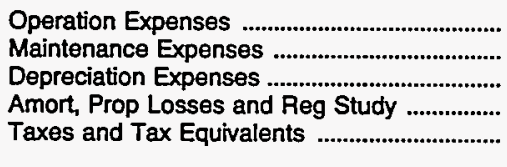 & $\begin{array}{r}19,338 \\
215 \\
0 \\
0 \\
1,029\end{array}$ & $\begin{array}{r}14,200 \\
193 \\
461 \\
0 \\
0\end{array}$ & $\begin{array}{r}13,593 \\
174 \\
0 \\
0 \\
698\end{array}$ & $\begin{array}{r}14,136 \\
791 \\
1,370 \\
0 \\
778\end{array}$ & $\begin{array}{r}26,622 \\
6,605 \\
5,315 \\
0 \\
279\end{array}$ & $\begin{array}{r}10,651 \\
112 \\
163 \\
0 \\
0\end{array}$ \\
\hline $\begin{array}{l}\text { Total Electric Utillty Operating } \\
\text { Expenses }\end{array}$ & 20,581 & 14,855 & 14,465 & 17,076 & 38,821 & 10,925 \\
\hline 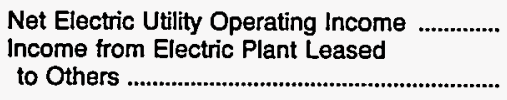 & $\begin{array}{r}2,260 \\
0\end{array}$ & 173 & 1,613 & 354 & $\begin{array}{r}11,353 \\
385\end{array}$ & 2,488 \\
\hline Electric Utility Operating Income ............. & 2,260 & 173 & 1,613 & 354 & 11,738 & 2,488 \\
\hline 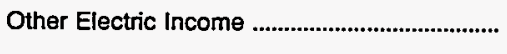 & 368 & 96 & 440 & 490 & 17,867 & 84 \\
\hline $\begin{array}{l}\text { Other Electric Deductions ................................... } \\
\text { Allowance for Other Funds Used } \\
\text { During Construction }\end{array}$ & 3,250 & 474 & 0 & 53 & 0 & 0 \\
\hline 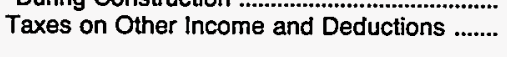 & 0 & 0 & $\begin{array}{l}0 \\
0\end{array}$ & $\begin{array}{l}0 \\
0\end{array}$ & $\begin{array}{l}0 \\
0\end{array}$ & $\begin{array}{l}0 \\
0\end{array}$ \\
\hline 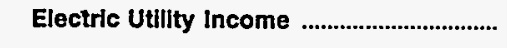 & -622 & -206 & 2,054 & 792 & 29,605 & 2,572 \\
\hline 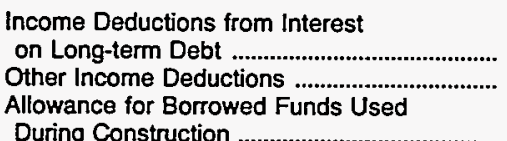 & $\begin{array}{l}0 \\
0\end{array}$ & $\begin{array}{l}0 \\
0\end{array}$ & $\begin{array}{r}19 \\
0\end{array}$ & $\begin{array}{r}0 \\
279\end{array}$ & $\begin{array}{r}6,300 \\
0\end{array}$ & $\begin{array}{r}0 \\
2,352\end{array}$ \\
\hline 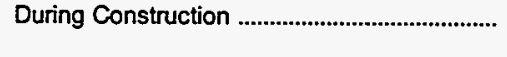 & 0 & 0 & 0 & 0 & 0 & 0 \\
\hline 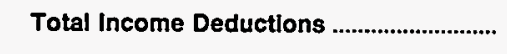 & $\mathbf{0}$ & 0 & 19 & 279 & 6,300 & 2,352 \\
\hline Income Before Extraordinary Items ................. & -622 & -206 & 2,034 & 513 & 23,305 & 220 \\
\hline Extraordinary Income & 0 & 0 & 0 & 0 & 0 & 0 \\
\hline 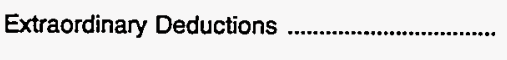 & 0 & 0 & 0 & 0 & 0 & 0 \\
\hline Net Income & -622 & -206 & 2,034 & 513 & 23,305 & 220 \\
\hline
\end{tabular}

because of independent rounding.

Source: Energy Information Administration, Form ElA-412, "Annual Report of Public Electric Utilities." 
Table 21. Statement of Income by Major U.S. Publicly Owned Electric Utility Within State, 1993 (Continued)

(Thousand Dollars)

\begin{tabular}{|c|c|c|c|c|c|c|}
\hline Item & $\begin{array}{l}\text { Georgia } \\
\text { East } \\
\text { Point } \\
\text { City of } \\
\text { June } 30\end{array}$ & $\begin{array}{c}\text { Georgia } \\
\text { Fitzgerald } \\
\text { Wtr Lgt } \\
\text { \& Bond Comm } \\
\text { December } 31\end{array}$ & $\begin{array}{l}\text { Georgia } \\
\text { Griffin } \\
\text { City of } \\
\text { June } 30\end{array}$ & $\begin{array}{l}\text { Georgia } \\
\text { La Grange } \\
\text { City of } \\
\text { June } 30\end{array}$ & $\begin{array}{l}\text { Georgia } \\
\text { Lawrenceville } \\
\text { City of } \\
\text { August } 30\end{array}$ & $\begin{array}{l}\text { Georgia } \\
\text { Marietta } \\
\text { City of } \\
\text { June } 30\end{array}$ \\
\hline Electric Utllity OperatIng Revenues ........... & 21,172 & 11,043 & 21,440 & 32,666 & 14,291 & 67,164 \\
\hline 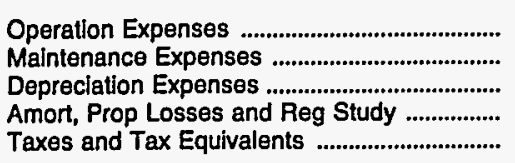 & $\begin{array}{r}15,955 \\
165 \\
383 \\
0 \\
0\end{array}$ & $\begin{array}{r}9,570 \\
642 \\
209 \\
0 \\
0\end{array}$ & $\begin{array}{r}17,435 \\
69 \\
403 \\
0 \\
0\end{array}$ & $\begin{array}{r}27,488 \\
0 \\
193 \\
0 \\
0\end{array}$ & $\begin{array}{r}12,612 \\
22 \\
437 \\
0 \\
0\end{array}$ & $\begin{array}{r}50,675 \\
0 \\
424 \\
0 \\
0\end{array}$ \\
\hline $\begin{array}{c}\text { Total Electric Uttlity Operating } \\
\text { Expenses }\end{array}$ & 16,503 & 10,421 & 17,906 & 27,680 & 13,072 & 51,100 \\
\hline $\begin{array}{l}\text { Net Electric Utility Operating Income } \\
\text { Income from Electric Plant Leased }\end{array}$ & 4,668 & 621 & 3,533 & 4,986 & 1,219 & 16,064 \\
\hline 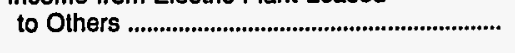 & 0 & 0 & 0 & 0 & 0 & 0 \\
\hline Electric Utillty Operating Income ............. & 4,668 & 621 & 3,533 & 4,986 & 1,219 & 16,064 \\
\hline 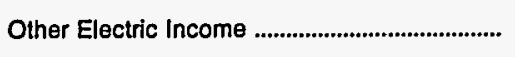 & 0 & 627 & 171 & 0 & 0 & 0 \\
\hline $\begin{array}{l}\text { Other Electric Deductions .................................... } \\
\text { Allowance for Other Funds Used }\end{array}$ & 0 & 0 & 0 & 0 & 0 & 0 \\
\hline $\begin{array}{l}\text { During Construction .......................................... } \\
\text { Taxes on Other Income and Deductions ....... }\end{array}$ & $\begin{array}{l}0 \\
0\end{array}$ & $\begin{array}{l}0 \\
0\end{array}$ & $\begin{array}{l}0 \\
0\end{array}$ & $\begin{array}{l}0 \\
0\end{array}$ & $\begin{array}{l}0 \\
0\end{array}$ & $\begin{array}{l}0 \\
0\end{array}$ \\
\hline 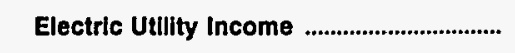 & 4,668 & 1,249 & 3,704 & 4,986 & 1,219 & 16,064 \\
\hline 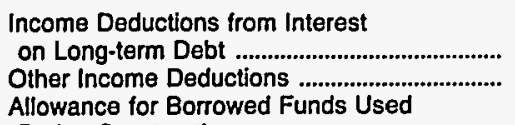 & $\begin{array}{l}0 \\
0\end{array}$ & $\begin{array}{r}216 \\
0\end{array}$ & $\begin{array}{l}0 \\
0\end{array}$ & $\begin{array}{l}0 \\
0\end{array}$ & $\begin{array}{r}0 \\
1,526\end{array}$ & $\begin{array}{l}0 \\
0\end{array}$ \\
\hline 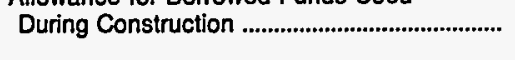 & 0 & 0 & 0 & 0 & 0 & 0 \\
\hline 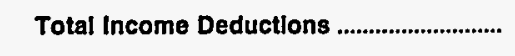 & 0 & 216 & $\mathbf{0}$ & 0 & 1,526 & 0 \\
\hline Income Before Extraordinary items .................. & 4,668 & 1,032 & 3,704 & 4,986 & -307 & 16,064 \\
\hline 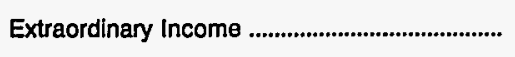 & 0 & 0 & 0 & 0 & 0 & 0 \\
\hline 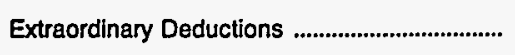 & 0 & 0 & 0 & 0 & 0 & 0 \\
\hline Net Income & 4,668 & 1,032 & 3,704 & 4,986 & -307 & 16,064 \\
\hline
\end{tabular}

Note: Totals may not equal sum of components because of independent rounding.

Source: Energy Information Administration, Form EIA-412, "Annual Report of Public Electric Utilities." 
Table 21. Statement of Income by Major U.S. Publicly Owned Electric Utllity Within State, 1993 (Continued)

(Thousand Dollars)

\begin{tabular}{|c|c|c|c|c|c|c|}
\hline Item & $\begin{array}{c}\text { Georgia } \\
\text { Moultrie } \\
\text { City of } \\
\text { September } 30\end{array}$ & $\begin{array}{l}\text { Georgia } \\
\text { Municipal } \\
\text { Electric } \\
\text { Authority } \\
\text { December } 31\end{array}$ & $\begin{array}{c}\text { Georgia } \\
\text { Thomasville } \\
\text { City of }\end{array}$ & $\begin{array}{l}\text { Idaho } \\
\text { Idaho } \\
\text { Falls } \\
\text { City of } \\
\text { September } 30\end{array}$ & $\begin{array}{l}\text { Illinois } \\
\text { Batavia } \\
\text { City of } \\
\text { December } 31\end{array}$ & $\begin{array}{l}\text { Illinois } \\
\text { Geneva } \\
\text { City of } \\
\text { April } 30\end{array}$ \\
\hline Electric Utllity Operating Revenues ............ & 11,623 & 537,785 & 26,838 & 32,622 & 13,938 & 9,531 \\
\hline 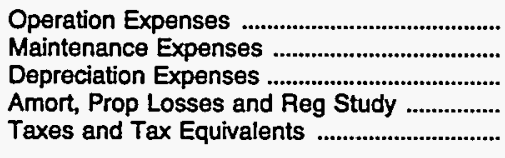 & $\begin{array}{r}10,205 \\
0 \\
208 \\
0 \\
0\end{array}$ & $\begin{array}{r}218,575 \\
42,849 \\
63,195 \\
26,310 \\
2,658\end{array}$ & $\begin{array}{r}22,817 \\
583 \\
586 \\
0 \\
1,072\end{array}$ & $\begin{array}{r}18,083 \\
2,339 \\
3,455 \\
0 \\
2,151\end{array}$ & $\begin{array}{r}13,046 \\
0 \\
603 \\
0 \\
0\end{array}$ & $\begin{array}{r}6,788 \\
608 \\
783 \\
0 \\
395\end{array}$ \\
\hline $\begin{array}{l}\text { Total Electric Utillty Operating } \\
\text { Expenses }\end{array}$ & 10,413 & 353,587 & 25,058 & 26,029 & 13,650 & 8,574 \\
\hline $\begin{array}{l}\text { Net Electric Utility Operating Income } \\
\text { Income from Electric Plant Leased } \\
\text { to Others }\end{array}$ & $\begin{array}{r}1,210 \\
0\end{array}$ & 184,198 & 1,780 & 6,594 & 288 & 957 \\
\hline Electric Utillty Operating Income .............. & 1,210 & 184,198 & 1,780 & 6,594 & 288 & 957 \\
\hline Other Electric Income & 99 & 45,488 & 33 & 3,061 & 459 & 349 \\
\hline $\begin{array}{l}\text { Other Electric Deductions .................................. } \\
\text { Allowance for Other Funds Used }\end{array}$ & 0 & 0 & 46 & 1,457 & 0 & 97 \\
\hline 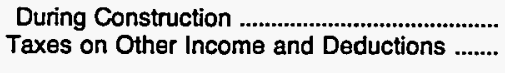 & $\begin{array}{l}0 \\
0\end{array}$ & $\begin{array}{r}0 \\
364\end{array}$ & $\begin{array}{l}0 \\
0\end{array}$ & $\begin{array}{l}0 \\
0\end{array}$ & $\begin{array}{l}0 \\
0\end{array}$ & $\begin{array}{l}0 \\
0\end{array}$ \\
\hline Electric Utillty Income & 1,309 & 229,322 & 1,767 & 8,198 & 747 & 1,210 \\
\hline $\begin{array}{l}\text { Income Deductions from Interest } \\
\text { on Long-term Debt ........................................... } \\
\text { Other Income Deductions ....................... } \\
\text { Allowance for Borrowed Funds Used }\end{array}$ & $\begin{array}{r}0 \\
1,887\end{array}$ & $\begin{array}{l}251,451 \\
-30,019\end{array}$ & $\begin{array}{l}0 \\
8\end{array}$ & $\begin{array}{r}7,700 \\
-141\end{array}$ & $\begin{array}{l}0 \\
0\end{array}$ & $\begin{array}{r}88 \\
9\end{array}$ \\
\hline 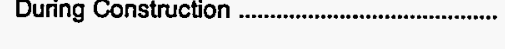 & 0 & 3,576 & 0 & 0 & 0 & $\mathbf{0}$ \\
\hline 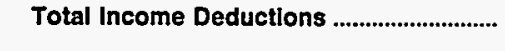 & 1,887 & 225,008 & 8 & 7,559 & 0 & 97 \\
\hline Income Before Extraordinary Items ....................... & -578 & 4,314 & 1,759 & 640 & 747 & 1,113 \\
\hline Extraordinary Income & 0 & 0 & 0 & 0 & 80 & 0 \\
\hline 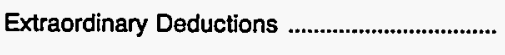 & 0 & 0 & 0 & $\mathbf{0}$ & 302 & 0 \\
\hline 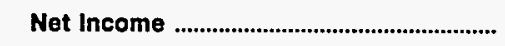 & -578 & 4,314 & 1,759 & 640 & 525 & 1,113 \\
\hline
\end{tabular}

Note: Totals may not equal sum of components because of independent rounding.

Source: Energy Information Administration, Form EIA-412, "Annual Report of Public Electric Utilities." 
Table 21. Statement of Income by Major U.S. Publicly Owned Electric Utillty Within State, 1993 (Continued)

(Thousand Dollars)

\begin{tabular}{|c|c|c|c|c|c|c|}
\hline Item & $\begin{array}{c}\text { Illinois } \\
\text { Illinois } \\
\text { Municipal } \\
\text { Elec Agency } \\
\text { April } 30\end{array}$ & $\begin{array}{l}\text { Illinois } \\
\text { Naperville } \\
\text { City of } \\
\text { April } 30\end{array}$ & $\begin{array}{l}\text { Illinois } \\
\text { Rochelle } \\
\text { Municipal } \\
\text { Utilities } \\
\text { April } 30\end{array}$ & $\begin{array}{c}\text { Illinois } \\
\begin{array}{c}\text { Springfield } \\
\text { City of }\end{array} \\
\text { February } 28\end{array}$ & $\begin{array}{l}\text { Illinois } \\
\text { St Charles } \\
\text { City of } \\
\text { April } 30\end{array}$ & $\begin{array}{l}\text { Indiana } \\
\text { Anderson } \\
\text { City of } \\
\text { December } \mathbf{3 1}\end{array}$ \\
\hline Electric Utility Operating Revenues ............ & 57,862 & 51,119 & 10,876 & 89,214 & 24,602 & 36,224 \\
\hline 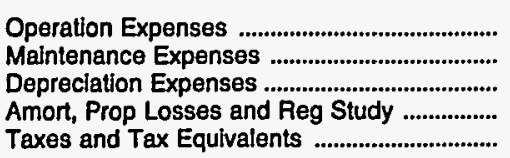 & $\begin{array}{r}46,248 \\
474 \\
3,044 \\
0 \\
0\end{array}$ & $\begin{array}{r}39,887 \\
736 \\
3.143 \\
0 \\
0\end{array}$ & $\begin{array}{r}8,063 \\
1,124 \\
998 \\
0 \\
110\end{array}$ & $\begin{array}{r}45,701 \\
18,035 \\
12,030 \\
87 \\
3,743\end{array}$ & $\begin{array}{r}17,506 \\
3,828 \\
898 \\
0 \\
0\end{array}$ & $\begin{array}{r}29,767 \\
1,296 \\
1,493 \\
0 \\
1,022\end{array}$ \\
\hline $\begin{array}{l}\text { Total Electric UtIlity Operating } \\
\text { Expenses ....................................................... }\end{array}$ & 49,767 & 43,767 & 10,294 & 79,597 & 22,232 & 33,577 \\
\hline 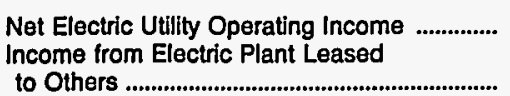 & $\begin{array}{r}8,095 \\
0\end{array}$ & 7,353 & 582 & 9,617 & 2,570 & 2,646 \\
\hline Electric UtIIIty Operating Income ............. & 8,095 & 7,353 & 582 & 9,617 & 2,570 & 2,646 \\
\hline Other Electric Income & 1,504 & 2,225 & 218 & 2,276 & 906 & 159 \\
\hline $\begin{array}{l}\text { Other Electric Deductions } \\
\text { Allowance for Other Funds Used }\end{array}$ & 0 & 0 & 0 & 0 & 0 & 0 \\
\hline $\begin{array}{l}\text { During Construction ...................................... } \\
\text { Texes on Other Income and Deductions ....... }\end{array}$ & $\begin{array}{l}0 \\
0\end{array}$ & $\begin{array}{l}0 \\
0\end{array}$ & $\begin{array}{l}0 \\
0\end{array}$ & $\begin{array}{l}0 \\
0\end{array}$ & $\begin{array}{l}0 \\
0\end{array}$ & $\begin{array}{l}0 \\
0\end{array}$ \\
\hline Electric Utillty Income .................................... & 9,599 & 9,577 & 800 & 11,894 & 3,476 & 2,806 \\
\hline $\begin{array}{l}\text { Income Deductions from Interest } \\
\text { on Long-term Debt ................................................. } \\
\text { Other Income Deductions ............................... } \\
\text { Allowance for Borrowed Funds Used }\end{array}$ & $\begin{array}{r}7,553 \\
640\end{array}$ & $\begin{array}{r}1,011 \\
0\end{array}$ & $\begin{array}{r}632 \\
0\end{array}$ & $\begin{array}{r}6,666 \\
253\end{array}$ & $\begin{array}{l}0 \\
0\end{array}$ & $\begin{array}{r}69 \\
7\end{array}$ \\
\hline 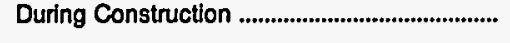 & 0 & 0 & -222 & 0 & 0 & 0 \\
\hline 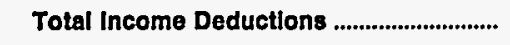 & 8,194 & 1,011 & 410 & 6,919 & 0 & 76 \\
\hline Income Before Extraordinary Items ..................... & 1,405 & 8,566 & 390 & 4,974 & 3,476 & 2,730 \\
\hline 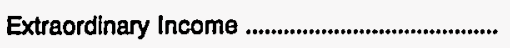 & 584 & 0 & 193 & 923 & 0 & 0 \\
\hline 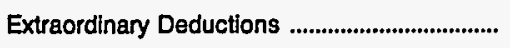 & 0 & 0 & 0 & 0 & 0 & 0 \\
\hline 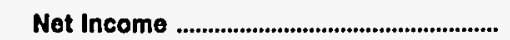 & 1,989 & 8,566 & 583 & 5,897 & 3,476 & 2,730 \\
\hline
\end{tabular}

Note: Totals may not equal sum of components because of independent rounding.

Source: Energy Information Administration, Form ElA-412, "Annual Report of Public Electric Utilities." 
Table 21. Statement of Income by Major U.S. Publicly Owned Electric Utility Within State, 1993 (Continued) (Thousand Dollars)

\begin{tabular}{|c|c|c|c|c|c|c|}
\hline Item & $\begin{array}{l}\text { Indiana } \\
\text { Auburn } \\
\text { City of } \\
\text { December } 31\end{array}$ & $\begin{array}{c}\text { Indiana } \\
\text { Bluffton } \\
\text { City of } \\
\text { December } 31\end{array}$ & $\begin{array}{c}\text { Indiana } \\
\text { Crawfordsville } \\
\text { Elec } \\
\text { Lgt\&Pwr Co } \\
\text { December } 31\end{array}$ & $\begin{array}{l}\text { Indiana } \\
\text { Frankfort } \\
\text { City of } \\
\text { December } 31\end{array}$ & $\begin{array}{c}\text { Indiana } \\
\text { Greenfield } \\
\text { City of } \\
\text { December } 31\end{array}$ & $\begin{array}{c}\text { Indiana } \\
\text { Indiana } \\
\text { Municipal } \\
\text { Power Agency } \\
\text { December } 31\end{array}$ \\
\hline Electric Utility Operating Revenues ........... & 15,617 & 8,317 & 20,852 & 14,963 & 8,781 & 142,066 \\
\hline 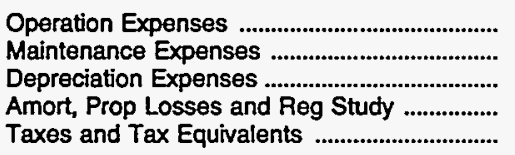 & $\begin{array}{r}12,488 \\
648 \\
370 \\
0 \\
183\end{array}$ & $\begin{array}{r}7,003 \\
237 \\
274 \\
0 \\
149\end{array}$ & $\begin{array}{r}16,610 \\
1,012 \\
937 \\
22 \\
471\end{array}$ & $\begin{array}{r}12,704 \\
189 \\
518 \\
0 \\
240\end{array}$ & $\begin{array}{r}7,098 \\
500 \\
233 \\
0 \\
0\end{array}$ & $\begin{array}{r}104,856 \\
2,582 \\
10,574 \\
14 \\
760\end{array}$ \\
\hline $\begin{array}{l}\text { Total Electric Utllity Operating } \\
\text { Expenses }\end{array}$ & 13,689 & 7,663 & 19,052 & 13,651 & 7,831 & 118,787 \\
\hline 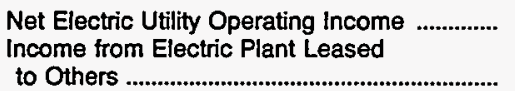 & 1,929 & 654 & 1,800 & 1,312 & 950 & 23,279 \\
\hline Electric Utility Operating Income ............. & 1,929 & 654 & 1,800 & 1,312 & 950 & 23,279 \\
\hline Other Electric Income & 277 & 127 & 212 & 157 & 101 & 5,986 \\
\hline $\begin{array}{l}\text { Other Electric Deductions ............................... } \\
\text { Allowance for Other Funds Used }\end{array}$ & 0 & 12 & 0 & 12 & 0 & 2 \\
\hline 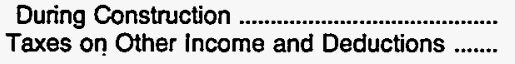 & $\begin{array}{l}0 \\
0\end{array}$ & $\begin{array}{l}\mathbf{0} \\
\mathbf{0}\end{array}$ & $\begin{array}{l}70 \\
15\end{array}$ & $\begin{array}{l}0 \\
0\end{array}$ & $\begin{array}{l}0 \\
0\end{array}$ & $\begin{array}{l}0 \\
0\end{array}$ \\
\hline Electric Utllity Income & 2,206 & 768 & 2,066 & 1,456 & 1,051 & 29,263 \\
\hline 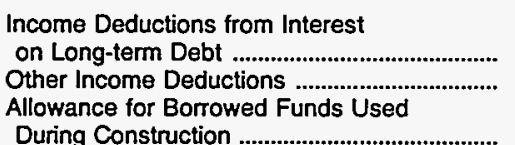 & $\begin{array}{r}42 \\
0\end{array}$ & $\begin{array}{l}0 \\
0\end{array}$ & $\begin{array}{l}480 \\
270\end{array}$ & $\begin{array}{l}0 \\
0\end{array}$ & $\begin{array}{r}133 \\
0\end{array}$ & $\begin{array}{r}23,772 \\
4,157 \\
-307\end{array}$ \\
\hline Total Income Deductions .............................. & 42 & 0 & 750 & 0 & 133 & 27,622 \\
\hline Income Before Extraordinary Items ................. & 2,164 & 768 & 1,316 & 1,456 & 918 & 1,641 \\
\hline 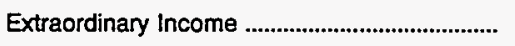 & 0 & 0 & 0 & 0 & 0 & 6,472 \\
\hline 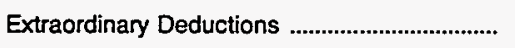 & 0 & 0 & 0 & 0 & 0 & 0 \\
\hline Net Income & 2,164 & 768 & 1,316 & 1,456 & 918 & 8,112 \\
\hline
\end{tabular}

Note: Totals may not equal sum of components because of independent rounding.

Source: Energy Information Administration, Form EIA-412, "Annual Report of Public Electric Utilities." 
Table 21. Statement of Income by Major U.S. Publicly Owned Electric Utility Within State, 1993 (Continued)

(Thousand Dollars)

\begin{tabular}{|c|c|c|c|c|c|c|}
\hline Item & $\begin{array}{c}\text { Indiana } \\
\text { Jasper } \\
\text { City of } \\
\text { December } 31\end{array}$ & $\begin{array}{c}\text { Indiana } \\
\text { Logansport } \\
\text { City of } \\
\text { December } 31\end{array}$ & $\begin{array}{c}\text { Indiana } \\
\text { Mishawaka } \\
\text { City of } \\
\text { December } 31\end{array}$ & $\begin{array}{c}\text { Indiana } \\
\text { Peru } \\
\text { City of } \\
\text { December } 31\end{array}$ & $\begin{array}{l}\text { Indiana } \\
\text { Richmond } \\
\text { City of } \\
\text { December } 31\end{array}$ & $\begin{array}{c}\text { Indiana } \\
\text { Washington } \\
\text { City of }\end{array}$ \\
\hline Electric Utility Operating Revenues ........... & 15,557 & 18,696 & 25,284 & 10,037 & 40,976 & 8,096 \\
\hline 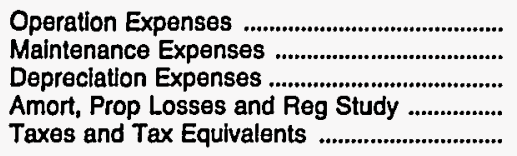 & $\begin{array}{r}12,442 \\
355 \\
240 \\
0 \\
283\end{array}$ & $\begin{array}{r}13,394 \\
1,239 \\
1,544 \\
0 \\
385\end{array}$ & $\begin{array}{r}20,611 \\
535 \\
1,070 \\
0 \\
414\end{array}$ & $\begin{array}{r}7,866 \\
425 \\
857 \\
0 \\
366\end{array}$ & $\begin{array}{r}30,811 \\
2,409 \\
2,848 \\
0 \\
2,305\end{array}$ & $\begin{array}{r}7,533 \\
247 \\
329 \\
0 \\
146\end{array}$ \\
\hline $\begin{array}{l}\text { Total Electrlc Utllity Operating } \\
\text { Expenses }\end{array}$ & 13,319 & 16,563 & 22,630 & 9,514 & 38,373 & 8,255 \\
\hline 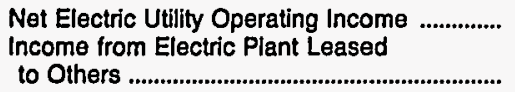 & 2,238 & 2,133 & 2,654 & 523 & 2,603 & $\begin{array}{r}-159 \\
0\end{array}$ \\
\hline Electric UtIlity Operating Income ............. & 2,238 & 2,133 & 2,654 & 523 & 2,603 & -159 \\
\hline 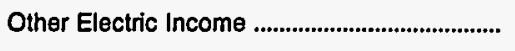 & 255 & 469 & 84 & 102 & 585 & 19 \\
\hline $\begin{array}{l}\text { Other Electric Deductions ................................ } \\
\text { Allowence for Other Funds Used }\end{array}$ & 7 & 0 & 0 & 0 & 210 & 0 \\
\hline $\begin{array}{l}\text { During Construction ....................................... } \\
\text { Taxes on Other Income and Deductions ....... }\end{array}$ & $\begin{array}{l}0 \\
0\end{array}$ & $\begin{array}{l}0 \\
0\end{array}$ & $\begin{array}{l}0 \\
0\end{array}$ & $\begin{array}{r}0 \\
220\end{array}$ & $\begin{array}{r}0 \\
420\end{array}$ & $\begin{array}{r}0 \\
52\end{array}$ \\
\hline Electric Utility Income ................................. & 2,486 & 2,602 & 2,738 & 405 & 2,558 & -192 \\
\hline 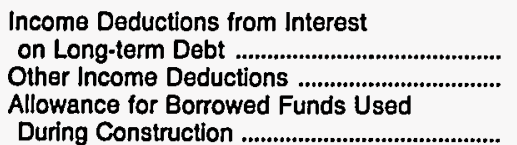 & $\begin{array}{r}510 \\
8\end{array}$ & $\begin{array}{r}1,090 \\
0\end{array}$ & $\begin{array}{l}78 \\
48\end{array}$ & $\begin{array}{r}93 \\
1\end{array}$ & $\begin{array}{l}0 \\
0\end{array}$ & $\begin{array}{l}0 \\
0\end{array}$ \\
\hline Total Income Deductlons ............................. & 519 & 1,090 & 126 & 94 & $\mathbf{0}$ & o \\
\hline Income Before Extraordinary Items .................. & 1,968 & 1,512 & 2,613 & 312 & 2,558 & -192 \\
\hline 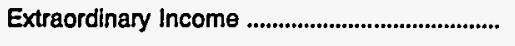 & -6 & 0 & 0 & 0 & 0 & 0 \\
\hline Extraordinary Deductions ...................................... & 146 & 0 & 0 & 0 & 0 & 0 \\
\hline Net Income & 1,816 & 1,512 & 2,613 & 312 & 2,558 & -192 \\
\hline
\end{tabular}

Note: Totals may not equal sum of components because of independent rounding.

Source: Energy Information Administration, Form EIA-412, "Annual Report of Public Electric Utilities." 
Table 21. Statement of Income by Major U.S. Publicly Owned Electric Utility Within State, 1993 (Continued)

(Thousand Dollars)

\begin{tabular}{|c|c|c|c|c|c|c|}
\hline Item & $\begin{array}{l}\text { lowa } \\
\text { Ames } \\
\text { City of } \\
\text { June } 30\end{array}$ & $\begin{array}{c}\text { lowa } \\
\text { Cedar } \\
\text { Falls } \\
\text { City of } \\
\text { December } 31\end{array}$ & $\begin{array}{c}\text { lowa } \\
\begin{array}{c}\text { Muscatine } \\
\text { City of }\end{array} \\
\text { December } 31\end{array}$ & $\begin{array}{l}\text { lowa } \\
\text { Pella } \\
\text { City of } \\
\text { June } 30\end{array}$ & $\begin{array}{l}\text { Kansas } \\
\text { Chanute } \\
\text { City of } \\
\text { December } 31\end{array}$ & $\begin{array}{c}\text { Kansas } \\
\text { Coffeyville } \\
\text { City of } \\
\text { December } 31\end{array}$ \\
\hline Electric Utility Operating Revenues ............. & 19,714 & 13,351 & 49,302 & 7,782 & 8,854 & 11,069 \\
\hline 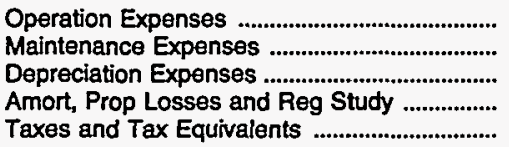 & $\begin{array}{r}13,299 \\
0 \\
3,224 \\
0 \\
0\end{array}$ & $\begin{array}{r}7,563 \\
1,732 \\
2,174 \\
73 \\
628\end{array}$ & $\begin{array}{r}26,538 \\
6,520 \\
9,411 \\
0 \\
101\end{array}$ & $\begin{array}{r}6,314 \\
285 \\
0 \\
0 \\
0\end{array}$ & $\begin{array}{r}5,031 \\
905 \\
0 \\
0 \\
0\end{array}$ & $\begin{array}{r}7,916 \\
1,380 \\
1,309 \\
0 \\
550\end{array}$ \\
\hline $\begin{array}{l}\text { Total Electric Utility Operating } \\
\text { Expenses }\end{array}$ & 16,523 & 12,170 & 42,569 & 6,598 & 5,935 & 11,155 \\
\hline 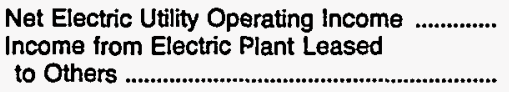 & 3,191 & 1,182 & 6,733 & 1,184 & 2,918 & -87 \\
\hline Electric Utility Operating Income ............. & 3,191 & 1,182 & 6,733 & 1,184 & 2,918 & -87 \\
\hline Other Electric Income & 1,121 & 932 & 12,217 & 629 & 165 & 121 \\
\hline $\begin{array}{l}\text { Other Electric Deductions } \\
\text { Allowance for Other Funds Used.............................. }\end{array}$ & 762 & 42 & 0 & 0 & 585 & 428 \\
\hline 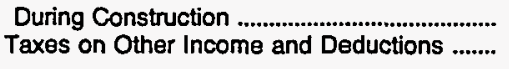 & $\begin{array}{l}0 \\
0\end{array}$ & $\begin{array}{l}0 \\
0\end{array}$ & $\begin{array}{l}0 \\
0\end{array}$ & $\begin{array}{l}0 \\
0\end{array}$ & $\begin{array}{l}0 \\
0\end{array}$ & $\begin{array}{l}0 \\
0\end{array}$ \\
\hline 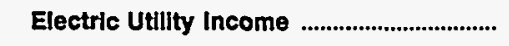 & 3,550 & 2,071 & 18,950 & 1,813 & 2,499 & -393 \\
\hline 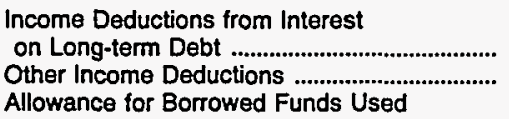 & $\begin{array}{r}1,977 \\
0\end{array}$ & $\begin{array}{r}227 \\
3\end{array}$ & $\begin{array}{r}12,866 \\
0\end{array}$ & $\begin{array}{r}343 \\
66\end{array}$ & $\begin{array}{r}1,763 \\
0\end{array}$ & $\begin{array}{r}58 \\
0\end{array}$ \\
\hline 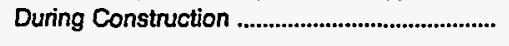 & 0 & 0 & 0 & 0 & 0 & 0 \\
\hline 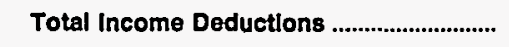 & 1,977 & 230 & 12,866 & 409 & 1,763 & 58 \\
\hline Income Before Extraordinary Items ....................... & 1,572 & 1,841 & 6,084 & 1,404 & 736 & -451 \\
\hline Extraordinary Income & 0 & 0 & $\mathbf{0}$ & 0 & 0 & 30 \\
\hline 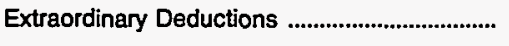 & 468 & 0 & $\mathbf{0}$ & 0 & 0 & 100 \\
\hline 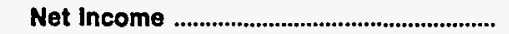 & 1,104 & 1,841 & 6,084 & $\mathbf{1 , 4 0 4}$ & 736 & -521 \\
\hline
\end{tabular}

Note: Totals may not equal sum of components because of independent rounding.

Source: Energy Information Administration, Form ElA-412, "Annual Report of Public Electric Utilities." 
Table 21. Statement of Income by Major U.S. Publicly Owned Electric Utility Within State, 1993 (Continued)

(Thousand Dollars)

\begin{tabular}{|c|c|c|c|c|c|c|}
\hline Item & $\begin{array}{c}\text { Kansas } \\
\text { Garden } \\
\text { City City of } \\
\text { December } 31\end{array}$ & $\begin{array}{c}\text { Kansas } \\
\text { Kansas } \\
\text { City City of } \\
\text { December } 31\end{array}$ & $\begin{array}{c}\text { Kansas } \\
\text { Kansas } \\
\text { Municipal } \\
\text { Energy } \\
\text { Agency } \\
\text { December } 31\end{array}$ & $\begin{array}{c}\text { Kansas } \\
\text { McPherson } \\
\text { City of }\end{array}$ & $\begin{array}{c}\text { Kansas } \\
\begin{array}{c}\text { Winfield } \\
\text { City of }\end{array} \\
\text { December } 31\end{array}$ & $\begin{array}{l}\text { Kentucky } \\
\text { Bowling } \\
\text { Green } \\
\text { City of } \\
\text { June } 30\end{array}$ \\
\hline Electric Utility Operating Revenues .............. & 11,140 & 121,928 & 10,033 & 19,023 & 12,591 & 36,350 \\
\hline 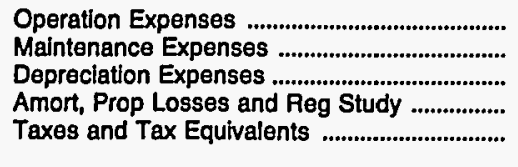 & $\begin{array}{r}10,470 \\
0 \\
592 \\
0 \\
0\end{array}$ & $\begin{array}{r}77,730 \\
16,045 \\
9,239 \\
1,159 \\
9,671\end{array}$ & $\begin{array}{r}11,153 \\
0 \\
184 \\
907 \\
25\end{array}$ & $\begin{array}{r}14,766 \\
1,016 \\
1,705 \\
0 \\
0\end{array}$ & $\begin{array}{r}10,125 \\
294 \\
820 \\
0 \\
0\end{array}$ & $\begin{array}{r}30,955 \\
1,041 \\
1,304 \\
0 \\
1,457\end{array}$ \\
\hline $\begin{array}{l}\text { Total Electric Utillty Operating } \\
\text { Expenses }\end{array}$ & 11,063 & 113,845 & 12,269 & 17,487 & 11,239 & 34,758 \\
\hline 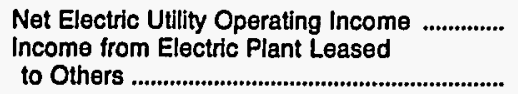 & 77 & 8,083 & $-2,236$ & 1,536 & 1,352 & 1,593 \\
\hline Electric Utillty Operating Income .............. & 77 & 8,083 & $-2,236$ & 1,536 & 1,352 & 1,593 \\
\hline 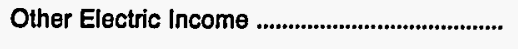 & 17 & 3,549 & 3,270 & 1,184 & 2,054 & 470 \\
\hline $\begin{array}{l}\text { Other Electric Deductions ................................ } \\
\text { Allowance for Other Funds Used } \\
\text { During Construction ........................................ } \\
\text { Taxes on Other Income and Deductions ....... }\end{array}$ & $\begin{array}{l}0 \\
0\end{array}$ & $\begin{array}{l}0 \\
0\end{array}$ & $\begin{array}{l}0 \\
0\end{array}$ & 740 & $\begin{array}{r}0 \\
885\end{array}$ & $\begin{array}{l}0 \\
0\end{array}$ \\
\hline Electric Utility Income ....................................... & 95 & 11,632 & 1,034 & 1,980 & 2,521 & 2,062 \\
\hline 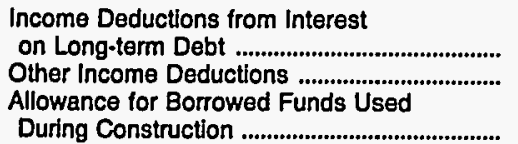 & $\begin{array}{r}0 \\
430\end{array}$ & $\begin{array}{r}10,416 \\
0\end{array}$ & $\begin{array}{r}957 \\
68\end{array}$ & $\begin{array}{r}851 \\
0\end{array}$ & $\begin{array}{r}445 \\
0\end{array}$ & $\begin{array}{l}384 \\
161\end{array}$ \\
\hline 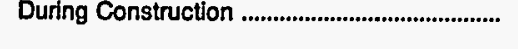 & 0 & 0 & 0 & 0 & 0 & 0 \\
\hline 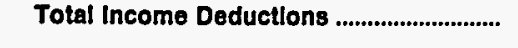 & 430 & 10,416 & 1,025 & 851 & 445 & 545 \\
\hline Income Before Extraordinary Items ...................... & -335 & 1,216 & 9 & 1,129 & 2,076 & 1,517 \\
\hline 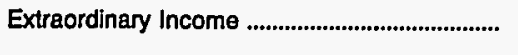 & 0 & 0 & 0 & 0 & -36 & 0 \\
\hline Extraordinary Deductions ........................................ & 0 & 0 & 0 & 0 & 0 & 0 \\
\hline 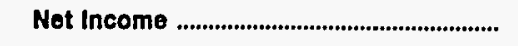 & -335 & 1,216 & 9 & 1,129 & 2,039 & 1,517 \\
\hline
\end{tabular}

Note: Totals may not equal sum of components because of independent rounding.

Source: Energy Information Administration, Form EIA-412, "Annual Report of Public Electric Utilities." 
Table 21. Statement of Income by Major U.S. Publicly Owned Electric Utility Within State, 1993 (Continued)

(Thousand Dollars)

\begin{tabular}{|c|c|c|c|c|c|c|}
\hline Item & $\begin{array}{l}\text { Kentucky } \\
\text { Frankfort } \\
\text { City of } \\
\text { June } 30\end{array}$ & $\begin{array}{l}\text { Kentucky } \\
\text { Franklin } \\
\text { City of } \\
\text { June } 30\end{array}$ & $\begin{array}{l}\text { Kentucky } \\
\text { Glasgow } \\
\text { City of } \\
\text { June } 30\end{array}$ & $\begin{array}{l}\text { Kentucky } \\
\text { Henderson } \\
\text { City } \\
\text { Utility Comm } \\
\text { May } 31\end{array}$ & $\begin{array}{l}\text { Kentucky } \\
\text { Hopkinsville } \\
\text { City of } \\
\text { June } 30\end{array}$ & $\begin{array}{c}\text { Kentucky } \\
\text { Madisonville } \\
\begin{array}{c}\text { Municipal } \\
\text { Utils }\end{array} \\
\text { June } 30\end{array}$ \\
\hline Electric Utillty Operating Revenues ............. & 22,462 & 9,362 & 14,648 & 23,594 & 19,439 & 11,392 \\
\hline 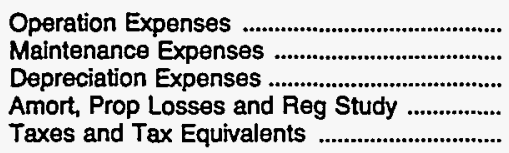 & $\begin{array}{r}20,090 \\
920 \\
800 \\
0 \\
80\end{array}$ & $\begin{array}{r}8,489 \\
194 \\
130 \\
0 \\
345\end{array}$ & $\begin{array}{r}13,264 \\
247 \\
540 \\
11 \\
376\end{array}$ & $\begin{array}{r}12,621 \\
4,012 \\
4,183 \\
0 \\
0\end{array}$ & $\begin{array}{r}17,734 \\
538 \\
474 \\
0 \\
687\end{array}$ & $\begin{array}{r}8.570 \\
763 \\
220 \\
0 \\
0\end{array}$ \\
\hline $\begin{array}{l}\text { Total Electric Utllity Operating } \\
\text { Expenses }\end{array}$ & 21,890 & 9,158 & 14,438 & 20,816 & 19,433 & 9,553 \\
\hline 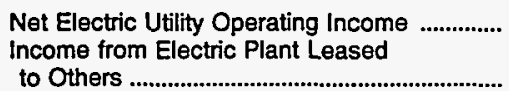 & $\begin{array}{r}572 \\
0\end{array}$ & 204 & $\begin{array}{r}210 \\
0\end{array}$ & $\begin{array}{r}2,778 \\
0\end{array}$ & 6 & 1,839 \\
\hline Electric Utllity Operating Income .............. & 572 & 204 & 210 & 2,778 & 6 & 1,839 \\
\hline Other Electric Income & 6,819 & 118 & 151 & 1,113 & 552 & 101 \\
\hline $\begin{array}{l}\text { Other Electric Deductions } \\
\text { Allowance for Other Funds Used }\end{array}$ & 5,903 & 0 & 7 & 0 & 0 & 0 \\
\hline 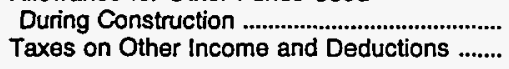 & $\begin{array}{l}0 \\
0\end{array}$ & $\begin{array}{l}0 \\
0\end{array}$ & $\begin{array}{l}0 \\
0\end{array}$ & $\begin{array}{l}0 \\
0\end{array}$ & $\begin{array}{l}0 \\
0\end{array}$ & $\begin{array}{l}0 \\
0\end{array}$ \\
\hline Electric Utility Income & 1,488 & 321 & 354 & 3,890 & 558 & 1,940 \\
\hline 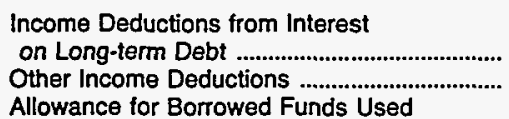 & $\begin{array}{r}285 \\
0\end{array}$ & $\begin{array}{l}0 \\
8\end{array}$ & $\begin{array}{r}267 \\
32\end{array}$ & $\begin{array}{r}2,638 \\
0\end{array}$ & $\begin{array}{r}193 \\
13\end{array}$ & $\begin{array}{r}0 \\
3,740\end{array}$ \\
\hline 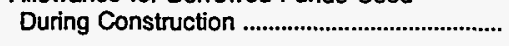 & 0 & 0 & 0 & 0 & 0 & 0 \\
\hline 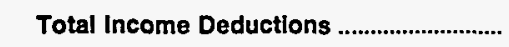 & 285 & 8 & 299 & 2,638 & 206 & 3,740 \\
\hline Income Before Extraordinary Items ................... & 1,203 & 313 & 55 & 1,253 & 352 & $-1,800$ \\
\hline Extraordinary Income & 0 & 0 & 0 & 0 & 0 & 0 \\
\hline 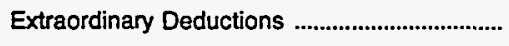 & 0 & 0 & 0 & 0 & 0 & 0 \\
\hline 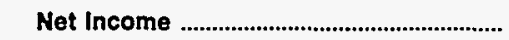 & 1,203 & 313 & 55 & 1,253 & 352 & $-1,800$ \\
\hline
\end{tabular}

Note: Totals may not equal sum of components because of independent rounding

Source: Energy Information Administration, Form ElA-412, "Annual Report of Public Electric Utilities." 
Table 21. Statement of Income by Major U.S. Publicly Owned Electric Utility Within State, 1993 (Continued)

(Thousand Dollars)

\begin{tabular}{|c|c|c|c|c|c|c|}
\hline Item & $\begin{array}{l}\text { Kentucky } \\
\text { Maytield } \\
\text { City of } \\
\text { June } 30\end{array}$ & $\begin{array}{l}\text { Kentucky } \\
\text { Murray } \\
\text { City of } \\
\text { June } 30\end{array}$ & $\begin{array}{l}\text { Kentucky } \\
\text { Owensboro } \\
\text { City of } \\
\text { May } 31\end{array}$ & $\begin{array}{l}\text { Kentucky } \\
\text { Paducah } \\
\text { City of } \\
\text { June } 30\end{array}$ & $\begin{array}{l}\text { Louisiana } \\
\text { Alexandria } \\
\text { City of } \\
\text { April } 30\end{array}$ & $\begin{array}{l}\text { Louisiana } \\
\text { Lafayette } \\
\text { City of } \\
\text { October } 31\end{array}$ \\
\hline Electric Utillty Operating Revenues ............. & 8,242 & 11,932 & 49,073 & 30,492 & 38,765 & 106,288 \\
\hline 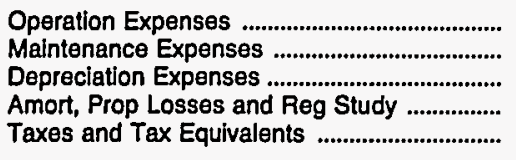 & $\begin{array}{r}7,299 \\
394 \\
170 \\
0 \\
353\end{array}$ & $\begin{array}{r}10,790 \\
442 \\
294 \\
0 \\
474\end{array}$ & $\begin{array}{r}31,661 \\
4,636 \\
3,980 \\
0 \\
3,073\end{array}$ & $\begin{array}{r}26,960 \\
733 \\
1,385 \\
0 \\
1,344\end{array}$ & $\begin{array}{r}25,744 \\
502 \\
1,782 \\
0 \\
1,992\end{array}$ & $\begin{array}{r}77,883 \\
3,389 \\
4,197 \\
2,046 \\
8,069\end{array}$ \\
\hline $\begin{array}{l}\text { Total Electrlc Utility Operating } \\
\text { Expenses }\end{array}$ & 8,215 & 12,000 & 43,350 & 30,422 & 30,020 & 95,584 \\
\hline 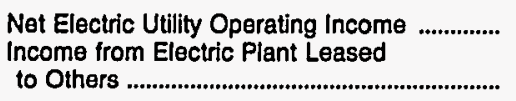 & $\begin{array}{r}27 \\
0\end{array}$ & $\begin{array}{r}-68 \\
0\end{array}$ & $\begin{array}{r}5,722 \\
0\end{array}$ & 70 & $\begin{array}{r}8,745 \\
0\end{array}$ & $\begin{array}{r}10,705 \\
0\end{array}$ \\
\hline Electric Utllity Operating Income .............. & 27 & -68 & 5,722 & 70 & 8,745 & 10,705 \\
\hline 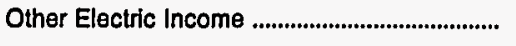 & 59 & 106 & 5,176 & 524 & 1,143 & 2,292 \\
\hline $\begin{array}{l}\text { Other Electric Deductions .............................. } \\
\text { Allowance for Other Funds Used } \\
\text { During Construction ......................................... } \\
\text { Texes on Other Income and Deductions ....... }\end{array}$ & $\begin{array}{l}0 \\
0\end{array}$ & $\begin{array}{l}0 \\
0\end{array}$ & $\begin{array}{l}0 \\
0\end{array}$ & $\begin{array}{l}0 \\
0\end{array}$ & $\begin{array}{r}1,525 \\
0 \\
802\end{array}$ & $\begin{array}{l}0 \\
0\end{array}$ \\
\hline 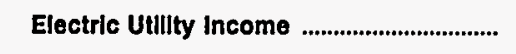 & 85 & 38 & 10,898 & 589 & 7,561 & 12,996 \\
\hline 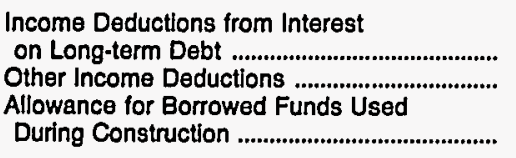 & $\begin{array}{l}5 \\
7\end{array}$ & $\begin{array}{r}0 \\
17\end{array}$ & $\begin{array}{r}6,427 \\
0\end{array}$ & $\begin{array}{r}290 \\
31\end{array}$ & $\begin{array}{l}3,214 \\
2,077\end{array}$ & $\begin{array}{r}2,925 \\
107\end{array}$ \\
\hline 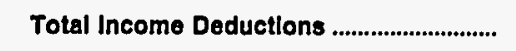 & 13 & 17 & 6,427 & 322 & 5,292 & 3,032 \\
\hline 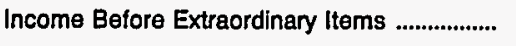 & 73 & 21 & 4,472 & 268 & 2,269 & 9,965 \\
\hline Extraordinary Income & 0 & 0 & 0 & 0 & 0 & 0 \\
\hline 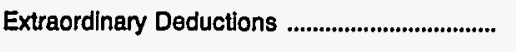 & 0 & 0 & 0 & 0 & 2,374 & 0 \\
\hline Net Income & 73 & 21 & 4,472 & 268 & -104 & 9,965 \\
\hline
\end{tabular}

Note: Totals may not equal sum of components because of independent rounding.

Source: Energy Information Administration, Form EIA-412, "Annual Report of Public Electric Utilities." 
Table 21. Statement of Income by Major U.S. Publicly Owned Electric Utility Within State, 1993 (Continued)

(Thousand Dollars)

\begin{tabular}{|c|c|c|c|c|c|c|}
\hline Item & $\begin{array}{l}\text { Louisiana } \\
\text { Lafayette } \\
\text { Public } \\
\text { Power Auth } \\
\text { October } 31\end{array}$ & $\begin{array}{c}\text { Louisiana } \\
\text { Louisiana } \\
\text { Energy } \\
\& \\
\text { Power Auth } \\
\text { December } 31\end{array}$ & $\begin{array}{l}\text { Louisiana } \\
\text { Morgan } \\
\text { City City of } \\
\text { December } 31\end{array}$ & $\begin{array}{c}\text { Louisiana } \\
\text { Natchitoches } \\
\text { City of } \\
\text { May } 31\end{array}$ & $\begin{array}{l}\text { Louisiana } \\
\text { Ruston } \\
\text { City of } \\
\text { September } 30\end{array}$ & $\begin{array}{l}\text { Louisiana } \\
\text { Terrebonne } \\
\text { Parish } \\
\text { Consol Govt } \\
\text { December } 31\end{array}$ \\
\hline Electric Utillty Operating Revenues ............ & 50,035 & 64,170 & 10,608 & 14,571 & 11,674 & 17,774 \\
\hline 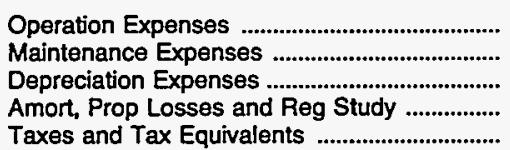 & $\begin{array}{r}33,687 \\
1,503 \\
4,314 \\
0 \\
0\end{array}$ & $\begin{array}{r}52,341 \\
911 \\
2,046 \\
1,464 \\
0\end{array}$ & $\begin{array}{r}8,040 \\
227 \\
832 \\
0 \\
0\end{array}$ & $\begin{array}{r}12,857 \\
0 \\
850 \\
0 \\
0\end{array}$ & $\begin{array}{r}8,009 \\
516 \\
778 \\
0 \\
0\end{array}$ & $\begin{array}{r}13,003 \\
1,160 \\
1,397 \\
0 \\
0\end{array}$ \\
\hline $\begin{array}{l}\text { Total Electric Utllity Operating } \\
\text { Expenses }\end{array}$ & 39,504 & 56,762 & 9,100 & 13,707 & 9,304 & 15,561 \\
\hline 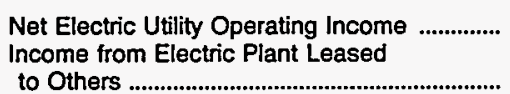 & 10,531 & 7,408 & 1,508 & 864 & 2,370 & 2,213 \\
\hline Electric Utility Operating Income ............. & 10,531 & 7,408 & 1,508 & 864 & 2,370 & 2,213 \\
\hline Other Electric Income & 612 & 1,415 & 21 & 0 & 195 & 2,686 \\
\hline 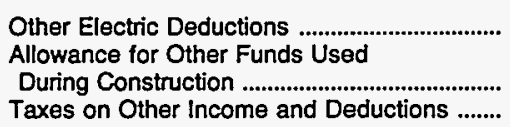 & $\begin{array}{l}0 \\
0\end{array}$ & $\begin{array}{l}0 \\
0\end{array}$ & $\begin{array}{l}0 \\
0\end{array}$ & $\begin{array}{l}0 \\
0\end{array}$ & $\begin{array}{l}0 \\
0\end{array}$ & $\begin{array}{l}0 \\
0\end{array}$ \\
\hline Electric Utility Income ................................ & 11,144 & 8,823 & 1,529 & 864 & 2,565 & 4,899 \\
\hline 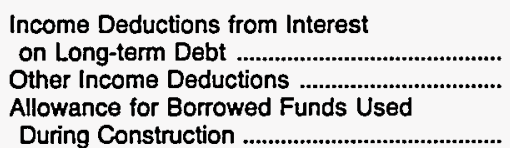 & $\begin{array}{r}11,041 \\
842\end{array}$ & $\begin{array}{r}8,468 \\
0\end{array}$ & $\begin{array}{r}400 \\
0\end{array}$ & $\begin{array}{l}0 \\
0\end{array}$ & $\begin{array}{r}241 \\
1,047\end{array}$ & $\begin{array}{r}874 \\
81\end{array}$ \\
\hline 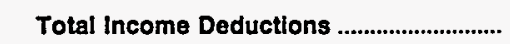 & 11,882 & 8,468 & 400 & $\mathbf{0}$ & 1,288 & 955 \\
\hline Income Before Extraordinary Items ................. & -739 & 355 & 1,129 & 864 & 1,277 & 3,944 \\
\hline Extraordinary Income & 0 & 0 & 480 & 0 & 0 & 0 \\
\hline 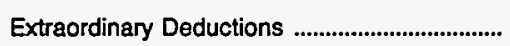 & 0 & 0 & 0 & 0 & 0 & 0 \\
\hline Net Income & -739 & 355 & 1,609 & 864 & 1,277 & 3,944 \\
\hline
\end{tabular}

Note: Totals may not equal sum of components because of independent rounding.

Source: Energy Information Administration, Form ElA-412, "Annual Report of Public Electric Utilities." 
Table 21. Statement of Income by Major U.S. Publicly Owned Electric Utility Within State, 1993 (Continued)

(Thousand Dollars)

\begin{tabular}{|c|c|c|c|c|c|c|}
\hline Item & $\begin{array}{l}\text { Maryland } \\
\text { Easton } \\
\text { Utilities } \\
\text { Comm } \\
\text { June } 30\end{array}$ & $\begin{array}{l}\text { Maryland } \\
\text { Hagerstown } \\
\text { City of } \\
\text { June } 30\end{array}$ & $\begin{array}{c}\text { Massachusetts } \\
\text { Braintree } \\
\text { Town of } \\
\text { December } 31\end{array}$ & $\begin{array}{l}\text { Massachusetts } \\
\text { Chicopee } \\
\text { City of } \\
\text { December } 31\end{array}$ & $\begin{array}{l}\text { Massachusetts } \\
\text { Concord } \\
\text { Town of } \\
\text { December } 31\end{array}$ & $\begin{array}{c}\text { Massachusetts } \\
\text { Danvers } \\
\text { Town of } \\
\text { December } 31\end{array}$ \\
\hline Electric Utility Operating Revenues ............. & 12,823 & 15,836 & 31,148 & 31,686 & 12,546 & 31,885 \\
\hline 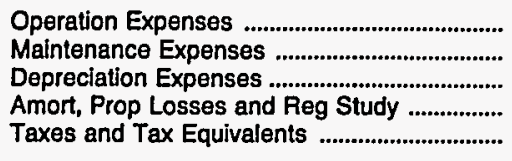 & $\begin{array}{r}8,684 \\
718 \\
1,251 \\
0 \\
438\end{array}$ & $\begin{array}{r}13,138 \\
268 \\
835 \\
395 \\
365\end{array}$ & $\begin{array}{r}24,799 \\
1,735 \\
1,861 \\
0 \\
0\end{array}$ & $\begin{array}{r}22,526 \\
2,464 \\
2,291 \\
0 \\
439\end{array}$ & $\begin{array}{r}10,148 \\
131 \\
449 \\
0 \\
250\end{array}$ & $\begin{array}{r}27,429 \\
668 \\
556 \\
0 \\
0\end{array}$ \\
\hline $\begin{array}{l}\text { Total Electric Utility Operating } \\
\text { Expenses }\end{array}$ & 11,091 & 15,001 & 28,395 & 27,720 & 10,978 & 28,653 \\
\hline 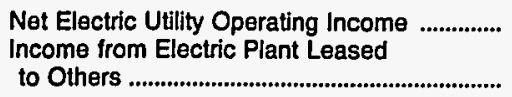 & $\begin{array}{r}1,732 \\
0\end{array}$ & 835 & $\begin{array}{r}2,754 \\
0\end{array}$ & 3,966 & 1,568 & 3,233 \\
\hline Electric Utility Operating Income ............. & 1,732 & 835 & 2,754 & 3,966 & 1,568 & 3,233 \\
\hline 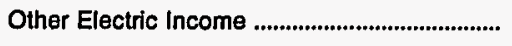 & 98 & 168 & 202 & 1,773 & 391 & 884 \\
\hline $\begin{array}{l}\text { Other Electric Deductions ............................. } \\
\text { Allowance for Other Funds Used } \\
\text { Durting Construction ................................... } \\
\text { Taxes on Other Income and Deductions ....... }\end{array}$ & $\begin{array}{l}0 \\
0\end{array}$ & $\begin{array}{l}0 \\
0\end{array}$ & $\begin{array}{l}0 \\
0\end{array}$ & $\begin{array}{l}\mathbf{0} \\
\mathbf{0}\end{array}$ & $\begin{array}{l}0 \\
0\end{array}$ & $\begin{array}{l}0 \\
0\end{array}$ \\
\hline 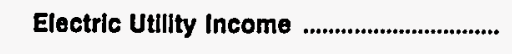 & 1,830 & 1,003 & 2,955 & 5,739 & 1,959 & 4,117 \\
\hline 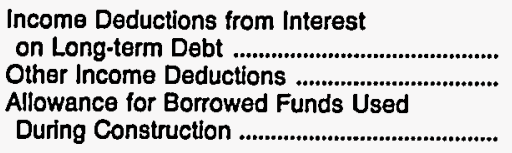 & $\begin{array}{l}708 \\
120\end{array}$ & $\begin{array}{r}72 \\
0\end{array}$ & $\begin{array}{r}141 \\
1\end{array}$ & $\begin{array}{r}2,112 \\
122\end{array}$ & $\begin{array}{r}222 \\
8\end{array}$ & $\begin{array}{r}34 \\
0\end{array}$ \\
\hline 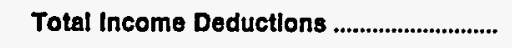 & 828 & 72 & 141 & 2,233 & 230 & 34 \\
\hline Income Before Extraordinary Items .................. & 1,002 & 931 & 2,814 & 3,506 & 1,729 & 4,083 \\
\hline Extraordinary Income & 0 & 0 & 0 & 0 & 0 & 0 \\
\hline 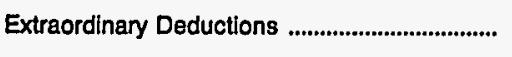 & 723 & 0 & 0 & 300 & 0 & 0 \\
\hline 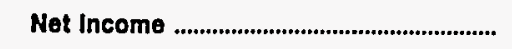 & 279 & 931 & 2,814 & 3,206 & 1,729 & 4,083 \\
\hline
\end{tabular}

Source: Energy Information Administration, Form ElA-412, "Annual Report of Public Electric Utilities." 
Table 21. Statement of Income by Major U.S. Publicly Owned Electric Utility Within State, 1993 (Continued) (Thousand Dollars)

\begin{tabular}{|c|c|c|c|c|c|c|}
\hline Item & $\begin{array}{l}\text { Massachusetts } \\
\text { Hingham } \\
\text { City of } \\
\text { December } 31\end{array}$ & $\begin{array}{l}\text { Massachusetts } \\
\text { Holyoke } \\
\text { City of } \\
\text { December } 31\end{array}$ & $\begin{array}{l}\text { Massachusetts } \\
\text { Hudson } \\
\text { Town of } \\
\text { December } 31\end{array}$ & $\begin{array}{l}\text { Massachusetts } \\
\text { Littleton } \\
\text { Town of } \\
\text { December } 31\end{array}$ & $\begin{array}{l}\text { Massachusetts } \\
\text { Mansfield } \\
\text { Town of } \\
\text { December } 31\end{array}$ & $\begin{array}{c}\text { Massachusetts } \\
\text { Massachusetts } \\
\text { Mun } \\
\text { Wh's } \\
\text { Elec Co } \\
\text { December } 31\end{array}$ \\
\hline Electric Utility Operatting Revenues ............ & 13,102 & 26,371 & 27,263 & 16,084 & 18,591 & 248,629 \\
\hline 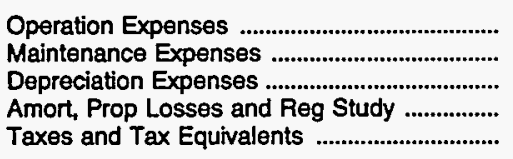 & $\begin{array}{r}11,165 \\
482 \\
605 \\
0 \\
0\end{array}$ & $\begin{array}{r}22,701 \\
1,312 \\
1,876 \\
0 \\
0\end{array}$ & $\begin{array}{r}25,112 \\
476 \\
529 \\
0 \\
224\end{array}$ & $\begin{array}{r}14,144 \\
421 \\
379 \\
0 \\
16\end{array}$ & $\begin{array}{r}17,242 \\
445 \\
433 \\
0 \\
180\end{array}$ & $\begin{array}{r}121,691 \\
10,361 \\
45,208 \\
0 \\
7,127\end{array}$ \\
\hline $\begin{array}{c}\text { Total Electric Utllity Operating } \\
\text { Expenses }\end{array}$ & 12,252 & 25,889 & 26,340 & 14,960 & 18,300 & 184,386 \\
\hline $\begin{array}{l}\text { Net Electric Utility Operating Income ............. } \\
\text { Income from Electric Plant Leased }\end{array}$ & 849 & 482 & 922 & 1.124 & 291 & 64,242 \\
\hline 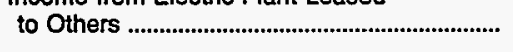 & 0 & 0 & 0 & 0 & 0 & 0 \\
\hline Electric Utility Operating Income ............. & 849 & 482 & 922 & 1,124 & 291 & 64,242 \\
\hline 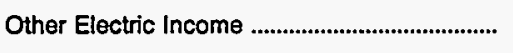 & 129 & 265 & 202 & 304 & 1,272 & 11,083 \\
\hline $\begin{array}{l}\text { Other Electric Deductions .......................................... } \\
\text { Allowance for Other Funds Used }\end{array}$ & 0 & 0 & 0 & 0 & 0 & 0 \\
\hline $\begin{array}{l}\text { During Construction ...................................... } \\
\text { Taxes on Other Income and Deductions ....... }\end{array}$ & $\begin{array}{l}0 \\
0\end{array}$ & $\begin{array}{l}0 \\
0\end{array}$ & $\begin{array}{l}0 \\
0\end{array}$ & $\begin{array}{l}0 \\
0\end{array}$ & $\begin{array}{l}0 \\
0\end{array}$ & $\begin{array}{r}169 \\
0\end{array}$ \\
\hline Electric Utility Income & 978 & 746 & 1,125 & 1,428 & 1,563 & 75,495 \\
\hline $\begin{array}{l}\text { Income Deductions from Interest } \\
\text { on Long-term Debt ............................................. } \\
\text { Other Income Deductions ............................... } \\
\text { Allowance for Borrowed Funds Used }\end{array}$ & $\begin{array}{r}239 \\
28\end{array}$ & $\begin{array}{r}341 \\
23\end{array}$ & $\begin{array}{l}0 \\
1\end{array}$ & $\begin{array}{l}7 \\
3\end{array}$ & $\begin{array}{l}9 \\
6\end{array}$ & $\begin{array}{r}86,015 \\
3,719\end{array}$ \\
\hline 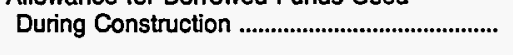 & 0 & 0 & 0 & 0 & 0 & 0 \\
\hline Total Income Deductlons .............................. & 267 & 364 & 1 & 11 & 15 & 89,735 \\
\hline Income Before Extraordinary Items ................. & 711 & 383 & 1,124 & 1,418 & 1,548 & $-14,240$ \\
\hline Extraordinary Income & 0 & 0 & 1,280 & 205 & 0 & 14,240 \\
\hline 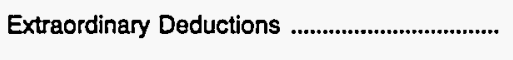 & 0 & 0 & 0 & 161 & 0 & 0 \\
\hline Net Income & 711 & 383 & 2,404 & 1,462 & 1,548 & 0 \\
\hline
\end{tabular}

Note: Totals may not equal sum of components because of independent rounding.

Source: Energy Information Administration, Form EIA-412, "Annual Report of Public Electric Utilities." 
Table 21. Statement of Income by Major U.S. Publicly Owned Electric Utility Within State, 1993 (Continued)

(Thousand Dollars)

\begin{tabular}{|c|c|c|c|c|c|c|}
\hline Item & $\begin{array}{l}\text { Massachusetts } \\
\text { Middleborough } \\
\text { Town of } \\
\text { December } 31\end{array}$ & $\begin{array}{l}\text { Massachusetts } \\
\text { North } \\
\text { Attleborough } \\
\text { Town of } \\
\text { December } 31\end{array}$ & $\begin{array}{l}\text { Massachusetts } \\
\text { Norwood } \\
\text { City of } \\
\text { June } 30\end{array}$ & $\begin{array}{l}\text { Massachusetts } \\
\text { Peabody } \\
\text { City of } \\
\text { December } 31\end{array}$ & $\begin{array}{l}\text { Massachusetts } \\
\text { Reading } \\
\text { Town of } \\
\text { December } 31\end{array}$ & $\begin{array}{l}\text { Massachusetts } \\
\text { Shrewsbury } \\
\text { Town of } \\
\text { December } 31\end{array}$ \\
\hline Electric Utillty Operating Revenues ............ & 16,503 & 17,500 & 27,291 & 38,397 & 48,805 & 19,897 \\
\hline 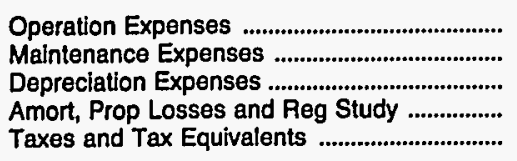 & $\begin{array}{r}14,952 \\
875 \\
381 \\
0 \\
270\end{array}$ & $\begin{array}{r}14,617 \\
658 \\
725 \\
0 \\
30\end{array}$ & $\begin{array}{r}23,527 \\
753 \\
1,014 \\
0 \\
0\end{array}$ & $\begin{array}{r}31,664 \\
511 \\
1,752 \\
17 \\
0\end{array}$ & $\begin{array}{r}44,902 \\
1,038 \\
582 \\
0 \\
438\end{array}$ & $\begin{array}{r}17,817 \\
611 \\
655 \\
0 \\
0\end{array}$ \\
\hline $\begin{array}{l}\text { Total Electrlc Utility Operating } \\
\text { Expenses }\end{array}$ & 16,478 & 16,030 & 25,294 & 33,943 & 46,961 & 19,084 \\
\hline $\begin{array}{l}\text { Net Electric Utility Operating Income .............. } \\
\text { Income from Electric Plant Leased }\end{array}$ & 26 & 1,470 & 1,997 & 4,453 & 1,844 & 813 \\
\hline Electrlc Utility Operating Income .............. & 26 & 1,470 & 1,997 & 4,453 & 1,844 & 813 \\
\hline 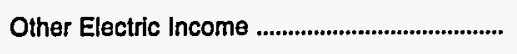 & 118 & 968 & 159 & 405 & 633 & 303 \\
\hline $\begin{array}{l}\text { Other Electric Deductions ................................. } \\
\text { Allowance for Other Funds Used } \\
\text { During Construction ........................................ } \\
\text { Taxes on Other Income and Deductions ........ }\end{array}$ & $\begin{array}{l}0 \\
0\end{array}$ & 251 & $\begin{array}{l}0 \\
0\end{array}$ & $\begin{array}{l}0 \\
0\end{array}$ & $\begin{array}{l}0 \\
0\end{array}$ & $\begin{array}{l}0 \\
0\end{array}$ \\
\hline 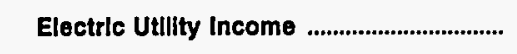 & 144 & 2,187 & 2,156 & 4,858 & 2,477 & 1,116 \\
\hline 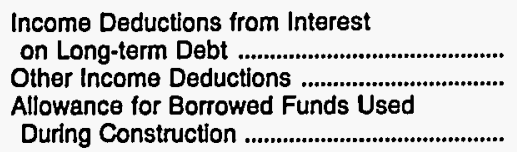 & $\begin{array}{r}124 \\
0\end{array}$ & $\begin{array}{l}0 \\
0\end{array}$ & $\begin{array}{r}0 \\
101\end{array}$ & $\begin{array}{l}1,438 \\
1,032\end{array}$ & $\begin{array}{r}255 \\
37\end{array}$ & $\begin{array}{l}19 \\
17\end{array}$ \\
\hline 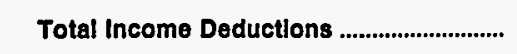 & 124 & 0 & 101 & 2,470 & 292 & 36 \\
\hline Income Before Extraordinary Items .................. & 20 & 2,187 & 2,055 & 2,388 & 2,185 & 1,080 \\
\hline Extraordinary Income & 0 & 0 & 0 & 0 & 0 & 0 \\
\hline 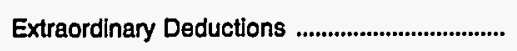 & 0 & 0 & 0 & 0 & 0 & 0 \\
\hline Net Income & 20 & 2,187 & 2,055 & 2,388 & 2,185 & 1,080 \\
\hline
\end{tabular}

Note: Totals may not equal sum of components because of independent rounding.

Source: Energy Information Administration, Form ElA-412, "Annual Report of Public Electric Utilities." 
Table 21. Statement of Income by Major U.S. Publicly Owned Electric Utility Within State, 1993 (Continued)

(Thousand Dollars)

\begin{tabular}{|c|c|c|c|c|c|c|}
\hline Item & $\begin{array}{l}\text { Massachusetts } \\
\text { Taunton } \\
\text { City of } \\
\text { December } 31\end{array}$ & $\begin{array}{l}\text { Massachusetts } \\
\text { Wakefield } \\
\text { Town of } \\
\text { December } 31\end{array}$ & $\begin{array}{c}\text { Massachusetts } \\
\text { Wellesley } \\
\text { Town of } \\
\text { December } 31\end{array}$ & $\begin{array}{l}\text { Massachusetts } \\
\text { Westfield } \\
\text { City of } \\
\text { December } 31\end{array}$ & $\begin{array}{c}\text { Michigan } \\
\text { Bay } \\
\text { City City of } \\
\text { June } 30\end{array}$ & $\begin{array}{l}\text { Michigan } \\
\text { Coldwater } \\
\text { Board } \\
\text { of } \\
\text { Public Util } \\
\text { June } 30\end{array}$ \\
\hline Electric Utillty Operating Revenues ............ & 39,882 & 15,208 & 16,751 & 31,148 & 17,564 & 10,664 \\
\hline 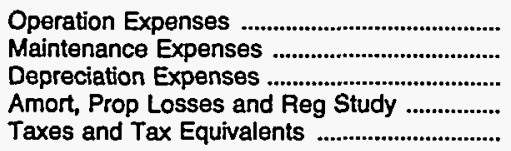 & $\begin{array}{r}22,159 \\
4,244 \\
6,125 \\
0 \\
2,360\end{array}$ & $\begin{array}{r}13,663 \\
378 \\
634 \\
0 \\
202\end{array}$ & $\begin{array}{r}12,529 \\
946 \\
669 \\
0 \\
649\end{array}$ & $\begin{array}{r}29,064 \\
843 \\
628 \\
0 \\
360\end{array}$ & $\begin{array}{r}12,823 \\
827 \\
1,346 \\
0 \\
238\end{array}$ & $\begin{array}{r}9,459 \\
200 \\
381 \\
0 \\
641\end{array}$ \\
\hline $\begin{array}{l}\text { Total Electric Utility Operating } \\
\text { Expenses }\end{array}$ & 34,887 & 14,877 & 14,793 & 30,895 & 15,235 & 10,681 \\
\hline $\begin{array}{l}\text { Net Electric Utility Operating Income .............. } \\
\text { Income from Electric Plant Leased }\end{array}$ & 4,995 & 332 & 1,958 & 253 & 2,329 & -16 \\
\hline 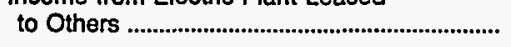 & 0 & 0 & 0 & 305 & 0 & 0 \\
\hline Electric Utility Operating Income ............. & 4,995 & 332 & 1,958 & 558 & 2,329 & -16 \\
\hline 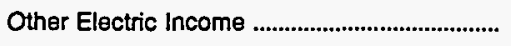 & 620 & 63 & 2,579 & 0 & 1,485 & 251 \\
\hline $\begin{array}{l}\text { Other Electric Deductions .................................. } \\
\text { Allowance for Other Funds Used }\end{array}$ & 0 & 297 & 0 & 0 & 561 & 0 \\
\hline $\begin{array}{l}\text { During Construction .................................... } \\
\text { Taxes on Other Income and Deductions ....... }\end{array}$ & $\begin{array}{l}0 \\
0\end{array}$ & $\begin{array}{l}0 \\
0\end{array}$ & $\begin{array}{l}0 \\
0\end{array}$ & $\begin{array}{l}0 \\
0\end{array}$ & $\begin{array}{l}0 \\
0\end{array}$ & $\begin{array}{l}0 \\
0\end{array}$ \\
\hline 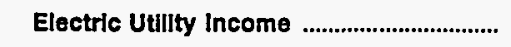 & 5,615 & 98 & 4,537 & 558 & 3,252 & 235 \\
\hline $\begin{array}{l}\text { Income Deductions from Interest } \\
\text { on Long-term Debt ........................................... } \\
\text { Other Income Deductions ................................ } \\
\text { Allowance for Borrowed Funds Used }\end{array}$ & $\begin{array}{r}1,363 \\
15\end{array}$ & $\begin{array}{r}0 \\
52\end{array}$ & $\begin{array}{l}40 \\
14\end{array}$ & $\begin{array}{r}161 \\
6\end{array}$ & $\begin{array}{r}1,754 \\
0\end{array}$ & $\begin{array}{r}81 \\
0\end{array}$ \\
\hline 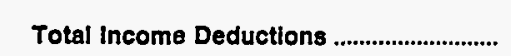 & 1,378 & 52 & 53 & 167 & 1,754 & 81 \\
\hline Income Before Extraordinary Items .................. & 4,237 & 45 & 4,484 & 391 & 1,499 & 154 \\
\hline Extraordinary Income & 0 & 0 & 0 & 0 & 0 & 0 \\
\hline 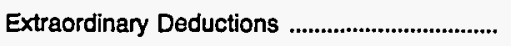 & 0 & 0 & 0 & 0 & 0 & 0 \\
\hline Net Income & 4,237 & 45 & 4,484 & 391 & 1,499 & 154 \\
\hline
\end{tabular}

Note: Totals may not equal sum of components because of independent rounding.

Source: Energy Information Administration, Form ElA-412, "Annual Report of Public Electric Utilities." 
Table 21. Statement of Income by Major U.S. Publicly Owned Electric Utility Within State, 1993 (Continued)

(Thousand Dollars)

\begin{tabular}{|c|c|c|c|c|c|c|}
\hline Item & $\begin{array}{l}\text { Michigan } \\
\text { Detroit } \\
\text { City of } \\
\text { June } 30\end{array}$ & $\begin{array}{c}\text { Michigan } \\
\text { Grand Haven } \\
\text { City of } \\
\text { June } 30\end{array}$ & $\begin{array}{l}\text { Michigan } \\
\text { Hillsdale } \\
\text { Board } \\
\text { of } \\
\text { Public Wks } \\
\text { June } 30\end{array}$ & $\begin{array}{l}\text { Michigan } \\
\text { Holland } \\
\text { City of } \\
\text { June } 30\end{array}$ & $\begin{array}{l}\text { Michigan } \\
\text { Lansing } \\
\text { City of } \\
\text { June } 30\end{array}$ & $\begin{array}{l}\text { Michigan } \\
\text { Marquette } \\
\text { City of } \\
\text { June } 30\end{array}$ \\
\hline Electric Utllity Operating Revenues ............. & 79,078 & 21,158 & 9,228 & 37,377 & 122,036 & 18,377 \\
\hline 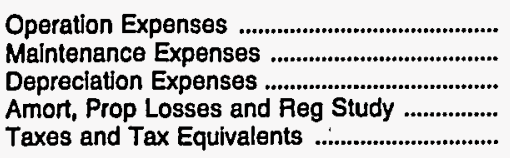 & $\begin{array}{r}41,926 \\
12,287 \\
4,903 \\
0 \\
0\end{array}$ & $\begin{array}{r}11,371 \\
1,357 \\
3,227 \\
0 \\
874\end{array}$ & $\begin{array}{r}8,209 \\
369 \\
516 \\
0 \\
270\end{array}$ & $\begin{array}{r}24,898 \\
2,053 \\
4,433 \\
0 \\
1,320\end{array}$ & $\begin{array}{r}98,677 \\
9,183 \\
12,703 \\
0 \\
0\end{array}$ & $\begin{array}{r}10,020 \\
1,408 \\
3,076 \\
0 \\
1,491\end{array}$ \\
\hline $\begin{array}{l}\text { Total Electric Utllity Operating } \\
\text { Expenses }\end{array}$ & 59,116 & 16,829 & 9,364 & 32,704 & 120,563 & 15,993 \\
\hline 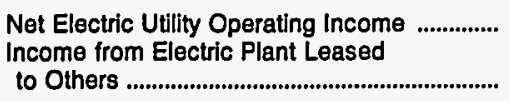 & 19,962 & 4,329 & -135 & 4,673 & 1,473 & 2,383 \\
\hline Electric UtIlity Operating Income .............. & 19,962 & 4,329 & -135 & 4,673 & 1,473 & 2,383 \\
\hline 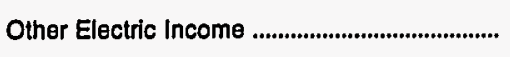 & 0 & 580 & 252 & 1,377 & 2,408 & 1,419 \\
\hline $\begin{array}{l}\text { Other Electric Deductions ................................ } \\
\text { Allowance for Other Funds Used } \\
\text { During Construction ......................................... } \\
\text { Taxes on Other Income and Deductions ....... }\end{array}$ & 1,696 & $\begin{array}{l}0 \\
0\end{array}$ & $\begin{array}{r}0 \\
53\end{array}$ & $\begin{array}{l}0 \\
0\end{array}$ & $\begin{array}{l}0 \\
0\end{array}$ & $\begin{array}{l}0 \\
0\end{array}$ \\
\hline 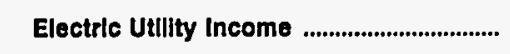 & 18,266 & 4,863 & -3 & 6,050 & 3,881 & 3,802 \\
\hline 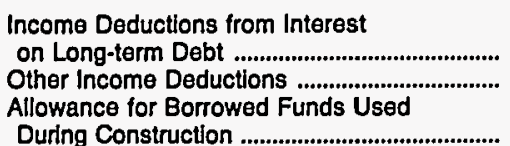 & $\begin{array}{r}6,353 \\
0\end{array}$ & $\begin{array}{r}6,663 \\
1\end{array}$ & $\begin{array}{l}0 \\
0\end{array}$ & $\begin{array}{r}2,148 \\
0\end{array}$ & $\begin{array}{l}561 \\
174\end{array}$ & $\begin{array}{r}3,273 \\
72\end{array}$ \\
\hline 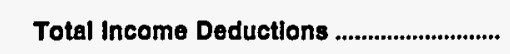 & 6,353 & 6,664 & 0 & 2,148 & 735 & 3,345 \\
\hline Income Before Extraordinary Items ..................... & 11,913 & $-1,802$ & -3 & 3,902 & 3,146 & 457 \\
\hline Extraordinary Income & 0 & 0 & 0 & 0 & 0 & 0 \\
\hline 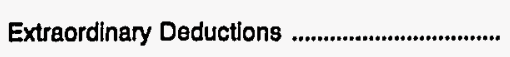 & 0 & 0 & 0 & 0 & 0 & 485 \\
\hline 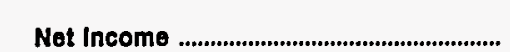 & 11,913 & $-1,802$ & -3 & 3,902 & 3,146 & -27 \\
\hline
\end{tabular}

Note: Totals may not equal sum of components because of independent rounding.

Source: Energy Information Administration, Form EIA-412, "Annual Report of Public Electric Utilities." 
Table 21. Statement of Income by Major U.S. Publicly Owned Electric Utility Within State, 1993 (Continued)

(Thousand Dollars)

\begin{tabular}{|c|c|c|c|c|c|c|}
\hline Item & $\begin{array}{c}\text { Michigan } \\
\text { Michigan } \\
\text { Public } \\
\text { Power Agency } \\
\text { December } 31\end{array}$ & $\begin{array}{l}\text { Michigan } \\
\text { Michigan } \\
\text { South } \\
\text { Central } \\
\text { Pwr Agy } \\
\text { June 30 }\end{array}$ & $\begin{array}{l}\text { Michigan } \\
\text { Sturgis } \\
\text { City of } \\
\text { September } 30\end{array}$ & $\begin{array}{l}\text { Michigan } \\
\text { Traverse } \\
\text { City City of } \\
\text { June } 30\end{array}$ & $\begin{array}{c}\text { Michigan } \\
\text { Wyandotte } \\
\text { Municipal } \\
\text { Serv Comm } \\
\text { September } 30\end{array}$ & $\begin{array}{l}\text { Michigan } \\
\text { Zeeland } \\
\text { City of } \\
\text { June } 30\end{array}$ \\
\hline Electric Utility Operating Revenues ............. & 98,529 & 23,193 & 13,051 & 13,358 & 18,550 & 7,426 \\
\hline 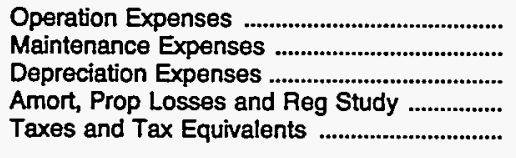 & $\begin{array}{r}55,820 \\
4,259 \\
13,613 \\
1,390 \\
605\end{array}$ & $\begin{array}{r}15,740 \\
900 \\
2,522 \\
0 \\
40\end{array}$ & $\begin{array}{r}8,418 \\
827 \\
1,044 \\
0 \\
880\end{array}$ & $\begin{array}{r}9,954 \\
1,572 \\
832 \\
8 \\
695\end{array}$ & $\begin{array}{r}15,024 \\
889 \\
2,189 \\
0 \\
0\end{array}$ & $\begin{array}{r}6.216 \\
253 \\
632 \\
0 \\
0\end{array}$ \\
\hline $\begin{array}{l}\text { Total Electric Utillty Operating } \\
\text { Expenses ..................................................... }\end{array}$ & 75,687 & 19,202 & 11,169 & 13,062 & 18,102 & 7,100 \\
\hline $\begin{array}{l}\text { Net Electric Utility Operating Income } \\
\text { Income from Electric Plant Leased } \\
\text { to Others }\end{array}$ & 22,842 & 3,991 & $\begin{array}{r}1,882 \\
0\end{array}$ & 296 & 449 & 326 \\
\hline Electric Utllity Operating Income .............. & 22,842 & 3,991 & 1,882 & 296 & 449 & 326 \\
\hline Other Electric Income & 6,342 & 2,154 & 763 & 547 & 823 & 365 \\
\hline $\begin{array}{l}\text { Other Electric Deductions } \\
\text { Allowance for Other Funds Used }\end{array}$ & 0 & 1 & 0 & 0 & 454 & 320 \\
\hline 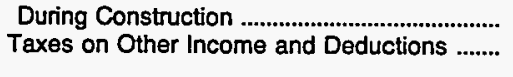 & $\begin{array}{l}0 \\
0\end{array}$ & $\begin{array}{l}0 \\
0\end{array}$ & $\stackrel{0}{0}$ & $\begin{array}{l}0 \\
0\end{array}$ & $\begin{array}{r}245 \\
0\end{array}$ & $\begin{array}{l}0 \\
0\end{array}$ \\
\hline 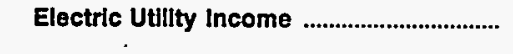 & 29,184 & 6,144 & 2,645 & 844 & 1,062 & 371 \\
\hline 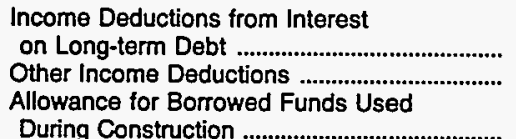 & $\begin{array}{r}24,834 \\
4,247\end{array}$ & $\begin{array}{r}6,087 \\
-7,433\end{array}$ & $\begin{array}{r}299 \\
0\end{array}$ & $\begin{array}{l}0 \\
4\end{array}$ & $\begin{array}{r}1,717 \\
111\end{array}$ & $\begin{array}{l}0 \\
0\end{array}$ \\
\hline 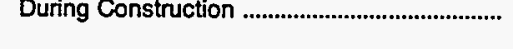 & 0 & 0 & 0 & 0 & 0 & 0 \\
\hline 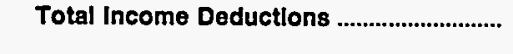 & 29,081 & $-1,346$ & 299 & 4 & 1,828 & $\mathbf{0}$ \\
\hline 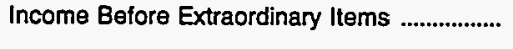 & 103 & 7,491 & 2,346 & 839 & -765 & 371 \\
\hline Extraordinary Income & 0 & 0 & 0 & 0 & 0 & 0 \\
\hline 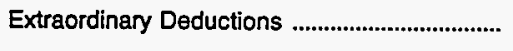 & 0 & 6,961 & 640 & 0 & 0 & 0 \\
\hline 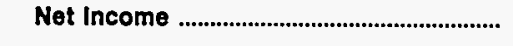 & 103 & 529 & 1,706 & 839 & -765 & 371 \\
\hline
\end{tabular}

Note: Totals may not equal sum of components because of independent rounding.

Source: Energy Information Administration, Form EIA-412, "Annual Report of Public Electric Utilities." 
Table 21. Statement of Income by Major U.S. Publicly Owned Electric Utility Within State, 1993 (Continued)

(Thousand Dollars)

\begin{tabular}{|c|c|c|c|c|c|c|}
\hline Item & $\begin{array}{c}\text { Minnesota } \\
\text { Alexandria } \\
\text { City of } \\
\text { December } 31\end{array}$ & $\begin{array}{c}\text { Minnesota } \\
\text { Anoka } \\
\text { City of } \\
\text { December } \mathbf{3 1}\end{array}$ & $\begin{array}{l}\text { Minnesota } \\
\text { Austin } \\
\text { City of } \\
\text { December } 31\end{array}$ & $\begin{array}{l}\text { Minnesota } \\
\text { Brainerd } \\
\text { City of } \\
\text { December } 31\end{array}$ & $\begin{array}{c}\text { Minnesota } \\
\text { Chaska } \\
\text { City of } \\
\text { December } 31\end{array}$ & $\begin{array}{l}\text { Minnesota } \\
\text { Fairmont } \\
\text { Public } \\
\text { Utilities } \\
\text { Comm } \\
\text { December } 31\end{array}$ \\
\hline Electric Utillty Operating Revenues ............. & 7,521 & 11,652 & 20,515 & 7,220 & 8,484 & 10,276 \\
\hline 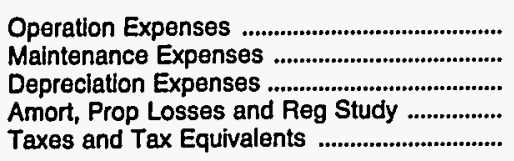 & $\begin{array}{r}6,162 \\
301 \\
421 \\
0 \\
376\end{array}$ & $\begin{array}{r}9,081 \\
226 \\
509 \\
0 \\
0\end{array}$ & $\begin{array}{r}18,119 \\
907 \\
704 \\
0 \\
3\end{array}$ & $\begin{array}{r}6,606 \\
67 \\
366 \\
0 \\
0\end{array}$ & $\begin{array}{r}6,577 \\
0 \\
370 \\
0 \\
0\end{array}$ & $\begin{array}{r}9,318 \\
803 \\
504 \\
0 \\
0\end{array}$ \\
\hline $\begin{array}{l}\text { Total Electric Utillty Operating } \\
\text { Expenses }\end{array}$ & 7,260 & 9,816 & 19,733 & 7,039 & 6,947 & 10,625 \\
\hline $\begin{array}{l}\text { Net Electric Utility Operating Income .............. } \\
\text { Income from Electric Plant Leased }\end{array}$ & 262 & 1,836 & 782 & 181 & 1,537 & -349 \\
\hline 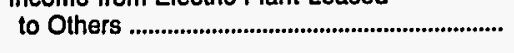 & 0 & 0 & 1 & 0 & 0 & 0 \\
\hline Electrlc UtIIIty Operating Income ............. & 262 & 1,836 & 783 & 181 & 1,537 & -349 \\
\hline 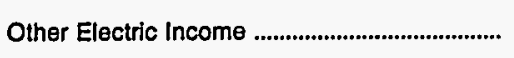 & 274 & 40 & 1,166 & 187 & 164 & 1,402 \\
\hline $\begin{array}{l}\text { Other Electric Deductions ................................ } \\
\text { Allowance for Other Funds Used }\end{array}$ & 0 & 893 & 0 & 0 & 0 & 560 \\
\hline $\begin{array}{l}\text { During Construction ....................................... } \\
\text { Taxes on Other Income and Deductions ....... }\end{array}$ & $\begin{array}{l}0 \\
0\end{array}$ & $\begin{array}{l}0 \\
0\end{array}$ & $\begin{array}{r}0 \\
898\end{array}$ & $\begin{array}{l}0 \\
0\end{array}$ & $\begin{array}{l}0 \\
0\end{array}$ & $\begin{array}{l}0 \\
0\end{array}$ \\
\hline 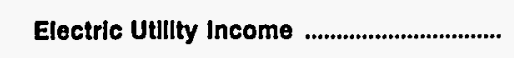 & 536 & 982 & 1,051 & 368 & 1,701 & 493 \\
\hline $\begin{array}{l}\text { Income Deductions from Interest } \\
\text { on Long-term Debt ......................................... } \\
\text { Other Income Deductions ................................. } \\
\text { Allowance for Borrowed Funds Used }\end{array}$ & $\begin{array}{l}0 \\
3\end{array}$ & $\begin{array}{l}0 \\
0\end{array}$ & $\begin{array}{l}0 \\
4\end{array}$ & $\begin{array}{l}0 \\
0\end{array}$ & $\begin{array}{l}113 \\
899\end{array}$ & $\begin{array}{l}183 \\
488\end{array}$ \\
\hline During Construction ......................................... & 0 & 0 & 0 & 0 & 0 & 0 \\
\hline Total Income Deductions ........................... & 3 & $\mathbf{0}$ & 4 & $\mathbf{0}$ & 1,012 & 671 \\
\hline Income Before Extraordinary Items ................. & 532 & 982 & 1,047 & 368 & 689 & -178 \\
\hline 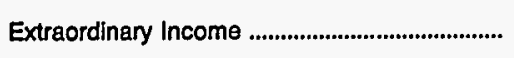 & 0 & 0 & 0 & 0 & 0 & 0 \\
\hline 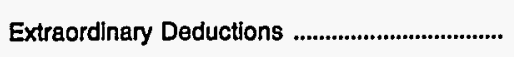 & 279 & 0 & 0 & 0 & 0 & 0 \\
\hline Net Income & 254 & 982 & 1,047 & 368 & 689 & -178 \\
\hline
\end{tabular}

Note: Totals may not equal sum of components because of independent rounding.

Source: Energy Information Administration, Form EIA-412, "Annual Report of Public Electric Utilities." 
Table 21. Statement of Income by Major U.S. Publicly Owned Electric Utility Within State, 1993 (Continued)

(Thousand Dollars)

\begin{tabular}{|c|c|c|c|c|c|c|}
\hline Item & $\begin{array}{l}\text { Minnesota } \\
\text { Hutchinson } \\
\text { Utilities } \\
\text { Comm } \\
\text { December } 31\end{array}$ & $\begin{array}{c}\text { Minnesota } \\
\text { Marshall } \\
\text { City of } \\
\text { December } 39\end{array}$ & $\begin{array}{l}\text { Minnesota } \\
\text { Moorhead } \\
\text { City of } \\
\text { December } 31\end{array}$ & $\begin{array}{l}\text { Minnesota } \\
\text { New Ulm } \\
\text { Public } \\
\text { Utilities } \\
\text { Comm } \\
\text { December } 31\end{array}$ & $\begin{array}{c}\text { Minnesota } \\
\text { Northern } \\
\text { Municipal } \\
\text { Power Agny } \\
\text { December } 31\end{array}$ & $\begin{array}{l}\text { Minnesota } \\
\text { Owatonna } \\
\text { City of } \\
\text { December } 31\end{array}$ \\
\hline Electrlc Utillty Operating Revenues ............. & 10,017 & 11,446 & 12,287 & 10,330 & 35,898 & 18,793 \\
\hline 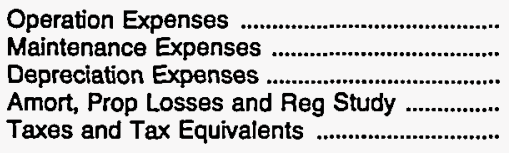 & $\begin{array}{r}7,331 \\
553 \\
681 \\
0 \\
0\end{array}$ & $\begin{array}{r}10,577 \\
469 \\
620 \\
0 \\
316\end{array}$ & $\begin{array}{r}8,719 \\
431 \\
726 \\
0 \\
2,700\end{array}$ & $\begin{array}{r}6,831 \\
636 \\
747 \\
0 \\
502\end{array}$ & $\begin{array}{r}10,560 \\
3,030 \\
3,940 \\
0 \\
0\end{array}$ & $\begin{array}{r}15,030 \\
1,454 \\
985 \\
0 \\
0\end{array}$ \\
\hline $\begin{array}{l}\text { Total Electric Utility Operating } \\
\text { Expenses }\end{array}$ & 8,566 & 11,981 & 12,576 & 8,715 & 17,530 & 17,469 \\
\hline 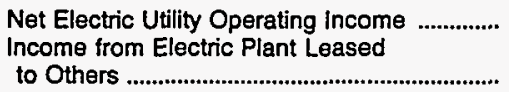 & 1,452 & -535 & -289 & 1,615 & 18,368 & 1,324 \\
\hline Electric Utillty Operating Income .............. & 1,452 & -287 & -289 & 1,615 & 18,368 & 1,324 \\
\hline Other Electric Income & 283 & 764 & 1,202 & 226 & 3,378 & 323 \\
\hline $\begin{array}{l}\text { Other Electric Deductions ............................ } \\
\text { Allowance for Other Funds Used } \\
\text { During Construction ................................. } \\
\text { Taxes on Other Income and Deductions ....... }\end{array}$ & $\begin{array}{l}0 \\
0\end{array}$ & $\begin{array}{r}177 \\
0\end{array}$ & $\begin{array}{r}70 \\
0\end{array}$ & $\begin{array}{l}0 \\
0\end{array}$ & $\begin{array}{l}0 \\
0\end{array}$ & 530 \\
\hline 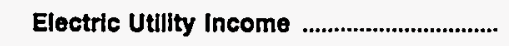 & 1,735 & 654 & 982 & 1,839 & 21,746 & 1,117 \\
\hline 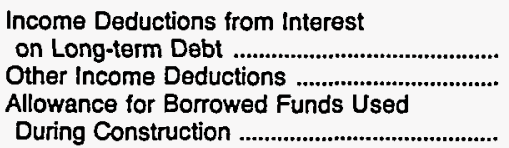 & $\begin{array}{r}420 \\
44\end{array}$ & $\begin{array}{l}0 \\
0\end{array}$ & $\begin{array}{r}246 \\
45\end{array}$ & $\begin{array}{r}136 \\
0\end{array}$ & $\begin{array}{r}21,746 \\
0\end{array}$ & $\begin{array}{r}419 \\
0\end{array}$ \\
\hline 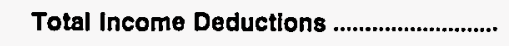 & 465 & 0 & 291 & 136 & 21,746 & 419 \\
\hline Income Before Extraordinary Items ....................... & 1,270 & 654 & 691 & 1,702 & 0 & 698 \\
\hline Extraordinary Income & 0 & 0 & 0 & 0 & 0 & 0 \\
\hline 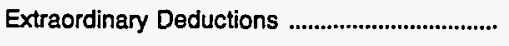 & 0 & 0 & 0 & 0 & 0 & 0 \\
\hline 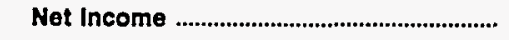 & 1,270 & 654 & 691 & 1,702 & 0 & 698 \\
\hline
\end{tabular}

Note: Totals may not equal sum of components because of independent rounding.

Source: Energy Information Administration, Form EIA-412, "Annual Report of Public Electric Utilities." 
Table 21. Statement of Income by Major U.S. Publicly Owned Electric Utility Within State, 1993 (Continued) (Thousand Dollars)

\begin{tabular}{|c|c|c|c|c|c|c|}
\hline Item & $\begin{array}{c}\text { Minnesota } \\
\text { Rochester } \\
\text { Public } \\
\text { Utilities } \\
\text { December } 31\end{array}$ & $\begin{array}{c}\text { Minnesota } \\
\text { Shakopee } \\
\text { Public } \\
\text { Utilities } \\
\text { Comm } \\
\text { December } 31\end{array}$ & $\begin{array}{c}\text { Minnesota } \\
\text { Southern } \\
\text { Minnesota } \\
\text { Mun P } \\
\text { Agny } \\
\text { December 31 }\end{array}$ & $\begin{array}{c}\text { Minnesota } \\
\text { Western } \\
\text { Minnesota } \\
\text { Mun } \\
\text { Pwr Agny } \\
\text { December } 31\end{array}$ & $\begin{array}{c}\text { Minnesota } \\
\text { Willmar } \\
\text { Municipal } \\
\text { Utils Comm } \\
\text { December } 31\end{array}$ & $\begin{array}{l}\text { Mississippi } \\
\text { Aberdeen } \\
\text { City of } \\
\text { June } \mathbf{3 0}\end{array}$ \\
\hline Electrlc UtIIIty OperatIng Revenues ............ & 70,723 & 7,114 & 119,709 & 42,628 & 10,931 & 7,695 \\
\hline 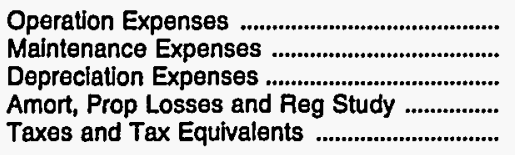 & $\begin{array}{r}59,577 \\
2,210 \\
1,977 \\
4 \\
5,374\end{array}$ & $\begin{array}{r}5,758 \\
462 \\
174 \\
64 \\
0\end{array}$ & $\begin{array}{r}50,102 \\
4,403 \\
12,562 \\
0 \\
7,366\end{array}$ & $\begin{array}{r}17,144 \\
4,241 \\
4,510 \\
0 \\
1,363\end{array}$ & $\begin{array}{r}7,367 \\
648 \\
928 \\
0 \\
0\end{array}$ & $\begin{array}{r}7,255 \\
117 \\
131 \\
0 \\
276\end{array}$ \\
\hline $\begin{array}{l}\text { Total Electric Utllity Operating } \\
\text { Expenses }\end{array}$ & 69,141 & 6,458 & 74,432 & 27,258 & 8,944 & $\mathbf{7 , 7 7 9}$ \\
\hline $\begin{array}{l}\text { Net Electric Utility Operating Income } \\
\text { Income from Electric Plant Leased..... }\end{array}$ & 1,582 & 655 & 45,276 & 15,370 & 1,987 & -84 \\
\hline to Others & 0 & 0 & 0 & 0 & 0 & 0 \\
\hline Electrle Utllity Operating Income ............. & 1,582 & 655 & 45,276 & 15,370 & 1,987 & -84 \\
\hline 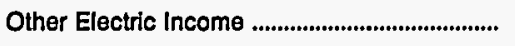 & 784 & 328 & 7,132 & 3,132 & 962 & 74 \\
\hline $\begin{array}{l}\text { Other Electric Deductions } \\
\text { Allowance for Other Funds Used }\end{array}$ & 32 & 401 & 0 & 0 & 0 & 8 \\
\hline $\begin{array}{l}\text { Durlng Construction ...................................... } \\
\text { Taxes on Other Income and Deductions ....... }\end{array}$ & $\begin{array}{l}0 \\
0\end{array}$ & $\begin{array}{l}0 \\
0\end{array}$ & $\begin{array}{l}0 \\
0\end{array}$ & $\begin{array}{l}0 \\
0\end{array}$ & $\begin{array}{l}0 \\
0\end{array}$ & $\begin{array}{l}0 \\
0\end{array}$ \\
\hline Electric Utility Income .................................. & 2,334 & 583 & 52,408 & 18,501 & 2,949 & -18 \\
\hline $\begin{array}{l}\text { Income Deductions from Interest } \\
\text { on Long-term Debt .............................................. } \\
\text { Other Income Deductions ............................. } \\
\text { Allowance for Borrowed Funds Used }\end{array}$ & $\begin{array}{r}0 \\
45\end{array}$ & $\begin{array}{r}125 \\
0\end{array}$ & $\begin{array}{r}38,900 \\
7,630\end{array}$ & $\begin{array}{r}18,501 \\
0\end{array}$ & $\begin{array}{r}927 \\
46\end{array}$ & $\begin{array}{l}0 \\
0\end{array}$ \\
\hline 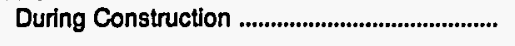 & 0 & 0 & -31 & 0 & 0 & 0 \\
\hline Total Income Deductlons .............................. & 45 & 125 & 46,499 & 18,501 & 973 & $\mathbf{0}$ \\
\hline Income Before Extraordinary ltems .................. & 2,289 & 457 & 5,909 & 0 & 1,976 & -18 \\
\hline Extraordinary Income & 0 & 0 & 0 & 0 & 0 & 0 \\
\hline Extraordinary Deductlons .................................... & 0 & 0 & 0 & 0 & 0 & 0 \\
\hline Net Income & 2,289 & 457 & 5,909 & $\mathbf{0}$ & 1,976 & -18 \\
\hline
\end{tabular}

Note: Totals may not equal sum of components because of independent rounding.

Source: Energy Information Administration, Form EIA-412, "Annual Report of Public Electric Utilities." 
Table 21. Statement of Income by Major U.S. Publicly Owned Electric Utility Within State, 1993 (Continued)

(Thousand Dollars)

\begin{tabular}{|c|c|c|c|c|c|c|}
\hline Item & $\begin{array}{l}\text { Mississippi } \\
\text { Clarksdale } \\
\text { City of } \\
\text { September } 30\end{array}$ & $\begin{array}{l}\text { Mississippi } \\
\text { Columbus } \\
\text { City of } \\
\text { June } 30\end{array}$ & $\begin{array}{l}\text { Mississippi } \\
\text { Greenwood } \\
\text { Utilities } \\
\text { Comm } \\
\text { September } 30\end{array}$ & $\begin{array}{l}\text { Mississippi } \\
\text { Holly } \\
\text { Springs } \\
\text { City of } \\
\text { June } 30\end{array}$ & $\begin{array}{l}\text { Mississippi } \\
\text { Louisville } \\
\text { Electric } \\
\text { System } \\
\text { June } 30\end{array}$ & $\begin{array}{c}\text { Mississippi } \\
\text { Municipal } \\
\text { Energy } \\
\text { Agency } \\
\text { of MS } \\
\text { September } 30\end{array}$ \\
\hline Electric Utilty Operating Revenues ............ & 12,517 & 22,422 & 16,267 & 11,731 & 8,018 & 31,252 \\
\hline 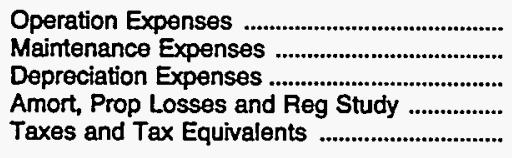 & $\begin{array}{r}9,354 \\
501 \\
842 \\
0 \\
0\end{array}$ & $\begin{array}{r}21,425 \\
624 \\
405 \\
0 \\
1,066\end{array}$ & $\begin{array}{r}12,647 \\
753 \\
786 \\
0 \\
0\end{array}$ & $\begin{array}{r}9,899 \\
399 \\
286 \\
0 \\
604\end{array}$ & $\begin{array}{r}7,240 \\
151 \\
231 \\
0 \\
216\end{array}$ & $\begin{array}{r}31,309 \\
0 \\
28 \\
65 \\
0\end{array}$ \\
\hline 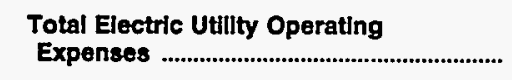 & 10,698 & 23,519 & 14,186 & 11,187 & 7,838 & 31,402 \\
\hline 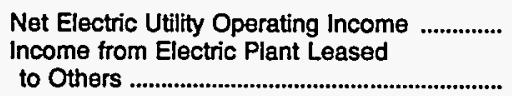 & 1,819 & $-1,098$ & 2,081 & 544 & 180 & $\begin{array}{r}-149 \\
0\end{array}$ \\
\hline Electric Utility Operating Income ............. & 1,819 & $-1,098$ & 2,081 & 544 & 180 & -149 \\
\hline Other Electric Income & 291 & 423 & 459 & 281 & 113 & 213 \\
\hline $\begin{array}{l}\text { Other Electric Deductions ............................ } \\
\text { Allowance for Other Funds Used }\end{array}$ & 54 & 4 & 1,129 & 4 & 5 & 0 \\
\hline $\begin{array}{l}\text { During Construction ................................................ } \\
\text { Taxes on Other Income and Deductions ..... }\end{array}$ & $\begin{array}{l}0 \\
0\end{array}$ & $\begin{array}{l}0 \\
0\end{array}$ & $\begin{array}{l}0 \\
0\end{array}$ & $\begin{array}{l}0 \\
0\end{array}$ & $\begin{array}{l}0 \\
0\end{array}$ & $\begin{array}{l}0 \\
0\end{array}$ \\
\hline 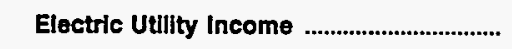 & 2,057 & -679 & 1,411 & 821 & 287 & 64 \\
\hline 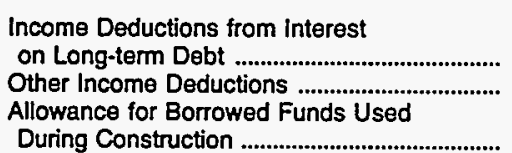 & $\begin{array}{r}169 \\
9\end{array}$ & $\begin{array}{r}0 \\
20\end{array}$ & $\begin{array}{r}16 \\
0\end{array}$ & $\begin{array}{r}0 \\
10\end{array}$ & $\begin{array}{l}0 \\
0\end{array}$ & $\begin{array}{l}0 \\
0\end{array}$ \\
\hline 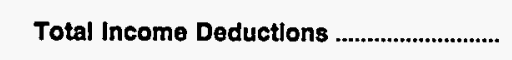 & 178 & 20 & 16 & 10 & 0 & 0 \\
\hline Income Before Extraordinary Items .................. & 1,878 & -699 & 1,395 & 811 & 287 & 64 \\
\hline Extraordinary Income & 0 & 0 & 572 & 0 & 0 & 0 \\
\hline 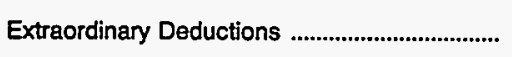 & 0 & 78 & 0 & 0 & 0 & 0 \\
\hline Net Income & 1,878 & -777 & 1,967 & 811 & 287 & 64 \\
\hline
\end{tabular}

Note: Totals may not equal sum of components because of independent rounding.

Source: Energy Information Administration, Form EIA-412, "Annual Report of Public Electric Utilities." 
Table 21. Statement of Income by Major U.S. Publicly Owned Electric Utility Within State, 1993 (Continued)

(Thousand Dollars)

\begin{tabular}{|c|c|c|c|c|c|c|}
\hline Item & $\begin{array}{l}\text { Mississippi } \\
\text { New Albany } \\
\text { City of } \\
\text { June } 30\end{array}$ & $\begin{array}{l}\text { Mississippi } \\
\text { Oxford } \\
\text { City of } \\
\text { June } 30\end{array}$ & $\begin{array}{l}\text { Mississippi } \\
\text { Starkville } \\
\text { City of } \\
\text { June } 30\end{array}$ & $\begin{array}{l}\text { Mississippi } \\
\text { Tupelo } \\
\text { City of } \\
\text { June } 30\end{array}$ & $\begin{array}{c}\text { Mississippi } \\
\text { West } \\
\text { Point } \\
\text { City of } \\
\text { June } 30\end{array}$ & $\begin{array}{l}\text { Missouri } \\
\text { Carthage } \\
\text { City of } \\
\text { June } 30\end{array}$ \\
\hline Electric Utllity Operating Revenues ............. & 12,747 & 7,443 & 15,698 & 31,584 & 9,566 & 8,398 \\
\hline 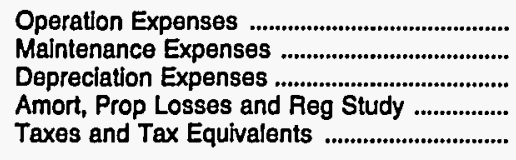 & $\begin{array}{r}11,583 \\
357 \\
287 \\
0 \\
479\end{array}$ & $\begin{array}{r}7,095 \\
168 \\
157 \\
0 \\
453\end{array}$ & $\begin{array}{r}14,080 \\
355 \\
325 \\
11 \\
763\end{array}$ & $\begin{array}{r}28,749 \\
414 \\
677 \\
0 \\
1,784\end{array}$ & $\begin{array}{r}8,382 \\
215 \\
208 \\
6 \\
552\end{array}$ & $\begin{array}{r}7,342 \\
402 \\
478 \\
0 \\
0\end{array}$ \\
\hline $\begin{array}{c}\text { Total Electric Utillty Operating } \\
\text { Expenses }\end{array}$ & 12,706 & 7,874 & 15,535 & 31,623 & 9,364 & 8,223 \\
\hline 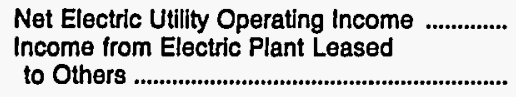 & 40 & $\begin{array}{r}-431 \\
0\end{array}$ & 163 & -40 & 202 & 175 \\
\hline Electric Utillty Operating Income .............. & 40 & -431 & 163 & -40 & 202 & 175 \\
\hline Other Electric Income & 273 & 243 & 183 & 542 & 57 & 156 \\
\hline $\begin{array}{l}\text { Other Electric Deductions ............................... } \\
\text { Allowance for Other Funds Used } \\
\text { During Construction .................................... } \\
\text { Taxes on Other Income and Deductions ....... }\end{array}$ & $\begin{array}{l}0 \\
0\end{array}$ & $\begin{array}{l}0 \\
0\end{array}$ & $\begin{array}{l}0 \\
0\end{array}$ & $\begin{array}{l}0 \\
0\end{array}$ & $\begin{array}{l}0 \\
0\end{array}$ & $\begin{array}{l}0 \\
0\end{array}$ \\
\hline Electric Utility Income ...................................... & 312 & -206 & 333 & 502 & 257 & 331 \\
\hline 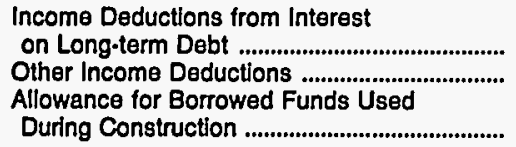 & $\begin{array}{r}14 \\
4\end{array}$ & $\begin{array}{r}0 \\
15\end{array}$ & $\begin{array}{r}0 \\
40\end{array}$ & $\begin{array}{l}0 \\
3\end{array}$ & $\begin{array}{r}25 \\
3\end{array}$ & $\begin{array}{l}0 \\
3\end{array}$ \\
\hline Total Income Deductlons ............................... & 18 & 15 & 40 & 3 & 28 & 3 \\
\hline Income Before Extraordinary Items ................... & 294 & -221 & 293 & 499 & 228 & 328 \\
\hline Extraordinary Income & 0 & 0 & 0 & 0 & 0 & 0 \\
\hline 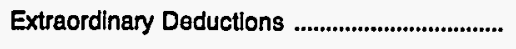 & 0 & 0 & 0 & 0 & 0 & 0 \\
\hline 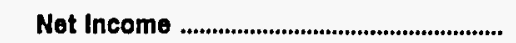 & 294 & -221 & 293 & 489 & 228 & 328 \\
\hline
\end{tabular}

Note: Totals may not equal sum of components because of independent rounding.

Source: Energy Information Administration, Form ElA-412, "Annual Report of Public Electric Utilities." 
Table 21. Statement of Income by Major U.S. Publicly Owned Electric Utility Within State, 1993 (Continued)

(Thousand Dollars)

\begin{tabular}{|c|c|c|c|c|c|c|}
\hline Item & $\begin{array}{l}\text { Missouri } \\
\text { Columbia } \\
\text { City of } \\
\text { September } 30\end{array}$ & $\begin{array}{l}\text { Missouri } \\
\text { Hannibal } \\
\text { City of } \\
\text { June } 30\end{array}$ & $\begin{array}{c}\text { Missouri } \\
\text { Independence } \\
\text { City of } \\
\text { June } 30\end{array}$ & $\begin{array}{l}\text { Missouri } \\
\text { Kennett } \\
\text { City of } \\
\text { June } 30\end{array}$ & $\begin{array}{l}\text { Missouri } \\
\text { Kirkwood } \\
\text { City of } \\
\text { March } 31\end{array}$ & $\begin{array}{l}\text { Missouri } \\
\text { Lebanon } \\
\text { City of } \\
\text { October } 31\end{array}$ \\
\hline Electric Utility Operating Revenues ............ & 47,025 & 9,630 & 52,945 & 4,296 & 11,281 & 8,942 \\
\hline 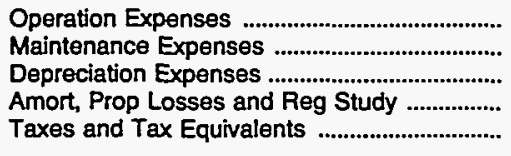 & $\begin{array}{r}34,380 \\
1,960 \\
3,195 \\
0 \\
4,076\end{array}$ & $\begin{array}{r}8,144 \\
552 \\
348 \\
0 \\
400\end{array}$ & $\begin{array}{r}32,532 \\
6,389 \\
5,181 \\
0 \\
5,763\end{array}$ & $\begin{array}{r}3,777 \\
297 \\
551 \\
0 \\
74\end{array}$ & $\begin{array}{r}8,232 \\
654 \\
166 \\
0 \\
0\end{array}$ & $\begin{array}{r}8,040 \\
0 \\
0 \\
0 \\
0\end{array}$ \\
\hline $\begin{array}{c}\text { Total Electric Utllity Operating } \\
\text { Expenses }\end{array}$ & 43,611 & 9,444 & 49,865 & 4,699 & 9,052 & 8,040 \\
\hline 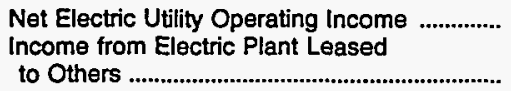 & $\begin{array}{r}3,414 \\
0\end{array}$ & $\begin{array}{r}186 \\
0\end{array}$ & $\begin{array}{r}3,080 \\
0\end{array}$ & $\begin{array}{r}-403 \\
178\end{array}$ & $\begin{array}{r}2,228 \\
0\end{array}$ & 902 \\
\hline Electric UtIIIty Operating Income ............. & 3,414 & 186 & 3,080 & -225 & 2,228 & 910 \\
\hline 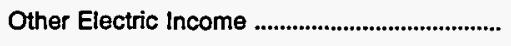 & 4,743 & 362 & 2,209 & 0 & 220 & 1,545 \\
\hline $\begin{array}{l}\text { Other Electric Deductions } \\
\text { Allowance for Other Funds Used }\end{array}$ & 236 & 0 & 0 & 0 & 8 & 1,448 \\
\hline $\begin{array}{l}\text { During Construction ........................................ } \\
\text { Taxes on Other Income and Deductions ....... }\end{array}$ & $\begin{array}{l}0 \\
0\end{array}$ & $\begin{array}{l}0 \\
0\end{array}$ & $\begin{array}{l}0 \\
0\end{array}$ & $\begin{array}{l}0 \\
0\end{array}$ & $\begin{array}{l}0 \\
0\end{array}$ & $\begin{array}{l}0 \\
0\end{array}$ \\
\hline 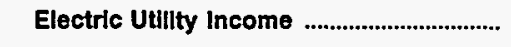 & 7,922 & 549 & 5,289 & -225 & 2,440 & 1,006 \\
\hline 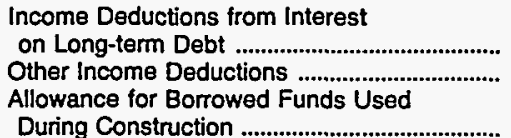 & $\begin{array}{r}2,694 \\
22\end{array}$ & $\begin{array}{l}\mathbf{0} \\
\mathbf{0}\end{array}$ & $\begin{array}{r}2,534 \\
111\end{array}$ & $\begin{array}{l}0 \\
0\end{array}$ & $\begin{array}{l}0 \\
0\end{array}$ & $\begin{array}{l}249 \\
185\end{array}$ \\
\hline 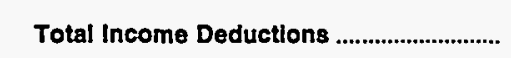 & 2,716 & $\mathbf{0}$ & 2,645 & $\mathbf{0}$ & 0 & 434 \\
\hline Income Before Extraordinary Items .................. & 5,206 & 549 & 2,644 & -225 & 2,440 & 573 \\
\hline 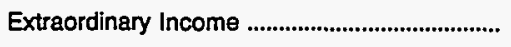 & 0 & $\mathbf{0}$ & 0 & 0 & 0 & 0 \\
\hline 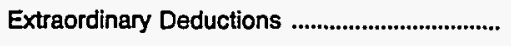 & 0 & 0 & 0 & 0 & 4,885 & 0 \\
\hline Net Income & 5,206 & 549 & 2,644 & -225 & $-2,445$ & 573 \\
\hline
\end{tabular}

Note: Totals may not equal sum of components because of independent rounding.

Source: Energy Information Administration, Form ElA-412, "Annual Report of Public Electric Utilities." 
Table 21. Statement of Income by Major U.S. Publicly Owned Electric Utility Within State, 1993 (Continued)

(Thousand Dollars)

\begin{tabular}{|c|c|c|c|c|c|c|}
\hline Item & $\begin{array}{c}\text { Missouri } \\
\text { Marshall } \\
\text { City of } \\
\text { September } 30\end{array}$ & $\begin{array}{l}\text { Missouri } \\
\text { Monett } \\
\text { City of } \\
\text { March } 31\end{array}$ & $\begin{array}{c}\text { Missouri } \\
\text { Poplar } \\
\text { Bluff } \\
\text { City of } \\
\text { December } 31\end{array}$ & $\begin{array}{c}\text { Missouri } \\
\text { Rolla } \\
\text { City of } \\
\text { September } 30\end{array}$ & $\begin{array}{l}\text { Missouri } \\
\text { Sikeston } \\
\text { City of } \\
\text { May } 31\end{array}$ & $\begin{array}{l}\text { Missouri } \\
\text { Springfield } \\
\text { City of } \\
\text { September } 30\end{array}$ \\
\hline Electric Utllity Operating Revenues ........... & 8,935 & 7,197 & 9,264 & 11,593 & 49,058 & 102,178 \\
\hline 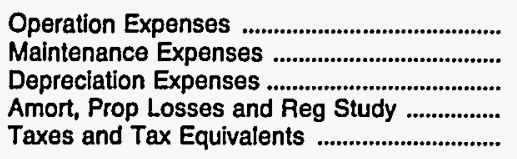 & $\begin{array}{r}4,592 \\
1,231 \\
1,169 \\
0 \\
0\end{array}$ & $\begin{array}{r}4,801 \\
0 \\
304 \\
0 \\
0\end{array}$ & $\begin{array}{r}6,628 \\
628 \\
645 \\
0 \\
0\end{array}$ & $\begin{array}{r}9,195 \\
386 \\
388 \\
0 \\
713\end{array}$ & $\begin{array}{r}26,603 \\
5,045 \\
2,433 \\
246 \\
0\end{array}$ & $\begin{array}{r}53,751 \\
13,216 \\
12,170 \\
0 \\
3,045\end{array}$ \\
\hline $\begin{array}{l}\text { Total Electrlc Utillty Operating } \\
\text { Expenses }\end{array}$ & 6,992 & 5,105 & 7,901 & 10,681 & 34,327 & 82,182 \\
\hline 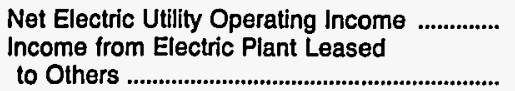 & $\begin{array}{r}1,944 \\
0\end{array}$ & $\begin{array}{r}2,091 \\
0\end{array}$ & $\begin{array}{r}1,363 \\
0\end{array}$ & $\begin{array}{r}911 \\
0\end{array}$ & 14,731 & $\begin{array}{r}19,996 \\
9,659\end{array}$ \\
\hline Electric Utility Operating Income ............. & 1,944 & 2,091 & 1,363 & 911 & 14,731 & 29,655 \\
\hline 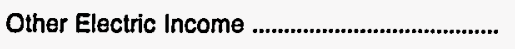 & 337 & 34 & 605 & 204 & 2,243 & 19,298 \\
\hline $\begin{array}{l}\text { Other Electric Deductions ....................................... } \\
\text { Allowance for Other Funds Used }\end{array}$ & 830 & 0 & 0 & 25 & 0 & 0 \\
\hline $\begin{array}{l}\text { During Construction ..................................... } \\
\text { Taxes on Other Income and Deductions ....... }\end{array}$ & $\begin{array}{l}0 \\
0\end{array}$ & $\begin{array}{l}0 \\
0\end{array}$ & $\begin{array}{l}0 \\
0\end{array}$ & $\begin{array}{l}0 \\
0\end{array}$ & $\begin{array}{l}0 \\
0\end{array}$ & $\begin{array}{r}714 \\
0\end{array}$ \\
\hline Electric Utility Income & 1,451 & 2,126 & 1,968 & 1,090 & 16,975 & 49,667 \\
\hline $\begin{array}{l}\text { Income Deductions from Interest } \\
\text { on Long-term Debt .......................................... } \\
\text { Other Income Deductions .................................. } \\
\text { Allowance for Borrowed Funds Used }\end{array}$ & $\begin{array}{r}127 \\
30\end{array}$ & $\begin{array}{l}0 \\
0\end{array}$ & $\begin{array}{l}2 \\
0\end{array}$ & $\begin{array}{r}0 \\
58\end{array}$ & $\begin{array}{r}13,448 \\
0\end{array}$ & $\begin{array}{l}8,505 \\
2,016\end{array}$ \\
\hline 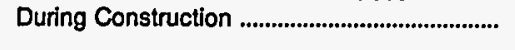 & 0 & 0 & 0 & 0 & 0 & -664 \\
\hline Total Income Deductlons ............................... & 157 & 0 & 2 & 58 & 13,448 & 9,857 \\
\hline Income Before Extraordinary Items ................. & 1,294 & 2,126 & 1,965 & 1,032 & 3,527 & 39,810 \\
\hline 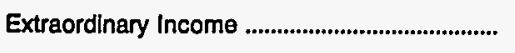 & 0 & 0 & 0 & 0 & 0 & 0 \\
\hline 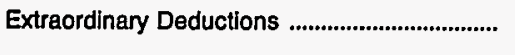 & 0 & 0 & 0 & 0 & 0 & 0 \\
\hline Net Income & 1,294 & 2,126 & 1,965 & 1,032 & 3,527 & 39,810 \\
\hline
\end{tabular}

Note: Totals may not equal sum of components because of independent rounding.

Source: Energy Information Administration, Form ElA-412, "Annual Report of Public Electric Utilities." 
Table 21. S\{atement of Income by Major U.S. Publicly Owned Electric Utility Within State, 1993 (Continued)

(Thousand Dollars)

\begin{tabular}{|c|c|c|c|c|c|c|}
\hline Item & $\begin{array}{c}\text { Nebraska } \\
\text { Central } \\
\text { Nebraska } \\
\text { Pub } \\
\text { P\&I Dist } \\
\text { December } 31\end{array}$ & $\begin{array}{c}\text { Nebraska } \\
\text { Cornhusker } \\
\text { Public } \\
\text { Power Dist } \\
\text { December } 31\end{array}$ & $\begin{array}{c}\text { Nebraska } \\
\text { Dawson } \\
\text { County } \\
\text { Public } \\
\text { Pwr Dist } \\
\text { December } 31\end{array}$ & $\begin{array}{l}\text { Nebraska } \\
\text { Fremont } \\
\text { City of } \\
\text { July } 31\end{array}$ & $\begin{array}{l}\text { Nebraska } \\
\text { Grand Island } \\
\text { City of } \\
\text { July } 31\end{array}$ & $\begin{array}{c}\text { Nebraska } \\
\text { Hastings } \\
\text { City of } \\
\text { December } 31\end{array}$ \\
\hline Eloctric Utility Operating Revenues .............. & 6,955 & 10,190 & 14,009 & 13,441 & 23,795 & 14,018 \\
\hline 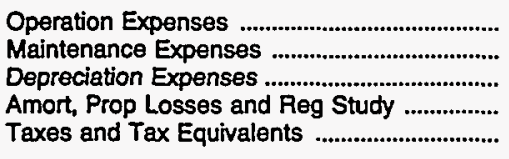 & $\begin{array}{r}4,691 \\
1,447 \\
2,820 \\
0 \\
8\end{array}$ & $\begin{array}{r}7,504 \\
558 \\
886 \\
0 \\
0\end{array}$ & $\begin{array}{r}9,817 \\
463 \\
1,145 \\
0 \\
166\end{array}$ & $\begin{array}{r}8,060 \\
1,993 \\
2,402 \\
0 \\
1,313\end{array}$ & $\begin{array}{r}11,293 \\
1,405 \\
4,907 \\
109 \\
555\end{array}$ & $\begin{array}{r}7,994 \\
982 \\
2,557 \\
0 \\
504\end{array}$ \\
\hline $\begin{array}{l}\text { Total Electric Utility Operating } \\
\text { Expenses }\end{array}$ & 8,965 & 8,948 & 11,591 & 13,767 & 18,269 & 12,037 \\
\hline $\begin{array}{l}\text { Net Electric Utility Operating Income } \\
\text { Income from Electric Plant Leased } \\
\text { to Others }\end{array}$ & $-2,010$ & 1,242 & 2,418 & -326 & 5,527 & 1,981 \\
\hline Electric Utility Operating Income .............. & $-1,996$ & 1,242 & 2,418 & -326 & 5,527 & 1,981 \\
\hline 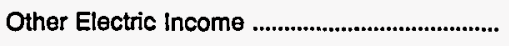 & 633 & 315 & 404 & 1,631 & 580 & 2,789 \\
\hline $\begin{array}{l}\text { Other Electric Deductions ..................................... } \\
\text { Allowance for Other Funds Ussed }\end{array}$ & 0 & 23 & 0 & 232 & 0 & 0 \\
\hline 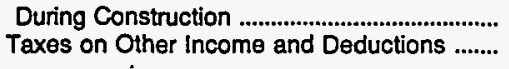 & $\begin{array}{l}0 \\
0\end{array}$ & $\begin{array}{l}0 \\
0\end{array}$ & $\begin{array}{l}0 \\
0\end{array}$ & $\begin{array}{l}0 \\
0\end{array}$ & $\begin{array}{l}0 \\
0\end{array}$ & $\begin{array}{l}0 \\
0\end{array}$ \\
\hline Electric Utllity Income & $-1,364$ & 1,535 & 2,822 & 1,073 & 6,106 & 4,770 \\
\hline $\begin{array}{l}\text { Income Deductions from Interest } \\
\text { on Long-term Debt ........................................... } \\
\text { Other Income Deductions ........................ } \\
\text { Allowance for Borrowed Funds Used }\end{array}$ & $\begin{array}{r}68 \\
114\end{array}$ & $\begin{array}{r}600 \\
-196\end{array}$ & $\begin{array}{r}75 \\
0\end{array}$ & $\begin{array}{r}1,031 \\
0\end{array}$ & $\begin{array}{r}2,402 \\
110\end{array}$ & $\begin{array}{r}3,911 \\
0\end{array}$ \\
\hline 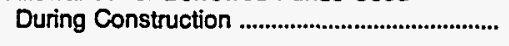 & 0 & 0 & 0 & 0 & 0 & 0 \\
\hline 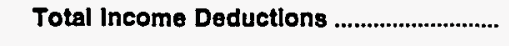 & 182 & 403 & 75 & 1,031 & 2,512 & 3,911 \\
\hline 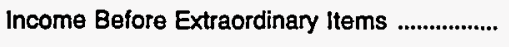 & $-1,545$ & 1,132 & 2,747 & 42 & 3,594 & 859 \\
\hline Extraordinary Income & 1,378 & 0 & 0 & 0 & 0 & 0 \\
\hline 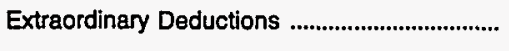 & 0 & 0 & 0 & 0 & 0 & 841 \\
\hline 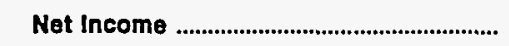 & -168 & 1,132 & 2,747 & 42 & 3,594 & 18 \\
\hline
\end{tabular}

Note: Totals may not equal sum of components because of independent rounding.

Source: Energy Information Administration, Form ElA-412, "Annual Report of Public Electric Utilities." 
Table 21. Statement of Income by Major U.S. Publicly Owned Electric Utility Within State, 1993 (Continued)

(Thousand Dollars)

\begin{tabular}{|c|c|c|c|c|c|c|}
\hline Item & $\begin{array}{c}\text { Nebraska } \\
\text { Lincoln } \\
\text { Electric } \\
\text { System } \\
\text { December } 31\end{array}$ & $\begin{array}{c}\text { Nebraska } \\
\text { Loup } \\
\text { River } \\
\text { Public } \\
\text { Power Dist } \\
\text { December } 31\end{array}$ & $\begin{array}{l}\text { Nebraska } \\
\text { Municipal } \\
\text { Energy } \\
\text { Agency } \\
\text { of NE } \\
\text { March } 31\end{array}$ & $\begin{array}{c}\text { Nebraska } \\
\text { Nebraska } \\
\text { Public } \\
\text { Power } \\
\text { District } \\
\text { December } 31\end{array}$ & $\begin{array}{c}\text { Nebraska } \\
\text { Norris } \\
\text { Public } \\
\text { Power } \\
\text { District } \\
\text { December } 31\end{array}$ & $\begin{array}{c}\text { Nebraska } \\
\text { North } \\
\text { Platte } \\
\text { City of } \\
\\
\text { July } 31\end{array}$ \\
\hline Electrlc Utility Operating Revenues ............. & 116,552 & 35,429 & 30,351 & 467,101 & 20,821 & 10,641 \\
\hline 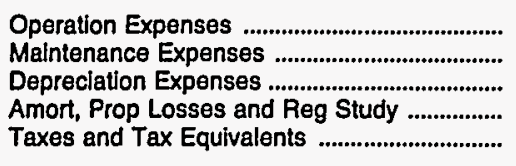 & $\begin{array}{r}73,848 \\
6,706 \\
11,933 \\
670 \\
4,975\end{array}$ & $\begin{array}{r}28,577 \\
1,344 \\
1,223 \\
0 \\
2,173\end{array}$ & $\begin{array}{r}26,306 \\
0 \\
1,357 \\
0 \\
0\end{array}$ & $\begin{array}{r}261,663 \\
51,535 \\
63,546 \\
7,297 \\
5,360\end{array}$ & $\begin{array}{r}14,880 \\
1,047 \\
1,801 \\
0 \\
129\end{array}$ & $\begin{array}{r}8.170 \\
355 \\
439 \\
0 \\
846\end{array}$ \\
\hline $\begin{array}{l}\text { Total Electrlc Utilty Operating } \\
\text { Expenses ........................................................... }\end{array}$ & 98,132 & 33,316 & 27,663 & 389,400 & 17,857 & 9,811 \\
\hline 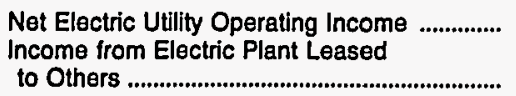 & 18,420 & $\begin{array}{r}2,114 \\
0\end{array}$ & 2,688 & 77,701 & 2,964 & 830 \\
\hline Electric Utlltty Operating Income .............. & 18,420 & 2,114 & 2,688 & 77,701 & 2,964 & 830 \\
\hline 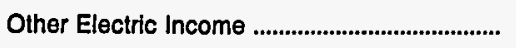 & 2,693 & 1,055 & 317 & 26,862 & 457 & 138 \\
\hline $\begin{array}{l}\text { Other Electric Deductions } \\
\text { Allowance for Other Funds Used.......................... }\end{array}$ & 0 & 0 & 0 & 8,657 & 0 & 0 \\
\hline $\begin{array}{l}\text { During Construction ..................................... } \\
\text { Taxes on Other Income and Deductions ........ }\end{array}$ & $\begin{array}{l}0 \\
0\end{array}$ & $\begin{array}{l}0 \\
0\end{array}$ & $\begin{array}{l}0 \\
0\end{array}$ & $\begin{array}{r}1,587 \\
0\end{array}$ & $\begin{array}{l}0 \\
0\end{array}$ & $\begin{array}{l}0 \\
0\end{array}$ \\
\hline 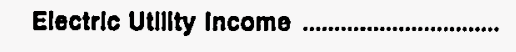 & 21,114 & 3,169 & 3,004 & 97,492 & 3,421 & 968 \\
\hline 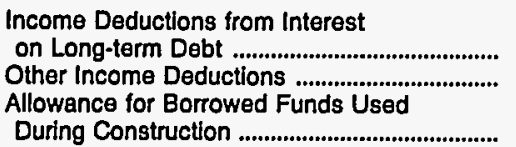 & $\begin{array}{r}15,192 \\
1,646\end{array}$ & $\begin{array}{r}0 \\
18\end{array}$ & $\begin{array}{r}2,978 \\
0\end{array}$ & $\begin{array}{l}63,869 \\
31,643\end{array}$ & $\begin{array}{r}1,121 \\
89\end{array}$ & $\begin{array}{l}0 \\
0\end{array}$ \\
\hline Total Income Deductions ................................ & 16,838 & 18 & 2,978 & 95,512 & 1,210 & 0 \\
\hline Income Before Extraordinary Items ................. & 4,276 & 3,151 & 26 & 1,980 & 2,211 & 968 \\
\hline 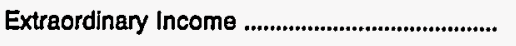 & 0 & 0 & 60 & 0 & 0 & 0 \\
\hline 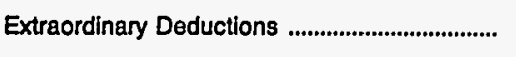 & 267 & 0 & 0 & 0 & 0 & 0 \\
\hline 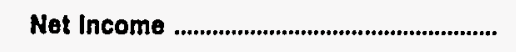 & 4,010 & 3,151 & 86 & 1,980 & 2,211 & 968 \\
\hline
\end{tabular}

Note: Totals may not equal sum of components because of independent rounding.

Source: Energy Information Administration, Form ElA-412, "Annual Report of Public Electric Utilities." 
Table 21. Statement of Income by Major U.S. Publicly Owned Electric Utility Within State, 1993 (Continued)

(Thousand Dollars)

\begin{tabular}{|c|c|c|c|c|c|c|}
\hline Item & $\begin{array}{c}\text { Nebraska } \\
\text { Omaha Public } \\
\text { Power } \\
\text { District } \\
\text { December } 31\end{array}$ & $\begin{array}{c}\text { Nebraska } \\
\text { Southern } \\
\text { Nebraska Rura! } \\
\text { P P D } \\
\text { December } 31\end{array}$ & $\begin{array}{c}\text { Nevada } \\
\text { Colorado } \\
\text { River } \\
\text { Comm } \\
\text { of Nevada } \\
\text { June } 30\end{array}$ & $\begin{array}{l}\text { New Jersey } \\
\text { Vineland } \\
\text { City of } \\
\text { June } 30\end{array}$ & $\begin{array}{l}\text { New Mexico } \\
\text { Farmington } \\
\text { City of } \\
\text { June } 30\end{array}$ & $\begin{array}{l}\text { New Mexico } \\
\text { Gallup } \\
\text { City of } \\
\text { June } 30\end{array}$ \\
\hline Electric Utility Operating Revenues ............. & 402,360 & 20,536 & 28,545 & 38,859 & 40,777 & 13,733 \\
\hline 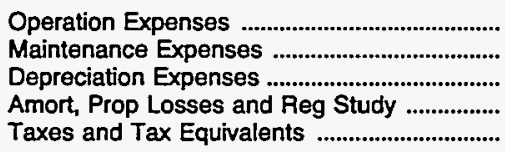 & $\begin{array}{r}191,782 \\
40,148 \\
62,868 \\
0 \\
15,104\end{array}$ & $\begin{array}{r}14,772 \\
1,044 \\
2,293 \\
0 \\
136\end{array}$ & $\begin{array}{r}28,425 \\
0 \\
0 \\
120 \\
0\end{array}$ & $\begin{array}{r}28,263 \\
1,973 \\
1,569 \\
0 \\
534\end{array}$ & $\begin{array}{r}15,057 \\
1,986 \\
4,341 \\
0 \\
2,938\end{array}$ & $\begin{array}{r}11,749 \\
80 \\
406 \\
0 \\
686\end{array}$ \\
\hline $\begin{array}{l}\text { Total Electric Utllity Operating } \\
\text { Expenses }\end{array}$ & 309,902 & 18,245 & 28,545 & 32,339 & 24,322 & 12,921 \\
\hline $\begin{array}{l}\text { Net Electric Utility Operating Income } \\
\text { Income from Electric Plant Leased } \\
\text { to Others }\end{array}$ & $\begin{array}{r}92,458 \\
0\end{array}$ & $\begin{array}{r}2,291 \\
0\end{array}$ & 0 & $\begin{array}{r}6,520 \\
0\end{array}$ & $\begin{array}{r}16,455 \\
0\end{array}$ & 812 \\
\hline Electric Utllity Operating Income .............. & 92,458 & 2,291 & $\mathbf{0}$ & 6,520 & 16,455 & 812 \\
\hline 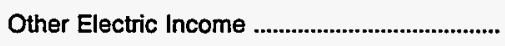 & 14,266 & 0 & 30 & 1,133 & 1,889 & 123 \\
\hline 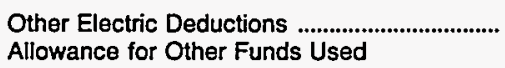 & 0 & 0 & 0 & 0 & 0 & 0 \\
\hline 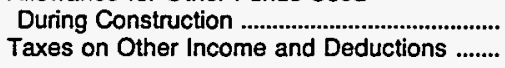 & $\begin{array}{r}1,513 \\
0\end{array}$ & $\begin{array}{l}\mathbf{0} \\
\mathbf{0}\end{array}$ & $\begin{array}{l}0 \\
0\end{array}$ & $\begin{array}{l}0 \\
0\end{array}$ & $\begin{array}{l}0 \\
0\end{array}$ & $\begin{array}{l}0 \\
0\end{array}$ \\
\hline Electric Utility Income & 108,238 & 2,291 & 30 & 7,652 & 18,344 & 936 \\
\hline 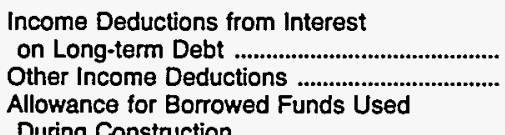 & $\begin{array}{r}59,944 \\
7,211\end{array}$ & $\begin{array}{r}255 \\
0\end{array}$ & $\begin{array}{l}0 \\
0\end{array}$ & $\begin{array}{r}329 \\
88\end{array}$ & $\begin{array}{r}11,800 \\
366\end{array}$ & $\begin{array}{l}0 \\
0\end{array}$ \\
\hline 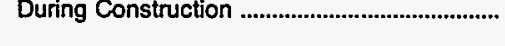 & $-4,119$ & 0 & 0 & 0 & 0 & 0 \\
\hline 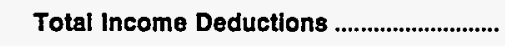 & 63,035 & 255 & $\mathbf{0}$ & 416 & 12,166 & 0 \\
\hline Income Before Extraordinary Items .................. & 45,203 & 2,036 & 30 & 7,236 & 6,178 & 936 \\
\hline Extraordinary Income & 0 & 486 & 0 & 0 & 0 & 0 \\
\hline 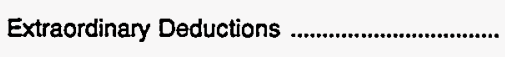 & 0 & 0 & 0 & 0 & 16,595 & 0 \\
\hline Net Income & 45,203 & 2,522 & 30 & 7,236 & $-10,418$ & 936 \\
\hline
\end{tabular}

Note: Totals may not equal sum of components because of independent rounding.

Source: Energy Information Administration, Form EIA-412, "Annual Report of Public Electric Utilities." 
Table 21. Statement of Income by Major U.S. Publicly Owned Electric Utility Within State, 1993 (Continued)

(Thousand Dollars)

\begin{tabular}{|c|c|c|c|c|c|c|}
\hline Item & $\begin{array}{l}\text { New Mexico } \\
\text { Los Alamos } \\
\text { County } \\
\text { June } 30\end{array}$ & $\begin{array}{l}\text { New York } \\
\text { Fairport } \\
\text { Village of } \\
\text { May } 31\end{array}$ & $\begin{array}{c}\text { New York } \\
\text { Freeport } \\
\begin{array}{c}\text { Village of } \\
\text { Inc }\end{array} \\
\text { February } 28\end{array}$ & $\begin{array}{l}\text { New York } \\
\text { Jamestown } \\
\text { City of } \\
\text { December } 31\end{array}$ & $\begin{array}{l}\text { New York } \\
\text { Massena } \\
\text { Town of } \\
\text { December } 31\end{array}$ & $\begin{array}{l}\text { New York } \\
\text { Plattsburgh } \\
\text { City of }\end{array}$ \\
\hline Electric UtIllty Operating Revenues ............ & 28,422 & 11,525 & 13,777 & 20,958 & 5,795 & 10,338 \\
\hline 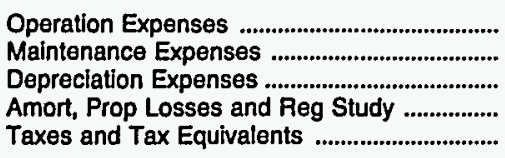 & $\begin{array}{r}15,957 \\
877 \\
2,624 \\
0 \\
838\end{array}$ & $\begin{array}{r}8,880 \\
234 \\
653 \\
0 \\
599\end{array}$ & $\begin{array}{r}10,139 \\
1,171 \\
946 \\
0 \\
1,560\end{array}$ & $\begin{array}{r}13,662 \\
1,299 \\
2,130 \\
0 \\
1,355\end{array}$ & $\begin{array}{r}3,215 \\
134 \\
398 \\
287 \\
0\end{array}$ & $\begin{array}{r}7,252 \\
405 \\
822 \\
0 \\
63\end{array}$ \\
\hline 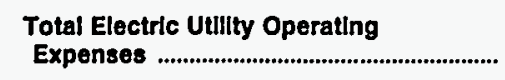 & 20,295 & 10,366 & 13,816 & 18,446 & 4,034 & 8,541 \\
\hline 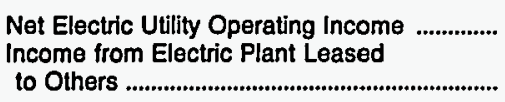 & $\begin{array}{r}8,128 \\
0\end{array}$ & $\begin{array}{r}1,159 \\
15\end{array}$ & -38 & 2,511 & 1,761 & 1,797 \\
\hline Electric UtIllty Operating Income .............. & 8,128 & 1,174 & -30 & 2,511 & 1,761 & 1,797 \\
\hline 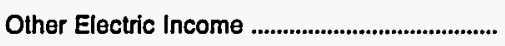 & 1,435 & 73 & 120 & 47 & 58 & 109 \\
\hline Other Electric Deductions ............................... & 176 & 6 & 0 & 2 & 0 & 0 \\
\hline $\begin{array}{l}\text { During Construction } \\
\text { Taxes on Other Income and Deductions ............................ }\end{array}$ & $\begin{array}{l}0 \\
0\end{array}$ & $\begin{array}{l}0 \\
0\end{array}$ & $\begin{array}{l}0 \\
0\end{array}$ & $\begin{array}{l}\mathbf{0} \\
\mathbf{0}\end{array}$ & $\begin{array}{r}0 \\
264\end{array}$ & $\begin{array}{l}0 \\
0\end{array}$ \\
\hline 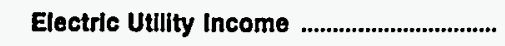 & 9,387 & 1,241 & 90 & 2,557 & 1,554 & 1,906 \\
\hline 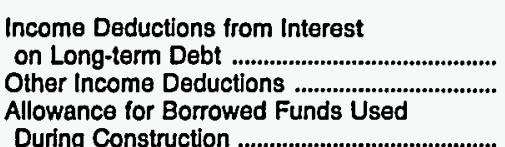 & $\begin{array}{r}7,821 \\
0\end{array}$ & $\begin{array}{l}82 \\
16\end{array}$ & $\begin{array}{r}148 \\
36\end{array}$ & $\begin{array}{r}1,137 \\
0\end{array}$ & $\begin{array}{r}638 \\
3\end{array}$ & $\begin{array}{r}452 \\
27\end{array}$ \\
\hline 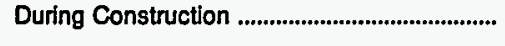 & 0 & 0 & 0 & 0 & 0 & 0 \\
\hline 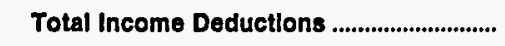 & 7,821 & 98 & 184 & 1,137 & 641 & 479 \\
\hline Income Before Extraordinary Items ................... & 1,566 & 1,143 & -94 & 1.420 & 913 & 1,427 \\
\hline Extraordinary Income & 0 & 0 & 0 & 0 & 0 & 0 \\
\hline 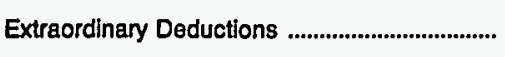 & 0 & 0 & 0 & 0 & 0 & 0 \\
\hline 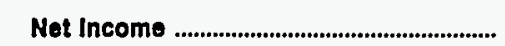 & 1,566 & 1,143 & -94 & 1,420 & 913 & 1,427 \\
\hline
\end{tabular}

Note: Totals may not equal sum of components because of independent rounding.

Source: Energy Information Administration, Form EIA-412, "Annual Report of Public Electric Utilities." 
Table 21. Statement of Income by Major U.S. Publicly Owned Electric Utility Within State, 1993 (Continued)

(Thousand Dollars)

\begin{tabular}{|c|c|c|c|c|c|c|}
\hline Item & $\begin{array}{c}\text { New York } \\
\text { Power } \\
\text { Authority } \\
\text { of State of NY } \\
\text { December } 31\end{array}$ & $\begin{array}{l}\text { New York } \\
\text { Rockville } \\
\text { Centre } \\
\text { Village of } \\
\text { May } 31\end{array}$ & $\begin{array}{c}\text { North Carolina } \\
\text { Albemarle } \\
\text { City of } \\
\text { June } 30\end{array}$ & $\begin{array}{l}\text { North Carolina } \\
\text { Concord } \\
\text { City of } \\
\text { June } 30\end{array}$ & $\begin{array}{l}\text { North Carolina } \\
\text { Elizabeth } \\
\text { City City of } \\
\text { June } 30\end{array}$ & $\begin{array}{l}\text { North Carolina } \\
\text { Fayetteville } \\
\text { Public } \\
\text { Works Comm } \\
\text { June } 30\end{array}$ \\
\hline Eloctric Utility Operating Revenues ............ & $1,429,791$ & 9,675 & 17,431 & 26,248 & 20,540 & 116,347 \\
\hline 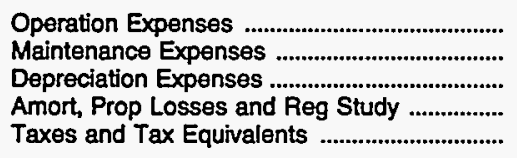 & $\begin{array}{r}979,179 \\
112,471 \\
178,019 \\
0 \\
0\end{array}$ & $\begin{array}{r}6,284 \\
1,661 \\
748 \\
0 \\
1,225\end{array}$ & $\begin{array}{r}15,409 \\
18 \\
587 \\
0 \\
0\end{array}$ & $\begin{array}{r}19,174 \\
3,484 \\
1,243 \\
0 \\
0\end{array}$ & $\begin{array}{r}17,577 \\
526 \\
861 \\
0 \\
0\end{array}$ & $\begin{array}{r}89,761 \\
4,792 \\
6,379 \\
76 \\
9,265\end{array}$ \\
\hline $\begin{array}{l}\text { Total Electric Utility Operating } \\
\text { Expenses }\end{array}$ & $1,269,669$ & 9,917 & 16,014 & 23,901 & 18,964 & 110,273 \\
\hline 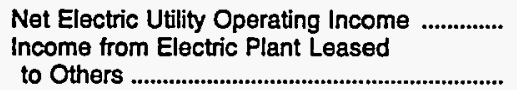 & $\begin{array}{r}160,122 \\
1,052\end{array}$ & $\begin{array}{r}-242 \\
0\end{array}$ & 1,417 & $\begin{array}{r}2,347 \\
0\end{array}$ & $\begin{array}{r}1,576 \\
0\end{array}$ & $\begin{array}{r}6,073 \\
0\end{array}$ \\
\hline Electric Utility Operating Income .............. & 161,174 & -242 & 1,417 & 2,347 & 1,576 & 6,073 \\
\hline Other Electric income & 107,822 & 333 & 89 & 437 & 119 & 1,626 \\
\hline $\begin{array}{l}\text { Other Electric Deductions ........................... } \\
\text { Allowance for Other Funds Used } \\
\text { During Construction ............................... } \\
\text { Texes on Other Income and Deductions ........ }\end{array}$ & $\begin{array}{l}0 \\
0\end{array}$ & $\begin{array}{l}0 \\
0\end{array}$ & $\begin{array}{l}0 \\
0\end{array}$ & $\begin{array}{l}0 \\
0\end{array}$ & 948 & $\begin{array}{l}0 \\
0\end{array}$ \\
\hline 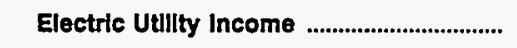 & 268,996 & 90 & 1,506 & 2,784 & 746 & 7,699 \\
\hline 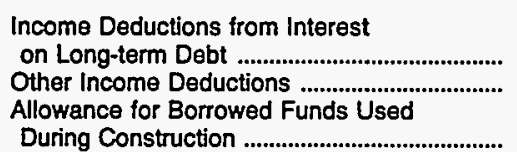 & $\begin{array}{r}207,105 \\
7,597\end{array}$ & $\begin{array}{l}649 \\
145\end{array}$ & $\begin{array}{r}0 \\
893\end{array}$ & $\begin{array}{r}250 \\
3,135\end{array}$ & $\begin{array}{r}0 \\
713\end{array}$ & $\begin{array}{r}2,543 \\
94\end{array}$ \\
\hline 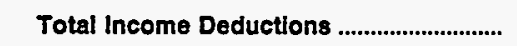 & 214,702 & 718 & 893 & 3,385 & 713 & 2,636 \\
\hline Income Before Extraordinary Items .................. & 54,294 & -627 & 613 & -602 & 34 & 5,063 \\
\hline Extraordinary Income & 0 & 0 & 0 & 0 & 0 & 0 \\
\hline 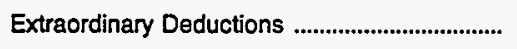 & 119,155 & 0 & 0 & 0 & 0 & 0 \\
\hline Net Income & $-64,861$ & -627 & 613 & -602 & 34 & 5,063 \\
\hline
\end{tabular}

Note: Totals may not equal sum of components because of independent rounding.

Source: Energy Information Administration, Form EIA-412, "Annual Report of Public Electric Utilities." 
Table 21. Statement of Income by Major U.S. Publicly Owned Electric Utility Within State, 1993 (Continued)

(Thousand Dollars)

\begin{tabular}{|c|c|c|c|c|c|c|}
\hline Item & $\begin{array}{l}\text { North Carolina } \\
\text { Forest City } \\
\text { Town of } \\
\text { June } 30\end{array}$ & $\begin{array}{l}\text { North Carolina } \\
\text { Gastonia } \\
\text { City of } \\
\text { June } 30\end{array}$ & $\begin{array}{c}\text { North Carolina } \\
\text { Greenville } \\
\text { Utilities } \\
\text { Comm } \\
\text { June } 30\end{array}$ & $\begin{array}{c}\text { North Carolina } \\
\text { High } \\
\text { Point } \\
\text { Town } \\
\text { of } \\
\text { June } 30\end{array}$ & $\begin{array}{l}\text { North Carolina } \\
\text { Kinston } \\
\text { City of } \\
\text { June } 30\end{array}$ & $\begin{array}{l}\text { North Carolina } \\
\text { Lexington } \\
\text { City of } \\
\text { June } 30\end{array}$ \\
\hline Electrlc Utllity Operating Revenues ............ & 7,974 & 42,187 & 90,763 & 58,903 & 35,485 & 31,877 \\
\hline 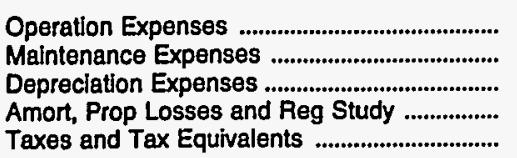 & $\begin{array}{r}6.468 \\
44 \\
141 \\
0 \\
0\end{array}$ & $\begin{array}{r}29,426 \\
996 \\
1,289 \\
0 \\
0\end{array}$ & $\begin{array}{r}80,634 \\
2,144 \\
3,691 \\
0 \\
0\end{array}$ & $\begin{array}{r}47,002 \\
2,499 \\
1,620 \\
0 \\
0\end{array}$ & $\begin{array}{r}31,276 \\
0 \\
309 \\
2 \\
843\end{array}$ & $\begin{array}{r}26,591 \\
132 \\
690 \\
0 \\
742\end{array}$ \\
\hline $\begin{array}{l}\text { Total Electric Utillty Operating } \\
\text { Expenses }\end{array}$ & 6,654 & 31,711 & 86,469 & 51,121 & 32,430 & 28,155 \\
\hline 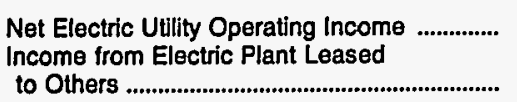 & $\begin{array}{r}1,319 \\
0\end{array}$ & 10,476 & 4,294 & 7,782 & 3,055 & 3,723 \\
\hline Electric Utility Operating Income ............. & 1,319 & 10,476 & 4,294 & 7,782 & 3,055 & 3,723 \\
\hline 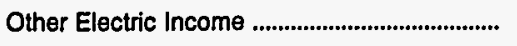 & 229 & 166 & 788 & 513 & 290 & 128 \\
\hline $\begin{array}{l}\text { Other Electric Deductions .............................. } \\
\text { Allowance for Other Funds Used } \\
\text { During Construction ....................................... } \\
\text { Taxes on Other Income and Deductions ....... }\end{array}$ & $\begin{array}{l}0 \\
0\end{array}$ & $\begin{array}{l}0 \\
0\end{array}$ & $\begin{array}{l}0 \\
0\end{array}$ & 4,645 & $\begin{array}{l}0 \\
0\end{array}$ & 3,600 \\
\hline Electric UtIllty Income .................................... & 1,549 & 10,642 & 5,082 & 3,650 & 3,344 & 251 \\
\hline 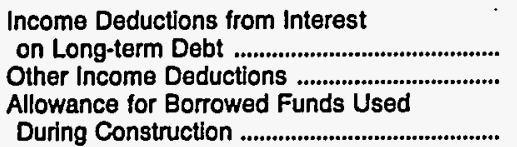 & $\begin{array}{l}0 \\
0\end{array}$ & $\begin{array}{r}10 \\
894\end{array}$ & $\begin{array}{r}145 \\
2,592\end{array}$ & $\begin{array}{r}63 \\
0\end{array}$ & $\begin{array}{r}256 \\
0\end{array}$ & $\begin{array}{r}20 \\
0\end{array}$ \\
\hline Total Income Deductlons .............................. & 0 & 904 & 2,737 & 63 & 256 & 20 \\
\hline Income Before Extraordinary Items ....................... & 1,549 & 9,739 & 2,345 & 3,587 & 3,089 & 231 \\
\hline Extraordinary Income & 0 & 0 & 0 & 0 & 0 & 0 \\
\hline 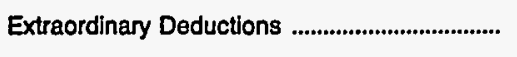 & 0 & 0 & 0 & 0 & 0 & 0 \\
\hline 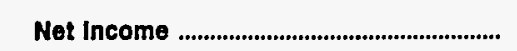 & 1,549 & 9,739 & 2,345 & 3,587 & 3,089 & 231 \\
\hline
\end{tabular}

Note: Totals may not equal sum of components because of independent rounding.

Source: Energy Information Administration, Form ElA-412, "Annual Report of Public Electric Utilities." 
Table 21. Statement of Income by Major U.S. Publicly Owned Electric Utility Within State, 1993 (Continued)

(Thousand Dollars)

\begin{tabular}{|c|c|c|c|c|c|c|}
\hline Item & $\begin{array}{c}\text { North Carolina } \\
\text { Lumberton } \\
\text { City of } \\
\text { June } 30\end{array}$ & $\begin{array}{c}\text { North Carolina } \\
\text { Monroe } \\
\text { City of } \\
\text { June } 30\end{array}$ & $\begin{array}{c}\text { North Carolina } \\
\begin{array}{c}\text { Morganton } \\
\text { City of }\end{array} \\
\text { June } 30\end{array}$ & $\begin{array}{l}\text { North Carolina } \\
\text { Murphy } \\
\text { City of } \\
\text { June } 30\end{array}$ & $\begin{array}{l}\text { North Carolina } \\
\text { New Bern } \\
\text { City of } \\
\text { June } 30\end{array}$ & $\begin{array}{l}\text { North Carolina } \\
\text { New River } \\
\text { Light } \\
\& \\
\text { Power Co } \\
\text { December } 31\end{array}$ \\
\hline Electric Utility Operating Revenues ............. & 21,558 & 25,653 & 17,698 & 7,227 & 34,054 & 11,973 \\
\hline 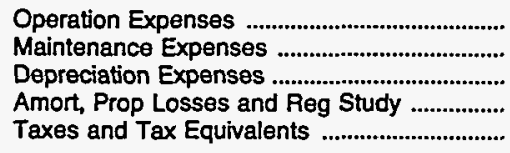 & $\begin{array}{r}20,376 \\
77 \\
475 \\
0 \\
0\end{array}$ & $\begin{array}{r}22,395 \\
0 \\
460 \\
0 \\
0\end{array}$ & $\begin{array}{r}14,303 \\
0 \\
381 \\
0 \\
0\end{array}$ & $\begin{array}{r}6,361 \\
111 \\
192 \\
0 \\
59\end{array}$ & $\begin{array}{r}30,062 \\
0 \\
786 \\
0 \\
0\end{array}$ & $\begin{array}{r}8,951 \\
408 \\
297 \\
0 \\
385\end{array}$ \\
\hline $\begin{array}{c}\text { Total Electric Utility Operating } \\
\text { Expenses }\end{array}$ & 20,928 & 22,854 & 14,684 & 6,723 & 30,848 & 10,041 \\
\hline 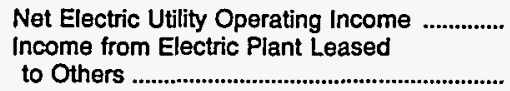 & $\begin{array}{r}630 \\
0\end{array}$ & $\begin{array}{r}2,799 \\
0\end{array}$ & $\begin{array}{r}3,013 \\
0\end{array}$ & $\begin{array}{r}504 \\
0\end{array}$ & $\begin{array}{r}3,207 \\
0\end{array}$ & 1,932 \\
\hline Electric Utility Operating Income .............. & 630 & 2,799 & 3,013 & 504 & 3,207 & 1,932 \\
\hline 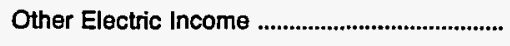 & 924 & 972 & 304 & 144 & 96 & 116 \\
\hline $\begin{array}{l}\text { Other Electric Deductions } \\
\text { Allowance for Other Funds Used................... } \\
\text { During Construction ........................................ } \\
\text { Taxes on Other Income and Deductions ....... }\end{array}$ & 1,701 & 1,185 & $\begin{array}{l}0 \\
0\end{array}$ & $\begin{array}{l}0 \\
0\end{array}$ & $\begin{array}{l}0 \\
0\end{array}$ & $\begin{array}{l}0 \\
0\end{array}$ \\
\hline Electric Utllity Income & -147 & 2,586 & 3,318 & 634 & 3,263 & 2,047 \\
\hline 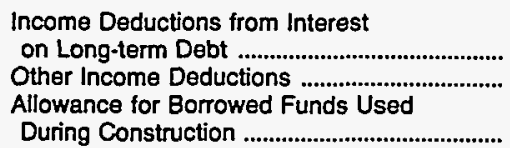 & $\begin{array}{r}3 \\
39\end{array}$ & $\begin{array}{r}-5 \\
0\end{array}$ & $\begin{array}{r}0 \\
2,605\end{array}$ & $\begin{array}{l}0 \\
0\end{array}$ & $\begin{array}{r}67 \\
0\end{array}$ & $\begin{array}{l}0 \\
0\end{array}$ \\
\hline 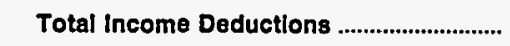 & 42 & -5 & 2,605 & 0 & 67 & 0 \\
\hline Income Before Extraordinary Items ................... & -189 & 2,591 & 712 & 634 & 3,196 & 2,047 \\
\hline Extraordinary Income & 0 & 0 & 0 & 0 & 0 & 0 \\
\hline 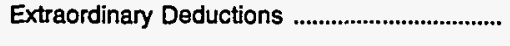 & 0 & 0 & 0 & 0 & 0 & 0 \\
\hline 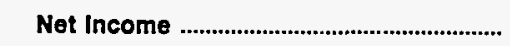 & -189 & 2,591 & 712 & 634 & 3,196 & 2,047 \\
\hline
\end{tabular}

Note: Totals may not equal sum of components because of independent rounding.

Source: Energy Information Administration, Form EIA-412, "Annual Report of Public Electric Utilities." 
Table 21. Statement of Income by Major U.S. Publicly Owned Electric Utility Within State, 1993 (Continued)

(Thousand Dollars)

\begin{tabular}{|c|c|c|c|c|c|c|}
\hline Item & $\begin{array}{c}\text { North Carolina } \\
\text { North } \\
\text { Carolina } \\
\text { Eastern M P A } \\
\text { December } 31\end{array}$ & $\begin{array}{c}\text { North Carolina } \\
\text { North } \\
\text { Carolina } \\
\text { Mun } \\
\text { Power Agny } \\
\text { December } 31\end{array}$ & $\begin{array}{l}\text { North Carolina } \\
\text { Rocky Mount } \\
\text { City of } \\
\text { June } 30\end{array}$ & $\begin{array}{c}\text { North Carolina } \\
\text { Shelby } \\
\text { City of } \\
\text { June } 30\end{array}$ & $\begin{array}{c}\text { North Carolina } \\
\text { Statesville } \\
\text { City of } \\
\text { June } 30\end{array}$ & $\begin{array}{c}\text { North Carolina } \\
\text { Tarboro } \\
\text { Town of } \\
\text { June } 30\end{array}$ \\
\hline Electrlc UtIlity Operating Revenues ............. & 444,271 & 443,511 & 59,009 & 12,156 & 24,884 & 20,386 \\
\hline 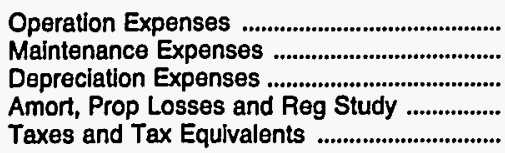 & $\begin{array}{r}232,300 \\
19,743 \\
50,478 \\
0 \\
17,298\end{array}$ & $\begin{array}{r}210,234 \\
42,839 \\
44,213 \\
0 \\
21,196\end{array}$ & $\begin{array}{r}53,939 \\
0 \\
1,023 \\
0 \\
0\end{array}$ & $\begin{array}{r}8,746 \\
1,108 \\
270 \\
0 \\
0\end{array}$ & $\begin{array}{r}20,511 \\
0 \\
521 \\
0 \\
0\end{array}$ & $\begin{array}{r}18,780 \\
0 \\
463 \\
0 \\
0\end{array}$ \\
\hline 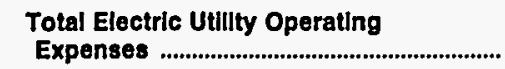 & 319,819 & 318,482 & 54,962 & 10,124 & 21,031 & 19,243 \\
\hline 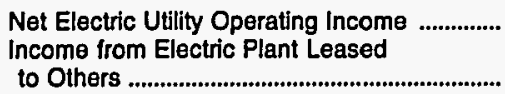 & 124,452 & 125,029 & 4,047 & 2,032 & 3,853 & 1,142 \\
\hline Electric Utllity Operating Income .............. & 124,452 & 125,029 & 4,047 & 2,032 & 3,853 & 1,142 \\
\hline Other Electric Income & 147,427 & 51,152 & 124 & 91 & 304 & 259 \\
\hline 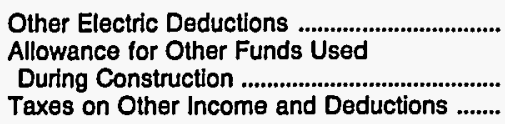 & $\begin{array}{l}0 \\
0\end{array}$ & $\begin{array}{l}0 \\
0\end{array}$ & $\begin{array}{l}0 \\
0\end{array}$ & $\begin{array}{l}0 \\
0\end{array}$ & 163 & $\begin{array}{l}0 \\
0\end{array}$ \\
\hline Electrlc Utllity Income & 271,879 & 176,181 & 4,172 & 2,121 & 3,993 & 1,401 \\
\hline 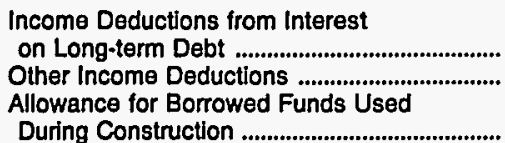 & $\begin{array}{r}216,519 \\
34,530\end{array}$ & $\begin{array}{r}146,842 \\
26,218\end{array}$ & $\begin{array}{r}77 \\
1,421\end{array}$ & $\begin{array}{r}12 \\
0\end{array}$ & $\begin{array}{r}0 \\
3,388\end{array}$ & $\begin{array}{r}0 \\
810\end{array}$ \\
\hline 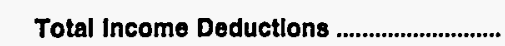 & 251,049 & 173,060 & 1,498 & 12 & 3,388 & 810 \\
\hline Income Before Extraordinary Items .................. & 20,830 & 3,121 & 2,674 & 2,109 & 605 & 592 \\
\hline 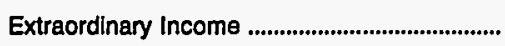 & 0 & 0 & 0 & 0 & 0 & 0 \\
\hline 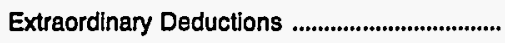 & 0 & 0 & 0 & 20 & 0 & 0 \\
\hline Net Income & 20,830 & 3,121 & 2,674 & 2,089 & 605 & 592 \\
\hline
\end{tabular}

Note: Totals may not equal sum of components because of independent rounding.

Source: Energy Information Administration, Form EIA-412, "Annual Report of Public Electric Utilities." 
Table 21. Statement of Income by Major U.S. Publicly Owned Electric Utility Within State, 1993 (Continued)

(Thousand Dollars)

\begin{tabular}{|c|c|c|c|c|c|c|}
\hline Item & $\begin{array}{c}\text { North Carolina } \\
\begin{array}{c}\text { Washington } \\
\text { City of }\end{array} \\
\text { June } 30\end{array}$ & $\begin{array}{l}\text { North Carolina } \\
\text { Wilson } \\
\text { City of } \\
\text { June } 30\end{array}$ & $\begin{array}{c}\text { Ohio } \\
\text { American } \\
\text { Mun } \\
\text { Power } \\
\text { Ohio Inc } \\
\text { December } 31\end{array}$ & $\begin{array}{c}\text { Ohio } \\
\text { Bowling } \\
\text { Green } \\
\text { City of } \\
\text { December } 31\end{array}$ & $\begin{array}{c}\text { Ohio } \\
\text { Bryan } \\
\text { City of } \\
\text { December } 31\end{array}$ & $\begin{array}{l}\text { Ohio } \\
\text { Celina } \\
\text { City of } \\
\text { December } 31\end{array}$ \\
\hline Electric Utillty Operating Revenues ............ & 20,979 & 76,635 & 141,215 & 16,053 & 11,270 & 7,888 \\
\hline 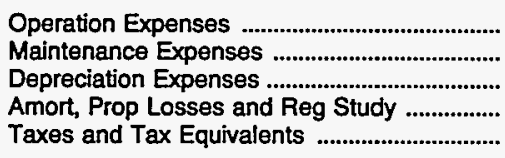 & $\begin{array}{r}17,628 \\
1,652 \\
885 \\
0 \\
0\end{array}$ & $\begin{array}{r}68,801 \\
711 \\
1,606 \\
0 \\
0\end{array}$ & $\begin{array}{r}117,585 \\
5,608 \\
3,162 \\
1,255 \\
6,619\end{array}$ & $\begin{array}{r}14,094 \\
805 \\
415 \\
0 \\
0\end{array}$ & $\begin{array}{r}13,486 \\
67 \\
0 \\
0 \\
0\end{array}$ & $\begin{array}{r}6,827 \\
524 \\
0 \\
0 \\
0\end{array}$ \\
\hline $\begin{array}{l}\text { Total Electric Utillty Operating } \\
\text { Expenses }\end{array}$ & 20,165 & 71,117 & 134,229 & 15,314 & 13,553 & 7,351 \\
\hline $\begin{array}{l}\text { Net Electric Utility Operating Income } \\
\text { Income from Electric Plant Leased } \\
\text { to Others }\end{array}$ & 814 & 5,518 & 6,986 & 740 & $-2,283$ & 537 \\
\hline Electric Utllity Operating Income .............. & 814 & 5,518 & 6,986 & 740 & $-2,283$ & 537 \\
\hline Other Electric Income & 679 & 1,206 & 1,148 & 605 & 0 & 65 \\
\hline $\begin{array}{l}\text { Other Electric Deductions } \\
\text { Allowance for Other Funds Used }\end{array}$ & 1,313 & 0 & 0 & 0 & 0 & 0 \\
\hline $\begin{array}{l}\text { During Construction ............................................ } \\
\text { Taxes on Other Income and Deductions ..... }\end{array}$ & $\begin{array}{l}0 \\
0\end{array}$ & $\begin{array}{l}0 \\
0\end{array}$ & $\begin{array}{l}0 \\
0\end{array}$ & $\begin{array}{l}0 \\
0\end{array}$ & $\begin{array}{l}0 \\
0\end{array}$ & $\begin{array}{l}0 \\
0\end{array}$ \\
\hline 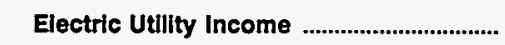 & 180 & 6,724 & 8,134 & 1,344 & $-2,283$ & 602 \\
\hline 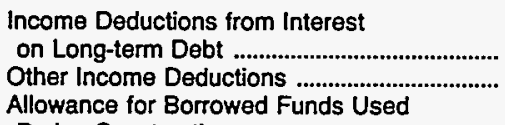 & $\begin{array}{r}134 \\
0\end{array}$ & $\begin{array}{r}17 \\
2,062\end{array}$ & $\begin{array}{r}7,326 \\
0\end{array}$ & $\begin{array}{r}17 \\
0\end{array}$ & $\begin{array}{l}0 \\
0\end{array}$ & $\begin{array}{r}0 \\
265\end{array}$ \\
\hline 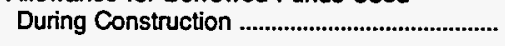 & 0 & 0 & 0 & 0 & 0 & 0 \\
\hline 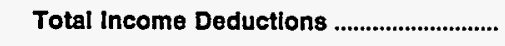 & 134 & 2,079 & 7,326 & 17 & 0 & 265 \\
\hline 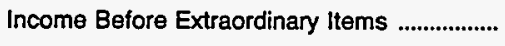 & 46 & 4,646 & 808 & 1,327 & $-2,283$ & 337 \\
\hline Extraordinary Income & 0 & 0 & 0 & 0 & 0 & 0 \\
\hline 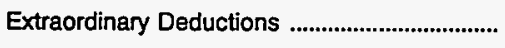 & 360 & 0 & 0 & 0 & 0 & 0 \\
\hline Net Income & -314 & 4,646 & 808 & 1,327 & $-2,283$ & 337 \\
\hline
\end{tabular}

Note: Totals may not equal sum of components because of independent rounding.

Source: Energy Information Administration, Form ElA-412, "Annual Report of Public Electric Utilities." 
Table 21. Statement of Income by Major U.S. Publicly Owned Electric Utillty Within State, 1993 (Continued)

(Thousand Dollars)

\begin{tabular}{|c|c|c|c|c|c|c|}
\hline Item & $\begin{array}{c}\text { Ohio } \\
\text { Cleveland } \\
\text { City of } \\
\text { December } 31\end{array}$ & $\begin{array}{l}\text { Ohio } \\
\text { Columbus } \\
\text { City of } \\
\text { December } 31\end{array}$ & $\begin{array}{c}\text { Ohio } \\
\text { Cuyahoga } \\
\text { Falls } \\
\text { City of } \\
\text { December } 31\end{array}$ & $\begin{array}{c}\text { Ohio } \\
\text { Dover } \\
\text { City of } \\
\text { December } 31\end{array}$ & $\begin{array}{c}\text { Ohio } \\
\text { Hamilton } \\
\text { City of } \\
\text { December } 31\end{array}$ & $\begin{array}{c}\text { Ohio } \\
\text { Napoleon } \\
\text { City of } \\
\text { December } 31\end{array}$ \\
\hline Electric Utllity Operating Revenues ............. & 67,287 & 38,243 & 18,262 & 9,514 & 43,511 & 7,980 \\
\hline 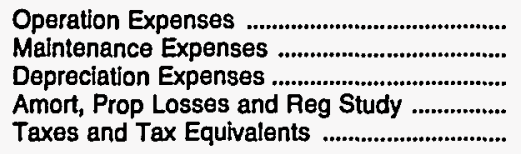 & $\begin{array}{r}40,451 \\
13,650 \\
4,376 \\
0 \\
0\end{array}$ & $\begin{array}{r}24,813 \\
8,956 \\
4,551 \\
0 \\
0\end{array}$ & $\begin{array}{r}17,272 \\
0 \\
559 \\
0 \\
0\end{array}$ & $\begin{array}{r}4,750 \\
3,797 \\
0 \\
0 \\
0\end{array}$ & $\begin{array}{r}22,508 \\
3,024 \\
6,218 \\
0 \\
0\end{array}$ & $\begin{array}{r}7,835 \\
0 \\
0 \\
0 \\
0\end{array}$ \\
\hline $\begin{array}{l}\text { Total Electric Utllity Operating } \\
\text { Expenses }\end{array}$ & 58,477 & 38,320 & 17,832 & 8,547 & 31,749 & 7,835 \\
\hline 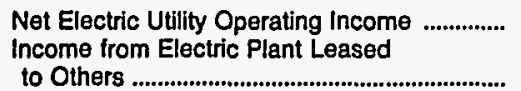 & $\begin{array}{r}8,810 \\
0\end{array}$ & $\begin{array}{r}-77 \\
8,759\end{array}$ & 430 & $\begin{array}{r}967 \\
0\end{array}$ & $\begin{array}{r}11,762 \\
0\end{array}$ & $\begin{array}{l}145 \\
540\end{array}$ \\
\hline Electrlc Utllity Operating Income .............. & 8,810 & 8,681 & 430 & 967 & 11,762 & 685 \\
\hline 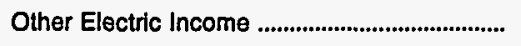 & 749 & 7,869 & 0 & 35 & 1,674 & 0 \\
\hline $\begin{array}{l}\text { Other Electric Deductions ........................................... } \\
\text { Allowance for Other Funds Used }\end{array}$ & 0 & 0 & 4 & 0 & 0 & 0 \\
\hline 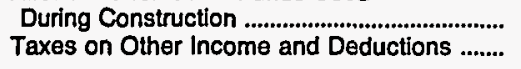 & $\begin{array}{l}0 \\
0\end{array}$ & $\begin{array}{l}0 \\
0\end{array}$ & $\begin{array}{l}0 \\
0\end{array}$ & $\begin{array}{l}0 \\
0\end{array}$ & $\begin{array}{l}0 \\
0\end{array}$ & $\begin{array}{l}0 \\
0\end{array}$ \\
\hline 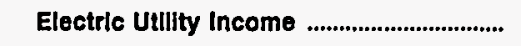 & 9,558 & 16,550 & 427 & 1,002 & 13,436 & 685 \\
\hline $\begin{array}{l}\text { Income Deductions from Interest } \\
\text { on Long-term Debt ............................................ } \\
\text { Other Income Deductions ...................... } \\
\text { Allowance for Borrowed Funds Used }\end{array}$ & $\begin{array}{r}1,375 \\
22,725\end{array}$ & $\begin{array}{r}10,579 \\
0\end{array}$ & $\begin{array}{r}271 \\
0\end{array}$ & $\begin{array}{r}363 \\
0\end{array}$ & $\begin{array}{r}12,661 \\
0\end{array}$ & $\begin{array}{l}0 \\
0\end{array}$ \\
\hline Total Income Deductions ............................. & 24,100 & 10,579 & 271 & 363 & 12,661 & 0 \\
\hline Income Before Extraordinary Items .................. & $-14,542$ & 5,971 & 156 & 639 & 775 & 685 \\
\hline 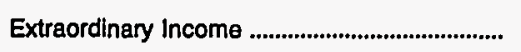 & 0 & 0 & 0 & 0 & 0 & 0 \\
\hline 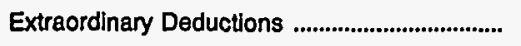 & 27 & 930 & 0 & 0 & 0 & 0 \\
\hline 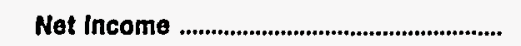 & $-14,569$ & 5,041 & 156 & 639 & 775 & 685 \\
\hline
\end{tabular}

Note: Totals may not equal sum of components because of independent rounding.

Source: Energy Information Administration, Form EIA-412, "Annual Report of Public Electric Utilities." 
Table 21. Statement of Income by Major U.S. Publicly Owned Electric Utility Within State, 1993 (Continued)

(Thousand Dollars)

\begin{tabular}{|c|c|c|c|c|c|c|}
\hline Item & $\begin{array}{c}\text { Ohio } \\
\text { Niles } \\
\text { City of } \\
\text { December } 31\end{array}$ & $\begin{array}{c}\text { Ohio } \\
\text { Orrville } \\
\text { City of }\end{array}$ & $\begin{array}{c}\text { Ohio } \\
\text { Painesville } \\
\text { City of } \\
\text { December } 31\end{array}$ & $\begin{array}{c}\text { Ohio } \\
\text { Piqua } \\
\text { City of } \\
\text { December } 31\end{array}$ & $\begin{array}{c}\text { Ohio } \\
\text { St Marys } \\
\text { City of } \\
\text { December } 31\end{array}$ & $\begin{array}{c}\text { Ohio } \\
\text { Wadsworth } \\
\text { City of } \\
\text { December } 31\end{array}$ \\
\hline Electric Utillty Operating Revenues .............. & 15,308 & 15,256 & 13,413 & 14,446 & 7,329 & 11,137 \\
\hline 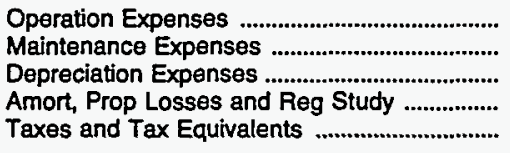 & $\begin{array}{r}13,557 \\
0 \\
415 \\
0 \\
0\end{array}$ & $\begin{array}{r}9,790 \\
2,227 \\
1,506 \\
0 \\
0\end{array}$ & $\begin{array}{r}11,444 \\
0 \\
1,114 \\
0 \\
0\end{array}$ & $\begin{array}{r}10,315 \\
1,378 \\
997 \\
0 \\
0\end{array}$ & $\begin{array}{r}5,354 \\
401 \\
327 \\
0 \\
71\end{array}$ & $\begin{array}{r}10,569 \\
0 \\
297 \\
0 \\
0\end{array}$ \\
\hline $\begin{array}{l}\text { Total Electric Utillty Operating } \\
\text { Expenses }\end{array}$ & 13,972 & 13,524 & 12,558 & 12,690 & 6,152 & 10,865 \\
\hline 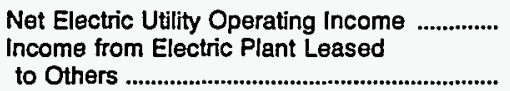 & $\begin{array}{r}1,336 \\
0\end{array}$ & $\begin{array}{r}1,733 \\
0\end{array}$ & 855 & 1,756 & $\begin{array}{r}1,177 \\
0\end{array}$ & 271 \\
\hline Electric Utillty Operating Income ................ & 1,336 & 1,733 & 855 & 1,756 & 1,177 & 271 \\
\hline Other Electric Income & 141 & 1,113 & -354 & 124 & 134 & 277 \\
\hline $\begin{array}{l}\text { Other Electric Deductions ............................. } \\
\text { Allowance for Other Funds Used } \\
\text { During Construction ................................. } \\
\text { Taxes on Other Income and Deductions ....... }\end{array}$ & $\begin{array}{l}0 \\
0\end{array}$ & 1,699 & $\begin{array}{l}0 \\
0\end{array}$ & 185 & $\begin{array}{l}0 \\
0\end{array}$ & 19 \\
\hline 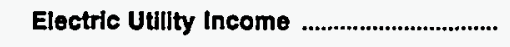 & 1,477 & 1,146 & 501 & 1,695 & 1,310 & 529 \\
\hline 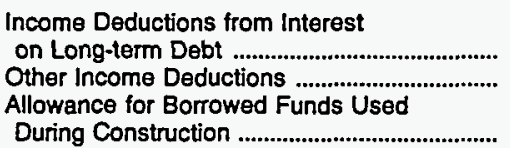 & $\begin{array}{r}158 \\
0\end{array}$ & $\begin{array}{l}0 \\
0\end{array}$ & $\begin{array}{r}442 \\
38\end{array}$ & $\begin{array}{r}560 \\
0\end{array}$ & $\begin{array}{r}376 \\
0\end{array}$ & $\begin{array}{l}0 \\
0\end{array}$ \\
\hline 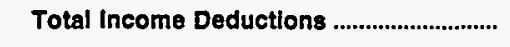 & 158 & $\mathbf{0}$ & 480 & 560 & 376 & o \\
\hline Income Before Extraordinary Items ....................... & 1,320 & 1,146 & 21 & 1,134 & 934 & 529 \\
\hline Extraordinary Income & 0 & 0 & 5 & 0 & 0 & 0 \\
\hline 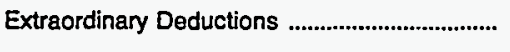 & 0 & 0 & $\mathbf{0}$ & 0 & 0 & 0 \\
\hline 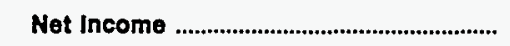 & 1,320 & 1,146 & 27 & 1,134 & 934 & 529 \\
\hline
\end{tabular}

Note: Totals may not equal sum of components because of independent rounding.

Source: Energy Information Administration, Form ElA-412, "Annual Report of Public Electric Utilities." 
Table 21. Statement of Income by Major U.S. Publicly Owned Electric Utility Within State, 1993 (Continued)

(Thousand Dollars)

\begin{tabular}{|c|c|c|c|c|c|c|}
\hline Item & $\begin{array}{c}\text { Ohio } \\
\text { Wapakoneta } \\
\text { City of }\end{array}$ & $\begin{array}{c}\text { Ohio } \\
\text { Westerville } \\
\text { City of }\end{array}$ & $\begin{array}{l}\text { Oklahoma } \\
\text { Altus } \\
\text { City of } \\
\text { June } 30\end{array}$ & $\begin{array}{l}\text { Oklahoma } \\
\text { Claremore } \\
\text { City of } \\
\text { June } 30\end{array}$ & $\begin{array}{l}\text { Oklahoma } \\
\text { Duncan } \\
\text { City of } \\
\text { June } 30\end{array}$ & $\begin{array}{l}\text { Oklahoma } \\
\text { Edmond } \\
\text { City of } \\
\text { June } 30\end{array}$ \\
\hline Electric Utllity Operating Revenues ............. & 6,594 & 17,916 & 9,218 & 11,669 & 7,987 & 24,727 \\
\hline 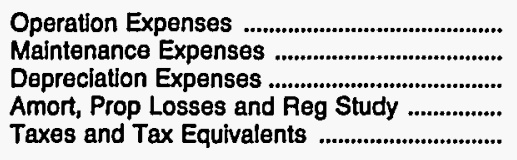 & $\begin{array}{r}6,973 \\
337 \\
0 \\
0 \\
0\end{array}$ & $\begin{array}{r}11,956 \\
1,633 \\
858 \\
0 \\
0\end{array}$ & $\begin{array}{r}7,088 \\
36 \\
439 \\
0 \\
0\end{array}$ & $\begin{array}{r}7,139 \\
976 \\
0 \\
0 \\
0\end{array}$ & $\begin{array}{r}4,205 \\
1,081 \\
677 \\
0 \\
0\end{array}$ & $\begin{array}{r}20,993 \\
88 \\
1,059 \\
0 \\
0\end{array}$ \\
\hline $\begin{array}{l}\text { Total Electrlc Utllity Operating } \\
\text { Expenses ...................................................... }\end{array}$ & 7,311 & 14,447 & 7,563 & 8,115 & 5,963 & 22,140 \\
\hline 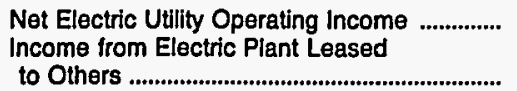 & $\begin{array}{r}-716 \\
0\end{array}$ & 3,469 & 1,655 & 3,555 & 2,025 & 2,587 \\
\hline Electric Utillty Operating Income ............. & -716 & 3,469 & 1,655 & 3,555 & 2,025 & 2,587 \\
\hline Other Electric Income & 0 & 0 & 187 & 0 & 513 & 1,162 \\
\hline $\begin{array}{l}\text { Other Electric Deductions ............................ } \\
\text { Allowance for Other Funds Used }\end{array}$ & 0 & 20 & 0 & 0 & 0 & 3,646 \\
\hline $\begin{array}{l}\text { During Construction ............................................ } \\
\text { Taxes on Other Income and Deductions ..... }\end{array}$ & $\begin{array}{l}0 \\
0\end{array}$ & $\begin{array}{l}0 \\
0\end{array}$ & $\begin{array}{l}0 \\
0\end{array}$ & $\begin{array}{l}0 \\
0\end{array}$ & $\begin{array}{l}0 \\
0\end{array}$ & $\begin{array}{l}0 \\
0\end{array}$ \\
\hline 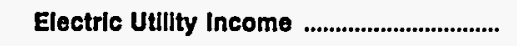 & -716 & 3,449 & 1,842 & 3,555 & 2,537 & 103 \\
\hline 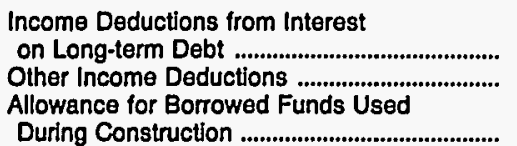 & $\begin{array}{l}0 \\
0\end{array}$ & $\begin{array}{r}0 \\
250\end{array}$ & $\begin{array}{l}0 \\
0\end{array}$ & $\begin{array}{l}0 \\
0\end{array}$ & $\begin{array}{l}0 \\
0\end{array}$ & $\begin{array}{r}51 \\
0\end{array}$ \\
\hline 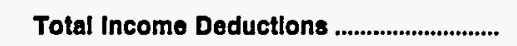 & $\mathbf{0}$ & 250 & 0 & $\mathbf{0}$ & 0 & 51 \\
\hline Income Before Extraordinary Items ..................... & -716 & 3,199 & 1,842 & 3,555 & 2,537 & 52 \\
\hline Extraordinary Income & 0 & 0 & 0 & $\mathbf{0}$ & 0 & 0 \\
\hline 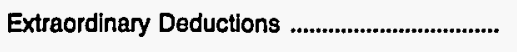 & 0 & 0 & 129 & 0 & 0 & 0 \\
\hline 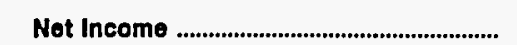 & -716 & 3,199 & 1,713 & 3,555 & 2,537 & 52 \\
\hline
\end{tabular}

Note: Totals may not equal sum of components because of independent rounding.

Source: Energy Information Administration, Form EIA-412, "Annual Report of Public Electric Utilities." 
Table 21. Statement of Income by Major U.S. Publicly Owned Electric Utility Within State, 1993 (Continued)

(Thousand Dollars)

\begin{tabular}{|c|c|c|c|c|c|c|}
\hline Item & $\begin{array}{c}\text { Oklahoma } \\
\text { Grand River } \\
\text { Dam } \\
\text { Authority } \\
\text { December } 31\end{array}$ & $\begin{array}{l}\text { Oklahoma } \\
\text { Miami } \\
\text { City of } \\
\text { June } 30\end{array}$ & $\begin{array}{c}\text { Oklahoma } \\
\text { Oklahoma } \\
\text { Municipal } \\
\text { Power Auth } \\
\text { December } 31\end{array}$ & $\begin{array}{l}\text { Oklahoma } \\
\text { Ponca } \\
\text { City City of } \\
\text { June } 30\end{array}$ & $\begin{array}{l}\text { Oklahoma } \\
\text { Stillwater } \\
\text { Utilities } \\
\text { Authority } \\
\text { June } 30\end{array}$ & $\begin{array}{l}\text { Oregon } \\
\text { Ashland } \\
\text { City of } \\
\text { June } 30\end{array}$ \\
\hline Electric Utilty Operating Revenues ............ & 160,923 & 6,460 & 66,846 & 19,053 & 21,003 & 7,502 \\
\hline 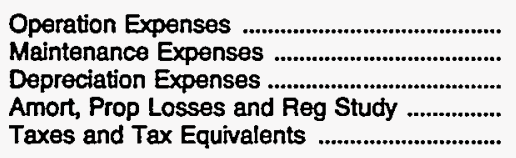 & $\begin{array}{r}65,707 \\
11,320 \\
25,928 \\
0 \\
0\end{array}$ & $\begin{array}{r}4,765 \\
530 \\
188 \\
0 \\
0\end{array}$ & $\begin{array}{r}49,429 \\
1,347 \\
4,834 \\
0 \\
1,265\end{array}$ & $\begin{array}{r}12,981 \\
1,931 \\
715 \\
0 \\
3,761\end{array}$ & $\begin{array}{r}13,065 \\
1,248 \\
964 \\
0 \\
3,073\end{array}$ & $\begin{array}{r}6,016 \\
270 \\
0 \\
84 \\
744\end{array}$ \\
\hline $\begin{array}{l}\text { Total Electric Utilty Operating } \\
\text { Expenses }\end{array}$ & 102,955 & 5,483 & 56,875 . & 19,388 & 18,349 & 7,114 \\
\hline 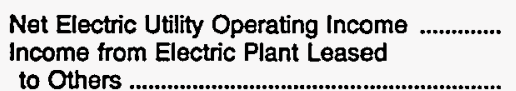 & 57,968 & 977 & 9,971 & -334 & 2,653 & 388 \\
\hline Electric Utillty Operating Income .............. & 57,968 & 977 & 9,971 & -334 & 2,653 & 388 \\
\hline Other Electric Income & 15,404 & 180 & 3,993 & 233 & 837 & 0 \\
\hline $\begin{array}{l}\text { Other Electric Deductions .......................... } \\
\text { Allowance for Other Funds Used } \\
\text { During Construction ................................. } \\
\text { Taxes on Other Income and Deductions ....... }\end{array}$ & $\begin{array}{l}0 \\
0\end{array}$ & 1,053 & $\begin{array}{l}0 \\
0\end{array}$ & $\begin{array}{l}0 \\
0\end{array}$ & $\begin{array}{l}0 \\
0\end{array}$ & $\begin{array}{l}0 \\
0\end{array}$ \\
\hline 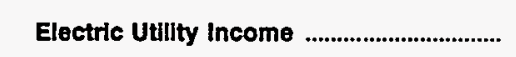 & 73,372 & 104 & 13,964 & -102 & 3,491 & 388 \\
\hline 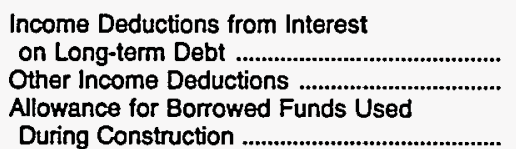 & $\begin{array}{l}64,242 \\
14,376\end{array}$ & $\begin{array}{l}0 \\
0\end{array}$ & $\begin{array}{r}21,505 \\
-462 \\
0\end{array}$ & $\begin{array}{l}0 \\
0\end{array}$ & $\begin{array}{l}1 \\
0\end{array}$ & $\begin{array}{l}0 \\
0\end{array}$ \\
\hline 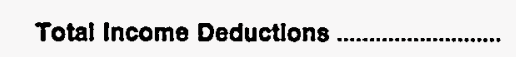 & 78,618 & 0 & 21,044 & 0 & 1 & o \\
\hline 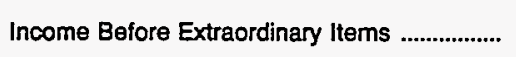 & $-5,245$ & 104 & $-7,079$ & -102 & 3,489 & 388 \\
\hline Extraordinary Income & $-1,800$ & 0 & 8,538 & 0 & 0 & 0 \\
\hline 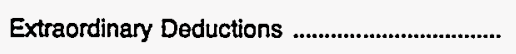 & 0 & 0 & 0 & 21 & 0 & 0 \\
\hline Net Income & $-7,046$ & 104 & 1,458 & -122 & 3,489 & 388 \\
\hline
\end{tabular}

Note: Totals may not equal sum of components because of independent rounding.

Source: Energy Information Administration, Form EIA-412, "Annual Report of Public Electric Utilities." 
Table 21. Statement of Income by Major U.S. Publicly Owned Electric Utility Within State, 1993 (Continued)

(Thousand Dollars)

\begin{tabular}{|c|c|c|c|c|c|c|}
\hline Item & $\begin{array}{l}\text { Oregon } \\
\text { Central } \\
\text { Lincoln } \\
\text { Peoples } \\
\text { UtI Dt } \\
\text { December } 31\end{array}$ & $\begin{array}{c}\text { Oregon } \\
\text { Clatskanie } \\
\text { Peoples } \\
\text { Util Dist } \\
\text { December } 31\end{array}$ & $\begin{array}{c}\text { Oregon } \\
\text { Columbia } \\
\text { River } \\
\text { Peoples } \\
\text { Ut Dist } \\
\text { December } 31\end{array}$ & $\begin{array}{l}\text { Oregon } \\
\text { Emerald } \\
\text { Peoples } \\
\text { Utility Dist } \\
\text { December } 31\end{array}$ & $\begin{array}{l}\text { Oregon } \\
\text { Eugene } \\
\text { City of } \\
\text { December } 31\end{array}$ & $\begin{array}{l}\text { Oregon } \\
\begin{array}{c}\text { Forest Grove } \\
\text { City of }\end{array} \\
\text { June } 30\end{array}$ \\
\hline Electric Utllity Operating Revenues ............ & 49,139 & 24,209 & 11,920 & 20,175 & 106,529 & 7,003 \\
\hline 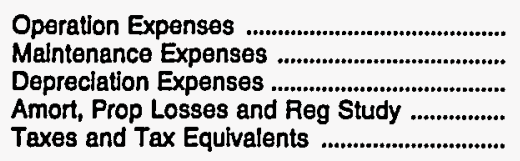 & $\begin{array}{r}38,815 \\
1,800 \\
3,241 \\
0 \\
1,862\end{array}$ & $\begin{array}{r}22,753 \\
316 \\
337 \\
0 \\
142\end{array}$ & $\begin{array}{r}8,966 \\
495 \\
456 \\
228 \\
196\end{array}$ & $\begin{array}{r}11,779 \\
763 \\
1,928 \\
619 \\
465\end{array}$ & $\begin{array}{r}81,292 \\
4,738 \\
7,752 \\
0 \\
7,409\end{array}$ & $\begin{array}{r}5,709 \\
278 \\
372 \\
0 \\
378\end{array}$ \\
\hline $\begin{array}{l}\text { Total Eloctric Utility Operating } \\
\text { Expenses }\end{array}$ & 45,719 & 23,549 & 10,341 & 15,554 & 101,192 & 6,737 \\
\hline 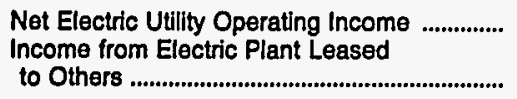 & $\begin{array}{r}3,421 \\
0\end{array}$ & 660 & 1,579 & 4,621 & 5,337 & 266 \\
\hline Electrlc Utllity Operating Income .............. & 3,421 & 660 & 1,579 & 4,678 & 5,337 & 266 \\
\hline 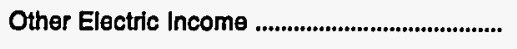 & 523 & 90 & 734 & 2,031 & 1,498 & 18 \\
\hline $\begin{array}{l}\text { Other Electric Deductions ............................... } \\
\text { Allowance for Other Funds Used } \\
\text { During Construction ...................................... } \\
\text { Taxes on Other Income and Deductions ....... }\end{array}$ & $\begin{array}{l}0 \\
0\end{array}$ & $\begin{array}{l}0 \\
0\end{array}$ & $\begin{array}{r}0 \\
74\end{array}$ & $\begin{array}{l}0 \\
0\end{array}$ & $\begin{array}{r}92 \\
0\end{array}$ & $\begin{array}{l}0 \\
0\end{array}$ \\
\hline 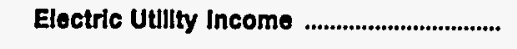 & 3,944 & 749 & 2,239 & 6,696 & 6,340 & 284 \\
\hline 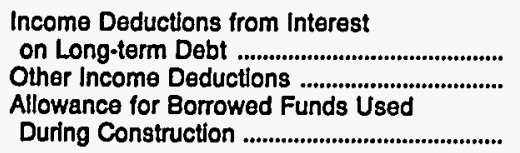 & $\begin{array}{r}1,052 \\
127\end{array}$ & $\begin{array}{l}0 \\
0\end{array}$ & $\begin{array}{r}1,229 \\
200\end{array}$ & $\begin{array}{r}4,102 \\
641\end{array}$ & $\begin{array}{r}2,139 \\
176 \\
-48\end{array}$ & $\begin{array}{r}0 \\
60\end{array}$ \\
\hline 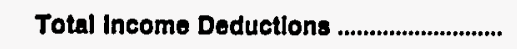 & 1,179 & $\mathbf{0}$ & 1,429 & 4,742 & 2,267 & 60 \\
\hline Income Before Extraordinary Items .................. & 2,764 & 749 & 810 & 1,954 & 4,073 & 224 \\
\hline Extraordinary Income & 0 & 0 & 0 & 0 & 0 & 0 \\
\hline 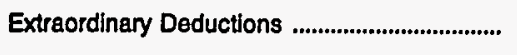 & 0 & 0 & 0 & 0 & 0 & 0 \\
\hline 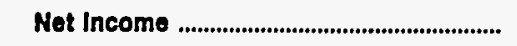 & 2,764 & 749 & 810 & 1,954 & 4,073 & 224 \\
\hline
\end{tabular}

Source: Energy Information Administration, Form EIA-412, "Annual Report of Public Electric Utilities." 
Table 21. Statement of Income by Major U.S. Publicly Owned Electric Utility Within State, 1993 (Continued)

(Thousand Dollars)

\begin{tabular}{|c|c|c|c|c|c|c|}
\hline Item & $\begin{array}{c}\text { Oregon } \\
\begin{array}{c}\text { McMinnville } \\
\text { City of }\end{array} \\
\text { June } 30\end{array}$ & $\begin{array}{l}\text { Oregon } \\
\text { Northern } \\
\text { Wasco County } \\
\text { P U D } \\
\text { December } 31\end{array}$ & $\begin{array}{c}\text { Oregon } \\
\text { Springfield } \\
\text { City of } \\
\text { December } 31\end{array}$ & $\begin{array}{c}\text { Oregon } \\
\text { Tillamook } \\
\text { Peoples } \\
\text { Utility Dist } \\
\text { December } 31\end{array}$ & $\begin{array}{c}\text { Pennsylvania } \\
\text { Chambersburg } \\
\text { Borough of } \\
\text { December } 31\end{array}$ & $\begin{array}{c}\text { Pennsylvania } \\
\text { Lansdale } \\
\text { Borough of } \\
\text { December } 31\end{array}$ \\
\hline Electric Utllity Operating Revenues ............ & 18,307 & 11,991 & 29,296 & 16,147 & 11,559 & 11,167 \\
\hline 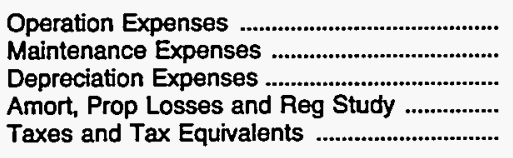 & $\begin{array}{r}16,568 \\
0 \\
664 \\
0 \\
910\end{array}$ & $\begin{array}{r}8,301 \\
477 \\
1,039 \\
0 \\
480\end{array}$ & $\begin{array}{r}24,105 \\
866 \\
1,003 \\
182 \\
1,291\end{array}$ & $\begin{array}{r}12,819 \\
1,082 \\
1,031 \\
41 \\
556\end{array}$ & $\begin{array}{r}10,203 \\
193 \\
800 \\
0 \\
0\end{array}$ & $\begin{array}{r}7,816 \\
0 \\
371 \\
0 \\
0\end{array}$ \\
\hline $\begin{array}{c}\text { Total Electric Utility Operating } \\
\text { Expenses }\end{array}$ & 18,142 & 10,296 & 27,447 & 15,530 & 11,196 & 8,187 \\
\hline 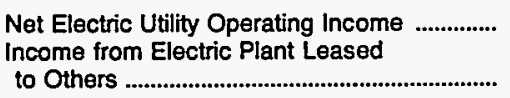 & 166 & 1,694 & 1,848 & $\begin{array}{r}618 \\
0\end{array}$ & 363 & $\begin{array}{r}2,981 \\
0\end{array}$ \\
\hline Electric Utillty Operating Income ............. & 166 & 1,694 & 1,848 & 618 & 363 & 2,981 \\
\hline 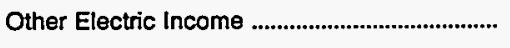 & 498 & 226 & 191 & 503 & 261 & 623 \\
\hline $\begin{array}{l}\text { Other Electric Deductions ................................... } \\
\text { Allowance for Other Funds Used }\end{array}$ & 0 & 0 & 0 & 0 & 550 & 0 \\
\hline $\begin{array}{l}\text { During Construction ....................................... } \\
\text { Taxes on Other Income and Deductions ....... }\end{array}$ & $\begin{array}{l}0 \\
0\end{array}$ & $\begin{array}{l}0 \\
0\end{array}$ & $\begin{array}{r}18 \\
0\end{array}$ & $\begin{array}{l}0 \\
0\end{array}$ & $\begin{array}{l}0 \\
0\end{array}$ & $\begin{array}{l}0 \\
0\end{array}$ \\
\hline 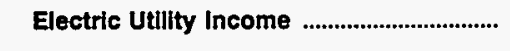 & 664 & 1,921 & 2,058 & 1,121 & 74 & 3,604 \\
\hline $\begin{array}{l}\text { Income Deductions from Interest } \\
\text { on Long-term Debt ....................................... } \\
\text { Other Income Deductions ........................... } \\
\text { Allowance for Borrowed Funds Used }\end{array}$ & $\begin{array}{r}0 \\
14\end{array}$ & $\begin{array}{r}1,828 \\
0\end{array}$ & $\begin{array}{l}26 \\
45\end{array}$ & $\begin{array}{r}618 \\
80\end{array}$ & $\begin{array}{l}0 \\
0\end{array}$ & $\begin{array}{r}492 \\
28\end{array}$ \\
\hline 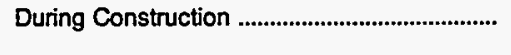 & 0 & 0 & 0 & -31 & 0 & 0 \\
\hline Total Income Deductions ............................ & 14 & 1,828 & 71 & 667 & $\mathbf{0}$ & 520 \\
\hline Income Before Extraordinary Items ................. & 650 & 93 & 1,987 & 454 & 74 & 3,084 \\
\hline Extraordinary Income & 0 & 0 & 0 & 0 & 0 & 0 \\
\hline 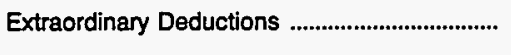 & 0 & 0 & 0 & 0 & 0 & 0 \\
\hline Net Income & 650 & 93 & 1,987 & 454 & 74 & 3,084 \\
\hline
\end{tabular}

Note: Totals may not equal sum of components because of independent rounding.

Source: Energy Information Administration, Form EIA-412, "Annual Report of Public Electric Utilities." 
Table 21. Statement of Income by Major U.S. Publicly Owned Electric Utility Within State, 1993 (Continued)

(Thousand Dollars)

\begin{tabular}{|c|c|c|c|c|c|c|}
\hline Item & $\begin{array}{l}\text { South Carolina } \\
\text { Camden } \\
\text { City of } \\
\text { June } 30\end{array}$ & $\begin{array}{c}\text { South Carolina } \\
\text { Easley } \\
\text { Combined } \\
\text { Utility } \\
\text { System } \\
\text { March } 31\end{array}$ & $\begin{array}{l}\text { South Carolina } \\
\text { Gaffney } \\
\text { City of } \\
\text { March } 31\end{array}$ & $\begin{array}{l}\text { South Carolina } \\
\text { Greenwood } \\
\text { Commissioners } \\
\text { Pub Wk } \\
\text { December } 31\end{array}$ & $\begin{array}{c}\text { South Garolina } \\
\text { Greer } \\
\text { Comm } \\
\text { of } \\
\text { Public Works } \\
\text { December } 31\end{array}$ & $\begin{array}{l}\text { South Carolina } \\
\text { Newberry } \\
\text { City of } \\
\text { June } 30\end{array}$ \\
\hline Electrlc UtIllty OperatIng Revenues ............ & 11,569 & 13,577 & 12,587 & 14,053 & 10,623 & 9,120 \\
\hline 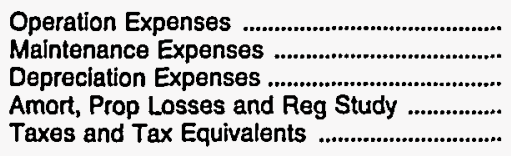 & $\begin{array}{r}10,355 \\
0 \\
389 \\
0 \\
0\end{array}$ & $\begin{array}{r}11,061 \\
621 \\
511 \\
0 \\
0\end{array}$ & $\begin{array}{r}11,075 \\
61 \\
391 \\
0 \\
0\end{array}$ & $\begin{array}{r}12,263 \\
0 \\
496 \\
0 \\
0\end{array}$ & $\begin{array}{r}8,903 \\
0 \\
571 \\
0 \\
0\end{array}$ & $\begin{array}{r}8,043 \\
0 \\
261 \\
0 \\
0\end{array}$ \\
\hline $\begin{array}{c}\text { Total Electric UtIlity Operating } \\
\text { Expenses }\end{array}$ & 10,744 & 12,193 & 11,527 & 12,758 & 9,474 & 8,304 \\
\hline $\begin{array}{l}\text { Net Electric Utility Operating Income } \\
\text { Income from Electric Plant Leased }\end{array}$ & 826 & 1,385 & 1,060 & 1,294 & 1,149 & 816 \\
\hline 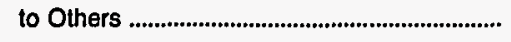 & 0 & 0 & 0 & 0 & 0 & 0 \\
\hline Electrlc UtIllty OperatIng Income ............. & 826 & 1,385 & 1,060 & 1,294 & 1,149 & 816 \\
\hline 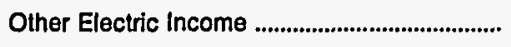 & 1,245 & 212 & 174 & 119 & 234 & 173 \\
\hline $\begin{array}{l}\text { Other Electric Deductions ................................ } \\
\text { Allowance for Other Funds Used }\end{array}$ & 0 & 151 & 5 & 0 & 0 & 77 \\
\hline $\begin{array}{l}\text { During Construction ....................................... } \\
\text { Taxes on Other Income and Deductions ....... }\end{array}$ & $\begin{array}{l}0 \\
0\end{array}$ & $\begin{array}{l}0 \\
0\end{array}$ & $\begin{array}{l}0 \\
0\end{array}$ & $\begin{array}{l}0 \\
0\end{array}$ & $\begin{array}{l}0 \\
0\end{array}$ & $\begin{array}{l}0 \\
0\end{array}$ \\
\hline 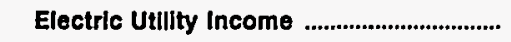 & 2,071 & 1,446 & 1,228 & 1,413 & 1,383 & 913 \\
\hline $\begin{array}{l}\text { Income Deductions from Interest } \\
\text { on Long-term Debt ............................................ } \\
\text { Other Income Deductions ................................. } \\
\text { Allowance for Borrowed Funds Used }\end{array}$ & $\begin{array}{r}270 \\
0\end{array}$ & $\begin{array}{l}165 \\
909\end{array}$ & $\begin{array}{l}0 \\
0\end{array}$ & $\begin{array}{l}0 \\
0\end{array}$ & $\begin{array}{r}4 \\
1,004\end{array}$ & $\begin{array}{r}145 \\
0\end{array}$ \\
\hline 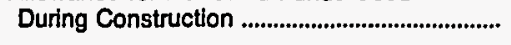 & 0 & 0 & 0 & 0 & 0 & 0 \\
\hline Total Income Deductions ............................ & 270 & 1,073 & 0 & $\mathbf{0}$ & 1,009 & 145 \\
\hline Income Before Extraordinary Items .................. & 1,801 & 372 & 1,228 & 1,413 & 374 & 768 \\
\hline 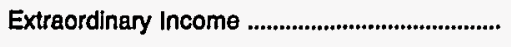 & 723 & 0 & 0 & 0 & 0 & 0 \\
\hline Extraordinary Deductions .................................... & 2,820 & 0 & 0 & 0 & 0 & 0 \\
\hline Net Income & -297 & 372 & 1,228 & 1,413 & 374 & 768 \\
\hline
\end{tabular}

Note: Totals may not equal sum of components because of independent rounding.

Source: Energy Information Administration, Form EIA-412, "Annual Report of Public Electric Utilities." 
Table 21. Statement of Income by Major U.S. Publicly Owned Electric Utility Within State, 1993 (Continued)

(Thousand Dollars)

\begin{tabular}{|c|c|c|c|c|c|c|}
\hline Item & $\begin{array}{l}\text { South Carolina } \\
\text { Orangeburg } \\
\text { City of } \\
\text { September } 30\end{array}$ & $\begin{array}{c}\text { South Carolina } \\
\text { Piedmont } \\
\text { Municipal } \\
\text { Power Agny } \\
\text { December } 31\end{array}$ & $\begin{array}{l}\text { South Carolina } \\
\text { Rock Hill } \\
\text { City of } \\
\text { December } 31\end{array}$ & $\begin{array}{l}\text { South Carolina } \\
\text { Seneca } \\
\text { City of } \\
\text { June } 30\end{array}$ & $\begin{array}{l}\text { South Carolina } \\
\text { South } \\
\text { Carolina } \\
\text { Pub } \\
\text { Serv Auth } \\
\text { December } 31\end{array}$ & $\begin{array}{c}\text { South Dakota } \\
\begin{array}{c}\text { Brookings } \\
\text { City of }\end{array} \\
\text { December } 31\end{array}$ \\
\hline Electric Utility Operating Revenues ............. & 36,007 & 155,630 & 40,204 & 11,956 & 589,483 & 7,891 \\
\hline $\begin{array}{l}\text { Operation Expenses } \\
\text { Maintenance Expenses } \\
\text { Depreciation Expenses } \\
\text { Amort, Prop Losses and Reg Study } \\
\text { Taxes and Tax Equivalents }\end{array}$ & $\begin{array}{r}28,731 \\
0 \\
1,156 \\
0 \\
0\end{array}$ & $\begin{array}{r}73,945 \\
18,343 \\
19,836 \\
0 \\
4,378\end{array}$ & $\begin{array}{r}26,023 \\
2,033 \\
1,002 \\
0 \\
0\end{array}$ & $\begin{array}{r}7,979 \\
1,075 \\
700 \\
0 \\
0\end{array}$ & $\begin{array}{r}313,865 \\
49,247 \\
78,329 \\
0 \\
3,643\end{array}$ & $\begin{array}{r}5,074 \\
649 \\
551 \\
4 \\
478\end{array}$ \\
\hline $\begin{array}{l}\text { Total Electric Utillty Operating } \\
\text { Expenses }\end{array}$ & 29,886 & 116,502 & 29,058 & 9,754 & 445,084 & 6,756 \\
\hline 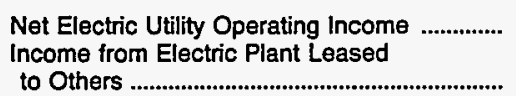 & 6,120 & 39,128 & 11,146 & 2,202 & 144,399 & 1,135 \\
\hline Electric Utillty Operating Income ............. & 6,120 & 39,128 & 11,146 & 2,202 & 144,399 & 1,135 \\
\hline Other Electric Income & 337 & 38,414 & 353 & 0 & 19,343 & 72 \\
\hline $\begin{array}{l}\text { Other Electric Deductions ............................. } \\
\text { Allowance for Other Funds Used }\end{array}$ & 0 & 1,983 & 35 & 1,366 & 0 & 0 \\
\hline $\begin{array}{l}\text { During Construction .................................. } \\
\text { Taxes on Other Income and Deductions ....... }\end{array}$ & $\begin{array}{l}0 \\
0\end{array}$ & $\begin{array}{l}0 \\
0\end{array}$ & $\begin{array}{l}0 \\
0\end{array}$ & $\begin{array}{l}0 \\
0\end{array}$ & $\begin{array}{l}0 \\
0\end{array}$ & $\begin{array}{l}0 \\
0\end{array}$ \\
\hline Electric Utility Income & 6,458 & 75,559 & 11,464 & 836 & 163,742 & 1,207 \\
\hline 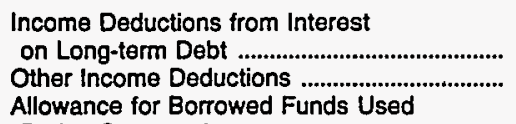 & $\begin{array}{r}272 \\
0\end{array}$ & $\begin{array}{r}87,064 \\
-11,786\end{array}$ & $\begin{array}{r}525 \\
8,502\end{array}$ & $\begin{array}{l}0 \\
0\end{array}$ & $\begin{array}{r}122,557 \\
3,602\end{array}$ & $\begin{array}{l}0 \\
0\end{array}$ \\
\hline 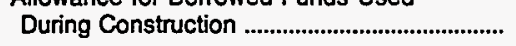 & 0 & 0 & 0 & 0 & 0 & 0 \\
\hline 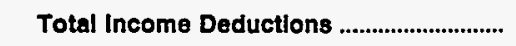 & 272 & 75,278 & 9,027 & 0 & 126,159 & o \\
\hline Income Before Extraordinary Items .................. & 6,185 & 281 & 2,437 & 836 & 37,583 & 1,207 \\
\hline Extraordinary Income & 0 & 0 & 0 & 0 & 0 & 0 \\
\hline 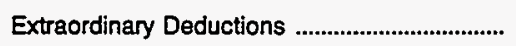 & 0 & 0 & 0 & 0 & 0 & 0 \\
\hline 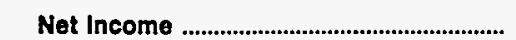 & 6,185 & 281 & 2,437 & 836 & 37,583 & 1,207 \\
\hline
\end{tabular}

Note: Totals may not equal sum of components because of independent rounding.

Source: Energy Information Administration, Form ElA-412, "Annual Report of Public Electric Utilities." 
Table 21. Statement of Income by Major U.S. Publicly Owned Electric Utility Within State, 1993 (Continued)

(Thousand Dollars)

\begin{tabular}{|c|c|c|c|c|c|c|}
\hline Item & $\begin{array}{l}\text { South Dakota } \\
\text { Heartland } \\
\text { Consumers } \\
\text { Power Dist } \\
\text { December } 31\end{array}$ & $\begin{array}{l}\text { South Dakota } \\
\text { Missouri } \\
\text { Basin } \\
\text { Mun } \\
\text { Power Agny } \\
\text { December } 31\end{array}$ & $\begin{array}{l}\text { South Dakota } \\
\text { Pierre } \\
\text { City of } \\
\text { December } 31\end{array}$ & $\begin{array}{l}\text { South Dakota } \\
\text { Watertown } \\
\text { Municipal } \\
\text { Utilities } \\
\text { December } 31\end{array}$ & $\begin{array}{c}\text { Tennessee } \\
\text { Alcoa } \\
\text { Utilities } \\
\text { June } 30\end{array}$ & $\begin{array}{l}\text { Tennessee } \\
\text { Athens } \\
\text { Utility } \\
\text { Board } \\
\text { June } 30\end{array}$ \\
\hline Electric Utllity Operating Revenues ............. & 12,002 & 51,834 & 6,405 & 7,987 & 23,384 & 25,545 \\
\hline $\begin{array}{l}\text { Operation Expenses } \\
\text { Malntenance Expenses } \\
\text { Depreciation Expenses } \\
\text { Amort, Prop Losses and Reg Study } \\
\text { Taxes and Tax Equivalents }\end{array}$ & $\begin{array}{r}8,859 \\
0 \\
1,016 \\
125 \\
259\end{array}$ & $\begin{array}{r}57,471 \\
0 \\
77 \\
0 \\
25\end{array}$ & $\begin{array}{r}4,073 \\
140 \\
277 \\
0 \\
0\end{array}$ & $\begin{array}{r}5,754 \\
646 \\
776 \\
0 \\
0\end{array}$ & $\begin{array}{r}20,989 \\
814 \\
639 \\
0 \\
486\end{array}$ & $\begin{array}{r}23,355 \\
590 \\
530 \\
2 \\
442\end{array}$ \\
\hline $\begin{array}{l}\text { Total Electrlc Utllity Operating } \\
\text { Expenses }\end{array}$ & 10,259 & 57,573 & 4,490 & 7,175 & 22,927 & 24,919 \\
\hline 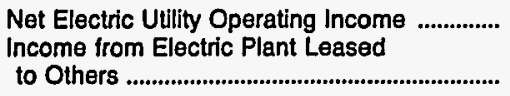 & 1,742 & $-5,739$ & 1,915 & 812 & 456 & 626 \\
\hline Electrlc Utllity Operating Income .............. & 1,742 & $-5,739$ & 1,915 & 812 & 456 & 626 \\
\hline 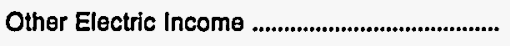 & 2,100 & 1,405 & 333 & 208 & 508 & 281 \\
\hline $\begin{array}{l}\text { Other Electric Deductions ................................ } \\
\text { Allowance for Other Funds Used } \\
\text { During Construction ........................................... } \\
\text { Taxes on Other Income and Deductions ....... }\end{array}$ & $\begin{array}{l}0 \\
0\end{array}$ & $\begin{array}{l}0 \\
0\end{array}$ & 1,938 & $\begin{array}{l}0 \\
0\end{array}$ & $\begin{array}{l}0 \\
0\end{array}$ & 28 \\
\hline 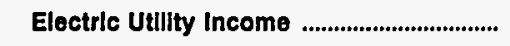 & 3,842 & $-4,334$ & 310 & 964 & 965 & 879 \\
\hline 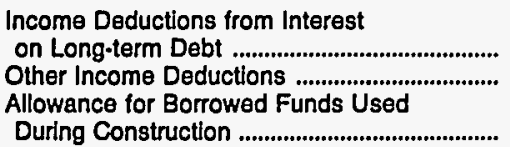 & $\begin{array}{r}4,019 \\
-188\end{array}$ & $\begin{array}{l}0 \\
0\end{array}$ & $\begin{array}{l}0 \\
0\end{array}$ & $\begin{array}{r}0 \\
1,090\end{array}$ & $\begin{array}{r}173 \\
6\end{array}$ & $\begin{array}{l}0 \\
0\end{array}$ \\
\hline Total Income Deductions ............................... & 3,831 & 0 & $\mathbf{0}$ & 1,090 & 179 & 0 \\
\hline Income Before Extraordinary ltems .................. & 11 & $-4,334$ & 310 & -126 & 786 & 879 \\
\hline 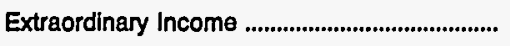 & 0 & 0 & 0 & 0 & 0 & 0 \\
\hline 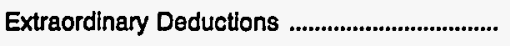 & 0 & 0 & 0 & 0 & 13 & 0 \\
\hline 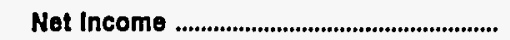 & 11 & $-4,334$ & 310 & -126 & 773 & 879 \\
\hline
\end{tabular}

Note: Totals may not equal sum of components because of independent rounding.

Source: Energy Information Administration, Form EIA-412, "Annual Report of Public Electric Utilities." 
Table 21. Statement of Income by Major U.S. Publicly Owned Electric Utility Within State, 1993 (Continued)

(Thousand Dollars)

\begin{tabular}{|c|c|c|c|c|c|c|}
\hline Item & $\begin{array}{l}\text { Tennessee } \\
\text { Benton } \\
\text { County } \\
\text { June } 30\end{array}$ & $\begin{array}{l}\text { Tennessee } \\
\text { Bolivar } \\
\text { City of } \\
\text { June } 30\end{array}$ & $\begin{array}{l}\text { Tennessee } \\
\text { Bristol } \\
\text { City of } \\
\text { June } 30\end{array}$ & $\begin{array}{c}\text { Tennessee } \\
\text { Brownsville } \\
\text { City of } \\
\text { June } 30\end{array}$ & $\begin{array}{l}\text { Tennessee } \\
\text { Carroll } \\
\text { County } \\
\text { June } 30\end{array}$ & $\begin{array}{l}\text { Tennessee } \\
\begin{array}{c}\text { Chattanooga } \\
\text { City of }\end{array} \\
\text { June } 30\end{array}$ \\
\hline Electric Utility Operating Revenues ............. & 3,346 & 12,731 & 40,360 & 9,322 & 19,866 & 280,610 \\
\hline 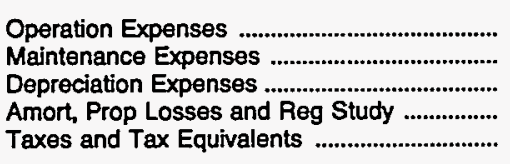 & $\begin{array}{r}2,914 \\
172 \\
86 \\
0 \\
112\end{array}$ & $\begin{array}{r}11,288 \\
354 \\
431 \\
0 \\
266\end{array}$ & $\begin{array}{r}35,412 \\
1,613 \\
1,269 \\
0 \\
972\end{array}$ & $\begin{array}{r}8,818 \\
70 \\
186 \\
37 \\
160\end{array}$ & $\begin{array}{r}17,735 \\
749 \\
488 \\
0 \\
380\end{array}$ & $\begin{array}{r}249,864 \\
8,913 \\
7,477 \\
0 \\
6,834\end{array}$ \\
\hline $\begin{array}{l}\text { Total Electric Utillty Operating } \\
\text { Expenses }\end{array}$ & 3,284 & 12,339 & 39,265 & 9,271 & 19,352 & 273,088 \\
\hline $\begin{array}{l}\text { Net Electric Utility Operating Income .............. } \\
\text { Income from Electric Plant Leased }\end{array}$ & 63 & 393 & 1,095 & 51 & 514 & 7,522 \\
\hline Electric Utillty Operating Income .............. & 63 & 393 & 1,095 & 51 & 514 & 7,522 \\
\hline Other Electric Income & 62 & 136 & 1,610 & 139 & 270 & 2,882 \\
\hline $\begin{array}{l}\text { Other Electric Deductions } \\
\text { Allowance for Other Funds Used }\end{array}$ & 2 & 0 & 0 & 0 & 0 & 3 \\
\hline 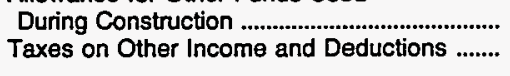 & $\begin{array}{l}0 \\
0\end{array}$ & $\begin{array}{l}0 \\
0\end{array}$ & $\begin{array}{l}0 \\
0\end{array}$ & $\begin{array}{l}0 \\
0\end{array}$ & $\begin{array}{l}0 \\
0\end{array}$ & $\begin{array}{l}0 \\
0\end{array}$ \\
\hline Electric Utillity Income & 123 & 529 & 2,705 & 190 & 784 & 10,402 \\
\hline 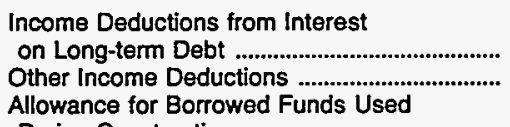 & $\begin{array}{l}0 \\
4\end{array}$ & $\begin{array}{r}93 \\
3\end{array}$ & $\begin{array}{r}0 \\
22\end{array}$ & $\begin{array}{r}44 \\
1\end{array}$ & $\begin{array}{r}77 \\
3\end{array}$ & $\begin{array}{r}18 \\
236\end{array}$ \\
\hline During Construction & 0 & 0 & 0 & 0 & 0 & 0 \\
\hline 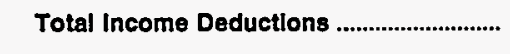 & 4 & 96 & 22 & 44 & 80 & 254 \\
\hline Income Before Extraordinary Items ...................... & 119 & 433 & 2,683 & 146 & 704 & 10,148 \\
\hline Extraordinary Income & 0 & 0 & 0 & 0 & 0 & 0 \\
\hline 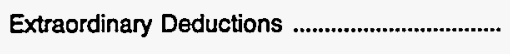 & 0 & 0 & 0 & 0 & 0 & 0 \\
\hline 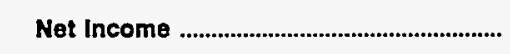 & 119 & 433 & 2,683 & 146 & 704 & 10,148 \\
\hline
\end{tabular}

Note: Totals may not equal sum of components because of independent rounding.

Source: Energy Information Administration, Form EIA-412, "Annual Report of Public Electric Utilities." 
Table 21. Statement of Income by Major U.S. Publicly Owned Electric Utility Within State, 1993 (Continued)

(Thousand Dollars)

\begin{tabular}{|c|c|c|c|c|c|c|}
\hline Item & $\begin{array}{c}\text { Tennessee } \\
\text { Clarksville } \\
\text { City of } \\
\text { June } 30\end{array}$ & $\begin{array}{l}\text { Tennessee } \\
\text { Cleveland } \\
\text { City of } \\
\text { June } 30\end{array}$ & $\begin{array}{l}\text { Tennessee } \\
\text { Clinton } \\
\text { City of } \\
\text { June } 30\end{array}$ & $\begin{array}{l}\text { Tennessee } \\
\text { Columbia } \\
\text { City of } \\
\text { June } 30\end{array}$ & $\begin{array}{l}\text { Tennessee } \\
\text { Cookeville } \\
\text { City of } \\
\text { June } 30\end{array}$ & $\begin{array}{l}\text { Tennessee } \\
\text { Covington } \\
\text { City of } \\
\text { June } 30\end{array}$ \\
\hline Electric Utillty Operating Revenues ............. & 44,318 & 44,329 & 32,442 & 25,898 & 23,562 & 10,290 \\
\hline 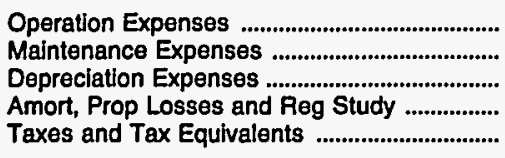 & $\begin{array}{r}39,019 \\
1,071 \\
920 \\
1,603 \\
787\end{array}$ & $\begin{array}{r}39,482 \\
1,417 \\
1,303 \\
136 \\
946\end{array}$ & $\begin{array}{r}28,895 \\
1,059 \\
1,067 \\
0 \\
858\end{array}$ & $\begin{array}{r}23,643 \\
765 \\
874 \\
0 \\
483\end{array}$ & $\begin{array}{r}21,466 \\
526 \\
496 \\
114 \\
383\end{array}$ & $\begin{array}{r}9,355 \\
207 \\
210 \\
191 \\
178\end{array}$ \\
\hline $\begin{array}{l}\text { Total Electric Utllity Operating } \\
\text { Expenses }\end{array}$ & 43,401 & 43,284 & 31,879 & 25,765 & 22,985 & 10,141 \\
\hline 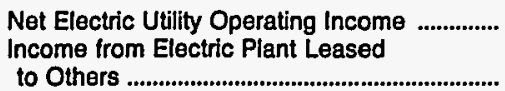 & $\begin{array}{r}917 \\
0\end{array}$ & $\begin{array}{r}1,045 \\
0\end{array}$ & $\begin{array}{r}563 \\
0\end{array}$ & $\begin{array}{r}133 \\
0\end{array}$ & $\begin{array}{r}578 \\
0\end{array}$ & 150 \\
\hline Electric Utillty Operating Income .............. & 917 & 1,045 & 563 & 133 & 578 & 150 \\
\hline Other Electric Income & 1,057 & 487 & 473 & 346 & 274 & 313 \\
\hline $\begin{array}{l}\text { Other Electric Deductions ............................... } \\
\text { Allowance for Other Funds Used } \\
\text { During Construction ....................................... } \\
\text { Taxes on Other Income and Deductions ....... }\end{array}$ & $\begin{array}{l}0 \\
0\end{array}$ & $\begin{array}{l}0 \\
0\end{array}$ & $\begin{array}{l}0 \\
0\end{array}$ & $\begin{array}{l}0 \\
0\end{array}$ & $\begin{array}{l}0 \\
0\end{array}$ & $\begin{array}{l}0 \\
0\end{array}$ \\
\hline 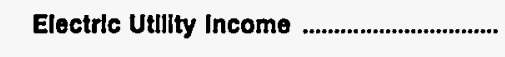 & 1,971 & 1,531 & 1,031 & 478 & 852 & 459 \\
\hline 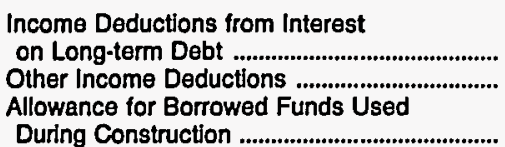 & $\begin{array}{r}473 \\
55\end{array}$ & $\begin{array}{r}0 \\
47\end{array}$ & $\begin{array}{l}0 \\
0\end{array}$ & $\begin{array}{r}0 \\
20\end{array}$ & $\begin{array}{l}75 \\
14\end{array}$ & $\begin{array}{r}43 \\
2\end{array}$ \\
\hline 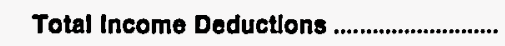 & 528 & 47 & $\mathbf{0}$ & 20 & 89 & 45 \\
\hline Income Before Extraordinary Items ..................... & 1,442 & 1,484 & 1,031 & 459 & 763 & 413 \\
\hline Extraordinary Income & 0 & 0 & 0 & 0 & 0 & 0 \\
\hline 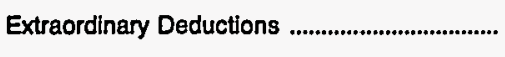 & 0 & 0 & 0 & 0 & 0 & 0 \\
\hline 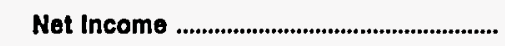 & 1,442 & 1,484 & 1,031 & 459 & 763 & 413 \\
\hline
\end{tabular}

Note: Totals may not equal sum of components because of independent rounding.

Source: Energy Information Administration, Form EIA-412, "Annual Report of Public Electric Utilities." 
Table 21. Statement of Income by Major U.S. Publicly Owned Electric Utility Within State, 1993 (Continued) (Thousand Dollars)

\begin{tabular}{|c|c|c|c|c|c|c|}
\hline Item & $\begin{array}{l}\text { Tennessee } \\
\text { Dayton } \\
\text { City of } \\
\text { June } 30\end{array}$ & $\begin{array}{l}\text { Tennessee } \\
\text { Dickson } \\
\text { City of } \\
\text { June } 30\end{array}$ & $\begin{array}{l}\text { Tennessee } \\
\text { Dyersburg } \\
\text { City of } \\
\text { June } 30\end{array}$ & $\begin{array}{c}\text { Tennessee } \\
\begin{array}{c}\text { Elizabethton } \\
\text { City of }\end{array} \\
\text { June } 30\end{array}$ & $\begin{array}{l}\text { Tennessee } \\
\text { Erwin } \\
\text { Town of } \\
\text { June } 30\end{array}$ & $\begin{array}{l}\text { Tennessee } \\
\text { Etowah } \\
\text { City of } \\
\text { June } 30\end{array}$ \\
\hline Electric Utillty Operating Revenues ............ & 10,462 & 31,201 & 27,389 & 27,074 & 10,417 & 7,241 \\
\hline 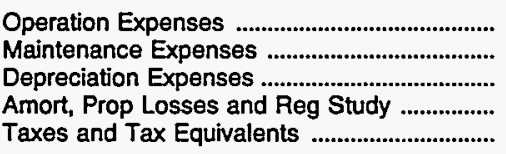 & $\begin{array}{r}9,385 \\
218 \\
234 \\
0 \\
195\end{array}$ & $\begin{array}{r}27,103 \\
850 \\
892 \\
0 \\
507\end{array}$ & $\begin{array}{r}24,092 \\
702 \\
858 \\
-10 \\
609\end{array}$ & $\begin{array}{r}23,953 \\
869 \\
650 \\
0 \\
706\end{array}$ & $\begin{array}{r}9,501 \\
241 \\
225 \\
0 \\
193\end{array}$ & $\begin{array}{r}6,595 \\
248 \\
162 \\
0 \\
128\end{array}$ \\
\hline $\begin{array}{l}\text { Total Electric Utillty OperatIng } \\
\text { Expenses }\end{array}$ & 10,032 & 29,352 & 26,251 & 26,177 & 10,160 & 7,132 \\
\hline $\begin{array}{l}\text { Net Electric Utility Operating Income } \\
\text { Income from Electric Plant Leased } \\
\text { to Others }\end{array}$ & 431 & 1,849 & 1,138 & 896 & 257 & 109 \\
\hline Electric Utility Operating Income ............. & 431 & 1,849 & 1,138 & 896 & 257 & 109 \\
\hline 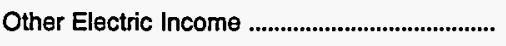 & 105 & 577 & 600 & 278 & 225 & 92 \\
\hline $\begin{array}{l}\text { Other Electric Deductions .................................... } \\
\text { Allowance for Other Funds Used }\end{array}$ & 0 & 0 & 6 & 0 & 0 & 3 \\
\hline $\begin{array}{l}\text { During Construction ....................................... } \\
\text { Taxes on Other Income and Deductions ....... }\end{array}$ & $\begin{array}{l}0 \\
0\end{array}$ & $\begin{array}{l}0 \\
0\end{array}$ & $\begin{array}{l}0 \\
0\end{array}$ & $\begin{array}{l}0 \\
0\end{array}$ & $\begin{array}{l}0 \\
0\end{array}$ & $\begin{array}{l}0 \\
0\end{array}$ \\
\hline Electric Utility Income ............................. & 535 & 2,426 & 1,732 & 1,174 & 483 & 198 \\
\hline $\begin{array}{l}\text { Income Deductions from Interest } \\
\text { on Long-term Debt .......................................... } \\
\text { Other Income Deductions ............................... } \\
\text { Allowance for Borrowed Funds Used }\end{array}$ & $\begin{array}{l}0 \\
0\end{array}$ & $\begin{array}{r}780 \\
38\end{array}$ & $\begin{array}{r}631 \\
23\end{array}$ & $\begin{array}{r}0 \\
48\end{array}$ & $\begin{array}{l}0 \\
9\end{array}$ & $\begin{array}{l}8 \\
0\end{array}$ \\
\hline During Construction .......................................... & 0 & 0 & 0 & 0 & 0 & 0 \\
\hline Total Income Deductions ........................... & 0 & 819 & 655 & 48 & 9 & 8 \\
\hline Income Before Extraordinary Items ................. & 535 & 1,607 & 1,077 & 1,126 & 473 & 190 \\
\hline Extraordinary Income ........................................ & 0 & 0 & 0 & 0 & 0 & 0 \\
\hline Extraordinary Deductions ................................... & 0 & 330 & 0 & 0 & 0 & 0 \\
\hline 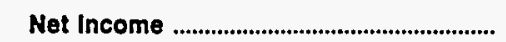 & $\mathbf{5 3 5}$ & 1,277 & 1,077 & 1,126 & 473 & 180 \\
\hline
\end{tabular}

Note: Totals may not equal sum of components because of independent rounding.

Source: Energy Information Administration, Form EIA-412, "Annual Report of Public Electric Utilities." 
Table 21. Statement of Income by Major U.S. Publicly Owned Electric Utility Within State, 1993 (Continued)

(Thousand Dollars)

\begin{tabular}{|c|c|c|c|c|c|c|}
\hline Item & $\begin{array}{c}\text { Tennessee } \\
\text { Fayetteville } \\
\text { City of } \\
\text { June } 30\end{array}$ & $\begin{array}{l}\text { Tennessee } \\
\text { Gallatin } \\
\text { City of } \\
\text { June } 30\end{array}$ & $\begin{array}{l}\text { Tennessee } \\
\text { Greeneville } \\
\text { City of } \\
\text { June } 30\end{array}$ & $\begin{array}{l}\text { Tennessee } \\
\text { Harriman } \\
\text { City of } \\
\text { June } 30\end{array}$ & $\begin{array}{l}\text { Tennessee } \\
\text { Humboldt } \\
\text { City of } \\
\text { June } 30\end{array}$ & $\begin{array}{l}\text { Tennessee } \\
\text { Jackson } \\
\text { City of } \\
\text { June } 30\end{array}$ \\
\hline Electric Utillty Operating Revenues ............. & 20,594 & 20,833 & 41,135 & 13,538 & 10,272 & 57,825 \\
\hline 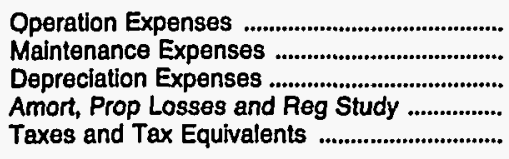 & $\begin{array}{r}17,718 \\
541 \\
766 \\
0 \\
550\end{array}$ & $\begin{array}{r}19,594 \\
334 \\
395 \\
41 \\
295\end{array}$ & $\begin{array}{r}40,177 \\
1,287 \\
1,268 \\
0 \\
845\end{array}$ & $\begin{array}{r}11,416 \\
657 \\
596 \\
0 \\
255\end{array}$ & $\begin{array}{r}10,130 \\
160 \\
207 \\
58 \\
141\end{array}$ & $\begin{array}{r}51,747 \\
1,111 \\
1,939 \\
65 \\
1,301\end{array}$ \\
\hline $\begin{array}{l}\text { Total Electrlc Utllity Operating } \\
\text { Expenses }\end{array}$ & 19,575 & 20,659 & 43,578 & 12,923 & 10,697 & 56,164 \\
\hline 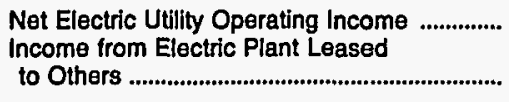 & 1,019 & 174 & $-2,443$ & 615 & -425 & 1,661 \\
\hline Electric Utility Operating Income ............... & 1,019 & 174 & $-2,443$ & 615 & -425 & 1,661 \\
\hline 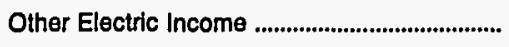 & 458 & 338 & 1,280 & 314 & 259 & 768 \\
\hline $\begin{array}{l}\text { Other Electric Deductions ................................ } \\
\text { Allowance for Other Funds Used } \\
\text { During Construction .......................................... } \\
\text { Taxes on Other Income and Deductions ....... }\end{array}$ & $\begin{array}{l}0 \\
0\end{array}$ & $\begin{array}{l}0 \\
0\end{array}$ & $\begin{array}{l}0 \\
0\end{array}$ & $\begin{array}{l}0 \\
0\end{array}$ & $\begin{array}{l}0 \\
0\end{array}$ & $\begin{array}{l}0 \\
0\end{array}$ \\
\hline Electric Utisity Income & $1, \mathbf{4 3 7}$ & 504 & $-1,181$ & 931 & -169 & 2,429 \\
\hline 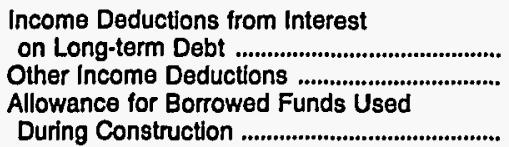 & $\begin{array}{r}396 \\
12\end{array}$ & $\begin{array}{l}0 \\
4\end{array}$ & $\begin{array}{l}0 \\
0\end{array}$ & $\begin{array}{r}48 \\
1\end{array}$ & $\begin{array}{l}0 \\
0\end{array}$ & $\begin{array}{r}675 \\
22\end{array}$ \\
\hline 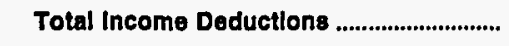 & 408 & 4 & 0 & 49 & 0 & 697 \\
\hline Income Before Extraordinary Items ..................... & 1,029 & 501 & $-1,181$ & 882 & -169 & 1,732 \\
\hline 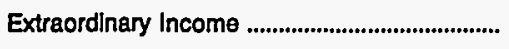 & 0 & 0 & 0 & 0 & 0 & 0 \\
\hline 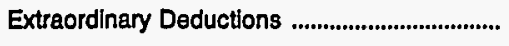 & 80 & 0 & 0 & 0 & 0 & 0 \\
\hline Net Income ............................................................ & 949 & 501 & $-1,181$ & 882 & -169 & 1,732 \\
\hline
\end{tabular}

Note: Totals may not equal sum of components because of independent rounding.

Source: Energy Intormation Administration, Form ElA-412, "Annual Report of Public Electric Utilities." 
Table 21. Statement of Income by Major U.S. Publicly Owned Electric Utility Within State, 1993 (Continued)

(Thousand Dollars)

\begin{tabular}{|c|c|c|c|c|c|c|}
\hline Item & $\begin{array}{l}\text { Tennessee } \\
\text { Johnson } \\
\text { City City of } \\
\text { June } 30\end{array}$ & $\begin{array}{c}\text { Tennessee } \\
\text { Knoxville } \\
\text { Utilities } \\
\text { Board } \\
\text { June } 30\end{array}$ & $\begin{array}{c}\text { Tennessee } \\
\begin{array}{c}\text { Lawrenceburg } \\
\text { City of }\end{array} \\
\text { June } 30\end{array}$ & $\begin{array}{l}\text { Tennessee } \\
\text { LaFollette } \\
\text { City of } \\
\text { June } 30\end{array}$ & $\begin{array}{l}\text { Tennessee } \\
\text { Lebanon } \\
\text { City of } \\
\text { June } 30\end{array}$ & $\begin{array}{l}\text { Tennessee } \\
\text { Lenoir } \\
\text { City City of } \\
\text { June } 30\end{array}$ \\
\hline Electric Utlilty Operating Revenues ............ & 78,438 & 251,851 & 23,644 & 18,768 & 16,979 & 56,280 \\
\hline 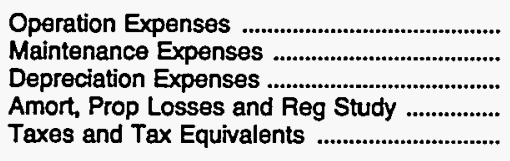 & $\begin{array}{r}71,726 \\
1,876 \\
1,388 \\
0 \\
1,174\end{array}$ & $\begin{array}{r}224,720 \\
7,891 \\
8,349 \\
0 \\
6,463\end{array}$ & $\begin{array}{r}21,147 \\
566 \\
700 \\
0 \\
478\end{array}$ & $\begin{array}{r}16,625 \\
806 \\
719 \\
0 \\
421\end{array}$ & $\begin{array}{r}15,540 \\
482 \\
335 \\
1 \\
299\end{array}$ & $\begin{array}{r}48,882 \\
1,690 \\
1,548 \\
0 \\
1,177\end{array}$ \\
\hline $\begin{array}{l}\text { Total Electric Utility Operating } \\
\text { Expenses }\end{array}$ & 76,163 & 247,423 & 22,891 & 18,571 & 16,656 & 53,297 \\
\hline $\begin{array}{l}\text { Net Electric Utility Operating Income } \\
\text { Income from Electric Plant Leased } \\
\text { to Others }\end{array}$ & 2,275 & 4,428 & 753 & 197 & 323 & $\begin{array}{r}2,983 \\
0\end{array}$ \\
\hline Electric Utllity Operating Income ............. & 2,275 & 4,428 & 753 & 197 & 323 & 2,983 \\
\hline Other Electric Income & 848 & 4,226 & 304 & 478 & 167 & 1,044 \\
\hline $\begin{array}{l}\text { Other Electric Deductions } \\
\text { Allowance for Other Funds Used......................... }\end{array}$ & 0 & 0 & 9 & 0 & 77 & 2 \\
\hline 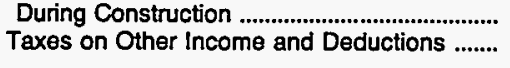 & $\begin{array}{l}0 \\
0\end{array}$ & $\begin{array}{l}0 \\
0\end{array}$ & $\begin{array}{l}0 \\
0\end{array}$ & $\begin{array}{l}0 \\
0\end{array}$ & $\begin{array}{l}0 \\
0\end{array}$ & $\begin{array}{l}0 \\
0\end{array}$ \\
\hline Electric Utillty Income & 3,123 & 8,654 & 1,047 & 675 & 413 & 4,025 \\
\hline $\begin{array}{l}\text { Income Deductions from Interest } \\
\text { on Long-term Debt ............................................. } \\
\text { Other Income Deductions ............................ } \\
\text { Allowance for Borrowed Funds Used }\end{array}$ & $\begin{array}{r}0 \\
131\end{array}$ & $\begin{array}{r}2,383 \\
365\end{array}$ & $\begin{array}{r}15 \\
0\end{array}$ & $\begin{array}{r}185 \\
18\end{array}$ & $\begin{array}{l}0 \\
0\end{array}$ & $\begin{array}{r}1,347 \\
53\end{array}$ \\
\hline 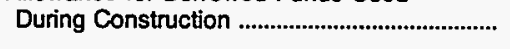 & 0 & 0 & 0 & 0 & 0 & 0 \\
\hline 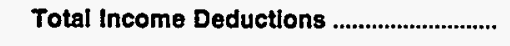 & 131 & 2,748 & 15 & 203 & 0 & 1,400 \\
\hline Income Before Extraordinary Items ...................... & 2,992 & 5,906 & 1,033 & 472 & 413 & 2,625 \\
\hline Extraordinary Income & 0 & 1,560 & 0 & 0 & 0 & 0 \\
\hline 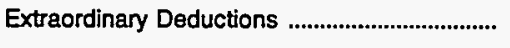 & 0 & 0 & 0 & 0 & 0 & 688 \\
\hline 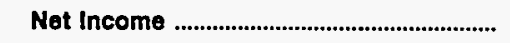 & 2,992 & 7,467 & 1,033 & 472 & 413 & 1,937 \\
\hline
\end{tabular}

Note: Totals may not equal sum of components because of independent rounding.

Source: Energy Information Administration, Form EIA-412, "Annual Report of Public Electric Utilities." 
Table 21. Statement of Income by Major U.S. Rublicly Owned Electric Utility Within State, 1993 (Continued)

(Thousand Dollars)

\begin{tabular}{|c|c|c|c|c|c|c|}
\hline Item & $\begin{array}{l}\text { Tennessee } \\
\text { Lewisburg } \\
\text { City of } \\
\text { June } 30\end{array}$ & $\begin{array}{l}\text { Tennessee } \\
\text { Lexington } \\
\text { City of } \\
\text { June } 30\end{array}$ & $\begin{array}{l}\text { Tennessee } \\
\text { Loudion } \\
\text { Utilities } \\
\text { Board } \\
\text { June } 30\end{array}$ & $\begin{array}{c}\text { Tennessee } \\
\text { Maryville } \\
\text { Utilities } \\
\text { June } 30\end{array}$ & $\begin{array}{l}\text { Tennessee } \\
\text { McMinnville } \\
\text { Electric } \\
\text { System } \\
\text { June } 30\end{array}$ & $\begin{array}{l}\text { Tennessee } \\
\text { Memphis } \\
\text { City of } \\
\text { June } 30\end{array}$ \\
\hline Electrlc Utllity Operating Revenues .............. & 13,819 & 20,905 & 13,603 & 25,050 & 11,122 & 626,724 \\
\hline 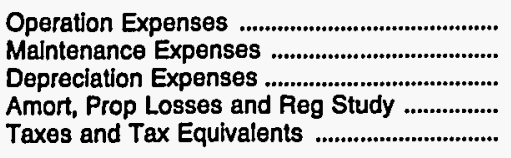 & $\begin{array}{r}12,458 \\
186 \\
300 \\
41 \\
260\end{array}$ & $\begin{array}{r}18,528 \\
633 \\
695 \\
0 \\
458\end{array}$ & $\begin{array}{r}11,761 \\
250 \\
349 \\
0 \\
337\end{array}$ & $\begin{array}{r}22,953 \\
685 \\
885 \\
5 \\
560\end{array}$ & $\begin{array}{r}10,235 \\
331 \\
396 \\
52 \\
268\end{array}$ & $\begin{array}{r}560,899 \\
24,259 \\
18,290 \\
641 \\
18,904\end{array}$ \\
\hline $\begin{array}{l}\text { Total Electrlc Utllity Operating } \\
\text { Expenses }\end{array}$ & 13,245 & 20,315 & 12,698 & 25,088 & 11,281 & 622,993 \\
\hline 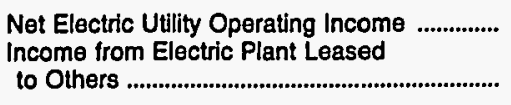 & $\begin{array}{r}574 \\
0\end{array}$ & 590 & 905 & -38 & $\begin{array}{r}-159 \\
0\end{array}$ & $\begin{array}{r}3.731 \\
0\end{array}$ \\
\hline Electric Utillty Operating Income .............. & 574 & 590 & 905 & -38 & -159 & 3,731 \\
\hline 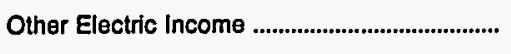 & 124 & 338 & 530 & 415 & 242 & 30,530 \\
\hline $\begin{array}{l}\text { Other Electric Deductions ............................ } \\
\text { Allowance for Other Funds Used } \\
\text { During Construction ................................... } \\
\text { Taxes on Other Income and Deductions ....... }\end{array}$ & $\begin{array}{l}0 \\
0\end{array}$ & $\begin{array}{l}0 \\
0\end{array}$ & $\begin{array}{l}0 \\
0\end{array}$ & $\begin{array}{l}0 \\
0\end{array}$ & $\begin{array}{l}0 \\
0\end{array}$ & 362 \\
\hline 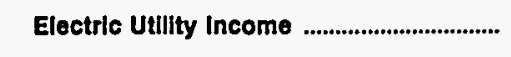 & 695 & 928 & 1,431 & 377 & 81 & 33,900 \\
\hline 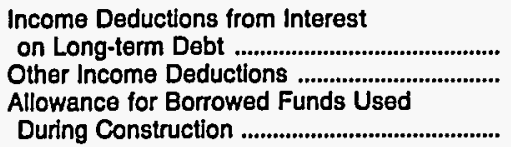 & $\begin{array}{r}30 \\
6\end{array}$ & $\begin{array}{l}0 \\
0\end{array}$ & $\begin{array}{r}493 \\
23\end{array}$ & $\begin{array}{r}95 \\
5\end{array}$ & $\begin{array}{r}0 \\
24\end{array}$ & $\begin{array}{r}15,489 \\
697\end{array}$ \\
\hline Total Income Deductions ............................... & 36 & 0 & 517 & 100 & 24 & 16,186 \\
\hline Income Before Extraordinary Items ................... & 659 & 928 & 914 & 277 & 58 & 17,714 \\
\hline 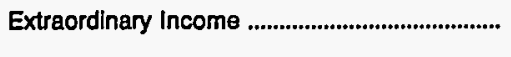 & 0 & 0 & 0 & 0 & 0 & 0 \\
\hline 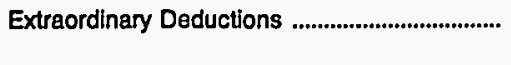 & 0 & 0 & 0 & 91 & 0 & 885 \\
\hline 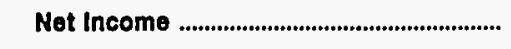 & 659 & 928 & 914 & 185 & 58 & 16,829 \\
\hline
\end{tabular}

Note: Totals may not equal sum of components because of independent rounding.

Source: Energy Information Administration, Form EIA-412, "Annual Report of Public Electric Utilities." 
Table 21. Statement of Income by Major U.S. Publicly Owned Electric Utility Within State, 1993 (Continued)

(Thousand Dollars)

\begin{tabular}{|c|c|c|c|c|c|c|}
\hline Item & $\begin{array}{c}\text { Tennessee } \\
\text { Morristown } \\
\text { City of } \\
\text { June } 30\end{array}$ & $\begin{array}{c}\text { Tennessee } \\
\begin{array}{c}\text { Murfreesboro } \\
\text { City of }\end{array} \\
\text { June } 30\end{array}$ & $\begin{array}{l}\text { Tennessee } \\
\text { Nashville } \\
\text { Electric } \\
\text { Service } \\
\text { June } 30\end{array}$ & $\begin{array}{l}\text { Tennessee } \\
\text { Newport } \\
\text { City of } \\
\text { June } 30\end{array}$ & $\begin{array}{l}\text { Tennessee } \\
\text { Oak Ridge } \\
\text { City of } \\
\text { June } 30\end{array}$ & $\begin{array}{c}\text { Tennessee } \\
\text { Paris } \\
\text { City of } \\
\text { June } 30\end{array}$ \\
\hline Electric Utility Operating Revenues ............ & 32,091 & 42,650 & 537,111 & 22,387 & 24,351 & 21,659 \\
\hline 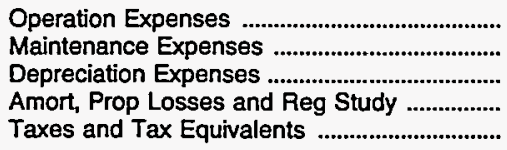 & $\begin{array}{r}29,128 \\
772 \\
747 \\
229 \\
594\end{array}$ & $\begin{array}{r}37,840 \\
531 \\
1,066 \\
119 \\
1,009\end{array}$ & $\begin{array}{r}479,747 \\
15,628 \\
17,638 \\
-54 \\
10,574\end{array}$ & $\begin{array}{r}19,550 \\
652 \\
819 \\
0 \\
593\end{array}$ & $\begin{array}{r}22,117 \\
693 \\
694 \\
11 \\
527\end{array}$ & $\begin{array}{r}19,843 \\
794 \\
780 \\
0 \\
471\end{array}$ \\
\hline $\begin{array}{l}\text { Total Electric Utility Operating } \\
\text { Expenses }\end{array}$ & 31,469 & 40,566 & 523,533 & 21,614 & 24,042 & 21,887 \\
\hline $\begin{array}{l}\text { Net Electric Utility Operating Income } \\
\text { Income from Electric Plant Leased } \\
\text { to Others }\end{array}$ & 622 & 2,084 & 13,578 & 773 & 309 & -228 \\
\hline Electric Utillty Operating Income ............. & 622 & 2,084 & 13,578 & 773 & 309 & -228 \\
\hline Other Electric Income & 418 & 817 & 9,629 & 484 & 278 & 433 \\
\hline $\begin{array}{l}\text { Other Electric Deductions ............................... } \\
\text { Allowance for Other Funds Used }\end{array}$ & 7 & 16 & 0 & 6 & 0 & 2 \\
\hline 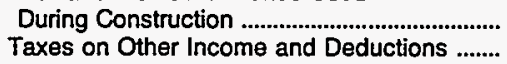 & $\begin{array}{l}0 \\
0\end{array}$ & $\begin{array}{l}0 \\
0\end{array}$ & $\begin{array}{l}0 \\
0\end{array}$ & $\begin{array}{l}0 \\
0\end{array}$ & $\begin{array}{l}0 \\
0\end{array}$ & $\begin{array}{l}0 \\
0\end{array}$ \\
\hline 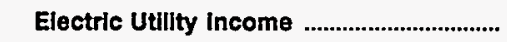 & 1,032 & 2,885 & 23,207 & 1,251 & 587 & 203 \\
\hline 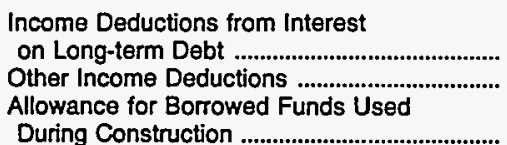 & $\begin{array}{r}2 \\
59\end{array}$ & $\begin{array}{r}240 \\
55\end{array}$ & $\begin{array}{r}12,630 \\
853\end{array}$ & $\begin{array}{r}282 \\
25\end{array}$ & $\begin{array}{r}190 \\
4\end{array}$ & $\begin{array}{r}175 \\
4\end{array}$ \\
\hline Total Income Deductions ............................ & 61 & 295 & 13,483 & 307 & 194 & 179 \\
\hline Income Before Extraordinary Items ................. & 971 & 2,590 & 9,724 & 944 & 393 & 24 \\
\hline Extraordinary Income & 0 & 0 & 0 & 0 & 0 & 0 \\
\hline 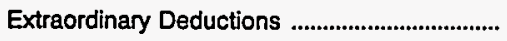 & 0 & 0 & 13,154 & 0 & 396 & 0 \\
\hline Net Income & 971 & 2,590 & $-3,429$ & 944 & -3 & 24 \\
\hline
\end{tabular}

Note: Totals may not equal sum of components because of independent rounding.

Source: Energy Information Administration, Form ElA-412, "Annual Report of Public Electric Utilities." 
Table 21. Statement of Income by Major U.S. Publicly Owned Electric Utility Within State, 1993 (Continued)

(Thousand Dollars)

\begin{tabular}{|c|c|c|c|c|c|c|}
\hline Item & $\begin{array}{l}\text { Tennessee } \\
\text { Pulaski } \\
\text { City of } \\
\text { June } 30\end{array}$ & $\begin{array}{l}\text { Tennessee } \\
\text { Ripley } \\
\text { City of } \\
\text { June } 30\end{array}$ & $\begin{array}{l}\text { Tennessee } \\
\begin{array}{c}\text { Rockwood } \\
\text { City of }\end{array} \\
\text { June } 30\end{array}$ & $\begin{array}{c}\text { Tennessee } \\
\text { Sevier } \\
\text { County } \\
\text { Electric } \\
\text { System } \\
\text { June } 30\end{array}$ & $\begin{array}{c}\text { Tennessee } \\
\begin{array}{c}\text { Shelbyville } \\
\text { City of }\end{array} \\
\text { June } 30\end{array}$ & $\begin{array}{l}\text { Tennessee } \\
\begin{array}{c}\text { Springfield } \\
\text { City of }\end{array} \\
\text { June } 30\end{array}$ \\
\hline Electric Utillty Operating Revenues ............. & 19,454 & 12,205 & 15,241 & 47,789 & 16,028 & 10,611 \\
\hline 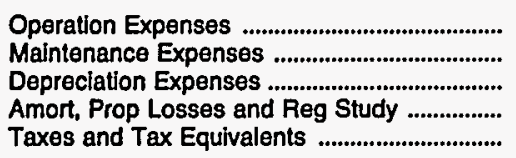 & $\begin{array}{r}17,112 \\
511 \\
631 \\
0 \\
471\end{array}$ & $\begin{array}{r}11,756 \\
114 \\
205 \\
29 \\
192\end{array}$ & $\begin{array}{r}13,331 \\
358 \\
462 \\
20 \\
385\end{array}$ & $\begin{array}{r}41,432 \\
1,070 \\
1,773 \\
27 \\
870\end{array}$ & $\begin{array}{r}14,909 \\
260 \\
377 \\
18 \\
348\end{array}$ & $\begin{array}{r}9,195 \\
141 \\
358 \\
73 \\
247\end{array}$ \\
\hline $\begin{array}{l}\text { Total Electric Utllity Operating } \\
\text { Expenses }\end{array}$ & 18,725 & 12,296 & 14,556 & 45,173 & 15,913 & 10,015 \\
\hline 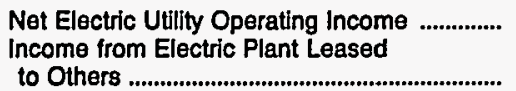 & 729 & -91 & 685 & 2,616 & 115 & 596 \\
\hline Electric Utility Operating Income ............. & 729 & -91 & 685 & 2,616 & $\$ 15$ & 596 \\
\hline Other Electric Income & 242 & 322 & 212 & 764 & 208 & 164 \\
\hline $\begin{array}{l}\text { Other Electric Deductions } \\
\text { Allowance for Other Funds Used....................... }\end{array}$ & 13 & 0 & 10 & 0 & 0 & 0 \\
\hline $\begin{array}{l}\text { During Construction .................................... } \\
\text { Taxes on Other Income and Deductions ....... }\end{array}$ & $\begin{array}{l}0 \\
0\end{array}$ & $\begin{array}{l}0 \\
0\end{array}$ & $\begin{array}{l}0 \\
0\end{array}$ & $\begin{array}{l}0 \\
0\end{array}$ & $\begin{array}{l}0 \\
0\end{array}$ & $\begin{array}{l}0 \\
0\end{array}$ \\
\hline 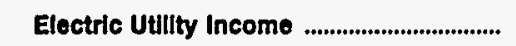 & 958 & 232 & 886 & 3,380 & 323 & 761 \\
\hline $\begin{array}{l}\text { Income Deductions from Interest } \\
\text { on Long-term Debt ................................................ } \\
\text { Other Income Deductions ............................... } \\
\text { Allowance for Borrowed Funds Used }\end{array}$ & $\begin{array}{r}214 \\
2\end{array}$ & $\begin{array}{l}0 \\
0\end{array}$ & $\begin{array}{r}18 \\
0\end{array}$ & $\begin{array}{r}275 \\
89\end{array}$ & $\begin{array}{r}0 \\
16\end{array}$ & $\begin{array}{r}114 \\
18\end{array}$ \\
\hline 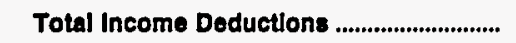 & 218 & 0 & 18 & 365 & 16 & 132 \\
\hline Income Before Extraordinary ltems .................... & 743 & 232 & 868 & 3,015 & 307 & 629 \\
\hline 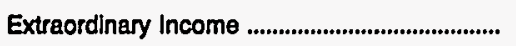 & 0 & 0 & 615 & 0 & 0 & 0 \\
\hline 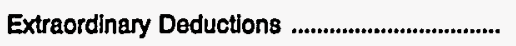 & 0 & 0 & 0 & 131 & 0 & 72 \\
\hline Net Income & 743 & 232 & 1,483 & 2,884 & 307 & 557 \\
\hline
\end{tabular}

Note: Totals may not equal sum of components because of independent rounding.

Source: Energy Information Administration, Form EIA-412, "Annual Report of Public Electric Utilities." 
Table 21. Statement of Income by Major U.S. Publicly Owned Electric Utility Within State, 1993 (Continued)

(Thousand Dollars)

\begin{tabular}{|c|c|c|c|c|c|c|}
\hline Item & $\begin{array}{l}\text { Tennessee } \\
\text { Sweetwater } \\
\text { City of } \\
\text { June } 30\end{array}$ & $\begin{array}{l}\text { Tennessee } \\
\text { Tullahoma } \\
\text { Board } \\
\text { of } \\
\text { Pub Utils } \\
\text { June } 30\end{array}$ & $\begin{array}{l}\text { Tennessee } \\
\text { Union } \\
\text { City City of } \\
\text { June } 30\end{array}$ & $\begin{array}{l}\text { Tennessee } \\
\text { Weakley } \\
\text { County } \\
\text { Mun } \\
\text { Elec Sys } \\
\text { June } 30\end{array}$ & $\begin{array}{c}\text { Texas } \\
\text { Austin } \\
\text { City of } \\
\text { September } 30\end{array}$ & $\begin{array}{l}\text { Texas } \\
\text { Brenham } \\
\text { City of } \\
\text { September } 30\end{array}$ \\
\hline Electric Utility Operating Revenues ............. & 9,705 & 13,800 & 14,532 & 24,355 & 488,844 & 12,110 \\
\hline 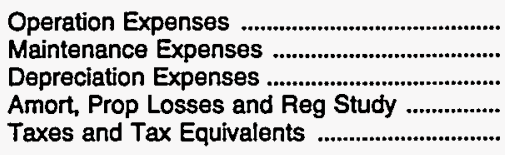 & $\begin{array}{r}8,438 \\
346 \\
360 \\
0 \\
210\end{array}$ & $\begin{array}{r}12,248 \\
458 \\
414 \\
12 \\
310\end{array}$ & $\begin{array}{r}13,909 \\
295 \\
343 \\
14 \\
271\end{array}$ & $\begin{array}{r}22,363 \\
532 \\
845 \\
0 \\
506\end{array}$ & $\begin{array}{r}246,644 \\
43,774 \\
58,175 \\
0 \\
0\end{array}$ & $\begin{array}{r}10,341 \\
451 \\
246 \\
0 \\
595\end{array}$ \\
\hline $\begin{array}{l}\text { Total Electric Utility Operating } \\
\text { Expenses }\end{array}$ & 9,354 & 13,442 & 14,831 & 24,246 & 348,593 & 11,634 \\
\hline 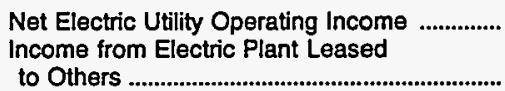 & $\begin{array}{r}350 \\
0\end{array}$ & $\begin{array}{r}358 \\
0\end{array}$ & $\begin{array}{r}-299 \\
0\end{array}$ & 109 & 140,251 & 476 \\
\hline Electric Utillty Operating Income .............. & 350 & 358 & -299 & 109 & 140,251 & 476 \\
\hline Other Electric Income & 166 & 279 & 279 & 363 & 17,952 & 20 \\
\hline 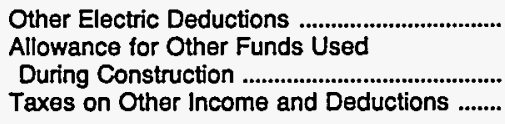 & $\begin{array}{l}0 \\
0\end{array}$ & $\begin{array}{l}0 \\
0\end{array}$ & $\begin{array}{l}0 \\
0\end{array}$ & $\begin{array}{l}0 \\
0\end{array}$ & 177 & $\begin{array}{l}0 \\
0\end{array}$ \\
\hline Electric Utllity Income & 516 & 634 & -24 & 472 & 158,027 & 495 \\
\hline 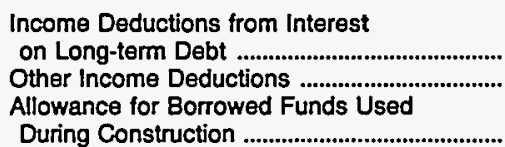 & $\begin{array}{l}0 \\
5\end{array}$ & $\begin{array}{r}125 \\
2\end{array}$ & $\begin{array}{l}0 \\
0\end{array}$ & $\begin{array}{r}0 \\
11\end{array}$ & $\begin{array}{r}138,549 \\
7,794\end{array}$ & $\begin{array}{r}51 \\
5\end{array}$ \\
\hline 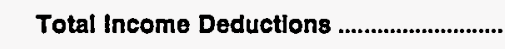 & 5 & 127 & 0 & 11 & 146,344 & 56 \\
\hline 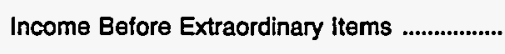 & 511 & 507 & -24 & 461 & 11,683 & 439 \\
\hline Extraordinary Income & 0 & 0 & 0 & 0 & 5,728 & 0 \\
\hline 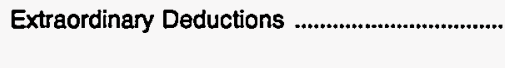 & 0 & 0 & 0 & $\mathbf{0}$ & 0 & 0 \\
\hline Net Income & 511 & 507 & -24 & 461 & 17,411 & 439 \\
\hline
\end{tabular}

Note: Totals may not equal sum of components because of independent rounding.

Source: Energy Information Administration, Form ElA-412, "Annual Report of Public Electric Utilities." 
Table 21. Statement of Income by Major U.S. Publicly Owned Electric Utility Within State, 1993 (Continued)

(Thousand Dollars)

\begin{tabular}{|c|c|c|c|c|c|c|}
\hline Item & $\begin{array}{c}\text { Texas } \\
\text { Brownsville } \\
\text { Public } \\
\text { Utils Board } \\
\text { September } 30\end{array}$ & $\begin{array}{c}\text { Texas } \\
\text { Bryan } \\
\text { City of } \\
\text { September } 30\end{array}$ & $\begin{array}{c}\text { Texas } \\
\text { College } \\
\text { Station } \\
\text { City of } \\
\text { September } 30\end{array}$ & $\begin{array}{c}\text { Texas } \\
\text { Denton } \\
\text { City of } \\
\text { September } 30\end{array}$ & $\begin{array}{c}\text { Texas } \\
\text { Floresville } \\
\text { City of }\end{array}$ & $\begin{array}{c}\text { Texas } \\
\text { Garland } \\
\text { City of } \\
\text { September } 30\end{array}$ \\
\hline Electric Utillty Operating Rovenues ............. & 43,939 & 75,703 & 29,048 & 64,870 & 10,168 & 149,780 \\
\hline 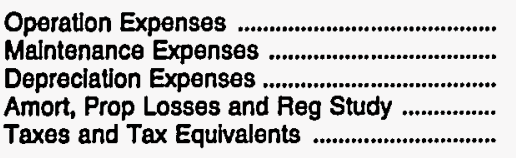 & $\begin{array}{r}28,447 \\
1,971 \\
3,482 \\
0 \\
329\end{array}$ & $\begin{array}{r}54,920 \\
2,234 \\
13,392 \\
0 \\
3,254\end{array}$ & $\begin{array}{r}22,061 \\
691 \\
841 \\
0 \\
0\end{array}$ & $\begin{array}{r}54,319 \\
1,435 \\
5,465 \\
0 \\
0\end{array}$ & $\begin{array}{r}8,325 \\
302 \\
602 \\
0 \\
0\end{array}$ & $\begin{array}{r}112,353 \\
11,410 \\
5,588 \\
0 \\
6,146\end{array}$ \\
\hline $\begin{array}{l}\text { Total Electric UtIlity Operating } \\
\text { Expenses }\end{array}$ & 34,229 & 73,800 & 23,593 & 61,219 & 9,228 & 135,497 \\
\hline 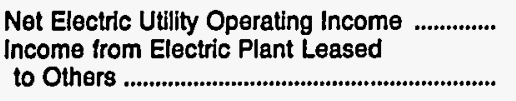 & 9,710 & 1,903 & 5,455 & 3,651 & 940 & 14,284 \\
\hline Electric Utllity Operating Income .............. & 9,710 & 1,903 & 5,455 & 3,651 & 940 & 14,284 \\
\hline Other Electric Income & 25,136 & 2,135 & 782 & 3,135 & 421 & 1,922 \\
\hline $\begin{array}{l}\text { Other Electric Deductions } \\
\text { Allowance for Other Funds Used } \\
\text { During Construction }\end{array}$ & 552 & 2,166 & 3,451 & 2,536 & 0 & 0 \\
\hline 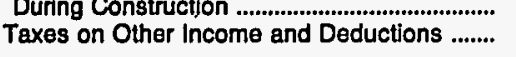 & $\begin{array}{l}0 \\
0\end{array}$ & $\begin{array}{l}0 \\
0\end{array}$ & $\begin{array}{l}0 \\
0\end{array}$ & $\begin{array}{l}0 \\
0\end{array}$ & $\begin{array}{l}0 \\
0\end{array}$ & 0 \\
\hline 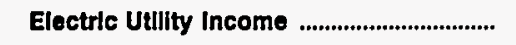 & 34,294 & 1,871 & 2,786 & 4,250 & 1,362 & 16,205 \\
\hline 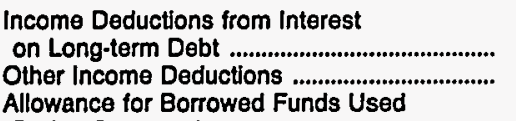 & $\begin{array}{r}7,905 \\
22,044\end{array}$ & $\begin{array}{l}0 \\
0\end{array}$ & $\begin{array}{l}450 \\
202\end{array}$ & $\begin{array}{r}1,900 \\
0\end{array}$ & $\begin{array}{r}310 \\
0\end{array}$ & $\begin{array}{r}1,565 \\
791\end{array}$ \\
\hline 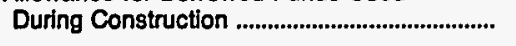 & 0 & 0 & 0 & 0 & 0 & 0 \\
\hline 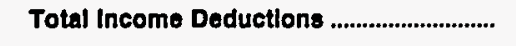 & 29,949 & 0 & 652 & 1,900 & 310 & 2,356 \\
\hline Income Before Extraordinary ltems ..................... & 4,345 & 1,871 & 2,134 & 2,350 & 1,052 & 13,849 \\
\hline 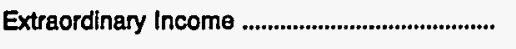 & 0 & $\mathbf{0}$ & 0 & 0 & 0 & 0 \\
\hline 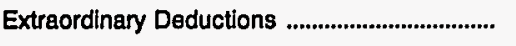 & 0 & 0 & 40 & 1,424 & 0 & 0 \\
\hline 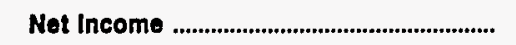 & 4,345 & 1,871 & 2,094 & 926 & 1,052 & 13,849 \\
\hline
\end{tabular}

Note: Totals may not equal sum of components because of independent rounding.

Source: Energy Information Administration, Form EIA-412, "Annual Report of Public Electric Utilities." 
Table 21. Statement of Income by Major U.S. Publicly Owned Electric Utility Within State, 1993 (Continued)

(Thousand Dollars)

\begin{tabular}{|c|c|c|c|c|c|c|}
\hline Item & $\begin{array}{c}\text { Texas } \\
\text { Georgetown } \\
\text { City of } \\
\text { September } 30\end{array}$ & $\begin{array}{c}\text { Texas } \\
\text { Greenville } \\
\text { Electric } \\
\text { Util Sys } \\
\text { September } 30\end{array}$ & $\begin{array}{c}\text { Texas } \\
\text { Kerville } \\
\text { Public } \\
\text { Utility } \\
\text { Board } \\
\text { September } 30\end{array}$ & $\begin{array}{l}\text { Texas } \\
\text { Lower } \\
\text { Colorado } \\
\text { River } \\
\text { Authority } \\
\text { June } 30\end{array}$ & $\begin{array}{l}\text { Texas } \\
\text { Lubbock } \\
\text { City of } \\
\text { September } 30\end{array}$ & $\begin{array}{c}\text { Texas } \\
\text { New Braunfels } \\
\text { City of } \\
\text { July } 31\end{array}$ \\
\hline Electric Utility Operating Revenues ........... & 11,538 & 31,973 & 21,187 & 349,568 & 52,949 & 36,817 \\
\hline 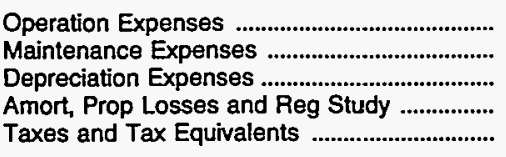 & $\begin{array}{r}8,748 \\
154 \\
242 \\
0 \\
229\end{array}$ & $\begin{array}{r}24,225 \\
1,800 \\
1,578 \\
0 \\
1,244\end{array}$ & $\begin{array}{r}16,612 \\
730 \\
915 \\
162 \\
14\end{array}$ & $\begin{array}{r}187,861 \\
31,408 \\
38,794 \\
0 \\
0\end{array}$ & $\begin{array}{r}38,731 \\
843 \\
3,463 \\
0 \\
0\end{array}$ & $\begin{array}{r}31,018 \\
697 \\
1,530 \\
0 \\
1,044\end{array}$ \\
\hline $\begin{array}{l}\text { Total Electric Utility Operating } \\
\text { Expenses }\end{array}$ & 9,372 & 28,847 & 18,433 & 258,063 & 43,037 & 34,288 \\
\hline $\begin{array}{l}\text { Net Electric Utility Operating Income } \\
\text { Income from Electric Plant Lea....... }\end{array}$ & 2,166 & 3,126 & 2,753 & 91,505 & 9,912 & 2,629 \\
\hline 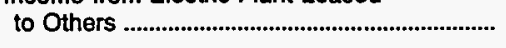 & 0 & 0 & 0 & 0 & 0 & 943 \\
\hline Electric Utility Operating Income .............. & 2,166 & 3,126 & 2,753 & 91,505 & 9,912 & 3,572 \\
\hline 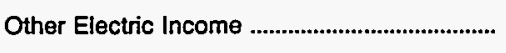 & 256 & 381 & 562 & 14,350 & 3,895 & 562 \\
\hline $\begin{array}{l}\text { Other Electric Deductions .................................. } \\
\text { Allowance for Other Funds Used }\end{array}$ & 0 & 0 & 0 & 36,348 & 0 & 0 \\
\hline $\begin{array}{l}\text { During Construction ..................................... } \\
\text { Taxes on Other Income and Deductions ....... }\end{array}$ & $\begin{array}{l}0 \\
0\end{array}$ & $\begin{array}{l}0 \\
0\end{array}$ & $\begin{array}{r}19 \\
0\end{array}$ & $\begin{array}{l}0 \\
0\end{array}$ & $\begin{array}{r}0 \\
6,166\end{array}$ & $\begin{array}{l}0 \\
0\end{array}$ \\
\hline Electric Utillty Income & 2,423 & 3,506 & 3,334 & 69,507 & 7,640 & 4,133 \\
\hline $\begin{array}{l}\text { Income Deductions from Interest } \\
\text { on Long-term Debt .............................................. } \\
\text { Other Income Deductions .............................. } \\
\text { Allowance for Borrowed Funds Used }\end{array}$ & $\begin{array}{r}4 \\
1,997\end{array}$ & $\begin{array}{r}1,034 \\
364\end{array}$ & $\begin{array}{r}2,046 \\
0\end{array}$ & $\begin{array}{l}76,848 \\
-4,251\end{array}$ & $\begin{array}{r}2,286 \\
0\end{array}$ & $\begin{array}{r}415 \\
0\end{array}$ \\
\hline 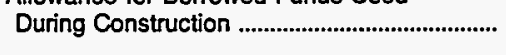 & 0 & 0 & 0 & 0 & 0 & 0 \\
\hline Total Income Deductions ............................ & 2,001 & 1,398 & 2,046 & 72,598 & 2,286 & 415 \\
\hline Income Before Extraordinary Items ................. & 421 & 2,108 & 1,288 & $-3,091$ & 5,355 & 3,718 \\
\hline Extraordinary Income & 0 & 0 & 0 & 0 & 0 & 0 \\
\hline Extraordinary Deductions .................................. & 0 & 0 & 0 & 0 & 0 & 496 \\
\hline Net Income & 421 & 2,108 & 1,288 & $-3,091$ & 5,355 & 3,222 \\
\hline
\end{tabular}

Note: Totals may not equal sum of components because of independent rounding.

Source: Energy Information Administration, Form EIA-412, "Annual Report of Public Electric Utilities." 
Table 21. Statement of Income by Major U.S. Publicly Owned Electric Utility Within State, 1993 (Continued)

(Thousand Dollars)

\begin{tabular}{|c|c|c|c|c|c|c|}
\hline Item & $\begin{array}{c}\text { Texas } \\
\text { Sam Raybum } \\
\text { Municipal } \\
\text { Pwr } \\
\text { Agny } \\
\text { September } 30\end{array}$ & $\begin{array}{l}\text { Texas } \\
\text { San Antonio } \\
\text { City of } \\
\text { January } 31\end{array}$ & $\begin{array}{c}\text { Texas } \\
\text { San Marcos } \\
\text { City of } \\
\text { September } 30\end{array}$ & $\begin{array}{l}\text { Texas } \\
\text { Seguin } \\
\text { City of } \\
\text { September } 30\end{array}$ & $\begin{array}{c}\text { Texas } \\
\text { Texas } \\
\text { Municipal } \\
\text { Power Agency } \\
\text { September } 30\end{array}$ & $\begin{array}{l}\text { Texas } \\
\text { Toledo Bend } \\
\text { Project } \\
\text { Joint } \\
\text { Oper } \\
\text { August } 30\end{array}$ \\
\hline Electric Utllity Operating Revenues ............. & 33,248 & 779,929 & 19,441 & 11,953 & 173,710 & 9,168 \\
\hline 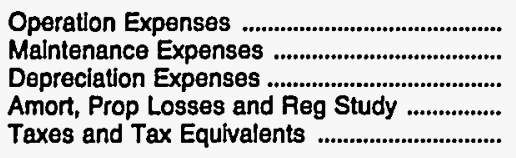 & $\begin{array}{r}14,895 \\
3,400 \\
4,549 \\
0 \\
0\end{array}$ & $\begin{array}{r}334,961 \\
79,399 \\
133,593 \\
0 \\
97,346\end{array}$ & $\begin{array}{r}14,950 \\
514 \\
430 \\
0 \\
1,418\end{array}$ & $\begin{array}{r}8,313 \\
142 \\
272 \\
0 \\
0\end{array}$ & $\begin{array}{r}74,944 \\
8,966 \\
23,737 \\
0 \\
0\end{array}$ & $\begin{array}{r}7,029 \\
0 \\
700 \\
0 \\
0\end{array}$ \\
\hline 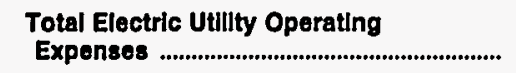 & 22,844 & 645,299 & 17,313 & 8,726 & 107,647 & 7,728 \\
\hline 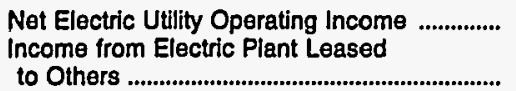 & 10,404 & $\begin{array}{r}134,631 \\
1,732\end{array}$ & 2,128 & 3,226 & $\begin{array}{r}66,063 \\
0\end{array}$ & 1,440 \\
\hline Electrle Utllity Operating Income .............. & 10,404 & 136,363 & 2,128 & 3,226 & 66,063 & 1,440 \\
\hline Other Electric Income & 9,745 & 24,431 & 687 & 122 & 12,424 & 0 \\
\hline $\begin{array}{l}\text { Other Electric Deductions .............................. } \\
\text { Allowance for Other Funds Used } \\
\text { During Construction ........................................ } \\
\text { Taxes on Other Income and Deductions ....... }\end{array}$ & $\begin{array}{l}0 \\
0\end{array}$ & $\begin{array}{r}0 \\
15,768\end{array}$ & $\begin{array}{l}0 \\
0\end{array}$ & $\begin{array}{l}0 \\
0\end{array}$ & $\begin{array}{r}21,796 \\
0\end{array}$ & $\begin{array}{l}0 \\
0\end{array}$ \\
\hline Electric Utllity Income ...................................... & 20,149 & 143,948 & 2,799 & 3,349 & 100,283 & 1,440 \\
\hline 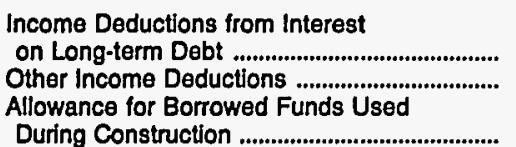 & $\begin{array}{r}14,822 \\
4,153\end{array}$ & $\begin{array}{r}168,507 \\
27,510\end{array}$ & $\begin{array}{r}946 \\
0\end{array}$ & $\begin{array}{l}0 \\
0\end{array}$ & $\begin{array}{r}84,275 \\
6,555\end{array}$ & $\begin{array}{r}2,327 \\
0\end{array}$ \\
\hline 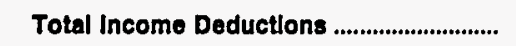 & 18,975 & 194,040 & 946 & 0 & 90,830 & 2,327 \\
\hline 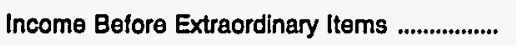 & 1,175 & $-50,092$ & 1,853 & 3,349 & 9,453 & -888 \\
\hline 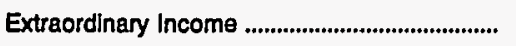 & 0 & 0 & 0 & 0 & 0 & 0 \\
\hline 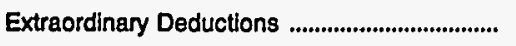 & 0 & 0 & 2,473 & 0 & 0 & 0 \\
\hline 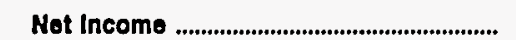 & 1,175 & $-50,092$ & -620 & 3,349 & 9,453 & -888 \\
\hline
\end{tabular}

Note: Totals may not equal sum of components because of independent rounding.

Source: Energy Information Administration, Form EIA-412, "Annual Report of Public Electric Utilities." 
Table 21. Statement of Income by Major U.S. Publicly Owned Electric Utility Within State, 1993 (Continued) (Thousand Dollars)

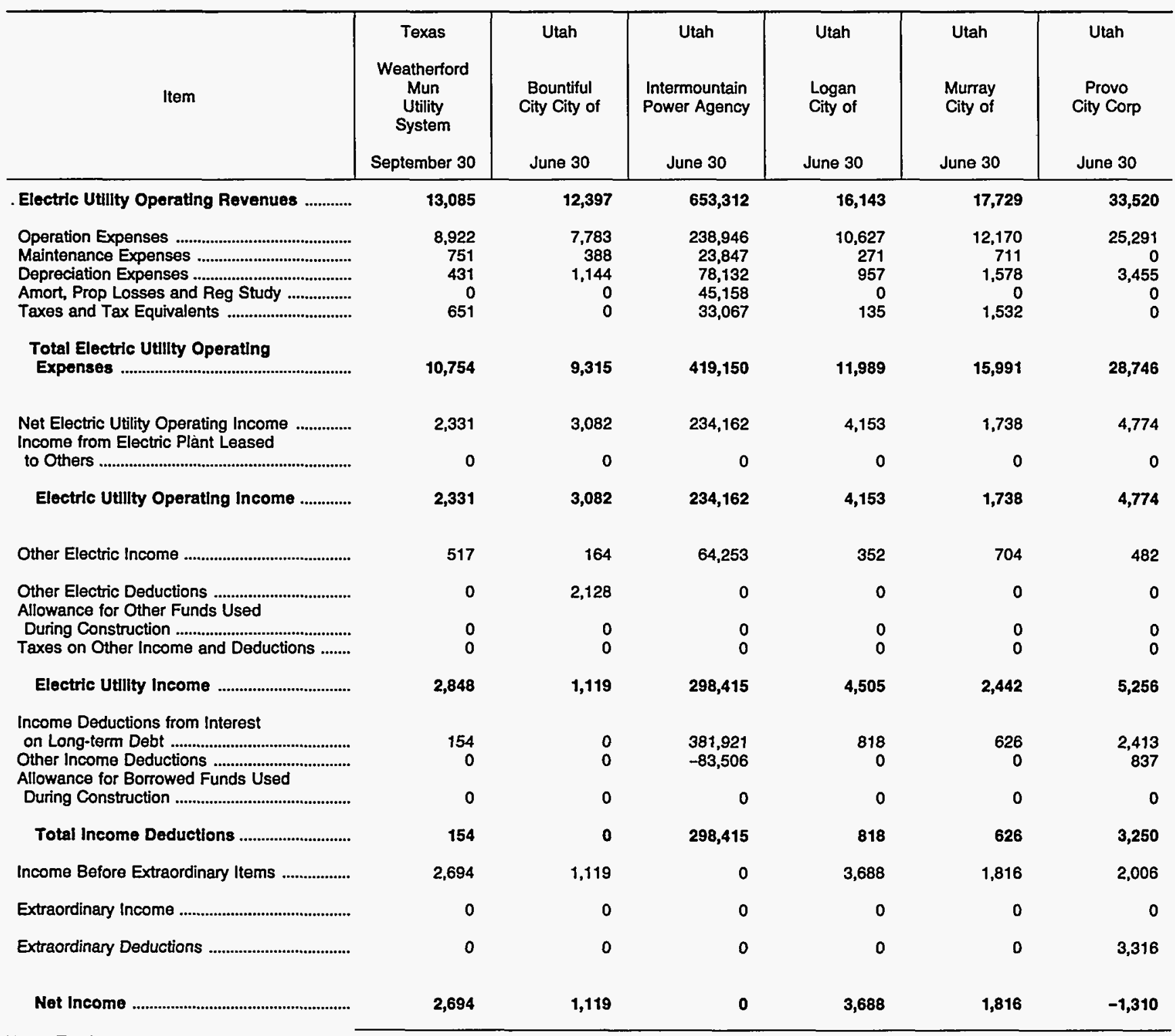

Note: Totals may not equal sum of components because of independent rounding.

Source: Energy Information Administration, Form ElA-412, "Annual Report of Public Electric Utilities." 
Table 21. Statement of Income by Major U.S. Publicly Owned Electric Utility Within State, 1993 (Continued)

(Thousand Dollars)

\begin{tabular}{|c|c|c|c|c|c|c|}
\hline Item & $\begin{array}{l}\text { Utah } \\
\text { St George } \\
\text { City of } \\
\text { June } 30\end{array}$ & $\begin{array}{c}\text { Utah } \\
\text { Utah } \\
\text { Associated } \\
\text { Mun } \\
\text { Power Sys } \\
\text { March 31 }\end{array}$ & $\begin{array}{c}\text { Utah } \\
\text { Utah } \\
\text { Municipal } \\
\text { Power Agency } \\
\text { June } 30\end{array}$ & $\begin{array}{c}\text { Vermont } \\
\text { Burlington } \\
\text { City of } \\
\text { December } 31\end{array}$ & $\begin{array}{l}\text { Vermont } \\
\text { Vermont } \\
\text { Public } \\
\text { Pwr } \\
\text { Supply Auth } \\
\text { December } 31\end{array}$ & $\begin{array}{l}\text { Virginia } \\
\text { Bedford } \\
\text { City of } \\
\text { June } 30\end{array}$ \\
\hline Electrlc Utillty Operating Revenues ............. & 16,698 & 38,337 & 30,391 & 39,527 & 8,319 & 11,541 \\
\hline 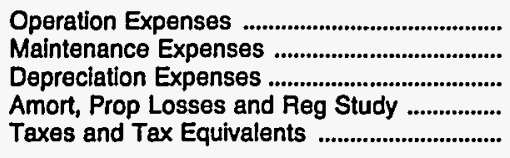 & $\begin{array}{r}13,784 \\
0 \\
955 \\
0 \\
1,434\end{array}$ & $\begin{array}{r}26,819 \\
804 \\
2,396 \\
0 \\
666\end{array}$ & $\begin{array}{r}26,292 \\
0 \\
866 \\
0 \\
135\end{array}$ & $\begin{array}{r}23,002 \\
1,608 \\
1,321 \\
1,691 \\
1,467\end{array}$ & $\begin{array}{r}4,744 \\
159 \\
890 \\
0 \\
335\end{array}$ & $\begin{array}{r}8,127 \\
60 \\
511 \\
0 \\
0\end{array}$ \\
\hline $\begin{array}{l}\text { Total Electrlc Utllity Operating } \\
\text { Expenses }\end{array}$ & 16,172 & 30,685 & 27,293 & 29,089 & 6,129 & 8,699 \\
\hline $\begin{array}{l}\text { Net Electric Utility Operating Income } \\
\text { Income from Electric Plant Leased } \\
\text { to Others }\end{array}$ & $\begin{array}{r}527 \\
0\end{array}$ & 7,652 & 3,097 & 10,438 & 2,190 & 2,842 \\
\hline Electric UtIllty Operating Income .............. & 527 & 7,652 & 3,097 & 10,438 & 2,190 & 2,842 \\
\hline Other Electric Income & 411 & 0 & 949 & 1,447 & 252 & 95 \\
\hline $\begin{array}{l}\text { Other Electric Deductions } \\
\text { Allowance for Other Funds Used }\end{array}$ & 0 & 1,300 & 0 & 124 & 21 & 0 \\
\hline 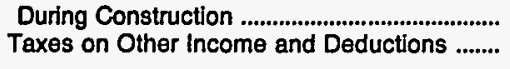 & $\begin{array}{l}0 \\
0\end{array}$ & $\begin{array}{l}0 \\
0\end{array}$ & $\begin{array}{l}0 \\
0\end{array}$ & $\begin{array}{l}0 \\
0\end{array}$ & $\begin{array}{l}0 \\
0\end{array}$ & $\begin{array}{l}0 \\
0\end{array}$ \\
\hline 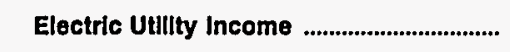 & 938 & 6,352 & 4,046 & 11,762 & 2,421 & 2,938 \\
\hline 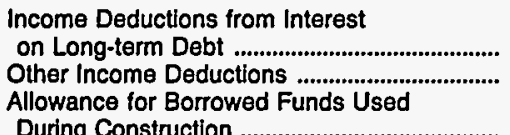 & $\begin{array}{l}0 \\
0\end{array}$ & $\begin{array}{r}6,862 \\
-510\end{array}$ & $\begin{array}{r}3,676 \\
0\end{array}$ & $\begin{array}{r}6,984 \\
223\end{array}$ & $\begin{array}{r}2,173 \\
478\end{array}$ & $\begin{array}{l}1,256 \\
1,618\end{array}$ \\
\hline 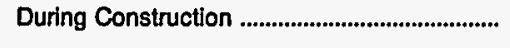 & 0 & 0 & 0 & -455 & 0 & 0 \\
\hline 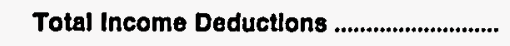 & o & 6,352 & 3,676 & 6,752 & 2,650 & 2,875 \\
\hline Income Before Extraordinary Items ................... & 938 & 0 & 370 & 5,010 & -229 & 63 \\
\hline Extraordinary Income & 0 & 0 & 0 & 0 & 0 & 0 \\
\hline 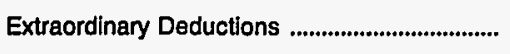 & 0 & 0 & 0 & 0 & 0 & 0 \\
\hline 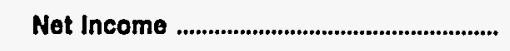 & 938 & $\mathbf{0}$ & 370 & 5,010 & -229 & 63 \\
\hline
\end{tabular}

Note: Totals may not equal sum of components because of independent rounding.

Source: Energy Information Administration, Form EIA-412, "Annual Report of Public Electric Utilities." 
Table 21. Statement of Income by Major U.S. Publicly Owned Electric Utility Within State, 1993 (Continued)

(Thousand Dollars)

\begin{tabular}{|c|c|c|c|c|c|c|}
\hline Item & $\begin{array}{l}\text { Virginia } \\
\text { Bristol } \\
\text { Utilities } \\
\text { Board } \\
\text { June } 30\end{array}$ & $\begin{array}{l}\text { Virginia } \\
\text { Danville } \\
\text { City of } \\
\text { June } 30\end{array}$ & $\begin{array}{c}\text { Virginia } \\
\begin{array}{l}\text { Harrisonburg } \\
\text { City of }\end{array} \\
\text { June } 30\end{array}$ & $\begin{array}{l}\text { Virginia } \\
\begin{array}{c}\text { Manassas } \\
\text { City of }\end{array} \\
\text { June } 30\end{array}$ & $\begin{array}{c}\text { Virginia } \\
\begin{array}{c}\text { Martinsville } \\
\text { City of }\end{array} \\
\text { June } 30\end{array}$ & $\begin{array}{l}\text { Virginia } \\
\text { Radford } \\
\text { City of } \\
\text { June } 30\end{array}$ \\
\hline Electric Utillty Operating Revenues ............ & 25,814 & 40,574 & 30,371 & 17,988 & 10,388 & 12,753 \\
\hline 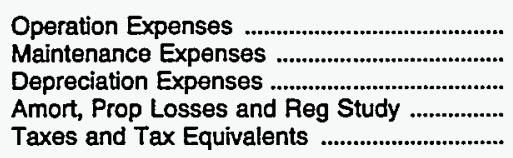 & $\begin{array}{r}23,484 \\
592 \\
653 \\
0 \\
480\end{array}$ & $\begin{array}{r}29,068 \\
1,142 \\
1,700 \\
0 \\
0\end{array}$ & $\begin{array}{r}23,817 \\
491 \\
1,333 \\
184 \\
155\end{array}$ & $\begin{array}{r}14,502 \\
361 \\
1,213 \\
0 \\
402\end{array}$ & $\begin{array}{r}7,874 \\
403 \\
688 \\
0 \\
81\end{array}$ & $\begin{array}{r}10,149 \\
338 \\
843 \\
0 \\
144\end{array}$ \\
\hline $\begin{array}{l}\text { Total Electric Utility Operating } \\
\text { Expenses }\end{array}$ & 25,208 & 31,909 & 25,979 & 16,477 & 9,045 & 11,473 \\
\hline $\begin{array}{l}\text { Net Electric Utility Operating Income } \\
\text { Income from Electric Plant Leased } \\
\text { to Others }\end{array}$ & $\begin{array}{r}607 \\
0\end{array}$ & $\begin{array}{r}8,665 \\
-32\end{array}$ & 4,392 & 1,510 & 1,343 & 1,280 \\
\hline Electric Utillty Operating Income .............. & 607 & 8,634 & 4,392 & 1,510 & 1,343 & 1,280 \\
\hline Other Electric Income & 453 & 188 & 73 & 1,015 & 58 & 412 \\
\hline $\begin{array}{l}\text { Other Electric Deductions ............................ } \\
\text { Allowance for Other Funds Used } \\
\text { During Construction ...................................... } \\
\text { Taxes On Other Income and Deductions ....... }\end{array}$ & $\begin{array}{l}0 \\
0\end{array}$ & 6,510 & $\begin{array}{l}0 \\
0\end{array}$ & $\begin{array}{l}0 \\
0\end{array}$ & 1,800 & 1,353 \\
\hline 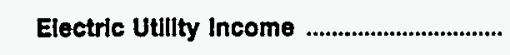 & 1,060 & 2,312 & 4,465 & 2,504 & -399 & 339 \\
\hline 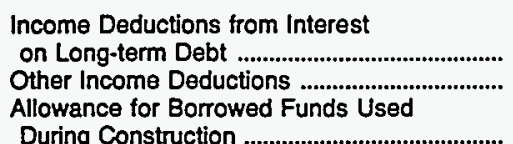 & $\begin{array}{r}0 \\
14\end{array}$ & $\begin{array}{r}97 \\
0\end{array}$ & $\begin{array}{r}211 \\
14\end{array}$ & $\begin{array}{r}682 \\
0\end{array}$ & $\begin{array}{l}0 \\
0\end{array}$ & $\begin{array}{r}250 \\
0\end{array}$ \\
\hline 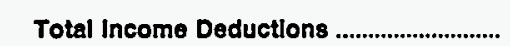 & 14 & 97 & 224 & 682 & $\mathbf{0}$ & 250 \\
\hline Income Before Extraordinary Items .................. & 1,046 & 2,215 & 4,241 & 1,821 & -399 & 90 \\
\hline Extraordinary Income & 0 & 0 & 0 & 0 & 0 & 0 \\
\hline 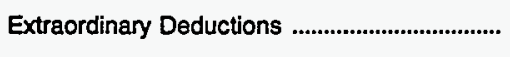 & 0 & 116 & 0 & 294 & 0 & 0 \\
\hline 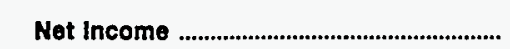 & 1,046 & 2,098 & 4,241 & 1,528 & -399 & 90 \\
\hline
\end{tabular}

Note: Totals may not equal sum of components because of independent rounding.

Source: Energy Information Administration. Form EIA-412, "Annual Report of Public Electric Utilities." 
Table 21. Statement of Income by Major U.S. Publicly Owned Electric Utility Within State, 1993 (Continued)

(Thousand Dollars)

\begin{tabular}{|c|c|c|c|c|c|c|}
\hline Item & $\begin{array}{l}\text { Virginia } \\
\text { Salem } \\
\text { City of } \\
\text { June } 30\end{array}$ & $\begin{array}{l}\text { Virginia } \\
\text { Virginia } \\
\text { Tech } \\
\text { Electric } \\
\text { Service } \\
\text { June } 30\end{array}$ & $\begin{array}{c}\text { Washington } \\
\text { Centralia } \\
\text { City of } \\
\text { December } 31\end{array}$ & $\begin{array}{l}\text { Washington } \\
\text { Ellensburg } \\
\text { City of }\end{array}$ & $\begin{array}{l}\text { Washington } \\
\begin{array}{l}\text { Port Angeles } \\
\text { City of }\end{array} \\
\text { December } 31\end{array}$ & $\begin{array}{c}\text { Washington } \\
\text { PUD No } 1 \\
\text { of } \\
\text { Benton } \\
\text { County } \\
\text { December } 31\end{array}$ \\
\hline Electrlc Utility Operating Revenues ............. & 16,405 & 10,835 & 7,542 & 6,937 & 20,581 & 55,091 \\
\hline 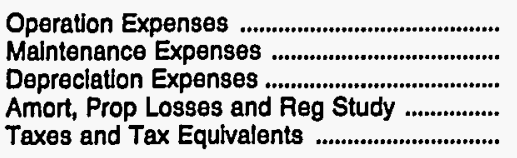 & $\begin{array}{r}13,524 \\
188 \\
767 \\
0 \\
635\end{array}$ & $\begin{array}{r}10,633 \\
674 \\
0 \\
0 \\
250\end{array}$ & $\begin{array}{r}7,166 \\
642 \\
453 \\
3 \\
787\end{array}$ & $\begin{array}{r}5,086 \\
274 \\
379 \\
0 \\
253\end{array}$ & $\begin{array}{r}16,958 \\
1,563 \\
660 \\
0 \\
1,999\end{array}$ & $\begin{array}{r}40,953 \\
1,792 \\
3,098 \\
0 \\
5,957\end{array}$ \\
\hline $\begin{array}{l}\text { Total Electric Utillty Operating } \\
\text { Expenses }\end{array}$ & 15,114 & 11,557 & 9,051 & 5,991 & 21,180 & 51,799 \\
\hline 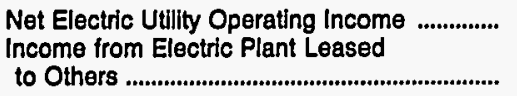 & 1,291 & -722 & $-1,509$ & 946 & -599 & 3,291 \\
\hline Electric Utllity Operating Income ................ & 1,291 & -722 & $-1,509$ & 946 & -599 & 3,281 \\
\hline 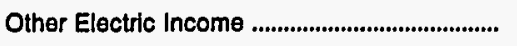 & 997 & 111 & 893 & 202 & 318 & 1,031 \\
\hline $\begin{array}{l}\text { Other Electric Deductions ................................. } \\
\text { Allowance for Other Funds Used } \\
\text { During Construction ......................................... } \\
\text { Taxes on Other Income and Deductions ........ }\end{array}$ & $\begin{array}{l}0 \\
0\end{array}$ & $\begin{array}{l}0 \\
0\end{array}$ & $\begin{array}{l}0 \\
0\end{array}$ & $\begin{array}{r}0 \\
453\end{array}$ & $\begin{array}{l}0 \\
0\end{array}$ & $\begin{array}{l}0 \\
0\end{array}$ \\
\hline Electric Utllity Income ..................................... & 2,287 & -611 & -616 & 641 & -281 & 4,322 \\
\hline 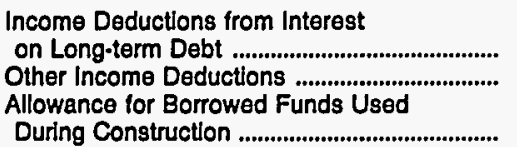 & $\begin{array}{r}691 \\
0\end{array}$ & $\begin{array}{r}188 \\
90\end{array}$ & $\begin{array}{l}77 \\
42\end{array}$ & $\begin{array}{r}62 \\
1\end{array}$ & $\begin{array}{l}137 \\
105\end{array}$ & $\begin{array}{r}2,860 \\
126\end{array}$ \\
\hline 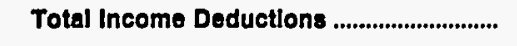 & 691 & 278 & 119 & 63 & 241 & 2,986 \\
\hline Income Before Extraordinary ltems ...................... & 1,597 & -889 & -735 & 578 & -522 & 1,336 \\
\hline Extraordinary Income & 0 & 0 & 0 & 0 & 0 & 0 \\
\hline 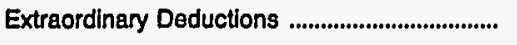 & 560 & 0 & 0 & 0 & 0 & 0 \\
\hline 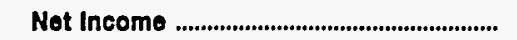 & 1,037 & -889 & -735 & 578 & -522 & 1,336 \\
\hline
\end{tabular}

Note: Totals may not equal sum of components because of independent rounding.

Source: Energy Information Administration, Form ElA-412, "Annual Report of Public Electric Utilities." 
Table 21. Statement of Income by Major U.S. Publicly Owned Electric Utility Within State, 1993 (Continued) (Thousand Dollars)

\begin{tabular}{|c|c|c|c|c|c|c|}
\hline Item & $\begin{array}{c}\text { Washington } \\
\text { PUD No } 1 \\
\text { of } \\
\text { Chelan } \\
\text { County } \\
\text { December } 31\end{array}$ & $\begin{array}{l}\text { Washington } \\
\text { PUD No } 1 \text { of } \\
\text { Clallam } \\
\text { County } \\
\text { December } 31\end{array}$ & $\begin{array}{c}\text { Washington } \\
\text { PUD No } 1 \\
\text { of } \\
\text { Clark } \\
\text { County } \\
\text { December } 31\end{array}$ & $\begin{array}{l}\text { Washington } \\
\text { PUD No } 1 \text { of } \\
\text { Cowlitz } \\
\text { County } \\
\text { December } 31\end{array}$ & $\begin{array}{l}\text { Washington } \\
\text { PUD No } 1 \text { of } \\
\text { Douglas } \\
\text { County } \\
\text { December } 31\end{array}$ & $\begin{array}{l}\text { Washington } \\
\text { PUD No } 1 \text { of } \\
\text { Franklin } \\
\text { County } \\
\text { December } 31\end{array}$ \\
\hline Electric Utility Operating Revenues ............ & 117,354 & 24,011 & 128,398 & 124,844 & 32,642 & 25,120 \\
\hline 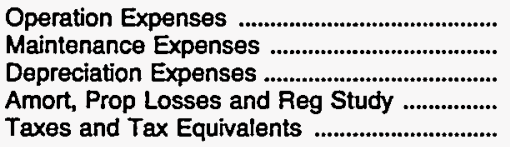 & $\begin{array}{r}50,672 \\
9,997 \\
13,271 \\
0 \\
4,846\end{array}$ & $\begin{array}{r}17,335 \\
960 \\
1,890 \\
0 \\
901\end{array}$ & $\begin{array}{r}109,240 \\
2,767 \\
8,205 \\
226 \\
7,300\end{array}$ & $\begin{array}{r}112,129 \\
1,993 \\
3,354 \\
72 \\
6,061\end{array}$ & $\begin{array}{r}13,832 \\
3,009 \\
3,973 \\
0 \\
1,610\end{array}$ & $\begin{array}{r}18,766 \\
726 \\
1,137 \\
0 \\
1,684\end{array}$ \\
\hline $\begin{array}{l}\text { Total Electric Utilty Operating } \\
\text { Expenses }\end{array}$ & 78,786 & 21,087 & 127,737 & 123,610 & 22,424 & 22,312 \\
\hline 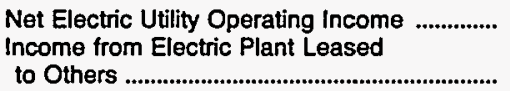 & 38,568 & 2,925 & 661 & 1,235 & 10,218 & 2,808 \\
\hline Electric Utillty Operating Income ............. & 38,568 & 2,925 & 661 & 1,235 & 10,218 & 2,808 \\
\hline 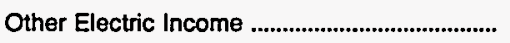 & 9,075 & 336 & 1,132 & 465 & 2,383 & 763 \\
\hline $\begin{array}{l}\text { Other Electric Deductions } \\
\text { Allowance for Other Funds Used........................ }\end{array}$ & 0 & 0 & 0 & 246 & 26 & 69 \\
\hline $\begin{array}{l}\text { During Construction .............................................. } \\
\text { Taxes on Other Income and Deductions .... }\end{array}$ & $\begin{array}{l}0 \\
0\end{array}$ & $\begin{array}{r}0 \\
502\end{array}$ & $\begin{array}{l}0 \\
0\end{array}$ & $\begin{array}{l}0 \\
0\end{array}$ & $\begin{array}{l}0 \\
0\end{array}$ & $\begin{array}{l}\mathbf{0} \\
\mathbf{0}\end{array}$ \\
\hline 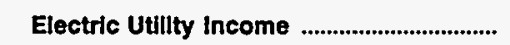 & 47,643 & 2,759 & 1,793 & 1,454 & 12,575 & 3,502 \\
\hline 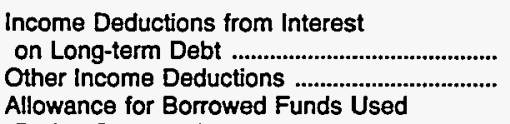 & $\begin{array}{r}45,568 \\
1,420\end{array}$ & $\begin{array}{r}562 \\
20\end{array}$ & $\begin{array}{r}4,633 \\
15\end{array}$ & $\begin{array}{r}127 \\
2\end{array}$ & $\begin{array}{r}10,033 \\
657\end{array}$ & $\begin{array}{r}1,470 \\
133\end{array}$ \\
\hline 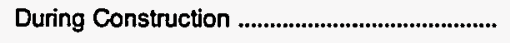 & 0 & 0 & 0 & 0 & 0 & 86 \\
\hline 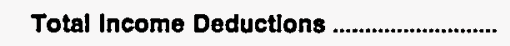 & 46,988 & 582 & 4,649 & 130 & 10,691 & 1,689 \\
\hline 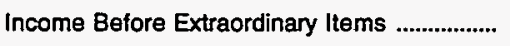 & 655 & 2,177 & $-2,855$ & 1,324 & 1,885 & 1,813 \\
\hline Extraordinary Income & 0 & 0 & $\mathbf{0}$ & 446 & 0 & 0 \\
\hline 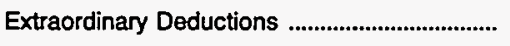 & 0 & 0 & 0 & 0 & 0 & 1,583 \\
\hline 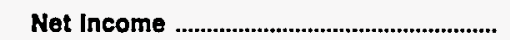 & 655 & 2,177 & $-2,855$ & 1,770 & 1,885 & 230 \\
\hline
\end{tabular}

Note: Totals may not equal sum of components because of independent rounding.

Source: Energy Information Administration, Form EIA-412, "Annual Report of Public Electric Utilities." 
Table 21. Statement of Income by Major U.S. Publicly Owned Electric Utility Within State, 1993 (Continued) (Thousand Dollars)

\begin{tabular}{|c|c|c|c|c|c|c|}
\hline Item & $\begin{array}{c}\text { Washington } \\
\text { PUD No } 1 \\
\text { of } \\
\text { Grays } \\
\text { Harbor Cnty } \\
\text { December } 31\end{array}$ & $\begin{array}{l}\text { Washington } \\
\text { PUD No } 1 \text { of } \\
\text { Klickitat } \\
\text { County } \\
\text { December } 31\end{array}$ & $\begin{array}{c}\text { Washington } \\
\text { PUD No } 1 \\
\text { of } \\
\text { Lewis } \\
\text { County } \\
\text { December } 31\end{array}$ & $\begin{array}{l}\text { Washington } \\
\text { PUD No } 1 \text { of } \\
\text { Okanogan } \\
\text { County } \\
\text { December } 31\end{array}$ & $\begin{array}{l}\text { Washington } \\
\text { PUD No } 1 \text { of } \\
\text { Pend Oreille } \\
\text { Cnty } \\
\text { December } 31\end{array}$ & $\begin{array}{l}\text { Washington } \\
\text { PUD No } 1 \text { of } \\
\text { Snohomish } \\
\text { County } \\
\text { December } 31\end{array}$ \\
\hline Electric Utility Operating Revenues ............ & 51,372 & 11,790 & 27,738 & 15,631 & 20,070 & 274,651 \\
\hline 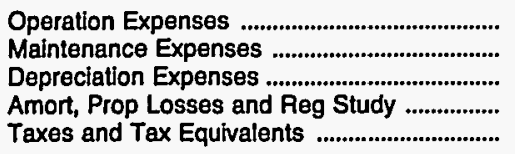 & $\begin{array}{r}38,368 \\
5,090 \\
3,194 \\
0 \\
2,548\end{array}$ & $\begin{array}{r}8,507 \\
611 \\
870 \\
0 \\
819\end{array}$ & $\begin{array}{r}19,735 \\
1,389 \\
1,353 \\
0 \\
1,732\end{array}$ & $\begin{array}{r}12,390 \\
622 \\
1,565 \\
28 \\
1,519\end{array}$ & $\begin{array}{r}14,485 \\
1,238 \\
953 \\
0 \\
1,184\end{array}$ & $\begin{array}{r}211,116 \\
14,549 \\
20,397 \\
0 \\
12,076\end{array}$ \\
\hline $\begin{array}{c}\text { Total Electric Utllity Operating } \\
\text { Expenses }\end{array}$ & 49,200 & 10,806 & 24,210 & 16,124 & 17,861 & 258,139 \\
\hline $\begin{array}{l}\text { Net Electric Utility Operating Income .............. } \\
\text { Income from Electric Plant Leased }\end{array}$ & 2,171 & 985 & 3,527 & -492 & 2,209 & 16,512 \\
\hline 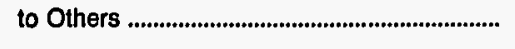 & 0 & 0 & 0 & 0 & 0 & 0 \\
\hline Electric Utilty Operating Income .............. & 2,171 & 985 & 3,527 & -492 & 2,209 & 16,512 \\
\hline Other Electric Income .......................................... & 3,134 & 252 & 458 & 556 & 395 & 9,425 \\
\hline $\begin{array}{l}\text { Other Electric Deductions } \\
\text { Allowance for Other Funds Used }\end{array}$ & 0 & 0 & 0 & 33 & 195 & 0 \\
\hline $\begin{array}{l}\text { During Construction .................................... } \\
\text { Taxes on Other Income and Deductions ....... }\end{array}$ & $\begin{array}{l}0 \\
0\end{array}$ & $\begin{array}{l}0 \\
0\end{array}$ & $\begin{array}{l}0 \\
0\end{array}$ & $\begin{array}{l}\mathbf{0} \\
\mathbf{0}\end{array}$ & $\begin{array}{l}0 \\
0\end{array}$ & $\begin{array}{r}1,359 \\
0\end{array}$ \\
\hline 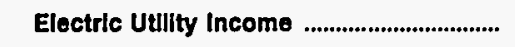 & 5,305 & 1,236 & 3,986 & 30 & 2,409 & 27,296 \\
\hline 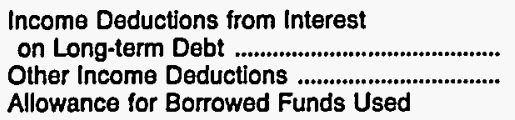 & $\begin{array}{r}0 \\
3,581\end{array}$ & $\begin{array}{r}632 \\
7\end{array}$ & $\begin{array}{l}0 \\
0\end{array}$ & $\begin{array}{l}5 \\
0\end{array}$ & $\begin{array}{l}223 \\
114\end{array}$ & $\begin{array}{r}33,384 \\
4,886\end{array}$ \\
\hline 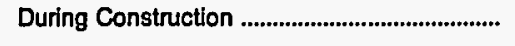 & 0 & 0 & 0 & 0 & 0 & 0 \\
\hline Total Income Deductlons ............................. & 3,581 & 639 & $\mathbf{0}$ & 5 & 337 & 38,270 \\
\hline Income Before Extraordinary Items ................... & 1,725 & 597 & 3,986 & 26 & 2,072 & $-10,974$ \\
\hline 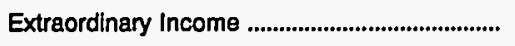 & 0 & 156 & 0 & 0 & 4 & 0 \\
\hline Extraordinary Deductions ................................... & 0 & 0 & 0 & 0 & 0 & 0 \\
\hline Net Income & 1,725 & 753 & 3,986 & 26 & 2,076 & $-10,974$ \\
\hline
\end{tabular}

Note: Totals may not equal sum of components because of independent rounding.

Source: Energy Information Administration, Form EIA-412, "Annual Report of Public Electric Utilities." 
Table 21. Statement of Income by Major U.S. Publicly Owned Electric Utility Within State, 1993 (Continued)

(Thousand Dollars)

\begin{tabular}{|c|c|c|c|c|c|c|}
\hline Item & $\begin{array}{l}\text { Washington } \\
\text { PUD No } 1 \text { of } \\
\text { Whatcom } \\
\text { County } \\
\text { December } 31\end{array}$ & $\begin{array}{c}\text { Washington } \\
\text { PUD No } 2 \\
\text { of } \\
\text { Grant } \\
\text { County } \\
\text { December } 31\end{array}$ & $\begin{array}{l}\text { Washington } \\
\text { PUD No } 2 \text { of } \\
\text { Pacific } \\
\text { County } \\
\text { December } 31\end{array}$ & $\begin{array}{c}\text { Washington } \\
\text { PUD No } 3 \\
\text { of } \\
\text { Mason } \\
\text { County } \\
\text { December } 31\end{array}$ & $\begin{array}{l}\text { Washington } \\
\text { Richland } \\
\text { City of } \\
\text { December } 31\end{array}$ & $\begin{array}{c}\text { Washington } \\
\text { Seattle } \\
\text { City of } \\
\text { December } 31\end{array}$ \\
\hline Electric Utillty Operating Revenues .............. & 3,373 & 89,552 & 12,863 & 22,159 & 25,681 & 320,359 \\
\hline 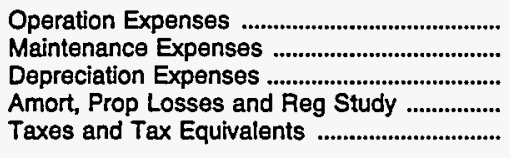 & $\begin{array}{r}3,467 \\
19 \\
16 \\
0 \\
204\end{array}$ & $\begin{array}{r}36,203 \\
19,643 \\
13,928 \\
0 \\
5,123\end{array}$ & $\begin{array}{r}9,145 \\
834 \\
1,037 \\
0 \\
611\end{array}$ & $\begin{array}{r}16,979 \\
1,454 \\
1,952 \\
0 \\
924\end{array}$ & $\begin{array}{r}19,769 \\
567 \\
1,038 \\
0 \\
2,731\end{array}$ & $\begin{array}{r}217,650 \\
21,312 \\
32,028 \\
0 \\
36,155\end{array}$ \\
\hline $\begin{array}{c}\text { Total Electric Utllity Operating } \\
\text { Expenses }\end{array}$ & 3,706 & 74,897 & 11,627 & 21,310 & 24,105 & 307,145 \\
\hline 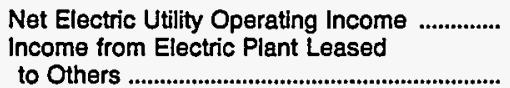 & $\begin{array}{r}-334 \\
0\end{array}$ & 14,655 & 1,236 & 850 & 1,576 & 13,215 \\
\hline Electrle Utllity Operating Income .............. & -334 & 14,655 & 1,236 & 850 & 1,576 & 13,215 \\
\hline 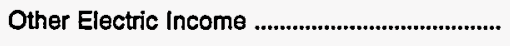 & 116 & 10,739 & 827 & 617 & 609 & 13,378 \\
\hline $\begin{array}{l}\text { Other Electric Deductions } \\
\text { Allowance for Other Funds Used...................... }\end{array}$ & 0 & 0 & 690 & 0 & 0 & 243 \\
\hline $\begin{array}{l}\text { During Construction .................................. } \\
\text { Taxes on Other Income and Deductions ....... }\end{array}$ & $\begin{array}{l}0 \\
0\end{array}$ & $\begin{array}{l}0 \\
0\end{array}$ & $\begin{array}{r}0 \\
274\end{array}$ & $\begin{array}{l}0 \\
0\end{array}$ & $\begin{array}{l}0 \\
0\end{array}$ & $\begin{array}{l}0 \\
0\end{array}$ \\
\hline 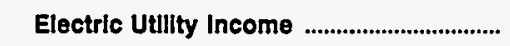 & -218 & 25,395 & 1,099 & 1,466 & 2,185 & 26,350 \\
\hline 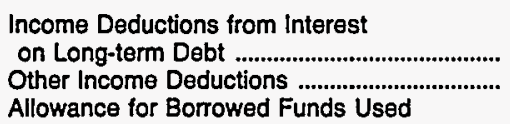 & $\begin{array}{l}0 \\
0\end{array}$ & $\begin{array}{r}21,796 \\
739\end{array}$ & $\begin{array}{r}237 \\
0\end{array}$ & $\begin{array}{r}1,092 \\
39\end{array}$ & $\begin{array}{r}1,268 \\
334\end{array}$ & $\begin{array}{r}34,159 \\
4,339\end{array}$ \\
\hline 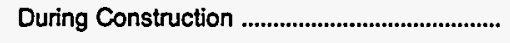 & 0 & 0 & 0 & 0 & 0 & $-2,025$ \\
\hline 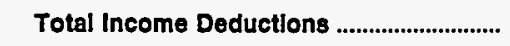 & 0 & 22,535 & 237 & 1,131 & 1,602 & 36,473 \\
\hline Income Before Extraordinary Items .................... & -218 & 2,860 & 862 & 335 & 583 & $-10,123$ \\
\hline Extraordinary Income & 0 & 0 & 0 & 0 & 0 & 0 \\
\hline 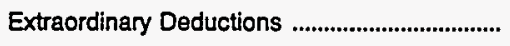 & 1 & 0 & 0 & 0 & 0 & 0 \\
\hline Net Income & -219 & 2,860 & 862 & 335 & 583 & $-10,123$ \\
\hline
\end{tabular}

Note: Totals may not equal sum of components because of independent rounding.

Source: Energy Information Administration, Form ElA-412, "Annual Report of Public Electric Utilities." 
Table 21. Statement of Income by Major U.S. Publicly Owned Electric Utility Within State, 1993 (Continued)

(Thousand Dollars)

\begin{tabular}{|c|c|c|c|c|c|c|}
\hline Item & $\begin{array}{c}\text { Washington } \\
\text { Tacoma } \\
\text { City of } \\
\text { December } 31\end{array}$ & $\begin{array}{c}\text { Washington } \\
\text { Vera } \\
\text { Irrigation } \\
\text { District \#15 } \\
\text { December } 31\end{array}$ & $\begin{array}{l}\text { Washington } \\
\text { Washington } \\
\text { Pub } \\
\text { Pwr } \\
\text { Supply Sys } \\
\text { June } 30\end{array}$ & $\begin{array}{l}\text { Wisconsin } \\
\text { Badger Power } \\
\begin{array}{c}\text { Marketing } \\
\text { Auth }\end{array} \\
\text { December } 31\end{array}$ & $\begin{array}{l}\text { Wisconsin } \\
\text { Jefferson } \\
\text { City of } \\
\text { December } 31\end{array}$ & $\begin{array}{c}\text { Wisconsin } \\
\begin{array}{c}\text { Kaukauna } \\
\text { City of }\end{array} \\
\text { December } 31\end{array}$ \\
\hline Electrle Utllity Operating Revenues ............. & 196,808 & 6,598 & 510,944 & 9,696 & 6,600 & 19,993 \\
\hline 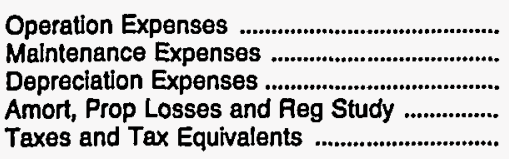 & $\begin{array}{r}129,536 \\
19,074 \\
16,914 \\
0 \\
20,665\end{array}$ & $\begin{array}{r}5,402 \\
263 \\
391 \\
0 \\
250\end{array}$ & $\begin{array}{r}144,080 \\
44,211 \\
110,311 \\
276 \\
2,252\end{array}$ & $\begin{array}{r}8,712 \\
7 \\
154 \\
36 \\
140\end{array}$ & $\begin{array}{r}5,545 \\
64 \\
196 \\
108 \\
205\end{array}$ & $\begin{array}{r}15,962 \\
799 \\
994 \\
0 \\
911\end{array}$ \\
\hline 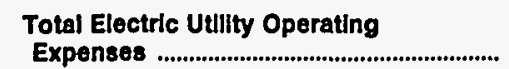 & 186,190 & 6,306 & 301,130 & 9,048 & 6,119 & 18,667 \\
\hline 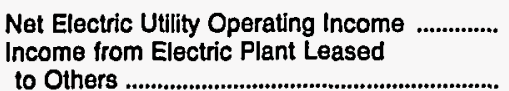 & 10,619 & 292 & 209,814 & 647 & $\begin{array}{r}481 \\
0\end{array}$ & $\begin{array}{r}1,326 \\
0\end{array}$ \\
\hline Electric Utlity Operating Income ............. & 10,619 & 298 & 209,814 & 647 & 481 & 1,326 \\
\hline 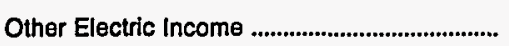 & 3,616 & 210 & 16,604 & 0 & 124 & 57 \\
\hline $\begin{array}{l}\text { Other Electric Deductions } \\
\text { Allowance for Other Funds Used }\end{array}$ & 276 & 8 & 11,877 & 0 & 8 & 0 \\
\hline 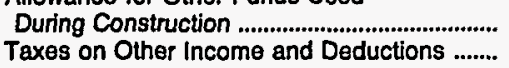 & $\begin{array}{l}0 \\
0\end{array}$ & $\begin{array}{l}0 \\
0\end{array}$ & $\begin{array}{l}0 \\
0\end{array}$ & $\begin{array}{l}0 \\
0\end{array}$ & $\begin{array}{l}0 \\
0\end{array}$ & $\begin{array}{r}0 \\
150\end{array}$ \\
\hline 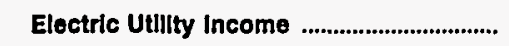 & 13,959 & 500 & 214,540 & 647 & 598 & 1,233 \\
\hline $\begin{array}{l}\text { Income Deductions from Interest } \\
\text { on Long-term Debt .......................................... } \\
\text { Other Income Deductions ........................ } \\
\text { Allowance for Borrowed Funds Used }\end{array}$ & $\begin{array}{r}23,246 \\
765\end{array}$ & $\begin{array}{l}92 \\
20\end{array}$ & $\begin{array}{r}164,263 \\
5,822\end{array}$ & $\begin{array}{r}425 \\
71\end{array}$ & $\begin{array}{r}356 \\
19\end{array}$ & $\begin{array}{r}1,150 \\
0\end{array}$ \\
\hline 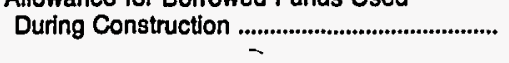 & $-3,738$ & 0 & 0 & 0 & 0 & 0 \\
\hline 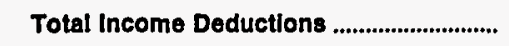 & 20,273 & 113 & 170,084 & 496 & 375 & 1,150 \\
\hline Income Before Extraordinary ltems .................. & $-6,314$ & 387 & 44,456 & 152 & 223 & 83 \\
\hline 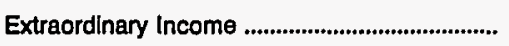 & 0 & 0 & 0 & 0 & 0 & 0 \\
\hline 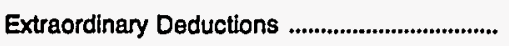 & 0 & 0 & 44,456 & 0 & 0 & 0 \\
\hline Net Income & $-6,314$ & 387 & $\mathbf{0}$ & 152 & 223 & 83 \\
\hline
\end{tabular}

Note: Totals may not equal sum of components because of independent rounding.

Source: Energy Information Administration, Form EIA-412, "Annual Report of Public Electric Utilities." 
Table 21. Statement of Income by Major U.S. Publicly Owned Electric Utility Within State, 1993 (Continued)

(Thousand Dollars)

\begin{tabular}{|c|c|c|c|c|c|c|}
\hline Item & $\begin{array}{l}\text { Wisconsin } \\
\text { Manitowoc } \\
\text { Public } \\
\text { Utilities } \\
\text { December } 31\end{array}$ & $\begin{array}{c}\text { Wisconsin } \\
\begin{array}{c}\text { Marshfield } \\
\text { City of }\end{array} \\
\text { December } 31\end{array}$ & $\begin{array}{c}\text { Wisconsin } \\
\text { Menasha } \\
\text { City of } \\
\text { December } 31\end{array}$ & $\begin{array}{l}\text { Wisconsin } \\
\begin{array}{c}\text { New London } \\
\text { City of }\end{array} \\
\text { December } 31\end{array}$ & $\begin{array}{l}\text { Wisconsin } \\
\begin{array}{c}\text { Oconomowoc } \\
\text { City of }\end{array} \\
\text { December } 31\end{array}$ & $\begin{array}{l}\text { Wisconsin } \\
\text { Plymouth } \\
\text { City of } \\
\text { December } 31\end{array}$ \\
\hline Electric UtIlity Operating Revenues ............ & 24,975 & 13,671 & 22,985 & 7,834 & 8,368 & 7,140 \\
\hline 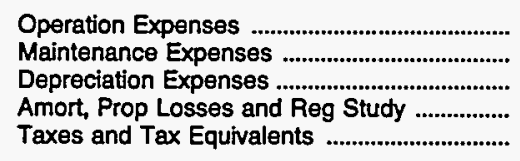 & $\begin{array}{r}16,980 \\
1,470 \\
2,011 \\
21 \\
1,700\end{array}$ & $\begin{array}{r}10,818 \\
448 \\
670 \\
0 \\
545\end{array}$ & $\begin{array}{r}20,628 \\
385 \\
745 \\
29 \\
704\end{array}$ & $\begin{array}{r}6,659 \\
0 \\
232 \\
0 \\
205\end{array}$ & $\begin{array}{r}6,461 \\
249 \\
447 \\
32 \\
394\end{array}$ & $\begin{array}{r}5,827 \\
183 \\
410 \\
0 \\
261\end{array}$ \\
\hline $\begin{array}{l}\text { Total Electric Utllity Operating } \\
\text { Expenses }\end{array}$ & 22,183 & 12,481 & 22,491 & 7,096 & 7,584 & 6,682 \\
\hline 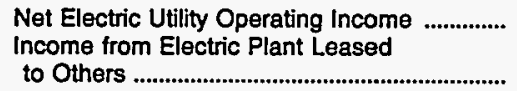 & $\begin{array}{r}2,792 \\
0\end{array}$ & $\begin{array}{r}1,190 \\
0\end{array}$ & 494 & 739 & 784 & 458 \\
\hline Electric Utility Operating Income ............. & 2,792 & 1,190 & 494 & 739 & 784 & 458 \\
\hline Other Electric Income & 490 & 104 & 153 & $\mathbf{0}$ & 105 & 69 \\
\hline Other Electric Deductions & 61 & 251 & 0 & 0 & 0 & 17 \\
\hline $\begin{array}{l}\text { During Construction ....................................... } \\
\text { Taxes on Other Income and Deductions ...... }\end{array}$ & $\begin{array}{l}0 \\
0\end{array}$ & $\begin{array}{l}0 \\
0\end{array}$ & $\begin{array}{l}0 \\
0\end{array}$ & $\begin{array}{r}0 \\
101\end{array}$ & $\begin{array}{l}0 \\
0\end{array}$ & $\begin{array}{l}0 \\
0\end{array}$ \\
\hline 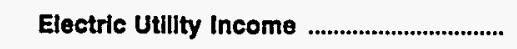 & 3,221 & 1,042 & 647 & 638 & 889 & 510 \\
\hline 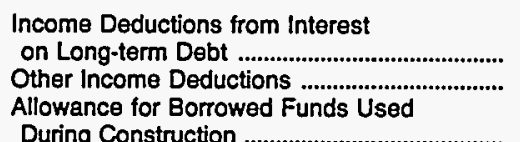 & $\begin{array}{r}1,512 \\
105\end{array}$ & $\begin{aligned} 232 \\
11\end{aligned}$ & $\begin{array}{r}513 \\
35\end{array}$ & $\begin{array}{l}0 \\
0\end{array}$ & $\begin{array}{r}186 \\
4\end{array}$ & $\begin{array}{l}18 \\
24\end{array}$ \\
\hline 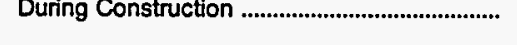 & 0 & 0 & 0 & 0 & 0 & 0 \\
\hline 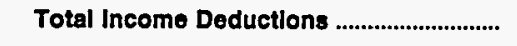 & 1,617 & 244 & 548 & 0 & 190 & 42 \\
\hline Income Before Extraordinary Items .................. & 1,605 & 799 & 99 & 638 & 699 & 468 \\
\hline Extraordinary Income & 0 & 0 & 0 & 0 & 0 & 0 \\
\hline 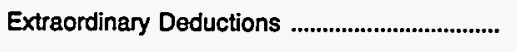 & 0 & 0 & 0 & 0 & 0 & 0 \\
\hline 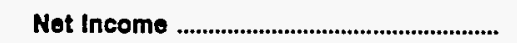 & 1,605 & 799 & 99 & 638 & 699 & 488 \\
\hline
\end{tabular}

Note: Totals may not equal sum of components because of independent rounding.

Source: Energy Information Administration, Form EIA-412, "Annual Report of Public Electric Utilities." 
Table 21. Statement of Income by Major U.S. Publicly Owned Electric Utility Within State, 1993 (Continued)

(Thousand Dollars)

\begin{tabular}{|c|c|c|c|c|c|c|}
\hline Item & $\begin{array}{l}\text { Wisconsin } \\
\text { Reedsburg } \\
\text { Utility Comm } \\
\text { December } 31\end{array}$ & $\begin{array}{c}\text { Wisconsin } \\
\text { Shawano } \\
\text { Municipal } \\
\text { Utilities } \\
\text { December } 31\end{array}$ & $\begin{array}{l}\text { Wisconsin } \\
\text { Sheboygan } \\
\text { Falls } \\
\text { City of } \\
\text { December } 31\end{array}$ & $\begin{array}{l}\text { Wisconsin } \\
\text { Sturgeon Bay } \\
\begin{array}{c}\text { Combined } \\
\text { Utils }\end{array} \\
\text { December } 31\end{array}$ & $\begin{array}{l}\text { Wisconsin } \\
\text { Sun Prairie } \\
\text { Water \& Light } \\
\text { Comm } \\
\text { December } 31\end{array}$ & $\begin{array}{l}\text { Wisconsin } \\
\text { Wisconsin } \\
\text { Public } \\
\text { Power } \\
\text { Inc Sys } \\
\text { December } 31\end{array}$ \\
\hline Electric Utillty Operating Revenues ............. & 6,651 & 8,181 & 7,033 & 7,746 & 6,635 & 108,801 \\
\hline 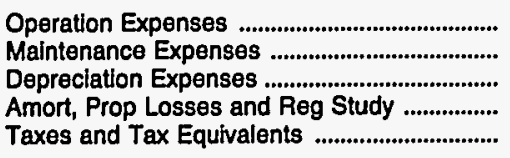 & $\begin{array}{r}6,091 \\
63 \\
265 \\
2 \\
226\end{array}$ & $\begin{array}{r}6,848 \\
77 \\
300 \\
0 \\
168\end{array}$ & $\begin{array}{r}6,233 \\
0 \\
264 \\
0 \\
173\end{array}$ & $\begin{array}{r}5,858 \\
215 \\
553 \\
0 \\
423\end{array}$ & $\begin{array}{r}5,813 \\
85 \\
344 \\
23 \\
266\end{array}$ & $\begin{array}{r}93,911 \\
1,429 \\
2,453 \\
935 \\
2,471\end{array}$ \\
\hline $\begin{array}{l}\text { Total Electric UtIllty Operating } \\
\text { Expenses }\end{array}$ & 6,648 & 7,394 & 6,670 & 7,049 & $\mathbf{6 , 5 3 1}$ & 101,200 \\
\hline $\begin{array}{l}\text { Net Electric Utility Operating Income } \\
\text { Income from Electric Plant Lea.... }\end{array}$ & 3 & 787 & 363 & 698 & 104 & 7,602 \\
\hline Electrlc Utility Operating Income ............... & 3 & 1,030 & 363 & 698 & 445 & 7,602 \\
\hline Other Electric Income & 139 & 135 & 0 & 98 & 73 & 5,997 \\
\hline $\begin{array}{l}\text { Other Electric Deductions .............................. } \\
\text { Allowance for Other Funds Used } \\
\text { During Construction ........................................ } \\
\text { Texes on Other Income and Deductions ...... }\end{array}$ & $\begin{array}{l}0 \\
0\end{array}$ & $\begin{array}{r}0 \\
119\end{array}$ & $\begin{array}{l}0 \\
0\end{array}$ & $\begin{array}{l}0 \\
0\end{array}$ & $\begin{array}{l}0 \\
0\end{array}$ & 667 \\
\hline 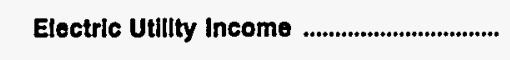 & 142 & 1,015 & 363 & 796 & 518 & 12,932 \\
\hline 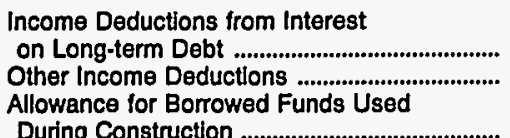 & $\begin{array}{r}303 \\
19\end{array}$ & $\begin{array}{r}139 \\
87\end{array}$ & $\begin{array}{l}0 \\
0\end{array}$ & $\begin{array}{r}486 \\
22\end{array}$ & $\begin{array}{l}0 \\
0\end{array}$ & $\begin{array}{l}7,645 \\
3,713\end{array}$ \\
\hline 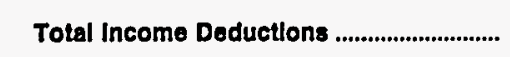 & 149 & 227 & $\mathbf{0}$ & 509 & 0 & 10,660 \\
\hline Income Before Extraordinary ltems ................... & -8 & 788 & 363 & 287 & 518 & 2,273 \\
\hline 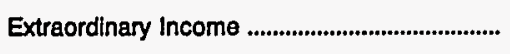 & 59 & 110 & 0 & 0 & 0 & 0 \\
\hline Extraordinary Deductions ........................................ & 0 & 14 & 0 & 0 & 0 & 0 \\
\hline 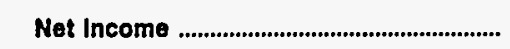 & 51 & 884 & 363 & 287 & 518 & 2,273 \\
\hline
\end{tabular}

Note: Totals may not equal sum of components because of independent rounding.

Source: Energy Information Administration, Form EIA-412, "Annual Report of Public Electric Utilities." 
Table 21. Statement of Income by Major U.S. Publicly Owned Electric Utility Within State, 1993 (Continued)

(Thousand Dollars)

\begin{tabular}{|c|c|c|c|}
\hline Item & $\begin{array}{l}\text { Wisconsin } \\
\text { Wisconsin } \\
\text { Rapids } W W \\
\& L \\
\text { Comm } \\
\text { December } 31\end{array}$ & $\begin{array}{l}\text { Wyoming } \\
\text { Gillette } \\
\text { City of } \\
\text { June } 30\end{array}$ & $\begin{array}{l}\text { Wyoming } \\
\text { Wyoming } \\
\text { Municipal } \\
\text { Power Agency } \\
\text { December } 31\end{array}$ \\
\hline Electric Utility Operating Revenues ............ & 10,196 & 9,987 & 5,472 \\
\hline 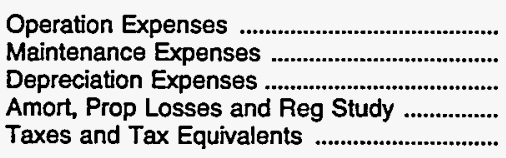 & $\begin{array}{r}7,843 \\
357 \\
589 \\
0 \\
496\end{array}$ & $\begin{array}{r}8,786 \\
0 \\
808 \\
33 \\
31\end{array}$ & $\begin{array}{r}3,192 \\
383 \\
674 \\
0 \\
92\end{array}$ \\
\hline $\begin{array}{l}\text { Total Electric Utility Operating } \\
\text { Expenses }\end{array}$ & 9,285 & 9,659 & 4,342 \\
\hline 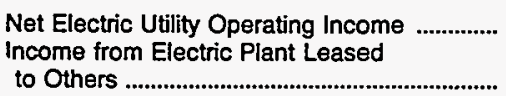 & 911 & 328 & $\begin{array}{r}1,130 \\
0\end{array}$ \\
\hline Electric Utillty Operating Income ............. & 911 & 328 & 1,130 \\
\hline Other Electric Income & 154 & 785 & 382 \\
\hline 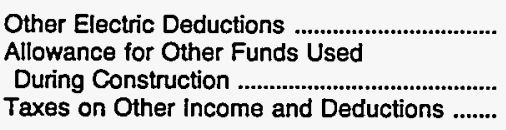 & $\begin{array}{l}0 \\
0\end{array}$ & $\begin{array}{l}0 \\
0\end{array}$ & $\begin{array}{l}0 \\
0\end{array}$ \\
\hline 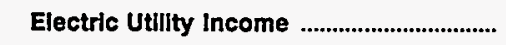 & 1,027 & 1,113 & 1,512 \\
\hline 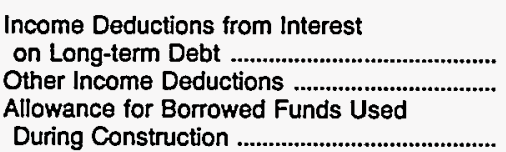 & $\begin{array}{r}25 \\
3\end{array}$ & $\begin{array}{r}135 \\
0\end{array}$ & $\begin{array}{r}1,272 \\
70\end{array}$ \\
\hline 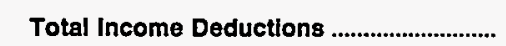 & 28 & 135 & 1,342 \\
\hline Income Before Extraordinary ltems .................... & 999 & 978 & 169 \\
\hline Extraordinary Income & 0 & 0 & 0 \\
\hline 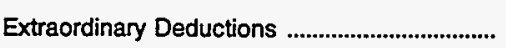 & 0 & 0 & 0 \\
\hline 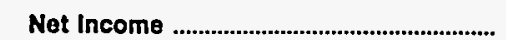 & 999 & 978 & 169 \\
\hline
\end{tabular}

Note: Totals may not equal sum of components because of independent rounding.

Source: Energy Information Administration, Form ElA-412, "Annual Report of Public Electric Utilities." 
Table 22. Balance Sheet by Major U.S. Publicly Owned Electric Utility Within State at End of Period, 1993

(Thousand Dollars)

\begin{tabular}{|c|c|c|c|c|c|c|}
\hline Item & $\begin{array}{l}\text { Alabama } \\
\text { Alabama } \\
\text { Municipal } \\
\text { Elec Auth } \\
\text { September } 30\end{array}$ & $\begin{array}{l}\text { Alabama } \\
\text { Albertville } \\
\text { Municipal } \\
\text { Utils Bd } \\
\text { June } 30\end{array}$ & $\begin{array}{l}\text { Alabama } \\
\text { Andalusia } \\
\text { City of } \\
\text { September } 30\end{array}$ & $\begin{array}{l}\text { Alabama } \\
\text { Athens } \\
\text { City of } \\
\text { December } 31\end{array}$ & $\begin{array}{c}\text { Bessemer } \\
\text { City of } \\
\text { June } 30\end{array}$ & $\begin{array}{l}\text { Cullman } \\
\text { Power Board }\end{array}$ \\
\hline \multicolumn{7}{|l|}{ Electric Utility Plant } \\
\hline Electric Utility Plant \& Adjust ............................. & 0 & 12,374 & 3,609 & 40,249 & 20,208 & 10,632 \\
\hline Const Work in Progress & 0 & 163 & 0 & 460 & 81 & 365 \\
\hline (less) Depr, Amort, and Depletion ................... & 0 & 4,522 & 1,197 & 13,410 & 8,493 & 5,333 \\
\hline Net Electric Utility Plant & 0 & 8,014 & 2,413 & 27,299 & 11,796 & 5,665 \\
\hline 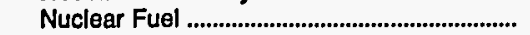 & 0 & 0 & 0 & 0 & 0 & 0 \\
\hline (less) Amort of Nucl Fuel ................................... & 0 & 0 & 0 & 0 & 0 & 0 \\
\hline Net Elec Plant Incl Nucl Fuel .......................... & 0 & 8,014 & 2,413 & 27,299 & 11,796 & 5,665 \\
\hline \multicolumn{7}{|l|}{ Other Property \& Investments } \\
\hline 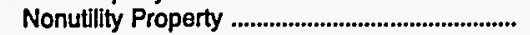 & 3,267 & 0 & 11,927 & $\mathbf{0}$ & 0 & 0 \\
\hline (less) Accum Provisions for Depr \& Amort .... & 54 & 0 & 1,812 & 0 & 0 & 0 \\
\hline 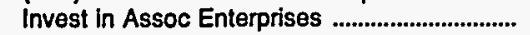 & 0 & 0 & 0 & $\mathbf{0}$ & 0 & 0 \\
\hline $\begin{array}{l}\text { Invest \& Special Funds ................................ } \\
\text { Total Other Property \& Investments ....... }\end{array}$ & $\begin{array}{l}25,108 \\
28,320\end{array}$ & $\begin{array}{l}11 \\
11\end{array}$ & $\begin{array}{r}411 \\
10,527\end{array}$ & $\begin{array}{l}6,792 \\
6,792\end{array}$ & $\begin{array}{l}48 \\
48\end{array}$ & $\begin{array}{l}214 \\
214\end{array}$ \\
\hline \multicolumn{7}{|l|}{ Current and Accrued Assets } \\
\hline Cash, Working Funds \& Investments ............. & 8,689 & 2,837 & 1,223 & 659 & 1,514 & 1,578 \\
\hline 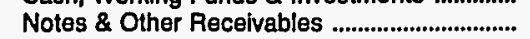 & & 1,509 & 41 & 2,990 & 3,477 & 2,295 \\
\hline 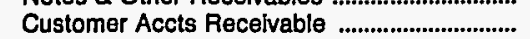 & 7,824 & 0 & 1,220 & 0 & 0 & 0 \\
\hline (less) Accum Prov for Uncollected Accts ...... & 0 & 0 & 0 & 0 & 0 & 0 \\
\hline Fuel Stock \& Exp Undistr ..................................... & 0 & 0 & 0 & 0 & 0 & 0 \\
\hline Materials \& Supplies .......................................... & 0 & 146 & 115 & 467 & 293 & 366 \\
\hline 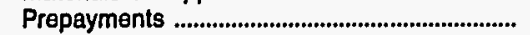 & 103,855 & 14 & 0 & 326 & 227 & 7 \\
\hline Accrued Utility Revenues ..................................... & 0 & 0 & 0 & 0 & 0 & 0 \\
\hline Miscellaneous Current \& Accrued Assets ..... & 0 & 24 & 0 & 90 & 25 & 31 \\
\hline $\begin{array}{l}\text { Total Current \& Accrued Assets ................ } \\
\text { Deferred Debits }\end{array}$ & 120,368 & 4,530 & 2,599 & 4,532 & 5,536 & 4,277 \\
\hline 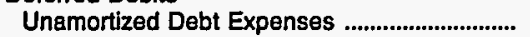 & 16,261 & 0 & 176 & 385 & 13 & 26 \\
\hline Extraordinary Losses, Study Cost ..................... & 0 & 0 & 0 & 0 & 0 & 0 \\
\hline Misc Debt, R \& D Exp, Unamrt Losses ......... & 41,210 & 1,070 & 1,969 & 1,074 & 1,199 & 927 \\
\hline 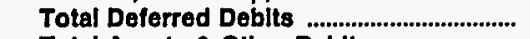 & 57,470 & 1,070 & 2,145 & 1,459 & 1,212 & 952 \\
\hline $\begin{array}{l}\text { Total Assets \& Other Deblts } \\
\text { Proprietary Capital }\end{array}$ & 206,158 & 13,625 & 17,684 & 40,081 & 18,592 & 11,107 \\
\hline 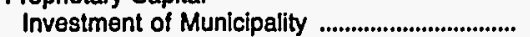 & 0 & 0 & 5,430 & 0 & 0 & Proprietary Capital \\
\hline 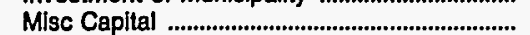 & 0 & 0 & 0 & 0 & 0 & 0 \\
\hline Retained Earnings ................................................ & 513 & 10,389 & 6,247 & 17,893 & 10,414 & 6,468 \\
\hline \multicolumn{3}{|l|}{ Long-term Debt } & 11,676 & 17,893 & 10,414 & 6,468 \\
\hline 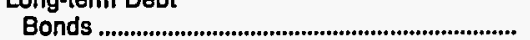 & 199,935 & 0 & 4,235 & 16,210 & 2,275 & 1,420 \\
\hline Advances from Municipality \& Other ............... & 0 & 1,061 & 0 & 1,042 & 1,145 & 935 \\
\hline Unamort Prem on Long-term Debt .................. & 0 & 0 & 0 & 0 & -21 & 0 \\
\hline (less) Unamort Discount on Long-term Debt & 1,637 & 0 & 0 & 0 & 0 & \\
\hline 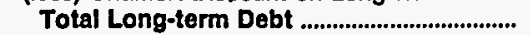 & 198,298 & 1,061 & 4,235 & 17,252 & 3,400 & 2,355 \\
\hline \multicolumn{7}{|l|}{ Other Noncurrent Labilities } \\
\hline Accum Operating Provisions ........................... & 0 & 0 & 0 & 0 & 0 & 0 \\
\hline 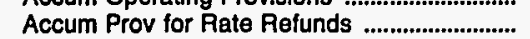 & 0 & 0 & 0 & 0 & 0 & 0 \\
\hline Total Other Noncurrent Llabilitles ............. & 0 & $\mathbf{0}$ & $\mathbf{0}$ & $\mathbf{0}$ & $\mathbf{0}$ & $\mathbf{0}$ \\
\hline \multicolumn{7}{|l|}{ Current and Accrued Liabilities } \\
\hline 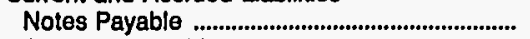 & 0 & 0 & 210 & 293 & 0 & 0 \\
\hline 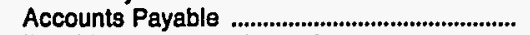 & 6,379 & 1,563 & 1,127 & 3,473 & 3,428 & 1,801 \\
\hline Payables to Assoc Enterprises .......................... & 0 & 0 & 0 & 0 & 0 & 0 \\
\hline 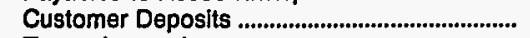 & 0 & 502 & 308 & 1,058 & 1,032 & 358 \\
\hline 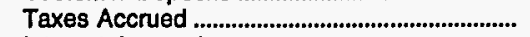 & 0 & 1 & 0 & 0 & 0 & 16 \\
\hline Interest Accrued & 952 & 0 & 100 & -167 & 13 & 32 \\
\hline Misc Current \& Accrued Llabilities .................... & 15 & 108 & 27 & 274 & 304 & 69 \\
\hline $\begin{array}{l}\text { Total Current \& Accrued Llabllitles .......... } \\
\text { Deferred Credits }\end{array}$ & 7,347 & 2,175 & 1,772 & 4,932 & 4,778 & 2,276 \\
\hline \multicolumn{7}{|l|}{ Deferred Credits } \\
\hline 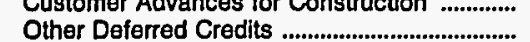 & $\begin{array}{l}0 \\
0\end{array}$ & 0 & 0 & 5 & $\begin{array}{l}0 \\
0\end{array}$ & $\begin{array}{l}0 \\
8\end{array}$ \\
\hline 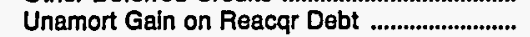 & 0 & 0 & 0 & 0 & 0 & 0 \\
\hline Total Deferred Credits ................................. & 0 & 0 & 0 & 5 & 0 & 8 \\
\hline Total Lab!litles and Other Credits ............. & 206,158 & 13,625 & 17,684 & 40,081 & 18,592 & 11,107 \\
\hline
\end{tabular}

Note: Totals may not equal sum of components because of independent rounding.

Source: Energy Information Administration, Form ElA-412, "Annual Report of Public Electric Utilities." 
Table 22. Balance Sheet by Major U.S. Publicly Owned Electric Utility Within State at End of Period, 1993 (Continued) (Thousand Dollars)

\begin{tabular}{|c|c|c|c|c|c|c|}
\hline Item & $\begin{array}{l}\text { Alabame } \\
\text { Decatur } \\
\text { City of } \\
\text { June } 30\end{array}$ & $\begin{array}{l}\text { Alabama } \\
\text { Dothan } \\
\text { City of } \\
\text { September } 30\end{array}$ & $\begin{array}{l}\text { Alabama } \\
\text { Florence } \\
\text { City of } \\
\text { June } 30\end{array}$ & $\begin{array}{c}\text { Alabama } \\
\text { Foley } \\
\text { City of } \\
\text { (Riviera Utils) } \\
\\
\text { December } 31\end{array}$ & $\begin{array}{c}\text { Alabama } \\
\text { Fort Payne } \\
\text { Improvement } \\
\text { Auth } \\
\text { June } 30\end{array}$ & $\begin{array}{l}\text { Alabama } \\
\text { Guntersville } \\
\text { Electric } \\
\text { Board } \\
\text { June } 30\end{array}$ \\
\hline \multicolumn{7}{|l|}{ Electric Utility Plant } \\
\hline 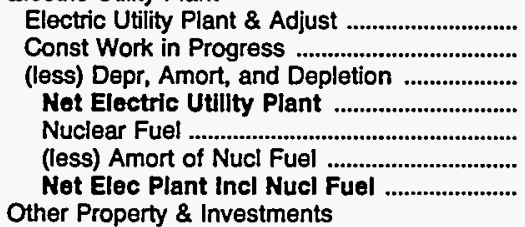 & $\begin{array}{r}38,583 \\
612 \\
16,402 \\
22,793 \\
0 \\
0 \\
22,793\end{array}$ & $\begin{array}{r}53,224 \\
0 \\
19,588 \\
33,636 \\
0 \\
0 \\
33,636\end{array}$ & $\begin{array}{r}70,420 \\
908 \\
28,833 \\
42,495 \\
0 \\
0 \\
42,495\end{array}$ & $\begin{array}{r}53,202 \\
0 \\
17,363 \\
35,840 \\
0 \\
0 \\
35,840\end{array}$ & $\begin{array}{r}11,393 \\
479 \\
4,019 \\
7,853 \\
0 \\
0 \\
7,853\end{array}$ & $\begin{array}{r}8,680 \\
237 \\
4,012 \\
4,904 \\
0 \\
0 \\
4,904\end{array}$ \\
\hline $\begin{array}{l}\text { Nonutility Property ............... } \\
\text { (less) Accum Provisions for Depr \& Amort .... } \\
\text { Invest in Assoc Enterprises ........................ } \\
\text { Invest \& Special Funds ............................ } \\
\text { Total Other Property \& Investments ...... } \\
\text { Current and Accrued Assets }\end{array}$ & $\begin{array}{l}3 \\
0 \\
0 \\
0 \\
3\end{array}$ & $\begin{array}{l}0 \\
0 \\
0 \\
0 \\
0\end{array}$ & $\begin{array}{r}0 \\
0 \\
0 \\
4,893 \\
4,893\end{array}$ & $\begin{array}{r}0 \\
0 \\
0 \\
8,326 \\
8,326\end{array}$ & $\begin{array}{r}0 \\
0 \\
0 \\
363 \\
363\end{array}$ & $\begin{array}{r}0 \\
0 \\
0 \\
382 \\
382\end{array}$ \\
\hline 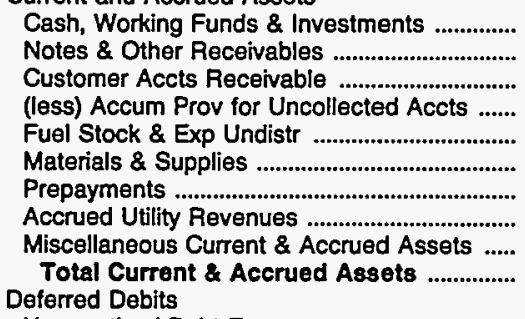 & $\begin{array}{r}4,363 \\
6,321 \\
0 \\
0 \\
0 \\
579 \\
29 \\
0 \\
0 \\
11,293\end{array}$ & $\begin{array}{r}7,311 \\
67 \\
3,528 \\
0 \\
0 \\
229 \\
0 \\
0 \\
45 \\
11,180\end{array}$ & $\begin{array}{r}4,184 \\
7,222 \\
0 \\
0 \\
0 \\
1,479 \\
41 \\
0 \\
51 \\
12,977\end{array}$ & $\begin{array}{r}7,001 \\
0 \\
4,504 \\
39 \\
24 \\
989 \\
856 \\
0 \\
82 \\
13,418\end{array}$ & $\begin{array}{r}2,007 \\
1,591 \\
0 \\
0 \\
0 \\
160 \\
31 \\
0 \\
49 \\
3,839\end{array}$ & $\begin{array}{r}1,091 \\
928 \\
0 \\
0 \\
0 \\
119 \\
52 \\
0 \\
36 \\
2,226\end{array}$ \\
\hline 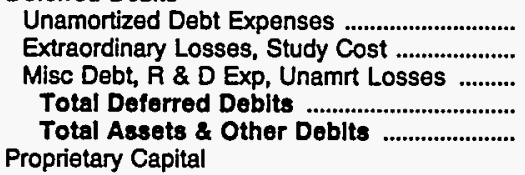 & $\begin{array}{r}0 \\
0 \\
2,008 \\
2,008 \\
36,096\end{array}$ & $\begin{array}{r}0 \\
0 \\
0 \\
0 \\
44,816\end{array}$ & $\begin{array}{r}152 \\
0 \\
2,688 \\
2,841 \\
63,205\end{array}$ & $\begin{array}{r}371 \\
0 \\
0 \\
371 \\
57,954\end{array}$ & $\begin{array}{r}145 \\
0 \\
2,058 \\
2,203 \\
14,257\end{array}$ & $\begin{array}{r}18 \\
0 \\
726 \\
744 \\
8,256\end{array}$ \\
\hline 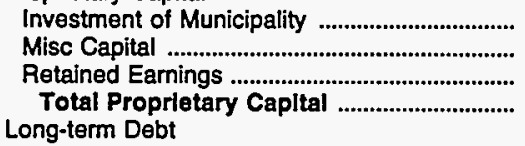 & $\begin{array}{r}0 \\
0 \\
30,794 \\
30,794\end{array}$ & $\begin{array}{r}0 \\
0 \\
38,680 \\
38,680\end{array}$ & $\begin{array}{r}0 \\
0 \\
41,710 \\
41,710\end{array}$ & $\begin{array}{r}0 \\
0 \\
42,018 \\
42,018\end{array}$ & $\begin{array}{r}0 \\
0 \\
6,176 \\
6,176\end{array}$ & $\begin{array}{r}0 \\
0 \\
5,845 \\
5,845\end{array}$ \\
\hline $\begin{array}{l}\text { Bonds ...e. from Municipality \& Other ................ } \\
\text { Unamort Prem on Long-term Debt ............... } \\
\text { (less) Unamort Discount on Long-term Debt } \\
\text { Total Long-term Debt ................................ } \\
\text { Other Noncurrent Liabilities }\end{array}$ & $\begin{array}{r}0 \\
584 \\
0 \\
0 \\
584\end{array}$ & $\begin{array}{l}0 \\
0 \\
0 \\
0 \\
0\end{array}$ & $\begin{array}{r}9,633 \\
2,755 \\
-4,266 \\
0 \\
8,122\end{array}$ & $\begin{array}{r}10,817 \\
0 \\
0 \\
0 \\
10,817\end{array}$ & $\begin{array}{r}5,020 \\
642 \\
0 \\
0 \\
5,662\end{array}$ & $\begin{array}{r}395 \\
703 \\
0 \\
0 \\
1,098\end{array}$ \\
\hline 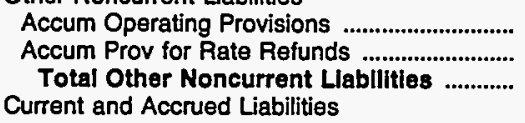 & $\begin{array}{l}0 \\
0 \\
0\end{array}$ & $\begin{array}{l}0 \\
0 \\
0\end{array}$ & $\begin{array}{l}0 \\
0 \\
0\end{array}$ & $\begin{array}{r}280 \\
0 \\
280\end{array}$ & $\begin{array}{l}0 \\
0 \\
0\end{array}$ & $\begin{array}{l}0 \\
0 \\
0\end{array}$ \\
\hline 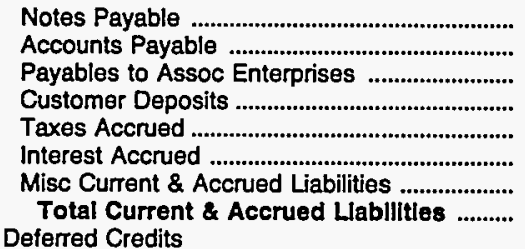 & $\begin{array}{r}0 \\
4,598 \\
0 \\
0 \\
0 \\
0 \\
120 \\
4,718\end{array}$ & $\begin{array}{r}0 \\
3,119 \\
0 \\
2,681 \\
9 \\
0 \\
327 \\
6,136\end{array}$ & $\begin{array}{r}0 \\
9,176 \\
0 \\
3,130 \\
0 \\
94 \\
933 \\
13,333\end{array}$ & $\begin{array}{r}0 \\
2,373 \\
0 \\
1,374 \\
459 \\
425 \\
15 \\
4,646\end{array}$ & $\begin{array}{r}0 \\
1,515 \\
0 \\
450 \\
0 \\
62 \\
255 \\
2,283\end{array}$ & $\begin{array}{r}0 \\
898 \\
0 \\
261 \\
0 \\
6 \\
109 \\
1,274\end{array}$ \\
\hline 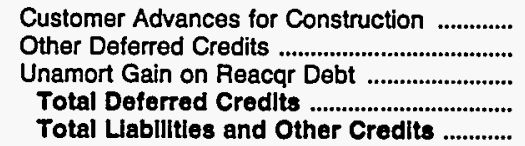 & $\begin{array}{r}0 \\
0 \\
0 \\
0 \\
36,096\end{array}$ & $\begin{array}{r}0 \\
0 \\
0 \\
0 \\
44,816\end{array}$ & $\begin{array}{r}0 \\
41 \\
0 \\
41 \\
63,205\end{array}$ & $\begin{array}{r}0 \\
193 \\
0 \\
193 \\
57,954\end{array}$ & $\begin{array}{r}0 \\
136 \\
0 \\
136 \\
14,257\end{array}$ & $\begin{array}{r}0 \\
38 \\
0 \\
38 \\
8,256\end{array}$ \\
\hline
\end{tabular}

Note: Totals may not equal sum of components because of independent rounding.

Source: Energy Information Administration, Form EIA-412, "Annual Report of Public Electric Utilities." 
Table 22. Balance Sheet by Major U.S. Publicly Owned Electric Utility Within State at End of Period, 1993 (Continued) (Thousand Dollars)

\begin{tabular}{|c|c|c|c|c|c|c|}
\hline Item & $\begin{array}{l}\text { Alabama } \\
\text { Huntsville } \\
\text { City of } \\
\text { September } 30\end{array}$ & $\begin{array}{l}\text { Alabama } \\
\text { Muscle } \\
\text { Shoals } \\
\text { City of } \\
\text { June } 30\end{array}$ & $\begin{array}{l}\text { Alabama } \\
\text { Opelika } \\
\text { City of } \\
\text { September } 30\end{array}$ & $\begin{array}{l}\text { Alabama } \\
\begin{array}{c}\text { Scottsboro } \\
\text { City of }\end{array} \\
\text { June } 30\end{array}$ & $\begin{array}{l}\text { Alabama } \\
\text { Sheffield } \\
\text { Utilities } \\
\text { June } 30\end{array}$ & $\begin{array}{c}\text { Alabama } \\
\text { Sylacauga } \\
\text { Utilities } \\
\text { Board } \\
\text { September } 30\end{array}$ \\
\hline \multicolumn{7}{|l|}{ Electric Utility Plant } \\
\hline Electric Utility Plant \& Adjust ................................ & 153,108 & 13,040 & 16,945 & 14,426 & 32,724 & 10,172 \\
\hline 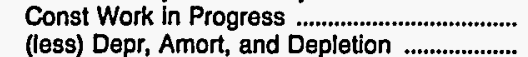 & $\begin{array}{r}3,554 \\
58,844\end{array}$ & $\begin{array}{r}689 \\
4,074\end{array}$ & $\begin{array}{r}991 \\
9,832\end{array}$ & $\begin{array}{r}253 \\
5.115\end{array}$ & $\begin{array}{r}289 \\
14,042\end{array}$ & $\begin{array}{r}0 \\
6.120\end{array}$ \\
\hline Not Electric UtIlity Plant ....................................... & 97,818 & 9,655 & 8,104 & 9,564 & 18,971 & 4,052 \\
\hline 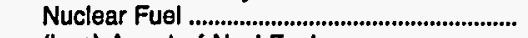 & 0 & 0 & 0 & 0 & 0 & 0 \\
\hline (less) Amort of Nucl Fuel ................................. & 0 & 0 & 0 & & 0 & \\
\hline $\begin{array}{l}\text { Net Elec Plant Incl Nucl Fuel ............................ } \\
\text { Other Property \& Investments }\end{array}$ & 97,818 & $\mathbf{9 , 6 5 5}$ & 8,104 & 9,564 & 18,971 & 4,052 \\
\hline 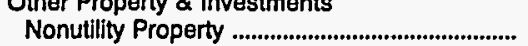 & 0 & \multicolumn{5}{|c|}{ Other Property \& Investments } \\
\hline (less) Accum Provisions for Depr \& Amort .... & 0 & 0 & 0 & 0 & 0 & 0 \\
\hline 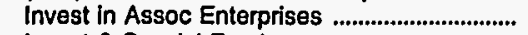 & 0 & 0 & 194 & 0 & 0 & 0 \\
\hline 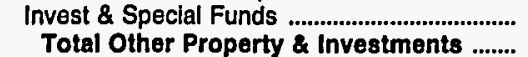 & $\begin{array}{l}9,739 \\
9,739\end{array}$ & $\begin{array}{l}144 \\
144\end{array}$ & $\begin{array}{l}1,136 \\
1,329\end{array}$ & $\begin{array}{l}669 \\
669\end{array}$ & $\begin{array}{l}2,181 \\
2,339\end{array}$ & $\begin{array}{l}4,470 \\
4,470\end{array}$ \\
\hline \multicolumn{7}{|l|}{ Current and Accrued Assets } \\
\hline Cash, Working Funds \& Investments .............. & 32,912 & 867 & 2,777 & 148 & 1,534 & 748 \\
\hline Notes \& Other Recelvables .................................. & 11,064 & 1,101 & 1,663 & 1,579 & 2,768 & \\
\hline 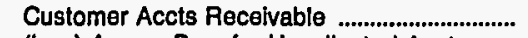 & 0 & 0 & 1,403 & 0 & 0 & 882 \\
\hline (less) Accum Prov for Uncollected Accts ....... & 0 & 0 & 0 & 0 & 0 & 0 \\
\hline 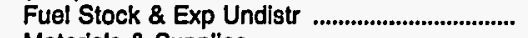 & 0 & 0 & 0 & 0 & 0 & 0 \\
\hline 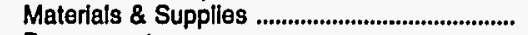 & 3,699 & 185 & 625 & 124 & 690 & 262 \\
\hline Prepayments & 44 & 110 & 12 & 1 & 182 & 0 \\
\hline 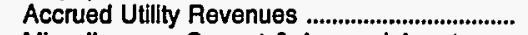 & 0 & 0 & 0 & 0 & 0 & 0 \\
\hline Mlscellaneous Current \& Accrued Assets ..... & 490 & 22 & 24 & 48 & 83 & 0 \\
\hline $\begin{array}{l}\text { Total Current \& Accrued Assets ................ } \\
\text { Deferred Debits }\end{array}$ & 48,208 & 2,285 & 6,505 & 1,900 & 5,257 & 1,892 \\
\hline Unamortized Debt Expenses .................................... & 234 & 32 & 0 & 110 & 16 & 0 \\
\hline 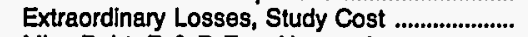 & & 0 & 0 & & 0 & 0 \\
\hline Misc Debt, R \& D Exp, Unamrt Losses .......... & 1,415 & 692 & 0 & 1,153 & 1,734 & 0 \\
\hline Total Doferred Debits ..................................... & $\begin{array}{r}1,649 \\
1,619\end{array}$ & 724 & 0 & 1,263 & $\begin{array}{r}1,750 \\
08017\end{array}$ & 0 \\
\hline \multirow{2}{*}{\multicolumn{7}{|c|}{ 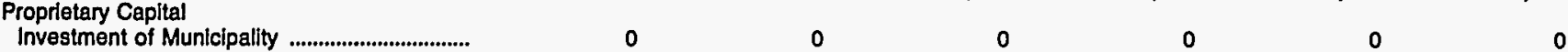 }} \\
\hline & 0 & 0 & 0 & 0 & 0 & $\mathbf{0}$ \\
\hline 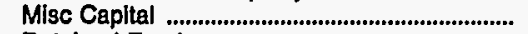 & 0 & 0 & 0 & 0 & 0 & 0 \\
\hline 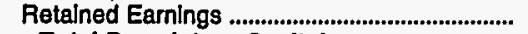 & 118,450 & 9,577 & 10,886 & 6,394 & 21,096 & 6,645 \\
\hline \\
\hline 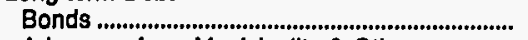 & 8,920 & 920 & 1,425 & 3,700 & 1,940 & 2,887 \\
\hline Advances from Municipality \& Other ................ & 730 & 700 & 1,503 & 1,177 & $\$, 789$ & 0 \\
\hline Unamort Prem on Long-term Debt ................... & 0 & 0 & 0 & 0 & 0 & 0 \\
\hline (less) Unamort Discount on Long-term Debt & & & & 0 & 0 & 0 \\
\hline Total Long-term Debt ............................................. & 9,650 & 1,620 & 2,928 & 4,877 & 3,729 & 2,887 \\
\hline \multicolumn{7}{|l|}{ Other Noncurrent Llablitites } \\
\hline 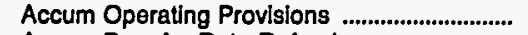 & 0 & 0 & 0 & 0 & 0 & 0 \\
\hline Accum Prov for Rate Refunds ........................ & 0 & 0 & 0 & 0 & 0 & 0 \\
\hline Total Other Noncurrent Llabilities ............ & 0 & 0 & o & $\mathbf{0}$ & 0 & o \\
\hline \multicolumn{7}{|l|}{ Current and Accrued Llabilities } \\
\hline 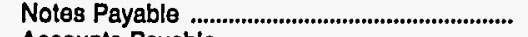 & & & 165 & 0 & 0 & 115 \\
\hline 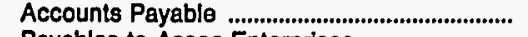 & 17,744 & 1,117 & 1,252 & 1,353 & 2,408 & 508 \\
\hline Payables to Assoc Enterprises ............................. & & 0 & 118 & 0 & 0 & 0 \\
\hline 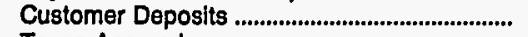 & 9,669 & 388 & 502 & 401 & 627 & 161 \\
\hline 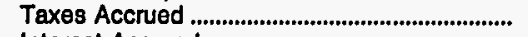 & 0 & 0 & 0 & 20 & 4 & 0 \\
\hline 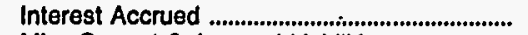 & 77 & 15 & 12 & 145 & 20 & 98 \\
\hline Misc Current \& Accrued Liabilities ..................... & 1,386 & 92 & 75 & 116 & 432 & 0 \\
\hline Total Current \& Accrued Llabilitles .......... & 28,876 & 1,612 & 2,124 & 2,035 & 3,491 & 882 \\
\hline \multicolumn{7}{|l|}{ Deferred Credits } \\
\hline Customer Advances for Construction .............. & $\begin{array}{r}0 \\
438\end{array}$ & 0 & 0 & 0 & 0 & 0 \\
\hline Other Deferred Credits ....................................... & $\begin{array}{r}438 \\
0\end{array}$ & 0 & 0 & 90 & 0 & 0 \\
\hline $\begin{array}{l}\text { Unamort Gain on Reacqr Debt } \\
\text { Total Deferred Credits }\end{array}$ & $\begin{array}{r}0 \\
438\end{array}$ & 0 & 0 & 0 & 0 & 0 \\
\hline 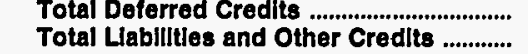 & $\begin{array}{r}438 \\
157,414\end{array}$ & $\begin{array}{r}0 \\
12,809\end{array}$ & $\begin{array}{r}0 \\
15,939\end{array}$ & $\begin{array}{r}90 \\
13,396\end{array}$ & $\begin{array}{r}0 \\
28,317\end{array}$ & $\begin{array}{r}0 \\
10,414\end{array}$ \\
\hline
\end{tabular}

Note: Totals may not equal sum of components because of independent rounding.

Source: Energy Information Administration, Form EIA-412, "Annual Report of Public Electric Utilities." 
Table 22. Balance Sheet by Major U.S. Publicly Owned Electric Utility Within State at End of Period, 1993 (Continued) (Thousand Dollars)

\begin{tabular}{|c|c|c|c|c|c|c|}
\hline Item & $\begin{array}{c}\text { Alabama } \\
\text { Troy } \\
\text { City of } \\
\text { September } 30\end{array}$ & $\begin{array}{l}\text { Alabama } \\
\text { Tuskegee } \\
\text { City of } \\
\text { September } 30\end{array}$ & $\begin{array}{l}\text { Alaska } \\
\text { Alaska } \\
\text { Energy } \\
\text { Authority } \\
\\
\text { June } 30\end{array}$ & $\begin{array}{c}\text { Alaska } \\
\text { Anchorage } \\
\text { City of } \\
\text { December } 31\end{array}$ & $\begin{array}{l}\text { Alaska } \\
\text { Fairbanks } \\
\text { City of } \\
\text { December } 31\end{array}$ & $\begin{array}{c}\text { Alaska } \\
\begin{array}{c}\text { Ketchikan } \\
\text { City of }\end{array} \\
\text { December } 31\end{array}$ \\
\hline \multicolumn{7}{|l|}{ Electric Utility Plant } \\
\hline 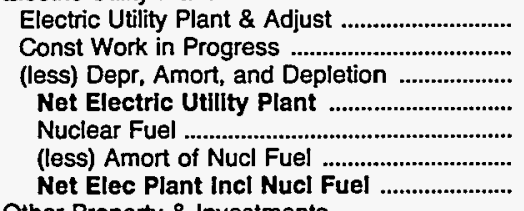 & $\begin{array}{r}9,620 \\
0 \\
5,346 \\
4,274 \\
0 \\
0 \\
4,274\end{array}$ & $\begin{array}{r}6,965 \\
0 \\
3,153 \\
3,812 \\
0 \\
0 \\
3,812\end{array}$ & $\begin{array}{r}935,245 \\
0 \\
150,917 \\
784,328 \\
0 \\
0 \\
784,328\end{array}$ & $\begin{array}{r}255,154 \\
6,560 \\
112,825 \\
148,890 \\
0 \\
0 \\
148,890\end{array}$ & $\begin{array}{r}48,348 \\
247 \\
27,484 \\
21,111 \\
0 \\
0 \\
21,111\end{array}$ & $\begin{array}{r}45,113 \\
2,085 \\
19,740 \\
27,459 \\
0 \\
0 \\
27,459\end{array}$ \\
\hline \multicolumn{7}{|l|}{ Other Property \& Investments } \\
\hline 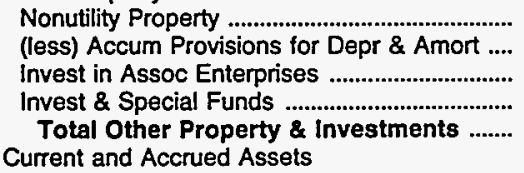 & $\begin{array}{r}0 \\
0 \\
0 \\
1,940 \\
1,940\end{array}$ & $\begin{array}{l}0 \\
0 \\
0 \\
0 \\
0\end{array}$ & $\begin{array}{r}3,394 \\
3,129 \\
0 \\
27,014 \\
27,279\end{array}$ & $\begin{array}{r}0 \\
0 \\
0 \\
32,975 \\
32,975\end{array}$ & $\begin{array}{r}270,916 \\
127,151 \\
0 \\
0 \\
143,765\end{array}$ & $\begin{array}{r}0 \\
0 \\
0 \\
7,823 \\
7,823\end{array}$ \\
\hline 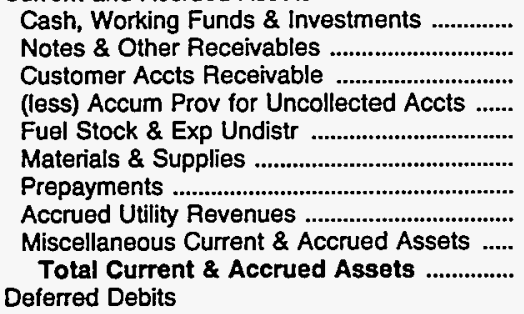 & $\begin{array}{r}314 \\
0 \\
2,179 \\
0 \\
0 \\
195 \\
10 \\
0 \\
0 \\
2,699\end{array}$ & $\begin{array}{r}1,557 \\
235 \\
3,195 \\
0 \\
0 \\
127 \\
0 \\
0 \\
0 \\
5,114\end{array}$ & $\begin{array}{r}60,046 \\
10,954 \\
0 \\
0 \\
0 \\
0 \\
0 \\
0 \\
2,499 \\
73,500\end{array}$ & $\begin{array}{r}8,926 \\
0 \\
5,099 \\
169 \\
622 \\
2,716 \\
1,566 \\
0 \\
566 \\
19,325\end{array}$ & $\begin{array}{r}3,336 \\
216 \\
4,810 \\
336 \\
0 \\
3,299 \\
181 \\
2,818 \\
0 \\
14,324\end{array}$ & $\begin{array}{r}2,995 \\
3,466 \\
519 \\
150 \\
0 \\
1,403 \\
288 \\
0 \\
690 \\
9,211\end{array}$ \\
\hline 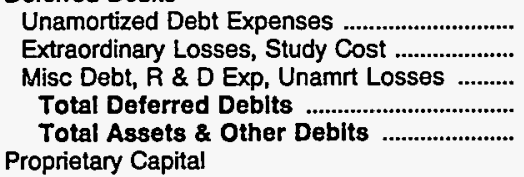 & $\begin{array}{r}179 \\
0 \\
0 \\
179 \\
9,092\end{array}$ & $\begin{array}{r}96 \\
0 \\
0 \\
96 \\
9,023\end{array}$ & $\begin{array}{r}40 \\
0 \\
104 \\
144 \\
885,251\end{array}$ & $\begin{array}{r}2,498 \\
0 \\
35,031 \\
37,530 \\
238,720\end{array}$ & $\begin{array}{r}0 \\
0 \\
0 \\
0 \\
179,200\end{array}$ & $\begin{array}{r}706 \\
0 \\
0 \\
706 \\
45,199\end{array}$ \\
\hline 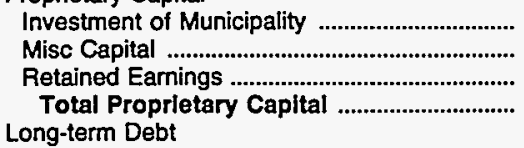 & $\begin{array}{r}0 \\
0 \\
614 \\
614\end{array}$ & $\begin{array}{r}4,515 \\
0 \\
1,384 \\
5,899\end{array}$ & $\begin{array}{r}619,801 \\
0 \\
-144,222 \\
475,579\end{array}$ & $\begin{array}{r}0 \\
0 \\
45,118 \\
45,118\end{array}$ & $\begin{array}{r}8,785 \\
65,426 \\
26,984 \\
101,196\end{array}$ & $\begin{array}{r}0 \\
0 \\
23,413 \\
23,413\end{array}$ \\
\hline 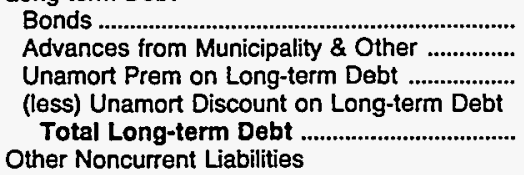 & $\begin{array}{r}7,340 \\
0 \\
0 \\
165 \\
7,175\end{array}$ & $\begin{array}{r}631 \\
0 \\
0 \\
0 \\
631\end{array}$ & $\begin{array}{r}158,987 \\
213,260 \\
0 \\
0 \\
372,247\end{array}$ & $\begin{array}{r}186,165 \\
0 \\
4,721 \\
7,811 \\
183,075\end{array}$ & $\begin{array}{r}52,150 \\
0 \\
0 \\
0 \\
52,150\end{array}$ & $\begin{array}{r}20,145 \\
0 \\
0 \\
0 \\
20,145\end{array}$ \\
\hline 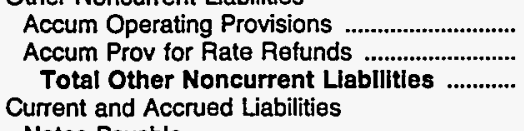 & $\begin{array}{l}0 \\
0 \\
0\end{array}$ & $\begin{array}{l}0 \\
0 \\
\mathbf{0}\end{array}$ & $\begin{array}{l}0 \\
0 \\
0\end{array}$ & $\begin{array}{r}2,023 \\
0 \\
2,023\end{array}$ & $\begin{array}{r}7,784 \\
0 \\
7,784\end{array}$ & $\begin{array}{l}\mathbf{0} \\
\mathbf{0} \\
\mathbf{0}\end{array}$ \\
\hline 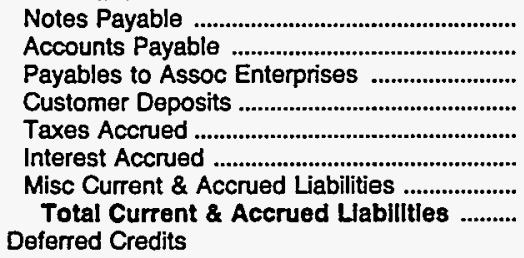 & $\begin{array}{r}24 \\
862 \\
0 \\
225 \\
11 \\
41 \\
141 \\
1,303\end{array}$ & $\begin{array}{r}0 \\
1,128 \\
0 \\
518 \\
0 \\
0 \\
846 \\
2,493\end{array}$ & $\begin{array}{r}4,081 \\
4,672 \\
12,083 \\
0 \\
0 \\
16,486 \\
0 \\
37,321\end{array}$ & $\begin{array}{r}0 \\
3,406 \\
0 \\
1,173 \\
0 \\
1,007 \\
1,506 \\
7,092\end{array}$ & $\begin{array}{r}3,470 \\
3,542 \\
0 \\
732 \\
0 \\
2,039 \\
8,287 \\
18,071\end{array}$ & $\begin{array}{r}0 \\
1,353 \\
0 \\
259 \\
0 \\
29 \\
0 \\
1,642\end{array}$ \\
\hline $\begin{array}{l}\text { Customer Advances for Construction } \\
\text { Other Deferred Credits ............................................. } \\
\text { Unamort Gain on Reacqr Debt ...................... } \\
\text { Total Deferred Credlts ............................... } \\
\text { Total Labllities and Other Credits ........... }\end{array}$ & $\begin{array}{r}0 \\
0 \\
0 \\
0 \\
9,092\end{array}$ & $\begin{array}{r}0 \\
0 \\
0 \\
0 \\
9,023\end{array}$ & $\begin{array}{r}104 \\
0 \\
0 \\
104 \\
885,251\end{array}$ & $\begin{array}{r}378 \\
1,034 \\
0 \\
1,412 \\
238,720\end{array}$ & $\begin{array}{r}0 \\
0 \\
0 \\
0 \\
179,200\end{array}$ & $\begin{array}{r}0 \\
0 \\
0 \\
0 \\
45,199\end{array}$ \\
\hline
\end{tabular}

Note: Totals may not equal sum of components because of independent rounding.

Source: Energy Information Administration, Form EIA-412, "Annual Report of Public Electric Utilities." 
Table 22. Balance Sheet by Major U.S. Publicly Owned Electric Utility Within State at End of Period, 1993 (Continued)

(Thousand Dollars)

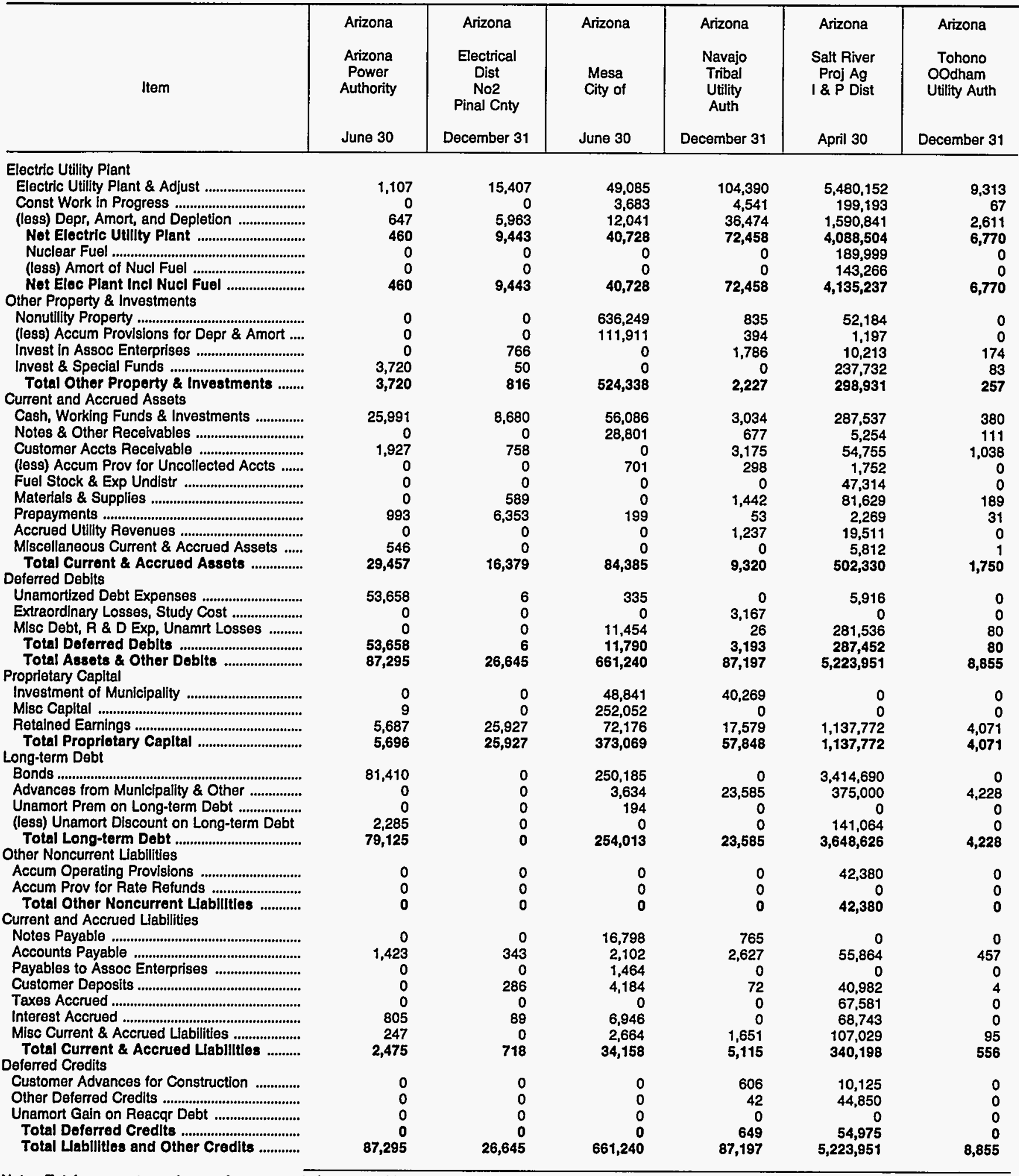

Note: Totals may not equal sum of components because of independent rounding.

Source: Energy Information Administration, Form EIA-412, "Annual Report of Public Electric Utilities." 
Table 22. Balance Sheet by Major U.S. Publicly Owned Electric Utility Within State at End of Period, 1993 (Continued)

(Thousand Dollars)

\begin{tabular}{|c|c|c|c|c|c|c|}
\hline Item & $\begin{array}{l}\text { Arkansas } \\
\text { Benton } \\
\text { City of } \\
\text { December } 31\end{array}$ & $\begin{array}{l}\text { Arkansas } \\
\begin{array}{c}\text { Bentonville } \\
\text { City of }\end{array} \\
\text { December } 31\end{array}$ & $\begin{array}{l}\text { Arkansas } \\
\text { Clarksville } \\
\text { Light } \\
\& \\
\text { Water Co } \\
\text { September } 30\end{array}$ & $\begin{array}{l}\text { Arkansas } \\
\text { Conway } \\
\text { Corp } \\
\text { December } 31\end{array}$ & $\begin{array}{c}\text { Arkansas } \\
\text { Hope } \\
\text { City of } \\
\text { December } 31\end{array}$ & $\begin{array}{l}\text { Arkansas } \\
\text { Jonesboro } \\
\text { City of } \\
\text { December } 31\end{array}$ \\
\hline \multicolumn{7}{|l|}{ Electric Utility Plant } \\
\hline 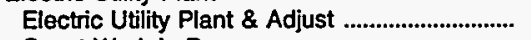 & 7,077 & 29,799 & 11,443 & 63,743 & 9,777 & 136,553 \\
\hline 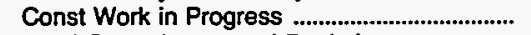 & & 1.087 & 424 & 362 & 1,813 & 1,082 \\
\hline 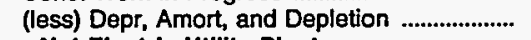 & 5,221 & 8,368 & 3,452 & 22,898 & 3,908 & 58,187 \\
\hline & 1,856 & 22,518 & 8,416 & 41,206 & 7,683 & 79,448 \\
\hline Nuclear Fuel .......................................... & 0 & 0 & 0 & 0 & 0 & 0 \\
\hline 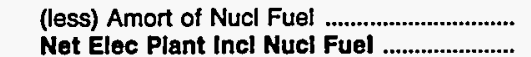 & & $\begin{array}{r}0 \\
22.518\end{array}$ & 0 & 0 & $\begin{array}{r}0 \\
7,683\end{array}$ & $\begin{array}{r}0 \\
79,448\end{array}$ \\
\hline \multicolumn{7}{|l|}{ Other Property \& Investments } \\
\hline 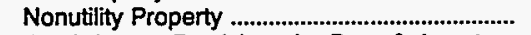 & 0 & 0 & 26,785 & 400 & 695 & 0 \\
\hline (less) Accum Provisions for Depr \& Amort .... & 0 & $\mathbf{0}$ & 3,006 & 0 & 0 & 0 \\
\hline 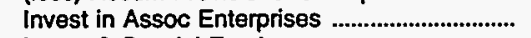 & 0 & 0 & & 1,017 & 0 & 17,098 \\
\hline 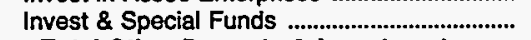 & 2,192 & 8,168 & 4,967 & 15,277 & 1,351 & 3,160 \\
\hline Total Other Property \& Investments ....... & 2,192 & 8,168 & 28,751 & 16,695 & 2,046 & 20,258 \\
\hline \multicolumn{7}{|l|}{ Current and Accrued Assets } \\
\hline Cash, Working Funds \& Investments .............. & 712 & 886 & 587 & 277 & 5,632 & 14,057 \\
\hline Notes \& Other Receivables .................................. & & 767 & 142 & 734 & 20 & $\begin{array}{r}0 \\
2,976\end{array}$ \\
\hline $\begin{array}{l}\text { Customer Accts Receivable } \\
\text { (less) Accum Prov for Uncollected Accts ....... }\end{array}$ & $\begin{array}{r}1,252 \\
0\end{array}$ & $\begin{array}{r}1,306 \\
0\end{array}$ & $\begin{array}{r}1,915 \\
0\end{array}$ & $\begin{array}{r}1,909 \\
94\end{array}$ & $\begin{array}{r}296 \\
0\end{array}$ & $\begin{array}{r}2,976 \\
98\end{array}$ \\
\hline 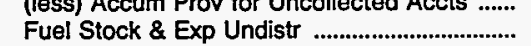 & 0 & 0 & 0 & 1,050 & 7 & 2,589 \\
\hline Materials \& Supplies ...................................................... & 170 & 650 & 1,038 & 1,560 & 146 & 1,688 \\
\hline 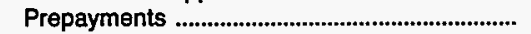 & 703 & 11 & 79 & 213 & 38 & 525 \\
\hline Accrued Utility Revenues ...................................... & 0 & 813 & 448 & 0 & 778 & 625 \\
\hline Miscellaneous Current \& Accrued Assets ..... & & 0 & 0 & 677 & 10 & 43 \\
\hline Total Current \& Accrued Assets ................. & 2,839 & 4,434 & 4,209 & 6,326 & 6,926 & 22,406 \\
\hline \multicolumn{7}{|l|}{ Deferred Debits } \\
\hline 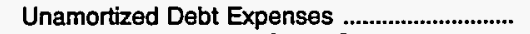 & 0 & 293 & 120 & $\mathbf{0}$ & 297 & 731 \\
\hline 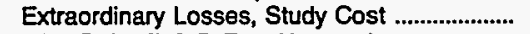 & 0 & 0 & 0 & 0 & 0 & \\
\hline Misc Debt, A \& D Exp, Unamrt Losses .......... & 0 & 0 & 0 & 668 & 868 & 0 \\
\hline Total Deferred Debits ........................................... & & 293 & 120 & 668 & 1,166 & 731 \\
\hline Total Assets \& Other Debits ........................... & 6,887 & 35,413 & 41,496 & 64,894 & 17,821 & 122,844 \\
\hline \multicolumn{7}{|l|}{ Proprietary Capital } \\
\hline 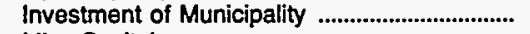 & 0 & 5,167 & 0 & 179 & 0 & 0 \\
\hline 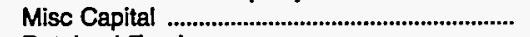 & 0 & & 9,195 & 1,875 & 0 & 234 \\
\hline 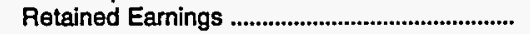 & 5,848 & 18,174 & 16,425 & 33,652 & 10,692 & 62,131 \\
\hline Total Proprletary Capital .................................. & 5,848 & 23,341 & 25,619 & 35,706 & 10,692 & 62,365 \\
\hline \\
\hline 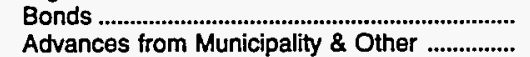 & $\begin{array}{l}0 \\
0\end{array}$ & $\begin{array}{r}9,695 \\
0\end{array}$ & $\begin{array}{r}13,942 \\
0\end{array}$ & $\begin{array}{r}27,000 \\
0\end{array}$ & $\begin{array}{r}5,680 \\
0\end{array}$ & $\begin{array}{r}47,490 \\
3,999\end{array}$ \\
\hline & $\begin{array}{l}0 \\
0\end{array}$ & 0 & 0 & 0 & 0 & $\begin{array}{r}0,800 \\
0\end{array}$ \\
\hline (less) Unamort Discount on Long-term Debt & 0 & 0 & 237 & 415 & 297 & 1,183 \\
\hline 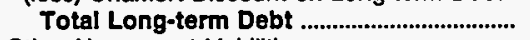 & 0 & 9,695 & 13,705 & 26,585 & 5,383 & 50,305 \\
\hline \multicolumn{7}{|l|}{ Other Noncurrent Liabilities } \\
\hline 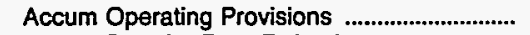 & 0 & 0 & 0 & 0 & 440 & 160 \\
\hline Accum Prov for Rate Refunds .............................. & 0 & 0 & 0 & 0 & 0 & \\
\hline Total Other Noncurrent Llabilities ............. & 0 & o & 0 & 0 & 440 & 160 \\
\hline \multicolumn{7}{|l|}{ Current and Accrued Liabilities } \\
\hline 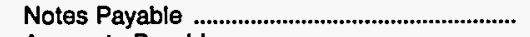 & 0 & 1,234 & 0 & 0 & 0 & 3,078 \\
\hline 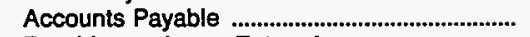 & 637 & 632 & 723 & 1,762 & 697 & 5,978 \\
\hline 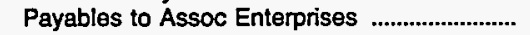 & 0 & 58 & 0 & 0 & 0 & \\
\hline 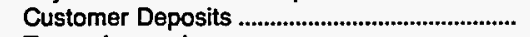 & 329 & 253 & 202 & 260 & 377 & 445 \\
\hline 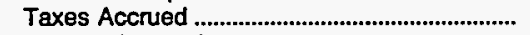 & 71 & 56 & 0 & 0 & 232 & 64 \\
\hline 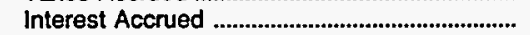 & 0 & 70 & 225 & 581 & 0 & 203 \\
\hline Misc Current \& Accrued Liabilities .......................... & & 74 & 1,021 & 0 & 0 & 244 \\
\hline Total Current \& Accrued Llabllities .......... & 1,039 & 2,378 & 2,172 & 2,603 & 1,306 & 10,013 \\
\hline \multicolumn{7}{|l|}{ Deferred Credits } \\
\hline Customer Advances for Construction .............. & $\begin{array}{l}0 \\
0\end{array}$ & 0 & $\begin{array}{l}0 \\
0\end{array}$ & $\begin{array}{l}0 \\
0\end{array}$ & $\begin{array}{l}0 \\
0\end{array}$ & $\begin{array}{l}0 \\
0\end{array}$ \\
\hline 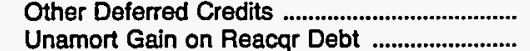 & $\begin{array}{l}0 \\
0\end{array}$ & $\begin{array}{l}0 \\
0\end{array}$ & $\begin{array}{l}0 \\
0\end{array}$ & 0 & 0 & 0 \\
\hline 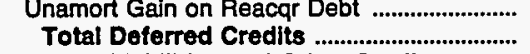 & 0 & & & & & \\
\hline Total Lablilties and Other Credits ............ & 6,887 & 35,413 & 41,496 & 64,894 & 17,821 & 122,844 \\
\hline
\end{tabular}

Note: Totals may not equal sum of components because of independent rounding.

Source: Energy Information Administration, Form ElA-412, "Annual Report of Public Electric Utilities." 
Table 22. Balance Sheet by Major U.S. Publicly Owned Electric Utility Within State at End of Period, 1993 (Continued) (Thousand Dollars)

\begin{tabular}{|c|c|c|c|c|c|c|}
\hline Item & $\begin{array}{c}\text { Arkansas } \\
\text { North } \\
\text { Little } \\
\text { Rock } \\
\text { City of } \\
\text { December } 31\end{array}$ & $\begin{array}{l}\text { Arkansas } \\
\text { Osceola } \\
\text { City of } \\
\text { December } 31\end{array}$ & $\begin{array}{c}\text { Arkansas } \\
\text { Paragould } \\
\text { Light } \\
\& \\
\text { Water Comm } \\
\text { December } 31\end{array}$ & $\begin{array}{c}\text { Arkansas } \\
\text { Siloam } \\
\text { Springs } \\
\text { City of } \\
\text { December } 31\end{array}$ & $\begin{array}{c}\text { Arkansas } \\
\text { West } \\
\text { Memphis } \\
\text { City of } \\
\text { December } 31\end{array}$ & $\begin{array}{l}\text { California } \\
\text { Alameda } \\
\text { City of } \\
\text { June } 30\end{array}$ \\
\hline \multicolumn{7}{|l|}{ Electric Utility Plant } \\
\hline Electric Utility Plant \& Adjust .................................. & 148,743 & 18,905 & 24,591 & 6,051 & 28,685 & 43,715 \\
\hline Const Work in Progress & 1,589 & & 146 & 962 & 0 & \\
\hline (less) Depr, Amort, and Depletion ...................... & 30,542 & 8,043 & 9,106 & 3,215 & 12,413 & 12,059 \\
\hline Noi Electric Utility Plant .................................... & 119,790 & 10,862 & 15,632 & 3,797 & 16,271 & 31,656 \\
\hline 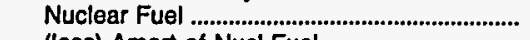 & & 0 & 0 & 0 & 0 & 0 \\
\hline 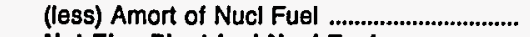 & 0 & 0 & 0 & 0 & 0 & 0 \\
\hline $\begin{array}{l}\text { Net Elec Plant Incl Nucl Fuel ............................ } \\
\text { Other Property \& Investments }\end{array}$ & 119,790 & 10,862 & 15,632 & 3,797 & 16,271 & 31,656 \\
\hline Nonutility Property ............................................................. & 0 & 0 & 0 & 0 & 28,639 & 0 \\
\hline (less) Accum Provisions for Depr \& Amort .... & 0 & 0 & 0 & 0 & 16,822 & 0 \\
\hline 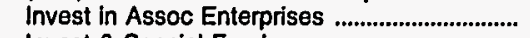 & 0 & 0 & 0 & 108 & 0 & 0 \\
\hline 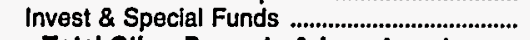 & 35,507 & 2,622 & 3,224 & 3,264 & 0 & 6,528 \\
\hline $\begin{array}{l}\text { Total Other Property \& Investments ....... } \\
\text { Current and Accrued Assets }\end{array}$ & 35,507 & 2,622 & 3,224 & 3,372 & 11,817 & 6,528 \\
\hline Cash, Working Funds \& Investments .............. & 14,466 & 106 & 1,985 & 2,372 & 23,698 & 8,548 \\
\hline 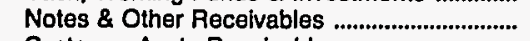 & & 0 & 263 & 0 & 208 & 0 \\
\hline Customer Accts Receivable & 6,151 & 834 & 913 & 721 & 1,953 & 3,651 \\
\hline (less) Accum Prov for Uncollected Accts ...... & 413 & 35 & 0 & 25 & 150 & 73 \\
\hline 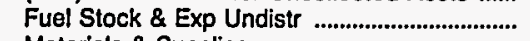 & 0 & 115 & 0 & 0 & 519 & 0 \\
\hline 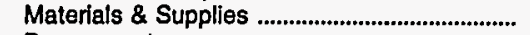 & 804 & 386 & 373 & 377 & 536 & 1,332 \\
\hline 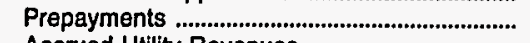 & 34 & 25 & 20 & 67 & 101 & 39 \\
\hline 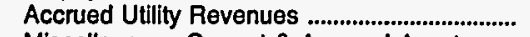 & 0 & 0 & 0 & 0 & 676 & 0 \\
\hline Miscellaneous Current \& Accrued Assets ...... & 0 & 820 & 0 & 0 & & 310 \\
\hline $\begin{array}{l}\text { Total Current \& Accrued Assets ............... } \\
\text { Deferred Debits }\end{array}$ & 21,041 & 2,251 & 3,553 & 3,512 & 27,543 & 13,807 \\
\hline 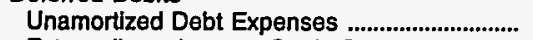 & 3,063 & 115 & 1,764 & 0 & 737 & 111 \\
\hline Extraordinary Losses, Study Cost ........................ & 0 & 0 & 0 & 0 & 0 & 0 \\
\hline Misc Debt, R \& D Exp, Unamrt Losses ........... & 0 & 0 & 0 & 0 & 1 & -113 \\
\hline 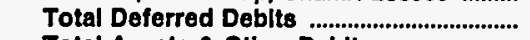 & 3,063 & 115 & 1,764 & & 737 & -2 \\
\hline $\begin{array}{l}\text { Total Assets \& Other Debits ............................ } \\
\text { Proprietary Capital }\end{array}$ & 179,401 & 15,851 & 24,173 & 10,680 & 56,368 & 51,989 \\
\hline 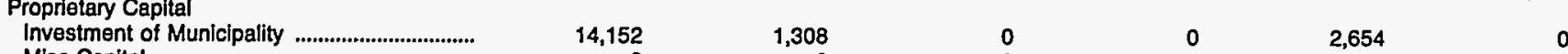 & 14,152 & 1,308 & 0 & 0 & 2,654 & 0 \\
\hline 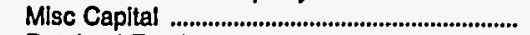 & 0 & & 0 & 0 & 0 & 0 \\
\hline 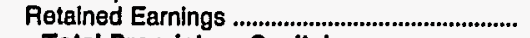 & 0 & 9,879 & 24,234 & 9,575 & 30,959 & 38,928 \\
\hline \\
\hline Bonds & 0 & 3,745 & 9,175 & 216 & 20,910 & 0 \\
\hline Advances from Municipality \& Other ................. & 155,725 & 338 & 0 & 0 & 0 & 9,595 \\
\hline Unamort Prem on Long-term Debt ................... & & 0 & 0 & 0 & 0 & \\
\hline (less) Unamort Discount on Long-term Debt & 0 & 0 & 0 & 1 & 1,019 & 0 \\
\hline \multicolumn{6}{|l|}{ Other Noncurrent Liabilitles } & 9,595 \\
\hline Accum Operating Provisions ............................ & 0 & 0 & 0 & 60 & 0 & 0 \\
\hline Accum Prov for Rate Refunds .............................. & 0 & 0 & 0 & 0 & 0 & 0 \\
\hline $\begin{array}{l}\text { Total Other Noncurrent Llabillties ............ } \\
\text { Current and Accrued Liablities }\end{array}$ & o & 0 & 0 & 60 & o & 0 \\
\hline 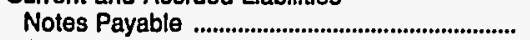 & 0 & 0 & 304 & 0 & 0 & 0 \\
\hline 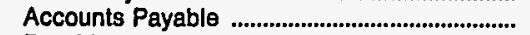 & 3,808 & 225 & 1,099 & 486 & 479 & 1,068 \\
\hline Payables to Assoc Enterprises ............................... & 0 & 20 & 0 & 109 & 201 & -1 \\
\hline Customer Deposits ......................................................... & 0 & 159 & 165 & 169 & 657 & 157 \\
\hline 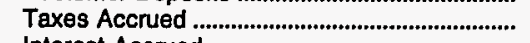 & 0 & 50 & 0 & 27 & 0 & 0 \\
\hline 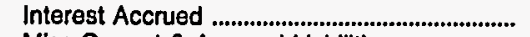 & 4,980 & 126 & 157 & 0 & 682 & 49 \\
\hline Mlsc Current \& Accrued Liablities .......................... & 737 & 0 & 17 & 40 & 845 & 1,727 \\
\hline $\begin{array}{l}\text { Total Current \& Accrued Llabllities .......... } \\
\text { Deferred Credits }\end{array}$ & 9,525 & 581 & 1,742 & 830 & 2,865 & 2,999 \\
\hline Customer Advances for Construction ............... & 0 & 0 & 0 & 0 & 0 & 0 \\
\hline 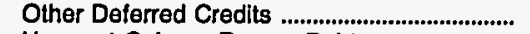 & 0 & 0 & $-10,978$ & 0 & 0 & 467 \\
\hline Unamort Gain on Reacqr Debt .......................... & 0 & 0 & 0 & 0 & 0 & 0 \\
\hline 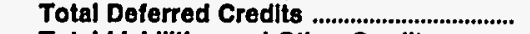 & & & $-10,978$ & & & \\
\hline Total Llabilitles and Other Credlts ............ & 179,401 & 15,851 & 24,173 & 10,680 & 56,368 & 51,989 \\
\hline
\end{tabular}

Note: Totals may not equal sum of components because of independent rounding.

Source: Energy Information Administration, Form ElA-412, "Annual Report of Public Electric Utilities." 
Table 22. Balance Sheet by Major U.S. Publicly Owned Electric Utility Within State at End of Period, 1993 (Continued) (Thousand Dollars)

\begin{tabular}{|c|c|c|c|c|c|c|}
\hline Item & $\begin{array}{l}\text { California } \\
\text { Anaheim } \\
\text { City of } \\
\text { June } 30\end{array}$ & $\begin{array}{l}\text { California } \\
\text { Azusa } \\
\text { City of } \\
\text { June } 30\end{array}$ & $\begin{array}{l}\text { California } \\
\text { Burbank } \\
\text { City of } \\
\text { June } 30\end{array}$ & $\begin{array}{c}\text { California } \\
\text { California } \\
\text { Dept } \\
\text { Wtr } \\
\text { Resources } \\
\text { June } 30\end{array}$ & $\begin{array}{l}\text { California } \\
\text { Colton } \\
\text { City of } \\
\text { June } 30\end{array}$ & $\begin{array}{c}\text { Glendale } \\
\text { City of } \\
\text { June } 30\end{array}$ \\
\hline \multicolumn{7}{|l|}{ Electric Utility Plant } \\
\hline 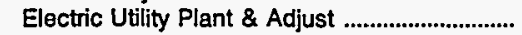 & 413,152 & 12,271 & 160,543 & 858,845 & 11,633 & 231,223 \\
\hline Const Work in Progress ............................................ & 12,362 & & 10,962 & & & 9,273 \\
\hline (less) Depr, Amort, and Depletion ....................... & 107,534 & 4,408 & 91,662 & 264,134 & 4,894 & 103,541 \\
\hline Net Electric Utility Plant .................................... & 317,980 & 7,863 & 79,843 & 594,711 & 6,739 & 136,955 \\
\hline 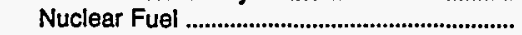 & 38,996 & & 0 & 0 & 0 & 0 \\
\hline (less) Amort of Nucl Fuel ............................... & 33,621 & & & 0 & & 0 \\
\hline Net Elec Plant Incl Nucl Fuel ............................ & 323,355 & 7,863 & 79,843 & 594,711 & 6,739 & 136,955 \\
\hline \multicolumn{7}{|l|}{ Other Property \& Investments } \\
\hline 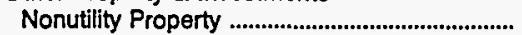 & 0 & 0 & 0 & 0 & 0 & 0 \\
\hline (less) Accum Provisions for Depr \& Amort .... & 0 & 0 & 0 & 0 & 0 & 0 \\
\hline Invest in Assoc Enterprises & 0 & 10,237 & 0 & 0 & 0 & 0 \\
\hline 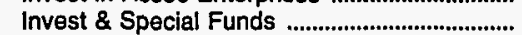 & 0 & 0 & 0 & 121,797 & 0 & 0 \\
\hline Total Other Property \& Investments ........ & o & 10,237 & o & 121,797 & 0 & 0 \\
\hline Cash, Working Funds \& Investments .................. & 184,179 & 12,616 & 33,162 & 161,696 & 3,634 & 22,268 \\
\hline 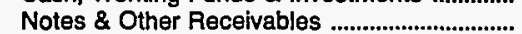 & & 200 & 0 & 15,210 & 1,997 & 8,736 \\
\hline 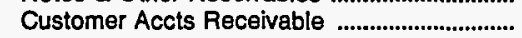 & 25,710 & 2,102 & 12,841 & 0 & 3,477 & 0 \\
\hline (less) Accum Prov for Uncollected Accts ....... & 0 & 0 & 0 & 0 & 0 & 285 \\
\hline 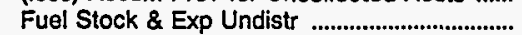 & 0 & 0 & 0 & 0 & 0 & 0 \\
\hline Materials \& Supplies & 3,584 & 369 & 3,655 & 8,850 & 1,560 & 2,996 \\
\hline 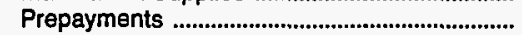 & 1,173 & 0 & 2,369 & 362 & 0 & 651 \\
\hline 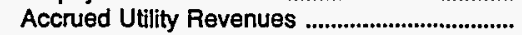 & 0 & 0 & 0 & 0 & 0 & 0 \\
\hline Miscellaneous Current \& Accrued Assets ..... & 3,469 & 0 & 0 & 0 & 2,510 & 0 \\
\hline Total Current \& Accrued Assets ................... & 218,115 & 15,287 & 52,027 & 186,118 & 13,179 & 34,366 \\
\hline \multicolumn{7}{|l|}{ Deferred Debits } \\
\hline Unamortized Debt Expenses ...................................... & 29,155 & 0 & 756 & 0 & 0 & 0 \\
\hline 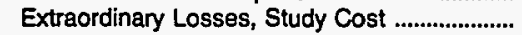 & & 0 & 0 & 0 & 0 & 0 \\
\hline Misc Debt, R \& D Exp, Unamrt Losses ........... & 1,555 & 0 & 0 & 278,247 & 0 & 0 \\
\hline Total Doferred Debits & 30,710 & 0 & 756 & 278,247 & 0 & 0 \\
\hline 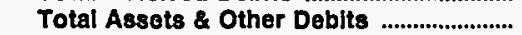 & 572,180 & 33,387 & 132,626 & $1,180,873$ & 19,918 & 171,321 \\
\hline \multicolumn{7}{|l|}{ Proprietary Capital } \\
\hline 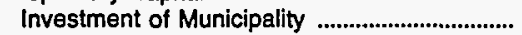 & 14,629 & 0 & 0 & 33,935 & 0 & 0 \\
\hline 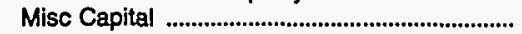 & & 637 & 5,852 & 0 & 0 & 21,913 \\
\hline 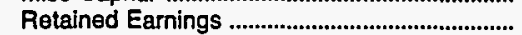 & 127,516 & 30,897 & 69,779 & $-10,824$ & 17,245 & 123,477 \\
\hline \\
\hline 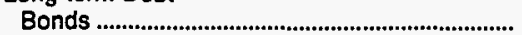 & 271,887 & 0 & 46,409 & 920,958 & 695 & 15,273 \\
\hline Advances from Municipality \& Other ................ & 19,683 & 104 & 1,531 & 0 & 0 & 0 \\
\hline Unamort Prem on Long-term Debt ...................... & & 0 & 0 & 0 & 0 & 0 \\
\hline (less) Unamort Discount on Long-term Debt & 9,372 & 0 & & 21,090 & 0 & 0 \\
\hline 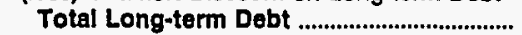 & 282,198 & 104 & 47,940 & 899,868 & 695 & 15,273 \\
\hline \multicolumn{7}{|l|}{ Other Noncurrent Liabilities } \\
\hline Accum Operating Provisions .................................. & 0 & 0 & 0 & 38,087 & 0 & 0 \\
\hline 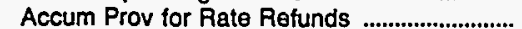 & 0 & 0 & 0 & & 0 & 0 \\
\hline Total Other Noncurrent Liabllities ............. & 0 & 0 & $\mathbf{0}$ & 38,087 & 0 & o \\
\hline \multicolumn{7}{|l|}{ Current and Accrued Liabilities } \\
\hline Notes Payable & 28,056 & 0 & 0 & 602 & 0 & 2,703 \\
\hline 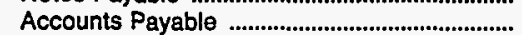 & 1,459 & 745 & 5,926 & 29,547 & 262 & 4,103 \\
\hline Payables to Assoc Enterprises .............................. & & 0 & 1,587 & 0 & 0 & 0 \\
\hline 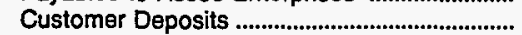 & 2,805 & 997 & 690 & 0 & 756 & 498 \\
\hline 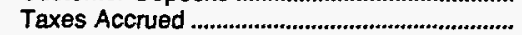 & 0 & 8 & 0 & 0 & 0 & 1,950 \\
\hline 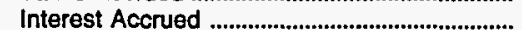 & 2,693 & 0 & 220 & 8,185 & 0 & 80 \\
\hline Misc Current \& Accrued Liabilities ...................... & 76,145 & & 632 & 23,587 & 960 & 456 \\
\hline Total Current \& Accrued Liabllities ........... & 111,158 & 1,749 & 9,055 & 61,921 & 1,978 & 9,780 \\
\hline \multicolumn{7}{|l|}{ Deferred Credits } \\
\hline Customer Advances for Construction ................. & 25,677 & 0 & 0 & 0 & 0 & 868 \\
\hline 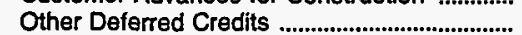 & 11,002 & 0 & 0 & 157,886 & 0 & 0 \\
\hline 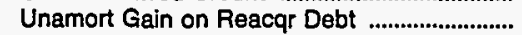 & 0 & 0 & 0 & 0 & 0 & 0 \\
\hline Total Deferred Credits ...................................... & 36,679 & & & 157,886 & & 868 \\
\hline Total Llablities and Other Credits ............. & 572,180 & 33,387 & 132,626 & $1,180,873$ & 19,918 & 171,321 \\
\hline
\end{tabular}

Note: Totals may not equal sum of components because of independent rounding.

Source: Energy Information Administration, Form EIA-412, "Annual Report of Public Electric Utilities." 
Table 22. Balance Sheet by Major U.S. Publicly Owned Electric Utility Within State at End of Period, 1993 (Continued) (Thousand Dollars)

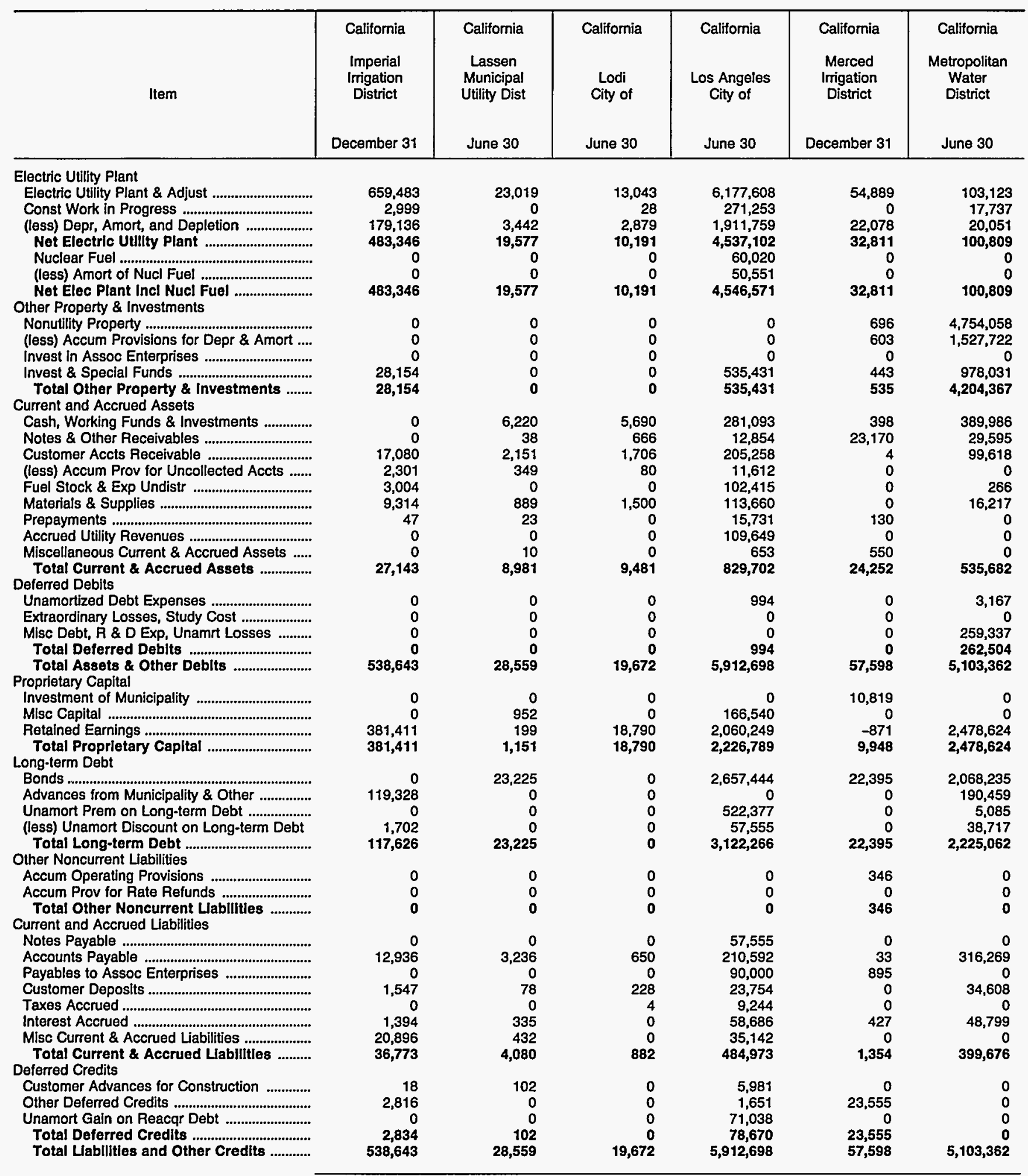

Note: Totals may not equal sum of components because of independent rounding.

Source: Energy Information Administration, Form EIA-412, "Annual Report of Public Electric Utilities." 
Table 22. Balance Sheet by Major U.S. Publicly Owned Electric Utility Within State at End of Period, 1993 (Continued)

(Thousand Dollars)

\begin{tabular}{|c|c|c|c|c|c|c|}
\hline Item & $\begin{array}{l}\text { California } \\
\text { Modesto } \\
\text { Irrigation } \\
\text { District } \\
\text { December } 31\end{array}$ & $\begin{array}{c}\text { California } \\
\text { MSR } \\
\text { Public } \\
\text { Power } \\
\text { Agency } \\
\text { December } 31\end{array}$ & $\begin{array}{l}\text { California } \\
\text { Northern } \\
\text { California } \\
\text { Power Agny } \\
\text { June } 30\end{array}$ & $\begin{array}{l}\text { California } \\
\text { Oakdale \& } \\
\text { South } \\
\text { San Joaquin } \\
\text { December } 31\end{array}$ & $\begin{array}{l}\text { California } \\
\text { Oroville } \\
\text { Wyandotte } \\
\text { Irrig Dist } \\
\text { December } 31\end{array}$ & $\begin{array}{l}\text { Palo Alto } \\
\text { City of } \\
\text { June } 30\end{array}$ \\
\hline \multicolumn{7}{|l|}{ Electric Utility Plant } \\
\hline 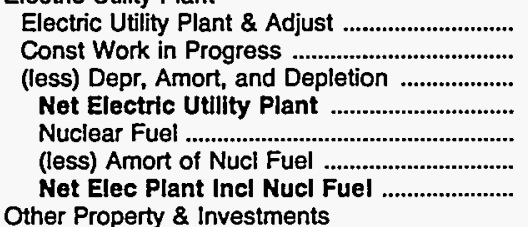 & $\begin{array}{r}256,475 \\
8,333 \\
82,924 \\
181,884 \\
0 \\
0 \\
181,884\end{array}$ & $\begin{array}{r}275,331 \\
16,036 \\
84,382 \\
206,986 \\
0 \\
0 \\
206,986\end{array}$ & $\begin{array}{r}912,354 \\
21,136 \\
201,724 \\
731,766 \\
0 \\
0 \\
731,766\end{array}$ & $\begin{array}{r}60,313 \\
339 \\
22,763 \\
37,889 \\
0 \\
0 \\
37,889\end{array}$ & $\begin{array}{r}84,197 \\
854 \\
36,167 \\
48,884 \\
0 \\
0 \\
48,884\end{array}$ & $\begin{array}{r}112,357 \\
3,102 \\
41,735 \\
73,724 \\
0 \\
0 \\
73,724\end{array}$ \\
\hline 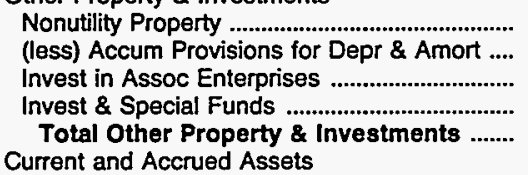 & $\begin{array}{r}0 \\
0 \\
-17,321 \\
110,680 \\
93,359\end{array}$ & $\begin{array}{r}15,383 \\
0 \\
0 \\
152,023 \\
167,406\end{array}$ & $\begin{array}{r}0 \\
0 \\
0 \\
692,385 \\
692,385\end{array}$ & $\begin{array}{l}0 \\
0 \\
0 \\
0 \\
0\end{array}$ & $\begin{array}{l}0 \\
0 \\
0 \\
0 \\
0\end{array}$ & $\begin{array}{l}0 \\
0 \\
0 \\
0 \\
0\end{array}$ \\
\hline 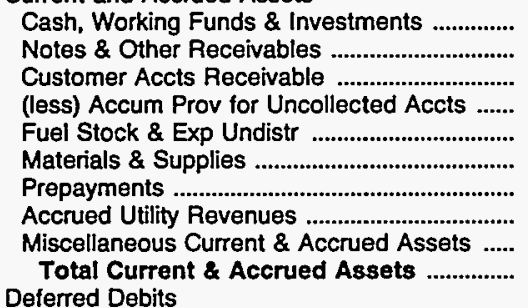 & $\begin{array}{r}105,977 \\
4,418 \\
15,328 \\
0 \\
341 \\
2,487 \\
5 \\
0 \\
4,188 \\
132,742\end{array}$ & $\begin{array}{r}26,114 \\
4,220 \\
0 \\
0 \\
1,161 \\
1,191 \\
0 \\
0 \\
6,019 \\
38,705\end{array}$ & $\begin{array}{r}36,453 \\
51 \\
2,435 \\
0 \\
0 \\
3,475 \\
508 \\
0 \\
2,053 \\
44,975\end{array}$ & $\begin{array}{r}17,872 \\
1,073 \\
0 \\
0 \\
0 \\
0 \\
218 \\
0 \\
132 \\
19,294\end{array}$ & $\begin{array}{r}17,929 \\
412 \\
0 \\
0 \\
0 \\
0 \\
205 \\
0 \\
-13 \\
18,533\end{array}$ & $\begin{array}{r}75,724 \\
8,089 \\
0 \\
195 \\
0 \\
0 \\
0 \\
0 \\
0 \\
83,618\end{array}$ \\
\hline 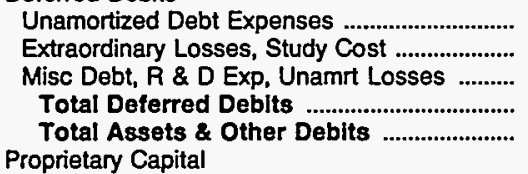 & $\begin{array}{r}3,857 \\
0 \\
0 \\
3,857 \\
411,843\end{array}$ & $\begin{array}{r}10,476 \\
0 \\
0 \\
10,476 \\
423,573\end{array}$ & $\begin{array}{r}24,556 \\
57 \\
387,656 \\
412,269 \\
1,881,395\end{array}$ & $\begin{array}{r}0 \\
0 \\
0 \\
0 \\
\mathbf{5 7 , 1 8 2}\end{array}$ & $\begin{array}{r}0 \\
0 \\
0 \\
0 \\
67,417\end{array}$ & $\begin{array}{r}0 \\
0 \\
0 \\
0 \\
157,342\end{array}$ \\
\hline 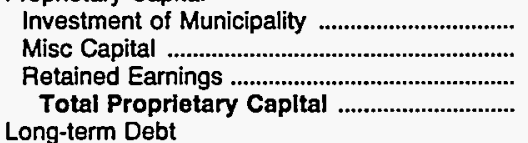 & $\begin{array}{r}0 \\
0 \\
128,240 \\
128,240\end{array}$ & $\begin{array}{r}0 \\
0 \\
-219,641 \\
-219,641\end{array}$ & $\begin{array}{r}0 \\
0 \\
10,382 \\
10,382\end{array}$ & $\begin{array}{r}0 \\
0 \\
55,246 \\
55,246\end{array}$ & $\begin{array}{r}0 \\
0 \\
3,013 \\
3,013\end{array}$ & $\begin{array}{r}0 \\
16,966 \\
135,994 \\
152,960\end{array}$ \\
\hline $\begin{array}{l}\text { Bonds } \\
\text { Advances from Municipality \& Other ............... } \\
\text { Unamort Prem on Long-term Debt .............. } \\
\text { (less) Unamort Discount on Long-term Debt } \\
\text { Total Long-term Debt ....................... } \\
\text { Other Noncurrent Liabilities }\end{array}$ & $\begin{array}{r}60,135 \\
207,534 \\
0 \\
10,385 \\
257,285\end{array}$ & $\begin{array}{r}647,825 \\
0 \\
0 \\
34,987 \\
612,838\end{array}$ & $\begin{array}{r}1,797,670 \\
0 \\
2,914 \\
66,059 \\
1,734,525\end{array}$ & $\begin{array}{r}0 \\
643 \\
0 \\
0 \\
643\end{array}$ & $\begin{array}{r}60,181 \\
14,230 \\
2,065 \\
15,011 \\
61,465\end{array}$ & $\begin{array}{r}273 \\
0 \\
0 \\
4 \\
269\end{array}$ \\
\hline $\begin{array}{l}\text { Accum Operating Provisions } \\
\text { Accum Prov for Rate Refunds ............................ } \\
\text { Total Other Noncurrent Llabilities ........... } \\
\text { Current and Accrued Liabilities }\end{array}$ & $\begin{array}{r}4,680 \\
0 \\
4,680\end{array}$ & $\begin{array}{l}0 \\
0 \\
0\end{array}$ & $\begin{array}{l}0 \\
0 \\
0\end{array}$ & $\begin{array}{l}0 \\
0 \\
0\end{array}$ & $\begin{array}{l}0 \\
0 \\
0\end{array}$ & $\begin{array}{r}632 \\
0 \\
632\end{array}$ \\
\hline Notes Payable & 0 & $\mathbf{0}$ & 0 & 0 & 0 & \\
\hline $\begin{array}{l}\text { Accounts Payable } \\
\text { Payables to Assoc Enterprises }\end{array}$ & $\begin{array}{r}13,760 \\
0\end{array}$ & $\begin{array}{r}3,763 \\
0\end{array}$ & $\begin{array}{r}11,018 \\
27\end{array}$ & $\begin{array}{r}218 \\
0\end{array}$ & $\begin{array}{r}238 \\
0\end{array}$ & $\begin{array}{r}3,032 \\
0\end{array}$ \\
\hline 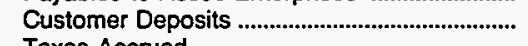 & 223 & 0 & 0 & 0 & 0 & 150 \\
\hline $\begin{array}{l}\text { Taxes Accrued } \\
\text { Interest Accrued }\end{array}$ & $\begin{array}{r}6 \\
4,146\end{array}$ & $\begin{array}{r}0 \\
22,203\end{array}$ & $\begin{array}{r}42 \\
48,574\end{array}$ & $\begin{array}{l}0 \\
0\end{array}$ & $\begin{array}{r}0 \\
1,461\end{array}$ & $\begin{array}{r}0 \\
11\end{array}$ \\
\hline $\begin{array}{l}\text { Misc Current \& Accrued Liabilities ................. } \\
\text { Total Current \& Accrued Llabilities ......... } \\
\text { Deferred Credits }\end{array}$ & $\begin{array}{r}781 \\
18,915\end{array}$ & $\begin{array}{r}4,409 \\
30,375\end{array}$ & $\begin{array}{r}9 \\
59,670\end{array}$ & $\begin{array}{l}1,075 \\
1,293\end{array}$ & $\begin{array}{l}1,240 \\
2,939\end{array}$ & $\begin{array}{r}288 \\
3,481\end{array}$ \\
\hline 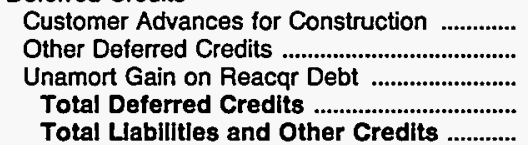 & $\begin{array}{r}409 \\
2,314 \\
0 \\
2,723 \\
411,843\end{array}$ & $\begin{array}{r}0 \\
0 \\
0 \\
0 \\
423,573\end{array}$ & $\begin{array}{r}3,998 \\
72,820 \\
0 \\
76,818 \\
1,881,395\end{array}$ & $\begin{array}{r}0 \\
0 \\
0 \\
0 \\
57,182\end{array}$ & $\begin{array}{r}0 \\
0 \\
0 \\
0 \\
67,417\end{array}$ & $\begin{array}{r}0 \\
0 \\
0 \\
0 \\
157,342\end{array}$ \\
\hline
\end{tabular}

Note: Totals may not equal sum of components because of independent rounding.

Source: Energy Information Administration, Form EIA-412, "Annual Report of Public Electric Utilities." 
Table 22. Balance Sheet by Major U.S. Publicly Owned Electric Utility Within State at End of Period, 1993 (Continued) (Thousand Dollars)

\begin{tabular}{|c|c|c|c|c|c|c|}
\hline Item & $\begin{array}{l}\text { California } \\
\text { Pasadena } \\
\text { City of } \\
\text { June } 30\end{array}$ & $\begin{array}{c}\text { California } \\
\text { Placer } \\
\text { County } \\
\text { Water } \\
\text { Agency } \\
\text { December } 31\end{array}$ & $\begin{array}{l}\text { California } \\
\text { Redding } \\
\text { City of } \\
\text { June } 30\end{array}$ & $\begin{array}{l}\text { California } \\
\text { Riverside } \\
\text { City of } \\
\text { June } 30\end{array}$ & $\begin{array}{l}\text { California } \\
\text { Roseville } \\
\text { City of } \\
\text { June } 30\end{array}$ & $\begin{array}{c}\text { California } \\
\text { Sacramento } \\
\text { Municipal } \\
\text { Util Dist } \\
\text { December } 31\end{array}$ \\
\hline \multicolumn{7}{|l|}{ Electric Utility Plant } \\
\hline 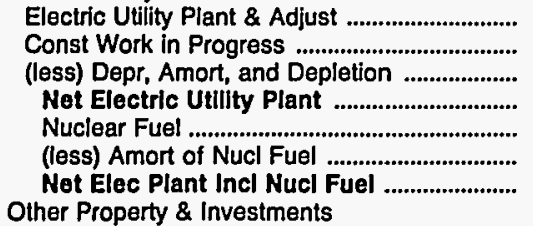 & $\begin{array}{r}225,516 \\
9,983 \\
105,736 \\
129,762 \\
0 \\
0 \\
129,762\end{array}$ & $\begin{array}{r}117,390 \\
68 \\
41,324 \\
76,134 \\
0 \\
0 \\
76,134\end{array}$ & $\begin{array}{r}120,529 \\
28,702 \\
39,005 \\
110,226 \\
0 \\
0 \\
110,226\end{array}$ & $\begin{array}{r}271,136 \\
23,415 \\
94,336 \\
200,214 \\
5,770 \\
1,403 \\
204,581\end{array}$ & $\begin{array}{r}77,592 \\
357 \\
13,141 \\
64,809 \\
0 \\
0 \\
64,809\end{array}$ & $\begin{array}{r}1,429,922 \\
166,245 \\
406,686 \\
1,189,481 \\
0 \\
0 \\
1,189,481\end{array}$ \\
\hline $\begin{array}{l}\text { Nonutility Property ...................................... } \\
\text { (less) Accum Provisions for Depr \& Amort ..... } \\
\text { Invest In Assoc Enterprises ............................ } \\
\text { Invest \& Special Funds ................................... } \\
\text { Total Other Property \& Investments ....... } \\
\text { Current and Accrued Assets }\end{array}$ & $\begin{array}{l}0 \\
0 \\
0 \\
0 \\
0\end{array}$ & $\begin{array}{r}0 \\
0 \\
0 \\
2,448 \\
2,448\end{array}$ & $\begin{array}{r}0 \\
0 \\
0 \\
70,695 \\
70,695\end{array}$ & $\begin{array}{r}0 \\
0 \\
0 \\
37,674 \\
37,674\end{array}$ & $\begin{array}{r}0 \\
0 \\
0 \\
1,429 \\
1,429\end{array}$ & $\begin{array}{r}0 \\
0 \\
130,789 \\
472,873 \\
603,662\end{array}$ \\
\hline 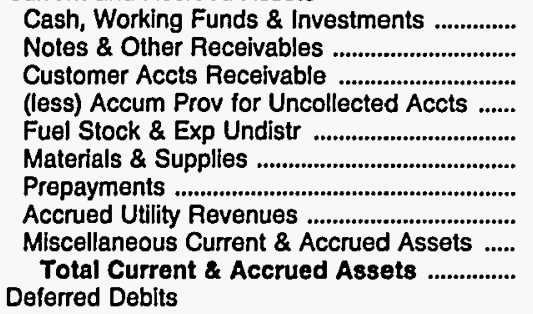 & $\begin{array}{r}63,828 \\
700 \\
14,349 \\
422 \\
3,232 \\
4,212 \\
3,199 \\
0 \\
0 \\
89,097\end{array}$ & $\begin{array}{r}696 \\
0 \\
73 \\
0 \\
0 \\
0 \\
319 \\
0 \\
21 \\
1,108\end{array}$ & $\begin{array}{r}13,361 \\
7,610 \\
5,138 \\
62 \\
0 \\
4,132 \\
453 \\
0 \\
0 \\
30,633\end{array}$ & $\begin{array}{r}71,899 \\
0 \\
22,334 \\
1,546 \\
0 \\
436 \\
2,958 \\
0 \\
1,016 \\
97,096\end{array}$ & $\begin{array}{r}10,519 \\
599 \\
9 \\
0 \\
0 \\
2,796 \\
6,767 \\
5,989 \\
0 \\
26,679\end{array}$ & $\begin{array}{r}217,115 \\
41,022 \\
99,450 \\
6,021 \\
0 \\
22,985 \\
6,293 \\
0 \\
60,418 \\
441,263\end{array}$ \\
\hline $\begin{array}{l}\text { Unamortized Debt Expenses ........................... } \\
\text { Extraordinary Losses, Study Cost ................... } \\
\text { Misc Debt, R \& D Exp, Unamrt Losses .......... } \\
\text { Total Deferred Debits .................................. } \\
\text { Total Assets \& Other Deblts ..................... } \\
\text { Proprietary Capital }\end{array}$ & $\begin{array}{r}0 \\
0 \\
0 \\
0 \\
218,860\end{array}$ & $\begin{array}{r}0 \\
0 \\
0 \\
0 \\
79,690\end{array}$ & $\begin{array}{r}2,701 \\
0 \\
4,721 \\
7,422 \\
218,976\end{array}$ & $\begin{array}{r}2,245 \\
0 \\
605 \\
2,850 \\
342,201\end{array}$ & $\begin{array}{r}238 \\
0 \\
0 \\
238 \\
93,156\end{array}$ & $\begin{array}{r}35,673 \\
0 \\
996,934 \\
1,032,607 \\
3,267,013\end{array}$ \\
\hline 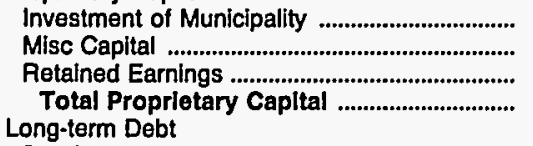 & $\begin{array}{r}0 \\
14,190 \\
110,748 \\
124,938\end{array}$ & $\begin{array}{r}0 \\
0 \\
9,651 \\
9,651\end{array}$ & $\begin{array}{r}0 \\
23,806 \\
35,844 \\
59,650\end{array}$ & $\begin{array}{r}0 \\
36,398 \\
60,020 \\
96,418\end{array}$ & $\begin{array}{r}0 \\
0 \\
78,973 \\
78,973\end{array}$ & $\begin{array}{r}0 \\
0 \\
214,785 \\
214,785\end{array}$ \\
\hline $\begin{array}{l}\text { Bonds } \\
\text { Advances from Municipality \& Other } \\
\text { Unamort Prem on Long-term Debt ....................... } \\
\text { (less) Unamort Discount on Long-term Debt } \\
\text { Total Long-term Debt ...................................... } \\
\text { Other Noncurrent Liabilities }\end{array}$ & $\begin{array}{r}77,150 \\
0 \\
0 \\
0 \\
77,150\end{array}$ & $\begin{array}{r}65,155 \\
478 \\
253 \\
0 \\
65,886\end{array}$ & $\begin{array}{r}149,337 \\
2,806 \\
0 \\
519 \\
151,624\end{array}$ & $\begin{array}{r}194,150 \\
152 \\
0 \\
4,216 \\
190,086\end{array}$ & $\begin{array}{r}9,795 \\
0 \\
0 \\
0 \\
9,795\end{array}$ & $\begin{array}{r}2,125,645 \\
17,823 \\
0 \\
32,913 \\
2,110,555\end{array}$ \\
\hline $\begin{array}{l}\text { Accum Operating Provisions ............................ } \\
\text { Accum Prov for Pate Pefunds ........................ } \\
\text { Total Other Noncurrent Llabllities ........... } \\
\text { Current and Accrued Liabilities }\end{array}$ & $\begin{array}{l}0 \\
0 \\
0\end{array}$ & $\begin{array}{r}148 \\
0 \\
148\end{array}$ & $\begin{array}{l}0 \\
0 \\
0\end{array}$ & $\begin{array}{l}0 \\
0 \\
0\end{array}$ & $\begin{array}{r}585 \\
0 \\
585\end{array}$ & $\begin{array}{r}7,441 \\
0 \\
7,441\end{array}$ \\
\hline 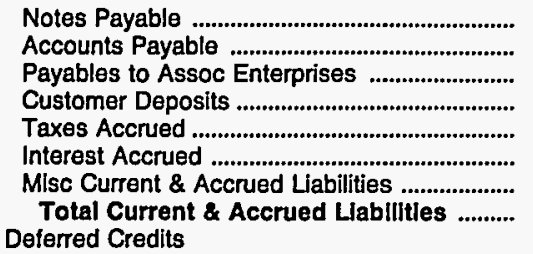 & $\begin{array}{r}0 \\
3,798 \\
0 \\
1,778 \\
0 \\
2,195 \\
9,001 \\
16,771\end{array}$ & $\begin{array}{r}2,505 \\
28 \\
9 \\
0 \\
0 \\
1,246 \\
217 \\
4,005\end{array}$ & $\begin{array}{r}0 \\
4,440 \\
0 \\
0 \\
0 \\
1,011 \\
2,170 \\
7,621\end{array}$ & $\begin{array}{r}0 \\
6,711 \\
0 \\
1,944 \\
0 \\
2,921 \\
28,242 \\
39,819\end{array}$ & $\begin{array}{r}0 \\
1,307 \\
0 \\
231 \\
0 \\
244 \\
274 \\
2,056\end{array}$ & $\begin{array}{r}195,121 \\
89,336 \\
0 \\
8,499 \\
4,567 \\
33,278 \\
75,015 \\
405,816\end{array}$ \\
\hline $\begin{array}{l}\text { Customer Advances for Construction ............ } \\
\text { Other Deferred Credits ....................................... } \\
\text { Unamort Gain on Reacqr Debt ...................... } \\
\text { Total Deferred Credits ................................ } \\
\text { Total Llabllitles and Other Credits ............ }\end{array}$ & $\begin{array}{r}0 \\
0 \\
0 \\
0 \\
218,860\end{array}$ & $\begin{array}{r}0 \\
0 \\
0 \\
0 \\
79,690\end{array}$ & $\begin{array}{r}81 \\
0 \\
0 \\
81 \\
218,976\end{array}$ & $\begin{array}{r}0 \\
15,878 \\
0 \\
15,878 \\
342,201\end{array}$ & $\begin{array}{r}0 \\
1,747 \\
0 \\
1,747 \\
93,156\end{array}$ & $\begin{array}{r}4,618 \\
500,082 \\
23,716 \\
528,416 \\
3,267,013\end{array}$ \\
\hline
\end{tabular}

Note: Totals may not equal sum of components because of independent rounding.

Source: Energy Information Administration, Form EIA-412, "Annual Report of Public Electric Utilities." 
Table 22. Balance Sheet by Major U.S. Publicly Owned Electric Utility Within State at End of Period, 1993 (Continued)

(Thousand Dollars)

\begin{tabular}{|c|c|c|c|c|c|c|}
\hline Item & $\begin{array}{c}\text { California } \\
\text { San Francisco } \\
\text { City } \\
\& \\
\text { County of } \\
\text { June } 30\end{array}$ & $\begin{array}{l}\text { California } \\
\text { Santa } \\
\text { Clara } \\
\text { City of } \\
\text { June } 30\end{array}$ & $\begin{array}{l}\text { California } \\
\text { Southern } \\
\text { California } \\
\text { P P } \\
\text { A } \\
\text { June } 30\end{array}$ & $\begin{array}{l}\text { California } \\
\text { Turlock } \\
\text { Irrigation } \\
\text { District } \\
\text { December } 31\end{array}$ & $\begin{array}{l}\text { California } \\
\text { Vernon } \\
\text { City of } \\
\text { June } 30\end{array}$ & $\begin{array}{l}\text { California } \\
\text { Yuba } \\
\text { County } \\
\text { Water } \\
\text { Agency } \\
\text { June } 30\end{array}$ \\
\hline \multicolumn{7}{|l|}{ Electric Utility Plant } \\
\hline Electric Utility Plant \& Adjust ............................... & 441,265 & 176,963 & $1,316,926$ & 218,469 & 71,029 & 196,918 \\
\hline 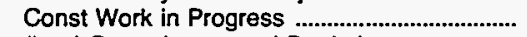 & 9,999 & 65,454 & 37,881 & 6,575 & 2,430 & \\
\hline (less) Depr, Amort, and Depletion ..................... & 184,601 & 52,700 & 294,048 & 72,545 & 22,376 & 52,337 \\
\hline Net Electric Utlity Plant ................................... & 266,663 & 189,718 & $1,060,759$ & 152,498 & 51,083 & 144,581 \\
\hline 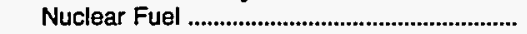 & & & 36,746 & & 0 & 0 \\
\hline 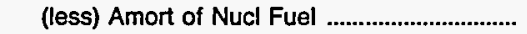 & 0 & 0 & 22,870 & 0 & 0 & 0 \\
\hline Net Elec Plant Incl Nucl Fuel .............................. & 266,663 & 189,718 & $1,074,635$ & 152,498 & 51,083 & 144,581 \\
\hline \multicolumn{7}{|l|}{ Other Property \& Investments } \\
\hline 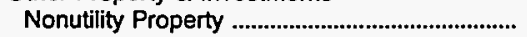 & 410 & 0 & 0 & 33,397 & 482 & 527 \\
\hline (less) Accum Provisions for Depr \& Amort .... & 0 & 0 & 0 & 0 & 0 & 103 \\
\hline 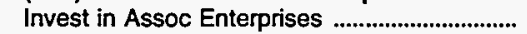 & 0 & 29,415 & 0 & 0 & 0 & 0 \\
\hline 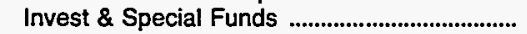 & 0 & 5,000 & 0 & 40,169 & 2,412 & 43,143 \\
\hline Total Other Property \& Investments ....... & 410 & 34,415 & $\mathbf{0}$ & 73,566 & 2,894 & 43,567 \\
\hline \multicolumn{7}{|l|}{ Current and Accrued Assets } \\
\hline Cash, Working Funds \& Investments ............... & 36,650 & 192,640 & $1,632,042$ & 25,395 & 74,018 & 1,736 \\
\hline 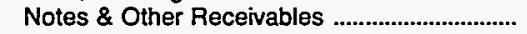 & 7,267 & 5,517 & 0 & 544 & 3,928 & 215 \\
\hline 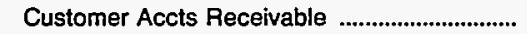 & 5,260 & 16,826 & 2,767 & 7,382 & 4,121 & 0 \\
\hline (less) Accum Prov for Uncollected Accts ...... & 0 & 17 & 0 & 324 & 0 & 0 \\
\hline 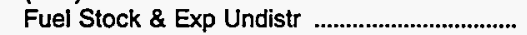 & 0 & 0 & 0 & 0 & 0 & 0 \\
\hline 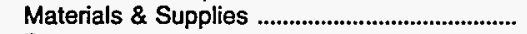 & 1,964 & 2,965 & 10,060 & 1,990 & 690 & 0 \\
\hline 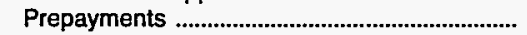 & 0 & 0 & 33,868 & 169 & 5,366 & 99 \\
\hline Accrued Utility Revenues & $\mathbf{0}$ & 0 & 0 & 0 & 3,585 & 0 \\
\hline Miscellaneous Current \& Accrued Assets ..... & 9 & 3,920 & 273,923 & & 506 & \\
\hline \multicolumn{7}{|l|}{ Deferred Debits } \\
\hline Unamortized Debt Expenses ........................................ & 0 & 0 & 40,372 & 23,293 & 0 & 1,605 \\
\hline 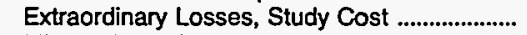 & 0 & 0 & 381,008 & 0 & 0 & 0 \\
\hline Misc Debt, R \& D Exp, Unamrt Losses ........... & 0 & 0 & 0 & 0 & 0 & 0 \\
\hline Total Deferred Debits ........................................ & $\mathbf{0}$ & 0 & 421,381 & 23,293 & $\mathbf{0}$ & 1,605 \\
\hline Total Assets \& Other Debits .......................... & 318,222 & 445,984 & $3,448,676$ & 284,514 & 146,190 & 191,804 \\
\hline \multicolumn{7}{|l|}{ Proprietary Capital } \\
\hline 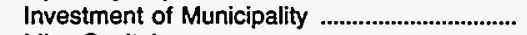 & 0 & 644 & 0 & 0 & 0 & 0 \\
\hline 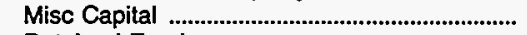 & 45,312 & 0 & 0 & 0 & 0 & 0 \\
\hline 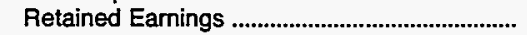 & 259,764 & 191,437 & 0 & 115,391 & 136,399 & 58,318 \\
\hline Total Proprletary Capital .............................. & 305,077 & 192,081 & 0 & 115,391 & 136,399 & 58,318 \\
\hline \multicolumn{7}{|l|}{ Long-term Debt } \\
\hline 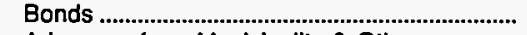 & 0 & 241,930 & $3,664,285$ & 85,995 & $\mathbf{0}$ & 108,231 \\
\hline Advances from Municipality \& Other ................ & 1,482 & 0 & 0 & 65,840 & 3,607 & 2,015 \\
\hline Unamort Prem on Long-term Debt .................... & 0 & 0 & 0 & 0 & 0 & 0 \\
\hline (less) Unamort Discount on Long-term Debt & 0 & 6,233 & 358,292 & 4,613 & 0 & 0 \\
\hline Total Long-term Debt ............................................. & 1,482 & 235,697 & $3,305,993$ & 147,222 & 3,607 & 110,246 \\
\hline \multicolumn{7}{|l|}{ Other Noncurrent Liabilities } \\
\hline Accum Operating Provisions .................................. & 0 & 0 & 0 & 0 & 0 & 0 \\
\hline 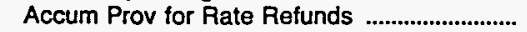 & 0 & 0 & 0 & 0 & 0 & 0 \\
\hline Total Other Noncurrent Llabilities ............ & 0 & o & 0 & 0 & 0 & $\mathbf{0}$ \\
\hline \multicolumn{7}{|l|}{ Current and Accrued Liabilities } \\
\hline Notes Payable & 0 & 2,340 & 10,000 & 4,210 & 0 & 0 \\
\hline 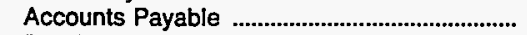 & 5,274 & 10,408 & 6,190 & 8,541 & 4,676 & 2,581 \\
\hline 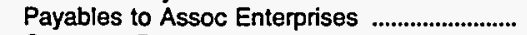 & 4,065 & 0 & 0 & 0 & 450 & 0 \\
\hline 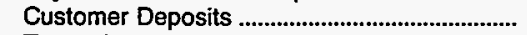 & 292 & 0 & 0 & 290 & 197 & 0 \\
\hline 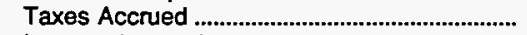 & 0 & 0 & 0 & 0 & 648 & 0 \\
\hline 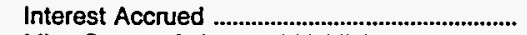 & 0 & 5,458 & 80,366 & 4,036 & 109 & 2,998 \\
\hline Misc Current \& Accrued Liabilities ......................... & 1,801 & & 46,127 & 3,552 & 104 & \\
\hline Total Current \& Accrued Llabillties .......... & 11,432 & 18,206 & 142,683 & 20,629 & 6,185 & 5,580 \\
\hline \multicolumn{7}{|l|}{ Deferred Credits } \\
\hline Customer Advances for Construction .............. & 94 & 0 & $\mathbf{0}$ & 1,272 & 0 & 0 \\
\hline 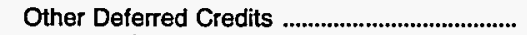 & 137 & 0 & 0 & 0 & 0 & 17,660 \\
\hline Unamort Gain on Reacqr Debt ............................... & 0 & 0 & 0 & 0 & 0 & 0 \\
\hline Total Deferred Credits .......................................... & 231 & & & 1,272 & & 17,660 \\
\hline Total Llabilities and Other Credits ............ & 318,222 & 445,984 & $3,448,676$ & 284,514 & 146,190 & 191,804 \\
\hline
\end{tabular}

Note: Totals may not equal sum of components because of independent rounding.

Source: Energy Information Administration, Form EIA-412, "Annual Report of Public Electric Utilities." 
Table 22. Balance Sheet by Major U.S. Publicly Owned Electric Utility Within State at End of Period, 1993 (Continued)

(Thousand Dollars)

\begin{tabular}{|c|c|c|c|c|c|c|}
\hline Item & $\begin{array}{l}\text { Colorado } \\
\text { Arkansas } \\
\text { River } \\
\text { Power } \\
\text { Authority } \\
\text { December } 31\end{array}$ & $\begin{array}{l}\text { Colorado } \\
\text { Colorado } \\
\text { Springs } \\
\text { City of } \\
\text { December } 31\end{array}$ & $\begin{array}{l}\text { Colorado } \\
\text { Fort Collins } \\
\text { City of }\end{array}$ & $\begin{array}{c}\text { Colorado } \\
\text { Fort Morgan } \\
\text { City of } \\
\text { December } 31\end{array}$ & $\begin{array}{l}\text { Colorado } \\
\text { Longmont } \\
\text { City of } \\
\text { December } 31\end{array}$ & $\begin{array}{l}\text { Colorado } \\
\text { Loveland } \\
\text { City of } \\
\text { December } 31\end{array}$ \\
\hline \multicolumn{7}{|l|}{ Electric Utility Plant } \\
\hline 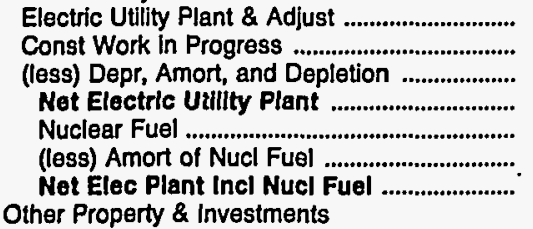 & $\begin{array}{r}2,710 \\
0 \\
282 \\
2,428 \\
0 \\
0 \\
2,428\end{array}$ & $\begin{array}{r}649,197 \\
25,478 \\
174,519 \\
500,157 \\
0 \\
0 \\
500,157\end{array}$ & $\begin{array}{r}83,866 \\
4,142 \\
35,072 \\
52,936 \\
0 \\
0 \\
52,936\end{array}$ & $\begin{array}{r}8,483 \\
708 \\
3,301 \\
5,889 \\
0 \\
0 \\
0 \\
5,889\end{array}$ & $\begin{array}{r}37,969 \\
0 \\
14,637 \\
23,332 \\
0 \\
0 \\
23,332\end{array}$ & $\begin{array}{r}43,508 \\
629 \\
9,732 \\
34,405 \\
0 \\
0 \\
34,405\end{array}$ \\
\hline 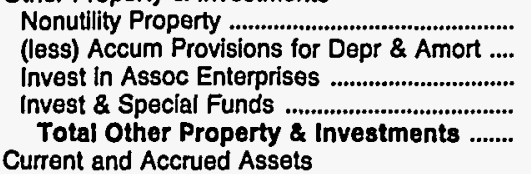 & $\begin{array}{r}214 \\
84 \\
0 \\
1,738 \\
1,869\end{array}$ & $\begin{array}{r}0 \\
0 \\
57 \\
131,562 \\
131,619\end{array}$ & $\begin{array}{l}0 \\
0 \\
0 \\
0 \\
0\end{array}$ & $\begin{array}{l}0 \\
0 \\
0 \\
0 \\
0\end{array}$ & $\begin{array}{l}0 \\
0 \\
0 \\
0 \\
0\end{array}$ & $\begin{array}{r}0 \\
0 \\
600 \\
4,769 \\
5,369\end{array}$ \\
\hline 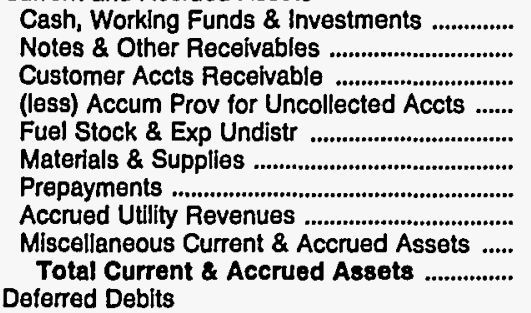 & $\begin{array}{r}2,876 \\
0 \\
914 \\
0 \\
0 \\
33 \\
98 \\
0 \\
0 \\
3,921\end{array}$ & $\begin{array}{r}38,967 \\
441 \\
19,141 \\
914 \\
0 \\
12,840 \\
632 \\
0 \\
822 \\
71,929\end{array}$ & $\begin{array}{r}13,640 \\
0 \\
6,202 \\
150 \\
0 \\
2,406 \\
0 \\
0 \\
258 \\
22,356\end{array}$ & $\begin{array}{r}1,568 \\
0 \\
714 \\
5 \\
0 \\
140 \\
70 \\
0 \\
0 \\
2,486\end{array}$ & $\begin{array}{r}5,493 \\
21 \\
4,015 \\
91 \\
0 \\
0 \\
0 \\
0 \\
45 \\
9,482\end{array}$ & $\begin{array}{r}6,325 \\
0 \\
1,561 \\
17 \\
0 \\
693 \\
4 \\
0 \\
190 \\
8,755\end{array}$ \\
\hline $\begin{array}{l}\text { Unamortized Debt Expenses ........................... } \\
\text { Extraordinary Losses, Study Cost .................... } \\
\text { Misc Debt, R \& D Exp, Unamrt Losses ......... } \\
\text { Total Deferred Debits .................................... } \\
\text { Total Assete \& Other Debits ...................... }\end{array}$ & $\begin{array}{r}94 \\
0 \\
0 \\
94 \\
8,312\end{array}$ & $\begin{array}{r}6,068 \\
0 \\
2,034 \\
8,102 \\
711,807\end{array}$ & $\begin{array}{r}0 \\
0 \\
0 \\
0 \\
75,293\end{array}$ & $\begin{array}{r}0 \\
0 \\
0 \\
0 \\
8,376\end{array}$ & $\begin{array}{r}0 \\
0 \\
0 \\
0 \\
32,814\end{array}$ & $\begin{array}{r}40 \\
0 \\
0 \\
40 \\
48,569\end{array}$ \\
\hline 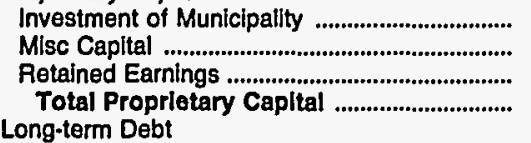 & $\begin{array}{r}0 \\
0 \\
4,321 \\
4,321\end{array}$ & $\begin{array}{r}0 \\
451 \\
217,441 \\
217,892\end{array}$ & $\begin{array}{r}28,634 \\
0 \\
42,621 \\
71,255\end{array}$ & $\begin{array}{r}0 \\
0 \\
7,645 \\
7,645\end{array}$ & $\begin{array}{r}9,351 \\
0 \\
20,902 \\
\mathbf{3 0 , 2 5 2}\end{array}$ & $\begin{array}{r}0 \\
0 \\
38,709 \\
38,709\end{array}$ \\
\hline 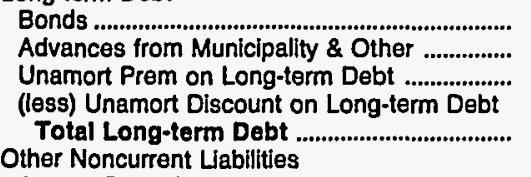 & $\begin{array}{r}2,995 \\
0 \\
0 \\
66 \\
2,929\end{array}$ & $\begin{array}{r}291,322 \\
4,384 \\
0 \\
0 \\
295,706\end{array}$ & $\begin{array}{l}0 \\
0 \\
0 \\
0 \\
0\end{array}$ & $\begin{array}{l}0 \\
0 \\
0 \\
0 \\
0\end{array}$ & $\begin{array}{l}0 \\
0 \\
0 \\
0 \\
0\end{array}$ & $\begin{array}{r}4,551 \\
949 \\
0 \\
0 \\
5,499\end{array}$ \\
\hline 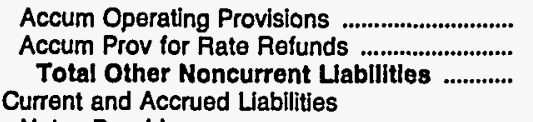 & $\begin{array}{l}0 \\
0 \\
0\end{array}$ & $\begin{array}{r}2,227 \\
266 \\
2,493\end{array}$ & $\begin{array}{l}0 \\
0 \\
0\end{array}$ & $\begin{array}{l}0 \\
0 \\
\mathbf{0}\end{array}$ & $\begin{array}{r}84 \\
0 \\
84\end{array}$ & $\begin{array}{l}0 \\
0 \\
0\end{array}$ \\
\hline 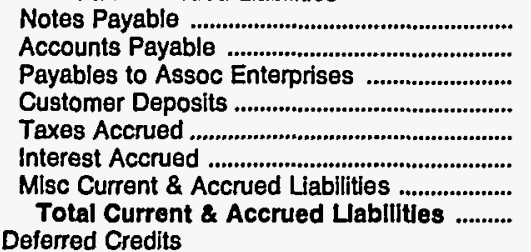 & $\begin{array}{r}0 \\
1,007 \\
0 \\
0 \\
0 \\
20 \\
34 \\
1,061\end{array}$ & $\begin{array}{r}0 \\
23,895 \\
0 \\
401 \\
0 \\
1,908 \\
6,206 \\
32,409\end{array}$ & $\begin{array}{r}0 \\
3,695 \\
140 \\
0 \\
0 \\
0 \\
202 \\
4,037\end{array}$ & $\begin{array}{r}0 \\
0 \\
0 \\
88 \\
0 \\
0 \\
0 \\
88\end{array}$ & $\begin{array}{r}0 \\
1,594 \\
0 \\
498 \\
66 \\
0 \\
320 \\
2,478\end{array}$ & $\begin{array}{r}358 \\
1,288 \\
0 \\
0 \\
0 \\
148 \\
199 \\
1,993\end{array}$ \\
\hline 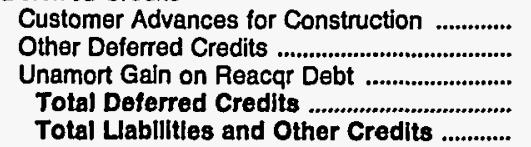 & $\begin{array}{r}0 \\
0 \\
0 \\
0 \\
8,312\end{array}$ & $\begin{array}{r}2,235 \\
605 \\
160,466 \\
163,307 \\
711,807\end{array}$ & $\begin{array}{r}0 \\
0 \\
0 \\
0 \\
75,293\end{array}$ & $\begin{array}{r}643 \\
0 \\
0 \\
643 \\
8,376\end{array}$ & $\begin{array}{r}0 \\
0 \\
0 \\
0 \\
32,814\end{array}$ & $\begin{array}{r}57 \\
2,310 \\
0 \\
2,367 \\
48,569\end{array}$ \\
\hline
\end{tabular}

Note: Totals may not equal sum of components because of independent rounding.

Source: Energy Information Administration, Form EIA-412, "Annual Report of Public Electric Utilities." 
Table 22. Balance Sheet by Major U.S. Publicly Owned Electric Utility Within State at End of Period, 1993 (Continued)

(Thousand Dollars)

\begin{tabular}{|c|c|c|c|c|c|c|}
\hline Item & $\begin{array}{c}\text { Colorado } \\
\text { Platte River } \\
\text { Power } \\
\text { Authority } \\
\text { December } 31\end{array}$ & $\begin{array}{c}\text { Connecticut } \\
\text { Connecticut } \\
\text { Mun } \\
\text { Elec } \\
\text { Engy Coop } \\
\text { December } 31\end{array}$ & $\begin{array}{l}\text { Connecticut } \\
\text { Groton } \\
\text { City of } \\
\text { June } 30\end{array}$ & $\begin{array}{l}\text { Connecticut } \\
\begin{array}{l}\text { Nonwich } \\
\text { City of }\end{array} \\
\text { June } 30\end{array}$ & $\begin{array}{l}\text { Connecticut } \\
\text { Wallingford } \\
\text { Town of } \\
\text { June } 30\end{array}$ & $\begin{array}{l}\text { Delaware } \\
\text { Dover } \\
\text { City of } \\
\text { June } 30\end{array}$ \\
\hline \multicolumn{7}{|l|}{ Electric Utility Plant } \\
\hline 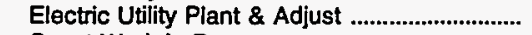 & 761,622 & 54,472 & 24,968 & 24,354 & 42,296 & 93,961 \\
\hline 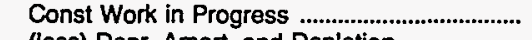 & 5,421 & & & 5,502 & 1,865 & \\
\hline & 228,092 & 12,486 & 14,427 & 16,083 & 24,430 & 30,245 \\
\hline $\begin{array}{l}\text { Net Electric Utility Plant } \\
\text { Nuclear Fuel }\end{array}$ & 538,951 & $\begin{array}{r}42,013 \\
3,882\end{array}$ & $\begin{array}{r}10,541 \\
0\end{array}$ & 13,772 & 19,731 & 63,716 \\
\hline 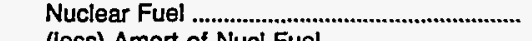 & 0 & 3,882 & 0 & 0 & 0 & 0 \\
\hline (less) Amort of Nucl Fuel .................................. & & 3,069 & 0 & 0 & 0 & 0 \\
\hline Net Elec Plant Incl Nucl Fuel ......................... & 538,951 & 42,825 & 10,541 & 13,772 & 19,731 & 63,716 \\
\hline \multicolumn{7}{|l|}{ Other Property \& Investments } \\
\hline 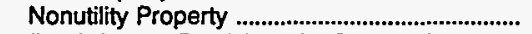 & 0 & 0 & 0 & 0 & 0 & 0 \\
\hline (less) Accum Provisions for Depr \& Amort .... & 0 & 0 & 0 & 0 & 0 & 0 \\
\hline 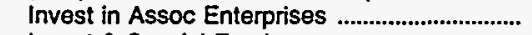 & 0 & 0 & 0 & 0 & 0 & 0 \\
\hline 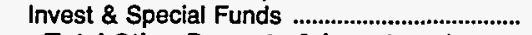 & 165,500 & 27,453 & 0 & 394 & 0 & 10,756 \\
\hline Total Other Property \& Investments ........ & 165,500 & 27,453 & 0 & 394 & 0 & 10,756 \\
\hline \multicolumn{7}{|l|}{ Current and Accrued Assets } \\
\hline Cash, Working Funds \& Investments .............. & 45,481 & 2,550 & 9,516 & 3,135 & 16,163 & 174 \\
\hline 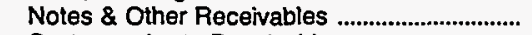 & 701 & & 0 & 3,941 & 0 & 1,141 \\
\hline 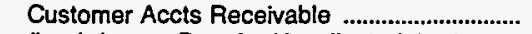 & 11,962 & 9,482 & 3,482 & 2,940 & 4,879 & 3,945 \\
\hline (less) Accum Prov for Uncollected Accts ....... & & 0 & 0 & 558 & 100 & 0 \\
\hline 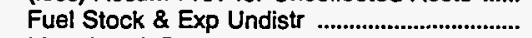 & 6,187 & 0 & 0 & 0 & 60 & 244 \\
\hline 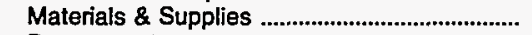 & 7,899 & 28 & 552 & 261 & 797 & 2,241 \\
\hline 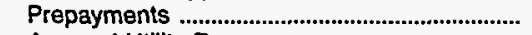 & 388 & 10,221 & 0 & 83 & 49 & 0 \\
\hline 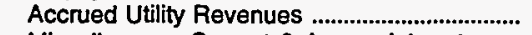 & 0 & 0 & 879 & 0 & 0 & 0 \\
\hline Miscellaneous Current \& Accrued Assets ..... & 3,317 & 0 & 832 & -370 & -12 & 0 \\
\hline $\begin{array}{l}\text { Total Current \& Accrued Assets ................ } \\
\text { Deferred Debits }\end{array}$ & 75,929 & 22,281 & 15,262 & 9,432 & 21,837 & 7,747 \\
\hline 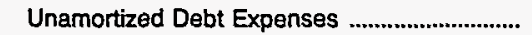 & 6,324 & 2,342 & 0 & 0 & 0 & 0 \\
\hline 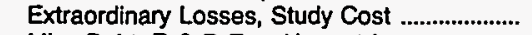 & 316 & 0 & 0 & 0 & 0 & 0 \\
\hline Misc Debt, R \& D Exp, Unamrt Losses .......... & 86,033 & 54,397 & 487 & 14 & 0 & 0 \\
\hline Total Deferred Deblts & 92,674 & 56,739 & 487 & 14 & 0 & $\mathbf{0}$ \\
\hline Total Assets \& Other Debits .............................. & 873,054 & 149,298 & 26,289 & 23,613 & 41,568 & 82,218 \\
\hline \multicolumn{7}{|l|}{ Proprietary Capital } \\
\hline 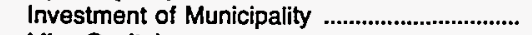 & 0 & 806 & 0 & 0 & 0 & 0 \\
\hline 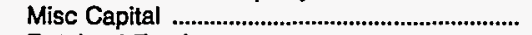 & 356 & & 0 & 0 & 0 & 0 \\
\hline 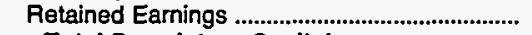 & 200,546 & 3,493 & 9,712 & 14,150 & 31,289 & 40,100 \\
\hline \\
\hline 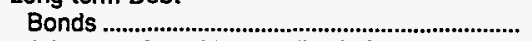 & 626,345 & 120,205 & 7,188 & 425 & 660 & 31,679 \\
\hline Advances from Municipality \& Other ................. & 41,515 & & & 3,787 & 0 & 0 \\
\hline Unamort Prem on Long-term Debt .................... & & 0 & 0 & 0 & 1 & 0 \\
\hline (less) Unamort Discount on Long-term Debt & 12,014 & 1,757 & 0 & 0 & 0 & 0 \\
\hline 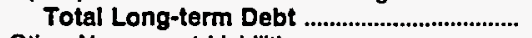 & 655,846 & 118,448 & 7,188 & 4,212 & 661 & 31,679 \\
\hline \multicolumn{7}{|l|}{ Other Noncurrent Liabilities } \\
\hline 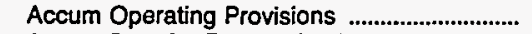 & 5,279 & 0 & 0 & 232 & 0 & 7,015 \\
\hline 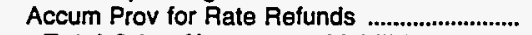 & & 0 & 0 & 0 & 0 & \\
\hline Total Other Noncurrent Llabillitles ............ & 5,279 & 0 & $\mathbf{0}$ & 232 & 0 & 7,015 \\
\hline \multicolumn{7}{|l|}{ Current and Accrued Liabilities } \\
\hline 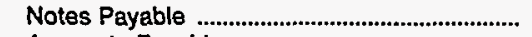 & 0 & 896 & 0 & 0 & 0 & 0 \\
\hline Accounts Payable & 6,176 & 4,236 & 5,231 & 3,135 & 6,737 & 1,597 \\
\hline 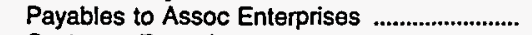 & & 851 & 0 & 0 & 0 & 0 \\
\hline 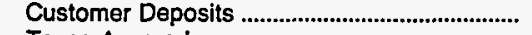 & 0 & 0 & 2,330 & 190 & 1,096 & 560 \\
\hline 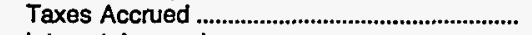 & 0 & 144 & 546 & 285 & 483 & 0 \\
\hline 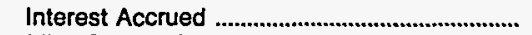 & 3,895 & 2,713 & 52 & 0 & 183 & 1,011 \\
\hline Misc Current \& Accrued Liabilities ...................... & 782 & 199 & 1,230 & 3 & 953 & 257 \\
\hline Total Current \& Accrued Llablities .......... & 10,852 & 9,039 & 9,389 & 3,613 & 9,453 & 3,425 \\
\hline \multicolumn{7}{|l|}{ Deferred Credits } \\
\hline Customer Advances for Construction .............. & 0 & 0 & 0 & 1,406 & 56 & 0 \\
\hline 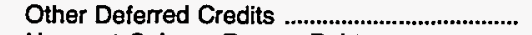 & 175 & 17,513 & 0 & 0 & 109 & 0 \\
\hline Unamort Gain on Reacqr Debt ............................... & 0 & 0 & 0 & 0 & 0 & 0 \\
\hline 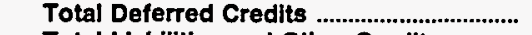 & 175 & 17,513 & & 1,406 & 165 & \\
\hline Total Llabilities and Other Credits ............ & 873,054 & 149,298 & 26,289 & 23,613 & 41,568 & 82,218 \\
\hline
\end{tabular}

Note: Totals may not equal sum of components because of independent rounding.

Source: Energy Information Administration, Form EIA-412, "Annual Report of Public Electric Utilities." 
Table 22. Balance Sheet by Major U.S. Publicly Owned Electric Utility Within State at End of Period, 1993 (Continued) (Thousand Dollars)

\begin{tabular}{|c|c|c|c|c|c|c|}
\hline Item & $\begin{array}{l}\text { Delaware } \\
\text { Milford } \\
\text { City of } \\
\text { September } 30\end{array}$ & $\begin{array}{c}\text { Delaware } \\
\begin{array}{c}\text { Newark } \\
\text { City of }\end{array} \\
\text { December } 31\end{array}$ & $\begin{array}{l}\text { Florida } \\
\text { Bartow } \\
\text { City of } \\
\text { September } 30\end{array}$ & $\begin{array}{c}\text { Florida } \\
\text { Florida } \\
\text { Municipal } \\
\text { Power Agency } \\
\text { September } 30\end{array}$ & $\begin{array}{c}\text { Florida } \\
\text { Fort Pierce } \\
\text { Utilities } \\
\text { Auth }\end{array}$ & $\begin{array}{c}\text { Florida } \\
\text { Gainesville } \\
\text { Regional } \\
\text { Utilities } \\
\text { September } 30\end{array}$ \\
\hline \multicolumn{7}{|l|}{ Electric Utility Plant } \\
\hline Electric Utility Plant \& Adjust ................................... & 6,818 & 0 & 10,815 & 319,549 & 98,576 & 404,123 \\
\hline Const Work in Progress & & 0 & & 19,940 & 9,080 & 22,628 \\
\hline (less) Depr, Amort, and Depletion ..................... & 3,575 & 0 & 4,870 & 64,757 & 42,128 & 134,569 \\
\hline Net Electrlc Utllity Plant ................................... & 3,243 & o & 5,946 & 274,732 & 65,528 & 292,182 \\
\hline 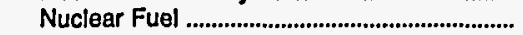 & 0 & 0 & 0 & 12,556 & 0 & 4,631 \\
\hline 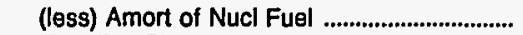 & 0 & 0 & 0 & 6,484 & 0 & 3,875 \\
\hline Net Elec Plant Incl Nucl Fuel ......................... & 3,243 & 0 & 5,946 & 280,804 & 65,528 & 292,937 \\
\hline 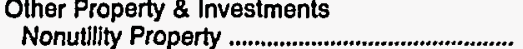 & 0 & 0 & \multicolumn{4}{|c|}{ Other Property \& Investments } \\
\hline (less) Accum Provisions for Depr \& Amort .... & 0 & 0 & 0 & 0 & 0 & 0 \\
\hline Invest in Assoc Enterprises ................................. & 0 & 0 & 0 & 0 & 0 & 0 \\
\hline Invest \& Special Funds ........................................... & 0 & 0 & 5,202 & 109,956 & 13,273 & 0 \\
\hline \multicolumn{7}{|l|}{ Current and Accrued Assets } \\
\hline Cash, Working Funds \& Investments .............. & 2,474 & 0 & 1,499 & 52,487 & 8,936 & 131,626 \\
\hline 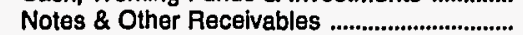 & & 0 & & 3,874 & 1,079 & -62 \\
\hline 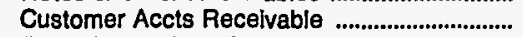 & 1,259 & 0 & 2,289 & 16,569 & 3,031 & 11,692 \\
\hline (less) Accum Prov for Uncollected Accts ....... & 0 & 0 & 150 & 0 & 37 & 558 \\
\hline 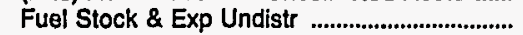 & 0 & 0 & 0 & 531 & 0 & 5,427 \\
\hline 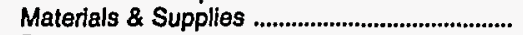 & 922 & 0 & 757 & 0 & 3,781 & 4,100 \\
\hline Prepayments ................................................................. & 3 & 0 & 0 & 1,829 & 451 & 7 \\
\hline 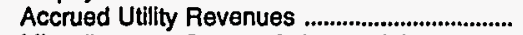 & 0 & 0 & 0 & 0 & 2,269 & 7,613 \\
\hline Miscellaneous Current \& Accrued Assets ..... & & 0 & 0 & 0 & 645 & 23 \\
\hline \multicolumn{7}{|l|}{ Deferred Debits } \\
\hline Unamortized Debt Expenses ................................... & 0 & 0 & 0 & 9,763 & 541 & 3,062 \\
\hline Extraordinary Losses, Study Cost ......................... & 0 & 0 & 0 & 9,146 & 266 & 0 \\
\hline Misc Debt, A \& D Exp, Unamrt Losses ........... & 0 & 0 & 0 & 186,380 & 544 & 49,997 \\
\hline Total Deferred Debits ........................................ & & 0 & 0 & 205,289 & 1,351 & 53,060 \\
\hline Total Assets \& Other Debits & 7,901 & 0 & 15,543 & 671,339 & 100,307 & 505,865 \\
\hline \multicolumn{7}{|l|}{ Proprietary Capital } \\
\hline 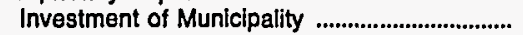 & 0 & 0 & 27 & 0 & 0 & 0 \\
\hline 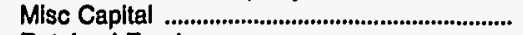 & 0 & 0 & 0 & 0 & 0 & 0 \\
\hline 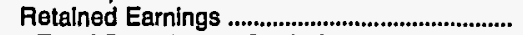 & 7,005 & 0 & 6,440 & 0 & 36,340 & 160,157 \\
\hline 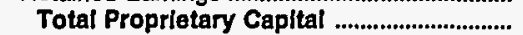 & 7,005 & 0 & 6,467 & 0 & 36,340 & 160,157 \\
\hline \multicolumn{7}{|l|}{ Long-term Debt } \\
\hline 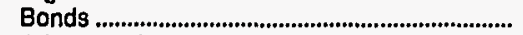 & $\mathbf{0}$ & 0 & 0 & 619,565 & 53,765 & 280,547 \\
\hline Advances from Municipality \& Other ................. & 0 & 0 & 0 & 18,384 & 0 & 51,513 \\
\hline Unamort Prem on Long-term Debt .................... & 0 & 0 & 0 & 0 & 0 & 0 \\
\hline (less) Unamort Discount on Long-term Debt & 0 & 0 & 0 & 24,975 & & 4,751 \\
\hline 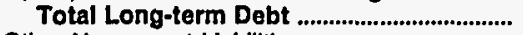 & 0 & 0 & 0 & 612,974 & 53,765 & 327,309 \\
\hline \multicolumn{7}{|l|}{ Other Noncurrent Ljabilities } \\
\hline 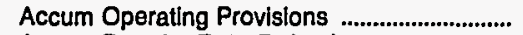 & 0 & 0 & 0 & 0 & 1,366 & 0 \\
\hline Accum Prov for Rate Refunds ............................. & 0 & 0 & 0 & 0 & & 0 \\
\hline Total Other Noncurrent Llabllities ............. & 0 & 0 & 0 & $\mathbf{0}$ & 1,366 & o \\
\hline \multicolumn{7}{|l|}{ Current and Accrued Liabilities } \\
\hline 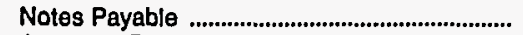 & 0 & 0 & 0 & 9,135 & 317 & 0 \\
\hline 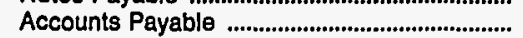 & 677 & 0 & 3,088 & 30,829 & 4,188 & 10,164 \\
\hline 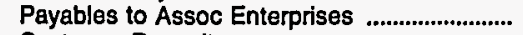 & 28 & 0 & 0 & 0 & & $-9,081$ \\
\hline 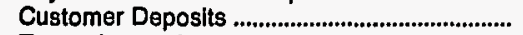 & 114 & 0 & 601 & 0 & 2,566 & 3,910 \\
\hline 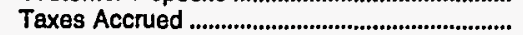 & 0 & 0 & 166 & 0 & 471 & 533 \\
\hline 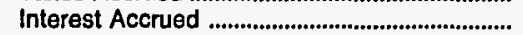 & 3 & 0 & 0 & 17,595 & 1,294 & 7,182 \\
\hline 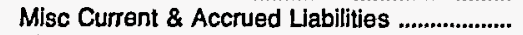 & 27 & 0 & 19 & 806 & & 2,638 \\
\hline $\begin{array}{l}\text { Total Current \& Accrued Llabilities ........... } \\
\text { Deferred Credits }\end{array}$ & 849 & $\mathbf{0}$ & 3,874 & 58,365 & 8,836 & 15,347 \\
\hline Customer Advances for Construction ................. & 0 & 0 & & 0 & 0 & 0 \\
\hline 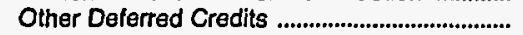 & 47 & 0 & 5,202 & 0 & 0 & 3,052 \\
\hline 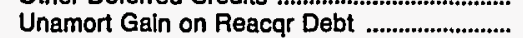 & 0 & 0 & 0 & 0 & 0 & 0 \\
\hline 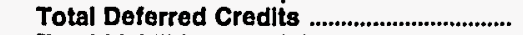 & 47 & 0 & 5,202 & 0 & 0 & 3,052 \\
\hline Total Labilities and Other Credits ............ & 7,901 & 0 & 15,543 & 671,339 & 100,307 & 505,865 \\
\hline
\end{tabular}

Note: Totals may not equal sum of components because of independent rounding.

Source: Energy Information Administration, Form ElA-412, "Annual Report of Public Electric Utilities." 
Table 22. Balance Sheet by Major U.S. Publicly Owned Electric Utility Within State at End of Period, 1993 (Continued)

(Thousand Dollars)

\begin{tabular}{|c|c|c|c|c|c|c|}
\hline Item & $\begin{array}{c}\text { Florida } \\
\begin{array}{c}\text { Homestead } \\
\text { City of }\end{array} \\
\text { September } 30\end{array}$ & $\begin{array}{c}\text { Florida } \\
\text { Jacksonville } \\
\text { Beach } \\
\text { City of } \\
\text { September } 30\end{array}$ & $\begin{array}{c}\text { Florida } \\
\text { Jacksonville } \\
\text { Electric } \\
\text { Auth } \\
\text { September } 30\end{array}$ & $\begin{array}{c}\text { Florida } \\
\text { Key West } \\
\text { City of } \\
\text { September } 30\end{array}$ & $\begin{array}{c}\text { Florida } \\
\text { Kissimmee } \\
\text { Utility } \\
\text { Authority } \\
\text { September } 30\end{array}$ & $\begin{array}{c}\text { Florida } \\
\text { Lake Worth } \\
\text { City of } \\
\text { September } 30\end{array}$ \\
\hline \multicolumn{7}{|l|}{ Electric Utility Plant } \\
\hline Electric Utility Plant \& Adjust ................................ & 40,422 & 61,643 & $2,806,373$ & 148,124 & 138,212 & 70,686 \\
\hline 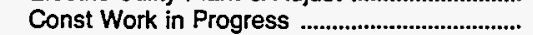 & & 10,867 & 25,797 & 8,639 & 13,403 & 5,638 \\
\hline (less) Depr, Amort, and Depletion ........................ & 17,657 & 19,578 & 561,085 & 58,466 & 49,484 & 36,798 \\
\hline Net Electric Utility Plant ..................................... & 22,765 & 52,932 & $2,271,085$ & 98,298 & 102,131 & 39,525 \\
\hline Nuclear Fuel .................................................... & 0 & 0 & 0 & 0 & 2,301 & 0 \\
\hline (less) Amort of Nucl Fuel .............................. & 0 & 0 & 0 & 0 & 1,951 & 0 \\
\hline 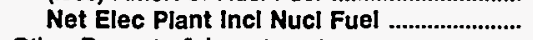 & 22,765 & 52,932 & $2,271,085$ & 98,298 & 102,481 & 39,525 \\
\hline \multicolumn{7}{|l|}{ Other Property \& Investments } \\
\hline 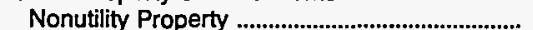 & 0 & $\mathbf{0}$ & 0 & 0 & 0 & 0 \\
\hline (less) Accum Provisions for Depr \& Amort .... & 0 & 0 & 0 & 0 & 0 & 0 \\
\hline Invest in Assoc Enterprises & 0 & 0 & 0 & 0 & 0 & 0 \\
\hline 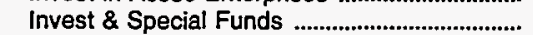 & 0 & 0 & 643,440 & 31,807 & 187,339 & 14,025 \\
\hline $\begin{array}{l}\text { Total Other Property \& Investments ....... } \\
\text { Current and Accrued Assets }\end{array}$ & o & 0 & 643,440 & 31,807 & 187,339 & 14,025 \\
\hline Cash, Working Funds \& Investments .............. & 8,132 & 30,440 & 176,293 & 201 & 8,929 & 3,795 \\
\hline 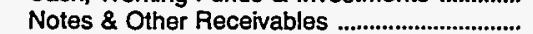 & 11,099 & 260 & 7,991 & 33 & 699 & 190 \\
\hline 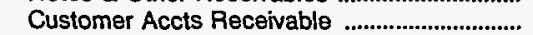 & 2,785 & 5,623 & 85,305 & 4,593 & 7,569 & 2,465 \\
\hline (less) Accum Prov for Uncollected Accts ....... & 1,299 & 134 & 1,857 & 85 & 217 & 0 \\
\hline 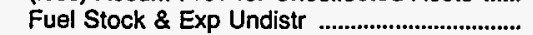 & 142 & 0 & 27,479 & 1,548 & 914 & 0 \\
\hline 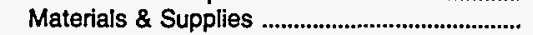 & 3,226 & 1,139 & 38,040 & 2,353 & 3,585 & 1,823 \\
\hline 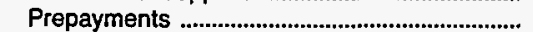 & 16 & 39 & 58 & 138 & 139 & 0 \\
\hline 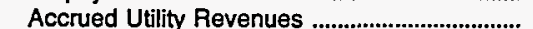 & 1,214 & 0 & 0 & 0 & 0 & 0 \\
\hline Miscellaneous Current \& Accrued Assets ..... & 47 & 0 & 9,923 & 0 & 644 & 0 \\
\hline 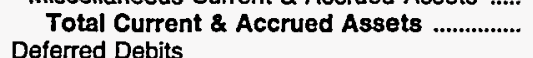 & 25,362 & 37,368 & 343,231 & 8,782 & 22,262 & 8,273 \\
\hline 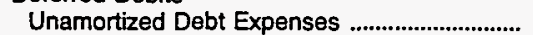 & 0 & 1,021 & 32,126 & 4,213 & 2,855 & 770 \\
\hline 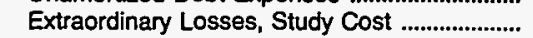 & 0 & & & 0 & & 0 \\
\hline Misc Debt, R \& D Exp, Unamrt Losses ............... & 0 & 7,225 & 349,019 & 0 & 50,095 & 0 \\
\hline 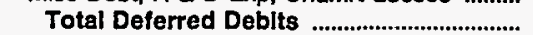 & $\mathbf{0}$ & 8,246 & 381,145 & 4,213 & 52,950 & 770 \\
\hline Total Assets \& Other Debits & 48,127 & 98,545 & $3,638,901$ & 143,099 & 365,032 & 62,593 \\
\hline \multicolumn{7}{|l|}{ Proprietary Capital } \\
\hline 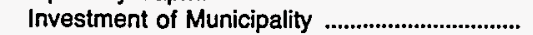 & 3,951 & 0 & 0 & 0 & 0 & 0 \\
\hline 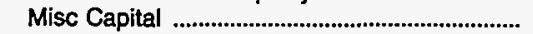 & & 4,841 & 0 & 0 & 0 & 0 \\
\hline 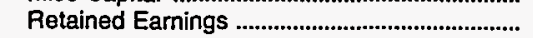 & 29,173 & 16,411 & 474,089 & 13,900 & 96,092 & 18,859 \\
\hline & 18,859 \\
\hline 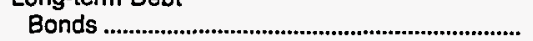 & 0 & 70,000 & $2,914,912$ & 119,214 & 245,040 & 39,034 \\
\hline Advances from Municipality \& Other ..................... & 9,402 & 0 & 0 & 0 & 0 & 0 \\
\hline Unamort Prem on Long-term Debt ......................... & 0 & 0 & 0 & 0 & 0 & 0 \\
\hline (less) Unamort Discount on Long-term Debt & & 501 & 87,641 & 0 & 5,397 & 0 \\
\hline 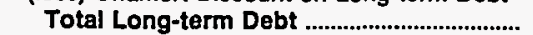 & 9,402 & 69,499 & $2,827,271$ & 119,214 & 239,643 & 39,034 \\
\hline \multicolumn{7}{|l|}{ Other Noncurrent Liabilities } \\
\hline 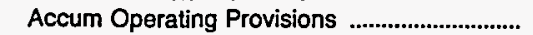 & 0 & 0 & 188,456 & 0 & 122 & 0 \\
\hline Accum Prov for Rate Refunds ................................ & 0 & 0 & & 0 & 0 & 0 \\
\hline 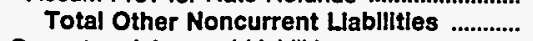 & 0 & 0 & 188,456 & 0 & 122 & 0 \\
\hline \multicolumn{7}{|l|}{ Current and Accrued Liabilities } \\
\hline Notes Payable & 117 & 0 & 0 & 10 & 0 & 0 \\
\hline Accounts Payable & 3,833 & 3,127 & 33,141 & 4,904 & 3,815 & 1,068 \\
\hline Payables to Assoc Enterprises .............................. & 0 & 0 & 3,980 & 0 & 2,708 & 1,412 \\
\hline 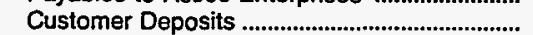 & 1,256 & 1,838 & 16,557 & 3,283 & 2,476 & 0 \\
\hline 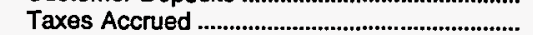 & 0 & 100 & 1,875 & 193 & 390 & 167 \\
\hline 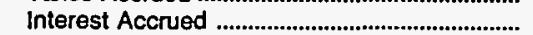 & 388 & 1,737 & 65,654 & 675 & 5,147 & 0 \\
\hline 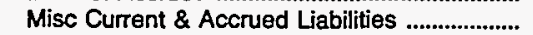 & & 992 & 19,450 & 788 & 8,502 & 2,052 \\
\hline 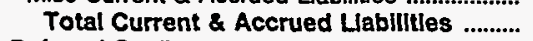 & 5,594 & 7,794 & 140,656 & 9,852 & 23,037 & 4,700 \\
\hline \multicolumn{7}{|l|}{ Deferred Credits } \\
\hline Customer Advances for Construction .............. & 0 & 0 & 0 & 0 & 6,137 & 0 \\
\hline 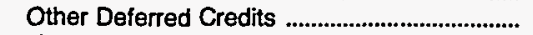 & 7 & 0 & 8,429 & 133 & 0 & 0 \\
\hline Unamort Gain on Reacqr Debt ............................ & 0 & 0 & 0 & 0 & 0 & 0 \\
\hline 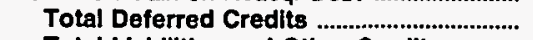 & & 0 & 8,429 & 133 & 6,137 & \\
\hline Total Llabillties and Other Credits ................. & 8,127 & 98,545 & $3,638,901$ & 143,099 & 65,032 & 62,593 \\
\hline
\end{tabular}

Note: Totals may not equal sum of components because of independent rounding.

Source: Energy Information Administration, Form EIA-412, "Annual Report of Public Electric Utilities." 
Table 22. Balance Sheet by Major U.S. Publicly Owned Electric Utility Within State at End of Period, 1993 (Continued) (Thousand Dollars)

\begin{tabular}{|c|c|c|c|c|c|c|}
\hline Item & $\begin{array}{l}\text { Florida } \\
\text { Lakeland } \\
\text { City of } \\
\text { September } 30\end{array}$ & $\begin{array}{l}\text { Florida } \\
\text { Leesburg } \\
\text { City of } \\
\text { September } 30\end{array}$ & $\begin{array}{l}\text { Florida } \\
\text { New Smyma } \\
\text { Beach } \\
\text { Utils Comm } \\
\text { September } 30\end{array}$ & $\begin{array}{l}\text { Florida } \\
\text { Ocala } \\
\text { City of }\end{array}$ & $\begin{array}{l}\text { Florida } \\
\text { Orlando } \\
\text { Utilities } \\
\text { Comm }\end{array}$ & $\begin{array}{l}\text { Florida } \\
\text { Quincy } \\
\text { City of }\end{array}$ \\
\hline \multicolumn{7}{|l|}{ Electric Utility Plant } \\
\hline 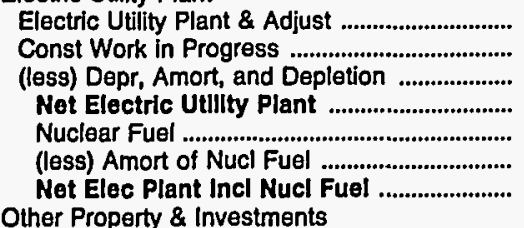 & $\begin{array}{r}537,036 \\
35,744 \\
165,317 \\
407,462 \\
0 \\
0 \\
407,462\end{array}$ & $\begin{array}{r}45,227 \\
1,902 \\
14,895 \\
32,234 \\
749 \\
479 \\
32,504\end{array}$ & $\begin{array}{r}50,690 \\
6,296 \\
19,058 \\
37,928 \\
1,733 \\
1,729 \\
37,932\end{array}$ & $\begin{array}{r}77,232 \\
11,404 \\
27,955 \\
60,680 \\
2,082 \\
1,408 \\
61,354\end{array}$ & $\begin{array}{r}1,221,204 \\
108,957 \\
309,567 \\
1,020,594 \\
19,426 \\
18,867 \\
1,021,152\end{array}$ & $\begin{array}{r}5,976 \\
0 \\
2,700 \\
3,276 \\
0 \\
0 \\
0 \\
3,276\end{array}$ \\
\hline 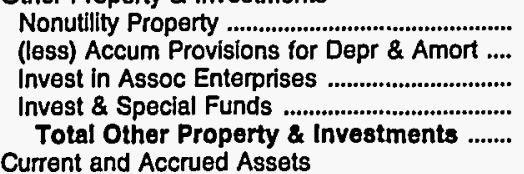 & $\begin{array}{r}42,667 \\
10,941 \\
0 \\
137,003 \\
168,729\end{array}$ & $\begin{array}{r}0 \\
0 \\
0 \\
10,832 \\
10,832\end{array}$ & $\begin{array}{r}48,250 \\
13,803 \\
3,962 \\
17,717 \\
56,126\end{array}$ & $\begin{array}{r}0 \\
0 \\
544 \\
43,424 \\
43,968\end{array}$ & $\begin{array}{r}398 \\
6 \\
0 \\
537,530 \\
537,921\end{array}$ & $\begin{array}{r}0 \\
0 \\
0 \\
900 \\
900\end{array}$ \\
\hline 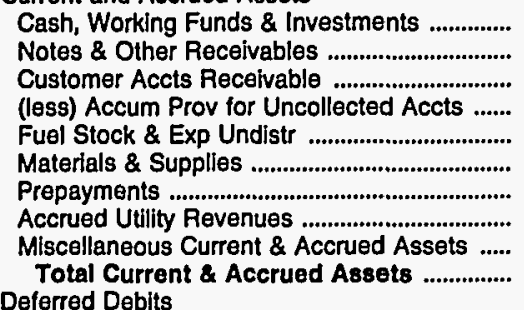 & $\begin{array}{r}15,768 \\
2,049 \\
15,112 \\
560 \\
5,527 \\
17,675 \\
7 \\
2,906 \\
2,108 \\
60,592\end{array}$ & $\begin{array}{r}5,769 \\
1,849 \\
1,984 \\
372 \\
0 \\
710 \\
0 \\
0 \\
0 \\
9,941\end{array}$ & $\begin{array}{r}298 \\
213 \\
1,390 \\
57 \\
0 \\
852 \\
204 \\
2,653 \\
0 \\
5,554\end{array}$ & $\begin{array}{r}2 \\
374 \\
5,855 \\
301 \\
0 \\
2,207 \\
149 \\
4,569 \\
269 \\
13,124\end{array}$ & $\begin{array}{r}80,410 \\
8,283 \\
30,287 \\
838 \\
9,252 \\
26,257 \\
1,163 \\
14,421 \\
388 \\
169,624\end{array}$ & $\begin{array}{r}372 \\
0 \\
807 \\
168 \\
0 \\
100 \\
38 \\
0 \\
0 \\
1,149\end{array}$ \\
\hline $\begin{array}{l}\text { Unamortized Debt Expenses .......................... } \\
\text { Extraordinary Losses, Study Cost ................... } \\
\text { Mlsc Debt, A \& D Exp, Unamrt Losses .......... } \\
\text { Total Deferred Debits ................................... } \\
\text { Total Assets \& Other Debits }\end{array}$ & $\begin{array}{r}1,650 \\
0 \\
0 \\
1,650 \\
638,433\end{array}$ & $\begin{array}{r}152 \\
0 \\
0 \\
152 \\
53,429\end{array}$ & $\begin{array}{r}752 \\
0 \\
0 \\
752 \\
100,364\end{array}$ & $\begin{array}{r}308 \\
0 \\
0 \\
308 \\
118,754\end{array}$ & $\begin{array}{r}74,866 \\
0 \\
5,634 \\
80,500 \\
1,809,198\end{array}$ & $\begin{array}{r}0 \\
0 \\
0 \\
0 \\
5,325\end{array}$ \\
\hline 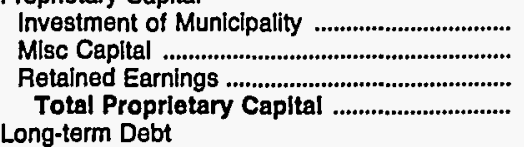 & $\begin{array}{r}0 \\
0 \\
188,037 \\
188,037\end{array}$ & $\begin{array}{r}0 \\
0 \\
31,787 \\
31,787\end{array}$ & $\begin{array}{r}23,207 \\
0 \\
4,607 \\
27,814\end{array}$ & $\begin{array}{r}0 \\
0 \\
66,592 \\
66,592\end{array}$ & $\begin{array}{r}0 \\
0 \\
284,682 \\
284,682\end{array}$ & $\begin{array}{r}0 \\
137 \\
4,002 \\
4,139\end{array}$ \\
\hline 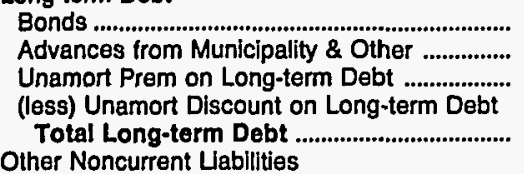 & $\begin{array}{r}407,701 \\
29,960 \\
0 \\
25,698 \\
411,963\end{array}$ & $\begin{array}{r}14,569 \\
1,162 \\
0 \\
126 \\
15,604\end{array}$ & $\begin{array}{r}66,690 \\
0 \\
0 \\
1,662 \\
65,028\end{array}$ & $\begin{array}{r}36,064 \\
0 \\
0 \\
0 \\
36,064\end{array}$ & $\begin{array}{r}1,430,664 \\
0 \\
0 \\
72,793 \\
1,357,870\end{array}$ & $\begin{array}{r}230 \\
0 \\
0 \\
0 \\
230\end{array}$ \\
\hline $\begin{array}{l}\text { Accum Operating Provisions ............................. } \\
\text { Accum Prov for Rate Refunds ....................... } \\
\text { Total Other Noncurrent Llabilitles ........... } \\
\text { Current and Accrued Liabilities }\end{array}$ & $\begin{array}{l}0 \\
0 \\
0\end{array}$ & $\begin{array}{l}0 \\
0 \\
0\end{array}$ & $\begin{array}{r}1,516 \\
0 \\
1,516\end{array}$ & $\begin{array}{r}1,017 \\
0 \\
1,017\end{array}$ & $\begin{array}{l}0 \\
0 \\
0\end{array}$ & $\begin{array}{l}0 \\
0 \\
0\end{array}$ \\
\hline 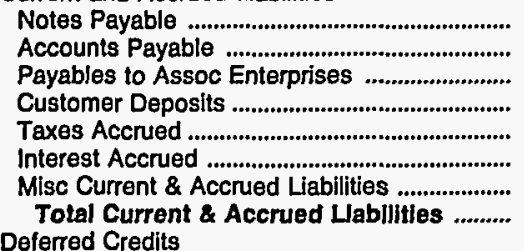 & $\begin{array}{r}0 \\
11,339 \\
0 \\
8,986 \\
464 \\
12,951 \\
1,543 \\
35,283\end{array}$ & $\begin{array}{r}0 \\
1,422 \\
0 \\
1,245 \\
0 \\
502 \\
419 \\
3,588\end{array}$ & $\begin{array}{r}0 \\
1,768 \\
484 \\
933 \\
0 \\
1,793 \\
975 \\
5,952\end{array}$ & $\begin{array}{r}0 \\
4,784 \\
990 \\
2,968 \\
0 \\
1,061 \\
188 \\
9,991\end{array}$ & $\begin{array}{r}17,092 \\
25,587 \\
552 \\
11,677 \\
583 \\
30,425 \\
9,675 \\
95,591\end{array}$ & $\begin{array}{r}0 \\
568 \\
0 \\
304 \\
0 \\
3 \\
66 \\
942\end{array}$ \\
\hline $\begin{array}{l}\text { Customer Advances for Construction .............. } \\
\text { Other Deferred Credits .......................................... } \\
\text { Unamort Gain on Reacqr Debt ......................... } \\
\text { Total Deferred Credits .................................. } \\
\text { Total Labllities and Other Credits ............ }\end{array}$ & $\begin{array}{r}0 \\
3,150 \\
0 \\
3,150 \\
638,433\end{array}$ & $\begin{array}{r}52 \\
2,397 \\
0 \\
2,449 \\
53,429\end{array}$ & $\begin{array}{r}29 \\
26 \\
0 \\
54 \\
100,364\end{array}$ & $\begin{array}{r}3,791 \\
1,299 \\
0 \\
5,090 \\
118,754\end{array}$ & $\begin{array}{r}24,204 \\
46,851 \\
0 \\
71,055 \\
1,809,198\end{array}$ & $\begin{array}{r}0 \\
14 \\
0 \\
14 \\
5,325\end{array}$ \\
\hline
\end{tabular}

Note: Totals may not equal sum of components because of independent rounding.

Source: Energy Information Administration, Form EIA-412, "Annual Report of Public Electric Utilities." 
Table 22. Balance Sheet by Major U.S. Publicly Owned Electric Utility Within State at End of Period, 1993 (Continued) (Thousand Dollars)

\begin{tabular}{|c|c|c|c|c|c|c|}
\hline Item & $\begin{array}{c}\text { Florida } \\
\text { Reedy Creek } \\
\text { Improvement } \\
\text { Dist }\end{array}$ & September 30 & $\begin{array}{c}\text { Tallahassee } \\
\text { City of }\end{array}$ & $\begin{array}{l}\text { Florida } \\
\text { Vero } \\
\text { Beach } \\
\text { City of }\end{array}$ & $\begin{array}{l}\text { Georgia } \\
\text { Albany Water } \\
\text { Gas \& Light } \\
\text { Comm } \\
\text { June } 30\end{array}$ & $\begin{array}{l}\text { Georgia } \\
\text { Calhoun } \\
\text { City of } \\
\text { June } 30\end{array}$ \\
\hline \multicolumn{7}{|l|}{ Electric Utility Plant } \\
\hline Electric Utility Plant \& Adjust ............................. & 98,322 & 53,673 & 364,621 & 142,756 & 28,021 & 64,339 \\
\hline Const Work in Progress & 16,511 & 2,446 & 47,861 & 8,483 & 0 & \\
\hline (less) Depr, Amort, and Depletion ...................... & 13,555 & 15,298 & 150,290 & 43,184 & 18,784 & 13,640 \\
\hline Net Electrlc Utility Plant .................................. & 101,278 & 40,820 & 262,192 & 108,055 & 9,238 & 50,698 \\
\hline Nuclear Fuel & 0 & 0 & 0 & 0 & 0 & 0 \\
\hline 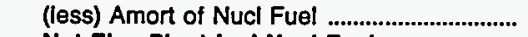 & 0 & 0 & 0 & 0 & 0 & 0 \\
\hline $\begin{array}{l}\text { Net Elec Plant Incl Nucl Fuel ............................ } \\
\text { Other Property \& Investments }\end{array}$ & 101,278 & 40,820 & 262,192 & 108,055 & 9,238 & 50,698 \\
\hline Nonutility Property & 0 & 0 & 6,750 & 0 & 41,265 & 0 \\
\hline (less) Accum Provisions for Depr \& Amort .... & 0 & $\mathbf{0}$ & 3,886 & 0 & 24,004 & 0 \\
\hline 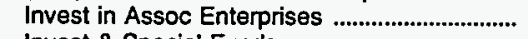 & 0 & 0 & 0 & 0 & 0 & 0 \\
\hline 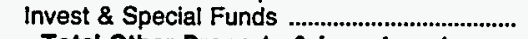 & 0 & 0 & 99,835 & 11,214 & 10,923 & 0 \\
\hline & 0 & $\mathbf{0}$ & 102,700 & 11,214 & 28,184 & $\mathbf{0}$ \\
\hline Cash, Working Funds \& Investments .............. & 32,088 & 682 & 18,334 & 6,627 & 2,301 & 5,948 \\
\hline 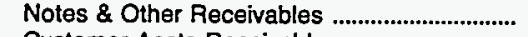 & 71 & 0 & 370 & 192 & 0 & 0 \\
\hline 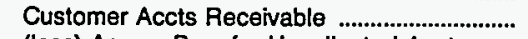 & 4,677 & 1,141 & 13,467 & 5,855 & 10,798 & 2,907 \\
\hline (less) Accum Prov for Uncollected Accts ...... & 0 & 94 & 1,857 & 657 & 125 & 0 \\
\hline Fuel Stock \& Exp Undistr ........................................ & 99 & 0 & 4,045 & 1,372 & 0 & 0 \\
\hline 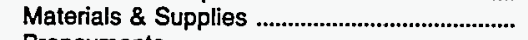 & 1,247 & 1,032 & 0 & 2,635 & 3,009 & 880 \\
\hline 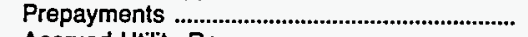 & 113 & 29 & 0 & 3 & 304 & 67 \\
\hline 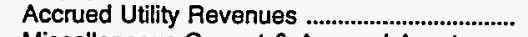 & 2,129 & 1,559 & 0 & 0 & 0 & 0 \\
\hline Miscellaneous Current \& Accrued Assets ..... & 0 & 0 & 0 & 194 & 61 & 26 \\
\hline $\begin{array}{l}\text { Total Current \& Accrued Assets ................ } \\
\text { Deferred Debits }\end{array}$ & 40,424 & 4,349 & 34,359 & 16,222 & 16,348 & 9,828 \\
\hline 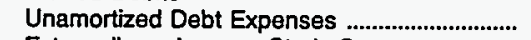 & 2,540 & 555 & 445 & 1,325 & 0 & 609 \\
\hline Extraordinary Losses, Study Cost .................... & 0 & 1,115 & 0 & 0 & 0 & 0 \\
\hline $\begin{array}{l}\text { Misc Debt, R \& D Exp, Unamrt Losses } \\
\text { Total Dete....... }\end{array}$ & $\begin{array}{r}0 \\
2540\end{array}$ & $\begin{array}{l}3,912 \\
558 ?\end{array}$ & $\begin{array}{r}0 \\
445\end{array}$ & $\begin{array}{r}0 \\
1325\end{array}$ & 738 & 0 \\
\hline $\begin{array}{l}\text { Total Assets \& Other Debits } \\
\text { Proprietary Capital }\end{array}$ & $\begin{array}{r}2,540 \\
144,241\end{array}$ & $\begin{array}{r}5,582 \\
50,752\end{array}$ & $\begin{array}{r}445 \\
399,696\end{array}$ & $\begin{array}{r}1,325 \\
136,816\end{array}$ & $\begin{array}{r}738 \\
54,508\end{array}$ & $\begin{array}{r}609 \\
61,136\end{array}$ \\
\hline & 0 & 0 & 0 & 0 & 0 & 5,728 \\
\hline 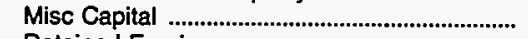 & 0 & 2,719 & 0 & 0 & 118 & 0 \\
\hline 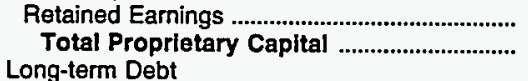 & $\begin{array}{l}8,165 \\
8,165\end{array}$ & $\begin{array}{l}19,621 \\
22,340\end{array}$ & $\begin{array}{l}253,641 \\
253,641\end{array}$ & $\begin{array}{l}41,101 \\
41,101\end{array}$ & $\begin{array}{l}44,431 \\
44,549\end{array}$ & $\begin{array}{l}30,860 \\
36,588\end{array}$ \\
\hline 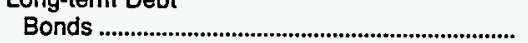 & \multicolumn{6}{|c|}{ Long-term Debt } \\
\hline 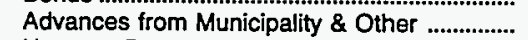 & $\begin{array}{r}124,606 \\
0\end{array}$ & $\begin{array}{r}25,765 \\
0\end{array}$ & $\begin{array}{r}118,872 \\
0\end{array}$ & 90,321 & 0 & 7,015 \\
\hline Unamort Prem on Long-term Debt ................... & 0 & 0 & 0 & $\begin{array}{r}406 \\
0\end{array}$ & $\begin{array}{l}0 \\
0\end{array}$ & $\begin{array}{r}12,860 \\
0\end{array}$ \\
\hline (less) Unamort Discount on Long-term Debt & 2,341 & 345 & 1,378 & 1,914 & 0 & 0 \\
\hline $\begin{array}{l}\text { Total Long-term Debt ............................................... } \\
\text { Other Noncurrent Liabilities }\end{array}$ & 122,265 & 25,420 & 117,495 & 88,813 & 0 & 19,875 \\
\hline $\begin{array}{l}\text { Other Noncurrent Liabilities } \\
\text { Accum Operating Provisions }\end{array}$ & 0 & & \multicolumn{4}{|c|}{ Other Noncurrent Liabilities } \\
\hline 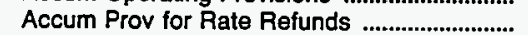 & 0 & $\begin{array}{l}0 \\
0\end{array}$ & 0 & 0 & 0 & 0 \\
\hline Total Other Noncurrent Liabilities ............ & $\mathbf{0}$ & $\begin{array}{l}0 \\
0\end{array}$ & 0 & 0 & $\mathbf{0}$ & 0 \\
\hline \multicolumn{7}{|l|}{ Current and Accrued Liabilities } \\
\hline Notes Payable & 0 & 635 & 0 & 140 & 0 & 828 \\
\hline 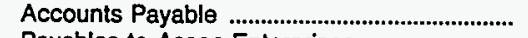 & 8,728 & 1,272 & 21,340 & 3,645 & 5,366 & 2,113 \\
\hline Payables to Assoc Enterprises ......................... & 0 & 0 & 0 & 0 & 1,582 & 542 \\
\hline 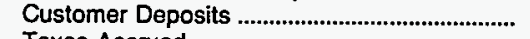 & 0 & 467 & 6,820 & 1,462 & 284 & 991 \\
\hline Taxes Accrued & 200 & 0 & 0 & 0 & 1,623 & 8 \\
\hline Interest Accrued & 0 & 267 & 0 & 1,350 & 2 & 168 \\
\hline Misc Current \& Accrued Liabilities .................... & 0 & 351 & 0 & 305 & 365 & 21 \\
\hline $\begin{array}{l}\text { Total Current \& Accrued Llabilltles .......... } \\
\text { Deferred Credits }\end{array}$ & 8,928 & 2,992 & 28,160 & 6,902 & 9,221 & 4,672 \\
\hline Customer Advances for Construction ............. & 0 & 0 & 0 & 0 & 0 & 0 \\
\hline 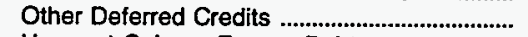 & 4,883 & 0 & 401 & 0 & 738 & 0 \\
\hline 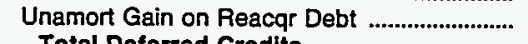 & 0 & 0 & 0 & 0 & 0 & 0 \\
\hline 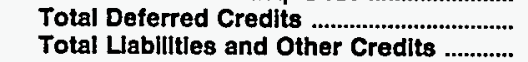 & $\begin{array}{r}4,883 \\
144,241\end{array}$ & $\begin{array}{r}0 \\
50,752\end{array}$ & $\begin{array}{r}401 \\
399,696\end{array}$ & $\begin{array}{r}0 \\
136.816\end{array}$ & $\begin{array}{r}738 \\
54508\end{array}$ & \\
\hline
\end{tabular}

Note: Totals may not equal sum of components because of independent rounding.

Source: Energy Information Administration, Form EIA-412, "Annual Report of Public Electric Utilities." 
Table 22. Balance Sheet by Major U.S. Publicly Owned Electric Utility Within State at End of Period, 1993 (Continued)

(Thousand Dollars)

\begin{tabular}{|c|c|c|c|c|c|c|}
\hline Item & $\begin{array}{l}\text { Georgia } \\
\text { Cartersville } \\
\text { City of } \\
\text { June } 30\end{array}$ & $\begin{array}{c}\text { Georgia } \\
\text { College } \\
\text { Park City of } \\
\text { June } 30\end{array}$ & $\begin{array}{l}\text { Georgia } \\
\text { Covington } \\
\text { City of } \\
\text { December } 31\end{array}$ & $\begin{array}{c}\text { Georgia } \\
\text { Crisp } \\
\text { County } \\
\text { Power } \\
\text { Comm } \\
\text { December } 31\end{array}$ & $\begin{array}{l}\text { Georgia } \\
\text { Dalton } \\
\text { City of } \\
\text { November } 30\end{array}$ & $\begin{array}{l}\text { Georgia } \\
\text { Douglas } \\
\text { City of } \\
\text { June } 30\end{array}$ \\
\hline \multicolumn{7}{|l|}{ Electric Utility Plant } \\
\hline Electric Utility Plant \& Adjust ............................. & 10,267 & 8,535 & 5,844 & 36,785 & 200,524 & 3,907 \\
\hline 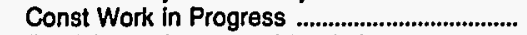 & & & 460 & 786 & 1,998 & \\
\hline (less) Depr, Amort, and Depletion .................... & 2,245 & 3,390 & 3,173 & 21,185 & 59,580 & 2,187 \\
\hline Not Electric Utility Plant ..................................... & 8,022 & 5,145 & 3,131 & 16,386 & 142,942 & 1,721 \\
\hline 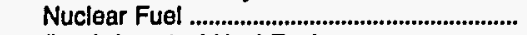 & 0 & 0 & 0 & & 15,447 & 0 \\
\hline 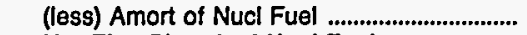 & 0 & 0 & 0 & 0 & 9,958 & 0 \\
\hline \multirow{2}{*}{\multicolumn{7}{|c|}{ Other Property \& Investments }} \\
\hline & & & & & & \\
\hline 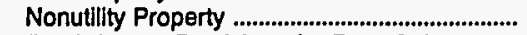 & 0 & 0 & 0 & 1,163 & 2,967 & 544 \\
\hline (less) Accum Provisions for Depr \& Amort .... & 0 & 0 & 0 & & 985 & 351 \\
\hline 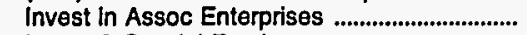 & 0 & 0 & 0 & 0 & 9,621 & 0 \\
\hline 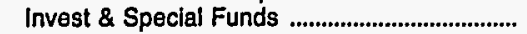 & 0 & 4,289 & 0 & $\mathbf{0}$ & 221,192 & 1,049 \\
\hline Total Other Property \& Investments ........ & 0 & 4,289 & 0 & 1,163 & 232,795 & 1,242 \\
\hline \multicolumn{7}{|l|}{ Current and Accrued Assets } \\
\hline Cash, Working Funds \& Investments .............. & 3,332 & 283 & 60 & 1,557 & 181 & 309 \\
\hline 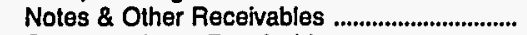 & 58 & 146 & 2 & 0 & 391 & 7 \\
\hline 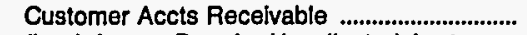 & 3,338 & 2,321 & 1,501 & 1,434 & 3,329 & 1,544 \\
\hline (less) Accum Prov for Uncollected Accts ....... & 292 & 292 & 11 & 49 & 38 & 22 \\
\hline 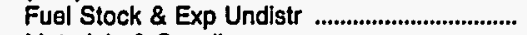 & 0 & 0 & 1 & 159 & 2,355 & 0 \\
\hline Materials \& Supplies ...................................................... & 656 & 0 & 249 & 431 & 4,707 & 541 \\
\hline 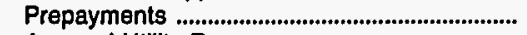 & 0 & 48 & 27 & 32 & 66 & 0 \\
\hline Accrued Utility Revenues ........................................... & 0 & 0 & 119 & 0 & 1,947 & 0 \\
\hline Miscellaneous Current \& Accrued Assets ..... & 0 & 22 & 29 & 0 & & 0 \\
\hline Total Current \& Accrued Assets ................. & 7,092 & 2,528 & 1,977 & 3,564 & 12,938 & 2,379 \\
\hline \multicolumn{7}{|l|}{ Deferred Debits } \\
\hline Unamortized Debt Expenses ................................. & 0 & 0 & 0 & 0 & 888 & 0 \\
\hline 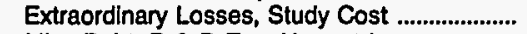 & 0 & $\mathbf{0}$ & 0 & 0 & 0 & 0 \\
\hline Misc Debt, R \& D Exp, Unamrt Losses .......... & 0 & 0 & 0 & 0 & 1,249 & 0 \\
\hline Total Deferred Deblts & & & & & 2,137 & \\
\hline Total Assets \& Other Deblts .......................... & 15,114 & 11,961 & 5,108 & 21,113 & 396,301 & 5,341 \\
\hline \multicolumn{7}{|l|}{ Proprletary Capital } \\
\hline 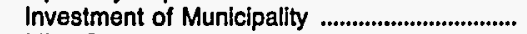 & 0 & 1,285 & 19 & 0 & 0 & 280 \\
\hline 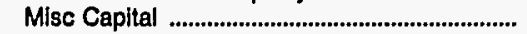 & 100 & & 0 & 0 & 0 & 1,292 \\
\hline Retained Earnings ......................................................... & 12,388 & 8,897 & 3,470 & 19,309 & 281,748 & 3,419 \\
\hline 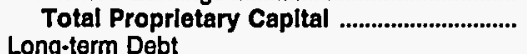 & 12,488 & 10,183 & 3,489 & 19,309 & 281,748 & 4,991 \\
\hline \multicolumn{7}{|l|}{ 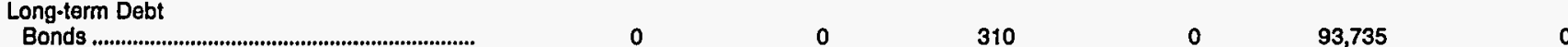 } \\
\hline & 0 & 0 & 310 & 0 & 93,735 & $\begin{array}{l}0 \\
0\end{array}$ \\
\hline 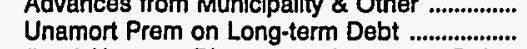 & 0 & $\begin{array}{l}0 \\
0\end{array}$ & 0 & 0 & $\begin{array}{l}0 \\
0\end{array}$ & $\begin{array}{l}0 \\
0\end{array}$ \\
\hline (less) Unamort Discount on Long-term Debt & 0 & 0 & 0 & 0 & 147 & 0 \\
\hline 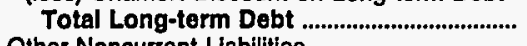 & 0 & 0 & 310 & 0 & 93,588 & 0 \\
\hline \multicolumn{7}{|l|}{ Other Noncurrent Liabilities } \\
\hline 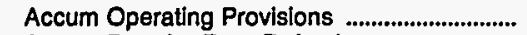 & 0 & 0 & 0 & 0 & 1,159 & 0 \\
\hline 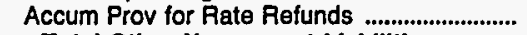 & 0 & 0 & 0 & 0 & & 0 \\
\hline Total Other Noncurrent Llabilltles ............ & 0 & 0 & 0 & 0 & 1,159 & 0 \\
\hline \multicolumn{7}{|l|}{ Current and Accrued Liabilities } \\
\hline 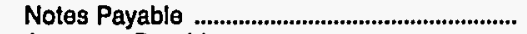 & 0 & 217 & 65 & & & 0 \\
\hline 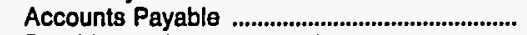 & 1,863 & 1,299 & 809 & 1,247 & 3,739 & 0 \\
\hline 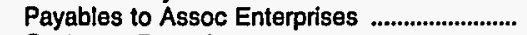 & 0 & 0 & 0 & 0 & 174 & 0 \\
\hline 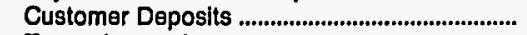 & 460 & 0 & 326 & 340 & 774 & 272 \\
\hline 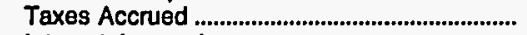 & 0 & 0 & 0 & 49 & 0 & 0 \\
\hline 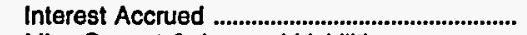 & 0 & 0 & 2 & 0 & 2,580 & 0 \\
\hline Misc Current \& Accrued Liabilities ..................... & 302 & 263 & 45 & 168 & 3,715 & 78 \\
\hline $\begin{array}{l}\text { Total Current \& Accrued Llabliltles .......... } \\
\text { Deferred Credits }\end{array}$ & 2,625 & 1,778 & 1,247 & 1,804 & 10,982 & 351 \\
\hline \multicolumn{7}{|l|}{$\begin{array}{l}\text { Deferred Credits } \\
\text { Customer Advances for Construction }\end{array}$} \\
\hline 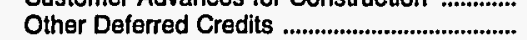 & 0 & 0 & 57 & 0 & 6,635 & 0 \\
\hline 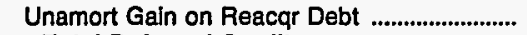 & 0 & 0 & 0 & 0 & 0 & 0 \\
\hline Total Deferred Credits ................................. & & $\begin{array}{r}0 \\
11061\end{array}$ & $\begin{array}{r}61 \\
5108\end{array}$ & 0 & 8,824 & \\
\hline Total Liabilltles and Other Credits ............ & 15,114 & 11,961 & 5,108 & 21,113 & 396,301 & 5,341 \\
\hline
\end{tabular}

Note: Totals may not equal sum of components because of independent rounding.

Source: Energy Information Administration, Form EIA-412, "Annual Report of Public Electric Utilities." 
Table 22. Balance Sheet by Major U.S. Publicly Owned Electric Utility Within State at End of Period, 1993 (Continued) (Thousand Dollars)

\begin{tabular}{|c|c|c|c|c|c|c|}
\hline Item & $\begin{array}{l}\text { Georgia } \\
\text { East } \\
\text { Point } \\
\text { City of } \\
\text { June } 30\end{array}$ & $\begin{array}{c}\text { Georgia } \\
\text { Fitzgerald } \\
\text { Wtr Lgt } \\
\text { \& Bond Comm } \\
\text { December } 31\end{array}$ & $\begin{array}{l}\text { Georgia } \\
\text { Griffin } \\
\text { City of } \\
\text { June } 30\end{array}$ & $\begin{array}{l}\text { Georgia } \\
\text { La Grange } \\
\text { City of } \\
\text { June } 30\end{array}$ & $\begin{array}{l}\text { Georgia } \\
\begin{array}{c}\text { Lawrenceville } \\
\text { City of }\end{array} \\
\text { August } 30\end{array}$ & $\begin{array}{l}\text { Georgia } \\
\text { Marietta } \\
\text { City of } \\
\text { June } 30\end{array}$ \\
\hline \multicolumn{7}{|l|}{ Electric Utility Plant } \\
\hline Electric Utility Plant \& Adjust .................................. & 8,774 & 6,045 & 10,530 & 6,996 & 13,285 & 38,685 \\
\hline Const Work in Progress & & & & & & \\
\hline (less) Depr, Amort, and Depletion ..................... & 5,598 & 2,793 & 403 & 1,885 & 2,956 & 14,956 \\
\hline Net Electric Utility Plant & 3,175 & 3,252 & 10,128 & 5,112 & 10,329 & 23,729 \\
\hline 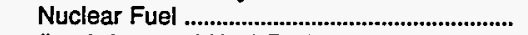 & 0 & 0 & 0 & 0 & 0 & 0 \\
\hline 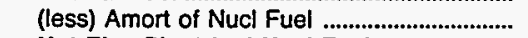 & 0 & 0 & 0 & 0 & 0 & 0 \\
\hline \multirow{2}{*}{\multicolumn{7}{|c|}{ Other Property \& Investments }} \\
\hline & & & & & & \\
\hline (less) Accum Provisions for Depr \& Amort .... & 0 & $\begin{array}{r}17,166 \\
4,204\end{array}$ & $\begin{array}{l}28,944 \\
16,756\end{array}$ & $\begin{array}{l}0 \\
0\end{array}$ & $\begin{array}{l}0 \\
0\end{array}$ & $\begin{array}{l}44,707 \\
17,284\end{array}$ \\
\hline 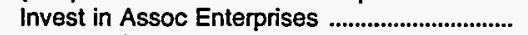 & o & 0 & 0 & 0 & 0 & 0 \\
\hline Invest \& Special Funds & 0 & 1,773 & 0 & 0 & 0 & 0 \\
\hline \multicolumn{6}{|l|}{ Current and Accrued Assets } & 27,422 \\
\hline Cash, Working Funds \& Investments .................. & 0 & 1,083 & 16 & 0 & 1,973 & 19,875 \\
\hline 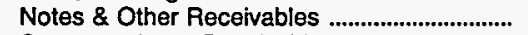 & 0 & 6 & 3,941 & 0 & 0 & 1,421 \\
\hline 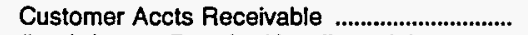 & 4,252 & 313 & 0 & 0 & 0 & 12,574 \\
\hline (less) Accum Prov for Uncollected Accts ...... & -114 & 104 & 0 & 0 & 0 & 1,231 \\
\hline 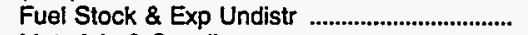 & 0 & 47 & 0 & 0 & 0 & 0 \\
\hline 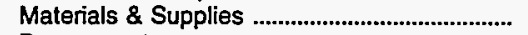 & 573 & 581 & 677 & 0 & 0 & 2,256 \\
\hline 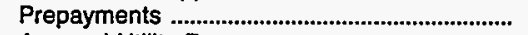 & 243 & 972 & 73 & 0 & 0 & 0 \\
\hline 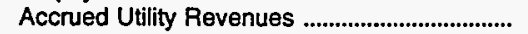 & 0 & 0 & 0 & 0 & 0 & 0 \\
\hline Miscellaneous Current \& Accrued Assets ..... & 0 & 0 & 0 & 0 & 0 & 3 \\
\hline Total Current \& Accrued Assets ............... & 5,182 & 2,899 & 4,707 & 0 & 1,973 & 34,897 \\
\hline \multicolumn{7}{|l|}{ Deferred Debits } \\
\hline 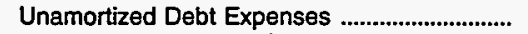 & 0 & 0 & 0 & 0 & 0 & 198 \\
\hline Extraordinary Losses, Study Cost ..................... & 0 & 0 & 0 & $\mathbf{0}$ & 0 & 0 \\
\hline Misc Debt, R \& D Exp, Unamrt Losses ........... & 0 & 0 & 0 & 0 & 0 & 4,377 \\
\hline Total Deferred Debits .......................................... & & 0 & & 0 & $\mathbf{0}$ & $\mathbf{4 , 5 7 4}$ \\
\hline Total Assets \& Other Deblts ........................ & 8,357 & 20,886 & 27,023 & 5,112 & 12,303 & 90,622 \\
\hline \multicolumn{7}{|l|}{ Proprietary Capital } \\
\hline 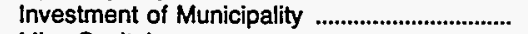 & 0 & 0 & 0 & 0 & 0 & 1,206 \\
\hline 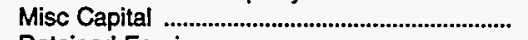 & 0 & 0 & 0 & 0 & 0 & 49 \\
\hline 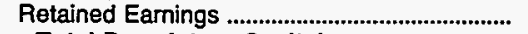 & 3,954 & 13,658 & 23,881 & 5,112 & 11,058 & 69,029 \\
\hline \multicolumn{7}{|l|}{ Long-term Debt } \\
\hline 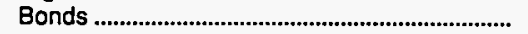 & 0 & 4,550 & 1,679 & 0 & 0 & 8,690 \\
\hline Advances from Municipality \& Other ................. & 0 & 0 & 0 & 0 & 0 & 39 \\
\hline Unamort Prem on Long-term Debt .................... & 0 & 1,813 & 0 & 0 & 0 & 0 \\
\hline (less) Unamort Discount on Long-term Debt & 0 & 0 & 0 & 0 & 0 & 0 \\
\hline Total Long-term Debt ........................................... & 0 & 6,363 & 1,679 & 0 & 0 & 8,729 \\
\hline \multicolumn{7}{|l|}{ Other Noncurrent Liabilities } \\
\hline 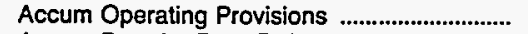 & 0 & 0 & 0 & 0 & 0 & 0 \\
\hline Accum Prov for Rate Refunds .............................. & 0 & 0 & 0 & 0 & 0 & 0 \\
\hline Total Other Noncurrent Llabilities ................. & 0 & 0 & 0 & 0 & 0 & 0 \\
\hline \multicolumn{7}{|l|}{ Current and Accrued Liabilities } \\
\hline 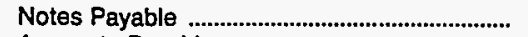 & 0 & 0 & 0 & 0 & 0 & 785 \\
\hline Accounts Payable & 3,417 & 557 & 1 & 0 & 1,245 & 6,042 \\
\hline Payables to Assoc Enterprises .............................. & 0 & 0 & 0 & 0 & 0 & 0 \\
\hline 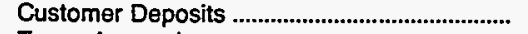 & 389 & 239 & 895 & 0 & 0 & 1,975 \\
\hline 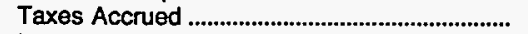 & 0 & 0 & 0 & 0 & 0 & 0 \\
\hline 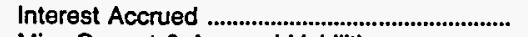 & 0 & 51 & 0 & 0 & 0 & 122 \\
\hline Misc Current \& Accrued Liabilities ...................... & 598 & 17 & 567 & 0 & 0 & 2,685 \\
\hline $\begin{array}{l}\text { Total Current \& Accrued Liabillities ........... } \\
\text { Deferred Credits }\end{array}$ & 4,403 & 864 & 1,463 & 0 & 1,245 & 11,609 \\
\hline \multicolumn{7}{|l|}{ Deferred Credits } \\
\hline Customer Advances for Construction ............. & 0 & 0 & 0 & 0 & $\mathbf{0}$ & 0 \\
\hline 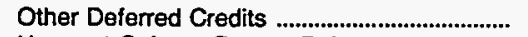 & 0 & 1 & 0 & 0 & 0 & 0 \\
\hline Unamort Gain on Reacqr Debt ................................ & 0 & 0 & 0 & 0 & 0 & 0 \\
\hline Total Deferred Credits ......................................... & & & & & & \\
\hline Total Llabillties and Other Credits ............ & 8,357 & 20,886 & 27,023 & 5,112 & 12,303 & 90,622 \\
\hline
\end{tabular}

Note: Totals may not equal sum of components because of independent rounding.

Source: Energy Information Administration, Form EIA-412, "Annual Report of Public Electric Utilities." 
Table 22. Balance Sheet by Major U.S. Publicly Owned Electric Utility Within State at End of Period, 1993 (Continued) (Thousand Dollars)

\begin{tabular}{|c|c|c|c|c|c|c|}
\hline Item & $\begin{array}{l}\text { Georgia } \\
\text { Moultrie } \\
\text { City of } \\
\text { September } 30\end{array}$ & $\begin{array}{l}\text { Georgia } \\
\text { Municipal } \\
\text { Electric } \\
\text { Authority } \\
\text { December } 31\end{array}$ & $\begin{array}{c}\text { Georgia } \\
\text { Thomasville } \\
\text { City of }\end{array}$ & $\begin{array}{c}\text { Idaho } \\
\text { Idaho } \\
\text { Falls } \\
\text { City of } \\
\text { September } 30\end{array}$ & $\begin{array}{c}\text { Illinois } \\
\text { Batavia } \\
\text { City of } \\
\text { December } 31\end{array}$ & $\begin{array}{l}\text { Geneva } \\
\text { City of } \\
\text { April } 30\end{array}$ \\
\hline \multicolumn{7}{|l|}{ Electric Utility Plant } \\
\hline Electric Utility Plant \& Adjust ................................ & 5,668 & $3,136,809$ & 11,688 & 127,498 & 15,266 & 19,812 \\
\hline 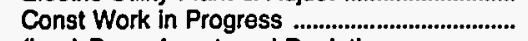 & & 20,099 & 85 & 1,321 & & \\
\hline (less) Depr, Amort, and Depletion ..................... & 3,623 & 868,403 & 4,388 & 30,875 & 6,375 & 8,286 \\
\hline $\begin{array}{l}\text { Net Electric Utllity Plant } \\
\text { Nuclear Fuel }\end{array}$ & $\begin{array}{r}2,047 \\
0\end{array}$ & $\begin{array}{r}2,288,505 \\
336,420\end{array}$ & $\begin{array}{r}7,385 \\
0\end{array}$ & $\begin{array}{r}97,944 \\
0\end{array}$ & $\begin{array}{r}8,891 \\
0\end{array}$ & $\begin{array}{r}11,525 \\
0\end{array}$ \\
\hline 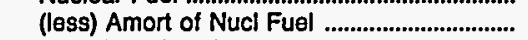 & & 285,306 & & 0 & 0 & \\
\hline 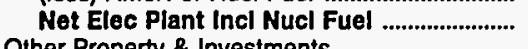 & 2,047 & $2,339,619$ & 7,385 & 97,944 & 8,891 & 11,525 \\
\hline \multicolumn{7}{|l|}{ Other Property \& Investments } \\
\hline & 716 & 0 & 0 & 0 & 0 & 0 \\
\hline $\begin{array}{l}\text { (less) Accum Provisions for Depr \& Amort .... } \\
\text { Invest in Assoc Enterprises ..................................... }\end{array}$ & $\begin{array}{r}456 \\
0\end{array}$ & $\begin{array}{l}0 \\
0\end{array}$ & $\begin{array}{l}0 \\
0\end{array}$ & $\begin{array}{l}0 \\
0\end{array}$ & $\begin{array}{l}0 \\
0\end{array}$ & $\begin{array}{l}0 \\
0\end{array}$ \\
\hline 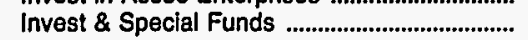 & 0 & $1,879,892$ & 0 & 22,650 & 0 & 443 \\
\hline Total Other Property \& Investments ........ & 260 & $1,879,892$ & 0 & 22,650 & 0 & 443 \\
\hline \multicolumn{7}{|l|}{ Current and Accrued Assets } \\
\hline Cash, Working Funds \& Investments ............... & 1,536 & 158,349 & 727 & 2,014 & 1,133 & 1,121 \\
\hline 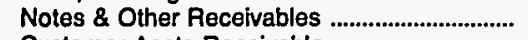 & 15 & 10,678 & 156 & 744 & 6,050 & 74 \\
\hline 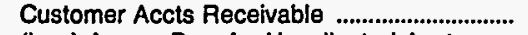 & 1,195 & 30,331 & 1,747 & 2,230 & 1,637 & 1,285 \\
\hline (less) Accum Prov for Uncollected Accts ....... & 255 & & 81 & 820 & 0 & 58 \\
\hline 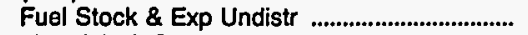 & 0 & 10,130 & 0 & 0 & 0 & 0 \\
\hline 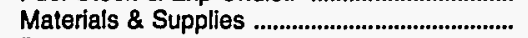 & 249 & 40,148 & 1,416 & 1,927 & 991 & 513 \\
\hline 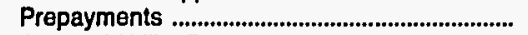 & 16 & 1,528 & 7 & 0 & 0 & 0 \\
\hline Accrued Utility Revenues .................... & 0 & 0 & 1,411 & 0 & 0 & 0 \\
\hline Miscellaneous Current \& Accrued Assets ..... & 0 & 0 & 0 & 7 & 0 & \\
\hline 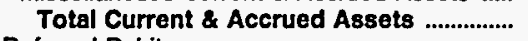 & 2,757 & 251,164 & 5,383 & 6,103 & 9,812 & 2,936 \\
\hline \multicolumn{7}{|l|}{ Deferred Debits } \\
\hline 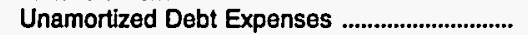 & 0 & 390,956 & 0 & 2,278 & 0 & 46 \\
\hline 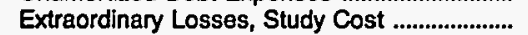 & 0 & 0 & 0 & 1,905 & 0 & 0 \\
\hline Misc Debt, A \& D Exp, Unamrt Losses ........... & 0 & 514,517 & 0 & 0 & 0 & 0 \\
\hline 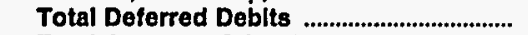 & & 905,473 & & 4,183 & 0 & 46 \\
\hline 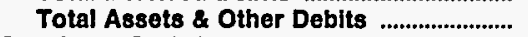 & 5,063 & $5,376,148$ & 12,767 & 130,880 & 18,703 & 14,949 \\
\hline \multicolumn{7}{|l|}{ Proprietary Capital } \\
\hline 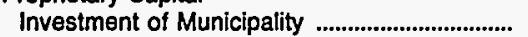 & 12 & 0 & 0 & 0 & 0 & o \\
\hline 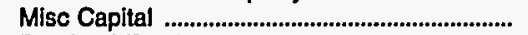 & 0 & 0 & 0 & 0 & 0 & 0 \\
\hline 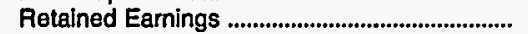 & 4,535 & 0 & 8,394 & 29,698 & 13,533 & 12,766 \\
\hline Total Proprletary Capital .................................... & 4,547 & 0 & 8,394 & 29,698 & 13,533 & 12,766 \\
\hline \multicolumn{7}{|l|}{ Long-term Debt } \\
\hline 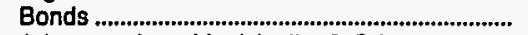 & 0 & $4,427,550$ & 0 & 84,108 & 0 & 445 \\
\hline Advances from Municipality \& Other ................. & 0 & 374,713 & 0 & 1,400 & $\mathbf{0}$ & 931 \\
\hline Unamort Prem on Long-term Debt ..................... & 0 & 27,983 & 0 & 3,879 & 0 & 0 \\
\hline (less) Unamort Discount on Long-term Debt & $\mathbf{0}$ & 36,663 & 0 & 1,612 & 0 & 0 \\
\hline 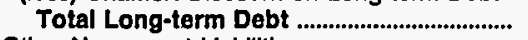 & 0 & $4,793,583$ & 0 & 87,775 & $\mathbf{0}$ & 1,376 \\
\hline \multicolumn{7}{|l|}{ Other Noncurrent Liabilities } \\
\hline 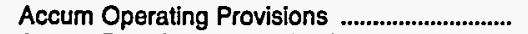 & 0 & 0 & 0 & 0 & 0 & 29 \\
\hline Accum Prov for Rate Refunds .............................. & 0 & 0 & 0 & 0 & 0 & 0 \\
\hline Total Other Noncurrent Llabilltles ............. & $\mathbf{0}$ & 0 & $\mathbf{0}$ & 0 & 0 & 29 \\
\hline \multicolumn{7}{|l|}{ Current and Accrued Llabilities } \\
\hline $\begin{array}{l}\text { Notes Payable } \\
\text { Accounts Payable }\end{array}$ & $\begin{array}{r}0 \\
515\end{array}$ & $\begin{array}{r}100,000 \\
35,147\end{array}$ & $\begin{array}{r}0 \\
1,992\end{array}$ & $\begin{array}{r}0 \\
2,317\end{array}$ & $\begin{array}{r}225 \\
4,837\end{array}$ & $\begin{array}{r}0 \\
778\end{array}$ \\
\hline Payables to Assoc Enterprises ............................ & 0 & 0 & 0 & 0 & 0 & 0 \\
\hline 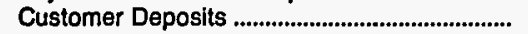 & 0 & 0 & 633 & 1 & 98 & 0 \\
\hline 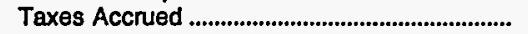 & 0 & 0 & 75 & 0 & 0 & 0 \\
\hline 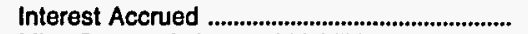 & 0 & 104,369 & 0 & 8,567 & 9 & 0 \\
\hline Misc Current \& Accrued Liabilities ...................... & 0 & 5,752 & 1,674 & 2,521 & 0 & 0 \\
\hline $\begin{array}{l}\text { Total Current \& Accrued Llabillties ........... } \\
\text { Deferred Credits }\end{array}$ & 515 & 245,268 & 4,374 & 13,406 & 5,170 & 778 \\
\hline Customer Advances for Construction .............. & 0 & 0 & 0 & 0 & 0 & 0 \\
\hline Other Deferred Credits .......................................... & 2 & 337,297 & 0 & 0 & 0 & 0 \\
\hline 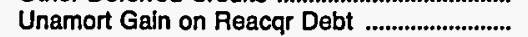 & 0 & 0 & 0 & 0 & 0 & 0 \\
\hline 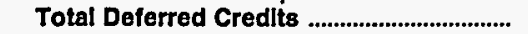 & 2 & 337,297 & 0 & 0 & o & \\
\hline Total Llabllitles and Other Credits ............. & 5,063 & $5,376,148$ & 12,767 & 130,880 & 18,703 & 14,949 \\
\hline
\end{tabular}

Note: Totals may not equal sum of components because of independent rounding.

Source: Energy Information Administration, Form EIA-412, "Annual Report of Public Electric Utilities." 
Table 22. Balance Sheet by Major U.S. Publicly Owned Electric Utility Within State at End of Period, 1993 (Continued)

(Thousand Dollars)

\begin{tabular}{|c|c|c|c|c|c|c|}
\hline Item & $\begin{array}{c}\text { Illinois } \\
\text { Illinois } \\
\text { Municipal } \\
\text { Elec Agency } \\
\text { April } 30\end{array}$ & $\begin{array}{c}\text { Naperville } \\
\text { City of } \\
\text { April } 30\end{array}$ & $\begin{array}{l}\text { Illinois } \\
\text { Rochelle } \\
\text { Municipal } \\
\text { Utilities } \\
\text { April } 30\end{array}$ & $\begin{array}{l}\text { Springfield } \\
\text { City of } \\
\text { February } 28\end{array}$ & $\begin{array}{l}\text { Illinois } \\
\text { St Charles } \\
\text { City of } \\
\text { April } 30\end{array}$ & $\begin{array}{c}\text { Indiana } \\
\text { Anderson } \\
\text { City of } \\
\text { December } 31\end{array}$ \\
\hline \multicolumn{7}{|l|}{ Electric Utility Plant } \\
\hline 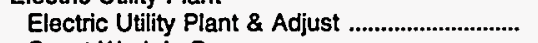 & 96,260 & 109,208 & 28,815 & 345,444 & 26,902 & 50,185 \\
\hline 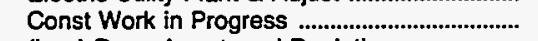 & 139 & & & 16,472 & & 688 \\
\hline (less) Depr, Amort, and Depletion ........................ & 6,450 & 19,867 & 14,648 & 167,726 & 7,864 & 20,448 \\
\hline $\begin{array}{l}\text { Net Electric Utllity Plant } \\
\text { Nuclear Fuel }\end{array}$ & $\begin{array}{r}89,950 \\
0\end{array}$ & $\begin{array}{r}89,342 \\
0\end{array}$ & $\begin{array}{r}14,168 \\
0\end{array}$ & $\begin{array}{r}194,190 \\
0\end{array}$ & $\begin{array}{r}19,038 \\
0\end{array}$ & $\begin{array}{r}30,425 \\
0\end{array}$ \\
\hline 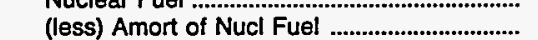 & 0 & 0 & 0 & 0 & 0 & 0 \\
\hline 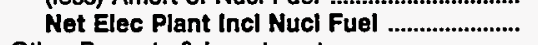 & 89,950 & 89,342 & 14,168 & 194,190 & 19,038 & 30,425 \\
\hline Other Property \& Investments & & & & & & \\
\hline 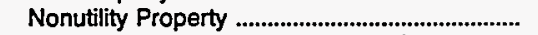 & 0 & 0 & 0 & 4,987 & 0 & 0 \\
\hline (less) Accum Provisions for Depr \& Amort .... & 0 & $\mathbf{0}$ & 0 & 0 & 0 & 0 \\
\hline 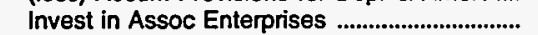 & 0 & 0 & 0 & 0 & 0 & 0 \\
\hline 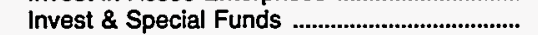 & 0 & 7,797 & 2,294 & 64,353 & 0 & 0 \\
\hline Total Other Property \& Investments ........ & 0 & 7,797 & 2,294 & 69,339 & $\mathbf{0}$ & o \\
\hline \multicolumn{7}{|l|}{ Current and Accrued Assets } \\
\hline Cash, Working Funds \& Investments ............... & 28,031 & 31,511 & 1,023 & 6,297 & 6,728 & 4,071 \\
\hline 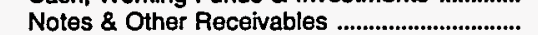 & & 285 & & 1,224 & 679 & 240 \\
\hline 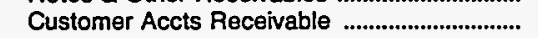 & 4,232 & 6,463 & 1,056 & 8,371 & 1,474 & 1,642 \\
\hline (less) Accum Prov for Uncollected Accts ....... & 0 & 514 & 30 & 478 & 4 & 610 \\
\hline 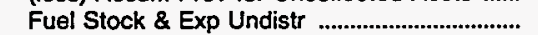 & 0 & 0 & 237 & 1,908 & 0 & 0 \\
\hline 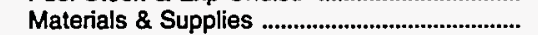 & 0 & 4,153 & 492 & 5,727 & 100 & 874 \\
\hline 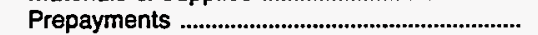 & 170 & 0 & 67 & 1,559 & 14 & 0 \\
\hline 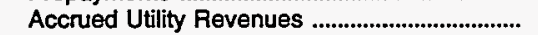 & 0 & 0 & 0 & 3,354 & 127 & 0 \\
\hline Miscellaneous Current \& Accrued Assets ..... & 0 & 881 & 42 & 18 & 19 & 0 \\
\hline 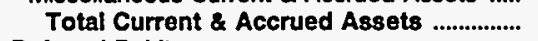 & 32,432 & 42,779 & 2,887 & 27,981 & 9,138 & 6,217 \\
\hline \multicolumn{7}{|l|}{ Deferred Debits } \\
\hline 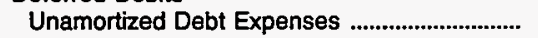 & 3,507 & 0 & 82 & 291 & 0 & 19 \\
\hline 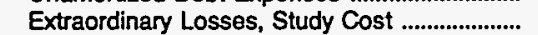 & & 0 & 0 & 0 & 0 & 0 \\
\hline Misc Debt, R \& D Exp, Unamrt Losses .......... & 2,428 & 0 & 325 & 0 & 0 & 646 \\
\hline 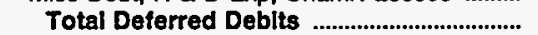 & 5,935 & $\mathbf{0}$ & 407 & 291 & & 665 \\
\hline 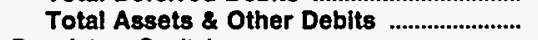 & 128,317 & 139,918 & 19,755 & 291,801 & 28,177 & 37,307 \\
\hline \multicolumn{7}{|l|}{ Proprietary Capital } \\
\hline 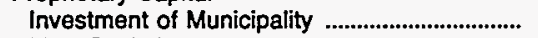 & 0 & 0 & 0 & 0 & 0 & 0 \\
\hline 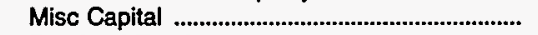 & 0 & 18,286 & 0 & 8,848 & 0 & 0 \\
\hline 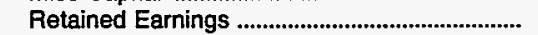 & 3,084 & 96,649 & 9,477 & 128,053 & 26,348 & 28,634 \\
\hline Total Proprietary Capital ................................... & 3,084 & 114,935 & 9,477 & 136,901 & 26,348 & 28,634 \\
\hline \multicolumn{7}{|l|}{ Long-term Debt } \\
\hline 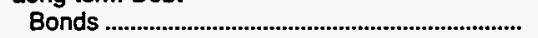 & 125,610 & 18,230 & 8.485 & 128,010 & 0 & 890 \\
\hline Advances from Municipality \& Other ................ & 0 & 464 & 0 & 0 & 0 & 0 \\
\hline Unamort Prem on Long-term Debt ....................... & 0 & 0 & 0 & 0 & 0 & 0 \\
\hline (less) Unamort Discount on Long-term Debt & 6,929 & & 120 & 1,228 & 0 & \\
\hline 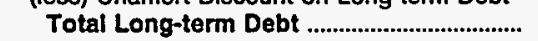 & 118,681 & 18,694 & 8,365 & 126,782 & $\mathbf{0}$ & 890 \\
\hline \multicolumn{7}{|l|}{ Other Noncurrent Liabilities } \\
\hline 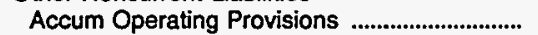 & 0 & 0 & 0 & 0 & 0 & 56 \\
\hline 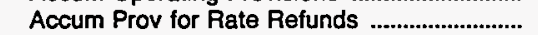 & 0 & 0 & 0 & 0 & 0 & \\
\hline Total Other Noncurrent Liabilities ............. & 0 & 0 & $\mathbf{0}$ & 0 & 0 & 56 \\
\hline \multicolumn{7}{|l|}{ Current and Accrued Liabilities } \\
\hline 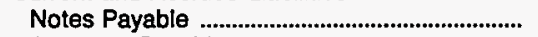 & 0 & 0 & 365 & 5,610 & 0 & \\
\hline 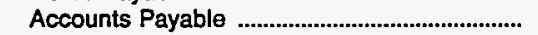 & 4,603 & 3,015 & 951 & 9,993 & 1,453 & 3,609 \\
\hline Payables to Assoc Enterprises ............................... & 0 & 0 & 0 & 0 & 238 & 0 \\
\hline 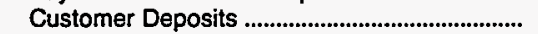 & 0 & 768 & 0 & 679 & 113 & 292 \\
\hline 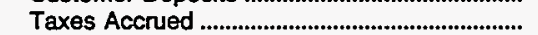 & 0 & 0 & 1 & 2 & 0 & 107 \\
\hline 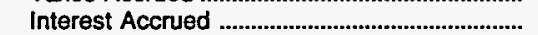 & 1,830 & 36 & 298 & 0 & 0 & 0 \\
\hline Misc Current \& Accrued Liabilities .......................... & 80 & 2,287 & 147 & 0 & 0 & \\
\hline Total Current \& Accrued Liabillties .......... & 6,512 & 6,106 & 1,762 & 16,284 & 1,803 & 4,008 \\
\hline \multicolumn{7}{|l|}{ Deferred Credits } \\
\hline Customer Advances for Construction ............... & 0 & 182 & 0 & 787 & 0 & 3,719 \\
\hline 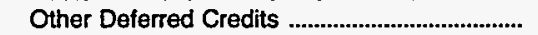 & 39 & 0 & 151 & 0 & 25 & 0 \\
\hline Unamort Gain on Reacqr Debt ............................... & 0 & 0 & 0 & 11,047 & 0 & 0 \\
\hline Total Deterred Credits ......................................... & 39 & 182 & 151 & 11,834 & 25 & 3,719 \\
\hline Total Llabulities and Other Credits ........... & 128,317 & 139,918 & 19,755 & 291,801 & 28,177 & 37,307 \\
\hline
\end{tabular}

Note: Totals may not equal sum of components because of independent rounding.

Source: Energy Information Administration, Form ElA-412, "Annual Report of Public Electric Utilities." 
Table 22. Balance Sheet by Major U.S. Publicly Owned Electric Utility Within State at End of Period, 1993 (Continued) (Thousand Dollars)

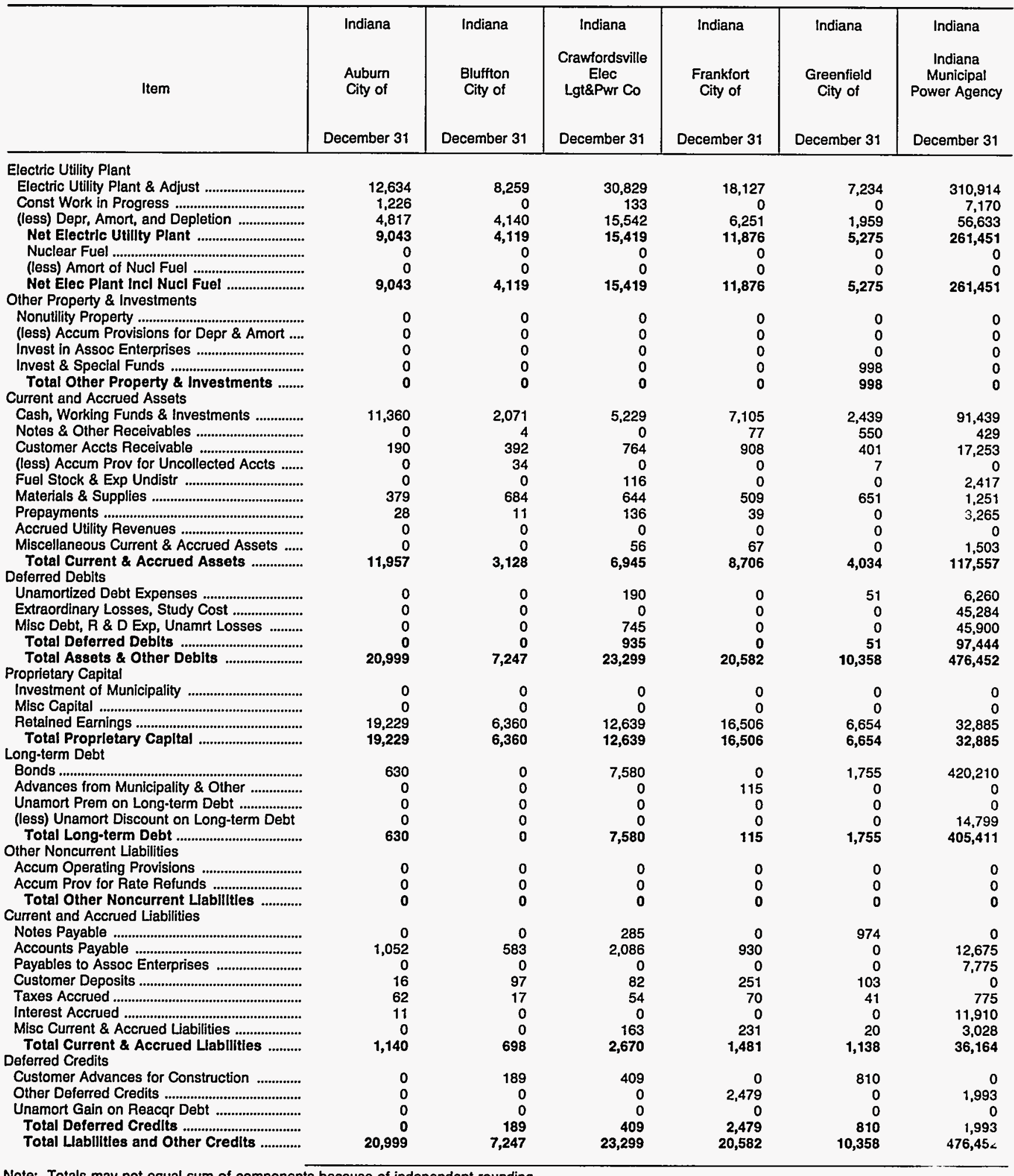

Note: Totals may not equal sum of components because of independent rounding.

Source: Energy Information Administration, Form EIA-412, "Annual Report of Public Electric Utilities." 
Table 22. Balance Sheet by Major U.S. Publicly Owned Electric Utility Within State at End of Period, 1993 (Continued)

(Thousand Dollars)

\begin{tabular}{|c|c|c|c|c|c|c|}
\hline Item & $\begin{array}{c}\text { Indiana } \\
\text { Jasper } \\
\text { City of } \\
\text { December } \mathbf{3 1}\end{array}$ & $\begin{array}{l}\text { Indiana } \\
\text { Logansport } \\
\text { City of } \\
\text { December } 31\end{array}$ & $\begin{array}{c}\text { Indiana } \\
\text { Mishawaka } \\
\text { City of } \\
\text { December } 31\end{array}$ & $\begin{array}{c}\text { Indiana } \\
\text { Peru } \\
\text { City of } \\
\text { December } 31\end{array}$ & $\begin{array}{l}\text { Indiana } \\
\text { Richmond } \\
\text { City of } \\
\text { December } 31\end{array}$ & $\begin{array}{c}\text { Indiana } \\
\text { Washington } \\
\text { City of } \\
\text { December } 31\end{array}$ \\
\hline \multicolumn{7}{|l|}{ Electric Utility Plant } \\
\hline Electric Utility Plant \& Adjust .................................... & 13,723 & 55,149 & 30,420 & 29,104 & 85,461 & 10,581 \\
\hline Const Work in Progress ....................................... & 5,890 & 2,289 & & 0 & 1,057 & 4 \\
\hline (less) Depr, Amort, and Depletion ...................... & 7,587 & 27,260 & 14,719 & 15,390 & 38,118 & 4,114 \\
\hline 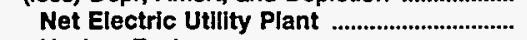 & 12,026 & 30,178 & 15,701 & 13,714 & 48,399 & 6,471 \\
\hline 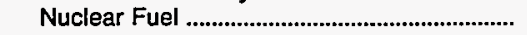 & & 0 & 0 & 0 & 0 & 0 \\
\hline (less) Amort of Nucl Fuel ..................................... & 0 & 0 & 0 & 0 & 0 & 0 \\
\hline Net Elec Plant Incl Nucl Fuel ............................ & 12,026 & 30,178 & 15,701 & 13,714 & 48,399 & 6,471 \\
\hline \multicolumn{7}{|l|}{ Other Property \& Investments } \\
\hline Nonutility Property ....................................................... & 0 & 0 & 18 & 22 & 476 & 0 \\
\hline (less) Accum Provisions for Depr \& Amort .... & 0 & 0 & 0 & 0 & 0 & 0 \\
\hline 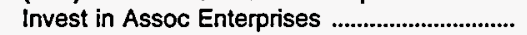 & 0 & 0 & 0 & 0 & 0 & 0 \\
\hline Invest \& Special Funds ............................................ & 3,845 & 8,467 & 1,108 & 0 & 11,925 & 245 \\
\hline \multicolumn{6}{|l|}{ Current and Accrued Assets } & 245 \\
\hline Cash, Working Funds \& Investments ............. & 1,463 & 908 & 2,248 & 1,776 & 4,003 & 1,029 \\
\hline 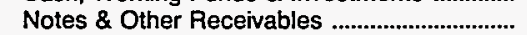 & & 67 & 0 & 28 & 2,500 & 12 \\
\hline Customer Accts Receivable .................................. & 1,068 & 1,381 & 2,707 & 437 & 3,279 & 507 \\
\hline (less) Accum Prov for Uncollected Accts ....... & 9 & 2 & 625 & 57 & 4 & 78 \\
\hline 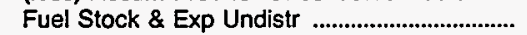 & 0 & 0 & 0 & 24 & 2,822 & 0 \\
\hline 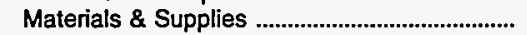 & 1,216 & 2,083 & 1,278 & 74 & 2,590 & 236 \\
\hline 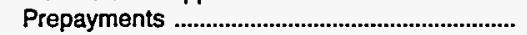 & 119 & 14 & 50 & 10 & 312 & 15 \\
\hline 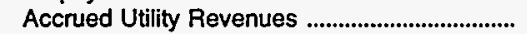 & 0 & 0 & 0 & 0 & 0 & 0 \\
\hline Miscellaneous Current \& Accrued Assets ..... & 0 & 0 & 1 & 845 & 190 & 0 \\
\hline Total Current \& Accrued Assets ................... & 3,858 & 4,452 & 5,658 & 3,136 & 15,691 & 1,721 \\
\hline \multicolumn{7}{|l|}{ Deferred Debits } \\
\hline Unamortized Debt Expenses .................................... & 117 & 262 & 8 & 31 & 898 & 0 \\
\hline 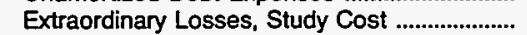 & 29 & 0 & 0 & 0 & 0 & $\mathbf{0}$ \\
\hline Misc Debt, R \& D Exp, Unamrt Losses ........... & 0 & 0 & -1 & 0 & 0 & 0 \\
\hline Total Deferred Debits ...................................... & 146 & 262 & 8 & 31 & 898 & \\
\hline 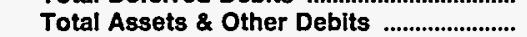 & 19,875 & 43,359 & 22,492 & 16,904 & 77,389 & 8,437 \\
\hline \multicolumn{7}{|l|}{ Proprietary Capital } \\
\hline Investment of Municipality & 0 & 0 & 0 & 199 & 0 & 466 \\
\hline 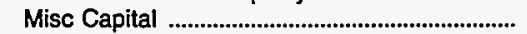 & 0 & 0 & 0 & 0 & 0 & 0 \\
\hline 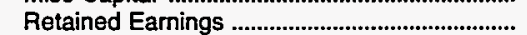 & 9,566 & 23,973 & 18,883 & 13,327 & 70,442 & 6,970 \\
\hline 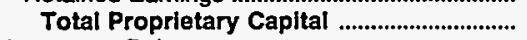 & 9,566 & 23,973 & 18,883 & 13,526 & 70,442 & 7,436 \\
\hline \multicolumn{7}{|l|}{ Long-term Debt } \\
\hline 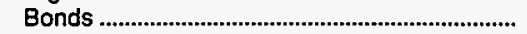 & 8,455 & 15,785 & 835 & 2,150 & 0 & 0 \\
\hline Advances from Municipality \& Other ................... & 30 & 0 & 241 & 0 & 0 & $\mathbf{0}$ \\
\hline Unamort Prem on Long-term Debt ....................... & 0 & 0 & 0 & 0 & 0 & $\mathbf{0}$ \\
\hline (less) Unamort Discount on Long-term Debt & & 0 & 16 & 13 & 0 & $\mathbf{0}$ \\
\hline 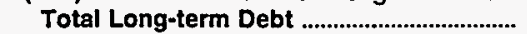 & 8,485 & 15,785 & 1,060 & 2,137 & 0 & $\mathbf{0}$ \\
\hline \multicolumn{7}{|l|}{ Other Noncurrent Liabilities } \\
\hline 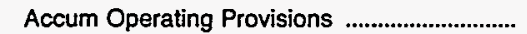 & $\mathbf{0}$ & 80 & 0 & 65 & 0 & 0 \\
\hline Accum Prov for Rate Refunds ........................... & 0 & 0 & 0 & 0 & 0 & 0 \\
\hline Total Other Noncurrent Liabillties ............. & 0 & 80 & o & 65 & $\mathbf{0}$ & 0 \\
\hline \multicolumn{7}{|l|}{ Current and Accrued Liabilities } \\
\hline 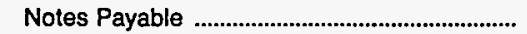 & 0 & 0 & 0 & 0 & 0 & \\
\hline Accounts Payable & 988 & 1,048 & 1,473 & 551 & 1,308 & 546 \\
\hline 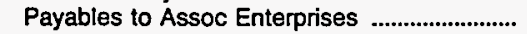 & 0 & 0 & 0 & 0 & 4,187 & 0 \\
\hline 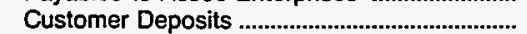 & 190 & 91 & 591 & 143 & 151 & 244 \\
\hline 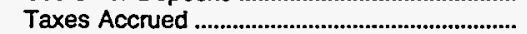 & 0 & 0 & 148 & 0 & 195 & 55 \\
\hline Interest Accrued .......................................................... & 0 & 545 & 32 & 0 & 3 & 0 \\
\hline Misc Current \& Accrued Liabilities .................... & 35 & 1,836 & 21 & 52 & 454 & 24 \\
\hline Total Current \& Accrued Liabilltles .............. & 1,212 & 3,521 & 2,264 & 746 & 6,298 & 869 \\
\hline \multicolumn{7}{|l|}{ Deferred Credits } \\
\hline Customer Advances for Construction ............... & 0 & 0 & 284 & 430 & 478 & 132 \\
\hline 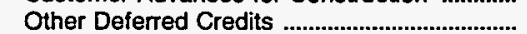 & 612 & 0 & 0 & 0 & 170 & 0 \\
\hline Unamort Gain on Reacqr Debt ................................ & 0 & 0 & 0 & 0 & 0 & 0 \\
\hline 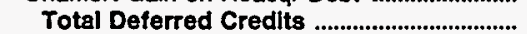 & 612 & & 284 & 430 & 649 & 132 \\
\hline Total Liablities and Other Credits ................ & 19,875 & 43,359 & 22,492 & 16,904 & 77,389 & 8,437 \\
\hline
\end{tabular}

Note: Totals may not equal sum of components because of independent rounding.

Source: Energy information Administration, Form ElA-412, "Annual Report of Public Electric Utilities." 
Table 22. Balance Sheet by Major U.S. Publicly Owned Electric Utility Within State at End of Period, 1993 (Continued)

(Thousand Dollars)

\begin{tabular}{|c|c|c|c|c|c|c|}
\hline Item & $\begin{array}{l}\text { lowa } \\
\text { Ames } \\
\text { City of } \\
\text { June } 30\end{array}$ & $\begin{array}{c}\text { lowa } \\
\text { Cedar } \\
\text { Falls } \\
\text { City of } \\
\text { December } 31\end{array}$ & $\begin{array}{c}\text { lowa } \\
\text { Muscatine } \\
\text { City of } \\
\text { December } 31\end{array}$ & $\begin{array}{l}\text { lowa } \\
\text { Pella } \\
\text { City of } \\
\text { June } 30\end{array}$ & $\begin{array}{c}\text { Kansas } \\
\text { Chanute } \\
\text { City of } \\
\text { December } 31\end{array}$ & $\begin{array}{c}\text { Kansas } \\
\text { Coffeyville } \\
\text { City of } \\
\text { December } 31\end{array}$ \\
\hline \multicolumn{7}{|l|}{ Electric Utility Plant } \\
\hline Electric Utility Plant \& Adjust ............................. & 98,631 & 67,281 & 273,391 & 0 & 25,870 & 32,726 \\
\hline 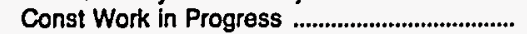 & & 991 & 10,515 & 0 & 0 & \\
\hline (less) Depr, Amort, and Depletion .................... & 51,288 & 33,464 & 115,671 & 0 & 0 & 22,141 \\
\hline Not Electrle Utllity Plant ................................. & 47,343 & 34,808 & 168,235 & o & 25,870 & 10,585 \\
\hline Nuclear Fuel .......................................................... & 0 & 0 & 0 & 0 & 0 & 0 \\
\hline 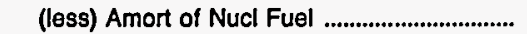 & 0 & 0 & 0 & 0 & 0 & 0 \\
\hline 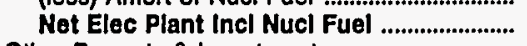 & 47,343 & 34,808 & 168,235 & 0 & 25,870 & 10,585 \\
\hline \multicolumn{7}{|l|}{ Other Property \& Investments } \\
\hline 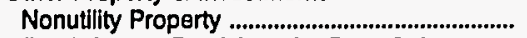 & 0 & 0 & 0 & 0 & 0 & 0 \\
\hline (less) Accum Provisions for Depr \& Amort .... & 0 & 0 & 0 & 0 & 4,657 & \\
\hline 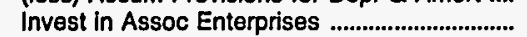 & 0 & 0 & 0 & 0 & 0 & 0 \\
\hline 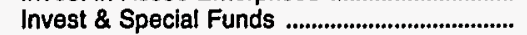 & 8,214 & 7,458 & 127,796 & 589 & 0 & 2,873 \\
\hline Total Other Property \& Investments ........ & 8,214 & 7,458 & 127,796 & 589 & $-4,657$ & 2,873 \\
\hline \multicolumn{7}{|l|}{ Current and Accrued Assets } \\
\hline Cash, Working Funds \& Investments ............... & 9,360 & 6,159 & 9,190 & 12,892 & 1,996 & 3,679 \\
\hline Notes \& Other Recelvables ................................... & 263 & 3 & 1 & 0 & 0 & 444 \\
\hline Customer Accts Receivable .................................... & 2,144 & 1,460 & 3,527 & 434 & 264 & 0 \\
\hline (less) Accum Prov for Uncollected Accts ....... & 20 & 10 & 20 & 0 & 0 & 0 \\
\hline 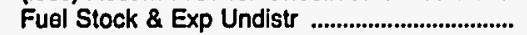 & 609 & 682 & 3,295 & 76 & 0 & 0 \\
\hline Materials \& Supplies ................................................. & 1,221 & 409 & 4,126 & 340 & 0 & 1,738 \\
\hline 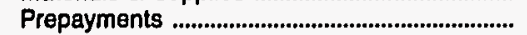 & 18 & 113 & 601 & 0 & 0 & 0 \\
\hline 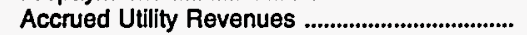 & 0 & 300 & 0 & 0 & 0 & 0 \\
\hline Miscellaneous Current \& Accrued Assets ..... & & 88 & 1,659 & 165 & 0 & 245 \\
\hline Total Current \& Accrued Assets ................... & 13,594 & 9,203 & 22,379 & 13,908 & 2,260 & 6,106 \\
\hline \multicolumn{7}{|l|}{ Deferred Debits } \\
\hline 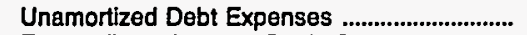 & 156 & 0 & 3,223 & 29 & 0 & 0 \\
\hline Extraordinary Losses, Study Cost ...................... & 0 & 0 & 14,517 & 0 & 0 & 0 \\
\hline Misc Debt, R \& D Exp, Unamrt Losses .......... & 0 & 1,472 & 1,731 & 0 & 0 & 0 \\
\hline 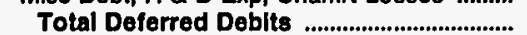 & 156 & 1,472 & 19,471 & 29 & 0 & 0 \\
\hline 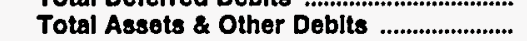 & 69,307 & 52,941 & 337,881 & 14,526 & 23,474 & 19,564 \\
\hline \multicolumn{7}{|l|}{ Proprietary Capital } \\
\hline 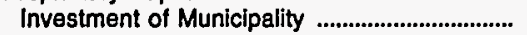 & 0 & 0 & 0 & 0 & 0 & 9,159 \\
\hline 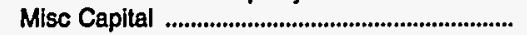 & 0 & 0 & 0 & 0 & 0 & 0 \\
\hline Retained Earnings ........................................................ & 34,374 & 48,198 & 131,739 & 7.502 & 6,384 & 6,951 \\
\hline 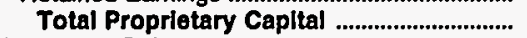 & 34,374 & 48,198 & 131,739 & 7,502 & 6,384 & 16,111 \\
\hline \multicolumn{7}{|l|}{ Long-term Debt } \\
\hline 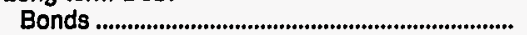 & 27,359 & 1,495 & 191,945 & 5,425 & 17,090 & 750 \\
\hline Advances from Municipality \& Other ................ & & 0 & 0 & 0 & 0 & 0 \\
\hline Unamort Prem on Long-term Debt ....................... & 0 & 0 & 0 & 0 & 0 & 0 \\
\hline (less) Unamort Discount on Long-term Debt & & & 11,430 & 96 & 0 & \\
\hline Total Long-term Debt ..................................... & 27,359 & 1,493 & 180,515 & 5,329 & 17,090 & 750 \\
\hline \multicolumn{7}{|l|}{ Other Noncurrent Liabilities } \\
\hline Accum Operating Provisions ..................................... & 315 & 0 & 0 & 0 & 0 & 0 \\
\hline 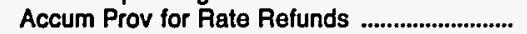 & 0 & 0 & 0 & 0 & 0 & 0 \\
\hline Total Other Noncurrent Llabllitles ............. & 315 & 0 & o & $\mathbf{0}$ & 0 & 0 \\
\hline \multicolumn{7}{|l|}{ Current and Accrued Liabilities } \\
\hline Notes Payable ................................................................. & 3,750 & 0 & 0 & 300 & 0 & \\
\hline 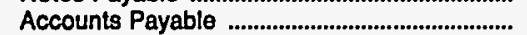 & 1,093 & 928 & 1,836 & 1,284 & 0 & 276 \\
\hline 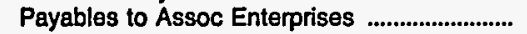 & & 5 & 414 & 0 & 0 & 0 \\
\hline 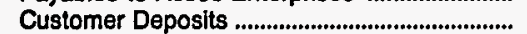 & 359 & 70 & 112 & 0 & 0 & 245 \\
\hline 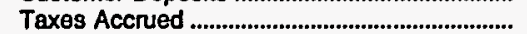 & 0 & 434 & 108 & 0 & 0 & 1.738 \\
\hline 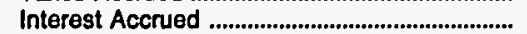 & 501 & 11 & 5,859 & 0 & 0 & 444 \\
\hline Mlsc Current \& Accrued Liabilities .................... & 1,557 & 330 & 2,781 & 111 & 0 & \\
\hline Total Current \& Accrued Llabllitles .......... & 7,260 & 1,779 & 11,109 & 1,695 & 0 & 2,703 \\
\hline \multicolumn{7}{|l|}{ Deferred Credits } \\
\hline Customer Advances for Construction ............. & 0 & 0 & 0 & 0 & 0 & \\
\hline Other Deferred Credits .......................................... & 0 & 1,472 & 14,517 & 0 & 0 & \\
\hline Unamort Gain on Reacqr Debt .............................. & 0 & 0 & 0 & 0 & 0 & 0 \\
\hline Total Deferred Credits .................................... & $\mathbf{0}$ & 1,472 & 14,517 & & & \\
\hline Total Llabllities and Other Credits ............. & 69,307 & 52,941 & 337,881 & 14,526 & 23,474 & 19,564 \\
\hline
\end{tabular}

Note: Totals may not equal sum of components because of independent rounding.

Source: Energy Information Administration, Form EIA-412, "Annual Report of Public Electric Utilities." 
Table 22. Balance Sheet by Major U.S. Publicly Owned Electric Utility Within State at End of Period, 1993 (Continued)

(Thousand Dollars)

\begin{tabular}{|c|c|c|c|c|c|c|}
\hline Item & $\begin{array}{c}\text { Kansas } \\
\text { Garden } \\
\text { City City of } \\
\text { December } 31\end{array}$ & $\begin{array}{c}\text { Kansas } \\
\text { Kansas } \\
\text { City City of } \\
\text { December } 31\end{array}$ & $\begin{array}{c}\text { Kansas } \\
\text { Kansas } \\
\text { Municipal } \\
\text { Energy } \\
\text { Agency } \\
\text { December } 31\end{array}$ & $\begin{array}{l}\text { Kansas } \\
\text { McPherson } \\
\text { - City of } \\
\text { December } 31\end{array}$ & $\begin{array}{c}\text { Kansas } \\
\text { Winfield } \\
\text { City of } \\
\text { December } 31\end{array}$ & $\begin{array}{l}\text { Kentucky } \\
\text { Bowling } \\
\text { Green } \\
\text { City of } \\
\text { June } 30\end{array}$ \\
\hline \multicolumn{7}{|l|}{ Electric Utility Plant } \\
\hline 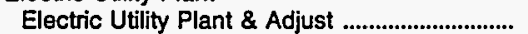 & 15,214 & 548,142 & 4,862 & 46,874 & 30,558 & 36,420 \\
\hline 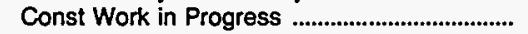 & & 44,674 & & 0 & 131 & 1,695 \\
\hline 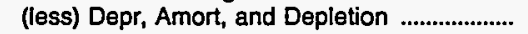 & 8,484 & 224,477 & 1,871 & 25,349 & 13,968 & 11,759 \\
\hline Net Electric Utllity Plant .................................... & 6,730 & 368,339 & 2,991 & 21,525 & 16,721 & 26,355 \\
\hline Nuclear Fuel ...................................................... & 0 & 0 & 0 & 0 & 0 & 0 \\
\hline 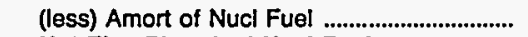 & & 0 & 0 & $\mathbf{0}$ & 0 & 0 \\
\hline $\begin{array}{l}\text { Net Elec Plant Incl Nucl Fuel ............................ } \\
\text { Other Property \& Investments }\end{array}$ & 6,730 & 368,339 & 2,991 & 21,525 & 16,721 & 26,355 \\
\hline Nonutility Property ..................................................... & 27 & 0 & 0 & 202 & 0 & 0 \\
\hline (less) Accum Provisions for Depr \& Amort .... & 24 & 0 & 0 & 0 & 0 & 0 \\
\hline 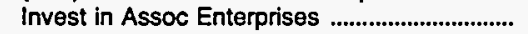 & 0 & 0 & 0 & 0 & 0 & 0 \\
\hline 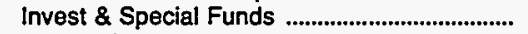 & 0 & 10,138 & 7,707 & 13,340 & 836 & 747 \\
\hline \multicolumn{6}{|l|}{ Current and Accrued Assets } & 747 \\
\hline Cash, Working Funds \& Investments .............. & 2,005 & 39,272 & 996 & 4,366 & 1,457 & 3,771 \\
\hline 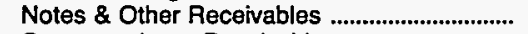 & 0 & 2,054 & 1,328 & 0 & 0 & 2,435 \\
\hline 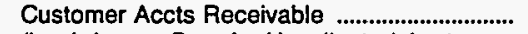 & 468 & 12,458 & 0 & 1,532 & 178 & 0 \\
\hline (less) Accum Prov for Uncollected Accts ....... & 0 & $-1,916$ & 0 & 0 & 0 & 0 \\
\hline 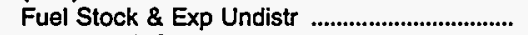 & 0 & 5,347 & 0 & 327 & 36 & 0 \\
\hline 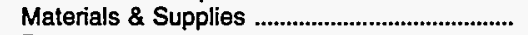 & 0 & 12,634 & 0 & 893 & 0 & 757 \\
\hline 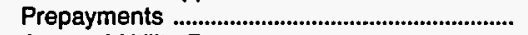 & 0 & 1,240 & 758 & 21 & 1,375 & 149 \\
\hline 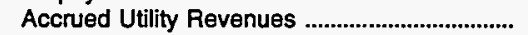 & 0 & 5,862 & 0 & 0 & 0 & 0 \\
\hline Miscellaneous Current \& Accrued Assets ...... & 0 & 1,733 & 0 & 279 & 0 & 26 \\
\hline $\begin{array}{l}\text { Total Current \& Accrued Assets ................... } \\
\text { Deferred Debits }\end{array}$ & 2,473 & 82,516 & 3,082 & 7,418 & 3,045 & 7,138 \\
\hline \multicolumn{7}{|l|}{ Deferred Debits } \\
\hline Unamortized Debt Expenses ............................. & 0 & 2,428 & 683 & 393 & 0 & 26 \\
\hline Extraordinary Losses, Study Cost ........................... & 0 & & 0 & 0 & 0 & 0 \\
\hline Misc Debt, R \& D Exp, Unamrt Losses .......... & 0 & 1,131 & 6,923 & 0 & 0 & 412 \\
\hline 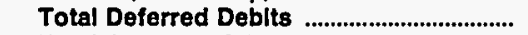 & 0 & 3,558 & 7,606 & 393 & 0 & 438 \\
\hline 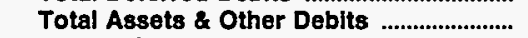 & 9,206 & 464,551 & 21,386 & 42,877 & 20,602 & 34,678 \\
\hline \multicolumn{7}{|l|}{ Proprietary Capital } \\
\hline 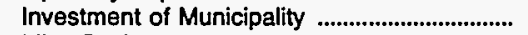 & 0 & 0 & 0 & 0 & 0 & 0 \\
\hline 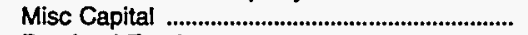 & 0 & 0 & 0 & 0 & 0 & 0 \\
\hline 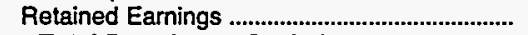 & 8,453 & 283,668 & 2,184 & 28,781 & 14,995 & 20,708 \\
\hline $\begin{array}{l}\text { Total Proprietary Capital ................................ } \\
\text { Long-term Debt }\end{array}$ & 8,453 & 283,668 & 2,184 & 28,781 & 14,995 & 20,708 \\
\hline 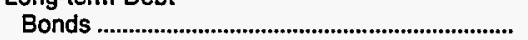 & 0 & 157,518 & 15,550 & 12,533 & 5,120 & 5,220 \\
\hline Advances from Municipality \& Other ................ & 0 & 0 & 0 & 0 & 0 & 431 \\
\hline Unamort Prem on Long-term Debt ................... & 0 & 0 & 0 & 0 & 0 & -60 \\
\hline (less) Unamort Discount on Long-term Debt & 0 & 0 & 217 & 0 & 0 & 0 \\
\hline 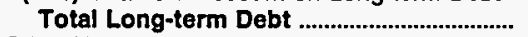 & 0 & 157,518 & 15,333 & 12,533 & 5,120 & 5,591 \\
\hline \multicolumn{7}{|l|}{ Other Noncurrent Liabilities } \\
\hline 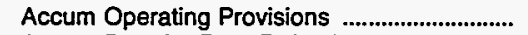 & 0 & 1,416 & 0 & 0 & 48 & 0 \\
\hline 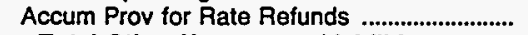 & $\mathbf{0}$ & & 0 & 0 & 45 & 0 \\
\hline Total Other Noncurrent Llabilities ............. & 0 & 1,416 & 0 & 0 & 93 & $\mathbf{0}$ \\
\hline \multicolumn{7}{|l|}{ Current and Accrued Liabilities } \\
\hline Notes Payable ................................................................. & 0 & 0 & 0 & 0 & 0 & 1,600 \\
\hline Accounts Payable & 667 & 17,129 & 731 & 1,131 & 287 & 3,468 \\
\hline 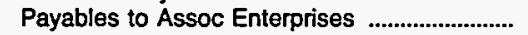 & 0 & & 0 & 0 & 0 & 0 \\
\hline 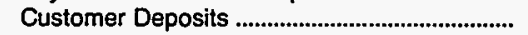 & 86 & 1,690 & 0 & 96 & 0 & 2,381 \\
\hline 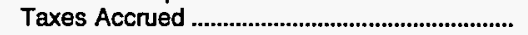 & 0 & 393 & 0 & $\mathbf{0}$ & 0 & 139 \\
\hline 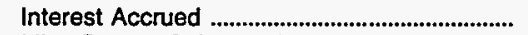 & 0 & 1,359 & 120 & 79 & 106 & 363 \\
\hline Misc Current \& Accrued Liabilities .......................... & 0 & 1,378 & 579 & 257 & 0 & 422 \\
\hline \multirow{2}{*}{\multicolumn{7}{|c|}{ Deferred Credits }} \\
\hline $\begin{array}{l}\text { Deterred Credits } \\
\text { Customer Advances for Construction ............. }\end{array}$ & 0 & 0 & & & & \\
\hline 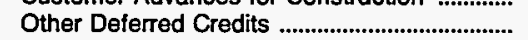 & 0 & 0 & 2,439 & 0 & 0 & 0 \\
\hline Unamort Gain on Reacqr Debt ............................ & 0 & 0 & 0 & 0 & 0 & 0 \\
\hline 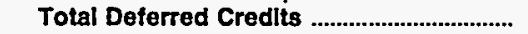 & o & o & 2,439 & o & 0 & 7 \\
\hline Total Llabilltles and Other Credits ............. & 9,206 & 464,551 & 21,386 & 42,877 & 20,602 & 34,678 \\
\hline
\end{tabular}

Note: Totals may not equal sum of components because of independent rounding.

Source: Energy Information Administration, Form EIA-412, "Annual Report of Public Electric Utilities." 
Table 22. Balance Sheet by Major U.S. Publicly Owned Electric Utility Within State at End of Period, 1993 (Continued) (Thousand Dollars)

\begin{tabular}{|c|c|c|c|c|c|c|}
\hline Item & $\begin{array}{l}\text { Kentucky } \\
\text { Frankfort } \\
\text { City of } \\
\text { June } 30\end{array}$ & $\begin{array}{l}\text { Kentucky } \\
\text { Franklin } \\
\text { City of } \\
\text { June } 30\end{array}$ & $\begin{array}{l}\text { Kentucky } \\
\text { Glasgow } \\
\text { City of } \\
\text { June } 30\end{array}$ & $\begin{array}{c}\text { Kentucky } \\
\text { Henderson } \\
\text { City } \\
\text { Utility Comm } \\
\text { May } 31\end{array}$ & $\begin{array}{l}\text { Kentucky } \\
\text { Hopkinsville } \\
\text { City of } \\
\text { June } 30\end{array}$ & $\begin{array}{l}\text { Kentucky } \\
\text { Madisonville } \\
\text { Municipal } \\
\text { Utils } \\
\text { June } 30\end{array}$ \\
\hline \multicolumn{7}{|l|}{ Electric Utility Plant } \\
\hline 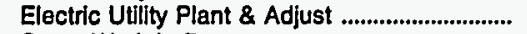 & 22,076 & 4,968 & 14,368 & 101,788 & 15,125 & 7,129 \\
\hline 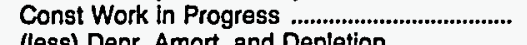 & & 210 & 115 & 1,265 & & \\
\hline 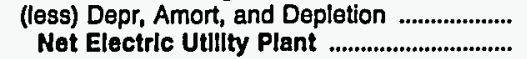 & $\begin{array}{l}11,631 \\
10,445\end{array}$ & $\begin{array}{l}1,763 \\
3,416\end{array}$ & $\begin{array}{l}5,063 \\
9,421\end{array}$ & $\begin{array}{l}57,864 \\
45,189\end{array}$ & $\begin{array}{l}6,375 \\
\mathbf{8 , 8 4 0}\end{array}$ & $\begin{array}{l}3,084 \\
4,046\end{array}$ \\
\hline Nuclear Fuel ............................................................ & 0 & 0 & 0 & 0 & 0 & 0 \\
\hline (less) Amort of Nucl Fuel ......................................... & & & & & & \\
\hline Net Elec Plant Incl Nucl Fuel ......................... & 10,445 & 3,416 & 9,421 & 45,189 & 8,840 & 4,046 \\
\hline \multicolumn{7}{|l|}{ Other Property \& Investments } \\
\hline 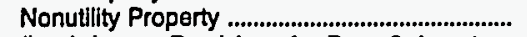 & 25,849 & 0 & 0 & 0 & 220 & 0 \\
\hline (less) Accum Provisions for Depr \& Amort .... & 8,599 & 0 & 0 & 0 & 0 & 0 \\
\hline 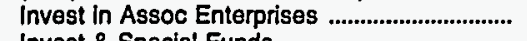 & 0 & 0 & 0 & 0 & 0 & 0 \\
\hline 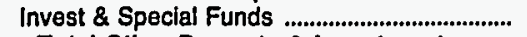 & 4,052 & 434 & 1,081 & 23,662 & 3,483 & 0 \\
\hline $\begin{array}{l}\text { Total Other Property \& Investments ....... } \\
\text { Current and Accrued Assets }\end{array}$ & 21,302 & 434 & 1,081 & 23,662 & 3,703 & 0 \\
\hline Cash, Working Funds \& Investments .............. & Current and Accrued Assets & 1,217 & 167 & 7,003 & 1,382 & 1,640 \\
\hline Notes \& Other Receivables .................................... & 0 & 770 & 1,342 & 0 & 1,756 & 1,096 \\
\hline 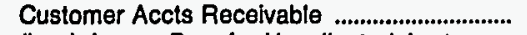 & 3,797 & 0 & 0 & 179 & 0 & 1,035 \\
\hline (less) Accum Prov for Uncollected Accts ....... & 2 & 0 & 0 & 3 & 0 & 0 \\
\hline 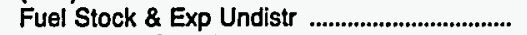 & 0 & 0 & 0 & 285 & 0 & $\mathbf{0}$ \\
\hline 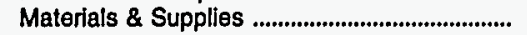 & 2,197 & 106 & 254 & 6,987 & 192 & 297 \\
\hline 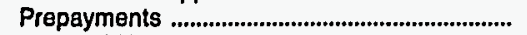 & 116 & 42 & 93 & 392 & 160 & 22 \\
\hline 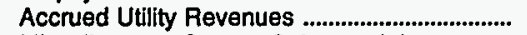 & 0 & 0 & 0 & 668 & 0 & 0 \\
\hline Miscellaneous Current \& Accrued Assets ..... & 8 & 11 & 10 & 0 & 109 & 456 \\
\hline Total Current \& Accrued Assets .................... & 6,930 & 2,147 & 1,867 & 15,511 & 3,599 & 4,546 \\
\hline \multicolumn{7}{|l|}{ Delerred Debits } \\
\hline Unamortized Debt Expenses .............................. & 0 & 0 & 49 & 581 & 17 & 0 \\
\hline 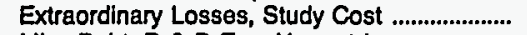 & 0 & 0 & 29 & 0 & 0 & 0 \\
\hline Mlsc Debt, R \& D Exp, Unamrt Losses .......... & 0 & 187 & 97 & 0 & 214 & 0 \\
\hline 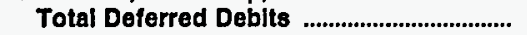 & o & 187 & 175 & 581 & 231 & 0 \\
\hline Total Assets \& Other Deblts .......................... & 38,678 & 6,184 & 12,543 & 84,942 & 16,374 & 8,592 \\
\hline \multicolumn{7}{|l|}{ Proprietary Capital } \\
\hline 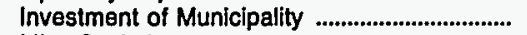 & 0 & 0 & 0 & 0 & 0 & 0 \\
\hline 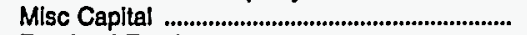 & 0 & 0 & 0 & 0 & 0 & 130 \\
\hline 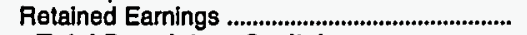 & 29,044 & 4,968 & 7,102 & 30,181 & 11,228 & 7,091 \\
\hline \multicolumn{7}{|l|}{ Long-term Debt } \\
\hline 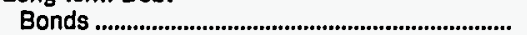 & 4,882 & 0 & 3,781 & 40,970 & 2,765 & 0 \\
\hline Advances from Municipality \& Other ................ & 0 & 165 & 32 & 0 & 219 & 0 \\
\hline Unamort Prem on Long-term Debt .................... & 0 & 0 & -66 & 0 & -19 & 0 \\
\hline (less) Unamort Discount on Long-term Debt & 0 & 0 & 0 & 0 & 0 & 0 \\
\hline Total Long-term Debt ........................................... & 4,882 & 165 & 3,747 & 40,970 & 2,965 & $\mathbf{0}$ \\
\hline \multicolumn{7}{|l|}{ Other Noncurrent Liablitiles } \\
\hline 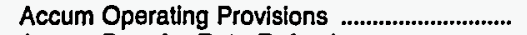 & 0 & 0 & 0 & 0 & 0 & 0 \\
\hline Accum Prov for Rate Refunds .......................... & 0 & 0 & 0 & 0 & 0 & 0 \\
\hline Total Other Noncurrent Llabilltles ............. & $\mathbf{0}$ & o & $\mathbf{0}$ & 0 & o & o \\
\hline \multicolumn{7}{|l|}{ Current and Accrued Liabilities } \\
\hline Notes Payable ............................................................... & 0 & 0 & 0 & 0 & 0 & 0 \\
\hline 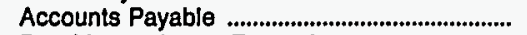 & 3,377 & 735 & 1,253 & 1,725 & 1,675 & 1,090 \\
\hline Payables to Assoc Enterprises ................................ & 0 & 0 & 0 & 0 & 0 & 0 \\
\hline 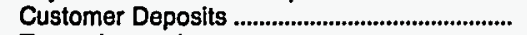 & 523 & 207 & 183 & 286 & 299 & 215 \\
\hline 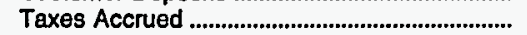 & 190 & 22 & 64 & 0 & 99 & 0 \\
\hline 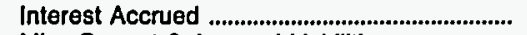 & 167 & 0 & 22 & 638 & 48 & 66 \\
\hline Misc Current \& Accrued Liabilities ...................... & 237 & 6 & 139 & 6,540 & 48 & 0 \\
\hline $\begin{array}{l}\text { Total Current \& Accrued Liabilltles ........... } \\
\text { Deferred Credits }\end{array}$ & $\mathbf{4 , 4 9 4}$ & 970 & 1,660 & $\mathbf{9 , 1 8 9}$ & 2,169 & 1,371 \\
\hline Customer Advances for Construction .................... & 0 & 0 & 1 & & 0 & 0 \\
\hline 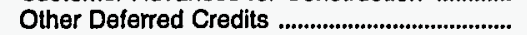 & 258 & 81 & 33 & 4,602 & 12 & 0 \\
\hline 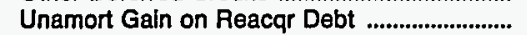 & 0 & 0 & 0 & 0 & 0 & 0 \\
\hline 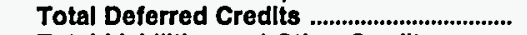 & 258 & 81 & 34 & 4,602 & 12 & \\
\hline Total Llabllities and Other Credlts ............ & 38,678 & 6,184 & 12,543 & 84,942 & 16,374 & 8,592 \\
\hline
\end{tabular}

Note: Totals may not equal sum of components because of independent rounding.

Source: Energy Information Administration, Form ElA-412, "Annual Report of Public Electric Utilities." 
Table 22. Balance Sheet by Major U.S. Publicly Owned Electric Utility Within State at End of Period, 1993 (Continued)

(Thousand Dollars)

\begin{tabular}{|c|c|c|c|c|c|c|}
\hline Item & $\begin{array}{l}\text { Kentucky } \\
\text { Mayfield } \\
\text { City of } \\
\text { June } 30\end{array}$ & $\begin{array}{l}\text { Kentucky } \\
\text { Murray } \\
\text { City of } \\
\text { June } 30\end{array}$ & $\begin{array}{l}\text { Kentucky } \\
\text { Owensboro } \\
\text { City of } \\
\text { May } 31\end{array}$ & $\begin{array}{l}\text { Kentucky } \\
\text { Paducah } \\
\text { City of } \\
\text { June } 30\end{array}$ & $\begin{array}{l}\text { Louisiana } \\
\text { Alexandria } \\
\text { City of } \\
\text { April } 30\end{array}$ & $\begin{array}{c}\text { Lafayette } \\
\text { City of } \\
\text { October } 31\end{array}$ \\
\hline \multicolumn{7}{|l|}{ Electric Utility Plant } \\
\hline Electric Utility Plant \& Adjust & 5,669 & 8,173 & 130,369 & 42,341 & 142,511 & 215,508 \\
\hline Const Work in Progress ........................................... & 166 & 29 & 50,732 & 2,326 & & \\
\hline 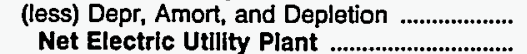 & 2,495 & 3,759 & $\begin{array}{r}71,612 \\
17,689\end{array}$ & $\begin{array}{l}12,481 \\
32,185\end{array}$ & $\begin{array}{l}59,946 \\
82,601\end{array}$ & $\begin{array}{r}85,087 \\
131,030\end{array}$ \\
\hline 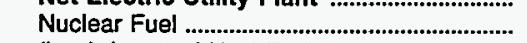 & $\begin{array}{r}3,340 \\
0\end{array}$ & $\begin{aligned} 9,443 \\
0\end{aligned}$ & $\begin{array}{r}709,489 \\
0\end{array}$ & $\begin{array}{r}32,185 \\
0\end{array}$ & $\begin{array}{r}82,607 \\
0\end{array}$ & $\begin{array}{r}131,030 \\
0\end{array}$ \\
\hline 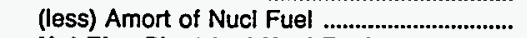 & 0 & 0 & 0 & 0 & 0 & 0 \\
\hline $\begin{array}{l}\text { Net Elec Plant Incl Nucl Fuel .................................... } \\
\text { Other Property \& Investments }\end{array}$ & 3,340 & 4,443 & 109,489 & 32,185 & 82,601 & 131,030 \\
\hline 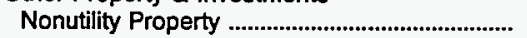 & 0 & 0 & 0 & 0 & 2,591 & 0 \\
\hline (less) Accum Provisions for Depr \& Amort .... & 0 & 0 & 0 & 0 & 0 & 0 \\
\hline 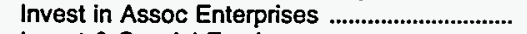 & 0 & 0 & 0 & 0 & 0 & 0 \\
\hline 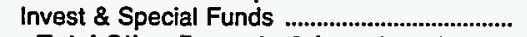 & 4 & 722 & 182,897 & 1,535 & 23,014 & 69,220 \\
\hline & 4 & 722 & 182,897 & 1,535 & Current and Accrued Assets & 69,220 \\
\hline Cash, Working Funds \& Investments .................. & 154 & 838 & 6,371 & 3,358 & 9,607 & 4,171 \\
\hline Notes \& Other Receivables .................................... & 890 & 1,021 & 136 & 1,627 & 5,791 & 969 \\
\hline Customer Accts Receivable & 0 & 0 & 2,314 & 0 & 0 & 16,796 \\
\hline (less) Accum Prov for Uncollected Accts ...... & 0 & 0 & 369 & 0 & 601 & 364 \\
\hline 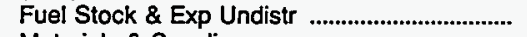 & 0 & 0 & 0 & 0 & 0 & 1,707 \\
\hline Materials \& Supplies & 81 & 144 & 1,001 & 788 & 1,455 & 1,081 \\
\hline 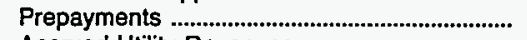 & 9 & 0 & 8 & 36 & 0 & 0 \\
\hline 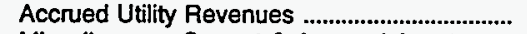 & 0 & 0 & 0 & 0 & 0 & 0 \\
\hline Miscellaneous Current \& Accrued Assets ..... & 5 & 21 & 0 & 57 & 1,258 & 1,096 \\
\hline $\begin{array}{l}\text { Total Current \& Accrued Assets .................... } \\
\text { Deferred Debits }\end{array}$ & 1,140 & 2,025 & 9,462 & 5,866 & 17,510 & 25,456 \\
\hline 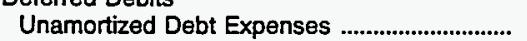 & 0 & 0 & 1,698 & 91 & 0 & 830 \\
\hline 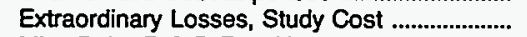 & 0 & 0 & & 0 & 0 & 3,953 \\
\hline Misc Debt, R \& D Exp, Unamrt Losses ........... & 11 & 10 & 2,355 & 505 & 0 & 0 \\
\hline Total Deferred Debits & 11 & 10 & 4,053 & 597 & 0 & 4,783 \\
\hline & 230,489 \\
\hline 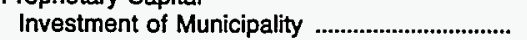 & 0 & 0 & 1,773 & 0 & 37,154 & 5,318 \\
\hline Misc Capital & 0 & 0 & 0 & 0 & 0 & 0 \\
\hline 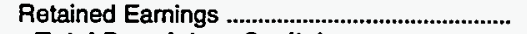 & 3,414 & 5,889 & 52,834 & 31,832 & 35,863 & 118,925 \\
\hline \multirow{2}{*}{\multicolumn{6}{|c|}{ Long-term Debt }} & 124,243 \\
\hline & & & & & 43,930 & 63,555 \\
\hline Advances from Municipality \& Other ................... & 6 & 5 & 5,757 & 512 & 399 & 0 \\
\hline Unamort Prem on Long-term Debt ................... & 0 & 0 & 0 & -78 & 0 & 0 \\
\hline (less) Unamort Discount on Long-term Debt & 0 & 0 & 0 & 0 & 0 & 0 \\
\hline Total Long-term Debt ............................................ & 6 & 5 & 226,005 & 4,905 & 44,329 & 63,555 \\
\hline \multicolumn{7}{|l|}{ Other Noncurrent Liabilities } \\
\hline 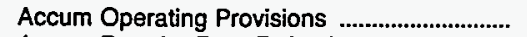 & 0 & 0 & 0 & $\mathbf{0}$ & 0 & $\mathbf{0}$ \\
\hline Accum Prov for Rate Refunds ............................... & 0 & 0 & 0 & 0 & 0 & 0 \\
\hline Total Other Noncurrent Liabllities ............. & 0 & 0 & o & $\mathbf{0}$ & 0 & 0 \\
\hline \multicolumn{7}{|l|}{ Current and Accrued Liabilities } \\
\hline 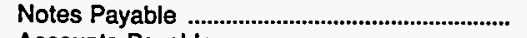 & 50 & 0 & 0 & 0 & 182 & 0 \\
\hline Accounts Payable & 629 & 863 & 3,648 & 2,292 & 812 & 5,808 \\
\hline 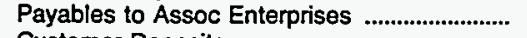 & 0 & 0 & 0 & 0 & 251 & 0 \\
\hline 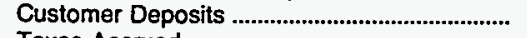 & 189 & 355 & 0 & 402 & 4,772 & 3,414 \\
\hline 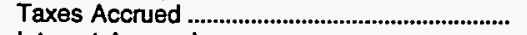 & 53 & 65 & 0 & 161 & 0 & 0 \\
\hline 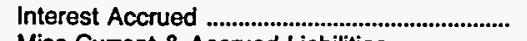 & 0 & 0 & 3,220 & 140 & 1,366 & 1,346 \\
\hline 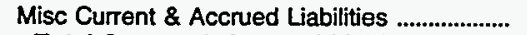 & 152 & 24 & 990 & 359 & 988 & 501 \\
\hline $\begin{array}{l}\text { Total Current \& Accrued Llabllitles } \\
\text { Defe......... }\end{array}$ & 1,074 & 1,307 & 7,858 & 3,354 & 8,370 & 11,169 \\
\hline $\begin{array}{l}\text { Deferred Credits } \\
\text { Customer Advances for Construction ............. }\end{array}$ & & 0 & & & 0 & 31,522 \\
\hline 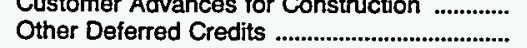 & 0 & 0 & 17,430 & 93 & 0 & $\begin{array}{r}31,0<2 \\
0\end{array}$ \\
\hline Unamort Gain on Reacqr Debt .............................. & 0 & 0 & 0 & 0 & 0 & 0 \\
\hline 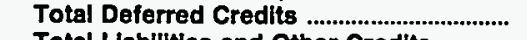 & & 0 & 17,430 & & 0 & 31,522 \\
\hline Total Llabilities and Other Credits ............ & 4,495 & 7,200 & 305,901 & 40,183 & 125,717 & 230,489 \\
\hline
\end{tabular}

Note: Totals may not equal sum of components because of independent rounding.

Source: Energy Information Administration, Form EIA-412, "Annual Report of Public Electric Utilities." 
Table 22. Balance Sheet by Major U.S. Publicly Owned Electric Utility Within State at End of Period, 1993 (Continued)

(Thousand Dollars)

\begin{tabular}{|c|c|c|c|c|c|c|}
\hline Item & $\begin{array}{c}\text { Louisiana } \\
\text { Lafayette } \\
\text { Public } \\
\text { Power Auth } \\
\text { October } 31\end{array}$ & $\begin{array}{l}\text { Louisiana } \\
\text { Louisiana } \\
\text { Energy } \\
\& \\
\text { Power Auth } \\
\text { December } 31\end{array}$ & $\begin{array}{l}\text { Louisiana } \\
\text { Morgan } \\
\text { City City of } \\
\text { December } 31\end{array}$ & $\begin{array}{l}\text { Louisiana } \\
\begin{array}{c}\text { Natchitoches } \\
\text { City of }\end{array} \\
\text { May } 31\end{array}$ & $\begin{array}{l}\text { Louisiana } \\
\begin{array}{c}\text { Ruston } \\
\text { City of }\end{array} \\
\text { September } 30\end{array}$ & $\begin{array}{l}\text { Louisiana } \\
\text { Terrebonne } \\
\text { Parish } \\
\text { Consol Govt } \\
\text { December } 31\end{array}$ \\
\hline \multicolumn{7}{|l|}{ Electric Utility Plant } \\
\hline 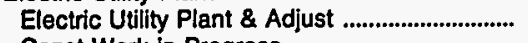 & 150,278 & 87,124 & 28,095 & 53,032 & 28,999 & 48,227 \\
\hline 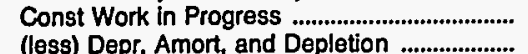 & $\begin{array}{r}1,181 \\
53,295\end{array}$ & $\begin{array}{r}214 \\
16,575\end{array}$ & $\begin{array}{r}8 \\
17,934\end{array}$ & $\begin{array}{r}0 \\
14,415\end{array}$ & $\begin{array}{r}291 \\
17,853\end{array}$ & $\begin{array}{r}1,568 \\
33,608\end{array}$ \\
\hline 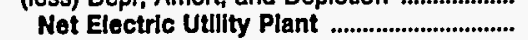 & 98,163 & 70,763 & 10,169 & 38,617 & 11,437 & 16,187 \\
\hline 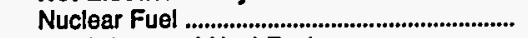 & 0 & 0 & 0 & 0 & 0 & \\
\hline 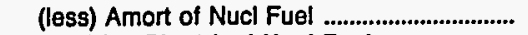 & & & 0 & 0 & 0 & \\
\hline Net Elec Plant Incl Nucl Fuel ............................ & 98,163 & 70,763 & 10,169 & 38,617 & 11,437 & 16,187 \\
\hline \multicolumn{7}{|l|}{ Other Property \& Investments } \\
\hline $\begin{array}{l}\text { Nonutility Property } \\
\text { (less) Accum Provisions for Depr \& Amort .... }\end{array}$ & $\begin{array}{l}0 \\
0\end{array}$ & $\begin{array}{r}146 \\
69\end{array}$ & $\begin{array}{l}0 \\
0\end{array}$ & $\begin{array}{l}0 \\
0\end{array}$ & $\begin{array}{l}0 \\
0\end{array}$ & $\begin{array}{l}7,831 \\
4,876\end{array}$ \\
\hline 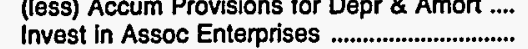 & $\begin{array}{l}0 \\
0\end{array}$ & 0 & 0 & 0 & 0 & 0 \\
\hline 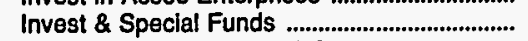 & 18,581 & 16,200 & 0 & 0 & 2,900 & 14,403 \\
\hline Total Other Property \& Investments ....... & 18,581 & 16,277 & 0 & $\mathbf{0}$ & 2,900 & 17,358 \\
\hline \multicolumn{7}{|l|}{ Current and Accrued Assets } \\
\hline Cash, Working Funds \& Investments .............. & 26,114 & 14,026 & 2,741 & 1,961 & 2,220 & 4,555 \\
\hline 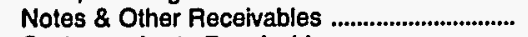 & & 81 & 157 & 46 & 25 & 1,706 \\
\hline Customer Accts Receivable ................................... & 1,818 & 5,128 & 1,128 & 1,749 & 706 & 861 \\
\hline (less) Accum Prov for Uncollected Accts ...... & & & 0 & 0 & 0 & \\
\hline 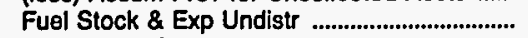 & 4,562 & 3,123 & 0 & 0 & 0 & 0 \\
\hline 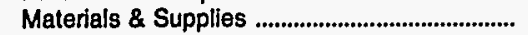 & 0 & 0 & 218 & 594 & 396 & 999 \\
\hline 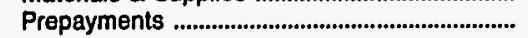 & 6 & 27 & 238 & 0 & 64 & 0 \\
\hline 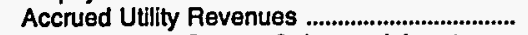 & 525 & 0 & 721 & 0 & 982 & 1,327 \\
\hline Miscellaneous Current \& Accrued Assets ..... & 0 & 0 & 383 & 0 & 0 & 3,762 \\
\hline Total Current \& Accrued Assets ............... & 33,032 & 22,386 & 5,587 & 4,350 & 4,394 & 13,212 \\
\hline \multicolumn{7}{|l|}{ Deferred Debits } \\
\hline 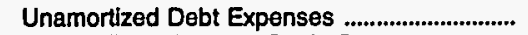 & 1,118 & 33,775 & 0 & 0 & 0 & 0 \\
\hline 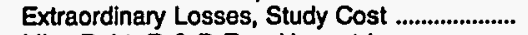 & 19,969 & & 0 & 0 & $\mathbf{0}$ & \\
\hline Mlsc Debt, R \& D Exp, Unamrt Losses .......... & 14,300 & 846 & 1,315 & 0 & 0 & \\
\hline 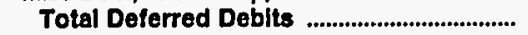 & 35,386 & 34,622 & 1,315 & o & 0 & \\
\hline Total Assets \& Other Deblts ............................. & 185,162 & 144,047 & 17,071 & 42,967 & 18,731 & 46,756 \\
\hline \multicolumn{7}{|l|}{ Proprietary Capital } \\
\hline 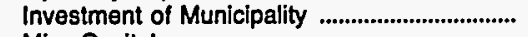 & 0 & 0 & 4,418 & 28,988 & 0 & 1,200 \\
\hline 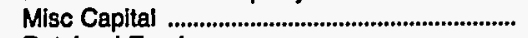 & 0 & 0 & & 0 & 0 & \\
\hline 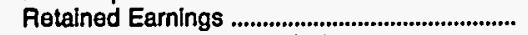 & 1,343 & 8,945 & 2,881 & 6,132 & 11,579 & 23,570 \\
\hline 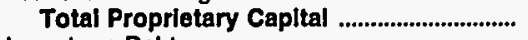 & 1,343 & 8,945 & 7,300 & 35,120 & 11,579 & 24,770 \\
\hline \multicolumn{7}{|l|}{ Long-term Debt } \\
\hline 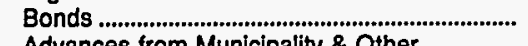 & 175,780 & 128,220 & 6,731 & 4,613 & 4,055 & 17,810 \\
\hline Advances from Municipality \& Other ................. & 0 & 0 & 1,053 & 0 & 105 & \\
\hline Unamort Prem on Long-term Debt ......................... & 0 & 0 & 0 & 0 & 0 & 0 \\
\hline (less) Unamort Discount on Long-term Debt & 1,161 & 5.765 & & & 0 & \\
\hline 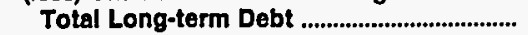 & 174,619 & 122,455 & 7,784 & 4,613 & 4,160 & 17,810 \\
\hline \multicolumn{7}{|l|}{ Other Noncurrent Liabilities } \\
\hline 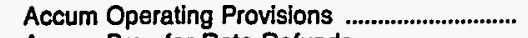 & $\mathbf{0}$ & 0 & $\mathbf{0}$ & 0 & 0 & \\
\hline Accum Prov for Rate Refunds ............................... & 0 & 0 & 0 & 0 & 0 & 0 \\
\hline Total Other Noncurrent Llabillties ............ & $\mathbf{0}$ & o & $\mathbf{0}$ & $\mathbf{0}$ & 0 & 0 \\
\hline \multicolumn{7}{|l|}{ Current and Accrued Llabilities } \\
\hline 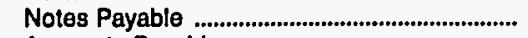 & 0 & 0 & 794 & 549 & 1,025 & 630 \\
\hline 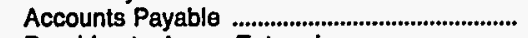 & 3,130 & 5,215 & 36 & 1,200 & 895 & 2,454 \\
\hline 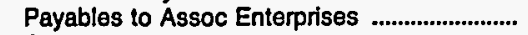 & 184 & 0 & 0 & 890 & 0 & \\
\hline 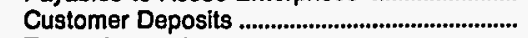 & 0 & 0 & 695 & 474 & 539 & 831 \\
\hline 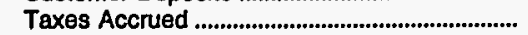 & 0 & 0 & $\mathbf{0}$ & 0 & 0 & 0 \\
\hline 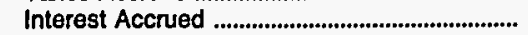 & 5,887 & 4,151 & 245 & 0 & 219 & \\
\hline Mlsc Current \& Accrued Liabilities ..................... & & 3,281 & 217 & 121 & 313 & 261 \\
\hline Total Current \& Accrued Llabilities .......... & 9,201 & 12,647 & 1,987 & 3,234 & 2,991 & 4,176 \\
\hline \multicolumn{7}{|l|}{ Deferred Credits } \\
\hline Customer Advances for Construction .............. & 0 & 0 & $\mathbf{0}$ & 0 & 0 & 0 \\
\hline 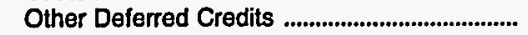 & 0 & 0 & 0 & 0 & 0 & 0 \\
\hline 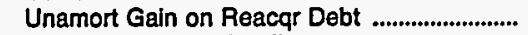 & 0 & 0 & 0 & 0 & 0 & \\
\hline 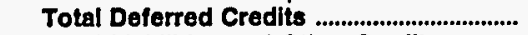 & & & & & & \\
\hline Total Llabilities and Other Credits ............. & 185,162 & 144,047 & 17,071 & 42,967 & 18,731 & 46,756 \\
\hline
\end{tabular}

Note: Totals may not equal sum of components because of independent rounding.

Source: Energy Information Administration, Form EIA-412, "Annual Report of Public Electric Utilities." 
Table 22. Balance Sheet by Major U.S. Publicly Owned Electric Utility Within State at End of Period, 1993 (Continued)

(Thousand Dollars)

\begin{tabular}{|c|c|c|c|c|c|c|}
\hline Item & $\begin{array}{l}\text { Maryland } \\
\text { Easton } \\
\text { Utilities } \\
\text { Comm } \\
\text { June } 30\end{array}$ & $\begin{array}{l}\text { Maryland } \\
\text { Hagerstown } \\
\text { City of } \\
\text { June } 30\end{array}$ & $\begin{array}{c}\text { Massachusetts } \\
\begin{array}{l}\text { Braintree } \\
\text { Town of }\end{array} \\
\text { December } 31\end{array}$ & $\begin{array}{l}\text { Massachusetts } \\
\text { Chicopee } \\
\text { City of } \\
\text { December } 31\end{array}$ & $\begin{array}{l}\text { Massachusetts } \\
\text { Concord } \\
\text { Town of } \\
\text { December } 31\end{array}$ & $\begin{array}{c}\text { Massachusetts } \\
\text { Danvers } \\
\text { Town of } \\
\text { December } 31\end{array}$ \\
\hline \multicolumn{7}{|l|}{ Electric Utility Plant } \\
\hline 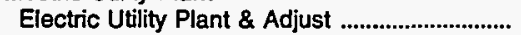 & 37,124 & 33,452 & 65,365 & 66,329 & 17,419 & 21,664 \\
\hline Const Work in Progress & 2,516 & 1,142 & & & 4,589 & \\
\hline 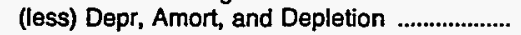 & 15,856 & 20,593 & 31,139 & 23,668 & 8,445 & 9,566 \\
\hline Net Electric Utility Plant .................................... & 23,783 & 14,000 & 34,226 & 43,061 & 13,563 & 12,147 \\
\hline Nuclear Fuel .................................................... & 0 & 0 & 0 & 3,890 & 0 & 0 \\
\hline 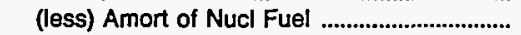 & 0 & 0 & 0 & 2,968 & 0 & 0 \\
\hline & 23,783 & 14,000 & 34,226 & 43,982 & 13,563 & 12,147 \\
\hline \multicolumn{7}{|l|}{ Other Property \& Investments } \\
\hline (less) Accum Provisions for Depr \& Amort .... & 39 & 0 & 0 & 0 & 0 & 0 \\
\hline 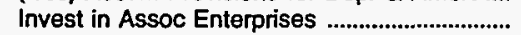 & 0 & 0 & 0 & 0 & 0 & 0 \\
\hline Invest \& Special Funds & 0 & 0 & 3,685 & 24,121 & 5,744 & 6,463 \\
\hline \multicolumn{7}{|l|}{ Current and Accrued Assets } \\
\hline Cash, Working Funds \& Investments ............... & 3,022 & 4,125 & 3.730 & 3,176 & 11,548 & 6,352 \\
\hline 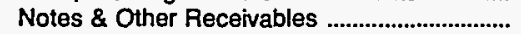 & 79 & 130 & 52 & 206 & 5 & 463 \\
\hline 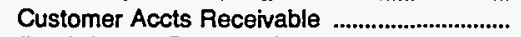 & 1,189 & 1.768 & 2,008 & 2,599 & 1,279 & 4,199 \\
\hline (less) Accum Prov for Uncollected Accts ...... & 0 & 636 & 48 & 101 & 30 & 161 \\
\hline 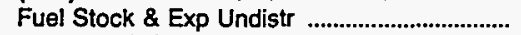 & 504 & 0 & 439 & 33 & 0 & 0 \\
\hline 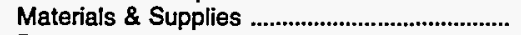 & 671 & 271 & 1,373 & 2,432 & 709 & 643 \\
\hline 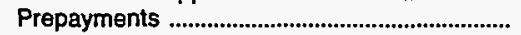 & 40 & 5 & 58 & 787 & 27 & 269 \\
\hline 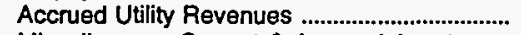 & 986 & 0 & 252 & 0 & 0 & 0 \\
\hline Miscellaneous Current \& Accrued Assets ..... & 0 & 0 & 13 & 3 & 495 & 238 \\
\hline $\begin{array}{l}\text { Total Current \& Accrued Assets ................ } \\
\text { Deferred Debits }\end{array}$ & 6,491 & 5,663 & 7,876 & 9,136 & 14,033 & 12,001 \\
\hline 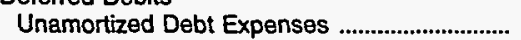 & 152 & 0 & 3 & 361 & 63 & 0 \\
\hline 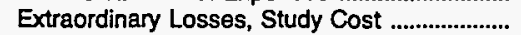 & 101 & 0 & 0 & 16 & 0 & 0 \\
\hline Misc Debt, R \& D Exp, Unamrt Losses .......... & 125 & 0 & 295 & 878 & 0 & 13 \\
\hline 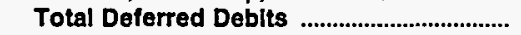 & 378 & & 297 & 1,255 & 63 & \\
\hline 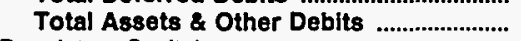 & 31,068 & 19,663 & 46,085 & 78,495 & 33,402 & 30,624 \\
\hline \multicolumn{7}{|l|}{ Proprietary Capital } \\
\hline 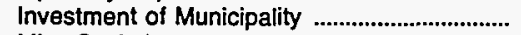 & 10,995 & 0 & 41,847 & 46,459 & 2,685 & 1,934 \\
\hline 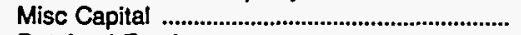 & & 620 & 0 & 0 & 0 & 0 \\
\hline 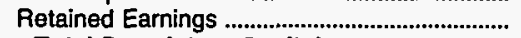 & 6,130 & 16,061 & 0 & 0 & 18,453 & 24,715 \\
\hline \multicolumn{7}{|l|}{ Long-term Debt } \\
\hline 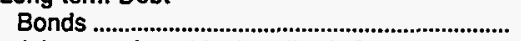 & 11,238 & 881 & 1,500 & 23,235 & 9,569 & 500 \\
\hline Advances from Municipality \& Other .................... & 194 & 0 & 0 & 0 & 0 & 0 \\
\hline Unamort Prem on Long-term Debt ......................... & 0 & 0 & 2 & 0 & 0 & 0 \\
\hline (less) Unamort Discount on Long-term Debt & & 0 & 0 & 0 & 0 & 0 \\
\hline 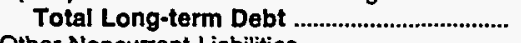 & 11,432 & 881 & 1,502 & 23,235 & 9,569 & 500 \\
\hline \multicolumn{7}{|l|}{ Other Noncurrent Liabilities } \\
\hline 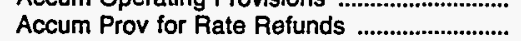 & $\begin{array}{l}0 \\
0\end{array}$ & 0 & $\begin{array}{l}0 \\
0\end{array}$ & $\begin{array}{l}0 \\
0\end{array}$ & 224 & $\begin{array}{l}0 \\
0\end{array}$ \\
\hline 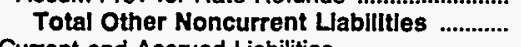 & 0 & 0 & 0 & 0 & 331 & 0 \\
\hline \multicolumn{7}{|l|}{ Current and Accrued Liabilities } \\
\hline 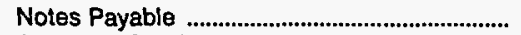 & 329 & 0 & 0 & 0 & 0 & 0 \\
\hline Accounts Payable & 692 & 1,017 & 2,255 & 2,122 & 1,633 & 1,078 \\
\hline Payables to Assoc Enterprises .............................. & 0 & 68 & 0 & 0 & 0 & 0 \\
\hline 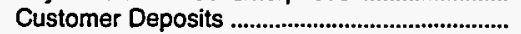 & 43 & 279 & 143 & 629 & 104 & 458 \\
\hline 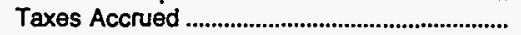 & 0 & 31 & 0 & 274 & 8 & 0 \\
\hline 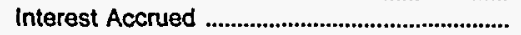 & 162 & 37 & 34 & 1,153 & 174 & 6 \\
\hline 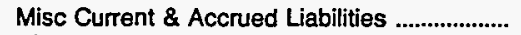 & 1,106 & 669 & 255 & 13 & 3 & 83 \\
\hline $\begin{array}{l}\text { Total Current \& Accrued Liablilities ........... } \\
\text { Deferred Credits }\end{array}$ & 2,333 & 2,101 & 2,686 & 4,189 & 1,922 & 1,625 \\
\hline Customer Advances for Construction .............. & 178 & 0 & 0 & 2,039 & 82 & 28 \\
\hline 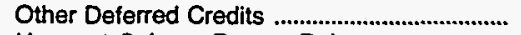 & 0 & 0 & 49 & 1,878 & 359 & 1,823 \\
\hline Unamort Gain on Reacqr Debt ............................... & 0 & 0 & 0 & 695 & 0 & 0 \\
\hline $\begin{array}{l}\text { Total Deferred Credits } \\
\text { Total Llablitities and Other Credits }\end{array}$ & $\begin{array}{r}178 \\
31,068\end{array}$ & $\begin{array}{r}0 \\
19,663\end{array}$ & $\begin{array}{r}49 \\
46,085\end{array}$ & $\begin{array}{r}4,611 \\
78,495\end{array}$ & $\begin{array}{r}441 \\
33,402\end{array}$ & $\begin{array}{r}1,851 \\
30,624\end{array}$ \\
\hline
\end{tabular}

Note: Totals may not equal sum of components because of independent rounding.

Source: Energy Information Administration, Form EIA-412, "Annual Report of Public Electric Utilities." 
Table 22. Balance Sheet by Major U.S. Publicly Owned Electric Utility Within State at End of Period, 1993 (Continued)

(Thousand Dollars)

\begin{tabular}{|c|c|c|c|c|c|c|}
\hline Item & $\begin{array}{l}\text { Massachusetts } \\
\begin{array}{l}\text { Hingham } \\
\text { City of }\end{array} \\
\text { December } 31\end{array}$ & $\begin{array}{c}\text { Massachusetts } \\
\text { Holyoke } \\
\text { City of } \\
\text { December } 31\end{array}$ & $\begin{array}{c}\text { Massachusetts } \\
\text { Hudson } \\
\text { Town of } \\
\text { December } 31\end{array}$ & $\begin{array}{l}\text { Massachusetts } \\
\text { Littleton } \\
\text { Town of } \\
\text { December } 31\end{array}$ & $\begin{array}{l}\text { Massachusetts } \\
\text { Mansfield } \\
\text { Town of } \\
\text { December } 31\end{array}$ & $\begin{array}{c}\text { Massachusetts } \\
\text { Massachusetts } \\
\text { Mun } \\
\text { Whis } \\
\text { Elec Co } \\
\text { December } 31\end{array}$ \\
\hline \multicolumn{7}{|l|}{ Electric Utility Plant } \\
\hline 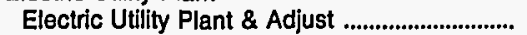 & 20,587 & 52,768 & 18,325 & 14,560 & 9,355 & $1,231,650$ \\
\hline Const Work in Progress & & 347 & & 170 & & 2,195 \\
\hline (less) Depr, Amort, and Depletion ..................... & 5,547 & 29,843 & 12,038 & 5,766 & 5,651 & 243,440 \\
\hline Net Electric Utllity Plant .................................. & 15,041 & 23,272 & 6,287 & 8,963 & $\mathbf{3 , 7 0 4}$ & 990,404 \\
\hline Nuclear Fuel ...................................................... & 0 & & 69 & 0 & 0 & 70,392 \\
\hline 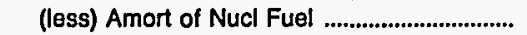 & 0 & 0 & 0 & 0 & 0 & 50,838 \\
\hline 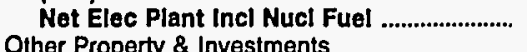 & 15,041 & 23,272 & 6,357 & 8,963 & 3,704 & $1,009,958$ \\
\hline 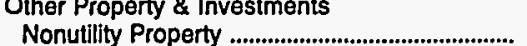 & 0 & \multicolumn{5}{|c|}{ Other Property \& Investments } \\
\hline (less) Accum Provisions for Depr \& Amort .... & 0 & 10,657 & 0 & 0 & 0 & 0 \\
\hline Invest in Assoc Enterprises .................................... & 0 & & 146 & 0 & 0 & 0 \\
\hline 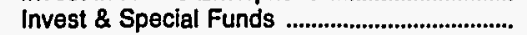 & 866 & 2,074 & 7,538 & 6,634 & 855 & 0 \\
\hline $\begin{array}{l}\text { Total Other Property \& Investments ........ } \\
\text { Current and Accrued Assets }\end{array}$ & 866 & 10,713 & 7,684 & 6,634 & 855 & 0 \\
\hline Cash, Working Funds \& Investments ............... & 1,261 & 4,300 & 3,109 & 234 & 1,512 & 192,112 \\
\hline 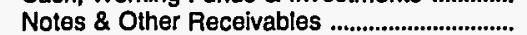 & & 600 & 42 & 69 & 86 & 7,463 \\
\hline Customer Accts Receivable ..................................... & 1,167 & 6,640 & 2,964 & 1,558 & 1,573 & 1,899 \\
\hline (less) Accum Prov for Uncollected Accts ...... & 0 & 500 & 0 & 100 & 0 & 0 \\
\hline 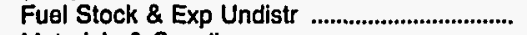 & 0 & 656 & 236 & 0 & 0 & 4,190 \\
\hline 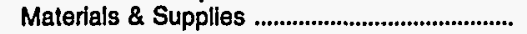 & 181 & 1,210 & 855 & 349 & 379 & 10,656 \\
\hline Prepayments ................................................................... & 671 & 978 & 419 & 2,111 & 2,632 & 7,636 \\
\hline 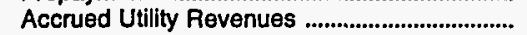 & 0 & 0 & 0 & 0 & 0 & 7,813 \\
\hline Miscellaneous Current \& Accrued Assets ..... & & 163 & 47 & 0 & 0 & 0 \\
\hline Total Current \& Accrued Assets ................ & 3,289 & 14,047 & 7,671 & 4,220 & 6,182 & 231,768 \\
\hline \multicolumn{7}{|l|}{ Deferred Debits } \\
\hline 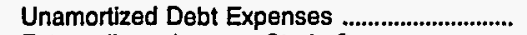 & 75 & 265 & 0 & 0 & 0 & 39,341 \\
\hline 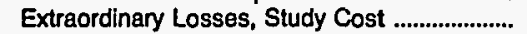 & 0 & 0 & 0 & 0 & 0 & 1,424 \\
\hline Misc Debt, R \& D Exp, Unamrt Losses .......... & 135 & 3,414 & 369 & 0 & 3 & 196,032 \\
\hline 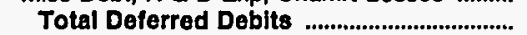 & 211 & 3,679 & 369 & 0 & $\mathbf{3}$ & 236,797 \\
\hline Total Assets \& Other Deblts ........................... & 19,406 & 51,711 & 22,081 & 19,818 & 10,743 & $1,478,523$ \\
\hline \multicolumn{7}{|l|}{ Propriatary Capital } \\
\hline 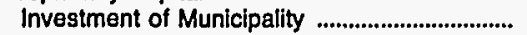 & 0 & 0 & 20 & 17,095 & 0 & 0 \\
\hline 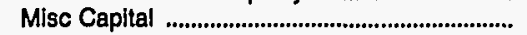 & 0 & 0 & 0 & 0 & 13 & 0 \\
\hline 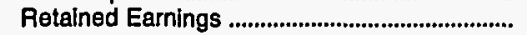 & 13,307 & 37,678 & 19,232 & 0 & 9,678 & 0 \\
\hline Total Proprletary Capltal .................................. & 13,307 & 37,678 & 19,252 & 17,095 & 9,690 & 0 \\
\hline \multicolumn{7}{|l|}{ Long-term Debt } \\
\hline 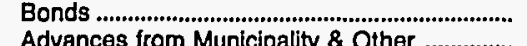 & 3,615 & 5,455 & 0 & 100 & 0 & $1,374,605$ \\
\hline Advances from Municipality \& Other .................. & 0 & 0 & 0 & 0 & 0 & 0 \\
\hline Unamort Prem on Long-term Debt ..................... & 0 & 0 & 0 & 0 & 0 & 0 \\
\hline (less) Unamort Discount on Long-term Debt & & & 0 & 0 & 0 & 0 \\
\hline 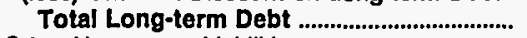 & 3,615 & 5,455 & 0 & 100 & 0 & $1,374,605$ \\
\hline \multicolumn{7}{|l|}{ Other Noncurrent Llabilities } \\
\hline 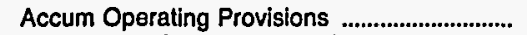 & 0 & 0 & 605 & 0 & 43 & 8,070 \\
\hline 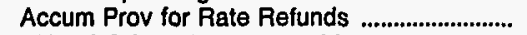 & 0 & 0 & 0 & 1,395 & 0 & 0 \\
\hline Total Other Noncurrent Llabllitles ............ & 0 & o & 605 & 1,395 & 43 & 8,070 \\
\hline \multicolumn{7}{|l|}{ Current and Accrued Liabilities } \\
\hline 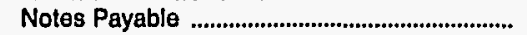 & 0 & 0 & 0 & 0 & 0 & 65 \\
\hline 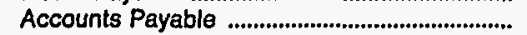 & 1,093 & 6,832 & 642 & 1,100 & 475 & 28,935 \\
\hline 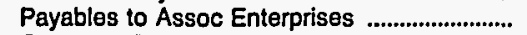 & 303 & 0 & 0 & 0 & 305 & 0 \\
\hline 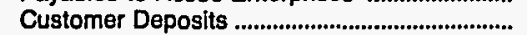 & 417 & 808 & 359 & 43 & 212 & 0 \\
\hline 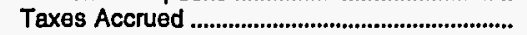 & 13 & 0 & 19 & 0 & 17 & 1,065 \\
\hline 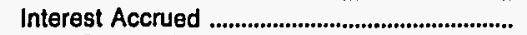 & 82 & 59 & 0 & 0 & 0 & 0 \\
\hline Misc Current \& Accrued Liabilities ...................... & 114 & & 0 & 0 & 0 & 43,852 \\
\hline Total Current \& Accrued Llabillties .......... & 2,022 & 7,700 & 1,020 & 1,144 & 1,009 & 73,916 \\
\hline \multicolumn{7}{|l|}{ Deferred Credits } \\
\hline Customer Advances for Construction .............. & 462 & 0 & 2 & 0 & 0 & -32 \\
\hline 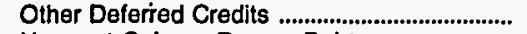 & 0 & 878 & 1,201 & 84 & 0 & 21,964 \\
\hline Unamort Gain on Reacqr Debt ............................ & 0 & 0 & 0 & 0 & 0 & 0 \\
\hline 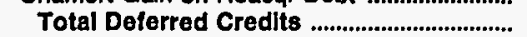 & 462 & 878 & 1,203 & 84 & & 21,932 \\
\hline Total Llabllitles and Other Credits ............. & 19,406 & 51,711 & 22,081 & 19,818 & 10,743 & $1,478,523$ \\
\hline
\end{tabular}

Note: Totals may not equal sum of components because of independent rounding.

Source: Energy Information Administration, Form ElA-412, "Annual Report of Public Electric Utilities." 
Table 22. Balance Sheet by Major U.S. Publicly Owned Electric Utility Within State at End of Period, 1993 (Continued)

(Thousand Dollars)

\begin{tabular}{|c|c|c|c|c|c|c|}
\hline Item & $\begin{array}{l}\text { Massachusetts } \\
\text { Middleborough } \\
\text { Town of } \\
\text { December } 31\end{array}$ & $\begin{array}{l}\text { Massachusetts } \\
\text { North } \\
\text { Attleborough } \\
\text { Town of } \\
\text { December } 31\end{array}$ & $\begin{array}{l}\text { Massachusetts } \\
\text { Norwood } \\
\text { City of } \\
\text { June } 30\end{array}$ & $\begin{array}{c}\text { Massachusetts } \\
\text { Peabody } \\
\text { City of } \\
\text { December } 31\end{array}$ & $\begin{array}{l}\text { Massachusetts } \\
\text { Reading } \\
\text { Town of } \\
\text { December } 31\end{array}$ & $\begin{array}{c}\text { Massachusetts } \\
\text { Shrewsbury } \\
\text { Town of } \\
\text { December } 31\end{array}$ \\
\hline \multicolumn{7}{|l|}{ Electric Utility Plant } \\
\hline 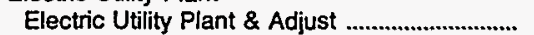 & 15,223 & 19,308 & 21,436 & 60,522 & 43,832 & 22,868 \\
\hline Const Work in Progress & & 270 & & & & \\
\hline (less) Depr, Amort, and Depletion ......................... & 6,064 & 5,642 & 14,037 & 21,929 & 19,380 & 10,944 \\
\hline Net Electric Utillty Plant ................................. & 9,159 & 13,936 & 7,398 & 38,593 & 24,453 & 11,923 \\
\hline 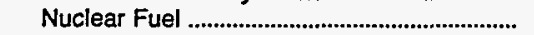 & 0 & 0 & 0 & 0 & 0 & 0 \\
\hline (less) Amort of Nucl Fuel ................................... & 0 & 0 & 0 & 0 & 0 & 0 \\
\hline Net Elec Plant Incl Nucl Fuel ............................. & 9,159 & 13,936 & 7,398 & 38,593 & 24,453 & 11,923 \\
\hline \multicolumn{7}{|l|}{ Other Property \& Investments } \\
\hline 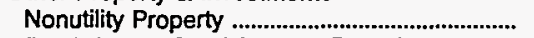 & 0 & 0 & 0 & 0 & 0 & 0 \\
\hline (less) Accum Provisions for Depr \& Amort .... & 0 & 0 & 0 & 0 & 0 & 0 \\
\hline 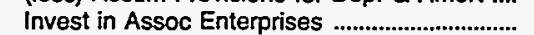 & 106 & 90 & 0 & & 0 & 160 \\
\hline 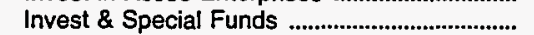 & 587 & 2,833 & 2,759 & 5,966 & 2,030 & 3,650 \\
\hline $\begin{array}{l}\text { Total Other Property \& Investments ....... } \\
\text { Current and Accrued Assets }\end{array}$ & 693 & 2,923 & 2,759 & 5,966 & 2,030 & 3,810 \\
\hline Cash, Working Funds \& Investments ............... & 842 & 3,645 & 1,844 & 4,121 & 10,137 & 3,806 \\
\hline 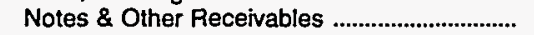 & 193 & 32 & 0 & 181 & 697 & 7 \\
\hline Customer Accts Receivable ................................... & 2,892 & 1,608 & 1,071 & 3,674 & 3,312 & 1,343 \\
\hline (less) Accum Prov for Uncollected Accts ....... & 0 & 137 & 485 & 100 & 300 & 0 \\
\hline 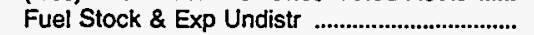 & 15 & 5 & 0 & 164 & 0 & 0 \\
\hline 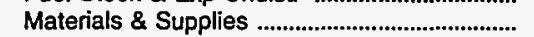 & 854 & 525 & 0 & 716 & 736 & 184 \\
\hline 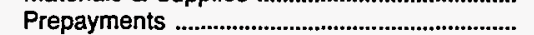 & 1,359 & 235 & 0 & 1,069 & 1,436 & 1,440 \\
\hline Accrued Utility Revenues ........................................ & 0 & 0 & 0 & 0 & 0 & 0 \\
\hline Miscellaneous Current \& Accrued Assets ..... & 0 & 0 & 0 & 0 & 0 & 0 \\
\hline Total Current \& Accrued Assets ....................... & 6,156 & 5,914 & 2,430 & 9,824 & 16,019 & 6,780 \\
\hline \multicolumn{7}{|l|}{ Deferred Debits } \\
\hline Unamortized Debt Expenses ...................................... & 0 & 0 & 0 & 216 & 0 & 0 \\
\hline 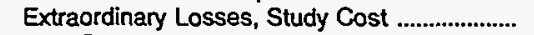 & 0 & 0 & 0 & 0 & 0 & 0 \\
\hline Misc Debt, R \& D Exp, Unamrt Losses .............. & 709 & 0 & 0 & 0 & 32 & 2 \\
\hline Total Deferred Debits & 709 & $\mathbf{0}$ & o & 216 & 32 & 2 \\
\hline 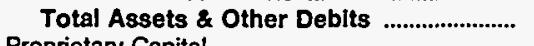 & 16,717 & 22,773 & 12,587 & 54,598 & 42,534 & 22,515 \\
\hline \multicolumn{7}{|l|}{ Proprietary Capital } \\
\hline 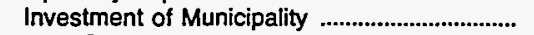 & 2,102 & 0 & 8,367 & 3,735 & 28,063 & $\mathbf{0}$ \\
\hline 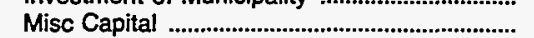 & & 674 & 0 & 0 & 0 & 0 \\
\hline 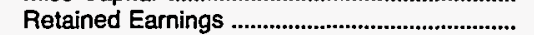 & 10,998 & 17,136 & 1,573 & 22,234 & 0 & 20,328 \\
\hline \multicolumn{7}{|l|}{ Long-term Debt } \\
\hline 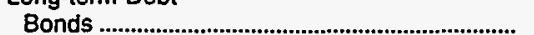 & 1,580 & 3,200 & 0 & 20,400 & 4,254 & 145 \\
\hline Advances from Municipality \& Other ................. & 305 & 0 & 0 & 0 & 0 & 70 \\
\hline Unamort Prem on Long-term Debt ....................... & 0 & 0 & 0 & 0 & 0 & 0 \\
\hline (less) Unamort Discount on Long-term Debt & 0 & 0 & 0 & 0 & 0 & 0 \\
\hline 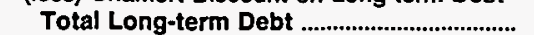 & 1,885 & 3,200 & 0 & 20,400 & 4,254 & 215 \\
\hline \multicolumn{7}{|l|}{ Other Noncurrent Liabilities } \\
\hline Accum Operating Provisions ................................ & 408 & 0 & 0 & 4,662 & 0 & 0 \\
\hline 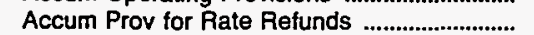 & 0 & 0 & 0 & 0 & 0 & 0 \\
\hline Total Other Noncurrent Llabilltles ............. & 408 & o & 0 & 4,662 & 0 & o \\
\hline $\begin{array}{c}\text { Current and Accrued Liabilities } \\
\text { Notes Payable }\end{array}$ & 0 & 0 & 0 & 0 & 0 & 0 \\
\hline 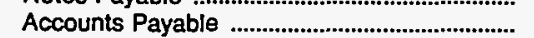 & 1,039 & 1,162 & 1,925 & 1,167 & 4,172 & 1,329 \\
\hline Payables to Assoc Enterprises ............................. & 0 & 0 & 0 & 386 & 0 & 0 \\
\hline 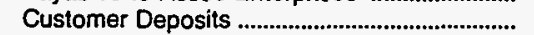 & 18 & 296 & 472 & 1,574 & 578 & 378 \\
\hline Taxes Accrued & 6 & 8 & 99 & 0 & 0 & 16 \\
\hline 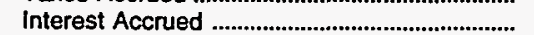 & 79 & 167 & 0 & 440 & 44 & 3 \\
\hline Misc Current \& Accrued Liabilities ...................... & 0 & 129 & 17 & 0 & 823 & 0 \\
\hline & 5,617 & 1,725 \\
\hline $\begin{array}{l}\text { Deferred Credits } \\
\text { Customer Advances for Construction .............. }\end{array}$ & 0 & 0 & 135 & 0 & 3,334 & 0 \\
\hline Other Deferred Credits & 184 & 0 & 0 & 0 & 1,267 & 247 \\
\hline Unamort Gain on Reacqr Debt & 0 & 0 & 0 & 0 & 0 & 0 \\
\hline Total Deferred Credits ........................................ & 184 & 0 & 135 & 0 & 4,600 & 247 \\
\hline 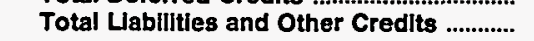 & 16,717 & 22,773 & 12,587 & 54,598 & 42,534 & 22,515 \\
\hline
\end{tabular}

Note: Totals may not equal sum of components because of independent rounding.

Source: Energy Information Administration, Form EIA-412, "Annual Report of Public Electric Utilities." 
Table 22. Balance Sheet by Major U.S. Publicly Owned Electric Utility Within State at End of Period, 1993 (Continued)

(Thousand Dollars)

\begin{tabular}{|c|c|c|c|c|c|c|}
\hline Item & $\begin{array}{l}\text { Massachusetts } \\
\text { Taunton } \\
\text { City of } \\
\text { December } 31\end{array}$ & $\begin{array}{c}\text { Massachusetts } \\
\text { Wakefield } \\
\text { Town of } \\
\text { December } 31\end{array}$ & $\begin{array}{c}\text { Massachusetts } \\
\text { Wellesley } \\
\text { Town of } \\
\text { December } 31\end{array}$ & $\begin{array}{c}\text { Massachusetts } \\
\text { Westfield } \\
\text { City of } \\
\text { December } 31\end{array}$ & $\begin{array}{c}\text { Michigan } \\
\text { Bay } \\
\text { City City of } \\
\text { June } 30\end{array}$ & $\begin{array}{l}\text { Michigan } \\
\text { Coldwater } \\
\text { Board } \\
\text { of } \\
\text { Public Util } \\
\text { June } 30\end{array}$ \\
\hline \multicolumn{7}{|l|}{ Electric Utility Plant } \\
\hline 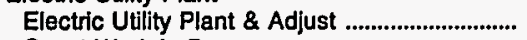 & 92,150 & 13,184 & 25,649 & 23,817 & 43,280 & 14,397 \\
\hline Const Work in Progress & 3,966 & & 648 & 124 & & \\
\hline (less) Depr, Amort, and Depletion ..................... & 52,755 & 10,728 & 11,738 & 9,554 & 12,335 & 8,266 \\
\hline Not Electric UtIIIty Plant ..........................,... & 43,361 & 2,455 & 14,560 & 14,387 & 30,945 & 6,131 \\
\hline 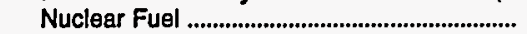 & 256 & 0 & 0 & 0 & 0 & 0 \\
\hline 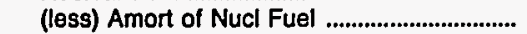 & 165 & 0 & 0 & 0 & 0 & 0 \\
\hline 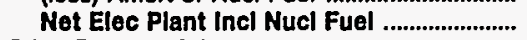 & 43,452 & 2,455 & 14,560 & 14,387 & 30,945 & 6,131 \\
\hline \multicolumn{7}{|l|}{ Other Property \& Investments } \\
\hline 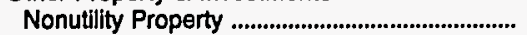 & 0 & 0 & 0 & 8,136 & 0 & 0 \\
\hline (less) Accum Provisions for Depr \& Amort .... & 0 & 0 & 0 & & 0 & 0 \\
\hline 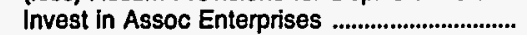 & 0 & 0 & 0 & 0 & 0 & 0 \\
\hline 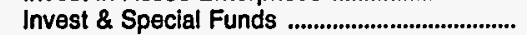 & 11,577 & 1,248 & 3,354 & 1,861 & 2,896 & 2,999 \\
\hline Total Other Property \& Investments ........ & 11,577 & 1,248 & $\mathbf{3 , 3 5 4}$ & 9,997 & 2,896 & 2,999 \\
\hline \multicolumn{7}{|l|}{ Current and Accrued Assets } \\
\hline Cash, Working Funds \& Investments ............... & 2,429 & 1,692 & 949 & 6,162 & 13,431 & 14 \\
\hline 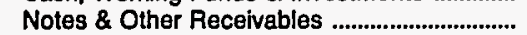 & 140 & 272 & 0 & 0 & 580 & 1,684 \\
\hline 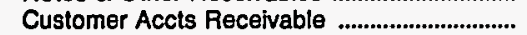 & 2,773 & 2,102 & 1,386 & 6,277 & 1,309 & 1,196 \\
\hline (less) Accum Prov for Uncollected Accts ...... & & 145 & 86 & 1,966 & 27 & 0 \\
\hline 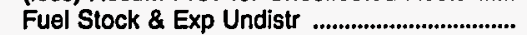 & 1,014 & 0 & 0 & 0 & 0 & 0 \\
\hline 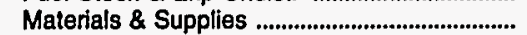 & 921 & 337 & 525 & 901 & 1,923 & 350 \\
\hline 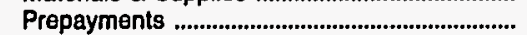 & 1,435 & 715 & 125 & 1,377 & 0 & 19 \\
\hline 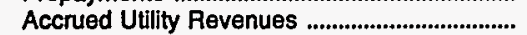 & 0 & 0 & 0 & 0 & 0 & 0 \\
\hline Miscollaneous Current \& Accrued Assets ..... & 528 & & 52 & 0 & 95 & 0 \\
\hline Total Current \& Accrued Assets ................ & 9,240 & 4,974 & 2,953 & 12,752 & 17,310 & 3,262 \\
\hline \multicolumn{7}{|l|}{ Deferred Debits } \\
\hline 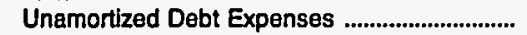 & 0 & 0 & 0 & 30 & 717 & 0 \\
\hline Extraordinary Losses, Study Cost ........................ & 0 & 0 & 0 & 0 & 0 & 0 \\
\hline Misc Debt, R \& D Exp, Unamrt Losses .......... & 232 & 450 & 0 & 35 & 2,266 & 0 \\
\hline 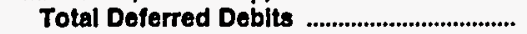 & 232 & 450 & o & & 2,982 & \\
\hline \multirow{2}{*}{\multicolumn{7}{|c|}{ Proprietary Capital }} \\
\hline & & & & & & \\
\hline 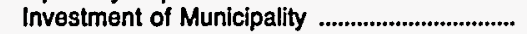 & 41,832 & 0 & 1,717 & 0 & 0 & 8,579 \\
\hline 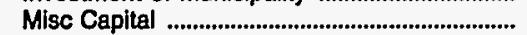 & 0 & 0 & 0 & 0 & 0 & 0 \\
\hline 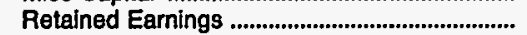 & 0 & 5,236 & 16,355 & 22,338 & 27,045 & 0 \\
\hline 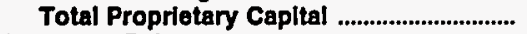 & 41,832 & 5,236 & 18,071 & 22,338 & 27,045 & $\mathbf{8 , 5 7 9}$ \\
\hline \multicolumn{7}{|l|}{ Long-term Debt } \\
\hline 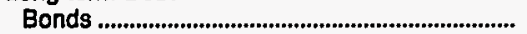 & 17,055 & 0 & 500 & 7,710 & 25,445 & 1,118 \\
\hline Advances from Municipality \& Other ................ & 0 & 0 & 0 & 0 & 121 & 980 \\
\hline Unamort Prem on Long-term Debt .................... & 0 & 0 & 0 & 0 & 0 & 0 \\
\hline (less) Unamort Discount on Long-term Debt & 0 & 0 & 0 & & 348 & \\
\hline 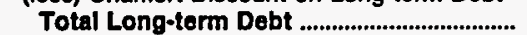 & 17,055 & 0 & 500 & 7,710 & 25,217 & 2,098 \\
\hline \multicolumn{7}{|l|}{ Other Noncurrent Liabilities } \\
\hline 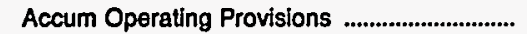 & 0 & 0 & 0 & 0 & 0 & 0 \\
\hline Accum Prov for Rate Refunds ............................. & 0 & 0 & 0 & 0 & 0 & 0 \\
\hline Total Other Noncurrent Llabillties ............. & o & 0 & 0 & 0 & 0 & $\mathbf{0}$ \\
\hline \multicolumn{7}{|l|}{ Current and Accrued Liabilities } \\
\hline 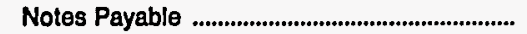 & 0 & 0 & 0 & 0 & 995 & 0 \\
\hline 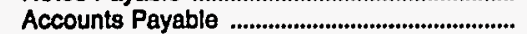 & 2,053 & 2,484 & 1,796 & 3,636 & 29 & 804 \\
\hline Payables to Assoc Enterprises ........................... & 0 & 0 & 0 & 349 & 497 & 58 \\
\hline 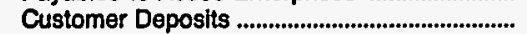 & 309 & 517 & 354 & 1 & 60 & 64 \\
\hline 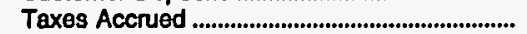 & 0 & 0 & 0 & 40 & 0 & 0 \\
\hline 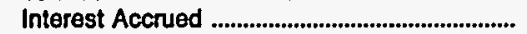 & 580 & 0 & 0 & 127 & 0 & 43 \\
\hline Misc Current \& Accrued Llabilities ..................... & 266 & 890 & 129 & 3,000 & 239 & 747 \\
\hline Total Current \& Accrued Llabllities ........... & 3,207 & 3,890 & 2,279 & 7,152 & 1,821 & 1,715 \\
\hline \multicolumn{7}{|l|}{ Deferred Credits } \\
\hline Customer Advances for Construction .............. & 2,408 & $\mathbf{0}$ & 16 & 0 & 50 & 0 \\
\hline Other Deferred Credits ............................................. & 0 & 0 & 0 & 0 & 0 & 0 \\
\hline Unamort Gain on Reacqr Debt ............................... & 0 & 0 & 0 & 0 & 0 & 0 \\
\hline Total Deferred Credits ......................................... & 2,408 & & & & & \\
\hline Total Luabllitles and Other Credits ............. & 64,501 & 9,127 & 20,867 & 37,200 & 54,134 & 12,393 \\
\hline
\end{tabular}

Note: Totals may not equal sum of components because of independent rounding.

Source: Energy Information Administration, Form EIA-412, "Annual Report of Public Electric Utilities." 
Table 22. Balance Sheet by Major U.S. Publicly Owned Electric Utility Within State at End of Period, 1993 (Continued)

(Thousand Dollars)

\begin{tabular}{|c|c|c|c|c|c|c|}
\hline Item & $\begin{array}{l}\text { Michigan } \\
\text { Detroit } \\
\text { City of } \\
\text { June } 30\end{array}$ & $\begin{array}{c}\text { Michigan } \\
\text { Grand Haven } \\
\text { City of } \\
\text { June } 30\end{array}$ & $\begin{array}{l}\text { Michigan } \\
\text { Hillsdale } \\
\text { Board } \\
\text { of } \\
\text { Public Wks } \\
\text { June } 30\end{array}$ & $\begin{array}{l}\text { Michigan } \\
\text { Holland } \\
\text { City of } \\
\text { June } 30\end{array}$ & $\begin{array}{l}\text { Michigan } \\
\text { Lansing } \\
\text { City of } \\
\text { June } 30\end{array}$ & $\begin{array}{l}\text { Marquette } \\
\text { City of } \\
\text { June } 30\end{array}$ \\
\hline \multicolumn{7}{|l|}{ Electric Utility Plant } \\
\hline 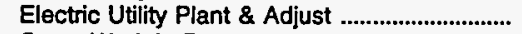 & 274,701 & 100,965 & 10,383 & 93,893 & 361,973 & 95,408 \\
\hline & 12,234 & 1,234 & 374 & & 17,029 & 225 \\
\hline $\begin{array}{l}\text { (less) Depr, Amort, and Depletion ................ } \\
\text { Net Electric Uttlity Plant }\end{array}$ & $\begin{array}{l}116,118 \\
170,817\end{array}$ & $\begin{array}{l}40,380 \\
61,820\end{array}$ & 6,776 & 36,723 & 214,180 & 39,097 \\
\hline $\begin{array}{l}\text { Net Electric Utllity Plant } \\
\text { Nuclear Fuel }\end{array}$ & $\begin{array}{r}170,811 \\
0\end{array}$ & $\begin{array}{r}07,820 \\
0\end{array}$ & $\begin{array}{r}3,981 \\
0\end{array}$ & $\begin{array}{r}57,178 \\
0\end{array}$ & $\begin{array}{r}164,822 \\
0\end{array}$ & $\begin{array}{r}56,535 \\
0\end{array}$ \\
\hline (less) Amort of Nucl Fuel ...................................... & 0 & 0 & 0 & 0 & 0 & 0 \\
\hline Net Elec Plant Incl Nucl Fuel ........................... & 170,817 & 61,820 & 3,981 & 57,178 & 164,822 & 56,535 \\
\hline 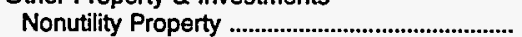 & 0 & \multicolumn{5}{|c|}{ Other Property \& Investments } \\
\hline (less) Accum Provisions for Depr \& Amort .... & 0 & 0 & 0 & 0 & 0 & 0 \\
\hline 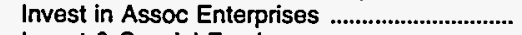 & 0 & 0 & 1,034 & 0 & 0 & 0 \\
\hline 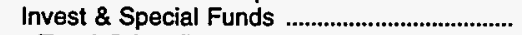 & 0 & 293 & 2,139 & 0 & 17,884 & 64,835 \\
\hline $\begin{array}{l}\text { Total Other Property \& Investments ....... } \\
\text { Current and Accrued Assets }\end{array}$ & o & 293 & 3,173 & 0 & 17,884 & 64,835 \\
\hline Cash, Working Funds \& Investments .............. & 83,884 & 18,224 & 1,912 & 31,880 & 52,147 & 6,436 \\
\hline 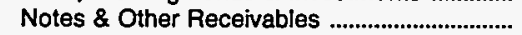 & 22,114 & 425 & 603 & 776 & 0 & 1 \\
\hline 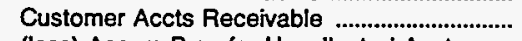 & 18,552 & 1,459 & 980 & 2,123 & 8,197 & 1,054 \\
\hline (less) Accum Prov for Uncollected Accts ....... & 1,808 & & 150 & 10 & 519 & 182 \\
\hline 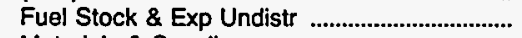 & 1,589 & 2,750 & 39 & 3,427 & 10,813 & 1,058 \\
\hline Materials \& Supplies .................................................. & 7,333 & 0 & 709 & 2,206 & 3,781 & 191 \\
\hline 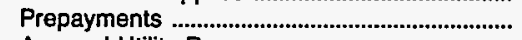 & 0 & 65 & 14 & 1 & 270 & 282 \\
\hline 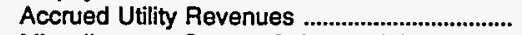 & 0 & 0 & 0 & 1,534 & 0 & 0 \\
\hline Miscellaneous Current \& Accrued Assets ...... & 0 & 9 & 34 & & 1,984 & 4 \\
\hline Total Current \& Accrued Assets ............... & \multicolumn{4}{|c|}{ Deferred Debits } & 76,673 & 8,844 \\
\hline Unamortized Debt Expenses ................................. & 0 & 6,353 & 0 & 0 & 0 & 576 \\
\hline Extraordinary Losses, Study Cost ........................... & 0 & 0 & 0 & 0 & 0 & 0 \\
\hline Misc Debt, R \& D Exp, Unamrt Losses .......... & 2,891 & 0 & 0 & 0 & 0 & 0 \\
\hline Total Deferred Debits & 2,891 & 6,353 & & & 0 & 576 \\
\hline \multirow{2}{*}{\multicolumn{6}{|c|}{ Proprietary Capital }} & 130,789 \\
\hline & 267,607 & 0 & 0 & 0 & 0 & 0 \\
\hline 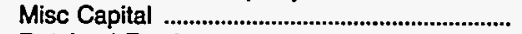 & $-194,458$ & 0 & 0 & $\mathbf{0}$ & $-34,315$ & 0 \\
\hline 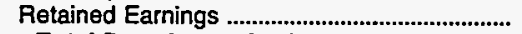 & 140,963 & 328 & 9,490 & 60,893 & 255,743 & 32,317 \\
\hline 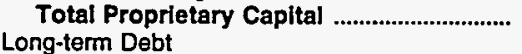 & 214,112 & 328 & $\mathbf{9 , 4 9 0}$ & 60,893 & 221,429 & 32,317 \\
\hline 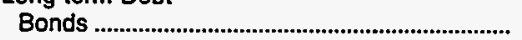 & 76,624 & 88,820 & 620 & 33,795 & 7,718 & 90,140 \\
\hline Advances from Municipality \& Other ................. & & 0 & 0 & 0 & 2,430 & 0 \\
\hline Unamort Prem on Long-term Debt ..................... & 0 & 0 & 0 & 0 & 0 & 0 \\
\hline (less) Unamort Discount on Long-term Debt & 0 & 3,156 & 0 & 225 & 0 & 588 \\
\hline Total Long-term Debt ............................................ & 76,624 & 85,664 & 620 & 33,570 & 10,148 & 89,552 \\
\hline \multicolumn{7}{|l|}{ Other Noncurrent Liabilities } \\
\hline Accum Operating Provisions ..................................... & 0 & 0 & 0 & 0 & 15,420 & 668 \\
\hline Accum Prov for Rate Refunds & 0 & 0 & 0 & 0 & 0 & 0 \\
\hline Total Other Noncurrent Llabilitles ............. & 0 & o & o & 0 & 15,420 & 668 \\
\hline \multicolumn{7}{|l|}{ Current and Accrued Liabilities } \\
\hline 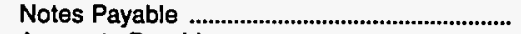 & 0 & $\mathbf{0}$ & 140 & 0 & 0 & 4,050 \\
\hline 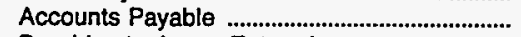 & 13,875 & 472 & 701 & 3,289 & 8,642 & 989 \\
\hline Payables to Assoc Enterprises ............................ & 0 & 0 & 0 & 48 & 0 & 0 \\
\hline 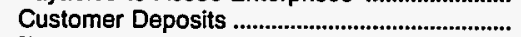 & 282 & 146 & 19 & 0 & 685 & 958 \\
\hline Taxes Accrued ................................................................ & 0 & 73 & 0 & 0 & 0 & 139 \\
\hline 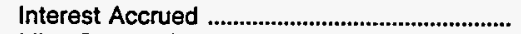 & 0 & 3,011 & 29 & 1,060 & 281 & 1,677 \\
\hline Misc Current \& Accrued Liabilities ....................... & 478 & 1,703 & 296 & 255 & 2,576 & 0 \\
\hline Total Current \& Accrued Llabilities .......... & 14,636 & 5,405 & 1,184 & 4,652 & 12,183 & 7,813 \\
\hline \multicolumn{7}{|l|}{ Deferred Credits } \\
\hline Customer Advances for Construction ............... & 0 & 0 & 0 & 0 & 200 & 439 \\
\hline & 0 & 0 & 0 & 0 & 0 & 0 \\
\hline Unamort Gain on Reacqr Debt .............................. & 0 & 0 & 0 & 0 & 0 & 0 \\
\hline 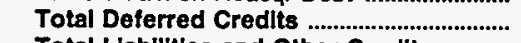 & & 0 & & & 200 & \\
\hline Total Liablitites and Other Credits ............ & 305,372 & 91,397 & 11,295 & 99,115 & 259,379 & 130,789 \\
\hline
\end{tabular}

Note: Totals may not equal sum of components because of independent rounding

Source: Energy Information Administration, Form EIA-412, "Annual Report of Public Electric Utilities." 
Table 22. Balance Sheet by Major U.S. Publicly Owned Electric Utility Within State at End of Period, 1993 (Continued)

(Thousand Dollars)

\begin{tabular}{|c|c|c|c|c|c|c|}
\hline Item & $\begin{array}{c}\text { Michigan } \\
\text { Michigan } \\
\text { Public } \\
\text { Power Agency } \\
\text { December } 31\end{array}$ & $\begin{array}{l}\text { Michigan } \\
\text { Michigan } \\
\text { South } \\
\text { Central } \\
\text { Pwr Agy } \\
\text { June } 30\end{array}$ & $\begin{array}{c}\text { Michigan } \\
\text { Sturgis } \\
\text { City of } \\
\text { September } 30\end{array}$ & $\begin{array}{l}\text { Michigan } \\
\text { Traverse } \\
\text { City City of } \\
\text { June } 30\end{array}$ & $\begin{array}{l}\text { Michigan } \\
\text { Wyandotte } \\
\text { Municipal } \\
\text { Serv Comm } \\
\text { September } 30\end{array}$ & $\begin{array}{l}\text { Michigan } \\
\text { Zeeland } \\
\text { City of } \\
\text { June } 30\end{array}$ \\
\hline \multicolumn{7}{|l|}{ Electric Utility Plant } \\
\hline 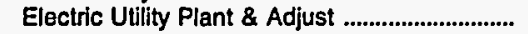 & 469,063 & 72,622 & 28,045 & 30,121 & 68,528 & 16,765 \\
\hline Const Work in Progress & & 35 & & 159 & 36,903 & 209 \\
\hline (less) Depr, Amort, and Depletion ..................... & 123,873 & 23,405 & 13,708 & 11,641 & 32,272 & 7.266 \\
\hline Net Electric Utility Plant ...................................... & 345,190 & 49,252 & 14,337 & 18,639 & 73,158 & 9,708 \\
\hline 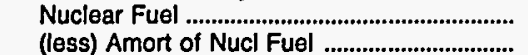 & & $\begin{array}{l}0 \\
0\end{array}$ & $\begin{array}{l}0 \\
0\end{array}$ & $\begin{array}{l}0 \\
0\end{array}$ & $\begin{array}{l}0 \\
0\end{array}$ & 0 \\
\hline 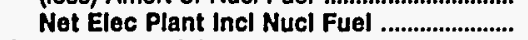 & 345,190 & 49,252 & 14,337 & 18,639 & 73,158 & 9,708 \\
\hline \multicolumn{7}{|l|}{ Other Property \& Investments } \\
\hline Nonutility Property .................................................... & 596 & 0 & 0 & 0 & 0 & 0 \\
\hline (less) Accum Provisions for Depr \& Amort .... & 30 & 0 & 0 & 0 & 0 & 0 \\
\hline 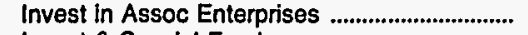 & & 0 & 0 & 0 & 0 & 0 \\
\hline 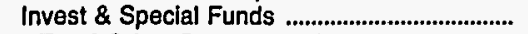 & 109,137 & 27,484 & 8,249 & 1,017 & 10,348 & 4,413 \\
\hline \multicolumn{7}{|l|}{ Current and Accrued Assets } \\
\hline Cash, Working Funds \& Investments ............... & 13,886 & 5 & 874 & 4,377 & 1,223 & 459 \\
\hline 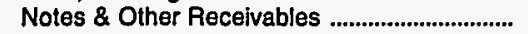 & & 105 & 464 & 18 & 3,087 & 0 \\
\hline Customer Accts Receivable & 6,300 & 2,305 & 1,327 & 1,279 & 0 & 768 \\
\hline (less) Accum Prov for Uncollected Accts ...... & & 0 & 0 & 22 & 68 & 0 \\
\hline 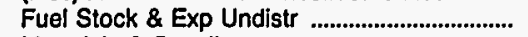 & 9,882 & 913 & 0 & 0 & 0 & 0 \\
\hline 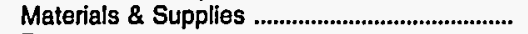 & 3,286 & 54 & 393 & 1,525 & 2,292 & 329 \\
\hline Prepayments ................................................................... & 0 & 42 & 140 & 13 & 15 & 71 \\
\hline 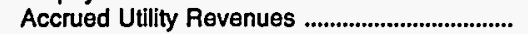 & 0 & 0 & 0 & 0 & 0 & 0 \\
\hline Miscellaneous Current \& Accrued Assets ..... & 119 & 335 & 1,292 & 0 & 121 & 0 \\
\hline Total Current \& Accrued Assets ................... & 33,472 & 3,760 & 4,490 & 7,190 & 6,670 & 1,627 \\
\hline \multicolumn{7}{|l|}{ Deferred Debits } \\
\hline Unamortized Debt Expenses ................................. & 4,515 & 2,457 & 0 & 116 & 0 & 0 \\
\hline 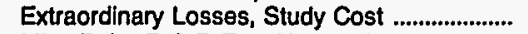 & & 786 & 0 & 0 & $\mathbf{0}$ & 0 \\
\hline Misc Debt, R \& D Exp, Unamrt Losses .......... & 341 & 23,319 & 0 & 0 & 0 & 0 \\
\hline 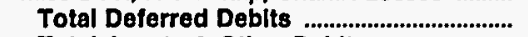 & 4,856 & 26,563 & & 116 & o & \\
\hline $\begin{array}{l}\text { Total Assets \& Other Deblts ........................... } \\
\text { Propristary Capital }\end{array}$ & 493,220 & & 27,076 & 26,962 & 90,176 & 15,748 \\
\hline 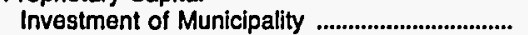 & 747 & 0 & 0 & 56 & 0 & 0 \\
\hline 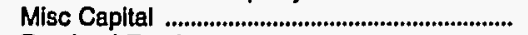 & 0 & 0 & 0 & 0 & 2,268 & 340 \\
\hline Retained Earnings …......................................................... & 202 & 4,056 & 20,841 & 22,424 & 16,195 & 12,231 \\
\hline Total Proprietary Capltal ................................... & 949 & 4,056 & 20,841 & 22,480 & 18,463 & 12,571 \\
\hline \multicolumn{7}{|l|}{ Long-term Debt } \\
\hline Advances from Municipality \& Other .............. & $\begin{array}{r}433,422 \\
0\end{array}$ & $\begin{array}{r}103,315 \\
0\end{array}$ & $\begin{array}{r}4,000 \\
0\end{array}$ & $\begin{array}{r}2,900 \\
0\end{array}$ & $\begin{array}{r}61,185 \\
67\end{array}$ & $\begin{array}{r}2,550 \\
0\end{array}$ \\
\hline Unamort Prem on Long-term Debt ........................ & 0 & 0 & 0 & 0 & 0 & 0 \\
\hline (less) Unamort Discount on Long-term Debt & 0 & 2,856 & 0 & 0 & 0 & 0 \\
\hline 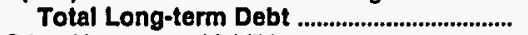 & 433,422 & 100,459 & 4,000 & 2,900 & 61,252 & 2,550 \\
\hline \multicolumn{7}{|l|}{ Other Noncurrent Llabilities } \\
\hline 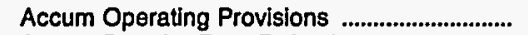 & 0 & 0 & 0 & 276 & 0 & $\mathbf{0}$ \\
\hline Accum Prov for Rate Refunds ............................ & 0 & 0 & 905 & 0 & 4,970 & 0 \\
\hline Total Other Noncurrent Llabllities ............. & 0 & $\mathbf{0}$ & 905 & 276 & 4,970 & $\mathbf{0}$ \\
\hline \multicolumn{7}{|l|}{ Current and Accrued Liabilities } \\
\hline 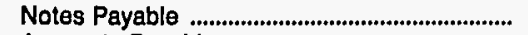 & 6.422 & & 0 & 150 & $\mathbf{0}$ & 0 \\
\hline 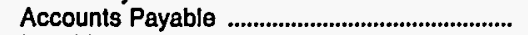 & 1,043 & 1,174 & 1,008 & 844 & 0 & 542 \\
\hline Payables to Assoc Enterprises ............................... & 0 & 0 & 0 & 35 & 0 & 0 \\
\hline 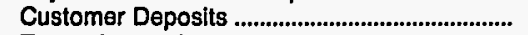 & 0 & 0 & 2 & 43 & 131 & 0 \\
\hline Taxes Accrued ................................................................ & 0 & 277 & $\overline{0}$ & 0 & 0 & 0 \\
\hline 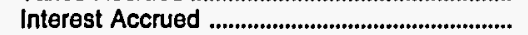 & 17,525 & 973 & 23 & 111 & 38 & 43 \\
\hline Misc Current \& Accrued Liabilities ...................... & 585 & 121 & & 122 & 5,322 & 42 \\
\hline Total Current \& Accrued Llabilities .......... & 25,574 & 2,545 & 1,033 & 1,306 & $\mathbf{5 , 4 9 0}$ & 627 \\
\hline \multicolumn{7}{|l|}{ Deferred Credits } \\
\hline Customer.Advances for Construction .............. & 0 & 0 & 297 & 0 & 0 & 0 \\
\hline 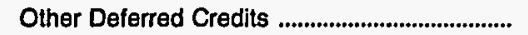 & 33,275 & 0 & 0 & 0 & 0 & 0 \\
\hline 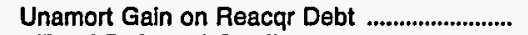 & 0 & 0 & $\mathbf{0}$ & 0 & 0 & 0 \\
\hline 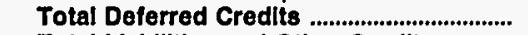 & 33,275 & & 297 & & o & \\
\hline Total Llabllities and Other Credits ........... & 493,220 & 107,059 & 27,076 & 26,962 & 90,176 & 15,748 \\
\hline
\end{tabular}

Note: Totals may not equal sum of components because of independent rounding.

Source: Energy Information Administration, Form EIA-412, "Annual Report of Public Electric Utilities." 
Table 22. Balance Sheet by Major U.S. Publicly Owned Electric Utility Within State at End of Period, 1993 (Continued) (Thousand Dollars)

\begin{tabular}{|c|c|c|c|c|c|c|}
\hline Item & $\begin{array}{l}\text { Minnesota } \\
\text { Alexandria } \\
\text { City of } \\
\text { December } 31\end{array}$ & $\begin{array}{c}\text { Minnesota } \\
\text { Anoka } \\
\text { City of } \\
\text { December } 31\end{array}$ & $\begin{array}{c}\text { Minnesota } \\
\text { Austin } \\
\text { City of } \\
\text { December } 31\end{array}$ & $\begin{array}{l}\text { Minnesota } \\
\text { Brainerd } \\
\text { City of } \\
\text { December } 31\end{array}$ & $\begin{array}{c}\text { Minnesota } \\
\text { Chaska } \\
\text { City of } \\
\text { December } 31\end{array}$ & $\begin{array}{l}\text { Minnesota } \\
\text { Fairmont } \\
\text { Public } \\
\text { Utilities } \\
\text { Comm } \\
\text { December } 31\end{array}$ \\
\hline \multicolumn{7}{|l|}{ Electric Utility Plant } \\
\hline 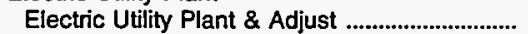 & 14,735 & 13,103 & 33,529 & 6,002 & 8,492 & 17,949 \\
\hline 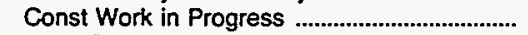 & & & 20 & 7 & 0 & 378 \\
\hline (less) Depr, Amort, and Depletion ......................... & 8,231 & 6,286 & 21,494 & 2,831 & 3,190 & 10,854 \\
\hline Net Electric Utility Plant ....................................... & 6,542 & 6,817 & 12,055 & 3,178 & 5,303 & 7,473 \\
\hline Nuclear Fuel ......................................................... & 0 & 0 & 0 & 0 & 0 & 0 \\
\hline (less) Amort of Nucl Fuel ...................................... & 0 & 0 & 0 & 0 & 0 & 0 \\
\hline 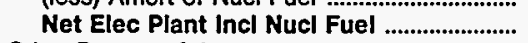 & 6,542 & 6,817 & 12,055 & 3,178 & 5,303 & 7,473 \\
\hline \multicolumn{7}{|l|}{ Other Property \& Investments } \\
\hline 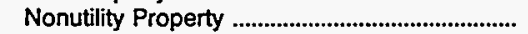 & 5,109 & 0 & 15,851 & 1,191 & 0 & 0 \\
\hline (less) Accum Provisions for Depr \& Amort .... & 1,962 & 0 & 7,090 & 665 & 0 & 0 \\
\hline Invest in Assoc Enterprises ..................................... & 0 & 0 & 0 & 525 & 0 & 0 \\
\hline Invest \& Special Funds & 5,477 & 0 & 4,930 & 4,095 & 0 & 0 \\
\hline \multicolumn{7}{|l|}{ Current and Accrued Assets } \\
\hline Cash, Working Funds \& Investments .................. & -9 & 4,277 & 9,241 & 52 & 4,625 & 591 \\
\hline 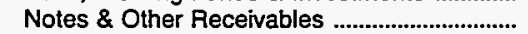 & 62 & 0 & 85 & 22 & 73 & 7,736 \\
\hline Customer Accts Receivable & 309 & 1,672 & 2,935 & 630 & 843 & 2,047 \\
\hline (less) Accum Prov for Uncollected Accts ...... & 12 & 0 & 62 & 0 & 8 & 33 \\
\hline 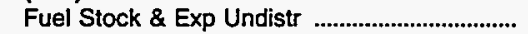 & 5 & 0 & 4 & 0 & 0 & 30 \\
\hline 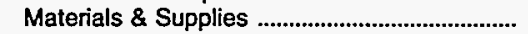 & 442 & 280 & 1,042 & 618 & 688 & 241 \\
\hline 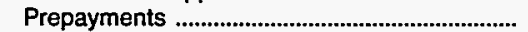 & 51 & 0 & 851 & 33 & 0 & 0 \\
\hline 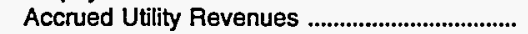 & 0 & 0 & o & 0 & 369 & 0 \\
\hline Miscellaneous Current \& Accrued Assets ..... & 0 & 138 & 125 & 0 & 0 & 0 \\
\hline Total Current \& Accrued Assets .................... & & 1,355 & 6,591 & 10,613 \\
\hline 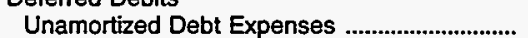 & 0 & 0 & 670 & 0 & 30 & 33 \\
\hline 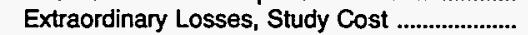 & 0 & 0 & 0 & 0 & 0 & 0 \\
\hline Misc Debt, R \& D Exp, Unamrt Losses .............. & 609 & 0 & 0 & 0 & 0 & 0 \\
\hline Total Deferred Debits ........................................ & 609 & 0 & 670 & o & 30 & 33 \\
\hline \multicolumn{7}{|l|}{ Proprietary Capital } \\
\hline 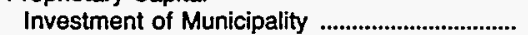 & 0 & 0 & 0 & 892 & 0 & 320 \\
\hline 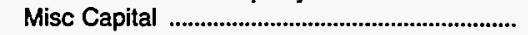 & 2,059 & 0 & 0 & 18 & 1,026 & 0 \\
\hline Retained Earnings ……………………………......... & 12,700 & 11,157 & 33,559 & 7,983 & 8,230 & 14,552 \\
\hline Total Proprietary Capital ..................................... & 14,759 & 11,157 & 33,559 & 8,894 & 9,255 & 14,871 \\
\hline \multicolumn{7}{|l|}{ Long-term Debt } \\
\hline 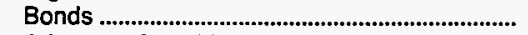 & 0 & 0 & 0 & 0 & 1,775 & 2,350 \\
\hline Advances from Municipality \& Other .................... & 0 & 0 & 0 & 0 & 112 & 6 \\
\hline Unamort Prem on Long-term Debt ....................... & 0 & 0 & 0 & 0 & 0 & 0 \\
\hline (less) Unamort Discount on Long-term Debt & 0 & 0 & 0 & 0 & 0 & 0 \\
\hline Total Long-term Debt & 0 & 0 & 0 & 0 & 1,887 & 2,356 \\
\hline \multicolumn{7}{|l|}{ Other Noncurrent Liabilities } \\
\hline 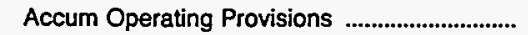 & 0 & 0 & 3,583 & 180 & 0 & 0 \\
\hline 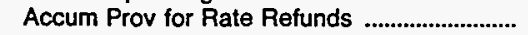 & 0 & 0 & 0 & 0 & 0 & 0 \\
\hline Total Other Noncurrent Liabillties ............. & 0 & $\mathbf{0}$ & 3,583 & 180 & 0 & 0 \\
\hline \multicolumn{7}{|l|}{ Current and Accrued Liabilities } \\
\hline 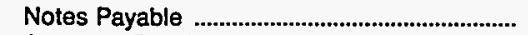 & 0 & 0 & 0 & 32 & 0 & 0 \\
\hline 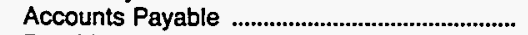 & 564 & 837 & 2,348 & 442 & 703 & 778 \\
\hline Payables to Assoc Enterprises ............................... & 341 & & 0 & 0 & 0 & 26 \\
\hline 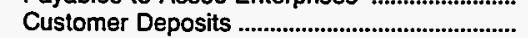 & 63 & 1,007 & 129 & 84 & 78 & 29 \\
\hline 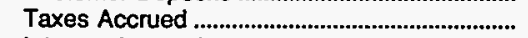 & 0 & 0 & 131 & 31 & 0 & 0 \\
\hline 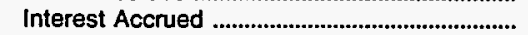 & 0 & 51 & 4 & 15 & 0 & 59 \\
\hline 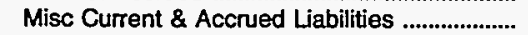 & 286 & 133 & 631 & 0 & 0 & 0 \\
\hline Total Current \& Accrued Llabilltles .......... & 1,254 & 2,028 & 3,242 & 604 & 781 & 892 \\
\hline \multicolumn{7}{|l|}{ Deferred Credits } \\
\hline Customer Advances for Construction .............. & 0 & 0 & 0 & 0 & 0 & 0 \\
\hline 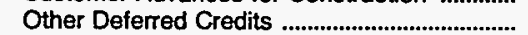 & 609 & 0 & 252 & 0 & 0 & 0 \\
\hline Unamort Gain on Reacqr Debt ................................ & 0 & 0 & 0 & 0 & 0 & 0 \\
\hline $\begin{array}{l}\text { Total Deferred Credits ....................................... } \\
\text { Total Llabilltes and Other Credits }\end{array}$ & $\begin{array}{r}609 \\
16,622\end{array}$ & $\begin{array}{r}0 \\
13,184\end{array}$ & $\begin{array}{r}252 \\
40,636\end{array}$ & $\begin{array}{r}0 \\
9,678\end{array}$ & $\begin{array}{r}0 \\
11,924\end{array}$ & $\begin{array}{r}0 \\
18,119\end{array}$ \\
\hline
\end{tabular}

Note: Totals may not equal sum of components because of independent rounding.

Source: Energy Information Administration, Form ElA-412, "Annual Report of Public Electric Utilities." 
Table 22. Balance Sheet by Major U.S. Publicly Owned Electric Utility Within State at End of Period, 1993 (Continued)

(Thousand Dollars).

\begin{tabular}{|c|c|c|c|c|c|c|}
\hline Item & $\begin{array}{l}\text { Minnesota } \\
\text { Hutchinson } \\
\text { Utilities } \\
\text { Comm } \\
\text { December } 31\end{array}$ & $\begin{array}{c}\text { Minnesota } \\
\text { Marshall } \\
\text { City of } \\
\text { December } 31\end{array}$ & $\begin{array}{l}\text { Minnesota } \\
\text { Moorhead } \\
\text { City of } \\
\text { December } 31\end{array}$ & $\begin{array}{l}\text { Minnesota } \\
\text { New Ulm } \\
\text { Public } \\
\text { Utilities } \\
\text { Comm } \\
\text { December } 31\end{array}$ & $\begin{array}{c}\text { Minnesota } \\
\text { Northern } \\
\text { Municipa! } \\
\text { Power Agny } \\
\text { December } 31\end{array}$ & $\begin{array}{l}\text { Minnesota } \\
\text { Owatonna } \\
\text { City of } \\
\text { December } 31\end{array}$ \\
\hline \multicolumn{7}{|l|}{ Electric Utility Plant } \\
\hline 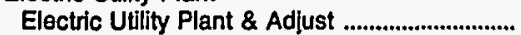 & 25,597 & 16,026 & 30,341 & 24,737 & 320,631 & 26,766 \\
\hline Const Work in Progress & 20,430 & 4,777 & & & & 363 \\
\hline $\begin{array}{l}\text { (less) Depr, Amort, and Depletion } \\
\text { Not Eloctric Utillty Plant }\end{array}$ & $\begin{array}{l}13,841 \\
32,185\end{array}$ & $\begin{array}{r}5,865 \\
14,938\end{array}$ & $\begin{array}{l}14,562 \\
15,791\end{array}$ & $\begin{array}{l}13,101 \\
11,636\end{array}$ & $\begin{array}{r}13,135 \\
307,496\end{array}$ & 12,511 \\
\hline 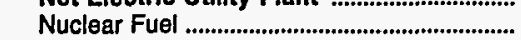 & & & & & 0 & 14,010 \\
\hline 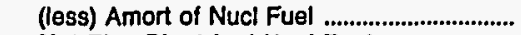 & & & 0 & 0 & 0 & 0 \\
\hline Net Elec Plant Incl Nucl Fuel ............................. & 32,185 & 14,938 & 15,791 & 11,636 & 307,496 & 14,617 \\
\hline \multicolumn{7}{|l|}{ Other Property \& Investments } \\
\hline 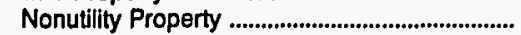 & 0 & 0 & 0 & 0 & 0 & 0 \\
\hline (less) Accum Provisions for Depr \& Amort .... & 0 & 0 & 0 & 0 & 0 & 0 \\
\hline 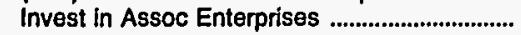 & 0 & 2,174 & 0 & 0 & 0 & 0 \\
\hline 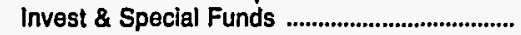 & 1,394 & 2,809 & 5,868 & 366 & 56,280 & 879 \\
\hline \multicolumn{7}{|l|}{ Current and Accrued Assets } \\
\hline Cash, Working Funds \& Investments ................. & 2,554 & 7,145 & 274 & 3,315 & 107 & 6,328 \\
\hline 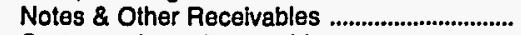 & & & 78 & 185 & 1,172 & 112 \\
\hline 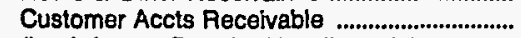 & 1,166 & 1,485 & 832 & -85 & 0 & 1,340 \\
\hline (less) Accum Prov for Uncollected Accts ...... & 25 & 0 & 0 & 0 & 0 & 70 \\
\hline 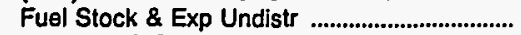 & 0 & 0 & 0 & 175 & 0 & 0 \\
\hline Materials \& Supplies ............................................. & 561 & 469 & 271 & 840 & 0 & 489 \\
\hline 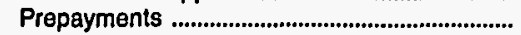 & 0 & 0 & 1 & 6 & 0 & 76 \\
\hline 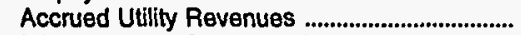 & 0 & 0 & 0 & 806 & 0 & 478 \\
\hline Miscellaneous Current \& Accrued Assets ..... & 42 & 0 & 0 & 796 & 0 & 756 \\
\hline Total Current \& Accrued Assets .................... & 4,297 & 9,099 & 1,456 & 6,039 & 1,279 & 9,510 \\
\hline \multicolumn{7}{|l|}{ Deferred Debits } \\
\hline 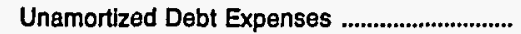 & 201 & 241 & 0 & 0 & 0 & 678 \\
\hline Extraordinary Losses, Study Cost ....................... & 0 & 123 & 0 & 0 & 0 & 0 \\
\hline Misc Debt, R \& D Exp, Unamrt Losses .......... & 0 & -40 & 0 & 0 & 0 & 6 \\
\hline 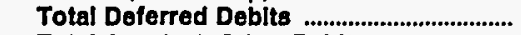 & 201 & 323 & & & 0 & 684 \\
\hline Total Assets \& Other Deblts .......................... & 38,078 & 29,343 & 23,114 & 18,041 & 365,055 & 25,690 \\
\hline \multicolumn{7}{|l|}{ Proprietary Capital } \\
\hline 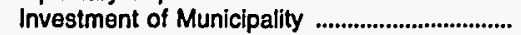 & 20,747 & 0 & 0 & 0 & 0 & 0 \\
\hline Misc Capital ...................................................... & 0 & 0 & 0 & 0 & 0 & 0 \\
\hline 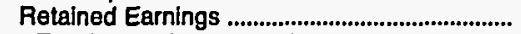 & 947 & 17,705 & 17,816 & 15,296 & 0 & 16,737 \\
\hline & \multicolumn{5}{|c|}{ Long-term Debt } & 16,737 \\
\hline 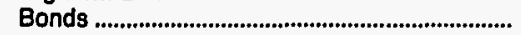 & 14,075 & 9,514 & 3,642 & 1,900 & 353.995 & 7,046 \\
\hline Advances from Municipality \& Other ................ & & 0 & 0 & 0 & 0 & 0 \\
\hline Unamort Prem on Long-term Debt ..................... & 0 & 0 & 0 & 0 & 0 & 0 \\
\hline (less) Unamort Discount on Long-term Debt & & & & 16 & 0 & 149 \\
\hline Total Long-term Debt ........................................ & 14,075 & 9,514 & 3,642 & 1,884 & 353,995 & 6,897 \\
\hline \multicolumn{7}{|l|}{ Other Noncurrent Liabilities } \\
\hline 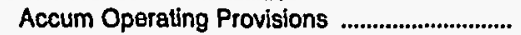 & 0 & 0 & 0 & 0 & 0 & 0 \\
\hline 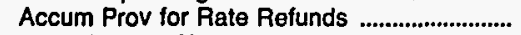 & 0 & 0 & 0 & 0 & 0 & 0 \\
\hline Total Other Noncurrent Llabilltles ................ & 0 & 0 & 0 & 0 & 0 & 0 \\
\hline \multicolumn{7}{|l|}{ Current and Accrued Liabilities } \\
\hline 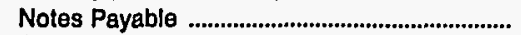 & 350 & 123 & 257 & 125 & 0 & 0 \\
\hline 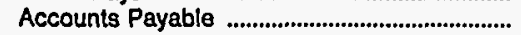 & 1,694 & 1,667 & 872 & 532 & 421 & 1,353 \\
\hline 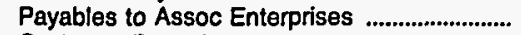 & 10 & 0 & 223 & 0 & 0 & 0 \\
\hline 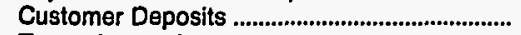 & 92 & 45 & 110 & $\mathbf{0}$ & 0 & 19 \\
\hline 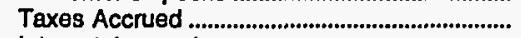 & 0 & 0 & 39 & 0 & 0 & 0 \\
\hline 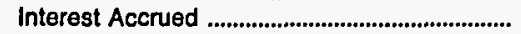 & 58 & 234 & 39 & 62 & 10,638 & 168 \\
\hline Mlsc Current \& Accrued Llabllities ................... & 105 & 56 & 117 & 142 & & 517 \\
\hline Total Current \& Accrued Llablititles ........... & 2,309 & 2,125 & 1,657 & 861 & 11,060 & 2,057 \\
\hline \multicolumn{7}{|l|}{ Deferred Credits } \\
\hline Customer Advances for Construction .............. & 0 & $\mathbf{0}$ & 0 & 0 & 0 & 0 \\
\hline 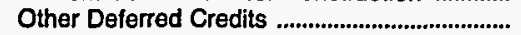 & 0 & 0 & 0 & 0 & 0 & 0 \\
\hline Unamort Gain on Reacqr Debt ................................ & 0 & 0 & 0 & 0 & 0 & 0 \\
\hline 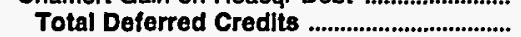 & & & & & & \\
\hline Total Llabilities and Other Credits ............ & 38,078 & 29,343 & 23,114 & 18,041 & 365,055 & 25,690 \\
\hline
\end{tabular}

Note: Totals may not equal sum of components because of independent rounding.

Source: Energy Information Administration, Form EIA-412, "Annual Report of Public Electric Utilities." 
Table 22. Balance Sheet by Major U.S. Publicly Owned Electric Utility Within State at End of Period, 1993 (Continued)

(Thousand Dollars)

\begin{tabular}{|c|c|c|c|c|c|c|}
\hline Item & $\begin{array}{c}\text { Minnesota } \\
\text { Rochester } \\
\text { Public } \\
\text { Utilities } \\
\text { December } 31\end{array}$ & $\begin{array}{c}\text { Minnesota } \\
\text { Shakopee } \\
\text { Public } \\
\text { Utilities } \\
\text { Comm } \\
\text { December } 31\end{array}$ & $\begin{array}{c}\text { Minnesota } \\
\text { Southern } \\
\text { Minnesota } \\
\text { Mun P } \\
\text { Agny } \\
\text { December } 31\end{array}$ & $\begin{array}{c}\text { Minnesota } \\
\text { Western } \\
\text { Minnesota } \\
\text { Mun } \\
\text { Pwr Agny } \\
\text { December } 31\end{array}$ & $\begin{array}{c}\text { Minnesota } \\
\text { Willmar } \\
\text { Municipal } \\
\text { Utils Comm } \\
\text { December } 31\end{array}$ & $\begin{array}{l}\text { Mississippi } \\
\text { Aberdeen } \\
\text { City of } \\
\text { June } 30\end{array}$ \\
\hline \multicolumn{7}{|l|}{ Electric Utility Plant } \\
\hline Electric Utility Plant \& Adjust ................................ & 96,427 & 6,177 & 520,574 & 238,437 & 28,785 & 4,319 \\
\hline Const Work in Progress & 6,156 & 772 & 2,804 & 486 & 154 & 33 \\
\hline (less) Depr, Amort, and Depletion ..................... & 51,390 & 2,240 & 100,341 & 46,518 & 15,099 & 1,941 \\
\hline Net Electric Utility Plant ..................................... & 51,193 & 4,709 & 423,037 & 192,405 & 13,840 & 2,411 \\
\hline 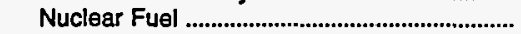 & 0 & 0 & & 0 & 0 & 0 \\
\hline (less) Amort of Nucl Fuel ............................... & 0 & 0 & 0 & 0 & 0 & 0 \\
\hline $\begin{array}{l}\text { Net Élec Plant Incl Nucl Fuel ............................ } \\
\text { Other Property \& Investments }\end{array}$ & 51,193 & 4,709 & 423,037 & 192,405 & 13,840 & 2,411 \\
\hline Nonutility Property .................................................. & 0 & 0 & 44 & 0 & 12,045 & 0 \\
\hline (less) Accum Provisions for Depr \& Amort .... & 0 & 0 & 0 & 0 & 3,095 & 0 \\
\hline 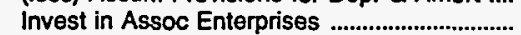 & 0 & 0 & 0 & 0 & 0 & 0 \\
\hline 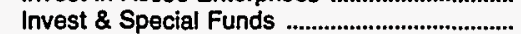 & 179 & 2,180 & 43,697 & 38,321 & 7,790 & 2 \\
\hline \multicolumn{6}{|l|}{ Current and Accrued Assets } & 2 \\
\hline Cash, Working Funds \& Investments .............. & 10,387 & 3,176 & 107,176 & 15,021 & 2,832 & 159 \\
\hline 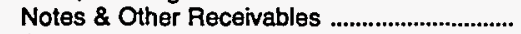 & 491 & 122 & 87 & 0 & 0 & 872 \\
\hline Customer Accts Receivable .............................. & 4,011 & 708 & 10,483 & 4,234 & 1,380 & 0 \\
\hline (less) Accum Prov for Uncollected Accts ...... & 30 & 0 & & 0 & 0 & 0 \\
\hline Fuel Stock \& Exp Undistr ............................. & 629 & 0 & 2,375 & 1,157 & 268 & 0 \\
\hline Materials \& Supplies .................................................... & 1,746 & 227 & 2,717 & 3,231 & 343 & 120 \\
\hline Prepayments .................................................... & 224 & 26 & 4,723 & 28 & 126 & 10 \\
\hline 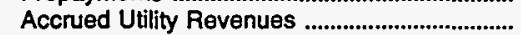 & 3,191 & 0 & 0 & 0 & 0 & 0 \\
\hline Miscellaneous Current \& Accrued Assets ..... & 165 & 56 & 9,545 & 3,873 & 248 & 24 \\
\hline Total Current \& Accrued Assets .................... & 20,813 & 4,315 & 137,106 & 27,544 & 5,199 & 1,185 \\
\hline \multicolumn{7}{|l|}{ Deferred Debits } \\
\hline Unamortized Debt Expenses ................................. & 0 & 88 & 184,066 & 7,348 & 248 & 0 \\
\hline Extraordinary Losses, Study Cost .......................... & 0 & 0 & 839 & 0 & 0 & 0 \\
\hline Misc Debt, R \& D Exp, Unamrt Losses ........... & 4 & 0 & 75,411 & 8,228 & 218 & 464 \\
\hline Total Deferred Debits & & 88 & 260,316 & 15,576 & 466 & 464 \\
\hline Total Assets \& Other Debits ........................... & 72,190 & 11,291 & 864,200 & 273,845 & 36,244 & 4,062 \\
\hline \multicolumn{7}{|l|}{ Proprietary Capital } \\
\hline 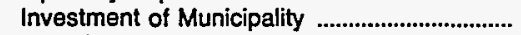 & 0 & 326 & 0 & 0 & 0 & 0 \\
\hline 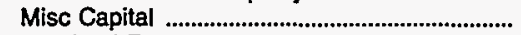 & 0 & 0 & 0 & 0 & 0 & 0 \\
\hline 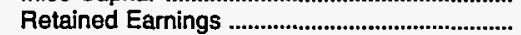 & 59,838 & 6,408 & 21,927 & 0 & 19,942 & 2,737 \\
\hline \multicolumn{7}{|l|}{ Long-term Debt } \\
\hline 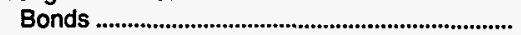 & 0 & 2,550 & 817,730 & 263,575 & 13,058 & 0 \\
\hline Advances from Municipality \& Other ................. & 79 & 835 & 0 & 0 & 0 & 475 \\
\hline Unamort Prem on Long-term Debt .................... & 0 & 0 & 0 & 0 & 0 & 0 \\
\hline (less) Unamort Discount on Long-term Debt & 0 & & 56,217 & 10,710 & 0 & 0 \\
\hline 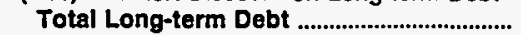 & 79 & 3,385 & 761,513 & 252,865 & 13,058 & 475 \\
\hline \multicolumn{7}{|l|}{ Other Noncurrent Liabilities } \\
\hline Accum Operating Provisions ..................................... & 3,752 & 0 & 0 & 9,233 & 0 & 0 \\
\hline 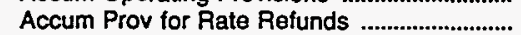 & & 0 & 0 & 0 & 0 & 0 \\
\hline Total Other Noncurrent Llabillties ................ & 3,752 & 0 & 0 & 9,233 & 0 & 0 \\
\hline \multicolumn{7}{|l|}{ Current and Accrued Liabilities } \\
\hline Notes Payable & 0 & 0 & 0 & 0 & 1,392 & 0 \\
\hline Accounts Payable & 4,366 & 707 & 5,136 & 1,688 & 488 & 655 \\
\hline Payables to Assoc Enterprises ........................... & 525 & 309 & 950 & 0 & 128 & 0 \\
\hline 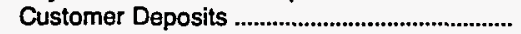 & 545 & 108 & 0 & 0 & 110 & 170 \\
\hline 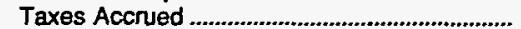 & 429 & 0 & 7,701 & 809 & 41 & 1 \\
\hline 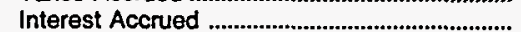 & 0 & 49 & 20,735 & 9,251 & 367 & 0 \\
\hline Misc Current \& Accrued Liabilities ...................... & 1,327 & 0 & 32,721 & 0 & 719 & 25 \\
\hline Total Current \& Accrued Llabillties .......... & 7,191 & 1,172 & 67,241 & 11,748 & 3,245 & 851 \\
\hline \multicolumn{7}{|l|}{ Deferred Credits } \\
\hline Customer Advances for Construction .............. & 0 & 0 & 0 & 0 & 0 & 0 \\
\hline Other Deferred Credits ............................. & 1,330 & 0 & 13,518 & 0 & 0 & 0 \\
\hline Unamort Gain on Reacqr Debt ............................ & 0 & 0 & 0 & 0 & 0 & 0 \\
\hline Total Deferred Credits ...................................... & 1,330 & & 13,518 & 0 & 0 & \\
\hline Total Llabllities and Other Credits ............ & 72,190 & 11,291 & 864,200 & 273,845 & 36,244 & 4,062 \\
\hline
\end{tabular}

Note: Totals may not equal sum of components because of independent rounding.

Source: Energy Information Administration, Form EIA-412, "Annual Report of Public Electric Utilities." 
Table 22. Balance Sheet by Major U.S. Publicly Owned Electric Utility Within State at End of Period, 1993 (Continued)

(Thousand Dollars)

\begin{tabular}{|c|c|c|c|c|c|c|}
\hline Item & $\begin{array}{l}\text { Mississippi } \\
\begin{array}{c}\text { Clarksdale } \\
\text { City of }\end{array} \\
\text { September } 30\end{array}$ & $\begin{array}{l}\text { Mississippi } \\
\text { Columbus } \\
\text { City of } \\
\text { June } 30\end{array}$ & $\begin{array}{l}\text { Mississippi } \\
\text { Greenwood } \\
\text { Utilities } \\
\text { Comm } \\
\text { September } 30\end{array}$ & $\begin{array}{l}\text { Mississippi } \\
\text { Holly } \\
\text { Springs } \\
\text { City of } \\
\text { June } 30\end{array}$ & $\begin{array}{l}\text { Mississippi } \\
\text { Louisville } \\
\text { Electric } \\
\text { System } \\
\text { June } 30\end{array}$ & $\begin{array}{l}\text { Mississippi } \\
\text { Municipal } \\
\text { Energy } \\
\text { Agency } \\
\text { of MS } \\
\text { September } 30\end{array}$ \\
\hline \multicolumn{7}{|l|}{ Electric Utility Plant } \\
\hline 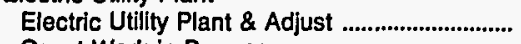 & 26,118 & 15,060 & 26,191 & 13,158 & 6,829 & 324 \\
\hline Const Work in Progress & & & 311 & 460 & 717 & 829 \\
\hline (less) Depr, Amort, and Depletion ..................... & 17,713 & 7,221 & 15,424 & 5,032 & 2,324 & 151 \\
\hline Net Electric Utility Plant & 8,405 & 7,842 & 11,078 & 8,586 & 5,222 & 1,001 \\
\hline 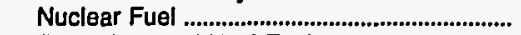 & 0 & 0 & 0 & 0 & 0 & 0 \\
\hline 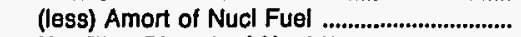 & & 0 & 0 & 0 & 0 & 0 \\
\hline Net Elec Plant Incl Nucl Fuel ........................ & $\mathbf{8 , 4 0 5}$ & 7,842 & 11,078 & 8,586 & 5,222 & 1,001 \\
\hline \multicolumn{7}{|l|}{ Other Property \& Investments } \\
\hline 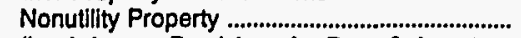 & 0 & 0 & 0 & 0 & 0 & 0 \\
\hline (less) Accum Provisions for Depr \& Amort .... & 0 & 0 & 0 & 0 & 0 & 0 \\
\hline 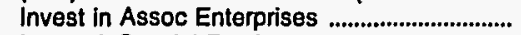 & 0 & 0 & 0 & 0 & 0 & 0 \\
\hline 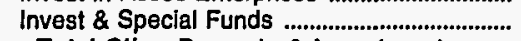 & 4,756 & 0 & 10,534 & 967 & 7 & 0 \\
\hline Total Other Property \& Investments ........ & 4,756 & 0 & 10,534 & 967 & 7 & o \\
\hline \multicolumn{7}{|l|}{ Current and Accrued Assets } \\
\hline Cash, Working Funds \& Investments ................ & 1,762 & 5,534 & 4,676 & 313 & 1,520 & 4,969 \\
\hline 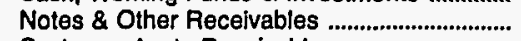 & 411 & 1,814 & 133 & 1,038 & 1,489 & 0 \\
\hline 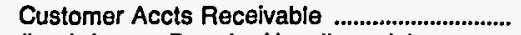 & 2,019 & 0 & 1,454 & 0 & 0 & 3,138 \\
\hline (less) Accum Prov for Uncollected Accts ...... & 0 & 0 & 50 & 0 & 0 & 0 \\
\hline 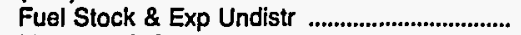 & 266 & 0 & 731 & 0 & 0 & 0 \\
\hline Materials \& Supplies & 134 & 427 & 317 & 252 & 122 & 0 \\
\hline 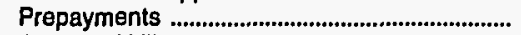 & 175 & 35 & 95 & 16 & 2 & 0 \\
\hline 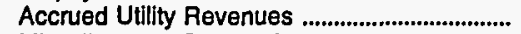 & 0 & 0 & 616 & 0 & 0 & 0 \\
\hline Miscellaneous Current \& Accrued Assets ..... & 2,196 & 64 & 0 & 48 & 11 & 32 \\
\hline Total Current \& Accrued Assets .................... & 6,964 & 7,873 & 7,971 & 1,668 & 3,143 & 8,139 \\
\hline \multicolumn{7}{|l|}{ Deferred Debits } \\
\hline 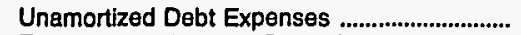 & 0 & 0 & 0 & 0 & 0 & 0 \\
\hline 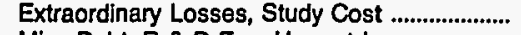 & 0 & $\mathbf{0}$ & 0 & 0 & 0 & 0 \\
\hline Misc Debt, R \& D Exp, Unamrt Losses .......... & 0 & 27 & 0 & 41 & 145 & 0 \\
\hline Total Deferred Deblts ........................................ & & 27 & & 41 & 145 & 0 \\
\hline \multirow{2}{*}{\multicolumn{7}{|c|}{ Proprietary Capital }} \\
\hline & & & & & & \\
\hline 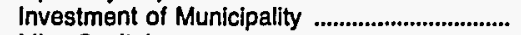 & 2,059 & 0 & 0 & 0 & 0 & 5,782 \\
\hline 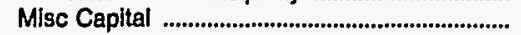 & 167 & 0 & 0 & 0 & 0 & 0 \\
\hline 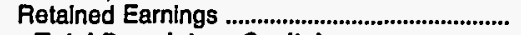 & 13,592 & 12,012 & 27,077 & 9,651 & 7,320 & 0 \\
\hline 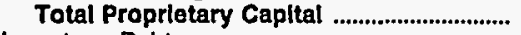 & 15,818 & 12,012 & 27,077 & 9,651 & 7,320 & 5,782 \\
\hline \multicolumn{7}{|l|}{ Long-term Debt } \\
\hline Bonds & 2,167 & 0 & 225 & 0 & 0 & 0 \\
\hline Advances from Municipality \& Other ................. & 0 & 33 & 4 & 38 & 24 & 0 \\
\hline Unamort Prem on Long-term Debt .................... & 0 & 0 & 0 & 0 & 0 & 0 \\
\hline (less) Unamort Discount on Long-term Debt & & 0 & 0 & 0 & 0 & 0 \\
\hline 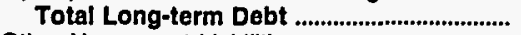 & 2,167 & 33 & 229 & 38 & 24 & 0 \\
\hline \multicolumn{7}{|l|}{ Other Noncurrent Liabilities } \\
\hline 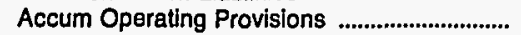 & 0 & 0 & 0 & 0 & 0 & 32 \\
\hline 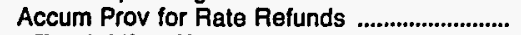 & 0 & 0 & 0 & 0 & 0 & 0 \\
\hline Total Other Noncurrent Llablitties ............. & 0 & 0 & 0 & 0 & 0 & 32 \\
\hline \multicolumn{7}{|l|}{ Current and Accrued Liabilities } \\
\hline 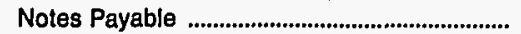 & 330 & 36 & 0 & 0 & 0 & 0 \\
\hline Accounts Payable & 948 & 2,690 & 1,365 & 1,022 & 801 & 3,261 \\
\hline 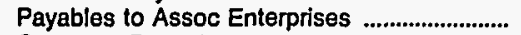 & 0 & 0 & 261 & 0 & 0 & 0 \\
\hline 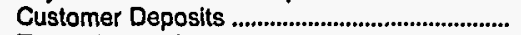 & 518 & 909 & 428 & 475 & 183 & 0 \\
\hline 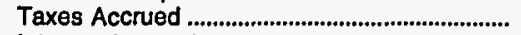 & 39 & 0 & 101 & 46 & 18 & 0 \\
\hline 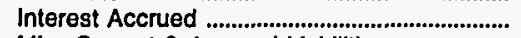 & 4 & 0 & 1 & 0 & 0 & 0 \\
\hline Misc Current \& Accrued Liabilities ...................... & 302 & 62 & 71 & 35 & 128 & 65 \\
\hline Total Current \& Accrued Llabilltles ........... & 2,141 & 3,697 & 2,228 & 1,578 & 1,130 & $\mathbf{3 , 3 2 6}$ \\
\hline \multicolumn{7}{|l|}{ Delerred Credits } \\
\hline Customer Advances for Construction ............... & 0 & 0 & 27 & 0 & 0 & $\mathbf{0}$ \\
\hline 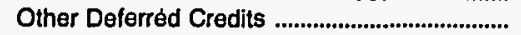 & 0 & 1 & 23 & -5 & 43 & 0 \\
\hline Unamort Gain on Reacqr Debt ........................... & 0 & 0 & 0 & 0 & 0 & 0 \\
\hline 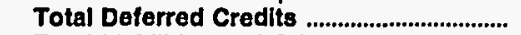 & & & & & 43 & \\
\hline Total Llabillties and Other Credits ............ & 20,126 & 15,742 & 29,583 & 11,262 & 8,517 & 9,140 \\
\hline
\end{tabular}

Note: Totals may not equal sum of components because of independent rounding.

Source: Energy Information Administration, Form ElA-412, "Annual Report of Public Electric Utilities." 
Table 22. Balance Sheet by Major U.S. Publicly Owned Electric Utility Within State at End of Period, 1993 (Continued)

(Thousand Dollars)

\begin{tabular}{|c|c|c|c|c|c|c|}
\hline Item & $\begin{array}{l}\text { Mississippi } \\
\text { New Albany } \\
\text { City of } \\
\text { June } 30\end{array}$ & $\begin{array}{l}\text { Mississippi } \\
\text { Oxford } \\
\text { City of } \\
\text { June } 30\end{array}$ & $\begin{array}{l}\text { Mississippi } \\
\text { Starkville } \\
\text { City of } \\
\text { June } 30\end{array}$ & $\begin{array}{l}\text { Mississippi } \\
\text { Tupelo } \\
\text { City of } \\
\text { June } 30\end{array}$ & $\begin{array}{l}\text { Mississippi } \\
\text { West } \\
\text { Point } \\
\text { City of } \\
\text { June } 30\end{array}$ & $\begin{array}{l}\text { Carthage } \\
\text { City of } \\
\text { June } 30\end{array}$ \\
\hline \multicolumn{7}{|l|}{ Electric Utility Plant } \\
\hline 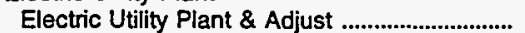 & 10,538 & 5,598 & 10,713 & 21,242 & 6,518 & 18,644 \\
\hline Const Work in Progress & 1,215 & 920 & & 1,384 & 198 & 64 \\
\hline (less) Depr, Amort, and Depletion ....................... & 3,769 & 2,089 & 3,553 & 7.086 & 2,245 & 13,113 \\
\hline Net Electric Utility Plant & 7,984 & 4,429 & 7,247 & 15,540 & 4,471 & 5,595 \\
\hline 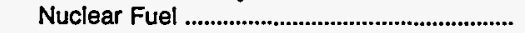 & 0 & 0 & 0 & 0 & 0 & 0 \\
\hline 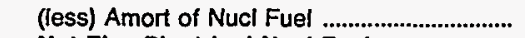 & 0 & 0 & 0 & 0 & 0 & 0 \\
\hline Net Elec Plant Incl Nucl Fuel ........................... & 7,984 & 4,429 & 7,247 & 15,540 & 4,471 & 5,595 \\
\hline \multicolumn{7}{|l|}{ Other Property \& Investments } \\
\hline 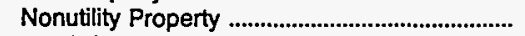 & 0 & 0 & 0 & 0 & 0 & $\mathbf{0}$ \\
\hline (less) Accum Provisions for Depr \& Amort .... & 0 & 0 & 0 & 0 & 0 & 0 \\
\hline Invest in Assoc Enterprises ................................ & 0 & 0 & 0 & 0 & 0 & 0 \\
\hline 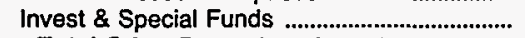 & 134 & 11 & 542 & 0 & 71 & 116 \\
\hline Total Other Property \& Investments ....... & 134 & 11 & 542 & 0 & 71 & 116 \\
\hline \multicolumn{7}{|l|}{ Current and Accrued Assets } \\
\hline Cash, Working Funds \& Investments .............. & 2,454 & 2,775 & 1,263 & 4,838 & 173 & 2,210 \\
\hline Notes \& Other Receivables .............................. & 1,617 & 1,030 & 1,416 & 3,362 & 1,165 & 15 \\
\hline Customer Accts Receivable ............................... & 0 & 0 & 0 & 0 & 0 & 580 \\
\hline (less) Accum Prov for Uncollected Accts ...... & 0 & 0 & 0 & 0 & 0 & 18 \\
\hline 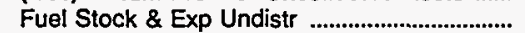 & 0 & 0 & 0 & 0 & 0 & 0 \\
\hline 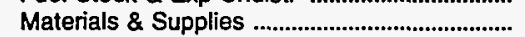 & 226 & 132 & 158 & 269 & 180 & 303 \\
\hline 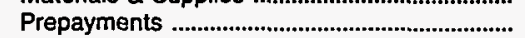 & 18 & 15 & 14 & 24 & 18 & 50 \\
\hline 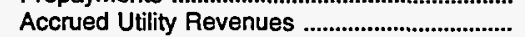 & 0 & 0 & 0 & 0 & 0 & 0 \\
\hline Miscellaneous Current \& Accrued Assets ..... & 51 & 11 & 22 & 28 & 23 & 49 \\
\hline Total Current \& Accrued Assets ............... & 4,366 & 3,964 & 2,873 & 8,521 & 1,560 & 3,190 \\
\hline \multicolumn{7}{|l|}{ Deferred Debits } \\
\hline 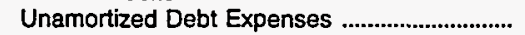 & 1 & 0 & 0 & 0 & 5 & $\mathbf{0}$ \\
\hline 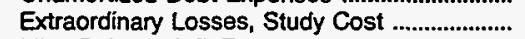 & 0 & 11 & 0 & 0 & 0 & 0 \\
\hline Misc Debt, R \& D Exp, Unamrt Losses ......... & 136 & 91 & 42 & 144 & 43 & 0 \\
\hline 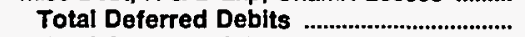 & 137 & 102 & 42 & 144 & 48 & $\mathbf{0}$ \\
\hline Total Assets \& Other Deblts ......................... & 12,621 & 8,505 & 10,704 & 24,205 & 6,149 & 8,901 \\
\hline \multicolumn{7}{|l|}{ Proprietary Capital } \\
\hline Investment of Municipality & 0 & 0 & 0 & 0 & 0 & 236 \\
\hline 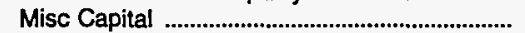 & 0 & 0 & 0 & 0 & 0 & 0 \\
\hline 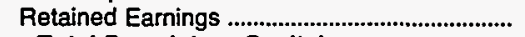 & 10,499 & 6,060 & 7,921 & 20,265 & 4,467 & 7,175 \\
\hline Total Proprietary Capital .................................. & 10,499 & 6,060 & 7,921 & 20,265 & 4,467 & 7,411 \\
\hline \multicolumn{7}{|l|}{ Long-term Debt } \\
\hline 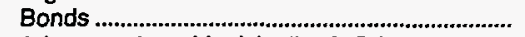 & 184 & 0 & 0 & 0 & 335 & 0 \\
\hline Advances from Municipality \& Other ................ & 100 & 86 & 38 & 158 & 46 & 331 \\
\hline Unamort Prem on Long-term Debt ................... & 0 & 0 & 0 & 0 & 0 & 0 \\
\hline (less) Unamort Discount on Long-term Debt & 0 & 0 & 0 & 0 & 0 & 0 \\
\hline 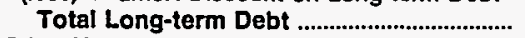 & 284 & 86 & 38 & 158 & 381 & 331 \\
\hline \multicolumn{7}{|l|}{ Other Noncurrent Liabilities } \\
\hline Accum Operating Provisions ............................... & 0 & 0 & 0 & 0 & 0 & 0 \\
\hline 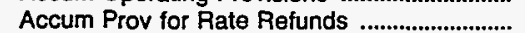 & 0 & 0 & 0 & 0 & 0 & 0 \\
\hline 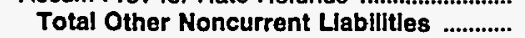 & 0 & 0 & 0 & $\mathbf{0}$ & 0 & 0 \\
\hline \multicolumn{7}{|l|}{ Current and Accrued Liabilities } \\
\hline 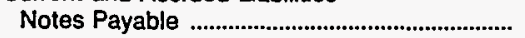 & 0 & 0 & 0 & 0 & 0 & 0 \\
\hline Accounts Payable & 1,196 & 1,593 & 1,642 & 2,885 & 873 & 725 \\
\hline 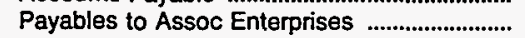 & 0 & 0 & 0 & 0 & 0 & 0 \\
\hline 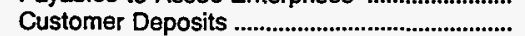 & 540 & 630 & 952 & 820 & 260 & 111 \\
\hline 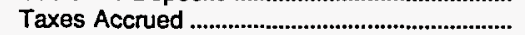 & 0 & 35 & 2 & 0 & 45 & 0 \\
\hline Interest Accrued & 14 & 0 & 0 & 0 & 9 & 0 \\
\hline Misc Current \& Accrued Liabilities ................... & 84 & 96 & 125 & 73 & 114 & 321 \\
\hline $\begin{array}{l}\text { Total Current \& Accrued Llabilltles } \\
\text { Defe....... }\end{array}$ & 1,834 & 2,354 & 2,720 & 3,778 & 1,301 & 1,157 \\
\hline Customer Advances for Construction ............. & 0 & 2 & 0 & 0 & 0 & 3 \\
\hline 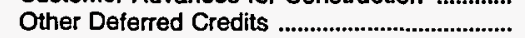 & 3 & 4 & 25 & 3 & 0 & 0 \\
\hline 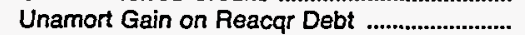 & 0 & 0 & 0 & $\mathbf{0}$ & 0 & 0 \\
\hline 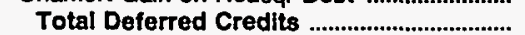 & 3 & 6 & 25 & 3 & & \\
\hline Total Llabllitles and Other Credits ............ & 12,621 & 8,505 & 10,704 & 24,205 & 6,149 & 8,901 \\
\hline
\end{tabular}

Note: Totals may not equal sum of components because of independent rounding

Source: Energy Information Administration, Form EIA-412, "Annual Report of Public Electric Utilities." 
Table 22. Balance Sheet by Major U.S. Publicly Owned Electric Utility Within State at End of Period, 1993 (Continued)

(Thousand Dollars)

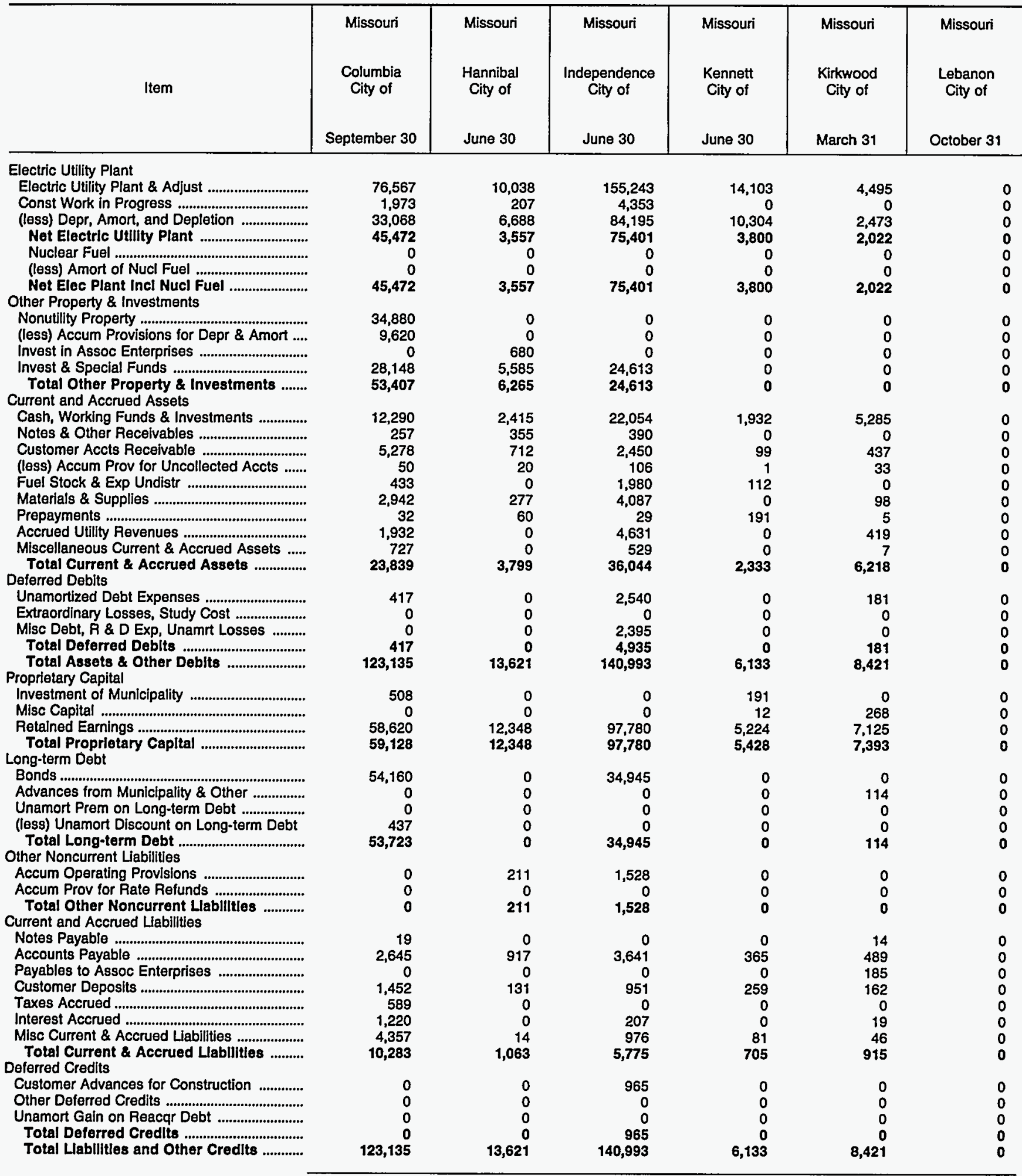

Note: Totals may not equal sum of components because of independent rounding.

Source: Energy Information Administration, Form EIA-412, "Annual Report of Public Electric Utilities." 
Table 22. Balance Sheet by Major U.S. Publicly Owned Electric Utility Within State at End of Period, 1993 (Continued)

(Thousand Dollars)

\begin{tabular}{|c|c|c|c|c|c|c|}
\hline Item & $\begin{array}{l}\text { Missouri } \\
\text { Marshall } \\
\text { City of } \\
\text { September } 30\end{array}$ & $\begin{array}{l}\text { Missouri } \\
\text { Monett } \\
\text { City of } \\
\text { March } 31\end{array}$ & $\begin{array}{c}\text { Missouri } \\
\text { Poplar } \\
\text { Bluff } \\
\text { City of } \\
\text { December } 31\end{array}$ & $\begin{array}{c}\text { Missouri } \\
\text { Rolla } \\
\text { City of } \\
\text { September } 30\end{array}$ & $\begin{array}{l}\text { Missouri } \\
\text { Sikeston } \\
\text { City of } \\
\text { May } 31\end{array}$ & $\begin{array}{c}\text { Missouri } \\
\begin{array}{c}\text { Springfield } \\
\text { City of }\end{array} \\
\text { September } 30\end{array}$ \\
\hline \multicolumn{7}{|l|}{ Electric Utility Plant } \\
\hline 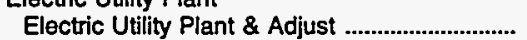 & 31,073 & 3,908 & 20,072 & 8,557 & 219,844 & 375,838 \\
\hline 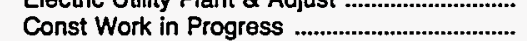 & 4,898 & & & 0 & 1,005 & 8,457 \\
\hline 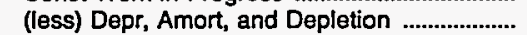 & 16,456 & 2,743 & 8,069 & 5,856 & 63,552 & 120,826 \\
\hline 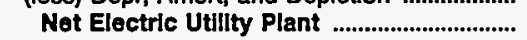 & 19,514 & 1,164 & 12,003 & 2,701 & 157,297 & 263,469 \\
\hline Nuclear Fuel ............................................... & 0 & 0 & 0 & 0 & 0 & 0 \\
\hline (less) Amort of Nucl Fuel ................................. & 0 & 0 & 0 & 0 & 0 & 0 \\
\hline Not Elec Plant Incl Nucl Fuel ............................... & 19,514 & 1,164 & 12,003 & 2,701 & 157,297 & 263,469 \\
\hline \multicolumn{7}{|l|}{ Other Property \& Investments } \\
\hline 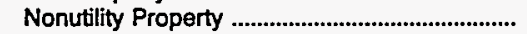 & 0 & 0 & 0 & 5,515 & 0 & 0 \\
\hline (less) Accum Provisions for Depr \& Amort .... & 0 & 0 & 0 & 2,671 & 0 & 0 \\
\hline 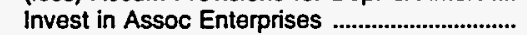 & 0 & 0 & 0 & 0 & 0 & 0 \\
\hline 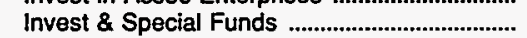 & 0 & 0 & 10,923 & 4,242 & 31,916 & 145,324 \\
\hline Total Other Property \& Investments ........ & o & 0 & 10,923 & 7,086 & 31,916 & 145,324 \\
\hline \multicolumn{7}{|l|}{ Current and Accrued Assets } \\
\hline Cash, Working Funds \& Investments ............... & 7,650 & 12,612 & 1,087 & 1,202 & 10,201 & 9,816 \\
\hline 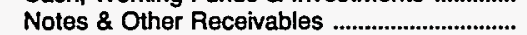 & 148 & 482 & 30 & 0 & 169 & 1,566 \\
\hline Customer Accts Receivable ................................. & 835 & 0 & 541 & 700 & 5,353 & 10,909 \\
\hline (less) Accum Prov for Uncollected Accts ....... & 0 & 0 & 117 & 5 & 128 & 81 \\
\hline 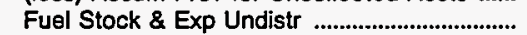 & 89 & 0 & 100 & 0 & 8,206 & 4,400 \\
\hline 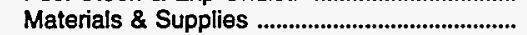 & 577 & 0 & 234 & 342 & 1,838 & 7,136 \\
\hline 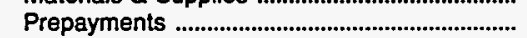 & 128 & 0 & 71 & 25 & 496 & 310 \\
\hline 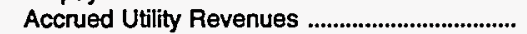 & 184 & 0 & 219 & 0 & 0 & 0 \\
\hline Miscellaneous Current \& Accrued Assets ..... & & 0 & 3,228 & 54 & 671 & 0 \\
\hline Total Current \& Accrued Assets .................... & 9,610 & 13,094 & 5,393 & 2,318 & 26,805 & 34,056 \\
\hline \multirow{2}{*}{\multicolumn{7}{|c|}{ Deferred Debits }} \\
\hline & & & & & & 522 \\
\hline 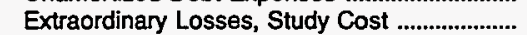 & 0 & 0 & 0 & 0 & 0 & 0 \\
\hline Misc Debt, R \& D Exp, Unamrt Losses ........... & 0 & 0 & 0 & 0 & 0 & 7,471 \\
\hline Total Deferred Deblts & & 0 & 0 & 0 & 16,436 & 7,993 \\
\hline 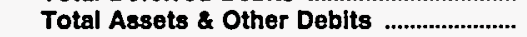 & 29,124 & 14,258 & 28,320 & 12,105 & 232,455 & 450,842 \\
\hline \multicolumn{7}{|l|}{ Proprietary Capital } \\
\hline 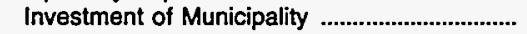 & 180 & 0 & 0 & 39 & 0 & 0 \\
\hline 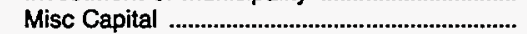 & 0 & 0 & 0 & 0 & 0 & 0 \\
\hline 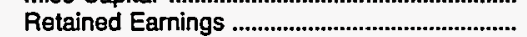 & 25,163 & 13,793 & 27,486 & 10,753 & $-5,808$ & 307,475 \\
\hline Total Proprletary Capital ................................. & 25,343 & 13,793 & 27,486 & 10,792 & $-5,808$ & 307,475 \\
\hline \multicolumn{7}{|l|}{ Long-term Debt } \\
\hline Bonds & 1,740 & 0 & 0 & 0 & 227,660 & 96,563 \\
\hline Advances from Municipality \& Other .................... & 0 & 0 & 0 & 0 & 0 & 17,450 \\
\hline Unamort Prem on Long-term Debt ..................... & 0 & 0 & 0 & 0 & 0 & 0 \\
\hline (less) Unamort Discount on Long-term Debt & 0 & 0 & 0 & 0 & 4,458 & 4,705 \\
\hline 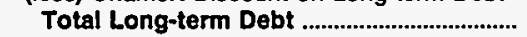 & 1,740 & 0 & 0 & 0 & 223,202 & 109,308 \\
\hline \multicolumn{7}{|l|}{ Other Noncurrent Liabilities } \\
\hline Accum Operating Provisions .................................... & 0 & 0 & 0 & 0 & 0 & 7,320 \\
\hline 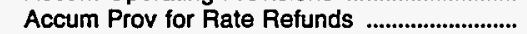 & 0 & 0 & 0 & 0 & 0 & \\
\hline Total Other Noncurrent Liabilities ............ & $\mathbf{0}$ & $\mathbf{0}$ & 0 & $\mathbf{0}$ & 0 & 7,320 \\
\hline \multicolumn{7}{|l|}{ Current and Accrued Liabilities } \\
\hline 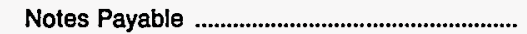 & 0 & 0 & 0 & $\mathbf{0}$ & 0 & 0 \\
\hline 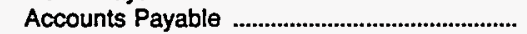 & 1,406 & 351 & 563 & 806 & 850 & 7,632 \\
\hline Payables to Assoc Enterprises ............................. & 0 & 2 & 0 & 148 & 0 & 1,056 \\
\hline 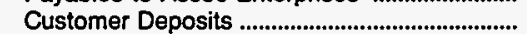 & 184 & 112 & 162 & 274 & 275 & 815 \\
\hline 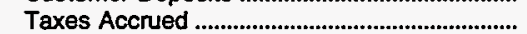 & 227 & 0 & 29 & 0 & 0 & 0 \\
\hline 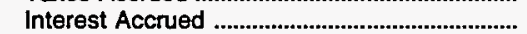 & 31 & 0 & 0 & 0 & 6,877 & 1,841 \\
\hline Misc Current \& Accrued Liabilities ......................... & 194 & 0 & 0 & 85 & 1,126 & 8,830 \\
\hline Total Current \& Accrued Liabilitles .............. & 2,042 & 465 & 754 & 1,313 & 9,129 & 20,174 \\
\hline \multicolumn{7}{|l|}{ Deferred Credits } \\
\hline Customer Advances for Construction .................. & 0 & 0 & 79 & 0 & 0 & \\
\hline Other Deferred Credits .......................................... & 0 & 0 & 0 & 0 & 5,932 & 6,564 \\
\hline 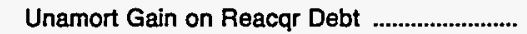 & 0 & 0 & 0 & 0 & 0 & 0 \\
\hline 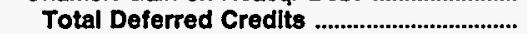 & & & & & 5,932 & 6,565 \\
\hline Total Llabillties and Other Credits ................. & 29,124 & 14,258 & 28,320 & 12,105 & 232,455 & 450,842 \\
\hline
\end{tabular}

Note: Totals may not equal sum of components because of independent rounding.

Source: Energy Information Administration, Form EIA-412, "Annual Report of Public Electric Utilities." 
Table 22. Balance Sheet by Major U.S. Publicly Owned Electric Utility Within State at End of Period, 1993 (Continued) (Thousand Dollars)

\begin{tabular}{|c|c|c|c|c|c|c|}
\hline Item & $\begin{array}{c}\text { Nebraska } \\
\text { Central } \\
\text { Nebraska } \\
\text { Pub } \\
\text { P\&I Dist } \\
\text { December } 31\end{array}$ & $\begin{array}{c}\text { Nebraska } \\
\text { Cornhusker } \\
\text { Public } \\
\text { Power Dist } \\
\text { December } 31\end{array}$ & $\begin{array}{c}\text { Nébraska } \\
\text { Dawson } \\
\text { County } \\
\text { Public } \\
\text { Pwr Dist } \\
\text { December } 31\end{array}$ & $\begin{array}{c}\text { Nebraska } \\
\text { Fremont } \\
\text { City of } \\
\text { July } 31\end{array}$ & $\begin{array}{l}\text { Nebraska } \\
\begin{array}{l}\text { Grand Island } \\
\text { City of }\end{array} \\
\text { July } 31\end{array}$ & $\begin{array}{l}\text { Nebraska } \\
\text { Hastings } \\
\text { City of } \\
\text { December } 31\end{array}$ \\
\hline \multicolumn{7}{|l|}{ Electric Utility Plant } \\
\hline 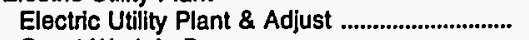 & 137,212 & 30,410 & 44,298 & 63,377 & 161,330 & 101,035 \\
\hline 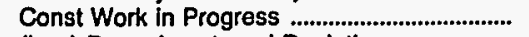 & & 377 & 473 & 1,619 & & 1,791 \\
\hline (less) Depr, Amort, and Depletion ....................... & $\begin{array}{l}54,317 \\
83,003\end{array}$ & $\begin{array}{r}9,877 \\
20,909\end{array}$ & $\begin{array}{l}20,089 \\
24.682\end{array}$ & $\begin{array}{l}45,311 \\
19,684\end{array}$ & $\begin{array}{l}62,577 \\
98,816\end{array}$ & $\begin{array}{l}35,035 \\
67,791\end{array}$ \\
\hline $\begin{array}{l}\text { Net Electrlc Utillty Plant } \\
\text { Nuclear Fuel }\end{array}$ & $\begin{array}{r}83,003 \\
0\end{array}$ & $\begin{array}{r}20,909 \\
0\end{array}$ & $\begin{array}{r}24,002 \\
0\end{array}$ & $\begin{array}{r}19,004 \\
0\end{array}$ & $\begin{array}{rl}50,0 & 10 \\
0\end{array}$ & 0 \\
\hline 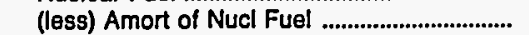 & 0 & 0 & 0 & 0 & 0 & 0 \\
\hline 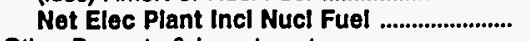 & 83,003 & 20,909 & 24,682 & 19,684 & 98,816 & 67,791 \\
\hline \multicolumn{7}{|l|}{ Other Property \& Investments } \\
\hline 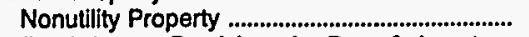 & 68 & 0 & 0 & 0 & 470 & 0 \\
\hline (less) Accum Provisions for Depr \& Amort .... & $\mathbf{0}$ & 0 & 0 & 0 & 0 & 0 \\
\hline 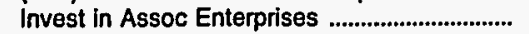 & 0 & 776 & 40 & 0 & 0 & 0 \\
\hline 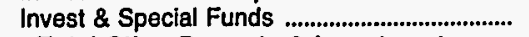 & 9,048 & 1,884 & 724 & 24,390 & 9,722 & 9,203 \\
\hline Total Other Property \& Investments ....... & 9,116 & 2,659 & 765 & 24,390 & 10,192 & 9,203 \\
\hline \multicolumn{2}{|l|}{ Current and Accrued Assets } & 3,058 & 8,243 & 24 & 7,275 & 7,188 \\
\hline 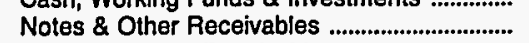 & 1,306 & 56 & 68 & 357 & 1,383 & 0 \\
\hline 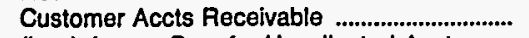 & 0 & 1,760 & 1,935 & 313 & 1,721 & 1,636 \\
\hline (less) Accum Prov for Uncollected Accts ...... & & & 84 & 32 & 114 & 0 \\
\hline 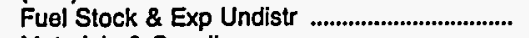 & 1,130 & 0 & 0 & 623 & 1,761 & 708 \\
\hline Materials \& Supplies .................................................. & 1,162 & 534 & 930 & 1,743 & 1,762 & 649 \\
\hline 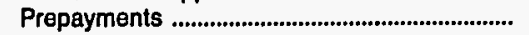 & 0 & 71 & 64 & 152 & 135 & 136 \\
\hline Accrued Utility Revenues ............................................. & 0 & 0 & 0 & 1,411 & 0 & 0 \\
\hline Miscellaneous Current \& Accrued Assets ..... & 2,030 & 26 & 71 & 620 & 0 & 196 \\
\hline Total Current \& Accrued Assets ................ & 6,520 & 5,506 & 11,227 & 5,210 & 13,923 & 10,513 \\
\hline \multicolumn{7}{|l|}{ Deferred Debits } \\
\hline Unamortized Debt Expenses ................................... & 2 & 1,133 & 0 & 206 & 564 & 0 \\
\hline Extraordinary Losses, Study Cost .......................... & $\boldsymbol{9}$ & & 0 & 0 & 0 & 0 \\
\hline Misc Debt, A \& D Exp, Unamrt Losses ........... & 138 & 0 & 0 & 52 & 2,169 & 322 \\
\hline 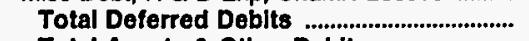 & 149 & 1,133 & & 259 & 2,732 & 322 \\
\hline \multicolumn{5}{|l|}{ Proprietary Capital } & 125,664 & 87,829 \\
\hline Investment of Municipality ...................................... & 0 & 0 & 0 & 0 & 0 & 0 \\
\hline 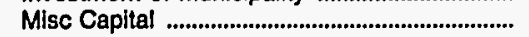 & & 0 & 0 & 0 & 0 & o \\
\hline 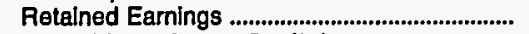 & 30,965 & 14,417 & 30,628 & 34,287 & 79,736 & 23,085 \\
\hline Total Proprletary Capltal ................................ & 30,965 & 14,417 & 30,628 & 34,287 & 79,736 & 23,085 \\
\hline \multicolumn{7}{|l|}{ Long-term Debt } \\
\hline 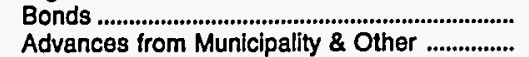 & $\begin{array}{r}1,020 \\
9 ?\end{array}$ & $\begin{array}{r}11,010 \\
0\end{array}$ & $\begin{array}{r}0 \\
3,589\end{array}$ & $\begin{array}{r}10,785 \\
0\end{array}$ & $\begin{array}{r}42,635 \\
941\end{array}$ & $\begin{array}{r}64,525 \\
0\end{array}$ \\
\hline & $\begin{array}{r}92 \\
0\end{array}$ & $\begin{array}{l}0 \\
0\end{array}$ & $\begin{array}{r}0,000 \\
0\end{array}$ & 0 & 0 & 0 \\
\hline (less) Unamort Discount on Long-term Debt & & & & & 0 & 1,679 \\
\hline 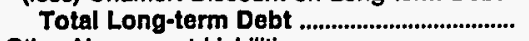 & 1,112 & 11,010 & 3,589 & 10,785 & 43,576 & 62,846 \\
\hline \multicolumn{7}{|l|}{ Other Noncurrent Liabilities } \\
\hline Accum Operating Provisions .................................. & 1,122 & 0 & 0 & 150 & 0 & $\mathbf{0}$ \\
\hline Accum Prov for Rate Refunds ............................... & & 0 & 0 & 0 & 0 & 0 \\
\hline Total Other Noncurrent Llabilltles ............. & 1,122 & 0 & $\mathbf{0}$ & 150 & o & $\mathbf{0}$ \\
\hline \multicolumn{7}{|l|}{ Current and Accrued Llabilities } \\
\hline Notes Payable & 0 & 0 & 0 & 0 & 0 & 0 \\
\hline 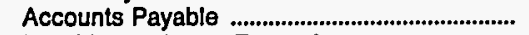 & 1,342 & 652 & 1,242 & 406 & 276 & 298 \\
\hline 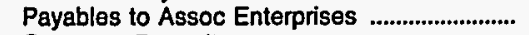 & 0 & 0 & 0 & 0 & 0 & 78 \\
\hline 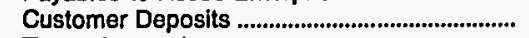 & 1 & 62 & 148 & 60 & 93 & 50 \\
\hline 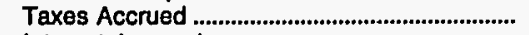 & 8 & 0 & 85 & 91 & 671 & 0 \\
\hline 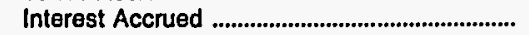 & 0 & $\mathbf{0}$ & 0 & 81 & 1,026 & 1,299 \\
\hline Misc Current \& Accrued Liabilities ......................... & 504 & 547 & 675 & 327 & 287 & 0 \\
\hline Total Current \& Accrued Llabilities ........... & 1,855 & 1,261 & 2,150 & 966 & 2,353 & 1,725 \\
\hline \multicolumn{7}{|l|}{ Deferred Credits } \\
\hline Customer Advances for Construction .............. & 0 & & & 0 & 0 & \\
\hline 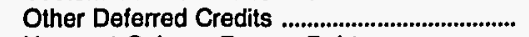 & 63,734 & 3,520 & 307 & 10 & 0 & 173 \\
\hline 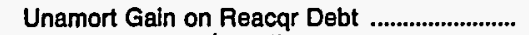 & & & 0 & 3,344 & 0 & 0 \\
\hline 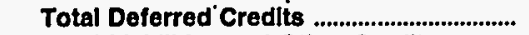 & 63,734 & 3,520 & 307 & 3,354 & 0 & 173 \\
\hline Total Llabllitles and Other Credits ............ & $\mathbf{9 8 , 7 8 8}$ & 30,208 & 36,674 & 49,542 & 125,664 & 87,829 \\
\hline
\end{tabular}

Note: Totals may not equal sum of components because of independent rounding.

Source: Energy Information Administration, Form EIA-412, "Annual Report of Public Electric Utilities." 
Table 22. Balance Sheet by Major U.S. Publicly Owned Electric Utility Within State at End of Period, 1993 (Continued)

(Thousand Dollars)

\begin{tabular}{|c|c|c|c|c|c|c|}
\hline Item & $\begin{array}{c}\text { Nebraska } \\
\text { Lincoln } \\
\text { Electric } \\
\text { System } \\
\text { December } 31\end{array}$ & $\begin{array}{c}\text { Nebraska } \\
\text { Loup } \\
\text { River } \\
\text { Public } \\
\text { Power Dist } \\
\text { December } 31\end{array}$ & $\begin{array}{c}\text { Nebraska } \\
\text { Municipal } \\
\text { Energy } \\
\text { Agency } \\
\text { of NE } \\
\text { March } 31\end{array}$ & $\begin{array}{c}\text { Nebraska } \\
\text { Nebraska } \\
\text { Public } \\
\text { Power } \\
\text { District } \\
\text { December } 31\end{array}$ & $\begin{array}{c}\text { Nebraska } \\
\text { Norris } \\
\text { Public } \\
\text { Power } \\
\text { District } \\
\text { December } 31\end{array}$ & $\begin{array}{l}\text { Nebraska } \\
\text { North } \\
\text { Platte } \\
\text { City of } \\
\\
\text { July } 31\end{array}$ \\
\hline \multicolumn{7}{|l|}{ Electric Utility Plant } \\
\hline 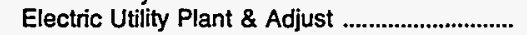 & 428,046 & 49,690 & 28,653 & $1,796,430$ & 58,523 & 12,680 \\
\hline 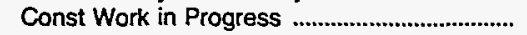 & 20,740 & 4,505 & 7,492 & 164,407 & 563 & 205 \\
\hline (iess) Depr, Amort, and Depletion ..................... & 129,052 & 24,566 & 2,256 & 702,822 & 18,124 & 7,851 \\
\hline 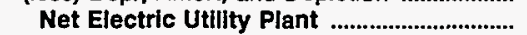 & 319,734 & 29,629 & 33,889 & $1,258,014$ & 40,962 & 5,033 \\
\hline 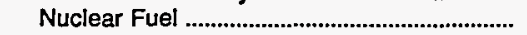 & & 0 & 0 & 399,867 & 0 & 0 \\
\hline (less) Amort of Nucl Fuel ........................................ & 0 & 0 & 0 & 322,841 & 0 & 0 \\
\hline Net Elec Plant Incl Nucl Fuel ............................. & 319,734 & 29,629 & 33,889 & $1,335,040$ & 40,962 & 5,033 \\
\hline \multicolumn{7}{|l|}{ Other Property \& Investments } \\
\hline 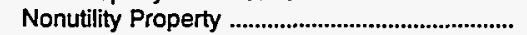 & 0 & 628 & 2,802 & 0 & 0 & 0 \\
\hline (less) Accum Provisions for Depr \& Amort .... & 0 & 0 & 546 & 0 & 0 & 0 \\
\hline 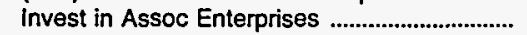 & 0 & 0 & 0 & 0 & 0 & 0 \\
\hline 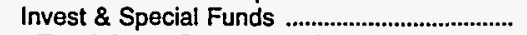 & 15,454 & 12,128 & 7,381 & 126,502 & 3,231 & 0 \\
\hline Total Other Property \& Investments ........ & 15,454 & 12,756 & 9,636 & 126,502 & 3,231 & 0 \\
\hline \multicolumn{7}{|l|}{ Current and Accrued Assets } \\
\hline Cash, Working Funds \& Investments ................ & 30,319 & 6,169 & 1,711 & 294,640 & 6,215 & 3,568 \\
\hline Notes \& Other Receivables .................................... & 3,683 & 178 & & 58,975 & 14 & 0 \\
\hline 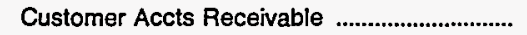 & 3,867 & 2,489 & 5,102 & 51,040 & 1,937 & 533 \\
\hline (less) Accum Prov for Uncollected Accts ....... & 225 & 3 & 0 & 296 & 43 & 61 \\
\hline Fuel Stock \& Exp Undistr & 1,013 & 0 & 0 & 2,831 & 0 & 0 \\
\hline 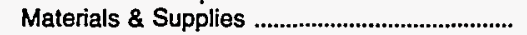 & 5,461 & 832 & 0 & 8,892 & 1,243 & 445 \\
\hline 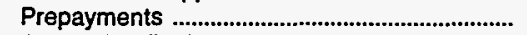 & 351 & 173 & 77 & 75,722 & 106 & 9 \\
\hline Accrued Utility Revenues ........................................ & 5,777 & 0 & 0 & 0 & 745 & 0 \\
\hline Miscellaneous Current \& Accrued Assets ..... & 1,269 & 75 & 0 & 3,472 & 0 & 35 \\
\hline Total Current \& Accrued Assets ................. & 51,516 & 9,911 & 6,889 & 495,277 & 10,217 & 4,530 \\
\hline \multicolumn{7}{|l|}{ Deferred Debits } \\
\hline 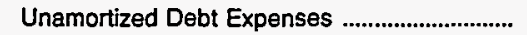 & 40,838 & 0 & 3,793 & 2,336 & 966 & 0 \\
\hline 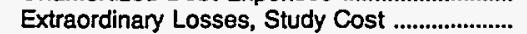 & & 0 & & 300 & 0 & 0 \\
\hline Misc Debt, R \& D Exp, Unamrt Losses ........... & 11,108 & 771 & 10,514 & 97,720 & 295 & 0 \\
\hline Total Deferred Debits ........................................ & 51,946 & 771 & 14,307 & 100,356 & 1,261 & \\
\hline 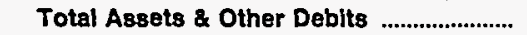 & 438,650 & 53,068 & 64,722 & $2,057,175$ & 55,671 & 9,564 \\
\hline \multicolumn{7}{|l|}{ Proprietary Capital } \\
\hline 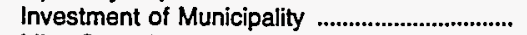 & 0 & 0 & 0 & 0 & 0 & 0 \\
\hline 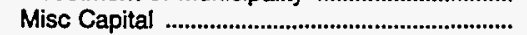 & 0 & 0 & 0 & 0 & 0 & 0 \\
\hline 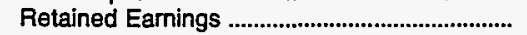 & 115,367 & 48,018 & 3,997 & 225,152 & 29,167 & 8,305 \\
\hline Total Proprietary Capltal ................................. & 115,367 & 48,018 & 3,997 & 225,152 & 29,167 & 8,305 \\
\hline \multicolumn{7}{|l|}{ Long-term Debt } \\
\hline Advances from Municipality \& Other ........... & $28 \%, 360$ & $\begin{array}{l}0 \\
0\end{array}$ & $\begin{array}{r}50,295 \\
0\end{array}$ & $\begin{array}{r}1,392,504 \\
2,345\end{array}$ & 22,010 & 0 \\
\hline Unamort Prem on Long-term Debt ......................... & 0 & 0 & 0 & $\begin{array}{r}2,140 \\
0\end{array}$ & 0 & $\begin{array}{l}0 \\
0\end{array}$ \\
\hline (less) Unamort Discount on Long-term Debt & 0 & 0 & 0 & 2,417 & 0 & 0 \\
\hline 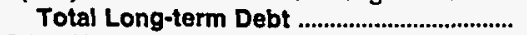 & 287,360 & 0 & 50,295 & $1,392,432$ & 22,010 & 0 \\
\hline \multicolumn{7}{|l|}{ Other Noncurrent Liabilities } \\
\hline 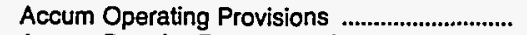 & 0 & 0 & 1,826 & 0 & 0 & 0 \\
\hline 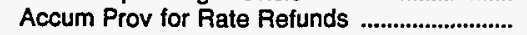 & 0 & 0 & 0 & 0 & 0 & 0 \\
\hline Total Other Noncurrent Llablilties ............. & 0 & 0 & 1,826 & 0 & 0 & $\mathbf{0}$ \\
\hline \multicolumn{7}{|l|}{ Current and Accrued Liabilities } \\
\hline 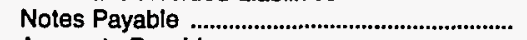 & 6,775 & 0 & 5,246 & 109,366 & 0 & 0 \\
\hline Accounts Payable & 8,795 & 2,508 & 2,070 & 32,707 & 3,538 & 1,123 \\
\hline 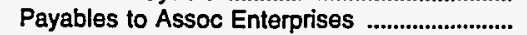 & 0 & 0 & 0 & 7,666 & 0 & 0 \\
\hline 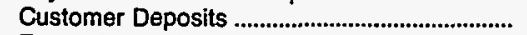 & 14 & 145 & 0 & 1,156 & 60 & 136 \\
\hline 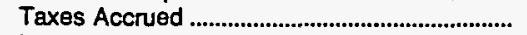 & 5,235 & 1,589 & 96 & 5,975 & 150 & 0 \\
\hline 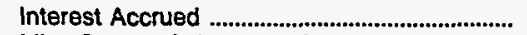 & 6,824 & 0 & 691 & 135 & 294 & 0 \\
\hline Misc Current \& Accrued Liabilities ......................... & 3,401 & 233 & 502 & 243,273 & 451 & \\
\hline $\begin{array}{l}\text { Total Current \& Accrued Llablittles .......... } \\
\text { Deferred Credits }\end{array}$ & 31,044 & 4,476 & 8,605 & 400,278 & 4,494 & 1,259 \\
\hline \multicolumn{7}{|l|}{ Deferred Credits } \\
\hline Customer Advances for Construction ............. & & 0 & 0 & 0 & 0 & 0 \\
\hline 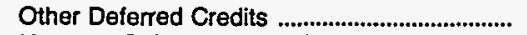 & 4,878 & 574 & 0 & 39,313 & 0 & 0 \\
\hline Unamort Gain on Reacqr Debt ........................... & & 0 & 0 & & 0 & 0 \\
\hline 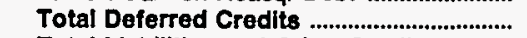 & 4,878 & 574 & & 39,313 & & \\
\hline Total Llabilitles and Other Credits ............ & 438,650 & 53,068 & 64,722 & $2,057,175$ & 55,671 & 9,564 \\
\hline
\end{tabular}

Note: Totals may not equal sum of components because of independent rounding.

Source: Energy Intormation Administration, Form ElA-412, "Annual Report of Public Electric Utilities." 
Table 22. Balance Sheet by Major U.S. Publicly Owned Electric Utility Within State at End of Period, 1993 (Continued) (Thousand Dollars)

\begin{tabular}{|c|c|c|c|c|c|c|}
\hline Item & $\begin{array}{c}\text { Nebraska } \\
\text { Omaha Public } \\
\text { Power } \\
\text { District } \\
\text { December } 31\end{array}$ & $\begin{array}{c}\text { Nebraska } \\
\text { Southern } \\
\text { Nebraska Rural } \\
\text { P P D } \\
\text { December } 31\end{array}$ & $\begin{array}{c}\text { Nevada } \\
\text { Colorado } \\
\text { River } \\
\text { Comm } \\
\text { of Nevada } \\
\text { June } 30\end{array}$ & $\begin{array}{l}\text { New Jersey } \\
\text { Vineland } \\
\text { City of } \\
\text { June } 30\end{array}$ & $\begin{array}{l}\text { New Mexico } \\
\text { Farmington } \\
\text { City of } \\
\text { June } 30\end{array}$ & $\begin{array}{c}\text { New Mexico } \\
\text { Gallup } \\
\text { City of } \\
\text { June } 30\end{array}$ \\
\hline \multicolumn{7}{|l|}{ Electric Utility Plant } \\
\hline Electric Utility Plant \& Adjust ................................ & $1,907,813$ & 70,427 & 0 & 67,602 & 170,316 & 11,156 \\
\hline 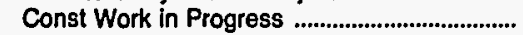 & 95,498 & 694 & 0 & 3,439 & 13,807 & \\
\hline (less) Depr, Amort, and Depletion ...................... & 695,752 & 31,526 & 0 & 33,252 & 53,843 & 6,042 \\
\hline Net Eloctric Utllity Plant .................................... & $1,307,558$ & 39,595 & $\mathbf{0}$ & 37,790 & 130,281 & 5,114 \\
\hline 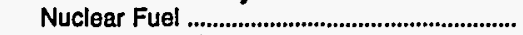 & 157,957 & 0 & 0 & 0 & 0 & 0 \\
\hline 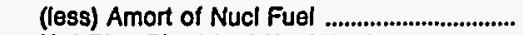 & 47,705 & 0 & 0 & 0 & 0 & o \\
\hline \multirow{2}{*}{\multicolumn{7}{|c|}{ Oiher Property \& Investments }} \\
\hline & & & & & & \\
\hline 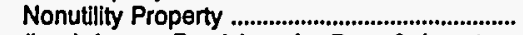 & 0 & 0 & 263,169 & 0 & 0 & 23,247 \\
\hline (less) Accum Provisions for Depr \& Amort .... & 0 & 0 & 71,492 & 0 & 0 & 10,373 \\
\hline Invest in Assoc Enterprises .................................. & 0 & 0 & & 0 & 0 & 0 \\
\hline 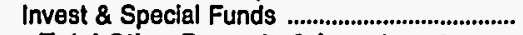 & 309,887 & 1.577 & 56,978 & 3,774 & 0 & 0 \\
\hline \multicolumn{6}{|l|}{ Current and Accrued Assets } & 12,874 \\
\hline Cash, Working Funds \& Investments .............. & 29,024 & 10,359 & 3,877 & 20,593 & 14,545 & 2,847 \\
\hline Notes \& Other Receivables ............................. & 46,353 & & 820 & & 0 & 0 \\
\hline 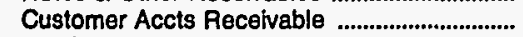 & 29,699 & 1,726 & 7,118 & 3,182 & 2,330 & 1,525 \\
\hline (less) Accum Prov for Uncollected Accts ....... & 847 & 0 & 0 & 0 & 13 & 173 \\
\hline Fuel Stock \& Exp Undistr ................................. & 6,858 & & 0 & 0 & 753 & 0 \\
\hline 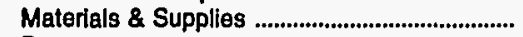 & 36,438 & 1,542 & 86 & 1.504 & 2,325 & 963 \\
\hline 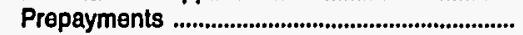 & 2,310 & 70 & 7,129 & 0 & 0 & 0 \\
\hline 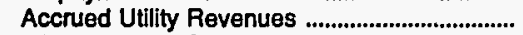 & 15,793 & 0 & 0 & 0 & 2,029 & 0 \\
\hline Miscellaneous Current \& Accrued Assets ..... & 2,892 & 52 & 0 & 0 & 18,354 & 1,820 \\
\hline \multirow{2}{*}{\multicolumn{7}{|c|}{ Deferred Debits }} \\
\hline & & & & & & \\
\hline Unamortized Debt Expenses ............................... & 2,094 & 0 & 633 & 0 & 5,179 & 78 \\
\hline 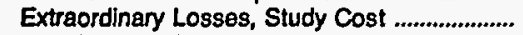 & & 0 & 0 & 0 & 0 & 0 \\
\hline Misc Debt, R \& D Exp, Unamrt Losses .......... & 107,650 & 857 & 50,947 & 0 & 0 & 0 \\
\hline 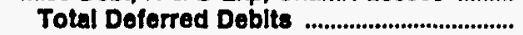 & 109,743 & 857 & 51,580 & 0 & 5,179 & \\
\hline 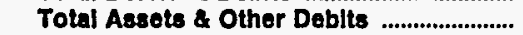 & $2,005,960$ & 55,778 & 319,267 & 66,842 & 175,783 & 25,048 \\
\hline \multicolumn{7}{|l|}{ Proprietary Capital } \\
\hline 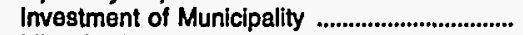 & 0 & 0 & 1,526 & 0 & 0 & 16,260 \\
\hline 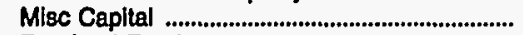 & 0 & 0 & & 0 & 13,362 & 4,311 \\
\hline 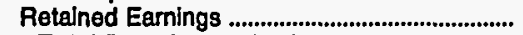 & 711,153 & 51,916 & $-52,217$ & 52,971 & -208 & 0 \\
\hline $\begin{array}{l}\text { Total Proprletary Capltal .................................. } \\
\text { Long-term Debt }\end{array}$ & \multicolumn{5}{|c|}{ Long-term Debt } & 20,571 \\
\hline 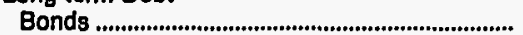 & 974,510 & 0 & 160,230 & 4,320 & 156,199 & 2,555 \\
\hline Advances from Municipality \& Other ............... & 74,388 & 0 & 185,218 & 0 & 0 & 72 \\
\hline Unamort Prem on Long.term Debt ....................... & & 0 & & 0 & 0 & 0 \\
\hline (less) Unamort Discount on Long-term Debt & 12,244 & 0 & 0 & & 2,754 & \\
\hline 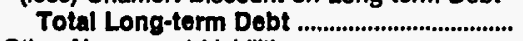 & $1,036,655$ & 0 & 345,452 & 4,320 & 153,445 & 2,627 \\
\hline \multicolumn{7}{|l|}{ Other Noncurrent Llabilities } \\
\hline 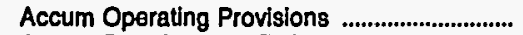 & 5,074 & 0 & 0 & 3,774 & 0 & 0 \\
\hline 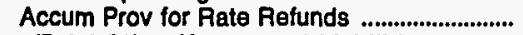 & & 0 & 0 & 0 & 0 & 0 \\
\hline Total Other Noncurrent Luabilities .............. & 5,074 & 0 & 0 & 3,774 & 0 & 0 \\
\hline \multicolumn{7}{|l|}{ Current and Accrued Liabilitios } \\
\hline Notes Payable ....................................................................... & 23,629 & 0 & 0 & 0 & 0 & 0 \\
\hline 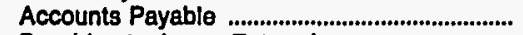 & 26,933 & 2,580 & 6,169 & 3,117 & 1,274 & 949 \\
\hline 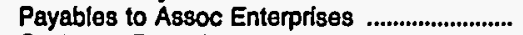 & & 0 & 0 & 0 & 0 & 0 \\
\hline 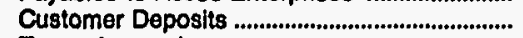 & 5,182 & 55 & 0 & 547 & 469 & 700 \\
\hline 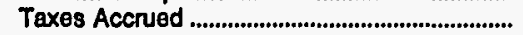 & 14,169 & 0 & & 0 & 563 & 67 \\
\hline 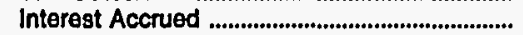 & 21,553 & 0 & 6,154 & 335 & 1,407 & 0 \\
\hline Misc Current \& Accrued Llablititles ...................... & 21,471 & 1,226 & 8,441 & 1,731 & 701 & 91 \\
\hline 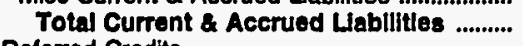 & 112,936 & 3,862 & 20,764 & 5,730 & 4,414 & 1,807 \\
\hline \multicolumn{7}{|l|}{ Deterred Credits } \\
\hline Customer Advances for Construction ............... & 444 & 0 & 0 & 47 & 2,343 & 0 \\
\hline 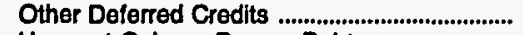 & 139,698 & 0 & 3,742 & 0 & 2,426 & 42 \\
\hline Unamort Gain on Reacqr Debt ............................ & 0 & 0 & 0 & 0 & 0 & 0 \\
\hline Total Deferred Credits ............................... & $\begin{array}{r}140,142 \\
2\end{array}$ & $\begin{array}{r}0 \\
5578\end{array}$ & $\begin{array}{r}3,742 \\
340067\end{array}$ & 47 & $\begin{array}{r}4,769 \\
75789\end{array}$ & \\
\hline & 005,960 & 55,778 & 319,267 & 66,842 & & 25,048 \\
\hline
\end{tabular}

Note: Totals may not equal sum of components because of independent rounding.

Source: Energy Information Administration, Form ElA-412, "Annual Report of Public Electric Utilities." 
Table 22. Balance Sheet by Major U.S. Publicly Owned Electric Utility Within State at End of Period, 1993 (Continued) (Thousand Dollars)

\begin{tabular}{|c|c|c|c|c|c|c|}
\hline Item & $\begin{array}{l}\text { New Mexico } \\
\text { Los Alamos } \\
\text { County } \\
\text { June } 30\end{array}$ & $\begin{array}{c}\text { New York } \\
\text { Fairport } \\
\text { Village of } \\
\text { May } 31\end{array}$ & $\begin{array}{c}\text { New York } \\
\text { Freeport } \\
\text { Village of } \\
\text { Inc } \\
\text { February } 28\end{array}$ & $\begin{array}{l}\text { New York } \\
\text { Jamestown } \\
\text { City of } \\
\text { December } 31\end{array}$ & $\begin{array}{l}\text { New York } \\
\text { Massena } \\
\text { Town of } \\
\text { December } 31\end{array}$ & $\begin{array}{c}\text { New York } \\
\text { Plattsburgh } \\
\text { City of } \\
\text { December } 31\end{array}$ \\
\hline \multicolumn{7}{|l|}{ Electric Utility Plant } \\
\hline Electric Utility Plant \& Adjust ............................... & 110,006 & 16,539 & 29,504 & 80,102 & 21,791 & 26,418 \\
\hline Const Work in Progress & 337 & & 2,373 & 1,647 & & 2,691 \\
\hline (less) Depr, Amort, and Depletion ...................... & 19,512 & 7,635 & 18,414 & 25,732 & 6,928 & 10,453 \\
\hline Net Eloctric Utility Plant .................................... & 90,831 & 8,907 & 13,463 & 56,016 & 14,943 & 18,656 \\
\hline 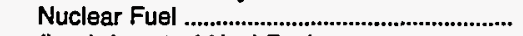 & & 0 & 0 & 0 & 0 & 0 \\
\hline 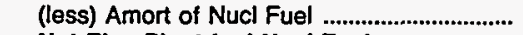 & 0 & 0 & 0 & 0 & 0 & 0 \\
\hline $\begin{array}{l}\text { Net Elec Plant Incl Nucl Fuel ............................ } \\
\text { Other Property \& Investments }\end{array}$ & 90,831 & 8,907 & 13,463 & 56,016 & 14,943 & 18,656 \\
\hline 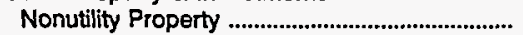 & 0 & 0 & 0 & 10 & 0 & 0 \\
\hline (less) Accum Provisions for Depr \& Amort .... & 0 & 0 & 0 & 0 & 0 & 0 \\
\hline 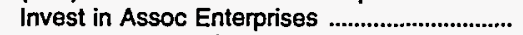 & 0 & 0 & 0 & 0 & 0 & 0 \\
\hline 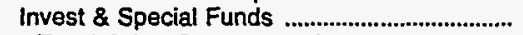 & 16,057 & 1,510 & 0 & 0 & 2,215 & 2,877 \\
\hline $\begin{array}{l}\text { Total Other Property \& Investments ....... } \\
\text { Current and Accrued Assets }\end{array}$ & 16,057 & 1,510 & $\mathbf{0}$ & 10 & 2,215 & 2,877 \\
\hline Cash, Working Funds \& Investments ............... & 1,484 & 1,149 & 5,245 & 78 & 949 & 273 \\
\hline 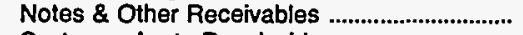 & & 29 & 36 & 0 & 0 & 1,558 \\
\hline 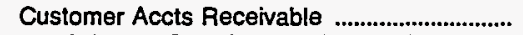 & 3,089 & 645 & 1,744 & 1,905 & 459 & 0 \\
\hline (less) Accum Prov for Uncollected Accts ....... & 174 & 8 & 117 & 68 & 27 & 67 \\
\hline 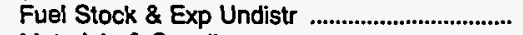 & 640 & 0 & 0 & 0 & 0 & 0 \\
\hline Materials \& Supplies ……………………………….......... & 442 & 493 & 1,572 & 769 & 702 & 825 \\
\hline 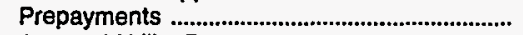 & 14 & 156 & 3 & 61 & 110 & 26 \\
\hline 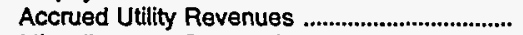 & 426 & 0 & 0 & 0 & 0 & 0 \\
\hline Miscellaneous Current \& Accrued Assets ..... & 1 & 0 & 0 & 0 & 0 & 0 \\
\hline Total Current \& Accrued Assets ................ & 5,922 & 2,463 & $\mathbf{8 , 4 8 2}$ & 2,745 & 2,193 & 2,616 \\
\hline \multicolumn{7}{|l|}{ Deferred Debits } \\
\hline Unamortized Debt Expenses ............................... & 5,308 & 0 & 0 & 0 & 0 & 28 \\
\hline Extraordinary Losses, Study Cost ...................... & & 0 & 0 & 0 & 0 & 0 \\
\hline Misc Debt, R \& D Exp, Unamrt Losses .......... & 0 & 0 & 0 & 167 & 233 & 0 \\
\hline 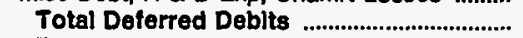 & 5,313 & & & 167 & 233 & 28 \\
\hline Total Assets \& Other Deblts ............................ & 118,124 & 12,880 & 21,945 & 58,938 & 19,583 & 24,178 \\
\hline \multicolumn{7}{|l|}{ Proprietary Capital } \\
\hline 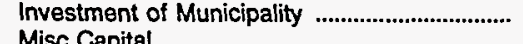 & 2,172 & $-4,430$ & 0 & 64,453 & 0 & $-9,345$ \\
\hline Misc Capital & & 399 & 0 & $-23,190$ & 0 & 0 \\
\hline 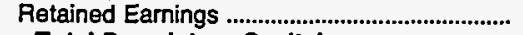 & 8,117 & 14,991 & 15,732 & 0 & 11,291 & 26,305 \\
\hline 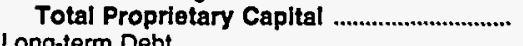 & 10,290 & 10,960 & 15,732 & 41,262 & 11,291 & 16,960 \\
\hline \multicolumn{7}{|l|}{ Long-term Debt } \\
\hline Advances from Municipality \& Other ............ & $\begin{array}{r}100,985 \\
0\end{array}$ & $\begin{array}{r}1,285 \\
0\end{array}$ & $\begin{array}{r}1,152 \\
0\end{array}$ & $\begin{array}{r}15,529 \\
0\end{array}$ & $\begin{array}{r}7,435 \\
0\end{array}$ & $\begin{array}{r}5,574 \\
0\end{array}$ \\
\hline 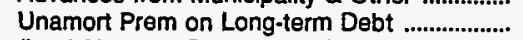 & 0 & 0 & 0 & 0 & 0 & 5 \\
\hline (less) Unamort Discount on Long-term Debt & & & & 0 & 0 & 0 \\
\hline 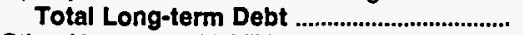 & 100,985 & 1,285 & 1,152 & 15,529 & $\mathbf{7 , 4 3 5}$ & 5,579 \\
\hline \multicolumn{7}{|l|}{ Other Noncurrent Liabilities } \\
\hline Accum Operating Provisions .................................. & 0 & 0 & 2,086 & 0 & 0 & 0 \\
\hline 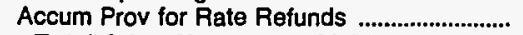 & 0 & 0 & 0 & 0 & 0 & 0 \\
\hline \multicolumn{3}{|l|}{ Current and Accrued Liabilities } & & o & 0 & 0 \\
\hline 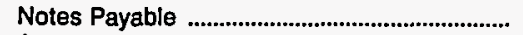 & 0 & 13 & 0 & 0 & 0 & 0 \\
\hline Accounts Payable & 1,060 & 375 & 541 & 1,027 & 353 & 845 \\
\hline 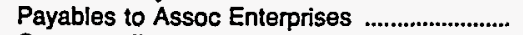 & 1,415 & 0 & 870 & 70 & 0 & 0 \\
\hline 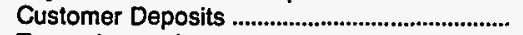 & 29 & 201 & 1,181 & 81 & 100 & 69 \\
\hline 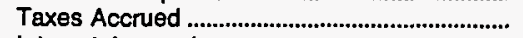 & 32 & 23 & 26 & 0 & 0 & 31 \\
\hline 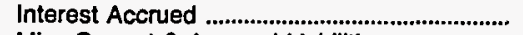 & 3,823 & 23 & 200 & 315 & 158 & 133 \\
\hline Misc Current \& Accrued Liabilities .......................... & & 0 & 0 & 453 & 0 & 561 \\
\hline $\begin{array}{l}\text { Total Current \& Accrued Llabllities ........... } \\
\text { Deferted Credits }\end{array}$ & 6,358 & 635 & 2,818 & 1,947 & 610 & 1,639 \\
\hline Customer Advances for Construction .............. & 0 & 0 & 156 & 200 & 247 & 0 \\
\hline 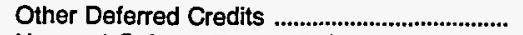 & 491 & 0 & 0 & 0 & 0 & 0 \\
\hline Unamort Gain on Reacqr Debt ............................... & 0 & 0 & 0 & 0 & 0 & 0 \\
\hline Total Deferred Credits & 491 & 0 & 156 & 200 & 247 & \\
\hline Total Llabilities and Other Credits ............. & 118,124 & 12,880 & 21,945 & 58,938 & 19,583 & 24,178 \\
\hline
\end{tabular}

Note: Totals may not equal sum of components because of independent rounding.

Source: Energy Information Administration, Form EIA-412, "Annual Report of Public Electric Utilities." 
Table 22. Balance Sheet by Major U.S. Publicly Owned Electric Utility Within State at End of Period, 1993 (Continued) (Thousand Dollars)

\begin{tabular}{|c|c|c|c|c|c|c|}
\hline Item & $\begin{array}{c}\text { New York } \\
\text { Power } \\
\text { Authority } \\
\text { of State of NY } \\
\text { December } 31\end{array}$ & $\begin{array}{c}\text { New York } \\
\text { Rockville } \\
\text { Centre } \\
\text { Village of } \\
\text { May } 31\end{array}$ & $\begin{array}{l}\text { North Carolina } \\
\text { Albemarle } \\
\text { City of } \\
\text { June } 30\end{array}$ & $\begin{array}{l}\text { North Carolina } \\
\text { Concord } \\
\text { City of } \\
\text { June } 30\end{array}$ & $\begin{array}{l}\text { North Carolina } \\
\text { Elizabeth } \\
\text { City City of } \\
\text { June } 30\end{array}$ & $\begin{array}{l}\text { North Carolina } \\
\text { Fayetteville } \\
\text { Public } \\
\text { Works Comm } \\
\text { June } 30\end{array}$ \\
\hline \multicolumn{7}{|l|}{ Electric Utility Plant } \\
\hline Electric Utility Plant \& Adjust ................................. & $4,913,044$ & 24,338 & 18,087 & 26,233 & 23,620 & 171,989 \\
\hline 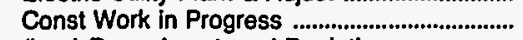 & 290,993 & 2,478 & & & 142 & 41,996 \\
\hline (less) Depr, Amort, and Depletion ..................... & $1,611,517$ & 13,855 & 9,668 & 18,215 & 7,181 & 58,568 \\
\hline Net Electric Utillty Plant .................................... & $3,592,520$ & 12,960 & 8,418 & 8,018 & 16,580 & 155,416 \\
\hline Nuclear Fuel ............................................................. & 310,625 & & 0 & 0 & 0 & 0 \\
\hline 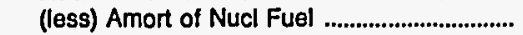 & 155,301 & 0 & 0 & 0 & 0 & 0 \\
\hline 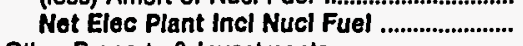 & $3,747,844$ & 12,960 & 8,418 & 8,018 & 16,580 & 155,416 \\
\hline \multicolumn{7}{|l|}{ Other Property \& Investments } \\
\hline 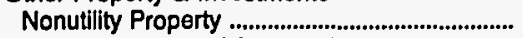 & 0 & 0 & 0 & 0 & 0 & 0 \\
\hline (less) Accum Provisions for Depr \& Amort .... & 0 & 0 & 0 & 0 & 0 & 0 \\
\hline 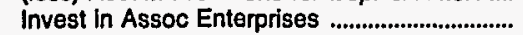 & 0 & 0 & 0 & 0 & 94 & 0 \\
\hline Invest \& Special Funds ............................................. & 240,927 & -641 & 0 & 0 & 0 & 0 \\
\hline Total Other Property \& Investments ....... & 240,927 & -641 & o & 0 & 94 & 0 \\
\hline \multicolumn{7}{|l|}{ Current and Accrued Assets } \\
\hline Cash, Working Funds \& Investments ................ & $1,317,713$ & 3,247 & 3,180 & 17,896 & 5,591 & 47,119 \\
\hline Notes \& Other Receivables .................................... & 18,207 & 71 & & 112 & & 3,152 \\
\hline 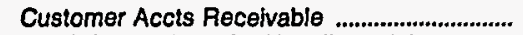 & 106,970 & 1,054 & 1,967 & 2,883 & 2,436 & 12,481 \\
\hline (less) Accum Prov for Uncollected Accts ....... & & 139 & 0 & 0 & 119 & 151 \\
\hline 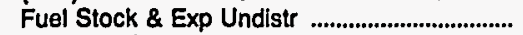 & 3,191 & 0 & 0 & 0 & 0 & 1,398 \\
\hline 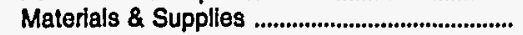 & 74,600 & 1,421 & 1,247 & 1,993 & 1,202 & 5,893 \\
\hline 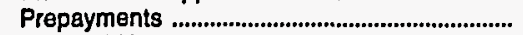 & 8,907 & 99 & 3 & 0 & 0 & 39 \\
\hline 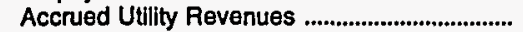 & & 638 & 0 & 0 & 0 & 0 \\
\hline Miscellaneous Current \& Accrued Assets ..... & 24,498 & 8,005 & & & & 709 \\
\hline Total Current \& Accrued Assets .................. & $1,554,086$ & 14,397 & 6,397 & 22,884 & 9,110 & 70,639 \\
\hline \multicolumn{7}{|l|}{ Deferred Debits } \\
\hline 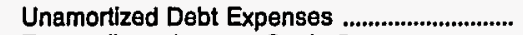 & 28,904 & 340 & 0 & 379 & 0 & 0 \\
\hline Extraordinary Losses, Study Cost ...................... & & 0 & 0 & 0 & 0 & 0 \\
\hline Misc Debt, R \& D Exp, Unamrt Losses ........... & 172,549 & 0 & 0 & 0 & 0 & 2,431 \\
\hline Total Deferred Debits .................................. & 201,453 & 341 & & 379 & $\mathbf{0}$ & 2,431 \\
\hline Total Assets \& Other Deblts ......................... & $5,744,310$ & 27,057 & 14,815 & 31,280 & 25,784 & 228,486 \\
\hline \multicolumn{7}{|l|}{ Proprietary Capital } \\
\hline Investment of Municipality & 0 & $-6,801$ & 5,315 & 0 & 125 & 0 \\
\hline 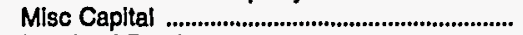 & 0 & & 0 & 0 & 34 & 0 \\
\hline 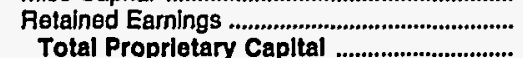 & $\begin{array}{l}1,445,602 \\
1,445,602\end{array}$ & $\begin{array}{l}17,510 \\
10,709\end{array}$ & $\begin{array}{r}7,688 \\
13,003\end{array}$ & $\begin{array}{l}16,015 \\
16,015\end{array}$ & $\begin{array}{l}23,579 \\
23,737\end{array}$ & $\begin{array}{l}144,755 \\
144,755\end{array}$ \\
\hline \multicolumn{7}{|l|}{ Long-term Debt } \\
\hline 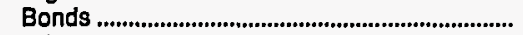 & $3,262,430$ & 13,079 & 0 & 11,899 & 0 & 66,077 \\
\hline Advances from Municipality \& Other ................. & 200,000 & 0 & 0 & 112 & 0 & 0 \\
\hline Unamort Prem on Long-term Debt .................... & & 0 & 0 & 0 & 0 & 0 \\
\hline (less) Unamort Discount on Long-term Debt & 67,174 & & 0 & 0 & 0 & 0 \\
\hline 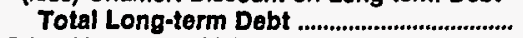 & $3,395,256$ & 13,079 & 0 & 12,011 & 0 & 66,077 \\
\hline \multicolumn{7}{|l|}{ Other Noncurrent Liabilities } \\
\hline Accum Operating Provisions ................................ & 18,042 & 1,366 & 0 & 0 & 0 & 0 \\
\hline Accum Prov for Rate Refunds ............................. & & & 0 & 0 & 0 & 0 \\
\hline Total Other Noncurrent Llabilltles ............. & 18,042 & 1,366 & 0 & 0 & 0 & 0 \\
\hline \multicolumn{7}{|l|}{ Current and Accrued Llabilities } \\
\hline 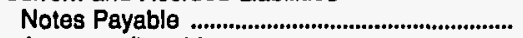 & 130,000 & 0 & 0 & 0 & 0 & $\mathbf{0}$ \\
\hline 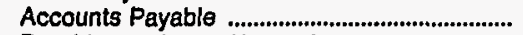 & 11,718 & 602 & 1.533 & 2,482 & 1,596 & 14,438 \\
\hline 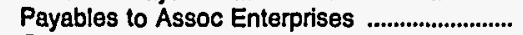 & 0 & 0 & 0 & 413 & 0 & 0 \\
\hline 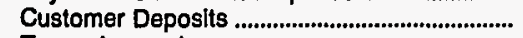 & 0 & 344 & 254 & 232 & 292 & 1,545 \\
\hline 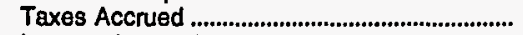 & 0 & 0 & 0 & 0 & 4 & 0 \\
\hline 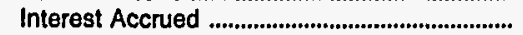 & 2,071 & 552 & 0 & 56 & 0 & 1,671 \\
\hline Mlsc Current \& Accrued Liabilities ................. & 142,522 & 296 & 25 & 72 & 155 & 0 \\
\hline Total Current \& Accrued Llabilities .......... & 286,311 & 1,795 & 1,812 & 3,254 & 2,047 & 17,654 \\
\hline \multicolumn{7}{|l|}{ Deferred Credits } \\
\hline Customer Advances for Construction ............... & 0 & 0 & 0 & 0 & 0 & 0 \\
\hline 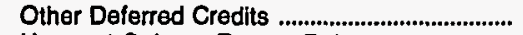 & 599,099 & 109 & 0 & 0 & 0 & 0 \\
\hline Unamort Gain on Reacqr Debt ............................. & 0 & 0 & 0 & 0 & 0 & 0 \\
\hline Total Deferred Credits ................................. & 599,099 & 109 & & & & \\
\hline Total Llabllittes and Other Credlts ............. & $5,744,310$ & 27,057 & 14,815 & 31,280 & 25,784 & 228,486 \\
\hline
\end{tabular}

Note: Totals may not equal sum of components because of independent rounding.

Source: Energy Information Administration, Form EIA-412, "Annual Report of Public Electric Utilities." 
Table 22. Balance Sheet by Major U.S. Publicly Owned Electric Utility Within State at End of Period, 1993 (Continued) (Thousand Dollars)

\begin{tabular}{|c|c|c|c|c|c|c|}
\hline Item & $\begin{array}{c}\text { North Carolina } \\
\text { Forest City } \\
\text { Town of } \\
\text { June } 30\end{array}$ & $\begin{array}{c}\text { North Carolina } \\
\text { Gastonia } \\
\text { City of } \\
\text { June } 30\end{array}$ & $\begin{array}{c}\text { North Carolina } \\
\text { Greenville } \\
\text { Utilities } \\
\text { Comm } \\
\text { June } 30\end{array}$ & $\begin{array}{c}\text { North Carolina } \\
\text { High } \\
\text { Point } \\
\text { Town } \\
\text { of } \\
\text { June } 30\end{array}$ & $\begin{array}{c}\text { North Carolina } \\
\text { Kinston } \\
\text { City of } \\
\text { June } 30\end{array}$ & $\begin{array}{l}\text { North Carolina } \\
\text { Lexington } \\
\text { City of } \\
\text { June } 30\end{array}$ \\
\hline \multicolumn{7}{|l|}{ Electric Utility Plant } \\
\hline Electric Utility Plant \& Adjust ................................ & 5,265 & 36,669 & 82,387 & 55,422 & 16,748 & 27,297 \\
\hline 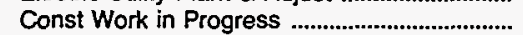 & & & 0 & 34 & 2,078 & 108 \\
\hline 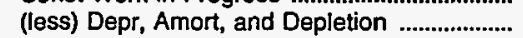 & 2,381 & 18,649 & 39,763 & 22,682 & 7,348 & 8,924 \\
\hline Net Electric Utility Plant ................................. & 2,884 & 18,019 & 42,624 & 32,774 & 11,479 & 18,481 \\
\hline 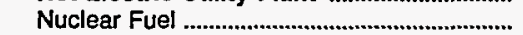 & 0 & 0 & 0 & 0 & 0 & 0 \\
\hline (less) Amort of Nucl Fuel ....................................... & 0 & 0 & 0 & 0 & 0 & 0 \\
\hline Net Elec Plant Incl Nucl Fuel ............................ & 2,884 & 18,019 & 42,624 & 32,774 & 11,479 & 18,481 \\
\hline \multicolumn{7}{|l|}{ Other Property \& Investments } \\
\hline 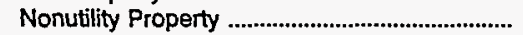 & 0 & 0 & 0 & 0 & 0 & 0 \\
\hline (less) Accum Provisions for Depr \& Amort .... & 0 & 0 & 0 & 0 & 0 & 0 \\
\hline 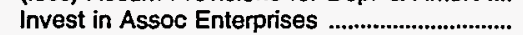 & 0 & 0 & 0 & 0 & 0 & 0 \\
\hline 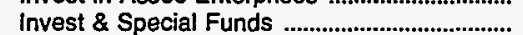 & 1,542 & 0 & 0 & 0 & 0 & 0 \\
\hline Total Other Property \& Investments ........ & 1,542 & 0 & $\mathbf{0}$ & 0 & 0 & 0 \\
\hline \multicolumn{7}{|l|}{ Current and Accrued Assets } \\
\hline Cash, Working Funds \& Investments ............... & 3,835 & 4,042 & 15,797 & 14,475 & 7,314 & 594 \\
\hline Notes \& Other Receivables ........................... & 744 & & 57 & 0 & 143 & 1,273 \\
\hline 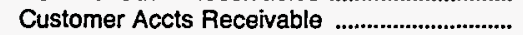 & 0 & 4,413 & 9,614 & 2,174 & 4,003 & 0 \\
\hline (less) Accum Prov for Uncollected Accts ....... & 0 & 2,077 & 0 & 0 & 271 & 0 \\
\hline 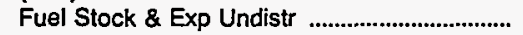 & 0 & 0 & 0 & 0 & 0 & 0 \\
\hline Materials \& Supplies & 0 & 482 & 1,435 & 0 & 794 & 443 \\
\hline 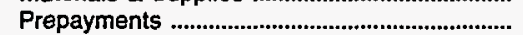 & 0 & 0 & 283 & 0 & 0 & 1,379 \\
\hline 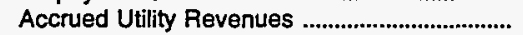 & 0 & 0 & 0 & 0 & 0 & 494 \\
\hline Miscellaneous Current \& Accrued Assets ...... & 0 & 3,869 & 273 & 46 & 0 & 685 \\
\hline Total Current \& Accrued Assets .................... & 4,579 & 10,729 & 27,459 & 16,695 & 11,983 & 4,868 \\
\hline \multicolumn{7}{|l|}{ Deferred Debits } \\
\hline 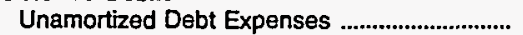 & 0 & 0 & 0 & 0 & 19 & 0 \\
\hline 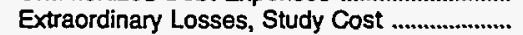 & 0 & 0 & 0 & 0 & 0 & 0 \\
\hline Misc Debt, R \& D Exp, Unamrt Losses .......... & 0 & 0 & 0 & 0 & 0 & 0 \\
\hline 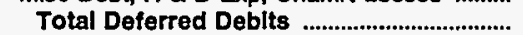 & & 0 & 0 & $\mathbf{0}$ & 19 & 0 \\
\hline \multirow{2}{*}{\multicolumn{7}{|c|}{ Proprietary Capital }} \\
\hline & & & & & & \\
\hline 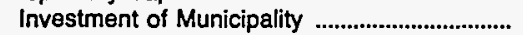 & 2,308 & 4,121 & 0 & 0 & 0 & 4,297 \\
\hline 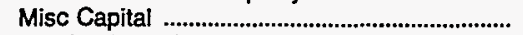 & & 0 & 0 & 158 & 0 & 0 \\
\hline 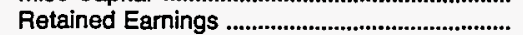 & 5,930 & 20,812 & 56,790 & 43,199 & 15,923 & 6,814 \\
\hline 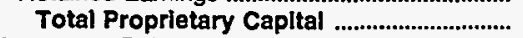 & 8,238 & 24,932 & 56,790 & 43,358 & 15,923 & 11,112 \\
\hline \multicolumn{7}{|l|}{ Long-term Debt } \\
\hline Bonds & 0 & 0 & 2,657 & 500 & 2,660 & 330 \\
\hline Advances from Municipality \& Other .................... & 0 & 0 & 0 & 31 & 1,176 & 8,157 \\
\hline Unamort Prem on Long-term Debt .................... & 0 & 0 & 0 & 519 & 0 & 0 \\
\hline (less) Unamort Discount on Long-term Debt & 0 & 0 & 0 & 0 & 0 & 0 \\
\hline 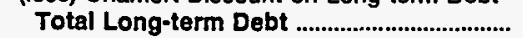 & 0 & 0 & 2,657 & 1,050 & 3,836 & 8,487 \\
\hline \multicolumn{7}{|l|}{ Other Noncurrent Liabilities } \\
\hline Accum Operating Provisions ................................ & 0 & 0 & 0 & 0 & 0 & 0 \\
\hline Accum Prov for Rate Refunds .............................. & 0 & 0 & 0 & 0 & 0 & 0 \\
\hline Total Other Noncurrent Llabilities ............ & 0 & 0 & 0 & 0 & 0 & 0 \\
\hline \multicolumn{7}{|l|}{ Current and Accrued Liabilities } \\
\hline 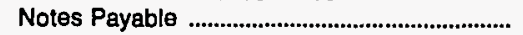 & 0 & 0 & 0 & 0 & 0 & 0 \\
\hline 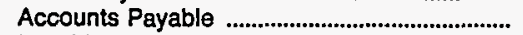 & 564 & 3,473 & 8,945 & 4,406 & 3,100 & 2,299 \\
\hline Payables to Assoc Enterprises ............................ & 0 & 0 & 0 & 34 & 114 & 908 \\
\hline 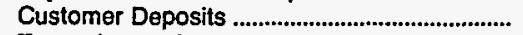 & 196 & 196 & 692 & 446 & 444 & 494 \\
\hline Taxes Accrued & 0 & 0 & 0 & 0 & 0 & 0 \\
\hline 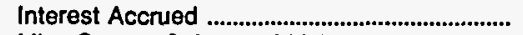 & 0 & 0 & 55 & 14 & 0 & 0 \\
\hline Misc Current \& Accrued Liabilities .......................... & 8 & 147 & 768 & 160 & 63 & 51 \\
\hline Total Current \& Accrued Llablilities ........... & 768 & 3,816 & 10,460 & 5,060 & 3,722 & 3,750 \\
\hline \multicolumn{7}{|l|}{ Deferred Credits } \\
\hline Customer Advances for Construction .................. & 0 & 0 & 177 & 0 & 0 & 0 \\
\hline 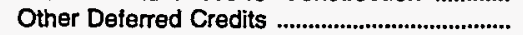 & 0 & 0 & 0 & 0 & 0 & 0 \\
\hline 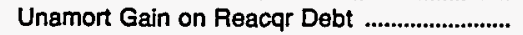 & 0 & 0 & 0 & 0 & 0 & 0 \\
\hline 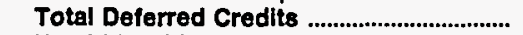 & 0 & & 177 & & & \\
\hline Total Llabilitles and Other Credits ............. & 9,006 & 28,748 & 70,083 & 49,468 & 23,480 & 23,349 \\
\hline
\end{tabular}

Note: Totals may not equal sum of components because of independent rounding.

Source: Energy Information Administration, Form EIA-412, "Annual Report of Public Electric Utilities." 
Table 22. Balance Sheet by Major U.S. Publicly Owned Electric Utility Within State at End of Period, 1993 (Continued) (Thousand Dollars)

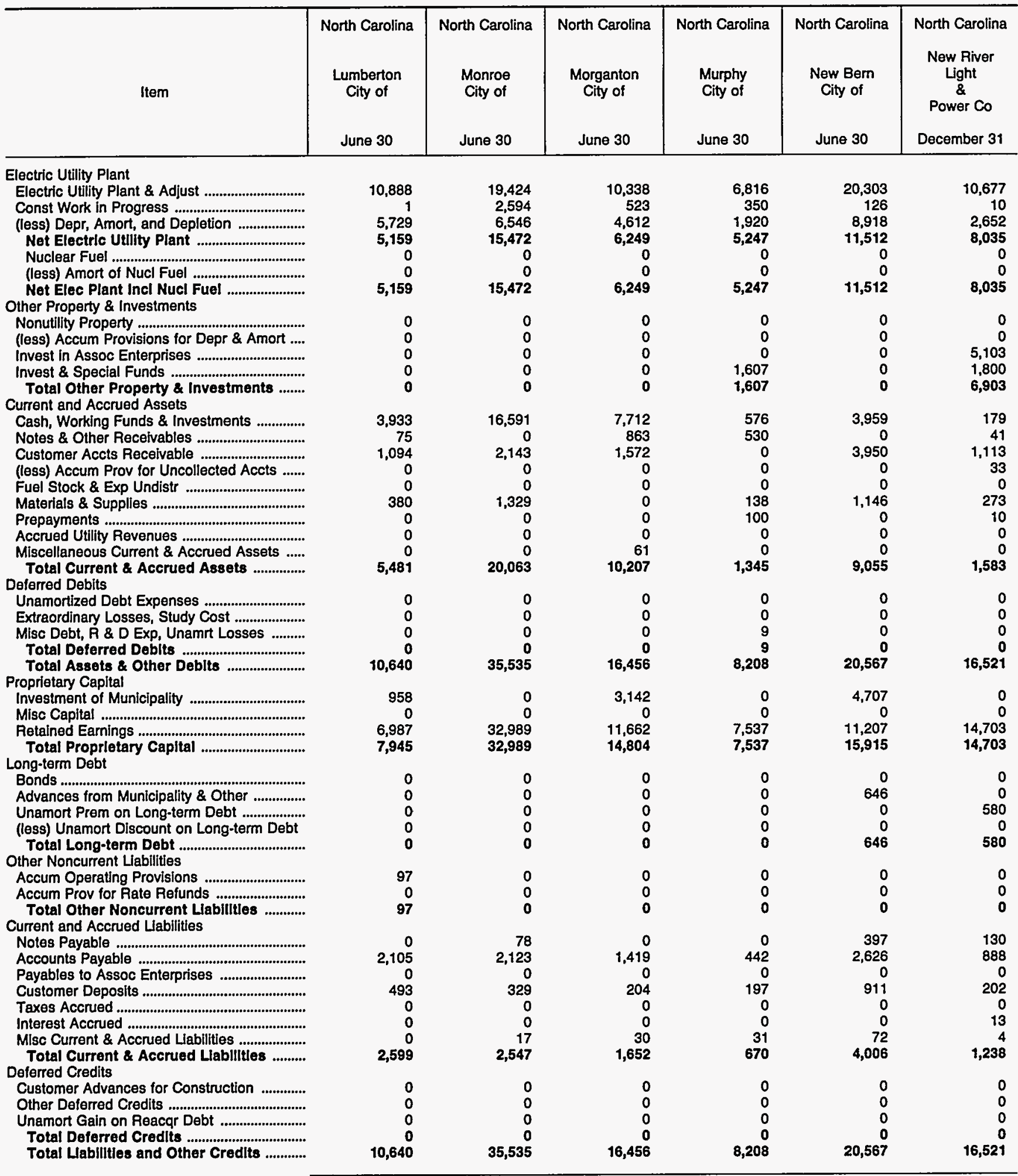

Note: Totals may not equal sum of components because of independent rounding.

Source: Energy Information Administration, Form EIA-412, "Annual Report of Public Electric Utilities." 
Table 22. Balance Sheet by Major U.S. Publicly Owned Electric Utility Within State at End of Period, 1993 (Continued)

(Thousand Dollars)

\begin{tabular}{|c|c|c|c|c|c|c|}
\hline Item & $\begin{array}{c}\text { North Carolina } \\
\text { North } \\
\text { Carolina } \\
\text { Eastern M P A } \\
\text { December } 31\end{array}$ & $\begin{array}{c}\text { North Carolina } \\
\text { North } \\
\text { Carolina } \\
\text { Mun } \\
\text { Power Agny } \\
\text { December } 31\end{array}$ & $\begin{array}{l}\text { North Carolina } \\
\text { Rocky Mount } \\
\text { City of } \\
\text { June } 30\end{array}$ & $\begin{array}{l}\text { North Carolina } \\
\text { Shelby } \\
\text { City of } \\
\text { June } 30\end{array}$ & $\begin{array}{c}\text { North Carolina } \\
\text { Statesville } \\
\text { City of } \\
\text { June } 30\end{array}$ & $\begin{array}{l}\text { North Carolina } \\
\text { Tarboro } \\
\text { Town of } \\
\text { June } 30\end{array}$ \\
\hline \multicolumn{7}{|l|}{ Electric Utility Plant } \\
\hline 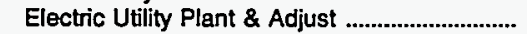 & $1,385,857$ & $1,402,387$ & 30,388 & 6,201 & 15,019 & 15,511 \\
\hline Const Work in Progress & 35,753 & 9,008 & 3,265 & 1,155 & & \\
\hline (less) Depr, Amort, and Depletion ......................... & 361,795 & 294,784 & 12,456 & 4,361 & 6,122 & $\mathbf{5 , 5 3 5}$ \\
\hline Net Electric Utility Plant ................................... & $1,059,815$ & $1,116,611$ & 21,198 & 2,995 & 8,920 & 9,976 \\
\hline 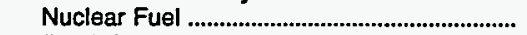 & 69,549 & 289,076 & 0 & 0 & 0 & 0 \\
\hline (less) Amort of Nucl Fuel ........................................ & 36,213 & 218,467 & 0 & 0 & 0 & 0 \\
\hline Net Elec Plant Incl Nucl Fuel ....................... & $1,093,151$ & $1,187,220$ & 21,198 & 2,995 & 8,920 & 9,976 \\
\hline \multicolumn{7}{|l|}{ Other Property \& Investments } \\
\hline 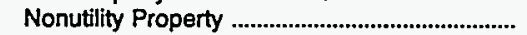 & 3,150 & 3,149 & 0 & 0 & 977 & 0 \\
\hline (less) Accum Provisions for Depr \& Amort .... & 1,071 & 1,087 & 0 & 0 & 419 & 0 \\
\hline Invest in Assoc Enterprises ................... & & 0 & 0 & 0 & 0 & 0 \\
\hline 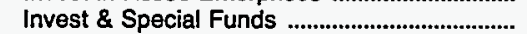 & 573,393 & 336,477 & 0 & 1,275 & 0 & 0 \\
\hline Total Other Property \& Investments ........ & 575,472 & 338,539 & 0 & 1,275 & 559 & 0 \\
\hline \multicolumn{7}{|l|}{ Current and Accrued Assets } \\
\hline Cash, Working Funds \& Investments .............. & 210,043 & 21,645 & 4,602 & 2,276 & 7,456 & 8,148 \\
\hline Notes \& Other Receivables .................................. & & 11,443 & 630 & 17 & 25 & 2,198 \\
\hline Customer Accts Receivable ................................. & 33,006 & 16,590 & 6,392 & 1,075 & 3,431 & 0 \\
\hline (less) Accum Prov for Uncollected Accts ....... & & 0 & 0 & 152 & 279 & 31 \\
\hline 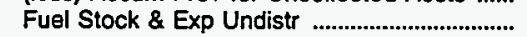 & 3,776 & 0 & 0 & 0 & 0 & 0 \\
\hline Materials \& Supplies ............................................... & 7,652 & 15,039 & 630 & 319 & 972 & 567 \\
\hline 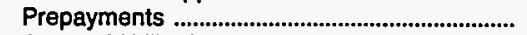 & 386 & 58 & 0 & 0 & 16 & 0 \\
\hline 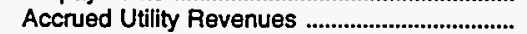 & 0 & 0 & 0 & 0 & 0 & 0 \\
\hline Miscellaneous Current \& Accrued Assets ..... & 0 & 444,930 & 0 & 364 & 0 & 0 \\
\hline Total Current \& Accrued Assets ................ & 254,863 & 509,705 & 12,255 & 3,900 & 11,620 & 10,883 \\
\hline \multicolumn{7}{|l|}{$\begin{array}{l}\text { Deferred Debits } \\
\text { Unamortized Debt Expenses }\end{array}$} \\
\hline 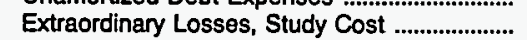 & $\begin{array}{r}41,1<4 \\
0\end{array}$ & 371,718 & 0 & 0 & 0 & 0 \\
\hline Misc Debt, R \& D Exp, Unamrt Losses .......... & $1,694,306$ & 93,962 & 0 & 0 & 0 & 0 \\
\hline Total Deferred Debits ....................................... & $1,735,430$ & 501,654 & 0 & & & \\
\hline Total Assets \& Other Deblts ........................ & $3,658,916$ & $2,537,118$ & 33,452 & 8,169 & 21,099 & 20,858 \\
\hline \multicolumn{7}{|l|}{ Proprietary Capital } \\
\hline & 0 & 0 & 0 & 0 & 28 & 906 \\
\hline $\begin{array}{l}\text { Misc Capital } \\
\text { Retained Earnings }\end{array}$ & 0 & 0 & 811 & 88 & 168 & 17,849 \\
\hline 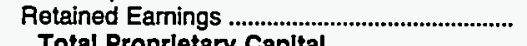 & 26,000 & 7,400 & 25,553 & 3,675 & 18,227 & 0 \\
\hline $\begin{array}{l}\text { Total Proprletary Capltal ........................................... } \\
\text { Long-term Debt }\end{array}$ & 26,000 & 7,400 & 26,364 & 3,763 & 18,423 & 18,755 \\
\hline Bonds & $3,472,275$ & $2,393,582$ & 1,256 & 2,659 & 595 & 0 \\
\hline Advances from Municipality \& Other ................... & 24,100 & 237,634 & 0 & 0 & 0 & 0 \\
\hline Unamort Prem on Long-term Debt ..................... & 20,040 & 12,133 & 0 & 0 & 0 & 0 \\
\hline (less) Unamort Discount on Long-term Debt & 153,454 & 196,571 & 0 & 0 & 0 & 0 \\
\hline Total Long-term Debt ................................... & $3,362,961$ & $2,446,778$ & 1,256 & 2,659 & 595 & 0 \\
\hline \multicolumn{7}{|l|}{ Other Noncurrent Liabilities } \\
\hline 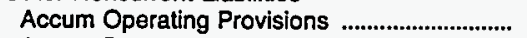 & 0 & 0 & 0 & 0 & 79 & 0 \\
\hline Accum Prov for Rate Refunds ............................... & 0 & 0 & 0 & 0 & 0 & $\mathbf{0}$ \\
\hline Total Other Noncurrent Llabilitles ............. & 0 & 0 & $\mathbf{0}$ & 0 & 79 & $\mathbf{0}$ \\
\hline \multicolumn{7}{|l|}{ Current and Accrued Liabilities } \\
\hline 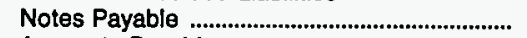 & 144,953 & 0 & 0 & 13 & & 0 \\
\hline Accounts Payable & 12,718 & 980 & 5,071 & 1,352 & 1,922 & 1,908 \\
\hline 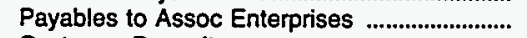 & 0 & 0 & 0 & 0 & 0 & 0 \\
\hline 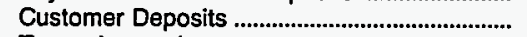 & 0 & 0 & 623 & 344 & 72 & 169 \\
\hline 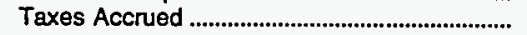 & 6,847 & 14,031 & 0 & 0 & 0 & 0 \\
\hline 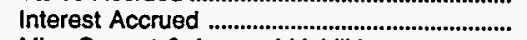 & 105,437 & 67,929 & 5 & 16 & 7 & 0 \\
\hline Misc Current \& Accrued Liabilities ........................ & 0 & 0 & 133 & 24 & 0 & 27 \\
\hline $\begin{array}{l}\text { Total Current \& Accrued Llabilltles ........... } \\
\text { Deferred Credits }\end{array}$ & 269,955 & 82,940 & 5,832 & 1,748 & 2,001 & 2,103 \\
\hline Customer Advances for Construction .................. & 0 & 0 & 0 & 0 & 0 & 0 \\
\hline 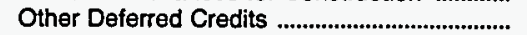 & 0 & 0 & 0 & 0 & 0 & 0 \\
\hline Unamort Gain on Reacqr Debt ............................... & 0 & 0 & 0 & 0 & 0 & 0 \\
\hline 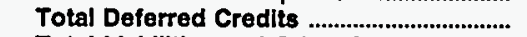 & 0 & $\mathbf{0}$ & 0 & 0 & $\mathbf{0}$ & \\
\hline Total Llabilities and Other Credits ............ & $3,658,916$ & $2,537,118$ & 33,452 & 8,169 & 21,099 & 20,858 \\
\hline
\end{tabular}

Note: Totals may not equal sum of components because of independent rounding.

Source: Energy Information Administration, Form EIA-412, "Annual Report of Public Electric Utilities." 
Table 22. Balance Sheet by Major U.S. Publicly Owned Electric Utility Within State at End of Period, 1993 (Continued)

(Thousand Dollars)

\begin{tabular}{|c|c|c|c|c|c|c|}
\hline Item & $\begin{array}{c}\text { North Carolina } \\
\begin{array}{c}\text { Washington } \\
\text { City of }\end{array} \\
\text { June } 30\end{array}$ & $\begin{array}{l}\text { North Carolina } \\
\text { Wilson } \\
\text { City of } \\
\text { June } 30\end{array}$ & $\begin{array}{c}\text { Ohio } \\
\text { American } \\
\text { Mun } \\
\text { Power } \\
\text { Ohio Inc } \\
\text { December } 31\end{array}$ & $\begin{array}{c}\text { Ohio } \\
\text { Bowling } \\
\text { Green } \\
\text { City of } \\
\text { December } 31\end{array}$ & $\begin{array}{c}\text { Ohio } \\
\text { Bryan } \\
\text { City of } \\
\text { December } 31\end{array}$ & $\begin{array}{c}\text { Ohio } \\
\text { Colina } \\
\text { City of } \\
\text { December } 31\end{array}$ \\
\hline \multicolumn{7}{|l|}{ Electric Utility Plant } \\
\hline 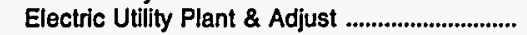 & 25,023 & 47,690 & 62,405 & 12,508 & 0 & 17,592 \\
\hline 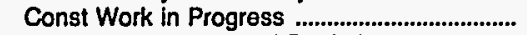 & 145 & 2,378 & 2,178 & 4,236 & 0 & \\
\hline (less) Depr, Amort, and Depletion ..................... & 10,918 & 24,795 & 16,119 & 8,394 & 0 & 0 \\
\hline 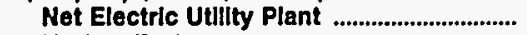 & 14,250 & 25,273 & 48,464 & 8,350 & $\mathbf{0}$ & 17,592 \\
\hline 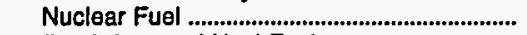 & 0 & 0 & 0 & 0 & 0 & 0 \\
\hline 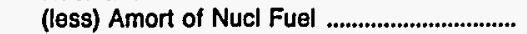 & 0 & 0 & 0 & 0 & 0 & 0 \\
\hline Net Elec Plant Incl Nucl Fuel ........................ & 14,250 & 25,273 & 48,464 & 8,350 & 0 & 17,592 \\
\hline \multicolumn{7}{|l|}{ Other Property \& Investments } \\
\hline 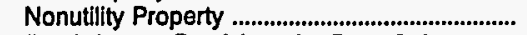 & 0 & 0 & 1,893 & 0 & 0 & 0 \\
\hline (less) Accum Provisions for Depr \& Amort .... & 0 & 0 & 859 & 0 & 0 & 0 \\
\hline 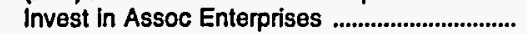 & 0 & 0 & 0 & 0 & 0 & 0 \\
\hline 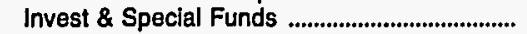 & 0 & 0 & 13,432 & 2,334 & 0 & 0 \\
\hline Total Other Property \& Investments ....... & 0 & o & 14,466 & 2,334 & 0 & o \\
\hline \multicolumn{7}{|l|}{ Current and Accrued Assets } \\
\hline Cash, Working Funds \& Investments .............. & 7,363 & 22,879 & 14,197 & 1,513 & 0 & 2,402 \\
\hline Notes \& Other Receivables ................................. & & 1,309 & & 247 & 0 & 0 \\
\hline 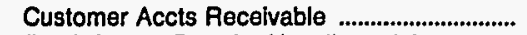 & 2,267 & 2,357 & 12,689 & 809 & 0 & 636 \\
\hline (less) Accum Prov for Uncollected Accts ...... & & 123 & 0 & 0 & 0 & 119 \\
\hline 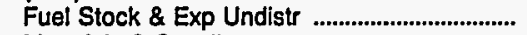 & 0 & 0 & 379 & 0 & 0 & 0 \\
\hline 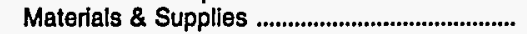 & 588 & 1,559 & 1,966 & 1,051 & 0 & 653 \\
\hline 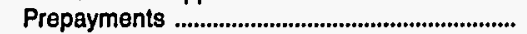 & 0 & 36 & 209 & 19 & 0 & 9 \\
\hline 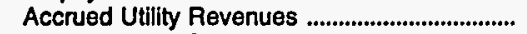 & 0 & 5,953 & 0 & 743 & 0 & 0 \\
\hline Miscellaneous Current \& Accrued Assets ..... & 0 & & 509 & 0 & 0 & \\
\hline Total Current \& Accrued Assets ................ & 10,227 & 33,969 & 29,979 & 4,382 & 0 & 3,581 \\
\hline \multicolumn{7}{|l|}{ Deferred Debits } \\
\hline 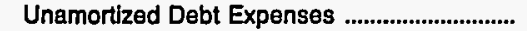 & 0 & 0 & $\mathbf{0}$ & 0 & 0 & 0 \\
\hline Extraordinary Losses, Study Cost ...................... & 0 & 0 & 0 & 0 & 0 & 0 \\
\hline Misc Debt, R \& D Exp, Unamrt Losses .......... & 0 & 0 & 0 & 0 & 0 & 0 \\
\hline Total Deterred Debits ............................................ & & 0 & 0 & o & 0 & 0 \\
\hline Total Assets \& Other Deblts ............................ & 24,477 & 59,243 & 92,910 & 15,066 & $\mathbf{0}$ & 21,172 \\
\hline \multicolumn{7}{|l|}{ Propriatary Capital } \\
\hline 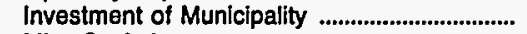 & 318 & 78 & 566 & 0 & 0 & 18,245 \\
\hline 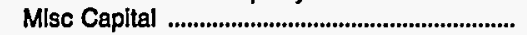 & & 10 & 0 & 11,225 & 0 & 0 \\
\hline 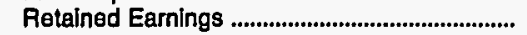 & 17,966 & 51,833 & 3,174 & 1,327 & 0 & 1,694 \\
\hline Total Proprletary Capltal .................................... & 18,284 & 51,922 & 3,740 & 12,552 & $\mathbf{0}$ & 19,939 \\
\hline \multicolumn{7}{|l|}{ Long-term Debt } \\
\hline 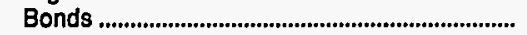 & 3,566 & 125 & 66,151 & 0 & 0 & 0 \\
\hline Advances from Municipality \& Other ................ & 438 & 0 & 0 & 0 & 0 & 0 \\
\hline Unamort Prem on Long-term Debt ..................... & 0 & 0 & 0 & 0 & 0 & 0 \\
\hline (less) Unamort Discount on Long-term Debt & & 0 & & 0 & 0 & 0 \\
\hline 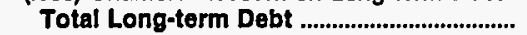 & 4,004 & 125 & 66,151 & 0 & 0 & $\mathbf{0}$ \\
\hline \multicolumn{7}{|l|}{ Other Noncurrent Llabilities } \\
\hline Accum Operating Provisions ................................ & 0 & 0 & 0 & 0 & 0 & 421 \\
\hline Accum Prov for Rate Refunds .............................. & 0 & 0 & 0 & 0 & 0 & 0 \\
\hline Total Other Noncurrent Llabilltles ............. & 0 & 0 & 0 & 0 & 0 & 421 \\
\hline \multicolumn{7}{|l|}{ Current and Accrued Llabilities } \\
\hline 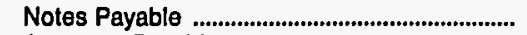 & 0 & 0 & & 595 & 0 & 0 \\
\hline 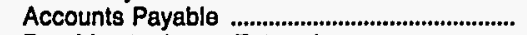 & 1,893 & 6,303 & 10,130 & 1,074 & 0 & 708 \\
\hline Payables to Assoc Enterprises .......................... & & 0 & 466 & 0 & 0 & 0 \\
\hline 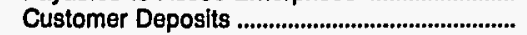 & 179 & 587 & 0 & 241 & 0 & 105 \\
\hline 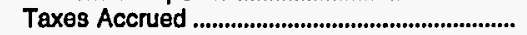 & 0 & 0 & 5,053 & 0 & 0 & 0 \\
\hline Interest Accrued ..................................................... & 0 & 2 & 1,849 & 8 & 0 & 0 \\
\hline Mlsc Current \& Accrued Llabilities ................... & 116 & 304 & 2,706 & 342 & 0 & 0 \\
\hline Total Current \& Accrued Llablittles ........... & 2,189 & 7,196 & 20,204 & 2,259 & 0 & 813 \\
\hline \multicolumn{7}{|l|}{ Deferred Credits } \\
\hline Customer Advances for Construction ............. & 0 & 0 & 0 & 0 & 0 & 0 \\
\hline 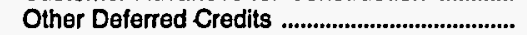 & 0 & 0 & 2,815 & 255 & 0 & 0 \\
\hline Unamort Gain on Reacqr Debt ............................. & 0 & 0 & 0 & 0 & 0 & 0 \\
\hline Total Deferred Credits ...................................... & 0 & & 2,815 & 255 & 0 & \\
\hline Total Llabllities and Other Credits ............ & 24,477 & 59,243 & 92,910 & 15,066 & $\mathbf{0}$ & 21,172 \\
\hline
\end{tabular}

Note: Totals may not equal sum of components because of independent rounding.

Source: Energy Information Administration, Form EIA-412, "Annual Report of Public Electric Utilities." 
Table 22. Balance Sheet by Major U.S. Publicly Owned Electric Utility Within State at End of Period, 1993 (Continued) (Thousand Dollars)

\begin{tabular}{|c|c|c|c|c|c|c|}
\hline Item & $\begin{array}{c}\text { Ohio } \\
\text { Cleveland } \\
\text { City of } \\
\text { December } 31\end{array}$ & $\begin{array}{c}\text { Columbus } \\
\text { City of }\end{array}$ & $\begin{array}{c}\text { Ohio } \\
\text { Cuyahoga } \\
\text { Falls } \\
\text { City of } \\
\text { December } 31\end{array}$ & $\begin{array}{l}\text { Dover } \\
\text { City of }\end{array}$ & $\begin{array}{l}\text { Hamilton } \\
\text { City of }\end{array}$ & $\begin{array}{c}\text { Napoleon } \\
\text { City of } \\
\text { December } 31\end{array}$ \\
\hline \multicolumn{7}{|l|}{ Electric Utility Plant } \\
\hline 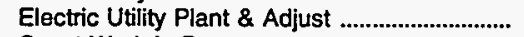 & 176,852 & 74,221 & 19,831 & 9,924 & 226,433 & 2,536 \\
\hline Const Work in Progress & 69,309 & 0 & 0 & 0 & 0 & 0 \\
\hline (less) Depr, Amort, and Depletion ....................... & 90,745 & 30,205 & 10,409 & 0 & 69,198 & 0 \\
\hline Net Electric Utllity Plant & 155,416 & 44,016 & 9,422 & 9,924 & 157,235 & 2,536 \\
\hline Nuclear Fuel ................................................ & 0 & 0 & 0 & 0 & o & 0 \\
\hline 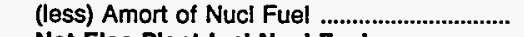 & 0 & 0 & 0 & 0 & 0 & 0 \\
\hline $\begin{array}{l}\text { Net Elec Plant incl Nucl Fuel .......................... } \\
\text { Other Property \& Investments }\end{array}$ & 155,416 & 44,016 & 9,422 & 9,924 & 157,235 & 2,536 \\
\hline 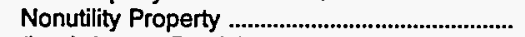 & 0 & 0 & 0 & 0 & 0 & 0 \\
\hline (less) Accum Provisions for Depr \& Amort .... & 0 & 0 & 0 & 0 & 0 & 0 \\
\hline Invest in Assoc Enterprises ............................... & 0 & 129,653 & 0 & 0 & 0 & 0 \\
\hline 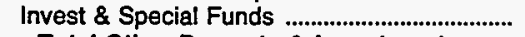 & 48,475 & 14,170 & 0 & 0 & 41,261 & 0 \\
\hline Total Other Property \& Investments ........ & 48,475 & 143,823 & $\mathbf{0}$ & 0 & 41,261 & 0 \\
\hline \multicolumn{7}{|l|}{ Current and Accrued Assets } \\
\hline Cash, Working Funds \& Investments .............. & 6,883 & 2,663 & 6,650 & 7 & 1,808 & 0 \\
\hline 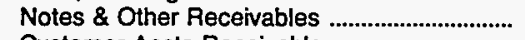 & 0 & 748 & 946 & 0 & 5,085 & 0 \\
\hline Customer Accts Receivable & 9,016 & 3,231 & 2,329 & 1,451 & 0 & 0 \\
\hline (less) Accum Prov for Uncollected Accts ...... & 240 & 0 & 0 & 0 & 0 & 0 \\
\hline 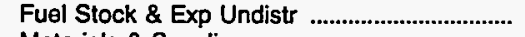 & 0 & 0 & 0 & 0 & 0 & 0 \\
\hline 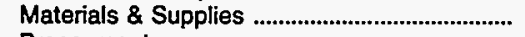 & 7,816 & 1,531 & 2,114 & 691 & 1,856 & 0 \\
\hline Prepayments & 15 & 0 & 43 & 89 & 110 & 0 \\
\hline 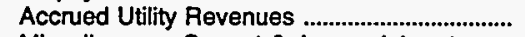 & 1,053 & 0 & $\mathbf{0}$ & 2,806 & 0 & 0 \\
\hline Miscellaneous Current \& Accrued Assets ..... & 28 & 0 & 0 & 96 & 5,394 & 0 \\
\hline $\begin{array}{l}\text { Total Current \& Accrued Assets ............... } \\
\text { Deferred Debits }\end{array}$ & 24,570 & 8,174 & 12,081 & 5,140 & 14,253 & 0 \\
\hline 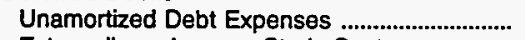 & 570 & 0 & $\mathbf{0}$ & 0 & 2,958 & 0 \\
\hline Extraordinary Losses, Study Cost ..................... & 0 & 0 & 0 & 0 & 0 & 0 \\
\hline Misc Debt, R \& D Exp, Unamrt Losses .......... & 0 & 628 & 0 & 0 & 0 & 0 \\
\hline 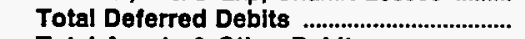 & $\mathbf{5 7 0}$ & 628 & $\mathbf{0}$ & 0 & 2,958 & $\mathbf{0}$ \\
\hline $\begin{array}{l}\text { Total Assets \& Other Debits ............................ } \\
\text { Proprietary Capital }\end{array}$ & 229,032 & 196,641 & 21,503 & 15,065 & 215,708 & 2,536 \\
\hline Investment of Municipality & 12,183 & 16,376 & $\mathbf{0}$ & 135 & 0 & 0 \\
\hline Misc Capital & 0 & 0 & 0 & 0 & 0 & 0 \\
\hline 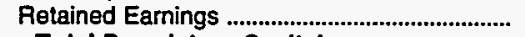 & 50,768 & $-33,569$ & 15,393 & 7,189 & $-6,611$ & 2,536 \\
\hline \multirow{2}{*}{\multicolumn{4}{|c|}{ Long-term Debt }} & 7,324 & $-6,611$ & 2,536 \\
\hline 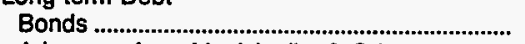 & 93,269 & 205,987 & 3,645 & 1,470 & & 0 \\
\hline Advances from Municipality \& Other ................ & 0 & 0 & $\begin{array}{r}0,0 \\
0\end{array}$ & 0 & $\begin{array}{r}21,00 \\
0\end{array}$ & 0 \\
\hline Unamort Prem on Long-term Debt ................... & 0 & 0 & 0 & 0 & 0 & 0 \\
\hline (less) Unamort Discount on Long-term Debt & $\mathbf{0}$ & 0 & 0 & 0 & 0 & 0 \\
\hline 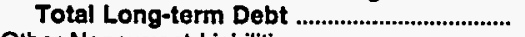 & 93,269 & 205,987 & 3,645 & 1,470 & 211,043 & 0 \\
\hline \multicolumn{7}{|l|}{ Other Noncurrent Liabilities } \\
\hline Accum Operating Provisions ................................ & 0 & 0 & 0 & $\mathbf{0}$ & 847 & 0 \\
\hline 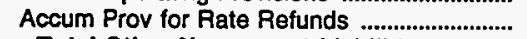 & 0 & 0 & 0 & 0 & 0 & 0 \\
\hline 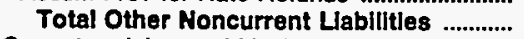 & 0 & 0 & 0 & $\mathbf{0}$ & 847 & 0 \\
\hline \multicolumn{7}{|l|}{ Current and Accrued Liabilities } \\
\hline Notes Payable & 57,380 & 0 & 0 & 5,050 & 2,630 & 0 \\
\hline Accounts Payable & 9,898 & 1,894 & 1,596 & 547 & 4,050 & 0 \\
\hline Payables to Assoc Enterprises ............................. & 0 & 385 & 122 & 92 & 0 & 0 \\
\hline 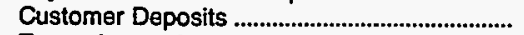 & 0 & 469 & 164 & 60 & 368 & 0 \\
\hline Taxes Accrued & 0 & 0 & 0 & 0 & 0 & 0 \\
\hline Interest Accrued & 1,239 & 3,908 & 22 & 23 & 2,764 & 0 \\
\hline Misc Current \& Accrued Liabilities .................... & 4,295 & 1,122 & 561 & 498 & 616 & 0 \\
\hline \multicolumn{5}{|l|}{ Deferred Credits } & 10,428 & 0 \\
\hline Customer Advances for Construction .............. & 0 & 0 & 0 & 0 & 0 & 0 \\
\hline 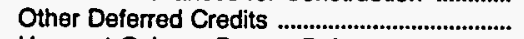 & 0 & 68 & 0 & 0 & 0 & 0 \\
\hline 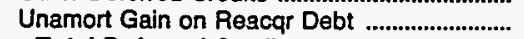 & 0 & 0 & 0 & 0 & 0 & 0 \\
\hline 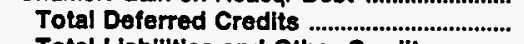 & 0 & 68 & $\mathbf{0}$ & 0 & $\mathbf{0}$ & \\
\hline Total Llabilities and Other Credits ............ & 229,032 & 196,641 & 21,503 & 15,065 & 215,708 & 2,536 \\
\hline
\end{tabular}

Note: Totals may not equal sum of components because of independent rounding.

Source: Energy Information Administration, Form ElA-412, "Annual Report of Public Electric Utilities." 
Table 22. Balance Sheet by Major U.S. Publicly Owned Electric Utility Within State at End of Period, 1993 (Continued)

(Thousand Dollars)

\begin{tabular}{|c|c|c|c|c|c|c|}
\hline Item & $\begin{array}{c}\text { Ohio } \\
\text { Niles } \\
\text { City of } \\
\text { December } 31\end{array}$ & $\begin{array}{c}\text { Ohio } \\
\text { Orville } \\
\text { City of } \\
\text { December } 31\end{array}$ & $\begin{array}{c}\text { Ohio } \\
\text { Painesville } \\
\text { City of } \\
\text { December } 31\end{array}$ & $\begin{array}{c}\text { Ohio } \\
\text { Piqua } \\
\text { City of } \\
\text { December } 31\end{array}$ & $\begin{array}{c}\text { Ohio } \\
\text { St Marys } \\
\text { City of } \\
\text { December } 31\end{array}$ & $\begin{array}{c}\text { Wadsworth } \\
\text { City of } \\
\text { December } 31\end{array}$ \\
\hline \multicolumn{7}{|l|}{ Electric Utility Plant } \\
\hline Electric Utility Plant \& Adjust .................................. & 12,013 & 50,645 & 38,440 & 42,967 & 15,696 & 10,465 \\
\hline 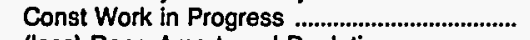 & & & & 653 & & \\
\hline 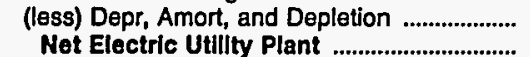 & 7,001 & 25,561 & $\begin{array}{l}21,654 \\
16,787\end{array}$ & 19,454 & 10,227 & 3,848 \\
\hline $\begin{array}{l}\text { Net Electrlc Utillty Plant } \\
\text { Nuclear Fuel }\end{array}$ & 5,012 & $\begin{array}{r}25,542 \\
0\end{array}$ & $\begin{array}{r}16,787 \\
0\end{array}$ & $\begin{array}{r}24,166 \\
0\end{array}$ & $\begin{array}{r}5,469 \\
0\end{array}$ & 6,617 \\
\hline 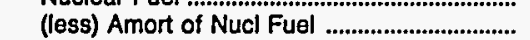 & 0 & 0 & 0 & 0 & 0 & 0 \\
\hline $\begin{array}{l}\text { Net Elec Plant Incl Nucl Fuel .............................. } \\
\text { Other Property \& Investments }\end{array}$ & 5,012 & 25,542 & 16,787 & 24,166 & 5,469 & 6,617 \\
\hline 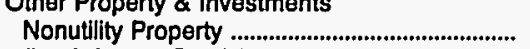 & \multicolumn{4}{|c|}{ Other Property \& Investments } & & \\
\hline (less) Accum Provisions for Depr \& Amort .... & 0 & 0 & 0 & 0 & 0 & 0 \\
\hline 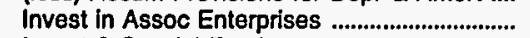 & 0 & 0 & 0 & 0 & 0 & 0 \\
\hline 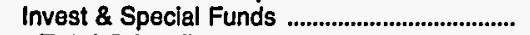 & 0 & 0 & 6,889 & 1,122 & 1,904 & 0 \\
\hline \multicolumn{7}{|l|}{ Current and Accrued Assets } \\
\hline Cesh, Working Funds \& investments ................. & 4,706 & 7,813 & -993 & 926 & 2,751 & 2,808 \\
\hline 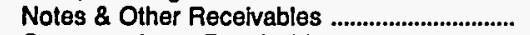 & & 25 & 34 & 16 & 0 & 1 \\
\hline Customer Accts Receivable ................................... & 1,612 & 1,905 & 1,534 & 1,016 & 562 & 1,618 \\
\hline (less) Accum Prov for Uncollected Accts ....... & 250 & 106 & 0 & 68 & 0 & 0 \\
\hline 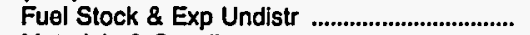 & 0 & 0 & 0 & 0 & 0 & 0 \\
\hline 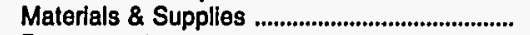 & 557 & 2,038 & 714 & 524 & 187 & 748 \\
\hline 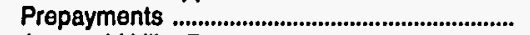 & $\mathbf{0}$ & 22 & 26 & 200 & 26 & 15 \\
\hline 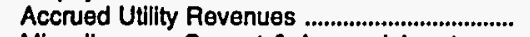 & 0 & 0 & 0 & 598 & 12 & 0 \\
\hline Mlscellaneous Current \& Accrued Assets ..... & 0 & 253 & & 129 & & 780 \\
\hline $\begin{array}{l}\text { Total Current \& Accrued Assets ................. } \\
\text { Deferred Debits }\end{array}$ & & 3,539 & 5,969 \\
\hline 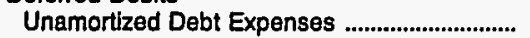 & 0 & 563 & 0 & 0 & 188 & 0 \\
\hline 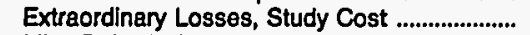 & 0 & 0 & 0 & 0 & 0 & 0 \\
\hline Misc Debt, R \& D Exp, Unamit Losses ........... & 0 & 0 & 0 & 0 & 0 & 0 \\
\hline Total Deferred Debits ............................................. & & 563 & & 0 & 188 & \\
\hline $\begin{array}{l}\text { Total Assets \& Other Deblts .......................... } \\
\text { Proprietary Capital }\end{array}$ & 11,636 & 38,055 & 24,992 & 28,630 & 11,100 & 12,586 \\
\hline Investment of Municipality ........................................ & 0 & 0 & 52 & 0 & 0 & 0 \\
\hline 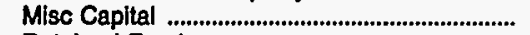 & 0 & 0 & 0 & 0 & 0 & 40 \\
\hline 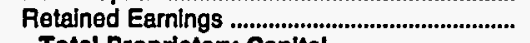 & 10,530 & 17,222 & 16,393 & 17,546 & 5,076 & 11,189 \\
\hline $\begin{array}{l}\text { Total Propriotary Capital .................................. } \\
\text { Long-term Debt }\end{array}$ & Long-term Debt & 17,222 & 16,445 & 17,546 & 5,076 & 11,228 \\
\hline Bonds & 0 & 18,585 & 6.540 & 9,499 & 5,340 & 0 \\
\hline Advances from Municipality \& Other ................ & 0 & 0 & 0 & 0 & 0 & 0 \\
\hline Unamort Prem on Long-term Debt ....................... & 0 & 0 & 0 & 0 & 0 & 0 \\
\hline (less) Unamort Discount on Long-term Debt & 0 & 0 & 0 & 0 & 0 & 0 \\
\hline \multicolumn{6}{|l|}{ Other Noncurrent Liabilities } & $\mathbf{0}$ \\
\hline Accum Operating Provisions ................................. & 0 & 0 & 531 & 351 & 0 & 0 \\
\hline Accum Prov for Rate Refunds ............................... & 0 & 0 & 0 & 0 & 0 & 0 \\
\hline $\begin{array}{l}\text { Total Other Noncurrent Llabllities ............. } \\
\text { Current and Accrued Llabilitities }\end{array}$ & 0 & 0 & 531 & 351 & 0 & 0 \\
\hline 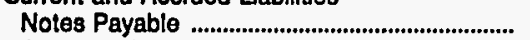 & 0 & 720 & 0 & 0 & 0 & 0 \\
\hline 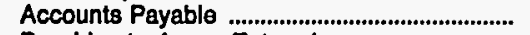 & 0 & 743 & 823 & 893 & 209 & 705 \\
\hline 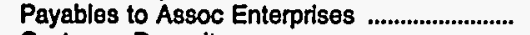 & 0 & 0 & 0 & 0 & 160 & 0 \\
\hline 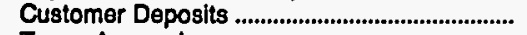 & 0 & 0 & 248 & 0 & 202 & 0 \\
\hline 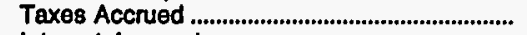 & 0 & 0 & 0 & 0 & $\mathbf{0}$ & 0 \\
\hline 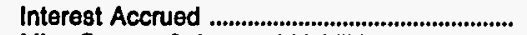 & 0 & 127 & 0 & 0 & 30 & 0 \\
\hline Misc Current \& Accrued Liabilities ....................... & 1,107 & 658 & 405 & 341 & 84 & 653 \\
\hline $\begin{array}{l}\text { Total Current \& Accrued Liabilltles ........... } \\
\text { Deferrod Credits }\end{array}$ & 1,107 & 2,248 & 1,476 & 1,233 & 684 & 1,358 \\
\hline \multirow{5}{*}{ 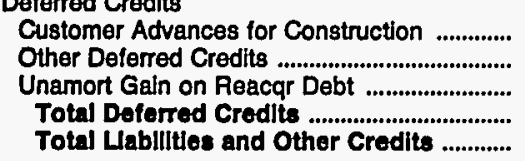 } & 0 & 0 & 0 & 0 & 0 & 0 \\
\hline & 0 & 0 & 0 & 0 & 0 & 0 \\
\hline & 0 & 0 & 0 & 0 & 0 & 0 \\
\hline & & & & & & \\
\hline & 11,636 & 38,055 & 24,992 & 28,630 & 11,100 & 12,586 \\
\hline
\end{tabular}

Note: Totals may not equal sum of components because of independent rounding.

Source: Energy Information Adminlstration, Form ElA-412, "Annual Report of Public Electric Utilities." 
Table 22. Balance Sheet by Major U.S. Publicly Owned Electric Utility Within State at End of Period, 1993 (Continued)

(Thousand Dollars)

\begin{tabular}{|c|c|c|c|c|c|c|}
\hline Item & $\begin{array}{c}\text { Ohio } \\
\text { Wapakoneta } \\
\text { City of }\end{array}$ & $\begin{array}{c}\text { Ohio } \\
\text { Westerville } \\
\text { City of }\end{array}$ & $\begin{array}{l}\text { Oklahoma } \\
\text { Altus } \\
\text { City of } \\
\text { June } 30\end{array}$ & $\begin{array}{l}\text { Oklahoma } \\
\text { Claremore } \\
\text { City of } \\
\text { June } 30\end{array}$ & $\begin{array}{l}\text { Oklahoma } \\
\text { Duncan } \\
\text { City of } \\
\text { June } 30\end{array}$ & $\begin{array}{l}\text { Oklahoma } \\
\text { Edmond } \\
\text { City of } \\
\text { June } 30\end{array}$ \\
\hline \multicolumn{7}{|l|}{ Electric Utility Plant } \\
\hline Electric Utility Plant \& Adjust .......................... & 0 & 19,301 & 7,855 & 0 & 18,263 & 33,929 \\
\hline Const Work in Progress & 0 & & & 0 & & 0 \\
\hline (less) Depr, Amort, and Depletion ..................... & 0 & 6,915 & 4,926 & 0 & 7,865 & 15,483 \\
\hline Not Electric Utility Plant ................................ & 0 & 12,385 & 2,929 & 0 & 10,486 & 18,446 \\
\hline Nuclear Fuel ..................................................... & 0 & 0 & 0 & 0 & 0 & 0 \\
\hline 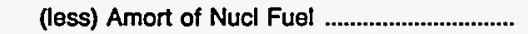 & 0 & 0 & 0 & 0 & 0 & 0 \\
\hline 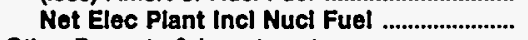 & 0 & 12,385 & 2,929 & 0 & 10,486 & 18,446 \\
\hline \multicolumn{7}{|l|}{ Other Property \& Investments } \\
\hline 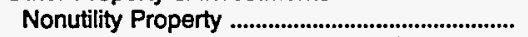 & 0 & 3,928 & 0 & 0 & 0 & 0 \\
\hline (less) Accum Provisions for Depr \& Amort .... & 0 & 1,835 & 0 & $\mathbf{0}$ & 0 & 0 \\
\hline 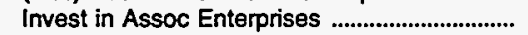 & 0 & 0 & 0 & 0 & 0 & 0 \\
\hline 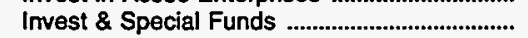 & 0 & 0 & 0 & 0 & 0 & 1,736 \\
\hline Total Other Property \& Investments ........ & 0 & 2,093 & 0 & 0 & 0 & 1,736 \\
\hline \multicolumn{7}{|l|}{ Current and Accrued Assets } \\
\hline Cash, Working Funds \& Investments ............... & 2,007 & 25,725 & 5,302 & 179 & 5,969 & 3,247 \\
\hline 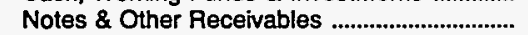 & 0 & & & 0 & 48 & 0 \\
\hline Customer Accts Receivable ................................... & 0 & 2,689 & 849 & 1,051 & 1,216 & 1,357 \\
\hline (less) Accum Prov for Uncollected Accts ...... & 0 & 68 & 208 & 0 & 0 & 67 \\
\hline 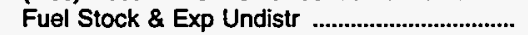 & 0 & 0 & 0 & 0 & 0 & 0 \\
\hline 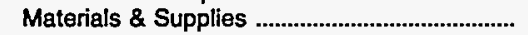 & 0 & 974 & 604 & 82 & 0 & 0 \\
\hline 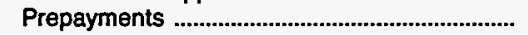 & 0 & 0 & 0 & 0 & 0 & 0 \\
\hline 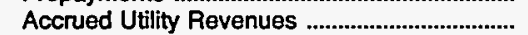 & 0 & 0 & 0 & 0 & 0 & 0 \\
\hline Miscellaneous Current \& Accrued Assets ...... & 0 & 0 & 638 & 0 & 0 & 28 \\
\hline Total Current \& Accrued Assets ................ & 2,007 & 29,336 & 7,185 & 1,313 & 7,232 & 4,565 \\
\hline \multicolumn{7}{|l|}{ Deferred Debits } \\
\hline 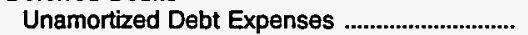 & 0 & 0 & 0 & 0 & 0 & 0 \\
\hline 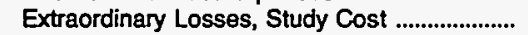 & 0 & 0 & 0 & 0 & 0 & 0 \\
\hline Misc Debt, R \& D Exp, Unamrt Losses .......... & 0 & 0 & 0 & 0 & 0 & 0 \\
\hline 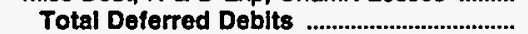 & o & $\mathbf{0}$ & o & $\mathbf{0}$ & 0 & 0 \\
\hline 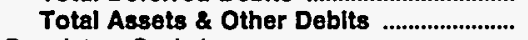 & 2,007 & 43,814 & 10,115 & 1,313 & 17,718 & 24,747 \\
\hline \multicolumn{7}{|l|}{ Proprietary Capital } \\
\hline 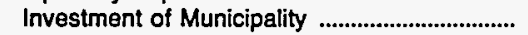 & 471 & 0 & 3,184 & 0 & 13,329 & 0 \\
\hline 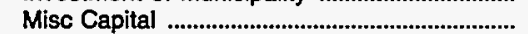 & 0 & 197 & 0 & 0 & 0 & 0 \\
\hline Retained Earnings ................................................. & 1,536 & 41,460 & 6,335 & 404 & 3,258 & 18,524 \\
\hline Total Proprietary Capital ............................... & 2,007 & 41,657 & 9,519 & 404 & 16,587 & 18,524 \\
\hline \multicolumn{7}{|l|}{ Long-term Debt } \\
\hline 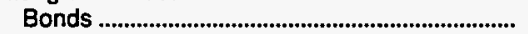 & $\mathbf{0}$ & 0 & 0 & 0 & 0 & 900 \\
\hline Advances from Municipality \& Other ................ & 0 & 0 & 0 & 0 & 0 & 0 \\
\hline Unamort Prem on Long-term Debt .................... & 0 & 0 & 0 & 0 & 0 & 0 \\
\hline (less) Unamort Discount on Long-term Debt & 0 & 0 & 0 & 0 & 0 & \\
\hline 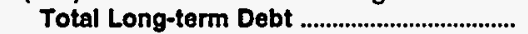 & $\mathbf{0}$ & 0 & 0 & $\mathbf{0}$ & $\mathbf{0}$ & 900 \\
\hline \multicolumn{7}{|l|}{ Other Noncurrent Liabilities } \\
\hline Accum Operating Provisions ..................................... & 0 & 270 & 0 & 0 & 0 & 0 \\
\hline 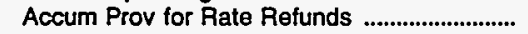 & 0 & 0 & 0 & 0 & 0 & 0 \\
\hline 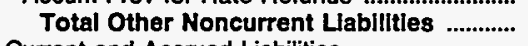 & 0 & 270 & 0 & $\mathbf{0}$ & o & 0 \\
\hline \multicolumn{7}{|l|}{ Current and Accrued Liabilities } \\
\hline 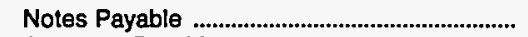 & 0 & 0 & 0 & 82 & 0 & 635 \\
\hline Accounts Payable & 0 & 1,693 & 596 & 827 & 466 & 2,927 \\
\hline 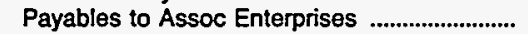 & 0 & 0 & 0 & 0 & 665 & 0 \\
\hline 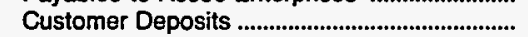 & 0 & 38 & 0 & 0 & 0 & 1,740 \\
\hline 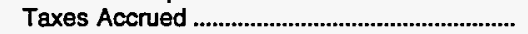 & 0 & 0 & 0 & 0 & 0 & 0 \\
\hline Interest Accrued .............................................. & 0 & 0 & 0 & 0 & 0 & 4 \\
\hline Misc Current \& Accrued Liabilities ...................... & 0 & 148 & 0 & 0 & 0 & 17 \\
\hline Total Current \& Accrued Llabilltes .......... & o & 1,879 & 596 & 909 & 1,131 & 5,323 \\
\hline \multicolumn{7}{|l|}{ Deferred Credits } \\
\hline Customer Advances for Construction .................. & 0 & 0 & 0 & 0 & 0 & 0 \\
\hline 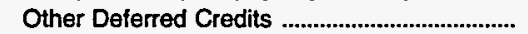 & 0 & 9 & 0 & 0 & 0 & 0 \\
\hline Unamort Gain on Reacqr Debt ............................... & 0 & 0 & 0 & 0 & 0 & 0 \\
\hline Total Deferred Credits ....................................... & 0 & & 0 & 0 & 0 & $\mathbf{0}$ \\
\hline Total Llabillties and Other Credits ............ & 2,007 & 43,814 & 10,115 & 1,313 & 17,718 & 24,747 \\
\hline
\end{tabular}

Note: Totals may not equal sum of components because of independent rounding.

Source: Energy Information Administration, Form ElA-412, "Annual Report of Public Electric Utilities." 
Table 22. Balance Sheet by Major U.S. Publicly Owned Electric Utility Within State at End of Period, 1993 (Continued)

(Thousand Dollars)

\begin{tabular}{|c|c|c|c|c|c|c|}
\hline ltem & $\begin{array}{c}\text { Oklahoma } \\
\text { Grand River } \\
\text { Dam } \\
\text { Authority } \\
\text { December } 31\end{array}$ & $\begin{array}{l}\text { Oklahoma } \\
\text { Miami } \\
\text { City of } \\
\text { June } 30\end{array}$ & $\begin{array}{c}\text { Oklahoma } \\
\text { Oklahoma } \\
\text { Municipal } \\
\text { Power Auth } \\
\text { December } 31\end{array}$ & $\begin{array}{l}\text { Oklahoma } \\
\text { Ponca } \\
\text { City City of } \\
\text { June } 30\end{array}$ & $\begin{array}{l}\text { Oklahoma } \\
\text { Stillwater } \\
\text { Utilities } \\
\text { Authority } \\
\text { June } 30\end{array}$ & $\begin{array}{l}\text { Oregon } \\
\text { Ashland } \\
\text { City of } \\
\text { June } 30\end{array}$ \\
\hline \multicolumn{7}{|l|}{ Electric Utility Plant } \\
\hline 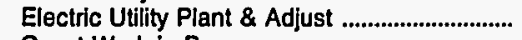 & 878,237 & 3,477 & 161,578 & 35,038 & 26,845 & 10,720 \\
\hline Const Work in Progress .................................... & 13,056 & & 13,854 & 0 & 4,933 & 637 \\
\hline 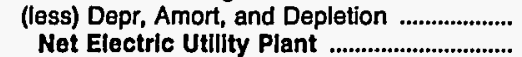 & $\begin{array}{l}278,448 \\
612,845\end{array}$ & $\begin{array}{l}2,471 \\
1,006\end{array}$ & $\begin{array}{r}30,173 \\
145,259\end{array}$ & $\begin{array}{l}14,894 \\
20,144\end{array}$ & $\begin{array}{l}12,823 \\
18,955\end{array}$ & $\begin{array}{r}0 \\
11,357\end{array}$ \\
\hline 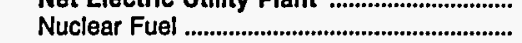 & $\begin{array}{r}012,045 \\
0\end{array}$ & & $\begin{array}{r}140,209 \\
0\end{array}$ & $\begin{array}{r}20,144 \\
0\end{array}$ & $\begin{array}{r}18,955 \\
0\end{array}$ & $\begin{array}{r}11,357 \\
0\end{array}$ \\
\hline 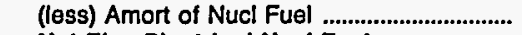 & & & 0 & 0 & 0 & 0 \\
\hline Net Elec Plant Incl Nucl Fuel .......................... & 612,845 & 1,006 & 145,259 & 20,144 & 18,955 & 11,357 \\
\hline \multicolumn{7}{|l|}{ Other Property \& Investments } \\
\hline (less) Accum Provisions for Depr \& Amort .... & $\begin{array}{r}33 \\
0\end{array}$ & $\begin{array}{r}11,160 \\
3,951\end{array}$ & 0 & 0 & 0 & 0 \\
\hline 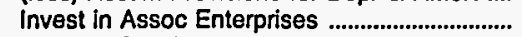 & 0 & $\begin{array}{r}0,901 \\
0\end{array}$ & 0 & $\begin{array}{l}0 \\
0\end{array}$ & $\begin{array}{l}0 \\
0\end{array}$ & $\begin{array}{l}0 \\
0\end{array}$ \\
\hline 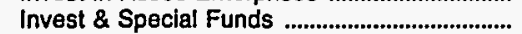 & 97,062 & 0 & 86,182 & 6,944 & 0 & 0 \\
\hline \multicolumn{7}{|l|}{ Current and Accrued Assats } \\
\hline Cash, Working Funds \& Investments ............... & 105,520 & 4,963 & 27,947 & 6 & 17,220 & 565 \\
\hline Notes \& Other Receivables .................................... & 24,501 & 8 & 5,250 & -193 & 31 & 118 \\
\hline Customer Accts Receivable ............................ & 13,910 & 694 & 0 & 1,575 & 3,355 & 390 \\
\hline (less) Accum Prov for Uncollected Accts ...... & 200 & 153 & 0 & 0 & 11 & 0 \\
\hline 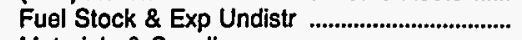 & 5,117 & 0 & 0 & 0 & 0 & 0 \\
\hline 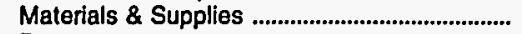 & 19,001 & 0 & 0 & 0 & 509 & 463 \\
\hline 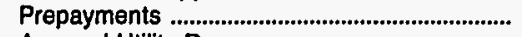 & 706 & 575 & 0 & 0 & 0 & 0 \\
\hline 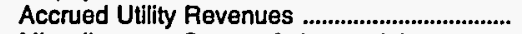 & 0 & 0 & 0 & 0 & 0 & 0 \\
\hline Miscellaneous Current \& Accrued Assets ..... & 1,239 & & 2,608 & & 0 & \\
\hline Total Current \& Accrued Assets ................. & 169,794 & 6,087 & 35,805 & 1,388 & 21,104 & 1,536 \\
\hline \multicolumn{7}{|l|}{ Deferred Debits } \\
\hline Unamortized Debt Expenses ................................ & 9,875 & 0 & 46,778 & 0 & 0 & 0 \\
\hline 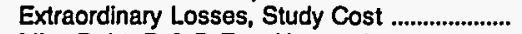 & & 0 & 0 & 0 & 0 & 0 \\
\hline Misc Debt, R \& D Exp, Unamrt Losses .......... & 258,544 & 0 & 44,076 & 0 & 0 & 1,084 \\
\hline 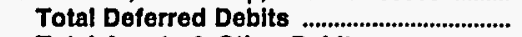 & 268,422 & & 90,854 & 0 & 0 & 1,084 \\
\hline \multicolumn{7}{|l|}{ Proprietary Capital } \\
\hline 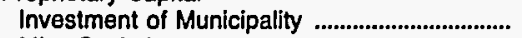 & 0 & 0 & 0 & 0 & 11,817 & 2,267 \\
\hline 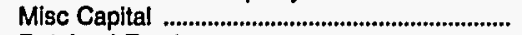 & 0 & 0 & 0 & 0 & 0 & 8,453 \\
\hline 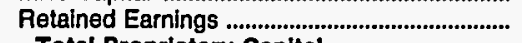 & 27,180 & 13,130 & 9,765 & 21,435 & 25,239 & 1,373 \\
\hline 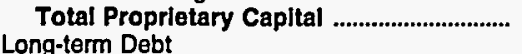 & 27,180 & 13,130 & 9,765 & 21,435 & 37,056 & 12,093 \\
\hline \multicolumn{7}{|l|}{ Long-term Debt } \\
\hline Advances from Municipality \& Other ................ & 1,889 & 0 & & 0 & 0 & 8 \\
\hline Unamort Prem on Long-term Debt ................... & & 0 & 0 & 0 & 0 & 0 \\
\hline (less) Unamort Discount on Long-term Debt & 27,650 & 0 & 15,331 & 27 & 0 & 0 \\
\hline 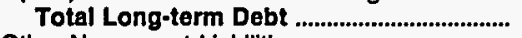 & $1,104,749$ & 0 & 324,724 & 6,062 & 0 & 1,084 \\
\hline \multicolumn{7}{|l|}{ Other Noncurrent Liabilities } \\
\hline 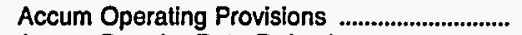 & 0 & 0 & 0 & 0 & 0 & 0 \\
\hline 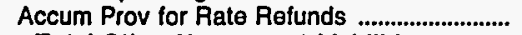 & 0 & 0 & 0 & 0 & 0 & 0 \\
\hline Total Other Noncurrent Llabilitles ............. & 0 & 0 & 0 & 0 & 0 & 0 \\
\hline \multicolumn{7}{|l|}{ Current and Accrued Liabilities } \\
\hline Notes Payable ............................................................ & 0 & 0 & 0 & 0 & 0 & 0 \\
\hline 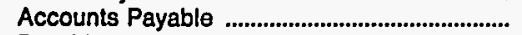 & 8,258 & 889 & 6,209 & 40 & 2,831 & 56 \\
\hline 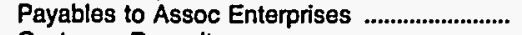 & 0 & 0 & 0 & 0 & 9 & 397 \\
\hline 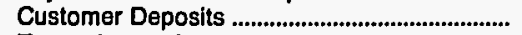 & 0 & 283 & 0 & 757 & 0 & 93 \\
\hline 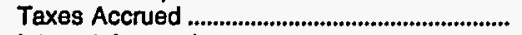 & -7 & 0 & 0 & 0 & 0 & 0 \\
\hline 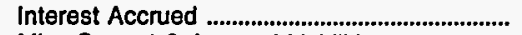 & 5,206 & 0 & 10,227 & 125 & 0 & 0 \\
\hline Misc Current \& Accrued Ljabilities ...................... & 1,834 & 0 & 2,852 & 56 & 163 & 198 \\
\hline Total Current \& Accrued Llabilities ........... & 15,290 & 1,172 & 19,289 & 979 & 3,003 & 745 \\
\hline \multicolumn{7}{|l|}{ Delerred Credits } \\
\hline Customer Advances for Construction .............. & 0 & 0 & 4,076 & 0 & 0 & 5 \\
\hline 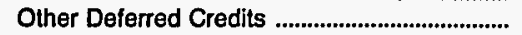 & 936 & 0 & 246 & 0 & 0 & 51 \\
\hline Unamort Gain on Reacqr Debt ............................. & 0 & 0 & 0 & 0 & o & 0 \\
\hline 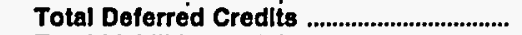 & 936 & & 4,323 & & & \\
\hline Total Llabllitles and Other Credits ............ & $1,148,156$ & 14,302 & 358,100 & 28,476 & 40,059 & 13,977 \\
\hline
\end{tabular}

Note: Totals may not equal sum of components because of independent rounding.

Source: Energy Information Administration, Form EIA-412, "Annual Report of Public Electric Utilities." 
Table 22. Balance Sheet by Major U.S. Publicly Owned Electric Utility Within State at End of Period, 1993 (Continued) (Thousand Dollars)

\begin{tabular}{|c|c|c|c|c|c|c|}
\hline Item & $\begin{array}{c}\text { Oregon } \\
\text { Central } \\
\text { Lincoln } \\
\text { Peoples } \\
\text { Utl Dt } \\
\text { December } 31\end{array}$ & $\begin{array}{l}\text { Oregon } \\
\text { Clatskanie } \\
\text { Peoples } \\
\text { Util Dist } \\
\text { December } 31\end{array}$ & $\begin{array}{c}\text { Oregon } \\
\text { Columbia } \\
\text { River } \\
\text { Peoples } \\
\text { Ut Dist } \\
\text { December } 31\end{array}$ & $\begin{array}{l}\text { Oregon } \\
\text { Emerald } \\
\text { Peoples } \\
\text { Utility Dist } \\
\text { December } 31\end{array}$ & $\begin{array}{l}\text { Oregon } \\
\text { Eugene } \\
\text { City of } \\
\text { December } 31\end{array}$ & $\begin{array}{c}\text { Forest Grove } \\
\text { City of } \\
\text { June } 30\end{array}$ \\
\hline \multicolumn{7}{|l|}{ Electric Utility Plant } \\
\hline Electric Utility Plant \& Adjust ............................ & 77,800 & 6,443 & 22,639 & 66,980 & 268,396 & 10,887 \\
\hline Const Work in Progress & 5,987 & & 129 & 4,454 & 5,688 & 164 \\
\hline 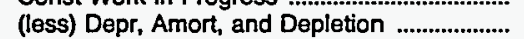 & 32,356 & 3,204 & 3,977 & 24,723 & 114,988 & 3,559 \\
\hline 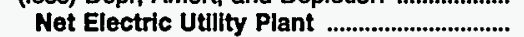 & 51,431 & 3,302 & 18,791 & 46,712 & 159,096 & 7,492 \\
\hline 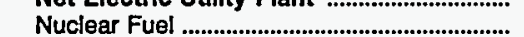 & $\begin{array}{r}1,401 \\
0\end{array}$ & 0 & 0 & 0 & 0 & 0 \\
\hline (less) Amort of Nucl Fuel ..................... & 0 & 0 & 0 & 0 & 0 & 0 \\
\hline 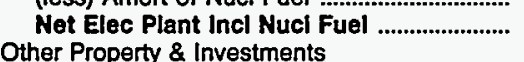 & 51,431 & 3,302 & 18,791 & 46,712 & 159,096 & 7,492 \\
\hline 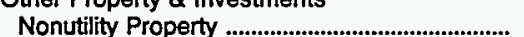 & 0 & 0 & 509 & 0 & 0 & 0 \\
\hline (less) Accum Provisions for Depr \& Amort .... & 0 & 0 & 133 & 0 & 0 & 0 \\
\hline 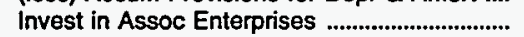 & 0 & 0 & 0 & 0 & 0 & 0 \\
\hline Invest \& Special Funds ........................................ & 8,796 & 0 & 2,946 & 6,890 & 4,280 & 0 \\
\hline Total Other Property \& Investments ....... & 8,796 & 0 & 3,321 & 6,890 & 4,280 & $\mathbf{0}$ \\
\hline \multicolumn{7}{|l|}{ Current and Accrued Assets } \\
\hline Cash, Working Funds \& Investments .............. & 1,563 & 2,153 & 1,136 & 3,126 & 16,059 & 918 \\
\hline 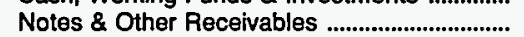 & & & 51 & 1,227 & 0 & 1 \\
\hline 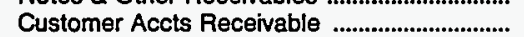 & 4,409 & 2,084 & 1,396 & 1,745 & 11,369 & 297 \\
\hline (less) Accum Prov for Uncollected Accts ...... & 168 & 11 & 17 & 35 & 214 & 65 \\
\hline 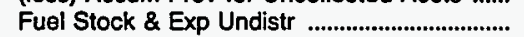 & 0 & 0 & 0 & 0 & 0 & 0 \\
\hline 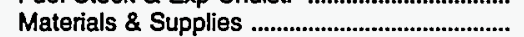 & 1,815 & 178 & 246 & 381 & 2,784 & 306 \\
\hline 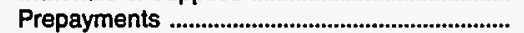 & 753 & 92 & 55 & 216 & 494 & 0 \\
\hline 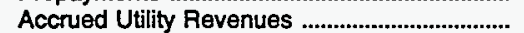 & 0 & 0 & 0 & 801 & 6,117 & 0 \\
\hline Miscellaneous Current \& Accrued Assets ..... & 174 & 0 & 10 & 0 & 6,155 & 107 \\
\hline $\begin{array}{l}\text { Total Current \& Accrued Assets ............... } \\
\text { Deferred Debits }\end{array}$ & 8,547 & 4,496 & 2,877 & 7,460 & 42,763 & 1,564 \\
\hline 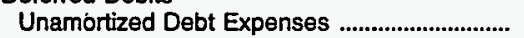 & 426 & 0 & 2,975 & 1,226 & 313 & 0 \\
\hline 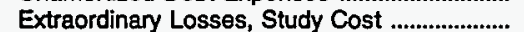 & 0 & 1,732 & 0 & 0 & 3,040 & 0 \\
\hline Misc Debt, R \& D Exp, Unamrt Losses .......... & 5,123 & 0 & 0 & 9,595 & 17,639 & 0 \\
\hline 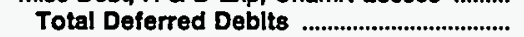 & 5,549 & 1,732 & 2,975 & 10,821 & 20,992 & 0 \\
\hline 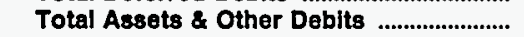 & 74,323 & 9,529 & 27,964 & 71,882 & 227,132 & 9,057 \\
\hline \multicolumn{7}{|l|}{ Proprietary Capital } \\
\hline 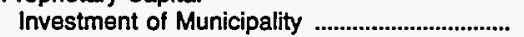 & 0 & 0 & 0 & 0 & 0 & 8,499 \\
\hline 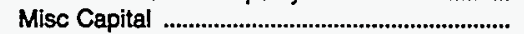 & 0 & 0 & 0 & 0 & 0 & 0 \\
\hline 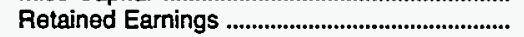 & 50,170 & 6,722 & 8,137 & 591 & 132,842 & 224 \\
\hline \multicolumn{7}{|l|}{ Long-term Debt } \\
\hline 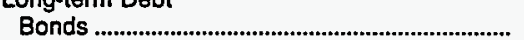 & 14,650 & 0 & 17,405 & 67,125 & 69,002 & 0 \\
\hline Advances from Municipality \& Other .............. & 0 & 0 & $\begin{array}{r}11,400 \\
0\end{array}$ & 135 & $\begin{array}{r}0,000 \\
0\end{array}$ & 0 \\
\hline Unamort Prem on Long-term Debt .................. & 0 & 0 & 0 & 0 & 0 & 0 \\
\hline (less) Unamort Discount on Long-term Debt & 0 & 0 & 0 & 800 & 327 & 0 \\
\hline 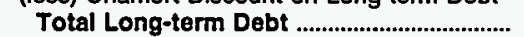 & 14,650 & o & 17,405 & 66,460 & 68,675 & 0 \\
\hline \multicolumn{7}{|l|}{ Other Noncurrent Liabilities } \\
\hline Accum Operating Provisions ............................. & 1,585 & 98 & 0 & 0 & 0 & 0 \\
\hline 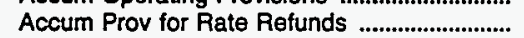 & & 0 & 0 & 0 & 0 & 0 \\
\hline 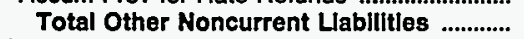 & 1,585 & 98 & 0 & o & $\mathbf{0}$ & 0 \\
\hline \multicolumn{7}{|l|}{ Current and Accrued Liabilities } \\
\hline 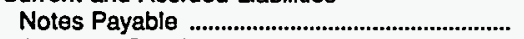 & 0 & 0 & 0 & 0 & 0 & 0 \\
\hline 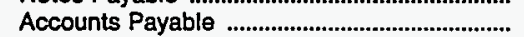 & 4,634 & 2,254 & 1,272 & 1,597 & 9,941 & 135 \\
\hline Payables to Assoc Enterprises ........................ & 0 & 0 & 0 & 0 & 0 & 0 \\
\hline 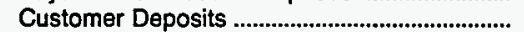 & 198 & 16 & 35 & 8 & 209 & 0 \\
\hline Taxes Accrued & 0 & 0 & 63 & 9 & 689 & 0 \\
\hline Interest Accrued & 270 & 0 & 203 & 713 & 2,315 & 0 \\
\hline Misc Current \& Accrued Liabilities ..................... & 0 & 0 & 194 & 2,438 & 9,464 & 0 \\
\hline Total Current \& Accrued Liabllitles .......... & 5,102 & 2,271 & 1,767 & 4,765 & 22,618 & 135 \\
\hline \multicolumn{7}{|l|}{ Deferred Credits } \\
\hline Customer Advances for Construction .............. & 2 & 439 & 134 & 0 & 103 & 157 \\
\hline 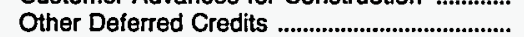 & 2,815 & 0 & 520 & 67 & 697 & 41 \\
\hline 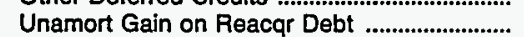 & 0 & $\mathbf{0}$ & 0 & 0 & 2,197 & 0 \\
\hline 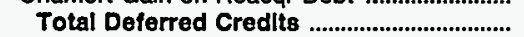 & 2,817 & 439 & 655 & 67 & 2,996 & 198 \\
\hline Total Llabilltes and Other Credits ............ & 74,323 & 9,529 & 27,964 & 71,882 & 227,132 & 9,057 \\
\hline
\end{tabular}

Note: Totals may not equal sum of components because of independent rounding.

Source: Energy Information Administration, Form ElA-412, "Annual Report of Public Electric Utilities." 
Table 22. Balance Sheet by Major U.S. Publicly Owned Electric Utility Within State at End of Period, 1993 (Continued)

(Thousand Dollars)

\begin{tabular}{|c|c|c|c|c|c|c|}
\hline Item & $\begin{array}{l}\text { Oregon } \\
\text { McMinnville } \\
\text { City of } \\
\text { June } 30\end{array}$ & $\begin{array}{l}\text { Oregon } \\
\text { Northern } \\
\text { Wasco County } \\
\text { PU D } \\
\text { December } 31\end{array}$ & $\begin{array}{l}\text { Springfield } \\
\text { City of } \\
\text { December } 31\end{array}$ & $\begin{array}{l}\text { Oregon } \\
\text { Tillamook } \\
\text { Peoples } \\
\text { Utility Dist } \\
\text { December } 31\end{array}$ & $\begin{array}{l}\text { Pennsylvania } \\
\text { Chambersburg } \\
\text { Borough of } \\
\text { December } 31\end{array}$ & $\begin{array}{l}\text { Pennsylvania } \\
\text { Lansdale } \\
\text { Borough of } \\
\text { December } 31\end{array}$ \\
\hline 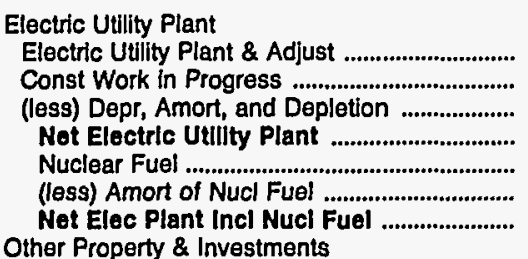 & $\begin{array}{r}20,333 \\
160 \\
5,183 \\
15,310 \\
0 \\
0 \\
15,310\end{array}$ & $\begin{array}{r}32,706 \\
118 \\
9,297 \\
23,528 \\
0 \\
0 \\
23,528\end{array}$ & $\begin{array}{r}41,346 \\
704 \\
12,209 \\
29,840 \\
0 \\
0 \\
29,840\end{array}$ & $\begin{array}{r}33,296 \\
962 \\
8,854 \\
25,403 \\
0 \\
0 \\
25,403\end{array}$ & $\begin{array}{r}25,424 \\
477 \\
13,304 \\
12,597 \\
0 \\
0 \\
12,597\end{array}$ & $\begin{array}{r}9,871 \\
0 \\
3,709 \\
6,162 \\
0 \\
0 \\
6,162\end{array}$ \\
\hline 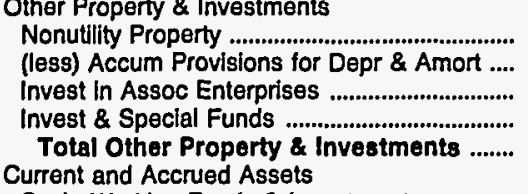 & $\begin{array}{l}0 \\
0 \\
0 \\
0 \\
0\end{array}$ & $\begin{array}{r}0 \\
0 \\
0 \\
2,501 \\
2,501\end{array}$ & $\begin{array}{r}0 \\
0 \\
0 \\
4,601 \\
4,601\end{array}$ & $\begin{array}{r}0 \\
0 \\
0 \\
4,152 \\
4,152\end{array}$ & $\begin{array}{r}0 \\
0 \\
232 \\
1,726 \\
1,958\end{array}$ & $\begin{array}{l}0 \\
0 \\
0 \\
0 \\
0\end{array}$ \\
\hline 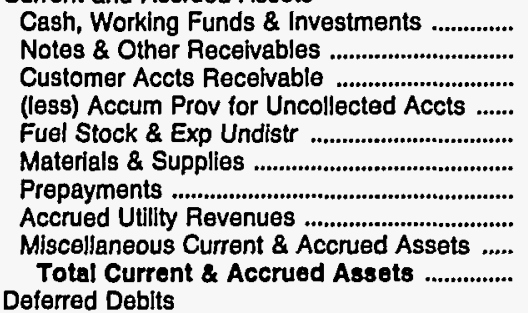 & $\begin{array}{r}3,922 \\
478 \\
1,287 \\
10 \\
0 \\
212 \\
0 \\
0 \\
0 \\
5,889\end{array}$ & $\begin{array}{r}34,999 \\
33 \\
1,001 \\
98 \\
0 \\
406 \\
143 \\
0 \\
0 \\
36,483\end{array}$ & $\begin{array}{r}1,934 \\
108 \\
3,967 \\
56 \\
0 \\
1,170 \\
16 \\
0 \\
33 \\
7,171\end{array}$ & $\begin{array}{r}5,176 \\
225 \\
1,442 \\
100 \\
0 \\
508 \\
327 \\
0 \\
51 \\
7,630\end{array}$ & $\begin{array}{r}2,017 \\
0 \\
1,418 \\
2 \\
47 \\
0 \\
8 \\
0 \\
34 \\
3,522\end{array}$ & $\begin{array}{r}18,329 \\
129 \\
1,196 \\
43 \\
0 \\
297 \\
0 \\
0 \\
0 \\
19,907\end{array}$ \\
\hline 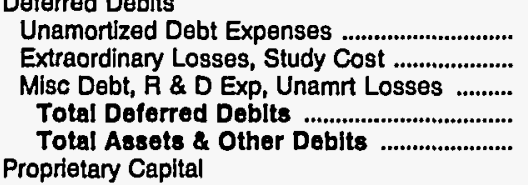 & $\begin{array}{r}0 \\
0 \\
631 \\
631 \\
21,830\end{array}$ & $\begin{array}{r}1,617 \\
1,699 \\
0 \\
3,316 \\
65,827\end{array}$ & $\begin{array}{r}97 \\
0 \\
883 \\
980 \\
42,593\end{array}$ & $\begin{array}{r}203 \\
37 \\
719 \\
960 \\
38,144\end{array}$ & $\begin{array}{r}0 \\
0 \\
0 \\
0 \\
18,077\end{array}$ & $\begin{array}{r}194 \\
0 \\
0 \\
194 \\
26,263\end{array}$ \\
\hline 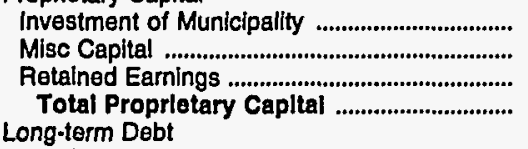 & $\begin{array}{r}440 \\
2,330 \\
15,863 \\
18,633\end{array}$ & $\begin{array}{r}76 \\
81 \\
9,767 \\
9,924\end{array}$ & $\begin{array}{r}0 \\
1,912 \\
30,516 \\
32,427\end{array}$ & $\begin{array}{r}0 \\
0 \\
21,868 \\
21,868\end{array}$ & $\begin{array}{r}997 \\
0 \\
15,957 \\
16,954\end{array}$ & $\begin{array}{r}0 \\
1,580 \\
15,203 \\
16,783\end{array}$ \\
\hline 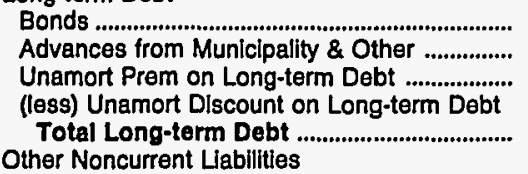 & $\begin{array}{r}0 \\
649 \\
0 \\
0 \\
649\end{array}$ & $\begin{array}{r}53,315 \\
0 \\
0 \\
0 \\
53,315\end{array}$ & $\begin{array}{r}4,138 \\
0 \\
0 \\
0 \\
4,138\end{array}$ & $\begin{array}{r}13,151 \\
0 \\
0 \\
0 \\
13,151\end{array}$ & $\begin{array}{l}0 \\
0 \\
0 \\
0 \\
0\end{array}$ & $\begin{array}{r}8,545 \\
0 \\
0 \\
0 \\
8,545\end{array}$ \\
\hline 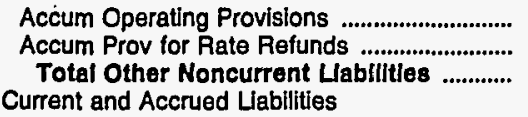 & $\begin{array}{l}0 \\
0 \\
0\end{array}$ & $\begin{array}{l}0 \\
0 \\
0\end{array}$ & $\begin{array}{l}0 \\
0 \\
0\end{array}$ & $\begin{array}{l}0 \\
0 \\
0\end{array}$ & $\begin{array}{l}0 \\
0 \\
0\end{array}$ & $\begin{array}{l}0 \\
0 \\
0\end{array}$ \\
\hline 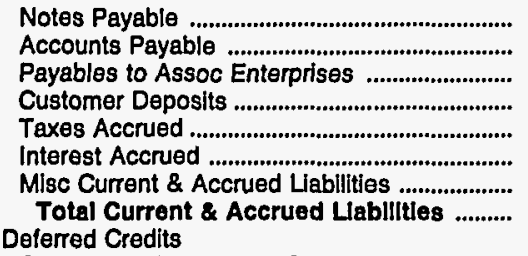 & $\begin{array}{r}0 \\
2,286 \\
0 \\
36 \\
0 \\
0 \\
225 \\
2,547\end{array}$ & $\begin{array}{r}0 \\
1,044 \\
0 \\
60 \\
48 \\
731 \\
249 \\
2,131\end{array}$ & $\begin{array}{r}0 \\
4,071 \\
0 \\
463 \\
24 \\
140 \\
537 \\
5,235\end{array}$ & $\begin{array}{r}0 \\
1,681 \\
0 \\
71 \\
0 \\
396 \\
293 \\
2,441\end{array}$ & $\begin{array}{r}0 \\
888 \\
0 \\
0 \\
0 \\
0 \\
108 \\
995\end{array}$ & $\begin{array}{r}0 \\
589 \\
0 \\
243 \\
0 \\
40 \\
62 \\
935\end{array}$ \\
\hline 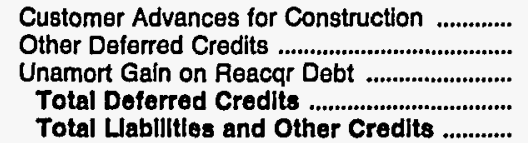 & $\begin{array}{r}0 \\
0 \\
0 \\
0 \\
21,830\end{array}$ & $\begin{array}{r}38 \\
419 \\
0 \\
457 \\
65,827\end{array}$ & $\begin{array}{r}49 \\
743 \\
0 \\
792 \\
42,593\end{array}$ & $\begin{array}{r}0 \\
685 \\
0 \\
685 \\
38,144\end{array}$ & $\begin{array}{r}127 \\
0 \\
0 \\
127 \\
18,077\end{array}$ & $\begin{array}{r}0 \\
0 \\
0 \\
0 \\
26,263\end{array}$ \\
\hline
\end{tabular}

Note: Totals may not equal sum of components because of independent rounding.

Source: Energy Information Administration, Form ElA-412, "Annual Report of Public Electric Utilities." 
Table 22. Balance Sheet by Major U.S. Publicly Owned Electric Utility Within State at End of Period, 1993 (Continued)

(Thousand Dollars)

\begin{tabular}{|c|c|c|c|c|c|c|}
\hline Item & $\begin{array}{l}\text { South Carolina } \\
\text { Camden } \\
\text { City of } \\
\text { June } 30\end{array}$ & $\begin{array}{l}\text { South Carolina } \\
\text { Easley } \\
\text { Combined } \\
\text { Utility } \\
\text { System } \\
\text { March } 31\end{array}$ & $\begin{array}{l}\text { South Carolina } \\
\begin{array}{c}\text { Gaffney } \\
\text { City of }\end{array} \\
\text { March } 31\end{array}$ & $\begin{array}{l}\text { South Carolina } \\
\text { Greenwood } \\
\text { Commissioners } \\
\text { Pub Wk } \\
\text { December } 31\end{array}$ & 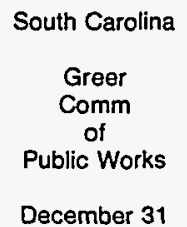 & $\begin{array}{l}\text { South Carolina } \\
\text { Newberry } \\
\text { City of } \\
\text { June } 30\end{array}$ \\
\hline \multicolumn{7}{|l|}{ Electric Utility Plant } \\
\hline 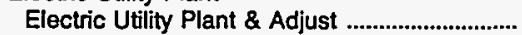 & 10,877 & 14,004 & 1,565 & 14,274 & 73,303 & 7,714 \\
\hline Const Work in Progress & & & 378 & & 2,729 & \\
\hline 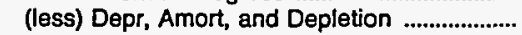 & 8,241 & 5,392 & 744 & 9,200 & 20,724 & 4,058 \\
\hline Net Electric Utillty Plant ............................... & 2,636 & 8,692 & 1,198 & 5,074 & 55,308 & 3,661 \\
\hline 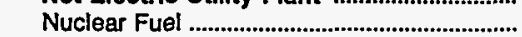 & 0 & 0 & 0 & 0 & 0 & 0 \\
\hline 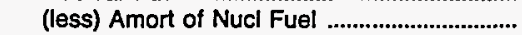 & 0 & 0 & 0 & 0 & 0 & 0 \\
\hline $\begin{array}{l}\text { Net Elec Plant Incl Nucl Fuel ........................... } \\
\text { Other Property \& Investments }\end{array}$ & 2,636 & 8,692 & 1,198 & 5,074 & 55,308 & 3,661 \\
\hline 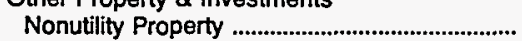 & 12,490 & 32,498 & 12,959 & 70,643 & 0 & 23,936 \\
\hline (less) Accum Provisions for Depr \& Amort .... & 2,299 & 10,484 & 4,511 & 19,708 & 0 & 8,986 \\
\hline 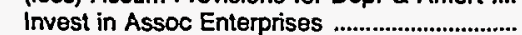 & 0 & 0 & 0 & 0 & 0 & 0 \\
\hline 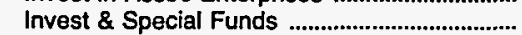 & 1,142 & 2,860 & 0 & 9,476 & 2,522 & 5,758 \\
\hline Total Other Property \& Investments ........ & 11,334 & 24,874 & 8,448 & 60,410 & 2,522 & 20,708 \\
\hline \multicolumn{7}{|l|}{ Current and Accrued Assets } \\
\hline Cash, Working Funds \& Investments ............... & 1,581 & 1,150 & 2,214 & 5,515 & 1,554 & 1,989 \\
\hline 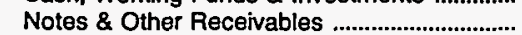 & & 55 & 0 & & 57 & 5 \\
\hline Customer Accts Receivable .................................... & 988 & 1,845 & 970 & 4,314 & 1,017 & 743 \\
\hline (less) Accum Prov for Uncollected Accts ...... & 0 & 0 & 10 & 0 & 0 & 109 \\
\hline 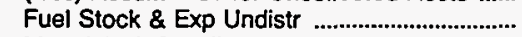 & 0 & 0 & 0 & 0 & 4 & 0 \\
\hline Materials \& Supplies ………………………….......... & 477 & 484 & 378 & 1,306 & 633 & 590 \\
\hline Prepayments ...................................................... & 46 & 0 & 3 & 55 & 0 & 0 \\
\hline Accrued Utility Revenues .................................... & 0 & 0 & 935 & 0 & 0 & 0 \\
\hline Miscellaneous Current \& Accrued Assets ...... & 0 & 0 & 0 & 922 & & 114 \\
\hline Total Current \& Accrued Assets .................... & 3,092 & 3,534 & 4,489 & 12,113 & 3,265 & 3,333 \\
\hline \multicolumn{7}{|l|}{ Deferred Debits } \\
\hline 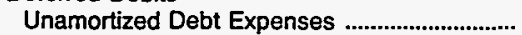 & 0 & 20 & 0 & 562 & 21 & 0 \\
\hline Extraordinary Losses, Study Cost ........................... & 0 & 0 & 0 & 0 & 0 & 0 \\
\hline Misc Debt, R \& D Exp, Unamrt Losses ........... & 0 & 0 & 0 & 0 & 0 & 0 \\
\hline 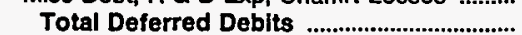 & 0 & 20 & o & 562 & 21 & 0 \\
\hline Total Assots \& Other Debits ............................ & 17,062 & 37,120 & 14,136 & 78,160 & 61,116 & 27,701 \\
\hline \multicolumn{7}{|l|}{ 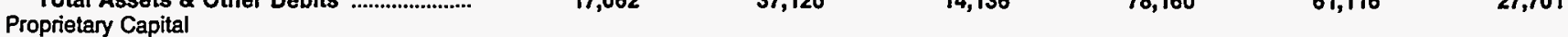 } \\
\hline 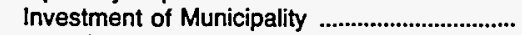 & 0 & 178 & 0 & 0 & 0 & 0 \\
\hline Misc Capital ................................................... & o & 12,899 & 0 & 6,341 & 11,462 & 320 \\
\hline Retained Earnings & 11,949 & 17,667 & 8,986 & 40,820 & 46,028 & 15,270 \\
\hline Total Proprietary Capltal .............................. & 11,949 & 30,744 & 8,986 & 47,161 & 57,490 & 15,590 \\
\hline \multicolumn{7}{|l|}{ Long-term Debt } \\
\hline 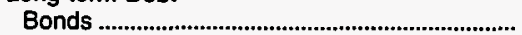 & 3,505 & 2,200 & 3,556 & 23,345 & 701 & 10,405 \\
\hline Advances from Municipality \& Other ................. & 0 & 27 & 0 & 0 & 0 & 611 \\
\hline Unamort Prem on Long-term Debt ...................... & 0 & 0 & 0 & 0 & 0 & 0 \\
\hline (iess) Unamort Discount on Long-term Debt & 0 & 0 & 0 & o & 0 & 0 \\
\hline Total Long-term Debt & 3,505 & 2,227 & 3,556 & 23,345 & 701 & 11,016 \\
\hline \multicolumn{7}{|l|}{ Other Noncurrent Liabilities } \\
\hline Accum Operating Provisions ............................. & 90 & 0 & 0 & 1,502 & 0 & 0 \\
\hline 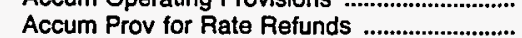 & 0 & 0 & 0 & 0 & 0 & 0 \\
\hline Total Other Noncurrent Liabilities ................. & 90 & 0 & 0 & 1,502 & 0 & 0 \\
\hline \multicolumn{7}{|l|}{ Current and Accrued Liabilities } \\
\hline 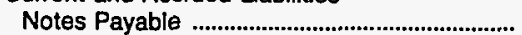 & 0 & 206 & 0 & 1,110 & 0 & 0 \\
\hline Accounts Payable .............................................. & 1,106 & 184 & 84 & 4,677 & 2,506 & 834 \\
\hline 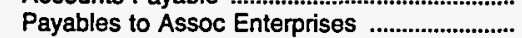 & 0 & 0 & 0 & 0 & 0 & 0 \\
\hline 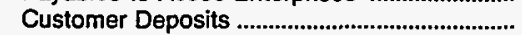 & 302 & 324 & 286 & 201 & 251 & 0 \\
\hline 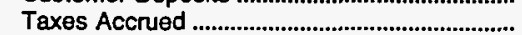 & 0 & 0 & 40 & 0 & 0 & 0 \\
\hline Interest Accrued & 78 & 53 & 0 & 101 & 0 & 183 \\
\hline 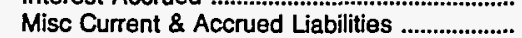 & 32 & 1,318 & 1,183 & 64 & 168 & 79 \\
\hline 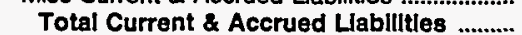 & 1,518 & 2,085 & 1,594 & 6,153 & 2,925 & 1,096 \\
\hline \multicolumn{7}{|l|}{ Deferred Credits } \\
\hline Customer Advances for Construction ................ & 0 & 238 & 0 & 0 & 0 & 0 \\
\hline Other Deferred Credits ............................................ & 0 & 1,826 & 0 & 0 & 0 & 0 \\
\hline Unamort Gain on Reacqr Debt .......................... & 0 & 0 & 0 & 0 & 0 & 0 \\
\hline Total Deferred Credits ................................. & & 2,064 & & 0 & 0 & \\
\hline Total Llabilities and Other Credlts ............ & 17,062 & 37,120 & 14,136 & 78,160 & 61,116 & 27,701 \\
\hline
\end{tabular}

Note: Totals may not equal sum of components because of independent rounding.

Source: Energy Information Administration, Form ElA-412, "Annual Report of Public Electric Utilities." 
Table 22. Balance Sheet by Major U.S. Publicly Owned Electric Utility Within State at End of Period, 1993 (Continued)

(Thousand Dollars)

\begin{tabular}{|c|c|c|c|c|c|c|}
\hline Item & $\begin{array}{l}\text { South Carolina } \\
\text { Orangeburg } \\
\text { City of } \\
\text { September } 30\end{array}$ & $\begin{array}{l}\text { South Carolina } \\
\text { Piedmont } \\
\text { Municipal } \\
\text { Power Agny } \\
\text { December } 31\end{array}$ & $\begin{array}{l}\text { South Carolina } \\
\text { Rock Hill } \\
\text { City of } \\
\text { December } 31\end{array}$ & $\begin{array}{l}\text { Seneca } \\
\text { City of } \\
\text { June } 30\end{array}$ & $\begin{array}{l}\text { South Carolina } \\
\text { South } \\
\text { Carolina } \\
\text { Pub } \\
\text { Serv Auth } \\
\text { December } 31\end{array}$ & $\begin{array}{l}\text { South Dakota } \\
\begin{array}{c}\text { Brookings } \\
\text { City of }\end{array} \\
\text { December } 31\end{array}$ \\
\hline \multicolumn{7}{|l|}{ Electric Utility Plant } \\
\hline 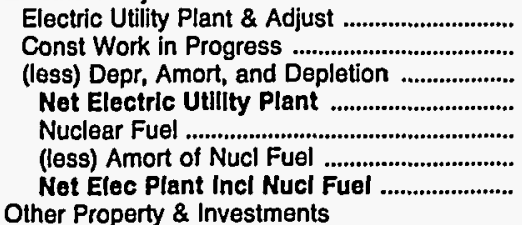 & $\begin{array}{r}45,617 \\
2,389 \\
11,457 \\
36,549 \\
0 \\
0 \\
36,549\end{array}$ & $\begin{array}{r}546,467 \\
5,749 \\
141,046 \\
411,170 \\
49,742 \\
27,563 \\
433,349\end{array}$ & $\begin{array}{r}28,883 \\
1,400 \\
11,077 \\
19,206 \\
0 \\
0 \\
19,206\end{array}$ & $\begin{array}{r}25,846 \\
507 \\
9,410 \\
16,943 \\
0 \\
0 \\
16,943\end{array}$ & $\begin{array}{r}2,540,433 \\
423,317 \\
814,425 \\
2,149,325 \\
14,082 \\
0 \\
2,163,407\end{array}$ & $\begin{array}{r}17,659 \\
174 \\
5,116 \\
12,717 \\
0 \\
0 \\
12,717\end{array}$ \\
\hline 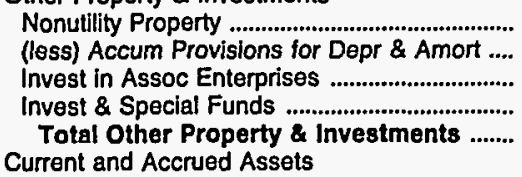 & $\begin{array}{r}4,361 \\
1,911 \\
0 \\
16,358 \\
18,808\end{array}$ & $\begin{array}{r}0 \\
0 \\
0 \\
177,984 \\
177,984\end{array}$ & $\begin{array}{r}106,962 \\
21,232 \\
0 \\
0 \\
85,730\end{array}$ & $\begin{array}{r}2,197 \\
794 \\
0 \\
0 \\
1,402\end{array}$ & $\begin{array}{r}1,979 \\
231 \\
0 \\
440,427 \\
442,175\end{array}$ & $\begin{array}{l}0 \\
0 \\
0 \\
0 \\
0\end{array}$ \\
\hline 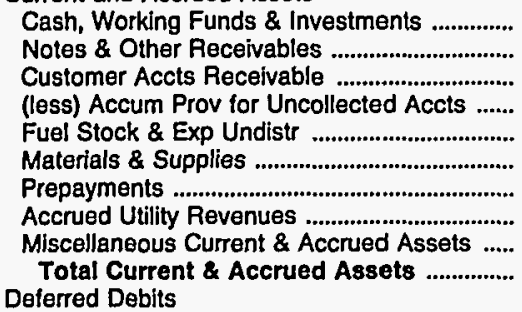 & $\begin{array}{r}1,344 \\
188 \\
2,442 \\
12 \\
97 \\
2,845 \\
317 \\
23 \\
51,559 \\
58,803\end{array}$ & $\begin{array}{r}302,602 \\
5,393 \\
5,788 \\
0 \\
0 \\
5,283 \\
0 \\
0 \\
0 \\
319,066\end{array}$ & $\begin{array}{r}7,617 \\
2,773 \\
6,700 \\
0 \\
0 \\
1,392 \\
0 \\
0 \\
0 \\
18,482\end{array}$ & $\begin{array}{r}4,957 \\
22 \\
1,169 \\
2 \\
0 \\
297 \\
12 \\
0 \\
45 \\
6,500\end{array}$ & $\begin{array}{r}136,081 \\
0 \\
59,953 \\
2,907 \\
26,901 \\
32,716 \\
1,312 \\
0 \\
3,203 \\
257,259\end{array}$ & $\begin{array}{r}1,784 \\
15 \\
1,304 \\
6 \\
0 \\
232 \\
5 \\
0 \\
0 \\
3,335\end{array}$ \\
\hline $\begin{array}{l}\text { Unamortized Debt Expenses .......................... } \\
\text { Extraordinary Losses, Study Cost .................... } \\
\text { Misc Debt, R \& D Exp, Unamrt Losses .......... } \\
\text { Total Doferred Deblts ................................... } \\
\text { Total Assets \& Other Debits ..................... } \\
\text { Proprietary Capital }\end{array}$ & $\begin{array}{r}0 \\
0 \\
0 \\
0 \\
114,160\end{array}$ & $\begin{array}{r}22,336 \\
0 \\
429,236 \\
451,572 \\
1,381,971\end{array}$ & $\begin{array}{r}5,455 \\
0 \\
0 \\
5,455 \\
128,873\end{array}$ & $\begin{array}{r}0 \\
0 \\
0 \\
0 \\
24,845\end{array}$ & $\begin{array}{r}24,954 \\
0 \\
701,947 \\
726,901 \\
3,589,742\end{array}$ & $\begin{array}{r}0 \\
0 \\
0 \\
0 \\
16,052\end{array}$ \\
\hline 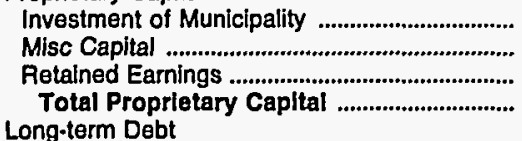 & $\begin{array}{r}0 \\
0 \\
100,497 \\
100,497\end{array}$ & $\begin{array}{r}0 \\
0 \\
12,462 \\
12,462\end{array}$ & $\begin{array}{r}0 \\
38,978 \\
25,876 \\
64,854\end{array}$ & $\begin{array}{r}4,084 \\
0 \\
19,535 \\
23,619\end{array}$ & $\begin{array}{r}34,438 \\
0 \\
621,684 \\
656,122\end{array}$ & $\begin{array}{r}0 \\
0 \\
15,258 \\
15,258\end{array}$ \\
\hline 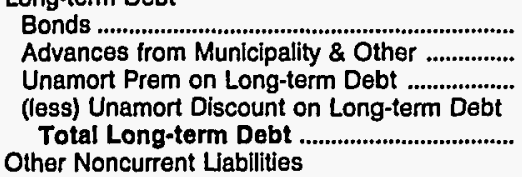 & $\begin{array}{r}7,050 \\
595 \\
0 \\
0 \\
7,645\end{array}$ & $\begin{array}{r}1,370,470 \\
0 \\
0 \\
69,881 \\
1,300,589\end{array}$ & $\begin{array}{r}59,285 \\
0 \\
0 \\
0 \\
59,285\end{array}$ & $\begin{array}{l}0 \\
0 \\
0 \\
0 \\
0\end{array}$ & $\begin{array}{r}2,487,394 \\
52,673 \\
0 \\
55,268 \\
2,484,799\end{array}$ & $\begin{array}{l}0 \\
0 \\
0 \\
0 \\
0\end{array}$ \\
\hline $\begin{array}{l}\text { Accum Operating Provisions } \\
\text { Accum Prov for Rate Refunds .............................. } \\
\text { Total Other Noncurrent Labilitles ............ } \\
\text { Current and Accrued Liabilities }\end{array}$ & $\begin{array}{r}438 \\
0 \\
438\end{array}$ & $\begin{array}{r}10,338 \\
0 \\
10,338\end{array}$ & $\begin{array}{l}0 \\
0 \\
0\end{array}$ & $\begin{array}{l}0 \\
0 \\
0\end{array}$ & $\begin{array}{l}0 \\
0 \\
0\end{array}$ & $\begin{array}{l}0 \\
0 \\
0\end{array}$ \\
\hline 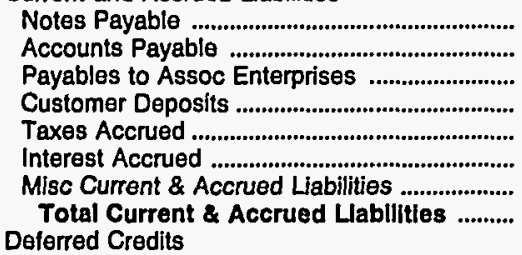 & $\begin{array}{r}0 \\
3,742 \\
0 \\
714 \\
0 \\
0 \\
1,124 \\
5,580\end{array}$ & $\begin{array}{r}0 \\
580 \\
0 \\
0 \\
4,405 \\
53,597 \\
0 \\
58,582\end{array}$ & $\begin{array}{r}0 \\
2,390 \\
0 \\
1,219 \\
0 \\
0 \\
1,126 \\
4,734\end{array}$ & $\begin{array}{r}0 \\
721 \\
0 \\
395 \\
28 \\
0 \\
81 \\
1,226\end{array}$ & $\begin{array}{r}263,115 \\
60,689 \\
0 \\
5,522 \\
1,896 \\
67,610 \\
48,563 \\
447,395\end{array}$ & $\begin{array}{r}0 \\
676 \\
54 \\
0 \\
32 \\
0 \\
32 \\
794\end{array}$ \\
\hline $\begin{array}{l}\text { Customer Advances for Construction ............. } \\
\text { Other Deferred Credits ......................................... } \\
\text { Unamort Gain on Reacqr Debt ...................... } \\
\text { Total Deferred Credlts ................................. } \\
\text { Total Llabilltles and Other Credits ........... }\end{array}$ & $\begin{array}{r}0 \\
0 \\
0 \\
0 \\
114,160\end{array}$ & $\begin{array}{r}0 \\
0 \\
0 \\
0 \\
1,381,971\end{array}$ & $\begin{array}{r}0 \\
0 \\
0 \\
0 \\
128,873\end{array}$ & $\begin{array}{r}0 \\
0 \\
0 \\
0 \\
24,845\end{array}$ & $\begin{array}{r}0 \\
956 \\
470 \\
1,426 \\
3,589,742\end{array}$ & $\begin{array}{r}0 \\
0 \\
0 \\
0 \\
16,052\end{array}$ \\
\hline
\end{tabular}

Note: Totals may not equal sum of components because of independent rounding.

Source: Energy Information Administration, Form ElA-412, "Annual Report of Public Electric Utijities." 
Table 22. Balance Sheet by Major U.S. Publicly Owned Electric Utility Within State at End of Period, 1993 (Continued) (Thousand Dollars)

\begin{tabular}{|c|c|c|c|c|c|c|}
\hline Item & $\begin{array}{c}\text { South Dakota } \\
\text { Heartiand } \\
\text { Consumers } \\
\text { Power Dist } \\
\text { December } 31\end{array}$ & $\begin{array}{l}\text { South Dakota } \\
\text { Missouri } \\
\text { Basin } \\
\text { Mun } \\
\text { Power Agny } \\
\text { December } 31\end{array}$ & $\begin{array}{c}\text { South Dakota } \\
\text { Pierre } \\
\text { City of } \\
\text { December } 31\end{array}$ & $\begin{array}{l}\text { South Dakota } \\
\text { Watertown } \\
\text { Municipal } \\
\text { Utilities } \\
\text { December } 31\end{array}$ & $\begin{array}{c}\text { Tennessee } \\
\text { Alcoa } \\
\text { Utilities } \\
\text { June } 30\end{array}$ & $\begin{array}{c}\text { Tennessee } \\
\text { Athens } \\
\text { Utility } \\
\text { Board } \\
\text { June } 30\end{array}$ \\
\hline \multicolumn{7}{|l|}{ Electric Utility Plant } \\
\hline 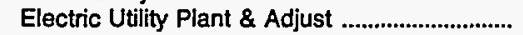 & 57,503 & 2,664 & 7,755 & 16,720 & 18,571 & 16,821 \\
\hline Const Work in Progress & & & & & 344 & 372 \\
\hline (less) Depr, Amort, and Depletion .................... & 7,191 & 642 & 2,641 & 10,379 & 5,959 & 6,330 \\
\hline 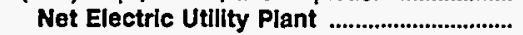 & 50,401 & 2,022 & 5,114 & 6,342 & 12,956 & 10,862 \\
\hline Nuclear Fuel .............................................................. & 0 & 0 & 0 & 0 & 0 & 0 \\
\hline 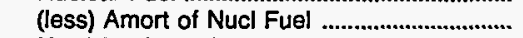 & 0 & 0 & 0 & 0 & 0 & 0 \\
\hline Net Elec Plant Incl Nucl Fuel ............................ & 50,401 & 2,022 & 5,114 & 6,342 & 12,956 & 10,862 \\
\hline \multicolumn{7}{|l|}{ Other Property \& Investments } \\
\hline 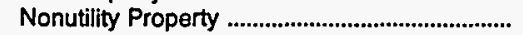 & 0 & 0 & 0 & 0 & 0 & 0 \\
\hline (less) Accum Provisions for Depr \& Amort .... & 0 & 0 & 0 & 0 & 0 & 0 \\
\hline 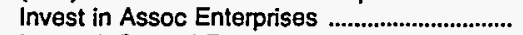 & 0 & 0 & 0 & 0 & 0 & 0 \\
\hline 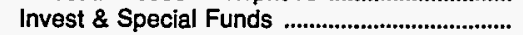 & 9,794 & 8,928 & 635 & 0 & 1,362 & 23 \\
\hline \multicolumn{7}{|l|}{ Current and Accrued Assets } \\
\hline Cash, Working Funds \& Investments ............... & 5,613 & 4,668 & 982 & 2,557 & 1,855 & 1,205 \\
\hline 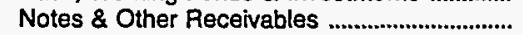 & 590 & & 0 & 0 & 1.744 & 1,845 \\
\hline 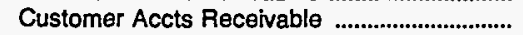 & 900 & 6,325 & 579 & 1,270 & 0 & 0 \\
\hline (less) Accum Prov for Uncollected Accts ...... & 0 & 0 & 57 & 3 & 0 & 0 \\
\hline 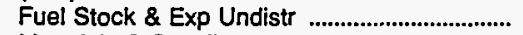 & 22 & 51 & 0 & 0 & 0 & 0 \\
\hline 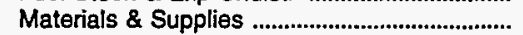 & 2,058 & 0 & 667 & 285 & 242 & 221 \\
\hline 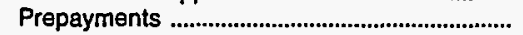 & 17 & 1,600 & 0 & 0 & 3 & 7 \\
\hline 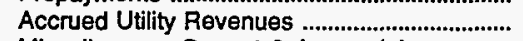 & 18 & 0 & 1,370 & 0 & 0 & 0 \\
\hline Miscellaneous Current \& Accrued Assets ..... & 86 & 596 & 16 & 1 & 82 & 60 \\
\hline $\begin{array}{l}\text { Total Current \& Accrued Assets ................ } \\
\text { Deferred Debits }\end{array}$ & 9,304 & 13,241 & 3,557 & 4,111 & 3,927 & 3,339 \\
\hline 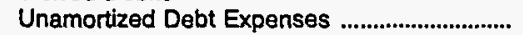 & 4,026 & 0 & 0 & 0 & 30 & 0 \\
\hline 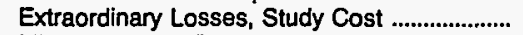 & & 0 & 0 & 0 & 0 & 0 \\
\hline Misc Debt, R \& D Exp, Unamrt Losses ........... & 956 & 58 & 0 & 0 & 1,129 & 935 \\
\hline 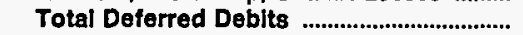 & 4,982 & $\mathbf{5 8}$ & 0 & & 1,160 & 935 \\
\hline Total Assets \& Other Deblts ........................... & $\mathbf{7 4 , 4 8 0}$ & 24,249 & 9,306 & 10,453 & 19,404 & 15,159 \\
\hline \multicolumn{7}{|l|}{ Proprietary Capital } \\
\hline 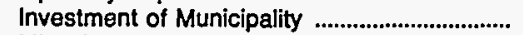 & 0 & 0 & 62 & 0 & 0 & 0 \\
\hline 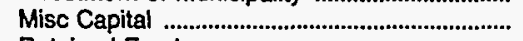 & 0 & 0 & 0 & 217 & 0 & 0 \\
\hline 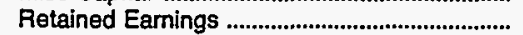 & 1,726 & 18,290 & 8,505 & 8,781 & 11,740 & 12,787 \\
\hline 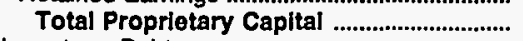 & 1,726 & 18,290 & 8,567 & 8,998 & 11,740 & 12,787 \\
\hline \multicolumn{7}{|l|}{ Long-term Debt } \\
\hline Bonds & 65,540 & 0 & 0 & 0 & 2,680 & 0 \\
\hline Advances from Municipality \& Other ................. & 0 & 0 & 0 & 0 & 965 & 843 \\
\hline Unamort Prem on Long-term Debt ...................... & 0 & 0 & 0 & 0 & -30 & 0 \\
\hline (less) Unamort Discount on Long-term Debt & & 0 & 0 & 0 & 0 & 0 \\
\hline 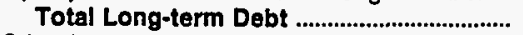 & 65,540 & 0 & $\mathbf{0}$ & 0 & 3,615 & 843 \\
\hline \multicolumn{7}{|l|}{ Other Noncurrent Liabilities } \\
\hline 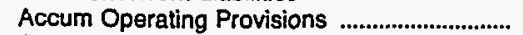 & 0 & 0 & 48 & 0 & 0 & 0 \\
\hline 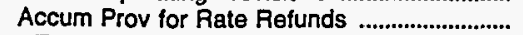 & 0 & 0 & 0 & 0 & 0 & 0 \\
\hline Total Other Noncurrent Llabillties ............. & 0 & 0 & 48 & 0 & 0 & 0 \\
\hline \multicolumn{7}{|l|}{ Current and Accrued Liabilities } \\
\hline 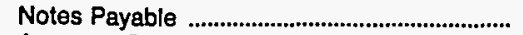 & 0 & & 0 & 0 & & 0 \\
\hline Accounts Payable .................................................. & 738 & 5,932 & 427 & 543 & 2,109 & 1,102 \\
\hline 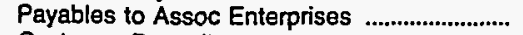 & 0 & 0 & 0 & 6 & 0 & 0 \\
\hline 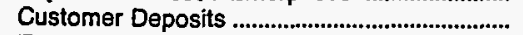 & 0 & 0 & 234 & 144 & 1,376 & 0 \\
\hline 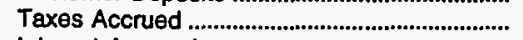 & 46 & 24 & 26 & 67 & 0 & 0 \\
\hline 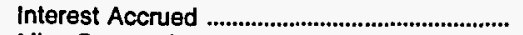 & 2,009 & 0 & 0 & 0 & 32 & 0 \\
\hline Misc Current \& Accrued Liabilities ......................... & 1,309 & 3 & 0 & 695 & 406 & 304 \\
\hline Total Current \& Accrued Liabllitles ........... & 4,103 & 5,959 & 687 & 1,455 & 3,923 & 1,406 \\
\hline \multicolumn{7}{|l|}{ Deferred Credits } \\
\hline Customer Advances for Construction .............. & 0 & 0 & 4 & 0 & 127 & 0 \\
\hline 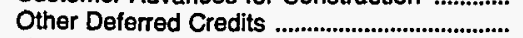 & 434 & 0 & 0 & 0 & 0 & 23 \\
\hline 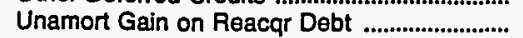 & 2,677 & 0 & 0 & 0 & 0 & 0 \\
\hline Total Deferred Credits ...................................... & 3,111 & & & & 127 & \\
\hline Total Llabillties and Other Credits ............. & 74,480 & 24,249 & 9,308 & 10,453 & 19,404 & 15,159 \\
\hline
\end{tabular}

Note: Totals may not equal sum of components because of independent rounding.

Source: Energy Information Administration, Form EIA-412, "Annual Report of Public Electric Utilities." 
Table 22. Balance Sheet by Major U.S. Publicly Owned Electric Utility Within State at End of Period, 1993 (Continued) (Thousand Dollars)

\begin{tabular}{|c|c|c|c|c|c|c|}
\hline Item & $\begin{array}{l}\text { Tennessee } \\
\text { Benton } \\
\text { County } \\
\text { June } 30\end{array}$ & $\begin{array}{l}\text { Tennessee } \\
\text { Bolivar } \\
\text { City of } \\
\text { June } 30\end{array}$ & $\begin{array}{l}\text { Tennessee } \\
\text { Bristol } \\
\text { City of } \\
\text { June } 30\end{array}$ & $\begin{array}{l}\text { Tennessee } \\
\text { Brownsville } \\
\text { City of } \\
\text { June } 30\end{array}$ & $\begin{array}{l}\text { Tennessee } \\
\text { Carroll } \\
\text { County } \\
\text { June } 30\end{array}$ & $\begin{array}{l}\text { Tennessee } \\
\text { Chattanooga } \\
\text { City of } \\
\text { June } 30\end{array}$ \\
\hline 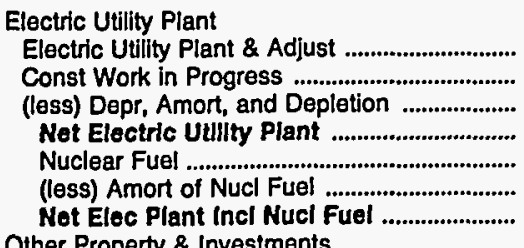 & $\begin{array}{r}2,992 \\
240 \\
1,226 \\
2,006 \\
0 \\
0 \\
2,006\end{array}$ & $\begin{array}{r}13,016 \\
1,769 \\
4,863 \\
9,922 \\
0 \\
0 \\
9,922\end{array}$ & $\begin{array}{r}39,007 \\
2,643 \\
21,171 \\
20,479 \\
0 \\
0 \\
20,479\end{array}$ & $\begin{array}{r}6,407 \\
689 \\
2,210 \\
4,886 \\
0 \\
0 \\
4,886\end{array}$ & $\begin{array}{r}17,259 \\
98 \\
5,797 \\
11,560 \\
0 \\
0 \\
11,560\end{array}$ & $\begin{array}{r}237,409 \\
6,870 \\
95,151 \\
149,128 \\
0 \\
0 \\
149,128\end{array}$ \\
\hline 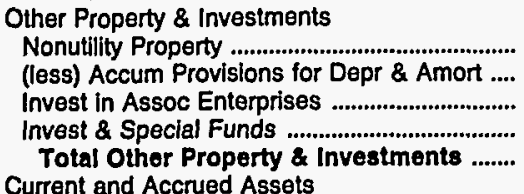 & $\begin{array}{r}0 \\
0 \\
0 \\
22 \\
22\end{array}$ & $\begin{array}{r}0 \\
0 \\
0 \\
135 \\
135\end{array}$ & $\begin{array}{r}190 \\
0 \\
0 \\
10,200 \\
10,390\end{array}$ & $\begin{array}{r}0 \\
0 \\
0 \\
752 \\
752\end{array}$ & $\begin{array}{r}0 \\
0 \\
0 \\
1,463 \\
1,463\end{array}$ & $\begin{array}{r}0 \\
0 \\
0 \\
12,333 \\
12,333\end{array}$ \\
\hline 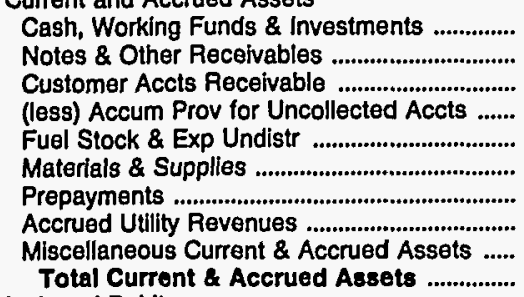 & $\begin{array}{r}1,002 \\
366 \\
0 \\
0 \\
0 \\
51 \\
7 \\
0 \\
10 \\
1,437\end{array}$ & $\begin{array}{r}-317 \\
1,491 \\
0 \\
0 \\
0 \\
224 \\
98 \\
0 \\
11 \\
1,507\end{array}$ & $\begin{array}{r}7,394 \\
3,311 \\
0 \\
0 \\
0 \\
481 \\
129 \\
0 \\
46 \\
11,361\end{array}$ & $\begin{array}{r}678 \\
615 \\
0 \\
0 \\
0 \\
166 \\
53 \\
0 \\
7 \\
1,519\end{array}$ & $\begin{array}{r}785 \\
1,608 \\
0 \\
0 \\
0 \\
334 \\
83 \\
0 \\
41 \\
2,851\end{array}$ & $\begin{array}{r}30,283 \\
20,363 \\
0 \\
0 \\
0 \\
3,775 \\
578 \\
0 \\
14,502 \\
69,501\end{array}$ \\
\hline 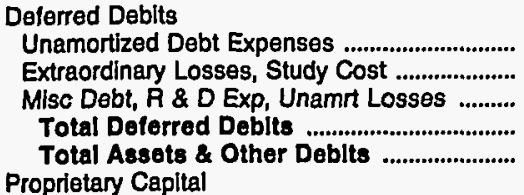 & $\begin{array}{r}0 \\
0 \\
22 \\
22 \\
3,487\end{array}$ & $\begin{array}{r}48 \\
0 \\
1,041 \\
1,090 \\
12,653\end{array}$ & $\begin{array}{r}0 \\
0 \\
5,152 \\
5,152 \\
47,381\end{array}$ & $\begin{array}{r}4 \\
0 \\
34 \\
38 \\
7,194\end{array}$ & $\begin{array}{r}15 \\
0 \\
249 \\
264 \\
16,138\end{array}$ & $\begin{array}{r}0 \\
0 \\
14,178 \\
14,178 \\
245,140\end{array}$ \\
\hline 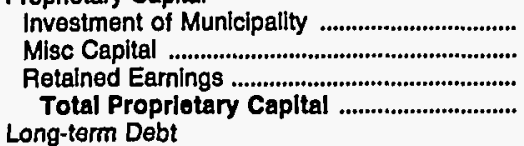 & $\begin{array}{r}0 \\
0 \\
3,079 \\
3,079\end{array}$ & $\begin{array}{r}0 \\
0 \\
7,841 \\
7,841\end{array}$ & $\begin{array}{r}0 \\
0 \\
37,508 \\
37,508\end{array}$ & $\begin{array}{r}0 \\
0 \\
5,178 \\
5,178\end{array}$ & $\begin{array}{r}0 \\
0 \\
12,065 \\
12,065\end{array}$ & $\begin{array}{r}0 \\
0 \\
165,024 \\
165,024\end{array}$ \\
\hline $\begin{array}{l}\text { Bonds } \\
\text { Advances from Municipality \& Other ................ } \\
\text { Unamort Prem On Long-term Debt ............... } \\
\text { (less) Unamort Discount on Long-term Debt } \\
\text { Total Long-term Debt ...................................... }\end{array}$ & $\begin{array}{r}0 \\
23 \\
0 \\
0 \\
23\end{array}$ & $\begin{array}{r}1,260 \\
1,480 \\
0 \\
0 \\
2,740\end{array}$ & $\begin{array}{r}0 \\
4,908 \\
0 \\
0 \\
4,908\end{array}$ & $\begin{array}{r}660 \\
5 \\
0 \\
0 \\
665\end{array}$ & $\begin{array}{r}1,085 \\
172 \\
-8 \\
0 \\
1,249\end{array}$ & $\begin{array}{r}11,609 \\
15,951 \\
0 \\
0 \\
27,560\end{array}$ \\
\hline 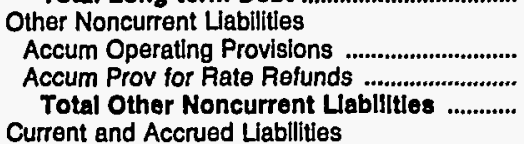 & $\begin{array}{l}0 \\
0 \\
0\end{array}$ & $\begin{array}{l}0 \\
0 \\
0\end{array}$ & $\begin{array}{l}0 \\
0 \\
0\end{array}$ & $\begin{array}{l}0 \\
0 \\
0\end{array}$ & $\begin{array}{l}0 \\
0 \\
0\end{array}$ & $\begin{array}{l}0 \\
0 \\
0\end{array}$ \\
\hline 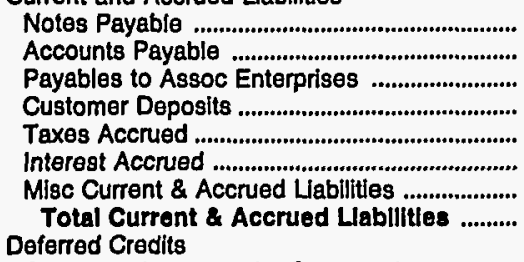 & $\begin{array}{r}0 \\
271 \\
0 \\
85 \\
19 \\
0 \\
9 \\
385\end{array}$ & $\begin{array}{r}0 \\
1,317 \\
0 \\
422 \\
0 \\
9 \\
235 \\
1,983\end{array}$ & $\begin{array}{r}0 \\
2,668 \\
0 \\
623 \\
206 \\
0 \\
1,452 \\
4,948\end{array}$ & $\begin{array}{r}0 \\
906 \\
0 \\
197 \\
0 \\
4 \\
14 \\
1,121\end{array}$ & $\begin{array}{r}0 \\
1,509 \\
0 \\
379 \\
291 \\
18 \\
508 \\
2,706\end{array}$ & $\begin{array}{r}0 \\
36,626 \\
0 \\
4,916 \\
5,672 \\
1,068 \\
1,958 \\
50,240\end{array}$ \\
\hline 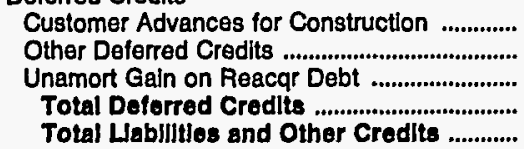 & $\begin{array}{r}0 \\
0 \\
0 \\
0 \\
3,487\end{array}$ & $\begin{array}{r}0 \\
90 \\
0 \\
90 \\
12,653\end{array}$ & $\begin{array}{r}0 \\
17 \\
0 \\
17 \\
47,381\end{array}$ & $\begin{array}{r}0 \\
230 \\
0 \\
230 \\
7,194\end{array}$ & $\begin{array}{r}7 \\
112 \\
0 \\
119 \\
16,138\end{array}$ & $\begin{array}{r}0 \\
2,316 \\
0 \\
2,316 \\
245,140\end{array}$ \\
\hline
\end{tabular}

Note: Totals may not equal sum of components because of independent rounding.

Source: Energy Information Administration, Form ElA-412, "Annual Report of Public Electric Utilities." 
Table 22. Balance Sheet by Major U.S. Publicly Owned Electric Utility Within State at End of Period, 1993 (Continued)

(Thousand Dollars)

\begin{tabular}{|c|c|c|c|c|c|c|}
\hline Item & $\begin{array}{l}\text { Tennessee } \\
\begin{array}{c}\text { Clarksville } \\
\text { City of }\end{array} \\
\text { June } 30\end{array}$ & $\begin{array}{l}\text { Tennessee } \\
\text { Cleveland } \\
\text { City of } \\
\text { June } 30\end{array}$ & $\begin{array}{l}\text { Tennessee } \\
\text { Clinton } \\
\text { City of } \\
\text { June } 30\end{array}$ & $\begin{array}{c}\text { Tennessee } \\
\text { Columbia } \\
\text { City of } \\
\text { June } 30\end{array}$ & $\begin{array}{l}\text { Tennessee } \\
\text { Cookeville } \\
\text { City of } \\
\text { June } 30\end{array}$ & $\begin{array}{l}\text { Tennessee } \\
\text { Covington } \\
\text { City of } \\
\text { June } 30\end{array}$ \\
\hline \multicolumn{7}{|l|}{ Electric Utility Plant } \\
\hline Electric Utility Plant \& Adjust ................................... & 43,911 & 46,391 & 33,780 & 24,417 & 17,693 & 7,885 \\
\hline 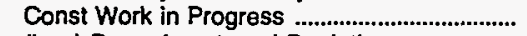 & 301 & 841 & 1,080 & 511 & 610 & 50 \\
\hline (less) Depr, Amort, and Depletion .................... & 10,758 & 15,456 & 11,976 & 9,706 & 4,728 & 2,076 \\
\hline Net Electric Utility Plant ................................. & $\mathbf{3 3 , 4 5 4}$ & 31,776 & 22,883 & 15,222 & 13,574 & 5,859 \\
\hline 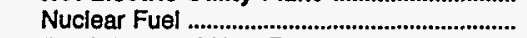 & & 0 & 0 & 0 & 0 & \\
\hline 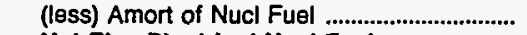 & 0 & 0 & 0 & 0 & 0 & 0 \\
\hline $\begin{array}{l}\text { Net Elec Plant incl Nucl Fuel .................................. } \\
\text { Other Property \& Investments }\end{array}$ & 33,454 & 31,776 & 22,883 & 15,222 & 13,574 & 5,859 \\
\hline 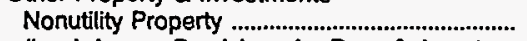 & 507 & 0 & 0 & 0 & 0 & 0 \\
\hline (less) Accum Provisions for Depr \& Amort .... & 0 & 0 & 0 & 0 & 0 & 0 \\
\hline 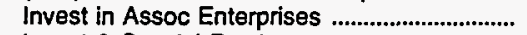 & 0 & 0 & 0 & 0 & 0 & 0 \\
\hline 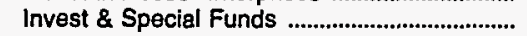 & 5,543 & 25 & 320 & 1,369 & 205 & 692 \\
\hline Total Other Property \& Investments ........ & 6,049 & 25 & 320 & 1,369 & 205 & 692 \\
\hline $\begin{array}{l}\text { Current and Accrued Assets } \\
\text { Cash, Working Funds \& investments .............. }\end{array}$ & 2,260 & \multicolumn{5}{|c|}{ Current and Accrued Assets } \\
\hline Notes \& Other Receivables ............................. & 3,027 & 4,774 & 3,070 & 1,284 & $\begin{array}{l}1,241 \\
1,729\end{array}$ & $\begin{array}{r}3,882 \\
997\end{array}$ \\
\hline 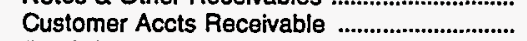 & $\begin{array}{r}0,0 \\
0\end{array}$ & 0 & 0 & $\begin{array}{r}1,209 \\
0\end{array}$ & $\begin{array}{r}1, r 29 \\
0\end{array}$ & $\begin{array}{r}991 \\
0\end{array}$ \\
\hline (less) Accum Prov for Uncollected Accts ....... & 0 & 0 & 0 & 0 & 0 & 0 \\
\hline 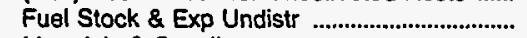 & 0 & 0 & 0 & 0 & 0 & 0 \\
\hline Materials \& Supplies ..................................................... & 481 & 786 & 546 & 558 & 472 & 108 \\
\hline 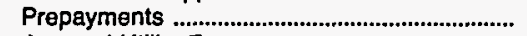 & 10 & 216 & 3 & 33 & 1 & 393 \\
\hline 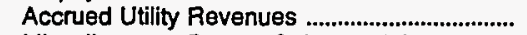 & 0 & 0 & 0 & 0 & 0 & 0 \\
\hline Miscellaneous Current \& Accrued Assets ..... & 161 & 54 & 104 & 35 & 31 & 19 \\
\hline $\begin{array}{l}\text { Total Current \& Accrued Assets .................... } \\
\text { Deferred Debits }\end{array}$ & 5,939 & 7,832 & 5,304 & 3,169 & $\mathbf{3 , 4 7 4}$ & 5,400 \\
\hline Unamortized Debt Expenses ............................. & 48 & 0 & 0 & 0 & 9 & 13 \\
\hline Extraordinary Losses, Study Cost ........................... & 0 & 0 & 0 & 0 & 0 & 0 \\
\hline Misc Debt, R \& D Exp, Unamrt Losses .......... & 4,648 & 2,294 & 2,525 & 1,402 & 400 & 365 \\
\hline 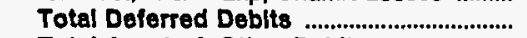 & 4,696 & 2,294 & 2,525 & 1,402 & 409 & 378 \\
\hline Total Assets \& Other Debits ......................... & 50,139 & 41,927 & 31,032 & 21,162 & 17,663 & 12,329 \\
\hline \multicolumn{7}{|l|}{ Proprietary Capital } \\
\hline & 0 & 0 & 0 & 0 & 0 & 0 \\
\hline $\begin{array}{l}\text { Misc Capital ........................................... } \\
\text { Retained Earnings }\end{array}$ & & & 0 & 0 & 0 & 0 \\
\hline & 26,595 & 32,346 & 24,641 & 17,693 & 13,330 & 9,196 \\
\hline $\begin{array}{l}\text { Total Proprietary Capital ......................................... } \\
\text { Long-term Debt }\end{array}$ & \multicolumn{5}{|c|}{ Long-term Debt } & 9,198 \\
\hline 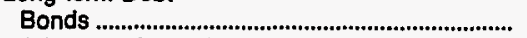 & 6,910 & 0 & 0 & 0 & 1,220 & 630 \\
\hline Advances from Municipality \& Other ................ & 3,359 & 2,217 & 2,340 & 1,210 & 409 & 137 \\
\hline Unamort Prem on Long-term Debt ..................... & -34 & 0 & 0 & 0 & 0 & -8 \\
\hline (less) Unamort Discount on Long-term Debt & & 0 & 0 & & 0 & \\
\hline 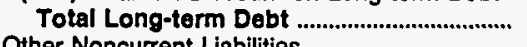 & 10,235 & 2,217 & 2,340 & 1,210 & 1,629 & 759 \\
\hline \multicolumn{7}{|l|}{ Other Noncurrent Liabilities } \\
\hline 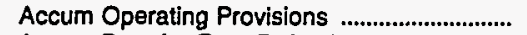 & 0 & 0 & 0 & 0 & 0 & 0 \\
\hline Accum Prov for Rate Refunds ............................. & 0 & 0 & 0 & 0 & 0 & 0 \\
\hline \multicolumn{7}{|l|}{ Current and Accrued Liabilities } \\
\hline 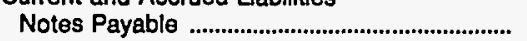 & 0 & 0 & 0 & 0 & 0 & 0 \\
\hline 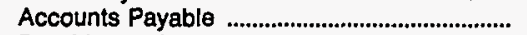 & 3,383 & 4,544 & 2,599 & 840 & 1,872 & 842 \\
\hline 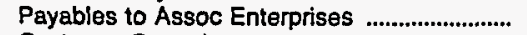 & & 0 & 0 & 0 & 0 & 0 \\
\hline 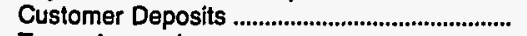 & 1,544 & 886 & 861 & 915 & 401 & 256 \\
\hline 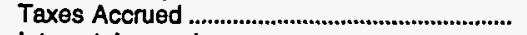 & 0 & 0 & 0 & 0 & 0 & 0 \\
\hline 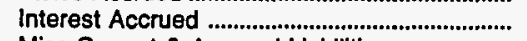 & 156 & 0 & 0 & 0 & 20 & 11 \\
\hline Misc Current \& Accrued Liabilities ........................ & 904 & 213 & 576 & 505 & 56 & 32 \\
\hline Total Current \& Accrued Llabilltles & 5,987 & 5,643 & 4,037 & 2,259 & 2,349 & 1,140 \\
\hline \multicolumn{7}{|l|}{ Deferred Credits } \\
\hline Customer Advances for Construction .............. & 0 & 0 & 0 & 0 & 0 & \\
\hline Other Deferred Credits ............................................ & 7,322 & 1,721 & 14 & 0 & 355 & 1,234 \\
\hline 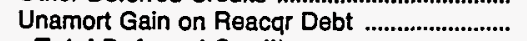 & & 0 & 0 & 0 & 0 & \\
\hline 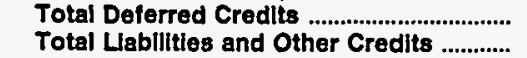 & $\begin{array}{r}7,322 \\
50,139\end{array}$ & $\begin{array}{r}1,721 \\
41,927\end{array}$ & $\begin{array}{r}14 \\
31,032\end{array}$ & $\begin{array}{r}0 \\
21,162\end{array}$ & $\begin{array}{r}355 \\
17,663\end{array}$ & $\begin{array}{r}1,234 \\
12,329\end{array}$ \\
\hline
\end{tabular}

Note: Totals may not equal sum of components because of independent rounding.

Source: Energy Information Administration, Form EIA-412, "Annual Report of Public Electric Utilities." 
Table 22. Balance Sheet by Major U.S. Publicly Owned Electric Utility Within State at End of Period, 1993 (Continued)

(Thousand Dollars)

\begin{tabular}{|c|c|c|c|c|c|c|}
\hline Item & $\begin{array}{l}\text { Tennessee } \\
\text { Dayton } \\
\text { City of } \\
\text { June } 30\end{array}$ & $\begin{array}{l}\text { Tennessee } \\
\text { Dickson } \\
\text { City of } \\
\text { June } 30\end{array}$ & $\begin{array}{l}\text { Tennessee } \\
\text { Dyersburg } \\
\text { City of } \\
\text { June } 30\end{array}$ & $\begin{array}{l}\text { Tennessee } \\
\text { Elizabethton } \\
\text { City of } \\
\text { June } 30\end{array}$ & $\begin{array}{c}\text { Tennessee } \\
\text { Erwin } \\
\text { Town of } \\
\text { June } 30\end{array}$ & $\begin{array}{l}\text { Tennessee } \\
\text { Etowah } \\
\text { City of } \\
\text { June } 30\end{array}$ \\
\hline \multicolumn{7}{|l|}{ Electric Utility Plant } \\
\hline Electric Utility Plant \& Adjust ............................... & 9,980 & 35,529 & 25,639 & $\begin{array}{r}23,896 \\
189\end{array}$ & $\begin{array}{r}7,574 \\
465\end{array}$ & $\begin{array}{r}5,031 \\
81\end{array}$ \\
\hline 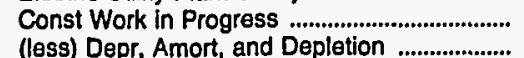 & $\begin{array}{r}68 \\
3,297\end{array}$ & $\begin{array}{r}1,688 \\
11,207\end{array}$ & $\begin{array}{r}947 \\
7,356\end{array}$ & $\begin{array}{r}189 \\
8,412\end{array}$ & $\begin{array}{r}465 \\
3,079\end{array}$ & $\begin{array}{r}81 \\
2,111\end{array}$ \\
\hline 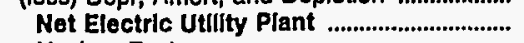 & 6,751 & 26,010 & 19,230 & 15,673 & 4,960 & 3,001 \\
\hline Nuclear Fuel .......................................................... & 0 & & 0 & 0 & 0 & 0 \\
\hline 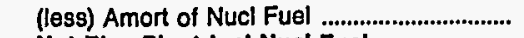 & & 0 & 0 & 0 & 0 & 0 \\
\hline Net Elec Plant Incl Nucl Fuel ............................. & 6,751 & 26,010 & 19,230 & 15,673 & 4,960 & 3,001 \\
\hline \multicolumn{7}{|l|}{ Other Property \& Investments } \\
\hline 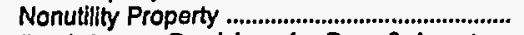 & 0 & 0 & 0 & 0 & 0 & 0 \\
\hline (less) Accum Provisions for Depr \& Amort .... & 0 & $\mathbf{0}$ & 0 & 0 & 0 & 0 \\
\hline 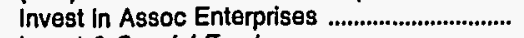 & 0 & 0 & 0 & 0 & 0 & 0 \\
\hline 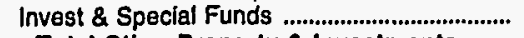 & 0 & 2,772 & 4,215 & 715 & 10 & 405 \\
\hline $\begin{array}{l}\text { Total Other Property \& Investments ....... } \\
\text { Current and Accrued Assets }\end{array}$ & 0 & 2,772 & 4,215 & 715 & 10 & 405 \\
\hline 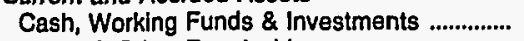 & 1,223 & 2,838 & 425 & 1,591 & 443 & 19 \\
\hline 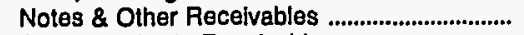 & 895 & 2,248 & 2,252 & 1,669 & 1,021 & 763 \\
\hline 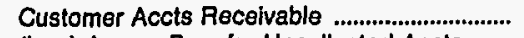 & 0 & 0 & 0 & 0 & 0 & 0 \\
\hline (less) Accum Prov for Uncollected Accts ...... & 0 & 0 & 0 & 0 & 0 & 0 \\
\hline 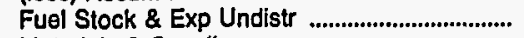 & 0 & 0 & 0 & 0 & 0 & 0 \\
\hline Materials \& Supplies ..................................................... & 89 & 548 & 495 & 363 & 191 & 112 \\
\hline 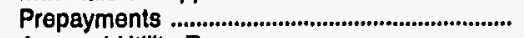 & 6 & 0 & 75 & 0 & 25 & 13 \\
\hline 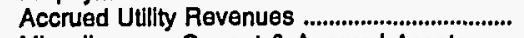 & 0 & 0 & 0 & 0 & 0 & 0 \\
\hline Miscellaneous Current \& Accrued Assets ..... & 39 & 122 & 36 & 83 & 330 & 14 \\
\hline \multicolumn{5}{|l|}{ Deferred Deblts } & 2,010 & 920 \\
\hline Unamortzed Debt Expenses ................................ & 0 & 94 & 88 & 0 & 0 & 0 \\
\hline 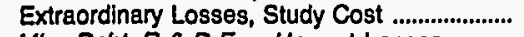 & 0 & 0 & 0 & 0 & 0 & 0 \\
\hline Misc Debt, R \& D Exp, Unamrt Losses .......... & 111 & 22 & 1,116 & 2,644 & 648 & 478 \\
\hline 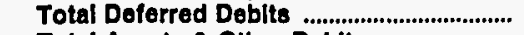 & 111 & 116 & 1,204 & 2,644 & 648 & 478 \\
\hline Total Assots \& Other Deblts .............................. & 9,113 & 34,653 & 27,932 & 22,739 & 7,628 & 4,804 \\
\hline \multicolumn{7}{|l|}{ Proprletary Capltal } \\
\hline Investment of Municlpality ..................................... & 0 & 0 & 0 & 0 & 0 & 0 \\
\hline 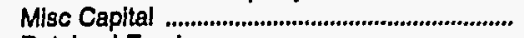 & 0 & 0 & 0 & 0 & 0 & 0 \\
\hline 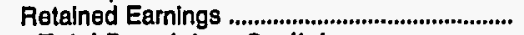 & 7,804 & 15,763 & 14,179 & 16,422 & 5,901 & 3,136 \\
\hline \multicolumn{7}{|l|}{ Long-term Debt } \\
\hline 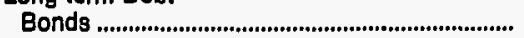 & 0 & 7,259 & 9,350 & 0 & 0 & 105 \\
\hline Advances from Municipality \& Other ................. & 134 & 7,844 & 1,059 & 2,317 & 606 & 397 \\
\hline Unamort Prem on Long-term Debt .................... & 0 & -16 & -86 & 0 & 0 & 0 \\
\hline (less) Unamort Dlscount on Long-term Debt & 0 & & & 0 & 0 & 0 \\
\hline 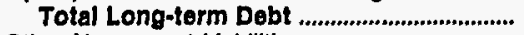 & 134 & 15,087 & 10,323 & 2,317 & 608 & 502 \\
\hline \multicolumn{7}{|l|}{ Other Noncurrent Luabilitles } \\
\hline 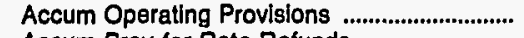 & 0 & 0 & 0 & 0 & 0 & 0 \\
\hline Accum Prov for Rate Refunds ........................... & 0 & 0 & 0 & 0 & 0 & 0 \\
\hline 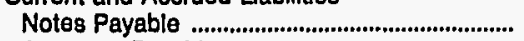 & 0 & 0 & 0 & 0 & 0 & Current and Accrued Llabilities \\
\hline 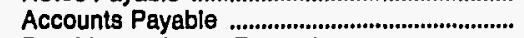 & 965 & 2,237 & 2,483 & 1,653 & 774 & 802 \\
\hline Payables to Assoc Enterprises ................................. & 0 & & 0 & 0 & 0 & 0 \\
\hline 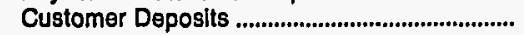 & 169 & 1,069 & 334 & 832 & 180 & 74 \\
\hline 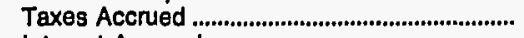 & 0 & 0 & 1 & 0 & 0 & 0 \\
\hline 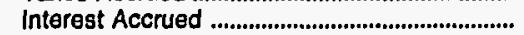 & 0 & 275 & 226 & 0 & 0 & 4 \\
\hline Misc Current \& Accrued Llabllities ....................... & 40 & 223 & 303 & 1,515 & 48 & 244 \\
\hline Total Current \& Accrued Llabillties ........... & 1,175 & 3,804 & 3,347 & 4,000 & 1,002 & 1,123 \\
\hline \multicolumn{7}{|l|}{ Deferred Credits } \\
\hline Customer Advances for Construction .............. & 0 & 0 & 0 & 0 & 2 & 0 \\
\hline Other Deferred Credits ............................................... & 0 & 0 & 83 & 0 & 117 & 42 \\
\hline Unamort Gain on Reacqr Debt ........................... & 0 & 0 & $\mathbf{0}$ & 0 & 0 & 0 \\
\hline Total Deferred Credits & 0 & 0 & 83 & 0 & 119 & 42 \\
\hline Total Llabilltles and Other Credlts ............ & 9,113 & 34,653 & 27,932 & 22,739 & 7,628 & 4,804 \\
\hline
\end{tabular}

Note: Totals may not equal sum of components because of independent rounding.

Source: Energy Information Administration, Form EIA-412, "Annual Report of Public Electric Utilities." 
Table 22. Balance Sheet by Major U.S. Publicly Owned Electric Utility Within State at End of Period, 1993 (Continued) (Thousand Dollars)

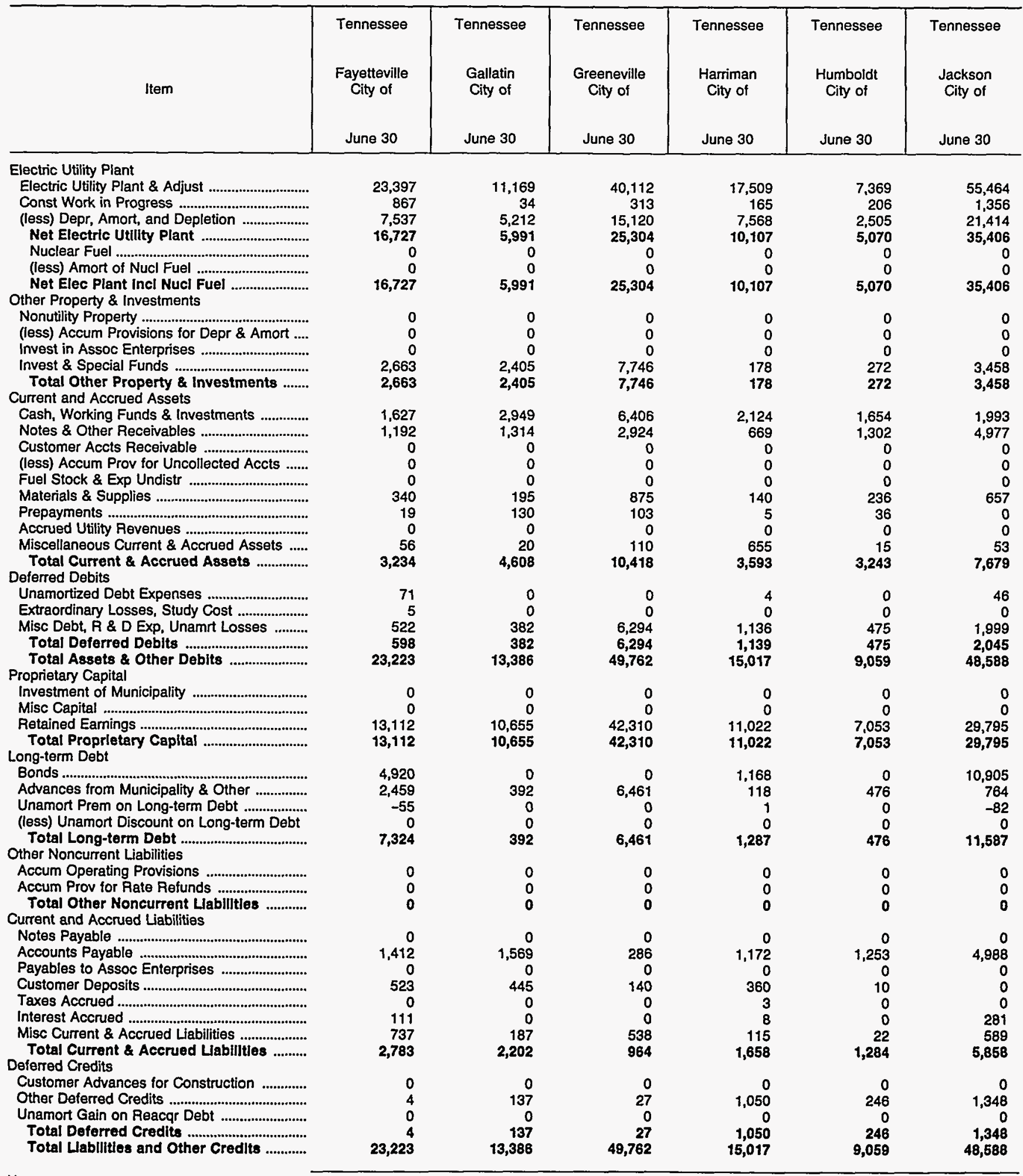

Note: Totals may not equal sum of components because of independent rounding.

Source: Energy Information Administration, Form EIA-412, "Annual Report of Public Electric Utilities." 
Table 22. Balance Sheet by Major U.S. Publicly Owned Electric Utility Within State at End of Period, 1993 (Continued)

(Thousand Dollars)

\begin{tabular}{|c|c|c|c|c|c|c|}
\hline Item & $\begin{array}{l}\text { Tennessee } \\
\text { Johnson } \\
\text { City City of } \\
\text { June } 30\end{array}$ & $\begin{array}{l}\text { Tennessee } \\
\text { Knoxville } \\
\text { Utilities } \\
\text { Board } \\
\text { June } 30\end{array}$ & $\begin{array}{l}\text { Tennessee } \\
\text { Lawrenceburg } \\
\text { City of } \\
\text { June } 30\end{array}$ & $\begin{array}{l}\text { Tennessee } \\
\text { LaFollette } \\
\text { City of } \\
\text { June } 30\end{array}$ & $\begin{array}{l}\text { Tennessee } \\
\text { Lebanon } \\
\text { City of } \\
\text { June } 30\end{array}$ & $\begin{array}{l}\text { Tennessee } \\
\text { Lenoir } \\
\text { City City of } \\
\text { June } 30\end{array}$ \\
\hline \multicolumn{7}{|l|}{ Electric Utility Plant } \\
\hline Electric Utility Plant \& Adjust .................................. & 55,196 & 275,261 & 22,912 & 25,149 & 11,796 & 59,462 \\
\hline 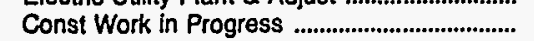 & 2,718 & 5,416 & 354 & 366 & 786 & 205 \\
\hline (less) Depr, Amort, and Depletion ..................... & 24,228 & 130,227 & 9,312 & 8,911 & 4,395 & 14,795 \\
\hline Net Electric Utillty Plant ......................................... & 33,686 & 150,450 & 13,954 & 16,604 & 8,188 & 44,872 \\
\hline 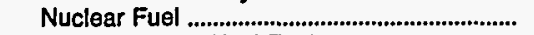 & 0 & 0 & 0 & 0 & 0 & 0 \\
\hline (less) Amort of Nucl Fuel ......................................... & & & & 0 & 0 & \\
\hline Net Elec Plant Incl Nucl Fuel ........................... & 33,686 & 150,450 & 13,954 & 16,604 & 8,188 & 44,872 \\
\hline \multicolumn{7}{|l|}{ Other Property \& Investments } \\
\hline 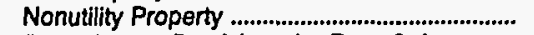 & 0 & 0 & 778 & 0 & 0 & 0 \\
\hline (less) Accum Provisions for Depr \& Amort .... & 0 & 0 & 0 & 0 & 0 & 0 \\
\hline 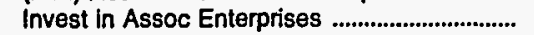 & 0 & 0 & 0 & 0 & 0 & 0 \\
\hline 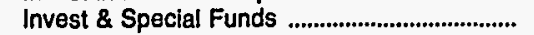 & 3,748 & 10,799 & 102 & 2,481 & 0 & 6,136 \\
\hline Total Other Property \& Investments ........ & 3,748 & 10,799 & 880 & 2,481 & o & 6,136 \\
\hline \multicolumn{7}{|l|}{ Current and Accrued Assets } \\
\hline Cash, Working Funds \& Investments .............. & 1,656 & 13,042 & 2,082 & 176 & 1,429 & 1,133 \\
\hline 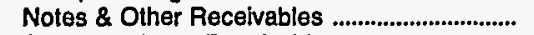 & 1,338 & 18,919 & 1,642 & 1,503 & 1,614 & $\mathbf{3 , 8 7 9}$ \\
\hline 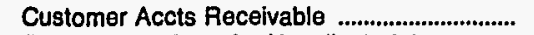 & 0 & 0 & 0 & 0 & 0 & 0 \\
\hline (less) Accum Prov for Uncollected Accts ....... & 0 & 0 & 0 & 0 & 0 & 0 \\
\hline 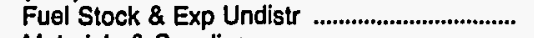 & 0 & 0 & 0 & 0 & 0 & 0 \\
\hline 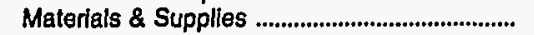 & 834 & 2,669 & 311 & 375 & 376 & 692 \\
\hline 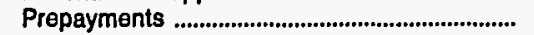 & 0 & 410 & 41 & 0 & 31 & 37 \\
\hline Accrued Utility Revenues ......................................... & 0 & 0 & 0 & 0 & 0 & 0 \\
\hline Miscellaneous Current \& Accrued Assets ..... & 242 & & 828 & 97 & 59 & 1,910 \\
\hline Total Current \& Accrued Assets ................... & 4,070 & 35,069 & 4,904 & 2,152 & 3,508 & 7,650 \\
\hline \multicolumn{7}{|l|}{ Deferred Debits } \\
\hline 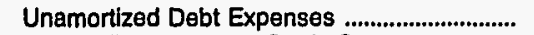 & 0 & 119 & 0 & 36 & 0 & 475 \\
\hline 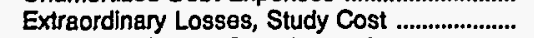 & & & 10 & 0 & 0 & 0 \\
\hline Misc Debt, R \& D Exp, Unamrt Losses ........... & 13,322 & 11,806 & 1,333 & 864 & 354 & 2,131 \\
\hline 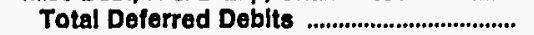 & 13,322 & 11,925 & 1,343 & 900 & 354 & 2,606 \\
\hline Total Assets \& Other Deblts ........................... & 54,825 & 208,243 & 21,081 & 22,137 & 12,050 & 61,265 \\
\hline \multicolumn{7}{|l|}{ Propriatary Capital } \\
\hline 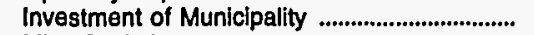 & 0 & $\mathbf{0}$ & 0 & 0 & 0 & 0 \\
\hline 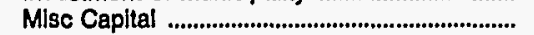 & 0 & 0 & 0 & 0 & 0 & 0 \\
\hline 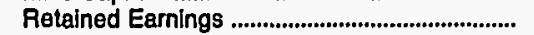 & 41,264 & 115,584 & 15,276 & 14,843 & 8,982 & 27,178 \\
\hline 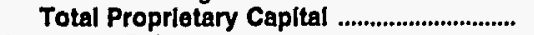 & 41,264 & 115,584 & 15,276 & 14,843 & 8,982 & 27,178 \\
\hline \multicolumn{7}{|l|}{ Long-term Debt } \\
\hline Bonds & 0 & 38,656 & 250 & 1,425 & 0 & 23,875 \\
\hline Advances from Municipality \& Other ................. & 5,495 & 10,779 & 1,391 & 3,365 & 307 & 2,355 \\
\hline Unamort Prem on Long-term Debt .................... & 0 & -268 & 0 & -8 & 0 & 0 \\
\hline (less) Unamort Discount on Long-term Debt & 0 & & 0 & 0 & 0 & 0 \\
\hline 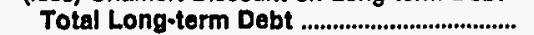 & 5,495 & 49,167 & 1,641 & 4,781 & 307 & 26,230 \\
\hline \multicolumn{7}{|l|}{ Other Noncurrent Llabilities } \\
\hline 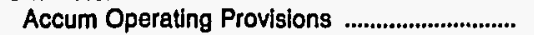 & 0 & 0 & 0 & 0 & 0 & 0 \\
\hline 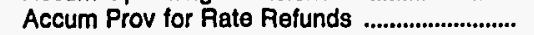 & 0 & 0 & 0 & 0 & $\mathbf{0}$ & 0 \\
\hline Total Other Noncurrent Llabilitles ............ & 0 & 0 & 0 & 0 & 0 & 0 \\
\hline \multicolumn{7}{|l|}{ Current and Accrued Liabilities } \\
\hline 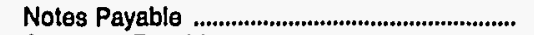 & 0 & 0 & 0 & 0 & 0 & 0 \\
\hline 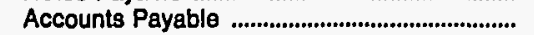 & 5,223 & 17,826 & 3,255 & 1,533 & 2,139 & 4,100 \\
\hline Payables to Assoc Enterprises ............................ & & & 0 & 0 & 0 & 0 \\
\hline 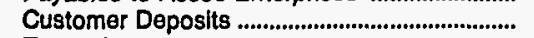 & 1,346 & 6,902 & 301 & 612 & 492 & 1,648 \\
\hline 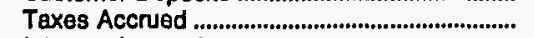 & 0 & 0 & 0 & 0 & 65 & 0 \\
\hline 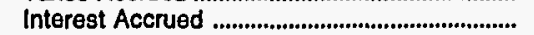 & 0 & 802 & 5 & 68 & 0 & 115 \\
\hline Mlsc Current \& Accrued Liabilities ...................... & 1,472 & 2,063 & 178 & 85 & 60 & 1,557 \\
\hline Total Current \& Accrued Llabiltiles .......... & 8,041 & 27,593 & 3,739 & 2,297 & 2,757 & 7,420 \\
\hline \multicolumn{7}{|l|}{ Deferred Credits } \\
\hline Customer Advances for Construction .............. & 24 & 1,772 & 35 & 0 & 0 & 414 \\
\hline 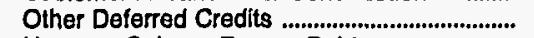 & 0 & 14,126 & 390 & 216 & 4 & 23 \\
\hline Unamort Gain on Reacqr Debt ............................ & 0 & & 0 & 0 & 0 & 0 \\
\hline Total Deferred Credits ........................................ & 24 & 15,899 & 425 & 216 & & 437 \\
\hline Total Llabilltles and Other Credits ............ & 54,825 & 208,243 & 21,081 & 22,137 & 12,050 & 61,265 \\
\hline
\end{tabular}

Note: Totals may not equal sum of components because of independent rounding.

Source: Energy Information Administration, Form EIA-412, "Annual Report of Public Electric Utilities." 
Table 22. Balance Sheet by Major U.S. Publicly Owned Electric Utility Within State at End of Period, 1993 (Continued) (Thousand Dollars)

\begin{tabular}{|c|c|c|c|c|c|c|}
\hline Item & $\begin{array}{l}\text { Tennessee } \\
\begin{array}{c}\text { Lewrisburg } \\
\text { City of }\end{array} \\
\text { June } 30\end{array}$ & $\begin{array}{l}\text { Tennessee } \\
\text { Lexington } \\
\text { City of } \\
\text { June } 30\end{array}$ & $\begin{array}{l}\text { Tennessee } \\
\text { Loudon } \\
\text { Utilities } \\
\text { Board } \\
\text { June } 30\end{array}$ & $\begin{array}{c}\text { Tennessee } \\
\text { Maryille } \\
\text { Utilities } \\
\text { June } 30\end{array}$ & $\begin{array}{l}\text { Tennessee } \\
\text { McMinnville } \\
\text { Electric } \\
\text { System } \\
\text { June } 30\end{array}$ & $\begin{array}{l}\text { Tennessee } \\
\text { Memphis } \\
\text { City of } \\
\text { June } 30\end{array}$ \\
\hline \multicolumn{7}{|l|}{ Electric Utility Plant } \\
\hline 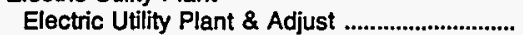 & 10,493 & 21,310 & 14,059 & 24,320 & 11,184 & 714,245 \\
\hline 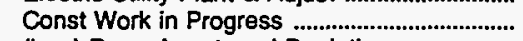 & & 259 & 2,805 & 82 & 23 & 24,156 \\
\hline (less) Depr, Amort, and Depletion ..................... & 3,165 & 7,644 & 3,532 & 7,353 & 4,428 & 243,331 \\
\hline Net Electric Utllity Plant & 7,365 & 13,925 & 13,333 & 17,049 & 6,779 & 495,071 \\
\hline 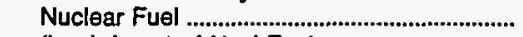 & 0 & 0 & 0 & 0 & 0 & 0 \\
\hline 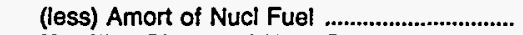 & & 0 & 0 & 0 & 0 & 0 \\
\hline Not Elec Plant Incl Nucl Fuel ............................ & 7,365 & 13,925 & 13,333 & 17,049 & 6,779 & 495,071 \\
\hline \multicolumn{7}{|l|}{ Other Property \& Investments } \\
\hline 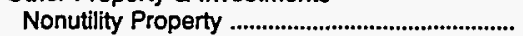 & 0 & 0 & 0 & 108 & 0 & 0 \\
\hline (less) Accum Provisions for Depr \& Amort .... & 0 & 0 & 0 & 0 & 0 & 0 \\
\hline 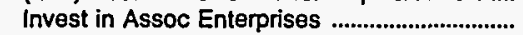 & 0 & 0 & 0 & 0 & 0 & 0 \\
\hline 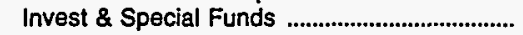 & 151 & 2,045 & 1,435 & 582 & 511 & 70,177 \\
\hline & \multicolumn{2}{|c|}{ Current and Accrued Assets } & 1,435 & 690 & 511 & 70,177 \\
\hline Cash, Working Funds \& Investments .............. & 1,741 & 1,249 & 250 & 1,610 & 849 & 46,215 \\
\hline Notes \& Other Receivables ................................... & 674 & 1,366 & 2,100 & 1,394 & 678 & 48,862 \\
\hline Customer Accts Receivable ................................ & 0 & 0 & 0 & 0 & 0 & 0 \\
\hline (less) Accum Prov for Uncollected Accts ...... & 0 & 0 & 0 & 0 & $\mathbf{0}$ & 0 \\
\hline 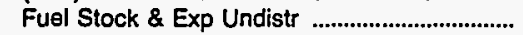 & 0 & 0 & 0 & 0 & 0 & 0 \\
\hline Materials \& Supplies ............................................ & 218 & 402 & 248 & 369 & 105 & 9,591 \\
\hline Prepayments ………………………......................... & 1 & 44 & 0 & 24 & 11 & 0 \\
\hline Accrued Utility Revenues .................................... & 0 & 0 & 0 & 0 & 0 & 0 \\
\hline Miscellaneous Current \& Accrued Assets ..... & 11 & 58 & 18 & 126 & 20 & 4,725 \\
\hline \multicolumn{7}{|l|}{ Deferred Debits } \\
\hline 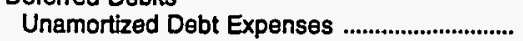 & 0 & 0 & 56 & 26 & 0 & 4,188 \\
\hline 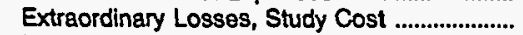 & 0 & 0 & 0 & 0 & 0 & 0 \\
\hline Misc Debt, A \& D Exp, Unamrt Losses .......... & 279 & 861 & 599 & 638 & 490 & 15,402 \\
\hline Total Deferred Debits & 279 & 861 & 656 & 664 & 490 & 19,590 \\
\hline 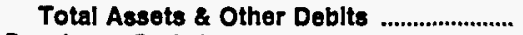 & 10,441 & 19,950 & 18,040 & 21,926 & 9,444 & 694,232 \\
\hline \multicolumn{7}{|l|}{ Proprietary Capital } \\
\hline 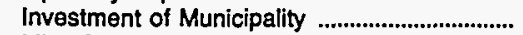 & 0 & 0 & 0 & 0 & 0 & 0 \\
\hline 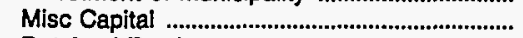 & 0 & 0 & 0 & 0 & 0 & 0 \\
\hline 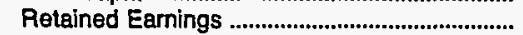 & 7,993 & 16,446 & 7,864 & 15,755 & 8,052 & 338,578 \\
\hline 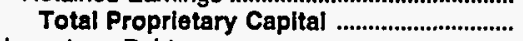 & 7,993 & 16,446 & 7,864 & 15,755 & 8,052 & 338,578 \\
\hline \multicolumn{7}{|l|}{ Long-term Debt } \\
\hline Bonds & 593 & 0 & 7,475 & 2,385 & 0 & 254,275 \\
\hline Advances from Municipality \& Other ............... & 206 & 907 & 7 & 488 & 513 & 6,734 \\
\hline Unamort Prem on Long-term Debt ................... & 0 & 0 & -59 & -20 & 0 & 0 \\
\hline (less) Unamort Discount on Long-term Debt & 0 & 0 & 0 & 0 & 0 & \\
\hline 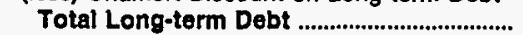 & 799 & 907 & $\mathbf{7 , 4 2 3}$ & 2,853 & 513 & 261,009 \\
\hline \multicolumn{7}{|l|}{ Other Noncurrent Liabilities } \\
\hline 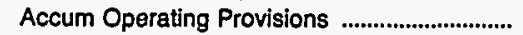 & 0 & 0 & 0 & 0 & 0 & 0 \\
\hline Accum Prov for Rate Refunds & 0 & 0 & 0 & 0 & 0 & 0 \\
\hline Total Other Noncurrent Llabilities ............. & 0 & 0 & 0 & o & 0 & 0 \\
\hline \multicolumn{7}{|l|}{ Current and Accrued Liabilities } \\
\hline 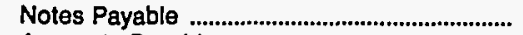 & 0 & 0 & 300 & & 0 & \\
\hline Accounts Payable & 1,094 & 1,625 & 2,000 & 2,633 & 130 & 56,657 \\
\hline Payables to Assoc Enterprises .............................. & 0 & 0 & 0 & 0 & 0 & 0 \\
\hline 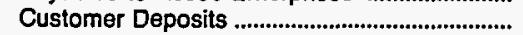 & 193 & 120 & 2 & 274 & 464 & 0 \\
\hline 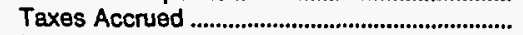 & 0 & 0 & 0 & 0 & 0 & 682 \\
\hline 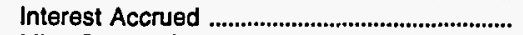 & 0 & 0 & 249 & 27 & 0 & 0 \\
\hline Misc Current \& Accrued Ljabilities ......................... & 54 & 852 & 174 & 384 & 155 & 4,582 \\
\hline Total Current \& Accrued Llabilities ........... & 1,341 & 2,597 & 2,725 & 3,317 & 749 & 61,920 \\
\hline \multicolumn{7}{|l|}{ Deferred Credits } \\
\hline Customer Advances for Construction .............. & 0 & 0 & 27 & 0 & 0 & 1,780 \\
\hline 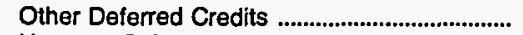 & 308 & 0 & 0 & 0 & 130 & 30,945 \\
\hline Unamort Gain on Reacqr Debt ........................... & 0 & 0 & 0 & 0 & 0 & \\
\hline Total Deferred Credits & 308 & & 27 & & 130 & 32,725 \\
\hline Total Llabllittes and Other Credits ............ & 10,441 & 19,950 & 18,040 & 21,926 & 9,444 & 694,232 \\
\hline
\end{tabular}

Note: Totals may not equal sum of components because of independent rounding.

Source: Energy Information Administration, Form EIA-412, "Annual Report of Public Electric Utilities." 
Table 22. Balance Sheet by Major U.S. Publicly Owned Electric Utility Within State at End of Period, 1993 (Continued)

(Thousand Dollars)

\begin{tabular}{|c|c|c|c|c|c|c|}
\hline Item & $\begin{array}{l}\text { Tennessee } \\
\text { Morristown } \\
\text { City of } \\
\text { June } 30\end{array}$ & $\begin{array}{l}\text { Tennessee } \\
\begin{array}{c}\text { Murtreesboro } \\
\text { City of }\end{array} \\
\text { June } 30\end{array}$ & $\begin{array}{l}\text { Tennessee } \\
\text { Nashville } \\
\text { Electric } \\
\text { Service } \\
\\
\text { June } 30\end{array}$ & $\begin{array}{l}\text { Tennessee } \\
\text { Newport } \\
\text { City of } \\
\text { June } 30\end{array}$ & $\begin{array}{l}\text { Tennessee } \\
\text { Oak Ridge } \\
\text { City of } \\
\text { June } 30\end{array}$ & $\begin{array}{c}\text { Tennessee } \\
\text { Paris } \\
\text { City of } \\
\text { June } 30\end{array}$ \\
\hline \multicolumn{7}{|l|}{ Electric Utility Plant } \\
\hline Electric Utility Plant \& Adjust .................................... & 26,928 & 33,721 & 527,094 & 25,196 & 23,506 & 25,383 \\
\hline 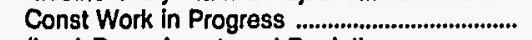 & 894 & 1,632 & 9,411 & & 2,643 & 544 \\
\hline 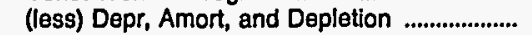 & 8,674 & 10,037 & 188,118 & 8,109 & 9,697 & 11,115 \\
\hline Net Electric Utility Plant .................................... & 19,148 & 25,315 & 348,387 & 17,115 & 16,453 & 14,812 \\
\hline Nuclear Fuel ............................................................. & & & & & 0 & 0 \\
\hline 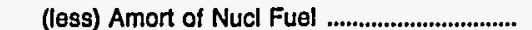 & 0 & 0 & 0 & 0 & 0 & 0 \\
\hline 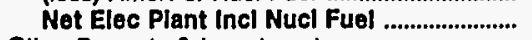 & 19,148 & 25,315 & 348,387 & 17,115 & 16,453 & 14,812 \\
\hline \multicolumn{7}{|l|}{ Other Property \& Investments } \\
\hline 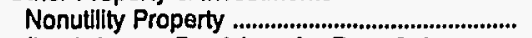 & 0 & 0 & 0 & 0 & 0 & 0 \\
\hline (less) Accum Provisions for Depr \& Amort .... & 0 & 0 & 0 & 0 & 0 & 0 \\
\hline 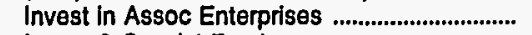 & 0 & 0 & 0 & 0 & 0 & 0 \\
\hline 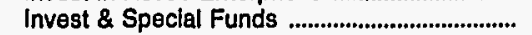 & 9 & 5,526 & 86,743 & 2,073 & 661 & 1,860 \\
\hline \multirow{2}{*}{\multicolumn{2}{|c|}{$\begin{array}{l}\text { Current and Accrued Assets } \\
\text { Cash Working Funds \& Investments }\end{array}$}} & 5,526 & 86,743 & 2,073 & 661 & 1,860 \\
\hline & 4,663 & 4,011 & 44,415 & 1,078 & 2,135 & 1,725 \\
\hline 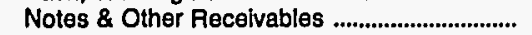 & 2,881 & 2,017 & 33,769 & 1,148 & 2,209 & 1,039 \\
\hline 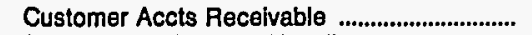 & 0 & 0 & 0 & 0 & 0 & 0 \\
\hline (less) Accum Prov for Uncollected Accts ....... & 0 & 0 & 0 & 0 & 0 & 0 \\
\hline Fuel Stock \& Exp Undistr ......................................... & 0 & 0 & 0 & 0 & 0 & 0 \\
\hline 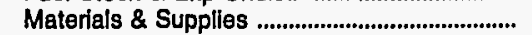 & 501 & 556 & 6,473 & 338 & 355 & 260 \\
\hline 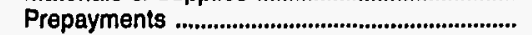 & 8 & 17 & 189 & 8 & 0 & 24 \\
\hline 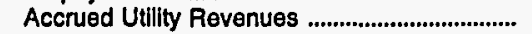 & 0 & 0 & 0 & 0 & 0 & 0 \\
\hline Miscellaneous Current \& Accrued Assets ...... & 643 & 46 & 18,232 & 1,264 & 25 & 51 \\
\hline $\begin{array}{l}\text { Total Current \& Accrued Assets ................ } \\
\text { Deferred Debits }\end{array}$ & 8,697 & 6,648 & 103,079 & 3,836 & 4,724 & 3,099 \\
\hline 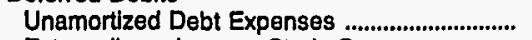 & 0 & 27 & 1,882 & 104 & 47 & 46 \\
\hline Extraordinary Losses, Study Cost ....................... & 0 & & 225 & 0 & 0 & 0 \\
\hline Mlsc Debt, A \& D Exp, Unamrt Losses ........... & 1,635 & 1,524 & 24,006 & 3,953 & 313 & 1,716 \\
\hline Total Deferred Debits ............................................ & 1,635 & 1,551 & 26,112 & 4,057 & 360 & 1,762 \\
\hline Total Assets \& Other Deblts .......................... & 29,489 & 39,040 & 564,321 & 27,081 & 22,197 & 21,533 \\
\hline \multicolumn{7}{|l|}{ Proprletary Capital } \\
\hline 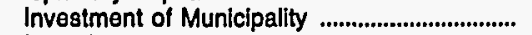 & 0 & 0 & 0 & 0 & 0 & 0 \\
\hline 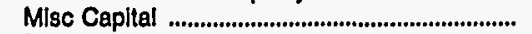 & 0 & 0 & 0 & 0 & 0 & 0 \\
\hline 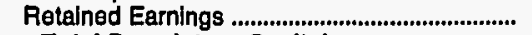 & 21,148 & 27,993 & 249,140 & 17,869 & 11,079 & 14,485 \\
\hline \multicolumn{7}{|l|}{ Long-term Débt } \\
\hline 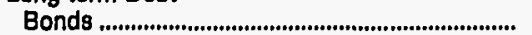 & 15 & 3,870 & 215,560 & 5,095 & 6,350 & 3,000 \\
\hline Advances from Municipality \& Other ................ & 1,618 & 1,295 & 23,039 & 1,309 & 321 & 1,711 \\
\hline Unamort Prem on Long-term Debt ..................... & 0 & 0 & & -60 & -77 & 0 \\
\hline (less) Unamort Discount on Long-term Debt & & 0 & 2,976 & 0 & & 0 \\
\hline 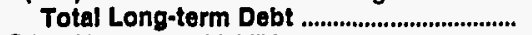 & 1,632 & 5,165 & 235,623 & 6,343 & 6,594 & 4,711 \\
\hline \multicolumn{7}{|l|}{ Other Noncurrent Liabilities } \\
\hline 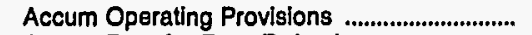 & 0 & 0 & 0 & 0 & 0 & 0 \\
\hline 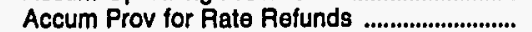 & 0 & 0 & 0 & 0 & 0 & 0 \\
\hline Total Other Noncurrent Llabllitles ............. & 0 & 0 & 0 & 0 & 0 & 0 \\
\hline \multicolumn{7}{|l|}{ Current and Accrued Llabilities } \\
\hline 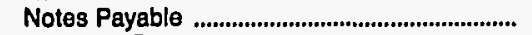 & & 0 & 0 & 0 & & 0 \\
\hline 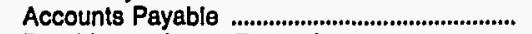 & 2,691 & 3,210 & 59,120 & 2,027 & 3,983 & 1,572 \\
\hline Payables to Assoc Enterprises .............................. & & & & 0 & 0 & 0 \\
\hline 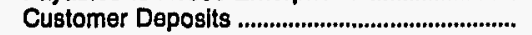 & 1,232 & 1,332 & 11,036 & 601 & 319 & 474 \\
\hline 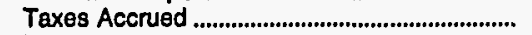 & 0 & 0 & 0 & 0 & 0 & 0 \\
\hline 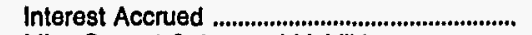 & & 19 & 2,637 & 99 & 71 & 13 \\
\hline 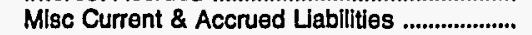 & 1,030 & 376 & 1,897 & 118 & 77 & 229 \\
\hline $\begin{array}{l}\text { Total Current \& Accrued Llabilitles ........... } \\
\text { Deferred Credits }\end{array}$ & 4,853 & 4,938 & 74,689 & 2,845 & 4,450 & 2,288 \\
\hline Customer Advances for Construction ................... & 0 & 0 & 838 & 23 & 0 & 0 \\
\hline 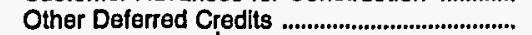 & 1,755 & 945 & 4,030 & 1 & 75 & 49 \\
\hline Unamort Gain on Reacqr Debt ............................ & & 0 & 0 & 0 & 0 & 0 \\
\hline Total Deferred Credits ..................................... & 1,755 & 945 & 4,868 & & & 49 \\
\hline Total Llabilitles and Other Credlts ............ & 29,489 & 39,040 & 564,321 & 27,081 & 22,197 & 21,533 \\
\hline
\end{tabular}

Note: Totals may not equal sum of components because of independent rounding.

Source: Energy Information Administration, Form ElA-412, "Annual Report of Public Electric Utilities." 
Table 22. Balance Sheet by Major U.S. Publicly Owned Electric Utility Within State at End of Period, 1993 (Continued) (Thousand Dollars)

\begin{tabular}{|c|c|c|c|c|c|c|}
\hline Item & $\begin{array}{l}\text { Tennessee } \\
\text { Pulaski } \\
\text { City of } \\
\text { June } 30\end{array}$ & $\begin{array}{l}\text { Tennessee } \\
\text { Ripley } \\
\text { City of } \\
\text { June } 30\end{array}$ & $\begin{array}{l}\text { Tennessee } \\
\text { Rockwood } \\
\text { City of } \\
\text { June } 30\end{array}$ & $\begin{array}{c}\text { Tennessee } \\
\text { Sevier } \\
\text { County } \\
\text { Electric } \\
\text { System } \\
\text { June } 30\end{array}$ & $\begin{array}{c}\text { Tennessee } \\
\text { Shelbyville } \\
\text { City of } \\
\text { June } 30\end{array}$ & $\begin{array}{l}\text { Tennessee } \\
\text { Springfield } \\
\text { City of } \\
\text { June } 30\end{array}$ \\
\hline \multicolumn{7}{|l|}{ Electric Utility Plant } \\
\hline Electric Utility Plant \& Adjust & 19,412 & 8,466 & 16,007 & 58,529 & 11,465 & 9,692 \\
\hline Const Work in Progress & 4,900 & & 886 & 530 & 172 & 818 \\
\hline (less) Depr, Amort, and Depletion .................... & 8,431 & 2,393 & 5,344 & 15,173 & 4,487 & 3,953 \\
\hline Net Electric Utility Plant & 15,880 & 6,082 & 11,550 & 43,886 & 7,149 & 6,557 \\
\hline Nuclear Fuel ............................................. & & 0 & & & 0 & \\
\hline 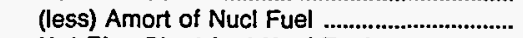 & 0 & 0 & 0 & 0 & 0 & 0 \\
\hline $\begin{array}{l}\text { Net Elec Plant Incl Nucl Fuel } \\
\text { Other Property \& Investments }\end{array}$ & 15,880 & 6,082 & 11,550 & 43,886 & 7,149 & 6,557 \\
\hline 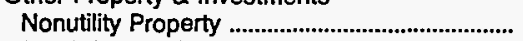 & 0 & 0 & 0 . & 0 & 0 & 0 \\
\hline (less) Accum Provisions for Depr \& Amort .... & 0 & 0 & 0 & 0 & 0 & 0 \\
\hline 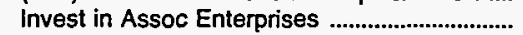 & 0 & 0 & 0 & 0 & 0 & 0 \\
\hline Invest \& Special Funds .............................................. & 880 & 5,334 & 7 & 1,136 & 8 & 1,370 \\
\hline Total Other Property \& Investments ....... & 880 & 5,334 & 7 & 1,136 & 8 & 1,370 \\
\hline \multicolumn{7}{|l|}{ Current and Accrued Assets } \\
\hline Cash, Working Funds \& Investments ............... & 430 & 300 & 384 & 3,304 & 3,529 & 273 \\
\hline 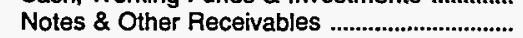 & 1,681 & 1,102 & 660 & 3,286 & 1,751 & 721 \\
\hline Customer Accts Receivable .................................. & 0 & 0 & 0 & 0 & 0 & 0 \\
\hline (less) Accum Prov for Uncollected Accts ....... & 0 & 0 & 0 & 0 & 0 & 0 \\
\hline Fuel Stock \& Exp Undistr ........................................ & 0 & 0 & 0 & 0 & 0 & 0 \\
\hline 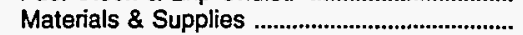 & 169 & 186 & 206 & 810 & 176 & 135 \\
\hline 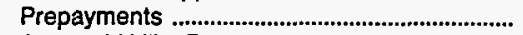 & 85 & 53 & 0 & 0 & 69 & 71 \\
\hline Accrued Utility Revenues & 0 & 0 & 0 & 0 & 0 & 0 \\
\hline Miscellaneous Current \& Accrued Assets ..... & 905 & 17 & 765 & 1,770 & 57 & 8 \\
\hline Total Current \& Accrued Assets ................... & 3,270 & 1,658 & 2,015 & 9,170 & 5,582 & 1,207 \\
\hline \multicolumn{7}{|l|}{ Deferred Debits } \\
\hline 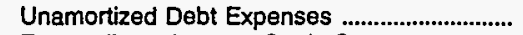 & 20 & 0 & 0 & 0 & 0 & 16 \\
\hline 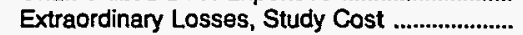 & 0 & 0 & 0 & 0 & 0 & 0 \\
\hline Misc Debt, R \& D Exp, Unamrt Losses .......... & 588 & 893 & 6 & 2,168 & 643 & 460 \\
\hline Total Deferred Debits ........................................ & 608 & 893 & 6 & 2,168 & 643 & 476 \\
\hline Total Assets \& Other Deblts ............................. & 20,639 & 13,967 & 13,577 & 56,359 & 13,382 & 9,610 \\
\hline \multicolumn{7}{|l|}{ Propriotary Capital } \\
\hline 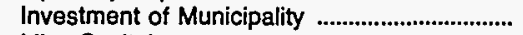 & 0 & 0 & 0 & 0 & 0 & 0 \\
\hline 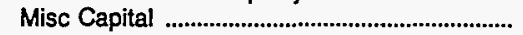 & 0 & 0 & 0 & 0 & 0 & 0 \\
\hline 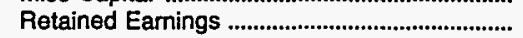 & 14,229 & 10,352 & 11,100 & 43,230 & 10,300 & 5,410 \\
\hline 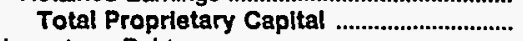 & 14,229 & 10,352 & 11,100 & 43,230 & 10,300 & 5,410 \\
\hline \multicolumn{7}{|l|}{ Long-term Debt } \\
\hline Bonds & 3,505 & 0 & 625 & 3,951 & 0 & 1,490 \\
\hline Advances from Municipality \& Other .................... & 600 & 901 & 7 & 1,652 & 678 & 511 \\
\hline Unamort Prem on Long-term Debt .................... & 0 & 0 & 0 & 0 & 0 & -11 \\
\hline (less) Unamort Discount on Long-term Debt & & 0 & 0 & 0 & 0 & 0 \\
\hline 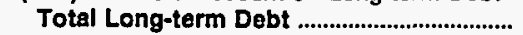 & 4,105 & 901 & 632 & 5,603 & 678 & 1,989 \\
\hline \multicolumn{7}{|l|}{ Other Noncurrent Liabilities } \\
\hline 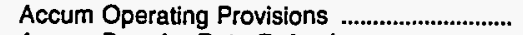 & 0 & 0 & 0 & 0 & 0 & 0 \\
\hline 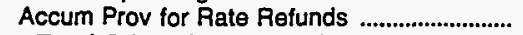 & 0 & 0 & 0 & 0 & 0 & 0 \\
\hline Total Other Noncurrent Llabillties ............. & 0 & o & 0 & 0 & 0 & 0 \\
\hline \multicolumn{7}{|l|}{ Current and Accrued Liabilities } \\
\hline 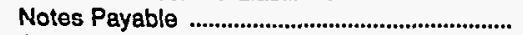 & 0 & 0 & 0 & 0 & 0 & 0 \\
\hline 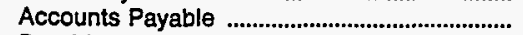 & 1,837 & 1,196 & 1,011 & 3,708 & 1,642 & 1,477 \\
\hline 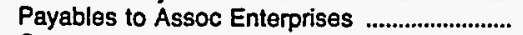 & 0 & 0 & 0 & 0 & 0 & 0 \\
\hline 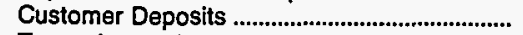 & 314 & 360 & 387 & 3,274 & 440 & 58 \\
\hline 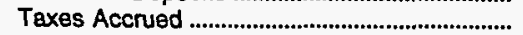 & 34 & 0 & 0 & 0 & 0 & 0 \\
\hline Interest Accrued & 16 & 0 & 5 & 49 & 0 & 6 \\
\hline Misc Current \& Accrued Liabilities ......................... & 101 & 145 & 334 & 475 & 80 & 214 \\
\hline Total Current \& Accrued Llabilltles ........... & 2,302 & 1,700 & 1,737 & 7,506 & 2,163 & 1,754 \\
\hline \multicolumn{7}{|l|}{ Deferred Credits } \\
\hline Customer Advances for Construction .............. & 0 & & 0 & 0 & 0 & \\
\hline 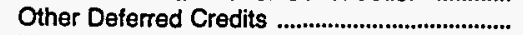 & 4 & 1,015 & 109 & 20 & 241 & 456 \\
\hline Unamort Gain on Reacqr Debt .......................... & 0 & 0 & 0 & 0 & 0 & 0 \\
\hline 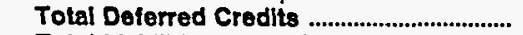 & & 1,015 & 109 & 20 & 241 & 456 \\
\hline Total Llabilltles and Other Credits ............ & 20,639 & 13,967 & 13,577 & 56,359 & 13,382 & 9,610 \\
\hline
\end{tabular}

Note: Totals may not equal sum of components because of independent rounding.

Source: Energy Information Administration, Form ElA-412, "Annual Report of Public Electric Utilities." 
Table 22. Balance Sheet by Major U.S. Publicly Owned Electric Utility Within State at End of Period, 1993 (Continued) (Thousand Dollars)

\begin{tabular}{|c|c|c|c|c|c|c|}
\hline Item & $\begin{array}{l}\text { Tennessee } \\
\text { Sweetwater } \\
\text { City of } \\
\text { June } 30\end{array}$ & $\begin{array}{c}\text { Tennessee } \\
\text { Tullahoma } \\
\text { Board } \\
\text { of } \\
\text { Pub Utils } \\
\text { June } 30\end{array}$ & $\begin{array}{l}\text { Tennessee } \\
\text { Union } \\
\text { City City of } \\
\text { June } 30\end{array}$ & $\begin{array}{c}\text { Tennessee } \\
\text { Weakley } \\
\text { County } \\
\text { Mun } \\
\text { Elec Sys } \\
\text { June } 30\end{array}$ & $\begin{array}{c}\text { Texas } \\
\text { Austin } \\
\text { City of } \\
\text { September } 30\end{array}$ & $\begin{array}{c}\text { Texas } \\
\text { Brenham } \\
\text { City of } \\
\text { September } 30\end{array}$ \\
\hline \multicolumn{7}{|l|}{ Electric Utility Plant } \\
\hline Electric Utility Plant \& Adjust ................................. & 11,175 & 12,173 & 9,431 & 26,484 & $2,090,945$ & 8,538 \\
\hline Const Work in Progress ........................................... & $\begin{array}{r}40 \\
3.350\end{array}$ & $\begin{array}{r}460 \\
5,260\end{array}$ & $\begin{array}{r}122 \\
3,402\end{array}$ & $\begin{array}{r}1,057 \\
12,491\end{array}$ & $\begin{array}{l}101,387 \\
556,085\end{array}$ & $\begin{array}{r}0 \\
2,996\end{array}$ \\
\hline 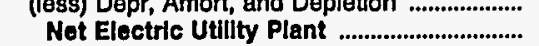 & 7,865 & 7,372 & $\begin{array}{l}5,40< \\
6,151\end{array}$ & 15,051 & $1,636,247$ & 5,541 \\
\hline 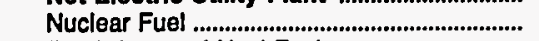 & 0 & & & 0 & 91,425 & 0 \\
\hline 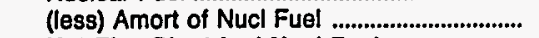 & & 0 & 0 & 0 & 40,290 & 0 \\
\hline 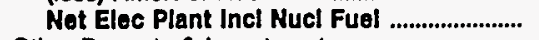 & 7,865 & 7,372 & 6,151 & 15,051 & $1,687,383$ & 5,541 \\
\hline \multicolumn{7}{|l|}{ Other Property \& Investments } \\
\hline 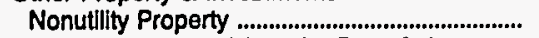 & 0 & 0 & 37 & 0 & 0 & 0 \\
\hline (less) Accum Provisions for Depr \& Amort .... & 0 & 0 & 0 & 0 & 0 & 0 \\
\hline Invest in Assoc Enterprises .................................. & 0 & 0 & 0 & 0 & 0 & \\
\hline 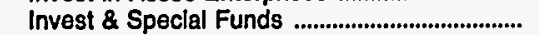 & 769 & 321 & 307 & 1,630 & 257.901 & 2,356 \\
\hline Total Other Property \& Investments ....... & 769 & 321 & 343 & 1,630 & 257,901 & 2,356 \\
\hline \multicolumn{7}{|l|}{ Current and Accrued Assets } \\
\hline Cash, Working Funds \& Investments ............... & 1,093 & 2,860 & 3,376 & 1,036 & 16,556 & 1,338 \\
\hline Notes \& Other Recelvables ................................. & 319 & 869 & 1,135 & 1,531 & 769 & \\
\hline Customer Accts Recelvable ................................ & 0 & 0 & 0 & 0 & 95,601 & 1,115 \\
\hline (less) Accum Prov for Uncollected Accts ...... & 0 & 0 & 0 & 0 & 43,695 & 29 \\
\hline 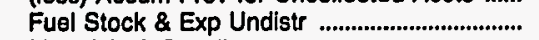 & 0 & 0 & 0 & 0 & 7,477 & 0 \\
\hline 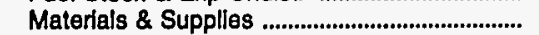 & 257 & 429 & 158 & 353 & 27,608 & 77 \\
\hline 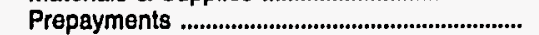 & 48 & 38 & 4 & 47 & 1,028 & 0 \\
\hline 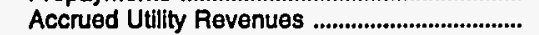 & 0 & 0 & 0 & 0 & 0 & 0 \\
\hline Mlscellaneous Current \& Accrued Assets ..... & 30 & 22 & 55 & 52 & 0 & \\
\hline \multirow{2}{*}{\multicolumn{7}{|c|}{ Deferred Deblts }} \\
\hline & & & & & & \\
\hline Unamortized Debt Expenses .................................. & 0 & 14 & 0 & 0 & 9,004 & 10 \\
\hline Extraordinary Losses, Study Cost ...................... & 0 & 0 & 4 & & 0 & 0 \\
\hline Mlsc Debt, R \& D Exp, Unamrt Losses .......... & 913 & 778 & 139 & 2,062 & 234,060 & \\
\hline Total Deferred Deblts ...................................... & 913 & 792 & 143 & 2,062 & 243,063 & 10 \\
\hline Total Assets \& Other Deblts ............................ & 11,295 & 12,704 & 11,365 & 21,761 & $2,293,692$ & 10,408 \\
\hline \multirow{2}{*}{\multicolumn{7}{|c|}{ Proprietary Capital }} \\
\hline & 0 & 0 & 0 & 0 & 47.177 & 0 \\
\hline 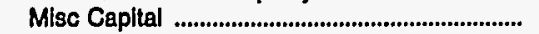 & 0 & 0 & 0 & 0 & 0 & 0 \\
\hline 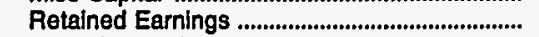 & 9,110 & 7,778 & 9,783 & 16,860 & 405,442 & 7,790 \\
\hline Total Proprletary Capltal .................................. & 9,110 & 7,778 & 9,783 & 16,860 & 452,619 & 7,790 \\
\hline \multicolumn{7}{|l|}{ Long-term Debt } \\
\hline 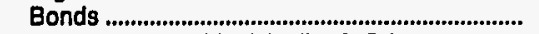 & 0 & 1,935 & 0 & 0 & $1,689,899$ & 770 \\
\hline Advances from Munlcipality \& Other ................. & 939 & 750 & 122 & 2,092 & 22,533 & 0 \\
\hline Unamort Prem on Long-term Debt ...................... & 0 & -8 & 0 & 0 & 16,380 & 0 \\
\hline (less) Unamort Discount on Long-term Debt & 0 & & 0 & 0 & 60,440 & \\
\hline 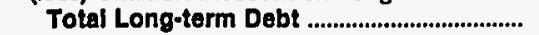 & 939 & 2,677 & 122 & 2,092 & $1,668,372$ & 770 \\
\hline \multicolumn{7}{|l|}{ Other Noncurrent Liabilities } \\
\hline 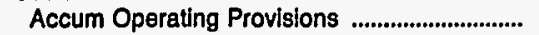 & 0 & 0 & 0 & 0 & 14,626 & 0 \\
\hline Accum Prov for Rate Refunds ................................ & 0 & 0 & 0 & 0 & 0 & 0 \\
\hline Total Other Noncurrent Llabllitles ............. & 0 & 0 & 0 & 0 & 14,626 & 0 \\
\hline \multicolumn{7}{|l|}{ Current and Accrued Liabilities } \\
\hline 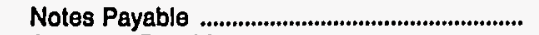 & 0 & & 0 & 0 & 28,000 & \\
\hline 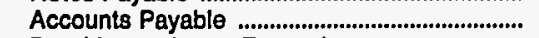 & 993 & 1,310 & 1,148 & 1,778 & 41,359 & 1,112 \\
\hline 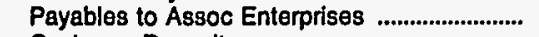 & 0 & & 0 & 0 & & \\
\hline 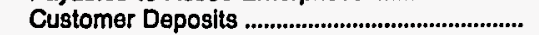 & 139 & 551 & 85 & 439 & 5,075 & 701 \\
\hline 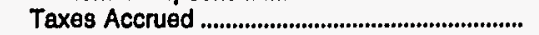 & 0 & 0 & 0 & 0 & 1,050 & 0 \\
\hline 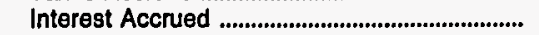 & 0 & 29 & 0 & 0 & 70,653 & 11 \\
\hline Misc Current \& Accrued Llabilities ...................... & 115 & 176 & 191 & 589 & 7,747 & 25 \\
\hline Total Current \& Accrued Lablilties .......... & 1,247 & 2,066 & 1,424 & 2,806 & 153,885 & 1,849 \\
\hline \multicolumn{7}{|l|}{ Deferred Credits } \\
\hline Customer Advances for Construction .............. & 0 & 0 & 0 & 0 & & \\
\hline 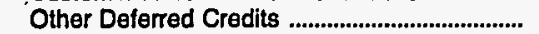 & 0 & 183 & 36 & 3 & 4,190 & 0 \\
\hline Unamort Gain on Reacqr Debt ............................ & 0 & 0 & 0 & 0 & 0 & 0 \\
\hline 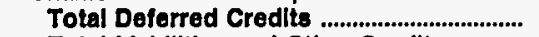 & & 183 & 36 & & 4,190 & \\
\hline Total Llabllitles and Other Credlts ............ & 11,295 & 12,704 & 11,365 & 21,761 & 2,293,692 & 10,408 \\
\hline
\end{tabular}

Note: Totals may not equal sum of components because of independent rounding.

Source: Energy Information Administration, Form EIA-412, "Annual Report of Public Electric Utilities." 
Table 22. Balance Sheet by Major U.S. Publicly Owned Electric Utility Within State at End of Period, 1993 (Continued) (Thousand Dollars)

\begin{tabular}{|c|c|c|c|c|c|c|}
\hline Item & $\begin{array}{c}\text { Texas } \\
\text { Brownsville } \\
\text { Public } \\
\text { Utils Board } \\
\text { September } 30\end{array}$ & $\begin{array}{l}\text { Texas } \\
\text { Bryan } \\
\text { City of }\end{array}$ & $\begin{array}{c}\text { Texas } \\
\text { College } \\
\text { Station } \\
\text { City of } \\
\text { September } 30\end{array}$ & $\begin{array}{l}\text { Denton } \\
\text { City of }\end{array}$ & $\begin{array}{c}\begin{array}{c}\text { Floresville } \\
\text { City of }\end{array} \\
\text { December } 31\end{array}$ & $\begin{array}{c}\text { Garland } \\
\text { City of } \\
\text { September } 30\end{array}$ \\
\hline \multicolumn{7}{|l|}{ Electric Utility Plant } \\
\hline 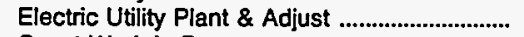 & 249,275 & 118,325 & 22,226 & 88,719 & 22,765 & 192,841 \\
\hline 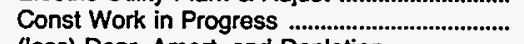 & 11,936 & 3,228 & 4,556 & & 0 & 157 \\
\hline $\begin{array}{l}\text { (less) Depr, Amort, and Depletion } \\
\text { Net Electric Utility Plant }\end{array}$ & $\begin{array}{r}75,727 \\
185,484\end{array}$ & $\begin{array}{l}49,616 \\
71,937\end{array}$ & $\begin{array}{r}8,196 \\
18,586\end{array}$ & $\begin{array}{l}48,761 \\
39,958\end{array}$ & $\begin{array}{r}8,961 \\
13,804\end{array}$ & $\begin{array}{r}78,546 \\
114,451\end{array}$ \\
\hline 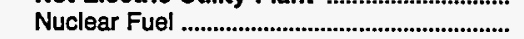 & 0 & 0 & 0 & $\begin{array}{r}0 \\
0\end{array}$ & $\begin{array}{r}10,004 \\
0\end{array}$ & $\begin{array}{r}174,401 \\
0\end{array}$ \\
\hline 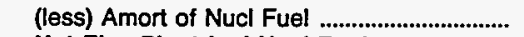 & 0 & 0 & 0 & 0 & 0 & 0 \\
\hline $\begin{array}{l}\text { Net Elec Plant Incl Nucl Fuel } \\
\text { Other Property \& Investments }\end{array}$ & 185,484 & 71,937 & 18,586 & 39,958 & 13,804 & 114,451 \\
\hline 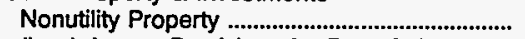 & 0 & 0 & 117 & 0 & 0 & 0 \\
\hline (less) Accum Provisions for Depr \& Amort .... & 0 & 0 & 39 & 0 & 0 & 0 \\
\hline 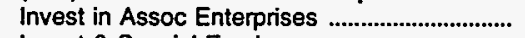 & 0 & 187 & 0 & 0 & 0 & 0 \\
\hline 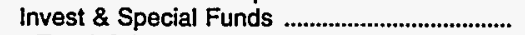 & 83,081 & 17,941 & 0 & 0 & 0 & 6,319 \\
\hline $\begin{array}{l}\text { Total Other Property \& Investments ....... } \\
\text { Current and Accrued Assets }\end{array}$ & 83,081 & 18,128 & 78 & 0 & $\mathbf{0}$ & 6,319 \\
\hline Cash, Working Funds \& Investments .............. & 12,056 & 6,815 & 10,713 & \multicolumn{3}{|c|}{ Current and Accrued Assets } \\
\hline 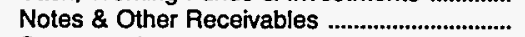 & 287 & 5,624 & 1,168 & 9,424 & 48 & $\begin{array}{r}39,864 \\
4,724\end{array}$ \\
\hline Customer Accts Receivable ................................ & 4,994 & 7,239 & 3,389 & 12,112 & 713 & 24,733 \\
\hline (less) Accum Prov for Uncollected Accts ...... & 187 & 202 & 513 & 5,762 & 15 & 0 \\
\hline 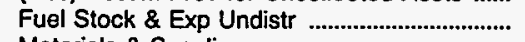 & 1,145 & 0 & 0 & 1,331 & 0 & 0 \\
\hline 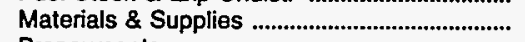 & 1,285 & 2,559 & 1,225 & 0 & 464 & 7,092 \\
\hline 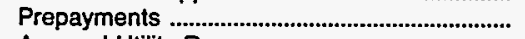 & 200 & 22 & 3 & 0 & 89 & 0 \\
\hline 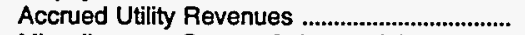 & 562 & 0 & 1,080 & 2,816 & 0 & 0 \\
\hline Miscellaneous Current \& Accrued Assets ..... & 425 & 0 & 952 & 0 & 0 & 283 \\
\hline $\begin{array}{l}\text { Total Current \& Accrued Assets ................. } \\
\text { Deferred Debits }\end{array}$ & 20,769 & 22,056 & 18,019 & 48,354 & 4,610 & 76,696 \\
\hline 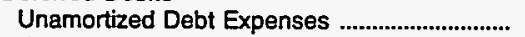 & 5,449 & 338 & 58 & 478 & 0 & 0 \\
\hline 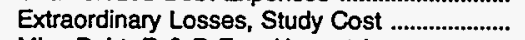 & 0 & 0 & 0 & 0 & 0 & 0 \\
\hline Misc Debt, A \& D Exp, Unamrt Losses .......... & 2,190 & 1,098 & 0 & 20,738 & 0 & 33 \\
\hline 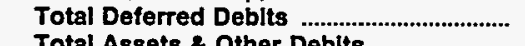 & 7,640 & 1,436 & 58 & 21,216 & 0 & 33 \\
\hline $\begin{array}{l}\text { Total Assets \& Other Deblts } \\
\text { Proprietary Capital }\end{array}$ & Proprietary Capital & 113,558 & 36,740 & 109,529 & 18,413 & 197,500 \\
\hline 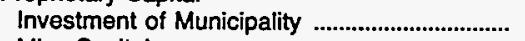 & 0 & 0 & 3,105 & 0 & 0 & 0 \\
\hline Misc Capital & 35,993 & 0 & 0 & 621 & 0 & 0 \\
\hline Retained Earnings ..................................................... & 49,487 & 71,794 & 22,366 & 70,792 & 13,414 & 161,777 \\
\hline $\begin{array}{l}\text { Total Proprletary Capital } \\
\text { Long-term Debt }\end{array}$ & 85,480 & 71,794 & 25,472 & 71,413 & 13,414 & 161,777 \\
\hline 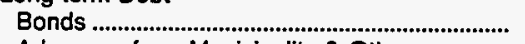 & 202,585 & 33,994 & 6,254 & 26,331 & 3,940 & 23,107 \\
\hline Advances from Municipality \& Other ................ & 51 & 0 & 79 & 0 & 0 & 0 \\
\hline Unamort Prem on Long-term Debt ....................... & 0 & 0 & 2 & 0 & 0 & 0 \\
\hline (less) Unamort Discount on Long-term Debt & 3,541 & 0 & 0 & 0 & 0 & 0 \\
\hline 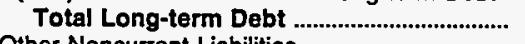 & 199,096 & 33,994 & 6,334 & 26,331 & 3,940 & 23,107 \\
\hline \multicolumn{7}{|l|}{ Other Noncurrent Liabilities } \\
\hline 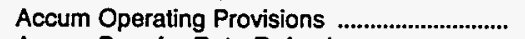 & 0 & 0 & 0 & 0 & 0 & 0 \\
\hline 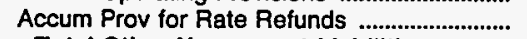 & 0 & 0 & 0 & 0 & 0 & 0 \\
\hline $\begin{array}{l}\text { Total Other Noncurrent Liabillties } \\
\text { Current and Accrued Lia.... }\end{array}$ & $\mathbf{0}$ & 0 & $\mathbf{0}$ & $\mathbf{0}$ & 0 & 0 \\
\hline \multicolumn{4}{|l|}{ Current and Accrued Liabilities } & & & \\
\hline $\begin{array}{l}\text { Notes Payable } \\
\text { Accounts Payable }\end{array}$ & $\begin{array}{r}50 \\
3,566\end{array}$ & $\begin{array}{r}285 \\
4,520\end{array}$ & 2,546 & 4,595 & $\begin{array}{l}149 \\
600\end{array}$ & $\begin{array}{r}0 \\
6.920\end{array}$ \\
\hline 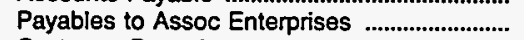 & 0 & 691 & 0 & 0 & 0 & $\begin{array}{r}6,920 \\
116\end{array}$ \\
\hline Customer Deposits & 1,663 & 962 & 1,834 & 1,284 & 264 & 3,775 \\
\hline Taxes Accrued & 28 & 0 & 0 & 0 & 47 & 0 \\
\hline Interest Accrued & 1,255 & 472 & 93 & 523 & 0 & 136 \\
\hline Misc Current \& Accrued Liabilities ..................... & 5,357 & 740 & 429 & 3,808 & 0 & 1,624 \\
\hline \multicolumn{7}{|l|}{ Deferred Credits } \\
\hline Customer Advances for Construction .............. & 133 & 0 & 30 & 0 & 0 & 0 \\
\hline Other Deferred Credits ..................................... & 346 & 100 & 3 & 1,575 & 0 & 44 \\
\hline Unamort Gain on Reacqr Debt .......................... & 0 & 0 & 0 & 0 & 0 & 0 \\
\hline Total Deferred Credlts .............................. & 479 & 100 & 32 & 1,575 & 0 & \\
\hline Total Ljabliltles and Other Credlts ............. & 296,973 & 113,558 & 36,740 & 109,529 & 18,413 & 187,500 \\
\hline
\end{tabular}

Note: Totals may not equal sum of components because of independent rounding.

Source: Energy Information Administration, Form EIA-412, "Annual Report of Public Electric Utilities." 
Table 22. Balance Sheet by Major U.S. Publicly Owned Electric Utility Within State at End of Period, 1993 (Continued)

(Thousand Dollars)

\begin{tabular}{|c|c|c|c|c|c|c|}
\hline Item & $\begin{array}{c}\text { Texas } \\
\text { Georgetown } \\
\text { City of }\end{array}$ & $\begin{array}{c}\text { Texas } \\
\text { Greenville } \\
\text { Electric } \\
\text { Util Sys } \\
\text { September } 30\end{array}$ & $\begin{array}{l}\text { Texas } \\
\text { Kerrville } \\
\text { Public } \\
\text { Utility } \\
\text { Board } \\
\text { September } 30\end{array}$ & $\begin{array}{l}\text { Texas } \\
\text { Lower } \\
\text { Colorado } \\
\text { River } \\
\text { Authority } \\
\text { June } 30\end{array}$ & $\begin{array}{c}\text { Texas } \\
\text { Lubbock } \\
\text { City of } \\
\text { September } 30\end{array}$ & $\begin{array}{c}\text { Texas } \\
\begin{array}{c}\text { New Braunfels } \\
\text { City of }\end{array} \\
\text { July } 31\end{array}$ \\
\hline \multicolumn{7}{|l|}{ Electric Utility Plant } \\
\hline Electric Utility Plant \& Adjust ..................................... & 4,828 & 46,398 & 26,850 & $1,375,585$ & 123,911 & 51,962 \\
\hline 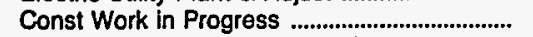 & 171 & 3,000 & 735 & 136,985 & 6,164 & 267 \\
\hline (less) Depr, Amort, and Depletion ...................... & 2,012 & 27,700 & 8,340 & 386,191 & 44,100 & 19,328 \\
\hline Net Electric Utllity Plant ....................................... & 2,987 & 21,698 & 19,244 & $1,126,379$ & 85,975 & 32,902 \\
\hline 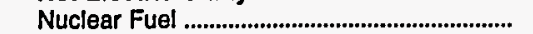 & 0 & 0 & 0 & 0 & 0 & \\
\hline 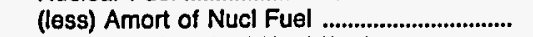 & 0 & 0 & 0 & 0 & 0 & 0 \\
\hline Net Elec Plant Incl Nucl Fuel .......................... & 2,987 & 21,698 & 19,244 & $1,126,379$ & 85,975 & 32,902 \\
\hline \multicolumn{7}{|l|}{ Other Property \& Investments } \\
\hline 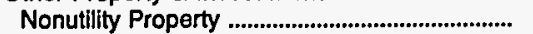 & 542 & 0 & 0 & 4,123 & 0 & 62,062 \\
\hline (less) Accum Provisions for Depr \& Amort .... & 73 & 0 & 0 & 1,347 & 0 & 19,178 \\
\hline 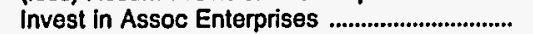 & 0 & 0 & 0 & 0 & 0 & 0 \\
\hline 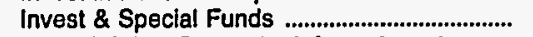 & 916 & 3,341 & 6,454 & 161,397 & 0 & 6,331 \\
\hline Total Other Property \& Investments ........ & 1,385 & 3,341 & 6,454 & 164,173 & $\mathbf{0}$ & 49,215 \\
\hline \multicolumn{7}{|l|}{ Current and Accrued Assets } \\
\hline Cash, Working Funds \& Investments .............. & 5,303 & 7,692 & 5,585 & 11,342 & 8,198 & 5,908 \\
\hline Notes \& Other Receivables ................................... & 594 & 198 & 40 & 5,676 & 4,256 & 1,870 \\
\hline Customer Accts Receivable ...................................... & 993 & 5,612 & 948 & 34,864 & 0 & 3,525 \\
\hline (less) Accum Prov for Uncollected Accts ....... & 76 & 165 & 111 & 492 & 0 & 0 \\
\hline 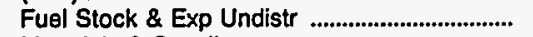 & 0 & 174 & 0 & 32,419 & 0 & 0 \\
\hline 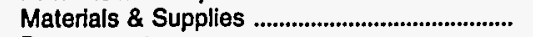 & 0 & 1,149 & 528 & 24,650 & 200 & 787 \\
\hline 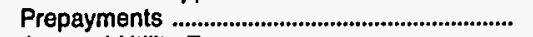 & 0 & 0 & o & 3,517 & 0 & 55 \\
\hline Accrued Utility Revenues ............................................ & 0 & 0 & 1,453 & 7,696 & 0 & 0 \\
\hline Miscellaneous Current \& Accrued Assets ..... & 0 & 0 & 50 & 3,783 & 177 & 0 \\
\hline Total Current \& Accrued Assets .................... & 6,813 & 14,659 & 8,494 & 123,454 & 12,832 & 12,145 \\
\hline \multicolumn{7}{|l|}{ Deferred Debits } \\
\hline Unamortized Debt Expenses .................................... & 0 & 0 & 716 & 18,143 & 0 & 0 \\
\hline Extraordinary Losses, Study Cost ...................... & 0 & 0 & 0 & & 0 & 0 \\
\hline Misc Debt, A \& D Exp, Unamrt Losses .......... & 0 & 0 & 125 & 443,445 & 33,722 & 0 \\
\hline 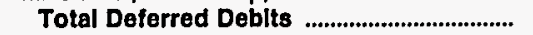 & & & 840 & 461,588 & 33,722 & \\
\hline Total Assets \& Other Deblts ........................... & 11,185 & 39,698 & 35,033 & $1,875,594$ & 132,529 & 94,262 \\
\hline \multirow{2}{*}{\multicolumn{7}{|c|}{$\begin{array}{l}\text { Proprietary Capital } \\
\text { Investment of Municipality }\end{array}$}} \\
\hline & 3,654 & 0 & 0 & 0 & 7,918 & 2,426 \\
\hline 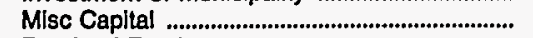 & & 0 & 0 & 12,154 & & 0 \\
\hline Retained Earnings ........................................................ & 6,054 & 16,624 & 1,721 & 393,237 & 83,902 & 34,999 \\
\hline Total Proprletary Capltal ........................... & 9,709 & 16,624 & 1,721 & 405,391 & 91,820 & 37,425 \\
\hline \multicolumn{7}{|l|}{ Long-term Debt } \\
\hline 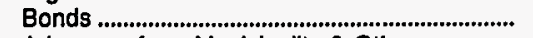 & 25 & 17,411 & 31,520 & $1,493,300$ & 31,674 & 27,575 \\
\hline Advances from Municipality \& Other ................ & 23 & & & 5,162 & 1,159 & 15,245 \\
\hline Unamort Prem on Long-term Debt .................... & 0 & 0 & 0 & 0 & 0 & 0 \\
\hline (less) Unamort Discount on Long-term Debt & 0 & 0 & 1,247 & 128,821 & 0 & 147 \\
\hline Total Long-term Debt ............................................... & 49 & 17,411 & 30,273 & $1,369,641$ & 32,833 & 42,673 \\
\hline \multicolumn{7}{|l|}{ Other Noncurrent Liabilities } \\
\hline 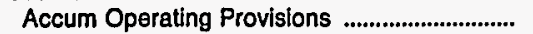 & 0 & 0 & 0 & 0 & 0 & 0 \\
\hline 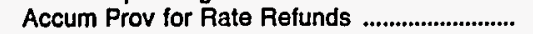 & 0 & 0 & 0 & 0 & 0 & 0 \\
\hline Total Other Noncurrent Llabilitles ............. & 0 & $\mathbf{0}$ & 0 & 0 & o & $\mathbf{0}$ \\
\hline \multicolumn{7}{|l|}{ Current and Accrued Liabilities } \\
\hline 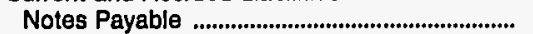 & 0 & 1,385 & & 0 & & 990 \\
\hline 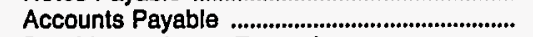 & 1,058 & 2,485 & 1,855 & 17,476 & 6,364 & 3,267 \\
\hline 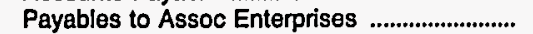 & & & 0 & 0 & 0 & 0 \\
\hline 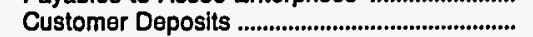 & 317 & 585 & 212 & 8 & 33 & 489 \\
\hline 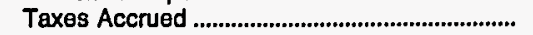 & & 0 & 0 & 92 & 124 & 0 \\
\hline 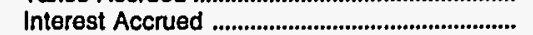 & 2 & 125 & 852 & 30,774 & 1,085 & 187 \\
\hline Mlsc Current \& Accrued Liabilities .......................... & 51 & 271 & 0 & 11,359 & 270 & 1,089 \\
\hline Total Current \& Accrued Llabllitles ........... & 1,428 & 4,852 & 2,919 & 59,708 & 7,875 & 6,021 \\
\hline \multicolumn{7}{|l|}{ Deferred Credits } \\
\hline Customer Advances for Construction .............. & 0 & 811 & 0 & 873 & 0 & 8,143 \\
\hline Other Deferred Credits ........................................... & 0 & 0 & 119 & 5,908 & 0 & 0 \\
\hline Unamort Gain on Reacqr Debt ............................ & 0 & 0 & 0 & 34,073 & 0 & 0 \\
\hline 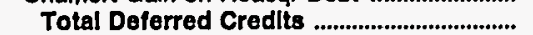 & & 811 & 119 & 40,855 & 0 & 8,143 \\
\hline Total Llabllitles and Other Credits ............. & 11,185 & 39,698 & 35,033 & $1,875,594$ & 132,529 & 94,262 \\
\hline
\end{tabular}

Note: Totals may not equal sum of components because of independent rounding.

Source: Energy Information Administration, Form ElA-412, "Annual Report of Public Electric Utilities." 
Table 22. Balance Sheet by Major U.S. Publicly Owned Electric Utility Within State at End of Period, 1993 (Continued)

(Thousand Dollars)

\begin{tabular}{|c|c|c|c|c|c|c|}
\hline Item & $\begin{array}{l}\text { Texas } \\
\text { Sam Rayburn } \\
\text { Municipal } \\
\text { Pwr } \\
\text { Agny } \\
\text { September } 30\end{array}$ & $\begin{array}{l}\text { San Antonio } \\
\text { City of } \\
\text { January } 31\end{array}$ & $\begin{array}{l}\text { Texas } \\
\text { San Marcos } \\
\text { Gity of } \\
\text { September } 30\end{array}$ & $\begin{array}{l}\text { Texas } \\
\text { Seguin } \\
\text { City of } \\
\text { September } 30\end{array}$ & $\begin{array}{c}\text { Texas } \\
\text { Texas } \\
\text { Municipal } \\
\text { Power Agency } \\
\text { September } 30\end{array}$ & $\begin{array}{l}\text { Texas } \\
\text { Toledo Bend } \\
\text { Project } \\
\text { Joint } \\
\text { Oper } \\
\text { August } 30\end{array}$ \\
\hline \multicolumn{7}{|l|}{ Electric Utility Plant } \\
\hline 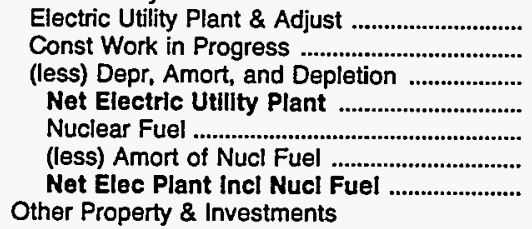 & $\begin{array}{r}138,300 \\
2,403 \\
39,840 \\
100,863 \\
0 \\
0 \\
100,863\end{array}$ & $\begin{array}{r}4,414,735 \\
112,719 \\
754,969 \\
3,772,485 \\
171,275 \\
74,345 \\
3,869,416\end{array}$ & $\begin{array}{r}15,307 \\
1,560 \\
5,941 \\
10,926 \\
0 \\
0 \\
10,926\end{array}$ & $\begin{array}{r}6,309 \\
0 \\
3,641 \\
2,668 \\
0 \\
0 \\
2,668\end{array}$ & $\begin{array}{r}765,804 \\
16,699 \\
243,683 \\
538,820 \\
0 \\
0 \\
538,820\end{array}$ & $\begin{array}{r}72,480 \\
0 \\
0 \\
72,480 \\
0 \\
0 \\
72,480\end{array}$ \\
\hline 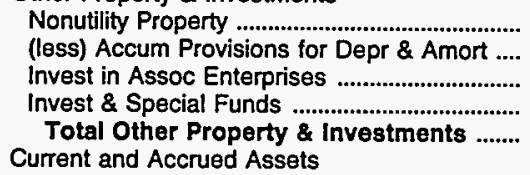 & $\begin{array}{r}0 \\
0 \\
0 \\
42,817 \\
42,817\end{array}$ & $\begin{array}{r}0 \\
0 \\
0 \\
241,479 \\
241,479\end{array}$ & $\begin{array}{l}0 \\
0 \\
0 \\
0 \\
0\end{array}$ & $\begin{array}{r}0 \\
0 \\
0 \\
1,794 \\
1,794\end{array}$ & $\begin{array}{r}0 \\
0 \\
0 \\
190,366 \\
190,366\end{array}$ & $\begin{array}{l}0 \\
0 \\
0 \\
0 \\
0\end{array}$ \\
\hline 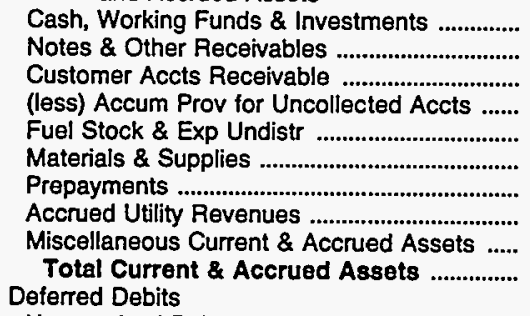 & $\begin{array}{r}21,795 \\
1,361 \\
2,730 \\
0 \\
932 \\
823 \\
106 \\
0 \\
152 \\
27,898\end{array}$ & $\begin{array}{r}206,376 \\
1,165 \\
59,558 \\
2,853 \\
10,367 \\
54,768 \\
3,155 \\
0 \\
3,800 \\
336,337\end{array}$ & $\begin{array}{r}13,588 \\
407 \\
3,697 \\
826 \\
0 \\
487 \\
0 \\
0 \\
26 \\
17,379\end{array}$ & $\begin{array}{r}556 \\
-34 \\
1,225 \\
0 \\
0 \\
621 \\
0 \\
460 \\
0 \\
2,828\end{array}$ & $\begin{array}{r}44,980 \\
8,932 \\
0 \\
0 \\
1,304 \\
3,476 \\
0 \\
0 \\
1,885 \\
60,577\end{array}$ & $\begin{array}{r}199 \\
0 \\
0 \\
0 \\
0 \\
0 \\
0 \\
0 \\
11 \\
210\end{array}$ \\
\hline $\begin{array}{l}\text { Unamortized Debt Expenses ......................... } \\
\text { Extraordinary Losses, Study Cost .................... } \\
\text { Misc Debt, R \& D Exp, Unamrt Losses ......... } \\
\text { Total Deferred Deblts ............................... } \\
\text { Total Assets \& Other Deblts .................... } \\
\text { Proprietary Capital }\end{array}$ & $\begin{array}{r}3,994 \\
0 \\
105,346 \\
109,340 \\
280,919\end{array}$ & $\begin{array}{r}6,385 \\
0 \\
190,446 \\
196,832 \\
4,644,064\end{array}$ & $\begin{array}{r}309 \\
0 \\
-101 \\
209 \\
28,513\end{array}$ & $\begin{array}{r}41 \\
0 \\
0 \\
41 \\
7,331\end{array}$ & $\begin{array}{r}20,154 \\
721 \\
600,598 \\
621,473 \\
1,411,236\end{array}$ & $\begin{array}{r}0 \\
0 \\
0 \\
0 \\
72,690\end{array}$ \\
\hline 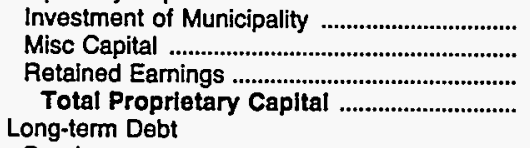 & $\begin{array}{r}0 \\
0 \\
38,686 \\
38,686\end{array}$ & $\begin{array}{r}0 \\
0 \\
1,738,671 \\
1,738,671\end{array}$ & $\begin{array}{r}0 \\
789 \\
7,200 \\
7,989\end{array}$ & $\begin{array}{r}0 \\
3,079 \\
3,019 \\
6,099\end{array}$ & $\begin{array}{r}0 \\
0 \\
32,948 \\
32,948\end{array}$ & $\begin{array}{r}72,480 \\
0 \\
130 \\
72,610\end{array}$ \\
\hline $\begin{array}{l}\text { Bonds ................................................... } \\
\text { Advances from Municipality \& Other ............... } \\
\text { Unamort Prem on Long-term Debt ................. } \\
\text { (less) Unamort Discount on Long-term Debt } \\
\text { Total Long-term Debt ..................................... } \\
\text { Other Noncurrent Liabilities }\end{array}$ & $\begin{array}{r}233,122 \\
0 \\
0 \\
0 \\
233,122\end{array}$ & $\begin{array}{r}2,722,470 \\
282,300 \\
0 \\
374,516 \\
2,630,254\end{array}$ & $\begin{array}{r}16,616 \\
0 \\
0 \\
0 \\
16,616\end{array}$ & $\begin{array}{l}0 \\
0 \\
0 \\
0 \\
0\end{array}$ & $\begin{array}{r}1,177,932 \\
178,318 \\
0 \\
34,528 \\
1,321,722\end{array}$ & $\begin{array}{l}0 \\
0 \\
0 \\
0 \\
0\end{array}$ \\
\hline 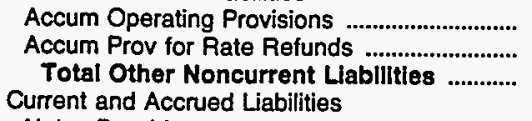 & $\begin{array}{l}0 \\
0 \\
0\end{array}$ & $\begin{array}{r}32,816 \\
0 \\
32,816\end{array}$ & $\begin{array}{r}58 \\
0 \\
58\end{array}$ & $\begin{array}{l}0 \\
0 \\
0\end{array}$ & $\begin{array}{l}0 \\
0 \\
0\end{array}$ & $\begin{array}{l}0 \\
0 \\
0\end{array}$ \\
\hline 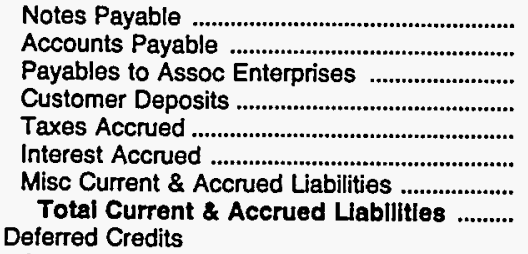 & $\begin{array}{r}0 \\
942 \\
0 \\
0 \\
0 \\
8,168 \\
0 \\
9,110\end{array}$ & $\begin{array}{r}0 \\
103,015 \\
92,680 \\
24,608 \\
863 \\
1,405 \\
1,817 \\
224,387\end{array}$ & $\begin{array}{r}470 \\
1,704 \\
296 \\
870 \\
61 \\
0 \\
450 \\
3,850\end{array}$ & $\begin{array}{r}0 \\
842 \\
0 \\
223 \\
0 \\
0 \\
168 \\
1,232\end{array}$ & $\begin{array}{r}36,000 \\
16,885 \\
769 \\
0 \\
0 \\
0 \\
2,912 \\
58,566\end{array}$ & $\begin{array}{r}0 \\
80 \\
0 \\
0 \\
0 \\
0 \\
0 \\
80\end{array}$ \\
\hline $\begin{array}{l}\text { Customer Advances for Construction ............. } \\
\text { Other Deferred Credits ........................................ } \\
\text { Unamort Gain on Reacqr Debt ..................... } \\
\text { Total Deferred Credits ............................... } \\
\text { Total Llabilltles and Other Credits ........... }\end{array}$ & $\begin{array}{r}0 \\
0 \\
0 \\
0 \\
280,919\end{array}$ & $\begin{array}{r}9,463 \\
8,473 \\
0 \\
17,936 \\
4,644,064\end{array}$ & $\begin{array}{r}0 \\
0 \\
0 \\
0 \\
28,513\end{array}$ & $\begin{array}{r}0 \\
0 \\
0 \\
0 \\
7,331\end{array}$ & $\begin{array}{r}0 \\
0 \\
0 \\
0 \\
1,411,236\end{array}$ & $\begin{array}{r}0 \\
0 \\
0 \\
0 \\
72,690\end{array}$ \\
\hline
\end{tabular}

Note: Totals may not equal sum of components because of independent rounding.

Source: Energy Information Administration, Form ElA-412, "Annual Report of Public Electric Utilities." 
Table 22. Balance Sheet by Major U.S. Publicly Owned Electric Utility Within State at End of Period, 1993 (Continued)

(Thousand Dollars)

\begin{tabular}{|c|c|c|c|c|c|c|}
\hline Item & $\begin{array}{c}\text { Texas } \\
\text { Weatherford } \\
\text { Mun } \\
\text { Utility } \\
\text { System } \\
\text { September } 30\end{array}$ & $\begin{array}{l}\text { Utah } \\
\text { Bountiful } \\
\text { City City of } \\
\text { June } 30\end{array}$ & $\begin{array}{c}\text { Intermountain } \\
\text { Power Agency } \\
\text { June } 30\end{array}$ & $\begin{array}{l}\text { Logan } \\
\text { City of } \\
\text { June } 30\end{array}$ & $\begin{array}{l}\text { Utah } \\
\text { Murray } \\
\text { City of } \\
\text { June } 30\end{array}$ & $\begin{array}{l}\text { Utah } \\
\text { Provo } \\
\text { City Corp } \\
\text { June } 30\end{array}$ \\
\hline \multicolumn{7}{|l|}{ Electric Utility Plant } \\
\hline 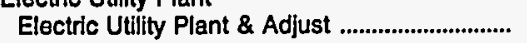 & $\cdot 11,758$ & 36,773 & $2,801,094$ & 27,936 & 40,195 & 84,895 \\
\hline 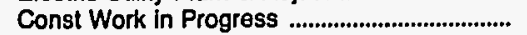 & & 733 & 30,490 & & 221 & \\
\hline (less) Depr, Amort, and Depletion ....................... & 6,517 & 11,596 & 507,819 & 8,940 & 19,295 & 35,946 \\
\hline 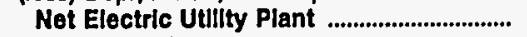 & 5,241 & 25,909 & $2,323,765$ & 18,996 & 21,121 & 48,949 \\
\hline 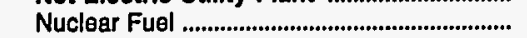 & 0 & 0 & 0 & 0 & 0 & 0 \\
\hline (less) Amort of Nucl Fuel ................................ & & 0 & 0 & 0 & 0 & 0 \\
\hline Net Elec Plant Inel Nucl Fuel .......................... & 5,241 & 25,909 & $2,323,765$ & 18,996 & 21,121 & 48,949 \\
\hline \multicolumn{7}{|l|}{ Other Property \& Investments } \\
\hline 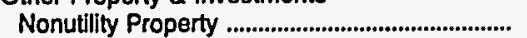 & 35,715 & 0 & 19,902 & 334 & 0 & 2,411 \\
\hline (less) Accum Provisions for Depr \& Amort .... & 5,717 & 0 & & 122 & 0 & 0 \\
\hline 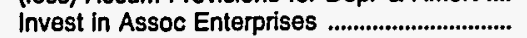 & 0 & 0 & 0 & 0 & 89 & 0 \\
\hline 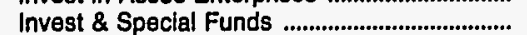 & 6,352 & 0 & $2,440,267$ & 0 & 46 & 0 \\
\hline Total Other Property \& Investments ....... & 36,351 & 0 & $2,460,169$ & 211 & 135 & 2,411 \\
\hline \multicolumn{7}{|l|}{ Current and Accrued Assets } \\
\hline Cash, Working Funds \& Investments ............... & 4,105 & 4,033 & 96,882 & 4,616 & 15,679 & 5,942 \\
\hline Notes \& Other Receivables ...................................... & 1,509 & & 25,548 & 260 & & 5,131 \\
\hline Customer Accts Receivable ............................... & 1,400 & 1,511 & 0 & 1,750 & 1,826 & 2,433 \\
\hline (less) Accum Prov for Uncollected Accts ....... & 30 & 14 & 0 & 53 & 123 & 0 \\
\hline 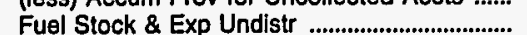 & 0 & 0 & 53,984 & 0 & 0 & 0 \\
\hline Materials \& Supplies ................................................... & 1,115 & 1,269 & 14,984 & 903 & 745 & 913 \\
\hline Prepayments & 3 & 71 & 0 & 0 & 1,670 & 0 \\
\hline 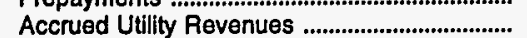 & 0 & 0 & 0 & 16 & 0 & 0 \\
\hline Miscellaneous Current \& Accrued Assets ...... & 194 & 0 & 2,571 & & 399 & 0 \\
\hline Total Current \& Accrued Assets .................... & 8,296 & 6,878 & 193,969 & 7,492 & 20,195 & 14,419 \\
\hline \multicolumn{7}{|l|}{ Deferred Debits } \\
\hline Unamortized Debt Expenses ................................... & 315 & 0 & 945,292 & 234 & 242 & 0 \\
\hline 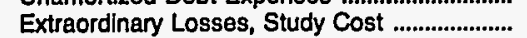 & 0 & 0 & & 0 & 0 & 0 \\
\hline Misc Debt, R \& D Exp, Unamrt Losses .......... & 0 & 0 & 968,436 & 0 & 0 & 0 \\
\hline Total Deferred Debits ...................................... & 315 & & $1,913,728$ & 234 & 242 & 0 \\
\hline 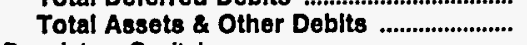 & 50,202 & 32,788 & $6,891,631$ & 26,933 & 41,693 & 65,778 \\
\hline \multicolumn{7}{|l|}{ Propriatary Capital } \\
\hline Investment of Municipality .................................... & 7,044 & 0 & 0 & 0 & 77 & 0 \\
\hline 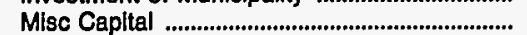 & & 531 & 0 & 874 & 88 & 0 \\
\hline 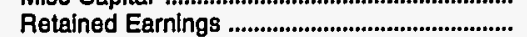 & 27,497 & 30,905 & 0 & 13,815 & 32,931 & 4,147 \\
\hline Total Proprietary Capltal ............................ & 34,540 & $\mathbf{3 1 , 4 3 5}$ & 0 & 14,689 & 33,096 & 4,147 \\
\hline \multicolumn{7}{|l|}{ Long-term Debt } \\
\hline 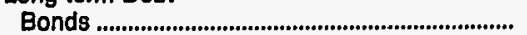 & 12,785 & 0 & $5,303,884$ & 9,905 & 7,425 & 60,890 \\
\hline Advances from Municipality \& Other ............. & & 0 & 19,550 & 185 & 0 & 436 \\
\hline Unamort Prem on Long-term Debt ................... & 0 & 0 & & 0 & 0 & 0 \\
\hline (less) Unamort Discount on Long-term Debt & 108 & 0 & 223,931 & & & 2,091 \\
\hline Total Long-term Debt ...................................... & 12,677 & 0 & $5,099,503$ & 10,090 & 7,425 & 59,235 \\
\hline \multicolumn{7}{|l|}{ Other Noncurrent Liablitios } \\
\hline Accum Operating Provisions ................................ & 0 & 0 & 0 & 0 & 0 & 0 \\
\hline Accum Prov for Rate Refunds . ............................ & 0 & 0 & 0 & 0 & 0 & 0 \\
\hline Total Other Noncurrent Liabilitles ............ & 0 & 0 & 0 & 0 & 0 & 0 \\
\hline \multicolumn{7}{|l|}{ Current and Accrued Llabilities } \\
\hline 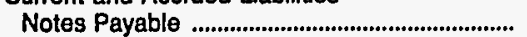 & 0 & 0 & 0 & 165 & 0 & 119 \\
\hline Accounts Payable & 1,877 & 931 & 34,697 & 1,086 & 310 & 244 \\
\hline Payables to Assoc Enterprises & 0 & 0 & 38,409 & 0 & 0 & 0 \\
\hline 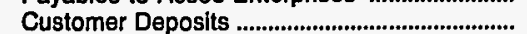 & 120 & 228 & 0 & 413 & 500 & 1,199 \\
\hline Taxes Accrued & 133 & 0 & 0 & 0 & 0 & 151 \\
\hline Interest Accrued & 71 & 0 & 102,227 & 359 & 42 & 89 \\
\hline Misc Current \& Accrued Llabilities & 372 & 194 & $1,616,795$ & 131 & 320 & 595 \\
\hline Total Current \& Accrued Llabllitles ........... & 2,573 & 1,353 & $1,792,128$ & 2,153 & 1,173 & 2,398 \\
\hline \multicolumn{7}{|l|}{ Deferred Credits } \\
\hline Customer Advances for Construction ............. & 0 & 0 & 0 & 0 & 0 & 0 \\
\hline Other Deferred Credits .......................................... & 412 & 0 & 0 & 0 & 0 & 0 \\
\hline 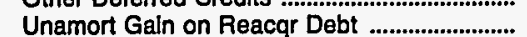 & 0 & 0 & 0 & 0 & 0 & 0 \\
\hline 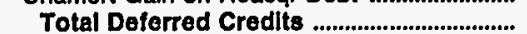 & 412 & 0 & o & $\mathbf{0}$ & 0 & 0 \\
\hline 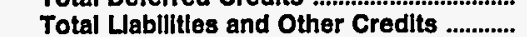 & 50,202 & 32,788 & $6,891,631$ & 26,933 & 41,693 & 65,778 \\
\hline
\end{tabular}

Note: Totals may not equal sum of components because of independent rounding.

Source: Energy Information Administration, Form ElA-412, "Annual Report of Public Electric Utilities." 
Table 22. Balance Sheet by Major U.S. Publicly Owned Electric Utility Within State at End of Period, 1993 (Continued) (Thousand Dollars)

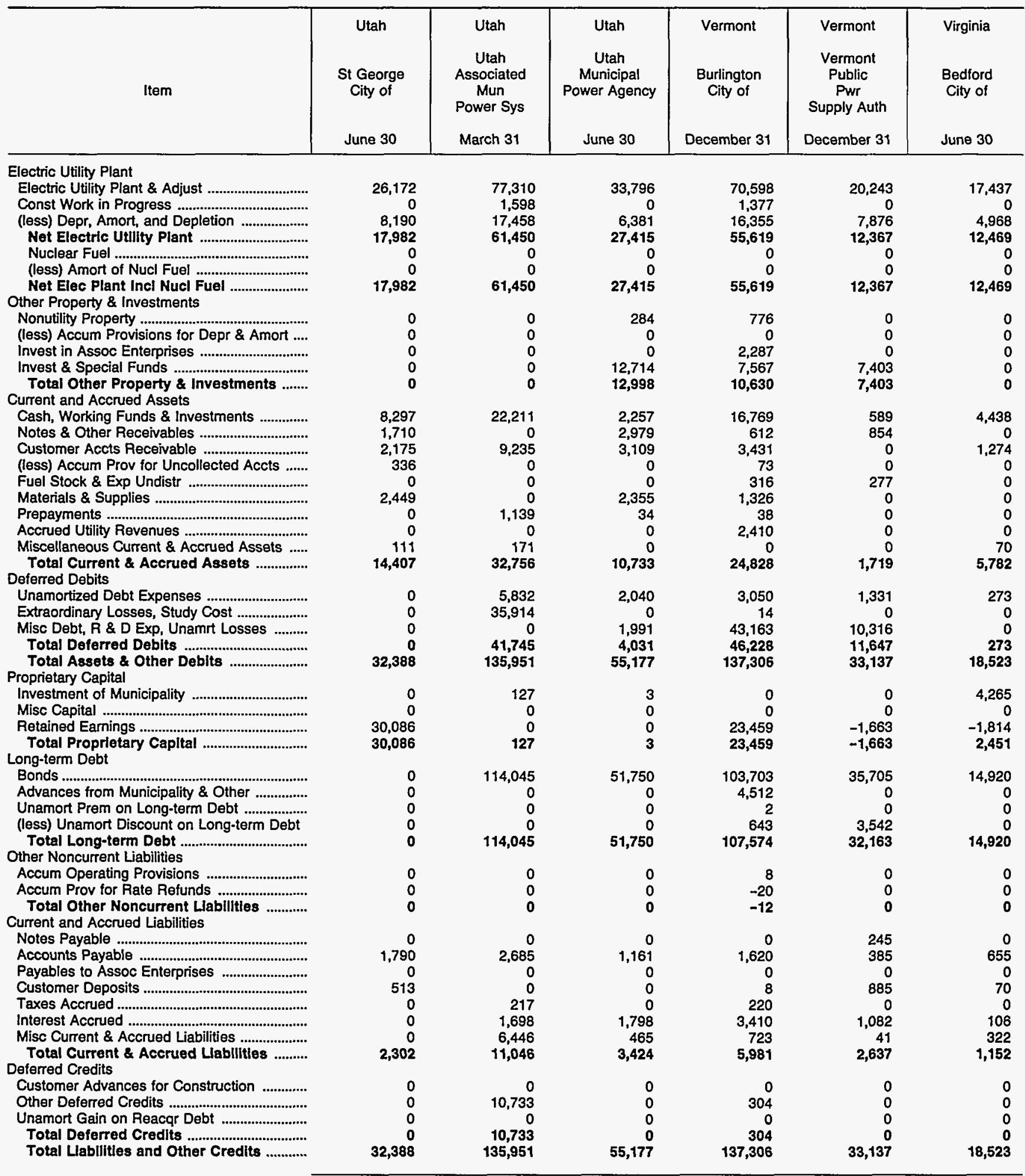

Note: Totals may not equal sum of components because of independent rounding.

Source: Energy Information Administration, Form EIA-412, "Annual Report of Public Electric Utilities." 
Table 22. Balance Sheet by Major U.S. Publicly Owned Electric Utility Within State at End of Period, 1993 (Continued)

(Thousand Dollars)

\begin{tabular}{|c|c|c|c|c|c|c|}
\hline Item & $\begin{array}{l}\text { Virginia } \\
\text { Bristol } \\
\text { Utilities } \\
\text { Board } \\
\text { June } 30\end{array}$ & $\begin{array}{l}\text { Virginia } \\
\text { Danville } \\
\text { City of } \\
\text { June } 30\end{array}$ & $\begin{array}{c}\text { Virginia } \\
\begin{array}{c}\text { Harrisonburg } \\
\text { City of }\end{array} \\
\text { June } 30\end{array}$ & $\begin{array}{l}\text { Virginia } \\
\begin{array}{l}\text { Manassas } \\
\text { City of }\end{array} \\
\text { June } 30\end{array}$ & $\begin{array}{l}\text { Virginia } \\
\text { Martinsville } \\
\text { City of } \\
\text { June } 30\end{array}$ & $\begin{array}{l}\text { Virginia } \\
\text { Radford } \\
\text { City of } \\
\text { June } 30\end{array}$ \\
\hline \multicolumn{7}{|l|}{ Electric Utility Plant } \\
\hline 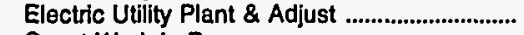 & 21,422 & 52,926 & 41,342 & 36,560 & 16,553 & 13,073 \\
\hline Const Work in Progress & 1,053 & 1,352 & 1,076 & & & \\
\hline (less) Depr, Amort, and Depletion ..................... & 10,306 & 22,542 & 13,564 & 11,109 & 6,042 & 7,065 \\
\hline 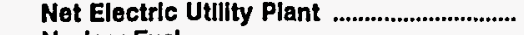 & 12,169 & 31,736 & 28,854 & 25,633 & 10,511 & 6,007 \\
\hline 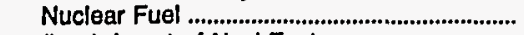 & 0 & 0 & 0 & 0 & 0 & 0 \\
\hline 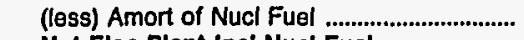 & & 0 & 0 & 0 & 0 & 0 \\
\hline Net Elec Plant Incl Nucl Fuel ........................... & 12,169 & 31,736 & 28,854 & 25,633 & 10,511 & 6,007 \\
\hline \multicolumn{7}{|l|}{ Other Property \& Investments } \\
\hline 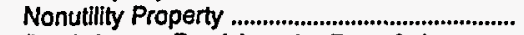 & 591 & 0 & 0 & 0 & $\mathbf{0}$ & 0 \\
\hline (less) Accum Provisions for Depr \& Amort .... & 0 & 0 & 0 & 0 & 0 & 0 \\
\hline 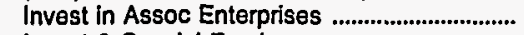 & 0 & 0 & 0 & 0 & 0 & 0 \\
\hline 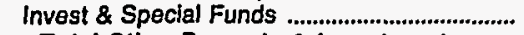 & 782 & 0 & 1 & 0 & 0 & 0 \\
\hline \multirow{2}{*}{\multicolumn{7}{|c|}{ Current and Accrued Assets }} \\
\hline & & & & & & \\
\hline Cash, Working Funds \& Investments ................ & 2,396 & 7,883 & 2,405 & 760 & 1,761 & 4,416 \\
\hline 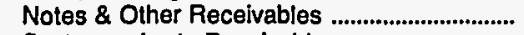 & 960 & 371 & 327 & 106 & 0 & 4,100 \\
\hline 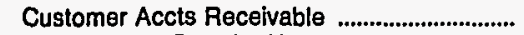 & 0 & 5,391 & 2,172 & 2,760 & 1,484 & 1,143 \\
\hline (less) Accum Prov for Uncollected Accts ...... & 0 & 0 & 0 & 5 & 33 & 83 \\
\hline Fuel Stock \& Exp Undistr ..................................... & 0 & 0 & 0 & 0 & 0 & 0 \\
\hline 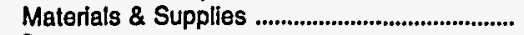 & 354 & 494 & 1,302 & 0 & 0 & 191 \\
\hline Prepayments ............................................................. & 0 & 0 & 35 & 0 & 0 & 0 \\
\hline 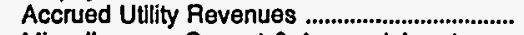 & 0 & 0 & 481 & 0 & 0 & 0 \\
\hline Miscellaneous Current \& Accrued Assets ..... & 1,255 & 0 & 0 & 0 & 0 & 0 \\
\hline \multicolumn{7}{|l|}{ Deferred Debits } \\
\hline 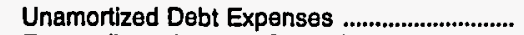 & 0 & 0 & 15 & 0 & 0 & 0 \\
\hline 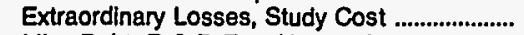 & 0 & 0 & 0 & 0 & 0 & 0 \\
\hline Misc Debt, R \& D Exp, Unamrt Losses .......... & 1,670 & 0 & 0 & 0 & 0 & 0 \\
\hline Total Deferred Debits ........................................ & 1,670 & & & & & \\
\hline 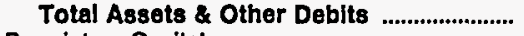 & 20,179 & 45,874 & 35,592 & 29,254 & 13,724 & 15,774 \\
\hline \multicolumn{7}{|l|}{ Propriatary Capital } \\
\hline 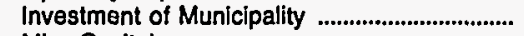 & 0 & 2,983 & 1,199 & 437 & 0 & 0 \\
\hline 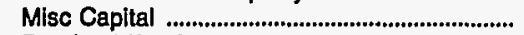 & 0 & 0 & 0 & 0 & 0 & 0 \\
\hline 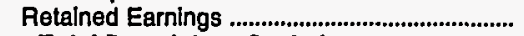 & 17,514 & 30,666 & 28,409 & 15,925 & 12,569 & 10,737 \\
\hline 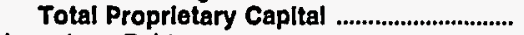 & 17,514 & 33,649 & 29,608 & 16,361 & 12,569 & 10,737 \\
\hline \multicolumn{7}{|l|}{ Long-term Debt } \\
\hline 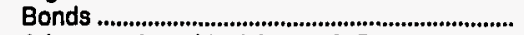 & 0 & 7,430 & 0 & 9,611 & 0 & 3,900 \\
\hline Advances from Municipality \& Other ................ & 0 & 260 & 0 & 187 & 0 & 0 \\
\hline Unamort Prem on Long-term Debt ...................... & 0 & 0 & 2,768 & 0 & 0 & 0 \\
\hline (less) Unamort Discount on Long-term Debt & 0 & 0 & 0 & 0 & 0 & 0 \\
\hline \multirow{2}{*}{\multicolumn{7}{|c|}{ Other Noncurrent Liabilities }} \\
\hline & & & & & & \\
\hline 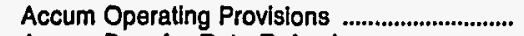 & 0 & 0 & 0 & 0 & 0 & 0 \\
\hline 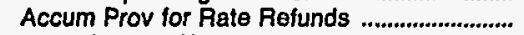 & 0 & 0 & 0 & 0 & 0 & 0 \\
\hline $\begin{array}{l}\text { Total Other Noncurrent Llablitities ............ } \\
\text { Current and Accrued Liabilities }\end{array}$ & $\mathbf{0}$ & 0 & 0 & 0 & 0 & o \\
\hline \multicolumn{7}{|l|}{ Current and Accrued Liabilities } \\
\hline 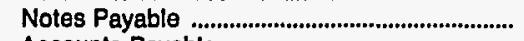 & 0 & 0 & 236 & 0 & 0 & 0 \\
\hline 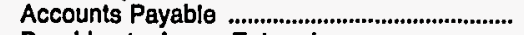 & 1,753 & 3,441 & 2,504 & 1,828 & 741 & 858 \\
\hline 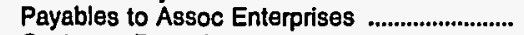 & & & 0 & 0 & 0 & 0 \\
\hline 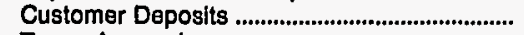 & 336 & 1,005 & 272 & 377 & 220 & 143 \\
\hline 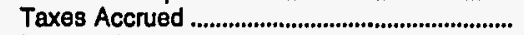 & 1 & 0 & 0 & 0 & 0 & 0 \\
\hline 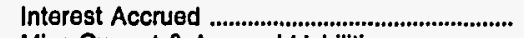 & 0 & 84 & 17 & 186 & 0 & 0 \\
\hline Misc Current \& Accrued Liabilities ...................... & 575 & 0 & 188 & 704 & 194 & 136 \\
\hline Total Current \& Accrued Liabilltles .......... & 2,665 & 4,530 & 3,215 & 3,095 & 1,155 & 1,137 \\
\hline \multicolumn{7}{|l|}{ Deferred Credits } \\
\hline Customer Advances for Construction .............. & 0 & 0 & 0 & 0 & 0 & 0 \\
\hline 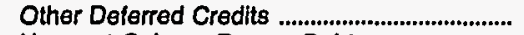 & 0 & 5 & 0 & 0 & 0 & 0 \\
\hline 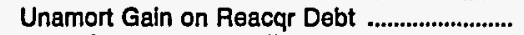 & 0 & 0 & 0 & 0 & 0 & 0 \\
\hline Total Deforred Credits ...................................... & & & & & & \\
\hline Total Llabllifles and Other Credits ............ & 20,179 & 45,874 & 35,592 & 29,254 & 13,724 & 15,774 \\
\hline
\end{tabular}

Note: Totals may not equal sum of components because of independent rounding.

Source: Energy Information Administration, Form ElA-412, "Annual Report of Public Electric Utilities." 
Table 22. Balance Sheet by Major U.S. Publicly Owned Electric Utility Within State at End of Period, 1993 (Continued)

(Thousand Dollars)

\begin{tabular}{|c|c|c|c|c|c|c|}
\hline Item & $\begin{array}{l}\text { Virginia } \\
\text { Salem } \\
\text { City of } \\
\text { June } 30\end{array}$ & $\begin{array}{c}\text { Virginia } \\
\text { Virginia } \\
\text { Tech } \\
\text { Electric } \\
\text { Service } \\
\text { June } 30\end{array}$ & $\begin{array}{l}\text { Washington } \\
\text { Centralia } \\
\text { City of } \\
\text { December } 31\end{array}$ & $\begin{array}{l}\text { Washington } \\
\text { Ellensburg } \\
\text { Gity of } \\
\text { December } 31\end{array}$ & $\begin{array}{l}\text { Washington } \\
\text { Port Angeles } \\
\text { City of } \\
\text { December } 31\end{array}$ & $\begin{array}{l}\text { Washington } \\
\text { PUD No } 1 \\
\text { of } \\
\text { Benton } \\
\text { County } \\
\text { December } 31\end{array}$ \\
\hline \multicolumn{7}{|l|}{ Electric Utility Plant } \\
\hline 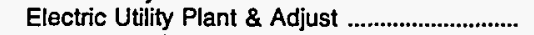 & 20,194 & 0 & 17,045 & 12,559 & 21,512 & 80,984 \\
\hline 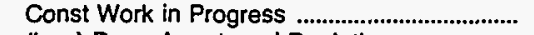 & & 0 & 719 & & 479 & 5,421 \\
\hline 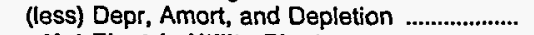 & 9,448 & 0 & 7,777 & 5,467 & 8,544 & 33,623 \\
\hline Net Electric Utility Plant & 10,746 & 0 & $\mathbf{9 , 9 8 7}$ & 7,092 & 13,447 & 52,782 \\
\hline 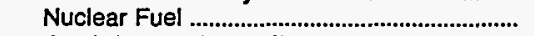 & 0 & 0 & 0 & 0 & 0 & 0 \\
\hline 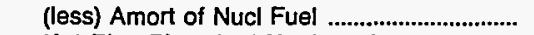 & 0 & 0 & 0 & 0 & 0 & 0 \\
\hline Net Elec Plant Incl Nucl Fuel ........................... & 10,746 & o & 9,987 & 7,092 & 13,447 & 52,782 \\
\hline \multicolumn{7}{|l|}{ Other Property \& Investments } \\
\hline 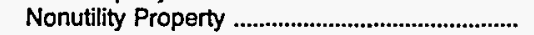 & 0 & 0 & 69 & 232 & 0 & 0 \\
\hline (less) Accum Provisions for Depr \& Amort .... & 0 & 0 & $\mathbf{0}$ & 107 & 0 & 0 \\
\hline 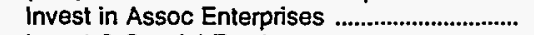 & 0 & 0 & 0 & 0 & 0 & 0 \\
\hline 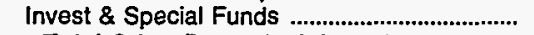 & 908 & 0 & 429 & 275 & 0 & 15,667 \\
\hline Total Other Property \& investments ........ & 908 & $\mathbf{0}$ & 498 & 400 & 0 & 15,667 \\
\hline \multicolumn{7}{|l|}{ Current and Accrued Assets } \\
\hline Cash, Working Funds \& Investments ............... & 3,081 & 1,254 & 382 & 700 & 3,490 & 4,045 \\
\hline 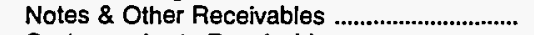 & 32 & 1,590 & 27 & 0 & 320 & 220 \\
\hline Customer Accts Receivable ................................... & 896 & 397 & 737 & 879 & 2,243 & 4,832 \\
\hline (less) Accum Prov for Uncollected Accts ....... & 47 & 0 & 12 & 9 & 0 & 11 \\
\hline 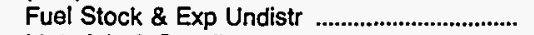 & 0 & 0 & 0 & 0 & 0 & 0 \\
\hline Materials \& Supplies ..................................................... & 543 & 297 & 163 & 389 & 785 & 1,519 \\
\hline 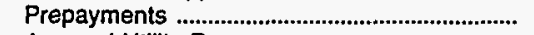 & 0 & 2 & 0 & 0 & 0 & 107 \\
\hline 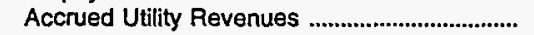 & 1,132 & 0 & 0 & 0 & 0 & 0 \\
\hline Miscellaneous Current \& Accrued Assets ..... & 0 & 0 & 135 & 25 & 413 & 502 \\
\hline Total Current \& Accrued Assets .................... & 5,637 & 3,540 & 1,431 & 1,984 & 7,251 & 11,215 \\
\hline \multicolumn{7}{|l|}{ Deferred Debits } \\
\hline 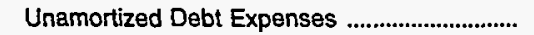 & 0 & 2,670 & 2 & 1 & 0 & 1,262 \\
\hline 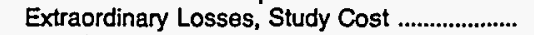 & 0 & & 0 & 0 & 0 & 0 \\
\hline Misc Debt, R \& D Exp, Unamrt Losses .......... & 0 & 0 & 0 & 0 & 0 & 4 \\
\hline 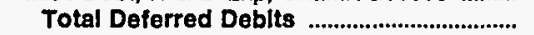 & 0 & 2,670 & 2 & 1 & 0 & 1,268 \\
\hline Total Assets \& Other Debits .............................. & 17,291 & 6,210 & 11,917 & 9,477 & 20,698 & 80,930 \\
\hline \multicolumn{7}{|l|}{ Proprietary Capital } \\
\hline 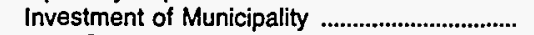 & 0 & 0 & 612 & $\mathbf{0}$ & 987 & 0 \\
\hline 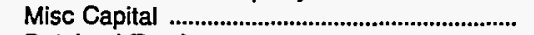 & 0 & 0 & 0 & 0 & 0 & 0 \\
\hline 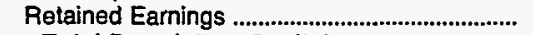 & 5,721 & 2,080 & 7,164 & 7,903 & 13,072 & 26,746 \\
\hline Total Proprietary Capltal ................................. & 5,721 & 2,080 & 7,776 & 7,903 & 14,059 & 26,746 \\
\hline \multicolumn{7}{|l|}{ Long-term Debt } \\
\hline 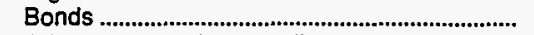 & 9,665 & 2,670 & 2,929 & 290 & 2,840 & 39,125 \\
\hline Advances from Municipality \& Other ................. & 0 & 0 & 0 & 460 & 0 & 1,200 \\
\hline Unamort Prem on Long-term Debt ...................... & 0 & 0 & 0 & 0 & 0 & 0 \\
\hline (less) Unamort Discount on Long-term Debt & 88 & 0 & 19 & 0 & 0 & 0 \\
\hline Total Long-term Debt ......................................... & 9,577 & 2,670 & 2,910 & 750 & 2,840 & 40,325 \\
\hline \multicolumn{7}{|l|}{ Other Noncurrent Liabilities } \\
\hline 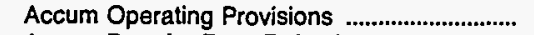 & 0 & 0 & 162 & 0 & 120 & 0 \\
\hline Accum Prov for Rate Refunds .............................. & 0 & 0 & 0 & 0 & 0 & 0 \\
\hline Total Other Noncurrent Llabillties ............. & 0 & 0 & 162 & 0 & 120 & 0 \\
\hline \multicolumn{7}{|l|}{ Current and Accrued Liabilities } \\
\hline 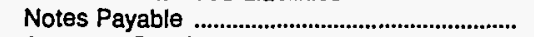 & 0 & 0 & 0 & 0 & 0 & 705 \\
\hline Accounts Payable & 1,173 & 1,317 & 754 & 641 & 1,800 & 4,654 \\
\hline 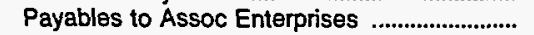 & 0 & 0 & 0 & 39 & 51 & 0 \\
\hline 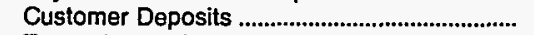 & 260 & 0 & 283 & 0 & 0 & 590 \\
\hline 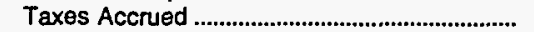 & 0 & 0 & 0 & 0 & 65 & 1,630 \\
\hline 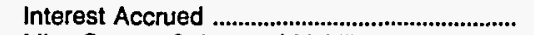 & 102 & 15 & 5 & 7 & 40 & 461 \\
\hline Misc Current \& Accrued Liabilities ......................... & 458 & 128 & 0 & 137 & 83 & 1,041 \\
\hline $\begin{array}{l}\text { Total Current \& Accrued Liabilitles ........... } \\
\text { Deferred Credits }\end{array}$ & 1,993 & 1,460 & 1,043 & 824 & 2,038 & 9,081 \\
\hline Customer Advances for Construction ............... & 0 & $\mathbf{0}$ & 15 & 0 & 1,640 & 4,761 \\
\hline 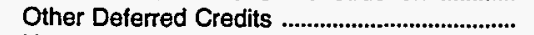 & 0 & 0 & 11 & 0 & 0 & 16 \\
\hline 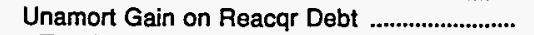 & 0 & 0 & 0 & 0 & 0 & 0 \\
\hline Total Deferred Credits & & & 25 & 0 & 1,640 & 4,777 \\
\hline Total Llabilltles and Other Credits ............. & 17,291 & 6,210 & 11,917 & 9,477 & 20,698 & 80,930 \\
\hline
\end{tabular}

Note: Totals may not equal sum of components because of independent rounding.

Source: Energy Information Administration, Form ElA-412, "Annual Report of Public Electric Utilities." 
Table 22. Balance Sheet by Major U.S. Publicly Owned Electric Utility Within State at End of Period, 1993 (Continued) (Thousand Dollars)

\begin{tabular}{|c|c|c|c|c|c|c|}
\hline Item & $\begin{array}{c}\text { Washington } \\
\text { PUD No } 1 \\
\text { of } \\
\text { Chelan } \\
\text { County } \\
\text { December } 31\end{array}$ & $\begin{array}{l}\text { Washington } \\
\text { PUD No } 1 \text { of } \\
\text { Clallam } \\
\text { County } \\
\text { December } 31\end{array}$ & $\begin{array}{l}\text { Washington } \\
\text { PUD No } 1 \\
\text { of } \\
\text { Clark } \\
\text { County } \\
\text { December } 31\end{array}$ & $\begin{array}{l}\text { Washington } \\
\text { PUD No } 1 \text { of } \\
\text { Cowlitz } \\
\text { County } \\
\text { December } 31\end{array}$ & $\begin{array}{l}\text { Washington } \\
\text { PUD No } 1 \text { of } \\
\text { Douglas } \\
\text { County } \\
\text { December } 31\end{array}$ & $\begin{array}{l}\text { Washington } \\
\text { PUD No } 1 \text { of } \\
\text { Franklin } \\
\text { County } \\
\text { December } 31\end{array}$ \\
\hline \multicolumn{7}{|l|}{ Electric Utility Plant } \\
\hline Electric Utility Plant \& Adjust ................................ & 859,568 & 46,054 & 217,827 & 112,183 & 275,013 & 40,151 \\
\hline 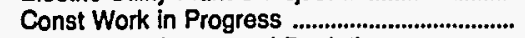 & 21,283 & 2,698 & 4,473 & 434 & 1,727 & 295 \\
\hline (less) Depr, Amort, and Depletion .................... & 155,825 & 18,372 & 87,029 & 48,688 & 45,853 & 15,193 \\
\hline 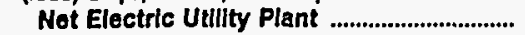 & 725,026 & 30,380 & 135,271 & 63,929 & 230,887 & 25,257 \\
\hline 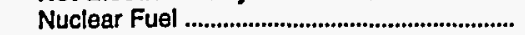 & & 0 & & 0 & 0 & 0 \\
\hline 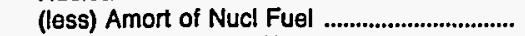 & 0 & 0 & 0 & 0 & 0 & 0 \\
\hline Net Elec Plant Incl Nucl Fuel ............................. & 725,026 & 30,380 & 135,271 & 63,929 & 230,887 & 25,257 \\
\hline \multicolumn{7}{|l|}{ Other Property \& Investments } \\
\hline 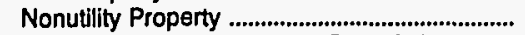 & 0 & 0 & 116 & 1 & 0 & 0 \\
\hline (less) Accum Provisions for Depr \& Amort .... & & 0 & 8 & 0 & 0 & 0 \\
\hline 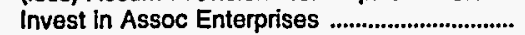 & 7,075 & 0 & & 1,248 & 0 & 0 \\
\hline 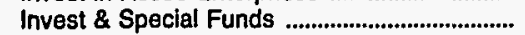 & 95,294 & 3,573 & 6,724 & 1,704 & 27,392 & 11,762 \\
\hline \multicolumn{7}{|l|}{ Current and Accrued Assets } \\
\hline Cash, Working Funds \& Investments ............. & 20,421 & 5,254 & 20,841 & 7,729 & 16,362 & 5,985 \\
\hline Notes \& Other Receivables ................................ & 6,051 & 427 & 1,058 & 2,491 & 686 & 0 \\
\hline Customer Accts Receivable ....................................... & 4,331 & 1,470 & 15,193 & 10,976 & 351 & 3,366 \\
\hline (less) Accum Prov for Uncollected Accts ...... & 30 & 29 & 1,462 & 156 & 33 & 3 \\
\hline 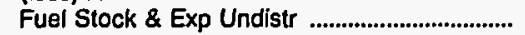 & & 0 & & 0 & 0 & 0 \\
\hline 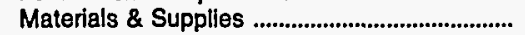 & 3,513 & 1,315 & 2,344 & 1,835 & 1,439 & 1,041 \\
\hline Prepayments ........................................................ & 1,370 & 183 & 485 & 494 & 708 & 35 \\
\hline 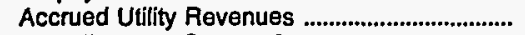 & 0 & 0 & 3,723 & 0 & 0 & 0 \\
\hline Miscellaneous Current \& Accrued Assets ..... & 642 & 48 & 0 & 92 & 878 & 742 \\
\hline \multicolumn{7}{|l|}{ Deferred Debits } \\
\hline 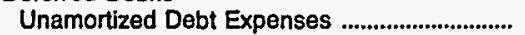 & 13,205 & 216 & 2,345 & 3 & 2,272 & 484 \\
\hline Extraordinary Losses, Study Cost ........................... & & 0 & & 355 & 156 & 0 \\
\hline Misc Debt, R \& D Exp, Unamit Losses .......... & 30,180 & 0 & 2,434 & 81 & 30,505 & -40 \\
\hline Total Deferred Deblts ....................................... & 43,385 & 216 & 4,779 & 440 & $\mathbf{3 2 , 9 3 3}$ & 444 \\
\hline Total Assets \& Other Deblts .......................... & 907,078 & 42,836 & 189,064 & 90,781 & 311,602 & 48,628 \\
\hline \multirow{2}{*}{\multicolumn{7}{|c|}{ Proprietary Capital }} \\
\hline & 16,907 & 0 & 0 & 0 & 0 & 918 \\
\hline 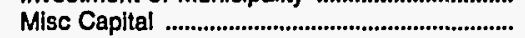 & & 0 & 0 & 0 & 0 & 0 \\
\hline 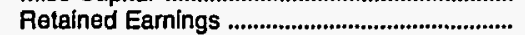 & 211,448 & 26,087 & 69,132 & 55,316 & 95,129 & 12,017 \\
\hline \multicolumn{7}{|l|}{ Long-term Debt } \\
\hline 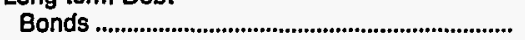 & 523,017 & 8,948 & 72,630 & 3,120 & 200,525 & 28,290 \\
\hline Advances from Municipality \& Other ................. & 124,787 & 193 & 5,000 & 5,300 & 4,551 & 0 \\
\hline Unamort Prem on Long-term Debt .................... & 0 & 0 & 0 & 0 & 0 & 0 \\
\hline (less) Unamort Discount on Long-term Debt & 62 & & & & & 683 \\
\hline 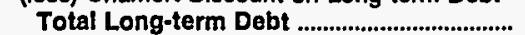 & 647,742 & 9,141 & 77,610 & 8,417 & 205,076 & 27,607 \\
\hline \multicolumn{7}{|l|}{ Other Noncurrent Liabilities } \\
\hline Accum Operating Provisions .................................. & 0 & 0 & 2,484 & 1,477 & 0 & 599 \\
\hline 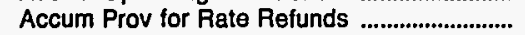 & 0 & 0 & 0 & 0 & 0 & 0 \\
\hline Total Other Noncurrent Liabilities ............. & $\mathbf{0}$ & 0 & $\mathbf{2 , 4 8 4}$ & 1,477 & $\mathbf{0}$ & 599 \\
\hline \multicolumn{7}{|l|}{ Current and Accrued Liabilities } \\
\hline 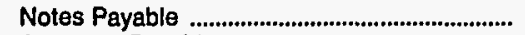 & 0 & 0 & 12,572 & 1,516 & 994 & 3,641 \\
\hline 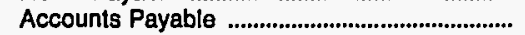 & 7,472 & 4,203 & 13,704 & 11,185 & 2,041 & 15 \\
\hline Payables to Assoc Enterprises & 8,796 & 0 & 0 & 139 & 0 & 0 \\
\hline 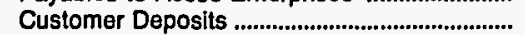 & 156 & 201 & 0 & 261 & 116 & 378 \\
\hline 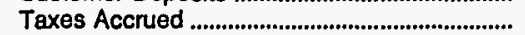 & 2,262 & 680 & 3,256 & 2,335 & 887 & 785 \\
\hline 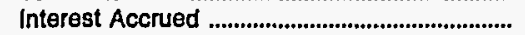 & 2,467 & 186 & 1,663 & 39 & 3,320 & 592 \\
\hline Misc Curtent \& Accrued Liabilities ................... & 8,806 & 476 & 8,446 & 623 & 1,310 & 1,891 \\
\hline Total Current \& Accrued Llabllitles ........... & 29,959 & $\mathbf{5 , 7 4 6}$ & 39,641 & 16,098 & 8,669 & 7,302 \\
\hline \multicolumn{7}{|l|}{ Deferred Credits } \\
\hline Customer Advances for Construction .............. & & 446 & 0 & 9,433 & & 0 \\
\hline Other Deferred Credits ......................................... & 1,022 & 1,417 & 197 & 39 & 2,729 & 186 \\
\hline Unamort Gain on Reacqr Debt ........................... & & & 0 & & 0 & 0 \\
\hline Total Deferred Credlts ........................................ & 1,022 & 1,862 & 198 & 9,473 & 2,729 & 186 \\
\hline Total Llabilitles and Other Credits ............ & 907,078 & 42,836 & 189,064 & 90,781 & 311,602 & 48,628 \\
\hline
\end{tabular}

Note: Totals may not equal sum of components because of independent rounding.

Source: Energy Information Administration, Form EIA-412, "Annual Report of Public Electric Utilities." 
Table 22. Balance Sheet by Major U.S. Publicly Owned Electric Utility Within State at End of Period, 1993 (Continued) (Thousand Dollars)

\begin{tabular}{|c|c|c|c|c|c|c|}
\hline Item & $\begin{array}{c}\text { Washington } \\
\text { PUD No } 1 \\
\text { of } \\
\text { Grays } \\
\text { Harbor Cnty } \\
\text { December } 31\end{array}$ & $\begin{array}{l}\text { Washington } \\
\text { PUD No } 1 \text { of } \\
\text { Klickitat } \\
\text { County }\end{array}$ & $\begin{array}{l}\text { Washington } \\
\text { PUD No } 1 \\
\text { of } \\
\text { Lewis } \\
\text { County } \\
\text { December } 31\end{array}$ & 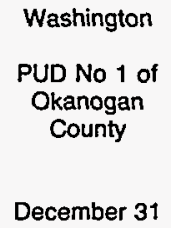 & $\begin{array}{l}\text { Washington } \\
\text { PUD No } 1 \text { of } \\
\text { Pend Oreille } \\
\text { Cnty } \\
\text { December } 31\end{array}$ & $\begin{array}{l}\text { Washington } \\
\text { PUD No } 1 \text { of } \\
\text { Snohomish } \\
\text { County }\end{array}$ \\
\hline \multicolumn{7}{|l|}{ Electric Utility Plant } \\
\hline 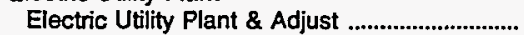 & 100,210 & 32,393 & 56,282 & 49,220 & 44,061 & 736,438 \\
\hline Const Work in Progress ......................................... & 4,115 & 6,992 & 141,888 & 2,331 & 1,058 & 41,661 \\
\hline 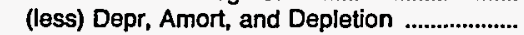 & 37,424 & 13,172 & 14,503 & 24,386 & 14,779 & 189,039 \\
\hline Net Electric Utility Plant .................................. & 66,900 & 26,213 & 183,667 & 27,165 & 30,340 & 589,059 \\
\hline 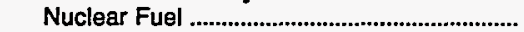 & 0 & 0 & 0 & 0 & 0 & 0 \\
\hline (less) Amort of Nucl Fuel ........................... & 0 & 0 & 0 & 0 & 0 & 0 \\
\hline $\begin{array}{l}\text { Net Elec Plant Incl Nucl Fuel ......................... } \\
\text { Other Property \& Investments }\end{array}$ & 66,900 & 26,213 & 183,667 & 27,165 & 30,340 & 589,059 \\
\hline 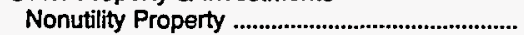 & 19 & 0 & 0 & 0 & 36 & 0 \\
\hline (less) Accum Provisions for Depr \& Amort .... & 0 & 0 & 0 & 0 & 0 & 0 \\
\hline 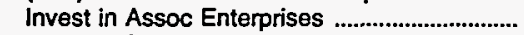 & 0 & 0 & 0 & 0 & 0 & 17,997 \\
\hline 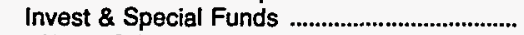 & 2,926 & 1,200 & 61,207 & 3,727 & 3,580 & 248,741 \\
\hline $\begin{array}{l}\text { Total Other Property \& Investments ....... } \\
\text { Current and Accrued Assets }\end{array}$ & 2,945 & 1,200 & 61,207 & 3,727 & 3,616 & 266,739 \\
\hline Cash, Working Funds \& Investments .............. & 9,547 & 3,996 & \multicolumn{4}{|c|}{ Current and Accrued Assets } \\
\hline Notes \& Other Receivables .................................... & 836 & & 20,380 & 110 & 476 & 10,094 \\
\hline Customer Accts Receivable ................................... & 4,123 & 1,106 & 2,040 & 908 & 325 & 44,154 \\
\hline (less) Accum Prov for Uncollected Accts ....... & 26 & 27 & 158 & 8 & 7 & 1,601 \\
\hline 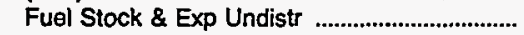 & 0 & 0 & 0 & 0 & 0 & 708 \\
\hline 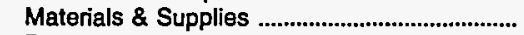 & 2,490 & 741 & 1,338 & 1,462 & 477 & 4,905 \\
\hline 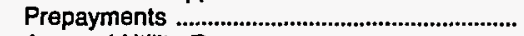 & 80 & 7 & 67 & 53 & 119 & 297 \\
\hline 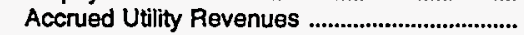 & 0 & 288 & 0 & 0 & 0 & 0 \\
\hline Miscellaneous Current \& Accrued Assets ..... & 14 & & 54 & & 145 & 1,868 \\
\hline \multirow{2}{*}{\multicolumn{7}{|c|}{ Deferred Debits }} \\
\hline & & & & & & \\
\hline Extraordinary Losses, Study Cost ...................... & $\begin{array}{r}414 \\
0\end{array}$ & $\begin{array}{r}44 \\
0\end{array}$ & $\begin{array}{r}1,867 \\
0\end{array}$ & 57 & $\begin{array}{r}60 \\
0\end{array}$ & $\begin{array}{r}0,531 \\
0\end{array}$ \\
\hline 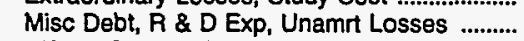 & 221 & -20 & 20,239 & -38 & -12 & 168,293 \\
\hline Total Deferred Deblts ...................................... & 635 & 24 & 22,101 & 19 & 48 & 173,830 \\
\hline Total Assets \& Other Debits ........................... & 87,543 & 33,548 & 296,226 & 47,737 & 44,757 & $1,127,215$ \\
\hline \multicolumn{7}{|l|}{ Proprietary Capital } \\
\hline 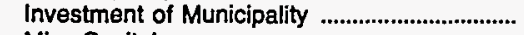 & 0 & 4,359 & 0 & 0 & 0 & 0 \\
\hline Misc Capital ................................................................... & & & 0 & 0 & 0 & 0 \\
\hline 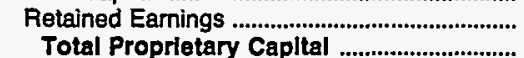 & $\begin{array}{l}60,155 \\
60,155\end{array}$ & $\begin{array}{l}13,739 \\
18,098\end{array}$ & $\begin{array}{l}61,242 \\
61,242\end{array}$ & $\begin{array}{l}42,646 \\
42,646\end{array}$ & $\begin{array}{l}34,747 \\
34,747\end{array}$ & $\begin{array}{l}196,819 \\
196,819\end{array}$ \\
\hline \multicolumn{7}{|l|}{ Long-term Debt } \\
\hline Bonds & 12,280 & 3,010 & 199,013 & 0 & 4,207 & 649,061 \\
\hline Advances from Municipality \& Other ............... & 187 & 9,305 & 461 & 624 & 1,296 & 17,997 \\
\hline Unamort Prem on Long-term Debt ................... & 0 & & 340 & 0 & 0 & 909 \\
\hline (less) Unamort Discount on Long-term Debt & & & 3,189 & 0 & 0 & 14,942 \\
\hline 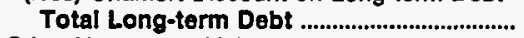 & 12,467 & 12,315 & 196,625 & 624 & 5,503 & 653,026 \\
\hline \multicolumn{7}{|l|}{ Other Noncurrent Liabilities } \\
\hline 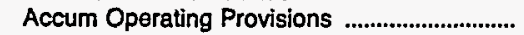 & 0 & 0 & 0 & 0 & 0 & 1,730 \\
\hline 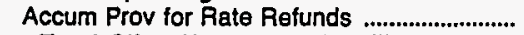 & 0 & 0 & 0 & 0 & 0 & \\
\hline Total Other Noncurrent Llabilltles ............. & 0 & o & 0 & 0 & 0 & 1,730 \\
\hline \multicolumn{7}{|l|}{ Current and Accrued Liabilities } \\
\hline 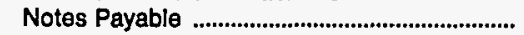 & 3,694 & 0 & 0 & 274 & 254 & 17,572 \\
\hline 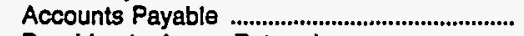 & 5,112 & 1,953 & 24,583 & $-3,232$ & 2,657 & 41,884 \\
\hline Payables to Assoc Enterprises ......................... & 0 & 0 & 470 & 0 & 0 & 0 \\
\hline 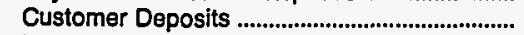 & 587 & 134 & 327 & 153 & 67 & 507 \\
\hline 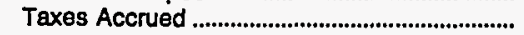 & 1,212 & 269 & 1.633 & 426 & 628 & 7,021 \\
\hline Interest Accrued .................................................... & 0 & 112 & 4,064 & 0 & 39 & 18,802 \\
\hline Misc Current \& Accrued Liabilities ...................... & 2,648 & 265 & 586 & 382 & 337 & 7,993 \\
\hline Total Current \& Accrued Llabilitles ........... & 13,253 & 2,734 & 31,662 & 4,467 & 3,982 & 93,980 \\
\hline \multicolumn{7}{|l|}{ Deferred Credits } \\
\hline Customer Advances for Construction .............. & 31 & 14 & 1,310 & 0 & 0 & 0 \\
\hline Other Deferred Credits ............................................ & 1,637 & 387 & 5,388 & -1 & 525 & 181,661 \\
\hline Unamort Gain on Reacqr Debt ........................... & 0 & 0 & 0 & 0 & 0 & 0 \\
\hline Total Doferred Credits ............................................ & 1,669 & 401 & 6,698 & -1 & 525 & 181,661 \\
\hline Total Llabillties and Other Credits ............ & 87,543 & 33,548 & 296,226 & 47,737 & 44,757 & $1,127,216$ \\
\hline
\end{tabular}

Note: Totals may not equal sum of components because of independent rounding.

Source: Energy Information Administration, Form ElA-412, "Annual Report of Public Electric Utitities." 
Table 22. Balance Sheet by Major U.S. Publicly Owned Electric Utility Within State at End of Period, 1993 (Continued)

(Thousand Dollars)

\begin{tabular}{|c|c|c|c|c|c|c|}
\hline Item & $\begin{array}{l}\text { Washington } \\
\text { PUD No } 1 \text { of } \\
\text { Whatcom } \\
\text { County } \\
\text { December } 31\end{array}$ & $\begin{array}{c}\text { Washington } \\
\text { PUD No } 2 \\
\text { of } \\
\text { Grant } \\
\text { County } \\
\text { December } 31\end{array}$ & $\begin{array}{l}\text { Washington } \\
\text { PUD No } 2 \text { of } \\
\text { Pacific } \\
\text { County } \\
\text { December } 31\end{array}$ & $\begin{array}{c}\text { Washington } \\
\text { PUD No } 3 \\
\text { of } \\
\text { Mason } \\
\text { County } \\
\text { December } 31\end{array}$ & $\begin{array}{l}\text { Washington } \\
\text { Richland } \\
\text { City of } \\
\text { December } 31\end{array}$ & $\begin{array}{c}\text { Washington } \\
\text { Seattle } \\
\text { City of } \\
\text { December } 31\end{array}$ \\
\hline \multicolumn{7}{|l|}{ Electric Utility Plant } \\
\hline 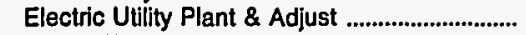 & 948 & 603,449 & 25,913 & 60,296 & 41,534 & $1,134,630$ \\
\hline Const Work in Progress & 1,008 & 34,946 & 5,730 & 4,855 & 3,535 & 85,676 \\
\hline (less) Depr, Amort, and Depletion ..................... & 582 & 209,405 & 14,321 & 16,078 & 15,711 & 511,163 \\
\hline Net Electrlc Utlity Plant ................................ & 1,375 & 428,990 & 17,322 & 49,073 & 29,358 & 709,143 \\
\hline 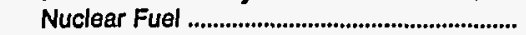 & 0 & 0 & 0 & 0 & 0 & 0 \\
\hline 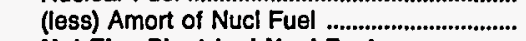 & & & 0 & 0 & & \\
\hline Net Elec Plant Incl Nucl Fuel ......................... & 1,375 & 428,990 & 17,322 & 49,073 & 29,358 & 709,143 \\
\hline \multicolumn{7}{|l|}{ Other Property \& Investments } \\
\hline 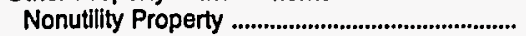 & 0 & 0 & 0 & 0 & 0 & 5,691 \\
\hline (less) Accum Provisions for Depr \& Amort .... & 0 & 0 & 0 & 0 & 0 & 2,258 \\
\hline 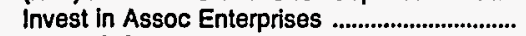 & 0 & 0 & 0 & 0 & 0 & 2,663 \\
\hline 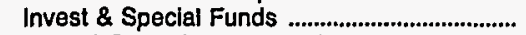 & 0 & 128,524 & 2,786 & 5,509 & 2,697 & 152,748 \\
\hline $\begin{array}{l}\text { Total Other Property \& Investments ........ } \\
\text { Current and Accrued Assets }\end{array}$ & 0 & 128,524 & 2,786 & 5,509 & 2,697 & 158,844 \\
\hline Cash, Working Funds \& Investments ............... & 670 & 132,094 & 927 & 12,307 & 3,392 & 72,730 \\
\hline Notes \& Other Receivables ................................... & 8 & 15,777 & 188 & 404 & 229 & 8,155 \\
\hline 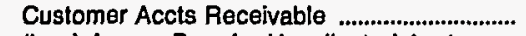 & 325 & 4,498 & 1,278 & 2,593 & 3,855 & 34,009 \\
\hline (less) Accum Prov for Uncollected Accts ...... & 0 & 221 & 75 & 36 & 126 & 1,752 \\
\hline Fuel Stock \& Exp Undistr .................................. & 0 & 0 & & 0 & 0 & 1,003 \\
\hline 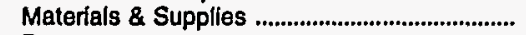 & 0 & 5,504 & 1,658 & 2,253 & 1,228 & 19,092 \\
\hline 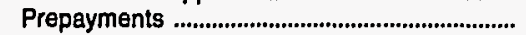 & 6 & 821 & 76 & 12 & 10 & 1,784 \\
\hline 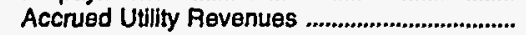 & 0 & 0 & 0 & 0 & 0 & 26,169 \\
\hline Miscellaneous Current \& Accrued Assets ..... & 1,963 & 1,725 & 0 & 11 & 12 & 1,452 \\
\hline \multicolumn{7}{|l|}{ Deferred Debits } \\
\hline Unamortized Debt Expenses ................................. & 0 & 3,910 & 73 & 355 & 0 & 1,333 \\
\hline 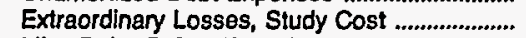 & 0 & & 0 & 248 & 0 & 0 \\
\hline Misc Debt, R \& D Exp, Unamrt Losses .......... & 0 & 966 & 101 & 31 & 689 & 108,292 \\
\hline Total Deferred Debits ..................................... & & 4,876 & 174 & 634 & 689 & 109,625 \\
\hline 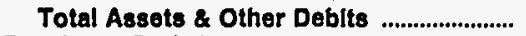 & 4,347 & 722,587 & 24,334 & 72,760 & 41,343 & $1,140,256$ \\
\hline \multirow{2}{*}{\multicolumn{7}{|c|}{ Proprietary Capital }} \\
\hline & 0 & 0 & 0 & 0 & 0 & 0 \\
\hline 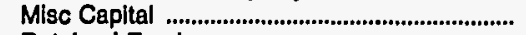 & 354 & 0 & 2,623 & 0 & 0 & 0 \\
\hline 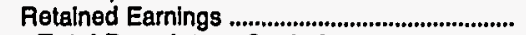 & 3,563 & 259,590 & 14,943 & 40,198 & 11,288 & 271,617 \\
\hline \multicolumn{7}{|l|}{ Long-term Debt } \\
\hline 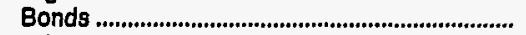 & 0 & 365,625 & 3,110 & 17,935 & 17,015 & 711,505 \\
\hline Advances from Municipality \& Other ................ & 0 & 230 & 367 & & 0 & 0 \\
\hline Unamort Prem on Long-term Debt .................... & 0 & & 0 & 0 & 0 & \\
\hline (less) Unamort Discount on Long-term Debt & 0 & 12,164 & & & 701 & 10,322 \\
\hline Total Long-term Debt ....................................... & 0 & 353,692 & 3,477 & 17,935 & 16,314 & 701,183 \\
\hline \multicolumn{7}{|l|}{ Other Noncurrent Liabilities } \\
\hline Accum Operating Provisions ................................... & 0 & 0 & 0 & & 0 & 4,359 \\
\hline Accum Prov for Rate Refunds .............................. & 0 & 0 & 0 & 0 & 0 & 107,604 \\
\hline Current and Accrued Liabilities & o & 0 & 0 & 0 & 0 & 111,963 \\
\hline 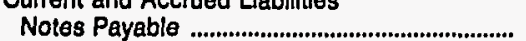 & 0 & 1,104 & 80 & 661 & & \\
\hline 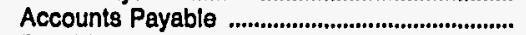 & 344 & 10,503 & 2,274 & 3,241 & 3,526 & 30,986 \\
\hline Payables to Assoc Enterprises ............................ & 2 & 13,157 & 0 & 0 & 0 & 6,233 \\
\hline 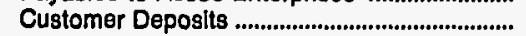 & 0 & 387 & 255 & 172 & 0 & 89 \\
\hline Taxes Accrued ............................................... & 84 & 2,834 & 351 & 553 & 0 & 3,247 \\
\hline 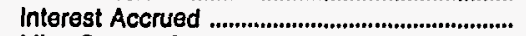 & 0 & 9,881 & 38 & 527 & 170 & 7,986 \\
\hline Misc Current \& Accrued Liabilities ...................... & 0 & 70,386 & 152 & 765 & 0 & 6,080 \\
\hline $\begin{array}{l}\text { Total Current \& Accrued Llabillties ........... } \\
\text { Delerred Credits }\end{array}$ & 430 & 108,252 & 3,149 & 5,919 & 3,697 & 54,601 \\
\hline \multicolumn{7}{|l|}{ Deferred Credits } \\
\hline 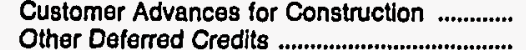 & 0 & 770 & 142 & 8,090 & 10,045 & 0 \\
\hline $\begin{array}{l}\text { Other Deferred Credits ............................................. } \\
\text { Unamort Gain On Reacar Debt }\end{array}$ & $\begin{array}{l}0 \\
0\end{array}$ & 284 & $\begin{array}{l}0 \\
0\end{array}$ & $\begin{array}{l}244 \\
375\end{array}$ & $\begin{array}{l}0 \\
0\end{array}$ & 892 \\
\hline 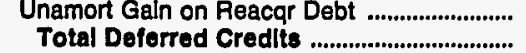 & $\mathbf{0}$ & 1,054 & 142 & 8,708 & 10,045 & 892 \\
\hline Total Llabillties and Other Credits ............ & 4,347 & 722,587 & 24,334 & $\mathbf{7 2 , 7 6 0}$ & 41,343 & $1,140,256$ \\
\hline
\end{tabular}

Note: Totals may not equal sum of components because of independent rounding.

Source: Energy Information Adminlstration, Form EIA-412, "Annual Report of Public Electric Utilities." 
Table 22. Balance Sheet by Major U.S. Publicly Owned Electric Utility Within State at End of Period, 1993 (Continued) (Thousand Dollars)

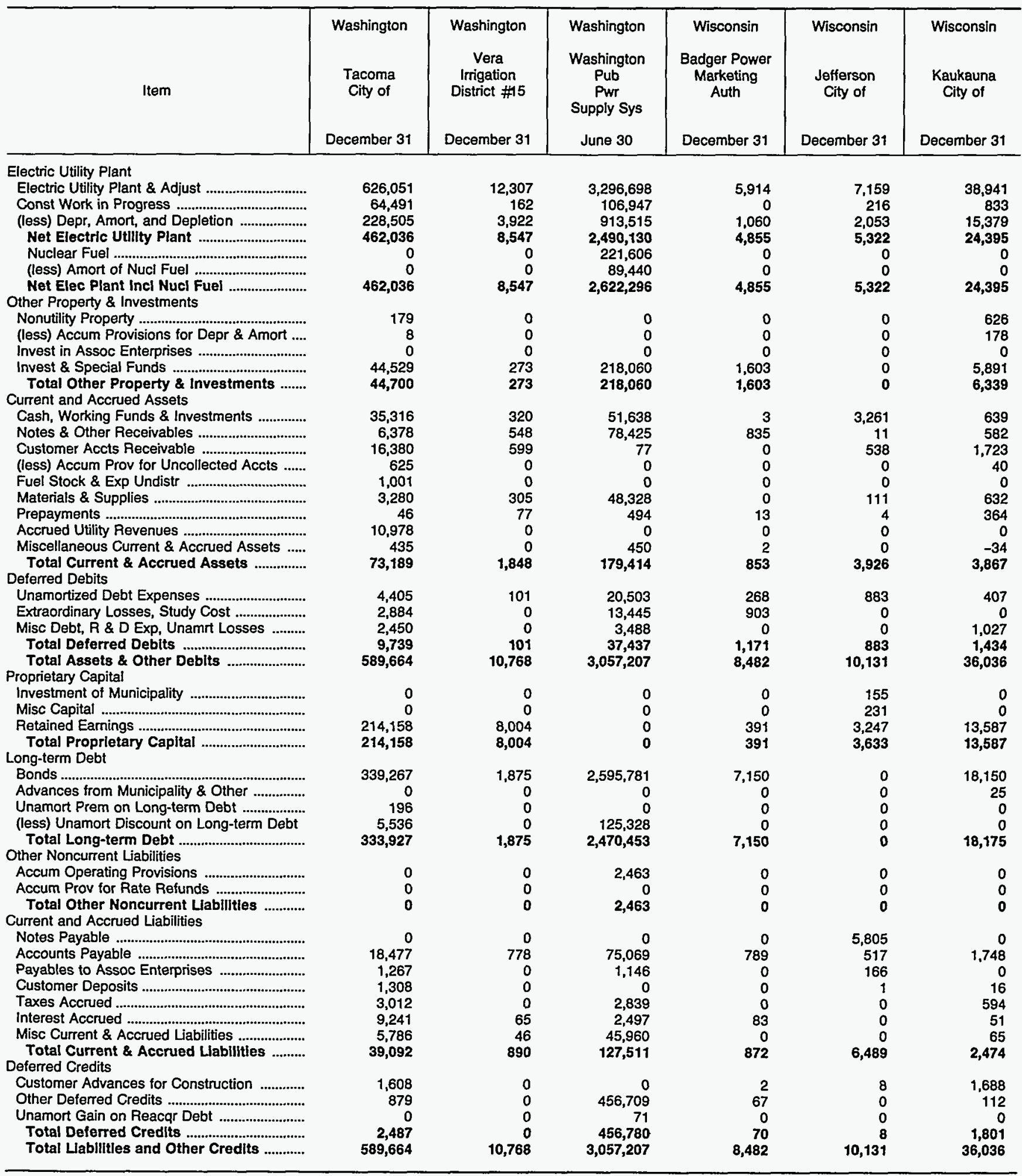

Note: Totals may not equal sum of components because of independent rounding.

Source: Energy Information Administration, Form EIA-412, "Annual Report of Public Electric Utilities." 
Table 22. Balance Sheet by Major U.S. Publicly Owned Electric Utility Within State at End of Period, 1993 (Continued).

(Thousand Dollars)

\begin{tabular}{|c|c|c|c|c|c|c|}
\hline Item & $\begin{array}{c}\text { Wisconsin } \\
\text { Manitowoc } \\
\text { Public } \\
\text { Utilities } \\
\text { December } 31\end{array}$ & $\begin{array}{l}\text { Wisconsin } \\
\begin{array}{c}\text { Marshfield } \\
\text { City of }\end{array} \\
\text { December } 31\end{array}$ & $\begin{array}{c}\text { Wisconsin } \\
\text { Menasha } \\
\text { City of } \\
\text { December } 31\end{array}$ & $\begin{array}{l}\text { Wisconsin } \\
\begin{array}{c}\text { New London } \\
\text { City of }\end{array} \\
\text { December } 31\end{array}$ & $\begin{array}{l}\text { Wisconsin } \\
\begin{array}{c}\text { Oconomowoc } \\
\text { City of }\end{array} \\
\text { December } 31\end{array}$ & $\begin{array}{l}\text { Wisconsin } \\
\text { Plymouth } \\
\text { City of } \\
\text { December } 31\end{array}$ \\
\hline \multicolumn{7}{|l|}{ Electric Utility Plant } \\
\hline Electric Utility Plant \& Adjust ................................ & 63,401 & 27,602 & 22,700 & 14,043 & 15,432 & 13,598 \\
\hline Const Work in Progress & 1,193 & & 1,458 & & & \\
\hline 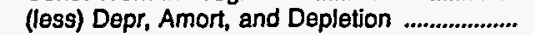 & 21,433 & 6,499 & 11,042 & 2,941 & 5,234 & 5,539 \\
\hline Net Electrlc Utility Plant .................................. & 43,161 & 21,487 & 13,115 & 11,159 & 10,205 & 8,059 \\
\hline 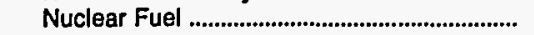 & 0 & 0 & 0 & 0 & 0 & 0 \\
\hline 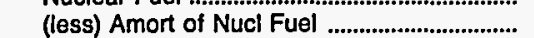 & 0 & 0 & 0 & 0 & 0 & 0 \\
\hline Net Elec Plant Incl Nucl Fuel ......................... & 43,161 & 21,487 & 13,115 & 11,159 & 10,205 & 8,059 \\
\hline \multicolumn{7}{|l|}{ Other Property \& Investments } \\
\hline 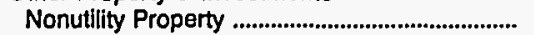 & 173 & 7,067 & 143 & 2 & 0 & 0 \\
\hline (less) Accum Provisions for Depr \& Amort .... & 3 & 5,727 & 0 & 2 & 0 & 0 \\
\hline 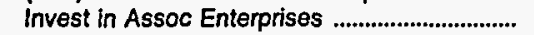 & 0 & 0 & 0 & 0 & 0 & 123 \\
\hline 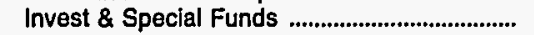 & 11,901 & 1.534 & 2,409 & 2,615 & 712 & 702 \\
\hline $\begin{array}{l}\text { Total Other Property } 2 \text { Investments ........ } \\
\text { Current and Accrued Assets }\end{array}$ & 12,071 & 2,874 & 2,553 & 2,615 & 712 & 824 \\
\hline 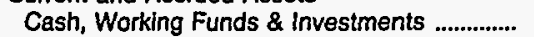 & -400 & 2,024 & -4 & 41 & 1,911 & 0 \\
\hline Notes \& Other Receivables .............................. & 712 & 35 & 63 & 85 & 988 & 12 \\
\hline 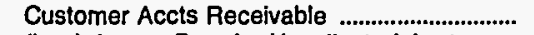 & 1,246 & 1,067 & 2,432 & 846 & 751 & 590 \\
\hline (less) Accum Prov for Uncollected Accts ....... & 0 & 0 & 3 & 0 & 0 & 0 \\
\hline 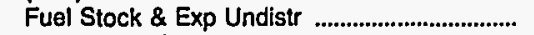 & 866 & 0 & 0 & 0 & 0 & 0 \\
\hline 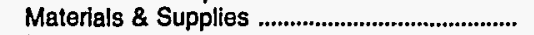 & 513 & 284 & 197 & 254 & 253 & 300 \\
\hline 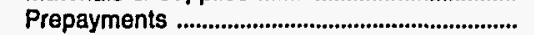 & 86 & 10 & 29 & 71 & 15 & 25 \\
\hline 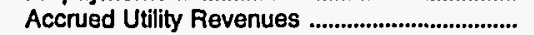 & 0 & 0 & 0 & 237 & 0 & 0 \\
\hline Miscellaneous Current \& Accrued Assets ..... & 82 & 11 & 19 & 21 & 0 & 0 \\
\hline Total Current \& Accrued Assets ................ & 3,106 & 3,431 & 2,734 & 1,555 & 3,918 & 928 \\
\hline \multicolumn{7}{|l|}{ Deferred Debits } \\
\hline 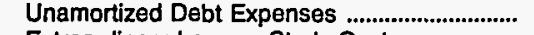 & 1,098 & 214 & 195 & 222 & 40 & 11 \\
\hline 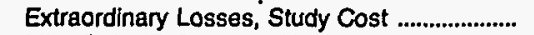 & 66 & 0 & o & 0 & 0 & 0 \\
\hline Misc Debt, A \& D Exp, Unamrt Losses .......... & 403 & 531 & 366 & 767 & 188 & 54 \\
\hline Total Deferred Deblts .................................... & 1,567 & 745 & 561 & 989 & 228 & 65 \\
\hline Total Assets \& Other Debits ............................. & 59,905 & 28,537 & 18,963 & 16,318 & 15,063 & 9,876 \\
\hline \multicolumn{7}{|l|}{ Proprietary Capital } \\
\hline 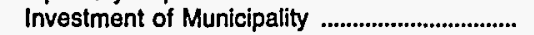 & 0 & 0 & 426 & 186 & 1,217 & 2,308 \\
\hline 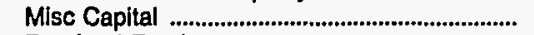 & 0 & 0 & 6,945 & 1,528 & 1,064 & 0 \\
\hline 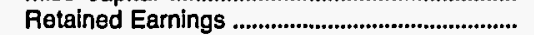 & 30,506 & 16,471 & 95 & 4,745 & 9,068 & 6,099 \\
\hline \\
\hline 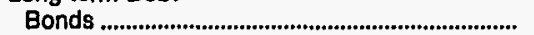 & 23,070 & 8,950 & 7,158 & 8,225 & 2,650 & 310 \\
\hline Advances from Municipality \& Other ................ & 600 & 0 & 1,250 & 0 & 0 & 306 \\
\hline Unamort Prem on Long-term Debt ..................... & 0 & 0 & 0 & 0 & 0 & 0 \\
\hline (less) Unamort Discount on Long-term Debt & & & & 0 & 0 & 0 \\
\hline 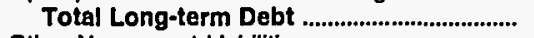 & 23,670 & 8,950 & $\mathbf{8 , 4 0 8}$ & 8,225 & 2,650 & 616 \\
\hline \multicolumn{7}{|l|}{ Other Noncurrent Liabilities } \\
\hline 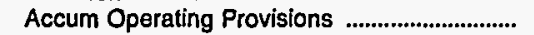 & 682 & 0 & 0 & 132 & 0 & 0 \\
\hline Accum Prov for Rate Refunds ............................... & 0 & 0 & 0 & 0 & 0 & 0 \\
\hline Total Other Noncurrent Llabilities ............ & 682 & 0 & 0 & 132 & 0 & 0 \\
\hline \multicolumn{7}{|l|}{ Current and Accrued Liabilities } \\
\hline 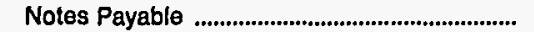 & 0 & 0 & 0 & 0 & 0 & 0 \\
\hline 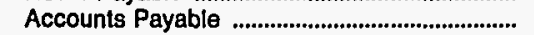 & 1,791 & 956 & 1,654 & 807 & 615 & 605 \\
\hline 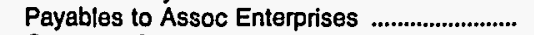 & 0 & 150 & 0 & 129 & 0 & 0 \\
\hline 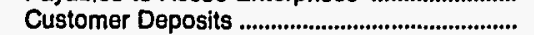 & 51 & 60 & 0 & 19 & 29 & 6 \\
\hline 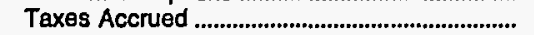 & 1,457 & 412 & 628 & 341 & 339 & 145 \\
\hline 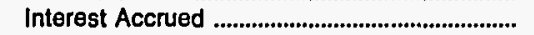 & 611 & 51 & 197 & 50 & 54 & 7 \\
\hline Misc Current \& Accrued Liabilities ..................... & 61 & 335 & & -1 & 0 & 45 \\
\hline Total Current \& Accrued Liabilltles ........... & 3,971 & 1,965 & $\mathbf{2 , 4 7 9}$ & 1,345 & 1,036 & 809 \\
\hline \multicolumn{7}{|l|}{ Deferred Credits } \\
\hline Customer Advances for Construction ............... & 1,071 & 1,150 & 363 & 5 & 27 & 0 \\
\hline 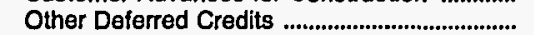 & 5 & 0 & 248 & 152 & 0 & 45 \\
\hline Unamort Gain on Reacqr Debt ........................... & 0 & 0 & 0 & 0 & 0 & 0 \\
\hline Total Deferred Credits ...................................... & 1,076 & 1,150 & 611 & 157 & & 45 \\
\hline Total Llabilltles and Other Credits ............ & 59,905 & 28,537 & 18,963 & 16,318 & 15,063 & 9,876 \\
\hline
\end{tabular}

Note: Totals may not equal sum of components because of independent rounding.

Source: Energy Information Administration, Form EIA-412, "Annual Report of Public Electric Utilities." 
Table 22. Balance Sheet by Major U.S. Publicly Owned Electric Utility Within State at End of Period, 1993 (Continued)

(Thousand Dollars)

\begin{tabular}{|c|c|c|c|c|c|c|}
\hline Item & $\begin{array}{l}\text { Wisconsin } \\
\text { Reedsburg } \\
\text { Utility Comm } \\
\text { December } 31\end{array}$ & $\begin{array}{c}\text { Wisconsin } \\
\text { Shawano } \\
\text { Municipal } \\
\text { Utilities } \\
\text { December } 31\end{array}$ & $\begin{array}{c}\text { Wisconsin } \\
\text { Sheboygan } \\
\text { Falls } \\
\text { City of } \\
\text { December } 31\end{array}$ & $\begin{array}{c}\text { Wisconsin } \\
\text { Sturgeon Bay } \\
\text { Combined } \\
\text { Utils }\end{array}$ & $\begin{array}{l}\text { Wisconsin } \\
\text { Sun Prairie } \\
\text { Water \& Light } \\
\text { Comm } \\
\text { December } 31\end{array}$ & $\begin{array}{l}\text { Wisconsin } \\
\text { Wisconsin } \\
\text { Public } \\
\text { Power } \\
\text { Inc Sys } \\
\text { December } 31\end{array}$ \\
\hline \multicolumn{7}{|l|}{ Electric Utility Plant } \\
\hline 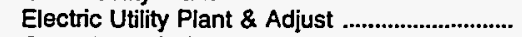 & 8,697 & 8,286 & 7,489 & 15,781 & 9,958 & 141,401 \\
\hline Const Work in Progress & & & 186 & 177 & 2,652 & \\
\hline (less) Depr, Amort, and Depletion .................... & 2,217 & 2,645 & 3,046 & 4,658 & 4,018 & 30,797 \\
\hline Net Electric Utility Plant ................................. & 6,495 & 5,676 & 4,630 & 11,300 & 8,592 & 110,670 \\
\hline 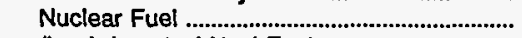 & & & 0 & 0 & 0 & 0 \\
\hline (less) Amort of Nucl Fuel ............................ & & 0 & 0 & 0 & 0 & 0 \\
\hline $\begin{array}{l}\text { Net Elec Plant Incl Nucl Fuel .......................... } \\
\text { Other Property \& Investments }\end{array}$ & 6,495 & 5,676 & 4,630 & 11,300 & 8,592 & 110,670 \\
\hline \multicolumn{7}{|l|}{ Other Property \& Investments } \\
\hline (less) Accum Provisions for Depr \& Amort .... & 631 & $\begin{array}{r}0,0<1 \\
0\end{array}$ & $\begin{array}{l}0 \\
0\end{array}$ & $\begin{array}{l}0 \\
0\end{array}$ & $\begin{array}{l}23 \\
12\end{array}$ & $\begin{array}{l}0 \\
0\end{array}$ \\
\hline 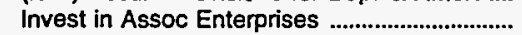 & 0 & 0 & 44 & 0 & $\begin{array}{r}12 \\
0\end{array}$ & 0 \\
\hline 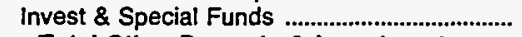 & 1,637 & 846 & 0 & 1,621 & 1,065 & 24,560 \\
\hline \multicolumn{6}{|l|}{ Current and Accrued Assets } & 24,560 \\
\hline Cash, Working Funds \& Investments .................. & 851 & 1.732 & 350 & 5 & 13 & 15,788 \\
\hline Notes \& Other Receivables ................................ & 0 & 24 & 0 & 63 & 31 & 10 \\
\hline 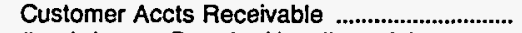 & 714 & 910 & 500 & 844 & 402 & 8,799 \\
\hline (less) Accum Prov for Uncollected Accts ...... & 0 & 0 & 0 & 15 & 0 & 0 \\
\hline 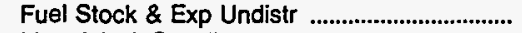 & 0 & 0 & 0 & 0 & 0 & 1,279 \\
\hline 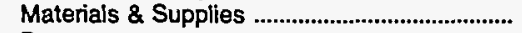 & 340 & 271 & 239 & 462 & 106 & 1,426 \\
\hline 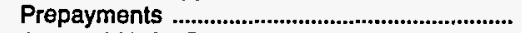 & 0 & 100 & 0 & 46 & 1 & 100 \\
\hline 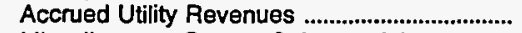 & 0 & 0 & 0 & 0 & 0 & 0 \\
\hline Miscellaneous Current \& Accrued Assets ...... & 325 & 0 & 0 & 29 & 0 & 84 \\
\hline $\begin{array}{l}\text { Total Current \& Accrued Assets ............... } \\
\text { Deferred Debits }\end{array}$ & 2,230 & 3,037 & 1,089 & 1,433 & 553 & 27,487 \\
\hline 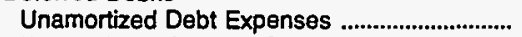 & 132 & 43 & 8 & 203 & 0 & 3,160 \\
\hline 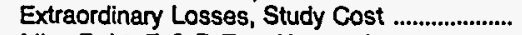 & 2 & 262 & 0 & 24 & 0 & 0 \\
\hline Misc Debt, R \& D Exp, Unamrt Losses .......... & 215 & 0 & 22 & 222 & 115 & 26,351 \\
\hline Total Deferred Debits & 350 & 305 & 31 & 449 & 115 & 29,511 \\
\hline Total Assets \& Other Debits .......................... & 13,809 & 16,184 & 5,794 & 14,804 & 10,337 & 192,227 \\
\hline \multicolumn{7}{|l|}{ Proprietary Capital } \\
\hline Investment of Municipality & 969 & 1,331 & 287 & 26 & 0 & 0 \\
\hline 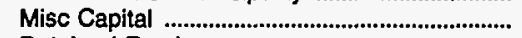 & 1,842 & 0 & 0 & 0 & 457 & 0 \\
\hline 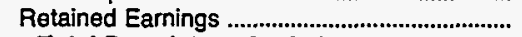 & 4,407 & 7,313 & 3,594 & 5,610 & 4,436 & 6,309 \\
\hline Total Proprietary Capital ................................. & 7,219 & 8,644 & 3,881 & 5,636 & 4,893 & 6,309 \\
\hline \multicolumn{7}{|l|}{ Long-term Debt } \\
\hline 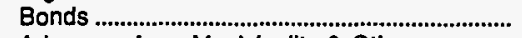 & 5,460 & 2,435 & 0 & 6,616 & 2,206 & 168,640 \\
\hline Advances from Municipality \& Other ............... & 25 & 1,350 & 770 & 0 & 351 & 0 \\
\hline Unamort Prem on Long-term Debt ................... & 0 & 0 & 0 & 0 & 0 & 0 \\
\hline (less) Unamort Discount on Long-term Debt & 0 & 0 & 0 & 0 & 0 & 3,678 \\
\hline 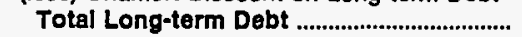 & 5,485 & 3,785 & 770 & 6,616 & 2,556 & 164,962 \\
\hline \multicolumn{7}{|l|}{ Other Noncurrent Liabilities } \\
\hline Accum Operating Provisions ............................. & 0 & 0 & 0 & 0 & 0 & 2,677 \\
\hline 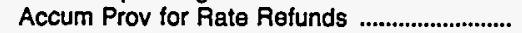 & 0 & 0 & 0 & 0 & 0 & 0 \\
\hline Total Other Noncurrent Llabilities ........... & 0 & 0 & $\mathbf{0}$ & $\mathbf{0}$ & 0 & 2,677 \\
\hline \multicolumn{7}{|l|}{ Current and Accrued Liabilities } \\
\hline 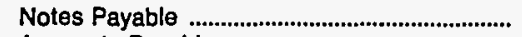 & 0 & 0 & 0 & 0 & 0 & \\
\hline Accounts Payable & 658 & 725 & 333 & 506 & 365 & 8,547 \\
\hline Payables to Assoc Enterprises ........................... & 78 & 0 & 60 & 0 & 3 & 0 \\
\hline 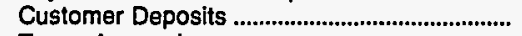 & 8 & 42 & 4 & 44 & 13 & 0 \\
\hline Taxes Accrued & 284 & 248 & 142 & 339 & 218 & 1,743 \\
\hline Interest Accrued & 37 & 36 & 4 & 247 & 56 & 3,673 \\
\hline Misc Current \& Accrued Liabilities .................... & -1 & 28 & 538 & 72 & 42 & 3,026 \\
\hline \multicolumn{6}{|l|}{ Deferred Credits } & 16,990 \\
\hline Customer Advances for Construction ............. & 0 & 2,416 & 44 & 10 & 2,163 & \\
\hline 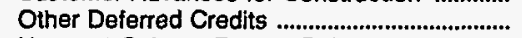 & 40 & 261 & 18 & 200 & 27 & 1,289 \\
\hline Unamort Gain on Reacqr Debt .......................... & 0 & 0 & 0 & 1,133 & 0 & 0 \\
\hline 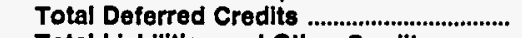 & 40 & 2,677 & 62 & 1,343 & 2,190 & 1,289 \\
\hline Total Liabllitles and Other Credits ............. & 13,809 & 16,184 & 5,794 & 14,804 & 10,337 & 192,227 \\
\hline
\end{tabular}

Note: Totals may not equal sum of components because of independent rounding.

Source: Energy Information Administration, Form ElA.412, "Annual Report of Public Electric Utilities." 
Table 22. Balance Sheet by Major U.S. Publicly Owned Electric Utility Within State at End of Period, 1993 (Continued)

(Thousand Dollars)

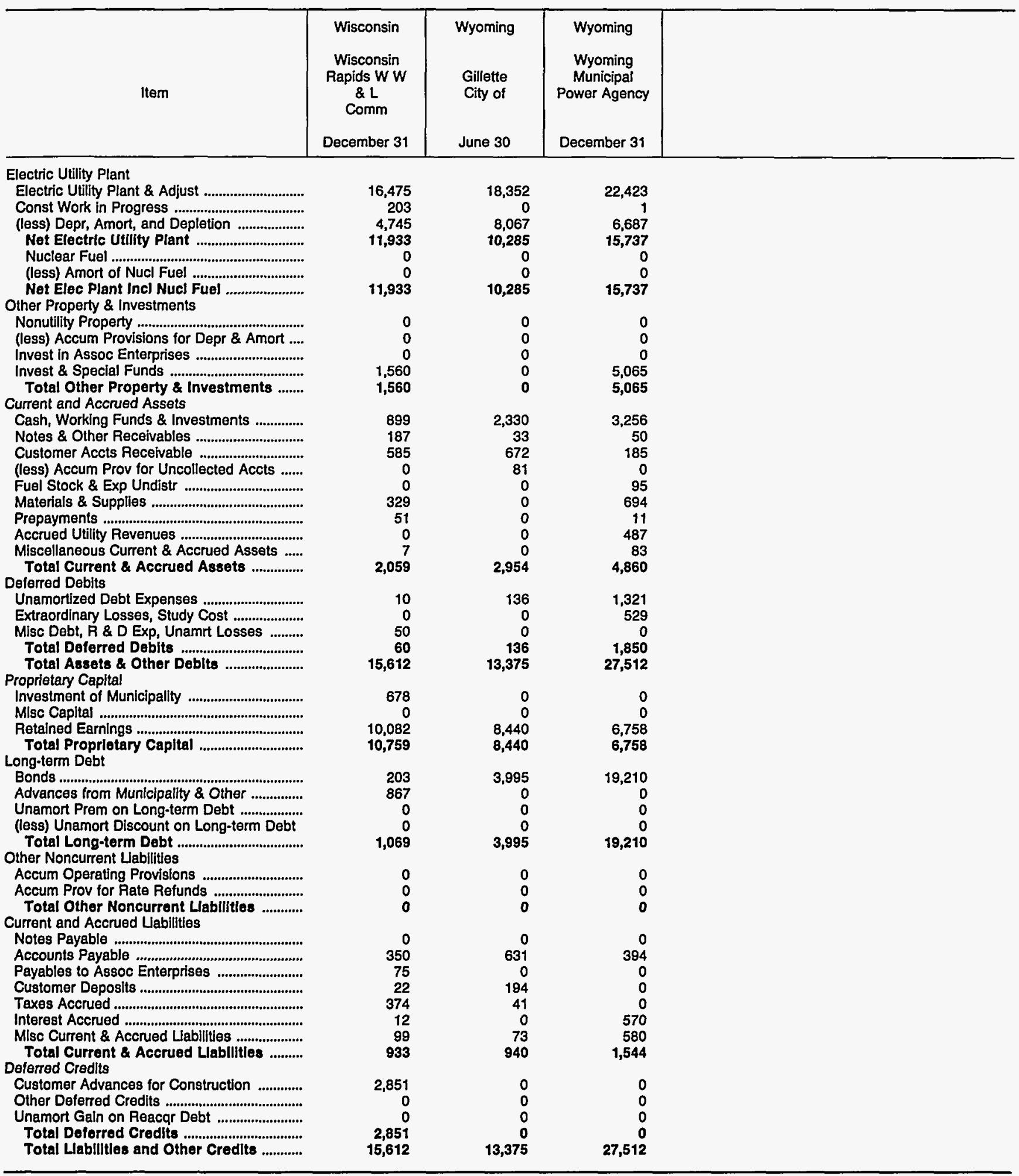

Note: Totals may not equal sum of components because of independent rounding.

Source: Energy Information Administration, Form ElA-412, "Annual Report of Public Electric Utilities." 
Table 23. Electric Operation and Maintenance Expenses by Major U.S. Publicly Owned Electric Utility Within State, 1993

(Thousand Dollars)

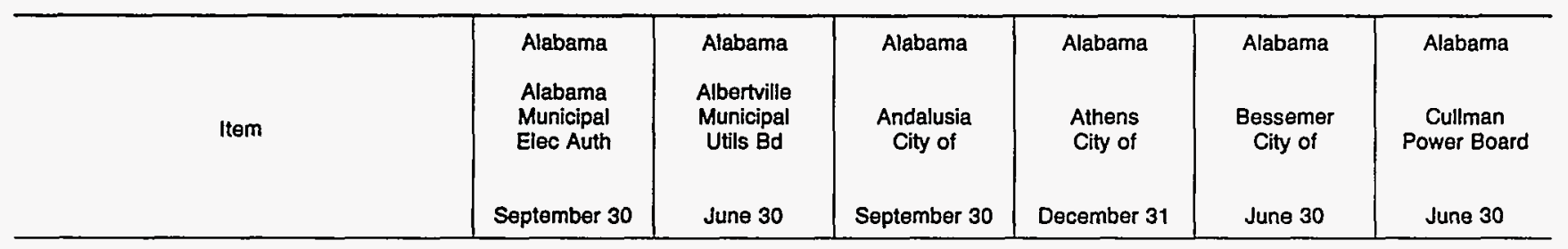

Production Expenses

Steam Power Generation

Nuclear Power Generation

Hydraulic Power Generation

Other Power Generation

Purchased Power

Other Production Expenses

Total Production Expenses

Transmission Expenses

Distribution Expenses

Customer Accounts Expenses ..........................

Customer Service and Information

Expenses

Sales Expenses ...

Administrative and General

Expenses

Total Electric Operation and

Malntenance Expenses

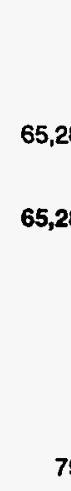

0
0
0
0
16,401
0

16,401

, 289

$0 \quad 0$

$\begin{array}{ll}0 & 807\end{array}$

288

$\begin{array}{ll}0 & 26 \\ 0 & \end{array}$

795

392

17,922

0
0
0
0
11,197
0

0
0
0
0
29,712

0

$11,197$.

29,712

186

1,370

619

25

12

705

643

12,000

32,629

Fuel Expenses In Operation

Steam Power Generation

0

0

0

Nuclear Power Generation

0

0

0

0

Other Power Generation

0

0

0

0

Number of Elec Dept Employees

Regular Full-time

5

33

12

66

37

22

Part-time \& Temporary

0

0

0

5

33

12

66

0

0

Total Elec Dept Employees

Note: Totals may not equal sum of components because of independent rounding.
Source: Energy Information Administration, Form EIA-412, "Annual Report of Public Electric Utilities." 
Table 23. Electric Operation and Maintenance Expenses by Major U.S. Publicly Owned Electric Utility Within State, 1993 (Continued)

(Thousand Dollars)

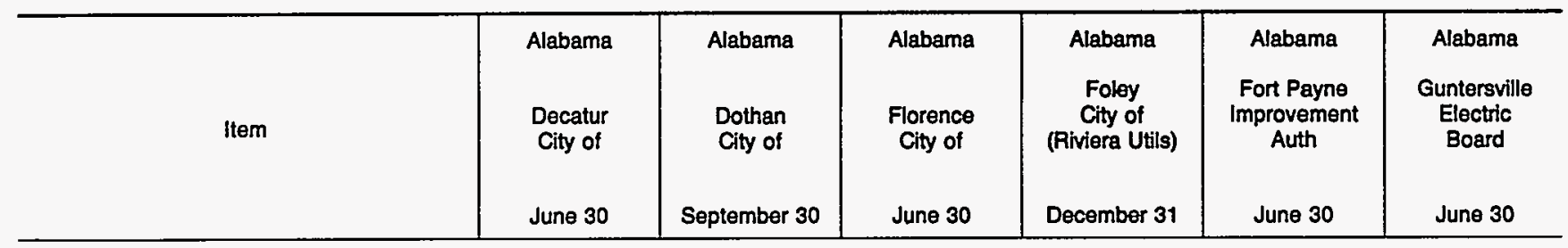

Production Expenses

Steam Power Generation

Nuclear Power Generation...

Hydraullic Power Generation

Other Power Generation

Purchased Power

Other Production Expenses

Total Production Expenses

Transmission Expenses

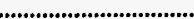

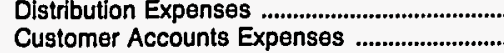

Customer Service and Information

Expenses

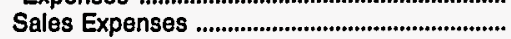

Administrative and General

Expenses

Total Electric Operation and

Maintenance Expenses .

Fuel Expenses in Operation

Steam Power Generation .................................

Nuclear Power Generation

Other Power Generation

Number of Elec Dept Employees

Regular Full-time

62

Part-time \& Temporary

0
0
0
0
52,168
0

52,168

0
1,509

434

26

24

791

54,952

39,802

0

0
0
0
0
45,968
0

45,968

36,938

0
2,070

2,070
0

0

0
0

794

531

2,740

772

116

113

2,193

52,434

23,861

0
0
0
0

20,695

20,695

256

923

454

21

54

1,458

0

0

9,761
0

0

649
212

0

188

12

19

324

363

14,543

10,797

Total Elec Dept Employees

162

112

24

23

2

0

62

74

162

114

23

Note: Totals may not equal sum of components because of independent rounding.

Source: Energy Information Administration, Form ElA-412, "Annual Report of Public Electric Utilities." 
Table 23. Electric Operation and Maintenance Expenses by Major U.S. Publicly Owned Electric Utility Within State, 1993 (Continued)

(Thousand Dollars)

\begin{tabular}{c|c|c|c|c|c|c}
\hline & Alabama & Alabama & Alabama & Alabama & Alabama & Alabama \\
& Huntsville & $\begin{array}{c}\text { Muscle } \\
\text { Shoals } \\
\text { City of }\end{array}$ & $\begin{array}{c}\text { City of } \\
\text { City of }\end{array}$ & $\begin{array}{c}\text { Scottsboro } \\
\text { City of }\end{array}$ & $\begin{array}{c}\text { Sheffield } \\
\text { Utilities } \\
\text { Utilities } \\
\text { Board }\end{array}$ \\
& September 30 & June 30 & September 30 & June 30 & June 30 & September 30 \\
\hline
\end{tabular}

Production Expenses

Steam Power Generation

Nuclear Power Generation

Hydraulic Power Genere

Other Power Generation

Purchased Power

Other Production Expenses

Total Production Expenses

Transmission Expenses

Distribution Expenses.

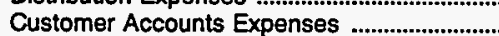

Customer Service and Information

Expenses.

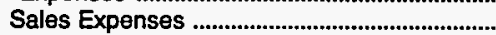

Administrative and General

Expenses

Total Electric Operation and

Maintenance Expenses .

Fuel Expenses in Operation

Steam Power Generation

Nuclear Power Generation

Other Power Generation

Number of Elec Dept Employees

Regular Full-time

Part-time \& Temporary

245

0

Total Elec Dept Employees

0
0
0
0
161,721
0

161,721

74
4,734

1,766

185

65

2,411

170,957

0
0
0
0
8,781

0
0
0
0
12,182
0

12,182

8,781

0

502

121

39

0

349

9,791

13,643

0
0
0
0
13,277
0

13,277

$$
\begin{array}{r}
0 \\
854
\end{array}
$$$$
\begin{aligned}
& 854 \\
& 286
\end{aligned}
$$

26

26
15

402

14,860

$\begin{array}{rr}0 & 0 \\ 0 & 0 \\ 0 & 0 \\ 0 & 0 \\ 18,115 & 6,181 \\ 0 & 0\end{array}$

18,115

6,181

43

1,593

503$$
18
$$

26

1,127

406

7,178

Note: Totals may not equal sum of components because of independent rounding

Source: Energy Information Administration, Form ElA-412, "Annual Report of Public Electric Utilities." 
Table 23. Electric Operation and Maintenance Expenses by Major U.S. Publicly Owned Electric Utility Within State, 1993 (Continued)

(Thousand Dollars)

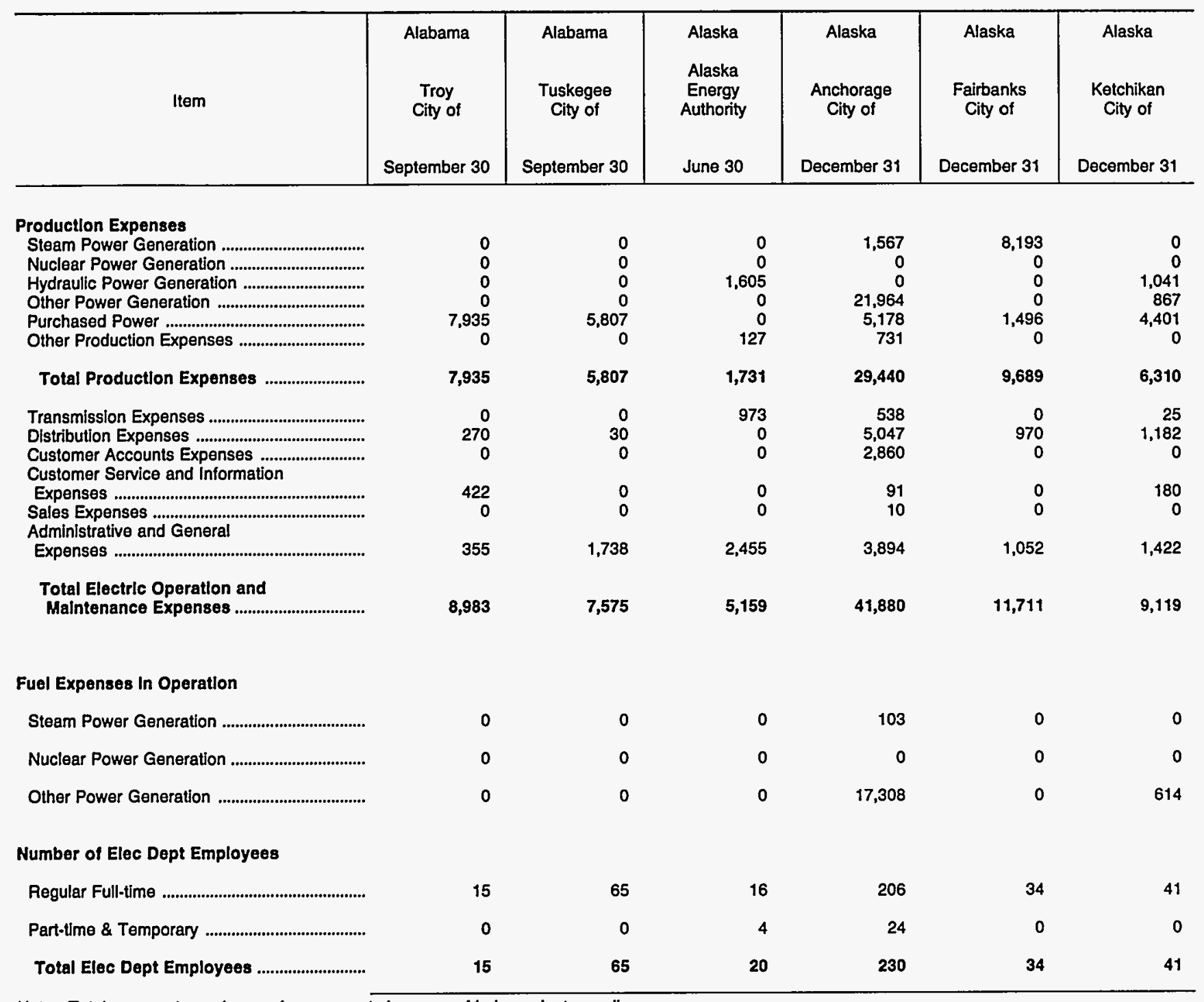

Note: Totals may not equal sum of components because of independent rounding.

Source: Energy Information Administration, Form ElA-412, "Annual Report of Public Electric Utilities." 
Table 23. Electric Operation and Maintenance Expenses by Major U.S. Publicly Owned Electric Utility Within State, 1993 (Continued) (Thousand Dollars)

\begin{tabular}{|c|c|c|c|c|c|c|}
\hline Item & $\begin{array}{l}\text { Arizona } \\
\text { Arizona } \\
\text { Power } \\
\text { Authority } \\
\\
\text { June } 30\end{array}$ & $\begin{array}{c}\text { Arizona } \\
\text { Electrical } \\
\text { Dist } \\
\text { No2 } \\
\text { Pinal Cnty } \\
\text { December } 31\end{array}$ & $\begin{array}{l}\text { Arizona } \\
\text { Mesa } \\
\text { City of } \\
\text { June } 30\end{array}$ & $\begin{array}{c}\text { Arizona } \\
\text { Navajo } \\
\text { Tribal } \\
\text { Utility } \\
\text { Auth } \\
\text { December } 31\end{array}$ & $\begin{array}{l}\text { Arizona } \\
\text { Salt River } \\
\text { Proj Ag } \\
\text { I \& P Dist } \\
\text { April } 30\end{array}$ & $\begin{array}{c}\text { Arizona } \\
\text { Tohono } \\
\text { OOdham } \\
\text { Utility Auth }\end{array}$ \\
\hline
\end{tabular}

Production Expenses

Steam Power Generation

Nuclear Power Generation...

Power Generation

Other Power Generation

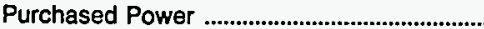

Other Production Expenses

Total Production Expenses

Transmission Expenses

Distribution Expenses ........

Customer Accounts Expenses ..........................

Customer Service and Information

Expenses ...

Administrative and General

Expenses

Total Electric Operation and

MaIntenance Expenses
0
0
0
0
12,192

12,192

12,192

2,757

7
0

0

0

1,200

16,156
0
0
0
0
5,178
0

5,178

0
469

469
182

$$
0
$$

331

6,160

0
0
0
0
13,967
0

0

0

19,599

13,967

19,599

484

2,379

1,491

5

58

3,528

27,543

17,680

657,565

286,557

98,337

12,665

15,216

61,576

3,925

478,276

12,885

36,090

21,835

6,384

5,600

96,496

Fuel Expenses in Operation

Steam Power Generation

Nuclear Power Generation
0

0

0
0

0

0
0

0

0
209,358

0

26,112

0

9,238

0

Number of Elec Dept Employees

Regular Full-time

9

20

55

3,655

23

Part-time \& Temporary

0

Total Elec Dept Employees

9

20

55

3,829

Note: Totals may not equal sum of components because of independent rounding.

Source: Energy Information Administration, Form ElA-412, "Annual Report of Public Electric Utilities." 
Table 23. Electric Operation and Maintenance Expenses by Major U.S. Publicly Owned Electric Utility Within State, 1993 (Continued)

(Thousand Dollars)

\begin{tabular}{|c|c|c|c|c|c|c|}
\hline Item & $\begin{array}{l}\text { Arkansas } \\
\text { Benton } \\
\text { City of } \\
\text { December } 31\end{array}$ & $\begin{array}{l}\text { Arkansas } \\
\text { Bentonville } \\
\text { City of } \\
\text { December } 31\end{array}$ & $\begin{array}{c}\text { Arkansas } \\
\text { Clarksville } \\
\text { Light } \\
\& \\
\text { Water Co } \\
\text { September } 30\end{array}$ & $\begin{array}{l}\text { Arkansas } \\
\text { Conway } \\
\text { Corp } \\
\text { December } 31\end{array}$ & $\begin{array}{c}\text { Arkansas } \\
\text { Hope } \\
\text { City of } \\
\text { December } 31\end{array}$ & $\begin{array}{l}\text { Arkansas } \\
\text { Jonesboro } \\
\text { City of } \\
\text { December } 31\end{array}$ \\
\hline 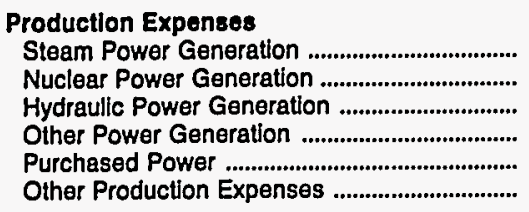 & $\begin{array}{r}0 \\
0 \\
0 \\
68 \\
7,783 \\
0\end{array}$ & $\begin{array}{r}0 \\
0 \\
0 \\
0 \\
6,887 \\
0\end{array}$ & $\begin{array}{r}0 \\
0 \\
0 \\
0 \\
4,651 \\
0\end{array}$ & $\begin{array}{r}10,252 \\
0 \\
0 \\
0 \\
7,473 \\
0\end{array}$ & $\begin{array}{r}0 \\
0 \\
0 \\
0 \\
7,198 \\
4\end{array}$ & $\begin{array}{r}5,746 \\
0 \\
0 \\
0 \\
12,400 \\
0\end{array}$ \\
\hline 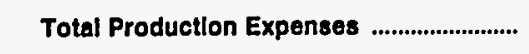 & 7,852 & 6,887 & 4,651 & 17,725 & 7,202 & 18,146 \\
\hline 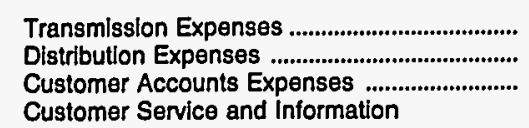 & $\begin{array}{r}0 \\
1,182 \\
0\end{array}$ & $\begin{array}{r}0 \\
723 \\
0\end{array}$ & $\begin{array}{r}0 \\
1,068 \\
0\end{array}$ & $\begin{array}{r}0 \\
941 \\
294\end{array}$ & $\begin{array}{r}157 \\
414 \\
0\end{array}$ & $\begin{array}{r}0 \\
1,645 \\
1,034\end{array}$ \\
\hline 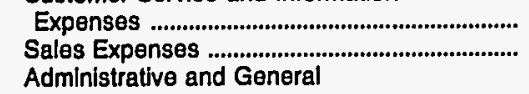 & $\begin{array}{r}0 \\
79\end{array}$ & $\begin{array}{l}0 \\
0\end{array}$ & $\begin{array}{l}0 \\
0\end{array}$ & $\begin{array}{l}0 \\
0\end{array}$ & $\begin{array}{l}0 \\
0\end{array}$ & $\begin{array}{r}0 \\
17\end{array}$ \\
\hline 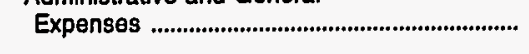 & 537 & 163 & 243 & 466 & 597 & 1,102 \\
\hline 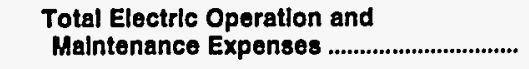 & 9,649 & 7,773 & 5,962 & 19,427 & 8,371 & 21,944 \\
\hline \multicolumn{7}{|l|}{ Fuel Expenses In Operation } \\
\hline 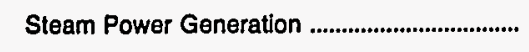 & 0 & 0 & 0 & 194 & 0 & 2,602 \\
\hline 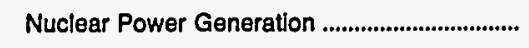 & 0 & 0 & 0 & 0 & 0 & 0 \\
\hline 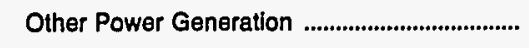 & 0 & 0 & 0 & 0 & 0 & 0 \\
\hline \multicolumn{7}{|l|}{ Number of Elec Dept Employees } \\
\hline 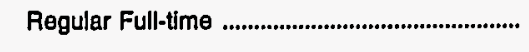 & 17 & 14 & 13 & 38 & 32 & 101 \\
\hline 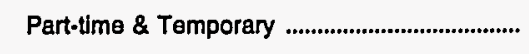 & 0 & 0 & 0 & 4 & 0 & 1 \\
\hline 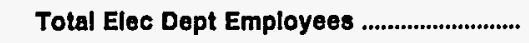 & 17 & 14 & 13 & 42 & 32 & 102 \\
\hline
\end{tabular}

Note: Totals may not equal sum of components because of independent rounding.

Source: Energy Information Administration, Form EIA-412, "Annual Report of Public Electric Utilities." 
Table 23. Electric Operation and Maintenance Expenses by Major U.S. Publicly Owned Electric Utility Within State, 1993 (Continued) (Thousand Dollars)

\begin{tabular}{|c|c|c|c|c|c|c|}
\hline Item & $\begin{array}{c}\text { Arkansas } \\
\text { North } \\
\text { Little } \\
\text { Rock } \\
\text { City of } \\
\text { December } 31\end{array}$ & $\begin{array}{l}\text { Arkansas } \\
\text { Osceola } \\
\text { City of } \\
\text { December } 31\end{array}$ & $\begin{array}{c}\text { Arkansas } \\
\text { Paragould } \\
\text { Light } \\
\& \\
\text { Water Comm } \\
\text { December } 31\end{array}$ & $\begin{array}{l}\text { Arkansas } \\
\text { Siloam } \\
\text { Springs } \\
\text { City of } \\
\text { December } 31\end{array}$ & $\begin{array}{c}\text { Arkansas } \\
\text { West } \\
\text { Memphis } \\
\text { City of } \\
\text { December } 31\end{array}$ & $\begin{array}{l}\text { California } \\
\text { Alameda } \\
\text { City of } \\
\text { June } 30\end{array}$ \\
\hline \multicolumn{7}{|l|}{ Production Expenses } \\
\hline 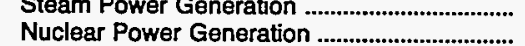 & $\begin{array}{l}0 \\
0\end{array}$ & $\begin{array}{l}0 \\
0\end{array}$ & 0 & 0 & 444 & \\
\hline Hydraulic Power Generation ......................................... & 733 & 0 & 0 & 0 & 0 & \\
\hline 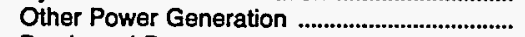 & 0 & 0 & 82 & 0 & 0 & 0 \\
\hline Purchased Power ................................................... & 34,768 & 6,071 & 6,220 & 5,689 & 12,369 & 29,222 \\
\hline 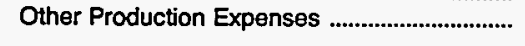 & 0 & 271 & 0 & 0 & 0 & 0 \\
\hline Total Production Expenses ............................. & 35,501 & 6,342 & 6,302 & 5,689 & 12,813 & 29,222 \\
\hline 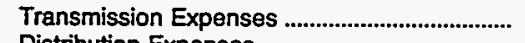 & 0 & 0 & 0 & 0 & 0 & 20 \\
\hline 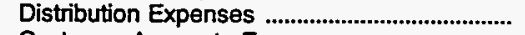 & 1,908 & 620 & 1,321 & 953 & 657 & 1,419 \\
\hline $\begin{array}{l}\text { Customer Accounts Expenses } \\
\text { Customer Service and Information...................... }\end{array}$ & 1,629 & 0 & 267 & 0 & 0 & 989 \\
\hline 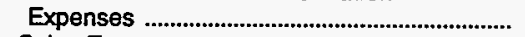 & 0 & 0 & 0 & 2 & 0 & 195 \\
\hline 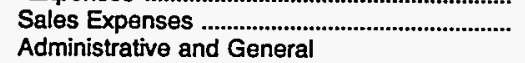 & 0 & 0 & 0 & 0 & 0 & 20 \\
\hline 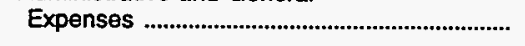 & 2,699 & 415 & 409 & 58 & 55 & 4,114 \\
\hline $\begin{array}{l}\text { Total Electric Operation and } \\
\text { Maintenance Expenses ............................... }\end{array}$ & 41,737 & 7,377 & 8,298 & 6,701 & 13,525 & 35,980 \\
\hline
\end{tabular}

Fuel Expenses in Operation

Steam Power Generation ....................................

Nuclear Power Generation

Other Power Generation

Number of Elec Dept Employees

Regular Full-time

Part-time \& Temporary

Total Elec Dept Employees

$\begin{array}{ll}0 & 0 \\ 0 & 0 \\ 0 & 0\end{array}$

95

0

95

$\begin{array}{rr}0 & 0 \\ 0 & 0 \\ 33 & 0\end{array}$

193

0

0

0

Note: Totals may not equal sum of components because of independent rounding.

Source: Energy Information Administration, Form ElA-412, "Annual Report of Public Electric Utilities." 
Table 23. Electric Operation and Maintenance Expenses by Major U.S. Publicly Owned Electric Utility Within State, 1993 (Continued)

(Thousand Dollars)

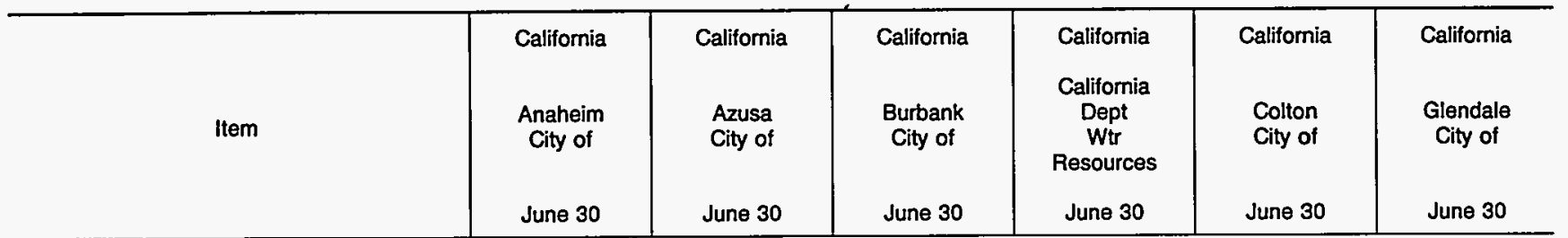

Production Expenses

Steam Power Generation

Nuclear Power Generation

Hydraulic Power Generation

Other Power Generation

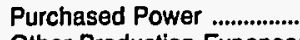

Total Production Expenses ........................

Transmission Expenses ......................................

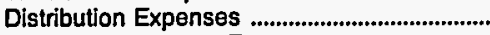

Customer Accounts Expenses ..........................

Customer Service and Information

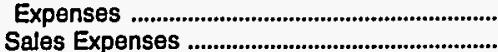

Sales Expenses .......................

Expenses

Total Electric Operation and

Malntenance Expenses

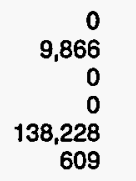

609

148,703

569

25,504

4,894

10
0

3,566

183,246

11,579

$\begin{array}{rr}14,860 & 40,080 \\ 0 & 0 \\ 0 & 9,267 \\ 0 & 0 \\ 47,477 & 0 \\ 10 & 0\end{array}$

62,347

1,917

5,191

1,140

0
0

6,991

77,586

8,380

27,834

0

0

275

0

275
16

15

299

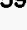

49,347

0

0
0

0

0

49,347

16,603

Total Elec Dept Employees

Source: Energy Information Administration, Form ElA-412, "Annual Report of Public Electric Utilities." 
Table 23. Electric Operation and Maintenance Expenses by Major U.S. Publicly Owned Electric Utility Within State, 1993 (Continued)

(Thousand Dollars)

\begin{tabular}{|c|c|c|c|c|c|c|}
\hline Item & $\begin{array}{c}\text { California } \\
\text { Imperial } \\
\text { Irrigation } \\
\text { District } \\
\text { December } 31\end{array}$ & $\begin{array}{l}\text { California } \\
\text { Lassen } \\
\text { Municipal } \\
\text { Utility Dist } \\
\text { June } 30\end{array}$ & $\begin{array}{l}\text { California } \\
\text { Lodi } \\
\text { City of } \\
\text { June } 30\end{array}$ & $\begin{array}{l}\text { California } \\
\text { Los Angeles } \\
\text { City of } \\
\text { June } 30\end{array}$ & $\begin{array}{c}\text { California } \\
\text { Merced } \\
\text { Irrigation } \\
\text { District } \\
\text { December } 31\end{array}$ & $\begin{array}{l}\text { California } \\
\text { Metropolitan } \\
\text { Water } \\
\text { District } \\
\text { June } 30\end{array}$ \\
\hline 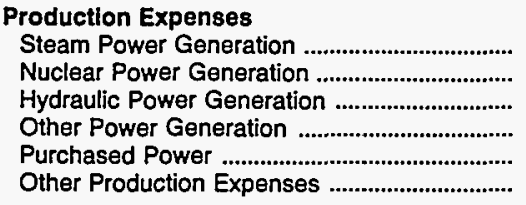 & $\begin{array}{r}25,451 \\
0 \\
1,796 \\
1,124 \\
81,372 \\
724\end{array}$ & $\begin{array}{r}0 \\
0 \\
0 \\
0 \\
9,434 \\
0\end{array}$ & $\begin{array}{r}0 \\
0 \\
0 \\
0 \\
25,216 \\
0\end{array}$ & $\begin{array}{r}356,361 \\
28,214 \\
14,967 \\
88 \\
648,157 \\
0\end{array}$ & $\begin{array}{r}0 \\
0 \\
1,787 \\
0 \\
0 \\
0\end{array}$ & $\begin{array}{r}0 \\
0 \\
1,515 \\
0 \\
0 \\
0\end{array}$ \\
\hline Total Production Expenses ........................... & 110,467 & 9,434 & 25,216 & $1,047,786$ & 1,787 & 1,515 \\
\hline 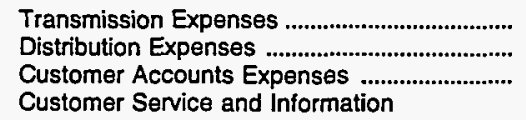 & $\begin{array}{l}3,326 \\
9,993 \\
3,135\end{array}$ & $\begin{array}{r}9 \\
861 \\
288\end{array}$ & $\begin{array}{r}0 \\
1,330 \\
1,368\end{array}$ & $\begin{array}{r}35,849 \\
155,261 \\
64,170\end{array}$ & $\begin{array}{l}0 \\
0 \\
0\end{array}$ & $\begin{array}{l}0 \\
0 \\
0\end{array}$ \\
\hline $\begin{array}{l}\text { Expenses } \\
\text { Sales Expenses } \\
\text { Administrative and General }\end{array}$ & $\begin{array}{l}0 \\
0\end{array}$ & $\begin{array}{r}103 \\
0\end{array}$ & $\begin{array}{l}0 \\
0\end{array}$ & $\begin{array}{r}23,607 \\
0\end{array}$ & $\begin{array}{l}0 \\
0\end{array}$ & $\begin{array}{l}0 \\
0\end{array}$ \\
\hline Expenses & 12,090 & 1,738 & 1,916 & 200,765 & 338 & 0 \\
\hline $\begin{array}{l}\text { Total Electric Operation and } \\
\text { Malntenance Expenses }\end{array}$ & 139,012 & 12,433 & 29,830 & $1,527,437$ & 2,125 & 1,515 \\
\hline \multicolumn{7}{|l|}{ Fuel Expenses in Operation } \\
\hline 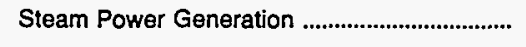 & 19,976 & 0 & 0 & 270,029 & 0 & 0 \\
\hline 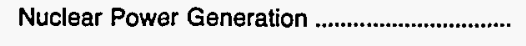 & 0 & 0 & 0 & 9,347 & 0 & 0 \\
\hline 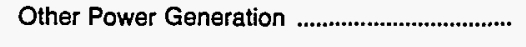 & 331 & 0 & 0 & 16 & 0 & 0 \\
\hline \multicolumn{7}{|l|}{ Number of Elec Dept Employees } \\
\hline Regular Full-time & 433 & 18 & 38 & 7,783 & 10 & 57 \\
\hline 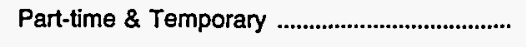 & 8 & 0 & 1 & 677 & 0 & 0 \\
\hline Total Elec Dept Employees ................................ & 441 & 18 & 39 & 8,460 & 10 & 57 \\
\hline
\end{tabular}

Note: Totals may not equal sum of components because of independent rounding.

Source: Energy Information Administration, Form ElA-412, "Annual Report of Public Electric Utilities." 
Table 23. Electric Operation and Maintenance Expenses by Major U.S. Publicly Owned Electric Utility Within State, 1993 (Continued) (Thousand Dollars)

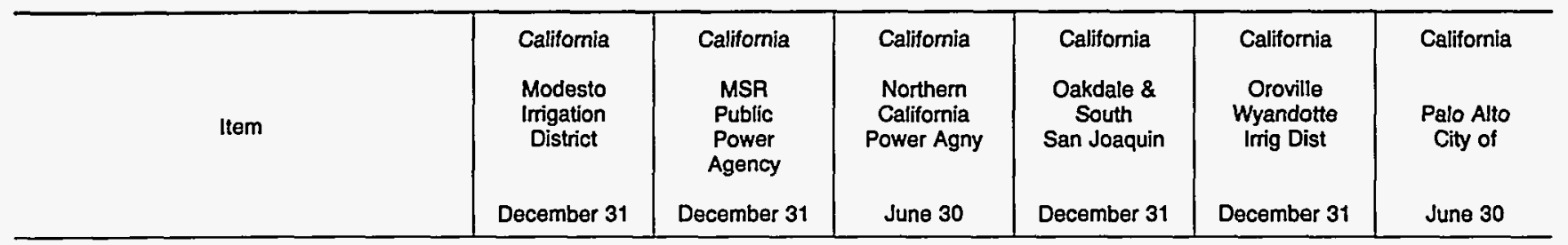

\section{Production Expenses}

Steam Power Generation

Nuclear Power Generation

Hydraulic Power Generation

Other Power Generation

Purchased Power .

Other Production Expenses

(n)

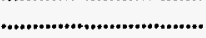

Total Productlon Expenses

Transmission Expenses

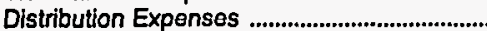

Customer Accounts Expenses ..........................

Customer Service and Information

Expenses

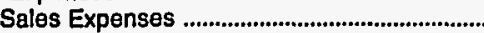

Administrative and General

Expenses

Total Electric Operation and

Malntenance Expenses

Fuel Expenses in Operation

Steam Power Generation

Nuclear Power Generation

Other Power Generation

每

Number of Elec Dept Employees

Regular Full-time

Part-time \& Temporary

310

4

Total Elec Dept Employees
0
0
710
1,924
71,487
1,539

21,940

0

0

15,727

51

75,660

37,718

137

5,289

3,575

1,023

8,718

94,401
366

0

0

1,475

39,559

17,439

0

0

656

0
52,712

0
2,277

1,628

8,423

2,284

67,324

8,065

0
0

0

5,476

80,865

44,886

0

372

177

0

177

0
0
777
0
0
0

0
0
8,828

$$
\begin{aligned}
& 0 \\
& 0
\end{aligned}
$$

8,828

777

0

$$
\begin{aligned}
& 0 \\
& 0 \\
& 0
\end{aligned}
$$

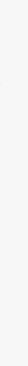

0

0
0
0

27,693
0

27,693

5,765

5,765
0

1,245

2,234

1,172

1,949

8,828

36,937

Note: Totals may not equal sum of components because of independent rounding.

Source: Energy Information Administration, Form ElA-412, "Annual Report of Public Electric Utilities." 
Table 23. Electric Operation and Maintenance Expenses by Major U.S. Publicly Owned Electric Utility Within State, 1993 (Continued)

(Thousand Dollars)

\begin{tabular}{|c|c|c|c|c|c|c|}
\hline Item & $\begin{array}{l}\text { California } \\
\text { Pasadena } \\
\text { City of } \\
\text { June } 30\end{array}$ & $\begin{array}{c}\text { California } \\
\text { Placer } \\
\text { County } \\
\text { Water } \\
\text { Agency } \\
\text { December } 31\end{array}$ & $\begin{array}{l}\text { California } \\
\text { Redding } \\
\text { City of } \\
\text { June } 30\end{array}$ & $\begin{array}{l}\text { California } \\
\text { Riverside } \\
\text { City of } \\
\text { June } 30\end{array}$ & $\begin{array}{l}\text { California } \\
\text { Roseville } \\
\text { City of } \\
\text { June } 30\end{array}$ & $\begin{array}{c}\text { California } \\
\text { Sacramento } \\
\text { Municipal } \\
\text { Util Dist } \\
\text { December } 31\end{array}$ \\
\hline \multicolumn{7}{|l|}{ Production Expenses } \\
\hline 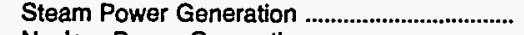 & 17,954 & 0 & 0 & 0 & 0 & 15,841 \\
\hline Nuclear Power Generation .................................... & & 0 & $\mathbf{0}$ & 9,039 & 0 & 26 \\
\hline Hydraulic Power Generation .................................... & 82 & 2,441 & 0 & 0 & 0 & 8,628 \\
\hline Other Power Generation .......................................... & 140 & 0 & 0 & 0 & 0 & 577 \\
\hline 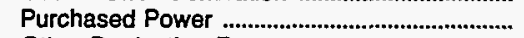 & 54,164 & 0 & 23,919 & 84,031 & 26,566 & 275,754 \\
\hline 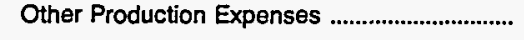 & 621 & 23 & 0 & 729 & 1,026 & 4,560 \\
\hline 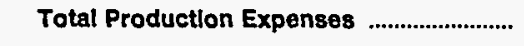 & 72,961 & 2,465 & 23,919 & 93,800 & 27,591 & 305,385 \\
\hline 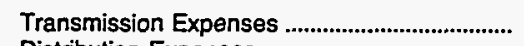 & 1,256 & 90 & 0 & 14,723 & 0 & 14,488 \\
\hline 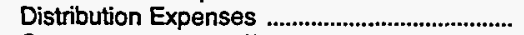 & 4,781 & 0 & 4,112 & 5,470 & 5,383 & 24,998 \\
\hline $\begin{array}{l}\text { Customer Accounts Expenses ........................... } \\
\text { Customer Service and Information }\end{array}$ & 1,033 & 0 & 1,350 & 4,184 & 941 & 24,627 \\
\hline 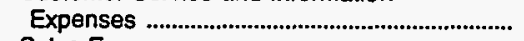 & 0 & 0 & 0 & 1,279 & 0 & 6,104 \\
\hline $\begin{array}{l}\text { Sales Expenses .... General } \\
\text { Administrative and }\end{array}$ & 181 & 0 & 0 & 0 & 0 & 0 \\
\hline 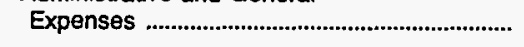 & 8,420 & 943 & 7,166 & 10,894 & 1,238 & 25,037 \\
\hline $\begin{array}{l}\text { Total Electric Operation and } \\
\text { Maintenance Expenses }\end{array}$ & 88.632 & 3,497 & 36.547 & 130.350 & 35.153 & \\
\hline \multicolumn{7}{|l|}{ Fuel Expenses in Operation } \\
\hline 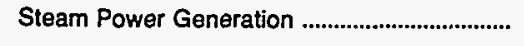 & 12,747 & 0 & 0 & 0 & 0 & 0 \\
\hline Nuclear Power Generation ....................................... & 0 & 0 & 0 & 1,582 & 0 & 0 \\
\hline 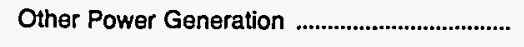 & 0 & 0 & 0 & 0 & 0 & 128 \\
\hline \multicolumn{7}{|l|}{ Number of Elec Dept Employees } \\
\hline 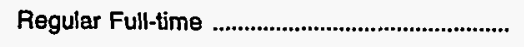 & 332 & 16 & 84 & 249 & 67 & 2,378 \\
\hline 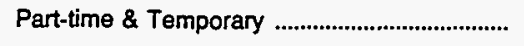 & 19 & 3 & 5 & 9 & 6 & з3 \\
\hline Total Elec Dept Employees ................................ & 351 & 19 & 89 & 258 & 73 & 2,411 \\
\hline
\end{tabular}

Note: Totals may not equal sum of components because of independent rounding.

Source: Energy Information Administration, Form EIA-412, "Annual Report of Public Electric Utilities." 
Table 23. Electric Operation and Maintenance Expenses by Major U.S. Publicly Owned Electric Utility Within State, 1993 (Continued)

(Thousand Dollars)

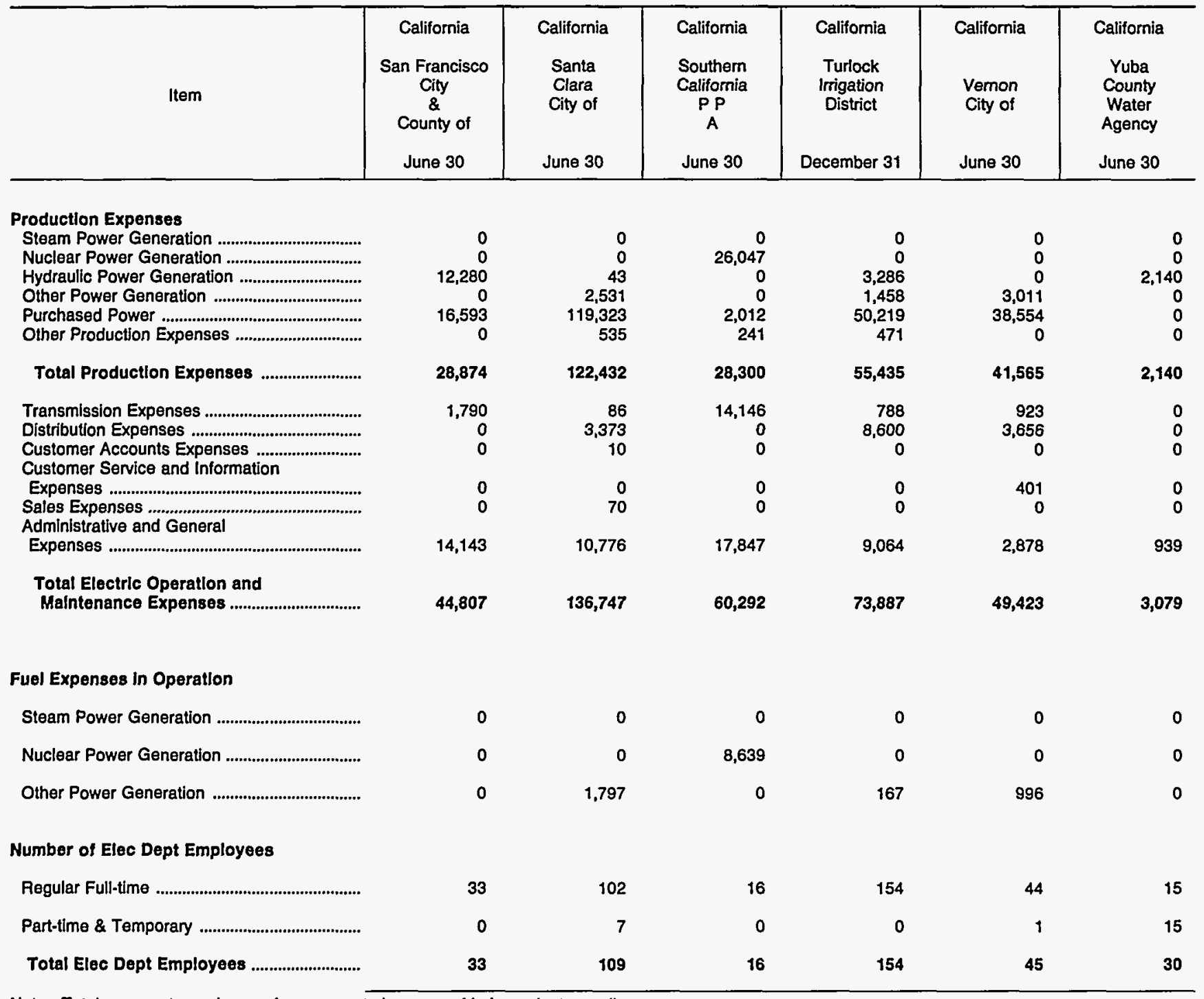

Note: Totals may not equal sum of components because of independent rounding

Source: Energy Information Administration, Form EIA-412, "Annual Report of Public Electric Utilities." 
Table 23. Electric Operation and Maintenance Expenses by Major U.S. Publicly Owned Electric Utility Within State, 1993 (Continued)

(Thousand Dollars)

\begin{tabular}{c|c|c|c|c|c|c}
\hline & $\begin{array}{c}\text { Colorado } \\
\text { Arkansas } \\
\text { River } \\
\text { Power } \\
\text { Authority } \\
\text { December 31 }\end{array}$ & $\begin{array}{c}\text { Colorado } \\
\text { Colorado } \\
\text { Springs } \\
\text { City of }\end{array}$ & $\begin{array}{c}\text { Colorado } \\
\text { December 31 }\end{array}$ & Collins & Colorado & Colt Morgan \\
City of & $\begin{array}{c}\text { Longmont } \\
\text { City of }\end{array}$ & $\begin{array}{c}\text { Loveland } \\
\text { City of }\end{array}$ \\
& December 31 & December 31 & December 31 & December 31 \\
\hline
\end{tabular}

Production Expenses

Steam Power Generation

Nuclear Power Generatior

Hydraulic Power Generation.

Other Power Generation

Purchased Power

Other Production Expenses

Total Production Expenses

Transmission Expenses

Distribution Expenses .........................................

Customer Accounts Expenses ...................

Customer Service and information

Expenses

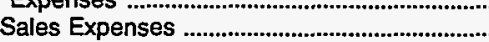

Administrative and General

Expenses

Total Electric Operation and

Malntenance Expenses

Fuel Expenses in Operation

Steam Power Generation ...

Nuclear Power Generation

0

45,884

0

Other Power Generation

0

0

0

3

509

27

536

4

60,857

256

10,124

26

71,262

1,815

11,903

327
0

10,563

100,447

Note: Totals may not equal sum of components because of independent rounding.

Source: Energy Information Administration, Form EIA-412, "Annual Report of Public Electric Utilities." 
Table 23. Electric Operation and Maintenance Expenses by Major U.S. Publicly Owned Electric Utility Within State, 1993 (Continued) (Thousand Dollars)

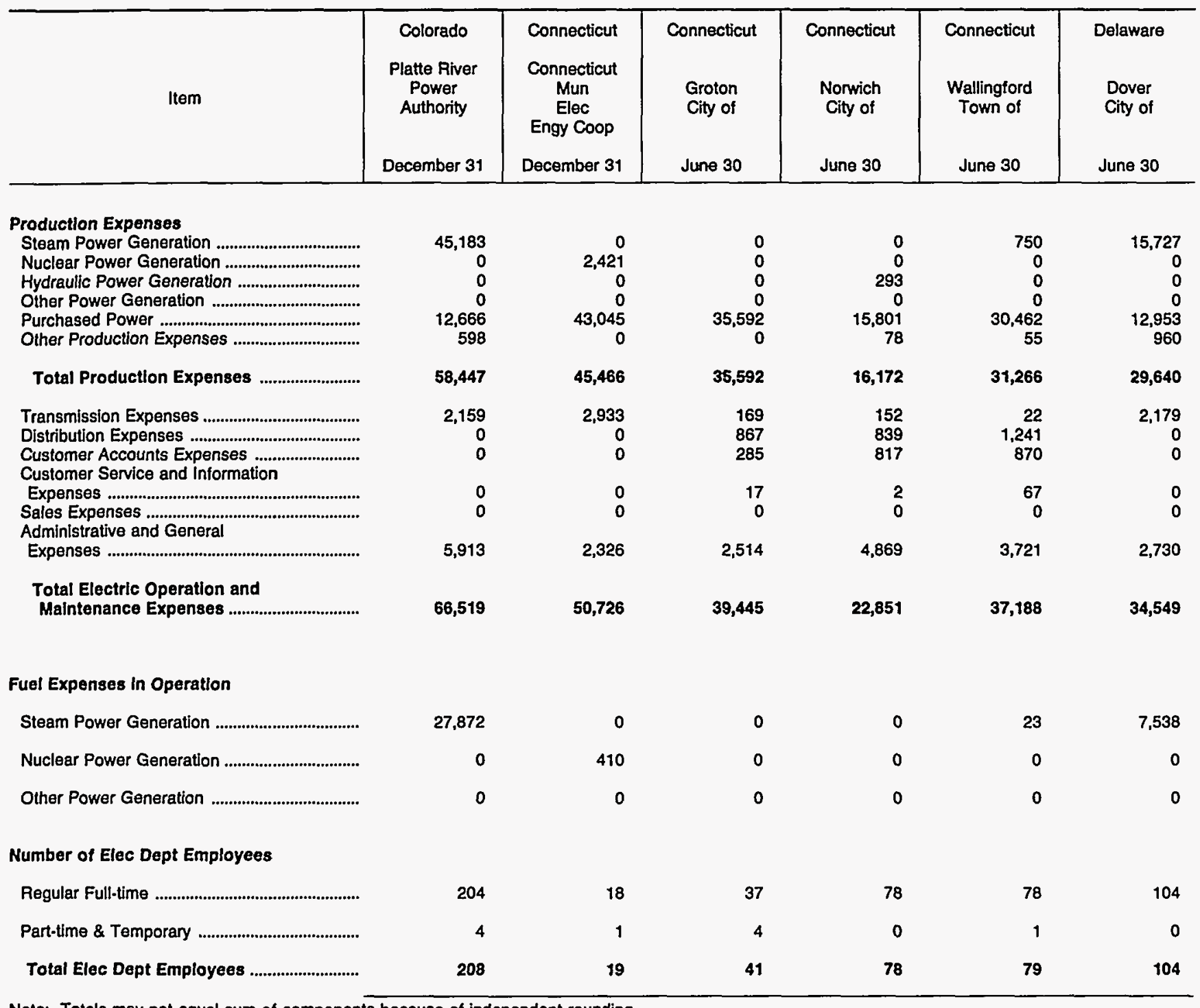

Note: Totals may not equal sum of components because of independent rounding.

Source: Energy Information Administration, Form ElA-412, "Annual Report of Public Electric Utilities." 
Table 23. Electric Operation and Maintenance Expenses by Major U.S. Publicly Owned Electric Utility Within State, 1993 (Continued)

(Thousand Dollars)

\begin{tabular}{|c|c|c|c|c|c|c|}
\hline Item & $\begin{array}{l}\text { Delaware } \\
\begin{array}{l}\text { Milford } \\
\text { City of }\end{array} \\
\text { September } 30\end{array}$ & $\begin{array}{c}\text { Delaware } \\
\begin{array}{c}\text { Newark } \\
\text { City of }\end{array} \\
\text { December } 31\end{array}$ & $\begin{array}{l}\text { Florida } \\
\text { Bartow } \\
\text { City of } \\
\text { September } 30\end{array}$ & $\begin{array}{c}\text { Florida } \\
\text { Florida } \\
\text { Municipal } \\
\text { Power Agency } \\
\text { September } 30\end{array}$ & $\begin{array}{c}\text { Fiorida } \\
\text { Fort Pierce } \\
\text { Utilities } \\
\text { Auth } \\
\text { September } 30\end{array}$ & $\begin{array}{c}\text { Florida } \\
\text { Gainesville } \\
\text { Regional } \\
\text { Utilities } \\
\text { September } 30\end{array}$ \\
\hline \multicolumn{7}{|l|}{ Production Expenses } \\
\hline 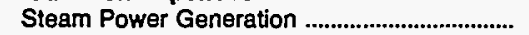 & 0 & 0 & 0 & 19,320 & 9,230 & 45,654 \\
\hline 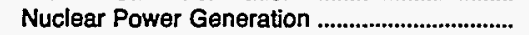 & 0 & 0 & 0 & 9,210 & 0 & 1.431 \\
\hline 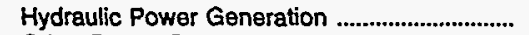 & 0 & 0 & 0 & 0 & 0 & 0 \\
\hline 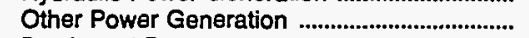 & & 0 & 0 & 700 & 27 & 881 \\
\hline 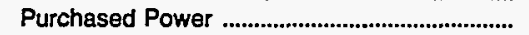 & 6,011 & 13,910 & 12,311 & 67,953 & 16,501 & 3,127 \\
\hline 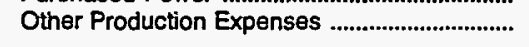 & 0 & 84 & 0 & 459 & 0 & 352 \\
\hline 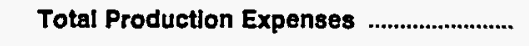 & 6,011 & 13,994 & 12,311 & 97,642 & 25,758 & 51,446 \\
\hline 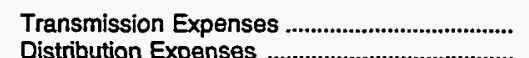 & $\begin{array}{r}0 \\
945\end{array}$ & $\begin{aligned} 0 \\
1252\end{aligned}$ & $\begin{array}{r}60 \\
336\end{array}$ & 12,035 & $\begin{array}{r}684 \\
1448\end{array}$ & $\begin{array}{r}607 \\
4471\end{array}$ \\
\hline $\begin{array}{l}\text { Customer Accounts Expenses ................................ } \\
\text { Customer Service and Information }\end{array}$ & $\begin{array}{r}945 \\
0\end{array}$ & 0 & 150 & 0 & 745 & 2,252 \\
\hline 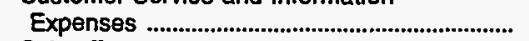 & 0 & 0 & 0 & 0 & 0 & 25 \\
\hline & 0 & 0 & 0 & 0 & 0 & 389 \\
\hline 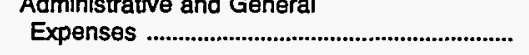 & 49 & 0 & 1,612 & 7,843 & 3,411 & 8,996 \\
\hline $\begin{array}{l}\text { Total Electric Operation and } \\
\text { Malntenance Expenses ................................ }\end{array}$ & 7,005 & 15,217 & 14,470 & 117,520 & 32,045 & 68,185 \\
\hline \multicolumn{7}{|l|}{ Fuel Expenses in Operation } \\
\hline 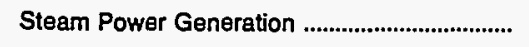 & 0 & 0 & 0 & 14,173 & 6,994 & 35,998 \\
\hline Nuclear Power Generation .................................... & 0 & 0 & 0 & 2,229 & 0 & 427 \\
\hline 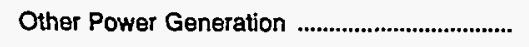 & 0 & 0 & 0 & 176 & 6 & 412 \\
\hline \multicolumn{7}{|l|}{ Number of Elec Dept Employees } \\
\hline Regular Full-time & 10 & 21 & 25 & 28 & 85 & 687 \\
\hline 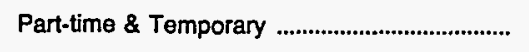 & 0 & 0 & 0 & 2 & 0 & 29 \\
\hline 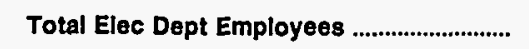 & 10 & 21 & 25 & 30 & 85 & 716 \\
\hline
\end{tabular}

Note: Totals may not equal sum of components because of independent rounding.

Source: Energy Information Administration, Form EIA-412, "Annual Report of Public Electric Utilities." 
Table 23. Electric Operation and Maintenance Expenses by Major U.S. Publicly Owned Electric Utility Within State, 1993 (Continued)

(Thousand Dollars)

\begin{tabular}{|c|c|c|c|c|c|c|}
\hline Item & $\begin{array}{c}\text { Florida } \\
\begin{array}{c}\text { Homestead } \\
\text { City of }\end{array} \\
\text { September } 30\end{array}$ & $\begin{array}{c}\text { Florida } \\
\text { Jacksonville } \\
\text { Beach } \\
\text { City of } \\
\text { September } 30\end{array}$ & $\begin{array}{l}\text { Florida } \\
\text { Jacksonville } \\
\text { Electric } \\
\text { Auth } \\
\text { September } 30\end{array}$ & $\begin{array}{l}\text { Florida } \\
\text { Key West } \\
\text { City of } \\
\text { September } 30\end{array}$ & $\begin{array}{c}\text { Florida } \\
\text { Kissimmeo } \\
\text { Utility } \\
\text { Authority } \\
\text { September } 30\end{array}$ & $\begin{array}{c}\text { Florida } \\
\text { Lake Worth } \\
\text { City of } \\
\text { September } 30\end{array}$ \\
\hline 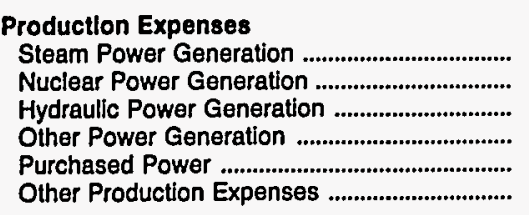 & $\begin{array}{r}0 \\
0 \\
0 \\
3,937 \\
9,919 \\
394\end{array}$ & $\begin{array}{r}0 \\
0 \\
0 \\
0 \\
26,010 \\
0\end{array}$ & $\begin{array}{r}257,958 \\
0 \\
0 \\
3,009 \\
74,313 \\
3\end{array}$ & $\begin{array}{r}4,434 \\
0 \\
0 \\
2,528 \\
19,563 \\
173\end{array}$ & $\begin{array}{r}4,398 \\
1,166 \\
0 \\
9,124 \\
20,533 \\
0\end{array}$ & $\begin{array}{r}7,929 \\
0 \\
0 \\
490 \\
11,967 \\
0\end{array}$ \\
\hline 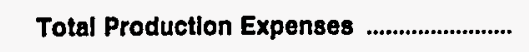 & 14,250 & 26,010 & 335,283 & 26,698 & 35,221 & 20,386 \\
\hline 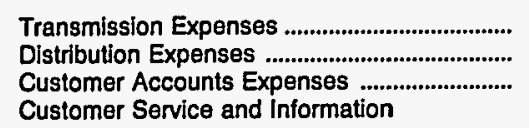 & $\begin{array}{r}5 \\
4,183 \\
1,551\end{array}$ & $\begin{array}{r}23 \\
1,307 \\
95\end{array}$ & $\begin{array}{r}7,009 \\
20,396 \\
10,851\end{array}$ & $\begin{array}{r}217 \\
1,731 \\
717\end{array}$ & $\begin{array}{r}366 \\
2,540 \\
1,668\end{array}$ & $\begin{array}{r}615 \\
1,307 \\
463\end{array}$ \\
\hline 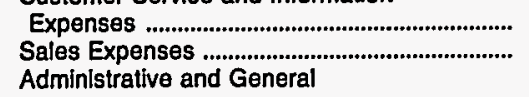 & $\begin{array}{l}0 \\
0\end{array}$ & $\begin{array}{l}0 \\
0\end{array}$ & $\begin{array}{r}880 \\
0\end{array}$ & $\begin{array}{r}24 \\
0\end{array}$ & $\begin{array}{r}686 \\
0\end{array}$ & $\begin{array}{l}0 \\
0\end{array}$ \\
\hline 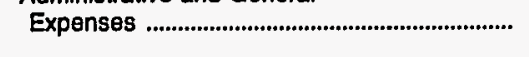 & 5,701 & 5,171 & 42,087 & 5,461 & 3,013 & 411 \\
\hline $\begin{array}{l}\text { Total Electric Operation and } \\
\text { Malntenance Expenses }\end{array}$ & 25,690 & 32,606 & 416,507 & 34,848 & 43,494 & 23,182 \\
\hline \multicolumn{7}{|l|}{ Fuel Expenses In Operation } \\
\hline 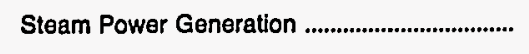 & 0 & 0 & 195,178 & 1,980 & 347 & 5,000 \\
\hline 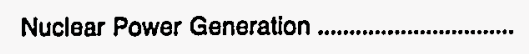 & 0 & 0 & 0 & $\mathbf{0}$ & 57 & 0 \\
\hline 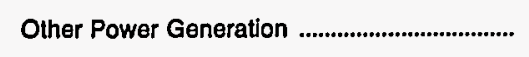 & 1,456 & 0 & 612 & 1,625 & 4,702 & 163 \\
\hline \multicolumn{7}{|l|}{ Number of Elec Dept Employees } \\
\hline 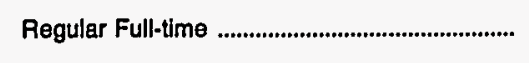 & 151 & 78 & 1,956 & 192 & 226 & 103 \\
\hline 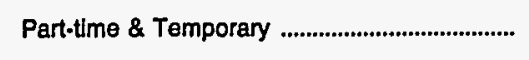 & 0 & 0 & 89 & 2 & 1 & 2 \\
\hline Total Elec Dept Employees ................................. & 151 & 78 & 2,045 & 194 & 227 & 105 \\
\hline
\end{tabular}

Note: Totals may not equal sum of components because of independent rounding.

Source: Energy Information Administration, Form EIA-412, "Annual Report of Public Electric Utilities." 
Table 23. Electric Operation and Maintenance Expenses by Major U.S. Publicly Owned Electric Utility Within State, 1993 (Continued)

(Thousand Dollars)

\begin{tabular}{|c|c|c|c|c|c|c|}
\hline Item & $\begin{array}{l}\text { Florida } \\
\text { Lakeland } \\
\text { City of } \\
\text { September } 30\end{array}$ & $\begin{array}{l}\text { Florida } \\
\text { Leesburg } \\
\text { City of } \\
\text { September } 30\end{array}$ & $\begin{array}{c}\text { Florida } \\
\text { New Smyrna } \\
\text { Beach } \\
\text { Utils Comm } \\
\text { September } 30\end{array}$ & $\begin{array}{c}\text { Florida } \\
\text { Ocala } \\
\text { City of } \\
\text { September } 30\end{array}$ & $\begin{array}{l}\text { Florida } \\
\text { Orlando } \\
\text { Utilities } \\
\text { Comm } \\
\text { September } 30\end{array}$ & $\begin{array}{l}\text { Florida } \\
\text { Quincy } \\
\text { City of } \\
\text { September } 30\end{array}$ \\
\hline 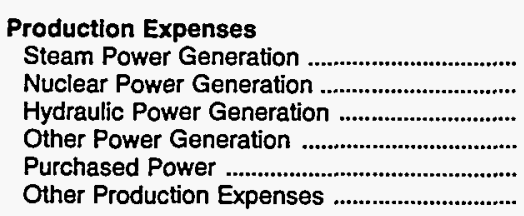 & $\begin{array}{r}46,743 \\
0 \\
0 \\
10,548 \\
10,769 \\
0\end{array}$ & $\begin{array}{r}0 \\
1,314 \\
0 \\
0 \\
14,755 \\
0\end{array}$ & $\begin{array}{r}0 \\
1,004 \\
0 \\
388 \\
13,294 \\
476\end{array}$ & $\begin{array}{r}0 \\
2,841 \\
0 \\
0 \\
39,775 \\
0\end{array}$ & $\begin{array}{r}118,444 \\
10,173 \\
0 \\
5,009 \\
5,369 \\
299\end{array}$ & $\begin{array}{r}0 \\
0 \\
0 \\
0 \\
5,366 \\
0\end{array}$ \\
\hline 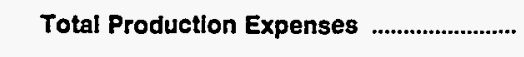 & 68,060 & 16,070 & 15,163 & 42,616 & 139,294 & 5,366 \\
\hline 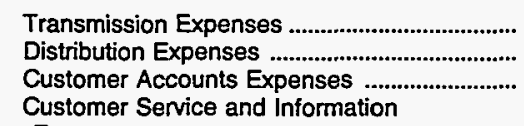 & $\begin{array}{l}1,420 \\
6,979 \\
2,596\end{array}$ & $\begin{array}{r}0 \\
2,125 \\
775\end{array}$ & $\begin{array}{r}339 \\
1,105 \\
497\end{array}$ & $\begin{array}{r}346 \\
3,974 \\
508\end{array}$ & $\begin{array}{l}5,789 \\
5,931 \\
5,473\end{array}$ & $\begin{array}{r}0 \\
350 \\
191\end{array}$ \\
\hline 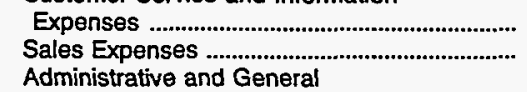 & $\begin{array}{r}632 \\
0\end{array}$ & $\begin{array}{l}0 \\
0\end{array}$ & $\begin{array}{l}0 \\
0\end{array}$ & $\begin{array}{l}181 \\
254\end{array}$ & $\begin{array}{r}1,776 \\
36\end{array}$ & $\begin{array}{l}0 \\
0\end{array}$ \\
\hline 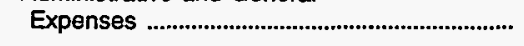 & 16,182 & 500 & 2,506 & 1,604 & 17,678 & 158 \\
\hline 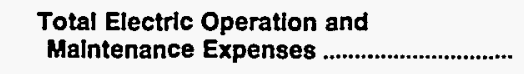 & 95,869 & 19,470 & 19,610 & 49,483 & 175,977 & 6,064 \\
\hline Fuel Expenses In Operation & & & & . & & \\
\hline 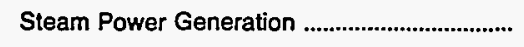 & 31,191 & 0 & 0 & 0 & 94,319 & 0 \\
\hline 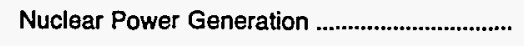 & 0 & 749 & 208 & 370 & 2,600 & 0 \\
\hline 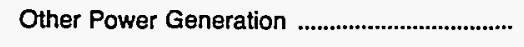 & 9,091 & 0 & 161 & 0 & 3,619 & 0 \\
\hline \multicolumn{7}{|l|}{ Number of Elec Dept Employees } \\
\hline Regular Full-time & 640 & 46 & 94 & 143 & 512 & 10 \\
\hline 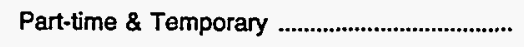 & 23 & 1 & 2 & 0 & 11 & 0 \\
\hline Total Elec Dept Employees .............................. & 663 & 47 & 96 & 143 & 523 & 10 \\
\hline
\end{tabular}

Note: Totals may not equal sum of components because of independent rounding.

Source: Energy Information Administration, Form EIA-412, "Annual Report of Public Electric Utilities." 
Table 23. Electric Operation and Maintenance Expenses by Major U.S. Publicly

Owned Electric Utility Within State, 1993 (Continued)

(Thousand Dollars)

\begin{tabular}{|c|c|c|c|c|c|c|}
\hline Item & $\begin{array}{c}\text { Florida } \\
\text { Reedy Creek } \\
\text { Improvement } \\
\text { Dist }\end{array}$ & $\begin{array}{l}\text { Florida } \\
\text { St Cloud } \\
\text { City of } \\
\text { September } 30\end{array}$ & $\begin{array}{l}\text { Florida } \\
\text { Tallahassee } \\
\text { City of } \\
\text { September } 30\end{array}$ & $\begin{array}{c}\text { Florida } \\
\text { Vero } \\
\text { Beach } \\
\text { City of } \\
\text { September } 30\end{array}$ & $\begin{array}{l}\text { Georgia } \\
\text { Albany Water } \\
\text { Gas \& Light } \\
\text { Comm } \\
\text { June } 30\end{array}$ & $\begin{array}{l}\text { Georgia } \\
\text { Calhoun } \\
\text { City of } \\
\text { June } 30\end{array}$ \\
\hline 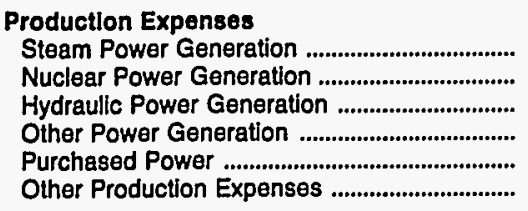 & $\begin{array}{r}1,293 \\
0 \\
0 \\
7,335 \\
22,397 \\
337\end{array}$ & $\begin{array}{r}0 \\
0 \\
0 \\
1,298 \\
9,746 \\
0\end{array}$ & $\begin{array}{r}44,381 \\
1,546 \\
170 \\
0 \\
33,456 \\
5,277\end{array}$ & $\begin{array}{r}13,871 \\
0 \\
0 \\
0 \\
13,125 \\
0\end{array}$ & $\begin{array}{r}0 \\
0 \\
0 \\
0 \\
42,524 \\
176\end{array}$ & $\begin{array}{r}0 \\
0 \\
0 \\
0 \\
14,391 \\
95\end{array}$ \\
\hline Total Production Expenses ......................... & 31,362 & 11,044 & 84,830 & 26,995 & 42,699 & 14,487 \\
\hline 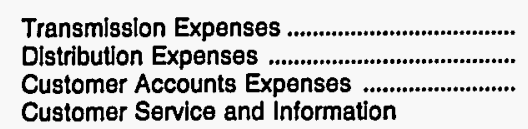 & $\begin{array}{r}0 \\
8,149 \\
1\end{array}$ & $\begin{array}{r}0 \\
2,273 \\
0\end{array}$ & $\begin{array}{l}1,007 \\
4,581 \\
6,793\end{array}$ & $\begin{array}{l}910 \\
910 \\
414\end{array}$ & $\begin{array}{r}2,908 \\
0 \\
0\end{array}$ & $\begin{array}{r}0 \\
845 \\
0\end{array}$ \\
\hline 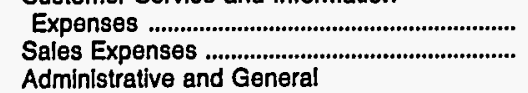 & $\begin{array}{l}0 \\
0\end{array}$ & $\begin{array}{r}1.160 \\
0\end{array}$ & $\begin{array}{l}0 \\
0\end{array}$ & $\begin{array}{r}414 \\
0\end{array}$ & $\begin{array}{l}0 \\
0\end{array}$ & $\begin{array}{l}0 \\
0\end{array}$ \\
\hline 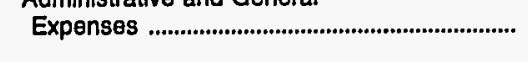 & 781 & -152 & 5,778 & 2,491 & 3,371 & 0 \\
\hline $\begin{array}{l}\text { Total Electrlc Operation and } \\
\text { Malntenance Expenses ................................ }\end{array}$ & 40,292 & 14,325 & 102,989 & 32,136 & 48,978 & 15,331 \\
\hline \multicolumn{7}{|l|}{ Fuel Expenses in Operation } \\
\hline Steam Power Generation .................................... & 1,029 & 0 & 38,701 & 9,611 & 0 & 0 \\
\hline Nuclear Power Generation ................................. & 0 & 0 & 302 & 0 & 0 & 0 \\
\hline Other Power Generation ........................................ & 5,133 & 389 & 0 & 0 & 0 & 0 \\
\hline \multicolumn{7}{|l|}{ Number of Elec Dept Employees } \\
\hline Regular Full-time .................................................. & 70 & 85 & 363 & 141 & 60 & 19 \\
\hline Part-time \& Temporary ........................................ & 0 & 2 & 2 & 0 & 0 & 0 \\
\hline Total Elec Dept Employees ............................. & 70 & 87 & 365 & 141 & 60 & 19 \\
\hline
\end{tabular}

Note: Totals may not equal sum of components because of independent rounding.

Source: Energy Information Administration, Form EIA-412, "Annual Report of Public Electric Utilities." 
Table 23. Electric Operation and Maintenance Expenses by Major U.S. Publicly Owned Electric Utility Within State, 1993 (Continued)

(Thousand Dollars)

\begin{tabular}{|c|c|c|c|c|c|c|}
\hline Item & $\begin{array}{l}\text { Georgia } \\
\text { Cartersville } \\
\text { City of } \\
\text { June } 30\end{array}$ & $\begin{array}{l}\text { Georgia } \\
\text { College } \\
\text { Park City of } \\
\text { June } 30\end{array}$ & $\begin{array}{c}\text { Georgia } \\
\text { Covington } \\
\text { City of } \\
\text { December } 31\end{array}$ & $\begin{array}{l}\text { Georgia } \\
\text { Crisp } \\
\text { County } \\
\text { Power } \\
\text { Comm } \\
\text { December } 31\end{array}$ & $\begin{array}{l}\text { Georgia } \\
\text { Dalton } \\
\text { City of } \\
\text { November } 30\end{array}$ & $\begin{array}{l}\text { Georgia } \\
\text { Douglas } \\
\text { City of } \\
\text { June } 30\end{array}$ \\
\hline \multicolumn{7}{|l|}{ Production Expenses } \\
\hline Steam Power Generation ........................................... & 0 & 0 & 0 & 471 & 5,196 & 0 \\
\hline 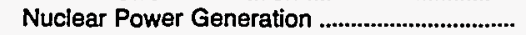 & 0 & 0 & 0 & 0 & 10,785 & 0 \\
\hline 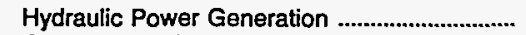 & 0 & 0 & 0 & 370 & 0 & 0 \\
\hline 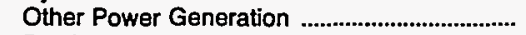 & 0 & 0 & 0 & 0 & 0 & 0 \\
\hline 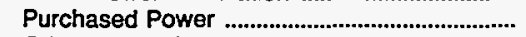 & 17,453 & 13,085 & 11,865 & 11,620 & 14,046 & 9,993 \\
\hline 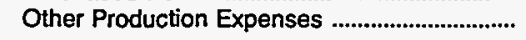 & 0 & 0 & 0 & 0 & 0 & 0 \\
\hline Total Production Expenses ............................... & 17,453 & 13,085 & 11,865 & 12,461 & 30,027 & 9,993 \\
\hline 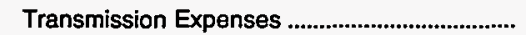 & 0 & 0 & 0 & 5 & 1,011 & 0 \\
\hline 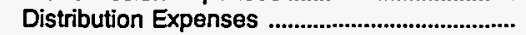 & 680 & 1,308 & 1,634 & 782 & 1,548 & 770 \\
\hline 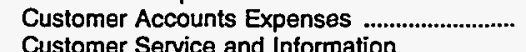 & 105 & 0 & 142 & 339 & 0 & 0 \\
\hline 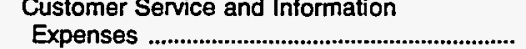 & 445 & 0 & 0 & 0 & 0 & 0 \\
\hline $\begin{array}{l}\text { Sales Expenses } \\
\text { Administrative and General }\end{array}$ & 0 & 0 & 0 & 0 & 0 & 0 \\
\hline 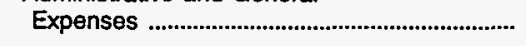 & 869 & 0 & 127 & 1,340 & 641 & 0 \\
\hline 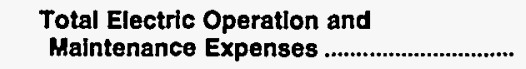 & 19,553 & 14,394 & 13,767 & 14,927 & 33,227 & 10,763 \\
\hline \multicolumn{7}{|l|}{ Fuel Expenses in Operation } \\
\hline 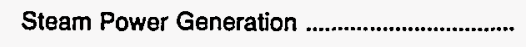 & 0 & 0 & 0 & 70 & 4,372 & 0 \\
\hline 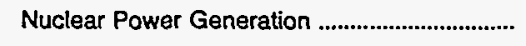 & 0 & 0 & 0 & 0 & 2,849 & 0 \\
\hline 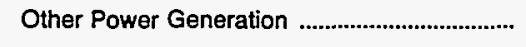 & 0 & 0 & 0 & 0 & 0 & 0 \\
\hline \multicolumn{7}{|l|}{ Number of Elec Dept Employees } \\
\hline Regular Full-time & 21 & 27 & 20 & 68 & 20 & 16 \\
\hline 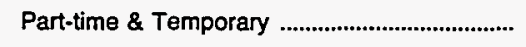 & 0 & 0 & 0 & 3 & 0 & 0 \\
\hline 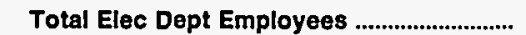 & 21 & 27 & 20 & 71 & 20 & 16 \\
\hline
\end{tabular}

Note: Totals may not equal sum of components because of independent rounding.

Source: Energy Information Administration, Form EIA-412, "Annual Report of Public Electric Utilities." 
Table 23. Electric Operation and Maintenance Expenses by Major U.S. Publicly Owned Electric Utility Within State, 1993 (Continued)

(Thousand Dollars)

\begin{tabular}{c|c|c|c|c|c|c}
\hline & Georgia & Georgia & Georgia & Georgia & Georgia & Georgia \\
Item & $\begin{array}{c}\text { East } \\
\text { Point } \\
\text { City of }\end{array}$ & $\begin{array}{c}\text { Fitzgerald } \\
\text { Wtr Lgt } \\
\& \text { Bond Comm }\end{array}$ & $\begin{array}{c}\text { Griffin } \\
\text { City of }\end{array}$ & $\begin{array}{c}\text { La Grange } \\
\text { City of }\end{array}$ & $\begin{array}{c}\text { Lawrenceville } \\
\text { City of }\end{array}$ & $\begin{array}{c}\text { Marietta } \\
\text { City of }\end{array}$ \\
& June 30 & December 31 & June 30 & June 30 & August 30 & June 30 \\
\hline
\end{tabular}

Production Expenses

Steam Power Generation

Nuclear Power Generation

Hydraulic Power Generation

Other Power Generation

Purchased Power

Other Production Expenses

Total Production Expenses

Transmission Expenses .

Distribution Expenses ..........................................

Customer Accounts Expenses ...

Customer Service and Information

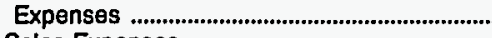

Sales Expenses ...................................................

Administrative and General

Expenses

0
0
0
0
14,104
0

0
0
0
0
8,811
3

$\begin{array}{rr}0 & 0 \\ 0 & 0 \\ 0 & 0 \\ 0 & 0 \\ 14,729 & 26,528 \\ 0 & 0\end{array}$

0
0
0
0
11,006
0

0
0
0
0
44,749
0

14,104

$\mathbf{8 , 8 1 3}$

14,729

26,528

11,006

44,749

0
1,739

0

0
979

0
2,699

0

587
0

0

3,884

1,480

185

0
0

0

93

76

372

0
0

Total Electrle Operation and

Malntenance Expenses

16,121

10,212

17,504

27,488

50,675

\section{Fuel Expenses in Operation}

Steam Power Generation

0

0

Nuclear Power Generation

Other Power Generation

Number of Elec Dept Employees

Regular Full-time

35

Part-time \& Temporary

Total Elec Dept Employees

Note: Totals may not equal sum of components because of independent rounding

Source: Energy Information Administration, Form EIA-412, "Annual Report of Public Electric Utilities."

\begin{tabular}{rrrrr}
16 & 24 & 13 & 13 & 91 \\
0 & 3 & 0 & 0 & 0 \\
16 & 27 & 13 & 13 & 91 \\
\hline
\end{tabular}

91

- 
Table 23. Electric Operation and Maintenance Expenses by Major U.S. Publicly Owned Electric Utility Within State, 1993 (Continued)

(Thousand Dollars)

\begin{tabular}{|c|c|c|c|c|c|c|}
\hline Item & $\begin{array}{c}\text { Georgia } \\
\text { Moultrie } \\
\text { City of }\end{array}$ & $\begin{array}{l}\text { Georgia } \\
\text { Municipal } \\
\text { Electric } \\
\text { Authority }\end{array}$ & $\begin{array}{l}\text { Georgia } \\
\text { Thomasville } \\
\text { City of }\end{array}$ & $\begin{array}{l}\text { Idaho } \\
\text { Idaho } \\
\text { Falls } \\
\text { City of }\end{array}$ & $\begin{array}{l}\text { Illinois } \\
\text { Batavia } \\
\text { City of }\end{array}$ & $\begin{array}{c}\text { Geneva } \\
\text { City of }\end{array}$ \\
\hline & September 30 & December 31 & December 31 & September 30 & December 31 & April 30 \\
\hline
\end{tabular}

\section{Productlon Expenses}

Steam Power Generation

Nuclear Power Generation

Hydraulic Power Generation

Other Power Generation

Purchased Power

Other Production Expenses .................................

Total Productlon Expenses

Transmission Expenses

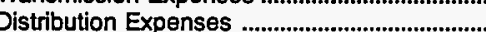

Customer Accounts Expenses

Customer Service and Information

Expenses

Expenses

Administrative and General

Expenses

Total Electric Operation and

Maintenance Expenses

$\begin{array}{rr}0 & 76,855 \\ 0 & 110,754 \\ 0 & 0 \\ 0 & 0 \\ 8,679 & 53,707 \\ 0 & 0\end{array}$

$8,679 \quad 241,316$

4,976
2,941

0
616
0

0

0

911

10,205

261,424

63,300

31,353

0

0

0

Nuclear Power Generation

Other Power Generation

...........

Number of Elec Dept Employees

Regular Full-time

16

Part-time \& Temporary

Total Elec Dept Employees

0
0
0
0
20,774
0

20,774

0
987

323

2
3

1,312

23,400

1,792

0
0
1,037
0
14,575
0

15,612

109

2,026

872

10
0

20,422

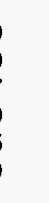

$\begin{array}{rr}0 & 0 \\ 0 & 0 \\ 0 & 0 \\ 0 & 0 \\ 11,598 & 5,695 \\ 0 & 0\end{array}$

11,598

5,695

0
896
277

0
1,352

277

35

0

37

275

277

13,046

7,396

Note: Totals may not equal sum of components because of independent rounding.

Source: Energy Information Administration, Form EIA-412, "Annual Report of Public Electric Utilities." 
Table 23. Electric Operation and Maintenance Expenses by Major U.S. Publicly Owned Electric Utility Within State, 1993 (Continued)

(Thousand Dollars)

\begin{tabular}{|c|c|c|c|c|c|c|}
\hline Item & $\begin{array}{c}\text { Illinois } \\
\text { Illinois } \\
\text { Municipal } \\
\text { Elec Agency } \\
\text { April } 30\end{array}$ & $\begin{array}{l}\text { Illinois } \\
\begin{array}{c}\text { Naperville } \\
\text { City of }\end{array} \\
\text { April } 30\end{array}$ & $\begin{array}{l}\text { Illinois } \\
\text { Rochelle } \\
\text { Municipal } \\
\text { Utilities } \\
\text { April } 30\end{array}$ & $\begin{array}{l}\text { Illinois } \\
\text { Springfield } \\
\text { City of } \\
\text { February } 28\end{array}$ & $\begin{array}{l}\text { Illinois } \\
\text { St Charles } \\
\text { City of } \\
\text { April } 30\end{array}$ & $\begin{array}{l}\text { Indiana } \\
\text { Anderson } \\
\text { City of } \\
\text { December } 31\end{array}$ \\
\hline 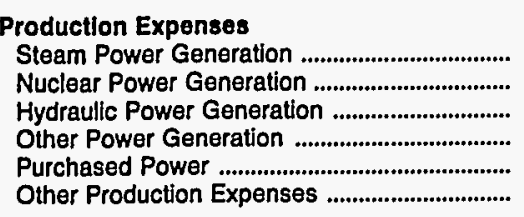 & $\begin{array}{r}6,914 \\
0 \\
0 \\
0 \\
32,576 \\
0\end{array}$ & $\begin{array}{r}0 \\
0 \\
0 \\
0 \\
31,778 \\
0\end{array}$ & $\begin{array}{r}2,625 \\
0 \\
0 \\
463 \\
4,443 \\
0\end{array}$ & $\begin{array}{r}44,109 \\
0 \\
0 \\
57 \\
226 \\
0\end{array}$ & $\begin{array}{r}0 \\
0 \\
0 \\
0 \\
17,506 \\
0\end{array}$ & $\begin{array}{r}0 \\
0 \\
0 \\
0 \\
25,218 \\
0\end{array}$ \\
\hline 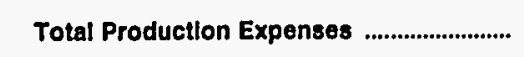 & 39,490 & 31,778 & 7,532 & 44,391 & 17,506 & 25,218 \\
\hline 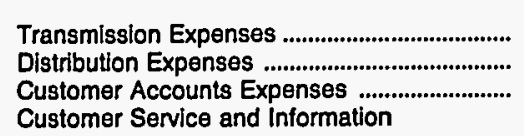 & $\begin{array}{r}5,639 \\
0 \\
0\end{array}$ & $\begin{array}{r}0 \\
3.835 \\
331\end{array}$ & $\begin{array}{r}4 \\
497 \\
117\end{array}$ & $\begin{array}{r}970 \\
5,785 \\
3,156\end{array}$ & $\begin{array}{r}0 \\
3,828 \\
0\end{array}$ & $\begin{array}{r}5 \\
2,820 \\
389\end{array}$ \\
\hline 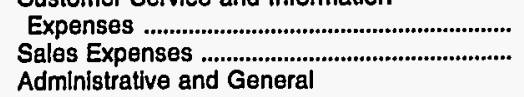 & $\begin{array}{l}0 \\
0\end{array}$ & $\begin{array}{r}976 \\
76\end{array}$ & $\begin{array}{l}0 \\
0\end{array}$ & $\begin{array}{r}397 \\
0\end{array}$ & $\begin{array}{l}0 \\
0\end{array}$ & $\begin{array}{l}0 \\
0\end{array}$ \\
\hline 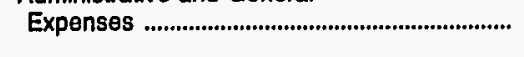 & 1,594 & 3,627 & 1,036 & 9,037 & 0 & 2,632 \\
\hline $\begin{array}{l}\text { Total Electric Operation and } \\
\text { Maintenance Expenses .................................. }\end{array}$ & 46,723 & 40,623 & 9,186 & 63,736 & 21,334 & 31,063 \\
\hline \multicolumn{7}{|l|}{ Fuel Expenses in Operation } \\
\hline 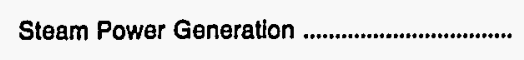 & 4,543 & 0 & 1,438 & 22,512 & 0 & 0 \\
\hline Nuclear Power Generation ........................................ & 0 & 0 & 0 & 0 & 0 & 0 \\
\hline 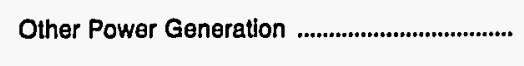 & 0 & 0 & 88 & 16 & 0 & 0 \\
\hline \multicolumn{7}{|l|}{ Number of Elec Dept Employees } \\
\hline 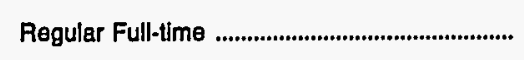 & 13 & 96 & 45 & 611 & 24 & 84 \\
\hline 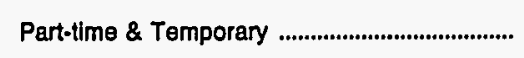 & 0 & 0 & 1 & 0 & 5 & 0 \\
\hline Total Elec Dept Employess ................................. & 13 & 96 & 46 & 611 & 29 & 84 \\
\hline
\end{tabular}

Note: Totals may not equal sum of components because of independent rounding.

Source: Energy Informatlon Administration, Form EIA-412, "Annual Report of Public Electric Utilities." 
Table 23. Electric Operation and Maintenance Expenses by Major U.S. Publicly Owned Electric Utility Within State, 1993 (Continued)

(Thousand Dollars)

\begin{tabular}{|c|c|c|c|c|c|c|}
\hline Item & $\begin{array}{l}\text { Indiana } \\
\text { Auburn } \\
\text { City of } \\
\text { December } 31\end{array}$ & $\begin{array}{l}\text { Indiana } \\
\text { Bluffton } \\
\text { City of } \\
\text { December } 31\end{array}$ & $\begin{array}{c}\text { Indiana } \\
\text { Crawtordsville } \\
\text { Elec } \\
\text { Lgt\&Pwr Co } \\
\text { December } 31\end{array}$ & $\begin{array}{c}\text { Indiana } \\
\text { Frankfort } \\
\text { City of } \\
\text { December } 31\end{array}$ & $\begin{array}{c}\text { Indiana } \\
\text { Greenfield } \\
\text { City of } \\
\text { December } 31\end{array}$ & $\begin{array}{c}\text { Indiana } \\
\text { Indiana } \\
\text { Municipal } \\
\text { Power Agency } \\
\text { December } 31\end{array}$ \\
\hline \multicolumn{7}{|l|}{ Production Expenses } \\
\hline 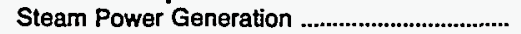 & 0 & 0 & 1,623 & 0 & 0 & 26,360 \\
\hline 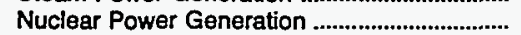 & 0 & 0 & 0 & 0 & 0 & 0 \\
\hline 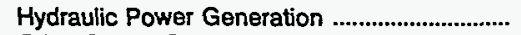 & 0 & 0 & 0 & 0 & 0 & 0 \\
\hline 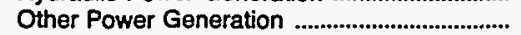 & 0 & 600 & 0 & 0 & 0 & 1,255 \\
\hline 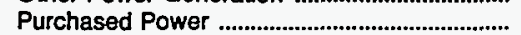 & 11,152 & 5,699 & 14,001 & 11,512 & 6,565 & 71,198 \\
\hline 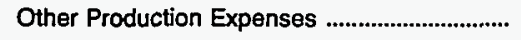 & 780 & 0 & 0 & 14 & 0 & 168 \\
\hline Total Production Expenses ............................... & 11,932 & 6,299 & 15,624 & 11,526 & 6,565 & 98,981 \\
\hline 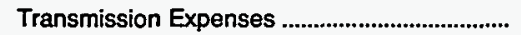 & 0 & 0 & 7 & 0 & 0 & 6,066 \\
\hline 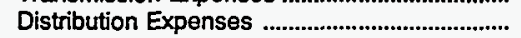 & 648 & 527 & 712 & 547 & 500 & 483 \\
\hline $\begin{array}{l}\text { Customer Accounts Expenses } \\
\text { Customer Service and Information }\end{array}$ & 24 & 31 & 198 & 185 & 140 & 0 \\
\hline 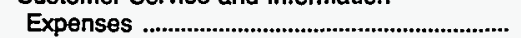 & 0 & 0 & 0 & 0 & 0 & 0 \\
\hline $\begin{array}{l}\text { Sales Expenses } \\
\text { Administrative and General }\end{array}$ & 0 & 0 & 0 & 0 & 0 & 0 \\
\hline 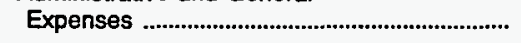 & 532 & 383 & 1,081 & 635 & 394 & 1,909 \\
\hline Total Electrlc Operation and & & & & & & \\
\hline 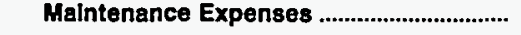 & 13,136 & 7,240 & 17,622 & 12,894 & 7,598 & 107,439 \\
\hline \multicolumn{7}{|l|}{ Fuel Expenses in Operation } \\
\hline 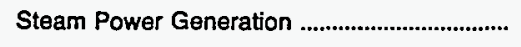 & 0 & 0 & 491 & 0 & 0 & 17,769 \\
\hline Nuclear Power Generation .................................... & 0 & 0 & 0 & 0 & 0 & 0 \\
\hline 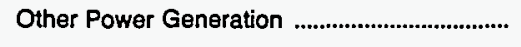 & 0 & 392 & 0 & 0 & 0 & 815 \\
\hline \multicolumn{7}{|l|}{ Number of Elec Dept Employees } \\
\hline Regular Full-time & 14 & 35 & 53 & 26 & 28 & 17 \\
\hline 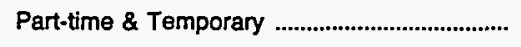 & 0 & 0 & 2 & 0 & 3 & 2 \\
\hline 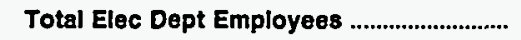 & 14 & 35 & 55 & 26 & 31 & 19 \\
\hline
\end{tabular}

Note: Totals may not equal sum of components because of independent rounding.

Source: Energy Information Administration, Form ElA-412, "Annual Report of Public Electric Utilities." 
Table 23. Electric Operation and Maintenance Expenses by Major U.S. Publicly Owned Electric Utility Within State, 1993 (Continued)

(Thousand Dollars)

\begin{tabular}{|c|c|c|c|c|c|c|}
\hline Item & $\begin{array}{l}\text { Indiana } \\
\text { Jasper } \\
\text { City of } \\
\text { December } 31\end{array}$ & $\begin{array}{c}\text { Indiana } \\
\text { Logansport } \\
\text { City of } \\
\text { December } 31\end{array}$ & $\begin{array}{c}\text { Indiana } \\
\text { Mishawaka } \\
\text { City of } \\
\text { December } 31\end{array}$ & $\begin{array}{c}\text { Indiana } \\
\text { Peru } \\
\text { City of } \\
\text { December } 31\end{array}$ & $\begin{array}{c}\text { Indiana } \\
\text { Richmond } \\
\text { City of } \\
\text { December } 31\end{array}$ & $\begin{array}{c}\text { Indiana } \\
\text { Washington } \\
\text { City of } \\
\text { December } 31\end{array}$ \\
\hline 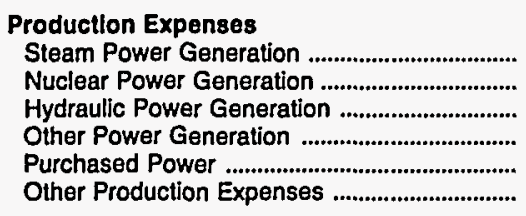 & $\begin{array}{r}1,803 \\
0 \\
0 \\
0 \\
9,554 \\
0\end{array}$ & $\begin{array}{r}5,683 \\
0 \\
0 \\
389 \\
5,787 \\
0\end{array}$ & $\begin{array}{r}0 \\
0 \\
0 \\
0 \\
17,992 \\
0\end{array}$ & $\begin{array}{r}595 \\
0 \\
0 \\
0 \\
5,919 \\
0\end{array}$ & $\begin{array}{r}13,061 \\
0 \\
0 \\
0 \\
13,364 \\
0\end{array}$ & $\begin{array}{r}0 \\
0 \\
0 \\
0 \\
6,693 \\
0\end{array}$ \\
\hline 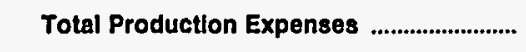 & 11,357 & 11,860 & 17,992 & 6,513 & 26,425 & 6,693 \\
\hline 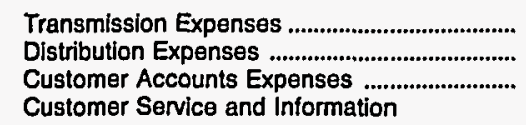 & $\begin{array}{r}0 \\
702 \\
71\end{array}$ & $\begin{array}{r}0 \\
1,505 \\
110\end{array}$ & $\begin{array}{r}0 \\
1,705 \\
563\end{array}$ & $\begin{array}{r}28 \\
620 \\
150\end{array}$ & $\begin{array}{r}29 \\
1,930 \\
481\end{array}$ & $\begin{array}{r}0 \\
641 \\
199\end{array}$ \\
\hline $\begin{array}{l}\text { Expenses } \\
\text { Sales Expenses } \\
\text { Administrative and General }\end{array}$ & $\begin{array}{l}0 \\
0\end{array}$ & $\begin{array}{r}24 \\
0\end{array}$ & $\begin{array}{l}0 \\
0\end{array}$ & $\begin{array}{l}0 \\
0\end{array}$ & $\begin{array}{r}22 \\
0\end{array}$ & $\begin{array}{l}0 \\
0\end{array}$ \\
\hline 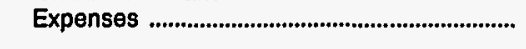 & 666 & 1,135 & 885 & 980 & 4,333 & 247 \\
\hline 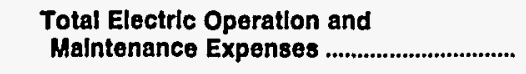 & 12,796 & 14,634 & 21,146 & 8,291 & 33,220 & 7,780 \\
\hline \multicolumn{7}{|l|}{ Fuel Expenses In Operation } \\
\hline 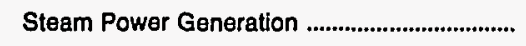 & 1,036 & 3,129 & 0 & 126 & 10.544 & 0 \\
\hline 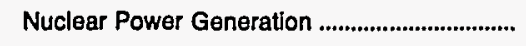 & 0 & 0 & 0 & 0 & 0 & 0 \\
\hline 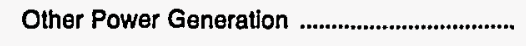 & 0 & 389 & 0 & 0 & 0 & 0 \\
\hline \multicolumn{7}{|l|}{ Number of Elec Dept Employees } \\
\hline Regular Full-time & 49 & 73 & 60 & 43 & 159 & 28 \\
\hline 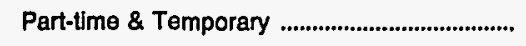 & 0 & 1 & 8 & 13 & 9 & 0 \\
\hline 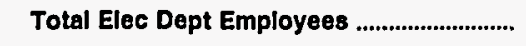 & 49 & 74 & 68 & 56 & 168 & 28 \\
\hline
\end{tabular}

Note: Totals may not equal sum of components because of independent rounding.

Source: Energy Information Administration, Form EIA-412, "Annual Report of Public Electric Utilities." 
Table 23. Electric Operation and Maintenance Expenses by Major U.S. Publicly Owned Electric Utility Within State, 1993 (Continued)

(Thousand Dollars)

\begin{tabular}{|c|c|c|c|c|c|c|}
\hline Item & $\begin{array}{l}\text { lowa } \\
\text { Ames } \\
\text { City of } \\
\text { June } 30\end{array}$ & $\begin{array}{c}\text { lowa } \\
\text { Cedar } \\
\text { Falls } \\
\text { City of } \\
\text { December } 31\end{array}$ & $\begin{array}{c}\text { lowa } \\
\text { Muscatine } \\
\text { City of } \\
\text { December } 31\end{array}$ & $\begin{array}{l}\text { lowa } \\
\text { Pella } \\
\text { City of } \\
\text { June } 30\end{array}$ & $\begin{array}{c}\text { Kansas } \\
\text { Chanute } \\
\text { City of } \\
\text { December } 31\end{array}$ & $\begin{array}{c}\text { Kansas } \\
\text { Coffeyville } \\
\text { City of } \\
\text { December } 31\end{array}$ \\
\hline \multicolumn{7}{|l|}{ Production Expenses } \\
\hline Steam Power Generation ........................................... & 8,048 & 4,393 & 23,620 & 2,958 & 0 & 3,893 \\
\hline 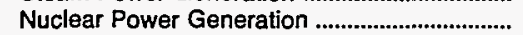 & & & & 0 & 0 & \\
\hline 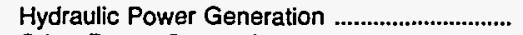 & 0 & 0 & 0 & 0 & 0 & 0 \\
\hline 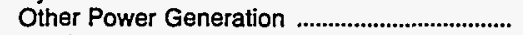 & 0 & $\mathbf{3 7}$ & 0 & 0 & 1,210 & 0 \\
\hline 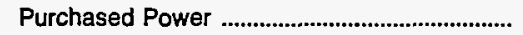 & 1,564 & 1,229 & 767 & 1,500 & 3,500 & 3,609 \\
\hline 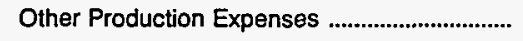 & 477 & 89 & 990 & 0 & 86 & 147 \\
\hline 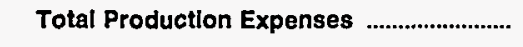 & 10,089 & 5,748 & 25,377 & 4,458 & 4,797 & 7,649 \\
\hline Transmission Expenses ........................................... & 0 & 428 & 1,894 & 0 & 697 & 0 \\
\hline 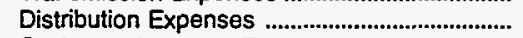 & 2,099 & 1,233 & 0 & 507 & 172 & 976 \\
\hline $\begin{array}{l}\text { Customer Accounts Expenses ............................... } \\
\text { Customer Service and Information }\end{array}$ & 309 & 334 & 422 & 44 & 45 & 0 \\
\hline 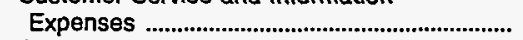 & 7 & 165 & 0 & 0 & 142 & 189 \\
\hline $\begin{array}{l}\text { Sales Expenses .............................................. } \\
\text { Administrative and General }\end{array}$ & 0 & 0 & 0 & 1 & 0 & 0 \\
\hline 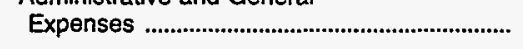 & 796 & 1,387 & 5,364 & 1,589 & 82 & 482 \\
\hline Total Electric Operation and & & & & & & \\
\hline 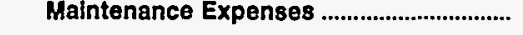 & 13,299 & 9,295 & 33,058 & 6,598 & 5,935 & $\mathbf{9 , 2 9 6}$ \\
\hline \multicolumn{7}{|l|}{ Fuel Expenses in Operation } \\
\hline 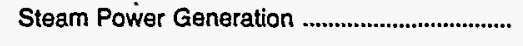 & 4,816 & 2,494 & 14,482 & 2,092 & 0 & 2,568 \\
\hline 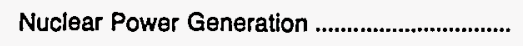 & 0 & 0 & 0 & 0 & 0 & 0 \\
\hline Other Power Generation & 0 & 16 & 0 & 0 & 317 & 0 \\
\hline \multicolumn{7}{|l|}{ Number of Elec Dept Employees } \\
\hline 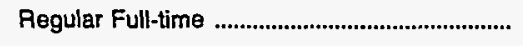 & 83 & 86 & 234 & 28 & 25 & 40 \\
\hline 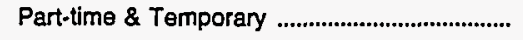 & 1 & 3 & 4 & 0 & 0 & 8 \\
\hline 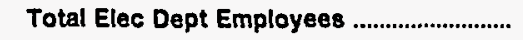 & 84 & 89 & 238 & 28 & 25 & 48 \\
\hline
\end{tabular}

Note: Totals may not equal sum of components because of independent rounding.

Source: Energy Information Administration, Form ElA-412, "Annual Report of Public Electric Utilities." 
Table 23. Electric Operation and Maintenance Expenses by Major U.S. Publicly Owned Electric Utillty Within State, 1993 (Continued)

(Thousand Dollars)

\begin{tabular}{|c|c|c|c|c|c|c|}
\hline Item & $\begin{array}{c}\text { Kansas } \\
\text { Garden } \\
\text { City City of } \\
\text { December } 31\end{array}$ & $\begin{array}{c}\text { Kansas } \\
\text { Kansas } \\
\text { City City of } \\
\text { December } 31\end{array}$ & $\begin{array}{l}\text { Kansas } \\
\text { Kansas } \\
\text { Municipal } \\
\text { Energy } \\
\text { Agency } \\
\text { December } 31\end{array}$ & $\begin{array}{c}\text { Kansas } \\
\text { McPherson } \\
\text { City of } \\
\text { December } 31\end{array}$ & $\begin{array}{l}\text { Kansas } \\
\text { Winfield } \\
\text { City of } \\
\text { December } 31\end{array}$ & $\begin{array}{l}\text { Kentucky } \\
\text { Bowling } \\
\text { Green } \\
\text { City of } \\
\text { June } 30\end{array}$ \\
\hline
\end{tabular}

Productlon Expenses

Steam Power Generation

Nuclear Power Generation ...................................

Hydraulic Power Generation

Other Power Generation

Purchased Power

(1)

Other Production Expenses

Total Production Expenses

$\begin{array}{rr}0 & 60,195 \\ 0 & \\ 0 & 136 \\ 0 & 5,224 \\ 8,892 & 1,286 \\ 31 & 66,8 \\ 8,923 & \end{array}$

Transmission Expenses

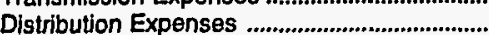

Customer Accounts Expenses

Customer Service and Information

Expenses ...

Eales Expenses

Administrative and General

Expenses

0
496
7

$0 \quad 452$

$7 \quad 9,420$

0
477

567

Total Electrlc Operation and

Malntenance Expenses

\section{and}

10,470
3,065

60,195

0
0

136

5,224

1,286

6,842

52
20

0

0

13,996

93,775

38,697

0

80

0
0
0
0
10,032
157

313
0
0
918
12,067
538

10,189

13,836

136

136
0
0

27
1,267

122

2

0
0

828

11,153

523

15,782

0
0
0

54
0
155

0
0
0
0
28,141
0

28,141

0

2,100

395

185

22

1,153

280

31,997

Fuel Expenses in Operation

Steam Power Generation

0

0

Nuclear Power Generation

0

16

878

0

878

16

981

0

0

0

Number of Elec Dept Employees

Part-time \& Temporary

16

5
1
6

60

$\begin{array}{rr}29 & 68 \\ 2 & 0 \\ 31 & 68\end{array}$

Note: Totals may not equal sum of components because of independent rounding

Source: Energy Information Administration, Form ElA-412. "Annual Report of Public Electric Utilities." 
Table 23. Electric Operation and Maintenance Expenses by Major U.S. Publicly Owned Electric Utility Within State, 1993 (Continued) (Thousand Dollars)

\begin{tabular}{|c|c|c|c|c|c|c|}
\hline Item & $\begin{array}{l}\text { Kentucky } \\
\text { Frankfort } \\
\text { City of } \\
\text { June } 30\end{array}$ & $\begin{array}{l}\text { Kentucky } \\
\text { Franklin } \\
\text { City of } \\
\text { June } 30\end{array}$ & $\begin{array}{l}\text { Kentucky } \\
\text { Glasgow } \\
\text { City of } \\
\text { June } 30\end{array}$ & $\begin{array}{l}\text { Kentucky } \\
\text { Henderson } \\
\text { City } \\
\text { Utility Comm } \\
\text { May } 31\end{array}$ & $\begin{array}{l}\text { Kentucky } \\
\text { Hopkinsville } \\
\text { City of } \\
\text { June } 30\end{array}$ & $\begin{array}{c}\text { Kentucky } \\
\begin{array}{c}\text { Madisonville } \\
\text { Municipal } \\
\text { Utils }\end{array} \\
\text { June } 30\end{array}$ \\
\hline 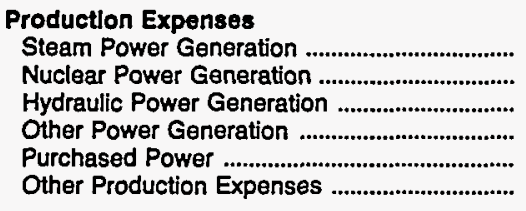 & $\begin{array}{r}0 \\
0 \\
0 \\
0 \\
18,002 \\
0\end{array}$ & $\begin{array}{r}0 \\
0 \\
0 \\
0 \\
7,708 \\
0\end{array}$ & $\begin{array}{r}0 \\
0 \\
0 \\
0 \\
12,311 \\
0\end{array}$ & $\begin{array}{r}10,969 \\
0 \\
0 \\
0 \\
422 \\
28\end{array}$ & $\begin{array}{r}0 \\
0 \\
0 \\
0 \\
16,276 \\
0\end{array}$ & $\begin{array}{r}0 \\
0 \\
0 \\
0 \\
8,178 \\
0\end{array}$ \\
\hline Total Production Expenses ......................... & 18,002 & 7,708 & 12,311 & 11,418 & 16,276 & 8,178 \\
\hline 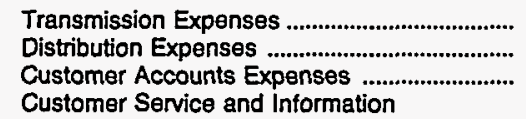 & $\begin{array}{r}37 \\
883 \\
338\end{array}$ & $\begin{array}{r}0 \\
447 \\
107\end{array}$ & $\begin{array}{r}0 \\
516 \\
152\end{array}$ & $\begin{array}{r}21 \\
1,008 \\
233\end{array}$ & $\begin{array}{r}0 \\
946 \\
296\end{array}$ & $\begin{array}{r}0 \\
763 \\
267\end{array}$ \\
\hline 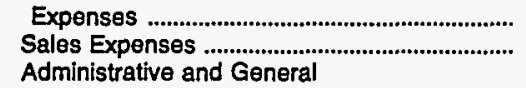 & $\begin{array}{l}0 \\
0\end{array}$ & $\begin{array}{l}34 \\
16\end{array}$ & $\begin{array}{r}118 \\
0\end{array}$ & $\begin{array}{l}0 \\
7\end{array}$ & $\begin{array}{l}35 \\
40\end{array}$ & $\begin{array}{l}0 \\
0\end{array}$ \\
\hline 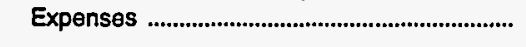 & 1,750 & 372 & 413 & 3,945 & 680 & 126 \\
\hline 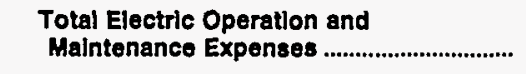 & 21,010 & 8,683 & 13,511 & 16,633 & 18,272 & 9,333 \\
\hline \multicolumn{7}{|l|}{ Fuel Expenses In Operation } \\
\hline 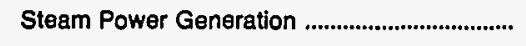 & 0 & 0 & 0 & 4,159 & 0 & 0 \\
\hline Nuclear Power Generation .................................... & 0 & 0 & 0 & 0 & 0 & 0 \\
\hline Other Power Generation ...................................... & 0 & 0 & 0 & 0 & 0 & 0 \\
\hline \multicolumn{7}{|l|}{ Number of Elec Dept Employees } \\
\hline 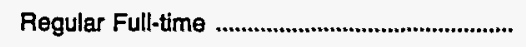 & 105 & 16 & 33 & 59 & 33 & 28 \\
\hline 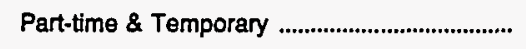 & 0 & 0 & 0 & 0 & 0 & 0 \\
\hline Total Elec Dept Employees ............................. & 105 & 16 & 33 & 59 & 33 & 28 \\
\hline
\end{tabular}

Note: Totals may not equal sum of components because of independent rounding.

Source: Energy Information Administration, Form EIA-412, "Annual Report of Public Electric Utilities." 
Table 23. Electric Operation and Maintenance Expenses by Major U.S. Publicly Owned Electric Utility Within State, 1993 (Continued)

(Thousand Dollars)

\begin{tabular}{c|c|c|c|c|c|c}
\hline & Kentucky & Kentucky & Kentucky & Kentucky & Louisiana & Louisiana \\
Item & $\begin{array}{c}\text { Mayfield } \\
\text { City of }\end{array}$ & $\begin{array}{c}\text { Murray } \\
\text { City of }\end{array}$ & $\begin{array}{c}\text { Owensboro } \\
\text { City of }\end{array}$ & $\begin{array}{c}\text { Paducah } \\
\text { City of }\end{array}$ & $\begin{array}{c}\text { Alexandria } \\
\text { City of }\end{array}$ & $\begin{array}{c}\text { Lafayette } \\
\text { City of }\end{array}$ \\
June 30 & June 30 & May 31 & June 30 & April 30 & October 31 \\
\hline
\end{tabular}

Productlon Expenses

Steam Power Generation

Nuclear Power Generation

Hydraulic Power Generation

Other Power Generation

Other Produc

Total Production Expenses

Transmission Expenses

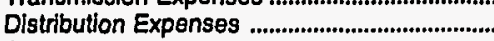

Customer Accounts Expenses ...........................

Customer Service and Information

Expenses

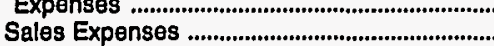

Administrative and General

Expenses

Total Electric Operation and

Melntenance Expenses..

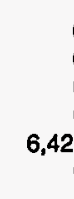

0
0
0
0
6,429
0

6,429

0
578

578
184

50
9

443

7,693
0
0
0
0
10,002
0

10,002

0
658

658
158

16
6

392

11,232

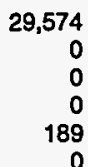

29,763

254

2,127

657

0
0

3,495

36,297

24,561

0

0

158

9

167

24

24

0

0
0
0
0
23,510
0

970
0
0
0
21,278
0

12,435

0

56,900

69,334

3,766

2,771

1,689

0

3,695

81,272

22

22
0

0

0
293

0

0
8,732

0

0

Total Elec Dept Employees

Note: Totals may not equal sum of components because of independent rounding.

Source: Energy Information Administration, Form EIA-412, "Annual Report of Public Electric Utilities." 
Table 23. Electric Operation and Maintenance Expenses by Major U.S. Publicly Owned Electric Utility Within State, 1993 (Continued)

(Thousand Dollars)

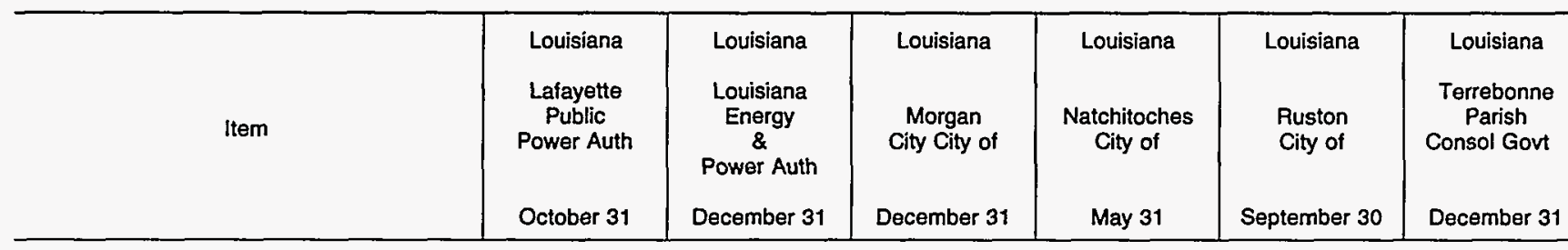

Production Expenses

Steam Power Generation

Nuclear Power Generation

Hydraulic Power Generation

Other Power Generation

Purchased Power

Other Production Expenses

Total Production Expenses

es

Transmission Expenses .

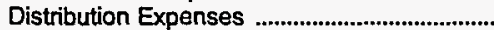

Customer Accounts Expenses

Customer Service and Information

Expenses

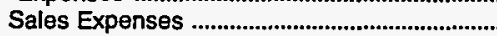

Administrative and General

Expenses

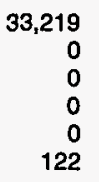

\section{0,050}

0
0
0
25,813
0

17
0
0
0
7,116
12

0
0
0
0
7,510
1,524

5,974

0

33,341

45,863

7,146

1,524

44
1,301

9,034

7,319

1,098

5,076

$\begin{array}{rr}0 & 5,076 \\ 0 & 0 \\ 0 & 0\end{array}$

678
0

0
0

1,481

1,4812
412

$$
\begin{array}{r}
0 \\
816
\end{array}
$$

816
391

0

$\begin{array}{ll}0 & 0 \\ 0 & 0\end{array}$

0

1,848

2,313

444

0
0

0
0

832

35,189

53,252

8,267

12,857

8,525

Fuel Expenses in Operation

Steam Power Generation

Nuclear Power Generation

30,575

15,804

0

0

0

0

966

Other Power Generation

0

0

0

o

0

0

0

0

Number of Elec Dept Employees

Regular Full-time

172

60

9
1

37
1
38

53

39

24

10

38

1

0

195

60

54

39

Note: Totals may not equal sum of components because of independent rounding.

Source: Energy Information Administration, Form ElA-412, "Annual Report of Public Electric Utilities." 
Table 23. Electric Operation and Maintenance Expenses by Major U.S. Publicly Owned Electric Utility Within State, 1993 (Continued) (Thousand Dollars)

\begin{tabular}{|c|c|c|c|c|c|c|}
\hline Item & $\begin{array}{l}\text { Maryland } \\
\text { Easton } \\
\text { Utilities } \\
\text { Comm } \\
\text { June } 30\end{array}$ & $\begin{array}{l}\text { Maryland } \\
\text { Hagerstown } \\
\text { City of } \\
\text { June } 30\end{array}$ & $\begin{array}{c}\text { Massachusetts } \\
\text { Braintree } \\
\text { Town of } \\
\text { December } 31\end{array}$ & $\begin{array}{c}\text { Massachusetts } \\
\text { Chicopee } \\
\text { City of } \\
\text { December } 31\end{array}$ & $\begin{array}{l}\text { Massachusetts } \\
\text { Concord } \\
\text { Town of } \\
\text { December } 31\end{array}$ & $\begin{array}{c}\text { Massachusetts } \\
\text { Danvers } \\
\text { Town of } \\
\text { December } 31\end{array}$ \\
\hline 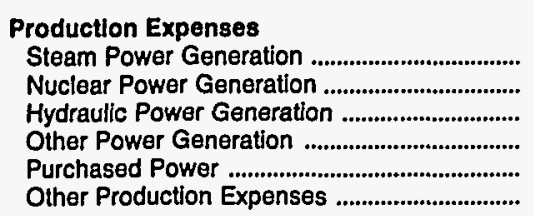 & $\begin{array}{r}0 \\
0 \\
0 \\
1,890 \\
5,383 \\
187\end{array}$ & $\begin{array}{r}0 \\
0 \\
0 \\
0 \\
11,254 \\
0\end{array}$ & $\begin{array}{r}4,303 \\
0 \\
0 \\
46 \\
16,231 \\
1,305\end{array}$ & $\begin{array}{r}0 \\
2,450 \\
0 \\
49 \\
15,348 \\
261\end{array}$ & $\begin{array}{r}0 \\
0 \\
0 \\
0 \\
8,305 \\
532\end{array}$ & $\begin{array}{r}0 \\
0 \\
0 \\
0 \\
23,346 \\
0\end{array}$ \\
\hline 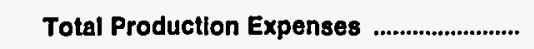 & 7,460 & 11,254 & 21,885 & 18,108 & 8,836 & 23,346 \\
\hline $\begin{array}{l}\text { Transmission Expenses ......................................... } \\
\text { Distribution Expenses .................................. } \\
\text { Customer Accounts Expenses ....................... } \\
\text { Customer Service and Information }\end{array}$ & $\begin{array}{r}69 \\
645 \\
210\end{array}$ & $\begin{array}{r}0 \\
867 \\
429\end{array}$ & $\begin{array}{r}89 \\
1,521 \\
528\end{array}$ & $\begin{array}{r}78 \\
2,982 \\
697\end{array}$ & $\begin{array}{r}42 \\
193 \\
281\end{array}$ & $\begin{array}{r}1,410 \\
1,463 \\
487\end{array}$ \\
\hline 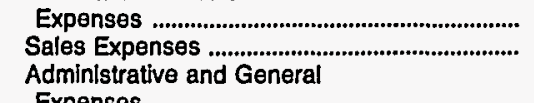 & $\begin{array}{l}0 \\
0\end{array}$ & $\begin{array}{l}6 \\
0\end{array}$ & $\begin{array}{r}0 \\
113\end{array}$ & $\begin{array}{r}130 \\
0\end{array}$ & $\begin{array}{r}52 \\
3\end{array}$ & $\begin{array}{l}0 \\
0\end{array}$ \\
\hline 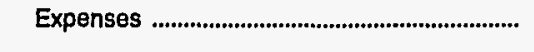 & 1,019 & 850 & 2,398 & 2,995 & 870 & 1,391 \\
\hline 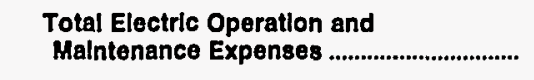 & 9,402 & 13,406 & 26,534 & 24,990 & 10,279 & 28,097 \\
\hline \multicolumn{7}{|l|}{ Fuel Expenses in Operation } \\
\hline 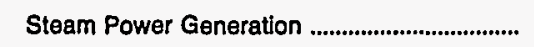 & 0 & 0 & 2,480 & 0 & 0 & 0 \\
\hline 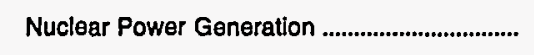 & 0 & 0 & 0 & 426 & 0 & 0 \\
\hline 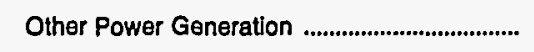 & 959 & 0 & 6 & 12 & 0 & 0 \\
\hline \multicolumn{7}{|l|}{ Number of Elec Dept Employees } \\
\hline 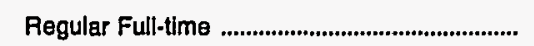 & 64 & 36 & 79 & 73 & 23 & 40 \\
\hline 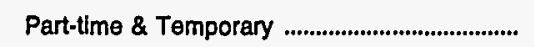 & 1 & 1 & 0 & 2 & 4 & 2 \\
\hline Total Elec Dept Employees .............................. & 65 & 37 & 79 & 75 & 27 & 42 \\
\hline
\end{tabular}

Note: Totals may not equal sum of components because of independent rounding.

Source: Energy Information Administration, Form EIA-412, "Annual Report of Public Electric Utilities." 
Table 23. Electric Operation and Maintenance Expenses by Major U.S. Publicly Owned Electric Utility Within State, 1993 (Continued)

(Thousand Dollars)

\begin{tabular}{|c|c|c|c|c|c|c|}
\hline Item & $\begin{array}{l}\text { Massachusetts } \\
\text { Hingham } \\
\text { City of } \\
\text { December } 31\end{array}$ & $\begin{array}{l}\text { Massachusetts } \\
\text { Holyoke } \\
\text { City of } \\
\text { December } 31\end{array}$ & $\begin{array}{l}\text { Massachusetts } \\
\text { Hudson } \\
\text { Town of } \\
\text { December } 31\end{array}$ & $\begin{array}{l}\text { Massachusetts } \\
\text { Littleton } \\
\text { Town of } \\
\text { December } 31\end{array}$ & $\begin{array}{l}\text { Massachusetts } \\
\text { Mansfield } \\
\text { Town of } \\
\text { December } 31\end{array}$ & $\begin{array}{l}\text { Massachusetts } \\
\text { Massachusetts } \\
\text { Mun } \\
\text { Whls } \\
\text { Elec Co } \\
\text { December } 31\end{array}$ \\
\hline 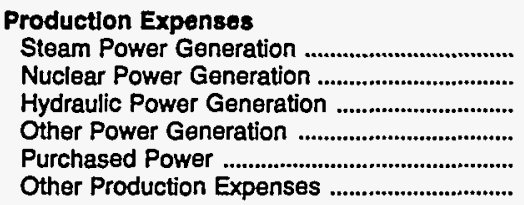 & $\begin{array}{r}0 \\
0 \\
0 \\
0 \\
9,207 \\
88\end{array}$ & $\begin{array}{r}803 \\
0 \\
283 \\
0 \\
17,298 \\
0\end{array}$ & $\begin{array}{r}0 \\
111 \\
0 \\
552 \\
22,189 \\
54\end{array}$ & $\begin{array}{r}123 \\
0 \\
0 \\
0 \\
11,244 \\
134\end{array}$ & $\begin{array}{r}0 \\
0 \\
0 \\
0 \\
15,685 \\
0\end{array}$ & $\begin{array}{r}699 \\
28,405 \\
0 \\
13,280 \\
69,921 \\
28\end{array}$ \\
\hline 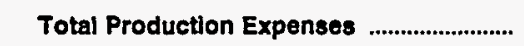 & 9,294 & 18,383 & 22,907 & 11,502 & 15,685 & 112,333 \\
\hline 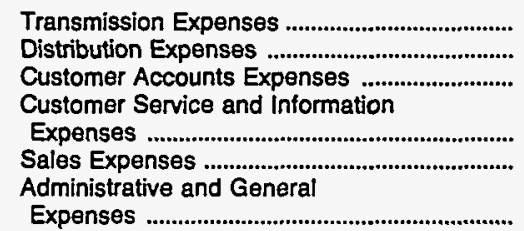 & $\begin{array}{r}487 \\
807 \\
350 \\
0 \\
0 \\
710\end{array}$ & $\begin{array}{r}825 \\
1,654 \\
1,093 \\
\\
0 \\
6\end{array}$ & $\begin{array}{r}923 \\
349 \\
271 \\
0 \\
12\end{array}$ & $\begin{array}{r}536 \\
824 \\
254 \\
0 \\
0\end{array}$ & $\begin{array}{r}482 \\
758 \\
186 \\
0 \\
0\end{array}$ & $\begin{array}{r}4,827 \\
0 \\
0\end{array}$ \\
\hline 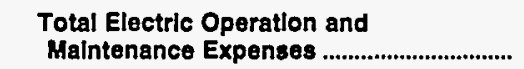 & 11,647 & 24,013 & 25,567 & 14,565 & 17,668 & 132,052 \\
\hline \multicolumn{7}{|l|}{ Fuel Exponses in Operation } \\
\hline 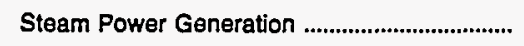 & 0 & 316 & 0 & 0 & 0 & 410 \\
\hline 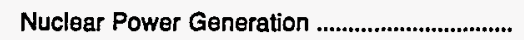 & 0 & 0 & 42 & 0 & 0 & 12,112 \\
\hline 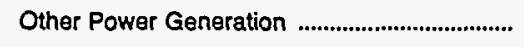 & 0 & 0 & 72 & 0 & 0 & 7,540 \\
\hline \multicolumn{7}{|l|}{ Number of Elec Dept Employees } \\
\hline Regular Full-time & 25 & 76 & 34 & 28 & 21 & 132 \\
\hline 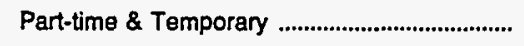 & 1 & 2 & 0 & 3 & 0 & 1 \\
\hline 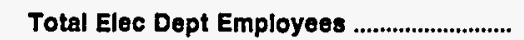 & 28 & 78 & 34 & 31 & 21 & 133 \\
\hline
\end{tabular}

Note: Totals may not equal sum of components because of independent rounding.

Source: Energy Information Administration, Form EIA-412, "Annual Report of Public Electric Utilities." 
Table 23. Electric Operation and Maintenance Expenses by Major U.S. Publicly Owned Electric Utility Within State, 1993 (Continued)

(Thousand Dollars)

\begin{tabular}{|c|c|c|c|c|c|c|}
\hline Item & $\begin{array}{c}\text { Massachusetts } \\
\text { Middleborough } \\
\text { Town of }\end{array}$ & $\begin{array}{c}\text { Massachusetts } \\
\text { North } \\
\text { Attleborough } \\
\text { Town of }\end{array}$ & $\begin{array}{c}\text { Massachusetts } \\
\text { Norwood } \\
\text { City of }\end{array}$ & $\begin{array}{c}\text { Massachusetts } \\
\text { Peabody } \\
\text { City of }\end{array}$ & $\begin{array}{c}\text { Massachusetts } \\
\text { Reading } \\
\text { Town of }\end{array}$ & $\begin{array}{c}\text { Massachusetts } \\
\text { Shrewsbury } \\
\text { Town of }\end{array}$ \\
\hline & December 31 & December 31 & June 30 & December 31 & December 31 & December 31 \\
\hline
\end{tabular}

\section{Production Expenses}

Steam Power Generation

Nuclear Power Generation

Hydraullic Power Generation

Other Power Generation

Other Production Expenses

Total Production Expenses

Transmission Expenses

Distribution Expenses

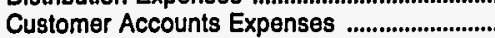

Customer Service and Information

Expenses ........

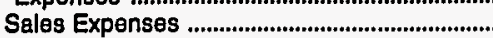

Administrative and General

Expenses

0
0
0
0
11,896
186

186

12,082

703

1,301

584

0

24

1,133

15,827

243
0
0
0
11,551
181

0
0
0
0
20,950
0

11,975

20,950

0
1,306

467

0

29

1,527

1,233

15,275

24,280

32,175

0
0
0
397
26,402
166

0

0

0

38,581

1,037

26,965

39,619

176
+1351

$\mathbf{5 6 5}$

8
2766

1,526

0

251

1,769

45,940

\section{Fuel Expenses In Operation}

Steam Power Generation

0

0

Nuclear Power Generation

Other Power Generation

Number of Elec Dept Employees

Regular Full-time

Part-time \& Temporary

Total Eloc Dept Employees

188
0
0

0
0
0

0
0

0

0

26

Note: Totals may not equal sum of components because of independent rounding.

Source: Energy Information Administration, Form ElA-412, "Annual Report of Public Electric Utilities." 
Table 23. Electric Operation and Maintenance Expenses by Major U.S. Publicly Owned Electric Utility Within State, 1993 (Continued)

(Thousand Dollars)

\begin{tabular}{|c|c|c|c|c|c|c|}
\hline Item & $\begin{array}{l}\text { Massachusetts } \\
\text { Taunton } \\
\text { City of } \\
\text { December } 31\end{array}$ & $\begin{array}{l}\text { Massachusetts } \\
\text { Wakefield } \\
\text { Town of } \\
\text { December } 31\end{array}$ & $\begin{array}{l}\text { Massachusetts } \\
\text { Wellesley } \\
\text { Town of } \\
\text { December } 31\end{array}$ & $\begin{array}{l}\text { Massachusetts } \\
\text { Westfield } \\
\text { City of } \\
\text { December } 31\end{array}$ & $\begin{array}{l}\text { Michigan } \\
\text { Bay } \\
\text { City City of } \\
\text { June } 30\end{array}$ & $\begin{array}{l}\text { Michigan } \\
\text { Coldwater } \\
\text { Board } \\
\quad \text { of } \\
\text { Public Util } \\
\text { June } 30\end{array}$ \\
\hline 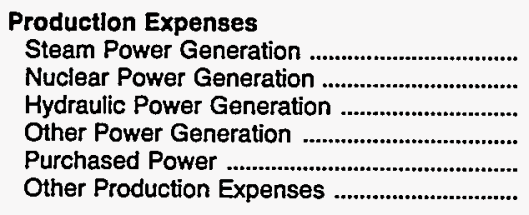 & $\begin{array}{r}6,839 \\
0 \\
0 \\
203 \\
13,670 \\
63\end{array}$ & $\begin{array}{r}0 \\
0 \\
0 \\
0 \\
11,563 \\
0\end{array}$ & $\begin{array}{r}0 \\
0 \\
0 \\
0 \\
11,088 \\
0\end{array}$ & $\begin{array}{r}0 \\
0 \\
0 \\
0 \\
22,120 \\
319\end{array}$ & $\begin{array}{r}0 \\
0 \\
0 \\
0 \\
9,778 \\
0\end{array}$ & $\begin{array}{r}100 \\
0 \\
0 \\
106 \\
8,209 \\
0\end{array}$ \\
\hline 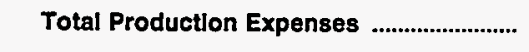 & 20,776 & 11,563 & 11,088 & 22,439 & 9,778 & 8,415 \\
\hline 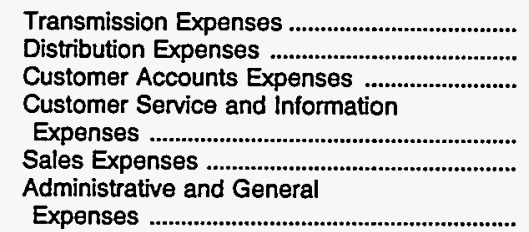 & $\begin{array}{r}259 \\
2,601 \\
2,098\end{array}$ & $\begin{array}{r}0 \\
1,051 \\
367\end{array}$ & $\begin{array}{r}235 \\
1,454 \\
385\end{array}$ & $\begin{array}{r}1,318 \\
2,135 \\
1,731 \\
0 \\
23\end{array}$ & $\begin{array}{r}0 \\
2,363 \\
0\end{array}$ & $\begin{array}{r}0 \\
420 \\
163\end{array}$ \\
\hline $\begin{array}{l}\text { Total Electric Operation and } \\
\text { Malntenance Expenses ................................. }\end{array}$ & 26,402 & 14,041 & 13,475 & 29,907 & 13,650 & 9,659 \\
\hline \multicolumn{7}{|l|}{ Fuel Expenses in Operation } \\
\hline 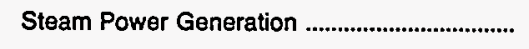 & 1,955 & 0 & 0 & 0 & 0 & 0 \\
\hline 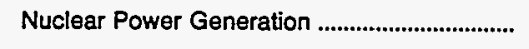 & 0 & 0 & 0 & 0 & 0 & 0 \\
\hline Other Power Generation & 192 & 0 & 0 & 0 & 0 & 5 \\
\hline \multicolumn{7}{|l|}{ Number of Elec Dept Employees } \\
\hline Regular Full-time & 162 & 33 & 48 & 64 & 46 & 18 \\
\hline 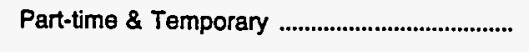 & 0 & 2 & 0 & 0 & 0 & 0 \\
\hline Total Elec Dept Employees ............................... & 162 & 35 & 48 & 64 & 46 & 18 \\
\hline
\end{tabular}

Note: Totals may not equal sum of components because of independent rounding.

Source: Energy Information Administration, Form ElA-412, "Annual Report of Public Electric Utilities." 
Table 23. Electric Operation and Maintenance Expenses by Major U.S. Publicly Owned Electric Utility Within State, 1993 (Continued) (Thousand Dollars)

\begin{tabular}{|c|c|c|c|c|c|c|}
\hline Item & $\begin{array}{l}\text { Michigan } \\
\text { Detroit } \\
\text { City of } \\
\text { June } 30\end{array}$ & $\begin{array}{c}\text { Michigan } \\
\text { Grand Haven } \\
\text { City of } \\
\text { June } 30\end{array}$ & $\begin{array}{c}\text { Michigan } \\
\text { Hillsdale } \\
\text { Board } \\
\text { of } \\
\text { Public Wks } \\
\text { June } 30\end{array}$ & $\begin{array}{l}\text { Michigan } \\
\text { Holland } \\
\text { City of } \\
\text { June } 30\end{array}$ & $\begin{array}{l}\text { Michigan } \\
\text { Lansing } \\
\text { City of } \\
\text { June } 30\end{array}$ & $\begin{array}{l}\text { Michigan } \\
\text { Marquette } \\
\text { City of } \\
\text { June } 30\end{array}$ \\
\hline 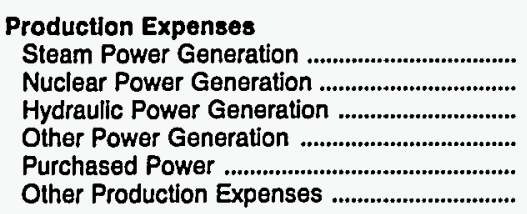 & $\begin{array}{r}14,941 \\
0 \\
0 \\
0 \\
15,332 \\
0\end{array}$ & $\begin{array}{r}9,286 \\
0 \\
0 \\
87 \\
895 \\
181\end{array}$ & $\begin{array}{r}0 \\
0 \\
0 \\
548 \\
7,329 \\
0\end{array}$ & $\begin{array}{r}10,876 \\
0 \\
0 \\
271 \\
12,841 \\
0\end{array}$ & $\begin{array}{r}50,418 \\
0 \\
24 \\
0 \\
23,833 \\
0\end{array}$ & $\begin{array}{r}7,477 \\
0 \\
120 \\
36 \\
331 \\
0\end{array}$ \\
\hline Total Production Expenses ........................... & 30,273 & 10,450 & 7,877 & 23,988 & 74,275 & 7,964 \\
\hline 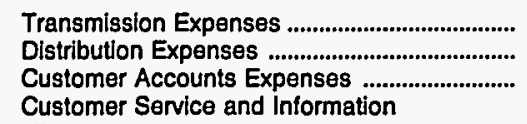 & $\begin{array}{r}1,290 \\
11,402 \\
0\end{array}$ & $\begin{array}{r}0 \\
641 \\
253\end{array}$ & $\begin{array}{r}0 \\
425 \\
14\end{array}$ & $\begin{array}{r}0 \\
1,394 \\
441\end{array}$ & $\begin{array}{l}1,284 \\
5,245 \\
2,880\end{array}$ & $\begin{array}{r}1 \\
844 \\
361\end{array}$ \\
\hline 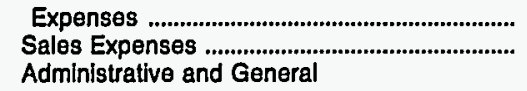 & $\begin{array}{l}0 \\
0\end{array}$ & $\begin{array}{l}0 \\
8\end{array}$ & $\begin{array}{l}1 \\
0\end{array}$ & $\begin{array}{r}169 \\
21\end{array}$ & $\begin{array}{r}0 \\
230\end{array}$ & $\begin{array}{l}24 \\
14\end{array}$ \\
\hline 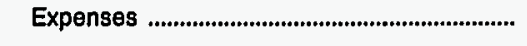 & 11,248 & 1,376 & 260 & 938 & 23,947 & 2,219 \\
\hline 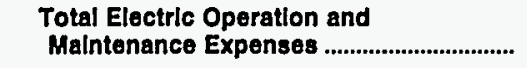 & 54,213 & 12,728 & 8,578 & 26,950 & 107,860 & 11,427 \\
\hline \multicolumn{7}{|l|}{ Fuel Expenses In Operatlon } \\
\hline 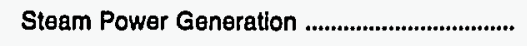 & 10,412 & 7,145 & 0 & 7,616 & 24,849 & 5,480 \\
\hline 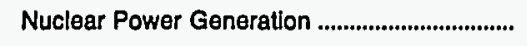 & 0 & 0 & 0 & 0 & 0 & 0 \\
\hline 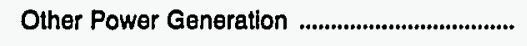 & 0 & 21 & 18 & 126 & 0 & 5 \\
\hline \multicolumn{7}{|l|}{ Number of Eloc Dept Employees } \\
\hline Regular Full-time & 119 & 64 & 30 & 99 & 721 & 87 \\
\hline 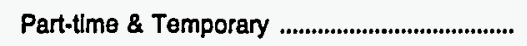 & 0 & 1 & 0 & 6 & 0 & 2 \\
\hline Total Elec Dopt Employees .................................. & 119 & 65 & 30 & 105 & 721 & 89 \\
\hline
\end{tabular}

Note: Totals may not equal sum of components because of independent rounding.

Source: Energy Information Administration, Form EIA-412, "Annual Report of Public Electric Utilities." 
Table 23. Electric Operation and Maintenance Expenses by Major U.S. Publicly Owned Electric Utility Within State, 1993 (Continued)

(Thousand Dollars)

\begin{tabular}{|c|c|c|c|c|c|c|}
\hline Item & $\begin{array}{c}\text { Michigan } \\
\text { Michigan } \\
\text { Public } \\
\text { Power Agency } \\
\text { December } 31\end{array}$ & $\begin{array}{l}\text { Michigan } \\
\text { Michigan } \\
\text { South } \\
\text { Central } \\
\text { Pwr Agy } \\
\text { June } 30\end{array}$ & $\begin{array}{l}\text { Michigan } \\
\text { Sturgis } \\
\text { City of } \\
\text { September } 30\end{array}$ & $\begin{array}{l}\text { Michigan } \\
\text { Traverse } \\
\text { City City of } \\
\text { June } 30\end{array}$ & $\begin{array}{c}\text { Michigan } \\
\text { Wyandotte } \\
\text { Municipal } \\
\text { Serv Comm } \\
\text { September } 30\end{array}$ & $\begin{array}{l}\text { Michigan } \\
\text { Zeeland } \\
\text { City of } \\
\text { June } 30\end{array}$ \\
\hline 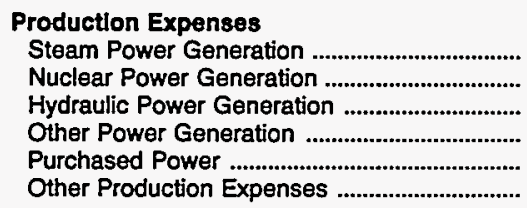 & $\begin{array}{r}32,398 \\
0 \\
0 \\
0 \\
14,799 \\
6,477\end{array}$ & $\begin{array}{r}10,796 \\
0 \\
0 \\
0 \\
4,357 \\
0\end{array}$ & $\begin{array}{r}0 \\
0 \\
70 \\
823 \\
6,527 \\
0\end{array}$ & $\begin{array}{r}2,099 \\
0 \\
60 \\
0 \\
6,343 \\
5\end{array}$ & $\begin{array}{r}11,781 \\
0 \\
0 \\
0 \\
0 \\
0\end{array}$ & $\begin{array}{r}0 \\
0 \\
0 \\
958 \\
4,439 \\
0\end{array}$ \\
\hline 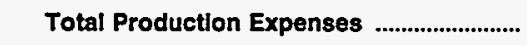 & 53,674 & 15,153 & 7,419 & 8,507 & 11,781 & 5,398 \\
\hline 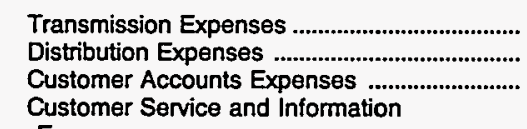 & $\begin{array}{r}2,025 \\
0 \\
0\end{array}$ & $\begin{array}{r}167 \\
0 \\
0\end{array}$ & $\begin{array}{r}64 \\
649 \\
178\end{array}$ & $\begin{array}{r}0 \\
1,383 \\
12\end{array}$ & $\begin{array}{l}729 \\
202 \\
191\end{array}$ & $\begin{array}{r}411 \\
120 \\
0\end{array}$ \\
\hline 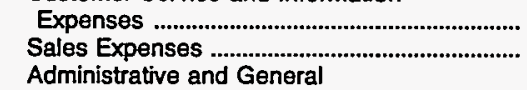 & $\begin{array}{l}0 \\
0\end{array}$ & $\begin{array}{l}0 \\
0\end{array}$ & $\begin{array}{l}0 \\
0\end{array}$ & $\begin{array}{r}254 \\
52\end{array}$ & $\begin{array}{l}415 \\
103\end{array}$ & $\begin{array}{l}0 \\
0\end{array}$ \\
\hline 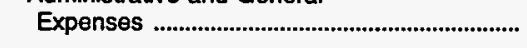 & 4,380 & 1,320 & 934 & 1,317 & 2,493 & 539 \\
\hline 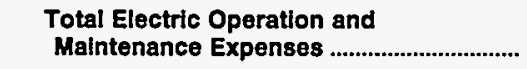 & 60,079 & 16,640 & 9,244 & 11,526 & 15,913 & 6,468 \\
\hline \multicolumn{7}{|l|}{ Fuel Expenses in Operation } \\
\hline 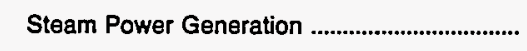 & 25,059 & 7,548 & 0 & 735 & 7,741 & 0 \\
\hline 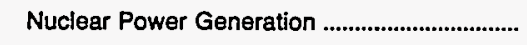 & 0 & 0 & 0 & 0 & 0 & 0 \\
\hline 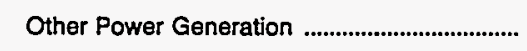 & 0 & 0 & 657 & 0 & 0 & 456 \\
\hline \multicolumn{7}{|l|}{ Number of Elec Dept Employees } \\
\hline Regular Full-time & 9 & 51 & 29 & 53 & 88 & 17 \\
\hline 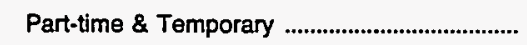 & 0 & 1 & 0 & 0 & 0 & 1 \\
\hline 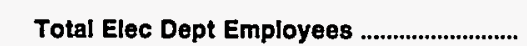 & 9 & 52 & 29 & 53 & 88 & 18 \\
\hline
\end{tabular}

Note: Totals may not equal sum of components because of independent rounding.

Source: Energy Information Administration, Form EIA-412, "Annual Report of Public Electric Utilities." 
Table 23. Electric Operation and Maintenance Expenses by Major U.S. Publicly Owned Electric Utility Within State, 1993 (Continued)

(Thousand Dollars)

\begin{tabular}{|c|c|c|c|c|c|c|}
\hline Item & $\begin{array}{l}\text { Minnesota } \\
\text { Alexandria } \\
\text { City of } \\
\text { December } 31\end{array}$ & $\begin{array}{l}\text { Minnesota } \\
\text { Anoka } \\
\text { City of } \\
\text { December } 31\end{array}$ & $\begin{array}{l}\text { Minnesota } \\
\text { Austin } \\
\text { City of } \\
\text { December } 31\end{array}$ & $\begin{array}{l}\text { Minnesota } \\
\text { Brainerd } \\
\text { City of } \\
\text { December } 31\end{array}$ & $\begin{array}{l}\text { Minnesota } \\
\text { Chaska } \\
\text { City of } \\
\text { December } 31\end{array}$ & $\begin{array}{l}\text { Minnesota } \\
\text { Fairmont } \\
\text { Public } \\
\text { Utilities } \\
\text { Comm } \\
\text { December } 31\end{array}$ \\
\hline 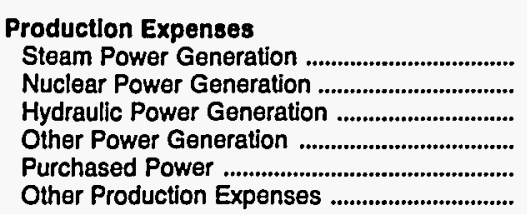 & $\begin{array}{r}0 \\
0 \\
0 \\
68 \\
4,205 \\
1,007\end{array}$ & $\begin{array}{r}0 \\
0 \\
0 \\
0 \\
7,801 \\
0\end{array}$ & $\begin{array}{r}3,306 \\
0 \\
0 \\
0 \\
13,714 \\
50\end{array}$ & $\begin{array}{r}0 \\
0 \\
0 \\
0 \\
5,424 \\
140\end{array}$ & $\begin{array}{r}0 \\
0 \\
0 \\
0 \\
5,717 \\
0\end{array}$ & $\begin{array}{r}1,113 \\
0 \\
0 \\
0 \\
8,382 \\
0\end{array}$ \\
\hline Total Production Expenses ........................... & 5,280 & 7,801 & 17,069 & 5,564 & 5,717 & 9,495 \\
\hline 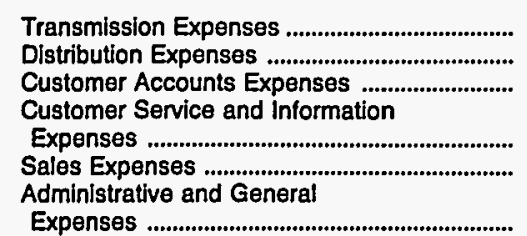 & $\begin{array}{r}0 \\
473 \\
226 \\
3 \\
0 \\
480\end{array}$ & $\begin{array}{r}0 \\
614 \\
437 \\
\\
0 \\
0 \\
456\end{array}$ & $\begin{array}{r}0 \\
784 \\
222 \\
87 \\
0 \\
864\end{array}$ & $\begin{array}{r}0 \\
854 \\
0\end{array}$ & $\begin{array}{r}0 \\
530 \\
0\end{array}$ & $\begin{array}{r}9 \\
544 \\
0\end{array}$ \\
\hline 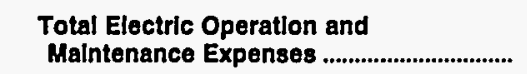 & 6,462 & 9,307 & 19,026 & 6,673 & 6,577 & 10,121 \\
\hline \multicolumn{7}{|l|}{ Fuel Expenses in Operation } \\
\hline 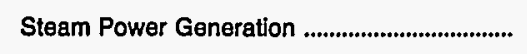 & 0 & 0 & 1,882 & 0 & 0 & 48 \\
\hline 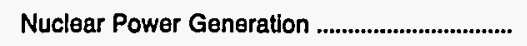 & 0 & 0 & 0 & 0 & 0 & 0 \\
\hline 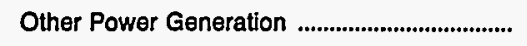 & 35 & 0 & 0 & 0 & 0 & 0 \\
\hline \multicolumn{7}{|l|}{ Number of Elec Dept Employees } \\
\hline Regular Full-time & 24 & 19 & 53 & 10 & 11 & 24 \\
\hline 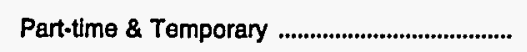 & 0 & 6 & 8 & 4 & 0 & 0 \\
\hline Total Elec Dept Employees ................................. & 24 & 25 & 61 & 14 & 11 & 24 \\
\hline
\end{tabular}

Note: Totals may not equal sum of components because of independent rounding.

Source: Energy Information Administration, Form ElA-412, "Annual Report of Public Electric Utilities." 
Table 23. Electric Operation and Maintenance Expenses by Major U.S. Publicly Owned Electric Utility Within State, 1993 (Continued)

(Thousand Dollars)

\begin{tabular}{c|c|c|c|c|c|c}
\hline & Minnesota & Minnesota & Minnesota & Minnesota & Minnesota & Minnesota \\
& $\begin{array}{c}\text { Hutchinson } \\
\text { Utilities } \\
\text { Comm }\end{array}$ & $\begin{array}{c}\text { Marshall } \\
\text { City of }\end{array}$ & $\begin{array}{c}\text { Moorhead } \\
\text { City of }\end{array}$ & $\begin{array}{c}\text { New Ulm } \\
\text { Public } \\
\text { Utilities } \\
\text { Comm } \\
\text { Demecember 31 }\end{array}$ & $\begin{array}{c}\text { Northern } \\
\text { Municipal } \\
\text { Power Agny }\end{array}$ & $\begin{array}{c}\text { Owatonna } \\
\text { City of }\end{array}$ \\
& December 31 & December 31 & December 31 & December 31 & December 31 \\
\hline
\end{tabular}

Production Expenses

Steam Power Generation

Nuclear Power Generation

ower Generation

Purchased Power

Total Production Expenses

Transmission Expenses

Distribution Expense

Customer Accounts Expenses ............................

Customer Service and Information

Expenses ....

Sales Expent

Administrative and General

Expenses

Total Electric Operation and

Malntenance Expenses .

0
0
0
1,177
5,366
0

0
0
0
0
8,325
0

6,543

64
305

305

106

19

847

7,885

772

0

665

11,046

\section{Fuel Expenses in Operation}

Steam Power Generation ..................................

Nuclear Power Generation

Other Power Generation

Number of Elec Dept Employees

Regular Full-time

Part-time \& Temporary

Total Elec Dept Employees

0
0
65

2

0

2

1,232
0
0

47

2

48
10

0

10

0

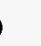

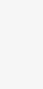

3,124
0
0
0
2,665
0

5,789

30
408

408
75

20

9,150

7,467

13,590

12,655

0

0

0
0

12,655

726

0
0

0

209

52

358

$\begin{array}{rr}7,321 & 0 \\ 0 & 0 \\ 0 & 0\end{array}$

Note: Totals may not equal sum of components because of independent rounding

Source: Energy Information Administration, Form ElA-412, "Annual Report of Public Electric Utilities." 
Table 23. Electric Operation and Maintenance Expenses by Major U.S. Publicly Owned Electric Utility Within State, 1993 (Continued)

(Thousand Dollars)

\begin{tabular}{|c|c|c|c|c|c|c|}
\hline Item & $\begin{array}{c}\text { Minnesota } \\
\text { Rochester } \\
\text { Public } \\
\text { Utilities } \\
\text { December } 31\end{array}$ & $\begin{array}{c}\text { Minnesota } \\
\text { Shakopee } \\
\text { Public } \\
\text { Utilities } \\
\text { Comm } \\
\text { December } 31\end{array}$ & $\begin{array}{l}\text { Minnesota } \\
\text { Southern } \\
\text { Minnesota } \\
\text { Mun P } \\
\text { Agny } \\
\text { December } 31\end{array}$ & $\begin{array}{c}\text { Minnesota } \\
\text { Western } \\
\text { Minnesota } \\
\text { Mun } \\
\text { Pwr Agny } \\
\text { December } 31\end{array}$ & $\begin{array}{c}\text { Minnesota } \\
\text { Willmar } \\
\text { Municipal } \\
\text { Utils Comm } \\
\text { December } 31\end{array}$ & $\begin{array}{l}\text { Mississippi } \\
\text { Aberdeen } \\
\text { City of } \\
\text { June } 30\end{array}$ \\
\hline 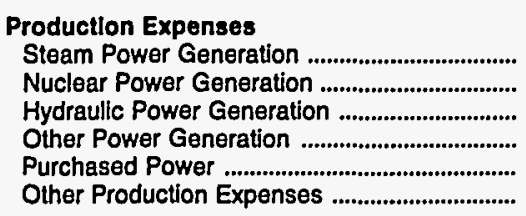 & $\begin{array}{r}5,338 \\
0 \\
70 \\
209 \\
48,705 \\
299\end{array}$ & $\begin{array}{r}0 \\
0 \\
0 \\
0 \\
5,198 \\
0\end{array}$ & $\begin{array}{r}33,671 \\
0 \\
0 \\
0 \\
15,499 \\
970\end{array}$ & $\begin{array}{r}17,536 \\
0 \\
0 \\
0 \\
0 \\
0\end{array}$ & $\begin{array}{r}1,968 \\
0 \\
0 \\
0 \\
4,174 \\
0\end{array}$ & $\begin{array}{r}0 \\
0 \\
0 \\
0 \\
6,729 \\
0\end{array}$ \\
\hline Total Production Expenses ............................. & 54,620 & 5,198 & 50,140 & 17,536 & 6,142 & 6,729 \\
\hline $\begin{array}{l}\text { Transmission Expenses ......................................... } \\
\text { Distribution Expenses ..................................... } \\
\text { Customer Accounts Expenses ..................... } \\
\text { Customer Service and Information }\end{array}$ & $\begin{array}{r}155 \\
2,143 \\
925\end{array}$ & $\begin{array}{r}0 \\
631 \\
132\end{array}$ & $\begin{array}{r}483 \\
0 \\
0\end{array}$ & $\begin{array}{r}562 \\
0 \\
0\end{array}$ & $\begin{array}{r}36 \\
641 \\
164\end{array}$ & $\begin{array}{r}0 \\
250 \\
112\end{array}$ \\
\hline $\begin{array}{l}\text { Expenses } \\
\text { Sales Expenses } \\
\text { Administrative and General }\end{array}$ & $\begin{array}{r}213 \\
14\end{array}$ & $\begin{array}{l}0 \\
0\end{array}$ & $\begin{array}{l}0 \\
0\end{array}$ & $\begin{array}{l}0 \\
0\end{array}$ & $\begin{array}{l}0 \\
0\end{array}$ & $\begin{array}{l}42 \\
29\end{array}$ \\
\hline 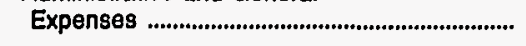 & 3,717 & 259 & 3,882 & 3,287 & 1,033 & 210 \\
\hline $\begin{array}{l}\text { Total Electrlc Operation and } \\
\text { Malntenance Expenses ................................. }\end{array}$ & 61,787 & 6,220 & 54,505 & 21,385 & 8,016 & 7,372 \\
\hline \multicolumn{7}{|l|}{ Fuel Expenses In Operation } \\
\hline 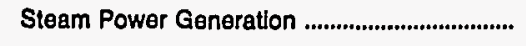 & 3,057 & 0 & 22,160 & 9,651 & 1,273 & 0 \\
\hline 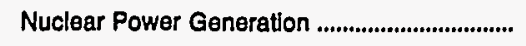 & 0 & 0 & 0 & 0 & 0 & 0 \\
\hline 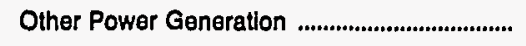 & 42 & 0 & 0 & 0 & 0 & 0 \\
\hline \multicolumn{7}{|l|}{ Number of Elec Dept Employees } \\
\hline 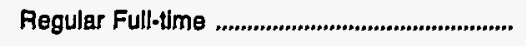 & 168 & 13 & 37 & 0 & 45 & 13 \\
\hline 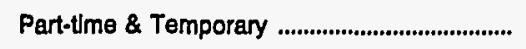 & 0 & 7 & 0 & 0 & 0 & 0 \\
\hline Total Eloc Dept Employees .............................. & 168 & 20 & 37 & 0 & 45 & 13 \\
\hline
\end{tabular}

Totals may not equal sum of components

Source: Energy Informatlon Administration, Form EIA-412, "Annual Report of Public Electric Utilities." 
Table 23. Electric Operation and Maintenance Expenses by Major U.S. Publicly Owned Electric Utility Within State, 1993 (Continued) (Thousand Dollars)

\begin{tabular}{|c|c|c|c|c|c|c|}
\hline Item & $\begin{array}{l}\text { Mississippi } \\
\text { Clarksdale } \\
\text { City of } \\
\text { September } 30\end{array}$ & $\begin{array}{l}\text { Mississippi } \\
\text { Columbus } \\
\text { City of } \\
\text { June } 30\end{array}$ & $\begin{array}{l}\text { Mississippi } \\
\text { Greenwood } \\
\text { Utilities } \\
\text { Comm } \\
\text { September } 30\end{array}$ & $\begin{array}{l}\text { Mississippi } \\
\text { Holly } \\
\text { Springs } \\
\text { City of } \\
\text { June } 30\end{array}$ & $\begin{array}{l}\text { Mississippi } \\
\text { Louisville } \\
\text { Electric } \\
\text { System } \\
\text { June } 30\end{array}$ & $\begin{array}{l}\text { Mississippi } \\
\text { Municipal } \\
\text { Energy } \\
\text { Agency } \\
\text { of MS } \\
\text { September } 30\end{array}$ \\
\hline 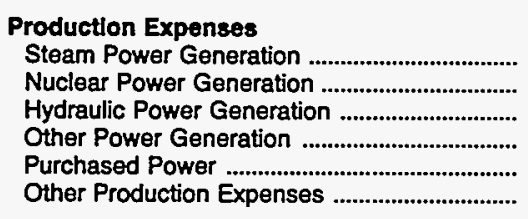 & $\begin{array}{r}2,195 \\
0 \\
0 \\
0 \\
6,401 \\
16\end{array}$ & $\begin{array}{r}0 \\
0 \\
0 \\
0 \\
20,333 \\
0\end{array}$ & $\begin{array}{r}1,708 \\
0 \\
0 \\
0 \\
9,862 \\
0\end{array}$ & $\begin{array}{r}0 \\
0 \\
0 \\
0 \\
9,108 \\
0\end{array}$ & $\begin{array}{r}0 \\
0 \\
0 \\
0 \\
6,714 \\
0\end{array}$ & $\begin{array}{r}0 \\
0 \\
0 \\
0 \\
28,042 \\
0\end{array}$ \\
\hline 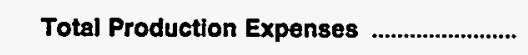 & 8,612 & 20,333 & 11,570 & 9,108 & 6,714 & 28,042 \\
\hline 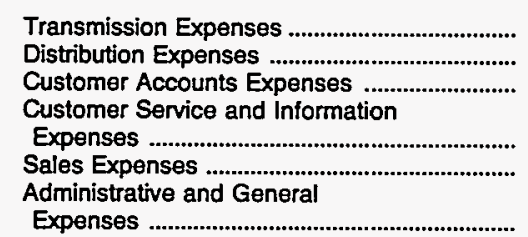 & $\begin{array}{r}0 \\
312 \\
177\end{array}$ & $\begin{array}{r}0 \\
893 \\
216\end{array}$ & $\begin{array}{r}0 \\
676 \\
189\end{array}$ & $\begin{array}{r}0 \\
632 \\
223\end{array}$ & $\begin{array}{r}0 \\
295 \\
95\end{array}$ & $\begin{array}{r}2,741 \\
0 \\
0\end{array}$ \\
\hline 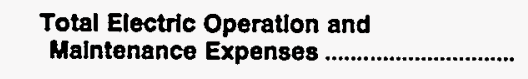 & 9,855 & 22,049 & 13,400 & 10,297 & 7,391 & 31,309 \\
\hline \multicolumn{7}{|l|}{ Fuel Expenses in Operation } \\
\hline 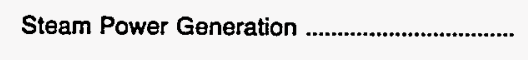 & 1,534 & 0 & 616 & 0 & 0 & 0 \\
\hline 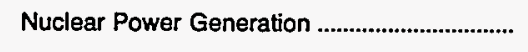 & 0 & 0 & 0 & 0 & 0 & 0 \\
\hline 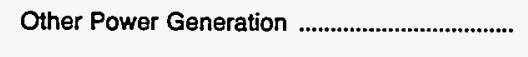 & 0 & 0 & 0 & 0 & 0 & 0 \\
\hline \multicolumn{7}{|l|}{ Number of Elec Dept Employees } \\
\hline Regular Full-time & 37 & 32 & 78 & 42 & 13 & 4 \\
\hline 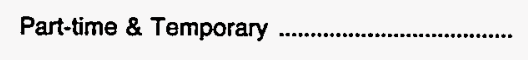 & 0 & 0 & 2 & 0 & 0 & 1 \\
\hline 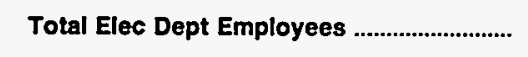 & 37 & 32 & 80 & 42 & 13 & 5 \\
\hline
\end{tabular}

Note: Totals may not equal sum of components because of independent rounding.

Source: Energy Information Administration, Form ElA-412, "Annual Report of Public Electric Utilities." 
Table 23. Electric Operation and Maintenance Expenses by Major U.S. Publicly Owned Electric Utility Within State, 1993 (Continued)

(Thousand Dollars)

\begin{tabular}{c|c|c|c|c|c|c}
\hline & Mississippi & Mississippi & Mississippi & Mississippi & Mississippi & Missouri \\
Item & $\begin{array}{c}\text { New Albany } \\
\text { City of }\end{array}$ & $\begin{array}{c}\text { Oxford } \\
\text { City of }\end{array}$ & $\begin{array}{c}\text { Starkville } \\
\text { City of }\end{array}$ & $\begin{array}{c}\text { Tupelo } \\
\text { City of }\end{array}$ & $\begin{array}{c}\text { Point } \\
\text { City of }\end{array}$ & $\begin{array}{c}\text { Carthage } \\
\text { City of }\end{array}$ \\
& June 30 & June 30 & June 30 & June 30 & June 30 & June 30 \\
\hline
\end{tabular}

\section{Production Expenses}

Steam Power Generation.

Nuclear Power Generation ..................................

Hydraulic Power Generation

Other Power Generation

Other Production Expenses

Total Production Expenses

Transmission Expenses .

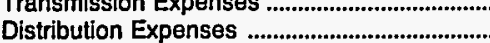

Customer Accounts Expenses ..........................

Customer Service and Information

Expenses

Sales Expenses

Administrative and General

Expenses

Total Electric Operation and

Malntenance Expenses

\section{Fuel Expenses In Operation}

Steam Power Generation

Nuclear Power Generation

Other Power Generation

Number of Elec Dept Employees

Regular Full-time

Part-time \& Temporary

Total Elec Dept Employees

0
0
0
0
10,797
0

0
0
0
0
6,566
0

10,797

0
677

204

4

12

247

11,940

\section{6,566}

0
310

148

19

39

181

7,263

0
0
0
0
13,297
0

13,297

0
654

183

17

12

273

14,436

0
0
0
0
27,540
0

27,540

4

739
337

337

63

58

422

29,163

$\begin{array}{rr}0 & 0 \\ 0 & 0 \\ 0 & 0 \\ 0 & 405 \\ 8,028 & 6,208 \\ 0 & 68\end{array}$

8,028

6,682

0

453

131

2
0

477

7,744

Note: Totals may not equal sum of components because of independent rounding.

Source: Energy Information Administration, Form ElA-412, "Annual Report of Public Electric Utilities." 
Table 23. Electric Operation and Maintenance Expenses by Major U.S. Publicly Owned Electric Utility Within State, 1993 (Continued) (Thousand Dollars)

\begin{tabular}{c|c|c|c|c|c|c}
\hline & Missouri & Missouri & Missouri & Missouri & Missouri & Missouri \\
& $\begin{array}{c}\text { Columbia } \\
\text { City of }\end{array}$ & $\begin{array}{c}\text { Hannibal } \\
\text { City of }\end{array}$ & $\begin{array}{c}\text { Independence } \\
\text { City of }\end{array}$ & $\begin{array}{c}\text { Kennett } \\
\text { City of }\end{array}$ & $\begin{array}{c}\text { Kirkwood } \\
\text { City of }\end{array}$ & $\begin{array}{c}\text { Lebanon } \\
\text { City of }\end{array}$ \\
September 30 & June 30 & June 30 & June 30 & March 31 & October 31 \\
\hline
\end{tabular}

\section{Production Expenses}

Steam Power Generation

Nuclear Power Generation

Hydraulic Power Generation

Other Power Generation

Purchased Power

Other Production Expenses

Total Production Expenses

Transmission Expenses

Distribution Expenses ..................

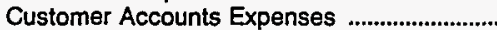

Customer Service and Information

Expenses

Sales Expenses

Administrative and General

Expenses

Total Electric Operation and

Maintenance Expenses

\section{Fuel Expenses In Operation}

Steam Power Generation

Nuclear Power Generation

Other Power Generation

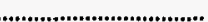

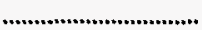

...................................

Number of Elec Dept Employees

Regular Full-time

Part-time \& Temporary

3,946
0
0
0
25,633
40

0
0
0
0
7,315

29,618

0

$$
\begin{array}{r}
0 \\
2,774
\end{array}
$$

1,165

$$
0
$$

7,315

552

114

23

70

2,783

622

36,340

8,696

0
0
0
0
5
0

5,988

0
0
945

18,707

492

26,131

2,227

4736

4,736
1,776

188

0

3,863

38,921

0
0
0
407
2,589
0

0
0
0
407
589
0

2,996

0
695

695

0

0

383

4,074

0
0
0
0
7,233
0

0

0
0
0

6,470

0

6,470

0
1,291

0

0

280

8,040

2,355
0
0

0

1,671

0

0

0

0

0

0

130

11

0

Total Elec Dept Employees

Note: Totals may not equal sum of components because of independent rounding.

Source: Energy Information Administration, Form EIA-412, "Annual Report of Public Electric Utilities." 
Table 23. Electric Operation and Maintenance Expenses by Major U.S. Publicly Owned Electric Utility Within State, 1993 (Continued) (Thousand Dollars)

\begin{tabular}{|c|c|c|c|c|c|c|}
\hline Item & $\begin{array}{l}\text { Missouri } \\
\text { Marshall } \\
\text { City of }\end{array}$ & $\begin{array}{l}\text { Missouri } \\
\text { Monett } \\
\text { City of }\end{array}$ & $\begin{array}{l}\text { Missouri } \\
\text { Poplar } \\
\text { Bluff } \\
\text { City of }\end{array}$ & $\begin{array}{l}\text { Missouri } \\
\text { Rolla } \\
\text { City of }\end{array}$ & $\begin{array}{l}\text { Missouri } \\
\text { Sikeston } \\
\text { City of }\end{array}$ & $\begin{array}{l}\text { Missouri } \\
\text { Springfield } \\
\text { City of }\end{array}$ \\
\hline & September 30 & March 31 & December 31 & September 30 & May 31 & September 30 \\
\hline
\end{tabular}

\section{Production Expenses}

Steam Power Generation

Nuclear Power Generation

Hydraulic Power Generation

Other Power Generation

Purchased Power...

Other Production Expenses

Total Production Expenses

Transmission Expenses

Distribution Expenses ..........................................

Customer Accounts Expenses ..........................

Customer Service and Information

Expenses

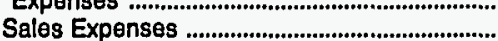

Administrative and General

Expenses

Total Electric Operatlon and

Malntenance Expenses

Fuel Expenses In Operation

Steam Power Generation

1,528

Nuclear Power Generation

Other Power Generation

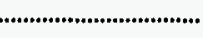

.................

Number of Elec Dept Employees

Regular Full-time

Part-time \& Temporary

59

Total Elec Dept Employees

2,896

0
0
0
1,589
0

0
0
0
0
4,459
0

4,486

7
538

368

0
0

425

5,823

4,459

0

335

0

0

7

4,801

0
0
0
26
4,788
121

0
0
0
0
8,645
0

4,935

8,645

0

386

141

0
0

409

1,392

7,256

9,580

23,308

39,017

0

1,749

9,811

50,577

27,738

256

6,942

1,619

0
0

7,573

2,687

66,967

31,648

Note: Totals may not equal sum of components because of independent rounding

Source: Energy Information Administration, Form EIA-412, "Annual Report of Public Electric Utilities." 
Table 23. Electric Operation and Maintenance Expenses by Major U.S. Publicly Owned Electric Utility Within State, 1993 (Continued)

(Thousand Dollars)

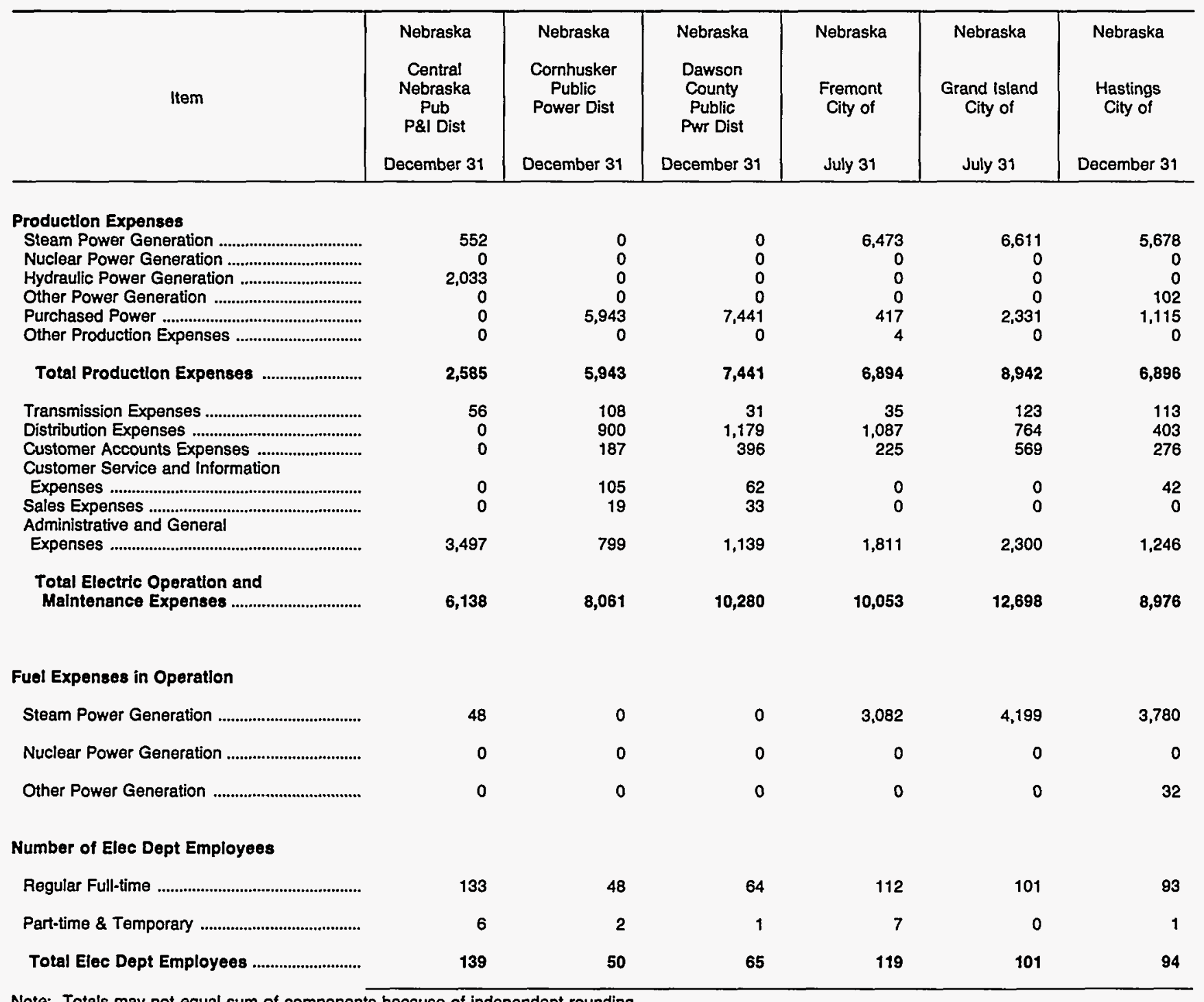

Note: Totals may not equal sum of components because of independent rounding.

Source: Energy Information Administration, Form ElA-412, "Annual Report of Public Electric Utilities." 
Table 23. Electric Operation and Maintenance Expenses by Major U.S. Publicly Owned Electric Utility Within State, 1993 (Continued) (Thousand Dollars)

\begin{tabular}{|c|c|c|c|c|c|c|}
\hline Item & $\begin{array}{l}\text { Nebraska } \\
\text { Lincoln } \\
\text { Electric } \\
\text { System } \\
\text { December } 31\end{array}$ & $\begin{array}{c}\text { Nebraska } \\
\text { Loup } \\
\text { River } \\
\text { Public } \\
\text { Power Dist } \\
\text { December } 31\end{array}$ & $\begin{array}{c}\text { Nebraska } \\
\text { Municipal } \\
\text { Energy } \\
\text { Agency } \\
\text { of NE } \\
\text { March } 31\end{array}$ & $\begin{array}{c}\text { Nebraska } \\
\text { Nebraska } \\
\text { Public } \\
\text { Power } \\
\text { District } \\
\text { December } 31\end{array}$ & $\begin{array}{c}\text { Nebraska } \\
\text { Norris } \\
\text { Public } \\
\text { Power } \\
\text { District } \\
\text { December } 31\end{array}$ & $\begin{array}{c}\text { Nebraska } \\
\text { North } \\
\text { Platto } \\
\text { City of } \\
\text { July } 31\end{array}$ \\
\hline
\end{tabular}

\section{Production Expenses}

Steam Power Generation

Nuclear Power Generation

Hydraulic Power Generation

Other Power Generatior

Purchased Power ......................................................

Other Production Expenses

Total Production Expenses

Transmission Expenses

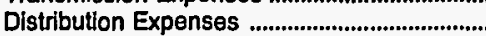

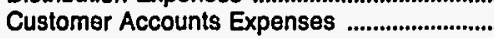

Customer Service and Information

Expenses ...

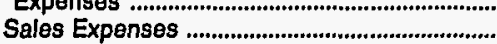

Adminlstrative and General

Expenses

Total Electrlc Operation and

Malntenance Expenses

Fuel Expenses In Operatton

Steam Power Generation

Nuclear Power Generation

6,979

Other Power Generation

...

Number of Elec Dept Employees

Regular Full-time

Part-time \& Temporary

Total Elec Dept Employees
12,930

0
1,054

48,787

1,001

63,772

1,890

5,358

2,092

1,602

5,841

80,555
420

396

0

0

0

0
0
1,159
0
24,897

24,897

26,056

252

942
486

109

30

2,044

29,920

2,117

17
0
0

17,730

0

19,847

4,334

0

0

0

2,126

26,306

313,198

15,927

0
0

104,771
99,487

2,423

1,828

36,650
804

245,962

13,260

12,787

7,265

2,257

4,864

26,803

12,518
0

12,518

75

1,807

434

216

879

0

393

1,359

73,194

18,914

257

0

2,246

72

35

17

127

1

0

124

2,373

73

35

Note: Totals may not equal sum of components because of independent rounding.

Source: Energy Information Administration, Form EIA-412, "Annual Report of Public Electric Utilities." 
Table 23. Electric Operation and Maintenance Expenses by Major U.S. Publicly Owned Electric Utility Within State, 1993 (Continued)

(Thousand Dollars)

\begin{tabular}{|c|c|c|c|c|c|c|}
\hline Item & $\begin{array}{c}\text { Nebraska } \\
\text { Omaha Public } \\
\text { Power } \\
\text { District } \\
\text { December } 31\end{array}$ & $\begin{array}{c}\text { Nebraska } \\
\text { Southern } \\
\text { Nebraska Rural } \\
\text { P P D } \\
\text { December } 31\end{array}$ & $\begin{array}{l}\text { Nevada } \\
\text { Colorado } \\
\text { River } \\
\text { Comm } \\
\text { of Nevada } \\
\text { June } 30\end{array}$ & $\begin{array}{l}\text { New Jersey } \\
\text { Vineland } \\
\text { City of } \\
\text { June } 30\end{array}$ & $\begin{array}{c}\text { New Mexico } \\
\text { Farmington } \\
\text { City of } \\
\text { June } 30\end{array}$ & $\begin{array}{c}\text { New Mexico } \\
\text { Gallup } \\
\text { City of } \\
\text { June } 30\end{array}$ \\
\hline 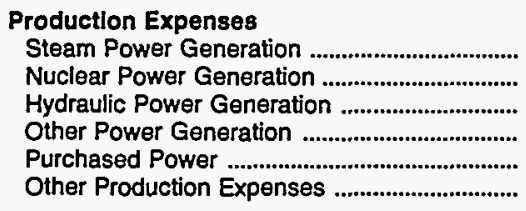 & $\begin{array}{r}75,655 \\
100,315 \\
0 \\
853 \\
-17,624 \\
11,496\end{array}$ & $\begin{array}{r}0 \\
0 \\
0 \\
0 \\
12,472 \\
0\end{array}$ & $\begin{array}{r}0 \\
0 \\
0 \\
0 \\
28,355 \\
0\end{array}$ & $\begin{array}{r}5,869 \\
0 \\
0 \\
241 \\
17,518 \\
82\end{array}$ & $\begin{array}{r}9,041 \\
0 \\
530 \\
0 \\
2,461 \\
215\end{array}$ & $\begin{array}{r}0 \\
0 \\
0 \\
0 \\
9,335 \\
0\end{array}$ \\
\hline Total Production Expenses ......................... & 170,696 & 12,472 & 28,355 & 23,711 & 12,246 & 9,335 \\
\hline 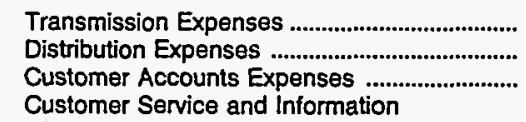 & $\begin{array}{r}3,628 \\
27,939 \\
10,723\end{array}$ & $\begin{array}{r}42 \\
1,291 \\
394\end{array}$ & $\begin{array}{l}0 \\
0 \\
0\end{array}$ & $\begin{array}{r}5 \\
2,245 \\
818\end{array}$ & $\begin{array}{r}408 \\
1,566 \\
829\end{array}$ & $\begin{array}{r}0 \\
80 \\
0\end{array}$ \\
\hline 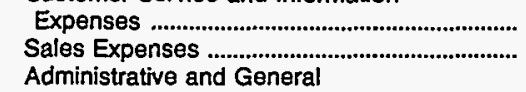 & $\begin{array}{r}3,545 \\
172\end{array}$ & $\begin{array}{r}113 \\
0\end{array}$ & $\begin{array}{l}0 \\
0\end{array}$ & $\begin{array}{l}0 \\
4\end{array}$ & $\begin{array}{r}50 \\
3\end{array}$ & $\begin{array}{r}222 \\
0\end{array}$ \\
\hline 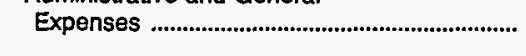 & 15,227 & 1,504 & 70 & 3,454 & 1,941 & 2,192 \\
\hline $\begin{array}{l}\text { Total Electric Operation and } \\
\text { Maintenance Expenses }\end{array}$ & 231,930 & 15,816 & 28,425 & 30,236 & 17,043 & 11,828 \\
\hline \multicolumn{7}{|l|}{ Fuel Expenses in Operation } \\
\hline Steam Power Generation .................................... & 45,900 & 0 & 0 & 1,816 & 6,826 & 0 \\
\hline Nuclear Power Generation .................................... & 27,557 & 0 & 0 & 0 & 0 & 0 \\
\hline Other Power Generation ........................................ & 562 & 0 & 0 & 119 & 0 & 0 \\
\hline \multicolumn{7}{|l|}{ Number of Elec Dept Employees } \\
\hline 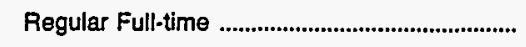 & 2,451 & 77 & 3 & 166 & 92 & 20 \\
\hline 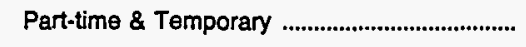 & 84 & 0 & 11 & 4 & 0 & 0 \\
\hline Total Elec Dept Employees ............................ & 2,535 & 77 & 14 & 170 & 92 & 20 \\
\hline
\end{tabular}

Note: Totels may not equal sum of components because of independent rounding.

Source: Energy Information Administration, Form EIA-412, "Annual Report of Public Electric Utilities." 
Table 23. Electric Operation and Maintenance Expenses by Major U.S. Publicly Owned Electric Utillty Within State, 1993 (Continued)

(Thousand Dollars)

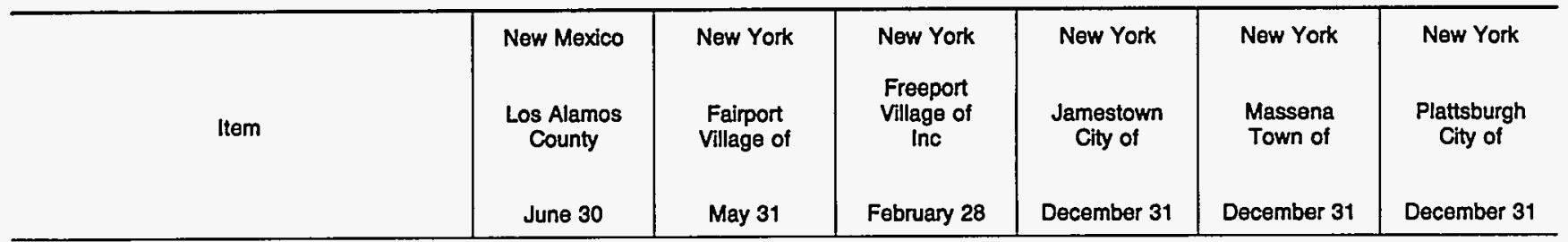

\section{Production Expenses}

Steam Power Generation

Nuclear Power Generation

Hydraulic Power Generation

Other Power Generation

Purchased Power

Production Expenses

Total Productlon Expenses

Transmission Expenses

Distribution Expenses ...........................................

Customer Accounts Expenses

Customer Service and Information

Sales Expenses ....................................................

Administrative and General

Expenses

Total Electrlc Operation and

Maintenance Expenses
Expenses .............................................................

4,952
0
303
0
6,951
560

12,766

1,770

371

91

0
0

1,836

16,834

3,926

0

Nuclear Power Generation

Other Power Generation

Number of Elec Dept Employees

Regular Full-time .

Part-time \& Temporary

Total Elec Dept Employees ..........................

0
0
0
0
6,947
0

6,947

40

914
334

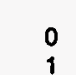

78

9,113

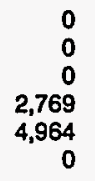

6,608
0
0
0
5,259
0

7,734

11,867

36

640

564

$$
84
$$

1,054

355

0
-48

$-48$

1,649

14,961

11,310

3,349

$\begin{array}{rr}0 & 0 \\ 0 & 0 \\ 0 & 0 \\ 0 & 0 \\ 2,101 & 5,237 \\ 0 & 126\end{array}$

2,101

5,362

462

778

158

185

$-29$

740

7,657

Note: Totals may not equal sum of components because of independent rounding.

Source: Energy Information Administration, Form EIA-412, "Annual Report of Public Electric Utilities." $\begin{array}{lll}4,172 & 0 & 0\end{array}$

0

0

929

0

0

0

22

33

0

33 
Table 23. Electric Operation and Maintenance Expenses by Major U.S. Publicly Owned Electric Utility Within State, 1993 (Continued)

(Thousand Dollars)

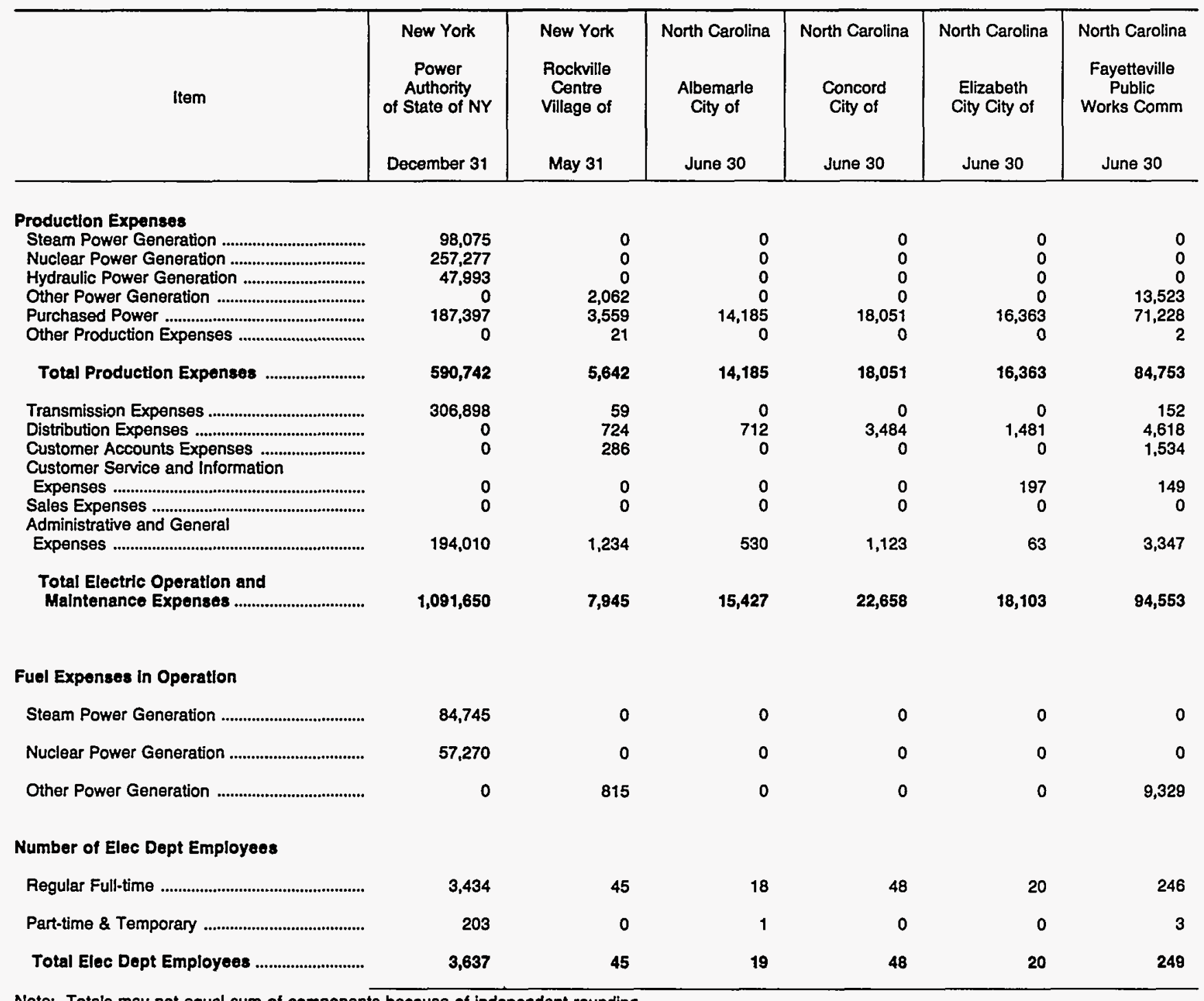

Note: Totals may not equal sum of components because of independent rounding.

Source: Energy Information Administration, Form ElA-412, "Annual Report of Publlc Electric Utilities." 
Table 23. Electric Operation and Maintenance Expenses by Major U.S. Publicly Owned Electric Utility Within State, 1993 (Continued)

(Thousand Dollars)

\begin{tabular}{|c|c|c|c|c|c|c|}
\hline Item & $\begin{array}{l}\text { North Carolina } \\
\text { Forest City } \\
\text { Town of } \\
\text { June } 30\end{array}$ & $\begin{array}{c}\text { North Carolina } \\
\text { Gastonia } \\
\text { City of } \\
\text { June } 30\end{array}$ & $\begin{array}{c}\text { North Carolina } \\
\text { Greenville } \\
\text { Utilities } \\
\text { Comm } \\
\text { June } 30\end{array}$ & $\begin{array}{c}\text { North Carolina } \\
\text { High } \\
\text { Point } \\
\text { Town } \\
\text { of } \\
\text { June } 30\end{array}$ & $\begin{array}{l}\text { North Carolina } \\
\text { Kinston } \\
\text { City of } \\
\text { June } 30\end{array}$ & $\begin{array}{l}\text { North Carolina } \\
\text { Lexington } \\
\text { City of } \\
\text { June } 30\end{array}$ \\
\hline 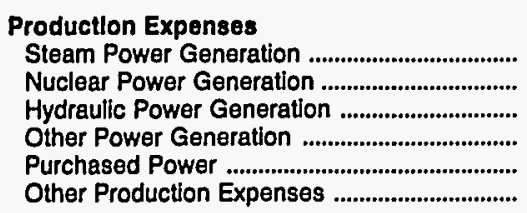 & $\begin{array}{r}0 \\
0 \\
0 \\
0 \\
5,942 \\
0\end{array}$ & $\begin{array}{r}0 \\
0 \\
0 \\
0 \\
27,708 \\
0\end{array}$ & $\begin{array}{r}0 \\
0 \\
0 \\
0 \\
74,462 \\
0\end{array}$ & $\begin{array}{r}0 \\
0 \\
0 \\
0 \\
42,813 \\
557\end{array}$ & $\begin{array}{r}0 \\
0 \\
0 \\
0 \\
28,766 \\
0\end{array}$ & $\begin{array}{r}0 \\
0 \\
0 \\
0 \\
24,495 \\
0\end{array}$ \\
\hline Total Production Expenses ............................. & 5,942 & 27,708 & 74,462 & 43,370 & 28,766 & 24,495 \\
\hline 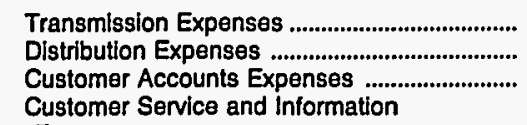 & $\begin{array}{r}0 \\
438 \\
0\end{array}$ & $\begin{array}{r}0 \\
1,143 \\
0\end{array}$ & $\begin{array}{r}135 \\
2,616 \\
733\end{array}$ & $\begin{array}{r}3,263 \\
784 \\
954\end{array}$ & $\begin{array}{r}0 \\
1,074 \\
0\end{array}$ & $\begin{array}{r}0 \\
2,229 \\
0\end{array}$ \\
\hline 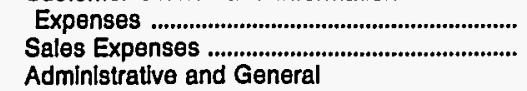 & $\begin{array}{l}0 \\
0\end{array}$ & $\begin{array}{l}0 \\
0\end{array}$ & $\begin{array}{l}374 \\
117\end{array}$ & $\begin{array}{r}553 \\
0\end{array}$ & $\begin{array}{l}0 \\
0\end{array}$ & $\begin{array}{l}0 \\
0\end{array}$ \\
\hline 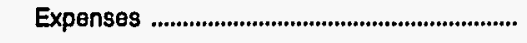 & 132 & 1,570 & 4,341 & 577 & 1,436 & 0 \\
\hline $\begin{array}{l}\text { Total Electrlc Operation and } \\
\text { Malntenance Expenses ................................... }\end{array}$ & 6,513 & 30,422 & 82,779 & 49,501 & 31,276 & 26,723 \\
\hline \multicolumn{7}{|l|}{ Fuel Expenses In Operation } \\
\hline 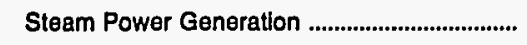 & 0 & 0 & 0 & 0 & 0 & 0 \\
\hline 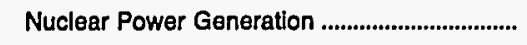 & 0 & 0 & 0 & 0 & 0 & 0 \\
\hline 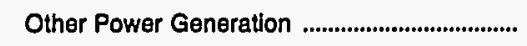 & 0 & 0 & 0 & 0 & 0 & 0 \\
\hline \multicolumn{7}{|l|}{ Number of Elec Dept Employees } \\
\hline Regular Full-time & 6 & 36 & 115 & 103 & 43 & 39 \\
\hline 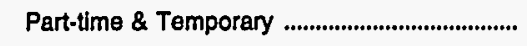 & 0 & 0 & 2 & 5 & 0 & 3 \\
\hline Total Elec Dept Employees ............................. & 6 & 36 & 117 & 108 & 43 & 42 \\
\hline
\end{tabular}

Note: Totals may not equal sum of components because of independent rounding.

Source: Energy Information Administration, Form EIA-412, "Annual Report of Public Electric Utilities." 
Table 23. Electric Operation and Maintenance Expenses by Major U.S. Publicly Owned Electric Utility Within State, 1993 (Continued)

(Thousand Dollars)

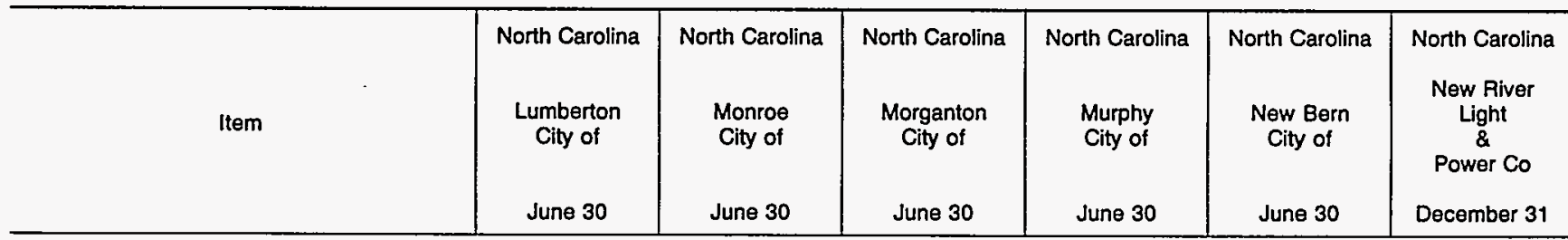

Production Expenses

Steam Power Generation

Nuclear Power Generation

Other Power Generation

Purchased Power

Other Production Expenses

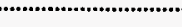

Total Production Expenses .

0
0
0
0
18,345
0

0
0
0
0
20,160
608

0
0
0
0
12,911

12,911
0

$18,345 \quad 20,768$

Transmission Expenses

Distribution Expenses

Customer Accounts Expenses ...........................

Customer Service and information

Expenses ....

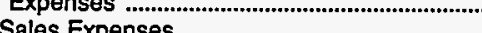

Administrative and General

Expenses

Total Electric Operation and

Maintenance Expenses

0

1,297

794

201

12,911

0

0
0

0
0

129

0
0

1,392

22,395

14,303

$\begin{array}{rr}0 & 0 \\ 0 & 0 \\ 0 & 0 \\ 0 & 0 \\ 5,759 & 26,200 \\ 0 & 237\end{array}$

5,759

26,437

8,302

408

307

23

8

17

330

319

6,472

30,062

9,359

Fuel Expenses in Operation

Steam Power Generation

Nuclear Power Generation

0

0

$\mathbf{0}$

Other Power Generation

Number of Elec Dept Employees

Regular Full-time

Part-time \& Temporary

Total Elec Dept Employees

Note: Totals may not equal sum of components because of independent rounding

Source: Energy Information Administration, Form EIA-412, "Annual Report of Public Electric Utilities." 
Table 23. Electric Operation and Maintenance Expenses by Major U.S. Publicly Owned Electric Utility Within State, 1993 (Continued)

(Thousand Dollars)

\begin{tabular}{c|c|c|c|c|c|c}
\hline & North Carolina & North Carolina & North Carolina & North Carolina & North Carolina & North Carolina \\
Item & $\begin{array}{c}\text { North } \\
\text { Eastern M P A }\end{array}$ & $\begin{array}{c}\text { Carolina } \\
\text { Mun } \\
\text { Power Agny }\end{array}$ & $\begin{array}{c}\text { Rocky Mount } \\
\text { City of }\end{array}$ & $\begin{array}{c}\text { Shelby } \\
\text { City of }\end{array}$ & $\begin{array}{c}\text { Statesville } \\
\text { City of }\end{array}$ & $\begin{array}{c}\text { Tarboro } \\
\text { Town of }\end{array}$ \\
& December 31 & $\begin{array}{c}\text { December 31 } \\
\text { June } 30\end{array}$ & June 30 & June 30 & June 30 \\
\hline
\end{tabular}

Production Expenses

Steam Power Generation

Nuclear Power Generation.

Hydraulic Power Generation

Other Power Generation

Purchased Power

ther Production Expenses

25,826

59,791

0

131,117

$-6,073$

210,661

Total Production Expenses

Transmission Expenses

Distribution Expenses

Customer Accounts Expenses ...........................

Customer Service and Information

Expenses .........

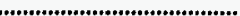

Administrative and Genera!

Expenses

Total Electric Operation and

Maintenance Expenses

Fuel Expenses in Operation

Steam Power Generation

Nuclear Power Generation

23,354

9,757

16,441

2,466

0

22,475

252,043

$$
\begin{array}{r}
0 \\
92,041 \\
0 \\
0 \\
115,660 \\
10,759
\end{array}
$$

218,460

10,010

2,185
0

0

22,418

253,073

53,939

0
0
0
0
49,490
0

49,490

$$
\begin{array}{r}
0 \\
4,044 \\
0
\end{array}
$$

0

0

405
0
0
0
0
8,336

8,336
0

8,336

1,108

1,108
0

0

0

410

9,854
20,511

18,780

$\begin{array}{rr}0 & 0 \\ 0 & 0 \\ 0 & 0 \\ 0 & 0 \\ 18,535 & 17,313 \\ 52 & 0 \\ 18,587 & 17,313 \\ 0 & 0 \\ 0 & 0 \\ 0 & 0 \\ 0 & 0 \\ 0 & 0 \\ 1,923 & 1,467 \\ 20,511 & 18,780\end{array}$

Other Power Generation

28,601

0

$$
\begin{aligned}
& 0 \\
& 0 \\
& 0
\end{aligned}
$$

48
0
49

Number of Elec Dept Employees

Regular Full-time .

0

0
0
0

49

$\begin{array}{lll}0 & 0 & 0 \\ 0 & 0 & 0 \\ 0 & 0 & 0\end{array}$

Part-time \& Temporary .......................................

0

0

17
0
17

25

19

1

Note: Totals may not equal sum of components because of independent rounding.

Source: Energy Information Administration, Form EIA-412, "Annual Report of Public Electric Utilites." 
Table 23. Electric Operation and Maintenance Expenses by Major U.S. Publicly Owned Electric Utility Within State, 1993 (Continued) (Thousand Dollars)

\begin{tabular}{|c|c|c|c|c|c|c|}
\hline Item & $\begin{array}{l}\text { North Carolina } \\
\begin{array}{c}\text { Washington } \\
\text { City of }\end{array} \\
\text { June } 30\end{array}$ & $\begin{array}{l}\text { North Carolina } \\
\text { Wilson } \\
\text { City of } \\
\text { June } 30\end{array}$ & $\begin{array}{c}\text { Ohio } \\
\text { American } \\
\text { Mun } \\
\text { Power } \\
\text { Ohio Inc } \\
\text { December } 31\end{array}$ & $\begin{array}{c}\text { Ohio } \\
\text { Bowling } \\
\text { Green } \\
\text { City of } \\
\text { December } 31\end{array}$ & $\begin{array}{c}\text { Ohio } \\
\text { Bryan } \\
\text { City of } \\
\text { December } 31\end{array}$ & $\begin{array}{l}\text { Ohio } \\
\text { Celina } \\
\text { City of } \\
\text { December } 31\end{array}$ \\
\hline
\end{tabular}

Production Expenses

Steam Power Generation

Nuclear Power Generation

Hydraulic Power Generation

Other Power Generation

Other Production Expenses

Total Production Expenses

Transmission Expenses .

Distribution Expens

Customer Accounts Expenses

Customer Service and Information

Expenses

Administrative and General

Expenses

Total Electric Operation and

Malntenance Expenses

0
0
0
0
16,140
0

16,140

63,531

0
1,652
0

0

0

1,488

19,280

0
0
0
0
63,531
0

19,312

0

98,927

18

118,257

0
451

2,440

2,028

0

442

69,511

4,485

123,193

0
0
0
0
12,536
0

12,536

219

994

340

0

68

742

14,899

0

0

0

6,292
68

68

0

0
617

158

6,454

7,351

Fuel Expenses in Operation

Steam Power Generation

Nuclear Power Generation

Other Power Generation

Number of Elec Dept Employees

Regular Full-time

Part-time \& Temporary

Total Elec Dept Employees
0

0

0

$\begin{array}{rr}39 & 83 \\ 0 & 0 \\ 39 & 83\end{array}$

9,793

0

0

114

30

$\mathbf{0}$

114

0

83

Note: Totals may not equal sum of components because of independent rounding.

Source: Energy Information Administration, Form EIA-412, "Annual Report of Public Electric Utilities." 
Table 23. Electric Operation and Maintenance Expenses by Major U.S. Publicly Owned Electric Utility Within State, 1993 (Continued)

(Thousand Dollars)

\begin{tabular}{|c|c|c|c|c|c|c|}
\hline Item & $\begin{array}{c}\text { Ohio } \\
\text { Cleveland } \\
\text { City of } \\
\text { December } 31\end{array}$ & $\begin{array}{l}\text { Ohio } \\
\text { Columbus } \\
\text { City of } \\
\text { December } 31\end{array}$ & $\begin{array}{l}\text { Ohio } \\
\text { Cuyanoga } \\
\text { Falls } \\
\text { City of } \\
\text { December } 31\end{array}$ & $\begin{array}{c}\text { Ohio } \\
\text { Dover } \\
\text { City of } \\
\text { December } 31\end{array}$ & $\begin{array}{c}\text { Ohio } \\
\text { Hamilton } \\
\text { City of } \\
\text { December } 31\end{array}$ & $\begin{array}{c}\text { Ohio } \\
\text { Napoleon } \\
\text { City of } \\
\text { December } 31\end{array}$ \\
\hline 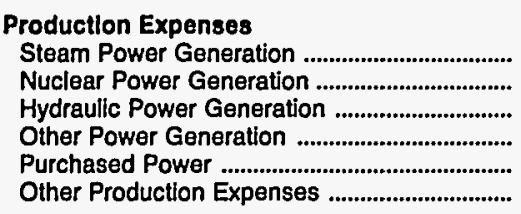 & $\begin{array}{r}282 \\
0 \\
0 \\
757 \\
32,392 \\
0\end{array}$ & $\begin{array}{r}5,462 \\
0 \\
216 \\
0 \\
16,240 \\
50\end{array}$ & $\begin{array}{r}0 \\
0 \\
0 \\
0 \\
12,463 \\
0\end{array}$ & $\begin{array}{r}0 \\
0 \\
0 \\
0 \\
3,605 \\
0\end{array}$ & $\begin{array}{r}10,487 \\
0 \\
700 \\
336 \\
6,956 \\
968\end{array}$ & $\begin{array}{r}0 \\
0 \\
0 \\
0 \\
5,811 \\
0\end{array}$ \\
\hline 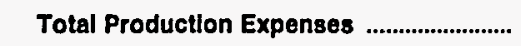 & 33,431 & 21,969 & 12,463 & 3,605 & 19,446 & 5,811 \\
\hline 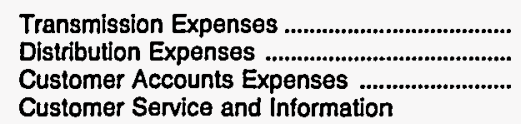 & $\begin{array}{r}646 \\
13,654 \\
1,733\end{array}$ & $\begin{array}{r}0 \\
6,809 \\
0\end{array}$ & $\begin{array}{r}0 \\
2,073 \\
444\end{array}$ & $\begin{array}{r}0 \\
4,879 \\
0\end{array}$ & $\begin{array}{r}324 \\
1,803 \\
157\end{array}$ & $\begin{array}{l}0 \\
0 \\
0\end{array}$ \\
\hline 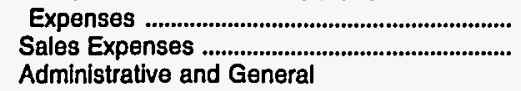 & $\begin{array}{r}284 \\
65\end{array}$ & $\begin{array}{r}492 \\
0\end{array}$ & $\begin{array}{l}0 \\
0\end{array}$ & $\begin{array}{l}0 \\
0\end{array}$ & $\begin{array}{r}420 \\
0\end{array}$ & $\begin{array}{l}0 \\
0\end{array}$ \\
\hline 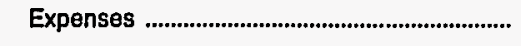 & 4,287 & 4,499 & 2,293 & 63 & 3,381 & 2,024 \\
\hline $\begin{array}{l}\text { Total Electric Operation and } \\
\text { Malntenance Expenses ................................... }\end{array}$ & 54,101 & 33,769 & 17,272 & 8,547 & 25,531 & 7,835 \\
\hline \multicolumn{7}{|l|}{ Fuel Expenses In Operation } \\
\hline Steam Power Generation & 0 & 697 & 0 & 0 & 6,920 & 0 \\
\hline 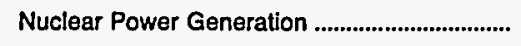 & 0 & 0 & 0 & $\mathbf{0}$ & 0 & 0 \\
\hline 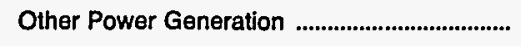 & 482 & 0 & 0 & $\mathbf{0}$ & 284 & 0 \\
\hline \multicolumn{7}{|l|}{ Number of Elec Dept Employees } \\
\hline Regular Full-time & 321 & 134 & 44 & 38 & 103 & 18 \\
\hline 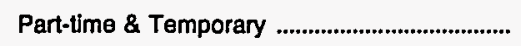 & 0 & 3 & 1 & 2 & 1 & 0 \\
\hline Total Elec Dept Employees .................................. & 321 & 137 & 45 & 40 & 104 & 18 \\
\hline
\end{tabular}

Note: Totals may not equal sum of components because of independent rounding.

Source: Energy Information Administration, Form EIA-412, "Annual Report of Public Electric Utilities." 
Table 23. Electric Operation and Maintenance Expenses by Major U.S. Publicly Owned Electric Utility Within State, 1993 (Continued)

(Thousand Dollars)

\begin{tabular}{|c|c|c|c|c|c|c|}
\hline Item & $\begin{array}{c}\text { Ohio } \\
\text { Niles } \\
\text { City of } \\
\text { December } 31\end{array}$ & $\begin{array}{c}\text { Ohio } \\
\text { Orrville } \\
\text { City of } \\
\text { December } 31\end{array}$ & $\begin{array}{c}\text { Ohio } \\
\text { Painesville } \\
\text { City of }\end{array}$ & $\begin{array}{c}\text { Ohio } \\
\text { Piqua } \\
\text { City of } \\
\text { December } 31\end{array}$ & $\begin{array}{c}\text { Ohio } \\
\text { St Marys } \\
\text { City of } \\
\text { December } 31\end{array}$ & $\begin{array}{c}\text { Ohio } \\
\text { Wadsworth } \\
\text { City of } \\
\text { December } 31\end{array}$ \\
\hline \multicolumn{7}{|l|}{ Production Expenses } \\
\hline Steam Power Generation .......................................... & 0 & 7,401 & 3,580 & 3,709 & 1,725 & 0 \\
\hline Nuclear Power Generation ........................................ & 0 & & & & & 0 \\
\hline 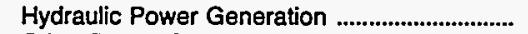 & 0 & 0 & 0 & 0 & 0 & 0 \\
\hline 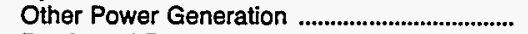 & 0 & 0 & 0 & 0 & 0 & 0 \\
\hline Purchased Power ....................................................... & 10,321 & 1,501 & 1,238 & 5,484 & 3,224 & 7,925 \\
\hline 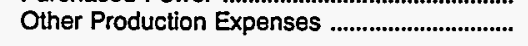 & 3,129 & 0 & 0 & 16 & 0 & 0 \\
\hline Total Production Expenses ............................. & 13,450 & 8,902 & 4,818 & 9,209 & 4,949 & 7,925 \\
\hline $\begin{array}{l}\text { Transmission Expenses } \\
\text { Distribution Expenses }\end{array}$ & $\begin{array}{l}0 \\
0\end{array}$ & $\begin{array}{r}0 \\
917\end{array}$ & $\begin{array}{r}0 \\
6.626\end{array}$ & $\begin{array}{r}29 \\
636\end{array}$ & 0 & 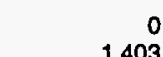 \\
\hline 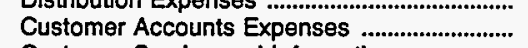 & 0 & 0 & $\begin{array}{r}0,620 \\
0\end{array}$ & $\begin{array}{l}636 \\
242\end{array}$ & $\begin{array}{l}646 \\
115\end{array}$ & $\begin{array}{r}1,403 \\
257\end{array}$ \\
\hline Customer Service and Information & & & & & & \\
\hline 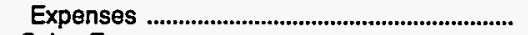 & 0 & 0 & 0 & 0 & 0 & 0 \\
\hline 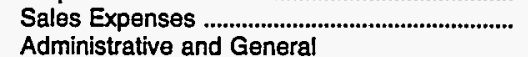 & 0 & 0 & 0 & 225 & 0 & 0 \\
\hline 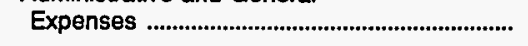 & 106 & 2,198 & 0 & 1,352 & 44 & 985 \\
\hline $\begin{array}{l}\text { Total Electric Operation and } \\
\text { Malntenance Expenses ................................. }\end{array}$ & 13,557 & 12,017 & 11,444 & 11,694 & 5,754 & 10,569 \\
\hline \multicolumn{7}{|l|}{ Fuel Expenses In Operation } \\
\hline Steam Power Generation & 0 & 4,352 & 3,580 & 1,788 & 717 & 0 \\
\hline 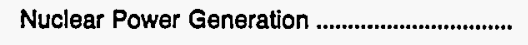 & 0 & 0 & 0 & 0 & 0 & 0 \\
\hline 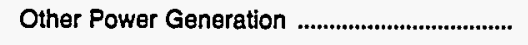 & 0 & 0 & 0 & 0 & 0 & 0 \\
\hline \multicolumn{7}{|l|}{ Number of Elec Dept Employees } \\
\hline Regular Full-time & 41 & 69 & 61 & 62 & 24 & 23 \\
\hline 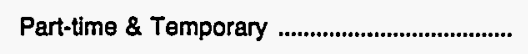 & 2 & 3 & 0 & 0 & 1 & 0 \\
\hline 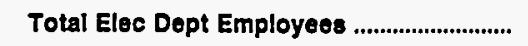 & 43 & 72 & 61 & 62 & 25 & 23 \\
\hline
\end{tabular}

Note: Totals may not equal sum of components because of independent rounding.

Source: Energy Information Administration, Form ElA-412, "Annual Report of Public Electric Utilities." 
Table 23. Electric Operation and Maintenance Expenses by Major U.S. Publicly Owned Electric Utillty Within State, 1993 (Continued)

(Thousand Dollars)

\begin{tabular}{c|c|c|c|c|c|c}
\hline & Ohio & Ohio & Oklahoma & Oklahoma & Oklahoma & Oklahoma \\
Item & $\begin{array}{c}\text { Wapakoneta } \\
\text { City of }\end{array}$ & $\begin{array}{c}\text { Westenille } \\
\text { City of }\end{array}$ & $\begin{array}{c}\text { Altus } \\
\text { City of }\end{array}$ & $\begin{array}{c}\text { Claremore } \\
\text { City of }\end{array}$ & $\begin{array}{c}\text { Duncan } \\
\text { City of }\end{array}$ & $\begin{array}{c}\text { Edmond } \\
\text { City of }\end{array}$ \\
December 31 & December 31 & June 30 & June 30 & June 30 & June 30 \\
\hline
\end{tabular}

Productlon Expenses

Steam Power Generation

Nuclear Power Generation

Hydraullc Power Genere

Other Power Generation .

Other Production Expenses

Total Production Expenses

Transmission Expenses

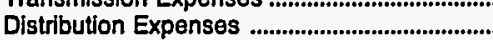

Customer Accounts Expenses .........................

Customer Service and Information

Expenses .........

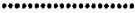

Sales Expenses

Administrative and General

Expenses

Total Electrlc Operation and

Malntenance Expenses

Fuel Expenses in Operation

Steam Power Generation

Nuclear Power Generation

Other Power Generation

..................................

........................................

Number of Elec Dept Employees

Regular Full-time

Part-time \& Temporary
0
0
0
0
5,231
0

5,231

0
1,906

78

0
0

95

7,311

13,589

0
0
0
0
5,946
0

0
0
0
0
6,847
0

5,946

6,847

0
976

292

0
0

0

8,115

7,124

0
0
0
0
4,205
0

4,205

$\begin{array}{rr}0 & 0 \\ 1,081 & 1,754 \\ 0 & 152\end{array}$

116

0

179

5,286

21,081
0

0

0

10

0

10

0
0
0

0

34

0

34

0
0
0

0

o

0

18
0
18

$\begin{array}{rrr}19 & 19 & 41 \\ 0 & 0 & 0 \\ 19 & 19 & 41\end{array}$

Note: Totals may not equal sum of components because of independent rounding.

Source: Energy Information AdmInistration, Form EIA-412, "Annual Report of Public Electric Utilities." 
Table 23. Electric Operation and Maintenance Expenses by Major U.S. Publicly Owned Electric Utility Within State, 1993 (Continued) (Thousand Dollars)

\begin{tabular}{|c|c|c|c|c|c|c|}
\hline Item & $\begin{array}{c}\text { Oklahoma } \\
\text { Grand River } \\
\text { Dam } \\
\text { Authority }\end{array}$ & $\begin{array}{l}\text { Oklahoma } \\
\text { Miami } \\
\text { City of }\end{array}$ & $\begin{array}{l}\text { Oklahoma } \\
\text { Oklahoma } \\
\text { Municipal } \\
\text { Power Auth }\end{array}$ & $\begin{array}{c}\text { Oklahoma } \\
\text { Ponca } \\
\text { City City of }\end{array}$ & $\begin{array}{l}\text { Oklahoma } \\
\text { Stillwater } \\
\text { Utilities } \\
\text { Authority }\end{array}$ & $\begin{array}{l}\text { Oregon } \\
\text { Ashland } \\
\text { City of }\end{array}$ \\
\hline & December 31 & June $\mathbf{3 0}$ & December 31 & June 30 & June 30 & June 30 \\
\hline
\end{tabular}

\section{Productlon Expenses}

Steam Power Generation

Nuclear Power Generation

Hydraulic Power Generation

Other Power Generation

Purchased Power

Other Production Expenses

Total Production Expenses

Transmission Expenses

Distribution Expenses

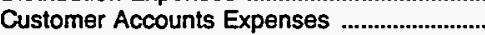

Customer Service and Information

Expenses

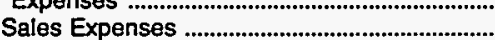

Administrative and General

Expenses

Total Electric Operation and

Malntenance Expenses

\section{Fuel Expenses in Operation}

Steam Power Generation

Nuclear Power Generation

Other Power Generation

Number of Elec Dept Employees

Regular Full-time

Part-time \& Temporary

Total Elec Dept Employees

55,761
0
2,679
0
3,209
0

0
0
0
0
4,431
0

61,648

6,135

0
164

74

9,005

77,027

5,296
13,933

0
500
0
24,415
968

39,816

8,994

0
0

0

1,965

50,776

44,705

0

0

$\begin{array}{rr}476 & 18 \\ 1 & 0 \\ 477 & 18\end{array}$

599
0
0
537
10,916
0

12,052

0
1,805

0

149

905

14,911

Note: Totals may not equal sum of components because of independent rounding.

Source: Energy Information Administration, Form EIA-412, "Annual Report of Public Electric Utilities." 
Table 23. Electric Operation and Maintenance Expenses by Major U.S. Publicly Owned Electric Utility Within State, 1993 (Continued)

(Thousand Dollars)

\begin{tabular}{|c|c|c|c|c|c|c|}
\hline Item & $\begin{array}{c}\text { Oregon } \\
\text { Central } \\
\text { Lincoln } \\
\text { Peoples } \\
\text { Utl Dt } \\
\text { December } 31\end{array}$ & $\begin{array}{l}\text { Oregon } \\
\text { Clatskanie } \\
\text { Peoples } \\
\text { Util Dist } \\
\text { December } 31\end{array}$ & $\begin{array}{c}\text { Oregon } \\
\text { Columbia } \\
\text { River } \\
\text { Peoples } \\
\text { Ut Dist } \\
\text { December } 31\end{array}$ & $\begin{array}{l}\text { Oregon } \\
\text { Emerald } \\
\text { Peoples } \\
\text { Utility Dist } \\
\text { December } 31\end{array}$ & $\begin{array}{l}\text { Oregon } \\
\text { Eugene } \\
\text { City of } \\
\text { December } 31\end{array}$ & $\begin{array}{c}\text { Oregon } \\
\text { Forest Grove } \\
\text { City of } \\
\text { June } 30\end{array}$ \\
\hline 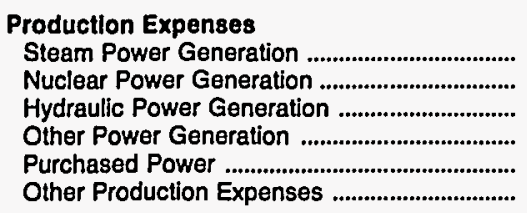 & $\begin{array}{r}0 \\
0 \\
0 \\
0 \\
33,436 \\
0\end{array}$ & $\begin{array}{r}0 \\
0 \\
0 \\
0 \\
21,553 \\
0\end{array}$ & $\begin{array}{r}0 \\
0 \\
0 \\
0 \\
6,669 \\
0\end{array}$ & $\begin{array}{r}0 \\
0 \\
0 \\
310 \\
9,556 \\
0\end{array}$ & $\begin{array}{r}7,003 \\
0 \\
2,273 \\
0 \\
51,937 \\
1,513\end{array}$ & $\begin{array}{r}0 \\
0 \\
0 \\
0 \\
4,452 \\
0\end{array}$ \\
\hline Total Production Expenses ........................... & 33,436 & 21,553 & 6,669 & 9,866 & 62,726 & 4,452 \\
\hline 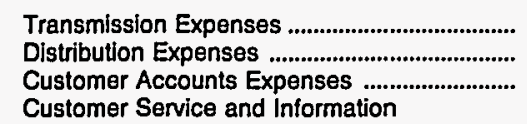 & $\begin{array}{r}0 \\
3,210 \\
1,104\end{array}$ & $\begin{array}{r}0 \\
372 \\
176\end{array}$ & $\begin{array}{r}0 \\
922 \\
332\end{array}$ & $\begin{array}{r}0 \\
1,178 \\
579\end{array}$ & $\begin{array}{l}1,698 \\
6,567 \\
2,880\end{array}$ & $\begin{array}{r}0 \\
387 \\
66\end{array}$ \\
\hline 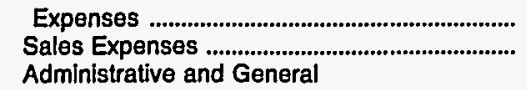 & $\begin{array}{r}324 \\
0\end{array}$ & $\begin{array}{r}213 \\
0\end{array}$ & $\begin{array}{l}125 \\
427\end{array}$ & $\begin{array}{r}149 \\
0\end{array}$ & $\begin{array}{r}2,234 \\
0\end{array}$ & $\begin{array}{l}0 \\
0\end{array}$ \\
\hline 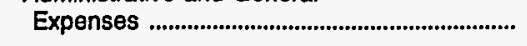 & 2,542 & 755 & 986 & 771 & 9,924 & 1,082 \\
\hline $\begin{array}{l}\text { Total Electric Operation and } \\
\text { Malntenance Expenses .................................. }\end{array}$ & 40,615 & 23,070 & 9,461 & 12,543 & 86,030 & 5,987 \\
\hline \multicolumn{7}{|l|}{ Fuel Expenses in Operation } \\
\hline 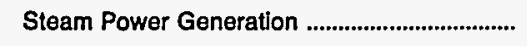 & 0 & 0 & 0 & 0 & 4,952 & 0 \\
\hline 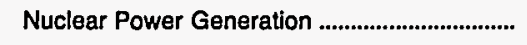 & 0 & 0 & 0 & 0 & 0 & 0 \\
\hline 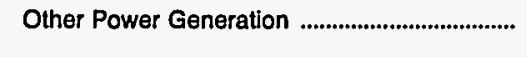 & 0 & 0 & 0 & 229 & 0 & 0 \\
\hline \multicolumn{7}{|l|}{ Number of Elec Dept Employees } \\
\hline Regular Full-time ........................................................... & 146 & 21 & 33 & 58 & 415 & 23 \\
\hline 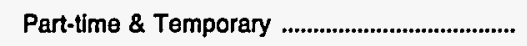 & 10 & 0 & 1 & 7 & 13 & 0 \\
\hline Total Elec Dept Employees ............................. & 156 & 21 & 34 & 65 & 428 & 23 \\
\hline
\end{tabular}

Note: Totals may not equal sum of components because of independent rounding.

Source: Energy Information Administration, Form ElA-412, "Annual Report of Public Electric Utilities." 
Table 23. Electric Operation and Maintenance Expenses by Major U.S. Publicly Owned Electric Utility Within State, 1993 (Continued)

(Thousand Dollars)

\begin{tabular}{c|c|c|c|c|c|c}
\hline & Oregon & Oregon & Oregon & Oregon & Pennsylvania & Pennsylvania \\
Item & $\begin{array}{c}\text { Morthern } \\
\text { City of }\end{array}$ & $\begin{array}{c}\text { Wasco County } \\
\text { P U D }\end{array}$ & $\begin{array}{c}\text { Springfield } \\
\text { City of }\end{array}$ & $\begin{array}{c}\text { Tillamook } \\
\text { Peoples } \\
\text { Utility Dist }\end{array}$ & $\begin{array}{c}\text { Chambersburg } \\
\text { Borough of }\end{array}$ & $\begin{array}{c}\text { Lansdale } \\
\text { Borough of }\end{array}$ \\
June 30 & December 31 & December 31 & December 31 & December 31 & December 31 \\
\hline
\end{tabular}

Production Expenses

Steam Power Generation

Nuclear Power Gener

Hydraulic Power Generation

Other Power Generation

Purchased Power

Other Production Expenses

Total Production Expenses

0
0
0
0
14,903
0

6,7

Transmission Expenses

Distribution Expenses

Customer Accounts Expenses ..........................

Customer Service and Information

Expenses

Sales Expenses

Administrative and General

Expenses

Total Electric Operation and

Maintenance Expenses

14,903

\section{861}

148

0

655

16,568
0

0

9,279

279
59

9,338

20,923

0
1,973

1,357
761

1,118

810

1,821

$\mathbf{9 , 3 5 0}$

5,980

27

197

9

692

0

0
0

487

1,120

10,396

7,816

Fuel Expenses in Operatlon

Steam Power Generation

Nuclear Power Generation

0

0

0

0

0

0

0

0

0

0

0

0

Other Power Generation

\begin{tabular}{rrrrrr}
32 & 34 & 82 & 67 & 28 & 18 \\
0 & 6 & 0 & 16 & 0 & 0 \\
32 & 40 & 82 & 83 & 28 & 19 \\
\hline
\end{tabular}

Note: Totals may not equal sum of components because of independent rounding.

Source: Energy Information Administration, Form ElA-412, "Annual Report of Public Electric Utilities." 
Table 23. Electric Operation and Maintenance Expenses by Major U.S. Publicly Owned Electric Utility Within State, 1993 (Continued)

(Thousand Dollars)

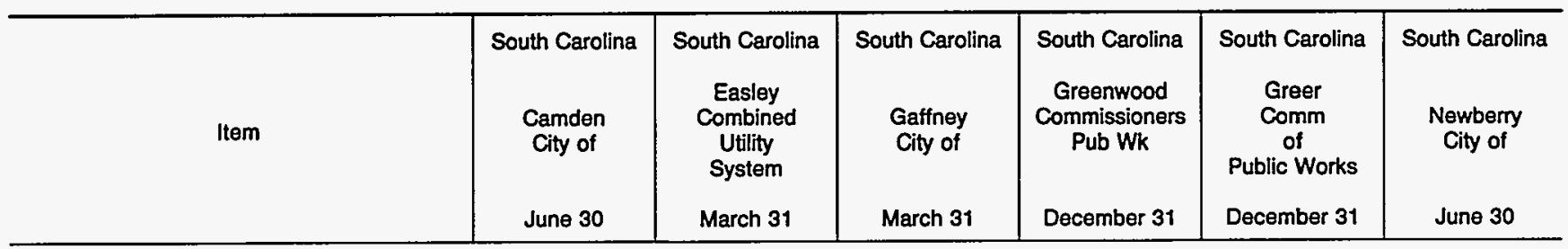

\section{Productlon Expenses}

Steam Power Generation

Nuclear Power Generation

.

Other Power Generat

Purchased Power ................................................

Other Production Expenses

Total Production Expenses

Transmission Expenses

Distribution Expen

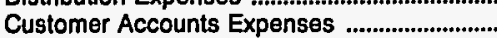

Customer Service and Information

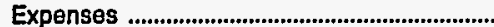

Sales Expenses ......................................................

Administrative and General

Expenses

Total Electric Operation and

Maintenance Expenses

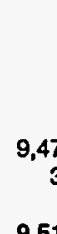

0
0
0
0
9,477
39

9,516

0
643

643
0

0

195

10,355

0
0
0
0
10,382
0

10,382

0

736
50

0

8

505

11,682

0
0
0
0
9,207
0

0
852

852
0

0

077

11,136

0
1,114

100

0
12,263

0
0
0
0
10,474
0

10,474

0

575

$\begin{array}{rr}0 & 0 \\ 0 & 0 \\ 0 & 0 \\ 0 & 0 \\ 7,592 & 7,219 \\ 0 & 0\end{array}$

7,592

7,219

965

215

0

13

131

72

197

Fuel Expenses In Operation

Steam Power Generation

Nuclear Power Generation

0

0

0

0

0

o

16

17

0

17

17

0

0

0

0

0

o

0

0

Number of Elec Dept Employees

Regular Full-time

Part-tlme \& Temporary

$\begin{array}{rrr}27 & 26 & 12 \\ 0 & 0 & 0 \\ 27 & 26 & 12\end{array}$

17

Note: Totals may not equal sum of components because of independent rounding.

Source: Energy Information Administration, Form EIA-412, "Annual Report of Public Electric Utilities." 
Table 23. Electric Operation and Maintenance Expenses by Major U.S. Publicly Owned Electric Utility Within State, 1993 (Continued) (Thousand Dollars)

\begin{tabular}{|c|c|c|c|c|c|c|}
\hline Item & $\begin{array}{l}\text { South Carolina } \\
\text { Orangeburg } \\
\text { City of }\end{array}$ & $\begin{array}{c}\text { South Carolina } \\
\text { Piedmont } \\
\text { Municipal } \\
\text { Power Agny } \\
\text { December } 31\end{array}$ & $\begin{array}{l}\text { South Carolina } \\
\text { Rock Hill } \\
\text { City of } \\
\text { December } 31\end{array}$ & $\begin{array}{l}\text { South Carolina } \\
\text { Seneca } \\
\text { City of } \\
\text { June } 30\end{array}$ & $\begin{array}{l}\text { South Carolina } \\
\text { South } \\
\text { Carolina } \\
\text { Pub } \\
\text { Serv Auth } \\
\text { December } 31\end{array}$ & $\begin{array}{l}\text { South Dakota } \\
\text { Brookings } \\
\text { City of } \\
\text { December } 31\end{array}$ \\
\hline \multicolumn{7}{|l|}{ Production Expenses } \\
\hline 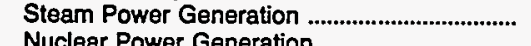 & 0 & 0 & 0 & 0 & 232,016 & 0 \\
\hline Nuclear Power Generation ................................... & 0 & 42,101 & 0 & 0 & 38,772 & 0 \\
\hline Hydraulic Power Generation ................................. & $\begin{array}{r}0 \\
0\end{array}$ & 0 & 0 & 0 & 5,366 & 0 \\
\hline 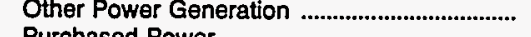 & 543 & 0 & 0 & 0 & 1,179 & 0 \\
\hline 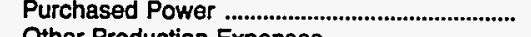 & 25,747 & 40,693 & 24,923 & 6,239 & 12,863 & 4,239 \\
\hline Other Production Expenses ................................. & 0 & 417 & 0 & 0 & 587 & 61 \\
\hline Total Production Expenses ......................... & 26,290 & 83,211 & 24,923 & 6,239 & 290,783 & 4,300 \\
\hline 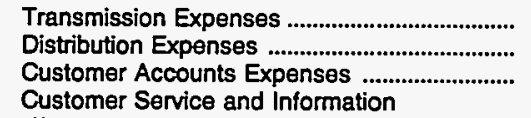 & $\begin{array}{r}0 \\
815 \\
52\end{array}$ & $\begin{array}{r}4,822 \\
1,863 \\
0\end{array}$ & $\begin{array}{r}0 \\
2,033 \\
0\end{array}$ & $\begin{array}{r}0 \\
2,361 \\
0\end{array}$ & $\begin{array}{r}10,295 \\
6,379 \\
2,762\end{array}$ & $\begin{array}{r}86 \\
723 \\
143\end{array}$ \\
\hline 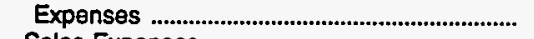 & 0 & 198 & 0 & 0 & 809 & 0 \\
\hline $\begin{array}{l}\text { Sales Expenses } \\
\text { Administrative and General }\end{array}$ & 0 & 0 & 0 & 0 & 1,618 & 0 \\
\hline 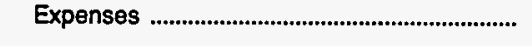 & 1,574 & 2,194 & 1,100 & 454 & 50,466 & 472 \\
\hline $\begin{array}{l}\text { Total Electric Operation and } \\
\text { Malntenance Expenses }\end{array}$ & \multicolumn{2}{|c|}{ Total Electric Operation and } & 28,056 & 9,054 & 363,112 & 5,723 \\
\hline \multicolumn{7}{|l|}{ Fuel Expenses in Operation } \\
\hline 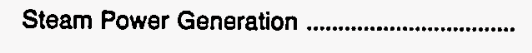 & 0 & 0 & 0 & 0 & 194,445 & 0 \\
\hline Nuclear Power Generation ...................................... & 0 & 9,083 & 0 & 0 & 9,698 & 0 \\
\hline Other Power Generation ...................................... & 222 & 0 & 0 & 0 & 413 & 0 \\
\hline \multicolumn{7}{|l|}{ Number of Elec Dept Employees } \\
\hline Regular Full-time & 38 & 10 & 34 & 7 & 1,776 & 24 \\
\hline 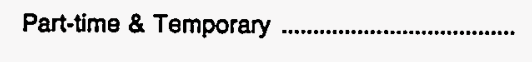 & 0 & 2 & 641 & 0 & 19 & 4 \\
\hline Total Elec Dept Employees ............................ & 38 & 12 & 675 & 7 & 1,795 & 28 \\
\hline
\end{tabular}

Note: Totals may not equal sum of components because of independent rounding.

Source: Energy Information Administration, Form EIA-412, "Annual Report of Public Electric Utilities." 
Table 23. Electric Operation and Maintenance Expenses by Major U.S. Publicly Owned Electric Utility Within State, 1993 (Continued) (Thousand Dollars)

\begin{tabular}{|c|c|c|c|c|c|c|}
\hline Item & $\begin{array}{l}\text { South Dakota } \\
\text { Heartland } \\
\text { Consumers } \\
\text { Power Dist } \\
\text { December } 31\end{array}$ & $\begin{array}{l}\text { South Dakota } \\
\text { Missouri } \\
\text { Basin } \\
\text { Mun } \\
\text { Power Agny } \\
\text { December } 31\end{array}$ & $\begin{array}{c}\text { South Dakota } \\
\text { Pierre } \\
\text { City of } \\
\text { December } 31\end{array}$ & $\begin{array}{l}\text { South Dakota } \\
\text { Watertown } \\
\text { Municipal } \\
\text { Utilities } \\
\text { December } 31\end{array}$ & $\begin{array}{c}\text { Tennessee } \\
\text { Alcoa } \\
\text { Utilities } \\
\text { June } 30\end{array}$ & $\begin{array}{c}\text { Tennessee } \\
\text { Athens } \\
\text { Utility } \\
\text { Board } \\
\text { June } 30\end{array}$ \\
\hline
\end{tabular}

Production Expenses

Steam Power Generation

Nuclear Power Generation ....

Power Generation

Other Power Generation .......

Purchased Power ....................................................

Other Production Expenses

Total Production Expenses

8

Transmission Expenses .

Distribution Expenses

Customer Accounts Expenses ............................

Customer Service and Information

Expenses ........

Adminlstrative and Genera

Expenses

$\begin{array}{rr}3,513 & \\ 0 & \\ 0 & \\ 0 & \\ 2,682 & \\ 73 & 44,684 \\ 6,268 & 44,749 \\ 1,719 & 10,85 \\ 0 & \\ 0 & \\ 0 & \\ 0 & \\ 872 & \end{array}$

Total Electric Operation and

Malntenance Expenses

8,859

57,471

0
0
0
0
3,292
0
3,292
0
921
0
0
0

0

4,213

6,400

21,803

\section{Fuel Expenses In Operation}

Steam Power Generation

Nuclear Power Generation

1,972

o

0

Other Power Generation

Number of Elec Dept Employees

Regular Full-time

7

Part-time \& Temporary

\section{1}

Total Elec Dept Employees
B

0
0
0
0
5,009
23

5,032

18,854
0

18,854

150

1,245

587

0

29

938

28

584

271

23,945

Note: Totals may not equal sum of components because of independent rounding.

Source: Energy Information Administration, Form EIA-412, "Annual Report of Public Electric Utilities." 
Table 23. Electric Operation and Maintenance Expenses by Major U.S. Publicly Owned Electric Utility Within State, 1993 (Continued)

(Thousand Dollars)

\begin{tabular}{c|c|c|c|c|c|c}
\hline & Tennessee & Tennessee & Tennessee & Tennessee & Tennessee & Tennessee \\
Item & $\begin{array}{c}\text { Benton } \\
\text { County }\end{array}$ & $\begin{array}{c}\text { Bolivar } \\
\text { City of }\end{array}$ & $\begin{array}{c}\text { Bristol } \\
\text { City of }\end{array}$ & $\begin{array}{c}\text { Brownsville } \\
\text { City of }\end{array}$ & $\begin{array}{c}\text { Carroll } \\
\text { County }\end{array}$ & $\begin{array}{c}\text { Chattanooga } \\
\text { City of }\end{array}$ \\
\hline
\end{tabular}

Production Expenses

Steam Power Generation

Nuclear Power Generation

Hydraulic Power Generation

Other Power Generation

Purchased Power ...................

Other Production Expenses

Total Production Expenses

Transmission Expenses

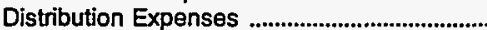

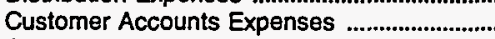

Customer Service and Information

Expenses

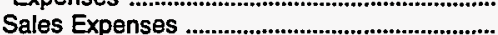

Administrative and General

Expenses

0
0
0
0
2,532
0

$2,532 \quad 10,344$

0

266
110

173

Total Electric Operatlon and

Maintenance Expenses
0
0
0
0
10,344

10,344
0

0

608
200

24

11

455

0
0
0
0
33,082
0

33,082

188

1,992

690

114

100

859

11,642

37,025 $\begin{array}{rr}0 & 0 \\ 0 & 0 \\ 0 & 0 \\ 0 & 0 \\ 16,172 & 226,889 \\ 0 & 0\end{array}$

16,172

226,889

1,285

14,830

5,610

280

8,883

196

8,888

18,484

258,777

Fuel Expenses in Operatlon

Steam Power Generation

Nuclear Power Generation

0

0

0

0

0

Other Power Generation

0

0

0

0

0

0

Number of Elec Dept Employees

Regular Full-time

11

38

61

13

48

508

Part-time \& Temporary

0

0

0

0

Total Elec Dept Employees

11

38

61

13

48

508

Note: Totals may not equal sum of components because of independent rounding.

Source: Energy Information Administration, Form EIA-412, "Annual Report of Public Electric Utilities." 
Table 23. Electric Operation and Maintenance Expenses by Major U.S. Publicly Owned Electric Utility Within State, 1993 (Continued)

(Thousand Dollars)

\begin{tabular}{|c|c|c|c|c|c|c|}
\hline \multirow{3}{*}{ Item } & Tennessee & Tennessee & Tennessee & Tennessee & Tennessee & Tennessee \\
\hline & $\begin{array}{c}\text { Clarksville } \\
\text { City of }\end{array}$ & $\begin{array}{l}\text { Cleveland } \\
\text { City of }\end{array}$ & $\begin{array}{l}\text { Clinton } \\
\text { City of }\end{array}$ & $\begin{array}{l}\text { Columbia } \\
\text { City of }\end{array}$ & $\begin{array}{c}\text { Cookeville } \\
\text { City of }\end{array}$ & $\begin{array}{l}\text { Covington } \\
\text { City of }\end{array}$ \\
\hline & June 30 & June 30 & June 30 & June 30 & June 30 & June 30 \\
\hline
\end{tabular}

Production Expenses

Steam Power Generation

Nuclear Power Generation .

Power Generation

Other Power Gener

Purchased Power .................................................

Other Production Expenses

Total Production Expenses

Transmission Expenses

Distribution Expenses .........................................

Customer Accounts Expenses .

Customer Service and Information

Expenses .............................................................

Sales Expenses ....................................................

Administrative and Genera

Expenses

Total Electric Operation and

Malntenance Expenses

0

35,499

0

35,499

188

2,047

960

194

57

1,145

40,090

36,910

0
0
0
0
10
0

36,910

149

2,091

602

58

125

963

40,899
0
0
0
0
26,313

26,313
0

26,313

106

1,728

748

14

40

1,006

29,954
24,408

0
0
0
0
22,045

0

22,045

0

1,421

333

30

26

553

$\begin{array}{rr}0 & 0 \\ 0 & 0 \\ 0 & 0 \\ 0 & 0 \\ 20,219 & 8,602 \\ 0 & 0\end{array}$

20,219

8,602

0
1,159

1,159
253

3

401

132

7

11

406

330

21,992

9,562

Fuel Expenses In Operatlon

Steam Power Generation

0

0

0

Other Power Generation

Number of Elec Dept Employees

Regular Full-time

76

0

76

Part-time \& Temporary

Total Elec Dept Employees
0

0

0
0

0

0

0

0

0

0

85

81

57

40

17

85

81

57

40

17

Note: Totals may not equal sum of components because of independent rounding

Source: Energy Information Administration, Form ElA-412, "Annual Report of Public Electric Utilities." 
Table 23. Electric Operation and Malntenance Expenses by Major U.S. Publicly Owned Electric Utility Within State, 1993 (Continued)

(Thousand Dollars)

\begin{tabular}{|c|c|c|c|c|c|c|}
\hline \multirow{3}{*}{ Item } & Tennessee & Tennessee & Tennessee & Tennessee & Tennessee & Tennessee \\
\hline & $\begin{array}{l}\text { Dayton } \\
\text { City of }\end{array}$ & $\begin{array}{l}\text { Dickson } \\
\text { City of }\end{array}$ & $\begin{array}{l}\text { Dyersburg } \\
\text { City of }\end{array}$ & $\begin{array}{c}\text { Elizabethton } \\
\text { City of }\end{array}$ & $\begin{array}{l}\text { Erwin } \\
\text { Town of }\end{array}$ & $\begin{array}{l}\text { Etowah } \\
\text { City of }\end{array}$ \\
\hline & June 30 & June 30 & June 30 & June 30 & June 30 & June 30 \\
\hline
\end{tabular}

Production Expenses

Steam Power Generation.

Nuclear Power Generation

Hydraulic Power Generation

Other Power Generation

Purchased Power

Other Production Expenses

Total Production Expenses

Transmission Expenses

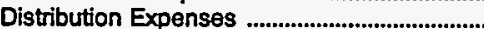

Customer Accounts Expenses

Customer Service and Information

Expenses

Sales Expenses

Administrative and General

Expenses

Total Electric Operation and

Malntenance Expenses

Fuel Expenses in Operation

Steam Power Generation

Nuclear Power Generation

Other Power Generation

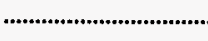

............

Number of Elec Dept Employees

Regular Full-time

Part-time \& Temporary

Total Elec Dept Employees

$\begin{array}{rr}0 & \\ 0 & \\ 0 & \\ 0 & \\ 8,781 & 25,35 \\ 0 & \end{array}$

0
0
0
0
22,379
0

0
0
0
0
21,423
0

22,379

21,423

8,748

$\begin{array}{rr}67 & 0\end{array}$

617

1,158

682

210

0
1,345

1

15

551

189

27,953

9,603

Note: Totals may not equal sum of components because of independent rounding.

Source: Energy Information Administration, Form EIA-412, "Annual Report of Public Electric Utilities." 
Table 23. Electric Operation and Maintenance Expenses by Major U.S. Publicly Owned Electric Utillty Within State, 1993 (Continued) (Thousand Dollars)

\begin{tabular}{c|c|c|c|c|c|c}
\hline & Tennessee & Tennessee & Tennessee & Tennessee & Tennessee & Tennessee \\
Item & $\begin{array}{c}\text { Fayetteville } \\
\text { City of }\end{array}$ & $\begin{array}{c}\text { Gallatin } \\
\text { City of }\end{array}$ & $\begin{array}{c}\text { Greeneville } \\
\text { City of }\end{array}$ & $\begin{array}{c}\text { Harriman } \\
\text { City of }\end{array}$ & $\begin{array}{c}\text { Humboldt } \\
\text { City of }\end{array}$ & $\begin{array}{c}\text { Jackson } \\
\text { City of }\end{array}$ \\
June 30 & June 30 & June 30 & June 30 & June 30 & June 30 \\
\hline
\end{tabular}

\section{Productlon Expenses}

Steam Power Generation

Nuclear Power Generation ...................................

Hydraulic Power Generation ..............................

Other Power Generation

Purchased Power .........................................................

Other Production Expenses ...............................

Total Production Expenses

Transmission Expenses ......................................

Distribution Expenses .........................................

Customer Accounts Expenses

Customer Service and Information

Expenses

Exponses

Administrative and General

Expenses

Total Electric Operation and

Malntenance Expenses

$\begin{array}{rrr}0 & 0 & \\ 0 & 0 & \\ 0 & 0 & \\ 0 & 0 & 37,08 \\ 15,893 & 18,546 & \\ 0 & 0 & \end{array}$

15,893

0
1,164

381

85

85
77

660

18,259

$$
18,546
$$

37,086

1
720

276

76
2,344

704

104

135

1,015

360

19,928

\section{0}

0
0
0
9,698

9,698
0

9,698

0

829

829
880

20

647

12,073

$\begin{array}{rr}0 & 0 \\ 0 & 0 \\ 0 & 0 \\ 0 & 0 \\ 9,433 & 48,493 \\ 0 & 0\end{array}$

9,433

48,493

11

449

211

1,779

136

48

1,538

242

10,291

52,859

\section{Fuel Expenses in Operation}

Steam Power Generation

Nuclear Power Generation

0

Other Power Generation

Number of Elec Dept Employees

Regular Full-time

63

Part-time \& Temporary

Total Elec Dept Employees

63

0

0

0

0

0

0

0

o

0

0

Note: Totals may not equal sum of components because of independent rounding.

Source: Energy Information Administration, Form ElA-412, "Annual Report of Public Electric Utilities." 
Table 23. Electric Operation and Maintenance Expenses by Major U.S. Publicly Owned Electric Utility Within State, 1993 (Continued)

(Thousand Dollars)

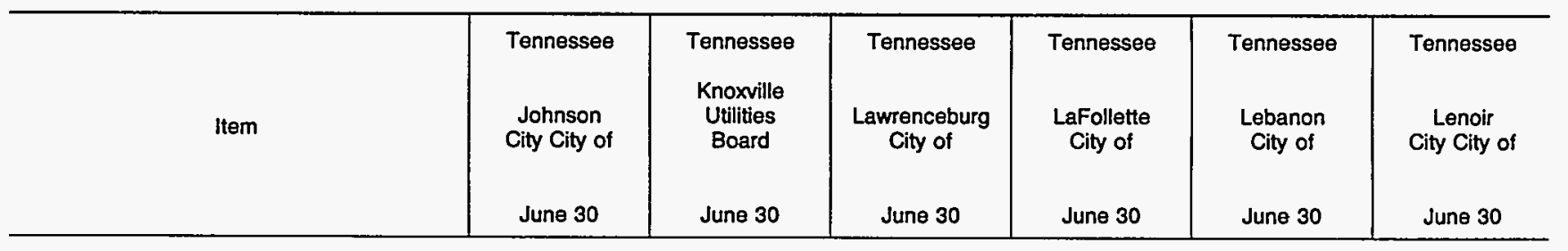

Production Expenses

Steam Power Generation

Nuclear Power Generation

Hydraulic Power Generat

Other Power Generation

Purchased Power

Other Production Expenses

Total Production Expenses

Transmission Expenses

Distribution Expenses ..........................................

Customer Accounts Expenses ............................

Customer Service and information

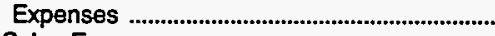

Administrative and General

Expenses

Total Electric Operation and

Maintenance Expenses

Fuel Expenses in Operation

Steam Power Generation .

Nuclear Power Generation

Other Power Generation

Number of Elec Dept Employees

Regular Full-time

109

Part-time \& Temporary

Total Elec Dept Employees

$\begin{array}{rr}0 & \\ 0 & \\ 0 & \\ 0 & \\ 67,284 & 203,51 \\ 0 & \end{array}$

67,284

664

2,947

1,465

64

149

1,030

73,602

203,511

0

0
12,534

6,107

481

977

232,511

232,611
0
0
0
0
14,771
0

14,771

19,343

64

891

457

20

13

925

21,713

17,431

1,478

517

73

27

544

$\begin{array}{rr}0 & 0 \\ 0 & 0 \\ 0 & 0 \\ 0 & 0 \\ 14,575 & 44,589 \\ 0 & 0\end{array}$

14,575

44,589

0
728

0

3,027

1,410

13

0
20

1,526

532

16,021

50,572

Note: Totals may not equal sum of components because of independent rounding.

Source: Energy Information Administration, Form ElA-412, "Annual Report of Public Electric Utilities." 
Table 23. Electric Operation and Maintenance Expenses by Major U.S. Publicly Owned Electric Utility Within State, 1993 (Continued) (Thousand Dollars)

\begin{tabular}{|c|c|c|c|c|c|c|}
\hline Item & $\begin{array}{l}\text { Tennessee } \\
\text { Lewisburg } \\
\text { City of } \\
\text { June } 30\end{array}$ & $\begin{array}{l}\text { Tennessee } \\
\text { Lexington } \\
\text { City of } \\
\text { June } 30\end{array}$ & $\begin{array}{l}\text { Tennessee } \\
\text { Loudon } \\
\text { Utilities } \\
\text { Board } \\
\text { June } 30\end{array}$ & $\begin{array}{c}\text { Tennessee } \\
\text { Maryville } \\
\text { Utilities } \\
\text { June } 30\end{array}$ & $\begin{array}{l}\text { Tennessee } \\
\text { McMinnville } \\
\text { Electric } \\
\text { System } \\
\text { June } 30\end{array}$ & $\begin{array}{l}\text { Tennessee } \\
\text { Memphis } \\
\text { City of } \\
\text { June } 30\end{array}$ \\
\hline 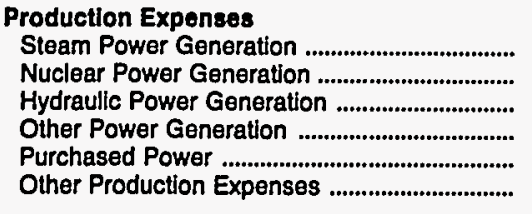 & $\begin{array}{r}0 \\
0 \\
0 \\
0 \\
11,712 \\
0\end{array}$ & $\begin{array}{r}0 \\
0 \\
0 \\
0 \\
16,337 \\
0\end{array}$ & $\begin{array}{r}0 \\
0 \\
0 \\
0 \\
11,042 \\
0\end{array}$ & $\begin{array}{r}0 \\
0 \\
0 \\
0 \\
21,520 \\
0\end{array}$ & $\begin{array}{r}0 \\
0 \\
0 \\
0 \\
9,218 \\
0\end{array}$ & $\begin{array}{r}0 \\
0 \\
0 \\
0 \\
494,152 \\
0\end{array}$ \\
\hline Total Productlon Expenses ............................. & 11,712 & 16,337 & 11,042 & 21,520 & 9,218 & 494,152 \\
\hline 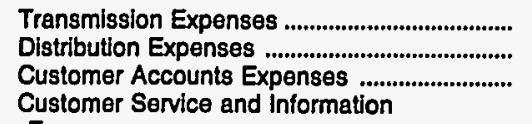 & $\begin{array}{r}0 \\
436 \\
125\end{array}$ & $\begin{array}{r}0 \\
1,420 \\
419\end{array}$ & $\begin{array}{r}1 \\
485 \\
106\end{array}$ & $\begin{array}{r}68 \\
1,034 \\
329\end{array}$ & $\begin{array}{r}0 \\
610 \\
178\end{array}$ & $\begin{array}{r}3,586 \\
42,327 \\
8,357\end{array}$ \\
\hline 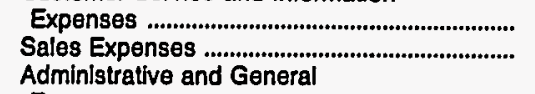 & $\begin{array}{r}20 \\
5\end{array}$ & $\begin{array}{l}21 \\
35\end{array}$ & $\begin{array}{r}0 \\
-1\end{array}$ & $\begin{array}{r}1 \\
16\end{array}$ & $\begin{array}{l}45 \\
24\end{array}$ & $\begin{array}{l}949 \\
659\end{array}$ \\
\hline Expenses ............................................................................... & 346 & 929 & 379 & 670 & 491 & 35,127 \\
\hline $\begin{array}{l}\text { Total Electric Operation and } \\
\text { Malntenance Expenses .................................. }\end{array}$ & 12,644 & 19,161 & 12,012 & 23,638 & 10,565 & 585,158 \\
\hline \multicolumn{7}{|l|}{ Fuel Expenses in Operation } \\
\hline 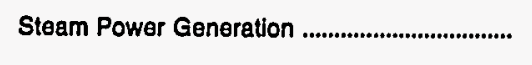 & 0 & 0 & 0 & 0 & 0 & 0 \\
\hline Nuclear Power Generation ..................................... & 0 & 0 & 0 & 0 & 0 & 0 \\
\hline 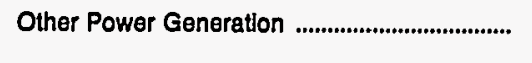 & 0 & 0 & 0 & 0 & 0 & 0 \\
\hline \multicolumn{7}{|l|}{ Number of Elec Dept Employees } \\
\hline 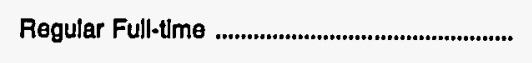 & 25 & 74 & 16 & 39 & 31 & 1,750 \\
\hline 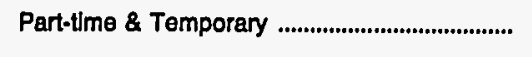 & 0 & 0 & 0 & 0 & 0 & 0 \\
\hline 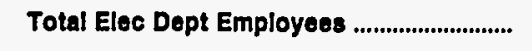 & 25 & 74 & 16 & 39 & 31 & 1,750 \\
\hline
\end{tabular}

Note: Totals may not equal sum of components because of independent rounding.

Source: Energy Information Administration, Form ElA-412, "Annual Report of Public Electric Utilities." 
Table 23. Electric Operation and Maintenance Expenses by Major U.S. Publicly Owned Electric Utility Within State, 1993 (Continued) (Thousand Dollars)

\begin{tabular}{|c|c|c|c|c|c|c|}
\hline Item & $\begin{array}{l}\text { Tennessee } \\
\text { Morristown } \\
\text { City of }\end{array}$ & $\begin{array}{c}\text { Tennessee } \\
\text { Murfreesboro } \\
\text { City of }\end{array}$ & $\begin{array}{c}\text { Tennessee } \\
\text { Nashville } \\
\text { Electric } \\
\text { Service }\end{array}$ & $\begin{array}{l}\text { Tennessee } \\
\text { Newport } \\
\text { City of }\end{array}$ & $\begin{array}{c}\text { Tennessee } \\
\text { Oak Ridge } \\
\text { City of }\end{array}$ & Tennessee \\
\hline & June 30 & June 30 & June 30 & June 30 & June 30 & June 30 \\
\hline
\end{tabular}

Productlon Expenses

Steam Power Generation

Nuclear Power Generation

.

Other Power

Purchased Power ......................................................

Other Production Expenses

Total Production Expenses

Transmission Expenses

Distribution Expenses

Customer Accounts Expenses ...........................

Customer Service and Information

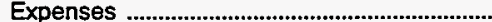

Sales Expenses .................................................

Administrative and General

Expenses

Total Electric Operation and

Maintenance Expenses
0
0
0
0
27,231
0

27,231

40

1,431

282

0

119

797

29,900

0
0
0
0
35,822
0

35,822

0
1,126

1,126
557

56

31

779

38,372

0
0
0
0
440,543
0

440,543

0

12,593

1,511

17,274

495,375
0
0
0
0
17,612
0

17,612

0
1,458

546

13

18

555

20,202

22,810

0
0
0
0
20,514
0

20,514

25

1,189
Fuel Expenses in Operation

Nuclear Power Generation

0

0

0

Other Power Generation

Number of Elec Dept Employees

Regular Full-time

63

66

0

Part-time \& Temporary

63

0

66

0

0

0

0

0

0

0

0

0
0

0

18,580

18,580

1. 0

383

34

16

525

Total Elec Dept Employees

925
0

52

67

50

Note: Totals may not equal sum of components because of independent rounding.

Source: Energy Information Administration, Form EIA-412, "Annual Report of Public Electric Utilities." 
Table 23. Electric Operation and Maintenance Expenses by Major U.S. Publicly Owned Electric Utility Within State, 1993 (Continued)

(Thousand Dollars)

\begin{tabular}{|c|c|c|c|c|c|c|}
\hline Item & $\begin{array}{l}\text { Tennessee } \\
\text { Pulaski } \\
\text { City of } \\
\text { June } 30\end{array}$ & $\begin{array}{l}\text { Tennessee } \\
\text { Ripley } \\
\text { City of } \\
\text { June } 30\end{array}$ & $\begin{array}{l}\text { Tennessee } \\
\text { Rockwood } \\
\text { City of } \\
\text { June } 30\end{array}$ & $\begin{array}{c}\text { Tennessee } \\
\text { Sevier } \\
\text { County } \\
\text { Electric } \\
\text { System } \\
\text { June } 30\end{array}$ & $\begin{array}{l}\text { Tennessee } \\
\text { Shelbyville } \\
\text { City of } \\
\text { June } 30\end{array}$ & $\begin{array}{l}\text { Tennessee } \\
\text { Springfield } \\
\text { City of } \\
\text { June } 30\end{array}$ \\
\hline 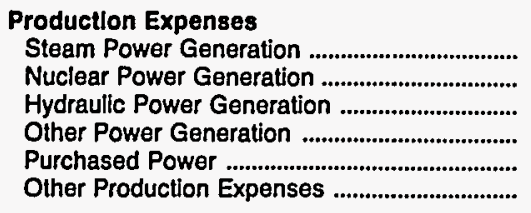 & $\begin{array}{r}0 \\
0 \\
0 \\
0 \\
15,781 \\
0\end{array}$ & $\begin{array}{r}0 \\
0 \\
0 \\
0 \\
10,687 \\
0\end{array}$ & $\begin{array}{r}0 \\
0 \\
0 \\
0 \\
12,289 \\
0\end{array}$ & $\begin{array}{r}0 \\
0 \\
0 \\
0 \\
38,446 \\
0\end{array}$ & $\begin{array}{r}0 \\
0 \\
0 \\
0 \\
13,909 \\
0\end{array}$ & $\begin{array}{r}0 \\
0 \\
0 \\
0 \\
8,397 \\
0\end{array}$ \\
\hline Total Production Expenses .......................... & 15,781 & 10,687 & 12,289 & 38,446 & 13,909 & 8,397 \\
\hline 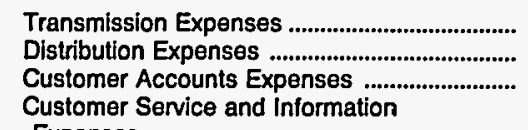 & $\begin{array}{r}0 \\
951 \\
222\end{array}$ & $\begin{array}{r}35 \\
385 \\
156\end{array}$ & $\begin{array}{r}0 \\
575 \\
297\end{array}$ & $\begin{array}{r}164 \\
1,813 \\
962\end{array}$ & $\begin{array}{r}0 \\
660 \\
204\end{array}$ & $\begin{array}{r}0 \\
451 \\
133\end{array}$ \\
\hline 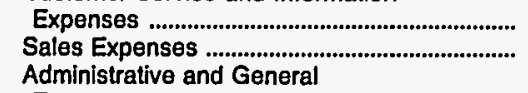 & $\begin{array}{l}48 \\
11\end{array}$ & $\begin{array}{r}4 \\
27\end{array}$ & $\begin{array}{l}4 \\
6\end{array}$ & $\begin{array}{l}39 \\
82\end{array}$ & $\begin{array}{r}17 \\
0\end{array}$ & $\begin{array}{r}20 \\
8\end{array}$ \\
\hline 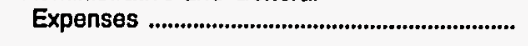 & 610 & 576 & 518 & 996 & 379 & 328 \\
\hline $\begin{array}{l}\text { Total Electric Operation and } \\
\text { Malntenance Expenses .................................. }\end{array}$ & 17,623 & 11,870 & 13,689 & 42,503 & 15,169 & 9,336 \\
\hline \multicolumn{7}{|l|}{ Fuel Expenses in Operation } \\
\hline Steam Power Generation ........................................ & 0 & 0 & 0 & 0 & 0 & 0 \\
\hline 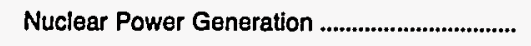 & 0 & 0 & 0 & 0 & 0 & 0 \\
\hline Other Power Generation & 0 & 0 & 0 & 0 & 0 & 0 \\
\hline \multicolumn{7}{|l|}{ Number of Elec Dept Employees } \\
\hline 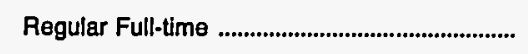 & 50 & 20 & 31 & 91 & 27 & 20 \\
\hline 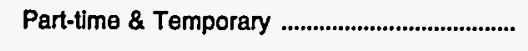 & $\mathbf{0}$ & 0 & 0 & 0 & 0 & 0 \\
\hline Total Elec Dept Employees .................................. & 50 & 20 & 31 & 91 & 27 & 20 \\
\hline
\end{tabular}

Note: Totals may not equal sum of components because of independent rounding.

Source: Energy Information Administration, Form EIA-412, "Annual Report of Public Electric Utilities." 
Table 23. Electric Operation and Maintenance Expenses by Major U.S. Publicly Owned Electric Utility Within State, 1993 (Continued)

(Thousand Dollars)

\begin{tabular}{|c|c|c|c|c|c|c|}
\hline Item & $\begin{array}{l}\text { Tennessee } \\
\text { Sweetwater } \\
\text { City of } \\
\text { June } 30\end{array}$ & $\begin{array}{l}\text { Tennessee } \\
\text { Tullahoma } \\
\text { Board } \\
\text { of } \\
\text { Pub Utils } \\
\text { June } 30\end{array}$ & $\begin{array}{l}\text { Tennessee } \\
\text { Union } \\
\text { City City of } \\
\text { June } 30\end{array}$ & $\begin{array}{l}\text { Tennessee } \\
\text { Weakley } \\
\text { County } \\
\text { Mun } \\
\text { Elec Sys } \\
\text { June } 30\end{array}$ & $\begin{array}{c}\text { Texas } \\
\text { Austin } \\
\text { City of } \\
\text { September } 30\end{array}$ & $\begin{array}{c}\text { Texas } \\
\text { Brenham } \\
\text { City of } \\
\text { September } 30\end{array}$ \\
\hline 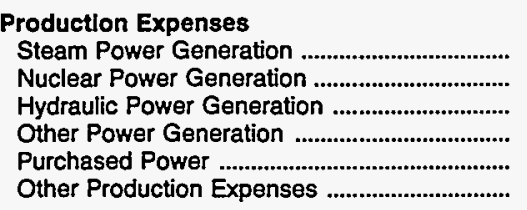 & $\begin{array}{r}0 \\
0 \\
0 \\
0 \\
7,869 \\
0\end{array}$ & $\begin{array}{r}0 \\
0 \\
0 \\
0 \\
11,474 \\
0\end{array}$ & $\begin{array}{r}0 \\
0 \\
0 \\
0 \\
13,054 \\
0\end{array}$ & $\begin{array}{r}0 \\
0 \\
0 \\
0 \\
20,574 \\
0\end{array}$ & $\begin{array}{r}159,582 \\
43,907 \\
0 \\
16 \\
11,450 \\
4,207\end{array}$ & $\begin{array}{r}0 \\
0 \\
0 \\
0 \\
9,751 \\
0\end{array}$ \\
\hline Total Production Expenses .............................. & 7,869 & 11,474 & 13,054 & 20,574 & 219,161 & 9,751 \\
\hline 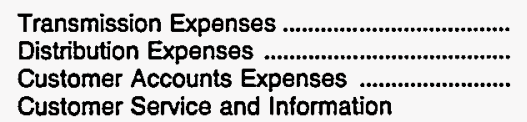 & $\begin{array}{r}0 \\
462 \\
163\end{array}$ & $\begin{array}{r}0 \\
635 \\
221\end{array}$ & $\begin{array}{r}44 \\
463 \\
164\end{array}$ & $\begin{array}{r}38 \\
1,093 \\
461\end{array}$ & $\begin{array}{r}1,826 \\
19,516 \\
12,457\end{array}$ & $\begin{array}{r}0 \\
451 \\
0\end{array}$ \\
\hline 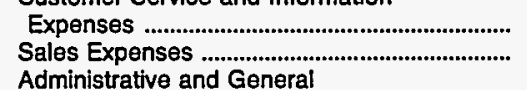 & $\begin{array}{r}10 \\
8\end{array}$ & $\begin{array}{l}15 \\
32\end{array}$ & $\begin{array}{l}18 \\
20\end{array}$ & $\begin{array}{l}33 \\
64\end{array}$ & $\begin{array}{r}10,800 \\
0\end{array}$ & $\begin{array}{l}0 \\
0\end{array}$ \\
\hline 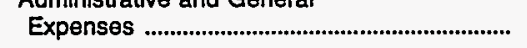 & 273 & 328 & 440 & 632 & 26,658 & 590 \\
\hline $\begin{array}{l}\text { Total Electric Operation and } \\
\text { Maintenance Expenses ..................................... }\end{array}$ & 8,785 & 12,705 & 14,204 & 22,895 & 290,418 & 10,792 \\
\hline \multicolumn{7}{|l|}{ Fuel Expenses in Operation } \\
\hline 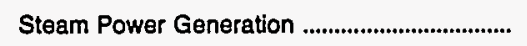 & 0 & 0 & 0 & 0 & 128,911 & 0 \\
\hline 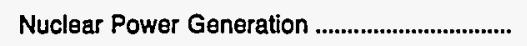 & 0 & 0 & 0 & 0 & 3,443 & 0 \\
\hline 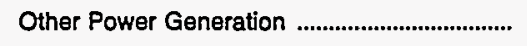 & 0 & 0 & 0 & 0 & 0 & 0 \\
\hline \multicolumn{7}{|l|}{ Number of Elec Dept Employees } \\
\hline Regular Full-time & 24 & 27 & 17 & 63 & 1,151 & 9 \\
\hline 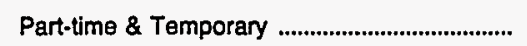 & 0 & 0 & 0 & 0 & 136 & 0 \\
\hline 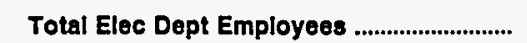 & 24 & 27 & 17 & 63 & 1,287 & 9 \\
\hline
\end{tabular}

Note: Totals may not equal sum of components because of independent rounding.

Source: Energy Information Administration, Form EIA-412, "Annual Report of Public Electric Utilities." 
Table 23. Electric Operation and Maintenance Expenses by Major U.S. Publicly Owned Electric Utility Within State, 1993 (Continued) (Thousand Dollars)

\begin{tabular}{|c|c|c|c|c|c|c|}
\hline Item & $\begin{array}{c}\text { Texas } \\
\text { Brownsville } \\
\text { Public } \\
\text { Utils Board } \\
\text { September } 30\end{array}$ & $\begin{array}{c}\text { Texas } \\
\text { Bryan } \\
\text { City of } \\
\text { September } 30\end{array}$ & $\begin{array}{c}\text { Texas } \\
\text { College } \\
\text { Station } \\
\text { City of } \\
\text { September } 30\end{array}$ & $\begin{array}{l}\text { Texas } \\
\text { Denton } \\
\text { City of } \\
\text { September } 30\end{array}$ & $\begin{array}{c}\text { Texas } \\
\text { Floresville } \\
\text { City of }\end{array}$ & $\begin{array}{c}\text { Texas } \\
\text { Garland } \\
\text { City of } \\
\text { September } 30\end{array}$ \\
\hline \multicolumn{7}{|l|}{ Production Expenses } \\
\hline 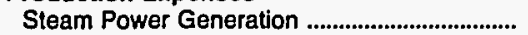 & 17,217 & 11,782 & 0 & 9,330 & 0 & 39,561 \\
\hline 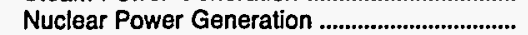 & & 0 & 0 & 0 & 0 & 0 \\
\hline 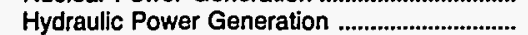 & 0 & 0 & 0 & 89 & 0 & 0 \\
\hline 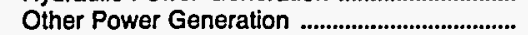 & 0 & 7,118 & 0 & 0 & 0 & 0 \\
\hline Purchased Power ........................................................... & 6,700 & 31,089 & 18,478 & 40,852 & 6,587 & 70,362 \\
\hline 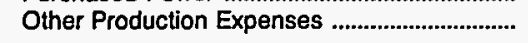 & 711 & 268 & 856 & 0 & 0 & 109 \\
\hline Total Production Expenses ............................. & 24,628 & 50,259 & 19,335 & 50,271 & 6,587 & 110,032 \\
\hline Transmission Expenses ........................................... & 1,529 & 0 & 148 & 0 & 0 & 732 \\
\hline 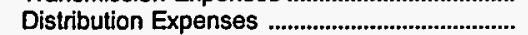 & 937 & 3,285 & 1,234 & 4,399 & 582 & 7,224 \\
\hline 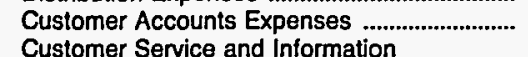 & 622 & 1,412 & 926 & 0 & 570 & 2,608 \\
\hline 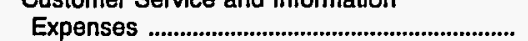 & 0 & 0 & 0 & 0 & 0 & 721 \\
\hline $\begin{array}{l}\text { Sales Expenses ................................................................... } \\
\text { Administrative and General }\end{array}$ & 0 & 0 & 0 & 0 & 0 & 1.051 \\
\hline 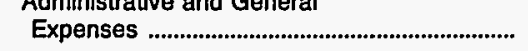 & 2,702 & 2,199 & 1,110 & 1,083 & 886 & 1,394 \\
\hline $\begin{array}{l}\text { Total Electric Operation and } \\
\text { Malntenance Expenses .................................... }\end{array}$ & 30,418 & 57,154 & 22,752 & 55,754 & 8,626 & 123,763 \\
\hline \multicolumn{7}{|l|}{ Fuel Expenses in Operation } \\
\hline 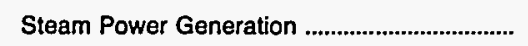 & 12,379 & 9,799 & 0 & 6,943 & 0 & 31,399 \\
\hline 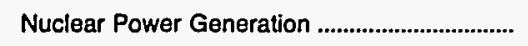 & 0 & 0 & 0 & 0 & 0 & 0 \\
\hline 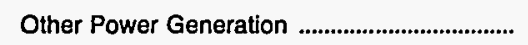 & 0 & 5,356 & 0 & 0 & 0 & 0 \\
\hline \multicolumn{7}{|l|}{ Number of Elec Dept Employees } \\
\hline Regular Full-time & 110 & 194 & 86 & 38 & 57 & 187 \\
\hline 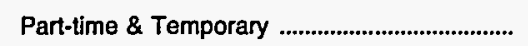 & 49 & 4 & 3 & $\mathbf{0}$ & 4 & 1 \\
\hline Total Elec Dept Employees ........................... & 159 & 198 & 89 & 38 & 61 & 188 \\
\hline
\end{tabular}

Note: Totals may not equal sum of components because of independent rounding.

Source: Energy Information Administration, Form EIA-412, "Annual Report of Public Electric Utilities." 
Table 23. Electric Operation and Maintenance Expenses by Major U.S. Publicly Owned Electric Utility Within State, 1993 (Continued)

(Thousand Dollars)

\begin{tabular}{|c|c|c|c|c|c|c|}
\hline Item & $\begin{array}{c}\text { Texas } \\
\text { Georgetown } \\
\text { City of }\end{array}$ & $\begin{array}{c}\text { Texas } \\
\text { Greenville } \\
\text { Electric } \\
\text { Util Sys } \\
\text { September } 30\end{array}$ & $\begin{array}{c}\text { Texas } \\
\text { Kerrville } \\
\text { Public } \\
\text { Utility } \\
\text { Board } \\
\text { September } 30\end{array}$ & $\begin{array}{l}\text { Texas } \\
\text { Lower } \\
\text { Colorado } \\
\text { River } \\
\text { Authority } \\
\text { June } 30\end{array}$ & $\begin{array}{c}\text { Texas } \\
\text { Lubbock } \\
\text { City of } \\
\text { September } 30\end{array}$ & $\begin{array}{c}\text { Texas } \\
\begin{array}{c}\text { New Braunfels } \\
\text { City of }\end{array} \\
\text { July } 31\end{array}$ \\
\hline 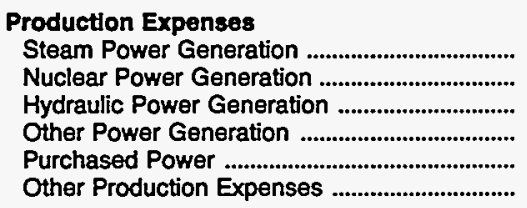 & $\begin{array}{r}0 \\
0 \\
0 \\
0 \\
7,456 \\
0\end{array}$ & $\begin{array}{r}4,380 \\
0 \\
0 \\
184 \\
17,854 \\
0\end{array}$ & $\begin{array}{r}0 \\
0 \\
0 \\
0 \\
14,711 \\
0\end{array}$ & $\begin{array}{r}179,694 \\
0 \\
4,342 \\
0 \\
1,288 \\
4,524\end{array}$ & $\begin{array}{r}16,457 \\
0 \\
0 \\
3,907 \\
11,184 \\
0\end{array}$ & $\begin{array}{r}0 \\
0 \\
83 \\
0 \\
28,836 \\
0\end{array}$ \\
\hline Total Production Expenses ............................ & 7,456 & 22,417 & 14,711 & 189,848 & 31,549 & 28,920 \\
\hline 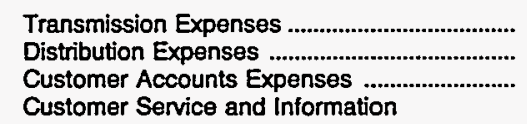 & $\begin{array}{r}0 \\
1,445 \\
0\end{array}$ & $\begin{array}{r}0 \\
1,220 \\
0\end{array}$ & $\begin{array}{r}0 \\
1.191 \\
430\end{array}$ & $\begin{array}{r}24,676 \\
0 \\
596\end{array}$ & $\begin{array}{r}0 \\
3.221 \\
3.491\end{array}$ & $\begin{array}{r}94 \\
978 \\
278\end{array}$ \\
\hline 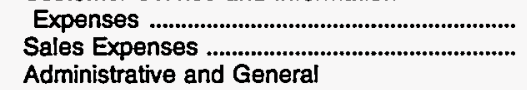 & $\begin{array}{l}0 \\
0\end{array}$ & $\begin{array}{l}0 \\
0\end{array}$ & $\begin{array}{r}51 \\
0\end{array}$ & $\begin{array}{r}908 \\
0\end{array}$ & $\begin{array}{r}0 \\
948\end{array}$ & $\begin{array}{l}0 \\
0\end{array}$ \\
\hline 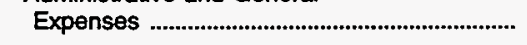 & 0 & 2,388 & 959 & 3,240 & 366 & 1,446 \\
\hline $\begin{array}{l}\text { Total Electric Operation and } \\
\text { Malntenance Expenses }\end{array}$ & 8,902 & 26,025 & 17,342 & 219,269 & 39,575 & 31,715 \\
\hline \multicolumn{7}{|l|}{ Fuel Expenses in Operation } \\
\hline 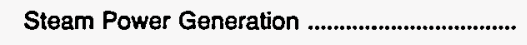 & 0 & 2,371 & 0 & 137,425 & 13,672 & 0 \\
\hline 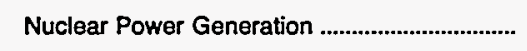 & 0 & 0 & 0 & 0 & 0 & 0 \\
\hline 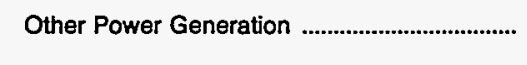 & 0 & 7 & 0 & 0 & 3,547 & 0 \\
\hline \multicolumn{7}{|l|}{ Number of Elec Dept Employees } \\
\hline Regutar Full-time & 10 & 74 & 68 & 738 & 204 & 70 \\
\hline Part-time \& Temporary & $\mathbf{0}$ & 1 & 0 & 0 & 1 & 0 \\
\hline Total Elec Dept Employees ................................. & 10 & 75 & 68 & 738 & 205 & 70 \\
\hline
\end{tabular}

Note: Totals may not equal sum of components because of independent rounding.

Source: Energy Information Administration, Form EIA-412, "Annual Report of Public Electric Utilities." 
Table 23. Electric Operation and Maintenance Expenses by Major U.S. Publicly Owned Electric Utility Within State, 1993 (Continued) (Thousand Dollars)

\begin{tabular}{|c|c|c|c|c|c|c|}
\hline Item & $\begin{array}{c}\text { Texas } \\
\text { Sam Rayburn } \\
\text { Municipal } \\
\text { Pwr } \\
\text { Agny } \\
\text { September } 30\end{array}$ & $\begin{array}{l}\text { Texas } \\
\text { San Antonio } \\
\text { City of } \\
\text { January } 31\end{array}$ & $\begin{array}{c}\text { Texas } \\
\text { San Marcos } \\
\text { City of } \\
\text { September } 30\end{array}$ & $\begin{array}{l}\text { Texas } \\
\text { Seguin } \\
\text { City of } \\
\text { September } 30\end{array}$ & $\begin{array}{c}\text { Texas } \\
\text { Texas } \\
\text { Municipal } \\
\text { Power Agency } \\
\text { September } 30\end{array}$ & $\begin{array}{l}\text { Texas } \\
\text { Toledo Bend } \\
\text { Project } \\
\text { Joint } \\
\text { Oper } \\
\text { August } 30\end{array}$ \\
\hline 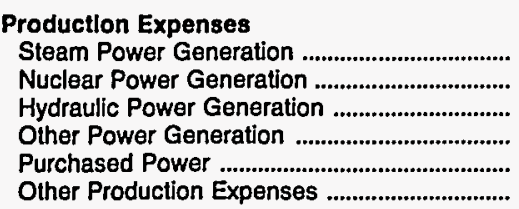 & $\begin{array}{r}14,249 \\
0 \\
0 \\
0 \\
2,950 \\
0\end{array}$ & $\begin{array}{r}229,012 \\
76,944 \\
0 \\
0 \\
1,894 \\
-229\end{array}$ & $\begin{array}{r}0 \\
0 \\
0 \\
0 \\
12,771 \\
0\end{array}$ & $\begin{array}{r}0 \\
0 \\
0 \\
0 \\
7,732 \\
0\end{array}$ & $\begin{array}{r}67,626 \\
0 \\
0 \\
0 \\
0 \\
28\end{array}$ & $\begin{array}{r}0 \\
0 \\
100 \\
0 \\
0 \\
0\end{array}$ \\
\hline Total Productlon Expenses ......................... & 17,199 & 307,622 & 12,771 & 7,732 & 67,654 & 100 \\
\hline 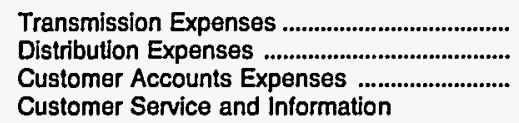 & $\begin{array}{l}0 \\
0 \\
0\end{array}$ & $\begin{array}{r}2,449 \\
28,691 \\
7,077\end{array}$ & $\begin{array}{r}0 \\
840 \\
825\end{array}$ & $\begin{array}{r}0 \\
723 \\
0\end{array}$ & $\begin{array}{r}4,005 \\
0 \\
0\end{array}$ & $\begin{array}{l}0 \\
0 \\
0\end{array}$ \\
\hline 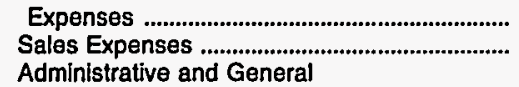 & $\begin{array}{l}0 \\
0\end{array}$ & $\begin{array}{r}2,061 \\
0\end{array}$ & $\begin{array}{r}66 \\
0\end{array}$ & $\begin{array}{l}0 \\
0\end{array}$ & $\begin{array}{l}0 \\
0\end{array}$ & $\begin{array}{l}0 \\
0\end{array}$ \\
\hline 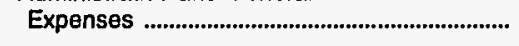 & 1,095 & 66,460 & 962 & $\mathbf{0}$ & 12,251 & 6,929 \\
\hline $\begin{array}{l}\text { Total Electric Operation and } \\
\text { Malntenance Expenses }\end{array}$ & 18,295 & 414,360 & 15,465 & 8,455 & 83,910 & 7,029 \\
\hline \multicolumn{7}{|l|}{ Fuel Expenses in Operation } \\
\hline Steam Power Generation ...................................... & 10,656 & 196,732 & 0 & 0 & 52,166 & 0 \\
\hline Nuclear Power Generation .................................. & 0 & 437 & 0 & 0 & 0 & 0 \\
\hline Other Power Generation ................................... & 0 & 0 & 0 & 0 & 0 & 0 \\
\hline \multicolumn{7}{|l|}{ Number of Elec Dept Employees } \\
\hline 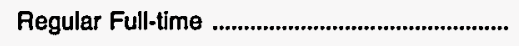 & 3 & 2,765 & 42 & 20 & 318 & 14 \\
\hline 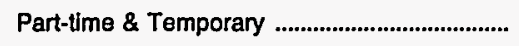 & 0 & 0 & 0 & 0 & 38 & 0 \\
\hline 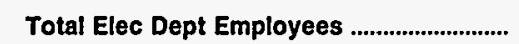 & 3 & 2,765 & 42 & 20 & 356 & 14 \\
\hline
\end{tabular}

Note: Totals may not equal sum of components because of independent rounding.

Source: Energy Information Administration, Form EIA-412, "Annual Report of Public Electric Utilities." 
Table 23. Electric Operation and Maintenance Expenses by Major U.S. Publicly Owned Electric Utility Within State, 1993 (Continued)

(Thousand Dollars)

\begin{tabular}{|c|c|c|c|c|c|c|}
\hline Item & $\begin{array}{c}\text { Texas } \\
\text { Weatherford } \\
\text { Mun } \\
\text { Utility } \\
\text { System } \\
\text { September } 30\end{array}$ & $\begin{array}{c}\text { Utah } \\
\text { Bountiful } \\
\text { City City of } \\
\text { June } 30\end{array}$ & $\begin{array}{c}\text { Utah } \\
\text { Intermountain } \\
\text { Power Agency } \\
\text { June } 30\end{array}$ & $\begin{array}{l}\text { Utah } \\
\text { Logan } \\
\text { City of } \\
\text { June } 30\end{array}$ & $\begin{array}{l}\text { Utah } \\
\text { Murray } \\
\text { City of } \\
\text { June } 30\end{array}$ & $\begin{array}{l}\text { Utah } \\
\text { Provo } \\
\text { City Corp } \\
\text { June } 30\end{array}$ \\
\hline \multicolumn{7}{|l|}{ Production Expenses } \\
\hline 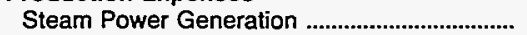 & 0 & 0 & 239,301 & 0 & 0 & 0 \\
\hline Nuclear Power Generation ......................................... & 0 & 0 & o & 0 & 0 & 0 \\
\hline Hydraulic Power Generation ................................... & 0 & 184 & 0 & 124 & 85 & 0 \\
\hline 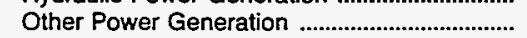 & 205 & 664 & 0 & 123 & 109 & 0 \\
\hline 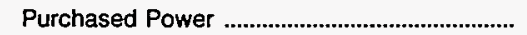 & 7,589 & 4,667 & 0 & 8,117 & 9,124 & 20,788 \\
\hline 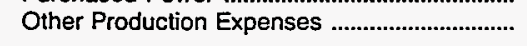 & 0 & 380 & 0 & 0 & 0 & 0 \\
\hline Total Production Expenses ......................... & 7,794 & 5,895 & 239,301 & 8,364 & 9,318 & 20,788 \\
\hline 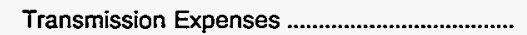 & 0 & 33 & 10,055 & 216 & 94 & 555 \\
\hline 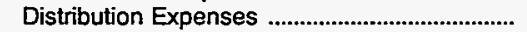 & 751 & 1,024 & 0 & 957 & 1,324 & 1,339 \\
\hline 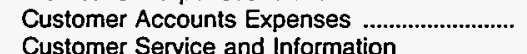 & 202 & 72 & 0 & 0 & 387 & 865 \\
\hline Customer Service and Information & & & & & & \\
\hline 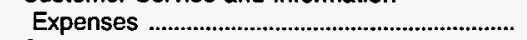 & 0 & 0 & 0 & 0 & 192 & 669 \\
\hline Sales Expenses ................................................... & 0 & 0 & 0 & 185 & 0 & 0 \\
\hline 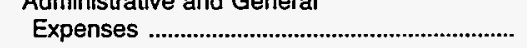 & 926 & 1,147 & 13,437 & 1,176 & 1,565 & 1,075 \\
\hline 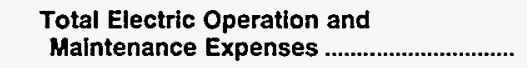 & 9,673 & 8,171 & 262,793 & 10,898 & 12,880 & 25,291 \\
\hline \multicolumn{7}{|l|}{ Fuel Expenses in Operation } \\
\hline 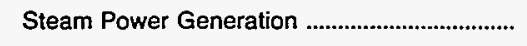 & 0 & 0 & 193,476 & 0 & 0 & 0 \\
\hline 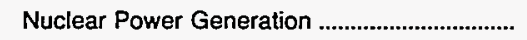 & 0 & 0 & 0 & 0 & 0 & 0 \\
\hline 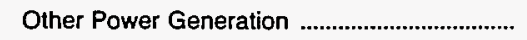 & 46 & 465 & 0 & 64 & 11 & 0 \\
\hline \multicolumn{7}{|l|}{ Number of Elec Dept Employees } \\
\hline Regular Full-time & 37 & 34 & 612 & 58 & 50 & 107 \\
\hline 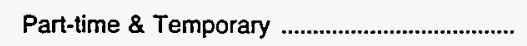 & 3 & 5 & 0 & 0 & 1 & 34 \\
\hline 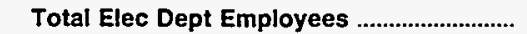 & 40 & 39 & 612 & 58 & 51 & 141 \\
\hline
\end{tabular}

Note: Totals may not equal sum of components because of independent rounding.

Source: Energy Information Administration, Form EIA-412, "Annual Report of Public Electric Utilities." 
Table 23. Electric Operation and Maintenance Expenses by Major U.S. Publicly Owned Electric Utility Within State, 1993 (Continued) (Thousand Dollars)

\begin{tabular}{|c|c|c|c|c|c|c|}
\hline Item & $\begin{array}{c}\text { Utah } \\
\text { St George } \\
\text { City of } \\
\text { June } 30\end{array}$ & $\begin{array}{c}\text { Utah } \\
\text { Utah } \\
\text { Associated } \\
\text { Mun } \\
\text { Power Sys } \\
\text { March } 31\end{array}$ & $\begin{array}{c}\text { Utah } \\
\text { Utah } \\
\text { Municipal } \\
\text { Power Agency } \\
\text { June } 30\end{array}$ & $\begin{array}{c}\text { Vermont } \\
\text { Burlington } \\
\text { City of } \\
\text { December } 31\end{array}$ & $\begin{array}{l}\text { Vermont } \\
\text { Vermont } \\
\text { Public } \\
\text { Pwr } \\
\text { Supply Auth } \\
\text { December } 31\end{array}$ & $\begin{array}{l}\text { Virginia } \\
\text { Bedford } \\
\text { City of } \\
\text { June } 30\end{array}$ \\
\hline 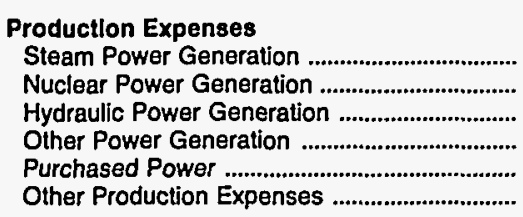 & $\begin{array}{r}0 \\
0 \\
0 \\
428 \\
11,315 \\
0\end{array}$ & $\begin{array}{r}6,628 \\
0 \\
0 \\
0 \\
14,531 \\
0\end{array}$ & $\begin{array}{r}7,300 \\
0 \\
0 \\
10,430 \\
6,940 \\
0\end{array}$ & $\begin{array}{r}2,914 \\
0 \\
0 \\
110 \\
14,248 \\
549\end{array}$ & $\begin{array}{r}1,118 \\
0 \\
0 \\
0 \\
2,577 \\
3\end{array}$ & $\begin{array}{r}0 \\
0 \\
124 \\
0 \\
7,150 \\
0\end{array}$ \\
\hline Total Production Expenses ............................. & 11,743 & 21,159 & 24,670 & 17,821 & 3,697 & 7,275 \\
\hline 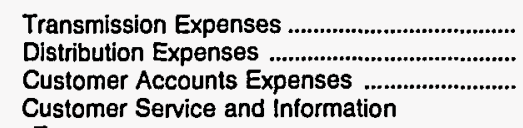 & $\begin{array}{l}0 \\
0 \\
0\end{array}$ & $\begin{array}{r}3,906 \\
0 \\
0\end{array}$ & $\begin{array}{r}1,222 \\
0 \\
0\end{array}$ & $\begin{array}{r}430 \\
2,079 \\
1,211\end{array}$ & $\begin{array}{r}26 \\
0 \\
0\end{array}$ & $\begin{array}{l}197 \\
205 \\
100\end{array}$ \\
\hline 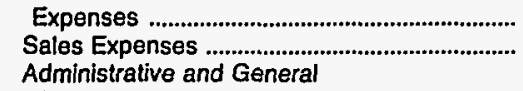 & $\begin{array}{l}0 \\
0\end{array}$ & $\begin{array}{l}0 \\
0\end{array}$ & $\begin{array}{l}0 \\
0\end{array}$ & $\begin{array}{r}221 \\
0\end{array}$ & $\begin{array}{l}0 \\
0\end{array}$ & $\begin{array}{l}0 \\
0\end{array}$ \\
\hline 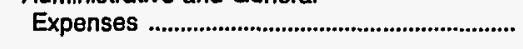 & 2,041 & 2,558 & 400 & 2,848 & 1,181 & 412 \\
\hline 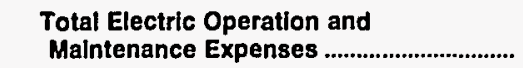 & 13,784 & 27,623 & 26,292 & 24,610 & 4,904 & 8,188 \\
\hline \multicolumn{7}{|l|}{ Fuel Expenses in Operation } \\
\hline 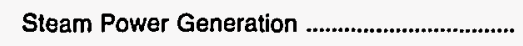 & 0 & 5,176 & 4,648 & 1,882 & 697 & 0 \\
\hline 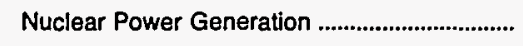 & 0 & 0 & 0 & 0 & 0 & 0 \\
\hline 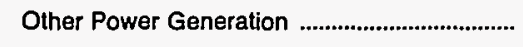 & 31 & 0 & 4,427 & 48 & 0 & 0 \\
\hline \multicolumn{7}{|l|}{ Number of Elec Dept Employees } \\
\hline Regular Full-time & 42 & 18 & 4 & 161 & 10 & 15 \\
\hline 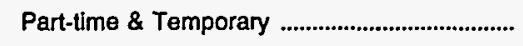 & 5 & 0 & 0 & 4 & 0 & 0 \\
\hline Total Elec Dept Employees ................................. & 47 & 18 & 4 & 165 & 10 & 15 \\
\hline
\end{tabular}

Note; Totals may not equal sum of components because of independent rounding.

Source: Energy Information Administration, Form ElA-412, "Annual Report of Public Electric Utilities." 
Table 23. Electric Operation and Maintenance Expenses by Major U.S. Publicly Owned Electric Utility Within State, 1993 (Continued)

(Thousand Dollars)

\begin{tabular}{c|c|c|c|c|c|c}
\hline & Virginia & Virginia & Virginia & Virginia & Virginia \\
Bristol & $\begin{array}{c}\text { Utilities } \\
\text { Board }\end{array}$ & $\begin{array}{c}\text { Danville } \\
\text { City of }\end{array}$ & $\begin{array}{c}\text { Harrisonburg } \\
\text { City of }\end{array}$ & $\begin{array}{c}\text { Manassas } \\
\text { City of }\end{array}$ & $\begin{array}{c}\text { Martinsville } \\
\text { City of }\end{array}$ & $\begin{array}{c}\text { Radford } \\
\text { City of }\end{array}$ \\
June 30 & June 30 & June 30 & June 30 & June 30 & June 30 \\
\hline
\end{tabular}

Production Expenses

Steam Power Generation

Nuclear Power Generation

Hydraulic Power Generation

Other Power Generation

Purchased Power

Other Production Expenses ...............................

Total Production Expenses

Transmission Expenses

Distribution Expenses

Customer Accounts Expenses

Customer Service and Information

Expenses

Sales Expenses

Administrative and General

Expenses

\section{Total Electric Operation and}

Malntenance Expenses

0
0
0
0
22,016
0

22,016

0
1,057

318

22

25

638

24,075

0
0
426
0
26,127
393

26,946

449

1,269

953

0
0

593

30,209

0
0
0
0
22,098
0

22,098

29
1,010

423

0
26

721

24,307

0
0
74
0
7,149
0

0

0

0

9,389

20

9,429

0

372
0

145

540

10,487

\section{Fuel Expenses in Operation}

Steam Power Generation .................................

Nuclear Power Generation

Other Power Generation

Number of Elec Dept Employees

Regular Full-time

Part-time \& Temporary

Total Elec Dept Employees
0

0

0

41

0

41
0

0

0

72

1

73
0

0

0

49

4

53

48
0
48

22

25

Note: Totals may not equal sum of components because of independent rounding.

Source: Energy Information Administration, Form ElA-412, "Annual Report of Public Electric Utilities." 
Table 23. Electric Operation and Maintenance Expenses by Major U.S. Publicly Owned Electric Utility Within State, 1993 (Continued) (Thousand Dollars)

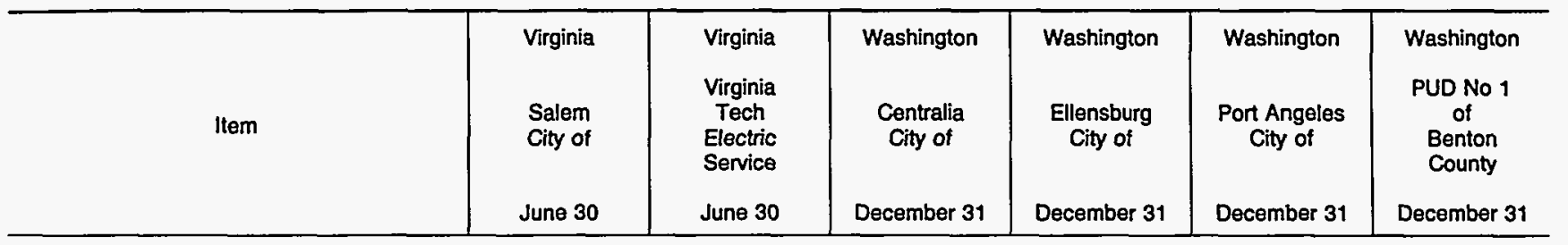

\section{Production Expenses}

Steam Power Generation

Nuclear Power Generation

Hydraulic Power Generation

Other Power Generation

Purchased Power.

Other Production Expenses

Total Production Expenses

Transmission Expenses

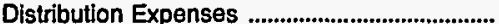

Customer Accounts Expenses ..........................

Customer Service and Information

Expenses .

Sales Expenses

Administrative and General

Expenses

Total Electrlc Operation and

Maintenance Expenses

Fuel Expenses in Operation

Steam Power Generation

Nuclear Power Generation

Other Power Generation

n ..................................

Number of Elec Dept Employees

Regular Full-time

Part-time \& Temporary

Total Elec Dept Employees

0
0
0
0
11,941
0

11,941

0
1,014

194

563

13,712

206

0

0

7,366

0

2,600

300

0
0
740
0
5,037
0

$\mathbf{5 , 7 7 7}$

104

715

815

0

398

835

11,307

7,809
0
0
31
0
15,606
0

15,637

1
1,531

1,531
832

287

233

18,521

42,745

Note: Totals may not equal sum of components because of independent rounding.

Source: Energy Information Administration, Form ElA-412, "Annual Report of Public Electric Utilities." 
Table 23. Electric Operation and Maintenance Expenses by Major U.S. Publicly Owned Electric Utility Within State, 1993 (Continued) (Thousand Dollars)

\begin{tabular}{c|c|c|c|c|c|c}
\hline & Washington & Washington & Washington & Washington & Washington & Washington \\
Item & $\begin{array}{c}\text { PUD No 1 } \\
\text { of } \\
\text { Chelan }\end{array}$ & $\begin{array}{c}\text { PUD No 1 of } \\
\text { Clallam } \\
\text { County }\end{array}$ & $\begin{array}{c}\text { PUD No 1 } \\
\text { of } \\
\text { Clark } \\
\text { County }\end{array}$ & $\begin{array}{c}\text { PUD No 1 of } \\
\text { Cowlitz } \\
\text { County }\end{array}$ & $\begin{array}{c}\text { PUD No 1 of } \\
\text { Douglas } \\
\text { County }\end{array}$ & $\begin{array}{c}\text { PUD No 1 of } \\
\text { Franklin } \\
\text { County }\end{array}$ \\
& $\begin{array}{c}\text { County } \\
\text { December 31 }\end{array}$ & December 31 & December 31 & December 31 & December 31 & December 31 \\
\hline
\end{tabular}

\section{Production Expenses}

Steam Power Generation

Nuclear Power Generation

Hydraulic Power Generation

Other Power Generation

Purchased Power

Other Production Expenses ................................

Total Production Expenses

Transmission Expenses

Distribution Expenses

Customer Accounts Expenses

Customer Service and Information

Expenses

penses

Administrative and General

Expenses

Total Electric Operation and

Maintenance Expenses
18,307

18,307

5,214

12,801

36,322

2,692

4,549

594

1,319

0

15,193

60,669

0

0

0
13,064

0

13,064

129

1,689

1,002

139
0

2,272

18,296
0
0
0
0

93,177

0

93,177

41
6,379

5,127

624

19

6,640

112,007
0
0
424
0
103,005
2,182

0

6,198

0

1,771

325

8,294

105,611

778

2,077

312

1,508

161

46
0

5,334

16,841

Fuel Expenses in Operation

Steam Power Generation .

Nuclear Power Generation

Other Power Generation

Number of Elec Dept Employees

Regular Full-time

Part-time \& Temporary

Total Elec Dept Employees
0

0

469

7

0
0
0

0

0

0

320

26

476
104

11

115
346

138

126

60

3

4

141

130

64

Note: Totals may not equal sum of components because of independent rounding

Source: Energy Information Administration, Form ElA-412, "Annual Report of Public Electric Utilities." 
Table 23. Electric Operation and Maintenance Expenses by Major U.S. Publicly Owned Electric Utility Within State, 1993 (Continued) (Thousand Dollars)

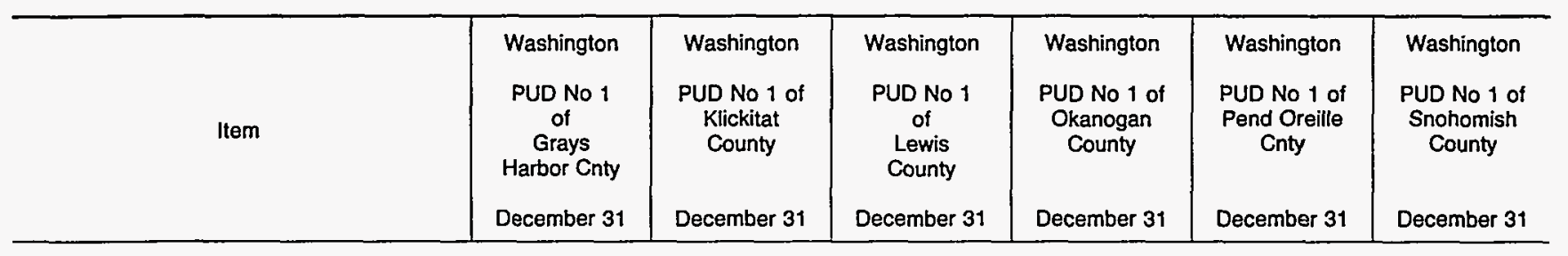

\section{Production Expenses}

Steam Power Generation

Nuclear Power Generation

Hydraulic Power Generation

Other Power Generation .

Other Production Expenses

Total Production Expenses

Transmission Expenses

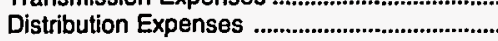

Customer Accounts Expenses ...........................

Customer Service and Information

Expenses

Sales Expenses .....................................................

Administrative and General

Expenses

Total Electric Operation and

Maintenance Expenses.

6,229
0
0
0
25,563
13
31,805
515
5,728
1,787
115
0
3,507

43,458

0
563

13

31,805

515

528
.787

115

0

507

\section{6,229}

5,153

0

0

0
0
0
0
6,844
0

0
0
13
0
17,001
97

6,844

17,110

32

933
408

79
0

822

9,117

147
2,108

1,149

0

2

608

21,125

0
0
9
0
9,502
33

1,500

1,500

0
9,935

843

9,544

12,278

30
1,516

482

6

1,247

367

16

177
0

15

1,794

13,421

0
1,672

0
88,638

30,659

174,390

2,943

22,136

7,570

2,428

1,263

16,199

13,012

15,723

225,666

\section{Fuel Expenses In Operation}

Steam Power Generation .................................

Nuclear Power Generation

Other Power Generation

Number of Elec Dept Employees

Regular Full-time

160

47

15

57

57

894

Part-time \& Temporary

$$
7
$$

167

7

54
0

15

67

894

Note: Totals may not equal sum of components because of independent rounding.

Source: Energy Information Administration, Form ElA-412, "Annual Report of Public Electric Utilities." 
Table 23. Electric Operation and Maintenance Expenses by Major U.S. Publicly Owned Electric Utility Within State, 1993 (Continued)

(Thousand Dollars)

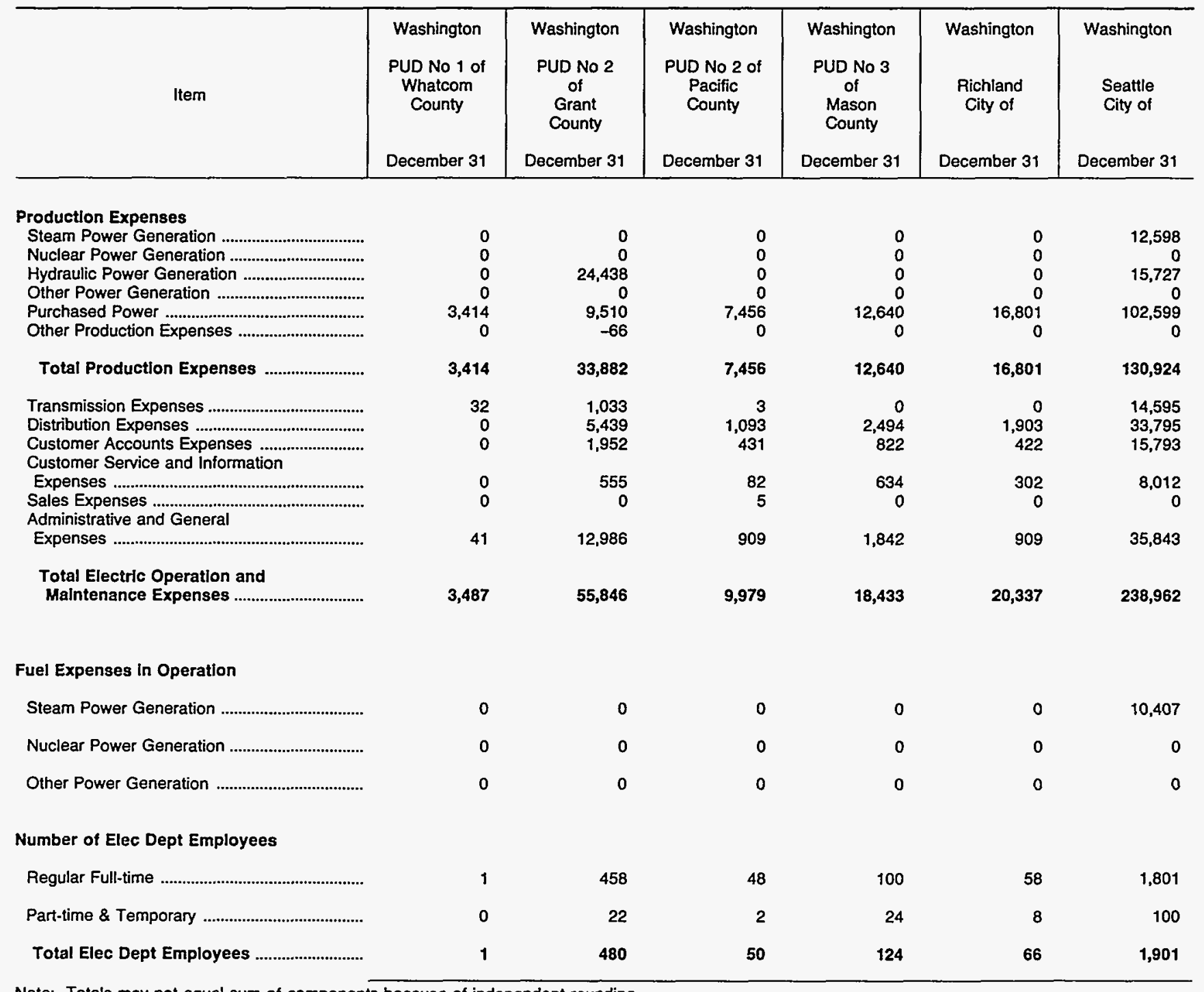

Note: Totals may not equal sum of components because of independent rounding.

Source: Energy Information Administration, Form ElA-412, "Annual Report of Public Electric Utilities." 
Table 23. Electric Operation and Maintenance Expenses by Major U.S. Publicly Owned Electric Utility Within State, 1993 (Continued) (Thousand Doliars)

\begin{tabular}{c|c|c|c|c|c|c}
\hline & Washington & Washington & Washington & Wisconsin & Wisconsin \\
Item & Tacoma & $\begin{array}{c}\text { Vera } \\
\text { Irrigation } \\
\text { District \#15 }\end{array}$ & $\begin{array}{c}\text { Washington } \\
\text { Pub } \\
\text { Pwr } \\
\text { Cupply Sys }\end{array}$ & $\begin{array}{c}\text { Badger Power } \\
\text { Marketing } \\
\text { Auth }\end{array}$ & $\begin{array}{c}\text { Jefferson } \\
\text { City of }\end{array}$ & $\begin{array}{c}\text { Kaukauna } \\
\text { City of }\end{array}$ \\
& December 31 & December 31 & June 30 & December 31 & December 31 & December 31 \\
\hline
\end{tabular}

Productlon Expenses

Steam Power Generation

Nuclear Power Generation

Hydraulic Power Generation

Other Power Generation

Purchased Power

Production Expenses

Total Production Expenses

Transmission Expenses

Distribution Expen

Customer Accounts Expenses ..........................

Customer Service and Information

Expenses

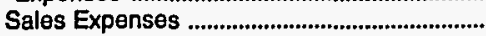

Administrative and General

Expenses

Total Electric Operation and

Malntenance Expenses
21,41

9,432

0
72,488

578

103,912

5,222

13,813

3,681

1,978

307

19,696

148,610
5,665

4,574

0

425

355

281

276

0

0

188,291

$\begin{array}{rr}0 & 0 \\ 0 & 138,829 \\ 0 & 291 \\ 0 & 0 \\ 4,574 & 0 \\ 0 & 0\end{array}$

139,120

48,896

13,888

o

0

Other Power Generation

Number of Elec Dept Employees

Regular Full-time

Part-time \& Temporary

Total Elec Dept Employees

771
0

0

0

30,252

0

1,287
138
1,425

0
0
0
0
8,548
0

8,548

25

0

0

146

8,719

5,610

Note: Totals may not equal sum of components because of independent rounding.

Source: Energy Information Administration, Form ElA-412, "Annual Report of Public Electric Utilities." 
Table 23. Electric Operation and Maintenance Expenses by Major U.S. Publicly Owned Electric Utility Within State, 1993 (Continued) (Thousand Dollars)

\begin{tabular}{|c|c|c|c|c|c|c|}
\hline Item & $\begin{array}{l}\text { Wisconsin } \\
\text { Manitowoc } \\
\text { Public } \\
\text { Utilities } \\
\text { December } 31\end{array}$ & $\begin{array}{l}\text { Wisconsin } \\
\text { Marshfield } \\
\text { City of } \\
\text { December } 31\end{array}$ & $\begin{array}{l}\text { Wisconsin } \\
\text { Menasha } \\
\text { City of } \\
\text { December } 31\end{array}$ & $\begin{array}{l}\text { Wisconsin } \\
\begin{array}{c}\text { New London } \\
\text { City of }\end{array} \\
\text { December } 31\end{array}$ & $\begin{array}{l}\text { Wisconsin } \\
\begin{array}{c}\text { Oconomowoc } \\
\text { City of }\end{array} \\
\text { December } 31\end{array}$ & $\begin{array}{l}\text { Wisconsin } \\
\begin{array}{c}\text { Plymouth } \\
\text { City of }\end{array} \\
\text { December } 31\end{array}$ \\
\hline \multicolumn{7}{|l|}{ Production Expenses } \\
\hline 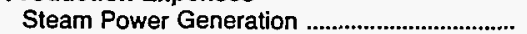 & 10,371 & 274 & 688 & 0 & 0 & 0 \\
\hline 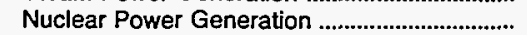 & 0 & 0 & 0 & 0 & 0 & 0 \\
\hline Hydraulic Power Generation ................................... & 0 & 0 & 0 & 0 & 0 & 0 \\
\hline 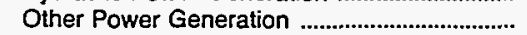 & 206 & 74 & 0 & 0 & 0 & 0 \\
\hline 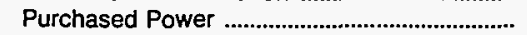 & 5,168 & 9,505 & 18,615 & 6,146 & 5,847 & 5,189 \\
\hline 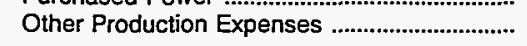 & 0 & 0 & 0 & 0 & 0 & 0 \\
\hline Total Production Expenses ............................. & 15,746 & 9,853 & 19,304 & 6,146 & 5,847 & 5,189 \\
\hline 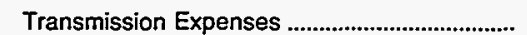 & 33 & 40 & 34 & 0 & 0 & 0 \\
\hline 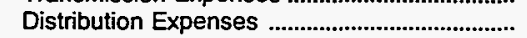 & 643 & 561 & 301 & 209 & 354 & 453 \\
\hline $\begin{array}{l}\text { Customer Accounts Expenses } \\
\text { Customer Service and Information }\end{array}$ & 241 & 164 & 132 & 64 & 111 & 99 \\
\hline 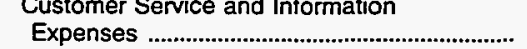 & 0 & 0 & 0 & 0 & 0 & 0 \\
\hline 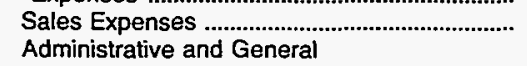 & 217 & 75 & 200 & 70 & 42 & 15 \\
\hline 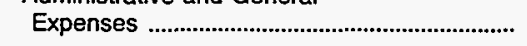 & 1,571 & 573 & 1,042 & 170 & 357 & 255 \\
\hline $\begin{array}{l}\text { Total Electric Operation and } \\
\text { Maintenance Expenses }\end{array}$ & 18,451 & 11,266 & 21,013 & 6,659 & 6,710 & 6,011 \\
\hline \multicolumn{7}{|l|}{ Fuel Expenses in Operation } \\
\hline 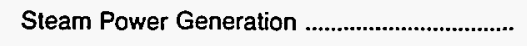 & 7,214 & 0 & 7 & 0 & 0 & 0 \\
\hline 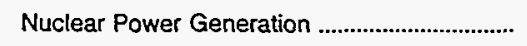 & 0 & 0 & 0 & 0 & 0 & 0 \\
\hline Other Power Generation & 83 & 10 & 0 & 0 & 0 & 0 \\
\hline \multicolumn{7}{|l|}{ Number of Elec Dept Employees } \\
\hline 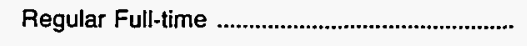 & 85 & 14 & 36 & 18 & 18 & 15 \\
\hline Part-time \& Temporary & 4 & 12 & 1 & 0 & 18 & 0 \\
\hline 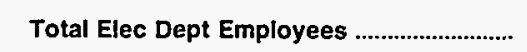 & 89 & 26 & 37 & 18 & 36 & 15 \\
\hline
\end{tabular}

Note: Totals may not equal sum of components because of independent rounding.

Source: Energy Information Administration, Form EIA-412, "Annual Report of Public Electric Utilities." 
Table 23. Electric Operation and Maintenance Expenses by Major U.S. Publicly Owned Electric Utility Within State, 1993 (Continued)

(Thousand Dollars)

\begin{tabular}{c|c|c|c|c|c|c}
\hline & Wisconsin & Wisconsin & Wisconsin & Wisconsin & Wisconsin & Wisconsin \\
Item & Reedsburg & $\begin{array}{c}\text { Shawano } \\
\text { Municipal }\end{array}$ & $\begin{array}{c}\text { Sheboygan } \\
\text { Falls } \\
\text { City of }\end{array}$ & $\begin{array}{c}\text { Sturgeon Bay } \\
\text { Combined } \\
\text { Utils }\end{array}$ & $\begin{array}{c}\text { Sun Prairie } \\
\text { Water \& Light } \\
\text { Comm }\end{array}$ & $\begin{array}{c}\text { Wisconsin } \\
\text { Public } \\
\text { Power } \\
\text { Inc Sys }\end{array}$ \\
& Utility Comm & December 31 & December 31 & December 31 & December 31 & December 31 \\
December 31 \\
\hline
\end{tabular}

\section{Production Expenses}

Steam Power Generation

Nuclear Power Generation

Hydraulic Power Generation

Other Power Generation

Purchased Power .um.utes

Other Production Expenses

Total Production Expenses

Transmission Expenses

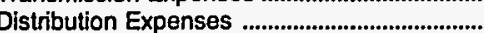

Customer Accounts Expenses

Customer Service and Information

Expenses

Sales Expenses

Administrative and General

Expenses

Total Electric Operation and

Maintenance Expenses

Fuel Expenses In Operation

Steam Power Generation

Nuclear Power Generation

Other Power Generation

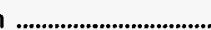

Number of Elec Dept Employees

Regular Full-time

Part-time \& Temporary

9

5

Total Elec Dept Employees
0
0
0
0
5,677
0

0
0
0
0
6,516
0

5,677

6,516

14
138

58

0

40

227

6,155

6,925

2
134

65

0

208

0
0
0
0
5,868
0

0

0
0
0

5,248

0

5,868

5,248

5

360

208

105

0
0

12,156

0

372

74,051

86,586

5,076

0
0

0

80

3,678

275

95,340

6,073

5,899

Note: Totals may not equal sum of components because of independent rounding.

Source: Energy Information Administration, Form ElA-412, "Annual Report of Public Electric Utilities." 
Table 23. Electric Operation and Maintenance Expenses by Major U.S. Publicly

Owned Electric Utility Within State, 1993 (Continued)

(Thousand Dollars)

\begin{tabular}{c|c|c|c|c}
\hline & Wisconsin & Wyoming & Wyoming & \\
Wisconsin & & Wyoming \\
Rapids $W W$ & Gillette & $\begin{array}{c}\text { Municipal } \\
\&\end{array}$ & City of & Power Agency \\
Comm & & \\
& December 31 & June 30 & December 31 & \\
\hline
\end{tabular}

Production Expenses

Steam Power Generation

Nuclear Power Generation

Hydraulic Power Generation

Other Power Generation

Purchased Power

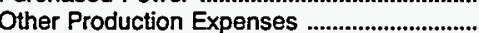

Total Production Expenses

Transmission Expenses .

Distribution Expenses

Customer Accounts Expenses .........................

Customer Service and Information

Expenses .

Sales Expenses

Administrative and General

Expenses

Total Electric Operation and

Maintenance Expenses

Fuel Expenses in Operation

Steam Power Generation

Nuclear Power Generation

Other Power Generation

Number of Elec Dept Employees

Regular Full-time

Part-time \& Temporary

Total Elec Dept Employees

Note: Totals may not equal sum of components because of independent rounding

Source: Energy Information Administration, Form ElA-412, "Annual Report of Public Electric Utilities."
1,756

0

0

1,385

3,142

46

0

56

330

3,575

937

0

0

\begin{tabular}{|c|c|c|}
\hline 29 & 10 & 5 \\
\hline 2 & 0 & 0 \\
\hline 31 & 10 & 5 \\
\hline
\end{tabular}


Table 24. Electric Utility Plant by Major U.S. Publicly Owned Electric Utility Within State at End of Period, 1993

(Thousand Dollars)

\begin{tabular}{|c|c|c|c|c|c|c|}
\hline Item & $\begin{array}{l}\text { Alabama } \\
\text { Alabama } \\
\text { Municipal } \\
\text { Elec Auth } \\
\text { September } 30\end{array}$ & $\begin{array}{l}\text { Alabama } \\
\text { Albertville } \\
\text { Municipal } \\
\text { Utils Bd } \\
\text { June } 30\end{array}$ & $\begin{array}{c}\text { Alabama } \\
\text { Andalusia } \\
\text { City of } \\
\text { September } 30\end{array}$ & $\begin{array}{c}\text { Alabama } \\
\text { Athens } \\
\text { City of } \\
\text { December } 31\end{array}$ & $\begin{array}{l}\text { Alabama } \\
\text { Bessemer } \\
\text { City of } \\
\text { June } 30\end{array}$ & $\begin{array}{c}\text { Alabama } \\
\text { Cullman } \\
\text { Power Board } \\
\text { June } 30\end{array}$ \\
\hline \multicolumn{7}{|l|}{ Electric Plant In Servlce } \\
\hline $\begin{array}{l}\text { Intangible Plant ............................................................. } \\
\text { Production Plant }\end{array}$ & 0 & 0 & 0 & 0 & 0 & 0 \\
\hline 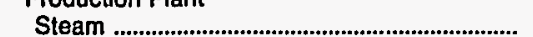 & 0 & 0 & 0 & 0 & 0 & 0 \\
\hline Nuclear & 0 & 0 & 0 & 0 & 0 & 0 \\
\hline 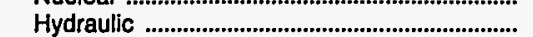 & 0 & 0 & 0 & 0 & 0 & 0 \\
\hline Other & 0 & 0 & 0 & 0 & 0 & 0 \\
\hline Total Production Plant .............................. & 0 & 0 & 0 & $\mathbf{0}$ & 0 & $\mathbf{0}$ \\
\hline 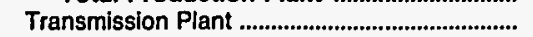 & 0 & 0 & 0 & 2,905 & 0 & 0 \\
\hline 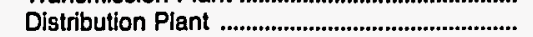 & $\mathbf{0}$ & 10,847 & 3,609 & 34,526 & 17,817 & 8,324 \\
\hline 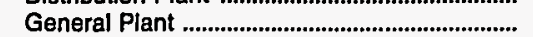 & 0 & 1,527 & 0 & 2,775 & 2,338 & 2,308 \\
\hline Total Electric Plant in Service .................... & $\mathbf{0}$ & 12,374 & 3,609 & 40,206 & 20,155 & 10,632 \\
\hline 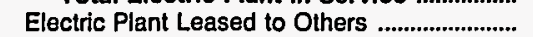 & 0 & 0 & 0 & 0 & 0 & 0 \\
\hline Electric Plant Held for Future Use ................... & 0 & 0 & 0 & 0 & 53 & 0 \\
\hline 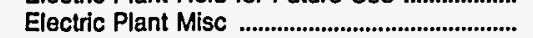 & 0 & 0 & 0 & 43 & 0 & 0 \\
\hline 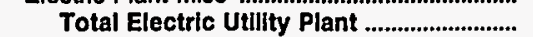 & 0 & 12,374 & 3,609 & 40,249 & 20,208 & 10,632 \\
\hline $\begin{array}{l}\text { Construction Work in Progress - Electric ........ } \\
\text { Accumulated Provision for Depreciation }\end{array}$ & 0 & 163 & 0 & 460 & 81 & 365 \\
\hline 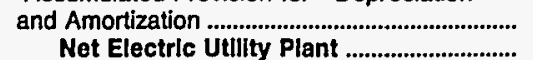 & $\begin{array}{l}\mathbf{0} \\
\mathbf{0}\end{array}$ & $\begin{array}{l}4,522 \\
8,014\end{array}$ & $\begin{array}{l}1,197 \\
2,413\end{array}$ & $\begin{array}{l}13,410 \\
27,299\end{array}$ & $\begin{array}{r}8,493 \\
\$ 1,796\end{array}$ & $\begin{array}{l}5,333 \\
5,665\end{array}$ \\
\hline
\end{tabular}

\begin{tabular}{|c|c|c|c|c|c|c|}
\hline Item & $\begin{array}{l}\text { Alabama } \\
\text { Decatur } \\
\text { City of } \\
\text { June } 30\end{array}$ & $\begin{array}{l}\text { Alabama } \\
\text { Dothan } \\
\text { City of } \\
\text { September } 30\end{array}$ & $\begin{array}{l}\text { Alabama } \\
\text { Florence } \\
\text { City of } \\
\text { June } 30\end{array}$ & $\begin{array}{c}\text { Alabama } \\
\text { Foley } \\
\text { City of } \\
\text { (Riviera Utils) } \\
\text { December } 31\end{array}$ & $\begin{array}{c}\text { Alabama } \\
\text { Fort Payne } \\
\text { Improvement } \\
\text { Auth } \\
\text { June } 30\end{array}$ & $\begin{array}{l}\text { Alabama } \\
\text { Guntersville } \\
\text { Electric } \\
\text { Board } \\
\text { June } 30\end{array}$ \\
\hline \multicolumn{7}{|l|}{ Electrlc Plant in Servlce } \\
\hline $\begin{array}{l}\text { Intangible Plant } \\
\text { Production Plant }\end{array}$ & 0 & 0 & 0 & 0 & 0 & 0 \\
\hline 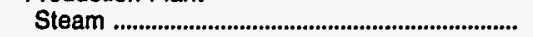 & 0 & 0 & 0 & 0 & 0 & 0 \\
\hline Nuclear & 0 & 0 & 0 & 0 & 0 & 0 \\
\hline 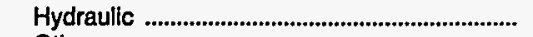 & 0 & 0 & 0 & 0 & 0 & 0 \\
\hline Other & 0 & 0 & 0 & 4 & 0 & 0 \\
\hline Total Production Plant .................................. & 0 & $\mathbf{0}$ & $\mathbf{0}$ & 4 & $\mathbf{0}$ & 0 \\
\hline 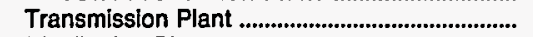 & 0 & 0 & 12,805 & 12,436 & 0 & 0 \\
\hline 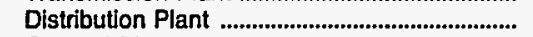 & 35,166 & 0 & 51,126 & 32,613 & 9,963 & 7,963 \\
\hline 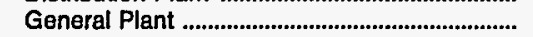 & 2,937 & 53,224 & 6,489 & 8,150 & 1,430 & 716 \\
\hline Total Electric Plant in Servlce .................... & 38,103 & 53,224 & 70,420 & 53,202 & 11,393 & 8,680 \\
\hline Electric Plant Leased to Others ......................... & 0 & 0 & 0 & 0 & 0 & 0 \\
\hline 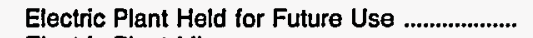 & 258 & 0 & 0 & 0 & 0 & 0 \\
\hline Electric Plant Misc & 222 & 0 & 0 & 0 & 0 & 0 \\
\hline 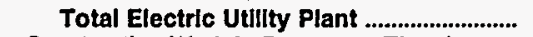 & 38,583 & 53,224 & 70,420 & 53,202 & 11,393 & 8,680 \\
\hline $\begin{array}{l}\text { Construction Work in Progress - Electric ........ } \\
\text { Accumulated Provision for Depreciation }\end{array}$ & 612 & 0 & 908 & 0 & 479 & 237 \\
\hline $\begin{array}{l}\text { and Amortization } \\
\text { Net Electrlc Utility Plant }\end{array}$ & $\begin{array}{l}16,402 \\
22,793\end{array}$ & $\begin{array}{l}19,588 \\
33,636\end{array}$ & $\begin{array}{l}28,833 \\
42,495\end{array}$ & $\begin{array}{l}17,363 \\
35,840\end{array}$ & $\begin{array}{l}4,019 \\
7,853\end{array}$ & $\begin{array}{l}4,012 \\
4,904\end{array}$ \\
\hline
\end{tabular}

Note: Totals may not equal sum of components because of independent rounding.

Source: Energy Information Administration, Form EIA-412, "Annual Report of Public Electric Utilities." 
Table 24. Electric Utility Plant by Major U.S. Publicly Owned Electric Utility Within State at End of Period, 1993 (Continued)

(Thousand Dollars)

\begin{tabular}{|c|c|c|c|c|c|c|}
\hline Item & $\begin{array}{c}\text { Alabama } \\
\text { Huntsville } \\
\text { City of }\end{array}$ & $\begin{array}{l}\text { Alabama } \\
\text { Muscle } \\
\text { Shoals } \\
\text { City of } \\
\\
\text { June } 30\end{array}$ & $\begin{array}{l}\text { Alabama } \\
\text { Opelika } \\
\text { Gity of } \\
\text { September } 30\end{array}$ & $\begin{array}{l}\text { Alabama } \\
\begin{array}{c}\text { Scottsboro } \\
\text { City of }\end{array} \\
\text { June } 30\end{array}$ & $\begin{array}{l}\text { Alabama } \\
\text { Sheffield } \\
\text { Utilities } \\
\text { June } 30\end{array}$ & $\begin{array}{l}\text { Alabama } \\
\text { Sylacauga } \\
\text { Utilities } \\
\text { Board } \\
\text { September } 30\end{array}$ \\
\hline \multicolumn{7}{|l|}{ Electric Plant in Service } \\
\hline $\begin{array}{l}\text { Intangible Plant } \\
\text { Production Plant }\end{array}$ & 0 & 0 & 0 & 0 & 0 & 0 \\
\hline Steam & 0 & 0 & 0 & 0 & 0 & 0 \\
\hline 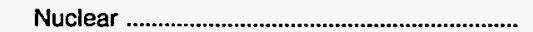 & 0 & 0 & 0 & 0 & 0 & 0 \\
\hline 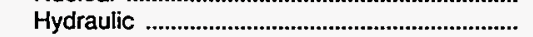 & 0 & 0 & 0 & 0 & 0 & 0 \\
\hline Other & 0 & 0 & 0 & 0 & 0 & 0 \\
\hline 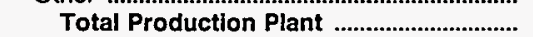 & 0 & 0 & $\mathbf{0}$ & $\mathbf{0}$ & 0 & 0 \\
\hline 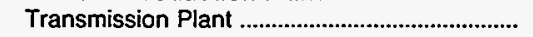 & 14,341 & 0 & 16,945 & 0 & 1,243 & 0 \\
\hline 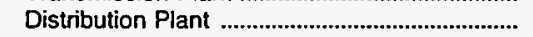 & 128,857 & 10,793 & 0 & 12,970 & 27,274 & 9,070 \\
\hline 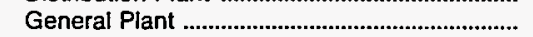 & 9,909 & 2,247 & 0 & 1,456 & 4,046 & 1,102 \\
\hline Total Electric Plant in Service & 153,108 & 13,040 & 16,945 & 14,426 & 32,562 & 10,172 \\
\hline 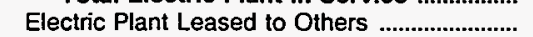 & 0 & 0 & 0 & 0 & 0 & 0 \\
\hline Electric Plant Held for Future Use ..................... & 0 & 0 & 0 & 0 & 0 & 0 \\
\hline 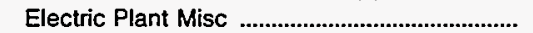 & 0 & 0 & 0 & 0 & 161 & 0 \\
\hline 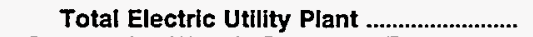 & 153,108 & 13,040 & 16,945 & 14,426 & 32,724 & 10,172 \\
\hline $\begin{array}{l}\text { Construction Work in Progress - Electric ....... } \\
\text { Accumulated Provision for Depreciation }\end{array}$ & 3,554 & 689 & 991 & 253 & 289 & 0 \\
\hline and Amortization & 58,844 & 4,074 & 9,832 & 5,115 & 14,042 & 6,120 \\
\hline 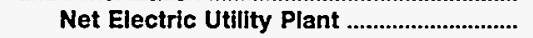 & 97,818 & 9,655 & 8,104 & 9,564 & 18,971 & 4,052 \\
\hline
\end{tabular}

\begin{tabular}{|c|c|c|c|c|c|c|}
\hline Item & $\begin{array}{c}\text { Alabama } \\
\text { Troy } \\
\text { City of } \\
\text { September } 30\end{array}$ & $\begin{array}{l}\text { Alabama } \\
\text { Tuskegee } \\
\text { City of } \\
\text { September } 30\end{array}$ & $\begin{array}{l}\text { Alaska } \\
\text { Alaska } \\
\text { Energy } \\
\text { Authority } \\
\\
\text { June 30 }\end{array}$ & $\begin{array}{c}\text { Alaska } \\
\text { Anchorage } \\
\text { City of } \\
\text { December } 31\end{array}$ & $\begin{array}{c}\text { Alaska } \\
\text { Fairbanks } \\
\text { City of } \\
\text { December } 31\end{array}$ & $\begin{array}{l}\text { Alaska } \\
\text { Ketchikan } \\
\text { City of } \\
\text { December } \mathbf{3 1}\end{array}$ \\
\hline \multicolumn{7}{|l|}{ Electric Plant in Service } \\
\hline $\begin{array}{l}\text { Intangible Plant .............................................. } \\
\text { Production Plant }\end{array}$ & 0 & 0 & 2,975 & 13,107 & 120 & 133 \\
\hline 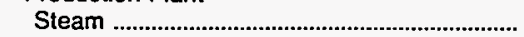 & 0 & 0 & 3,535 & 17,830 & 30,655 & 0 \\
\hline 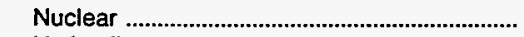 & 0 & 0 & 0 & 0 & 0 & 0 \\
\hline 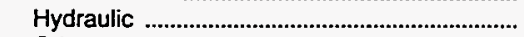 & 0 & 0 & 580,406 & 0 & 0 & 16,907 \\
\hline Other & 0 & 0 & 0 & 90,424 & 4,311 & 4,875 \\
\hline Total Production Plant & 0 & 0 & 583,941 & 108,255 & 34,966 & 21,782 \\
\hline Transmission Plant & 0 & 0 & 341,131 & 16,414 & 3,698 & 1,183 \\
\hline 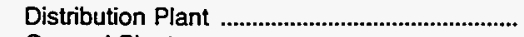 & 8,461 & 6,965 & 0 & 84,840 & 8,397 & 19,114 \\
\hline General Plant & 1,159 & 0 & 7,198 & 26,333 & 1,168 & 2,826 \\
\hline Total Electric Plant in Service .................... & 9,620 & 6,965 & 935,245 & 248,948 & 48,348 & 45,037 \\
\hline Electric Plant Leased to Others ........................... & 0 & 0 & 0 & 0 & 0 & 0 \\
\hline Electric Plant Held for Future Use ................... & 0 & 0 & 0 & 0 & 0 & 76 \\
\hline 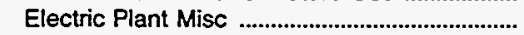 & 0 & 0 & 0 & 6,206 & 0 & 0 \\
\hline 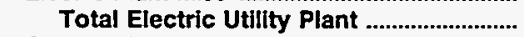 & 9,620 & 6,965 & 935,245 & 255,154 & 48,348 & 45,113 \\
\hline $\begin{array}{l}\text { Construction Work in Progress - Electric ........ } \\
\text { Accumulated Provision for Depreciation }\end{array}$ & 0 & 0 & 0 & 6,560 & 247 & 2,085 \\
\hline 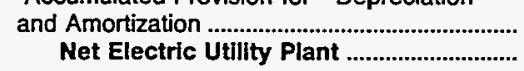 & $\begin{array}{l}5,346 \\
4,274\end{array}$ & $\begin{array}{l}3,153 \\
\mathbf{3}, 812\end{array}$ & $\begin{array}{l}150,917 \\
\mathbf{7 8 4 , 3 2 8}\end{array}$ & $\begin{array}{l}112,825 \\
148,890\end{array}$ & $\begin{array}{l}27,484 \\
21,111\end{array}$ & $\begin{array}{l}19,740 \\
\mathbf{2 7 , 4 5 9}\end{array}$ \\
\hline
\end{tabular}

Note: Totals may not equal sum of components because of independent rounding.

Source: Energy Information Administration, Form ElA-412, "Annual Report of Public Electric Utilities." 
Table 24. Electric Utility Plant by Major U.S. Publicly Owned Electric Utility Within State at End of Period, 1993 (Continued)

(Thousand Dollars)

\begin{tabular}{|c|c|c|c|c|c|c|}
\hline Item & $\begin{array}{l}\text { Arizona } \\
\text { Arizona } \\
\text { Power } \\
\text { Authority } \\
\\
\text { June } 30\end{array}$ & $\begin{array}{c}\text { Arizona } \\
\text { Electrical } \\
\text { Dist } \\
\text { No2 } \\
\text { Pinal Cnty } \\
\text { December } 31\end{array}$ & $\begin{array}{l}\text { Arizona } \\
\text { Mesa } \\
\text { City of } \\
\text { June } 30\end{array}$ & $\begin{array}{c}\text { Arizona } \\
\text { Navajo } \\
\text { Tribal } \\
\text { Utility } \\
\text { Auth } \\
\text { December } \mathbf{3 1}\end{array}$ & $\begin{array}{l}\text { Arizona } \\
\text { Salt River } \\
\text { Proj Ag } \\
\text { I \& P Dist } \\
\text { April } 30\end{array}$ & $\begin{array}{c}\text { Arizona } \\
\text { Tohono } \\
\text { OOdham } \\
\text { Utility Auth } \\
\text { December } 31\end{array}$ \\
\hline \multicolumn{7}{|l|}{ Electric Plant in Service } \\
\hline $\begin{array}{l}\text { Intangible Plant } \\
\text { Production Plant }\end{array}$ & 0 & 0 & 0 & 0 & 27,709 & 0 \\
\hline Steam & 0 & 0 & 0 & 0 & $1,517,647$ & 0 \\
\hline 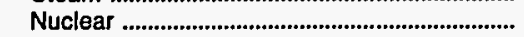 & 0 & 0 & 0 & 0 & $1,562,697$ & 0 \\
\hline 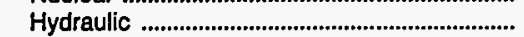 & 0 & 0 & 0 & 0 & 72,824 & 0 \\
\hline Other & 0 & 0 & 0 & 0 & 112,434 & 0 \\
\hline Totai Production Plant .............................. & 0 & 0 & $\mathbf{0}$ & $\mathbf{0}$ & $3,265,601$ & $\mathbf{0}$ \\
\hline 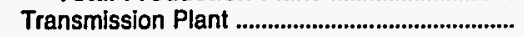 & 289 & 0 & 0 & 7,328 & 481,692 & 938 \\
\hline 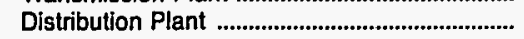 & 150 & 14,192 & 0 & 78,627 & $1,054,325$ & 7,522 \\
\hline 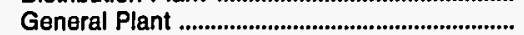 & 667 & 1,215 & 49,085 & 11,301 & 515,252 & 854 \\
\hline Total Electric Plant In Service & 1,107 & 15,407 & 49,085 & 97,255 & $5,344,580$ & 9,313 \\
\hline Electric Plant Leased to Others ........................ & 0 & 0 & 0 & 0 & 0 & 0 \\
\hline Electric Plant Held for Future Use ................... & 0 & 0 & 0 & 0 & 93,726 & 0 \\
\hline 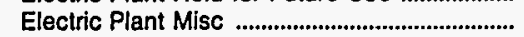 & 0 & 0 & 0 & 7,135 & 41,847 & 0 \\
\hline 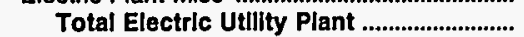 & 1,107 & 15,407 & 49,085 & 104,390 & $5,480,152$ & 9,313 \\
\hline $\begin{array}{l}\text { Construction Work in Progress - Electric ....... } \\
\text { Accumulated Provision for Depreciation }\end{array}$ & 0 & 0 & 3,683 & 4,541 & 199,193 & 67 \\
\hline 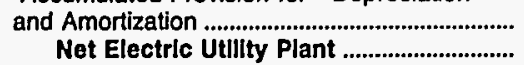 & $\begin{array}{l}647 \\
460\end{array}$ & $\begin{array}{l}5,963 \\
9,443\end{array}$ & $\begin{array}{l}12,041 \\
40,728\end{array}$ & $\begin{array}{l}36,474 \\
72,458\end{array}$ & $\begin{array}{l}1,590,841 \\
4,088,504\end{array}$ & $\begin{array}{l}2,611 \\
6,770\end{array}$ \\
\hline
\end{tabular}

\begin{tabular}{|c|c|c|c|c|c|c|}
\hline Item & $\begin{array}{c}\text { Arkansas } \\
\text { Benton } \\
\text { City of } \\
\text { December } 31\end{array}$ & $\begin{array}{l}\text { Arkansas } \\
\text { Bentonville } \\
\text { City of } \\
\text { December } 31\end{array}$ & $\begin{array}{l}\text { Arkansas } \\
\text { Clarksville } \\
\text { Light } \\
\text { \& } \\
\text { Water Co } \\
\text { September } 30\end{array}$ & $\begin{array}{l}\text { Arkansas } \\
\text { Conway } \\
\text { Corp }\end{array}$ & $\begin{array}{c}\text { Arkansas } \\
\text { Hope } \\
\text { City of } \\
\text { December } 31\end{array}$ & $\begin{array}{c}\text { Arkansas } \\
\begin{array}{c}\text { Jonesboro } \\
\text { City of }\end{array} \\
\text { December } 31\end{array}$ \\
\hline \multicolumn{7}{|l|}{ Electrlc Plant In Service } \\
\hline 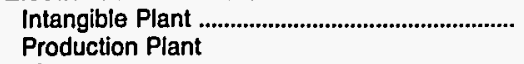 & 0 & 5,352 & $\mathbf{0}$ & 0 & 0 & 8,128 \\
\hline Steam & 0 & 0 & 0 & 38,747 & 0 & 76,017 \\
\hline 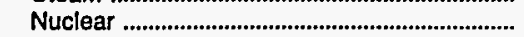 & 0 & 0 & $\mathbf{0}$ & 0 & 0 & 0 \\
\hline 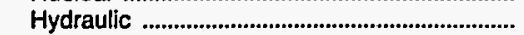 & 0 & 0 & $\mathbf{0}$ & 0 & 0 & 0 \\
\hline Other & 1,696 & 0 & 0 & 0 & 3,770 & 0 \\
\hline Total Productlon Plant & 1,696 & 0 & $\mathbf{0}$ & 38,747 & 3,770 & 76,017 \\
\hline 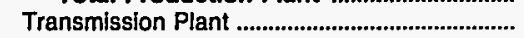 & 0 & 0 & 2,317 & 0 & 0 & 511 \\
\hline 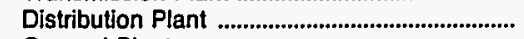 & 5,381 & 0 & 8,421 & 19,662 & 5,379 & 44,303 \\
\hline 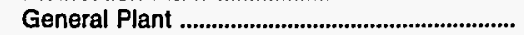 & 0 & 24,447 & 705 & 5,334 & 628 & 7,593 \\
\hline Total Electric Plant In Service .................. & 7,077 & 29,799 & 11,443 & 63,743 & 9,777 & 136,553 \\
\hline 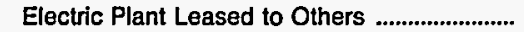 & 0 & 0 & $\mathbf{0}$ & 0 & 0 & 0 \\
\hline Electric Plant Held for Future Use .................... & $\mathbf{0}$ & 0 & 0 & 0 & 0 & 0 \\
\hline 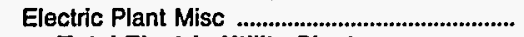 & 0 & 0 & $\mathbf{0}$ & 0 & 0 & 0 \\
\hline Total Electric UtIlity Plant ............................. & 7,077 & 29,799 & 11,443 & 63,743 & 9,777 & 136,553 \\
\hline $\begin{array}{l}\text { Construction Work in Progress - Electric ....... } \\
\text { Accumulated Provision for Depreciation }\end{array}$ & 0 & 1,087 & 424 & 362 & 1,813 & 1,082 \\
\hline and Amortization & 5,221 & 8,368 & 3,452 & 22,898 & 3,908 & 58,187 \\
\hline 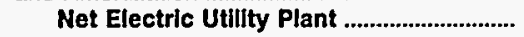 & 1,856 & 22,518 & 8,416 & 41,206 & 7,683 & 79,448 \\
\hline
\end{tabular}

Note: Totals may not equal sum of components because of independent rounding.

Source: Energy Information Administration, Form ElA-412, "Annual Report of Public Electric Utilities." 
Table 24. Electric Utility Plant by Major U.S. Publicly Owned Electric Utility Within State at End of Period, 1993 (Continued)

(Thousand Dollars)

\begin{tabular}{|c|c|c|c|c|c|c|}
\hline Item & $\begin{array}{c}\text { Arkansas } \\
\text { North } \\
\text { Little } \\
\text { Rock } \\
\text { City of } \\
\text { December } 31\end{array}$ & $\begin{array}{l}\text { Arkansas } \\
\text { Osceola } \\
\text { City of } \\
\text { December } 31\end{array}$ & $\begin{array}{c}\text { Arkansas } \\
\text { Paragould } \\
\text { Light } \\
\& \\
\text { Water Comm } \\
\text { December } 31\end{array}$ & $\begin{array}{c}\text { Arkansas } \\
\text { Siloam } \\
\text { Springs } \\
\text { City of } \\
\text { December } 31\end{array}$ & $\begin{array}{c}\text { Arkansas } \\
\text { West } \\
\text { Memphis } \\
\text { City of } \\
\text { December } 31\end{array}$ & $\begin{array}{l}\text { California } \\
\text { Alameda } \\
\text { City of } \\
\text { June } 30\end{array}$ \\
\hline \multicolumn{7}{|l|}{ Electric Plant in Service } \\
\hline 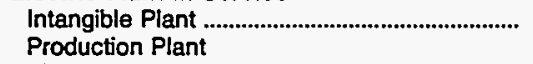 & 0 & 0 & 0 & 0 & 10,137 & 0 \\
\hline 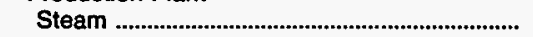 & 0 & 0 & 0 & 0 & 18,547 & 0 \\
\hline 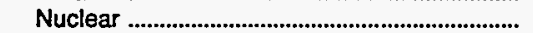 & 0 & 0 & 0 & 0 & 0 & 0 \\
\hline 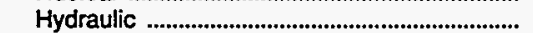 & 111,246 & 0 & 0 & 0 & 0 & 0 \\
\hline Other & 0 & 0 & 8,863 & 0 & $\mathbf{0}$ & 0 \\
\hline Total Production Plant & 111,246 & 0 & 8,863 & 0 & 18,547 & $\mathbf{0}$ \\
\hline 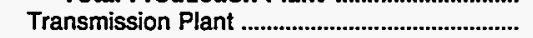 & 0 & 0 & 0 & 550 & 0 & 3,494 \\
\hline Distribution Plant & 31,981 & 10,760 & 10,142 & 5,451 & 0 & 33,461 \\
\hline 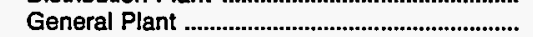 & 5,517 & 8,146 & 5,586 & 50 & 0 & 6,760 \\
\hline Total Electric Plant In Servlce & 148,743 & 18,905 & 24,591 & 6,051 & 28,685 & 43,715 \\
\hline 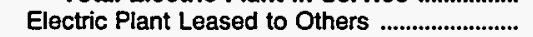 & 0 & 0 & 0 & 0 & 0 & 0 \\
\hline 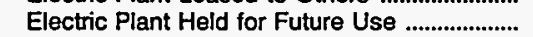 & 0 & 0 & 0 & 0 & 0 & 0 \\
\hline 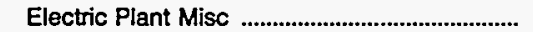 & 0 & 0 & $\mathbf{0}$ & 0 & $\mathbf{0}$ & 0 \\
\hline 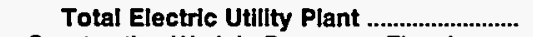 & 148,743 & 18,905 & 24,591 & 6,051 & 28,685 & 43,715 \\
\hline $\begin{array}{l}\text { Construction Work in Progress - Electric ........ } \\
\text { Accumulated Provision for Depreciation }\end{array}$ & 1,589 & 0 & 146 & 962 & 0 & 0 \\
\hline 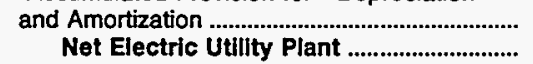 & $\begin{array}{r}30,542 \\
119,790\end{array}$ & $\begin{array}{r}8,043 \\
10,862\end{array}$ & $\begin{array}{r}9,106 \\
15,632\end{array}$ & $\begin{array}{l}3,215 \\
3,797\end{array}$ & $\begin{array}{l}12,413 \\
16,271\end{array}$ & $\begin{array}{l}12,059 \\
31,656\end{array}$ \\
\hline
\end{tabular}

\begin{tabular}{|c|c|c|c|c|c|c|}
\hline Item & $\begin{array}{l}\text { California } \\
\text { Anaheim } \\
\text { Gity of } \\
\text { June } 30\end{array}$ & $\begin{array}{l}\text { California } \\
\text { Azusa } \\
\text { City of } \\
\text { June } 30\end{array}$ & $\begin{array}{l}\text { California } \\
\text { Burbank } \\
\text { City of } \\
\text { June } 30\end{array}$ & $\begin{array}{l}\text { California } \\
\text { California } \\
\text { Dept } \\
\text { Wtr } \\
\text { Resources } \\
\text { June } 30\end{array}$ & $\begin{array}{l}\text { California } \\
\text { Colton } \\
\text { City of } \\
\text { June } 30\end{array}$ & $\begin{array}{l}\text { California } \\
\text { Glendale } \\
\text { City of } \\
\text { June } 30\end{array}$ \\
\hline \multicolumn{7}{|l|}{ Electric Plant in Service } \\
\hline $\begin{array}{l}\text { Intangible Plant } \\
\text { Production Plant }\end{array}$ & 0 & 0 & 16,023 & 0 & 0 & 0 \\
\hline Steam & 0 & 0 & 43,124 & 311,095 & 0 & 48,729 \\
\hline 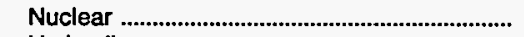 & 186,953 & 0 & 0 & 0 & 0 & 0 \\
\hline 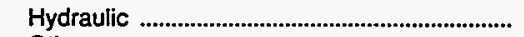 & 0 & 0 & 0 & 547,750 & 0 & 0 \\
\hline Other & 33,921 & 0 & 0 & 0 & 0 & 0 \\
\hline 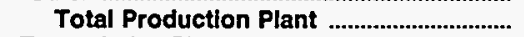 & 220,874 & 0 & 43,124 & 858,845 & 0 & 48,729 \\
\hline 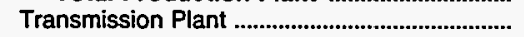 & 13,300 & 0 & 17,097 & 0 & 0 & 45,690 \\
\hline 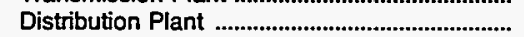 & 131,553 & 12,271 & 74,091 & 0 & 0 & 102,354 \\
\hline 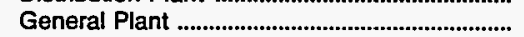 & 47,425 & 0 & 10,208 & 0 & 11,633 & 34,450 \\
\hline Total Electric Plant in Service ..................... & 413,152 & 12,271 & 160,543 & 858,845 & 11,633 & 231,223 \\
\hline Electric Plant Leased to Others ....................... & 0 & 0 & 0 & 0 & 0 & 0 \\
\hline Electric Plant Held for Future Use ..................... & 0 & 0 & 0 & 0 & 0 & 0 \\
\hline Electric Plant Misc & 0 & 0 & 0 & 0 & 0 & 0 \\
\hline 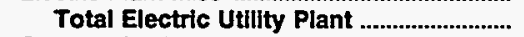 & 413,152 & 12,271 & 160,543 & 858,845 & 11,633 & 231,223 \\
\hline $\begin{array}{l}\text { Construction Work in Progress - Electric ........ } \\
\text { Accumulated Provision for Depreciation }\end{array}$ & 12,362 & 0 & 10,962 & 0 & 0 & 9,273 \\
\hline 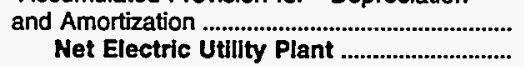 & $\begin{array}{l}107,534 \\
317,980\end{array}$ & $\begin{array}{l}4,408 \\
7,863\end{array}$ & $\begin{array}{l}91,662 \\
79,843\end{array}$ & $\begin{array}{l}264,134 \\
594,711\end{array}$ & $\begin{array}{l}4,894 \\
6,739\end{array}$ & $\begin{array}{l}103,541 \\
136,955\end{array}$ \\
\hline
\end{tabular}

Note: Totals may not equal sum of components because of independent rounding.

Source: Energy Information Administration, Form ElA-412, "Annual Report of Public Electric Utilities." 
Table 24. Electric Utility Plant by Major U.S. Publicly Owned Electric Utility Within State at End of Period, 1993 (Continued)

(Thousand Dollars)

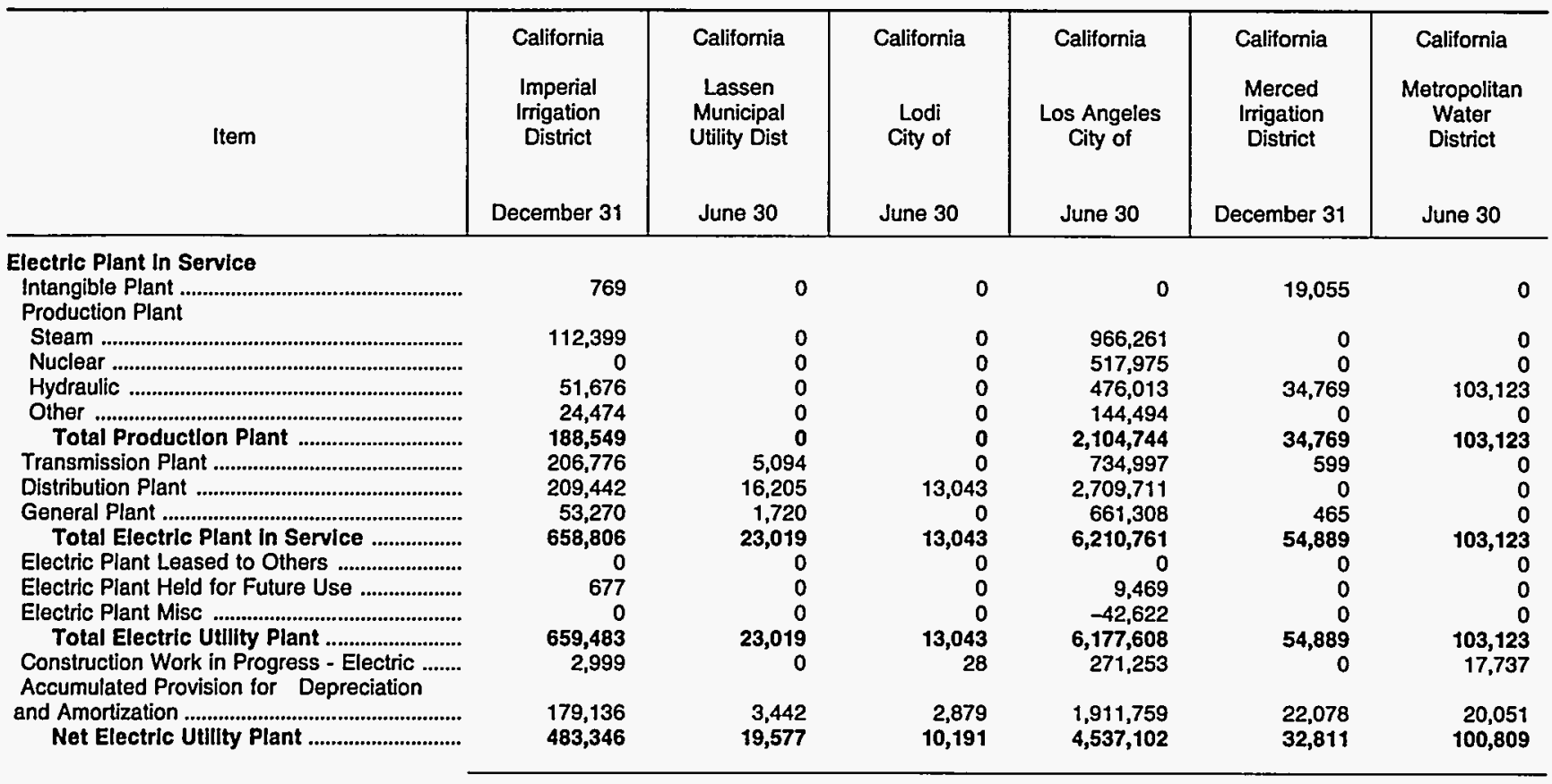

\begin{tabular}{|c|c|c|c|c|c|c|}
\hline Item & $\begin{array}{l}\text { California } \\
\text { Modesto } \\
\text { Irrigation } \\
\text { District } \\
\text { December } 31\end{array}$ & $\begin{array}{c}\text { California } \\
\text { MSR } \\
\text { Public } \\
\text { Power } \\
\text { Agency } \\
\text { December } 31\end{array}$ & $\begin{array}{l}\text { California } \\
\text { Northern } \\
\text { California } \\
\text { Power Agny } \\
\text { June } 30\end{array}$ & $\begin{array}{c}\text { California } \\
\text { Oakdale \& } \\
\text { South } \\
\text { San Joaquin } \\
\text { December } 31\end{array}$ & $\begin{array}{c}\text { California } \\
\text { Oroville } \\
\text { Wyandotte } \\
\text { Irrig Dist } \\
\text { December } 31\end{array}$ & $\begin{array}{l}\text { California } \\
\text { Palo Alto } \\
\text { City of } \\
\text { June } 30\end{array}$ \\
\hline \multicolumn{7}{|l|}{ Electrlc Plant In Service } \\
\hline $\begin{array}{l}\text { Intangible Plant } \\
\text { Production Plant }\end{array}$ & 122 & 99 & 0 & 0 & 0 & 0 \\
\hline Steam & 0 & 261,623 & 491,337 & 0 & 0 & 0 \\
\hline Nuclear & 0 & 0 & 0 & 0 & $\mathbf{0}$ & 0 \\
\hline 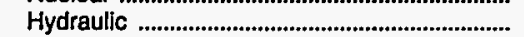 & 26,575 & 0 & 364,405 & 58,410 & 79,926 & 0 \\
\hline Other & 71,648 & $\mathbf{0}$ & 47,866 & 0 & 0 & 0 \\
\hline 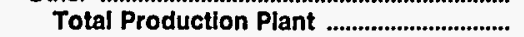 & 98,223 & 261,623 & 903,608 & 58,410 & 79,926 & $\mathbf{0}$ \\
\hline 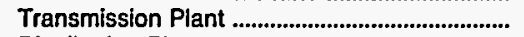 & 9,389 & 12,655 & 3,790 & 0 & 1,136 & 0 \\
\hline 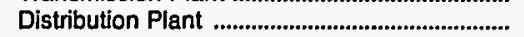 & 110,185 & 0 & 0 & 0 & 0 & 112,357 \\
\hline 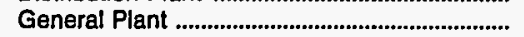 & 38,556 & 954 & 4,956 & 1,903 & 3,135 & 0 \\
\hline Total Electric Plant In Service & 256,475 & 275,331 & 912,354 & 60,313 & 84,197 & 112,357 \\
\hline 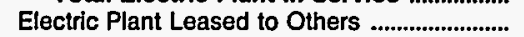 & 0 & 0 & 0 & 0 & 0 & 0 \\
\hline Electric Plant Held for Future Use ....................... & 0 & 0 & 0 & 0 & 0 & 0 \\
\hline 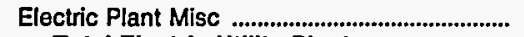 & 0 & $\mathbf{0}$ & $\mathbf{0}$ & 0 & 0 & 0 \\
\hline 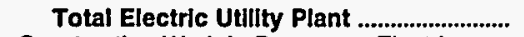 & 256,475 & 275,331 & 912,354 & 60,313 & 84,197 & 112,357 \\
\hline $\begin{array}{l}\text { Construction Work in Progress - Electric ....... } \\
\text { Accumulated Provision for Depreciation }\end{array}$ & 8,333 & 16,036 & 21,136 & 339 & 854 & 3,102 \\
\hline $\begin{array}{l}\text { and Amortization } \\
\text { Net Electrlc Utillty Plant }\end{array}$ & $\begin{array}{r}82,924 \\
181,884\end{array}$ & $\begin{array}{r}84,382 \\
206,986\end{array}$ & $\begin{array}{l}201,724 \\
731,766\end{array}$ & $\begin{array}{l}22,763 \\
37,889\end{array}$ & $\begin{array}{l}36,167 \\
48,884\end{array}$ & $\begin{array}{l}41,735 \\
73,724\end{array}$ \\
\hline
\end{tabular}

Note: Totals may not equal sum of components because of independent rounding.

Source: Energy Information Administration, Form ElA-412, "Annual Report of Public Electric Utilities." 
Table 24. Electric Utility Plant by Major U.S. Publicly Owned Electric Utility Within State at End of Period, 1993 (Continued)

(Thousand Dollars)

\begin{tabular}{|c|c|c|c|c|c|c|}
\hline Item & $\begin{array}{l}\text { California } \\
\text { Pasadena } \\
\text { City of } \\
\text { June } 30\end{array}$ & $\begin{array}{c}\text { California } \\
\text { Placer } \\
\text { County } \\
\text { Water } \\
\text { Agency } \\
\text { December } 31\end{array}$ & $\begin{array}{l}\text { California } \\
\text { Redding } \\
\text { City of } \\
\text { June } 30\end{array}$ & $\begin{array}{l}\text { California } \\
\text { Riverside } \\
\text { City of } \\
\text { June } 30\end{array}$ & $\begin{array}{l}\text { California } \\
\text { Roseville } \\
\text { City of } \\
\text { June } 30\end{array}$ & $\begin{array}{l}\text { California } \\
\text { Sacramento } \\
\text { Municipal } \\
\text { Util Dist } \\
\text { December } 31\end{array}$ \\
\hline $\begin{array}{l}\text { Electric Plant in Service } \\
\text { Intangible Plant ................................................... }\end{array}$ & 0 & 143 & 0 & 0 & 0 & 147 \\
\hline Steam & 40,885 & 0 & 0 & 0 & 0 & 93,356 \\
\hline 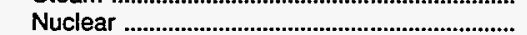 & & 0 & 0 & 118,985 & 0 & \\
\hline Hydraulic ……………………………………...... & 5,606 & 110,976 & 0 & 0 & 0 & 230,699 \\
\hline Other & 6,388 & 8 & 0 & 0 & 0 & 31,912 \\
\hline 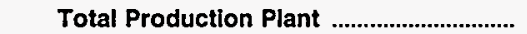 & 52,879 & 110,984 & 0 & 118,985 & o & 355,967 \\
\hline Transmission Plant & 39,966 & 439 & 0 & 11,666 & 0 & 146,058 \\
\hline Distribution Plant & 128,406 & 0 & 0 & 132,139 & 76,785 & 657,950 \\
\hline 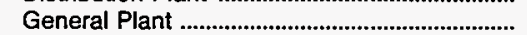 & 4,264 & 5,824 & 106,795 & 8,345 & 807 & 204,873 \\
\hline Total Electric Plant in Service & 225,516 & 117,390 & 106,795 & 271,136 & 77,592 & $1,364,996$ \\
\hline Electric Plant Leased to Others ............................. & 0 & 0 & 0 & 0 & 0 & 14,043 \\
\hline Electric Plant Held for Future Use ......................... & 0 & 0 & 13,734 & 0 & 0 & 111 \\
\hline Electric Plant Misc .............................................. & 0 & 0 & 0 & 0 & 0 & 50,772 \\
\hline Total Electric Utility Plant & 225,516 & 117,390 & 120,529 & 271,136 & 77,592 & $1,429,922$ \\
\hline $\begin{array}{l}\text { Construction Work in Progress - Electric ........ } \\
\text { Accumulated Provision for Depreciation }\end{array}$ & 9,983 & 68 & 28,702 & 23,415 & 357 & 166,245 \\
\hline 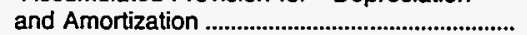 & 105,736 & 41,324 & 39,005 & 94,336 & 13,141 & 406,686 \\
\hline 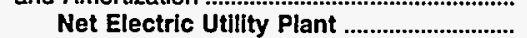 & 129,762 & 76,134 & 110,226 & 200,214 & 64,809 & $1,189,481$ \\
\hline
\end{tabular}

\begin{tabular}{|c|c|c|c|c|c|c|}
\hline Item & $\begin{array}{c}\text { California } \\
\text { San Francisco } \\
\text { City } \\
\& \\
\text { County of } \\
\text { June } 30\end{array}$ & $\begin{array}{l}\text { California } \\
\text { Santa } \\
\text { Clara } \\
\text { City of } \\
\text { June } 30\end{array}$ & $\begin{array}{l}\text { California } \\
\text { Southern } \\
\text { California } \\
\text { P P } \\
\text { A } \\
\text { June } 30\end{array}$ & $\begin{array}{c}\text { California } \\
\text { Turlock } \\
\text { Irrigation } \\
\text { District } \\
\text { December } 31\end{array}$ & $\begin{array}{l}\text { California } \\
\text { Vernon } \\
\text { City of } \\
\text { June } 30\end{array}$ & $\begin{array}{c}\text { California } \\
\text { Yuba } \\
\text { County } \\
\text { Water } \\
\text { Agency } \\
\text { June } 30\end{array}$ \\
\hline $\begin{array}{l}\text { Electric Plant in Service } \\
\text { Intangible Plant .................................................. } \\
\text { Production Plant }\end{array}$ & 7,658 & 0 & 7,998 & 0 & 0 & 346 \\
\hline 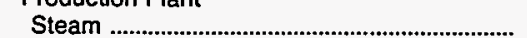 & 0 & 0 & 0 & 0 & $\mathbf{0}$ & 0 \\
\hline 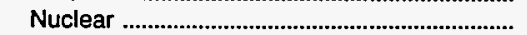 & 0 & 0 & 598,730 & 0 & 0 & 0 \\
\hline 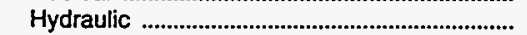 & 92,594 & 58,345 & 0 & 65,481 & 0 & 188,064 \\
\hline 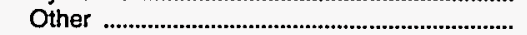 & 0 & 19,057 & 0 & 15,070 & 4,330 & 0 \\
\hline Total Production Plant & 92,594 & $\mathbf{7 7 , 4 0 2}$ & 598,730 & 80,551 & 4,330 & 188,064 \\
\hline 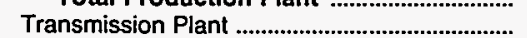 & 14,040 & 0 & 688,918 & 18,909 & 45,970 & 1,164 \\
\hline Distribution Plant & 78,101 & 0 & 0 & 84,495 & 18,731 & 0 \\
\hline 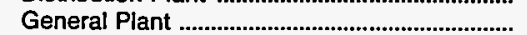 & 3,279 & 99,561 & 21,280 & 34,514 & 1,997 & 2,859 \\
\hline Total Electric Plant in Service ....................... & 195,672 & 176,963 & $1,316,926$ & 218,469 & 71,029 & 192,433 \\
\hline Electric Plant Leased to Others ............................. & 0 & 0 & 0 & 0 & 0 & 0 \\
\hline Electric Plant Held for Future Use ......................... & & 0 & 0 & 0 & 0 & 0 \\
\hline 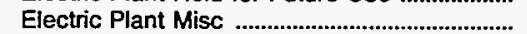 & 245,593 & 0 & 0 & 0 & 0 & 4,485 \\
\hline Total Electric Utility Plant & 441,265 & 176,963 & $1,316,926$ & 218,469 & 71,029 & 196,918 \\
\hline $\begin{array}{l}\text { Construction Work in Progress - Electric ........ } \\
\text { Accumulated Provision for Depreciation }\end{array}$ & 9,999 & 65,454 & 37,881 & 6,575 & 2,430 & \\
\hline and Amortization & 184,601 & 52,700 & 294,048 & 72,545 & 22,376 & 52,337 \\
\hline & 266,663 & 189,718 & $1,060,759$ & 152,498 & 51,083 & 144,581 \\
\hline
\end{tabular}

Note: Totals may not equal sum of components because of independent rounding.

Source: Energy Information Administration, Form EIA-412, "Annual Report of Public Electric Utilities." 
Table 24. Electric Utility Plant by Major U.S. Publicly Owned Electric Utility Within State at End of Period, 1993 (Continued)

(Thousand Dollars)

\begin{tabular}{|c|c|c|c|c|c|c|}
\hline Item & $\begin{array}{c}\text { Colorado } \\
\text { Arkansas } \\
\text { River } \\
\text { Power } \\
\text { Authority } \\
\text { December } 31\end{array}$ & $\begin{array}{l}\text { Colorado } \\
\text { Colorado } \\
\text { Springs } \\
\text { City of } \\
\text { December } 31\end{array}$ & $\begin{array}{l}\text { Colorado } \\
\text { Fort Collins } \\
\text { City of } \\
\text { December } 31\end{array}$ & $\begin{array}{c}\text { Colorado } \\
\text { Fort Morgan } \\
\text { City of }\end{array}$ & $\begin{array}{l}\text { Colorado } \\
\text { Longmont } \\
\text { City of }\end{array}$ & $\begin{array}{l}\text { Colorado } \\
\text { Loveland } \\
\text { City of } \\
\text { December } 31\end{array}$ \\
\hline \multicolumn{7}{|l|}{ Electric Plant in Servlce } \\
\hline 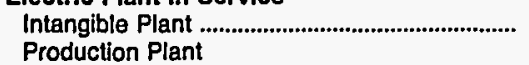 & 0 & $\mathbf{0}$ & 5 & 0 & 0 & 0 \\
\hline Steam & 0 & 232,490 & 0 & 0 & 0 & $\mathbf{0}$ \\
\hline 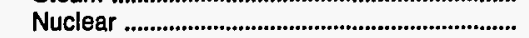 & 0 & 0 & 0 & 0 & 0 & 0 \\
\hline 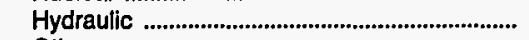 & 0 & 2,545 & 0 & 0 & 380 & 1,387 \\
\hline Other & 0 & 0 & 0 & 0 & 3,358 & 0 \\
\hline Total Productlon Plant & $\mathbf{0}$ & 235,036 & o & $\mathbf{0}$ & 3,738 & 1,387 \\
\hline 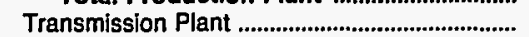 & 2,710 & 49,122 & 1,782 & 0 & 0 & 3,933 \\
\hline 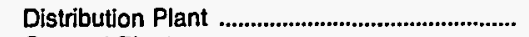 & 0 & 331,318 & 68,246 & 7,709 & 33,831 & 33,132 \\
\hline 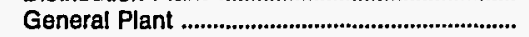 & 0 & 33,344 & 13,833 & 774 & 399 & 5,055 \\
\hline Total Electric Plant in Service .................... & 2,710 & 648,820 & 83,866 & 8,483 & 37,969 & 43,508 \\
\hline Electric Plant Leased to Others ......................... & 0 & 377 & 0 & 0 & 0 & 0 \\
\hline Electric Plant Held for Future Use ..................... & 0 & 0 & 0 & 0 & 0 & 0 \\
\hline 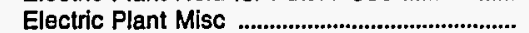 & 0 & 0 & 0 & 0 & 0 & 0 \\
\hline 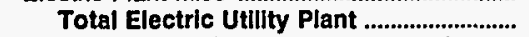 & 2,710 & 649,197 & 83,866 & 8,483 & 37,969 & 43,508 \\
\hline $\begin{array}{l}\text { Construction Work in Progress - Electric ........ } \\
\text { Accumulated Provision for Depreciation }\end{array}$ & 0 & 25,478 & 4,142 & 708 & 0 & 629 \\
\hline 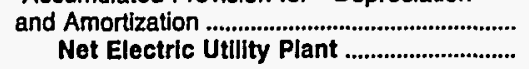 & $\begin{array}{r}282 \\
2,428\end{array}$ & $\begin{array}{l}174,519 \\
500,157\end{array}$ & $\begin{array}{l}35,072 \\
52,936\end{array}$ & $\begin{array}{l}3,301 \\
5,889\end{array}$ & $\begin{array}{l}14,637 \\
23,332\end{array}$ & $\begin{array}{r}9,732 \\
34,405\end{array}$ \\
\hline
\end{tabular}

\begin{tabular}{|c|c|c|c|c|c|c|}
\hline Item & $\begin{array}{c}\text { Colorado } \\
\text { Platte River } \\
\text { Power } \\
\text { Authority } \\
\text { December } 31\end{array}$ & $\begin{array}{l}\text { Connecticut } \\
\text { Connecticut } \\
\text { Mun } \\
\text { Elec } \\
\text { Engy Coop } \\
\text { December } 31\end{array}$ & $\begin{array}{l}\text { Connecticut } \\
\text { Groton } \\
\text { City of } \\
\text { June } 30\end{array}$ & $\begin{array}{c}\text { Norwich } \\
\text { City of } \\
\text { June } 30\end{array}$ & $\begin{array}{l}\text { Connecticut } \\
\text { Wallingford } \\
\text { Town of } \\
\text { June } 30\end{array}$ & $\begin{array}{l}\text { Dover } \\
\text { City of } \\
\text { June } 30\end{array}$ \\
\hline \multicolumn{7}{|l|}{ Electrlc Plant In Service } \\
\hline $\begin{array}{l}\text { Intangible Plant } \\
\text { Production Plant }\end{array}$ & 0 & 942 & 0 & 0 & 0 & 0 \\
\hline Steam & 630,324 & 0 & 0 & 0 & 6,506 & 60,139 \\
\hline Nuclear & 0 & 50,468 & 0 & 0 & 0 & 0 \\
\hline 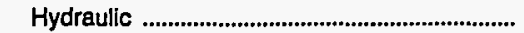 & 0 & 0 & 0 & 2,910 & 0 & 0 \\
\hline Other & 0 & 0 & 0 & 2,377 & 0 & 0 \\
\hline Total Productlon Plant ................................ & 630,324 & 50,468 & $\mathbf{0}$ & 5,286 & 6,506 & 60,139 \\
\hline 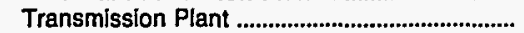 & 94,628 & 1,188 & 5,210 & 2,523 & 1,276 & 15,337 \\
\hline 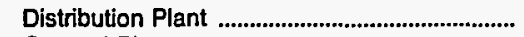 & 0 & 0 & 15,148 & 13,525 & 30,465 & 16,943 \\
\hline 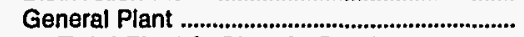 & 11,344 & 1,874 & 2,955 & 3,019 & 4,050 & 1,542 \\
\hline Total Electric Plant in Service ................. & 736,297 & 54,472 & 23,313 & 24,354 & 42,296 & 93,961 \\
\hline Electric Plant Leased to Others ....................... & 0 & 0 & 0 & 0 & 0 & 0 \\
\hline Electric Plant Held for Future Use ................... & 0 & 0 & 0 & 0 & 0 & 0 \\
\hline 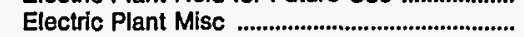 & 25,325 & 0 & 1,655 & 0 & 0 & 0 \\
\hline 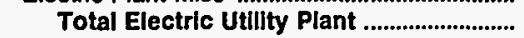 & 761,622 & 54,472 & 24,968 & 24,354 & 42,296 & 93,961 \\
\hline $\begin{array}{l}\text { Construction Work in Progress - Electric ........ } \\
\text { Accumulated Provision for Depreciation }\end{array}$ & 5,421 & 26 & 0 & 5,502 & 1,865 & 0 \\
\hline 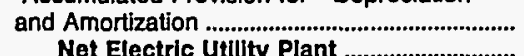 & $\begin{array}{l}228,092 \\
538,951\end{array}$ & $\begin{array}{l}12,486 \\
42,013\end{array}$ & $\begin{array}{l}14,427 \\
10.541\end{array}$ & $\begin{array}{r}16,083 \\
13,772\end{array}$ & $\begin{array}{l}24,430 \\
19,731\end{array}$ & $\begin{array}{l}30,245 \\
63,716\end{array}$ \\
\hline
\end{tabular}

Note: Totals may not equal sum of components because of independent rounding.

Source: Energy Information Administration, Form EIA-412, "Annual Report of Public Electric Utilities." 
Table 24. Electric Utility Plant by Major U.S. Publicly Owned Electric Utility Within State at End of Period, 1993 (Continued) (Thousand Dollars)

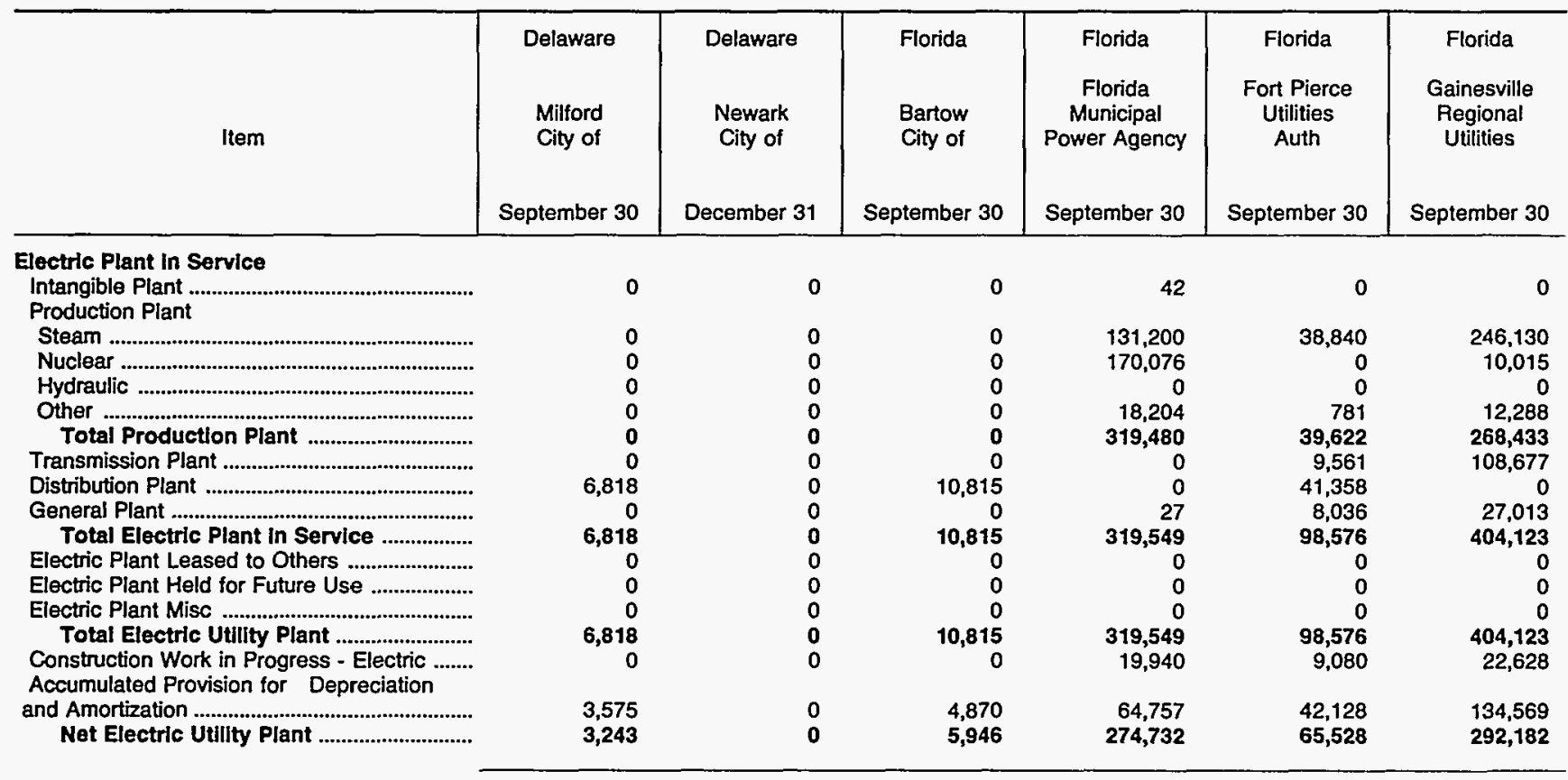

\begin{tabular}{|c|c|c|c|c|c|c|}
\hline Item & $\begin{array}{c}\text { Florida } \\
\text { Homestead } \\
\text { City of } \\
\text { September } 30\end{array}$ & $\begin{array}{c}\text { Florida } \\
\text { Jacksonville } \\
\text { Beach } \\
\text { City of } \\
\text { September } 30\end{array}$ & $\begin{array}{c}\text { Florida } \\
\text { Jacksonville } \\
\text { Electric } \\
\text { Auth } \\
\text { September } 30\end{array}$ & $\begin{array}{c}\text { Florida } \\
\text { Key West } \\
\text { City of } \\
\text { September } 30\end{array}$ & $\begin{array}{c}\text { Florida } \\
\text { Kissimmee } \\
\text { Utility } \\
\text { Authority } \\
\text { September } 30\end{array}$ & $\begin{array}{c}\text { Florida } \\
\text { Lake Worth } \\
\text { City of }\end{array}$ \\
\hline \multicolumn{7}{|l|}{ Electric Plant in Service } \\
\hline $\begin{array}{l}\text { Intangible Plant } \\
\text { Production Plant }\end{array}$ & 0 & 0 & 612 & 220 & 412 & 59 \\
\hline Steam & 0 & 0 & $1,836,802$ & 43,077 & 19,895 & 22,456 \\
\hline 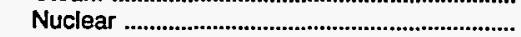 & 0 & 0 & 0 & 0 & 4,753 & 0 \\
\hline 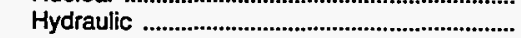 & 0 & 0 & $\mathbf{0}$ & 0 & 0 & $\mathbf{0}$ \\
\hline Other & 40,422 & $\mathbf{0}$ & 48,338 & 35,699 & 40,813 & 17,964 \\
\hline Total Production Plant & 40,422 & 0 & $1,885,140$ & 78,776 & 65,462 & 40,420 \\
\hline 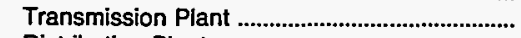 & 0 & $\mathbf{0}$ & 257,208 & 31,636 & 21,279 & 26,595 \\
\hline Distribution Plant & 0 & 61,643 & 561,014 & 29,155 & 36,541 & 0 \\
\hline 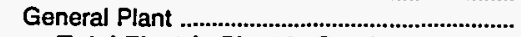 & 0 & 0 & 101,351 & 8,337 & 13,491 & $\mathbf{0}$ \\
\hline Total Electric Plant in Servlce .................... & 40,422 & 61,643 & $2,805,324$ & 148,124 & 137,184 & 67,074 \\
\hline Electric Plant Leased to Others .......................... & 0 & 0 & 0 & 0 & 0 & 0 \\
\hline Electric Plant Held for Future Use .................... & 0 & 0 & 1,048 & 0 & 1,027 & 68 \\
\hline 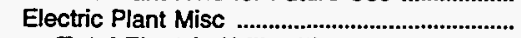 & 0 & 0 & 0 & 0 & 0 & 3,543 \\
\hline 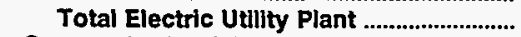 & 40,422 & 61,643 & $2,806,373$ & 148,124 & 138,212 & 70,686 \\
\hline $\begin{array}{l}\text { Construction Work in Progress - Electric ........ } \\
\text { Accumulated Provision for Depreciation }\end{array}$ & 0 & 10,867 & 25,797 & 8,639 & 13,403 & 5,638 \\
\hline 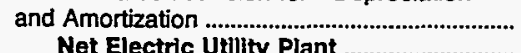 & 17,657 & 19,578 & 561,085 & 58,466 & 49,484 & 36,798 \\
\hline Net Electric Utility Plant ............................. & 22,765 & 52,932 & $2,271,085$ & 98,298 & 102,131 & 39,525 \\
\hline
\end{tabular}

Note: Totals may not equal sum of components because of independent rounding.

Source: Energy Information Administration, Form EIA-412, "Annual Report of Public Electric Utilities." 
Table 24. Electric Utility Plant by Major U.S. Publicly Owned Electric Utility Within State at End of Period, 1993 (Continued) (Thousand Dollars)

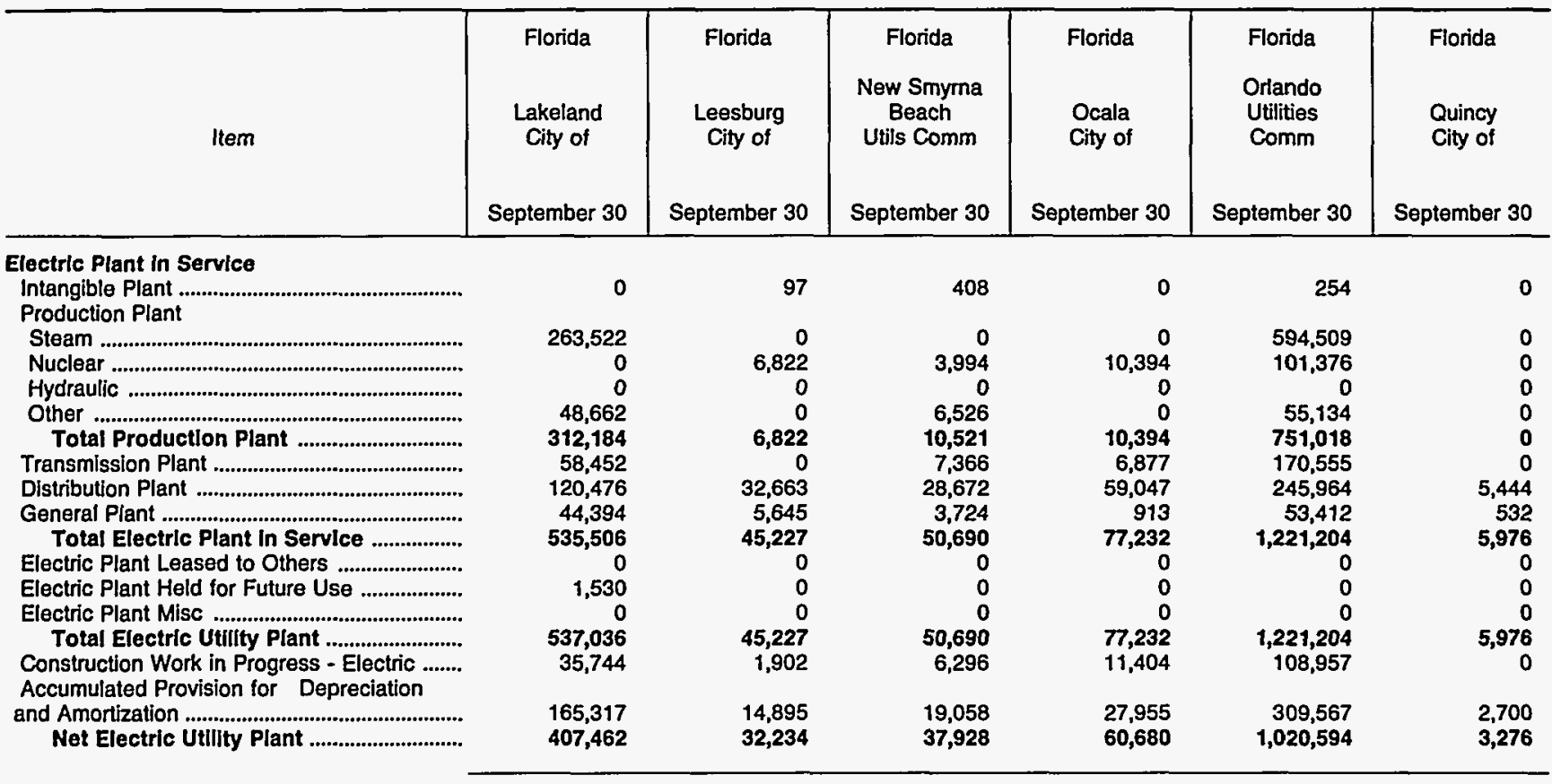

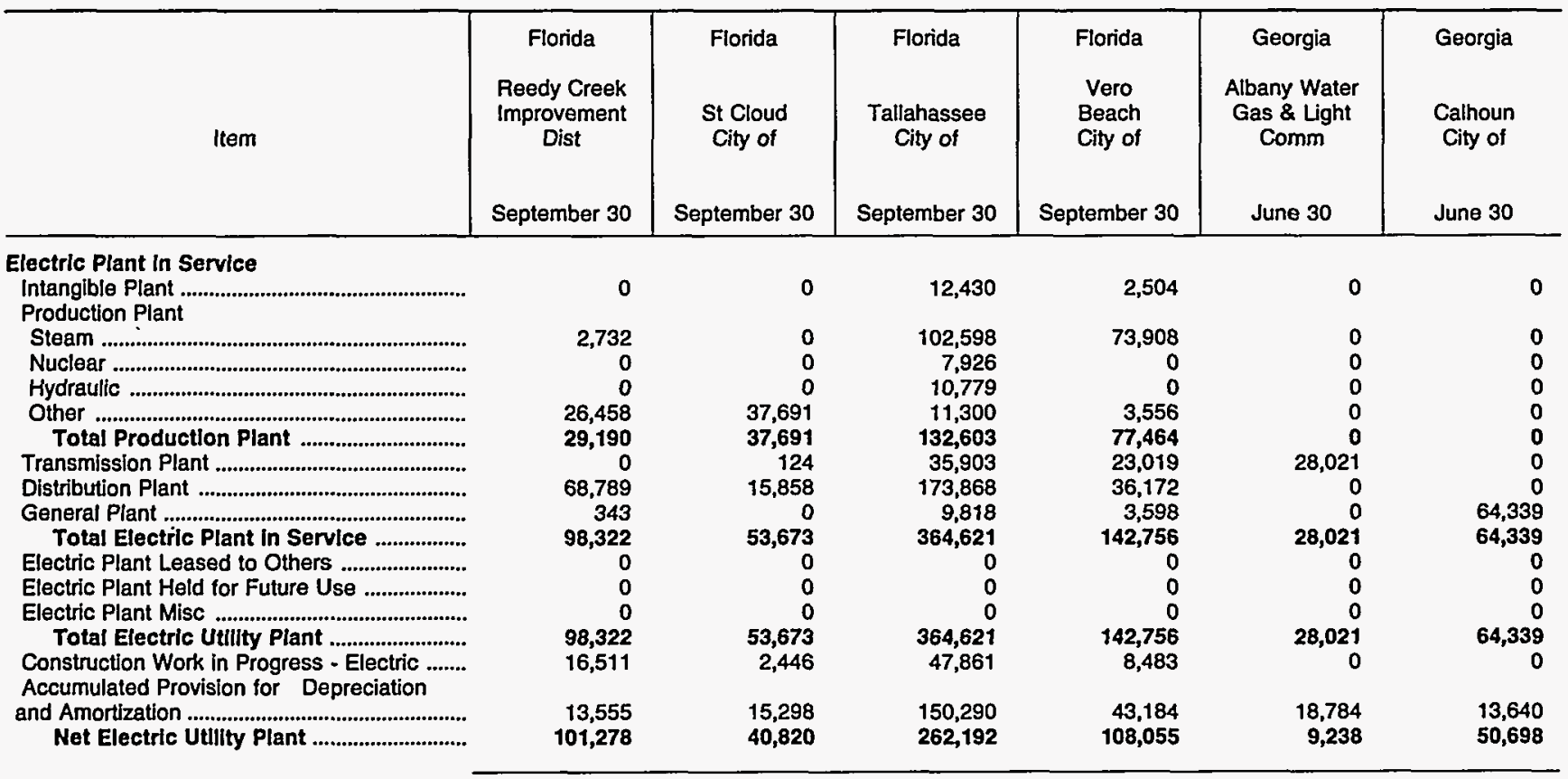

Note: Totals may not equal sum of components because of independent rounding.

Source: Energy Information Administration, Form EIA-412, "Annual Report of Public Electric Utilities." 
Table 24. Electric Utility Plant by Major U.S. Publicly Owned Electric Utility Within State at End of Period, 1993 (Continued) (Thousand Dollars)

\begin{tabular}{|c|c|c|c|c|c|c|}
\hline Item & $\begin{array}{c}\text { Georgia } \\
\text { Cartersville } \\
\text { City of } \\
\text { June } 30\end{array}$ & $\begin{array}{c}\text { Georgia } \\
\text { College } \\
\text { Park City of } \\
\text { June } 30\end{array}$ & $\begin{array}{l}\text { Georgia } \\
\text { Covington } \\
\text { City of } \\
\text { December } 31\end{array}$ & $\begin{array}{c}\text { Georgia } \\
\text { Crisp } \\
\text { County } \\
\text { Power } \\
\text { Comm } \\
\text { December } 31\end{array}$ & $\begin{array}{l}\text { Georgia } \\
\text { Dalton } \\
\text { City of } \\
\text { November } 30\end{array}$ & $\begin{array}{l}\text { Georgia } \\
\text { Douglas } \\
\text { City of } \\
\text { June } 30\end{array}$ \\
\hline \multicolumn{7}{|l|}{ Electric Plant In Service } \\
\hline $\begin{array}{l}\text { Intangible Plant } \\
\text { Production Plant }\end{array}$ & 0 & 0 & 0 & 106 & 0 & 0 \\
\hline Steam & $\mathbf{0}$ & 0 & 0 & 5,050 & 22,309 & 0 \\
\hline Nuclear & 0 & 0 & 0 & 0 & 130,702 & 0 \\
\hline 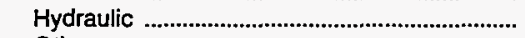 & 0 & 0 & 0 & 4,540 & 0 & 0 \\
\hline Other & 0 & 0 & 0 & 0 & 0 & 0 \\
\hline Total Production Plant .................................. & $\mathbf{0}$ & $\mathbf{0}$ & 0 & 9,590 & 153,011 & $\mathbf{0}$ \\
\hline 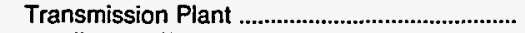 & 0 & 0 & 0 & 1,879 & 27,440 & 0 \\
\hline 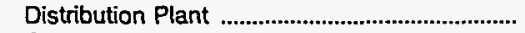 & 10,267 & 7,821 & 5,844 & 21,601 & 17,106 & 3,907 \\
\hline General Plant & 0 & 714 & 0 & 3,610 & 2,967 & 0 \\
\hline Total Electric Plant in Service .................... & 10,267 & 8,535 & 5,844 & 36,785 & 200,524 & 3,907 \\
\hline 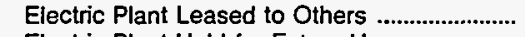 & 0 & 0 & 0 & 0 & 0 & 0 \\
\hline Electric Plant Heid for Future Use ..................... & $\mathbf{0}$ & 0 & 0 & 0 & 0 & 0 \\
\hline 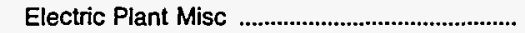 & 0 & 0 & 0 & 0 & 0 & 0 \\
\hline 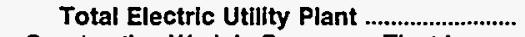 & 10,267 & 8,535 & 5,844 & 36,785 & 200,524 & 3,907 \\
\hline $\begin{array}{l}\text { Construction Work in Progress - Electric ........ } \\
\text { Accumulated Provision for Depreciation }\end{array}$ & 0 & 0 & 460 & 786 & 1,998 & 0 \\
\hline and Amortization & 2,245 & 3,390 & 3,173 & 21,185 & 59,580 & 2,187 \\
\hline Net Electric Utility Plant .................................. & 8,022 & 5,145 & 3,131 & 16,386 & 142,942 & 1,721 \\
\hline
\end{tabular}

\begin{tabular}{|c|c|c|c|c|c|c|}
\hline Item & $\begin{array}{c}\text { Georgia } \\
\text { East } \\
\text { Point } \\
\text { City of } \\
\text { June } 30\end{array}$ & $\begin{array}{c}\text { Georgia } \\
\text { Fitzgerald } \\
\text { Wtr Lgt } \\
\text { \& Bond Comm } \\
\text { December } 31\end{array}$ & $\begin{array}{l}\text { Georgia } \\
\text { Griffin } \\
\text { City of } \\
\text { June } 30\end{array}$ & $\begin{array}{l}\text { Georgia } \\
\text { La Grange } \\
\text { City of } \\
\text { June } 30\end{array}$ & $\begin{array}{c}\text { Georgia } \\
\text { Lawrenceville } \\
\text { City of } \\
\text { August } 30\end{array}$ & $\begin{array}{l}\text { Georgia } \\
\text { Marietta } \\
\text { City of } \\
\text { June } 30\end{array}$ \\
\hline \multicolumn{7}{|l|}{ Electric Plant in Service } \\
\hline $\begin{array}{l}\text { Intangible Plant ....................................................... } \\
\text { Production Plant }\end{array}$ & 0 & 0 & 0 & 0 & 0 & $\mathbf{0}$ \\
\hline Steam & 0 & 0 & 0 & 0 & 0 & 0 \\
\hline Nuclear & 0 & 0 & 0 & 0 & 0 & 0 \\
\hline 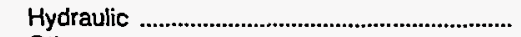 & 0 & 0 & 0 & 0 & 0 & 0 \\
\hline Other & 0 & 0 & 0 & 0 & 0 & 0 \\
\hline Total Production Plant ................................... & 0 & 0 & 0 & $\mathbf{0}$ & 0 & $\mathbf{0}$ \\
\hline Transmission Plant & 0 & 1,812 & 0 & 0 & 0 & 0 \\
\hline 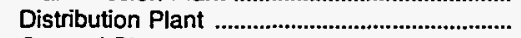 & 1,504 & 2,953 & 0 & 0 & 13,285 & 38,685 \\
\hline General Plant & 7,269 & 1,280 & 10,530 & 6,996 & 0 & 0 \\
\hline 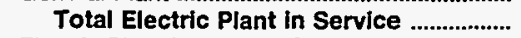 & 8,774 & 6,045 & 10,530 & 6,996 & 13,285 & 38,685 \\
\hline Electric Plant Leased to Others .......................... & 0 & 0 & 0 & 0 & 0 & 0 \\
\hline 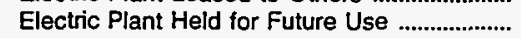 & 0 & 0 & 0 & 0 & 0 & 0 \\
\hline Electric Plant Misc & $\mathbf{0}$ & 0 & 0 & 0 & $\mathbf{0}$ & 0 \\
\hline 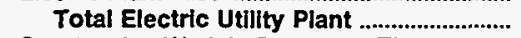 & 8,774 & 6,045 & 10,530 & 6,996 & 13,285 & 38,685 \\
\hline $\begin{array}{l}\text { Construction Work in Progress - Electric ........ } \\
\text { Accumulated Provision for Depreciation }\end{array}$ & 0 & 0 & 0 & 0 & 0 & 0 \\
\hline and Amortization & 5,598 & 2,793 & 403 & 1,885 & 2,956 & 14,956 \\
\hline 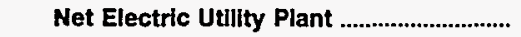 & 3,175 & 3,252 & 10,128 & 5,112 & 10,329 & 23,729 \\
\hline
\end{tabular}

Note: Totals may not equal sum of components because of independent rounding.

Source: Energy Information Administration, Form ElA-412, "Annual Report of Public Electric Utilities." 
Table 24. Electric Utility Plant by Major U.S. Publicly Owned Electric Utility Within State at End of Period, 1993 (Continued)

(Thousand Dollars)

\begin{tabular}{|c|c|c|c|c|c|c|}
\hline Item & $\begin{array}{c}\text { Georgia } \\
\text { Moultrie } \\
\text { City of } \\
\text { September } 30\end{array}$ & $\begin{array}{l}\text { Georgia } \\
\text { Municipal } \\
\text { Electric } \\
\text { Authority } \\
\text { December } 31\end{array}$ & $\begin{array}{c}\text { Georgia } \\
\text { Thomasville } \\
\text { City of }\end{array}$ & $\begin{array}{c}\text { Idaho } \\
\text { Idaho } \\
\text { Falls } \\
\text { City of } \\
\text { September } 30\end{array}$ & $\begin{array}{c}\text { Illinois } \\
\text { Batavia } \\
\text { City of } \\
\text { December } 31\end{array}$ & $\begin{array}{l}\text { Illinois } \\
\text { Geneva } \\
\text { City of } \\
\text { April } 30\end{array}$ \\
\hline $\begin{array}{l}\text { Electric Plant in Service } \\
\text { Intangible Plant ....................................................... } \\
\text { Production Plant }\end{array}$ & 0 & 147 & 0 & 2,036 & 0 & 0 \\
\hline Steam & 0 & 413,830 & 0 & 0 & 0 & 0 \\
\hline Nuclear & 0 & $2,296,978$ & 0 & 0 & 0 & 0 \\
\hline 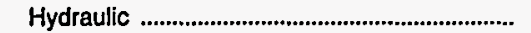 & 0 & 0 & 0 & 92,768 & 0 & 0 \\
\hline Other & 0 & 2,092 & 0 & 0 & 0 & 0 \\
\hline Total Production Plant & $\mathbf{0}$ & $2,712,900$ & 0 & 92,768 & 0 & $\mathbf{0}$ \\
\hline 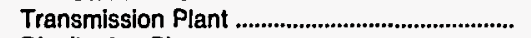 & 0 & 219,258 & 0 & 6,195 & 0 & 0 \\
\hline Distribution Plant ................................................... & 5,619 & 89,855 & 10,109 & 22,561 & 13,254 & 12,522 \\
\hline 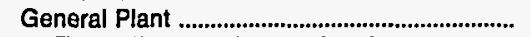 & 49 & 5,749 & 1,579 & 3,938 & 2,012 & 7,290 \\
\hline Total Electric Plant In Servlce ................... & 5,668 & $3,027,909$ & 11,688 & 127,498 & 15,266 & 19,812 \\
\hline Electric Plant Leased to Others ........................ & 0 & 0 & 0 & 0 & 0 & 0 \\
\hline Electric Plant Held for Future Use ................... & 0 & 482 & 0 & 0 & 0 & 0 \\
\hline 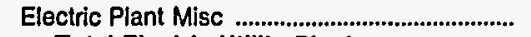 & 0 & 108,418 & 0 & 0 & 0 & 0 \\
\hline 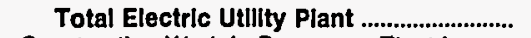 & 5,668 & $3,136,809$ & 11,688 & 127,498 & 15,266 & 19,812 \\
\hline $\begin{array}{l}\text { Construction Work in Progress - Electric ....... } \\
\text { Accumulated Provision for Depreciation }\end{array}$ & 2 & 20,099 & 85 & 1,321 & 0 & 0 \\
\hline 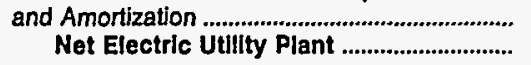 & $\begin{array}{l}3,623 \\
2,047\end{array}$ & $\begin{array}{r}868,403 \\
2,288,505\end{array}$ & $\begin{array}{l}4,388 \\
7,385\end{array}$ & $\begin{array}{l}30,875 \\
97,944\end{array}$ & $\begin{array}{l}6,375 \\
8,891\end{array}$ & $\begin{array}{r}8,286 \\
11,525\end{array}$ \\
\hline
\end{tabular}

\begin{tabular}{|c|c|c|c|c|c|c|}
\hline Item & $\begin{array}{c}\text { Illinois } \\
\text { Illinois } \\
\text { Municipal } \\
\text { Elec Agency } \\
\text { April } 30\end{array}$ & $\begin{array}{l}\text { Illinois } \\
\text { Naperville } \\
\text { City of } \\
\text { April } 30\end{array}$ & $\begin{array}{l}\text { Illinois } \\
\text { Rochelle } \\
\text { Municipai } \\
\text { Utilities } \\
\text { April } 30\end{array}$ & $\begin{array}{l}\text { Illinois } \\
\text { Springfield } \\
\text { City of } \\
\text { February } 28\end{array}$ & $\begin{array}{l}\text { St Charles } \\
\text { City of } \\
\text { April } 30\end{array}$ & $\begin{array}{c}\text { Indiana } \\
\text { Anderson } \\
\text { City of } \\
\text { December } 31\end{array}$ \\
\hline \multicolumn{7}{|l|}{ Electric PJant in Service } \\
\hline $\begin{array}{l}\text { Intangible Plant } \\
\text { Production Plant }\end{array}$ & 0 & 0 & 0 & 0 & 0 & 0 \\
\hline 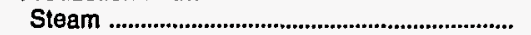 & 94,183 & 0 & 10,843 & 172,110 & 0 & 0 \\
\hline 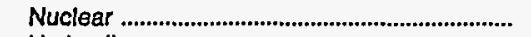 & 0 & 0 & 0 & 0 & 0 & 0 \\
\hline 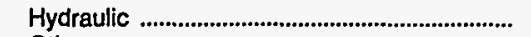 & 0 & 0 & 0 & 0 & 0 & 0 \\
\hline Other & 0 & 0 & 5,721 & 6,508 & 0 & 0 \\
\hline Total Production Plant ................................. & 94,183 & $\mathbf{0}$ & 16,563 & 178,618 & 0 & 0 \\
\hline 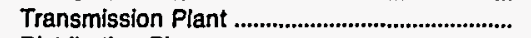 & 0 & 6,425 & 1,687 & 34,440 & 0 & 1,178 \\
\hline Distribution Plant & 0 & 89,869 & 8,868 & 105,466 & 26,835 & 41,920 \\
\hline General Plant & 2,077 & 12,915 & 1,696 & 19,841 & 67 & 7,087 \\
\hline Total Electric Plant in Service .................... & 96,260 & 109,208 & 28,815 & 338,365 & 26,902 & 50,185 \\
\hline Electric Plant Leased to Others .......................... & 0 & 0 & 0 & 0 & 0 & 0 \\
\hline Electric Plant Held for Future Use .................... & 0 & 0 & 0 & 4,987 & 0 & 0 \\
\hline 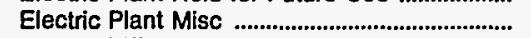 & 0 & 0 & 0 & 2,092 & 0 & 0 \\
\hline 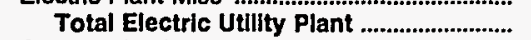 & 96,260 & 109,208 & 28,815 & 345,444 & 26,902 & 50,185 \\
\hline $\begin{array}{l}\text { Construction Work in Progress - Electric ........ } \\
\text { Accumulated Provision for Depreciation }\end{array}$ & 139 & 0 & 0 & 16,472 & 0 & 688 \\
\hline and Amortization & 6,450 & 19,867 & 14,648 & 167,726 & 7,864 & 20,448 \\
\hline 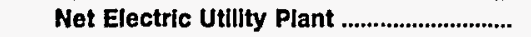 & 89,950 & 89,342 & 14,168 & 194,190 & 19,038 & 30,425 \\
\hline
\end{tabular}

Note: Totals may not equal sum of components because of independent rounding.

Source: Energy Information Administration, Form EIA-412, "Annual Report of Public Electric Utilities." 
Table 24. Electric Utility Plant by Major U.S. Publicly Owned Electric Utility Within State at End of Period, 1993 (Continued)

(Thousand Dollars)

\begin{tabular}{|c|c|c|c|c|c|c|}
\hline Item & $\begin{array}{l}\text { Indiana } \\
\text { Aubum } \\
\text { City of } \\
\text { December } 31\end{array}$ & $\begin{array}{l}\text { Indiana } \\
\text { Bluffton } \\
\text { City of } \\
\text { December } 31\end{array}$ & $\begin{array}{c}\text { Indiana } \\
\text { Crawfordsville } \\
\text { Elec } \\
\text { Lgt\&Pwr Co } \\
\text { December } 31\end{array}$ & $\begin{array}{l}\text { Indiana } \\
\text { Frankfort } \\
\text { City of } \\
\text { December } 31\end{array}$ & $\begin{array}{c}\text { Greenfield } \\
\text { City of }\end{array}$ & $\begin{array}{c}\text { Indiana } \\
\text { Indiana } \\
\text { Municipal } \\
\text { Power Agency } \\
\text { December } 31\end{array}$ \\
\hline 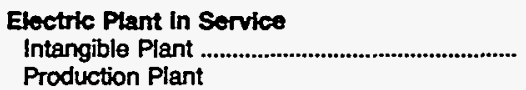 & 0 & 0 & 184 & 0 & 0 & 0 \\
\hline 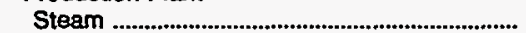 & 0 & 0 & 12,622 & 0 & 0 & 194,441 \\
\hline 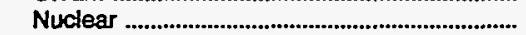 & 0 & 0 & 0 & 0 & 0 & 0 \\
\hline 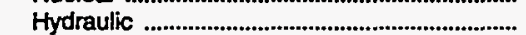 & 0 & $\mathbf{0}$ & 0 & 0 & 0 & 0 \\
\hline 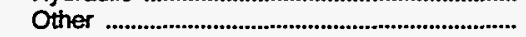 & 26 & 1,237 & 0 & 0 & 0 & 66,700 \\
\hline 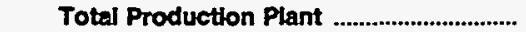 & 26 & 1,237 & 12,622 & $\mathbf{0}$ & $\mathbf{0}$ & 261,141 \\
\hline 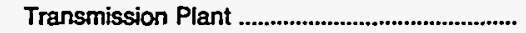 & 267 & 268 & 1,034 & $\mathbf{0}$ & o & 41,104 \\
\hline 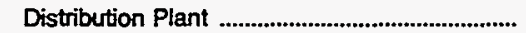 & 10,793 & 5,807 & 13,673 & 15,589 & 6,295 & 6,589 \\
\hline General Plant & 1,547 & 947 & 3,189 & 2,538 & 939 & 2,080 \\
\hline Total Electric Plant In Service ...................... & 12,634 & 8,259 & 30,702 & 18,127 & 7,234 & 310,914 \\
\hline Electric Plant Leased to Others ........................ & 0 & 0 & 0 & 0 & 0 & 0 \\
\hline Electric Plant Held for Future Use .................... & 0 & 0 & 51 & $\mathbf{0}$ & 0 & 0 \\
\hline 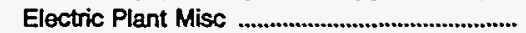 & 0 & 0 & 76 & 0 & 0 & 0 \\
\hline Total Electric Utility Plant ............................ & 12,634 & 8,259 & 30,829 & 18,127 & 7,234 & 310,914 \\
\hline $\begin{array}{l}\text { Construction Work in Progress - Electric ........ } \\
\text { Accumulated Provision for Depreciation }\end{array}$ & 1,226 & 0 & 133 & $\mathbf{0}$ & 0 & 7,170 \\
\hline and Amortization & $\begin{array}{l}4,817 \\
9,043\end{array}$ & $\begin{array}{l}4,140 \\
4,119\end{array}$ & $\begin{array}{l}15,542 \\
15,419\end{array}$ & $\begin{array}{r}6,251 \\
11,876\end{array}$ & $\begin{array}{l}1,959 \\
5,275\end{array}$ & $\begin{array}{r}56,633 \\
261,451\end{array}$ \\
\hline
\end{tabular}

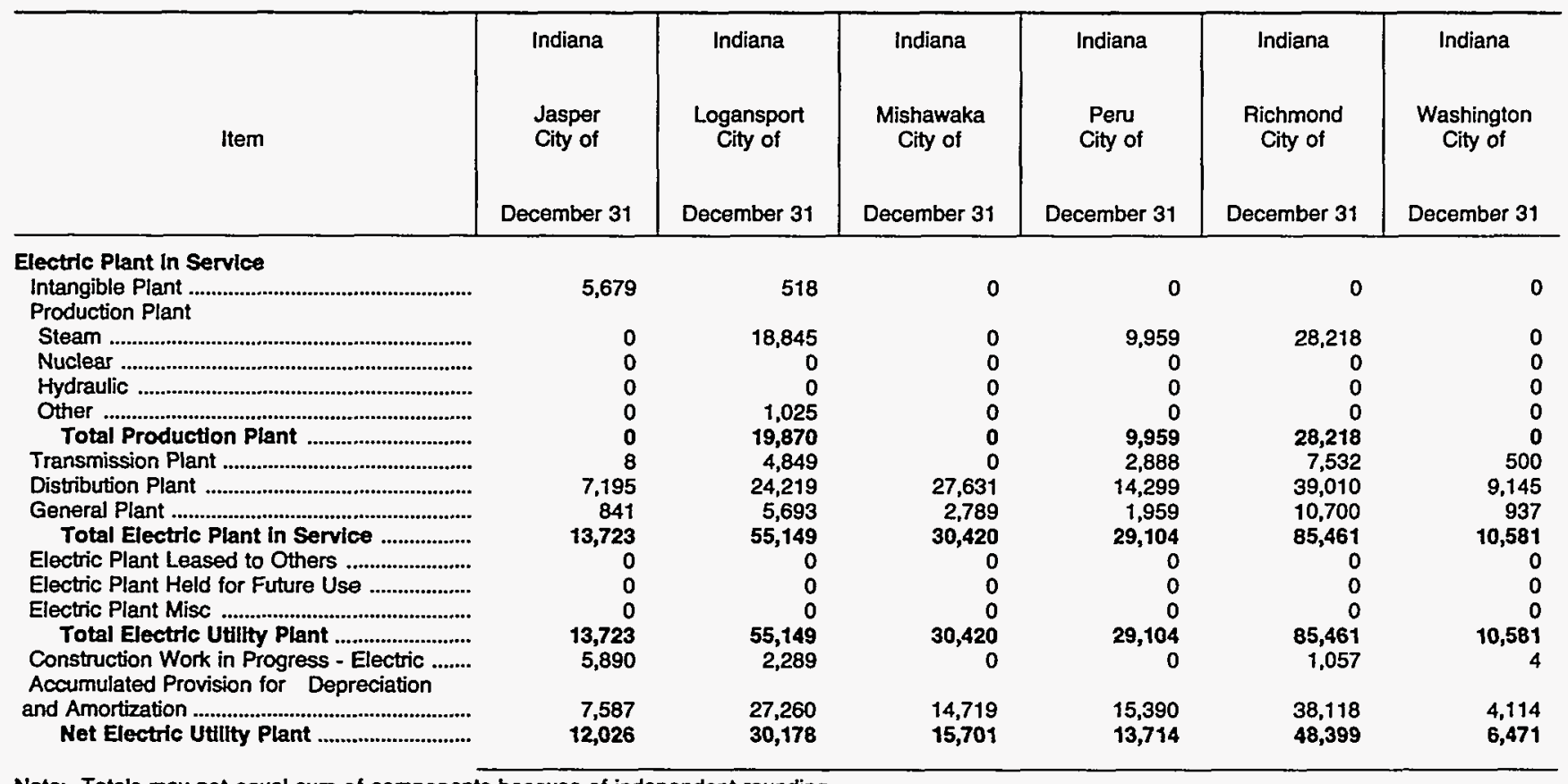

Note: Totals may not equal sum of components because of independent rounding.

Source: Energy Information Administration, Form EIA-412, "Annual Report of Public Electric Utilities." 
Table 24. Electric Utillty Plant by Major U.S. Publicly Owned Electric Utility Within State at End of Period, 1993 (Continued)

(Thousand Dollars)

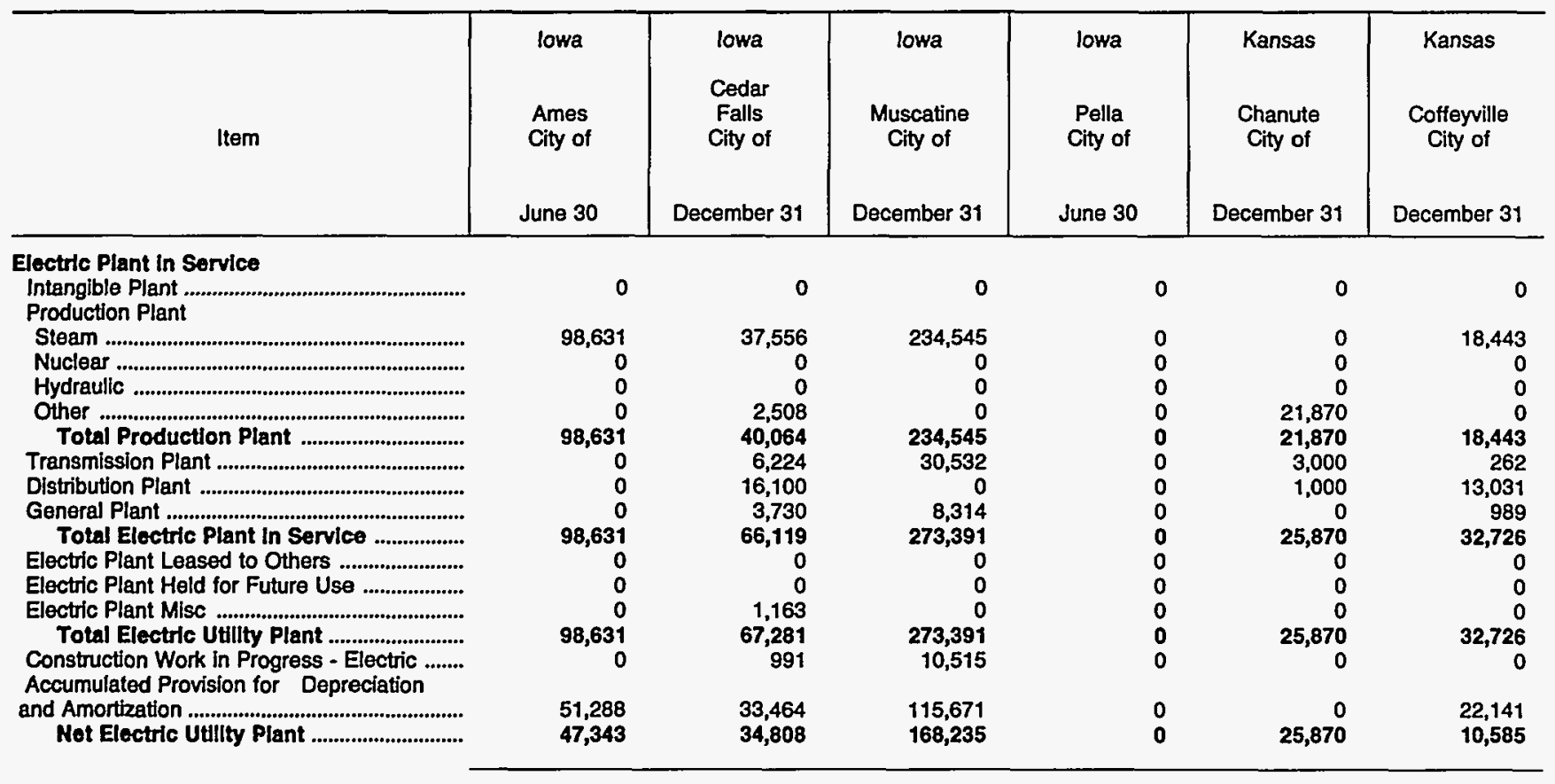

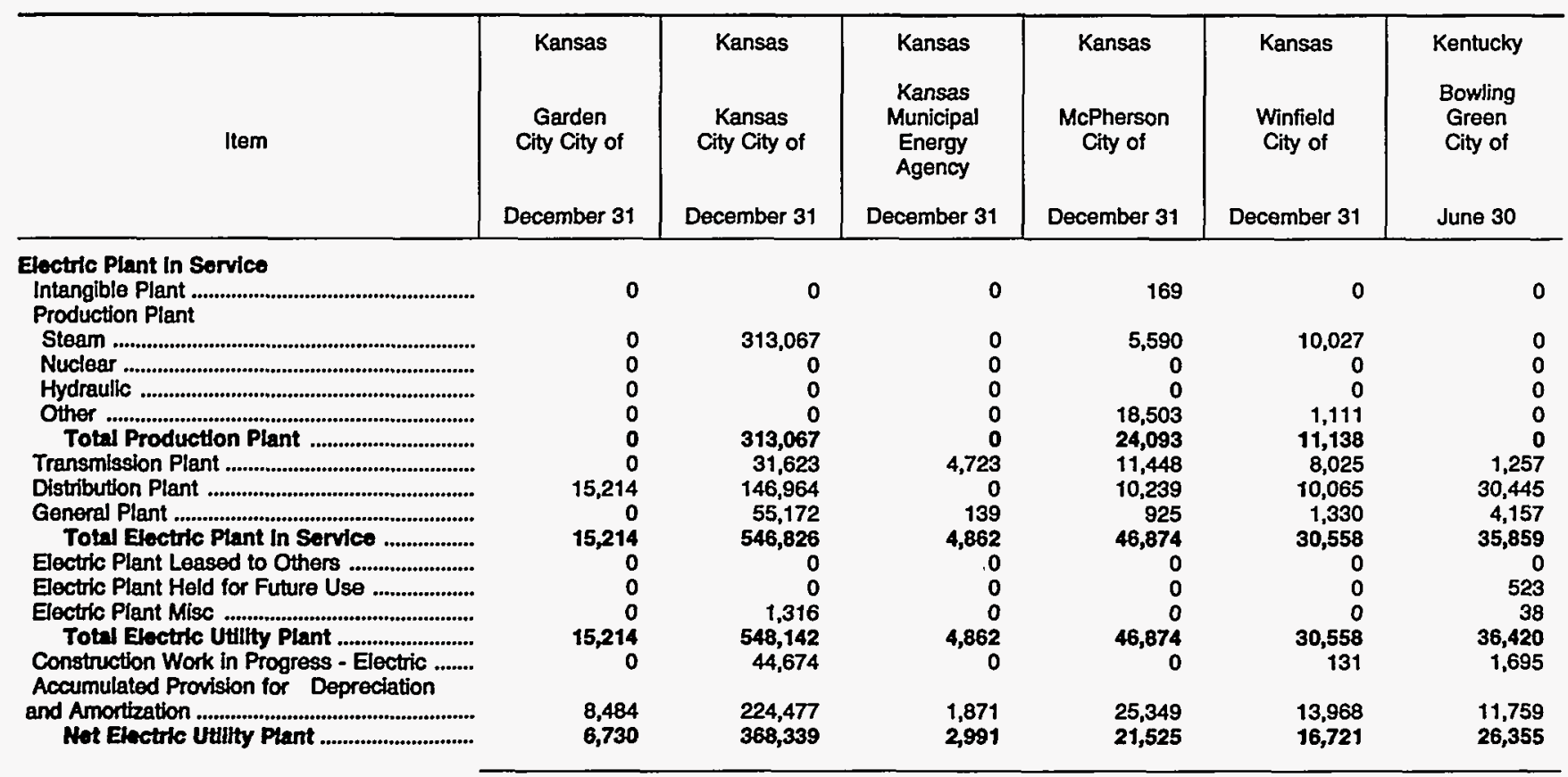

Note: Totals may not equal sum of components because of independent rounding.

Source: Energy Information Administration, Form EIA-412, "Annual Report of Public Electric Utilities." 
Table 24. Electric Utility Plant by Major U.S. Publicly Owned Electric Utility Within State at End of Period, 1993 (Continued)

(Thousand Dollars)

\begin{tabular}{|c|c|c|c|c|c|c|}
\hline Itern & $\begin{array}{l}\text { Kentucky } \\
\text { Frankfort } \\
\text { City of } \\
\text { June } 30\end{array}$ & $\begin{array}{l}\text { Kentucky } \\
\text { Franklin } \\
\text { City of } \\
\text { June } 30\end{array}$ & $\begin{array}{l}\text { Kentucky } \\
\text { Glasgow } \\
\text { City of } \\
\text { June } 30\end{array}$ & $\begin{array}{l}\text { Kentucky } \\
\text { Henderson } \\
\text { City } \\
\text { Utility Comm } \\
\text { May } 31\end{array}$ & $\begin{array}{l}\text { Kentucky } \\
\text { Hopkinsville } \\
\text { City of } \\
\text { June } 30\end{array}$ & $\begin{array}{l}\text { Kentucky } \\
\text { Madisonville } \\
\text { Municipal } \\
\text { Utils }\end{array}$ \\
\hline \multicolumn{7}{|l|}{ Electric Plant in Service } \\
\hline $\begin{array}{l}\text { Intangible Plant } \\
\text { Production Plant }\end{array}$ & 0 & 0 & 0 & 0 & 0 & 0 \\
\hline Steam & 0 & 0 & 0 & 82,235 & 0 & 0 \\
\hline Nuclear & 0 & 0 & 0 & 0 & 0 & 0 \\
\hline 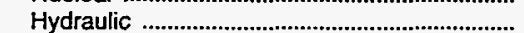 & $\mathbf{0}$ & 0 & $\mathbf{0}$ & 0 & 0 & 0 \\
\hline Other & 0 & 0 & $\mathbf{0}$ & 413 & 0 & 0 \\
\hline 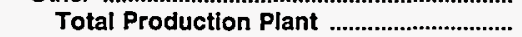 & 0 & 0 & 0 & 82,648 & $\mathbf{0}$ & 0 \\
\hline 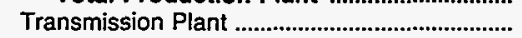 & 7,932 & 0 & 954 & 5,826 & 445 & 0 \\
\hline 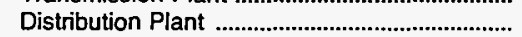 & 14,145 & 3,980 & 9,446 & 10,919 & 10,839 & 7,129 \\
\hline General Plant & 0 & 988 & 3,897 & 2,395 & 3,840 & 0 \\
\hline Total Electric Plant in Service & 22,076 & 4,968 & 14,298 & 101,788 & 15,125 & 7,129 \\
\hline 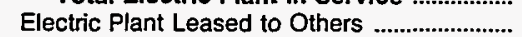 & 0 & 0 & 0 & 0 & 0 & 0 \\
\hline 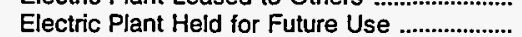 & 0 & 0 & 0 & 0 & 0 & 0 \\
\hline 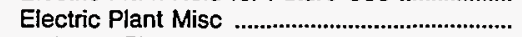 & 0 & 0 & 71 & 0 & 0 & 0 \\
\hline 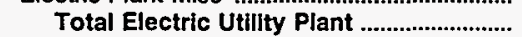 & 22,076 & 4,968 & 14,368 & 101,788 & 15,125 & 7,129 \\
\hline $\begin{array}{l}\text { Construction Work in Progress - Electric ........ } \\
\text { Accumulated Provision for Depreciation }\end{array}$ & 0 & 210 & 115 & 1,265 & 90 & 0 \\
\hline $\begin{array}{l}\text { and Amortization } \\
\text { Net Electric Utillity Plant }\end{array}$ & $\begin{array}{l}11,631 \\
10,445\end{array}$ & $\begin{array}{l}1,763 \\
3,416\end{array}$ & $\begin{array}{l}5,063 \\
9,421\end{array}$ & $\begin{array}{l}57,864 \\
45,189\end{array}$ & $\begin{array}{l}6,375 \\
8,840\end{array}$ & $\begin{array}{l}3,084 \\
4,046\end{array}$ \\
\hline
\end{tabular}

\begin{tabular}{|c|c|c|c|c|c|c|}
\hline Item & $\begin{array}{l}\text { Kentucky } \\
\text { Mayfield } \\
\text { City of } \\
\text { June } 30\end{array}$ & $\begin{array}{l}\text { Kentucky } \\
\text { Murray } \\
\text { City of } \\
\text { June } 30\end{array}$ & $\begin{array}{l}\text { Kentucky } \\
\text { Owensboro } \\
\text { City of } \\
\text { May } 31\end{array}$ & $\begin{array}{l}\text { Kentucky } \\
\text { Paducah } \\
\text { City of } \\
\text { June } 30\end{array}$ & $\begin{array}{l}\text { Louisiana } \\
\text { Alexandria } \\
\text { City of } \\
\text { April } 30\end{array}$ & $\begin{array}{l}\text { Louisiana } \\
\text { Lafayette } \\
\text { City of } \\
\text { October } 31\end{array}$ \\
\hline \multicolumn{7}{|l|}{ Electric Plant in Service } \\
\hline $\begin{array}{l}\text { Intangible Plant } \\
\text { Production Plant }\end{array}$ & 0 & 0 & 0 & 0 & 15,365 & 31 \\
\hline Steam & 0 & 0 & 79,326 & 0 & 0 & 50,709 \\
\hline 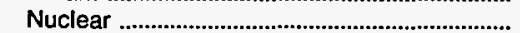 & 0 & 0 & 0 & 0 & 0 & 0 \\
\hline 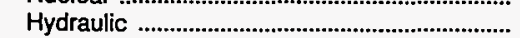 & 0 & 0 & 0 & 0 & 0 & 0 \\
\hline Other & 0 & 0 & $\mathbf{0}$ & 0 & 0 & 263 \\
\hline 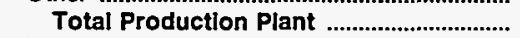 & 0 & $\mathbf{0}$ & 79,326 & 0 & 0 & 50,972 \\
\hline 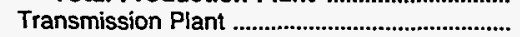 & 45 & 434 & 15,298 & 2,247 & 0 & 5,497 \\
\hline 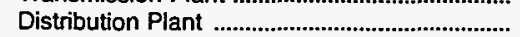 & 4,827 & 6,779 & 31,237 & 32,730 & 34,582 & 75,939 \\
\hline General Plant & 797 & 959 & 4,508 & 3,580 & $\begin{array}{r}0 \\
0\end{array}$ & 22,324 \\
\hline Total Electric Plant In Service ..................... & 5,669 & 8,173 & 130,369 & 38,557 & 49,947 & 154,764 \\
\hline 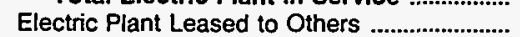 & 0 & 0 & 0 & 0 & 0 & 0 \\
\hline Electric Plant Held for Future Use .................... & 0 & 0 & 0 & 0 & 92,565 & 0 \\
\hline 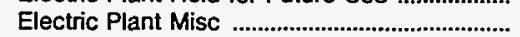 & 0 & 0 & 0 & 3,785 & 0 & 60,745 \\
\hline Total Electric Utility Plant & 5,669 & 8,173 & 130,369 & 42,341 & 142,511 & 215,508 \\
\hline $\begin{array}{l}\text { Construction Work in Progress - Electric ........ } \\
\text { Accumulated Provision for Depreciation }\end{array}$ & 166 & 29 & 50,732 & 2,326 & 36 & 608 \\
\hline 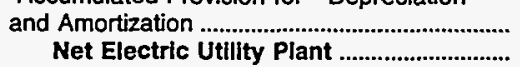 & $\begin{array}{l}2,495 \\
3,340\end{array}$ & $\begin{array}{l}3,759 \\
4,443\end{array}$ & $\begin{array}{r}71,612 \\
109,489\end{array}$ & $\begin{array}{l}12,481 \\
32,185\end{array}$ & $\begin{array}{l}59,946 \\
82,601\end{array}$ & $\begin{array}{r}85,087 \\
131,030\end{array}$ \\
\hline
\end{tabular}

Note: Totals may not equal sum of components because of independent rounding.

Source: Energy Information Administration, Form EIA-412, "Annual Report of Public Electric Utilities." 
Table 24. Electric Utility Plant by Major U.S. Publicly Owned Electric Utility Within State at End of Period, 1993 (Continued)

(Thousand Dollars)

\begin{tabular}{|c|c|c|c|c|c|c|}
\hline Item & $\begin{array}{l}\text { Louisiana } \\
\text { Lafayette } \\
\text { Public } \\
\text { Power Auth } \\
\text { October } 31\end{array}$ & $\begin{array}{c}\text { Louisiana } \\
\text { Louisiana } \\
\text { Energy } \\
\& \\
\text { Power Auth } \\
\text { December } 31\end{array}$ & $\begin{array}{c}\text { Morgan } \\
\text { City City of } \\
\text { December } 31\end{array}$ & $\begin{array}{c}\text { Natchitoches } \\
\text { City of } \\
\text { May } 31\end{array}$ & $\begin{array}{c}\begin{array}{c}\text { Ruston } \\
\text { City of }\end{array} \\
\text { September } 30\end{array}$ & $\begin{array}{l}\text { Louisiana } \\
\text { Terrebonne } \\
\text { Parish } \\
\text { Consol Govt } \\
\text { December } 31\end{array}$ \\
\hline \multicolumn{7}{|l|}{ Electrlc Plant In Service } \\
\hline 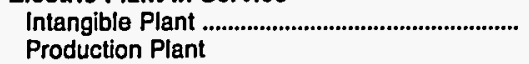 & 0 & 8,575 & 11 & 0 & 0 & 0 \\
\hline 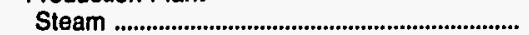 & 126,514 & 57,761 & 18,496 & 0 & 13,037 & 25,554 \\
\hline Nuclear & 0 & 0 & 0 & 0 & 0 & 0 \\
\hline 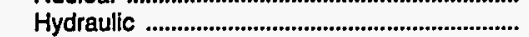 & 0 & 0 & 0 & 0 & 0 & 0 \\
\hline Other & 0 & 0 & 0 & 0 & 3,190 & 0 \\
\hline 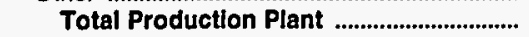 & 126,514 & 57,761 & 18,496 & D & 16,227 & 25,554 \\
\hline 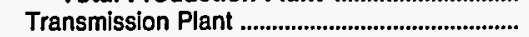 & 0 & 410 & 8,524 & 0 & 0 & 0 \\
\hline 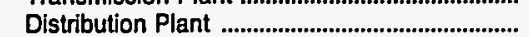 & $\mathbf{0}$ & 16 & 0 & 53,032 & 12,223 & 22,673 \\
\hline 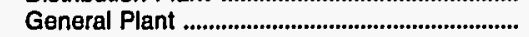 & 23,764 & 4,641 & 0 & 0 & 549 & 0 \\
\hline Total Electric Plant in Servlce .................... & 150,278 & 71,402 & 27,031 & 53,032 & 28,999 & 48,227 \\
\hline Electric Plant Leased to Others ....................... & 0 & 0 & 0 & 0 & 0 & 0 \\
\hline Electric Plant Held for Future Use .................... & 0 & 0 & 0 & 0 & 0 & 0 \\
\hline Electric Plant Misc & $\mathbf{0}$ & 15,722 & 1,063 & 0 & 0 & 0 \\
\hline Total Electrlc Utility Plant ......................... & 150,278 & 87,124 & 28,095 & 53,032 & 28,999 & 48,227 \\
\hline $\begin{array}{l}\text { Construction Work in Progress - Electric ........ } \\
\text { Accumulated Provision for Depreciation }\end{array}$ & 1,181 & 214 & 8 & 0 & 291 & 1,568 \\
\hline and Amortization & 53,295 & 16,575 & 17,934 & 14,415 & 17,853 & 33,608 \\
\hline 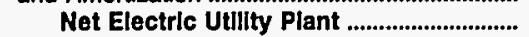 & 98,163 & 70,763 & 10,169 & 38,617 & 11,437 & 16,187 \\
\hline
\end{tabular}

\begin{tabular}{|c|c|c|c|c|c|c|}
\hline Item & $\begin{array}{l}\text { Maryland } \\
\text { Easton } \\
\text { Utilities } \\
\text { Comm } \\
\text { June } 30\end{array}$ & $\begin{array}{l}\text { Maryland } \\
\text { Hagerstown } \\
\text { City of } \\
\text { June } 30\end{array}$ & $\begin{array}{l}\text { Massachusetts } \\
\text { Braintree } \\
\text { Town of } \\
\text { December } 31\end{array}$ & $\begin{array}{l}\text { Massachusetts } \\
\text { Chicopee } \\
\text { City of } \\
\text { December } 31\end{array}$ & $\begin{array}{l}\text { Massachusetts } \\
\text { Concord } \\
\text { Town of } \\
\text { December } 31\end{array}$ & $\begin{array}{c}\text { Massachusetts } \\
\text { Danvers } \\
\text { Town of } \\
\text { December } 31\end{array}$ \\
\hline \multicolumn{7}{|l|}{ Electric Plant in Service } \\
\hline 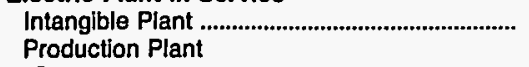 & 0 & 0 & 0 & 0 & 1,056 & 0 \\
\hline 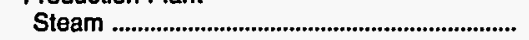 & 0 & 11,710 & 28,195 & $\mathbf{0}$ & 0 & 0 \\
\hline Nuclear & 0 & 0 & 0 & 38,474 & 0 & 0 \\
\hline 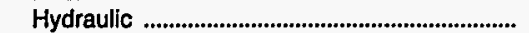 & 0 & 0 & 0 & 0 & 0 & 0 \\
\hline Other & 20,471 & 8 & 755 & 1,727 & 0 & 0 \\
\hline 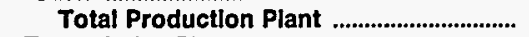 & 20,471 & 11,718 & 28,950 & 40,201 & o & $\mathbf{0}$ \\
\hline 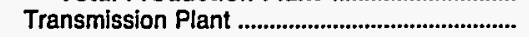 & 0 & 1,839 & 13,207 & 204 & 2,936 & $\mathbf{0}$ \\
\hline 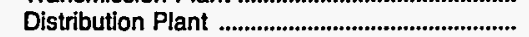 & 14,529 & 18,490 & 19,875 & 20,388 & 11,088 & 18,970 \\
\hline 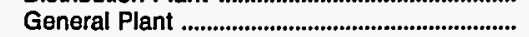 & 2,124 & 1,404 & 3,333 & 4,985 & 2,339 & 2,693 \\
\hline Total Electric Plant in Service & 37,124 & 33,452 & 65,365 & 65,777 & 17,419 & 21,664 \\
\hline 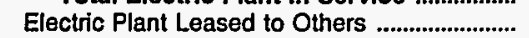 & 0 & 0 & 0 & 0 & 0 & 0 \\
\hline Electric Plant Held for Future Use .................... & 0 & 0 & 0 & 0 & 0 & 0 \\
\hline 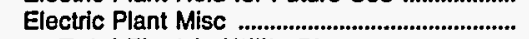 & 0 & 0 & 0 & 552 & 0 & 0 \\
\hline 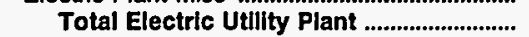 & 37,124 & 33,452 & 65,365 & 66,329 & 17,419 & 21,664 \\
\hline $\begin{array}{l}\text { Construction Work in Progress - Electric ........ } \\
\text { Accumulated Provision for Depreciation }\end{array}$ & 2,516 & 1,142 & 0 & 400 & 4,589 & 50 \\
\hline 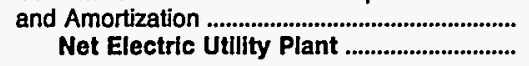 & $\begin{array}{l}15,856 \\
23,783\end{array}$ & $\begin{array}{l}20,593 \\
14,000\end{array}$ & $\begin{array}{l}31,139 \\
34,226\end{array}$ & $\begin{array}{l}23,668 \\
43,061\end{array}$ & $\begin{array}{r}8,445 \\
13,563\end{array}$ & $\begin{array}{r}9,566 \\
12,147\end{array}$ \\
\hline
\end{tabular}

Note: Totals may not equal sum of components because of independent rounding.

Source: Energy Information Administration, Form ElA-412, "Annual Report of Public Electric Utilities." 
Table 24. Electric Utility Plant by Major U.S. Publicly Owned Electric Utility Within State at End of Period, 1993 (Continued)

(Thousand Dollars)

\begin{tabular}{|c|c|c|c|c|c|c|}
\hline Item & $\begin{array}{l}\text { Massachusetts } \\
\text { Hingham } \\
\text { City of } \\
\text { December } 31\end{array}$ & $\begin{array}{c}\text { Massachusetts } \\
\text { Holyoke } \\
\text { City of } \\
\text { December } 31\end{array}$ & $\begin{array}{c}\text { Massachusetts } \\
\text { Hudson } \\
\text { Town of } \\
\text { December } 31\end{array}$ & $\begin{array}{l}\text { Massachusetts } \\
\text { Littleton } \\
\text { Town of } \\
\text { December } 31\end{array}$ & $\begin{array}{l}\text { Massachusetts } \\
\text { Mansfield } \\
\text { Town of } \\
\text { December } 31\end{array}$ & $\begin{array}{c}\text { Massachusetts } \\
\text { Massachusetts } \\
\text { Mun } \\
\text { Whis } \\
\text { Elec Co } \\
\text { December } 31\end{array}$ \\
\hline $\begin{array}{l}\text { Electric Plant in Service } \\
\text { Intangible Plant . . } \\
\text { Production Plant }\end{array}$ & 0 & 0 & 4 & 0 & 0 & 1,168 \\
\hline Steam & 0 & 17,277 & 0 & 342 & 0 & 7,274 \\
\hline 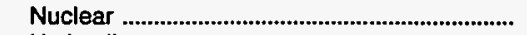 & 0 & 0 & 2,708 & 0 & 0 & 990,943 \\
\hline 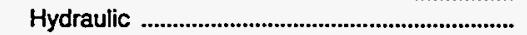 & 0 & 3,810 & 0 & 0 & 0 & 0 \\
\hline Other & 0 & 0 & 4,168 & 0 & 0 & 184,480 \\
\hline Total Production Plant & o & 21,087 & 6,876 & 342 & 0 & $1,182,697$ \\
\hline 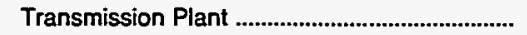 & 1,438 & 6,183 & 1,643 & 15 & 0 & 30,656 \\
\hline 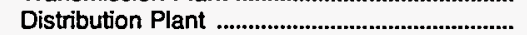 & 17,925 & 23,055 & 8,212 & 10,314 & 8,392 & 0 \\
\hline 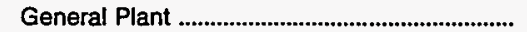 & 1,224 & 2,443 & 1,590 & 3,889 & 963 & 17,129 \\
\hline Total Electric Plant in Service ....................... & 20,587 & 52,768 & 18,325 & 14,560 & 9,355 & $1,231,650$ \\
\hline 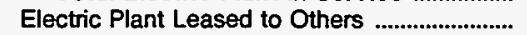 & 0 & 0 & 0 & 0 & 0 & 0 \\
\hline Electric Plant Held for Future Use ........................ & 0 & 0 & 0 & 0 & 0 & 0 \\
\hline 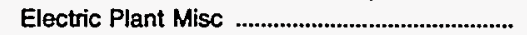 & 0 & 0 & 0 & 0 & 0 & 0 \\
\hline Total Electric Utility Plant ................................... & 20,587 & 52,768 & 18,325 & 14,560 & 9,355 & $1,231,650$ \\
\hline $\begin{array}{l}\text { Construction Work in Progress - Electric ........ } \\
\text { Accumulated Provision for Depreciation }\end{array}$ & & 347 & 0 & 170 & 0 & 2,195 \\
\hline 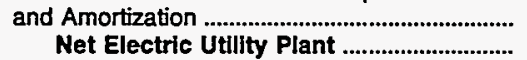 & $\begin{array}{r}5,547 \\
15,041\end{array}$ & $\begin{array}{l}29,843 \\
23,272\end{array}$ & $\begin{array}{r}12,038 \\
6,287\end{array}$ & $\begin{array}{l}5,766 \\
8,963\end{array}$ & $\begin{array}{l}5,651 \\
3,704\end{array}$ & $\begin{array}{l}243,440 \\
990,404\end{array}$ \\
\hline
\end{tabular}

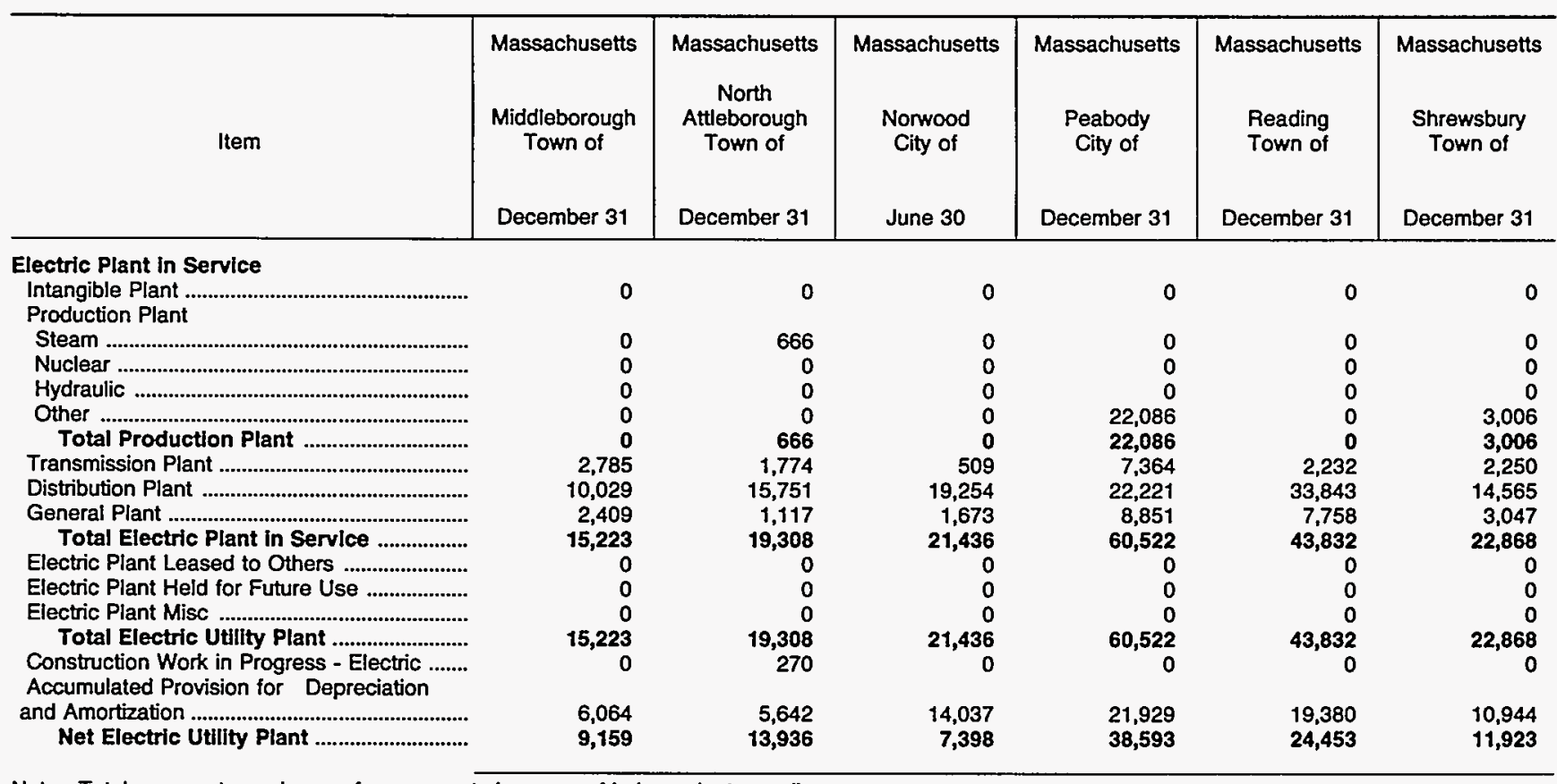

Note: Totals may not equal sum of components because of independent rounding.

Source: Energy Information Administration, Form EIA-412, "Annual Report of Public Electric Utilities." 
Table 24. Electric Utility Plant by Major U.S. Publicly Owned Electric Utility Within State at End of Period, 1993 (Continued)

(Thousand Dollars)

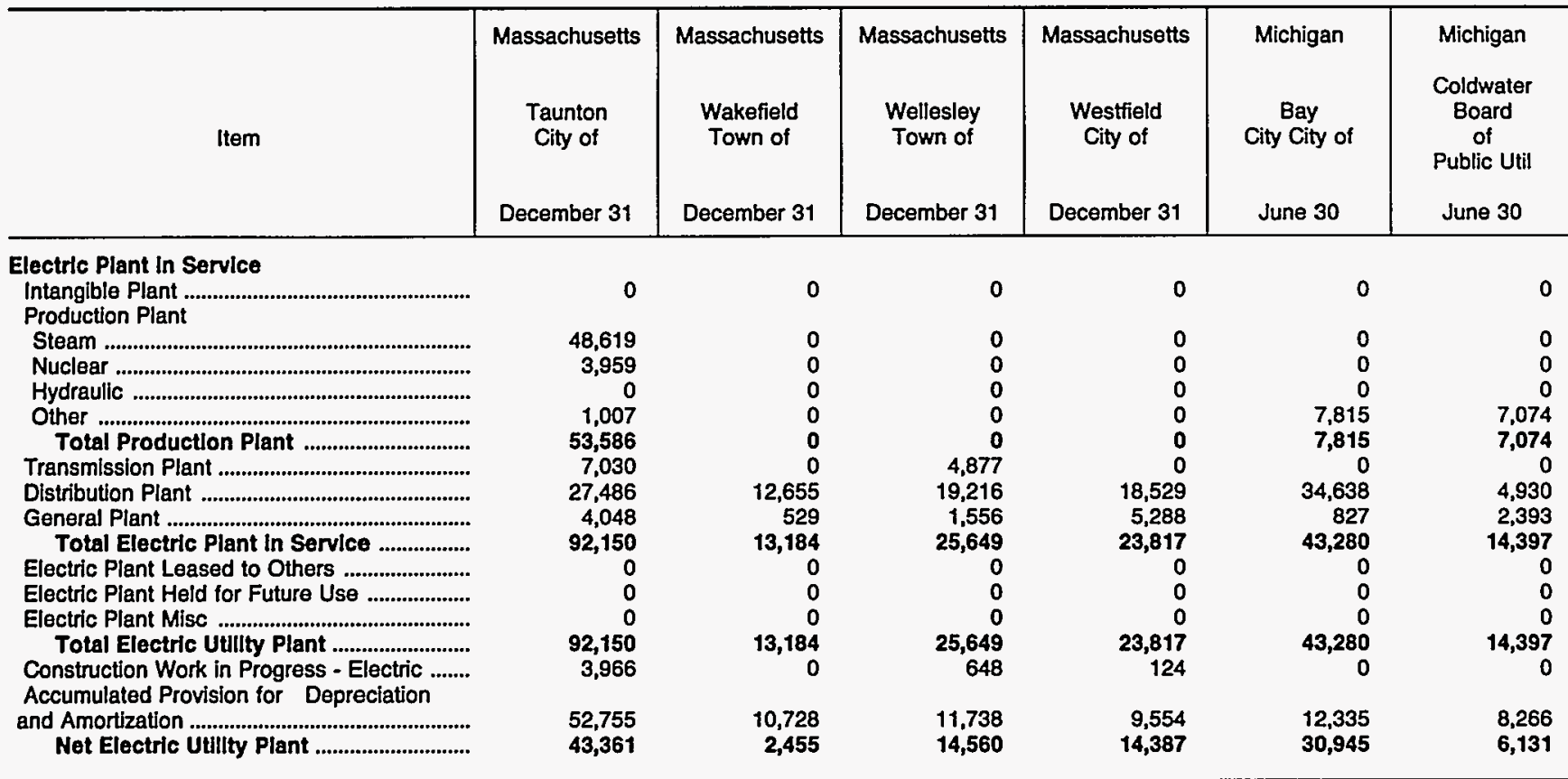

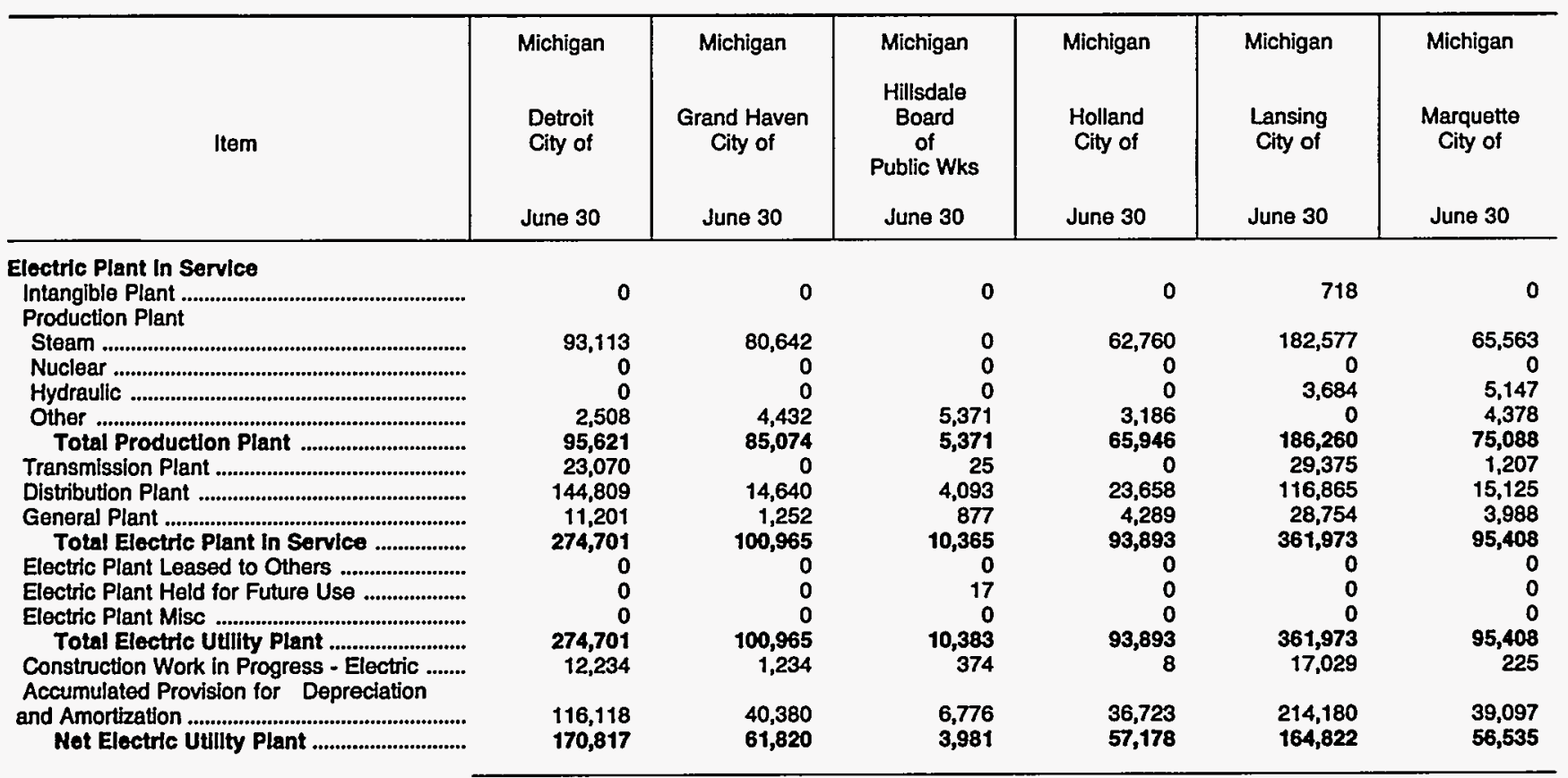

Note: Totals may not equal sum of components because of independent rounding.

Source: Energy Information Administration, Form EIA-412, "Annual Report of Public Electric Utilities." 
Table 24. Electric Utility Plant by Major U.S. Publicly Owned Electric Utility Within State at End of Period, 1993 (Continued)

(Thousand Dollars)

\begin{tabular}{|c|c|c|c|c|c|c|}
\hline Item & $\begin{array}{l}\text { Michigan } \\
\text { Michigan } \\
\text { Public } \\
\text { Power Agency } \\
\text { December } 31\end{array}$ & $\begin{array}{l}\text { Michigan } \\
\text { Michigan } \\
\text { South } \\
\text { Central } \\
\text { Pwr Agy } \\
\text { June } 30\end{array}$ & $\begin{array}{c}\text { Michigan } \\
\text { Sturgis } \\
\text { City of } \\
\text { September } 30\end{array}$ & $\begin{array}{l}\text { Michigan } \\
\text { Traverse } \\
\text { City City of } \\
\text { June } 30\end{array}$ & $\begin{array}{l}\text { Michigan } \\
\text { Wyandotte } \\
\text { Municipal } \\
\text { Serv Comm } \\
\text { September } 30\end{array}$ & $\begin{array}{l}\text { Michigan } \\
\text { Zeeland } \\
\text { City of } \\
\text { June } 30\end{array}$ \\
\hline \multicolumn{7}{|l|}{ Electric Plant in Service } \\
\hline $\begin{array}{l}\text { Intangible Plant } \\
\text { Production Plant }\end{array}$ & 0 & 0 & 0 & 0 & 0 & 0 \\
\hline Steam & 428,366 & 50,357 & 0 & 9,359 & 44,384 & 0 \\
\hline Nuclear & 0 & 0 & 0 & 0 & 0 & 0 \\
\hline 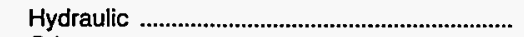 & 0 & 0 & 5,408 & 4,590 & 0 & 0 \\
\hline Other & 0 & 0 & 4,006 & 972 & 0 & 10,537 \\
\hline Total Production Plant & 428,366 & 50,357 & 9,414 & 14,921 & 44,384 & 10,537 \\
\hline 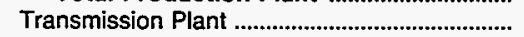 & 37,318 & 18,185 & 5,187 & 4,729 & 5,511 & 0 \\
\hline 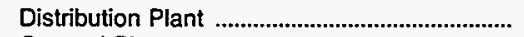 & 0 & 265 & 5,503 & 10,003 & 16,151 & 5,021 \\
\hline 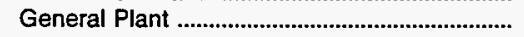 & 3,378 & 3,815 & 7,941 & 468 & 2,481 & 1,207 \\
\hline 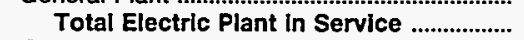 & 469,063 & 72,622 & 28,045 & 30,121 & 68,528 & 16,765 \\
\hline 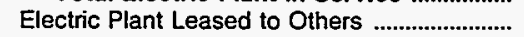 & 0 & 0 & 0 & 0 & 0 & 0 \\
\hline Electric Plant Held for Future Use .................... & 0 & 0 & 0 & 0 & 0 & 0 \\
\hline Electric Plant Misc & 0 & 0 & 0 & 0 & 0 & 0 \\
\hline 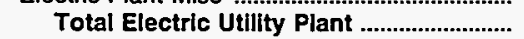 & 469,063 & 72,622 & 28,045 & 30,121 & 68,528 & 16,765 \\
\hline $\begin{array}{l}\text { Construction Work in Progress - Electric ........ } \\
\text { Accumulated Provision for Depreciation }\end{array}$ & 0 & 35 & 0 & 159 & 36,903 & 209 \\
\hline 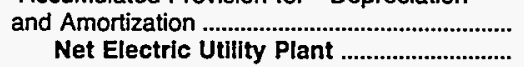 & $\begin{array}{l}123,873 \\
345,190\end{array}$ & $\begin{array}{l}23,405 \\
49,252\end{array}$ & $\begin{array}{l}13,708 \\
14,337\end{array}$ & $\begin{array}{l}11,641 \\
18,639\end{array}$ & $\begin{array}{l}32,272 \\
73,158\end{array}$ & $\begin{array}{l}7,266 \\
9,708\end{array}$ \\
\hline
\end{tabular}

\begin{tabular}{|c|c|c|c|c|c|c|}
\hline Item & $\begin{array}{l}\text { Minnesota } \\
\text { Alexandria } \\
\text { City of } \\
\text { December } 31\end{array}$ & $\begin{array}{c}\text { Minnesota } \\
\text { Anoka } \\
\text { City of } \\
\text { December } 31\end{array}$ & $\begin{array}{c}\text { Minnesota } \\
\text { Austin } \\
\text { City of } \\
\text { December } 31\end{array}$ & $\begin{array}{c}\text { Minnesota } \\
\text { Brainerd } \\
\text { City of } \\
\text { December } 31\end{array}$ & $\begin{array}{c}\text { Minnesota } \\
\text { Chaska } \\
\text { City of } \\
\text { December } 31\end{array}$ & $\begin{array}{l}\text { Minnesota } \\
\text { Fairmont } \\
\text { Public } \\
\text { Utilities } \\
\text { Comm } \\
\text { December } 31\end{array}$ \\
\hline \multicolumn{7}{|l|}{ Electric Plant in Service } \\
\hline \multicolumn{7}{|l|}{ Production Plant } \\
\hline Steam & 494 & 0 & 15,255 & 0 & 0 & 5,086 \\
\hline 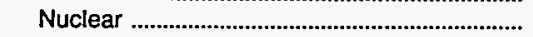 & 0 & 0 & 0 & 0 & 0 & 0 \\
\hline 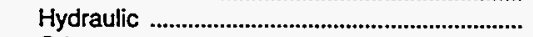 & 0 & 0 & 0 & 0 & 0 & 0 \\
\hline Other & 2,055 & 0 & 0 & 0 & 0 & 2,349 \\
\hline 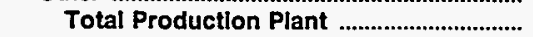 & 2,549 & $\mathbf{0}$ & 15,255 & 0 & 0 & 7,435 \\
\hline 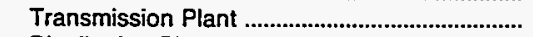 & 863 & 0 & 1,175 & 0 & 0 & 2,756 \\
\hline 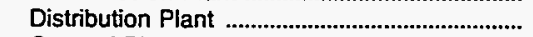 & 9,541 & 11,882 & 14,158 & 6,002 & 7,751 & 5,016 \\
\hline 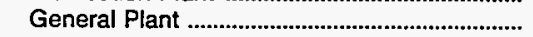 & 1,781 & 1,220 & 1,871 & 0 & 741 & 2,351 \\
\hline Total Electric Plant In Service .................. & 14,735 & 13,103 & 32,458 & 6,002 & 8,492 & 17,949 \\
\hline Electric Plant Leased to Others ........................... & 0 & 0 & 1,071 & 0 & 0 & 0 \\
\hline Electric Plant Held for Future Use ................... & 0 & 0 & 0 & 0 & 0 & 0 \\
\hline 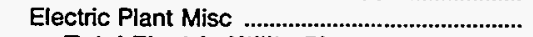 & 0 & 0 & 0 & 0 & 0 & 0 \\
\hline 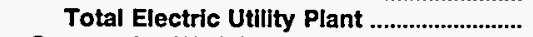 & 14,735 & 13,103 & 33,529 & 6,002 & 8,492 & 17,949 \\
\hline $\begin{array}{l}\text { Construction Work in Progress - Electric ....... } \\
\text { Accumulated Provision for Depreciation }\end{array}$ & 38 & 0 & 20 & 7 & 0 & 378 \\
\hline and Amortization & 8,231 & 6,286 & 21,494 & 2,831 & 3,190 & 10,854 \\
\hline 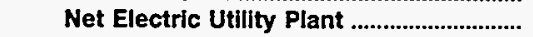 & 6,542 & 6,817 & 12,055 & 3,178 & 5,303 & 7,473 \\
\hline
\end{tabular}

Note: Totals may not equal sum of components because of independent rounding.

Source: Energy Information Administration, Form EIA-412, "Annual Report of Public Electric Utilities." 
Table 24. Electric Utility Plant by Major U.S. Publicly Owned Electric Utility Within State at End of Period, 1993 (Continued)

(Thousand Dollars)

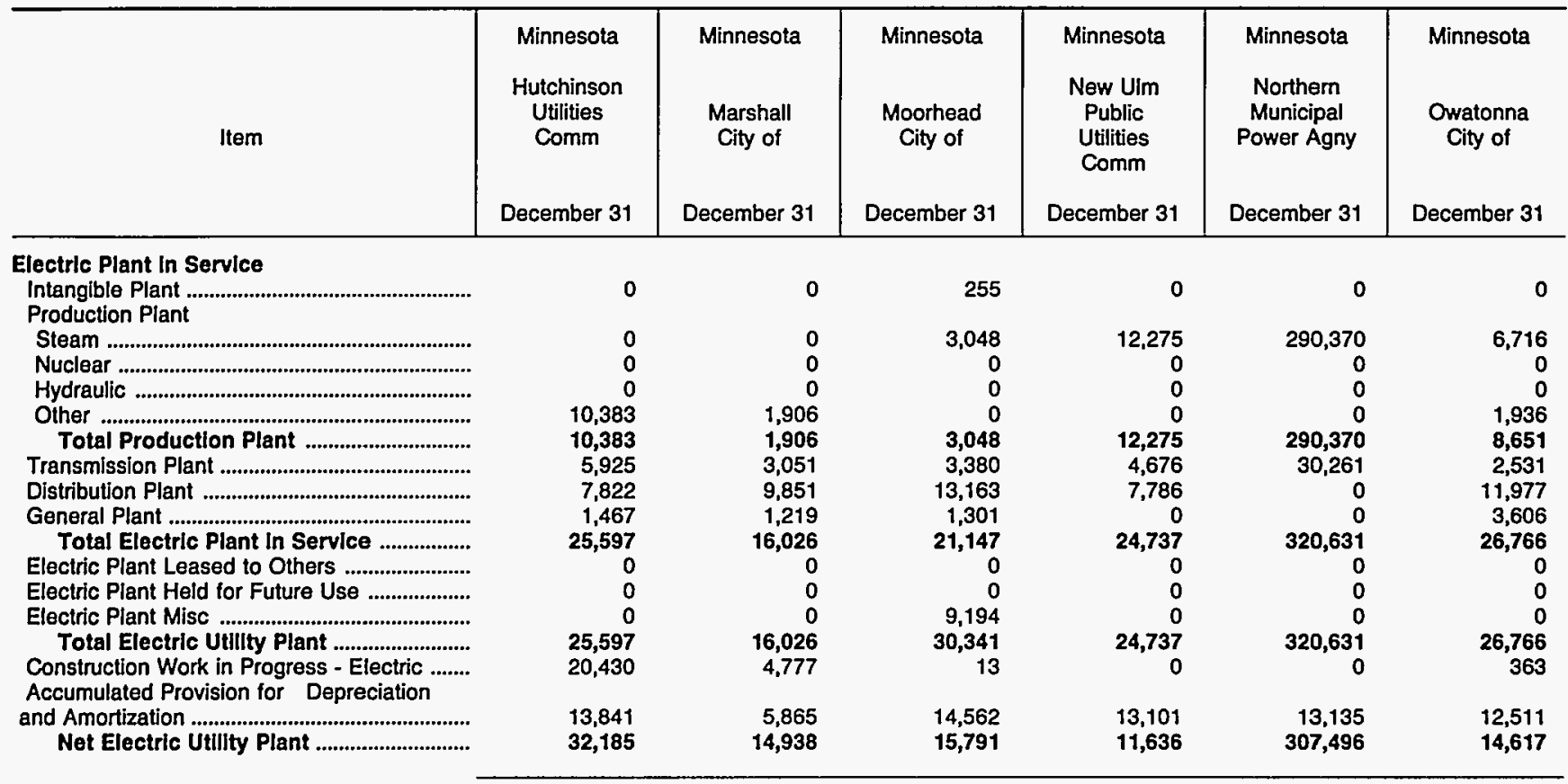

\begin{tabular}{|c|c|c|c|c|c|c|}
\hline Item & $\begin{array}{c}\text { Minnesota } \\
\text { Rochester } \\
\text { Public } \\
\text { Utilities } \\
\text { December } 31\end{array}$ & $\begin{array}{c}\text { Minnesota } \\
\text { Shakopee } \\
\text { Public } \\
\text { Utilities } \\
\text { Comm } \\
\text { December } 31\end{array}$ & $\begin{array}{l}\text { Minnesota } \\
\text { Southern } \\
\text { Minnesota } \\
\text { Mun P } \\
\text { Agny } \\
\text { December } 31\end{array}$ & $\begin{array}{c}\text { Minnesota } \\
\text { Western } \\
\text { Minnesota } \\
\text { Mun } \\
\text { Pwr Agny } \\
\text { December } 31\end{array}$ & $\begin{array}{c}\text { Minnesota } \\
\text { Willmar } \\
\text { Municipal } \\
\text { Utils Comm } \\
\text { December } 31\end{array}$ & $\begin{array}{l}\text { Mississippi } \\
\text { Aberdeen } \\
\text { City of } \\
\text { June } 30\end{array}$ \\
\hline \multicolumn{7}{|l|}{ Electric Plant in Service } \\
\hline 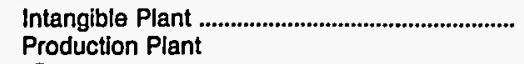 & 148 & 0 & 19,804 & 0 & 0 & 0 \\
\hline Steam & 25,360 & 0 & 435,165 & 168,356 & 7,705 & 0 \\
\hline 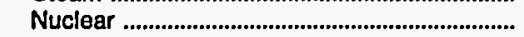 & 0 & 0 & 0 & 0 & 0 & 0 \\
\hline 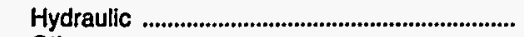 & 2,467 & 0 & 0 & 0 & 0 & 0 \\
\hline Other & 2,554 & 0 & 0 & 0 & 0 & 0 \\
\hline Total Production Plant & 30,381 & 0 & 435,165 & 168,356 & 7,705 & 0 \\
\hline 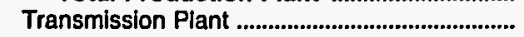 & 6,267 & 0 & 61,197 & 55,941 & 6,167 & 0 \\
\hline Distribution Plant & 42,269 & 5,650 & 0 & 0 & 11,464 & 3,433 \\
\hline General Plant & 17,362 & 527 & 4,001 & 0 & 2,644 & 886 \\
\hline Total Electric Plant in Servlce .................... & 96,427 & 6,177 & 520,167 & 224,297 & 27,980 & 4,319 \\
\hline Electric Plant Leased to Others ......................... & 0 & 0 & 0 & 0 & 806 & 0 \\
\hline Electric Plant Held for Future Use .................... & 0 & 0 & 0 & 14,140 & 0 & 0 \\
\hline 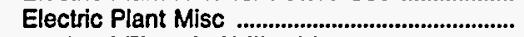 & 0 & 0 & 407 & 0 & 0 & 0 \\
\hline 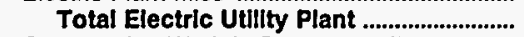 & 96,427 & 6,177 & 520,574 & 238,437 & 28,785 & 4,319 \\
\hline $\begin{array}{l}\text { Construction Work in Progress - Electric ....... } \\
\text { Accumulated Provision for Depreciation }\end{array}$ & 6,156 & 772 & 2,804 & 486 & 154 & 33 \\
\hline $\begin{array}{l}\text { and Amortization } \\
\text { Net Electric Utility Plant }\end{array}$ & $\begin{array}{l}51,390 \\
51,193\end{array}$ & $\begin{array}{l}2,240 \\
4,709\end{array}$ & $\begin{array}{l}100,341 \\
423,037\end{array}$ & $\begin{array}{r}46,518 \\
192,405\end{array}$ & $\begin{array}{l}15,099 \\
13,840\end{array}$ & $\begin{array}{l}1,941 \\
2,411\end{array}$ \\
\hline
\end{tabular}

Note: Totals may not equal sum of components because of independent rounding.

Source: Energy Information Administration, Form EIA-412, "Annual Report of Public Electric Utilities." 
Table 24. Electric Utility Plant by Major U.S. Publicly Owned Electric Utility Within State at End of Period, 1993 (Continued)

(Thousand Dollars)

\begin{tabular}{|c|c|c|c|c|c|c|}
\hline Item & $\begin{array}{l}\text { Mississippi } \\
\text { Clarksdale } \\
\text { City of } \\
\text { September } 30\end{array}$ & $\begin{array}{l}\text { Mississippi } \\
\text { Columbus } \\
\text { City of } \\
\text { June } 30\end{array}$ & $\begin{array}{l}\text { Mississippi } \\
\text { Greenwood } \\
\text { Utilities } \\
\text { Comm } \\
\text { September } 30\end{array}$ & $\begin{array}{l}\text { Mississippi } \\
\text { Holly } \\
\text { Springs } \\
\text { City of } \\
\text { June } 30\end{array}$ & $\begin{array}{l}\text { Mississippi } \\
\text { Louisville } \\
\text { Electric } \\
\text { System } \\
\text { June } 30\end{array}$ & $\begin{array}{c}\text { Mississippi } \\
\text { Municipal } \\
\text { Energy } \\
\text { Agency } \\
\text { of MS } \\
\text { September } 30\end{array}$ \\
\hline $\begin{array}{l}\text { Electric Plant in Service } \\
\text { Intangible Plant }\end{array}$ & 0 & 0 & 0 & 0 & 0 & 65 \\
\hline 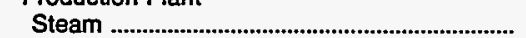 & 14,704 & 0 & 13,878 & 0 & 0 & 0 \\
\hline Nuclear & 0 & 0 & 0 & $\mathbf{0}$ & 0 & 0 \\
\hline 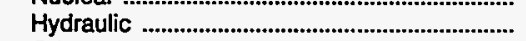 & 0 & 0 & 0 & 0 & 0 & 0 \\
\hline 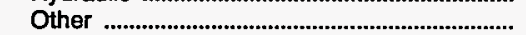 & 0 & 0 & 1,163 & 0 & 0 & 0 \\
\hline 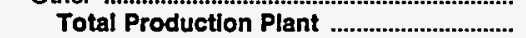 & 14,704 & 0 & 15,041 & 0 & 0 & $\mathbf{0}$ \\
\hline 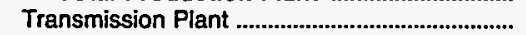 & 1,774 & 10 & 731 & 0 & 202 & 0 \\
\hline Distribution Plant ..................................................... & 8,560 & 12,907 & 8,273 & 11,028 & 5,620 & 0 \\
\hline 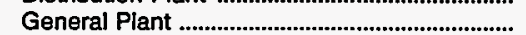 & 1,081 & 2,143 & 2,147 & 2,130 & 1,007 & 258 \\
\hline Total Electric Plant in Service & 26,118 & 15,060 & 26,191 & 13,158 & 6,829 & 324 \\
\hline 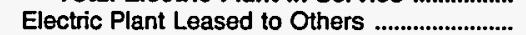 & 0 & 0 & 0 & 0 & 0 & 0 \\
\hline Electric Plant Held for Future Use .......................... & 0 & 0 & 0 & 0 & 0 & 0 \\
\hline 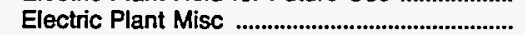 & 0 & 0 & 0 & 0 & 0 & \\
\hline Total Electric Utility Plant ................................ & 26,118 & 15,060 & 26,191 & 13,158 & 6,829 & 324 \\
\hline $\begin{array}{l}\text { Construction Work in Progress - Electric ....... } \\
\text { Accumulated Provision for Depreciation }\end{array}$ & 0 & 2 & 311 & 460 & 717 & 829 \\
\hline 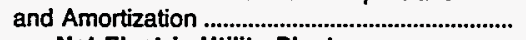 & 17,713 & 7,221 & 15.424 & 5,032 & 2,324 & 151 \\
\hline Net Electric Utility Plant .................................... & 8,405 & 7,842 & 11,078 & 8,586 & 5,222 & 1,001 \\
\hline
\end{tabular}

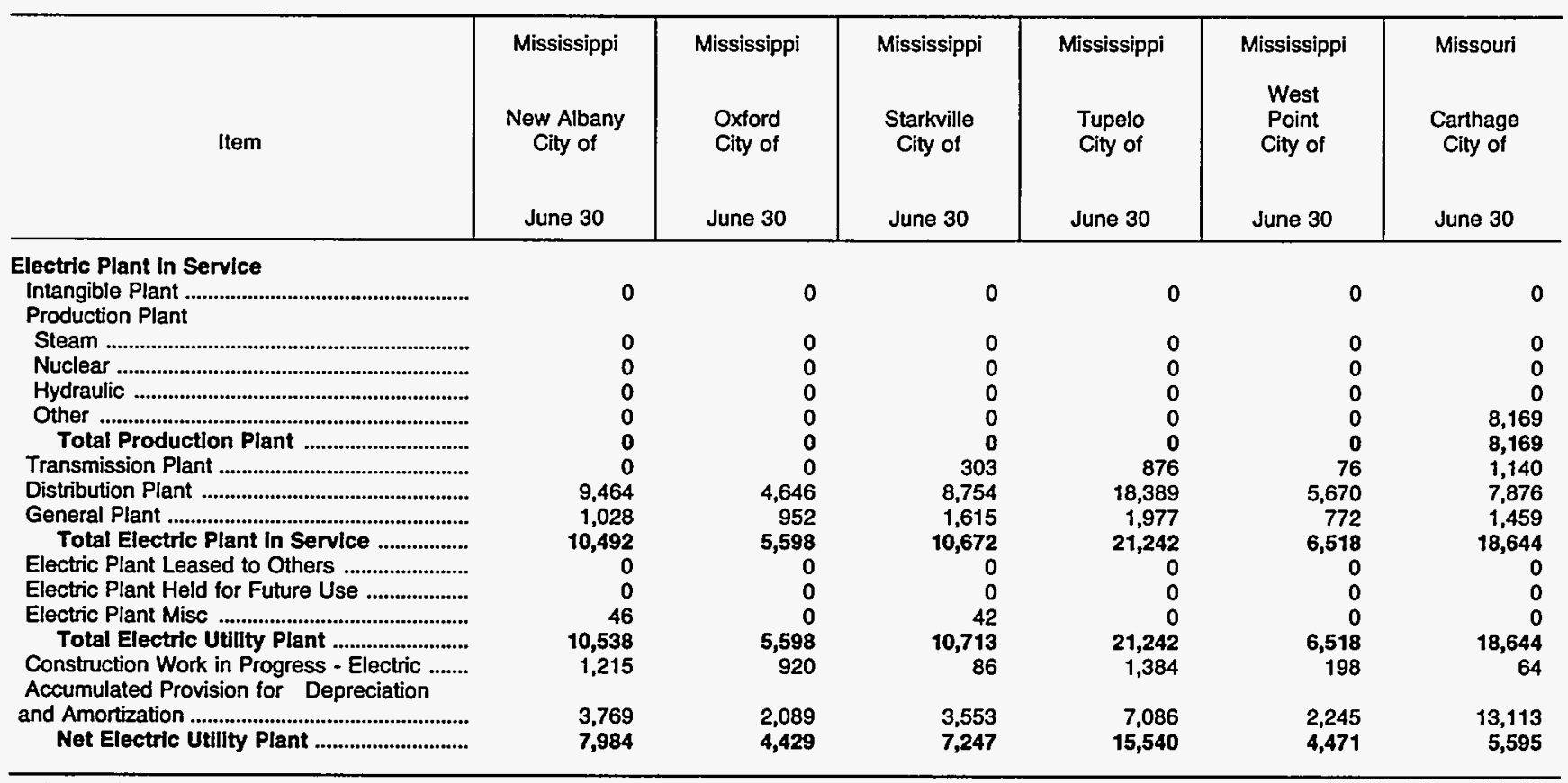

Note: Totals may not equal sum of components because of independent rounding.

Source: Energy Information Administration, Form EIA-412, "Annual Report of Public Electric Utilities." 
Table 24. Electric Utility Plant by Major U.S. Publicly Owned Electric Utility Within State at End of Period, 1993 (Continued)

(Thousand Dollars)

\begin{tabular}{|c|c|c|c|c|c|c|}
\hline Item & $\begin{array}{l}\text { Missouri } \\
\text { Columbia } \\
\text { City of } \\
\text { September } 30\end{array}$ & $\begin{array}{l}\text { Missouri } \\
\text { Hannibal } \\
\text { City of } \\
\text { June } 30\end{array}$ & $\begin{array}{c}\text { Missouri } \\
\text { Independence } \\
\text { City of } \\
\text { June } 30\end{array}$ & $\begin{array}{l}\text { Missouri } \\
\text { Kennett } \\
\text { City of } \\
\text { June } 30\end{array}$ & $\begin{array}{l}\text { Missouri } \\
\text { Kirkwood } \\
\text { City of } \\
\text { March } 31\end{array}$ & $\begin{array}{l}\text { Missouri } \\
\text { Lebanon } \\
\text { City of } \\
\text { October } \mathbf{3 1}\end{array}$ \\
\hline \multicolumn{7}{|l|}{ Electric Plant In Servlce } \\
\hline $\begin{array}{l}\text { Intangible Plant .................................................. } \\
\text { Production Plant }\end{array}$ & 0 & 0 & 0 & 0 & 0 & 0 \\
\hline 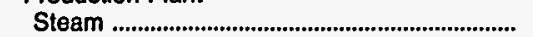 & 21,233 & 0 & 53,161 & 0 & 0 & 0 \\
\hline Nuclear & 0 & 0 & 0 & 0 & 0 & 0 \\
\hline 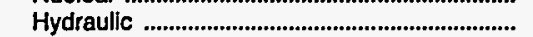 & 0 & 0 & $\mathbf{0}$ & 0 & 0 & 0 \\
\hline Other & 2,134 & 0 & 21,431 & 8,202 & 0 & 0 \\
\hline 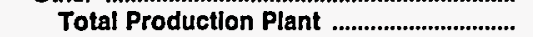 & 23,368 & $\mathbf{0}$ & 74,592 & 8,202 & 0 & 0 \\
\hline 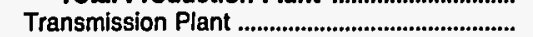 & 14,948 & 1,989 & 19,092 & 790 & 0 & 0 \\
\hline Distribution Plant & 33,736 & 6,332 & 48,074 & 5,111 & 3,458 & 0 \\
\hline 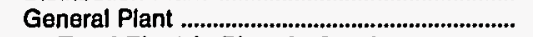 & 4,515 & 1,717 & 10,728 & 0 & 0 & 0 \\
\hline Total Electric Plant In Service ................... & 76,567 & 10,038 & 152,487 & 14,103 & 3,458 & 0 \\
\hline Electric Plant Leased to Others ........................... & 0 & 0 & 0 & 0 & 0 & 0 \\
\hline Electric Plant Held for Future Use ................... & 0 & 0 & 0 & 0 & 0 & 0 \\
\hline 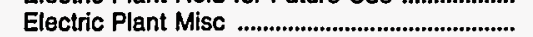 & 0 & 0 & 2,756 & 0 & 1,038 & 0 \\
\hline Total Electric Utility Plant ............................. & 76,567 & 10,038 & 155,243 & 14,103 & 4,495 & 0 \\
\hline $\begin{array}{l}\text { Construction Work in Progress - Electric ....... } \\
\text { Accumulated Provision for Depreciation }\end{array}$ & 1,973 & 207 & 4,353 & 0 & 0 & 0 \\
\hline 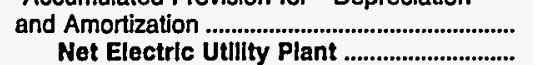 & $\begin{array}{l}33,068 \\
45,472\end{array}$ & $\begin{array}{l}6,688 \\
3,557\end{array}$ & $\begin{array}{l}84,195 \\
75,401\end{array}$ & $\begin{array}{r}10,304 \\
3,800\end{array}$ & $\begin{array}{l}2,473 \\
2,022\end{array}$ & $\begin{array}{l}0 \\
0\end{array}$ \\
\hline
\end{tabular}

\begin{tabular}{|c|c|c|c|c|c|c|}
\hline Item & $\begin{array}{c}\text { Missouri } \\
\text { Marshall } \\
\text { City of } \\
\text { September } 30\end{array}$ & $\begin{array}{l}\text { Missouri } \\
\text { Monett } \\
\text { City of } \\
\text { March } 31\end{array}$ & $\begin{array}{c}\text { Missouri } \\
\text { Poplar } \\
\text { Bluff } \\
\text { City of } \\
\text { December } 31\end{array}$ & $\begin{array}{c}\text { Missouri } \\
\text { Rolla } \\
\text { City of } \\
\text { September } 30\end{array}$ & $\begin{array}{l}\text { Missouri } \\
\text { Sikeston } \\
\text { City of } \\
\text { May } 31\end{array}$ & $\begin{array}{l}\text { Missouri } \\
\text { Springfield } \\
\text { City of } \\
\text { September } 30\end{array}$ \\
\hline \multicolumn{7}{|l|}{ Electric Plant In Service } \\
\hline $\begin{array}{l}\text { Intangible Plant } \\
\text { Production Plant }\end{array}$ & 0 & 0 & 0 & 0 & 0 & 0 \\
\hline 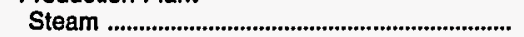 & 13,179 & 0 & 0 & 0 & 198,710 & 152,068 \\
\hline Nuclear & 0 & 0 & 0 & 0 & 0 & 0 \\
\hline 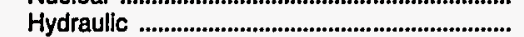 & 0 & 0 & 0 & 0 & 0 & 0 \\
\hline Other & 7,062 & 0 & 3,122 & 0 & 0 & 51,848 \\
\hline Total Productlon Plant ............................... & 20,241 & $\mathbf{0}$ & 3,122 & $\mathbf{0}$ & 198,710 & 203,916 \\
\hline 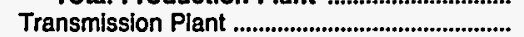 & 4,937 & 0 & 0 & 109 & 4,594 & 46,828 \\
\hline 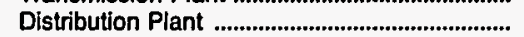 & 3,985 & 3,908 & 14,191 & 6,267 & 13,676 & 116,670 \\
\hline 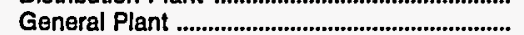 & 1,911 & 0 & 2,759 & 2,181 & 2,864 & 8,424 \\
\hline Total Electric Plant in Service .................... & 31,073 & 3,908 & 20,072 & 8,557 & 219,844 & 375,838 \\
\hline 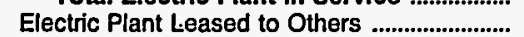 & 0 & 0 & 0 & 0 & 0 & 0 \\
\hline Electric Plant Held for Future Use .................... & 0 & 0 & 0 & $\mathbf{0}$ & 0 & 0 \\
\hline 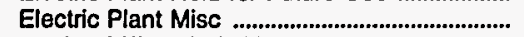 & 0 & 0 & 0 & 0 & 0 & 0 \\
\hline Total Electric UtIlity Plant .......................... & 31,073 & 3,908 & 20,072 & 8,557 & 219,844 & 375,838 \\
\hline $\begin{array}{l}\text { Construction Work in Progress - Electric ....... } \\
\text { Accumulated Provision for Depreciation }\end{array}$ & 4,898 & 0 & 0 & 0 & 1,005 & 8,457 \\
\hline 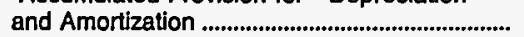 & 16,456 & 2,743 & 8,069 & 5,856 & 63,552 & 120,826 \\
\hline 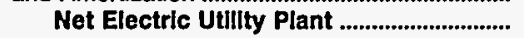 & 19,514 & 1,164 & 12,003 & 2,701 & 157,297 & 263,469 \\
\hline
\end{tabular}

Note: Totals may not equal sum of components because of independent rounding.

Source: Energy Information Administration, Form EIA-412, "Annual Report of Public Electric Utilities." 
Table 24. Electric Utility Plant by Major U.S. Publicly Owned Electric Utility Within State at End of Period, 1993 (Continued)

(Thousand Dollars)

\begin{tabular}{|c|c|c|c|c|c|c|}
\hline Item & $\begin{array}{c}\text { Nebraska } \\
\text { Central } \\
\text { Nebraska } \\
\text { Pub } \\
\text { P\&l Dist } \\
\text { December } 31\end{array}$ & $\begin{array}{c}\text { Nebraska } \\
\text { Cornhusker } \\
\text { Public } \\
\text { Power Dist } \\
\text { December } 31\end{array}$ & $\begin{array}{c}\text { Nebraska } \\
\text { Dawson } \\
\text { County } \\
\text { Public } \\
\text { Pwr Dist } \\
\text { December } 31\end{array}$ & $\begin{array}{l}\text { Nebraska } \\
\text { Fremont } \\
\text { City of } \\
\text { July } 31\end{array}$ & $\begin{array}{l}\text { Grand Island } \\
\text { City of } \\
\text { July } 31\end{array}$ & $\begin{array}{l}\text { Nebraska } \\
\text { Hastings } \\
\text { City of } \\
\text { December } 31\end{array}$ \\
\hline \multicolumn{7}{|l|}{ Electric Plant in Service } \\
\hline $\begin{array}{l}\text { Intangible Plant } \\
\text { Production Plant }\end{array}$ & 14,605 & 1 & 3 & 0 & 3,117 & 0 \\
\hline 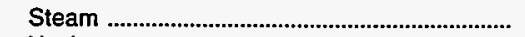 & 16,180 & 0 & 0 & 47,518 & 117,226 & 74,869 \\
\hline 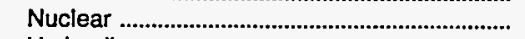 & 0 & 0 & 0 & 0 & 0 & 0 \\
\hline 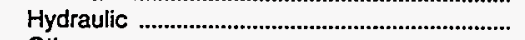 & 96,295 & 0 & 0 & 0 & 0 & 0 \\
\hline Other & 0 & 0 & 0 & 0 & 0 & 2,628 \\
\hline Total Production Plant & 112,476 & $\mathbf{0}$ & 0 & 47,518 & 117,226 & 77,497 \\
\hline 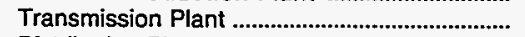 & 5,717 & 2,570 & 4,500 & 289 & 9,573 & 6,327 \\
\hline 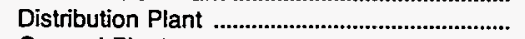 & 0 & 24,657 & 35,029 & 12,242 & 26,678 & 15,227 \\
\hline General Plant & 4,414 & 3,200 & 4,761 & 3,328 & 2,569 & 1,983 \\
\hline Total Electric Plant in Service & 137,212 & 30,429 & 44,293 & 63,377 & 159,163 & 101,035 \\
\hline 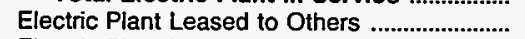 & 0 & 0 & 4 & 0 & 0 & 0 \\
\hline 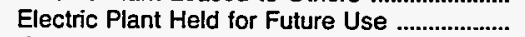 & 0 & 0 & 1 & 0 & 0 & 0 \\
\hline Electric Plant Misc & 0 & -19 & 0 & 0 & 2,167 & 0 \\
\hline 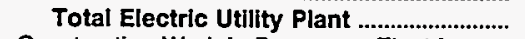 & 137,212 & 30,410 & 44,298 & 63,377 & 161,330 & 101,035 \\
\hline $\begin{array}{l}\text { Construction Work in Progress - Electric ........ } \\
\text { Accumulated Provision for Depreciation }\end{array}$ & 108 & 377 & 473 & 1,618 & 63 & 1,791 \\
\hline and Amortization & 54,317 & 9,877 & 20,089 & 45,311 & 62,577 & 35,035 \\
\hline 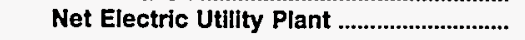 & 83,003 & 20,909 & 24,682 & 19,684 & 98,816 & 67,791 \\
\hline
\end{tabular}

\begin{tabular}{|c|c|c|c|c|c|c|}
\hline Item & $\begin{array}{c}\text { Nebraska } \\
\text { Lincoln } \\
\text { Electric } \\
\text { System } \\
\text { December } 31\end{array}$ & $\begin{array}{c}\text { Nebraska } \\
\text { Loup } \\
\text { River } \\
\text { Public } \\
\text { Power Dist } \\
\text { December } 31\end{array}$ & $\begin{array}{c}\text { Nebraska } \\
\text { Municipal } \\
\text { Energy } \\
\text { Agency } \\
\text { of NE } \\
\text { March } 31\end{array}$ & $\begin{array}{c}\text { Nebraska } \\
\text { Nebraska } \\
\text { Public } \\
\text { Power } \\
\text { District } \\
\text { December } 31\end{array}$ & $\begin{array}{c}\text { Nebraska } \\
\text { Norris } \\
\text { Public } \\
\text { Power } \\
\text { District } \\
\text { December } 31\end{array}$ & $\begin{array}{c}\text { Nebraska } \\
\text { North } \\
\text { Platte } \\
\text { City of } \\
\\
\text { July } 31\end{array}$ \\
\hline \multicolumn{7}{|l|}{ Electric Plant in Service } \\
\hline $\begin{array}{l}\text { Intangible Plant } \\
\text { Production Plant }\end{array}$ & 10,188 & 0 & 0 & 1,452 & 2 & 0 \\
\hline Steam & 138,931 & 0 & 28,653 & 788,459 & $\mathbf{0}$ & 0 \\
\hline Nuclear & 0 & 0 & 0 & 370,853 & 0 & 0 \\
\hline 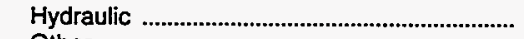 & 0 & 9,707 & 0 & 16,268 & 0 & 0 \\
\hline Other & 13,006 & 0 & 0 & 15,105 & 0 & 0 \\
\hline Total Production Plant & 151,937 & 9,707 & 28,653 & $1,190,685$ & $\mathbf{0}$ & 0 \\
\hline Transmission Plant & 84,188 & 11,109 & 0 & 421,012 & 7,684 & 561 \\
\hline 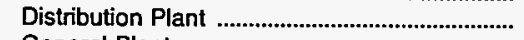 & 149,486 & 20,901 & 0 & 81,530 & 43,647 & 9,265 \\
\hline General Plant & 27,417 & 7,517 & 0 & 101,751 & 6,730 & 2,854 \\
\hline Total Electric Plant In Service ...................... & 423,216 & 49,233 & 28,653 & $1,796,430$ & 58,064 & 12,680 \\
\hline 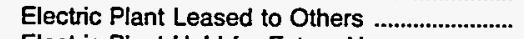 & 0 & 0 & 0 & 0 & 0 & 0 \\
\hline Electric Plant Held for Future Use .................... & 0 & 0 & 0 & 0 & 0 & 0 \\
\hline Electric Plant Misc & 4,829 & 457 & 0 & 0 & 459 & 0 \\
\hline Total Electric Utllity Plant ............................... & 428,046 & 49,690 & 28,653 & $1,796,430$ & 58,523 & 12,680 \\
\hline $\begin{array}{l}\text { Construction Work in Progress - Electric ........ } \\
\text { Accumulated Provision for Depreciation }\end{array}$ & 20,740 & 4,505 & 7,492 & 164,407 & 563 & 205 \\
\hline and Amortization & 129,052 & 24,566 & 2,256 & 702,822 & 18,124 & 7,851 \\
\hline 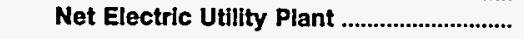 & 319,734 & 29,629 & 33,889 & $1,258,014$ & 40,962 & 5,033 \\
\hline
\end{tabular}

Note: Totals may not equal sum of components because of independent rounding.

Source: Energy Information Administration, Form ElA-412, "Annual Report of Public Electric Utilities." 
Table 24. Electric Utility Plant by Major U.S. Publicly Owned Electric Utility Within State at End of Period, 1993 (Continued)

(Thousand Dollars)

\begin{tabular}{|c|c|c|c|c|c|c|}
\hline Item & $\begin{array}{c}\text { Nebraska } \\
\text { Omaha Public } \\
\text { Power } \\
\text { District } \\
\text { December } 31\end{array}$ & $\begin{array}{l}\text { Nebraska } \\
\text { Southern } \\
\text { Nebraska Rural } \\
\text { P P D } \\
\text { December } 31\end{array}$ & $\begin{array}{c}\text { Nevada } \\
\text { Colorado } \\
\text { River } \\
\text { Comm } \\
\text { of Nevada } \\
\text { June } 30\end{array}$ & $\begin{array}{l}\text { New Jersey } \\
\text { Vineland } \\
\text { City of } \\
\text { June } 30\end{array}$ & $\begin{array}{l}\text { New Mexico } \\
\text { Farmington } \\
\text { City of } \\
\text { June } 30\end{array}$ & $\begin{array}{l}\text { New Mexico } \\
\text { Gallup } \\
\text { City of } \\
\text { June } 30\end{array}$ \\
\hline $\begin{array}{l}\text { Electric Plant In Service } \\
\text { Intangible Plant ................................................ } \\
\text { Production Plant }\end{array}$ & 0 & 0 & 0 & 0 & 5,784 & 0 \\
\hline Steam & 616,994 & 0 & 0 & 35,686 & 73,224 & 0 \\
\hline 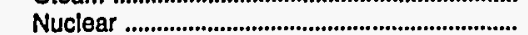 & 399,400 & 0 & 0 & 0 & 0 & 0 \\
\hline 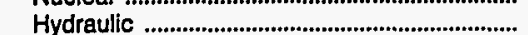 & & 0 & 0 & 0 & 16,400 & 0 \\
\hline 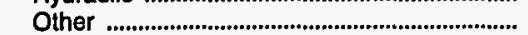 & 21,256 & 0 & 0 & 4,097 & 0 & 0 \\
\hline Total Production Plant ............................... & $1,037,649$ & 0 & 0 & 39,783 & 89,624 & o \\
\hline 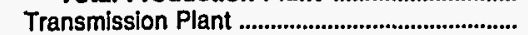 & 148,836 & 3,125 & 0 & 1,491 & 16,326 & 0 \\
\hline 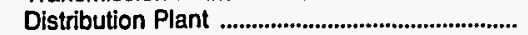 & 541,610 & 61,177 & 0 & 23,183 & 51,419 & 9,869 \\
\hline 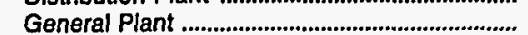 & 171,720 & 6,125 & 0 & 3,145 & 7,163 & 1,287 \\
\hline Total Electrle Plant In Service & $1,899,815$ & 70,427 & 0 & 67,602 & 170,316 & 11,156 \\
\hline Electric Plant Leased to Others ........................... & 0 & 0 & 0 & 0 & 0 & 0 \\
\hline Electric Plant Held for Future Use ..................... & 0 & 0 & 0 & 0 & 0 & 0 \\
\hline 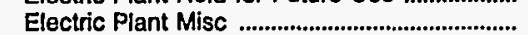 & 7,998 & 0 & 0 & 0 & 0 & 0 \\
\hline 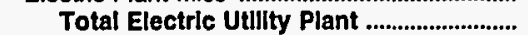 & $1,907,813$ & 70,427 & 0 & 67,602 & 170,316 & 11,156 \\
\hline $\begin{array}{l}\text { Construction Work in Progress - Electric ......... } \\
\text { Accumulated Provision for Depreciation }\end{array}$ & 95,498 & 694 & 0 & 3,439 & 13,807 & 0 \\
\hline 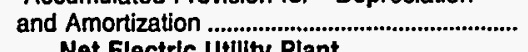 & $\begin{array}{r}695,752 \\
\end{array}$ & 31,526 & 0 & 33,252 & $\begin{array}{r}53,843 \\
130281\end{array}$ & 6,042 \\
\hline Net Electrlc Utility Plant .................................. & $1,307,558$ & 39,595 & D & $\mathbf{3 7 , 7 9 0}$ & 130,281 & 5,114 \\
\hline
\end{tabular}

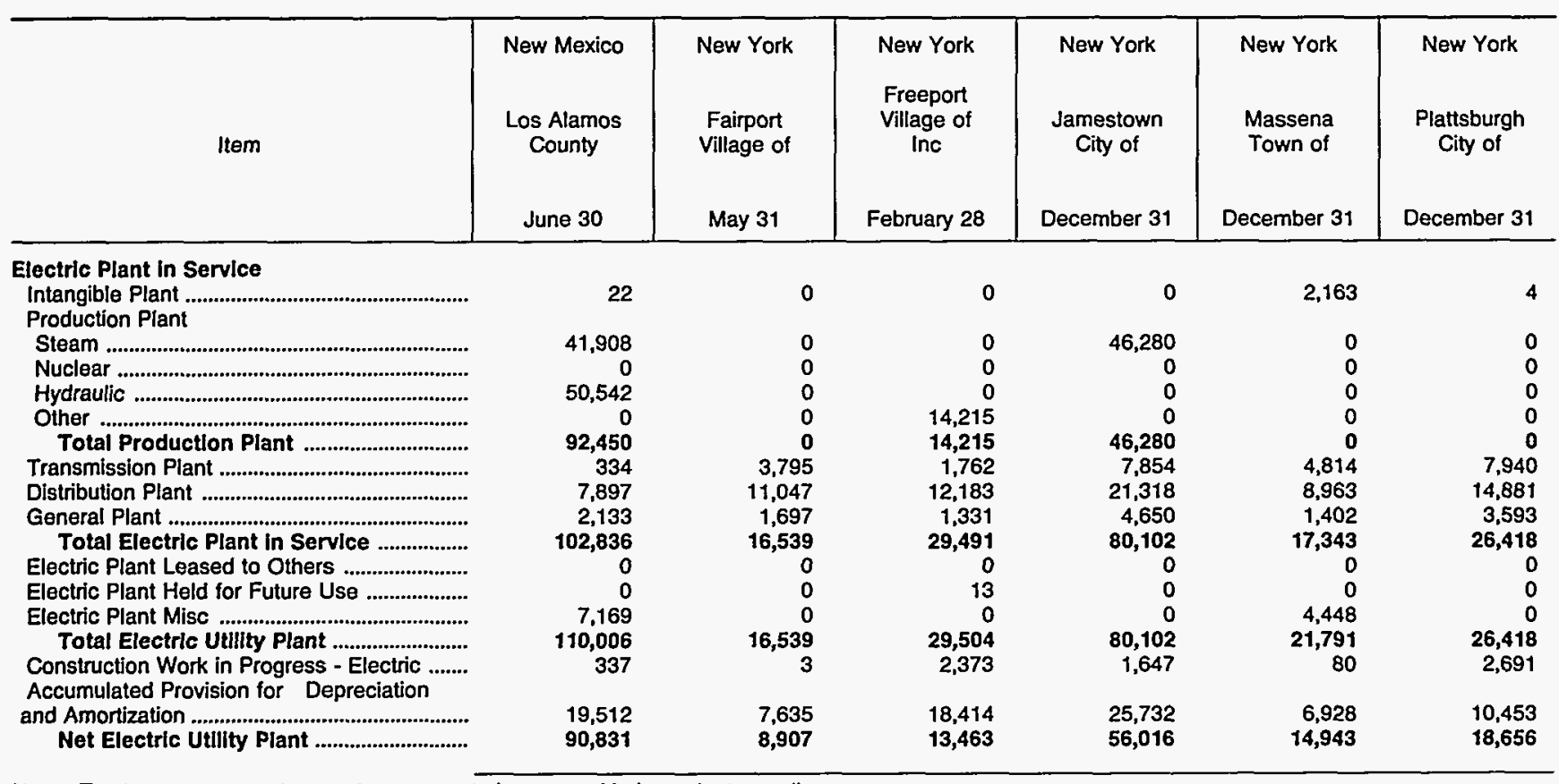

Note: Totals may not equal sum of components because of independent rounding.

Source: Energy Information Administration, Form ElA-412, "Annual Report of Public Electric Utilities." 
Table 24. Electric Utility Plant by Major U.S. Publicly Owned Electric Utility Within State at End of Period, 1993 (Continued) (Thousand Dollars)

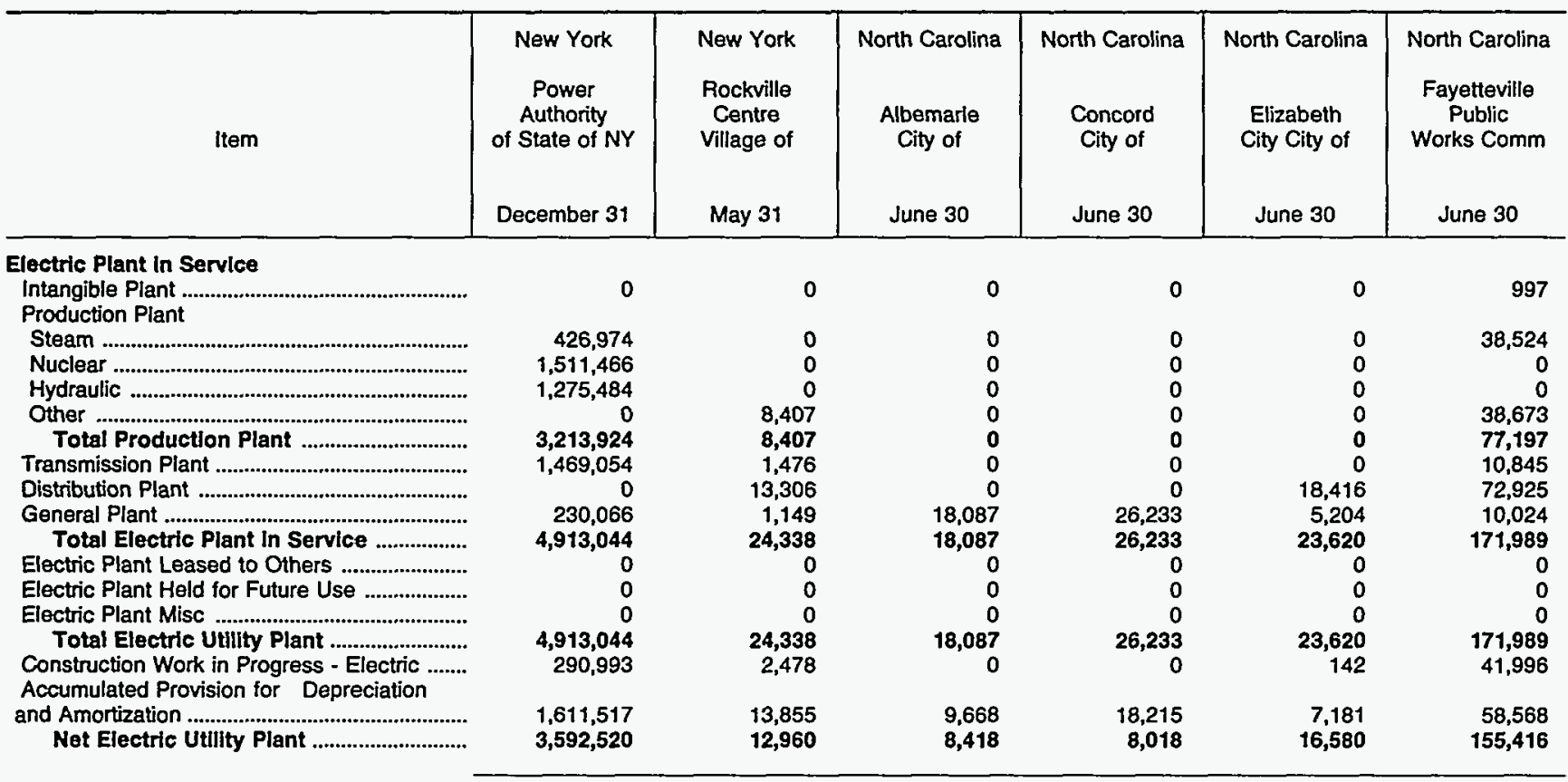

\begin{tabular}{|c|c|c|c|c|c|c|}
\hline Item & $\begin{array}{l}\text { North Carolina } \\
\text { Forest City } \\
\text { Town of } \\
\text { June } 30\end{array}$ & $\begin{array}{c}\text { North Carolina } \\
\text { Gastonia } \\
\text { City of } \\
\text { June } 30\end{array}$ & $\begin{array}{c}\text { North Carolina } \\
\text { Greenville } \\
\text { Utilities } \\
\text { Comm } \\
\text { June } 30\end{array}$ & $\begin{array}{c}\text { North Carolina } \\
\text { High } \\
\text { Point } \\
\text { Town } \\
\text { of } \\
\text { June } 30\end{array}$ & $\begin{array}{l}\text { North Carolina } \\
\text { Kinston } \\
\text { City of } \\
\text { June } 30\end{array}$ & $\begin{array}{c}\text { North Carolina } \\
\text { Lexington } \\
\text { City of } \\
\text { June } 30\end{array}$ \\
\hline \multicolumn{7}{|l|}{ Electric Plant In Service } \\
\hline $\begin{array}{l}\text { Intangible Plant ....................................................... } \\
\text { Production Plant }\end{array}$ & 0 & 0 & 0 & 0 & 0 & 0 \\
\hline Steam & 0 & 0 & 0 & 0 & 0 & 0 \\
\hline Nuclear & 0 & 0 & 0 & 0 & 0 & 0 \\
\hline 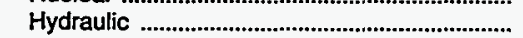 & 0 & 0 & 0 & 0 & 0 & 0 \\
\hline Other & 0 & 0 & $\mathbf{0}$ & 0 & 0 & $\mathbf{0}$ \\
\hline Total Production Plant & $\mathbf{0}$ & $\mathbf{0}$ & $\mathbf{0}$ & $\mathbf{0}$ & 0 & $\mathbf{0}$ \\
\hline 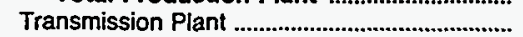 & 0 & 36,669 & 0 & 0 & 0 & 3,486 \\
\hline 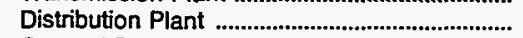 & 4,960 & 0 & 73,016 & 0 & 11,393 & 20,570 \\
\hline 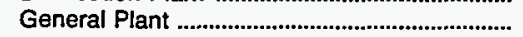 & 306 & 0 & 9,372 & 55,422 & 5,355 & 3,241 \\
\hline Total Electric Plant in Service & 5,265 & 36,669 & 82,387 & 55,422 & 16,748 & 27,297 \\
\hline Electric Plant Leased to Others ......................... & 0 & 0 & 0 & 0 & 0 & 0 \\
\hline Electric Plant Held for Future Use ................... & 0 & 0 & 0 & 0 & 0 & 0 \\
\hline Electric Plant Misc & 0 & 0 & 0 & 0 & 0 & 0 \\
\hline Total Electric Utility Plant & 5,265 & 36,669 & 82,387 & 55,422 & 16,748 & 27,297 \\
\hline $\begin{array}{l}\text { Construction Work in Progress - Electric ....... } \\
\text { Accumulated Provision for Depreciation }\end{array}$ & 0 & 0 & 0 & 34 & 2,078 & 108 \\
\hline 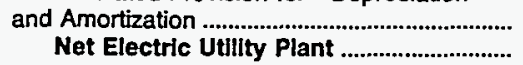 & $\begin{array}{l}2,381 \\
2,884\end{array}$ & $\begin{array}{l}18,649 \\
18,019\end{array}$ & $\begin{array}{l}39,763 \\
42,624\end{array}$ & $\begin{array}{l}22,682 \\
32,774\end{array}$ & $\begin{array}{r}7,348 \\
11,479\end{array}$ & $\begin{array}{r}8,924 \\
18,481\end{array}$ \\
\hline
\end{tabular}

Note: Totals may not equal sum of components because of independent rounding.

Source: Energy Information Administration, Form EIA-412, "Annual Report of Public Electric Utilities." 
Table 24. Electric Utility Plant by Major U.S. Publicly Owned Electric Utility Within State at End of Period, 1993 (Continued) (Thousand Dollars)

\begin{tabular}{|c|c|c|c|c|c|c|}
\hline Item & $\begin{array}{c}\text { North Carolina } \\
\text { Lumberton } \\
\text { City of } \\
\text { June } 30\end{array}$ & $\begin{array}{l}\text { North Carolina } \\
\text { Monroe } \\
\text { City of } \\
\text { June } 30\end{array}$ & $\begin{array}{c}\text { North Carolina } \\
\text { Morganton } \\
\text { City of } \\
\text { June } 30\end{array}$ & $\begin{array}{l}\text { North Carolina } \\
\text { Murphy } \\
\text { City of } \\
\text { June } 30\end{array}$ & $\begin{array}{l}\text { North Carolina } \\
\text { New Bern } \\
\text { City of } \\
\text { June } 30\end{array}$ & $\begin{array}{c}\text { North Carolina } \\
\text { New River } \\
\text { Light } \\
\& \\
\text { Power Co } \\
\text { December } 31\end{array}$ \\
\hline 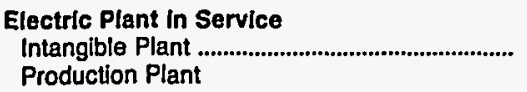 & 0 & 0 & 0 & 0 & $\mathbf{0}$ & 0 \\
\hline 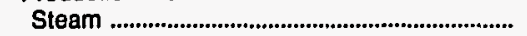 & 0 & 0 & 0 & 0 & 0 & 0 \\
\hline 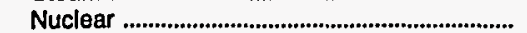 & 0 & 0 & 0 & 0 & $\mathbf{0}$ & 0 \\
\hline 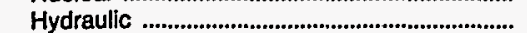 & 0 & 0 & 0 & 0 & 0 & 0 \\
\hline Other & 0 & 0 & 0 & 0 & 0 & 0 \\
\hline Total Production Plant .............................. & $\mathbf{0}$ & $\mathbf{0}$ & $\mathbf{0}$ & $\mathbf{0}$ & $\mathbf{0}$ & $\mathbf{0}$ \\
\hline 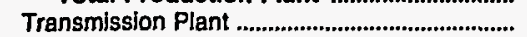 & 0 & 0 & 0 & 0 & 0 & 0 \\
\hline 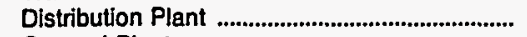 & 8,617 & 19,424 & 10,338 & 5,364 & 0 & 8,615 \\
\hline 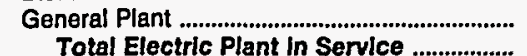 & $\begin{array}{r}2,271 \\
10,888\end{array}$ & $\begin{array}{r}0 \\
19,424\end{array}$ & $\begin{array}{r}0 \\
10,338\end{array}$ & $\begin{array}{l}1,452 \\
6,816\end{array}$ & $\begin{array}{l}20,303 \\
20,303\end{array}$ & $\begin{array}{r}2,062 \\
10,677\end{array}$ \\
\hline 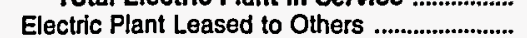 & $\begin{array}{r}0,000 \\
0\end{array}$ & 0 & $\begin{array}{r}10,000 \\
0\end{array}$ & 0 & $\begin{array}{r}20,000 \\
0\end{array}$ & 0 \\
\hline Electric Plant Held for Future Use .................... & 0 & 0 & 0 & 0 & 0 & 0 \\
\hline 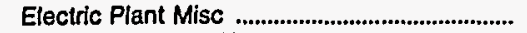 & 0 & 0 & 0 & 0 & 0 & 0 \\
\hline Total Electric Utllity Plant ............................... & 10,888 & 19,424 & 10,338 & 6,816 & 20,303 & 10,677 \\
\hline $\begin{array}{l}\text { Construction Work in Progress - Electric ....... } \\
\text { Accumulated Provision for Depreciation }\end{array}$ & 1 & 2,594 & 523 & 350 & 126 & 10 \\
\hline 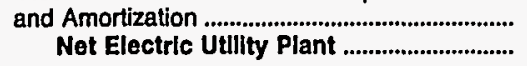 & $\begin{array}{l}5,729 \\
5,159\end{array}$ & $\begin{array}{r}6,546 \\
15,472\end{array}$ & $\begin{array}{l}4,612 \\
6,249\end{array}$ & $\begin{array}{l}1,920 \\
5,247\end{array}$ & $\begin{array}{r}8,918 \\
11,512\end{array}$ & $\begin{array}{l}2,652 \\
8,035\end{array}$ \\
\hline
\end{tabular}

\begin{tabular}{|c|c|c|c|c|c|c|}
\hline Item & $\begin{array}{c}\text { North Carolina } \\
\text { North } \\
\text { Carolina } \\
\text { Eastem M P A } \\
\text { December } 31\end{array}$ & $\begin{array}{c}\text { North Carolina } \\
\text { North } \\
\text { Carolina } \\
\text { Mun } \\
\text { Power Agny } \\
\text { December } 31\end{array}$ & $\begin{array}{l}\text { North Carolina } \\
\text { Rocky Mount } \\
\text { City of } \\
\text { June } 30\end{array}$ & $\begin{array}{c}\text { North Carolina } \\
\text { Shelby } \\
\text { City of } \\
\text { June } 30\end{array}$ & $\begin{array}{c}\text { North Carolina } \\
\text { Statesville } \\
\text { City of } \\
\text { June } \mathbf{3 0}\end{array}$ & $\begin{array}{c}\text { North Carolina } \\
\text { Tarboro } \\
\text { Town of } \\
\text { June } 30\end{array}$ \\
\hline \multicolumn{7}{|l|}{ Electrlc Plant in Service } \\
\hline $\begin{array}{l}\text { Intangible Plant ....................................................... } \\
\text { Production Plant }\end{array}$ & 0 & 0 & 0 & 0 & 0 & 102 \\
\hline Steam & 128,468 & $\mathbf{0}$ & 0 & 0 & 0 & 0 \\
\hline 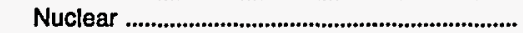 & $1,123,293$ & $1,391,474$ & 0 & 0 & 0 & 0 \\
\hline 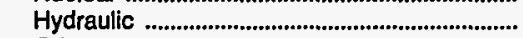 & 0 & 0 & 0 & 0 & 0 & 0 \\
\hline Other & 0 & 0 & 0 & 0 & 0 & 0 \\
\hline Total Productlon Plant .............................. & $1,251,761$ & $1,391,474$ & $\mathbf{0}$ & $\mathbf{0}$ & 0 & $\mathbf{0}$ \\
\hline 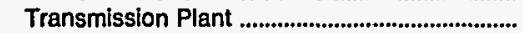 & 0 & 10,913 & 0 & o & 0 & 0 \\
\hline 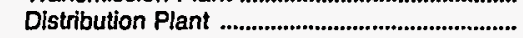 & 0 & 0 & 30,388 & 6,201 & 15,019 & 15,409 \\
\hline General Plant & 0 & $\mathbf{0}$ & 0 & 0 & 0 & 0 \\
\hline 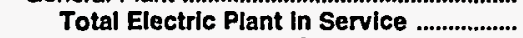 & $1,251,761$ & $1,402,387$ & 30,388 & 6,201 & 15,019 & 15,511 \\
\hline 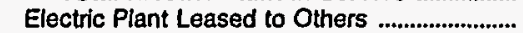 & 0 & 0 & 0 & 0 & 0 & 0 \\
\hline Electric Plant Held for Future Use ................... & 0 & 0 & 0 & 0 & 0 & 0 \\
\hline Electric Plant Misc & 134,096 & $\mathbf{0}$ & 0 & 0 & 0 & 0 \\
\hline Total Electric Utillty Plant ........................... & $1,385,657$ & $1,402,387$ & 30,388 & 6,201 & 15,019 & 15,511 \\
\hline $\begin{array}{l}\text { Construction Work in Progress - Electric ........ } \\
\text { Accumulated Provision for Depreciation }\end{array}$ & 35,753 & 9,008 & 3,265 & 1,155 & 22 & 0 \\
\hline 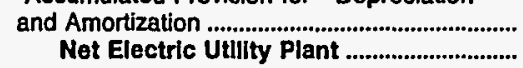 & $\begin{array}{r}361,795 \\
1,059,815\end{array}$ & $\begin{array}{r}294,784 \\
1,116,611\end{array}$ & $\begin{array}{l}12,456 \\
21,198\end{array}$ & $\begin{array}{l}4,361 \\
2,995\end{array}$ & $\begin{array}{l}6,122 \\
8,920\end{array}$ & $\begin{array}{l}5,535 \\
9,976\end{array}$ \\
\hline
\end{tabular}

Note: Totals may not equal sum of components because of independent rounding

Source: Energy Information Administration, Form EIA-412, "Annual Report of Public Electric Utilities." 
Table 24. Electric Utility Plant by Major U.S. Publicly Owned Electric Utility Within State at End of Period, 1993 (Continued)

(Thousand Dollars)

\begin{tabular}{|c|c|c|c|c|c|c|}
\hline Item & $\begin{array}{l}\text { North Carolina } \\
\text { Washington } \\
\text { City of } \\
\text { June } 30\end{array}$ & $\begin{array}{c}\text { North Carolina } \\
\text { Wilson } \\
\text { City of } \\
\text { June } 30\end{array}$ & $\begin{array}{c}\text { Ohio } \\
\text { American } \\
\text { Mun } \\
\text { Power } \\
\text { Ohio Inc } \\
\text { December } 31\end{array}$ & $\begin{array}{c}\text { Ohio } \\
\text { Bowling } \\
\text { Green } \\
\text { City of } \\
\text { December } 31\end{array}$ & $\begin{array}{c}\text { Ohio } \\
\text { Bryan } \\
\text { City of } \\
\text { December } 31\end{array}$ & $\begin{array}{l}\text { Ohio } \\
\text { Celina } \\
\text { City of } \\
\text { December } 31\end{array}$ \\
\hline $\begin{array}{l}\text { Electric Plant in Service } \\
\text { Intangible Plant } \\
\text { Production Plant }\end{array}$ & 0 & 0 & 7,718 & 0 & 0 & 0 \\
\hline 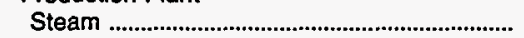 & 0 & 0 & 48,862 & 0 & 0 & 5,898 \\
\hline 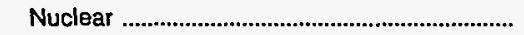 & 0 & 0 & 0 & 0 & 0 & 0 \\
\hline Hydraulic …………………………………….. & 0 & 0 & 0 & 0 & $\mathbf{0}$ & 0 \\
\hline 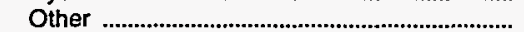 & 0 & 0 & 0 & 0 & 0 & 0 \\
\hline Total Production Plant & 0 & 0 & 48,862 & 0 & 0 & 5,898 \\
\hline Transmission Plant & 22,382 & 0 & 4,957 & 588 & 0 & 0 \\
\hline 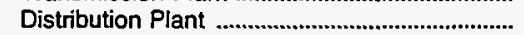 & 0 & 42,364 & 0 & 8,644 & 0 & 11,162 \\
\hline 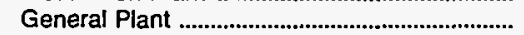 & 2,641 & 5,326 & 868 & 3,276 & 0 & 532 \\
\hline Total Electric Plant In Service ...................... & 25,023 & 47,690 & 62,405 & 12,508 & 0 & 17,592 \\
\hline Electric Plant Leased to Others ............................ & 0 & 0 & 0 & 0 & 0 & 0 \\
\hline Electric Plant Held for Future Use ........................ & 0 & 0 & 0 & 0 & 0 & 0 \\
\hline Electric Plant Misc ........................................... & 0 & 0 & 0 & 0 & 0 & 0 \\
\hline Total Electric Utility Plant ............................. & 25,023 & 47,690 & 62,405 & 12,508 & 0 & 17,592 \\
\hline $\begin{array}{l}\text { Construction Work in Progress - Electric ........ } \\
\text { Accumulated Provision for Depreciation }\end{array}$ & 145 & 2,378 & 2,178 & 4,236 & 0 & 0 \\
\hline 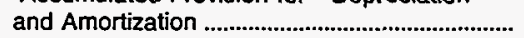 & 10,918 & 24,795 & 16,119 & 8,394 & 0 & 0 \\
\hline 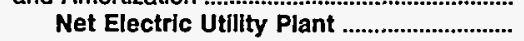 & 14,250 & 25,273 & 48,464 & 8,350 & 0 & 17,592 \\
\hline
\end{tabular}

\begin{tabular}{|c|c|c|c|c|c|c|}
\hline Item & $\begin{array}{c}\text { Ohio } \\
\text { Cleveland } \\
\text { City of } \\
\text { December } 31\end{array}$ & $\begin{array}{c}\text { Ohio } \\
\text { Columbus } \\
\text { City of } \\
\text { December } 31\end{array}$ & $\begin{array}{c}\text { Ohio } \\
\text { Cuyahoga } \\
\text { Falls } \\
\text { City of } \\
\text { December } 31\end{array}$ & $\begin{array}{c}\text { Ohio } \\
\text { Dover } \\
\text { City of } \\
\text { December } \mathbf{3 1}\end{array}$ & $\begin{array}{c}\text { Ohio } \\
\text { Hamilton } \\
\text { City of } \\
\text { December } 31\end{array}$ & $\begin{array}{c}\text { Onio } \\
\text { Napoleon } \\
\text { City of } \\
\text { December } 31\end{array}$ \\
\hline \multicolumn{7}{|l|}{ Electric Plant in Service } \\
\hline $\begin{array}{l}\text { Intangible Plant ................................................... } \\
\text { Production Plant }\end{array}$ & 0 & 0 & 0 & 0 & 0 & 0 \\
\hline Steam & 37,037 & 3,081 & 0 & 0 & 27,511 & 0 \\
\hline 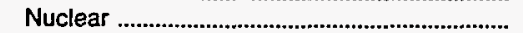 & 0 & 0 & 0 & 0 & 0 & 0 \\
\hline 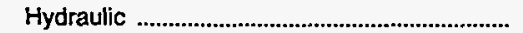 & 0 & 0 & 0 & 0 & 141,075 & 0 \\
\hline Other & 6,528 & 0 & 0 & 0 & 5,973 & 0 \\
\hline Total Production Plant & 43,565 & 3,081 & 0 & 0 & 174,560 & 0 \\
\hline 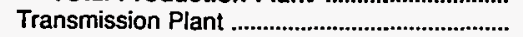 & 62,976 & 39,186 & 711 & 0 & 24,923 & 0 \\
\hline 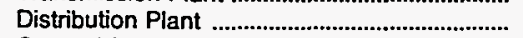 & 56,658 & 8,287 & 17,359 & 0 & 20,717 & 2,536 \\
\hline 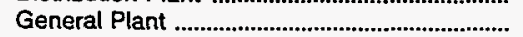 & 13,652 & 23,667 & 1,760 & 9,924 & 6,233 & 0 \\
\hline Total Electric Plant in Service & 176,852 & 74,221 & 19,831 & 9,924 & 226,433 & 2,536 \\
\hline 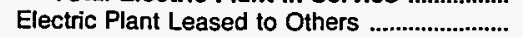 & 0 & 0 & 0 & 0 & 0 & 0 \\
\hline Electric Plant Held for Future Use .................. & 0 & 0 & $\mathbf{0}$ & 0 & 0 & 0 \\
\hline 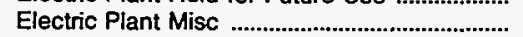 & 0 & 0 & $\mathbf{0}$ & 0 & 0 & 0 \\
\hline Total Electric Utility Plant & 176,852 & 74,221 & 19,831 & 9,924 & 226,433 & 2,536 \\
\hline $\begin{array}{l}\text { Construction Work in Progress - Electric ........ } \\
\text { Accumulated Provision for Depreciation }\end{array}$ & 69,309 & 0 & 0 & 0 & 0 & 0 \\
\hline 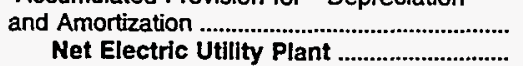 & $\begin{array}{r}90,745 \\
155,416\end{array}$ & $\begin{array}{l}30,205 \\
44,016\end{array}$ & $\begin{array}{r}10,409 \\
9,422\end{array}$ & $\begin{array}{r}0 \\
9,924\end{array}$ & $\begin{array}{r}69,198 \\
157,235\end{array}$ & $\begin{array}{r}0 \\
2,536\end{array}$ \\
\hline
\end{tabular}

Note: Totals may not equal sum of components because of independent rounding.

Source: Energy Information Administration, Form EIA-412, "Annual Report of Public Electric Utilities." 
Table 24. Electric Utility Plant by Major U.S. Publicly Owned Electric Utility Within State at End of Period, 1993 (Continued)

(Thousand Dollars)

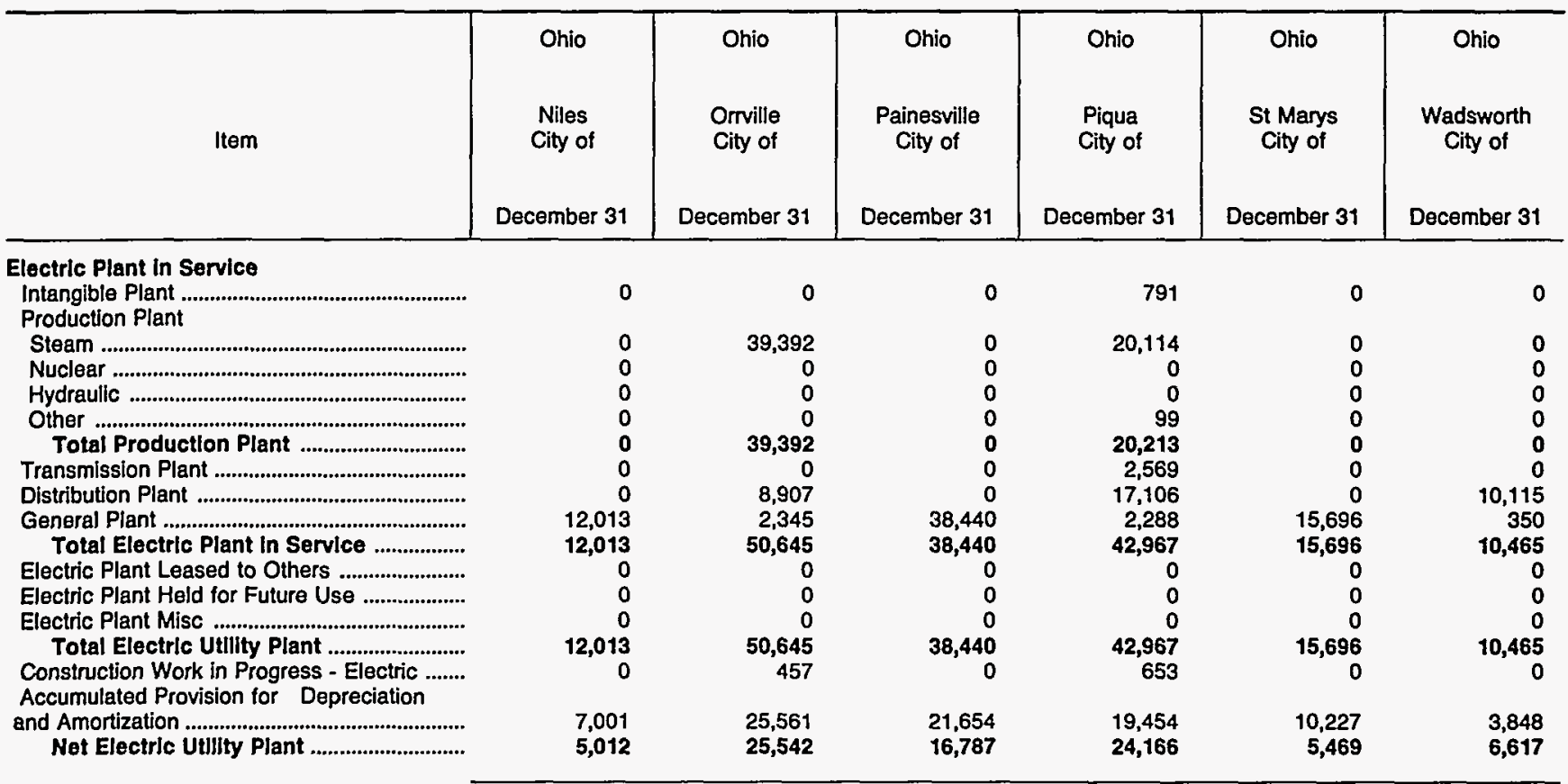

\begin{tabular}{|c|c|c|c|c|c|c|}
\hline Item & $\begin{array}{c}\text { Ohio } \\
\begin{array}{c}\text { Wapakoneta } \\
\text { City of }\end{array} \\
\text { December } 31\end{array}$ & $\begin{array}{c}\text { Ohio } \\
\text { Westerville } \\
\text { City of } \\
\text { December } 31\end{array}$ & $\begin{array}{l}\text { Oklahoma } \\
\text { Altus } \\
\text { City of } \\
\text { June } 30\end{array}$ & $\begin{array}{c}\text { Oklahoma } \\
\text { Claremore } \\
\text { City of } \\
\text { June } 30\end{array}$ & $\begin{array}{l}\text { Oklahoma } \\
\text { Duncan } \\
\text { City of } \\
\text { June } 30\end{array}$ & $\begin{array}{l}\text { Oklahoma } \\
\text { Edmond } \\
\text { City of } \\
\text { June } 30\end{array}$ \\
\hline \multicolumn{7}{|l|}{ Electric Plant In Service } \\
\hline $\begin{array}{l}\text { Intangible Plant ....................................................... } \\
\text { Production Plant }\end{array}$ & 0 & 0 & 0 & 0 & 0 & 0 \\
\hline Steam & 0 & 0 & 0 & 0 & 0 & 0 \\
\hline 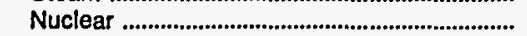 & 0 & 0 & 0 & 0 & 0 & 0 \\
\hline 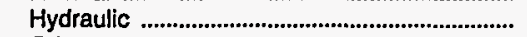 & 0 & 0 & 0 & 0 & 0 & 0 \\
\hline Other & 0 & 0 & 0 & 0 & 0 & 0 \\
\hline 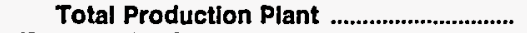 & $\mathbf{0}$ & 0 & $\mathbf{0}$ & $\mathbf{0}$ & $\mathbf{0}$ & $\mathbf{0}$ \\
\hline Transmission Plant & 0 & 0 & 7,855 & 0 & 0 & 0 \\
\hline Distribution Plant & 0 & 19,301 & 0 & 0 & 18,263 & 33,929 \\
\hline General Plant & 0 & 0 & 0 & 0 & 0 & 0 \\
\hline Total Electrlc Plant in Service ................ & $\mathbf{0}$ & 19,301 & 7,855 & $\mathbf{0}$ & 18,263 & 33,929 \\
\hline 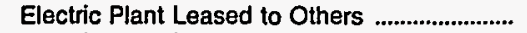 & 0 & 0 & 0 & 0 & 0 & 0 \\
\hline Electric Plant Held for Future Use ....................... & 0 & 0 & 0 & $\mathbf{0}$ & 0 & 0 \\
\hline 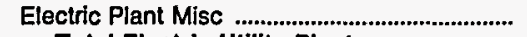 & 0 & 0 & 0 & 0 & 0 & 0 \\
\hline Total Electrlc Utillty Plant & $\mathbf{0}$ & 19,301 & 7,855 & $\mathbf{0}$ & 18,263 & 33,929 \\
\hline $\begin{array}{l}\text { Construction Work in Progress - Electric ....... } \\
\text { Accumulated Provision for Depreciation }\end{array}$ & 0 & 0 & 0 & 0 & 88 & 0 \\
\hline 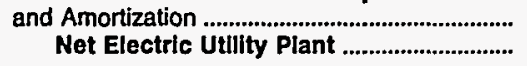 & $\begin{array}{l}\mathbf{0} \\
\mathbf{0}\end{array}$ & $\begin{array}{r}6,915 \\
12,385\end{array}$ & $\begin{array}{l}4,926 \\
2,929\end{array}$ & $\begin{array}{l}0 \\
0\end{array}$ & $\begin{array}{r}7,865 \\
10,486\end{array}$ & $\begin{array}{l}15,483 \\
18,446\end{array}$ \\
\hline
\end{tabular}

Note: Totals may not equal sum of components because of independent rounding.

Source: Energy Information Administration, Form EIA-412, "Annual Report of Public Electric Utilities," 
Table 24. Electric Utility Plant by Major U.S. Publicly Owned Electric Utility Within State at End of Period, 1993 (Continued) (Thousand Dollars)

\begin{tabular}{|c|c|c|c|c|c|c|}
\hline Item & $\begin{array}{c}\text { Oklahoma } \\
\text { Grand River } \\
\text { Dam } \\
\text { Authority } \\
\text { December } 31\end{array}$ & $\begin{array}{l}\text { Oklahoma } \\
\text { Miami } \\
\text { City of } \\
\text { June } 30\end{array}$ & $\begin{array}{c}\text { Oklahoma } \\
\text { Oklahoma } \\
\text { Municipal } \\
\text { Power Auth } \\
\text { December } 31\end{array}$ & $\begin{array}{l}\text { Oklahoma } \\
\text { Ponca } \\
\text { City City of } \\
\text { June } 30\end{array}$ & $\begin{array}{l}\text { Oklahoma } \\
\text { Stillwater } \\
\text { Utilities } \\
\text { Authority } \\
\text { June } 30\end{array}$ & $\begin{array}{l}\text { Oregon } \\
\text { Ashland } \\
\text { City of } \\
\text { June } 30\end{array}$ \\
\hline 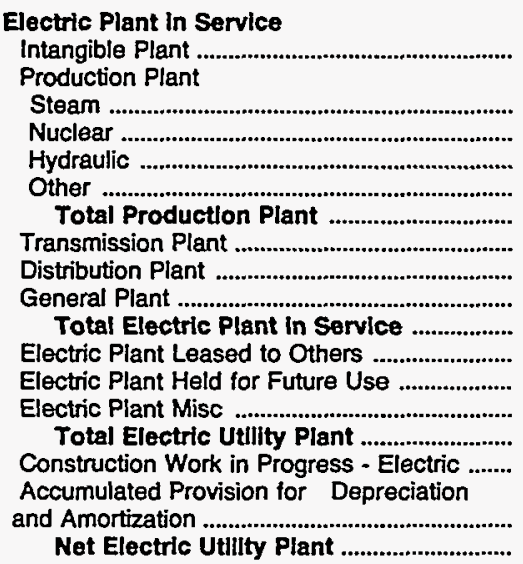 & $\begin{array}{r}611,500 \\
0 \\
70,716 \\
0 \\
682,215 \\
102,201 \\
0 \\
16,838 \\
801,255 \\
0 \\
14 \\
76,967 \\
878,237 \\
13,056 \\
\\
278,448 \\
612,845\end{array}$ & $\begin{array}{r}0 \\
0 \\
0 \\
0 \\
0 \\
0 \\
0 \\
0 \\
1,548 \\
1,929 \\
3,477 \\
0 \\
0 \\
0 \\
3,477 \\
0\end{array}$ & $\begin{array}{r}116,210 \\
0 \\
35,311 \\
0 \\
151,521 \\
4,237 \\
2,443 \\
0 \\
158,201 \\
0 \\
3,377 \\
0 \\
161,578 \\
13,854\end{array}$ & $\begin{array}{r}16,500 \\
0 \\
0 \\
6,270 \\
22,770 \\
1,888 \\
10,047 \\
333 \\
35,038 \\
0 \\
0 \\
0 \\
35,038 \\
0 \\
\\
14,894 \\
20,144\end{array}$ & $\begin{array}{r}4,050 \\
0 \\
0 \\
0 \\
4,050 \\
1,010 \\
18,453 \\
3,331 \\
26,845 \\
0 \\
0 \\
0 \\
26,845 \\
4,933 \\
\\
12,823 \\
18,955\end{array}$ & $\begin{array}{r}0 \\
0 \\
940 \\
0 \\
940 \\
0 \\
9,780 \\
0 \\
10,720 \\
0 \\
0 \\
0 \\
10,720 \\
637\end{array}$ \\
\hline
\end{tabular}

\begin{tabular}{|c|c|c|c|c|c|c|}
\hline Item & $\begin{array}{c}\text { Oregon } \\
\text { Central } \\
\text { Lincoln } \\
\text { Peoples } \\
\text { Utl Dt } \\
\text { December } 31\end{array}$ & $\begin{array}{c}\text { Oregon } \\
\text { Clatskanie } \\
\text { Peoples } \\
\text { Util Dist } \\
\text { December } 31\end{array}$ & $\begin{array}{c}\text { Oregon } \\
\text { Columbia } \\
\text { Aiver } \\
\text { Peoples } \\
\text { Ut Dist } \\
\text { December 31 }\end{array}$ & $\begin{array}{c}\text { Oregon } \\
\text { Emerald } \\
\text { Peoples } \\
\text { Utility Dist } \\
\text { December } 31\end{array}$ & $\begin{array}{l}\text { Oregon } \\
\text { Eugene } \\
\text { City of } \\
\text { December } 31\end{array}$ & $\begin{array}{c}\text { Oregon } \\
\begin{array}{c}\text { Forest Grove } \\
\text { City of }\end{array} \\
\text { June } 30\end{array}$ \\
\hline \multicolumn{7}{|l|}{ Electric Plant in Service } \\
\hline $\begin{array}{l}\text { Intangible Plant } \\
\text { Production Plant }\end{array}$ & 148 & 7 & 0 & 147 & 0 & 0 \\
\hline Steam & 0 & 0 & 0 & 0 & 14,365 & 0 \\
\hline 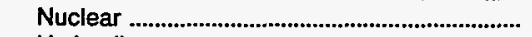 & 0 & 0 & 0 & 0 & 0 & 0 \\
\hline 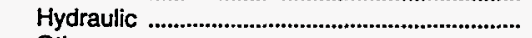 & 0 & 0 & 0 & 0 & 67,625 & 0 \\
\hline Other & 0 & 0 & 0 & 1,581 & 0 & 0 \\
\hline 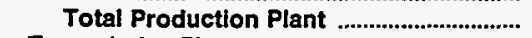 & $\mathbf{0}$ & $\mathbf{0}$ & $\mathbf{0}$ & 1,581 & 81,989 & $\mathbf{0}$ \\
\hline 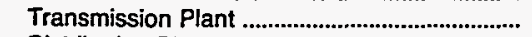 & 0 & 0 & 693 & 1,033 & 23,956 & 22 \\
\hline 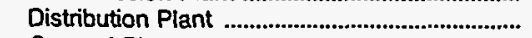 & 59,268 & 4,840 & 10,250 & 39,021 & 117,122 & 9,264 \\
\hline General Plant & 18,386 & 1,596 & 3,822 & 8,669 & 41,384 & 1,600 \\
\hline Total Electric Plant in Service .................... & 77,800 & 6,443 & 14,765 & 50,451 & 264,452 & 10,887 \\
\hline Electric Plant Leased to Others ...................... & 0 & 0 & 0 & 0 & 0 & 0 \\
\hline Electric Plant Held for Future Use .................... & 0 & 0 & 0 & 0 & 500 & 0 \\
\hline 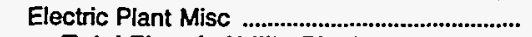 & 0 & 0 & 7,874 & 16,530 & 3,444 & 0 \\
\hline 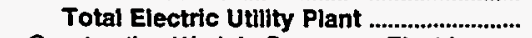 & 77,800 & 6,443 & 22,639 & 66,980 & 268,396 & 10,887 \\
\hline $\begin{array}{l}\text { Construction Work in Progress - Electric ....... } \\
\text { Accumulated Provision for Depreciation }\end{array}$ & 5,987 & 63 & 129 & 4,454 & 5,688 & 164 \\
\hline and Amortization & 32,356 & 3,204 & 3,977 & 24,723 & 114,988 & 3,559 \\
\hline 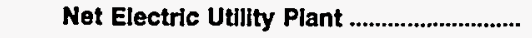 & 51,431 & 3,302 & 18,791 & 46,712 & 159,096 & 7,492 \\
\hline
\end{tabular}

Note: Totals may not equal sum of components because of independent rounding.

Source: Energy Information Administration, Form EIA-412, "Annual Report of Public Electric Utilities." 
Table 24. Electric Utility Plant by Major U.S. Publicly Owned Electric Utility Within State at End of Period, 1993 (Continued)

(Thousand Dollars)

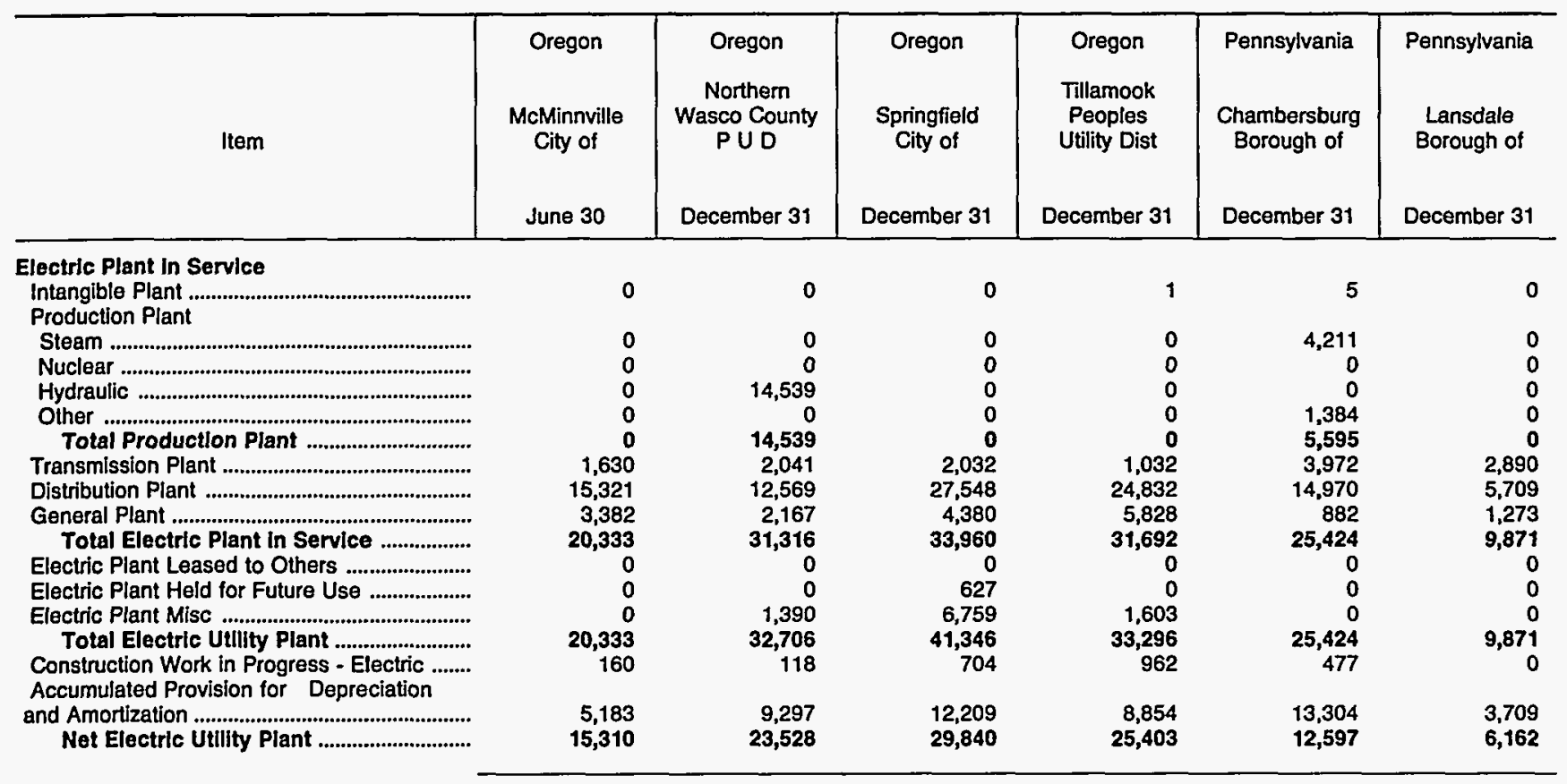

\begin{tabular}{|c|c|c|c|c|c|c|}
\hline Item & $\begin{array}{l}\text { South Carolina } \\
\text { Camden } \\
\text { City of } \\
\text { June } 30\end{array}$ & $\begin{array}{c}\text { South Carolina } \\
\text { Easley } \\
\text { Combined } \\
\text { Utility } \\
\text { System } \\
\text { March } 31\end{array}$ & $\begin{array}{l}\text { South Carolina } \\
\text { Gaffney } \\
\text { City of } \\
\text { March } 31\end{array}$ & $\begin{array}{l}\text { South Carolina } \\
\text { Greenwood } \\
\text { Commissioners } \\
\text { Pub Wk } \\
\text { December } 31\end{array}$ & $\begin{array}{c}\text { South Carolina } \\
\text { Greer } \\
\text { Comm } \\
\text { of } \\
\text { Public Works } \\
\text { December } 31\end{array}$ & $\begin{array}{l}\text { South Carolina } \\
\text { Newberry } \\
\text { City of } \\
\text { June } 30\end{array}$ \\
\hline \multicolumn{7}{|l|}{ Electric Plant in Servlce } \\
\hline $\begin{array}{l}\text { Intangible Plant ....................................................... } \\
\text { Production Plant }\end{array}$ & 0 & 0 & 0 & 0 & 0 & 0 \\
\hline 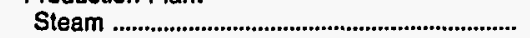 & 0 & 0 & 0 & 0 & 0 & 0 \\
\hline Nuclear & 0 & 0 & 0 & 0 & 0 & 0 \\
\hline 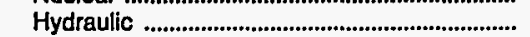 & 0 & 0 & 0 & 0 & 0 & 0 \\
\hline Other & 0 & $\mathbf{0}$ & 0 & 0 & 0 & 0 \\
\hline 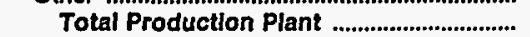 & $\mathbf{0}$ & 0 & $\mathbf{0}$ & 0 & 0 & $\mathbf{0}$ \\
\hline 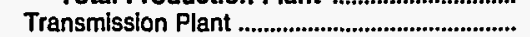 & 0 & $\mathbf{0}$ & 0 & 0 & 10,489 & 0 \\
\hline Distribution Plant & 0 & 14,004 & 1,565 & 14,274 & 0 & 0 \\
\hline General Plant & 10,877 & 0 & 0 & 0 & 62,814 & 7,714 \\
\hline Total Electric Plant In Servlce & 10,877 & 14,004 & 1,565 & 14,274 & 73,303 & 7,714 \\
\hline 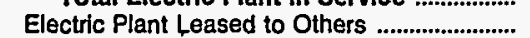 & 0 & 0 & 0 & 0 & 0 & 0 \\
\hline Electric Plant Held for Future Use .................. & 0 & 0 & 0 & 0 & 0 & 0 \\
\hline Electric Plant Misc & 0 & 0 & 0 & 0 & 0 & 0 \\
\hline Total Electric Utillty Plant & 10,877 & 14,004 & 1,565 & 14,274 & 73,303 & 7,714 \\
\hline $\begin{array}{l}\text { Construction Work in Progress - Electric ........ } \\
\text { Accumulated Provision for Depreciation }\end{array}$ & 0 & 80 & 378 & 0 & 2,729 & 4 \\
\hline 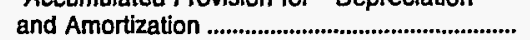 & 8,241 & 5,392 & 744 & 9,200 & 20,724 & 4,058 \\
\hline 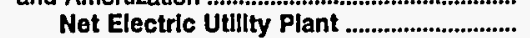 & 2,636 & 8,692 & 1,198 & 5,074 & 55,308 & 3,661 \\
\hline
\end{tabular}

Note: Totals may not equal sum of components because of independent rounding.

Source: Energy Information Administration, Form EIA-412, "Annual Report of Public Electric Utilities." 
Table 24. Electric Utility Plant by Major U.S. Publicly Owned Electric Utility Within State at End of Period, 1993 (Continued)

(Thousand Dollars)

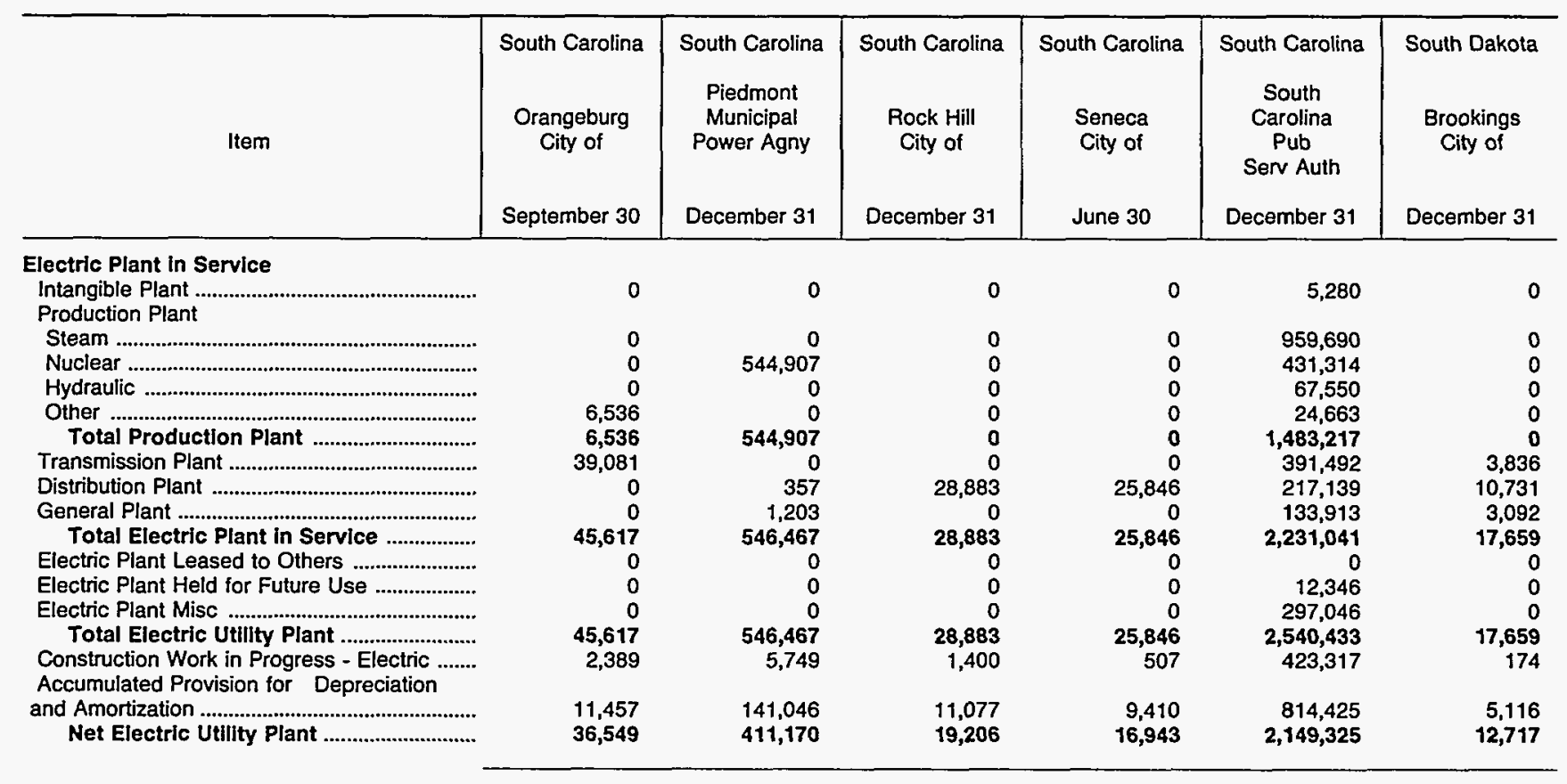

\begin{tabular}{|c|c|c|c|c|c|c|}
\hline Item & $\begin{array}{c}\text { South Dakota } \\
\text { Heartland } \\
\text { Consumers } \\
\text { Power Dist } \\
\text { December } 31\end{array}$ & $\begin{array}{l}\text { South Dakota } \\
\text { Missouri } \\
\text { Basin } \\
\text { Mun } \\
\text { Power Agny } \\
\text { December } 31\end{array}$ & $\begin{array}{c}\text { South Dakota } \\
\text { Pierre } \\
\text { City of } \\
\text { December } 31\end{array}$ & $\begin{array}{l}\text { South Dakota } \\
\text { Watertown } \\
\text { Municipal } \\
\text { Utilities } \\
\text { December } 31\end{array}$ & $\begin{array}{c}\text { Tennessee } \\
\text { Alcoa } \\
\text { Utilities } \\
\text { June } 30\end{array}$ & $\begin{array}{c}\text { Tennessee } \\
\text { Athens } \\
\text { Utility } \\
\text { Board } \\
\text { June } 30\end{array}$ \\
\hline \multicolumn{7}{|l|}{ Electric Plant in Service } \\
\hline $\begin{array}{l}\text { Intangible Plant } \\
\text { Production Plant }\end{array}$ & 0 & 0 & 0 & 12 & 0 & 0 \\
\hline Steam & 48,312 & 0 & 0 & 0 & 0 & 0 \\
\hline 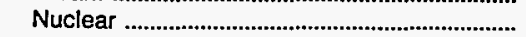 & 0 & 0 & 0 & 0 & 0 & 0 \\
\hline 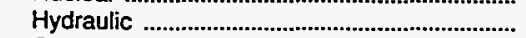 & 0 & 0 & 0 & 0 & 0 & 0 \\
\hline Other & 0 & 0 & 0 & 194 & 0 & 0 \\
\hline 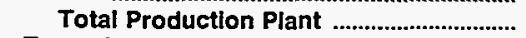 & 48,312 & $\mathbf{0}$ & $\mathbf{0}$ & 194 & 0 & 0 \\
\hline 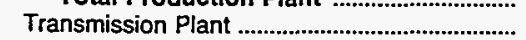 & 8,414 & 0 & 0 & 364 & 1,131 & 1,350 \\
\hline Distribution Plant & 0 & $\mathbf{0}$ & 6,800 & 15,225 & 15,824 & 13,940 \\
\hline General Plant & 777 & 2,664 & 955 & 926 & 1,617 & 1,518 \\
\hline Total Electric Plant in Service & 57,503 & 2,664 & 7,755 & 16,720 & 18,571 & 16,809 \\
\hline 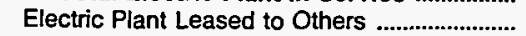 & 0 & 0 & 0 & 0 & 0 & 0 \\
\hline Electric Plant Held for Future Use ..................... & 0 & 0 & 0 & 0 & 0 & 0 \\
\hline Electric Plant Misc & 0 & 0 & 0 & 0 & 0 & 12 \\
\hline 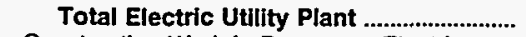 & 57,503 & 2,664 & $\mathbf{7 , 7 5 5}$ & 16,720 & 18,571 & 16,821 \\
\hline $\begin{array}{l}\text { Construction Work in Progress - Electric ........ } \\
\text { Accumulated Provision for Depreciation }\end{array}$ & 88 & 0 & 0 & 0 & 344 & 372 \\
\hline $\begin{array}{l}\text { and Amortization } \\
\text { Net Electric Utility Plant }\end{array}$ & $\begin{array}{r}7,191 \\
50,401\end{array}$ & $\begin{array}{r}642 \\
2,022\end{array}$ & $\begin{array}{l}2,641 \\
5,114\end{array}$ & $\begin{array}{r}10,379 \\
6,342\end{array}$ & $\begin{array}{r}5,959 \\
12,956\end{array}$ & $\begin{array}{r}6,330 \\
10,862\end{array}$ \\
\hline
\end{tabular}

Note: Totals may not equal sum of components because of independent rounding.

Source: Energy Information Administration, Form EIA-412, "Annual Report of Public Electric Utitities." 
Table 24. Electric Utility Plant by Major U.S. Publicly Owned Electric Utility Within State at End of Period, 1993 (Continued) (Thousand Dollars)

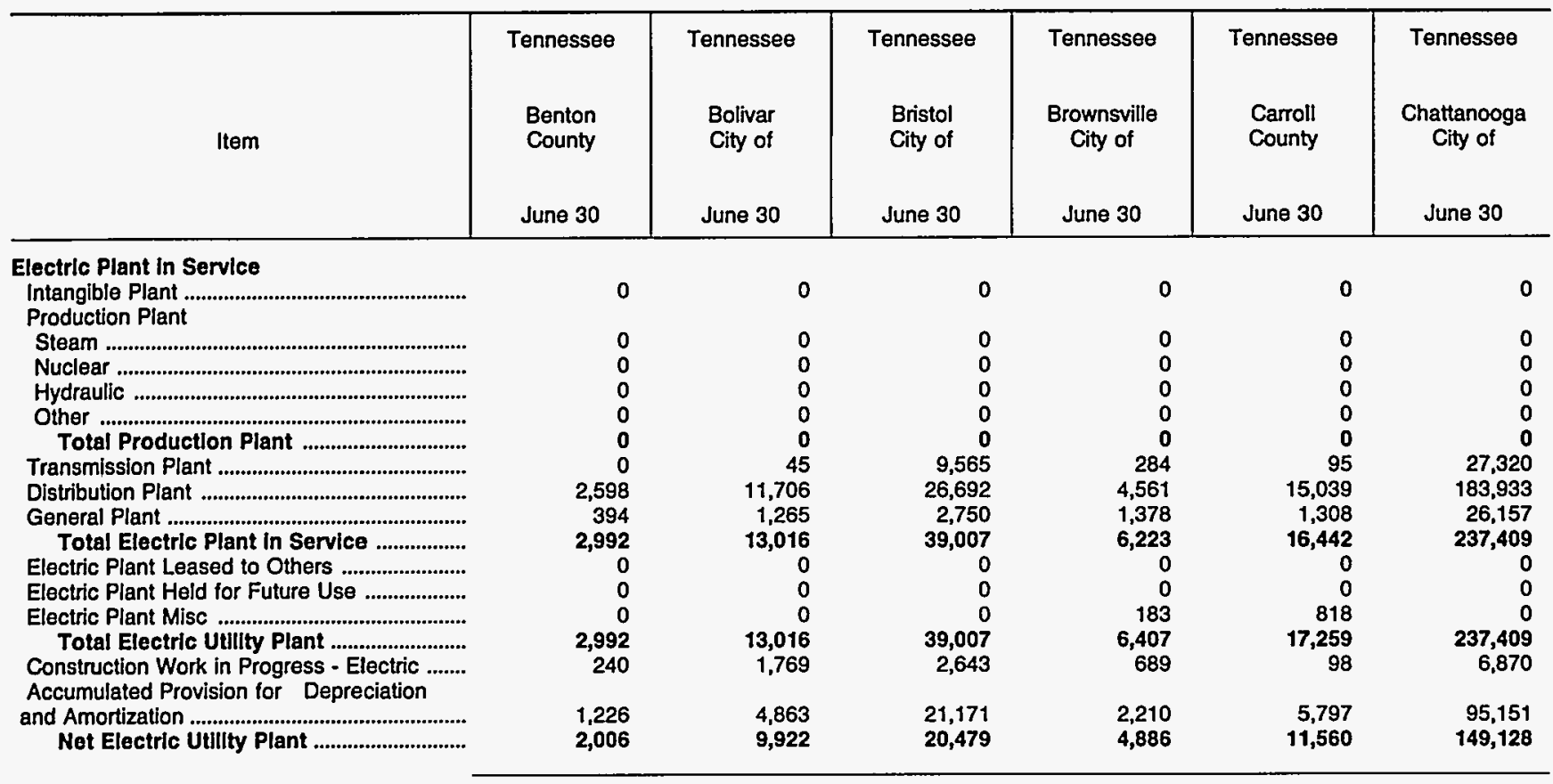

\begin{tabular}{|c|c|c|c|c|c|c|}
\hline Item & $\begin{array}{c}\text { Tennessee } \\
\text { Clarksville } \\
\text { City of } \\
\text { June } 30\end{array}$ & $\begin{array}{l}\text { Tennessee } \\
\text { Cleveland } \\
\text { City of } \\
\text { June } 30\end{array}$ & $\begin{array}{l}\text { Tennessee } \\
\text { Clinton } \\
\text { City of } \\
\text { June } 30\end{array}$ & $\begin{array}{c}\text { Tennessee } \\
\text { Columbia } \\
\text { City of } \\
\text { June } 30\end{array}$ & $\begin{array}{l}\text { Tennessee } \\
\text { Cookeville } \\
\text { City of } \\
\text { June } \mathbf{3 0}\end{array}$ & $\begin{array}{l}\text { Tennessee } \\
\text { Covington } \\
\text { City of } \\
\text { June } 30\end{array}$ \\
\hline 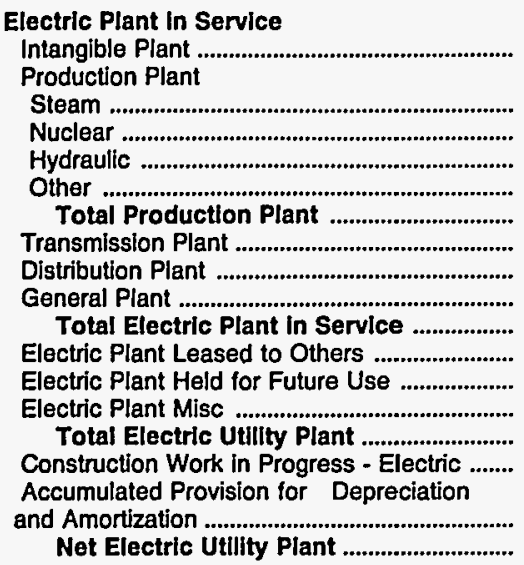 & $\begin{array}{r}0 \\
0 \\
0 \\
0 \\
0 \\
1,524 \\
28,606 \\
4,697 \\
34,827 \\
0 \\
0 \\
9,084 \\
43,911 \\
301 \\
10,758 \\
33,454\end{array}$ & $\begin{array}{r}0 \\
0 \\
0 \\
0 \\
0 \\
0 \\
0 \\
3,628 \\
36,817 \\
3,888 \\
44,334 \\
0 \\
0 \\
2,057 \\
46,391 \\
841 \\
15,456 \\
31,776\end{array}$ & $\begin{array}{r}0 \\
0 \\
0 \\
0 \\
0 \\
0 \\
0 \\
5,422 \\
25,155 \\
3,202 \\
33,780 \\
0 \\
0 \\
0 \\
33,780 \\
1,080\end{array}$ & $\begin{array}{r}0 \\
0 \\
0 \\
0 \\
0 \\
0 \\
0 \\
1,729 \\
19,735 \\
2,949 \\
24,413 \\
0 \\
0 \\
4 \\
24,417 \\
511 \\
\\
9,706 \\
15,222\end{array}$ & $\begin{array}{r}0 \\
0 \\
0 \\
0 \\
0 \\
0 \\
265 \\
13,679 \\
3,026 \\
16,970 \\
0 \\
0 \\
723 \\
17,693 \\
610 \\
4,728 \\
13,574\end{array}$ & $\begin{array}{r}0 \\
0 \\
0 \\
0 \\
0 \\
1,307 \\
4,355 \\
814 \\
6,475 \\
0 \\
0 \\
1,410 \\
7,885 \\
50 \\
\\
2,076 \\
5,859\end{array}$ \\
\hline
\end{tabular}

Note: Totals may not equal sum of components because of independent rounding.

Source: Energy Information Administration, Form EIA-412, "Annual Report of Public Electric Utilities." 
Table 24. Electric Utility Plant by Major U.S. Publicly Owned Electric Utility Within State at End of Period, 1993 (Continued) (Thousand Dollars)

\begin{tabular}{|c|c|c|c|c|c|c|}
\hline Item & $\begin{array}{l}\text { Tennessee } \\
\text { Dayton } \\
\text { City of } \\
\text { June } 30\end{array}$ & $\begin{array}{l}\text { Tennessee } \\
\text { Dickson } \\
\text { City of } \\
\text { June } 30\end{array}$ & $\begin{array}{c}\text { Tennessee } \\
\text { Dyersburg } \\
\text { City of } \\
\text { June } 30\end{array}$ & $\begin{array}{c}\text { Tennessee } \\
\text { Elizabethton } \\
\text { City of } \\
\text { June } 30\end{array}$ & $\begin{array}{c}\text { Tennessee } \\
\text { Erwin } \\
\text { Town of } \\
\text { June } 30\end{array}$ & $\begin{array}{l}\text { Tennessee } \\
\text { Etowah } \\
\text { City of } \\
\text { June } 30\end{array}$ \\
\hline \multicolumn{7}{|l|}{ Electric Plant In Service } \\
\hline $\begin{array}{l}\text { Intangible Plant } \\
\text { Production Plant }\end{array}$ & 0 & 0 & 0 & 0 & 0 & 0 \\
\hline 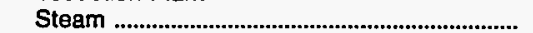 & 0 & 0 & 0 & 0 & 0 & 0 \\
\hline Nuclear & 0 & 0 & 0 & 0 & 0 & 0 \\
\hline 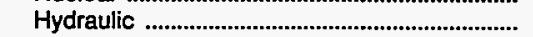 & 0 & 0 & 0 & 0 & 0 & 0 \\
\hline Other & 0 & 0 & 0 & 0 & 0 & 0 \\
\hline Total Production Plant & 0 & 0 & $\mathbf{0}$ & $\mathbf{0}$ & 0 & 0 \\
\hline 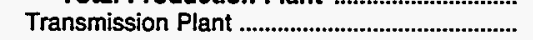 & 0 & 0 & 1,988 & 597 & 0 & 0 \\
\hline 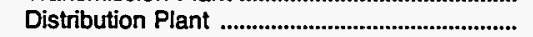 & 8,744 & 33,342 & 19,101 & 19,892 & 6,386 & 4,641 \\
\hline 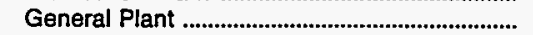 & 1,236 & 1,884 & 4,549 & 3,407 & 1,189 & 389 \\
\hline Total Electric Plant in Service .................... & 9,980 & 35,225 & 25,639 & 23,896 & $\mathbf{7 , 5 7 4}$ & 5,031 \\
\hline Electric Plant Leased to Others ............................ & 0 & 0 & 0 & 0 & 0 & 0 \\
\hline Electric Plant Held for Future Use ................... & 0 & 303 & 0 & 0 & 0 & 0 \\
\hline Electric Plant Misc & 0 & 0 & 0 & 0 & 0 & 0 \\
\hline 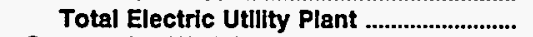 & 9,980 & 35,529 & 25,639 & 23,896 & 7,574 & 5,031 \\
\hline $\begin{array}{l}\text { Construction Work in Progress - Electric ........ } \\
\text { Accumulated Provision for Depreciation }\end{array}$ & 68 & 1,688 & 947 & 189 & 465 & 81 \\
\hline and Amortization & 3,297 & 11,207 & 7,356 & 8,412 & 3,079 & 2,111 \\
\hline 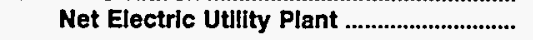 & 6,751 & 26,010 & 19,230 & 15,673 & 4,960 & 3,001 \\
\hline
\end{tabular}

\begin{tabular}{|c|c|c|c|c|c|c|}
\hline Item & $\begin{array}{c}\text { Tennessee } \\
\begin{array}{c}\text { Fayetteville } \\
\text { City of }\end{array} \\
\text { June } 30\end{array}$ & $\begin{array}{l}\text { Tennessee } \\
\text { Gallatin } \\
\text { City of } \\
\text { June } 30\end{array}$ & $\begin{array}{c}\text { Tennessee } \\
\text { Greeneville } \\
\text { City of } \\
\text { June } 30\end{array}$ & $\begin{array}{l}\text { Tennessee } \\
\text { Harriman } \\
\text { City of } \\
\text { June } 30\end{array}$ & $\begin{array}{l}\text { Tennessee } \\
\text { Humboldt } \\
\text { City of } \\
\text { June } 30\end{array}$ & $\begin{array}{l}\text { Tennessee } \\
\text { Jackson } \\
\text { City of } \\
\text { June } 30\end{array}$ \\
\hline \multicolumn{7}{|l|}{ Electric Plant In Service } \\
\hline $\begin{array}{l}\text { Intangible Plant } \\
\text { Production Plant }\end{array}$ & 0 & 0 & 0 & 0 & 0 & 0 \\
\hline Steam & 0 & 0 & $\mathbf{0}$ & 0 & 0 & 0 \\
\hline Nuclear & 0 & 0 & 0 & 0 & 0 & 0 \\
\hline 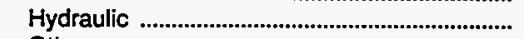 & 0 & 0 & 0 & 0 & 0 & 0 \\
\hline Other & 0 & 0 & 0 & 0 & 0 & 0 \\
\hline Total Production Plant ................................... & 0 & $\mathbf{0}$ & 0 & 0 & $\mathbf{0}$ & 0 \\
\hline 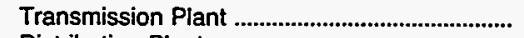 & 619 & 501 & 6,131 & 1,351 & 668 & 9,155 \\
\hline Distribution Plant & 18,190 & 9,244 & 29,806 & 14,249 & 4,553 & 37,517 \\
\hline General Plant & 4,589 & 1,294 & 4,174 & 1,861 & 1,662 & 8,545 \\
\hline Total Electric Plant in Service .................. & 23,397 & 11,039 & 40,112 & 17,461 & 6,883 & 55,217 \\
\hline Electric Plant Leased to Others ............................. & 0 & 0 & 0 & 0 & 0 & 0 \\
\hline 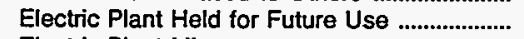 & 0 & 0 & 0 & 0 & 0 & 0 \\
\hline Electric Plant Misc & 0 & 130 & 0 & 48 & 485 & 247 \\
\hline Total Electric Utility Plant & 23,397 & 11,169 & 40,112 & 17,509 & 7,369 & 55,464 \\
\hline $\begin{array}{l}\text { Construction Work in Progress - Electric ........ } \\
\text { Accumulated Provision for Depreciation }\end{array}$ & 867 & 34 & 313 & 165 & 206 & 1,356 \\
\hline $\begin{array}{l}\text { and Amortization } \\
\text { Net Electric Utility Plant }\end{array}$ & $\begin{array}{r}7,537 \\
16,727\end{array}$ & $\begin{array}{l}5,212 \\
5,991\end{array}$ & $\begin{array}{l}15,120 \\
25,304\end{array}$ & $\begin{array}{r}7,568 \\
10,107\end{array}$ & $\begin{array}{l}2,505 \\
5,070\end{array}$ & $\begin{array}{l}21,414 \\
35,406\end{array}$ \\
\hline
\end{tabular}

Note: Totals may not equal sum of components because of independent rounding.

Source: Energy Information Administration, Form ElA-412, "Annual Report of Public Electric Utilities." 
Table 24. Electric Utility Plant by Major U.S. Publicly Owned Electric Utility Within State at End of Period, 1993 (Continued)

(Thousand Dollars)

\begin{tabular}{|c|c|c|c|c|c|c|}
\hline Item & $\begin{array}{l}\text { Tennessee } \\
\text { Johnson } \\
\text { City City of } \\
\text { June } 30\end{array}$ & $\begin{array}{c}\text { Tennessee } \\
\text { Knoxville } \\
\text { Utilities } \\
\text { Board } \\
\text { June } 30\end{array}$ & $\begin{array}{c}\text { Tennessee } \\
\begin{array}{c}\text { Lawrenceburg } \\
\text { City of }\end{array} \\
\text { June } 30\end{array}$ & $\begin{array}{l}\text { Tennessee } \\
\text { LaFollette } \\
\text { City of } \\
\text { June } 30\end{array}$ & $\begin{array}{l}\text { Tennessee } \\
\text { Lebanon } \\
\text { City of } \\
\text { June } 30\end{array}$ & $\begin{array}{l}\text { Tennessee } \\
\text { Lenoir } \\
\text { City City of } \\
\text { June } 30\end{array}$ \\
\hline \multicolumn{7}{|l|}{ Electrlc Plant in Service } \\
\hline $\begin{array}{l}\text { Intangible Plant } \\
\text { Production Plant }\end{array}$ & $\mathbf{0}$ & 0 & $\mathbf{0}$ & 0 & $\mathbf{0}$ & 0 \\
\hline Steam & 0 & 0 & $\mathbf{0}$ & 0 & 0 & 0 \\
\hline 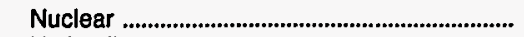 & 0 & 0 & 0 & 0 & 0 & 0 \\
\hline 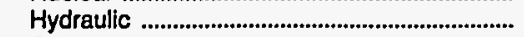 & 0 & 0 & $\mathbf{0}$ & 0 & 0 & 0 \\
\hline Other & 0 & 0 & 0 & 0 & 0 & 0 \\
\hline 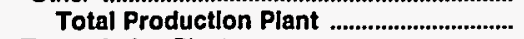 & $\mathbf{0}$ & $\mathbf{0}$ & $\mathbf{0}$ & $\mathbf{0}$ & $\mathbf{0}$ & 0 \\
\hline Transmission Plant & 10,380 & 0 & 3,935 & 0 & 0 & 0 \\
\hline 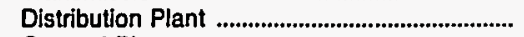 & 42,397 & 254,610 & 16,743 & 22,646 & 10,346 & 56,307 \\
\hline General Plant ............................................... & $\begin{array}{r}2,418 \\
55,196\end{array}$ & $\begin{array}{r}20,651 \\
275,261\end{array}$ & $\begin{array}{r}2,235 \\
22,912\end{array}$ & $\begin{array}{r}2,503 \\
25,149\end{array}$ & $\begin{array}{r}1,368 \\
11,714\end{array}$ & $\begin{array}{r}3,155 \\
59,462\end{array}$ \\
\hline 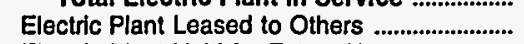 & 0 & 0 & 0 & 0 & 0 & 0 \\
\hline Electric Plant Held for Future Use ................... & 0 & 0 & 0 & 0 & 0 & 0 \\
\hline 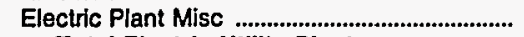 & 0 & 0 & 0 & 0 & 82 & 0 \\
\hline Total Electric Utility Plant & 55,196 & 275,261 & 22,912 & 25,149 & 11,796 & 59,462 \\
\hline $\begin{array}{l}\text { Construction Work in Progress - Electric ........ } \\
\text { Accumulated Provision for Depreciation }\end{array}$ & 2,718 & 5,416 & 354 & 366 & 786 & 205 \\
\hline $\begin{array}{l}\text { and Amortization } \\
\text { Net Electric Utility Plant }\end{array}$ & $\begin{array}{l}24,228 \\
33,686\end{array}$ & $\begin{array}{l}130,227 \\
150,450\end{array}$ & $\begin{array}{r}9,312 \\
13,954\end{array}$ & $\begin{array}{r}8,911 \\
16,604\end{array}$ & $\begin{array}{l}4,395 \\
8,188\end{array}$ & $\begin{array}{l}14,795 \\
44,872\end{array}$ \\
\hline
\end{tabular}

\begin{tabular}{|c|c|c|c|c|c|c|}
\hline Item & $\begin{array}{l}\text { Tennessee } \\
\text { Lewisburg } \\
\text { City of } \\
\text { June } 30\end{array}$ & $\begin{array}{l}\text { Tennessee } \\
\text { Lexington } \\
\text { City of } \\
\text { June } 30\end{array}$ & $\begin{array}{l}\text { Tennessee } \\
\text { Loudon } \\
\text { Utilities } \\
\text { Board } \\
\text { June } 30\end{array}$ & $\begin{array}{c}\text { Tennessee } \\
\begin{array}{c}\text { Maryville } \\
\text { Utilities }\end{array} \\
\text { June } 30\end{array}$ & $\begin{array}{l}\text { Tennessee } \\
\text { McMinnville } \\
\text { Electric } \\
\text { System } \\
\text { June } 30\end{array}$ & $\begin{array}{l}\text { Tennessee } \\
\text { Memphis } \\
\text { City of } \\
\text { June } 30\end{array}$ \\
\hline \multicolumn{7}{|l|}{ Electric Plant In Service } \\
\hline 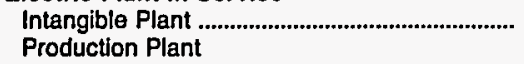 & 0 & 0 & 0 & 0 & 0 & 0 \\
\hline 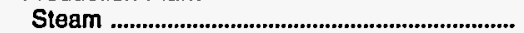 & 0 & 0 & 0 & 0 & 0 & 0 \\
\hline 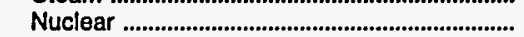 & 0 & 0 & 0 & 0 & 0 & 0 \\
\hline 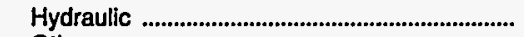 & 0 & 0 & 0 & 0 & 0 & 0 \\
\hline Other & 0 & 0 & 0 & 0 & 0 & 0 \\
\hline 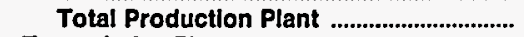 & 0 & 0 & 0 & $\mathbf{0}$ & 0 & 0 \\
\hline 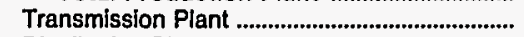 & $\mathbf{0}$ & 0 & 3,396 & 2,297 & 0 & 131,532 \\
\hline 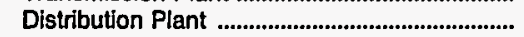 & 8,433 & 18,549 & 10,153 & 17,569 & 9,444 & 533,605 \\
\hline 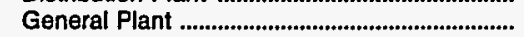 & 1,791 & 2,761 & 510 & 4,432 & 1,521 & 49,108 \\
\hline Total Electric Plant In Service ................. & 10,224 & 21,310 & 14,059 & 24,298 & 10,966 & $\mathbf{7 1 4 , 2 4 5}$ \\
\hline Electric Plant Leased to Others ........................... & 0 & 0 & 0 & 0 & 0 & 0 \\
\hline Electric Plant Held for Future Use ................... & 0 & 0 & 0 & 0 & 0 & 0 \\
\hline Electric Plant Misc & 269 & 0 & 0 & 22 & 219 & 0 \\
\hline Total Electric Utillty Plant ......................... & 10,493 & 21,310 & 14,059 & 24,320 & 11,184 & 714,245 \\
\hline $\begin{array}{l}\text { Construction Work in Progress - Electric ........ } \\
\text { Accumulated Provision for Depreciation }\end{array}$ & 38 & 259 & 2,805 & 82 & 23 & 24,156 \\
\hline $\begin{array}{l}\text { and Amortization } \\
\text { Net Electric Utility Plant }\end{array}$ & $\begin{array}{l}3,165 \\
7,365\end{array}$ & $\begin{array}{r}7,644 \\
13,925\end{array}$ & $\begin{array}{r}3,532 \\
13,333\end{array}$ & $\begin{array}{r}7,353 \\
17,049\end{array}$ & $\begin{array}{l}4,428 \\
6,779\end{array}$ & $\begin{array}{l}243,331 \\
495,071\end{array}$ \\
\hline
\end{tabular}

Note: Totals may not equal sum of components because of independent rounding.

Source: Energy Information Administration, Form ElA-412, "Annual Report of Public Electric Utilities." 
Table 24. Electric Utility Plant by Major U.S. Publicly Owned Electric Utility Within State at End of Period, 1993 (Continued) (Thousand Dollars)

\begin{tabular}{|c|c|c|c|c|c|c|}
\hline Item & $\begin{array}{c}\text { Tennessee } \\
\text { Morristown } \\
\text { City of } \\
\text { June } 30\end{array}$ & $\begin{array}{c}\text { Tennessee } \\
\begin{array}{c}\text { Murfreesboro } \\
\text { City of }\end{array} \\
\text { June } 30\end{array}$ & $\begin{array}{l}\text { Tennessee } \\
\text { Nashville } \\
\text { Electric } \\
\text { Service } \\
\text { June } 30\end{array}$ & $\begin{array}{l}\text { Tennessee } \\
\text { Newport } \\
\text { City of } \\
\text { June } 30\end{array}$ & $\begin{array}{l}\text { Tennessee } \\
\text { Oak Ridge } \\
\text { City of } \\
\text { June } 30\end{array}$ & $\begin{array}{c}\text { Tennessee } \\
\text { Paris } \\
\text { City of } \\
\text { June } 30\end{array}$ \\
\hline \multicolumn{7}{|l|}{ Electric Plant in Service } \\
\hline $\begin{array}{l}\text { Intangible Plant ............................................................. } \\
\text { Production Plant }\end{array}$ & 0 & 0 & 0 & 0 & 0 & 0 \\
\hline 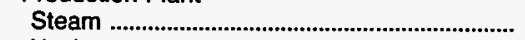 & 0 & 0 & 0 & 0 & 0 & 0 \\
\hline 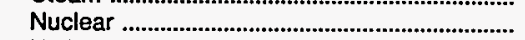 & 0 & 0 & 0 & $\mathbf{0}$ & 0 & 0 \\
\hline 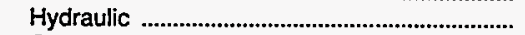 & $\mathbf{0}$ & 0 & 0 & 0 & 0 & 0 \\
\hline Other & 0 & 0 & 0 & 0 & 0 & 0 \\
\hline Total Production Plant & 0 & 0 & 0 & $\mathbf{0}$ & $\mathbf{0}$ & 0 \\
\hline 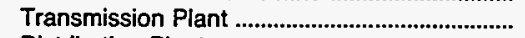 & 3,498 & 0 & 0 & 0 & 818 & 1,902 \\
\hline 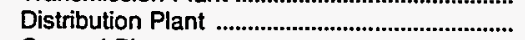 & 17,468 & 28,418 & 476,378 & 21,087 & 21,416 & 21,863 \\
\hline General Plant & 3,727 & 4,417 & 50,717 & 4,108 & 1,151 & 1,618 \\
\hline Total Electric Plant in Service & 24,693 & 32,834 & 527,094 & 25,196 & 23,384 & 25,383 \\
\hline 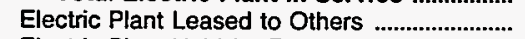 & 0 & 0 & 0 & 0 & 0 & 0 \\
\hline 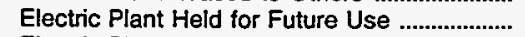 & 0 & 0 & 0 & 0 & 0 & 0 \\
\hline 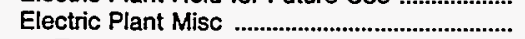 & 2,234 & 886 & 0 & 0 & 122 & 0 \\
\hline Total Electric Utility Plant & 26,928 & 33,721 & 527,094 & 25,196 & 23,506 & 25,383 \\
\hline $\begin{array}{l}\text { Construction Work in Progress - Electric ........ } \\
\text { Accumulated Provision for Depreciation }\end{array}$ & 894 & 1,632 & 9,411 & 28 & 2,643 & 544 \\
\hline 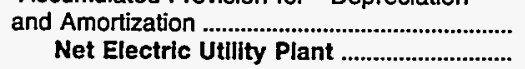 & $\begin{array}{r}8,674 \\
19,148\end{array}$ & $\begin{array}{l}10,037 \\
25,315\end{array}$ & $\begin{array}{l}188,118 \\
348,387\end{array}$ & $\begin{array}{r}8,109 \\
17,115\end{array}$ & $\begin{array}{r}9,697 \\
16,453\end{array}$ & $\begin{array}{l}11,115 \\
14,812\end{array}$ \\
\hline
\end{tabular}

\begin{tabular}{|c|c|c|c|c|c|c|}
\hline Item & $\begin{array}{l}\text { Tennessee } \\
\text { Pulaski } \\
\text { City of } \\
\text { June } 30\end{array}$ & $\begin{array}{l}\text { Tennessee } \\
\text { Ripley } \\
\text { City of } \\
\text { June } 30\end{array}$ & $\begin{array}{l}\text { Tennessee } \\
\text { Rockwood } \\
\text { City of } \\
\text { June } 30\end{array}$ & $\begin{array}{c}\text { Tennessee } \\
\text { Sevier } \\
\text { County } \\
\text { Electric } \\
\text { System } \\
\text { June } 30\end{array}$ & $\begin{array}{c}\text { Tennessee } \\
\text { Shelbyville } \\
\text { City of } \\
\text { June } 30\end{array}$ & $\begin{array}{l}\text { Tennessee } \\
\text { Springfield } \\
\text { City of } \\
\text { June } 30\end{array}$ \\
\hline \multicolumn{7}{|l|}{ Electric Plant in Service } \\
\hline $\begin{array}{l}\text { Intangible Plant } \\
\text { Production Plant }\end{array}$ & 0 & 0 & 0 & 0 & 0 & 0 \\
\hline Steam & 0 & 0 & 0 & $\mathbf{0}$ & 0 & 0 \\
\hline 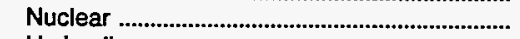 & 0 & 0 & 0 & 0 & 0 & 0 \\
\hline 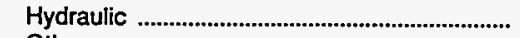 & 0 & 0 & 0 & $\mathbf{0}$ & 0 & 0 \\
\hline Other & 0 & 0 & 0 & 0 & 0 & 0 \\
\hline Total Production Plant & $\mathbf{0}$ & 0 & $\mathbf{0}$ & $\mathbf{0}$ & $\mathbf{0}$ & 0 \\
\hline Transmission Plant & 0 & 583 & 0 & 10,010 & 0 & 0 \\
\hline 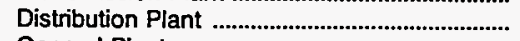 & 16,570 & 5,256 & 14.701 & 43,211 & 9,825 & 7,979 \\
\hline General Plant & 2,841 & 1.411 & 1,055 & 4,818 & 1,363 & 1,288 \\
\hline Total Electric Plant in Service .................... & 19,412 & 7,250 & 15,756 & 58,039 & 11,188 & 9,266 \\
\hline 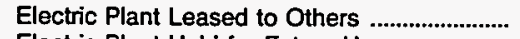 & 0 & 0 & 0 & 0 & 0 & 0 \\
\hline Electric Plant Held for Future Use ...................... & 0 & 0 & 0 & 0 & 0 & 0 \\
\hline 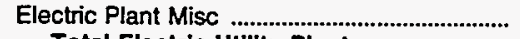 & 0 & 1,216 & 251 & 490 & 277 & 426 \\
\hline Total Electric Utillty Plant & 19,412 & 8,466 & 16,007 & 58,529 & 11,465 & 9,692 \\
\hline $\begin{array}{l}\text { Construction Work in Progress - Electric ....... } \\
\text { Accumulated Provision for Depreciation }\end{array}$ & 4,900 & 8 & 886 & 530 & 172 & 818 \\
\hline 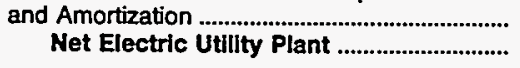 & $\begin{array}{r}8,431 \\
15,880\end{array}$ & $\begin{array}{l}2,393 \\
6,082\end{array}$ & $\begin{array}{r}5,344 \\
11,550\end{array}$ & $\begin{array}{l}15,173 \\
43,886\end{array}$ & $\begin{array}{l}4,487 \\
7,149\end{array}$ & $\begin{array}{l}3,953 \\
6,557\end{array}$ \\
\hline
\end{tabular}

Note: Totals may not equal sum of components because of independent rounding.

Source: Energy Information Administration, Form ElA-412, "Annual Report of Public Electric Utilities." 
Table 24. Electric Utility Plant by Major U.S. Publicly Owned Electric Utility Within State at End of Period, 1993 (Continued) (Thousand Dollars)

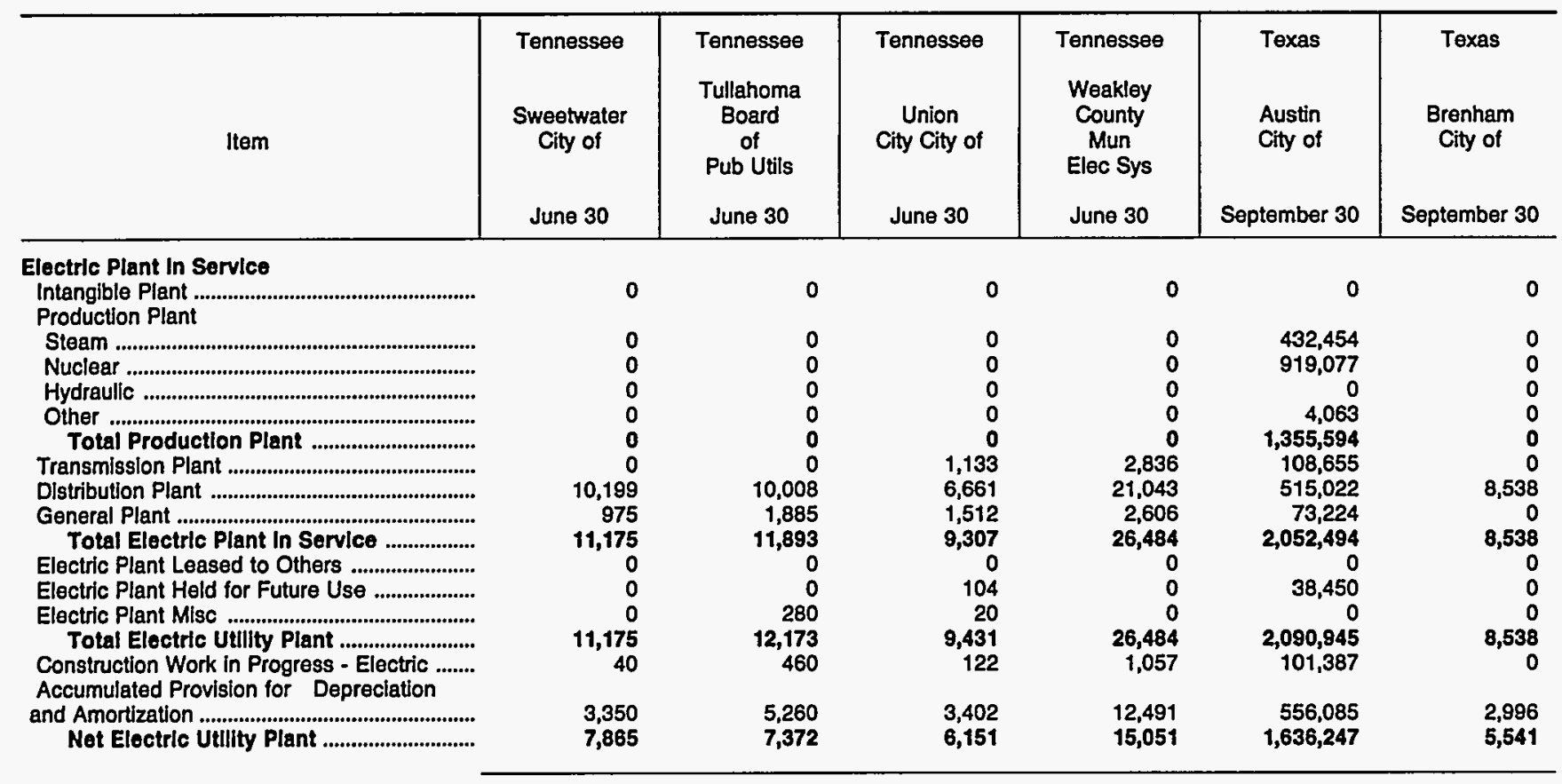

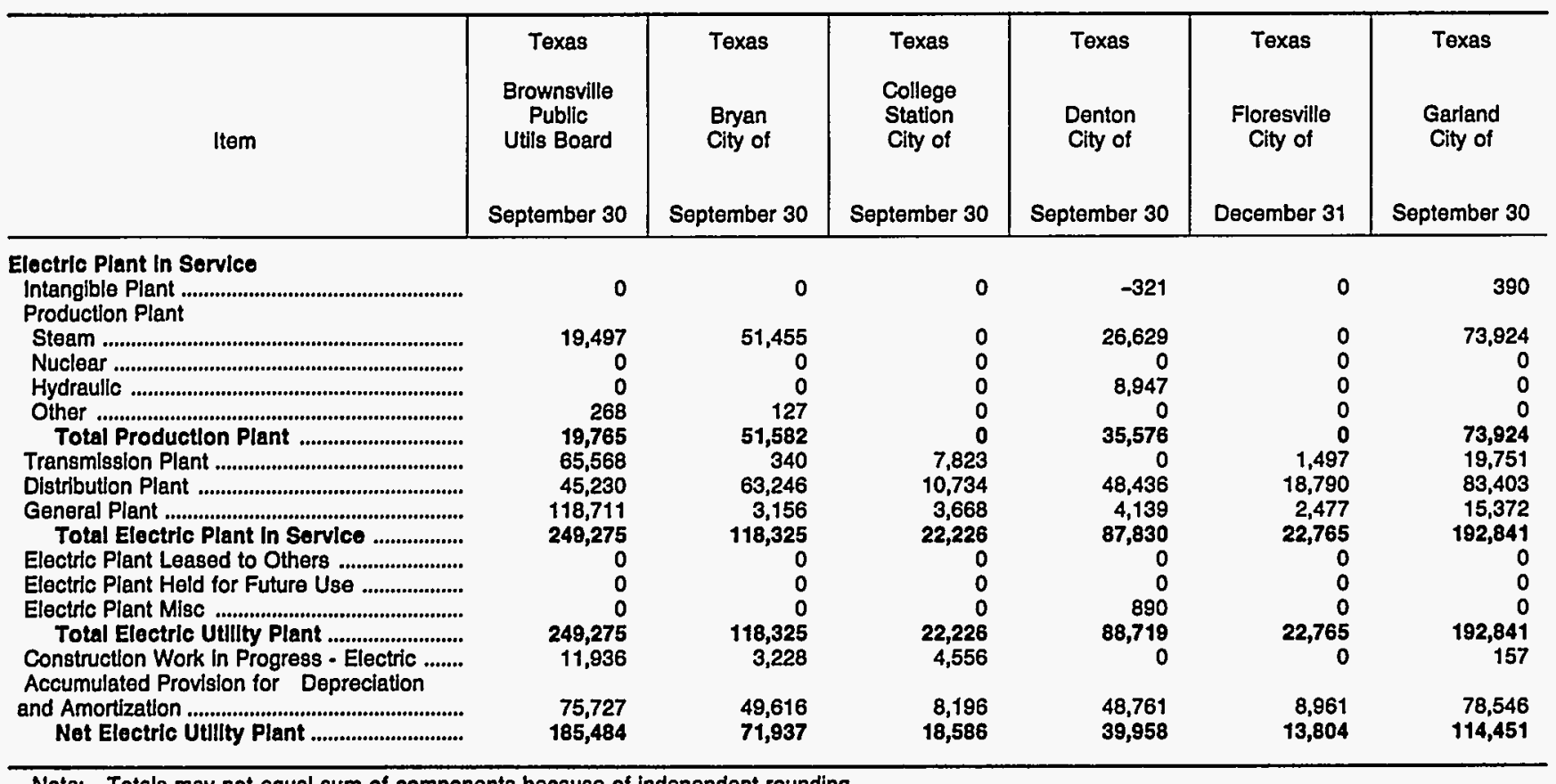

Note: Totals may not equal sum of components because of independent rounding.

Source: Energy Information Administration, Form ElA-412, "Annual Report of Public Electric Utilities." 
Table 24. Electric Utility Plant by Major U.S. Publicly Owned Electric Utility Within State at End of Period, 1993 (Continued)

(Thousand Dollars)

\begin{tabular}{|c|c|c|c|c|c|c|}
\hline Item & $\begin{array}{c}\text { Texas } \\
\text { Georgetown } \\
\text { City of } \\
\text { September } 30\end{array}$ & $\begin{array}{c}\text { Texas } \\
\text { Greenville } \\
\text { Electric } \\
\text { Util Sys } \\
\text { September } 30\end{array}$ & $\begin{array}{l}\text { Texas } \\
\text { Kerrville } \\
\text { Public } \\
\text { Utility } \\
\text { Board } \\
\text { September } 30\end{array}$ & $\begin{array}{l}\text { Texas } \\
\text { Lower } \\
\text { Colorado } \\
\text { River } \\
\text { Authority } \\
\text { June } 30\end{array}$ & $\begin{array}{c}\text { Texas } \\
\text { Lubbock } \\
\text { City of } \\
\text { September } 30\end{array}$ & $\begin{array}{c}\text { New Braunfels } \\
\text { City of } \\
\text { July } 31\end{array}$ \\
\hline \multicolumn{7}{|l|}{ Electric Plant In Service } \\
\hline 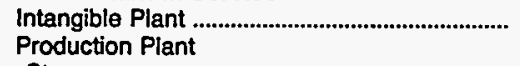 & 0 & 0 & 217 & 366 & 0 & 0 \\
\hline Steam & 0 & 20,200 & 0 & 877,666 & 123,911 & 0 \\
\hline 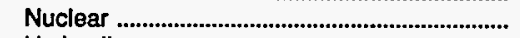 & 0 & 0 & 0 & 0 & 0 & 0 \\
\hline 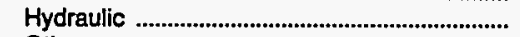 & 0 & 0 & 0 & 70,793 & 0 & 14,752 \\
\hline Other & 0 & 3,353 & 0 & 0 & 0 & 0 \\
\hline Total Production Plant ............................... & 0 & 23,553 & $\mathbf{0}$ & 948,459 & 123,911 & 14,752 \\
\hline 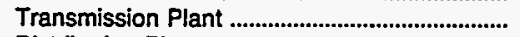 & 0 & 0 & 0 & 249,695 & 0 & 9,755 \\
\hline 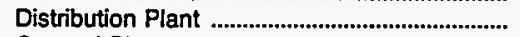 & 0 & 20,235 & 22,868 & 3,660 & 0 & 22,169 \\
\hline 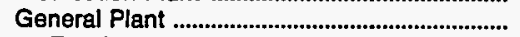 & 4,828 & 2,610 & 4,430 & 109,522 & 0 & 5,287 \\
\hline Total Electric Plant in Servlce & 4,828 & 46,398 & 27,515 & $1,311,703$ & 123,911 & 51,962 \\
\hline Electric Plant Leased to Others ............................ & 0 & 0 & 0 & 1 & 0 & 0 \\
\hline Electric Plant Held for Future Use ..................... & 0 & 0 & 0 & 0 & 0 & 0 \\
\hline 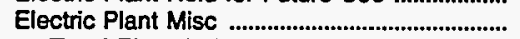 & 0 & 0 & -665 & 63,882 & 0 & 0 \\
\hline Total Electric Utllity Plant ........................... & 4,828 & 46,398 & 26,850 & $1,375,585$ & 123,911 & 51,962 \\
\hline $\begin{array}{l}\text { Construction Work in Progress - Electric ........ } \\
\text { Accumulated Provision for Depreciation }\end{array}$ & 171 & 3,000 & 735 & 136,985 & 6,164 & 267 \\
\hline 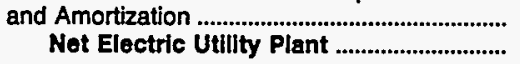 & $\begin{array}{l}2,012 \\
2,987\end{array}$ & $\begin{array}{l}27,700 \\
21,698\end{array}$ & $\begin{array}{r}8,340 \\
19,244\end{array}$ & $\begin{array}{r}386,191 \\
1,126,379\end{array}$ & $\begin{array}{l}44,100 \\
85,975\end{array}$ & $\begin{array}{l}19,328 \\
32,902\end{array}$ \\
\hline
\end{tabular}

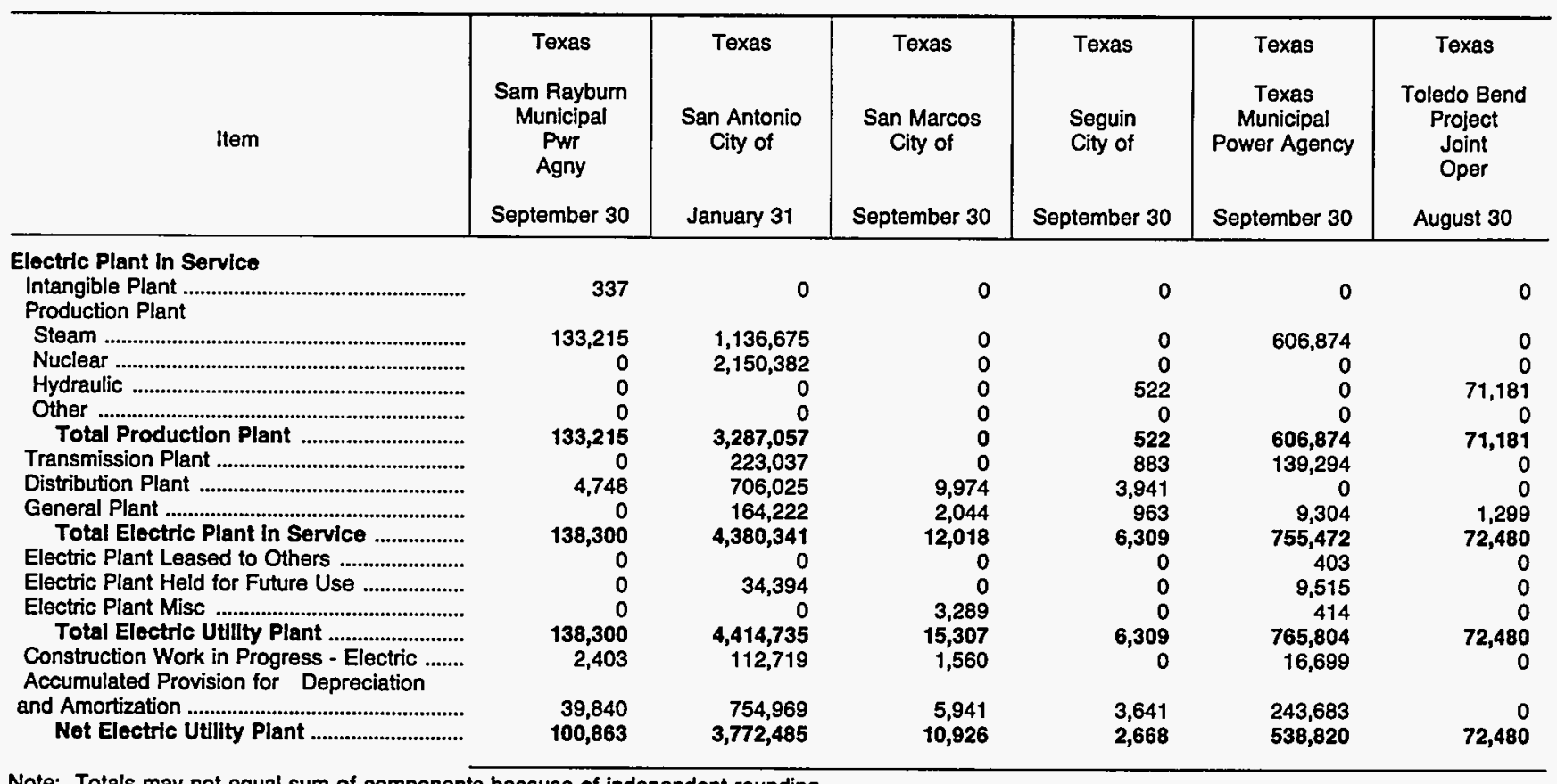

Note: Totals may not equal sum of components because of independent rounding.

Source: Energy Information Administration, Form ElA-412, "Annual Report of Public Electric Utilities." 
Table 24. Electric Utility Plant by Major U.S. Publicly Owned Electric Utility Within State at End of Period, 1993 (Continued) (Thousand Dollars)

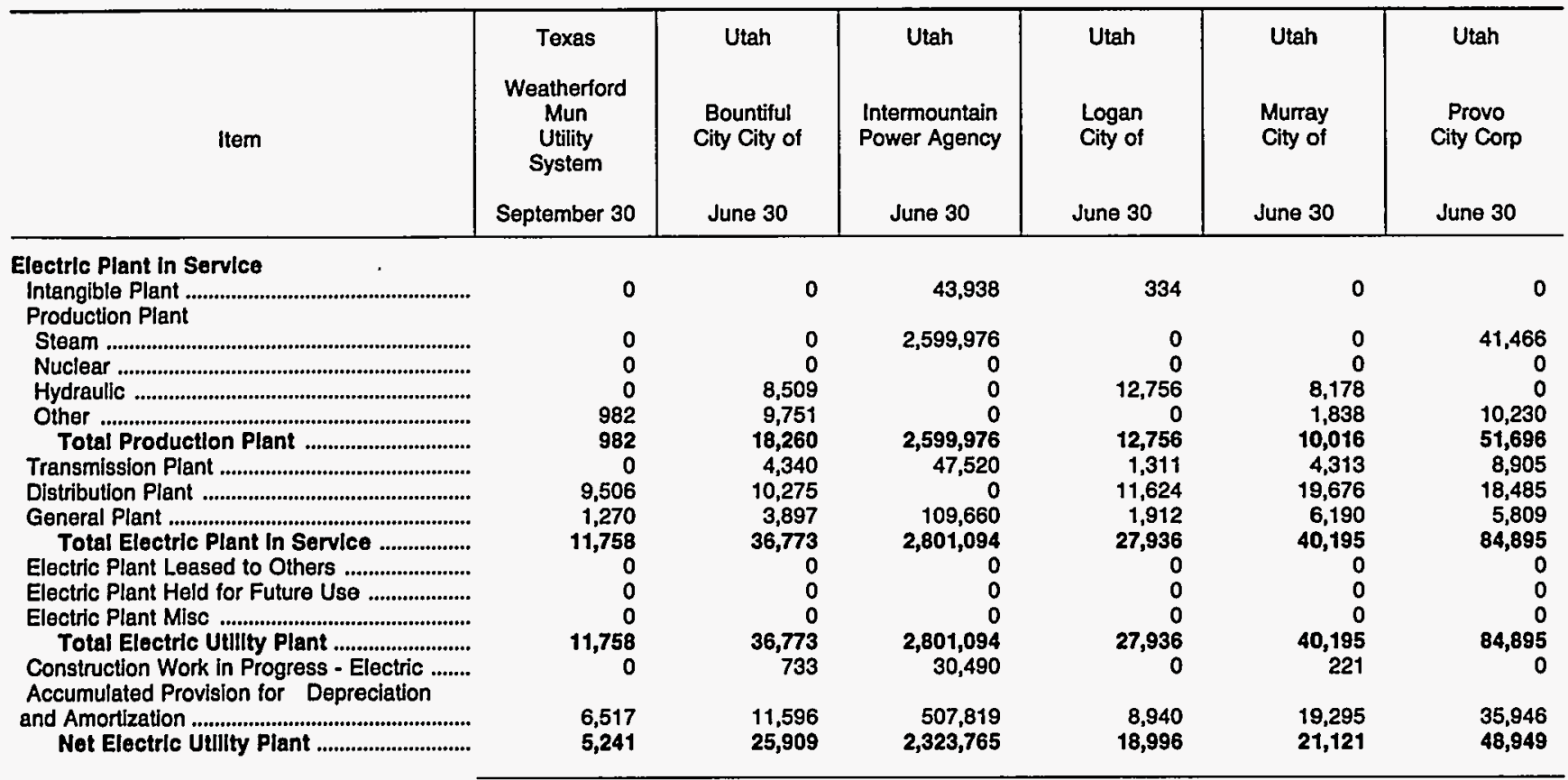

\begin{tabular}{|c|c|c|c|c|c|c|}
\hline Item & $\begin{array}{c}\text { Utah } \\
\text { St George } \\
\text { City of } \\
\text { June } 30\end{array}$ & $\begin{array}{c}\text { Utah } \\
\text { Utah } \\
\text { Associated } \\
\text { Mun } \\
\text { Power Sys } \\
\text { March } 31\end{array}$ & $\begin{array}{c}\text { Utah } \\
\text { Utah } \\
\text { Municipal } \\
\text { Power Agency } \\
\text { June } 30\end{array}$ & $\begin{array}{c}\text { Vermont } \\
\text { Burlington } \\
\text { City of } \\
\text { December } 31\end{array}$ & $\begin{array}{l}\text { Vermont } \\
\text { Vermont } \\
\text { Public } \\
\text { Pwr } \\
\text { Supply Auth } \\
\text { December } 31\end{array}$ & $\begin{array}{l}\text { Virginia } \\
\text { Bedford } \\
\text { City of } \\
\text { June } 30\end{array}$ \\
\hline $\begin{array}{l}\text { Electric Plant In Service } \\
\text { Intangible Plant ................................................... } \\
\text { Production Plant }\end{array}$ & 0 & 0 & 0 & 484 & 0 & 164 \\
\hline 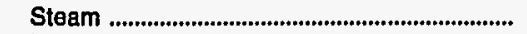 & 0 & 44,740 & 25,739 & 39,477 & 16,818 & $\mathbf{0}$ \\
\hline 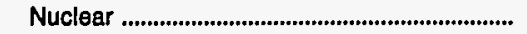 & 0 & 0 & 0 & 0 & 0 & 0 \\
\hline 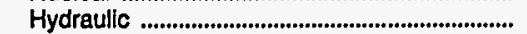 & 0 & 0 & 0 & 0 & 0 & 11,093 \\
\hline Other & 7,068 & 0 & 10 & 3,474 & 0 & 0 \\
\hline Total Production Plant ................................ & 7,068 & 44,740 & 25,749 & 42,951 & 16,818 & 11,093 \\
\hline 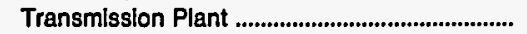 & 8,606 & 31,888 & 8,047 & 3,673 & 2,953 & 2,196 \\
\hline 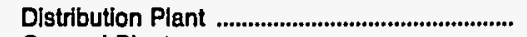 & 8,315 & 0 & 0 & 19,770 & 0 & 3,458 \\
\hline General Plant ........................................................... & 2,183 & 681 & 0 & 3,630 & 472 & 527 \\
\hline Total Electric Plant In Servlce .................... & 26,172 & 77,310 & 33,796 & 70,508 & 20,243 & 17,437 \\
\hline Electric Plant Leased to Others ............................... & 0 & 0 & 0 & 0 & 0 & 0 \\
\hline Electric Plant Held for Future Use ......................... & 0 & 0 & 0 & 89 & 0 & 0 \\
\hline Electric Plant Mlsc .............................................. & 0 & 0 & 0 & & 0 & \\
\hline 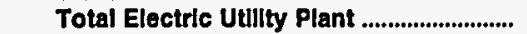 & 26,172 & 77,310 & 33,796 & 70,598 & 20,243 & 17,437 \\
\hline $\begin{array}{l}\text { Construction Work in Progress - Electric ........ } \\
\text { Accumulated Provision for Depreciation }\end{array}$ & & 1,598 & & 1,377 & 0 & \\
\hline and Amortization & 8,190 & 17,458 & $\begin{array}{r}6,381 \\
07415\end{array}$ & 16,355 & $\begin{array}{r}7,876 \\
1,867\end{array}$ & 4,968 \\
\hline 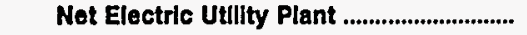 & 17,982 & 61,450 & 27,415 & 55,619 & 12,367 & 12,469 \\
\hline
\end{tabular}

Note: Totals may not equal sum of components because of independent rounding.

Source: Energy Information Administration, Form EIA-412, "Annual Report of Public Electric Utilities." 
Table 24. Electric Utility Plant by Major U.S. Publicly Owned Electric Utility Within State at End of Period, 1993 (Continued)

(Thousand Dollars)

\begin{tabular}{|c|c|c|c|c|c|c|}
\hline Item & $\begin{array}{l}\text { Virginia } \\
\text { Bristol } \\
\text { Utilities } \\
\text { Board } \\
\text { June } 30\end{array}$ & $\begin{array}{l}\text { Virginia } \\
\text { Danville } \\
\text { City of } \\
\text { June } 30\end{array}$ & $\begin{array}{c}\text { Harrisonburg } \\
\text { City of } \\
\text { June } 30\end{array}$ & $\begin{array}{c}\text { Manassas } \\
\text { City of } \\
\text { June } 30\end{array}$ & $\begin{array}{c}\text { Martinsville } \\
\text { City of } \\
\text { June } 30\end{array}$ & $\begin{array}{l}\text { Virginia } \\
\text { Radford } \\
\text { City of } \\
\text { June } 30\end{array}$ \\
\hline \multicolumn{7}{|l|}{ Electric Plant in Service } \\
\hline $\begin{array}{l}\text { Intangible Plant } \\
\text { Production Plant }\end{array}$ & 0 & 908 & 0 & 0 & 0 & $\mathbf{0}$ \\
\hline Steam & 0 & 0 & 286 & 0 & 0 & 0 \\
\hline Nuclear & 0 & 0 & 0 & 0 & 0 & 0 \\
\hline 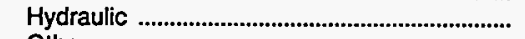 & 0 & 3,243 & 0 & 0 & 262 & 455 \\
\hline Other & 0 & 0 & 2,913 & 4,448 & 0 & 0 \\
\hline Total Production Plant .................................. & 0 & 3,243 & 3,199 & 4,448 & 262 & 455 \\
\hline 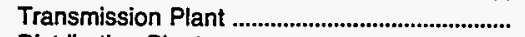 & 0 & 1,909 & 4,648 & 15 & 0 & 3,835 \\
\hline 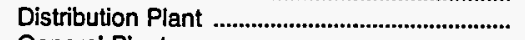 & 18,489 & 44,658 & 26,431 & 32,096 & 15,550 & 8,783 \\
\hline 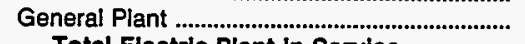 & 2,933 & 2,208 & 3,297 & 0 & 741 & 0 \\
\hline Total Electric Plant In Service ................... & 21,422 & 52,926 & 37,575 & 36,560 & 16,553 & 13,073 \\
\hline Electric Plant Leased to Others .......................... & 0 & 0 & 0 & 0 & 0 & 0 \\
\hline Electric Plant Held for Future Use .................... & 0 & 0 & 0 & 0 & 0 & 0 \\
\hline 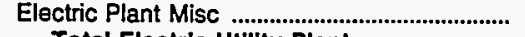 & 0 & 0 & 3,767 & 0 & 0 & 0 \\
\hline Total Electric UtIlity Plant ........................... & 21,422 & 52,926 & 41,342 & 36,560 & 16,553 & 13,073 \\
\hline $\begin{array}{l}\text { Construction Work in Progress - Electric ........ } \\
\text { Accumulated Provision for Depreciation }\end{array}$ & 1,053 & 1,352 & 1,076 & 182 & 0 & 0 \\
\hline 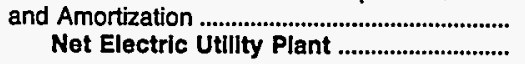 & $\begin{array}{l}10,306 \\
12,169\end{array}$ & $\begin{array}{l}22,542 \\
31,736\end{array}$ & $\begin{array}{l}13,564 \\
28,854\end{array}$ & $\begin{array}{l}11,109 \\
25,633\end{array}$ & $\begin{array}{r}6,042 \\
10,511\end{array}$ & $\begin{array}{l}7,065 \\
6,007\end{array}$ \\
\hline
\end{tabular}

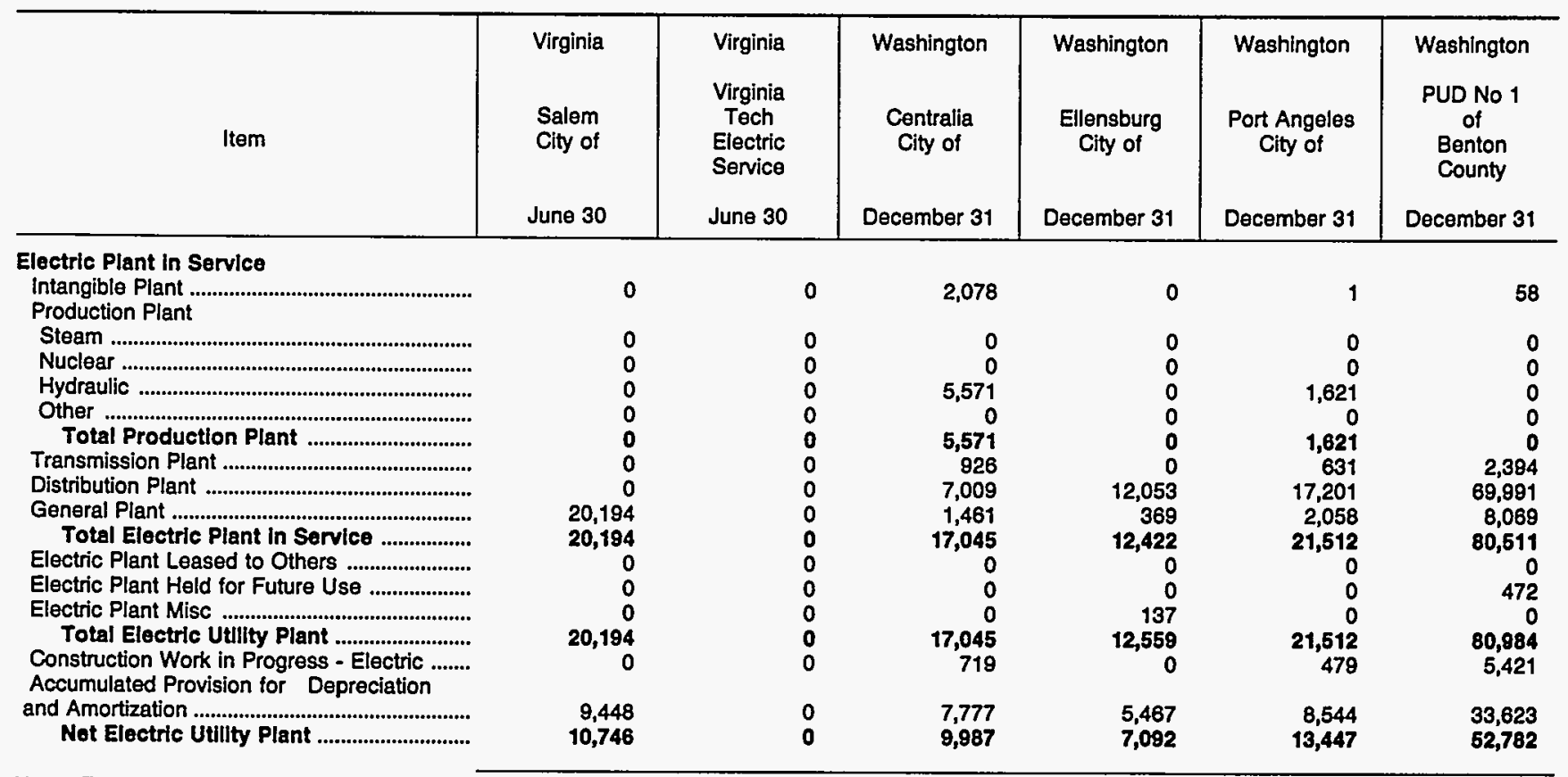

Note: Totals may not equal sum of components because of independent rounding.

Source: Energy Information Administration, Form ElA-412, "Annual Report of Public Electric Utilities." 
Table 24. Electric Utility Plant by Major U.S. Publicly Owned Electric Utility Within State at End of Period, 1993 (Continued) (Thousand Dollars)

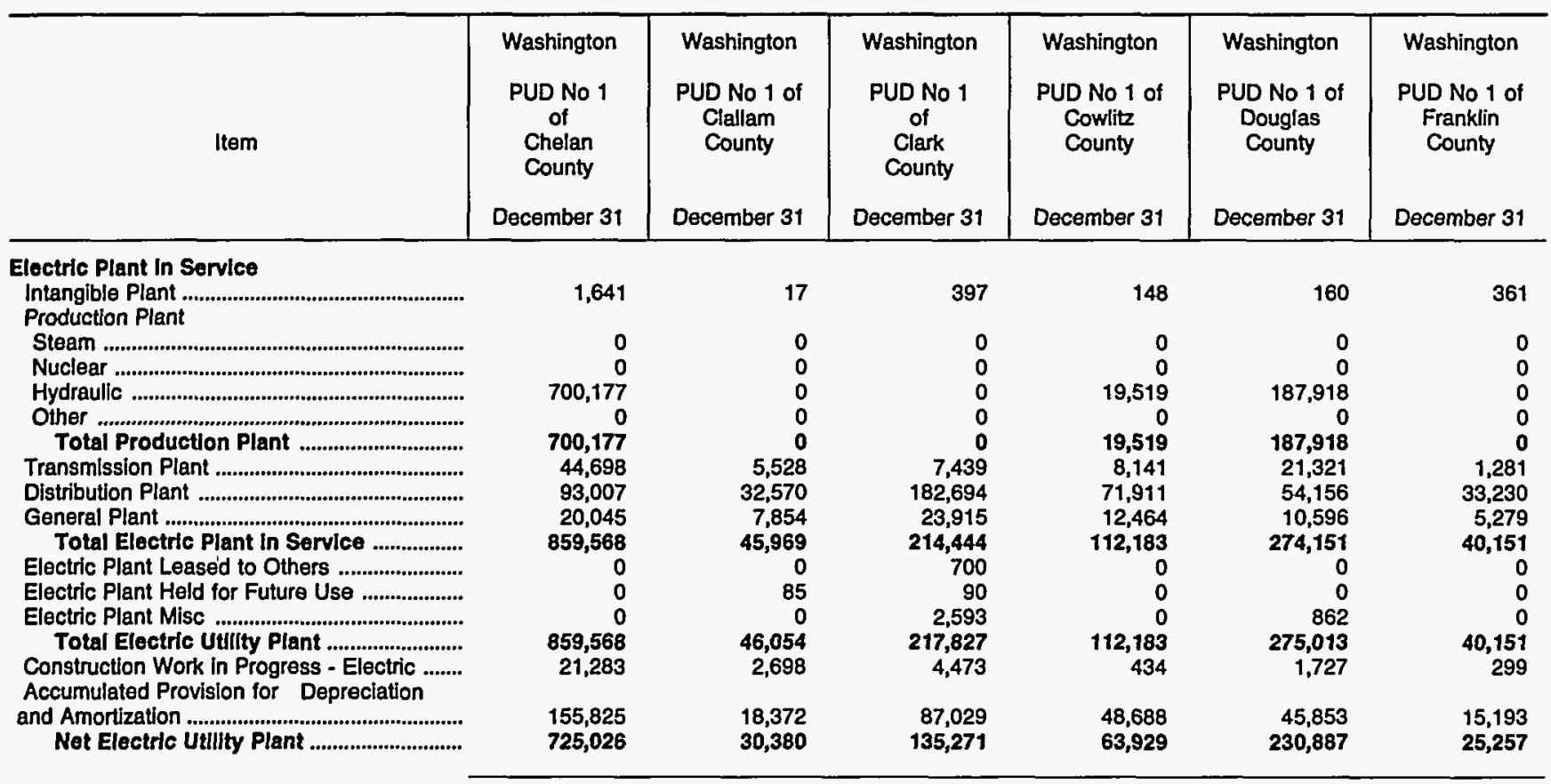

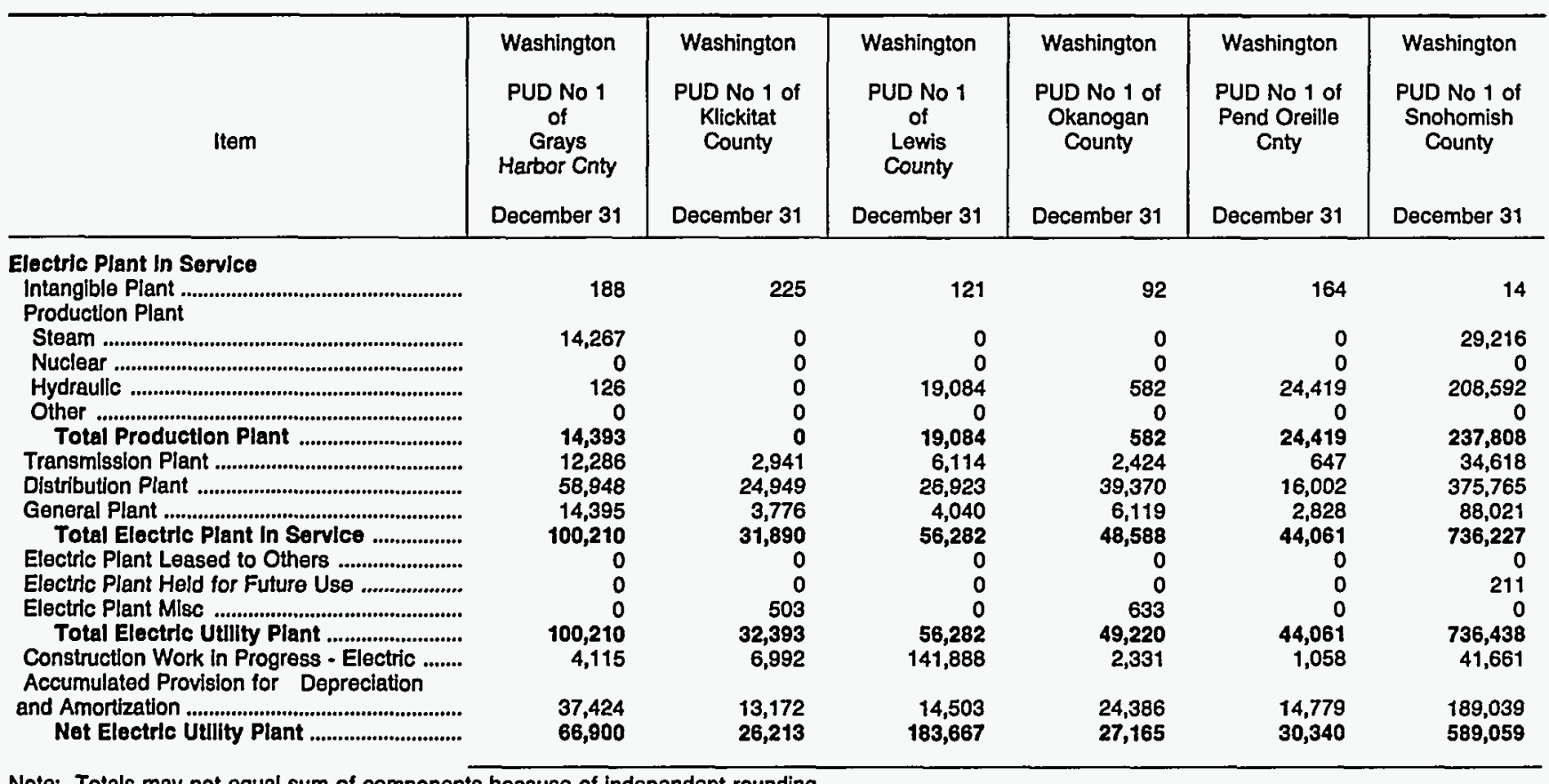

Note: Totals may not equal sum of components because of independent rounding.

Source: Energy Information Administration, Form EIA-412, "Annual Report of Public Electric Utilities." 
Table 24. Electric Utility Plant by Major U.S. Publicly Owned Electric Utility Within State at End of Period, 1993 (Continued)

(Thousand Doliars)

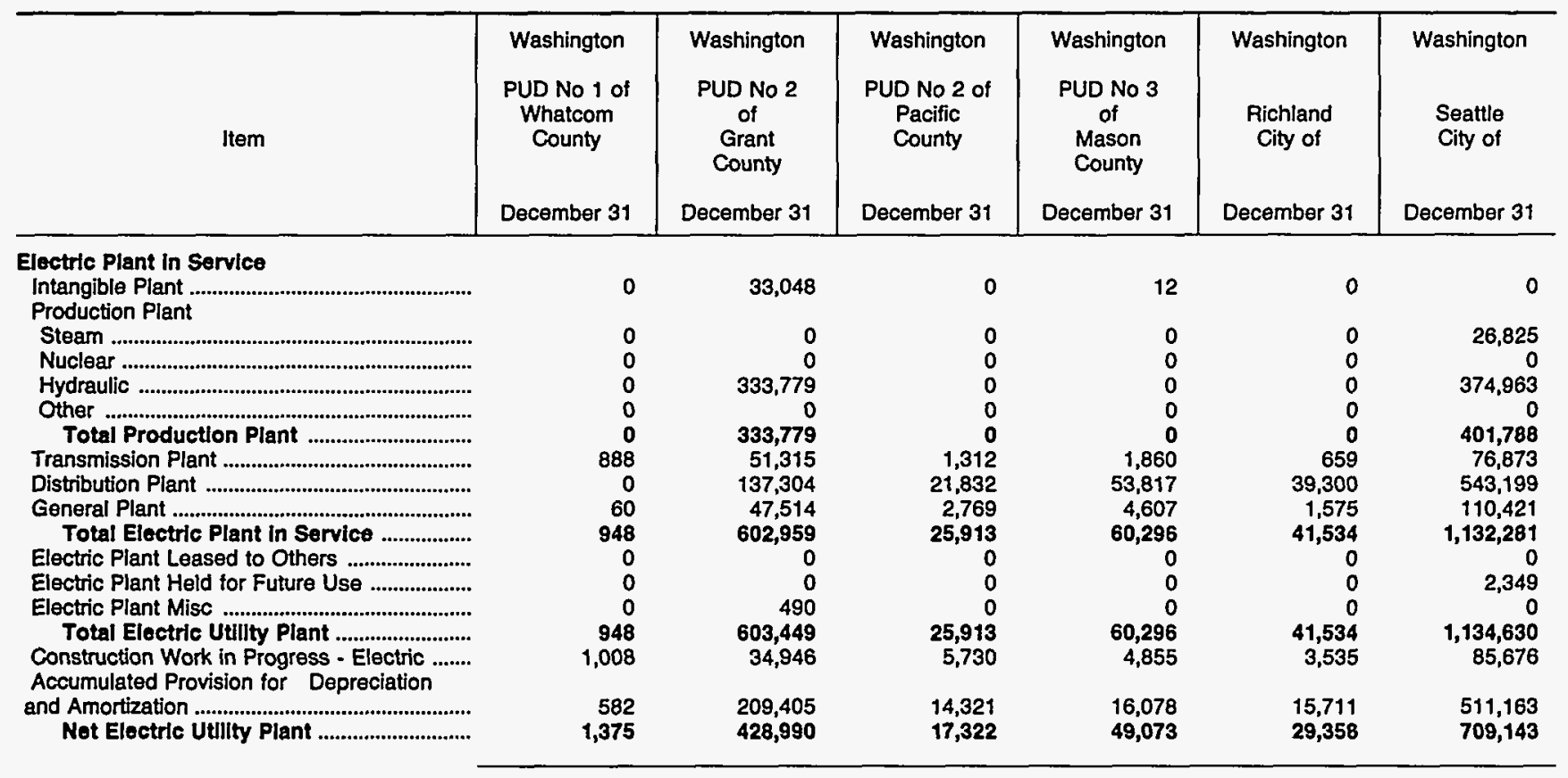

\begin{tabular}{|c|c|c|c|c|c|c|}
\hline Item & $\begin{array}{c}\text { Washington } \\
\text { Tacoma } \\
\text { City of } \\
\text { December } 31\end{array}$ & $\begin{array}{c}\text { Washington } \\
\text { Vera } \\
\text { Irrigation } \\
\text { District \#5 } \\
\text { December } 31\end{array}$ & $\begin{array}{l}\text { Washington } \\
\text { Washington } \\
\text { Pub } \\
\text { Pwr } \\
\text { Supply Sys } \\
\text { June } 30\end{array}$ & $\begin{array}{l}\text { Wisconsin } \\
\text { Badger Power } \\
\text { Marketing } \\
\text { Auth }\end{array}$ & $\begin{array}{c}\text { Wisconsin } \\
\text { Jefferson } \\
\text { City of } \\
\text { December } 31\end{array}$ & $\begin{array}{c}\text { Wisconsin } \\
\text { Kaukauna } \\
\text { City of } \\
\text { December } 31\end{array}$ \\
\hline $\begin{array}{l}\text { Electric Plant in Service } \\
\text { Intangible Plant } \\
\text { Production Plant }\end{array}$ & 2,549 & 0 & 0 & 11 & 0 & 0 \\
\hline Steam & 84,247 & 0 & 0 & 0 & 0 & 0 \\
\hline 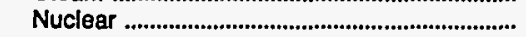 & 0 & 0 & $3,157,817$ & 0 & 0 & 0 \\
\hline 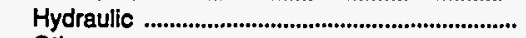 & 254,402 & 0 & 12,074 & 0 & 0 & 16,097 \\
\hline Other & 0 & 0 & 0 & 0 & 0 & 2,446 \\
\hline & 338,649 & 0 & $3,169,891$ & 0 & 0 & 18,543 \\
\hline $\begin{array}{l}\text { Transmission Plant } \\
\text { Distribution Plant }\end{array}$ & 68,793 & $\begin{array}{r}0 \\
0707\end{array}$ & $\begin{array}{r}5,202 \\
0\end{array}$ & 5,222 & 0 & 3,175 \\
\hline 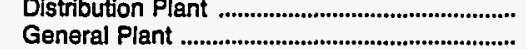 & $\begin{array}{r}180,087 \\
35,702\end{array}$ & $\begin{array}{l}9,767 \\
2,540\end{array}$ & $\begin{array}{r}0 \\
121,604\end{array}$ & $\begin{array}{r}0 \\
112\end{array}$ & $\begin{array}{r}6,517 \\
642\end{array}$ & $\begin{array}{r}14,299 \\
2,923\end{array}$ \\
\hline 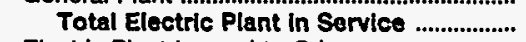 & 625,780 & 12,307 & $3,298,698$ & 5,345 & 7,159 & 38,941 \\
\hline $\begin{array}{l}\text { Electric Plant Leased to Others ........................ } \\
\text { Electric Plant Held for Future Use .................. }\end{array}$ & $\begin{array}{r}0 \\
271\end{array}$ & $\begin{array}{l}0 \\
0\end{array}$ & $\begin{array}{l}0 \\
0\end{array}$ & $\begin{array}{l}0 \\
0\end{array}$ & $\begin{array}{l}0 \\
0\end{array}$ & $\begin{array}{l}0 \\
0\end{array}$ \\
\hline 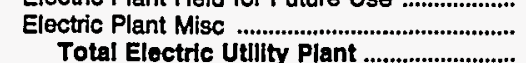 & $\begin{array}{r}0 \\
626,051\end{array}$ & $\begin{array}{r}0 \\
12,307\end{array}$ & $\begin{array}{r}0 \\
3,298,698\end{array}$ & $\begin{array}{r}568 \\
5,914\end{array}$ & $\begin{array}{r}0 \\
7,159\end{array}$ & $\begin{array}{r}0 \\
38,941\end{array}$ \\
\hline $\begin{array}{l}\text { Construction Work in Progress - Electric ........ } \\
\text { Accumulated Provision for Depreciation }\end{array}$ & 64,491 & 162 & 106,947 & 0 & 216 & 833 \\
\hline and Amortization & $\begin{array}{l}228,505 \\
462,036\end{array}$ & $\begin{array}{l}3,922 \\
8,547\end{array}$ & $\begin{array}{r}913,515 \\
2,490,130\end{array}$ & $\begin{array}{l}1,060 \\
4,855\end{array}$ & $\begin{array}{l}2,053 \\
5,322\end{array}$ & $\begin{array}{l}15,379 \\
24,395\end{array}$ \\
\hline
\end{tabular}

Note: Totals may not equal sum of components because of independent rounding.

Source: Energy Information Administration, Form EIA-412, "Annual Report of Public Electric Utilities." 
Table 24. Electric Utility Plant by Major U.S. Publicly Owned Electric Utility Within State at End of Period, 1993 (Continued) (Thousand Dollars)

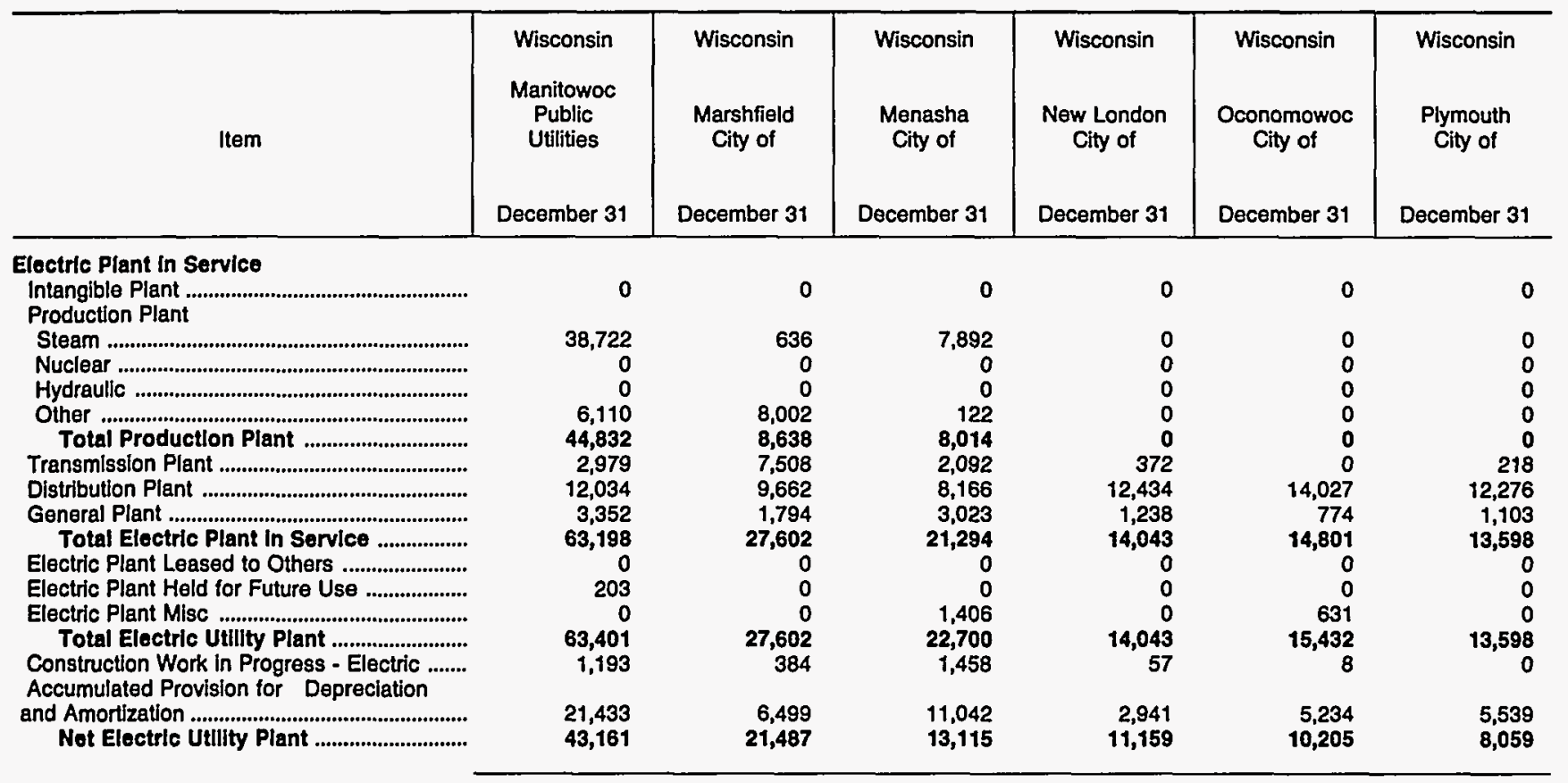

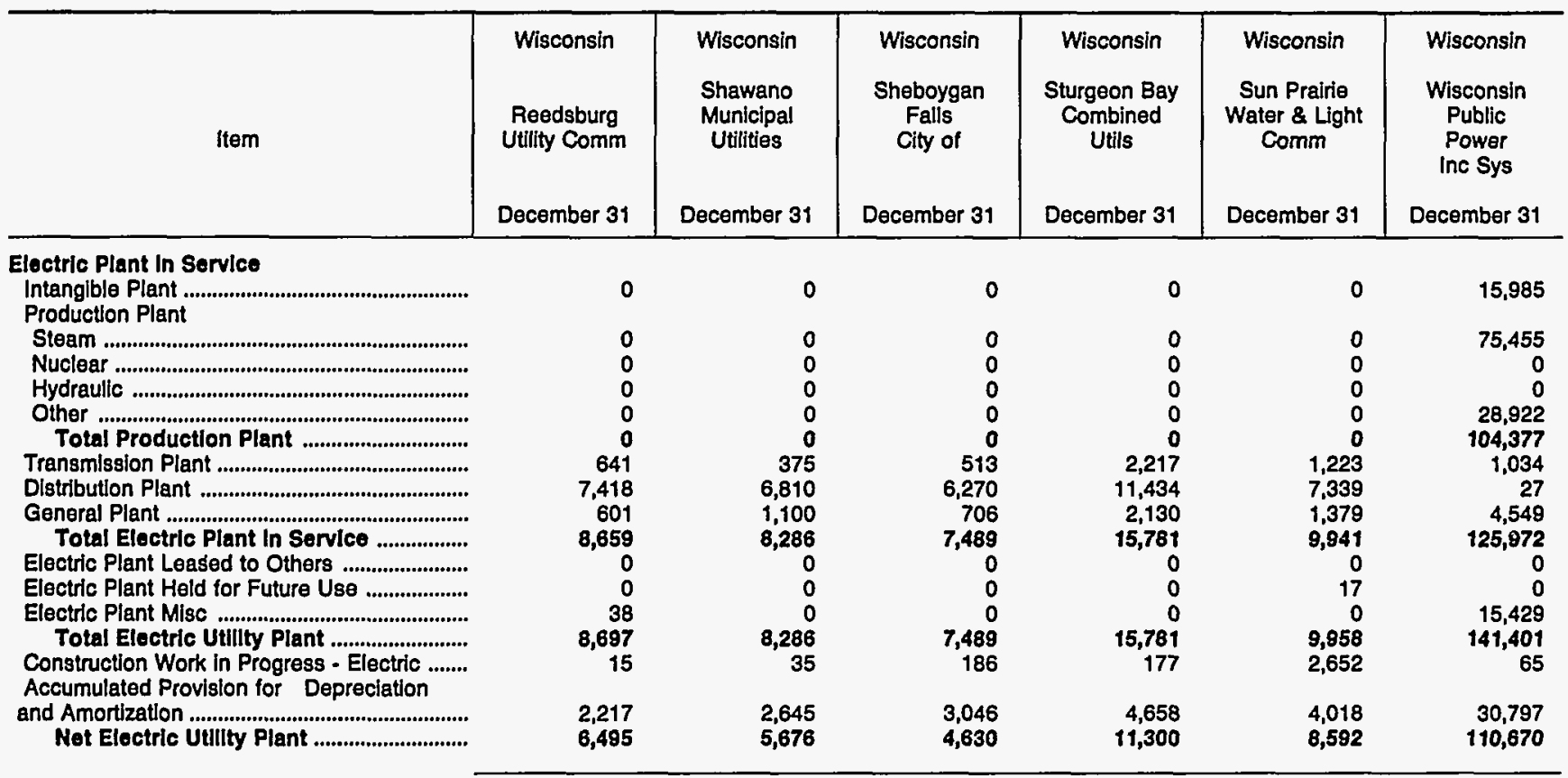

Note: Totals may not equal sum of components because of independent rounding.

Source: Energy Information Administration, Form EIA-412, "Annual Report of Public Electric Utilities." 
Table 24. Electric Utility Plant by Major U.S. Publicly Owned Electric Utility Within State at End of Period, 1993 (Continued) (Thousand Dollars)

\begin{tabular}{c|c|c|c|c}
\hline & Wisconsin & Wyoming & Wyoming \\
Wisconsin & & Wyoming \\
Rapids $W W$ & Gillette & $\begin{array}{c}\text { Municipal } \\
\& L\end{array}$ & City of & Power Agency \\
Comm & & \\
& December 31 & June 30 & December 31 & \\
\hline
\end{tabular}

\section{Electric Plant in Service}

Intangible Plant

Production Plant

Steam

Nuclear .

Hydraulic

$$
\text { Other }
$$

Total Production Plant

Transmission Plan

Distribution Plant

General Plant

Plant in Service

Electric Plant Leased to Others

Electric Plant Held for Future Use

Electric Plant Misc

Total Electric Utillty Plant

Construction Work in Progress - Electric.

Accumulated Provision for Depreciation

and Amortization

Net Electric Utllity Plant ...........................

$\begin{array}{rrr}0 & 0 & 882 \\ 0 & 0 & 15,495 \\ 0 & 0 & 0 \\ 0 & 0 & 0 \\ 0 & 0 & 0 \\ 0 & 0 & 15,495 \\ 0 & 1,155 & 5,220 \\ 15,039 & 16,885 & 0 \\ 1,435 & 311 & 824 \\ 16,474 & 18,352 & 22,421 \\ 0 & 0 & 0 \\ 1 & 0 & 0 \\ 0 & 0 & 2 \\ 16,475 & 18,352 & 22,423 \\ 203 & 0 & 1 \\ & & \\ 4,745 & 8,067 & 6,687 \\ 11,933 & 10,285 & 15,737\end{array}$

Note: Totals may not equal sum of components because of independent rounding.

Source: Energy Information Administration, Form ElA-412, "Annual Report of Public Electric Utilities." 
Table 25. Number of Consumers, Sales, and Operating Revenue by Major U.S. Publicly Owned Electric Utility Within State, 1993

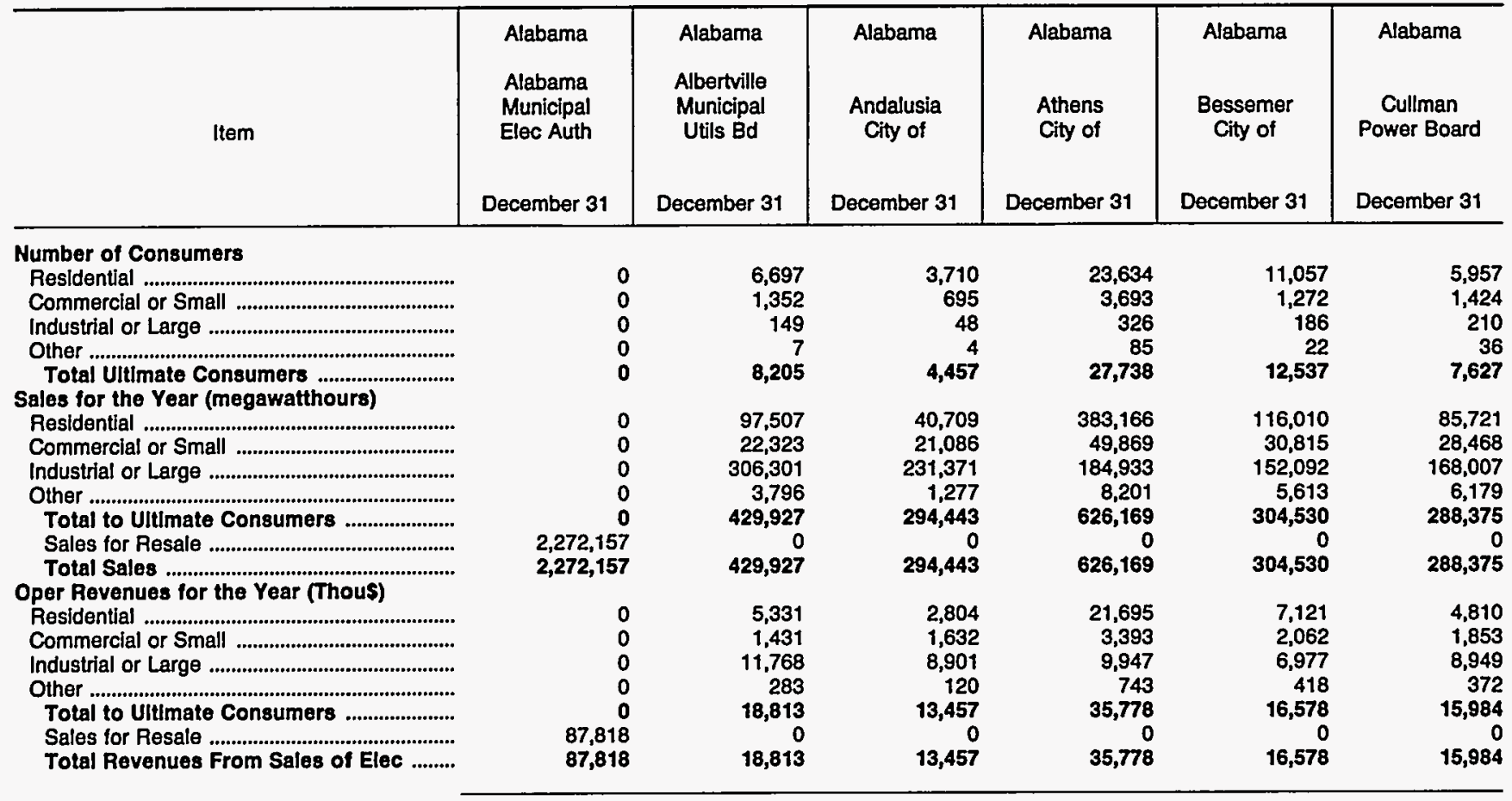

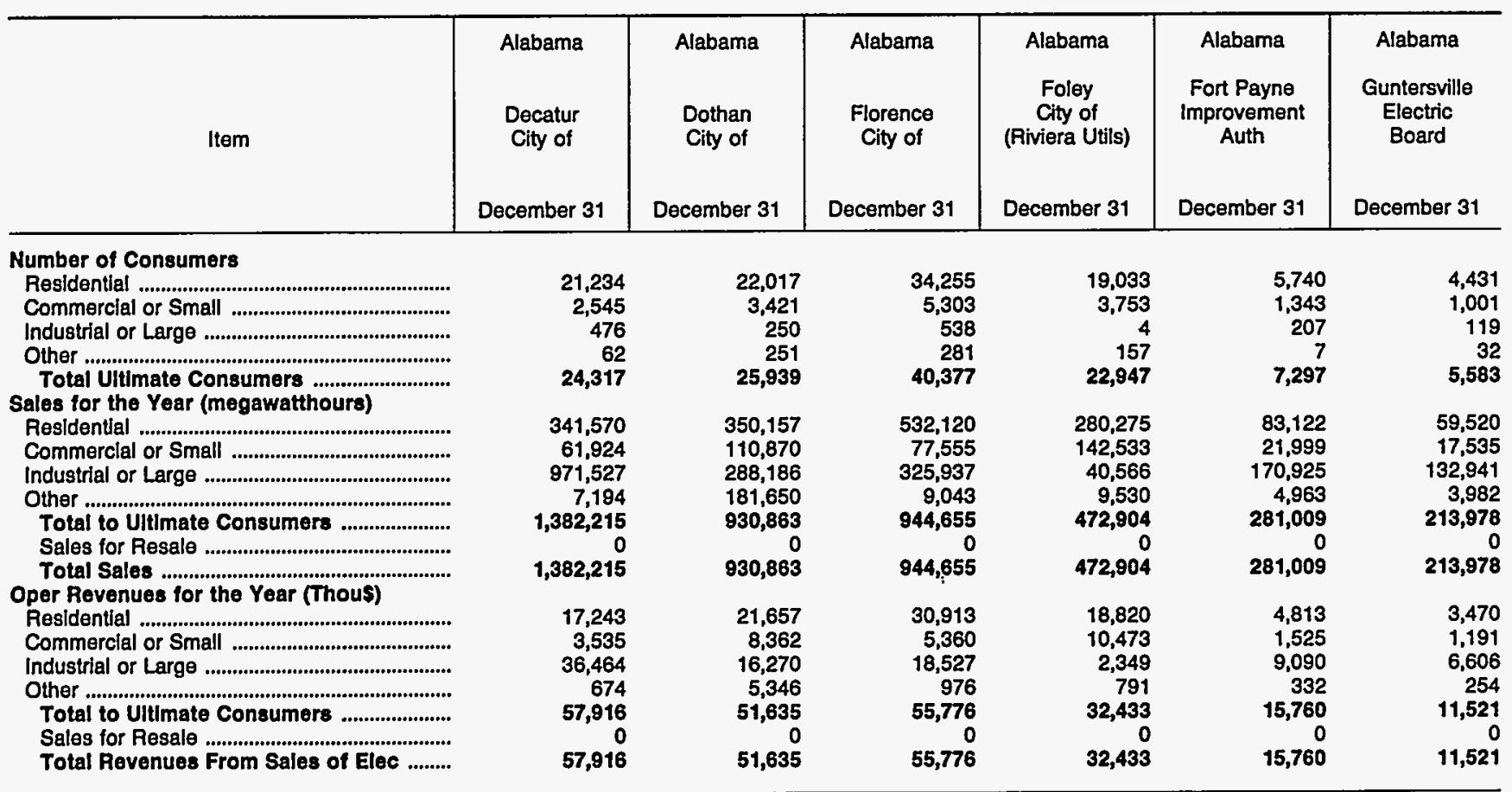

Note: Totals may not equal sum of components because of independent rounding.

Source: Energy Information Administration, Form ElA-861, "Annual Electric Utility Report." Data are submitted on a calendar year. 
Table 25. Number of Consumers, Sales, and Operating Revenue by Major U.S. Publicly Owned Electric Utllity Within State, 1993 (Continued)

\begin{tabular}{|c|c|c|c|c|c|c|}
\hline Item & $\begin{array}{c}\text { Alabama } \\
\text { Huntsville } \\
\text { City of } \\
\text { December } 31\end{array}$ & $\begin{array}{c}\text { Alabama } \\
\text { Muscle } \\
\text { Shoals } \\
\text { City of } \\
\text { December } 31\end{array}$ & $\begin{array}{l}\text { Alabama } \\
\text { Opelika } \\
\text { City of } \\
\text { December } 31\end{array}$ & $\begin{array}{c}\text { Scottsboro } \\
\text { City of } \\
\text { December } 31\end{array}$ & $\begin{array}{c}\text { Sheffield } \\
\text { Utilities } \\
\text { December } 31\end{array}$ & $\begin{array}{c}\text { Alabama } \\
\text { Sylacauga } \\
\text { Utilities } \\
\text { Board } \\
\text { December } 31\end{array}$ \\
\hline \multicolumn{7}{|l|}{ Number of Consumers } \\
\hline 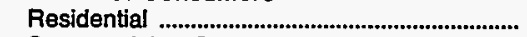 & 100,929 & 4,205 & 8,672 & 6,065 & 14,337 & 5,116 \\
\hline Commercial or Small ............................................ & 12,476 & 922 & 1,234 & 1,229 & 2,271 & 771 \\
\hline Industrial or Large & 1,877 & 147 & 4 & 159 & 241 & 13 \\
\hline Other & 69 & 31 & 24 & 6 & 171 & \\
\hline $\begin{array}{l}\text { Total Ultimate Consumers .......................... } \\
\text { Sales for the Year (megawatthours) }\end{array}$ & 115,351 & 5,305 & 9,934 & 7,459 & 17,020 & 5,901 \\
\hline 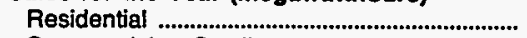 & $1,625,061$ & 66,893 & 96,000 & 90,802 & 208,473 & 59,716 \\
\hline Commercial or Small & 252,090 & 20,150 & 110,000 & 21,823 & 34,151 & 48,568 \\
\hline Industrial or Large & $1,643,330$ & 90,394 & 91,000 & 203,947 & 130,227 & 55,204 \\
\hline Other & 24,119 & 3,521 & 5,000 & 3,688 & 5,141 & 2,664 \\
\hline Total to UItimate Consumers ....................... & $3,544,600$ & 180,958 & 302,000 & 320,260 & 377,992 & 166,152 \\
\hline 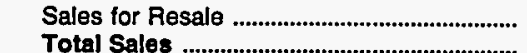 & 0 & 0 & 0 & & 0 & \\
\hline \multicolumn{7}{|l|}{ Oper Revenues for the Year (Thous) } \\
\hline 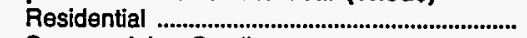 & 85,904 & 3,868 & 5,835 & 5,252 & 12,686 & 4,067 \\
\hline 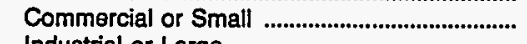 & 15,214 & 1,350 & 7,470 & 1,484 & 2,479 & 3,813 \\
\hline Industrial or Large & 78,541 & 5,104 & 4,095 & 8,892 & 7,739 & 3,035 \\
\hline \multirow{4}{*}{ 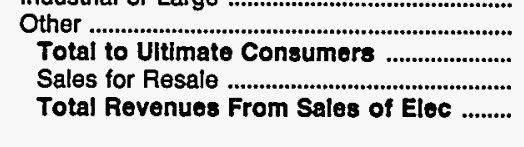 } & 2,146 & 297 & 323 & 293 & 414 & 153 \\
\hline & 181,805 & 10,619 & 17,723 & 15,921 & 23,318 & 11,068 \\
\hline & $\begin{array}{r}0 \\
181,805\end{array}$ & $\begin{array}{r}0 \\
10.619\end{array}$ & $\begin{array}{r}0 \\
17723\end{array}$ & $\begin{array}{r}0 \\
15921\end{array}$ & $\begin{array}{r}0 \\
03318\end{array}$ & $\begin{array}{r}0 \\
11,068\end{array}$ \\
\hline & & & & & & 11,068 \\
\hline
\end{tabular}

\begin{tabular}{|c|c|c|c|c|c|c|}
\hline Item & $\begin{array}{c}\text { Alabama } \\
\text { Troy } \\
\text { Clty of } \\
\text { December } 31\end{array}$ & $\begin{array}{c}\text { Alabama } \\
\text { Tuskegee } \\
\text { City of } \\
\text { December } 31\end{array}$ & $\begin{array}{c}\text { Alaska } \\
\text { Alaska } \\
\text { Energy } \\
\text { Authority } \\
\text { December } 31\end{array}$ & $\begin{array}{c}\text { Aleska } \\
\text { Anchorage } \\
\text { City of } \\
\text { December } 31\end{array}$ & $\begin{array}{c}\text { Alaska } \\
\text { Fairbanks } \\
\text { City of } \\
\text { December } 31\end{array}$ & $\begin{array}{c}\text { Alaska } \\
\text { Ketchikan } \\
\text { City of } \\
\text { December } 31\end{array}$ \\
\hline \multicolumn{7}{|l|}{ Number of Consumers } \\
\hline 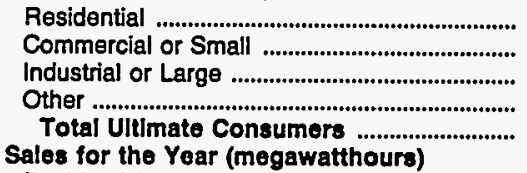 & $\begin{array}{r}5,057 \\
939 \\
101 \\
56 \\
6,153\end{array}$ & $\begin{array}{r}6,431 \\
622 \\
75 \\
0 \\
7,128\end{array}$ & $\begin{array}{l}0 \\
0 \\
0 \\
0 \\
0\end{array}$ & $\begin{array}{r}23,680 \\
5,559 \\
0 \\
275 \\
28,514\end{array}$ & $\begin{array}{r}4,473 \\
1,483 \\
0 \\
51 \\
6,007\end{array}$ & $\begin{array}{r}5,700 \\
956 \\
11 \\
2 \\
6,669\end{array}$ \\
\hline 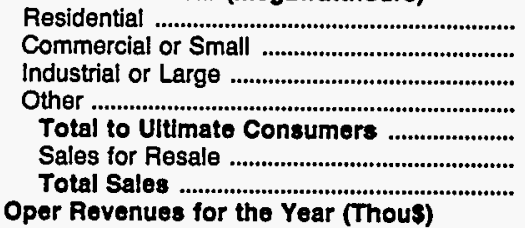 & $\begin{array}{r}73,987 \\
21,076 \\
114,676 \\
1,452 \\
211,191 \\
0 \\
211,191\end{array}$ & $\begin{array}{r}48,546 \\
12,572 \\
63,359 \\
0 \\
124,477 \\
0 \\
124,477\end{array}$ & $\begin{array}{r}0 \\
0 \\
0 \\
0 \\
0 \\
563,920 \\
563,920\end{array}$ & $\begin{array}{r}145,354 \\
648,579 \\
0 \\
19,271 \\
813,204 \\
12,627 \\
825,831\end{array}$ & $\begin{array}{r}26,396 \\
105,190 \\
0 \\
11,488 \\
143,074 \\
0 \\
143,074\end{array}$ & $\begin{array}{r}55,005 \\
55,851 \\
13,972 \\
11,443 \\
136,271 \\
0 \\
136,271\end{array}$ \\
\hline 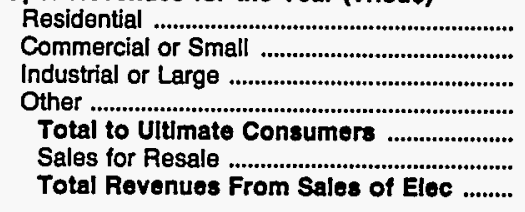 & $\begin{array}{r}4,213 \\
1,385 \\
6,770 \\
84 \\
12,452 \\
0 \\
12,452\end{array}$ & $\begin{array}{r}4,095 \\
1,028 \\
3,234 \\
0 \\
8,357 \\
0 \\
8,357\end{array}$ & $\begin{array}{r}0 \\
0 \\
0 \\
0 \\
0 \\
27,682 \\
27,682\end{array}$ & $\begin{array}{r}14,052 \\
51,384 \\
0 \\
1,660 \\
67,096 \\
392 \\
67,488\end{array}$ & $\begin{array}{r}2,558 \\
11,032 \\
0 \\
1,126 \\
14,716 \\
0 \\
14,716\end{array}$ & $\begin{array}{r}4,591 \\
4,269 \\
964 \\
421 \\
10,245 \\
0 \\
10,245\end{array}$ \\
\hline
\end{tabular}

Note: Totals may not equal sum of components because of independent rounding.

Source: Energy Information Administration, Form EIA-861, "Annual Electric Utllity Report." Data are submitted on a calendar year. 
Table 25. Number of Consumers, Sales, and Operating Revenue by Major U.S. Publicly Owned Electric Utility Within State, 1993 (Continued)

\begin{tabular}{|c|c|c|c|c|c|c|}
\hline Item & $\begin{array}{c}\text { Arizona } \\
\text { Arizona } \\
\text { Power } \\
\text { Authority } \\
\text { December } 31\end{array}$ & $\begin{array}{l}\text { Arizona } \\
\text { Electrical } \\
\text { Dist } \\
\text { No2 } \\
\text { Pinal Cnty } \\
\text { December } 31\end{array}$ & $\begin{array}{c}\text { Arizona } \\
\text { Mesa } \\
\text { City of } \\
\text { December } 31\end{array}$ & $\begin{array}{c}\text { Arizona } \\
\text { Navajo } \\
\text { Tribal } \\
\text { Utility } \\
\text { Auth } \\
\text { December } 31\end{array}$ & $\begin{array}{l}\text { Arizona } \\
\text { Salt River } \\
\text { Proj Ag } \\
\text { I \& P Dist } \\
\text { December } 31\end{array}$ & $\begin{array}{c}\text { Arizona } \\
\text { Tohono } \\
\text { OOdham } \\
\text { Utility Auth } \\
\text { December } 31\end{array}$ \\
\hline \multicolumn{7}{|l|}{ Number of Consumers } \\
\hline 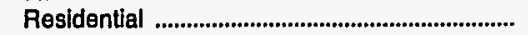 & 0 & 1,734 & 12,581 & 22,992 & 514,032 & 2,451 \\
\hline 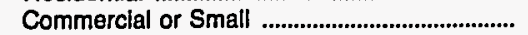 & 0 & 277 & 2,051 & 2,672 & 43,580 & 371 \\
\hline 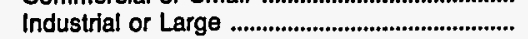 & 0 & 18 & 0 & 3 & 38 & 1 \\
\hline Other & 0 & 420 & 198 & 521 & 9,003 & 20 \\
\hline \multicolumn{7}{|l|}{ Sales for the Year (megawatthours) } \\
\hline 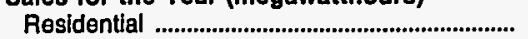 & 0 & 24,444 & 122,475 & 110,547 & $6,703,679$ & 16,672 \\
\hline Commercial or Small & 0 & 9,261 & 136,509 & 146,037 & $5,291,055$ & 17,968 \\
\hline Industrial or Large ............................................... & 0 & 30,546 & 0 & 232,785 & $3,116,408$ & 121,106 \\
\hline 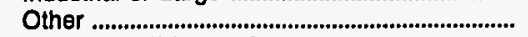 & 0 & 58,653 & 48,975 & 12,707 & 578,494 & 3,060 \\
\hline Total to UltImate Consumers ...................... & 0 & 122,904 & 307,959 & 502,076 & $15,689,636$ & 158,806 \\
\hline 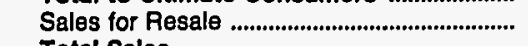 & 612,863 & & 5,307 & 0 & $3,543,142$ & \\
\hline $\begin{array}{l}\text { Total Sales .................................................... } \\
\text { Oper Revenues for the Year (Thou\$) }\end{array}$ & 612,863 & 122,904 & 313,266 & 502,076 & $19,232,778$ & 158,806 \\
\hline 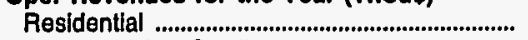 & 0 & 2,069 & 10,277 & 8,200 & 594,870 & 1,164 \\
\hline Commercial or Small ............................................ & 0 & 1,014 & 10,324 & 11,140 & 397,161 & 1,193 \\
\hline 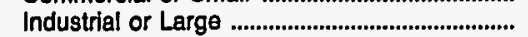 & 0 & 2,270 & 0 & 13,349 & 155,018 & 5,892 \\
\hline Other & 0 & 1,703 & 2,716 & 994 & 44,763 & 273 \\
\hline Total to Ulitmate Consumers ..................... & 0 & 7,056 & 23,317 & 33,683 & $1,191,812$ & 8,522 \\
\hline $\begin{array}{l}\text { Sales for Resale ............................................ } \\
\text { Total Revenues From Sales of Elec ........ }\end{array}$ & $\begin{array}{l}17,105 \\
17,105\end{array}$ & $\begin{array}{r}0 \\
7,056\end{array}$ & $\begin{array}{r}118 \\
23,435\end{array}$ & $\begin{array}{r}0 \\
33,683\end{array}$ & $\begin{array}{r}99,866 \\
1,291,678\end{array}$ & $\begin{array}{r}0 \\
8,522\end{array}$ \\
\hline
\end{tabular}

\begin{tabular}{|c|c|c|c|c|c|c|}
\hline Item & $\begin{array}{c}\text { Arkansas } \\
\text { Benton } \\
\text { City of } \\
\text { December } 31\end{array}$ & $\begin{array}{c}\text { Arkansas } \\
\text { Bentonville } \\
\text { City of } \\
\text { December } 31\end{array}$ & $\begin{array}{c}\text { Arkansas } \\
\text { Clarksville } \\
\text { Light } \\
\& \\
\text { Water Co } \\
\text { December } 31\end{array}$ & $\begin{array}{l}\text { Arkansas } \\
\text { Conway } \\
\text { Corp } \\
\text { December } 31\end{array}$ & $\begin{array}{c}\text { Arkansas } \\
\text { Hope } \\
\text { City of } \\
\text { December } 31\end{array}$ & $\begin{array}{c}\text { Arkansas } \\
\begin{array}{c}\text { Jonesboro } \\
\text { City of }\end{array} \\
\text { December } 31\end{array}$ \\
\hline \multicolumn{7}{|l|}{ Number of Consumers } \\
\hline 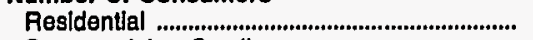 & 7,542 & 4,937 & 2,668 & 12,142 & 5,618 & 20,113 \\
\hline 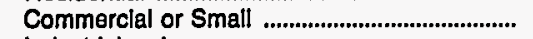 & 1,011 & 634 & 492 & 1,591 & 930 & 3,322 \\
\hline 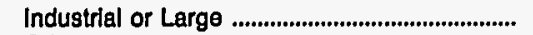 & 19 & 155 & 62 & 58 & 51 & 153 \\
\hline Other & 0 & 0 & 0 & 3 & 1 & 1 \\
\hline $\begin{array}{l}\text { Total Ultimate Consumers } \\
\text { Sales for the Year (megawa...................... }\end{array}$ & 8,572 & 5,726 & 3,222 & 13,794 & 6,600 & 23,589 \\
\hline 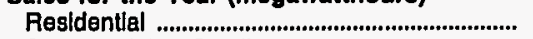 & 71,233 & 47,832 & 28,002 & 132,053 & 57,938 & 263,998 \\
\hline Commercial or Small & 40,517 & 12,455 & 14,827 & 69,894 & 29,236 & 105,229 \\
\hline Industrial or Large & 32,010 & 152,473 & 121,815 & 264,582 & 88,501 & 392,807 \\
\hline Other & 0 & 0 & 0 & 7,858 & 3,681 & 14,177 \\
\hline Total to UltImate Consumers ......................... & 143,760 & 212,760 & 164,644 & 474,387 & 179,356 & 776,211 \\
\hline Sales for Resale & & & & & & 34,350 \\
\hline Total Sales & 143,760 & 212,760 & 164,644 & 474,387 & 179,356 & 810,561 \\
\hline \\
\hline 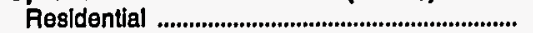 & 7,618 & 2,874 & 1,615 & 8,065 & 4,055 & 12,600 \\
\hline 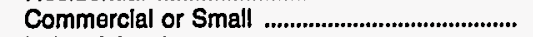 & 4,521 & 795 & 1,223 & 4,630 & 2,473 & 5,791 \\
\hline Industrlal or Large ................................................ & 2,183 & 5,508 & 5,840 & 12,514 & 4,423 & 13,523 \\
\hline Other & 0 & 0 & 0 & 525 & 564 & 254 \\
\hline Total to Ultimate Consumers .................... & 14,322 & 9,177 & 8,678 & 25,734 & 11,515 & 32,168 \\
\hline Sales for Resale & & & & & & 874 \\
\hline Total Revenues From Sales of Elec ........ & 14,322 & 9,177 & 8,678 & 25,734 & 11,515 & 33,042 \\
\hline
\end{tabular}

Note: Totals may not equal sum of components because of independent rounding.

Source: Energy Information Administration, Form EIA-861, "Annual Electric Utility Report." Data are submilted on a calendar year. 
Table 25. Number of Consumers, Sales, and Operating Revenue by Major U.S. Publicly Owned Electric Utility Within State, 1993 (Continued)

\begin{tabular}{|c|c|c|c|c|c|c|}
\hline Item & $\begin{array}{c}\text { Arkansas } \\
\text { North } \\
\text { Little } \\
\text { Rock } \\
\text { City of } \\
\text { December } 31\end{array}$ & $\begin{array}{l}\text { Arkansas } \\
\text { Osceola } \\
\text { City of } \\
\text { December } 31\end{array}$ & $\begin{array}{c}\text { Arkansas } \\
\text { Paragould } \\
\text { Light } \\
\& \\
\text { Water Comm } \\
\text { December } 31\end{array}$ & $\begin{array}{c}\text { Arkansas } \\
\text { Siloam } \\
\text { Springs } \\
\text { City of } \\
\text { December } 31\end{array}$ & $\begin{array}{c}\text { Arkansas } \\
\text { West } \\
\text { Memphis } \\
\text { City of } \\
\text { December } 31\end{array}$ & $\begin{array}{l}\text { California } \\
\text { Alameda } \\
\text { City of } \\
\text { December } 31\end{array}$ \\
\hline \multicolumn{7}{|l|}{ Number of Consumers } \\
\hline 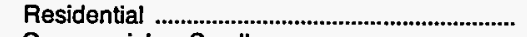 & 31,236 & 3,177 & 8,141 & 3,736 & 9,986 & 27,933 \\
\hline 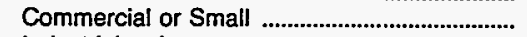 & 3,848 & 518 & 1,299 & 583 & 1,286 & 3,173 \\
\hline Industrial or Large & 236 & 20 & 47 & 77 & 0 & 3 \\
\hline Other & 2 & 0 & 994 & 0 & 41 & 221 \\
\hline $\begin{array}{l}\text { Total Ultimate Consumers } \\
\text { Sales for the Year (megawatthours) }\end{array}$ & 35,322 & 3,715 & 10,481 & 4,396 & 11,313 & 31,330 \\
\hline 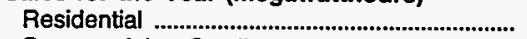 & 292,442 & 49,626 & 125,165 & 39,478 & 130,650 & 128,919 \\
\hline 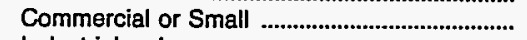 & 255,888 & 19,380 & 48,244 & 11,388 & 156,425 & 178,916 \\
\hline Industrial or Large & 255,888 & 104,945 & 152,464 & 124,904 & 0 & 159,532 \\
\hline Other & 8,123 & 0 & 4,431 & 0 & 3,678 & 7,898 \\
\hline Total to Ultimate Consumers ...................... & 812,341 & 173,951 & 330,304 & 175,770 & 290,753 & 475,265 \\
\hline Sales for Resale & 0 & 0 & 0 & 0 & 0 & 0 \\
\hline \multirow{2}{*}{\multicolumn{7}{|c|}{ Oper Revenues for the Year (Thous) }} \\
\hline 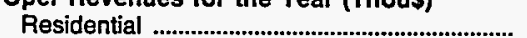 & & & & & & \\
\hline Commercial or Small & 16,781 & $\begin{array}{l}2,000 \\
1,372\end{array}$ & $\begin{array}{l}4,858 \\
1,954\end{array}$ & $\begin{array}{r}2,5 / 6 \\
939\end{array}$ & $\begin{array}{l}8,303 \\
9,785\end{array}$ & $\begin{array}{l}13,413 \\
17,637\end{array}$ \\
\hline 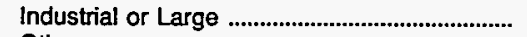 & 16,783 & 5,116 & 4,726 & 5,613 & 0 & 11,682 \\
\hline Other & 210 & 0 & 184 & 0 & 299 & 827 \\
\hline 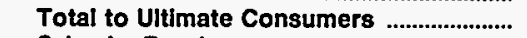 & 64,790 & 9,348 & 11,722 & 9,128 & 18,387 & 43,559 \\
\hline 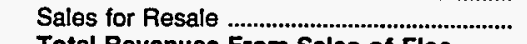 & & & & 0 & 0 & \\
\hline Total Revenues From Sales of Elec ......... & 64,790 & 9,348 & 11,722 & 9,128 & 18,387 & 43,559 \\
\hline
\end{tabular}

\begin{tabular}{|c|c|c|c|c|c|c|}
\hline Item & $\begin{array}{l}\text { California } \\
\begin{array}{c}\text { Anaheim } \\
\text { City of }\end{array} \\
\text { December } 31\end{array}$ & $\begin{array}{l}\text { California } \\
\begin{array}{c}\text { Azusa } \\
\text { City of }\end{array} \\
\text { December } 31\end{array}$ & $\begin{array}{l}\text { California } \\
\begin{array}{c}\text { Burbank } \\
\text { City of }\end{array} \\
\text { December } 31\end{array}$ & $\begin{array}{c}\text { California } \\
\text { California } \\
\text { Dept } \\
\text { Wtr } \\
\text { Resources } \\
\text { December } 31\end{array}$ & $\begin{array}{l}\text { California } \\
\text { Colton } \\
\text { City of } \\
\text { December } 31\end{array}$ & $\begin{array}{l}\text { California } \\
\text { Glendale } \\
\text { City of } \\
\text { December } 31\end{array}$ \\
\hline \multicolumn{7}{|l|}{ Number of Consumers } \\
\hline 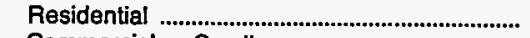 & 87,601 & 12,624 & 43,725 & 0 & 14,519 & 69,892 \\
\hline Commercial or Small ...................................................... & 14,649 & 1,310 & 6,245 & 0 & 1,654 & 12,109 \\
\hline Industrial or Large & 574 & 28 & 216 & 0 & 18 & 181 \\
\hline Other & 609 & 172 & 46 & 0 & 131 & \\
\hline $\begin{array}{l}\text { Total Ultimate Consumers } \\
\text { Sales for the Year (megawatthours) }\end{array}$ & 103,433 & 14,134 & 50,232 & o & 16,322 & 82,186 \\
\hline 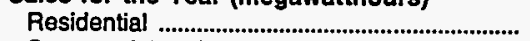 & 418,342 & 64,320 & 224,660 & 0 & 79,530 & 329,804 \\
\hline 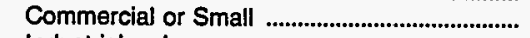 & 416,176 & 61,130 & 212,952 & 0 & 75,770 & 332,165 \\
\hline Industrial or Large & 938,466 & 56,006 & 494,449 & 0 & 40,575 & 324,570 \\
\hline Other & 63,032 & 5,224 & 30,119 & 0 & 8,652 & 9,573 \\
\hline $\begin{array}{l}\text { Total to UItimate Consumers } \\
\text { Sales for Resale }\end{array}$ & $\begin{array}{r}1,836,016 \\
529,154\end{array}$ & $\begin{array}{r}186,680 \\
0\end{array}$ & 962,180 & $\begin{array}{r}0 \\
4174176\end{array}$ & 204,527 & 998,212 \\
\hline $\begin{array}{l}\text { Total Sales } \\
\text { Oper Revenues for the Year (Thous) }\end{array}$ & $2,365,170$ & 186,680 & 962,475 & $\begin{array}{l}4,174,176 \\
4,174,176\end{array}$ & 204,527 & $\begin{array}{r}0 \\
998,212\end{array}$ \\
\hline 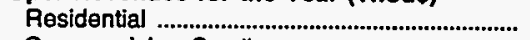 & 47,936 & 5,592 & 21,516 & 0 & 6,312 & 32,202 \\
\hline 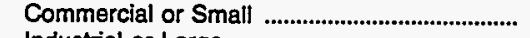 & 52,760 & 6,308 & 20,079 & 0 & 7,208 & 33,204 \\
\hline Industrial or Large & 98,319 & 4,820 & 43,699 & 0 & 3,488 & 26,375 \\
\hline Other & 7,507 & 441 & 2,862 & 0 & 760 & 934 \\
\hline Total to Ultimate Consumers ......................... & 208,522 & 17,161 & 88,156 & 0 & 17,768 & 92,716 \\
\hline 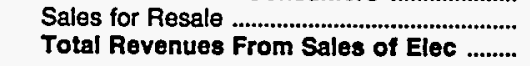 & $\begin{array}{r}9,980 \\
216,502\end{array}$ & $\begin{array}{r}0 \\
17,161\end{array}$ & $\begin{array}{r}8 \\
88,164\end{array}$ & $\begin{array}{l}123,004 \\
123,004\end{array}$ & $\begin{array}{r}0 \\
17,768\end{array}$ & $\begin{array}{r}0 \\
92,715\end{array}$ \\
\hline
\end{tabular}

Note: Totals may not equal sum of components because of independent rounding.

Source: Energy Information Administration, Form EIA-861, "Annual Electric Utility Report." Data are submitted on a calendar year. 
Table 25. Number of Consumers, Sales, and Operating Revenue by Major U.S. Publicly Owned Electric Utility Within State, 1993 (Continued)

\begin{tabular}{|c|c|c|c|c|c|c|}
\hline Item & $\begin{array}{l}\text { California } \\
\text { Imperial } \\
\text { Imigation } \\
\text { District } \\
\text { December } 31\end{array}$ & $\begin{array}{l}\text { California } \\
\text { Lassen } \\
\text { Municipal } \\
\text { Utility Dist } \\
\text { December } 31\end{array}$ & $\begin{array}{l}\text { California } \\
\text { Lodi } \\
\text { City of } \\
\text { December } 31\end{array}$ & $\begin{array}{l}\text { Los Angeles } \\
\text { City of } \\
\text { December } 31\end{array}$ & $\begin{array}{l}\text { California } \\
\text { Merced } \\
\text { Irrigation } \\
\text { District } \\
\text { December } 31\end{array}$ & $\begin{array}{l}\text { California } \\
\text { Metropolitan } \\
\text { Water } \\
\text { District } \\
\text { December } 31\end{array}$ \\
\hline \multicolumn{7}{|l|}{ Number of Consumers } \\
\hline 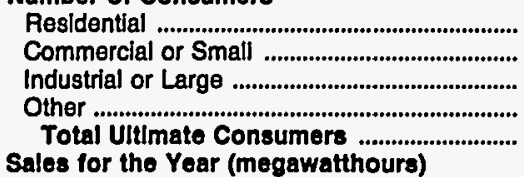 & $\begin{array}{r}67,021 \\
12,395 \\
0 \\
1,451 \\
80,867\end{array}$ & $\begin{array}{r}8,187 \\
1,175 \\
3 \\
104 \\
9,469\end{array}$ & $\begin{array}{r}18,880 \\
2,833 \\
26 \\
259 \\
21,998\end{array}$ & $\begin{array}{r}1,168,229 \\
170,868 \\
17,165 \\
1,417 \\
1,357,679\end{array}$ & $\begin{array}{l}0 \\
0 \\
0 \\
0 \\
0\end{array}$ & $\begin{array}{l}0 \\
0 \\
0 \\
0 \\
0\end{array}$ \\
\hline 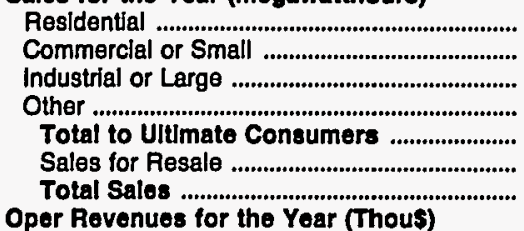 & $\begin{array}{r}830,756 \\
1,246,544 \\
0 \\
58,660 \\
2,135,960 \\
458,650 \\
2,594,610\end{array}$ & $\begin{array}{r}66,958 \\
39,805 \\
17,034 \\
3,977 \\
127,774 \\
0 \\
127,774\end{array}$ & $\begin{array}{r}123,525 \\
119,481 \\
108,402 \\
10,490 \\
361,898 \\
0 \\
361,898\end{array}$ & $\begin{array}{r}5,929,489 \\
12,220,766 \\
2,608,413 \\
377,889 \\
21,136,557 \\
650,592 \\
21,787,149\end{array}$ & $\begin{array}{r}0 \\
0 \\
0 \\
0 \\
0 \\
350,312 \\
350,312\end{array}$ & $\begin{array}{r}0 \\
0 \\
0 \\
0 \\
0 \\
280,944 \\
280,944\end{array}$ \\
\hline 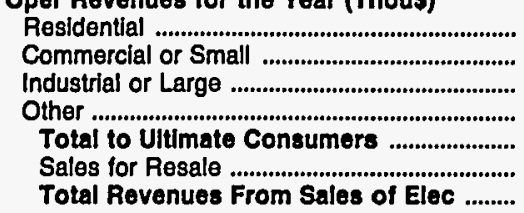 & $\begin{array}{r}69,424 \\
99,029 \\
0 \\
4,846 \\
173,299 \\
10,448 \\
183,747\end{array}$ & $\begin{array}{r}6,375 \\
4,478 \\
2,969 \\
133 \\
13,955 \\
0 \\
13,955\end{array}$ & $\begin{array}{r}13,061 \\
12,268 \\
8,297 \\
1,028 \\
34,654 \\
0 \\
34,654\end{array}$ & $\begin{array}{r}583,782 \\
1,092,283 \\
221,821 \\
33,320 \\
1,931,206 \\
18,359 \\
1,949,565\end{array}$ & $\begin{array}{r}0 \\
0 \\
0 \\
0 \\
0 \\
4,573 \\
4,573\end{array}$ & $\begin{array}{r}0 \\
0 \\
0 \\
0 \\
0 \\
13,213 \\
13,213\end{array}$ \\
\hline
\end{tabular}

\begin{tabular}{|c|c|c|c|c|c|c|}
\hline Item & $\begin{array}{c}\text { California } \\
\text { Modesto } \\
\text { Irrigation } \\
\text { District } \\
\text { December } 31\end{array}$ & $\begin{array}{c}\text { California } \\
\text { MSR } \\
\text { Public } \\
\text { Power } \\
\text { Agency } \\
\text { December } 31\end{array}$ & $\begin{array}{c}\text { California } \\
\text { Northern } \\
\text { California } \\
\text { Power Agny } \\
\text { December } 31\end{array}$ & $\begin{array}{c}\text { California } \\
\text { Oakdale \& } \\
\text { South } \\
\text { San Joaquin } \\
\text { December } 31\end{array}$ & $\begin{array}{c}\text { California } \\
\text { Oroville } \\
\text { Wyandotte } \\
\text { Irrig Dist } \\
\text { December } 31\end{array}$ & $\begin{array}{l}\text { California } \\
\text { Palo Alto } \\
\text { City of } \\
\text { December } 31\end{array}$ \\
\hline \multicolumn{7}{|l|}{ Number of Consumers } \\
\hline 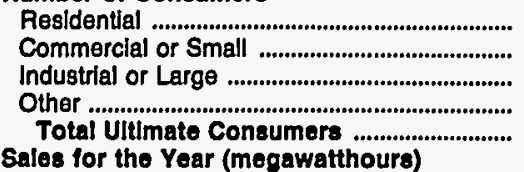 & $\begin{array}{r}73,636 \\
8,665 \\
1,370 \\
3,710 \\
87,381\end{array}$ & $\begin{array}{l}0 \\
0 \\
0 \\
0 \\
0\end{array}$ & $\begin{array}{l}0 \\
0 \\
0 \\
0 \\
0\end{array}$ & $\begin{array}{l}0 \\
0 \\
0 \\
0 \\
0\end{array}$ & $\begin{array}{l}0 \\
0 \\
0 \\
0 \\
0\end{array}$ & $\begin{array}{r}24,494 \\
2,398 \\
191 \\
3 \\
27,086\end{array}$ \\
\hline 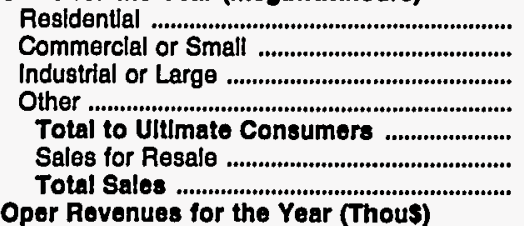 & $\begin{array}{r}651,460 \\
583,232 \\
481,106 \\
48,215 \\
1,764,013 \\
30,910 \\
1,794,923\end{array}$ & $\begin{array}{r}0 \\
0 \\
0 \\
0 \\
0 \\
1,205,645 \\
1,205,645\end{array}$ & $\begin{array}{r}0 \\
0 \\
0 \\
0 \\
0 \\
2,481,750 \\
2,481,750\end{array}$ & $\begin{array}{r}0 \\
0 \\
0 \\
0 \\
0 \\
518,645 \\
518,645\end{array}$ & $\begin{array}{r}0 \\
0 \\
0 \\
0 \\
0 \\
718,946 \\
718,946\end{array}$ & $\begin{array}{r}153,970 \\
356,567 \\
474,963 \\
59,596 \\
1,045,096 \\
0 \\
1,045,096\end{array}$ \\
\hline 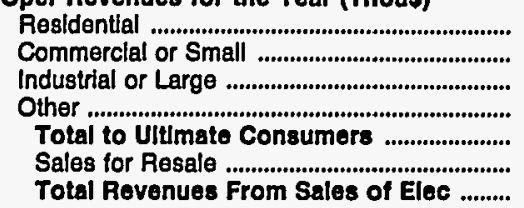 & $\begin{array}{r}46,213 \\
49,055 \\
29,196 \\
3,340 \\
127,804 \\
589 \\
128,393\end{array}$ & $\begin{array}{r}0 \\
0 \\
0 \\
0 \\
0 \\
0 \\
61,934 \\
61,934\end{array}$ & $\begin{array}{r}0 \\
0 \\
0 \\
0 \\
0 \\
165,056 \\
165,056\end{array}$ & $\begin{array}{r}0 \\
0 \\
0 \\
0 \\
0 \\
5,593 \\
5,593\end{array}$ & $\begin{array}{r}0 \\
0 \\
0 \\
0 \\
0 \\
8,828 \\
8,828\end{array}$ & $\begin{array}{r}8,409 \\
23,293 \\
28,381 \\
3,785 \\
63,868 \\
0 \\
63,888\end{array}$ \\
\hline
\end{tabular}

Note: Totals may not equal sum of components because of independentrounding.

Source: Energy Information Administration, Form ElA-861, "Annual Electric Utility Report." Data are submitted on a calendar year. 
Table 25. Number of Consumers, Sales, and Operating Revenue by Major U.S. Publicly Owned Electric Utility Within State, 1993 (Continued)

\begin{tabular}{|c|c|c|c|c|c|c|}
\hline Item & $\begin{array}{c}\text { California } \\
\text { Pasadena } \\
\text { City of } \\
\text { December } 31\end{array}$ & $\begin{array}{c}\text { California } \\
\text { Placer } \\
\text { County } \\
\text { Water } \\
\text { Agency } \\
\text { December } 31\end{array}$ & $\begin{array}{l}\text { California } \\
\text { Redding } \\
\text { City of } \\
\text { December } 31\end{array}$ & $\begin{array}{c}\text { California } \\
\text { Riverside } \\
\text { City of } \\
\text { December } 31\end{array}$ & $\begin{array}{c}\text { Roseville } \\
\text { City of }\end{array}$ & $\begin{array}{l}\text { California } \\
\text { Sacramento } \\
\text { Municipal } \\
\text { Util Dist } \\
\text { December } 31\end{array}$ \\
\hline \multicolumn{7}{|l|}{ Number of Consumers } \\
\hline 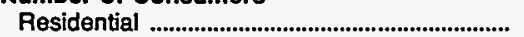 & 48,780 & 0 & 29,053 & 80,828 & 21,871 & 416,364 \\
\hline 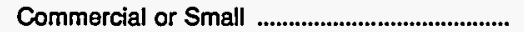 & 7,432 & 0 & 4,879 & 8,395 & 2,894 & 43,868 \\
\hline Industrial or Large & 917 & 0 & 581 & 195 & 30 & 7,310 \\
\hline 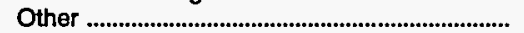 & 174 & 0 & 451 & 144 & 122 & 1,639 \\
\hline \multicolumn{7}{|l|}{ Sales for the Year (megawatthours) } \\
\hline Residential & 264,063 & 0 & 292,789 & 524,406 & 179,855 & $3,635,715$ \\
\hline 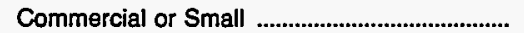 & 139,223 & 0 & 290,628 & 387,095 & 155,836 & 729,443 \\
\hline Industrial or Large & 631,832 & 0 & 23,834 & 591,538 & 178,162 & $4,015,176$ \\
\hline Other & 46,733 & 0 & 28,278 & 42,385 & 29,597 & 67,885 \\
\hline Total to Ultimate Consumers ...................... & $1,081,851$ & $\mathbf{0}$ & 635,529 & $1,545,424$ & 543,450 & $8,448,219$ \\
\hline Sales for Resale & 69,400 & $1,274,981$ & 53,760 & 100,561 & 0 & 97,150 \\
\hline \multicolumn{7}{|l|}{ Oper Revenues for the Year (Thous) } \\
\hline 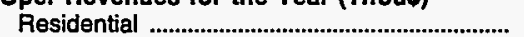 & 24,496 & 0 & 21,077 & 55,421 & 14,527 & 278,085 \\
\hline Commercial or Small & 12,995 & 0 & 22,156 & 41,250 & 13,955 & 58,187 \\
\hline Industrial or Large & 55,989 & 0 & 1,960 & 51,249 & 13,302 & 272,509 \\
\hline Other & 4,181 & 0 & 3,163 & 4,851 & 2,277 & 4,104 \\
\hline Total to Ultimate Consumers ......................... & 97,661 & 0 & 48,356 & 152,771 & 44,061 & 612,885 \\
\hline 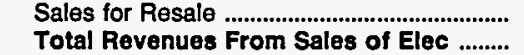 & $\begin{array}{r}3,858 \\
101,519\end{array}$ & $\begin{array}{l}8,815 \\
8,815\end{array}$ & $\begin{array}{r}1,619 \\
49,975\end{array}$ & $\begin{array}{r}2,123 \\
154,894\end{array}$ & $\begin{array}{r}0 \\
44,061\end{array}$ & $\begin{array}{r}1,916 \\
614,801\end{array}$ \\
\hline
\end{tabular}

\begin{tabular}{|c|c|c|c|c|c|c|}
\hline Item & $\begin{array}{c}\text { California } \\
\text { San Francisco } \\
\text { City } \\
\& \\
\text { County of } \\
\text { December } 31\end{array}$ & $\begin{array}{c}\text { California } \\
\text { Santa } \\
\text { Clara } \\
\text { City of } \\
\text { December } 31\end{array}$ & $\begin{array}{l}\text { California } \\
\text { Southern } \\
\text { California } \\
\text { P P } \\
\text { A } \\
\text { December } 31\end{array}$ & $\begin{array}{c}\text { California } \\
\text { Turlock } \\
\text { Irrigation } \\
\text { District } \\
\text { December } 31\end{array}$ & $\begin{array}{l}\text { California } \\
\text { Vernon } \\
\text { City of } \\
\text { December } 31\end{array}$ & $\begin{array}{c}\text { California } \\
\text { Yuba } \\
\text { County } \\
\text { Water } \\
\text { Agency } \\
\text { December } 31\end{array}$ \\
\hline \multicolumn{7}{|l|}{ Number of Consumers } \\
\hline 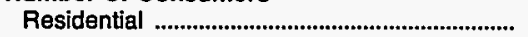 & 0 & 38,129 & 0 & 50,627 & 27 & 0 \\
\hline Commercial or Small & 6 & 5,268 & 0 & 5,885 & 1,044 & 0 \\
\hline Industrial or Large & 0 & 1,506 & 0 & 878 & 952 & 0 \\
\hline Other & 2 & 650 & 0 & 4,685 & 29 & 0 \\
\hline $\begin{array}{l}\text { Total Uitimate Consumers } \\
\text { Sales for the Year (megawatthours) }\end{array}$ & 8 & 45,553 & 0 & 62,075 & 2,052 & 0 \\
\hline 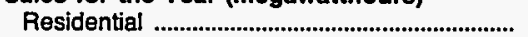 & 0 & 200,807 & 0 & 461,989 & 122 & 0 \\
\hline 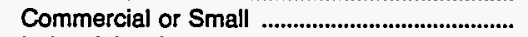 & 477 & 87,745 & 0 & 108,527 & 224,659 & 0 \\
\hline Industrial or Large & 0 & $1,907,522$ & 0 & 464,588 & 796,800 & 0 \\
\hline Other & 557,046 & 18,841 & 0 & 135,014 & 8,017 & 0 \\
\hline Total to Ultimate Consumers & 557,523 & $2,214,915$ & 0 & $1,170,118$ & $1,029,598$ & 0 \\
\hline 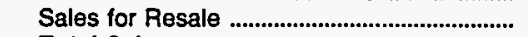 & $1,429,310$ & 90,640 & $1,562,606$ & 14,155 & 0 & $2,041,064$ \\
\hline \multicolumn{7}{|l|}{ Oper Revenues for the Year (Thous) } \\
\hline 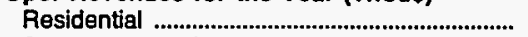 & 0 & 14,656 & 0 & 39,457 & 3 & 0 \\
\hline 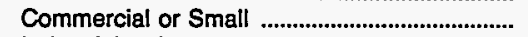 & 20 & 9,354 & 0 & 11,457 & 14,030 & 0 \\
\hline 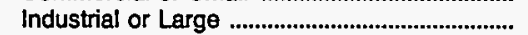 & 0 & 145,824 & 0 & 36,909 & 39,077 & 0 \\
\hline Other & 24,472 & 1,535 & 0 & 9,991 & 764 & 0 \\
\hline Total to Ultimate Consumers & 24,492 & 171,369 & 0 & 97,814 & 53,874 & 0 \\
\hline Sales for Resale ................................................ & $\begin{array}{l}42,584 \\
67,076\end{array}$ & $\begin{array}{r}3,509 \\
174,878\end{array}$ & $\begin{array}{l}124,914 \\
124,914\end{array}$ & $\begin{array}{r}319 \\
98,133\end{array}$ & $\begin{array}{r}0 \\
53,874\end{array}$ & $\begin{array}{l}7,700 \\
7,700\end{array}$ \\
\hline
\end{tabular}

Note: Totals may not equal sum of components because of independent rounding.

Source: Energy Information Administration, Form ElA-861, "Annual Electric Utility Report." Data are submitted on a calendar year. 
Table 25. Number of Consumers, Sales, and Operating Revenue by Major U.S. Publicly Owned Electric Utility Within State, 1993 (Continued)

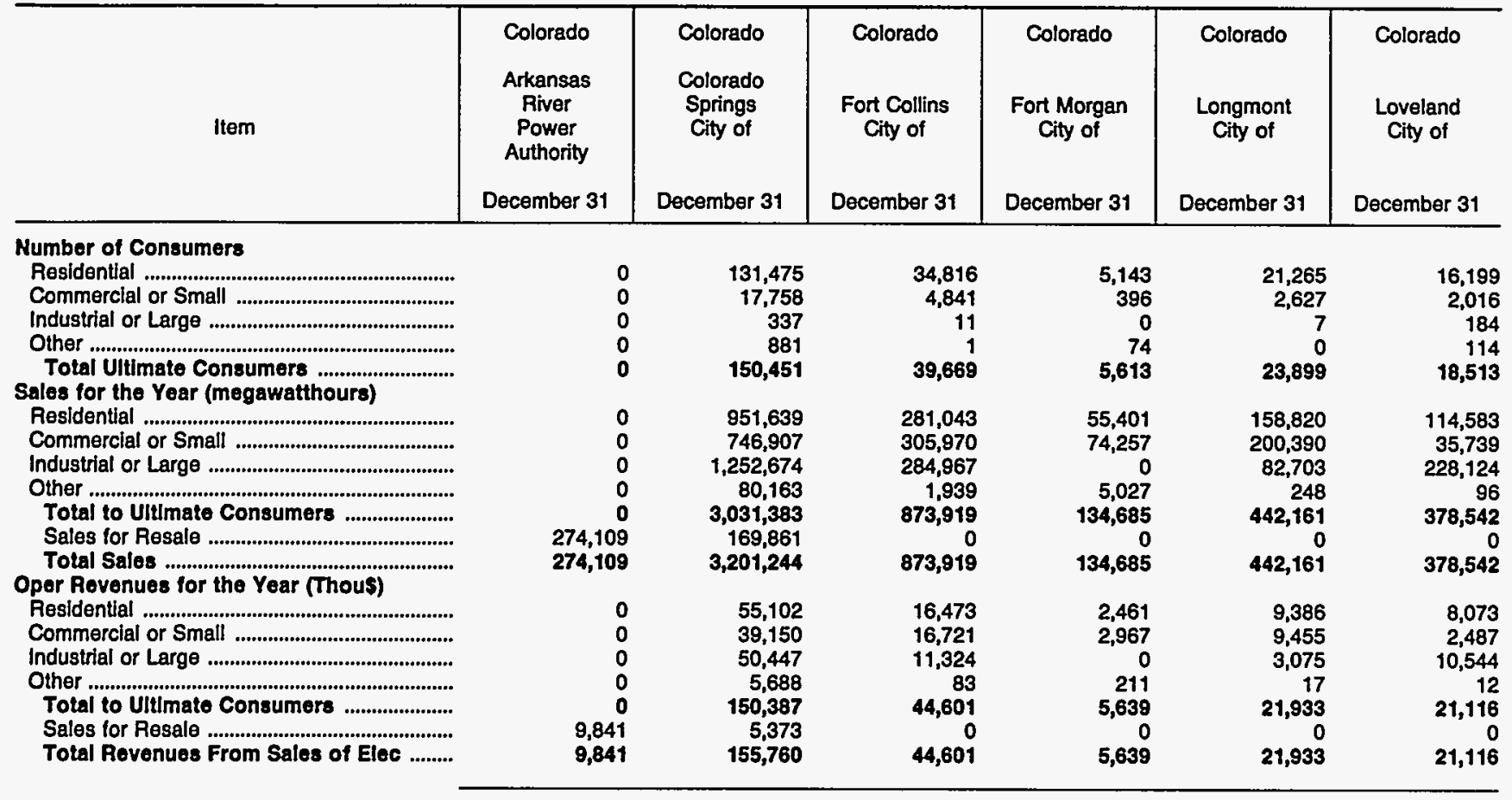

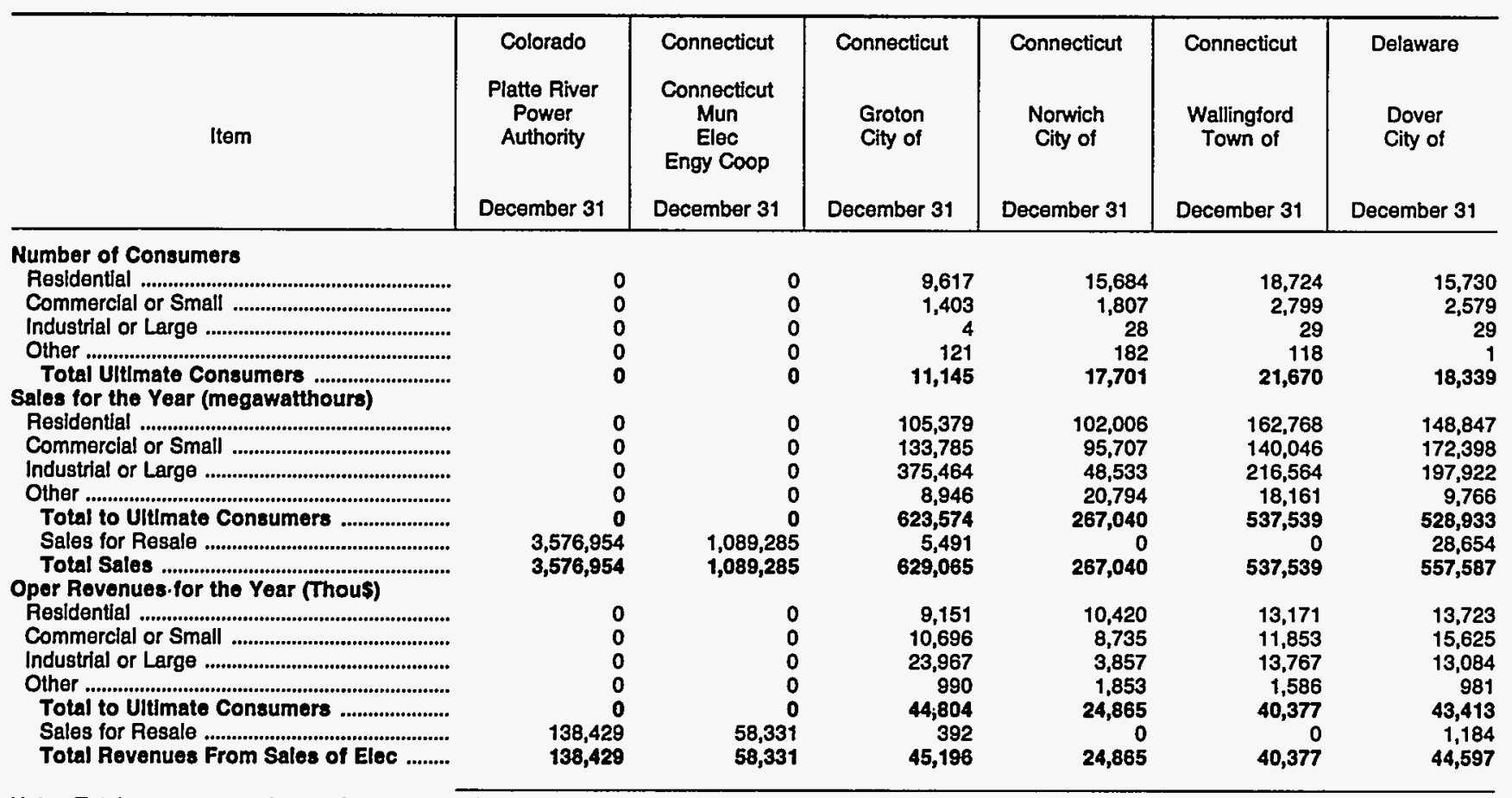

Note: Totals may not equal sum of components because of independent rounding.

Source: Energy Information Administration, Form ElA-861, "Annual Electric Utility Report." Data are submitted on a calendar year. 
Table 25. Number of Consumers, Sales, and Operating Revenue by Major U.S. Publicly Owned Electric Utility Within State, 1993 (Continued)

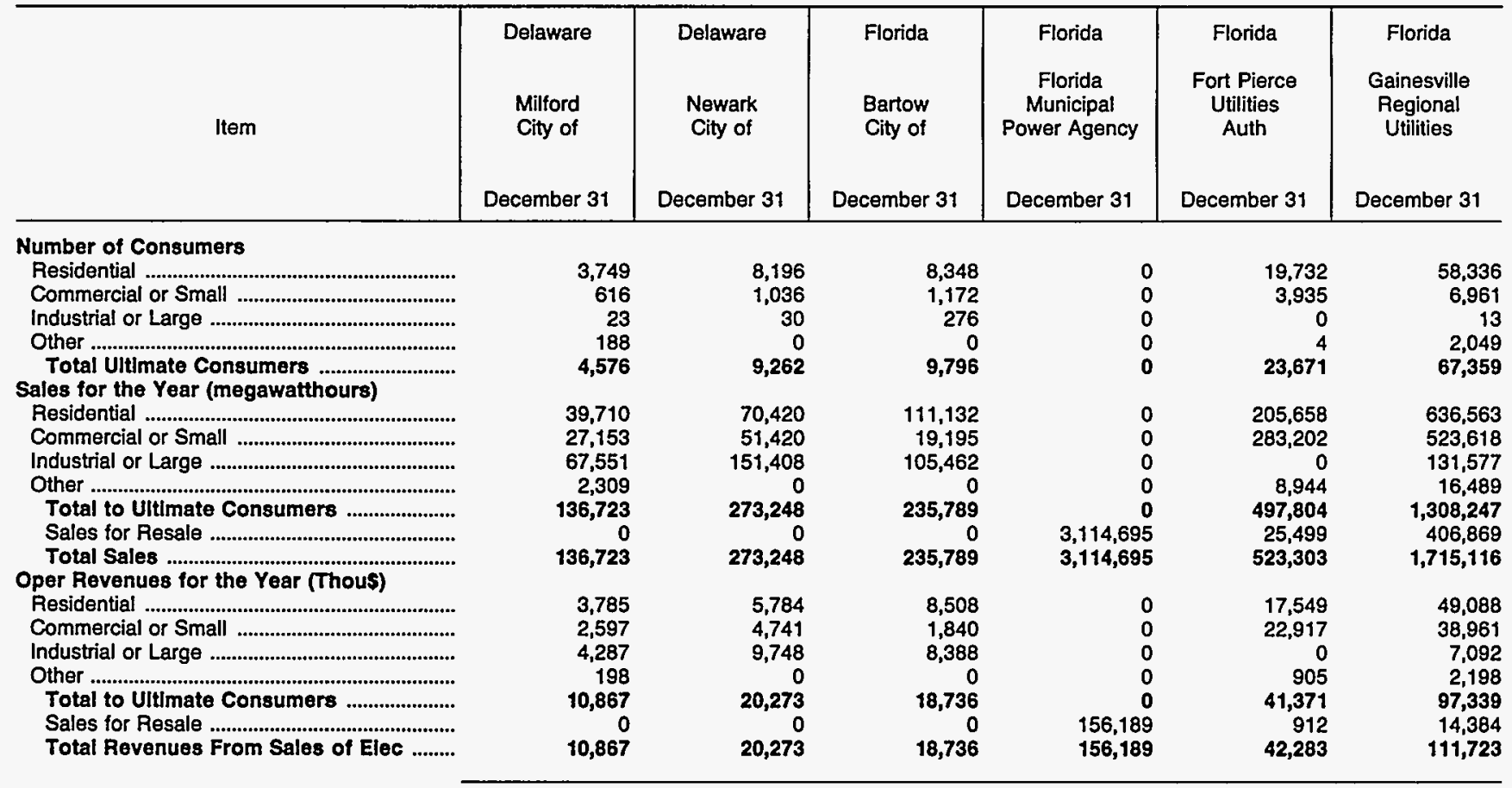

\begin{tabular}{|c|c|c|c|c|c|c|}
\hline Item & $\begin{array}{c}\text { Florida } \\
\text { Homestead } \\
\text { City of } \\
\text { December } 31\end{array}$ & $\begin{array}{c}\text { Florida } \\
\text { Jacksonville } \\
\text { Beach } \\
\text { City of } \\
\text { December } 31\end{array}$ & $\begin{array}{l}\text { Florida } \\
\text { Jacksonville } \\
\text { Electric } \\
\text { Auth } \\
\text { December } 31\end{array}$ & $\begin{array}{c}\text { Fiorida } \\
\text { Key West } \\
\text { City of } \\
\text { December } 31\end{array}$ & $\begin{array}{c}\text { Florida } \\
\text { Kissimmee } \\
\text { Utility } \\
\text { Authority } \\
\text { December } 31\end{array}$ & $\begin{array}{l}\text { Florida } \\
\begin{array}{c}\text { Lake Worth } \\
\text { City of }\end{array} \\
\text { December } 31\end{array}$ \\
\hline \multicolumn{7}{|l|}{ Number of Consumers } \\
\hline 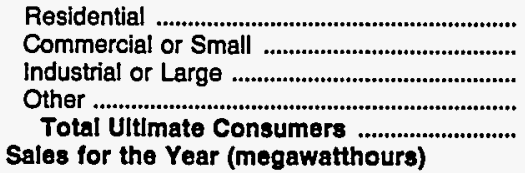 & $\begin{array}{r}9,754 \\
1,301 \\
248 \\
72 \\
11,375\end{array}$ & $\begin{array}{r}21,313 \\
3,629 \\
0 \\
468 \\
25,410\end{array}$ & $\begin{array}{r}270,818 \\
31,924 \\
125 \\
1,874 \\
304,741\end{array}$ & $\begin{array}{r}20,482 \\
2,803 \\
0 \\
1,489 \\
24,784\end{array}$ & $\begin{array}{r}30,200 \\
6,864 \\
27 \\
11 \\
37,102\end{array}$ & $\begin{array}{r}20,219 \\
2,887 \\
72 \\
1 \\
23,179\end{array}$ \\
\hline 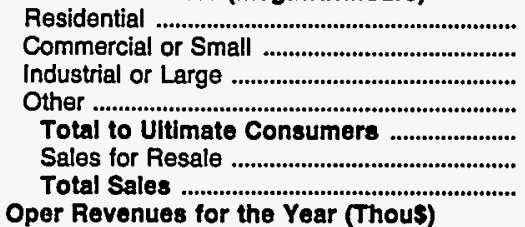 & $\begin{array}{r}109,642 \\
25,609 \\
70,640 \\
5,978 \\
211,869 \\
10,516 \\
222,385\end{array}$ & $\begin{array}{r}287,656 \\
208,885 \\
0 \\
4,453 \\
500,994 \\
0 \\
500,994\end{array}$ & $\begin{array}{r}3,830,309 \\
2,777,868 \\
1,972,353 \\
61,032 \\
8,641,562 \\
560,878 \\
9,202,440\end{array}$ & $\begin{array}{r}219,935 \\
305,180 \\
0 \\
5,458 \\
530,573 \\
0 \\
530,573\end{array}$ & $\begin{array}{r}368,682 \\
311,288 \\
73,250 \\
6,802 \\
760,022 \\
8 \\
760,030\end{array}$ & $\begin{array}{r}179,810 \\
73,389 \\
65,382 \\
2,022 \\
320,603 \\
10,245 \\
330,848\end{array}$ \\
\hline 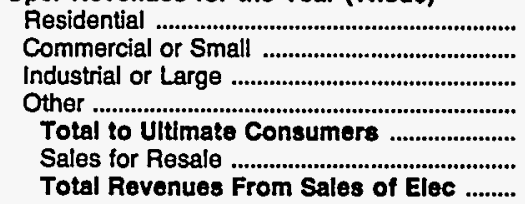 & $\begin{array}{r}8,256 \\
2,283 \\
5,813 \\
572 \\
16,924 \\
596 \\
17,520\end{array}$ & $\begin{array}{r}20,899 \\
17,081 \\
0 \\
393 \\
38,373 \\
0 \\
38,373\end{array}$ & $\begin{array}{r}269,379 \\
185,100 \\
114,361 \\
6,487 \\
575,327 \\
25,533 \\
600,860\end{array}$ & $\begin{array}{r}19,952 \\
29,774 \\
0 \\
631 \\
50,357 \\
0 \\
50,357\end{array}$ & $\begin{array}{r}31,213 \\
23,867 \\
4,697 \\
808 \\
60,585 \\
0 \\
60,585\end{array}$ & $\begin{array}{r}17,914 \\
8,113 \\
6,121 \\
304 \\
32,462 \\
528 \\
32,978\end{array}$ \\
\hline
\end{tabular}

Note: Totals may not equal sum of components because of independent rounding.

Source: Energy Information Administration, Form EIA-861, "Annual Electric Utility Report." Data are submitted on a calendar year. 
Table 25. Number of Consumers, Sales, and Operating Revenue by Major U.S. Publicly Owned Electric Utility Within State, 1993 (Continued)

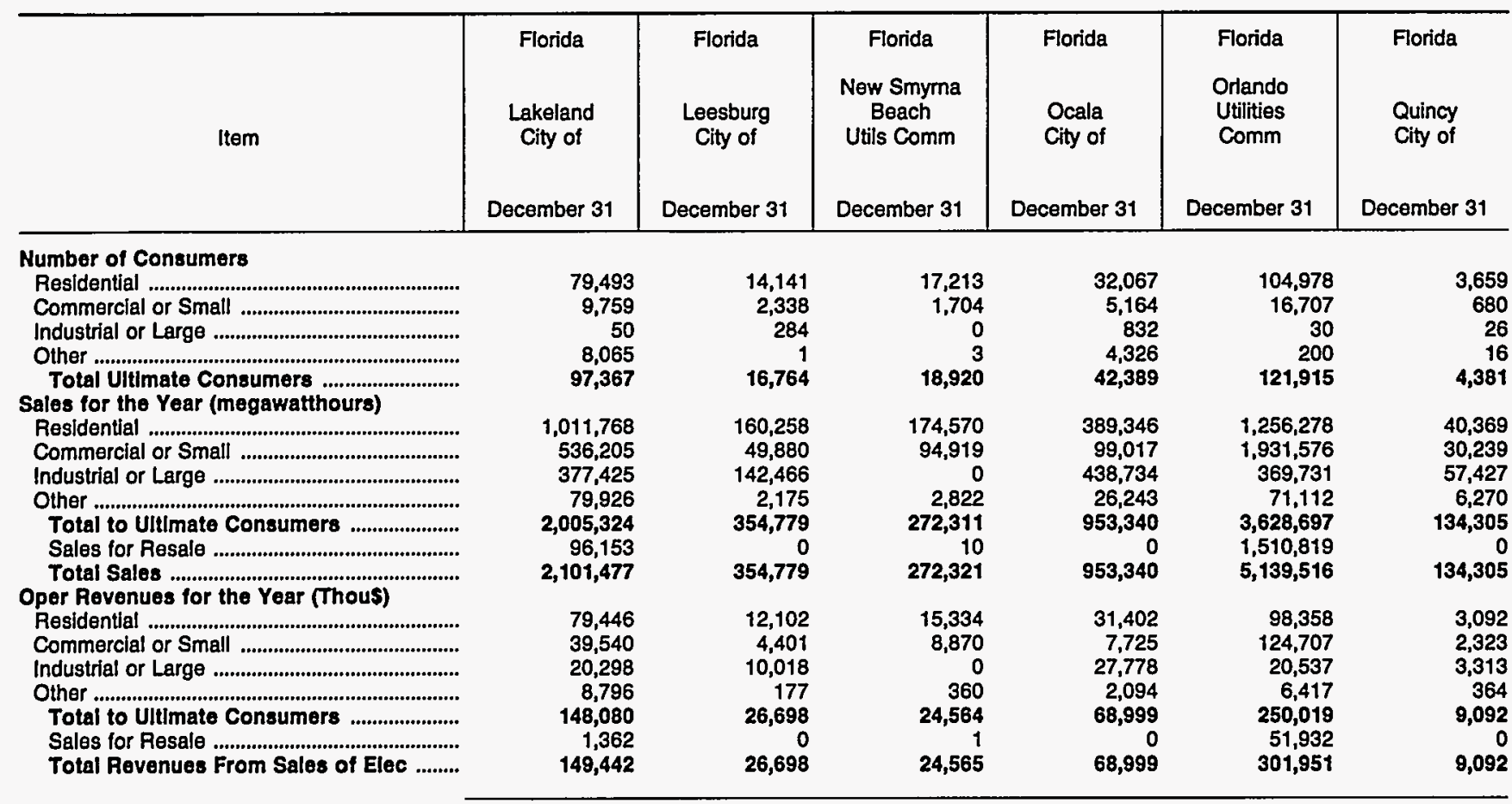

\begin{tabular}{|c|c|c|c|c|c|c|}
\hline Item & $\begin{array}{c}\text { Florida } \\
\text { Reedy Creek } \\
\text { Improvement } \\
\text { Dist }\end{array}$ & $\begin{array}{l}\text { Florida } \\
\text { St Cloud } \\
\text { City of } \\
\text { December } 31\end{array}$ & $\begin{array}{c}\text { Florida } \\
\begin{array}{c}\text { Tallahassee } \\
\text { City of }\end{array} \\
\text { December } 31\end{array}$ & $\begin{array}{c}\text { Florida } \\
\text { Vero } \\
\text { Beach } \\
\text { City of } \\
\text { December } 31\end{array}$ & $\begin{array}{l}\text { Georgia } \\
\text { Albany Water } \\
\text { Gas \& Light } \\
\text { Comm } \\
\text { December } 31\end{array}$ & $\begin{array}{l}\text { Georgia } \\
\text { Calhoun } \\
\text { City of } \\
\text { December } 31\end{array}$ \\
\hline \multicolumn{7}{|l|}{ Number of Consumers } \\
\hline Residential .......................... & 0 & 13,430 & 68,176 & 21,864 & 31,800 & 2,835 \\
\hline Commerclal or Small & 921 & 1,308 & 9,565 & 3,981 & 4,800 & 663 \\
\hline Industrial or Large & 0 & 112 & & 1 & 35 & 54 \\
\hline Other & 107 & & 4,035 & 328 & 3,605 & \\
\hline & \multicolumn{6}{|c|}{ Sales for the Year (megawatthours) } \\
\hline Residentlal ........................................................... & 0 & 150,004 & 796,390 & 268,674 & 371,416 & 24,143 \\
\hline 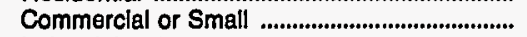 & 659,559 & 15,364 & $1,073,288$ & 220,670 & 441,292 & 43,670 \\
\hline 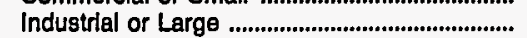 & & 47,665 & & 10,340 & 9,162 & 203,536 \\
\hline Other & 135,190 & & 86,747 & 2,767 & 18,325 & 23,005 \\
\hline Total to Uitimate Consumers ........................ & 794,749 & 213,033 & $1,956,425$ & 502,451 & 840,195 & 294,354 \\
\hline 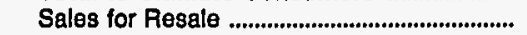 & & & 77,710 & 62,661 & & \\
\hline \multicolumn{7}{|l|}{ Oper Revenues for the Year (Thous) } \\
\hline 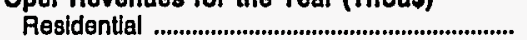 & 0 & 14,467 & 70,115 & 23,019 & 26,491 & 1,648 \\
\hline 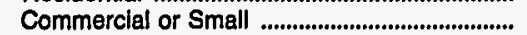 & 44,094 & 1,875 & 86,419 & 16,934 & 27,492 & 3,292 \\
\hline 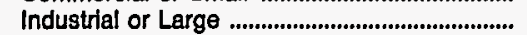 & & 4,508 & & 768 & 569 & 11,923 \\
\hline Other & 9,786 & & 7,134 & 316 & 1,446 & 1,656 \\
\hline Total to Ultimate Consumers & 53,880 & 20,850 & 163,668 & 41,037 & 55,998 & 18,519 \\
\hline Sales for Resale .................................... & $\begin{array}{r}0 \\
53,880\end{array}$ & $\begin{array}{r}0 \\
20,850\end{array}$ & $\begin{array}{r}3,363 \\
167,031\end{array}$ & $\begin{array}{r}2,167 \\
43,204\end{array}$ & $\begin{array}{r}0 \\
55,998\end{array}$ & $\begin{array}{r}0 \\
18,519\end{array}$ \\
\hline
\end{tabular}

Note: Totals may not equal sum of components because of independent rounding.

Source: Energy Information Administration, Form EIA-861, "Annual Electric Utility Report" Data are submitted on a calendar year. 
Table 25. Number of Consumers, Sales, and Operating Revenue by Major U.S. Publicly Owned Electric Utility Within State, 1993 (Continued)

\begin{tabular}{|c|c|c|c|c|c|c|}
\hline Item & $\begin{array}{c}\text { Georgia } \\
\text { Cartersville } \\
\text { City of }\end{array}$ & $\begin{array}{c}\text { Georgia } \\
\text { College } \\
\text { Park City of } \\
\text { December } 31\end{array}$ & $\begin{array}{l}\text { Georgia } \\
\text { Covington } \\
\text { City of } \\
\text { December } 31\end{array}$ & $\begin{array}{l}\text { Georgia } \\
\text { Crisp } \\
\text { County } \\
\text { Power } \\
\text { Comm } \\
\text { December } 31\end{array}$ & $\begin{array}{l}\text { Georgia } \\
\text { Dalton } \\
\text { City of } \\
\text { December } 31\end{array}$ & $\begin{array}{c}\text { Georgia } \\
\text { Douglas } \\
\text { City of } \\
\text { December } 31\end{array}$ \\
\hline \multicolumn{7}{|l|}{ Number of Consumers } \\
\hline 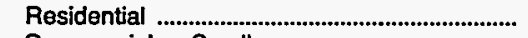 & 4,125 & 9,841 & 6,468 & 8,335 & 9,135 & 3,830 \\
\hline Commercial or Small & 1,010 & 722 & 1,154 & 1,830 & 2,558 & 1,050 \\
\hline Industrial or Large & 30 & 0 & 7 & 70 & 93 & 9 \\
\hline Other & 1 & 0 & 0 & 119 & 536 & 1 \\
\hline $\begin{array}{l}\text { Total Ultimate Consumers } \\
\text { Sales for the Year (megawatthours) }\end{array}$ & 5,166 & 10,563 & 7,629 & 10,354 & 12,322 & 4,890 \\
\hline 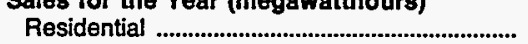 & 48,840 & 94,370 & \multicolumn{4}{|c|}{ Sales for the Year (megawatthours) } \\
\hline Commercial or Small & 73,113 & 143,452 & 80,533 & $\begin{array}{r}1<1,030 \\
68,784\end{array}$ & 305,114 & $\begin{array}{l}47,041 \\
30,228\end{array}$ \\
\hline Industrial or Large & 290,057 & 0 & 58,716 & 110,042 & 662,404 & 113,012 \\
\hline Other & 18,312 & 0 & 0 & 19,581 & 1,451 & 2,238 \\
\hline Total to Ultimate Consumers ......................... & 430,322 & 237,822 & 217,757 & 319,943 & $1,104,041$ & 193,119 \\
\hline Sales for Resale & 0 & 0 & 0 & 0 & 54,522 & 0 \\
\hline \multicolumn{7}{|l|}{ Oper Revenues for the Year (Thous) } \\
\hline 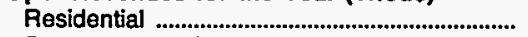 & 3,382 & 6,961 & 6.704 & 6,842 & 5,046 & 3,649 \\
\hline 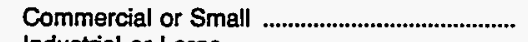 & 5,905 & 9,182 & 7,317 & 4,609 & 16,226 & 2,278 \\
\hline Industrial or Large & 13,473 & 0 & 2,057 & 4,864 & 26,068 & 7,209 \\
\hline Other & 1,341 & 0 & 0 & 1,115 & 197 & 183 \\
\hline Total to Ultimate Consumers ........................ & 24,101 & 16,143 & 16,078 & 17,430 & 47,537 & 13,319 \\
\hline Sales for Resale & & 0 & 0 & 0 & 1,415 & \\
\hline Total Revenues From Sales of Elec ......... & 24,101 & 16,143 & 16,078 & 17,430 & 48,952 & 13,319 \\
\hline
\end{tabular}

\begin{tabular}{|c|c|c|c|c|c|c|}
\hline Item & $\begin{array}{c}\text { Georgia } \\
\text { East } \\
\text { Point } \\
\text { City of } \\
\text { December } 31\end{array}$ & $\begin{array}{c}\text { Georgia } \\
\text { Fitzgerald } \\
\text { Wtr Lgt } \\
\text { \& Bond Comm } \\
\text { December } 31\end{array}$ & $\begin{array}{c}\text { Georgia } \\
\text { Griffin } \\
\text { City of } \\
\text { December } 31\end{array}$ & $\begin{array}{c}\text { Georgia } \\
\text { La Grange } \\
\text { City of } \\
\text { December } 31\end{array}$ & $\begin{array}{c}\text { Georgia } \\
\text { Lawrenceville } \\
\text { City of } \\
\text { December } 31\end{array}$ & $\begin{array}{c}\text { Georgia } \\
\text { Marietta } \\
\text { City of } \\
\text { December } 31\end{array}$ \\
\hline \multicolumn{7}{|l|}{ Number of Consumers } \\
\hline 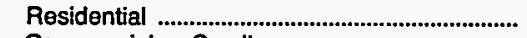 & 15,650 & 4,977 & 11,891 & 10,044 & 6,585 & 32,576 \\
\hline Commercial or Small & 1,043 & 628 & 1,801 & 1,521 & 1,038 & 5,061 \\
\hline 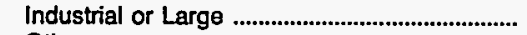 & 57 & 43 & 12 & 33 & 0 & \\
\hline 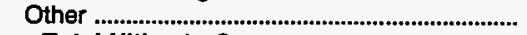 & 2 & 0 & 107 & 0 & 0 & 3,831 \\
\hline \multicolumn{7}{|l|}{ Sales for the Year (megawatthours) } \\
\hline 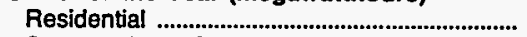 & 109,013 & 68,529 & 106,997 & 98,048 & 74,208 & 309,061 \\
\hline Commercial or Small ..................................................... & 103,773 & 31,739 & 115,663 & 110,483 & 118,457 & 495,742 \\
\hline Industrial or Large & 69,182 & 60,720 & 30,973 & 278,602 & 0 & \\
\hline Other & 13,630 & 0 & 27,938 & 0 & 0 & 13,090 \\
\hline Total to Ultimate Consumers .......................... & 295,598 & 160,988 & 281,571 & 487,133 & 192,665 & 817,893 \\
\hline 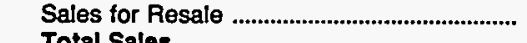 & & & 0 & & & \\
\hline \multicolumn{7}{|l|}{ Oper Revenues for the Year (Thous) } \\
\hline 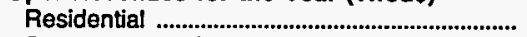 & 9,136 & 4,794 & 6,913 & 7,080 & 5,419 & 28,246 \\
\hline 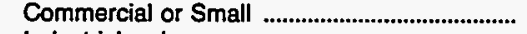 & 6,472 & 2,511 & 7,324 & 8,529 & 8,473 & 41,995 \\
\hline Industrial or Large & 4,315 & 3,614 & 2,001 & 15,119 & 0 & \\
\hline Other & 815 & & 1,953 & & 0 & 1,598 \\
\hline Total to Ultimate Consumers ........................ & 20,738 & 10,919 & 18,191 & 30,728 & 13,892 & 71,839 \\
\hline 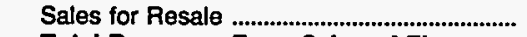 & & & & & & \\
\hline Total Revenues From Sales of Elec ......... & 20,738 & 10,919 & 18,191 & 30,728 & 13,892 & 71,839 \\
\hline
\end{tabular}

Note: Totals may not equal sum of components because of independentrounding.

Source: Energy Information Administration, Form ElA-861, "Annual Electric Utility Report." Data are submitted on a calendar year. 
Table 25. Number of Consumers, Sales, and Operating Revenue by Major U.S. Publicly Owned Electric Utility Within State, 1993 (Continued)

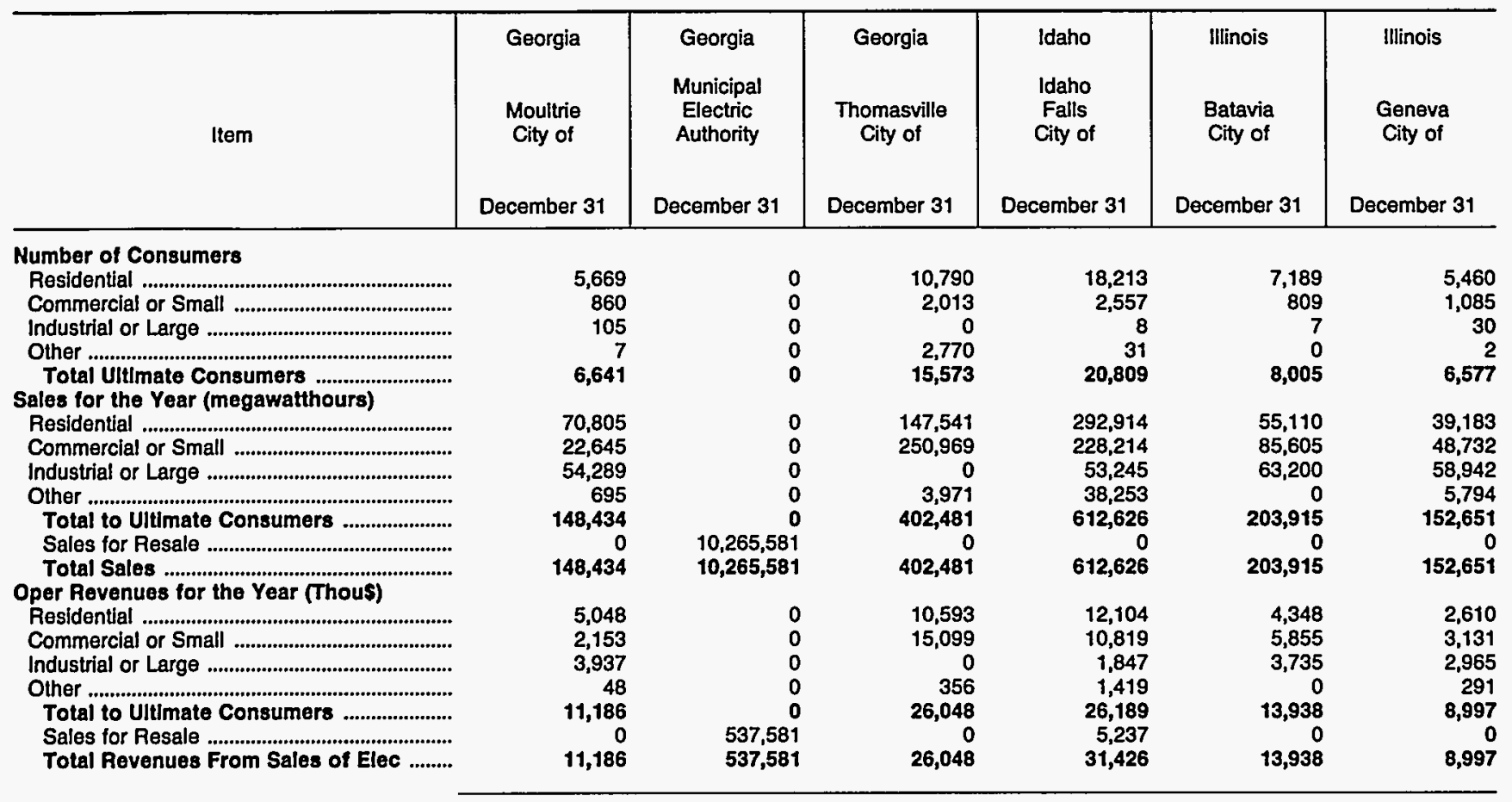

\begin{tabular}{|c|c|c|c|c|c|c|}
\hline Item & $\begin{array}{c}\text { Illinois } \\
\text { Illinois } \\
\text { Municipal } \\
\text { Elec Agency } \\
\text { December } 31\end{array}$ & $\begin{array}{c}\text { Illinois } \\
\text { Naperville } \\
\text { City of } \\
\text { December } 31\end{array}$ & $\begin{array}{c}\text { Illinois } \\
\text { Rochelle } \\
\text { Municipal } \\
\text { Utilities } \\
\text { December } 31\end{array}$ & $\begin{array}{c}\text { Illinois } \\
\text { Springfield } \\
\text { City of }\end{array}$ & $\begin{array}{c}\text { Illinois } \\
\text { St Charles } \\
\text { City of } \\
\text { December } 31\end{array}$ & $\begin{array}{l}\text { Indiana } \\
\begin{array}{c}\text { Anderson } \\
\text { City of }\end{array} \\
\text { December } 31\end{array}$ \\
\hline \multicolumn{7}{|l|}{ Number of Consumers } \\
\hline 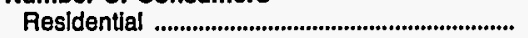 & 0 & 33,368 & 5,624 & 54,457 & 9,232 & 30,527 \\
\hline 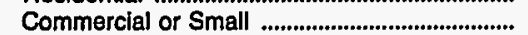 & 0 & 2,520 & 737 & 6,325 & 1,431 & 3,248 \\
\hline 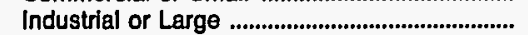 & 0 & 25 & 18 & 1 & 0 & 35 \\
\hline Other & 0 & 190 & 3 & 4 & 60 & 2,702 \\
\hline Total Uitimate Consumers ................................... & 0 & 36,103 & 6,382 & 60,787 & 10,723 & 36,512 \\
\hline \multicolumn{7}{|l|}{ Sales for the Year (megawatthours) } \\
\hline 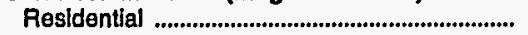 & 0 & 271,656 & 39,781 & 572,509 & 65,819 & 286,851 \\
\hline 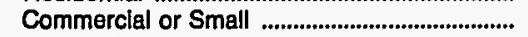 & 0 & 274,496 & 41,354 & 833,670 & 256,571 & 260,575 \\
\hline 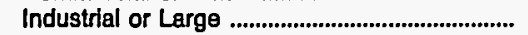 & 0 & 27,148 & 74,019 & 22,716 & 0 & 71,455 \\
\hline Other & 0 & 60,300 & 997 & 84,802 & 8,903 & 11,211 \\
\hline Total to Ultimate Consumers .......................... & 0 & 633,600 & 156,151 & $1,513,697$ & 331,293 & 630,092 \\
\hline Sales for Resale ................................................. & $1,389,068$ & & & 249,643 & & 0 \\
\hline 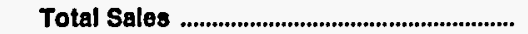 & $1,389,068$ & 633,600 & 156,151 & $1,763,340$ & 331,293 & 630,092 \\
\hline \multicolumn{7}{|l|}{ Oper Revenues for the Year (Thous) } \\
\hline 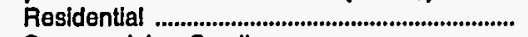 & 0 & 23,493 & 3,188 & 30,286 & 5,528 & 17,797 \\
\hline 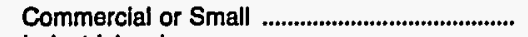 & 0 & 21,087 & 3,098 & 51,761 & 17,627 & 14,566 \\
\hline 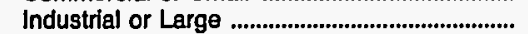 & 0 & 2,086 & 4,255 & 1,112 & 0 & 3,104 \\
\hline Other & 0 & 4,225 & 417 & 4,987 & 677 & 756 \\
\hline Total to Uitlmate Consumers .......................... & 0 & 50,891 & 10,958 & 88,146 & 23,832 & 36,223 \\
\hline 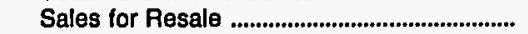 & 60,196 & & & 6,372 & & \\
\hline Total Revenues From Sales of Elec ......... & 60,196 & 50,891 & 10,958 & 94,518 & 23,832 & 36,223 \\
\hline
\end{tabular}

Note: Totals may not equal sum of components because of independent rounding.

Source: Energy Information Administration, Form EIA-861, "Annual Electric Utility Report." Data are submitted on a calendar year. 
Table 25. Number of Consumers, Sales, and Operating Revenue by Major U.S. Publicly Owned Electric Utility Within State, 1993 (Continued)

\begin{tabular}{|c|c|c|c|c|c|c|}
\hline Item & $\begin{array}{l}\text { Indiana } \\
\text { Auburn } \\
\text { City of } \\
\text { December } 31\end{array}$ & $\begin{array}{c}\text { Indiana } \\
\text { Bluffton } \\
\text { City of } \\
\text { December } 31\end{array}$ & $\begin{array}{c}\text { Indiana } \\
\text { Crawfordsville } \\
\text { Elec } \\
\text { Lgt\&Pwr Co } \\
\text { December } 31\end{array}$ & $\begin{array}{l}\text { Indiana } \\
\text { Frankfort } \\
\text { City of } \\
\text { December } 31\end{array}$ & $\begin{array}{l}\text { Indiana } \\
\text { Greenfield } \\
\text { City of } \\
\text { December } 31\end{array}$ & $\begin{array}{c}\text { Indiana } \\
\text { Indiana } \\
\text { Municipal } \\
\text { Power Agency } \\
\text { December } 31\end{array}$ \\
\hline \multicolumn{7}{|l|}{ Number of Consumers } \\
\hline 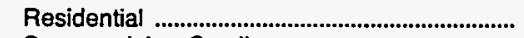 & 4,438 & 4,160 & 7,224 & 7,463 & 4,963 & 0 \\
\hline Commercial or Small & 636 & 559 & 1,157 & 1,061 & 600 & 0 \\
\hline Industrial or Large & 74 & 30 & 118 & 89 & 22 & 0 \\
\hline Other & 3 & 66 & 38 & 2 & 48 & 0 \\
\hline $\begin{array}{l}\text { Total Ultimate Consumers ......................... } \\
\text { Sales for the Year (megawatthours) }\end{array}$ & 5,151 & 4,815 & 8,537 & 8,615 & 5,633 & 0 \\
\hline 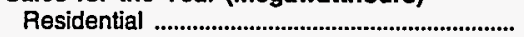 & 39,529 & 37,508 & 66,286 & 63,254 & 43,046 & 0 \\
\hline 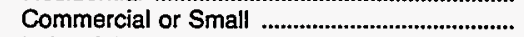 & 16,417 & 23,816 & 25,564 & 23,257 & 32,645 & 0 \\
\hline Industrial or Large & 280,438 & 92,882 & 252,816 & 199,953 & 77,271 & 0 \\
\hline Other & 1,192 & 4,342 & 3,258 & 2,638 & 3,646 & $\mathbf{0}$ \\
\hline Total to UltImate Consumers .......................... & 337,576 & 158,548 & 347,924 & 289,102 & 156,608 & 0 \\
\hline Sales for Resale & $\begin{array}{r}0 \\
0\end{array}$ & 0 & 14,910 & & 0 & $3,688,050$ \\
\hline \multicolumn{7}{|l|}{ Oper Revenues for the Year (Thous) } \\
\hline Residential & 1,918 & 2,186 & 4,599 & 4,089 & 2,750 & 0 \\
\hline 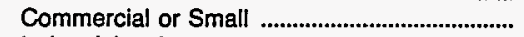 & 1,013 & 1,492 & 1,735 & 1,519 & 2,092 & 0 \\
\hline 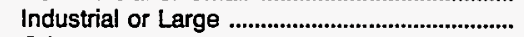 & 12,583 & 4,378 & 12,182 & 8,858 & 3,677 & 0 \\
\hline Other & 103 & 261 & 264 & 218 & 202 & 0 \\
\hline Total to Ultimate Consumers ........................ & 15,617 & 8,317 & 18,780 & 14,684 & $8, \overline{721}$ & $\mathbf{0}$ \\
\hline 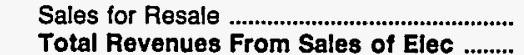 & $\begin{array}{r}0 \\
15,617\end{array}$ & $\begin{array}{r}0 \\
8,317\end{array}$ & $\begin{array}{r}1,984 \\
20,764\end{array}$ & $\begin{array}{r}0 \\
14,684\end{array}$ & $\begin{array}{r}0 \\
8,721\end{array}$ & $\begin{array}{l}142,066 \\
142,066\end{array}$ \\
\hline
\end{tabular}

\begin{tabular}{|c|c|c|c|c|c|c|}
\hline Item & $\begin{array}{l}\text { Indiana } \\
\text { Jasper } \\
\text { City of } \\
\text { December } 31\end{array}$ & $\begin{array}{l}\text { Indiana } \\
\text { Logansport } \\
\text { City of } \\
\text { December } 31\end{array}$ & $\begin{array}{c}\text { Indiana } \\
\text { Mishawaka } \\
\text { City of } \\
\text { December } \mathbf{3 1}\end{array}$ & $\begin{array}{l}\text { Indiana } \\
\text { Peru } \\
\text { City of } \\
\text { December } 31\end{array}$ & $\begin{array}{l}\text { Indiana } \\
\text { Richmond } \\
\text { City of } \\
\text { December } 31\end{array}$ & $\begin{array}{c}\text { Indiana } \\
\text { Washington } \\
\text { City of } \\
\text { December } 31\end{array}$ \\
\hline \multicolumn{7}{|l|}{ Number of Consumers } \\
\hline 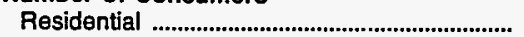 & 4,726 & 9,798 & 19,609 & 9,577 & 18,260 & 6,088 \\
\hline Commercial or Small & 736 & 2,223 & 2,691 & 378 & 2,422 & 850 \\
\hline 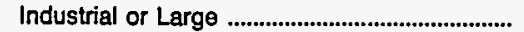 & 127 & 57 & 0 & 723 & 168 & 2 \\
\hline Other & 2 & 66 & 144 & 55 & 7 & $4 \overline{6}$ \\
\hline $\begin{array}{l}\text { Total Ultimate Consumers ........................... } \\
\text { Sales for the Year (megawatthours) }\end{array}$ & $5,59 \bar{t}$ & 12,144 & 22,444 & 10,333 & 20,857 & 6,986 \\
\hline 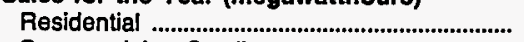 & 59,318 & 84,415 & 142,718 & 79,126 & 177,987 & 60,867 \\
\hline 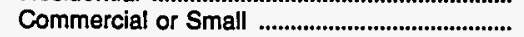 & 33,068 & 73,983 & 261,834 & 8,473 & 108,842 & 55,707 \\
\hline 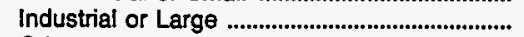 & 156,533 & 138,028 & 0 & 91,225 & 451,853 & 20,002 \\
\hline Other & 6,375 & 11,842 & 21,256 & 8,711 & 10,671 & 8,368 \\
\hline 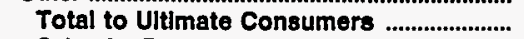 & 255,294 & 308,268 & 425,808 & 187,535 & 749,353 & 144,942 \\
\hline Sales for Resale & 0 & 0 & & 0 & & \\
\hline \multicolumn{7}{|l|}{ Oper Revenues for the Year (Thous) } \\
\hline 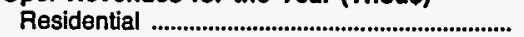 & 3,890 & 5,657 & 8,868 & 4,721 & 11,240 & 3,748 \\
\hline 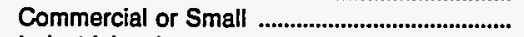 & 2,237 & 5,031 & 14,563 & 464 & 7,112 & 3,068 \\
\hline 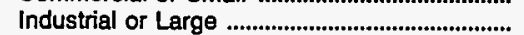 & 8,936 & 7,313 & 0 & 4,356 & 21,253 & 854 \\
\hline Other & 426 & 629 & 1,408 & 433 & 991 & 374 \\
\hline Total to Ultimate Consumers ......................... & 15,489 & 18,630 & 24,839 & 9,974 & 40,596 & 8,044 \\
\hline 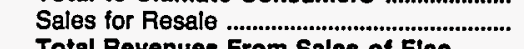 & & & & & & \\
\hline Total Revenues From Sales of Elec ......... & 15,489 & 18,630 & 24,839 & 9,974 & 40,596 & 8,044 \\
\hline
\end{tabular}

Note: Totals may not equal sum of components because of independent rounding.

Source: Energy Information Administration, Form ElA-861, "Annual Electric Utility Report." Data are submitted on a calendar year. 
Table 25. Number of Consumers, Sales, and Operating Revenue by Major U.S. Publicly Owned Electric Utility Within State, 1993 (Continued)

\begin{tabular}{|c|c|c|c|c|c|c|}
\hline Item & $\begin{array}{l}\text { lowa } \\
\text { Ames } \\
\text { City of } \\
\text { December } 31\end{array}$ & $\begin{array}{c}\text { lowa } \\
\text { Cedar } \\
\text { Falls } \\
\text { City of } \\
\text { December } 31\end{array}$ & $\begin{array}{c}\text { lowa } \\
\text { Muscatine } \\
\text { City of } \\
\text { December } 31\end{array}$ & $\begin{array}{c}\text { lowa } \\
\text { Pella } \\
\text { City of } \\
\text { December } \mathbf{3 1}\end{array}$ & $\begin{array}{l}\text { Kansas } \\
\text { Chanute } \\
\text { City of } \\
\text { December } 31\end{array}$ & $\begin{array}{c}\text { Kansas } \\
\text { Coffeyville } \\
\text { City of } \\
\text { December } 31\end{array}$ \\
\hline \multicolumn{7}{|l|}{ Number of Consumers } \\
\hline 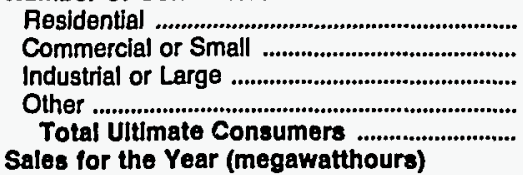 & $\begin{array}{r}14,925 \\
1,789 \\
251 \\
157 \\
17,122\end{array}$ & $\begin{array}{r}12,798 \\
1,585 \\
41 \\
238 \\
14,662\end{array}$ & $\begin{array}{r}8,948 \\
1,374 \\
108 \\
32 \\
10,462\end{array}$ & $\begin{array}{r}3,555 \\
470 \\
35 \\
55 \\
4,115\end{array}$ & $\begin{array}{r}4,611 \\
826 \\
80 \\
2 \\
5,519\end{array}$ & $\begin{array}{r}6,963 \\
959 \\
0 \\
0 \\
7,922\end{array}$ \\
\hline 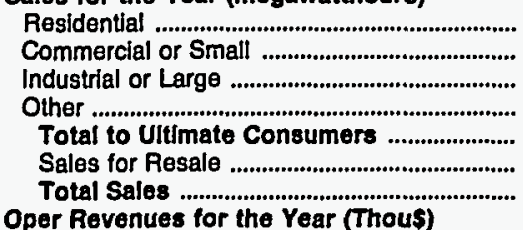 & $\begin{array}{r}101,633 \\
40,359 \\
140,645 \\
84,662 \\
367,299 \\
10,306 \\
377,605\end{array}$ & $\begin{array}{r}120,324 \\
86,114 \\
44,337 \\
46,709 \\
297,484 \\
16,436 \\
313,920\end{array}$ & $\begin{array}{r}87,420 \\
42,138 \\
650,382 \\
16,602 \\
796,542 \\
256,515 \\
1,053,057\end{array}$ & $\begin{array}{r}29,925 \\
17,902 \\
85,150 \\
4,053 \\
137,030 \\
0 \\
137,030\end{array}$ & $\begin{array}{r}39,536 \\
36,814 \\
69,648 \\
115 \\
146,113 \\
0 \\
146,113\end{array}$ & $\begin{array}{r}52,127 \\
118,073 \\
0 \\
0 \\
170,200 \\
0 \\
170,200\end{array}$ \\
\hline 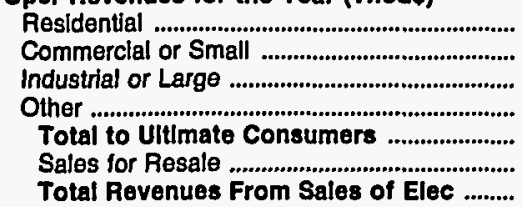 & $\begin{array}{r}7,353 \\
2,666 \\
7,094 \\
2,999 \\
20,112 \\
200 \\
20,312\end{array}$ & $\begin{array}{r}5,794 \\
3,750 \\
1,742 \\
1,795 \\
13,081 \\
270 \\
13,351\end{array}$ & $\begin{array}{r}5,436 \\
2,669 \\
26,672 \\
651 \\
35,428 \\
13,052 \\
48,480\end{array}$ & $\begin{array}{r}2,104 \\
1,372 \\
4,667 \\
234 \\
8,377 \\
0 \\
8,377\end{array}$ & $\begin{array}{r}2,830 \\
2,331 \\
3,570 \\
66 \\
8,797 \\
0 \\
0 \\
8,797\end{array}$ & $\begin{array}{r}3,785 \\
7,284 \\
0 \\
0 \\
11,069 \\
0 \\
11,069\end{array}$ \\
\hline
\end{tabular}

\begin{tabular}{|c|c|c|c|c|c|c|}
\hline Item & $\begin{array}{c}\text { Kansas } \\
\text { Garden } \\
\text { City City of } \\
\text { December } 31\end{array}$ & $\begin{array}{c}\text { Kansas } \\
\text { Kansas } \\
\text { City City of } \\
\text { December } 31\end{array}$ & $\begin{array}{c}\text { Kansas } \\
\text { Kansas } \\
\text { Municipal } \\
\text { Energy } \\
\text { Agency } \\
\text { December } 31\end{array}$ & $\begin{array}{l}\text { Kansas } \\
\text { McPherson } \\
\text { City of } \\
\text { December } 31\end{array}$ & $\begin{array}{c}\text { Kansas } \\
\text { Winfield } \\
\text { City of } \\
\text { December } 31\end{array}$ & $\begin{array}{c}\text { Kentucky } \\
\text { Bowling } \\
\text { Green } \\
\text { City of } \\
\text { December } 31\end{array}$ \\
\hline \multicolumn{7}{|l|}{ Number of Consumers } \\
\hline Rosldential ..................... & 8,434 & 59,047 & 0 & 6,490 & 5,600 & 17,358 \\
\hline 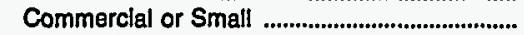 & 819 & 6,581 & 0 & 963 & 1,171 & 2,749 \\
\hline 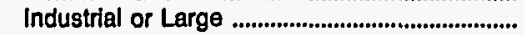 & 372 & 131 & 0 & 10 & 104 & 465 \\
\hline Other & 0 & 239 & 0 & 1 & 1,192 & 124 \\
\hline \multicolumn{7}{|l|}{ Sales for the Year (megawatthours) } \\
\hline 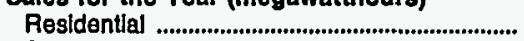 & 61,453 & 474,657 & 0 & 65,801 & 49,905 & 173,345 \\
\hline 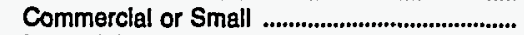 & 11,521 & 748,629 & 0 & 85,940 & 18,744 & 62,419 \\
\hline 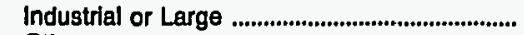 & 73,410 & 726,016 & 0 & 318,760 & 140,964 & 381,487 \\
\hline 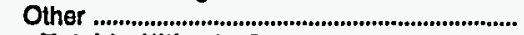 & & 75,579 & 0 & 4,243 & 6,037 & 8,249 \\
\hline Total to Ultimate Consumers ........................ & 146,384 & $2,024,881$ & 0 & 474,744 & 215,650 & 625,500 \\
\hline Sales for Resale & $\begin{array}{r}0 \\
146,384\end{array}$ & $\begin{array}{r}399,838 \\
2,424,719\end{array}$ & $\begin{array}{l}323,038 \\
323,038\end{array}$ & $\begin{array}{r}26,033 \\
500,777\end{array}$ & $\begin{array}{r}4,742 \\
220,392\end{array}$ & $\begin{array}{r}0 \\
625.500\end{array}$ \\
\hline \multicolumn{7}{|l|}{ Oper Revenues for the Year (Thous) } \\
\hline 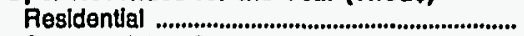 & 5,314 & 30,481 & 0 & 3,088 & 3,819 & 10,715 \\
\hline Commercial or Small ................................................... & 829 & 42,729 & 0 & 3,806 & 1,389 & 4,342 \\
\hline 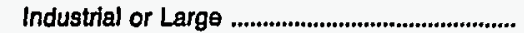 & 4,997 & 30,363 & 0 & 9,288 & 6,737 & 20,486 \\
\hline Other & 0 & 4,365 & 0 & 148 & 393 & 609 \\
\hline Total to Ultimate Consumers ....................... & 11,140 & 107,938 & & 16,330 & 12,338 & 36,152 \\
\hline Sales for Resale ....................................................... & & 12,280 & 10,032 & 2,693 & 253 & \\
\hline Total Rovenues From Sales of Elec ......... & 11,140 & 120,218 & 10,032 & 19,023 & 12,591 & 36,152 \\
\hline
\end{tabular}

Note: Totals may not equal sum of components because of independent rounding.

Source: Energy Information Administration, Form ElA-861, "Annual Electric Utility Report." Data are submitted on a calendar year. 
Table 25. Number of Consumers, Sales, and Operating Revenue by Major U.S. Publicly Owned Electric Utility Within State, 1993 (Continued)

\begin{tabular}{|c|c|c|c|c|c|c|}
\hline Item & $\begin{array}{c}\text { Kentucky } \\
\text { Frankfort } \\
\text { Gity of } \\
\text { December } 31\end{array}$ & $\begin{array}{c}\text { Kentucky } \\
\text { Franklin } \\
\text { City of } \\
\text { December } 31\end{array}$ & $\begin{array}{l}\text { Kentucky } \\
\text { Glasgow } \\
\text { City of } \\
\text { December } 31\end{array}$ & $\begin{array}{l}\text { Kentucky } \\
\text { Henderson } \\
\text { City } \\
\text { Utility Comm } \\
\\
\text { December } 31\end{array}$ & $\begin{array}{c}\text { Kentucky } \\
\text { Hopkinsville } \\
\text { City of }\end{array}$ & $\begin{array}{l}\text { Kentucky } \\
\text { Madisonville } \\
\text { Municipal } \\
\text { Utils } \\
\text { December } 31\end{array}$ \\
\hline \multicolumn{7}{|l|}{ Number of Consumers } \\
\hline 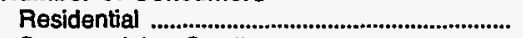 & 14,721 & 3,571 & 5,130 & 9,235 & 11,285 & 7,024 \\
\hline Commercial or Smalt & 2,264 & 579 & 870 & 1,521 & 1,692 & 1,293 \\
\hline 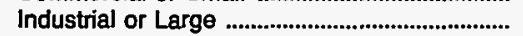 & 281 & 72 & 152 & 10 & 235 & 0 \\
\hline Other & 459 & 24 & 47 & 94 & 17 & 0 \\
\hline $\begin{array}{l}\text { Total Uitimate Consumers } \\
\text { Sales for the Year (megawatthours) }\end{array}$ & 17,725 & 4,246 & 6,199 & 10,860 & 13,229 & 8,317 \\
\hline 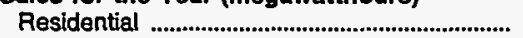 & 175,552 & 40,254 & 54,059 & 106,391 & 124,222 & 71,794 \\
\hline Commercial or Small & 63,999 & 10,266 & 17,556 & 152,928 & 35,187 & 193,043 \\
\hline Industrial or Large & 322,966 & 135,956 & 199,755 & 99,717 & 220,770 & 0 \\
\hline Other & 29,500 & 1,693 & 2,822 & 7,499 & 5,747 & 0 \\
\hline Total to Ultimate Consumers ...................... & 592,017 & 188,169 & 274,192 & 366,535 & 385,926 & 264,837 \\
\hline Sales for Resale & & & 0 & $1,333,940$ & 0 & \\
\hline \multicolumn{7}{|l|}{ Oper Revenues for the Year (Thous) } \\
\hline 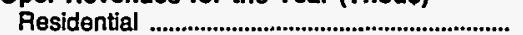 & 7,539 & 2,327 & 3,192 & 3,968 & 6,908 & 3,764 \\
\hline Commercial or Small & 2,911 & 683 & 1,197 & 4,968 & 2,286 & 8,061 \\
\hline Industrial or Large & 11,668 & 6,194 & 9,993 & 2,746 & 9,709 & 0 \\
\hline Other & 1,382 & 123 & 230 & 510 & 434 & 0 \\
\hline Total to Uitimate Consumers & 23,500 & 9,327 & 14,612 & 12,192 & 19,337 & 11,825 \\
\hline 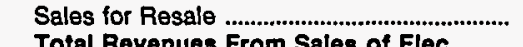 & $\begin{array}{r}0 \\
0350\end{array}$ & & $\begin{array}{r}0 \\
14612\end{array}$ & 11,161 & $\begin{array}{r}0 \\
10337\end{array}$ & \\
\hline Total Revenues From Sales of Elec ........ & 23,500 & 9,327 & 14,612 & 23,353 & 19,337 & 11,825 \\
\hline
\end{tabular}

\begin{tabular}{|c|c|c|c|c|c|c|}
\hline Item & $\begin{array}{l}\text { Kentucky } \\
\text { Mayfield } \\
\text { City of } \\
\text { December } 31\end{array}$ & $\begin{array}{l}\text { Kentucky } \\
\text { Murray } \\
\text { City of } \\
\text { December } 31\end{array}$ & $\begin{array}{l}\text { Kentucky } \\
\text { Owensboro } \\
\text { City of } \\
\text { December } 31\end{array}$ & $\begin{array}{l}\text { Kentucky } \\
\text { Paducah } \\
\text { City of } \\
\text { December } 31\end{array}$ & $\begin{array}{l}\text { Louisiana } \\
\text { Alexandria } \\
\text { City of } \\
\text { December } 31\end{array}$ & $\begin{array}{l}\text { Louisiana } \\
\text { Lafayette } \\
\text { City of } \\
\text { December } 31\end{array}$ \\
\hline \multicolumn{7}{|l|}{ Number of Consumers } \\
\hline 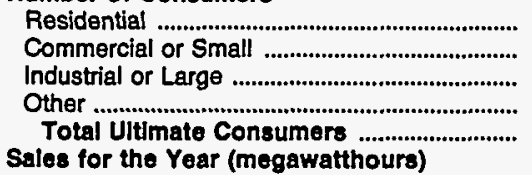 & $\begin{array}{r}4,896 \\
730 \\
121 \\
48 \\
5,795\end{array}$ & $\begin{array}{r}5,221 \\
933 \\
131 \\
15 \\
6,300\end{array}$ & $\begin{array}{r}21,523 \\
2,628 \\
1,872 \\
5 \\
26,028\end{array}$ & $\begin{array}{r}18,201 \\
2,729 \\
478 \\
321 \\
21,729\end{array}$ & $\begin{array}{r}20,789 \\
3,700 \\
0 \\
635 \\
25,124\end{array}$ & $\begin{array}{r}41,035 \\
5,891 \\
0 \\
2,101 \\
49,127\end{array}$ \\
\hline 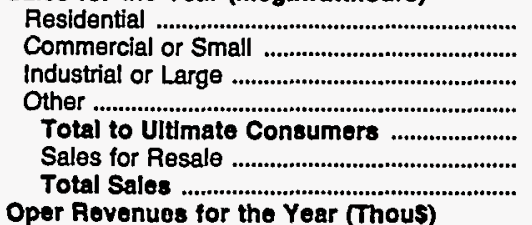 & $\begin{array}{r}51,122 \\
13,769 \\
65,407 \\
2,403 \\
132,701 \\
0 \\
132,701\end{array}$ & $\begin{array}{r}70,791 \\
19,802 \\
127,894 \\
2,266 \\
220,753 \\
0 \\
220,753\end{array}$ & $\begin{array}{r}201,879 \\
39,869 \\
425,178 \\
51,188 \\
718,114 \\
1,570,770 \\
2,288,884\end{array}$ & $\begin{array}{r}204,685 \\
51,724 \\
241,125 \\
8,662 \\
508,196 \\
0 \\
506,196\end{array}$ & $\begin{array}{r}249,743 \\
325,906 \\
0 \\
5,291 \\
580,940 \\
0 \\
580,940\end{array}$ & $\begin{array}{r}592,114 \\
705,108 \\
0 \\
73,189 \\
1,370,419 \\
586,131 \\
1,956,550\end{array}$ \\
\hline 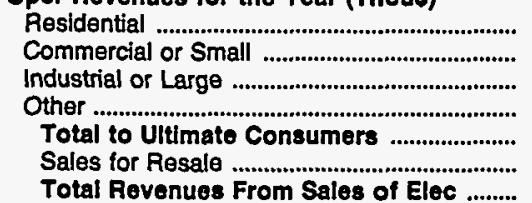 & $\begin{array}{r}3,193 \\
974 \\
3,875 \\
153 \\
8,195 \\
0 \\
8,195\end{array}$ & $\begin{array}{r}4,004 \\
1,276 \\
6,446 \\
168 \\
11,894 \\
0 \\
11,894\end{array}$ & $\begin{array}{r}9,668 \\
1,951 \\
13,659 \\
1,090 \\
26,368 \\
22,606 \\
48,974\end{array}$ & $\begin{array}{r}12,169 \\
3,624 \\
13,776 \\
755 \\
30,324 \\
0 \\
30,324\end{array}$ & $\begin{array}{r}17,960 \\
22,512 \\
0 \\
171 \\
40,643 \\
0 \\
40,643\end{array}$ & $\begin{array}{r}38,158 \\
43,041 \\
0 \\
4,087 \\
85,286 \\
20,792 \\
108,078\end{array}$ \\
\hline
\end{tabular}

Note: Totals may not equal sum of components because of independent rounding.

Source: Energy Information Administration, Form ElA-861, "Annual Electric Utility Report." Data are submitted on a calendar year. 
Table 25. Number of Consumers, Sales, and Operating Revenue by Major U.S. Publicly Owned Electric Utility Within State, 1993 (Continued)

\begin{tabular}{|c|c|c|c|c|c|c|}
\hline Item & $\begin{array}{l}\text { Louisiana } \\
\text { Lafayette } \\
\text { Public } \\
\text { Power Auth } \\
\text { December } 31\end{array}$ & $\begin{array}{c}\text { Louisiana } \\
\text { Louisiana } \\
\text { Energy } \\
\& \\
\text { Power Auth } \\
\text { December } 31\end{array}$ & $\begin{array}{l}\text { Louisiana } \\
\text { Morgan } \\
\text { City City of } \\
\text { December } 31\end{array}$ & $\begin{array}{c}\text { Natchitoches } \\
\text { City of }\end{array}$ & $\begin{array}{l}\text { Louisiana } \\
\text { Ruston } \\
\text { City of } \\
\text { December } 31\end{array}$ & $\begin{array}{c}\text { Louisiana } \\
\text { Terrebonne } \\
\text { Parish } \\
\text { Consol Govt } \\
\\
\text { December } 31\end{array}$ \\
\hline \multicolumn{7}{|l|}{ Number of Consumers } \\
\hline 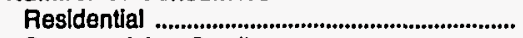 & 0 & 0 & 4,962 & 5,787 & 7.331 & 7,591 \\
\hline 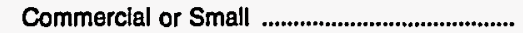 & 0 & 0 & 1,260 & 792 & 1,109 & 1,345 \\
\hline Industrial or Large & 0 & 0 & 0 & 9 & 87 & 0 \\
\hline Other & 0 & 0 & 0 & 1 & 117 & 0 \\
\hline $\begin{array}{l}\text { Total Ultimate Consumers .......................... } \\
\text { Sales for the Year (megawatthours) }\end{array}$ & $\mathbf{0}$ & 0 & 6,222 & 6,589 & 8,644 & 8,936 \\
\hline 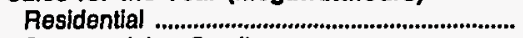 & 0 & 0 & 86,765 & 58,778 & 77,297 & 106,961 \\
\hline 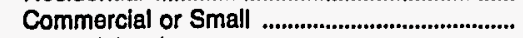 & 0 & 0 & 71,127 & 47,252 & 45,148 & 112,995 \\
\hline Industrial or Large ................................................. & 0 & 0 & 0 & 68,274 & 47,906 & 0 \\
\hline Other & 0 & 0 & 0 & 5,073 & 34,596 & 0 \\
\hline Total to Uitimate Consumers & 0 & $\mathbf{0}$ & 157,892 & 179,377 & 204,947 & 219,956 \\
\hline 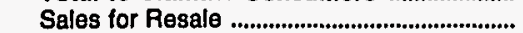 & $1,421,186$ & $1,537,920$ & 0 & 0 & 0 & 113,244 \\
\hline 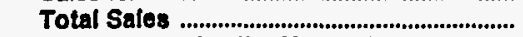 & $1,421,186$ & $1,537,920$ & 157,892 & 179,377 & 204,947 & 333,200 \\
\hline \multicolumn{7}{|l|}{ Oper Revenues for the Year (Thous) } \\
\hline 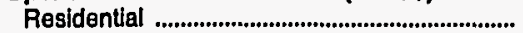 & 0 & 0 & 8,026 & 3,732 & 5,171 & 6,401 \\
\hline 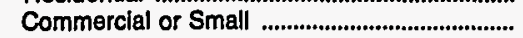 & 0 & 0 & 2,582 & 3,344 & 2,857 & 8,143 \\
\hline 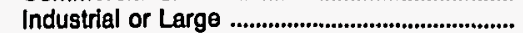 & 0 & 0 & 0 & 3,724 & 2,973 & 0 \\
\hline Other & 0 & 0 & 0 & 341 & 194 & 0 \\
\hline Total to UltImate Consumers ...................... & $\mathbf{0}$ & 0 & 10,608 & 11,141 & 11,195 & 14,544 \\
\hline Sales tor Resale ................................... & 49,627 & 64,170 & 0 & 0 & $\begin{array}{r}0 \\
1+105\end{array}$ & 3,230 \\
\hline Total Revenues From Sales of Elec ......... & & 64,170 & 10,608 & 11,141 & 11,195 & $\mathbf{1 7 , 7 7 4}$ \\
\hline
\end{tabular}

\begin{tabular}{|c|c|c|c|c|c|c|}
\hline Item & $\begin{array}{l}\text { Maryland } \\
\text { Easton } \\
\text { Utilities } \\
\text { Comm } \\
\text { December } 31\end{array}$ & $\begin{array}{l}\text { Maryland } \\
\text { Hagerstown } \\
\text { City of } \\
\text { December } 31\end{array}$ & $\begin{array}{l}\text { Massachusetts } \\
\text { Braintree } \\
\text { Town of } \\
\text { December } 31\end{array}$ & $\begin{array}{c}\text { Massachusetts } \\
\text { Chicopee } \\
\text { City of } \\
\text { December } 31\end{array}$ & $\begin{array}{l}\text { Massachusetts } \\
\text { Concord } \\
\text { Town of } \\
\text { December } 31\end{array}$ & $\begin{array}{l}\text { Massachusetts } \\
\text { Danvers } \\
\text { Town of } \\
\text { December } 31\end{array}$ \\
\hline \multicolumn{7}{|l|}{ Number of Consumers } \\
\hline 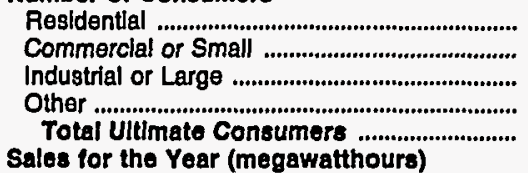 & $\begin{array}{r}5,920 \\
1,518 \\
0 \\
113 \\
7,551\end{array}$ & $\begin{array}{r}15,302 \\
1,969 \\
129 \\
66 \\
17,466\end{array}$ & $\begin{array}{r}11,502 \\
1,816 \\
10 \\
285 \\
13,613\end{array}$ & $\begin{array}{r}22,099 \\
1,919 \\
0 \\
480 \\
24,498\end{array}$ & $\begin{array}{r}5,994 \\
1,061 \\
14 \\
55 \\
7,124\end{array}$ & $\begin{array}{r}9,237 \\
1,419 \\
216 \\
255 \\
11,127\end{array}$ \\
\hline 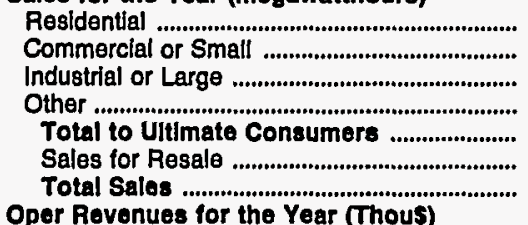 & $\begin{array}{r}69,468 \\
122,253 \\
0 \\
9,894 \\
201,615 \\
634 \\
202,249\end{array}$ & $\begin{array}{r}113,010 \\
57,486 \\
115,838 \\
8,426 \\
294,760 \\
0 \\
294,760\end{array}$ & $\begin{array}{r}90,300 \\
201,959 \\
50,774 \\
12,440 \\
355,473 \\
28,251 \\
383,724\end{array}$ & $\begin{array}{r}157,430 \\
171,322 \\
0 \\
47,946 \\
376,698 \\
22,469 \\
399,167\end{array}$ & $\begin{array}{r}53,330 \\
37,015 \\
43,942 \\
6,180 \\
140,467 \\
0 \\
140,467\end{array}$ & $\begin{array}{r}71,231 \\
45,767 \\
161,648 \\
15,167 \\
293,813 \\
2,348 \\
298,161\end{array}$ \\
\hline 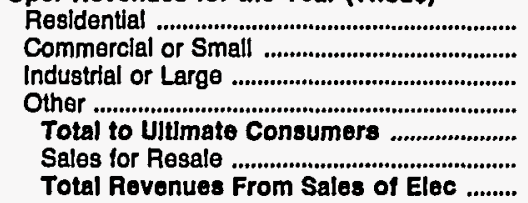 & $\begin{array}{r}4,562 \\
7,711 \\
0 \\
686 \\
12,959 \\
79 \\
13,038\end{array}$ & $\begin{array}{r}6,786 \\
3,295 \\
5,086 \\
508 \\
15,675 \\
0 \\
15,675\end{array}$ & $\begin{array}{r}6,927 \\
17,127 \\
3,882 \\
1,033 \\
28,969 \\
2,179 \\
31,148\end{array}$ & $\begin{array}{r}12,465 \\
13,984 \\
0 \\
3,630 \\
30,079 \\
1,489 \\
31,568\end{array}$ & $\begin{array}{r}4,638 \\
4,388 \\
3,111 \\
354 \\
12,491 \\
0 \\
12,491\end{array}$ & $\begin{array}{r}7,374 \\
5,340 \\
17,580 \\
1,464 \\
31,758 \\
130 \\
31,888\end{array}$ \\
\hline
\end{tabular}

Note: Totals may not equal sum of components because of independentrounding.

Source: Energy Information Administration, Form EIA-861, "Annual Electric Utility Report." Data are submitted on a calendar year. 
Table 25. Number of Consumers, Sales, and Operating Revenue by Major U.S. Publicly Owned Electric Utility Within State, 1993 (Continued)

\begin{tabular}{|c|c|c|c|c|c|c|}
\hline Item & $\begin{array}{l}\text { Massachusetts } \\
\text { Hingham } \\
\text { City of } \\
\text { December } 31\end{array}$ & $\begin{array}{l}\text { Massachusetts } \\
\text { Holyoke } \\
\text { City of } \\
\text { December } 31\end{array}$ & $\begin{array}{c}\text { Massachusetts } \\
\text { Hudson } \\
\text { Town of } \\
\text { December } 31\end{array}$ & $\begin{array}{l}\text { Massachusetts } \\
\text { Littleton } \\
\text { Town of } \\
\text { December } 31\end{array}$ & $\begin{array}{c}\text { Massachusetts } \\
\text { Mansfield } \\
\text { Town of } \\
\text { December } 31\end{array}$ & $\begin{array}{c}\text { Massachusetts } \\
\text { Massachusetts } \\
\text { Mun } \\
\text { Whis } \\
\text { Elec Co } \\
\text { December } 31\end{array}$ \\
\hline \multicolumn{7}{|l|}{ Number of Consumers } \\
\hline Residential & 7,714 & 15,235 & 8,666 & 4,842 & 7,348 & 0 \\
\hline Commercial or Small & 871 & 2,177 & 1,102 & 415 & 528 & 0 \\
\hline Industrial or Large & 40 & 12 & 189 & 56 & 214 & 0 \\
\hline Other & 52 & 530 & 250 & 4 & 1 & 0 \\
\hline Total Ultimate Consumers .......................... & 8,677 & 17,954 & 10,207 & 5,317 & 8,091 & $\mathbf{0}$ \\
\hline \multicolumn{7}{|l|}{ Sales for the Year (megawatthours) } \\
\hline 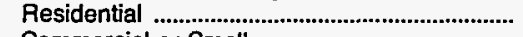 & 64,049 & 91,080 & 67,593 & 43,677 & 51,100 & 0 \\
\hline 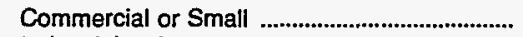 & 22,390 & 133,450 & 11,748 & 8,115 & 6,110 & 0 \\
\hline Industrial or Large & 46,108 & 9,816 & 163,787 & 116,209 & 110,550 & 0 \\
\hline Other & 5,260 & 23,003 & 13,845 & 5,257 & 7,070 & 0 \\
\hline 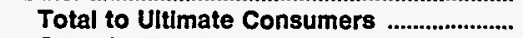 & 137,807 & 257,349 & 256,973 & 173,258 & 174,830 & 0 \\
\hline 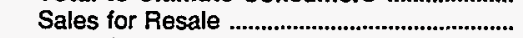 & 231 & 11,965 & 0 & 444 & 1,970 & $3,226,270$ \\
\hline Total Sales & 138,038 & 269,314 & 256,973 & 173,702 & 176,800 & $3,226,270$ \\
\hline \multicolumn{7}{|l|}{ Oper Revenues for the Year (Thous) } \\
\hline 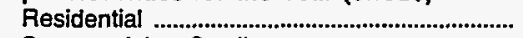 & 5,519 & 8,746 & 7,391 & 3,573 & 5,513 & 0 \\
\hline 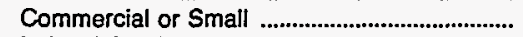 & 2,688 & 14,122 & 1,704 & 862 & 806 & 0 \\
\hline Industrial or Large & 4,025 & 880 & 17,098 & 11,164 & 11.154 & 0 \\
\hline Other & 579 & 2,333 & 1,030 & 457 & 859 & 0 \\
\hline 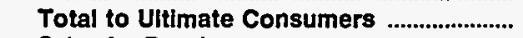 & 12,811 & 26,081 & 27,223 & 16,056 & 18,332 & $\mathbf{0}$ \\
\hline 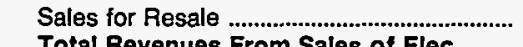 & $\begin{array}{r}54 \\
12865\end{array}$ & 290 & & 28 & 117 & 248,629 \\
\hline Total Revenues From Sales of Elec ......... & 12,865 & 26,371 & 27,223 & 16,084 & 18,449 & 248,629 \\
\hline
\end{tabular}

\begin{tabular}{|c|c|c|c|c|c|c|}
\hline Item & $\begin{array}{l}\text { Massachusetts } \\
\text { Middleborough } \\
\text { Town of } \\
\text { December } 31\end{array}$ & $\begin{array}{l}\text { Massachusetts } \\
\text { North } \\
\text { Attleborough } \\
\text { Town of } \\
\text { December } 31\end{array}$ & $\begin{array}{l}\text { Massachusetts } \\
\text { Norwood } \\
\text { City of } \\
\text { December } 31\end{array}$ & $\begin{array}{l}\text { Massachusetts } \\
\text { Peabody } \\
\text { City of } \\
\text { December } 31\end{array}$ & $\begin{array}{l}\text { Massachusetts } \\
\text { Reading } \\
\text { Town of } \\
\text { December } 31\end{array}$ & $\begin{array}{c}\text { Massachusetts } \\
\text { Shrewsbury } \\
\text { Town of } \\
\text { December } 31\end{array}$ \\
\hline \multicolumn{7}{|l|}{ Number of Consumers } \\
\hline 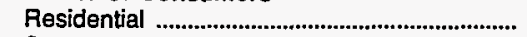 & 9,571 & 9,807 & 12,471 & 18,822 & 21,839 & 11,449 \\
\hline Commercial or Small & 1,317 & 815 & 2,047 & 1,759 & 0 & 766 \\
\hline Industrial or Large & 26 & 112 & 70 & 1,151 & 2,242 & 47 \\
\hline $\begin{array}{l}\text { Other } \\
\text { Total Ultimate Consumers } \\
\text { Sales for the Year (megawatthours) }\end{array}$ & 10,916 & $\begin{array}{r}653 \\
11,387\end{array}$ & $\begin{array}{r}8 \\
14,596\end{array}$ & $\begin{array}{r}113 \\
21,845\end{array}$ & $\begin{array}{r}402 \\
24,483\end{array}$ & $\begin{array}{r}76 \\
12,338\end{array}$ \\
\hline 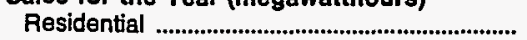 & 69,650 & 80,337 & 71,102 & 142,689 & 177,147 & 90,562 \\
\hline 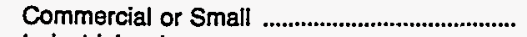 & 51,431 & 16,608 & 83,498 & 18,747 & 0 & 28,567 \\
\hline Industrial or Large & 38,569 & 74,936 & 155,207 & 198,854 & 356,166 & 109,188 \\
\hline Other .......................................................... & $\begin{array}{r}6,247 \\
165,897\end{array}$ & $\begin{array}{r}12,492 \\
184,373\end{array}$ & $\begin{array}{r}7,320 \\
317,127\end{array}$ & $\begin{array}{r}18,722 \\
370,012\end{array}$ & $\begin{array}{r}21,242 \\
554555\end{array}$ & $\begin{array}{r}14,489 \\
242,806\end{array}$ \\
\hline 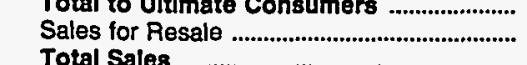 & $\begin{array}{r}165,897 \\
22 \\
165,910\end{array}$ & $\begin{array}{r}184,373 \\
113 \\
184,486\end{array}$ & $\begin{array}{r}317,127 \\
0 \\
317,127\end{array}$ & $\begin{array}{r}379,012 \\
1,123\end{array}$ & $\begin{array}{r}554,555 \\
575 \\
555,130\end{array}$ & $\begin{array}{r}242,806 \\
1,193 \\
\end{array}$ \\
\hline \multicolumn{7}{|l|}{ Oper Revenues for the Year (Thous) } \\
\hline 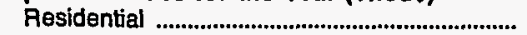 & 6,365 & 7,546 & 5,749 & 13,702 & 17,175 & 7,005 \\
\hline 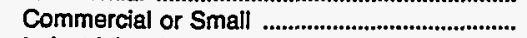 & 5,472 & 1,804 & 9,512 & 2,186 & & 2,856 \\
\hline Industrial or Large & 3,673 & 6,839 & 11,921 & 20,434 & 28,754 & 8,756 \\
\hline Other & 718 & 1,128 & 544 & 2,050 & 2,061 & 1,187 \\
\hline Total to Ultumate Consumers & $\begin{array}{r}16,228 \\
36\end{array}$ & $\begin{array}{r}17,317 \\
36\end{array}$ & $\begin{array}{r}27,726 \\
0\end{array}$ & $\begin{array}{r}38,372 \\
25\end{array}$ & $\begin{array}{r}47,990 \\
51\end{array}$ & $\begin{array}{r}19,804 \\
93\end{array}$ \\
\hline Total Revenues From Sales of Elec ......... & 16,264 & 17,353 & 27,726 & 38,397 & 48,041 & 19,897 \\
\hline
\end{tabular}

Note: Totals may not equal sum of components because of independent rounding.

Source: Energy Information Administration, Form EIA-861, "Annual Electric Utility Report." Data are submitted on a calendar year. 
Table 25. Number of Consumers, Sales, and Operating Revenue by Major U.S. Publicly Owned Electric Utility Within State, 1993 (Continued)

\begin{tabular}{|c|c|c|c|c|c|c|}
\hline Item & $\begin{array}{l}\text { Massachusetts } \\
\text { Taunton } \\
\text { City of } \\
\text { December } 31\end{array}$ & $\begin{array}{l}\text { Massachusetts } \\
\text { Wakefield } \\
\text { Town of } \\
\text { December } 31\end{array}$ & $\begin{array}{l}\text { Massachusetts } \\
\text { Wellesley } \\
\text { Town of } \\
\text { December } 31\end{array}$ & $\begin{array}{l}\text { Massachusetts } \\
\text { Westfield } \\
\text { City of } \\
\text { December } 31\end{array}$ & $\begin{array}{c}\text { Michigan } \\
\text { Bay } \\
\text { City City of } \\
\text { December } 31\end{array}$ & $\begin{array}{l}\text { Michigan } \\
\text { Coldwater } \\
\text { Board } \\
\text { of } \\
\text { Public Util } \\
\text { December } 31\end{array}$ \\
\hline \multicolumn{7}{|l|}{ Number of Consumers } \\
\hline Residential & 26,122 & 9,344 & 8,523 & 14,290 & 19,137 & 4,800 \\
\hline Commerclal or Small & 3,970 & 1,203 & 969 & 1,669 & 2,668 & 782 \\
\hline 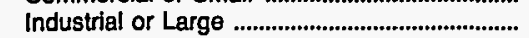 & 74 & 293 & 0 & 129 & 58 & 150 \\
\hline Other & 129 & 1 & 70 & 95 & 120 & 151 \\
\hline $\begin{array}{l}\text { Total Ultumate Consumers } \\
\text { Sales tor the Year (megawathours) }\end{array}$ & 30,295 & 10,841 & 9,562 & 16,183 & 21,983 & 5,883 \\
\hline 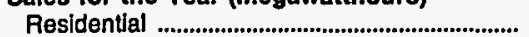 & 185,407 & 59,430 & 71,940 & 102,268 & 100,257 & 29,168 \\
\hline 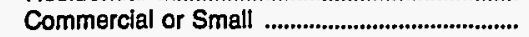 & 143,336 & 17,170 & 121,289 & 83,805 & 89,810 & 15,948 \\
\hline 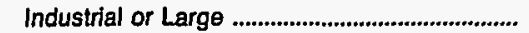 & 123,373 & 62,909 & 0 & 69,741 & 60,150 & 96,767 \\
\hline Other & 23,205 & 4,649 & 8,608 & 10,285 & 25,302 & 306 \\
\hline Total to Ultimate Consumers ...................... & 475,321 & 144,158 & 201,837 & 266,099 & 275,519 & 142,189 \\
\hline Sales for Resale & 27,665 & 0 & 0 & 8,919 & & \\
\hline 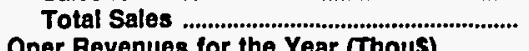 & 502,986 & 144,158 & 201,837 & 275,018 & 275,519 & 142,189 \\
\hline $\begin{array}{l}\text { Oper Revenues for the Year (Thous) } \\
\text { Residential ........................................................... }\end{array}$ & 14,035 & 5,749 & 6,036 & 10,454 & 6,467 & Oper Revenues for the Year (Thous) \\
\hline Commercial or Small & 12,443 & 1,995 & 9,754 & 10,484 & 6,530 & 1,662 \\
\hline 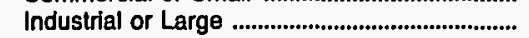 & 8,408 & 7,025 & 0 & 7,547 & 2,909 & 6,168 \\
\hline Other & 1,923 & 439 & 758 & 1,274 & 1,582 & 37 \\
\hline Total to Ultimate Consumers & 36,809 & 15,208 & 16,548 & 29,759 & 17,488 & 10,543 \\
\hline 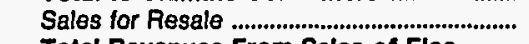 & 2,607 & & & 1,388 & & \\
\hline Total Revenues From Sales of Elec ......... & 39,416 & 15,208 & 16,548 & 31,147 & 17,488 & 10,543 \\
\hline
\end{tabular}

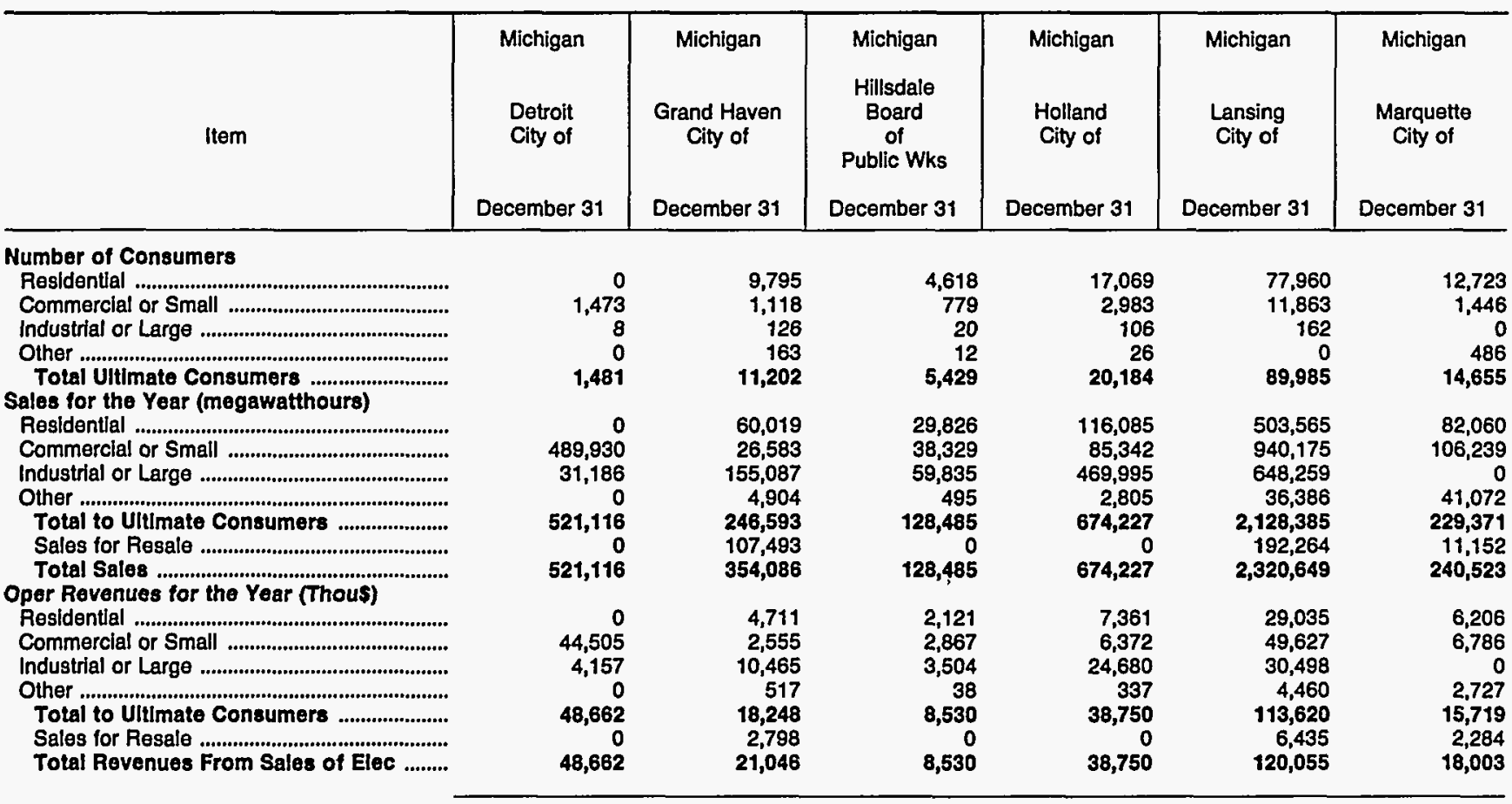

Note: Totals may not equal sum of components because of independent rounding.

Source: Energy Information Administration, Form ElA-861, "Annual Electric Utility Report." Data are submitted on a calendar year. 
Table 25. Number of Consumers, Sales, and Operating Revenue by Major U.S. Publicly Owned Electric Utllity Within State, 1993 (Continued)

\begin{tabular}{|c|c|c|c|c|c|c|}
\hline Item & $\begin{array}{c}\text { Michigan } \\
\text { Michigan } \\
\text { Public } \\
\text { Power Agency } \\
\text { December } 31\end{array}$ & $\begin{array}{l}\text { Michigan } \\
\text { Michigan } \\
\text { South } \\
\text { Central } \\
\text { Pwr Agy } \\
\text { December 31 }\end{array}$ & $\begin{array}{c}\text { Michigan } \\
\text { Sturgis } \\
\text { City of } \\
\text { December } 31\end{array}$ & $\begin{array}{c}\text { Michigan } \\
\text { Traverse } \\
\text { City City of } \\
\text { December } 31\end{array}$ & $\begin{array}{l}\text { Michigan } \\
\text { Wyandotte } \\
\text { Municipal } \\
\text { Serv Comm } \\
\text { December } 31\end{array}$ & $\begin{array}{l}\text { Michigan } \\
\text { Zeeland } \\
\text { City of } \\
\text { December } 31\end{array}$ \\
\hline \multicolumn{7}{|l|}{ Number of Consumers } \\
\hline 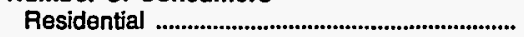 & 0 & 0 & 5,570 & 6,672 & 12,176 & 2,840 \\
\hline 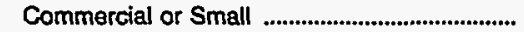 & 0 & 0 & 807 & 1,964 & 1,191 & 430 \\
\hline 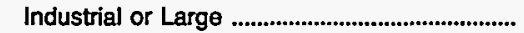 & 0 & 0 & 73 & 19 & 137 & 0 \\
\hline 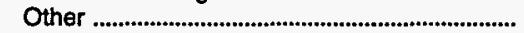 & 0 & 0 & 239 & 1 & 1 & 15 \\
\hline $\begin{array}{l}\text { Total Ultimate Consumers ............................. } \\
\text { Sales for the Year (megawatthours) }\end{array}$ & \multicolumn{4}{|c|}{ Sales for the Year (megawatthours) } & 13,505 & 3,285 \\
\hline 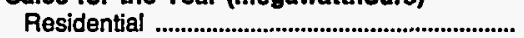 & 0 & 0 & 44,799 & 37,566 & 67,584 & 17,881 \\
\hline Commercial or Small & 0 & 0 & 53,403 & 103,968 & 20,605 & 126,609 \\
\hline 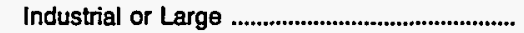 & 0 & 0 & 100,495 & 61,081 & 139,367 & 0 \\
\hline Other & 0 & 0 & 1,779 & 885 & 4,127 & 481 \\
\hline Total to Ultimate Consumers ...................... & 0 & $\mathbf{0}$ & 200,476 & 203,500 & 231,683 & 144,971 \\
\hline Sales for Resale & $2,024,277$ & 431,593 & 0 & 0 & 1,956 & \\
\hline 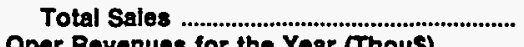 & $2,024,277$ & 431,593 & 200,476 & 203,500 & 233,639 & 144,971 \\
\hline \multicolumn{7}{|l|}{ Oper Revenues for the Year (Thous) } \\
\hline & $\begin{array}{l}0 \\
0\end{array}$ & $\begin{array}{l}0 \\
0\end{array}$ & $\begin{array}{l}2,965 \\
4,012\end{array}$ & $\begin{array}{l}2,521 \\
7,544\end{array}$ & 6,108 & $\begin{array}{r}1,145 \\
6875\end{array}$ \\
\hline $\begin{array}{l}\text { Commercial or Small } \\
\text { Industrial or Large }\end{array}$ & $\begin{array}{l}0 \\
0\end{array}$ & $\begin{array}{l}0 \\
0\end{array}$ & $\begin{array}{l}4,012 \\
5,782\end{array}$ & $\begin{array}{l}7,544 \\
3,115\end{array}$ & $\begin{array}{l}2,057 \\
9,913\end{array}$ & $\begin{array}{r}6,875 \\
0\end{array}$ \\
\hline 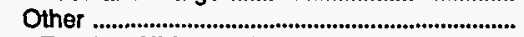 & 0 & 0 & 122 & 139 & 454 & 44 \\
\hline Total to Ultimate Consumers ...................... & & 0 & 12,881 & 13,319 & 18,532 & 8,064 \\
\hline Sales for Resale & 98,228 & 22,759 & 0 & $\begin{array}{r}0 \\
0\end{array}$ & 18 & \\
\hline Total Revenues From Sales of Elec ......... & 98,228 & 22,759 & 12,881 & 13,319 & 18,550 & 8,064 \\
\hline
\end{tabular}

\begin{tabular}{|c|c|c|c|c|c|c|}
\hline Item & $\begin{array}{l}\text { Minnesota } \\
\text { Alexandria } \\
\text { City of }\end{array}$ & $\begin{array}{c}\text { Minnesota } \\
\text { Anoka } \\
\text { City of } \\
\text { December } 31\end{array}$ & $\begin{array}{c}\text { Minnesota } \\
\text { Austin } \\
\text { City of } \\
\text { December } 31\end{array}$ & $\begin{array}{c}\text { Minnesota } \\
\text { Brainerd } \\
\text { City of } \\
\text { December } 31\end{array}$ & $\begin{array}{c}\text { Minnesota } \\
\text { Chaska } \\
\text { City of } \\
\text { December } 31\end{array}$ & $\begin{array}{c}\text { Minnesota } \\
\text { Fairmont } \\
\text { Public } \\
\text { Utilities } \\
\text { Comm } \\
\text { December } 31\end{array}$ \\
\hline \multicolumn{7}{|l|}{ Number of Consumers } \\
\hline 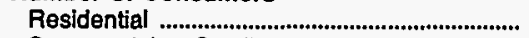 & 5,948 & 9,392 & 9,757 & 5,468 & 4,553 & 5,042 \\
\hline 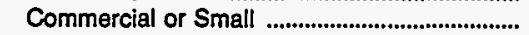 & 1,174 & 1,007 & 1,117 & 1,042 & 282 & 760 \\
\hline Industrial or Large & 46 & 17 & 1 & 15 & 188 & 17 \\
\hline Other & 102 & 0 & 361 & 50 & 54 & 8 \\
\hline $\begin{array}{l}\text { Total Ultimate Consumers ........................... } \\
\text { Sales for the Year (megawatthours) }\end{array}$ & 7,270 & 10,416 & 11,236 & 6,575 & 5,077 & 5,827 \\
\hline 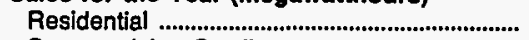 & 50,630 & 59,316 & 65,080 & 37,780 & 33,356 & 35,717 \\
\hline 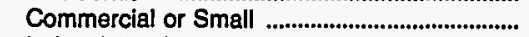 & 41,651 & 57,113 & 116,133 & 60,700 & 3,943 & 36,989 \\
\hline 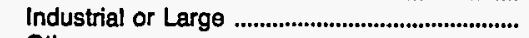 & 72,414 & 87,317 & 53,016 & 29,638 & 102,607 & 58,867 \\
\hline 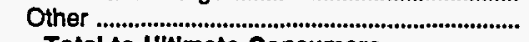 & 2,574 & 0 & 4,478 & 4,435 & 5,394 & 5,451 \\
\hline Total to Ultimate Consumers ....................... & 167,269 & 203,746 & 238,707 & 132,553 & 145,300 & 137,124 \\
\hline 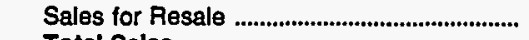 & & & 80,422 & & & \\
\hline \multicolumn{7}{|l|}{ Oper Revenues for the Year (Thous) } \\
\hline 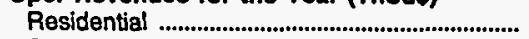 & 2,341 & 4,090 & 5,813 & 2,173 & 2,193 & 2,815 \\
\hline 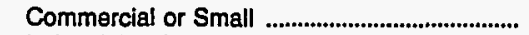 & 1,927 & 3,471 & 8,117 & 3,299 & 277 & 2,675 \\
\hline Industrial or Large & 3,083 & 3,877 & 3,398 & 1,405 & 5,618 & 3,350 \\
\hline Other & 97 & 0 & 436 & 343 & 226 & 257 \\
\hline Total to Ultimate Consumers ....................... & 7,448 & 11,438 & 17,764 & 7,220 & 8,314 & 9,097 \\
\hline Sales for Resale & & & & & & \\
\hline Total Revenues From Sales of Elec ......... & 7,448 & 11,438 & 17,764 & 7,220 & 8,314 & 9,097 \\
\hline
\end{tabular}

Note: Totals may not equal sum of components because of independent rounding.

Source: Energy Information Administration, Form ElA-861, "Annual Electric Utility Report." Data are submitted on a calendar year. 
Table 25. Number of Consumers, Sales, and Operating Revenue by Major U.S. Publicly Owned Electric Utility Within State, 1993 (Continued)

\begin{tabular}{|c|c|c|c|c|c|c|}
\hline Item & $\begin{array}{l}\text { Minnesota } \\
\text { Hutchinson } \\
\text { Utilities } \\
\text { Comm } \\
\text { December } 31\end{array}$ & $\begin{array}{c}\text { Minnesota } \\
\text { Marshall } \\
\text { City of } \\
\text { December } 31\end{array}$ & $\begin{array}{l}\text { Moorhead } \\
\text { City of } \\
\text { December } 31\end{array}$ & $\begin{array}{l}\text { Minnesota } \\
\text { New Ulm } \\
\text { Public } \\
\text { Utilities } \\
\text { Comm } \\
\text { December } 31\end{array}$ & $\begin{array}{c}\text { Minnesota } \\
\text { Northern } \\
\text { Municipal } \\
\text { Power Agny } \\
\text { December } 31\end{array}$ & $\begin{array}{c}\text { Minnesota } \\
\text { Owatonna } \\
\text { City of }\end{array}$ \\
\hline \multicolumn{7}{|l|}{ Number of Consumers } \\
\hline 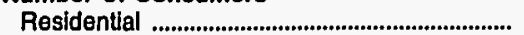 & 4,716 & 5,018 & 11,256 & 5,594 & 0 & 8,007 \\
\hline Commercial or Small & 712 & 758 & 1,501 & 837 & 0 & 801 \\
\hline Industrial or Large & 1 & 180 & 159 & 4 & 0 & 106 \\
\hline Other & 1 & 1 & 3 & 71 & 0 & 24 \\
\hline & \multicolumn{2}{|c|}{ Sales for the Year (megawatthours) } & 12,919 & 6,506 & $\mathbf{0}$ & 8,938 \\
\hline 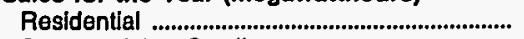 & 37,545 & 47,704 & 126,751 & 37,856 & 0 & 53,071 \\
\hline Commercial or Small ............................................. & 87,180 & 19,841 & 17,098 & 50,121 & 0 & 18,348 \\
\hline 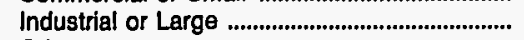 & 126,616 & 277,881 & 171,938 & 60,300 & 0 & 152,399 \\
\hline Other & 1,077 & 424 & 6,725 & 10,283 & 0 & 3,424 \\
\hline Total to Uitimate Consumers ...................... & 252,418 & 345,850 & 322,512 & 158,560 & $\mathbf{0}$ & 227,242 \\
\hline 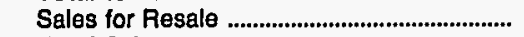 & 26 & 0 & 0 & 0 & 798,679 & \\
\hline Total Sales .......................................... & 252,444 & 345,850 & 322,512 & 158,560 & 798,679 & 227,242 \\
\hline \multicolumn{7}{|l|}{ Oper Revenues for the Year (Thous) } \\
\hline 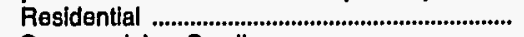 & 1,812 & 2,010 & 4,820 & 2,606 & 0 & 4,963 \\
\hline 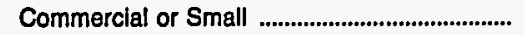 & 3,876 & 844 & 790 & 3,210 & 0 & 1,475 \\
\hline Industrial or Large & 4,287 & 8,451 & 6,286 & 3,205 & 0 & 8,985 \\
\hline 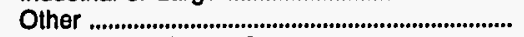 & 41 & 142 & 292 & 725 & 0 & 197 \\
\hline Total to UitImate Consumers ........................ & 10,016 & 11,447 & 12,188 & 9,746 & $\mathbf{0}$ & 15,620 \\
\hline 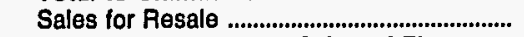 & & & & & 35,898 & \\
\hline Total Revenues From Sales of Elec ......... & 10,017 & 11,447 & 12,188 & 9,746 & 35,898 & 15,620 \\
\hline
\end{tabular}

\begin{tabular}{|c|c|c|c|c|c|c|}
\hline Item & $\begin{array}{c}\text { Minnesota } \\
\begin{array}{c}\text { Rochester } \\
\text { Public } \\
\text { Utilities }\end{array} \\
\text { December } 31\end{array}$ & $\begin{array}{c}\text { Minnesota } \\
\text { Shakopee } \\
\text { Public } \\
\text { Utilities } \\
\text { Comm } \\
\text { December } 31\end{array}$ & $\begin{array}{c}\text { Minnesota } \\
\text { Southern } \\
\text { Minnesota } \\
\text { Mun P } \\
\text { Agny } \\
\text { December } 31\end{array}$ & $\begin{array}{c}\text { Minnesota } \\
\text { Western } \\
\text { Minnesota } \\
\text { Mun } \\
\text { Pwr Agny } \\
\text { December } 31\end{array}$ & $\begin{array}{c}\text { Minnesota } \\
\text { Willmar } \\
\text { Municipal } \\
\text { Utils Comm } \\
\text { December } 31\end{array}$ & $\begin{array}{c}\text { Mississippl } \\
\text { Aberdeen } \\
\text { City of } \\
\text { December } 31\end{array}$ \\
\hline 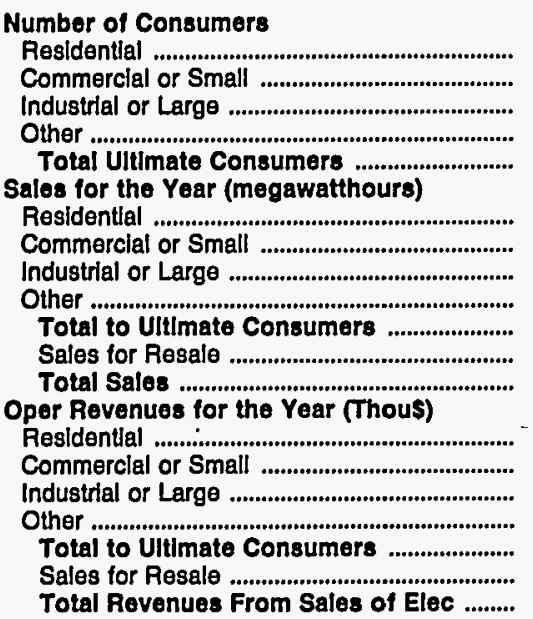 & $\begin{array}{r}29,437 \\
3,182 \\
15 \\
4 \\
32,638 \\
\\
200,562 \\
281,811 \\
395,355 \\
12,929 \\
890,657 \\
124,973 \\
1,015,630\end{array}$ & $\begin{array}{r}41,905 \\
83,116 \\
0 \\
1,323 \\
128,344 \\
0 \\
126,344\end{array}$ & $\begin{array}{r}0 \\
0 \\
0 \\
0 \\
0 \\
0 \\
2,389,972 \\
2,389,972\end{array}$ & $\begin{array}{r}0 \\
0 \\
0 \\
0 \\
0 \\
1,665,354 \\
1,665,354\end{array}$ & $\begin{array}{r}52,592 \\
139,542 \\
0 \\
0 \\
192,134 \\
0 \\
192,134\end{array}$ & $\begin{array}{r}2,894 \\
561 \\
67 \\
24 \\
3,546 \\
35,937 \\
9,018 \\
106,217 \\
2,937 \\
154,109 \\
0 \\
154,109\end{array}$ \\
\hline
\end{tabular}

Note: Totals may not equal sum of components because of independent rounding.

Source: Energy Information Administration, Form ElA-861, "Annual Electric Utility Report." Data are submitted on a calendar year. 
Table 25. Number of Consumers, Sales, and Operating Revenue by Major U.S. Publicly Owned Electric Utility Within State, 1993 (Continued)

\begin{tabular}{|c|c|c|c|c|c|c|}
\hline Item & $\begin{array}{l}\text { Mississippi } \\
\text { Clarksdale } \\
\text { City of } \\
\text { December } 31\end{array}$ & $\begin{array}{l}\text { Mississippi } \\
\text { Columbus } \\
\text { City of } \\
\text { December } 31\end{array}$ & $\begin{array}{l}\text { Mississippi } \\
\text { Greenwood } \\
\text { Utilities } \\
\text { Comm } \\
\text { December } 31\end{array}$ & $\begin{array}{c}\text { Mississippi } \\
\text { Holly } \\
\text { Springs } \\
\text { City of } \\
\text { December } 31\end{array}$ & $\begin{array}{c}\text { Mississippi } \\
\text { Louisville } \\
\text { Electric } \\
\text { System } \\
\text { December } 31\end{array}$ & $\begin{array}{c}\text { Mississippi } \\
\text { Municipal } \\
\text { Energy } \\
\text { Agency } \\
\text { of MS } \\
\text { December } 31\end{array}$ \\
\hline \multicolumn{7}{|l|}{ Number of Consumers } \\
\hline 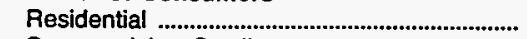 & 6,382 & 9,219 & 8,715 & 7,878 & 2,745 & 0 \\
\hline Commercial or Small & 1,405 & 2,030 & 1,343 & 1,503 & 667 & 0 \\
\hline Industrial or Large & 18 & 290 & 4 & 94 & 71 & 0 \\
\hline Other & 84 & 21 & 138 & 18 & 28 & 0 \\
\hline $\begin{array}{l}\text { Total Ultimate Consumers ......................... } \\
\text { Sales for the Year (megawatthours) }\end{array}$ & 7,889 & 11,560 & 10,200 & 9,493 & 3,511 & $\mathbf{0}$ \\
\hline 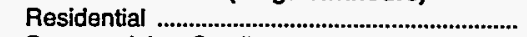 & 72,227 & 114,277 & 95,277 & 103,649 & 30,250 & 0 \\
\hline Commercial or Small & 56,887 & 39,894 & 115,085 & 17,776 & 10,124 & 0 \\
\hline Industrial or Large & 28,753 & 275,137 & 45,797 & 66,660 & 104,838 & 0 \\
\hline Other & 8,558 & 4,453 & 9,041 & 4,678 & 2,277 & 0 \\
\hline Total to Ultimate Consumers ........................ & 166,425 & 433,761 & 265,200 & 192,763 & 147,489 & 0 \\
\hline Sales for Resale & 50,651 & 0 & 0 & 0 & 0 & 818,696 \\
\hline $\begin{array}{l}\text { Total Sales ..................................... } \\
\text { Oper Revenues for the Year (Thous) }\end{array}$ & 217,076 & 433,761 & 265,200 & 192,763 & 147,489 & 818,696 \\
\hline \multicolumn{7}{|l|}{ Oper Revenues for the Year (Thou\$) } \\
\hline 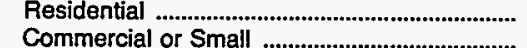 & 4,742 & 6,083 & 5,584 & 6,107 & 1,790 & 0 \\
\hline 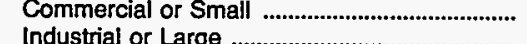 & 3,692 & 2,482 & 7,087 & 1,284 & 698 & 0 \\
\hline 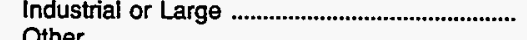 & 1,538 & 13,358 & 2,372 & 3,758 & 5,322 & 0 \\
\hline Other & 579 & 382 & 759 & 428 & 177 & 0 \\
\hline Total to Ultimate Consumers ......................... & 10,551 & 22,305 & 15,802 & 11,577 & 7,987 & o \\
\hline Sales for Resale .......................................... & 2,027 & & $\begin{aligned} 0 \\
15\end{aligned}$ & 0 & 0 & 30,782 \\
\hline Total Revenues From Sales of Elec ........ & 12,578 & 22,305 & 15,802 & 11,577 & 7,987 & 30,782 \\
\hline
\end{tabular}

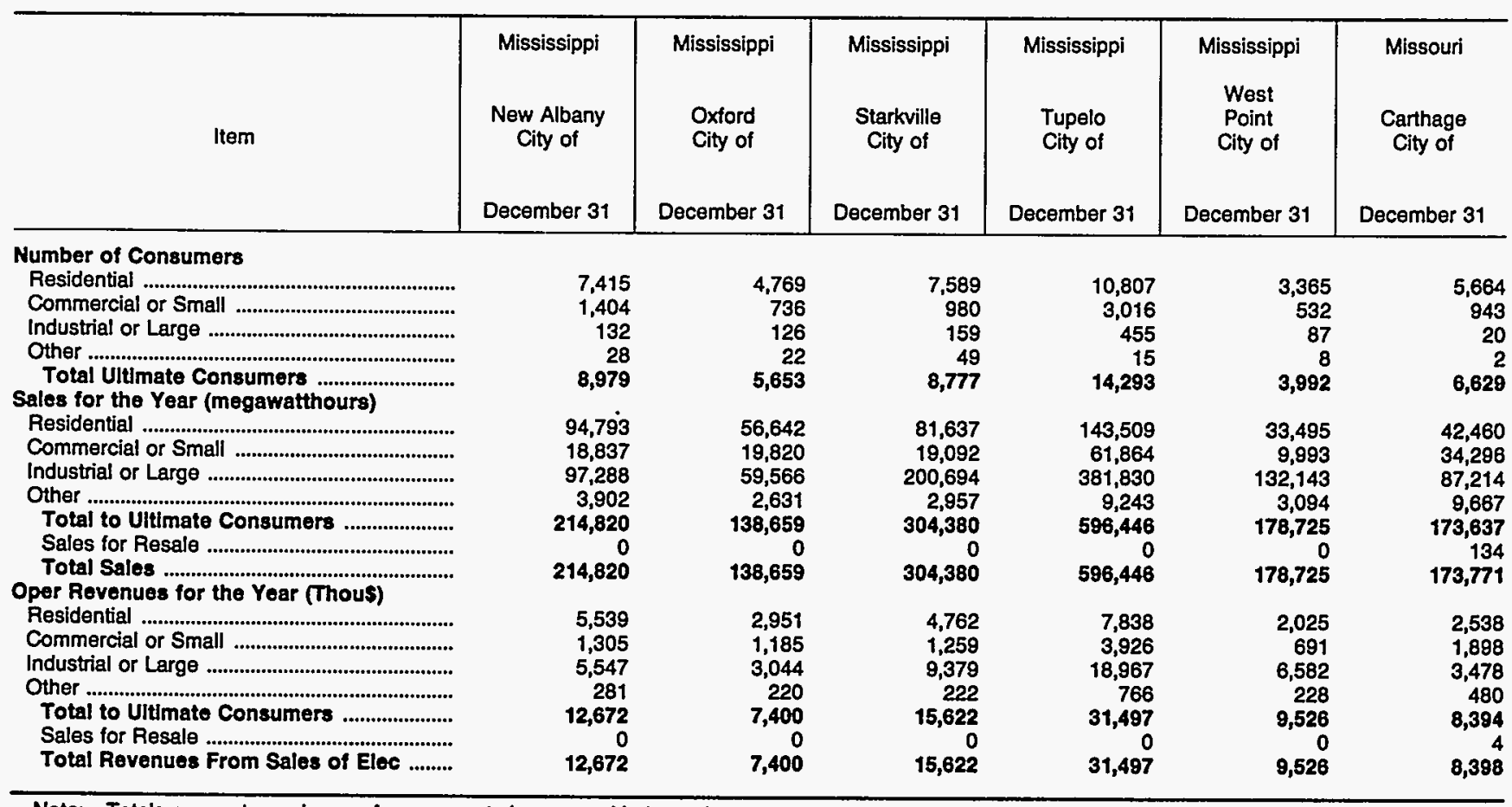

Note: Totals may not equal sum of components because of independentrounding

Source: Energy Information Administration, Form ElA-861, "Annual Electric Utility Report." Data are submitted on a calendar year. 
Table 25. Number of Consumers, Sales, and Operating Revenue by Major U.S. Publicly Owned Electric Utillty Within State, 1993 (Continued)

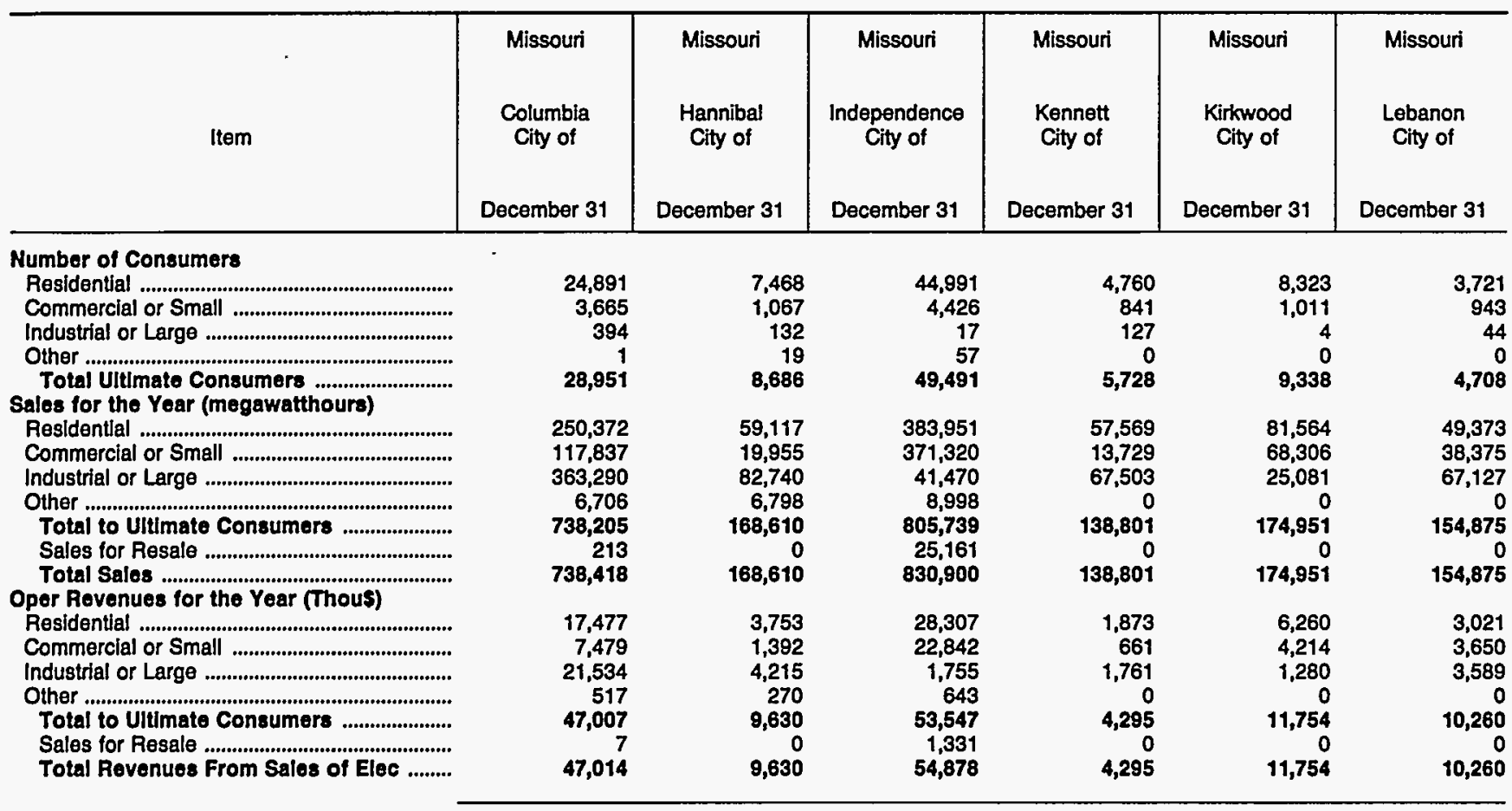

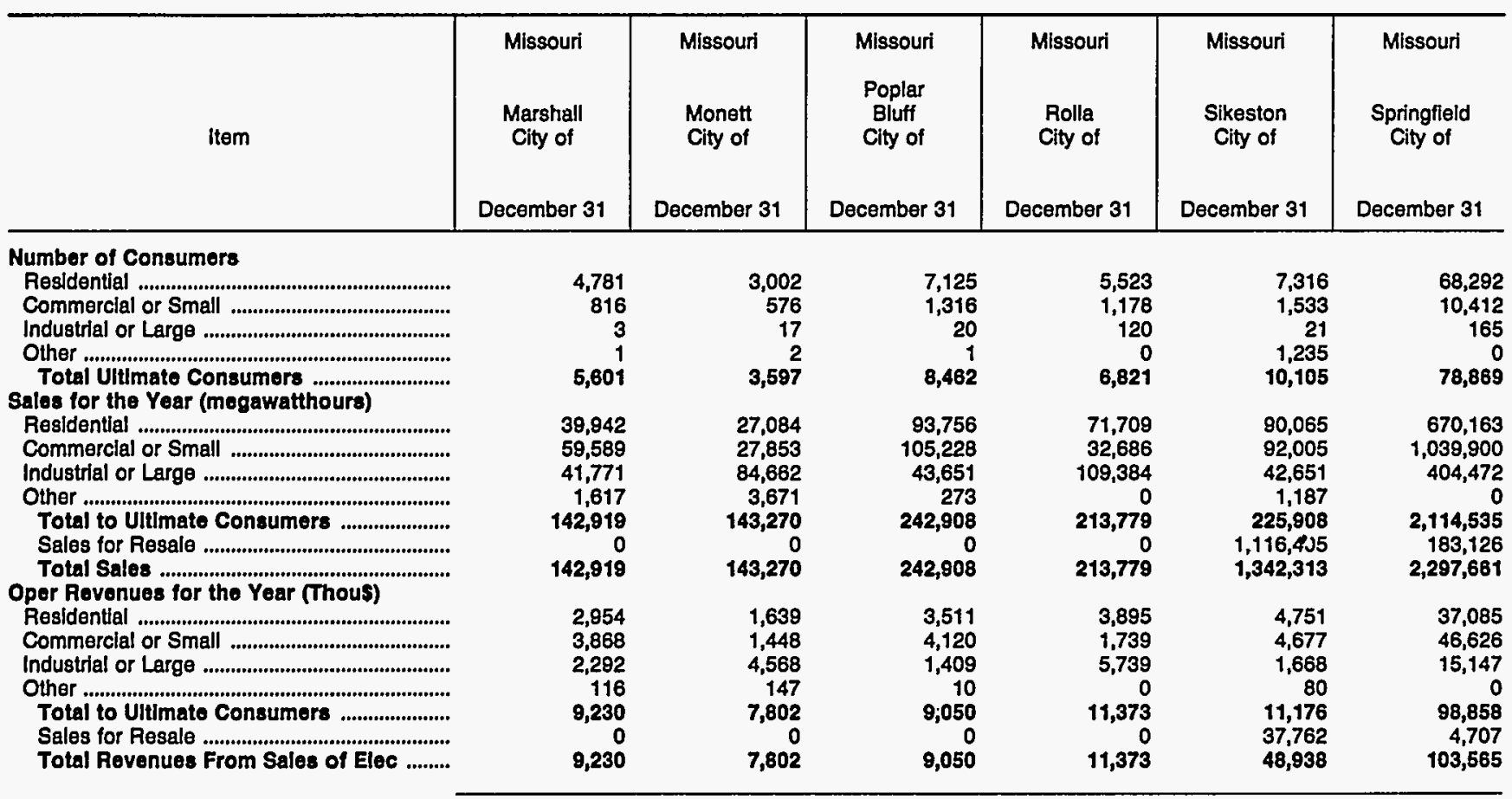

Note: Totals may not equal sum of components because of independent rounding.

Source: Energy Information Administration, Form EIA-861, "Annual Electric Utility Report." Data are submitted on a calendar year. 
Table 25. Number of Consumers, Sales, and Operating Revenue by Major U.S. Publicly Owned Electric Utility Within State, 1993 (Continued)

\begin{tabular}{|c|c|c|c|c|c|c|}
\hline Item & $\begin{array}{c}\text { Nebraska } \\
\text { Central } \\
\text { Nebraska } \\
\text { Pub } \\
\text { P\&l Dist } \\
\text { December } 31\end{array}$ & $\begin{array}{c}\text { Nebraska } \\
\text { Cornhusker } \\
\text { Public } \\
\text { Power Dist } \\
\text { December } 31\end{array}$ & $\begin{array}{c}\text { Nebraska } \\
\text { Dawson } \\
\text { County } \\
\text { Public } \\
\text { Pwr Dist } \\
\text { December } 31\end{array}$ & $\begin{array}{c}\text { Nebraska } \\
\text { Fremont } \\
\text { City of } \\
\text { December } 31\end{array}$ & $\begin{array}{l}\text { Grand Island } \\
\text { City of }\end{array}$ & $\begin{array}{c}\text { Nebraska } \\
\text { Hastings } \\
\text { City of } \\
\text { December } 31\end{array}$ \\
\hline \multicolumn{7}{|l|}{ Number of Consumers } \\
\hline 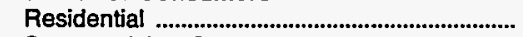 & 0 & 5,055 & 11,198 & 10,669 & 17,048 & 9,635 \\
\hline Commercial or Small & 0 & 200 & 717 & 1,334 & 3,051 & 1,828 \\
\hline Industrial or Large & 0 & 5 & 3 & 422 & 56 & 36 \\
\hline Other & 0 & 2,389 & 4,092 & 3 & 128 & 82 \\
\hline Total Ultimate Consumers & $\mathbf{0}$ & 7,649 & 16,010 & 12,428 & 20,283 & 11,581 \\
\hline \multicolumn{7}{|l|}{ Sales for the Year (megawatthours) } \\
\hline 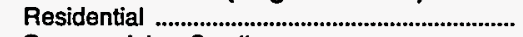 & 0 & 121,898 & 157,373 & 98,715 & 144,047 & 78,062 \\
\hline 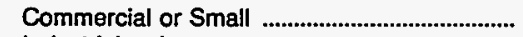 & 0 & 20,003 & 34,619 & 36,054 & 119,857 & 66,648 \\
\hline Industrial or Large & 0 & 33,161 & 7,890 & 143,725 & 209,968 & 105,569 \\
\hline Other & 0 & 6,495 & 18,831 & 7,605 & 7,116 & 11,886 \\
\hline 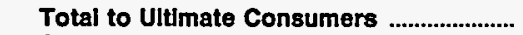 & $\mathbf{0}$ & 181,557 & 218,713 & 286,099 & 480,988 & 262,165 \\
\hline 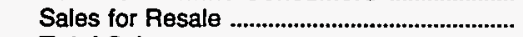 & 278,782 & 2,151 & 4,773 & 20,985 & 80,272 & 162,513 \\
\hline Total Sales & 278,782 & 183,708 & 223,486 & 307,084 & 561,260 & 424,678 \\
\hline \multicolumn{7}{|l|}{ Oper Revenues for the Year (Thous) } \\
\hline 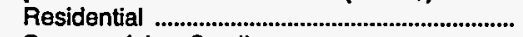 & 0 & 6,674 & 8,461 & 4,716 & 8,451 & 4,590 \\
\hline Commercial or Small & $\mathbf{0}$ & 1,031 & 1,931 & 1,931 & 6,748 & 3,494 \\
\hline Industrial or Large & $\mathbf{0}$ & 1,218 & 365 & 6,045 & 8,073 & 3,779 \\
\hline Other & $\mathbf{0}$ & 1,142 & 2,971 & 290 & 372 & 455 \\
\hline Total to Ultimate Consumers ......................... & $\mathbf{0}$ & 10,065 & 13,728 & 12,982 & 23,644 & 12,318 \\
\hline Sales for Resale & 6,955 & 29 & 280 & 459 & 1,057 & 1,699 \\
\hline Total Revenues From Sales of Elec ......... & 6,955 & 10,094 & 14,008 & 13,441 & 24,701 & 14,017 \\
\hline
\end{tabular}

\begin{tabular}{|c|c|c|c|c|c|c|}
\hline Item & $\begin{array}{c}\text { Nebraska } \\
\text { Lincoln } \\
\text { Electric } \\
\text { System } \\
\text { December } 31\end{array}$ & $\begin{array}{c}\text { Nebraska } \\
\text { Loup } \\
\text { River } \\
\text { Public } \\
\text { Power Dist } \\
\text { December } 31\end{array}$ & $\begin{array}{c}\text { Nebraska } \\
\text { Municipal } \\
\text { Energy } \\
\text { Agency } \\
\text { of NE } \\
\text { December } 31\end{array}$ & $\begin{array}{c}\text { Nebraska } \\
\text { Nebraska } \\
\text { Public } \\
\text { Power } \\
\text { District } \\
\text { December } 31\end{array}$ & $\begin{array}{c}\text { Nebraska } \\
\text { Norris } \\
\text { Public } \\
\text { Power } \\
\text { District } \\
\text { December } 31\end{array}$ & $\begin{array}{c}\text { Nebraska } \\
\text { North } \\
\text { Platte } \\
\text { City of } \\
\text { December } 31\end{array}$ \\
\hline \multicolumn{7}{|l|}{ Number of Consumers } \\
\hline 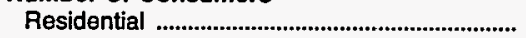 & 84,377 & 13,147 & 0 & 84,836 & 10,005 & 11,610 \\
\hline 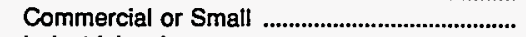 & 11,035 & 2,708 & 0 & 20,188 & 2,702 & 1,931 \\
\hline 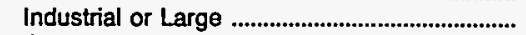 & 232 & 35 & 0 & 68 & 61 & \\
\hline Other & 1,270 & 733 & 0 & 3,170 & 55 & \\
\hline \multicolumn{6}{|l|}{ Sales for the Year (megawatthours) } & 13,543 \\
\hline 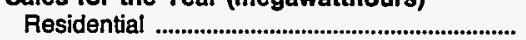 & 743,247 & 188,392 & 0 & 890,014 & 175,272 & 83,133 \\
\hline Commercial or Small & 739,909 & 121,942 & 0 & 754,793 & 27,479 & 104,575 \\
\hline Industrial or Large & 416,911 & 203,244 & 0 & 859,849 & 181,893 & \\
\hline Other & 238,046 & 28,203 & 0 & 164,142 & 745 & 18,967 \\
\hline Total to Uitimate Consumers & $2,138,113$ & 541,781 & $\mathbf{0}$ & $2,668,798$ & 385,389 & 206,675 \\
\hline Sales for Resale & 707,941 & 427,181 & $1,008,437$ & $10,166,654$ & 14,840 & \\
\hline \multicolumn{7}{|l|}{ Oper Revenues for the Year (Thous) } \\
\hline 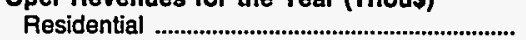 & 45,410 & 8,773 & 0 & 59,321 & 10,750 & 4,732 \\
\hline 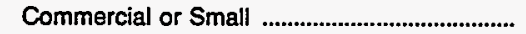 & 31,896 & 5,746 & 0 & 47,204 & 2,526 & 5,250 \\
\hline 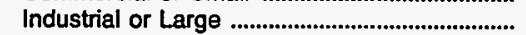 & 15,826 & 6,425 & 0 & 29,877 & 6,839 & \\
\hline 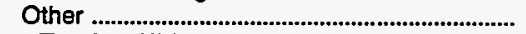 & 11,305 & 1,475 & 0 & 9,509 & 71 & 522 \\
\hline 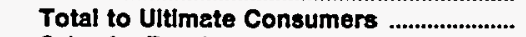 & 104,437 & 22,419 & 0 & 145,911 & 20,186 & 10,504 \\
\hline 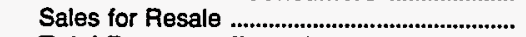 & 11,577 & 12,519 & 28,550 & 321,190 & 513 & \\
\hline Total Revenues From Sales of Elec ......... & 116,014 & 34,938 & 28,550 & 467,101 & 20,699 & 10,504 \\
\hline
\end{tabular}

Note: Totals may not equal sum of components because of independent rounding.

Source: Energy Information Administration, Form EIA-861, "Annual Electric Utility Report." Data are submitted on a calendar year. 
Table 25. Number of Consumers, Sales, and Operating Revenue by Major U.S. Publicly Owned Electric Utility Within State, 1993 (Continued)

\begin{tabular}{|c|c|c|c|c|c|c|}
\hline Item & $\begin{array}{c}\text { Nebraska } \\
\text { Omaha Public } \\
\text { Power } \\
\text { District } \\
\text { December } 31\end{array}$ & $\begin{array}{c}\text { Nebraska } \\
\text { Southem } \\
\text { Nebraska Rural } \\
\text { P P D } \\
\text { December } 31\end{array}$ & $\begin{array}{c}\text { Nevada } \\
\text { Colorado } \\
\text { River } \\
\text { Comm } \\
\text { of Nevada } \\
\text { December } 31\end{array}$ & $\begin{array}{c}\text { New Jersey } \\
\text { Vineland } \\
\text { City of } \\
\text { December } 31\end{array}$ & $\begin{array}{l}\text { New Mexico } \\
\text { Farmington } \\
\text { City of } \\
\text { December } 31\end{array}$ & $\begin{array}{c}\text { New Mexico } \\
\text { Gallup } \\
\text { City of } \\
\text { December } 31\end{array}$ \\
\hline \multicolumn{7}{|l|}{ Number of Consumers } \\
\hline 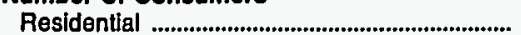 & 227,181 & 10,672 & 0 & 14,982 & 23,695 & 7,301 \\
\hline Commercial or Smalt & 31,685 & 895 & 2 & 2,316 & 4,330 & 1,578 \\
\hline 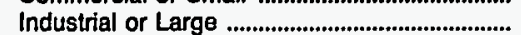 & 94 & 139 & 5 & 81 & 3 & 0 \\
\hline Other & & 6,956 & 0 & & 2,021 & 460 \\
\hline \multirow{2}{*}{\multicolumn{7}{|c|}{ Sales for the Year (megawatthours) }} \\
\hline & & & 0 & 124,398 & 151.233 & 39.291 \\
\hline Commercial or Small & $2,434,322$ & 14,161 & 25,952 & 90,373 & 248,951 & 109,038 \\
\hline 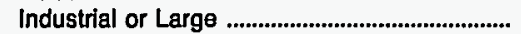 & $1,854,402$ & 115,298 & 743,674 & 200,845 & 126,701 & 0 \\
\hline Other & 81,080 & 22,571 & 0 & 2,320 & 9,789 & 21,551 \\
\hline 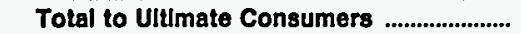 & $6,725,968$ & 331,950 & 769,626 & 417,936 & 536,674 & 169,880 \\
\hline 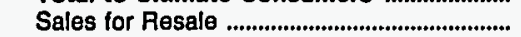 & 153,396 & & 831,697 & & 18,250 & \\
\hline 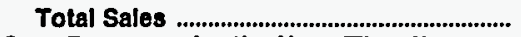 & $6,879,364$ & 331,950 & $1,601,323$ & 417,936 & 554,924 & 169,880 \\
\hline \multicolumn{7}{|l|}{ Oper Revenues for the Year (Thous) } \\
\hline 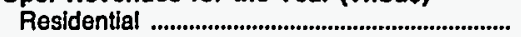 & 160,000 & 9,428 & 0 & 13,090 & 12,523 & 3,059 \\
\hline Commercial or Small .................................................. & 144,732 & 909 & 628 & 10,118 & 19,609 & 8,368 \\
\hline 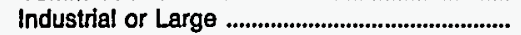 & 77,549 & 5,066 & 15,071 & 16,950 & 6,250 & \\
\hline Other & 10,502 & 5,062 & & 362 & 1,608 & 1,554 \\
\hline Total to Ultimate Consumers ........................... & 392,783 & 20,465 & 15,699 & 40,520 & 39,990 & 12,981 \\
\hline 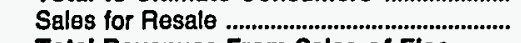 & 3,673 & 0 & 16,777 & 0 & 995 & \\
\hline Total Revenues From Sales of Elec ......... & 396,456 & 20,465 & 32,476 & 40,520 & 40,985 & 12,981 \\
\hline
\end{tabular}

\begin{tabular}{|c|c|c|c|c|c|c|}
\hline Item & $\begin{array}{l}\text { New Mexico } \\
\text { Los Alamos } \\
\text { County } \\
\text { December } 31\end{array}$ & $\begin{array}{c}\text { New York } \\
\text { Fairport } \\
\text { Village of } \\
\text { December } 31\end{array}$ & $\begin{array}{c}\text { New York } \\
\text { Freeport } \\
\text { Village of } \\
\text { Inc } \\
\text { December } 31\end{array}$ & $\begin{array}{c}\text { New York } \\
\text { Jamestown } \\
\text { City of } \\
\text { December } 31\end{array}$ & $\begin{array}{c}\text { New York } \\
\text { Massena } \\
\text { Town of } \\
\text { December } 31\end{array}$ & $\begin{array}{l}\text { New York } \\
\text { Plattsburgh } \\
\text { City of } \\
\text { December } 31\end{array}$ \\
\hline 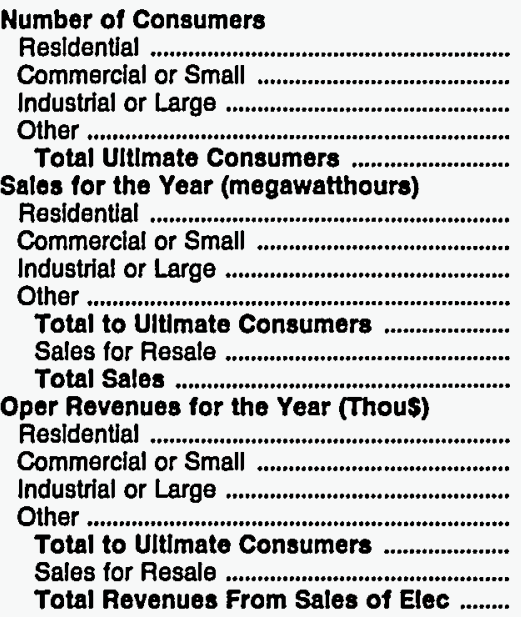 & $\begin{array}{r}44,634 \\
30,143 \\
0 \\
382,696 \\
457,473 \\
46,966 \\
504,439\end{array}$ & $\begin{array}{r}206,982 \\
59,098 \\
71,586 \\
3,041 \\
340,707 \\
0 \\
340,707\end{array}$ & $\begin{array}{r}101,126 \\
117,222 \\
0 \\
15,059 \\
233,407 \\
0 \\
233,407\end{array}$ & $\begin{array}{r}135,267 \\
125,926 \\
153,644 \\
34,169 \\
449,006 \\
148,520 \\
597,526\end{array}$ & $\begin{array}{r}75,724 \\
12,511 \\
56,742 \\
4,080 \\
149,057 \\
0 \\
149,057\end{array}$ & $\begin{array}{r}159,561 \\
169,145 \\
178,778 \\
5,103 \\
512,587 \\
0 \\
512,587\end{array}$ \\
\hline
\end{tabular}

Note: Totals may not equal sum of components because of independent rounding.

Source: Energy Information Administration, Form EIA-861, "Annual Electric Utility Report." Data are submitted on a calendar year. 
Table 25. Number of Consumers, Sales, and Operating Revenue by Major U.S. Publicly Owned Electric Utility Within State, 1993 (Continued)

\begin{tabular}{|c|c|c|c|c|c|c|}
\hline Item & $\begin{array}{c}\text { New York } \\
\text { Power } \\
\text { Authority } \\
\text { of State of NY } \\
\text { December } 31\end{array}$ & $\begin{array}{c}\text { New York } \\
\text { Rockville } \\
\text { Centre } \\
\text { Village of } \\
\text { December } 31\end{array}$ & $\begin{array}{l}\text { North Carolina } \\
\text { Albemarle } \\
\text { City of } \\
\text { December } 31\end{array}$ & $\begin{array}{l}\text { North Carolina } \\
\text { Concord } \\
\text { City of } \\
\text { December } 31\end{array}$ & $\begin{array}{l}\text { North Carolina } \\
\text { Elizabeth } \\
\text { City City of } \\
\text { December } 31\end{array}$ & $\begin{array}{l}\text { North Carolina } \\
\text { Fayetteville } \\
\text { Public } \\
\text { Works Comm } \\
\\
\text { December } 31\end{array}$ \\
\hline \multicolumn{7}{|l|}{ Number of Consumers } \\
\hline 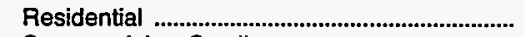 & 0 & 8,844 & 8,921 & 14,600 & 8,480 & 54,467 \\
\hline 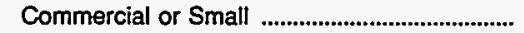 & 3 & 1,190 & 1,700 & 1,989 & 1,357 & 6,102 \\
\hline 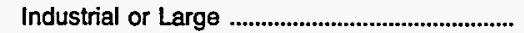 & 19 & 0 & 24 & 0 & 0 & 10 \\
\hline Other & 82 & 48 & 1 & 1 & 67 & 3,672 \\
\hline \multicolumn{6}{|l|}{ Sales for the Year (megawatthours) } & 64,251 \\
\hline 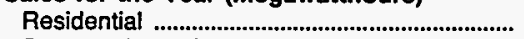 & 0 & 72,717 & 108,482 & 216,714 & 104.708 & 753,966 \\
\hline Commercial or Small & 60,387 & 86,483 & 81,981 & 140,560 & 115,655 & 521,350 \\
\hline 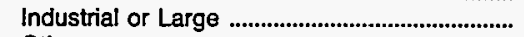 & $4,768,602$ & 0 & 53,885 & 0 & 0 & 392,441 \\
\hline Other & $8,556,998$ & 5,332 & 8,594 & 853 & 7,774 & 25,730 \\
\hline Total to Uitimate Consumers .......................... & $13,385,987$ & 164,532 & 252,942 & 358,127 & 228,137 & $1,693,487$ \\
\hline Sales for Resale & $25,134,370$ & 0 & 0 & 0 & 0 & \\
\hline Total Sales & $38,520,357$ & 164,532 & 252,942 & 358,127 & 228,137 & $1,693,487$ \\
\hline \multicolumn{7}{|l|}{ Oper Revenues for the Year (Thous) } \\
\hline 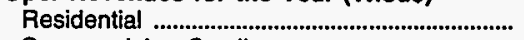 & 0 & 4,213 & 9,397 & 15,854 & 10,407 & 56,953 \\
\hline Commercial or Small & 3,252 & 4,962 & 6,549 & 9,215 & 9,765 & 34,424 \\
\hline Industrial or Large & 99,549 & 0 & 3,162 & 0 & 0 & 21,553 \\
\hline 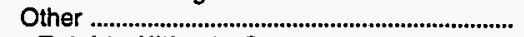 & 727,481 & 314 & 550 & 57 & 634 & 2,536 \\
\hline Total to Ultimate Consumers ......................... & 830,282 & 9,489 & 19,658 & 25,126 & 20,806 & 115,486 \\
\hline Sales for Resale & 544,020 & & & & & \\
\hline Total Revenues From Sales of Elec ......... & $1,374,302$ & 9,489 & 19,658 & 25,126 & 20,806 & 115,466 \\
\hline
\end{tabular}

\begin{tabular}{|c|c|c|c|c|c|c|}
\hline Item & $\begin{array}{l}\text { North Carolina } \\
\text { Forest City } \\
\text { Town of } \\
\text { December } 31\end{array}$ & $\begin{array}{l}\text { North Carolina } \\
\text { Gastonia } \\
\text { City of } \\
\text { December } 31\end{array}$ & $\begin{array}{l}\text { North Carolina } \\
\text { Greenville } \\
\text { Utilities } \\
\text { Comm } \\
\text { December } 31\end{array}$ & $\begin{array}{l}\text { North Carolina } \\
\text { High } \\
\text { Point } \\
\text { Town } \\
\text { of } \\
\text { December } 31\end{array}$ & $\begin{array}{l}\text { North Carolina } \\
\text { Kinston } \\
\text { City of } \\
\text { December } 31\end{array}$ & $\begin{array}{l}\text { North Carolina } \\
\text { Lexington } \\
\text { Clty of }\end{array}$ \\
\hline \multicolumn{7}{|l|}{ Number of Consumers } \\
\hline 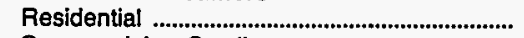 & 3,415 & 20,539 & 34,509 & 26,819 & 10,857 & 14,359 \\
\hline 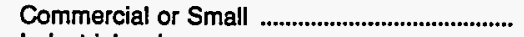 & 862 & 2,697 & 4,526 & 4,249 & 1,837 & 2,032 \\
\hline Industrial or Large & 0 & 72 & 19 & 325 & 9 & 61 \\
\hline Other & 0 & 180 & 1 & 3 & 3,596 & 3,732 \\
\hline $\begin{array}{l}\text { Total UltImate Consumers } \\
\text { Sales for the Year (megawathours) }\end{array}$ & 4,277 & 23,488 & 39,055 & 31,396 & 16,299 & 20,184 \\
\hline 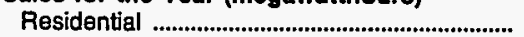 & 36,665 & 216,275 & 433,572 & 274,355 & 133.765 & 184.14 \\
\hline Commercial or Small & 90,077 & 247,863 & 296,278 & 364,913 & 151,568 & 128,675 \\
\hline Industrial or Large & 0 & 97,260 & 350,437 & 117,179 & 125,893 & 117,182 \\
\hline Other & 0 & 27,344 & 8,162 & 14,100 & 17,928 & 8,292 \\
\hline 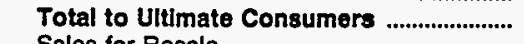 & 126,742 & 588,742 & $1,088,449$ & 770,547 & 429,154 & 438,291 \\
\hline Sales for Resale & & & 24,182 & & & \\
\hline $\begin{array}{l}\text { Total Sales ......................................................... } \\
\text { Oper Revenues for the Year (Thous) }\end{array}$ & 126,742 & 588,742 & $1,112,631$ & 770,547 & 429,154 & 438,291 \\
\hline \multirow{7}{*}{ 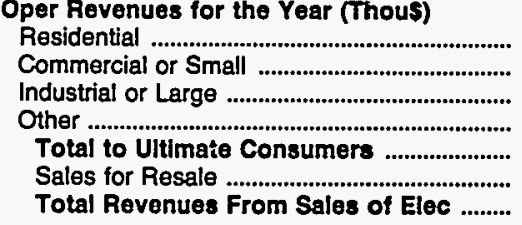 } & 2,847 & 18,695 & 41,696 & 23,264 & 13,266 & 15,348 \\
\hline & 5,127 & 19,197 & 25,896 & 26,248 & 12,853 & 9,839 \\
\hline & 0 & 6,290 & 23,127 & 7,757 & 8,322 & 7,296 \\
\hline & 0 & 1,366 & 1,186 & 1,634 & 1,750 & 646 \\
\hline & 7,974 & 45,548 & 91,905 & 58,903 & 36,191 & 33,129 \\
\hline & & & 1,822 & & & \\
\hline & 7,974 & 45,548 & 93,727 & 58,903 & 36,191 & 33,129 \\
\hline
\end{tabular}

Note: Totals may not equal sum of components because of independent rounding.

Source: Energy Information Administration, Form EIA-861. "Annual Electric Utility Report." Data are submitted on a calendar year. 
Table 25. Number of Consumers, Sales, and Operating Revenue by Major U.S. Publicly Owned Electric Utility Within State, 1993 (Continued)

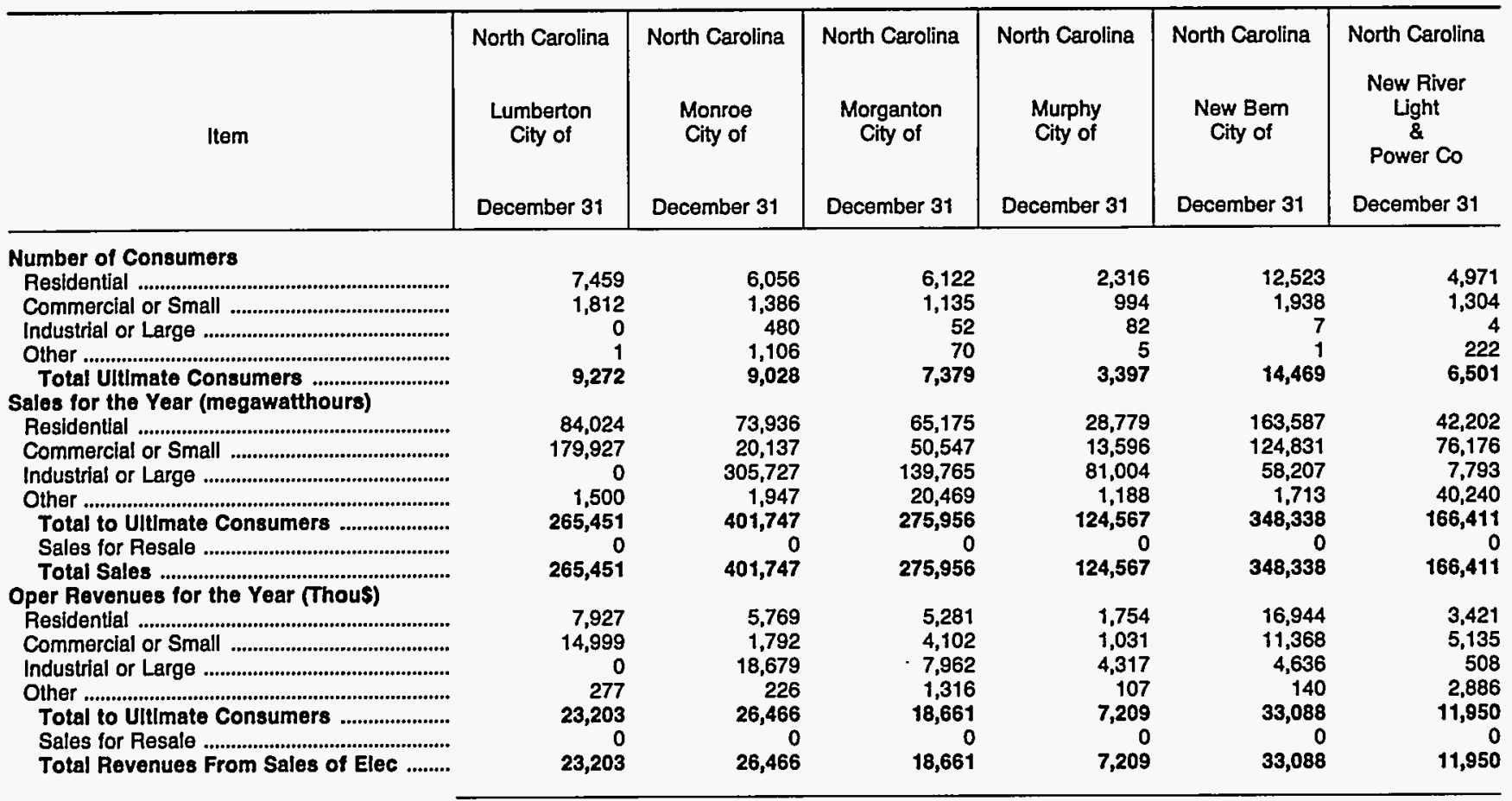

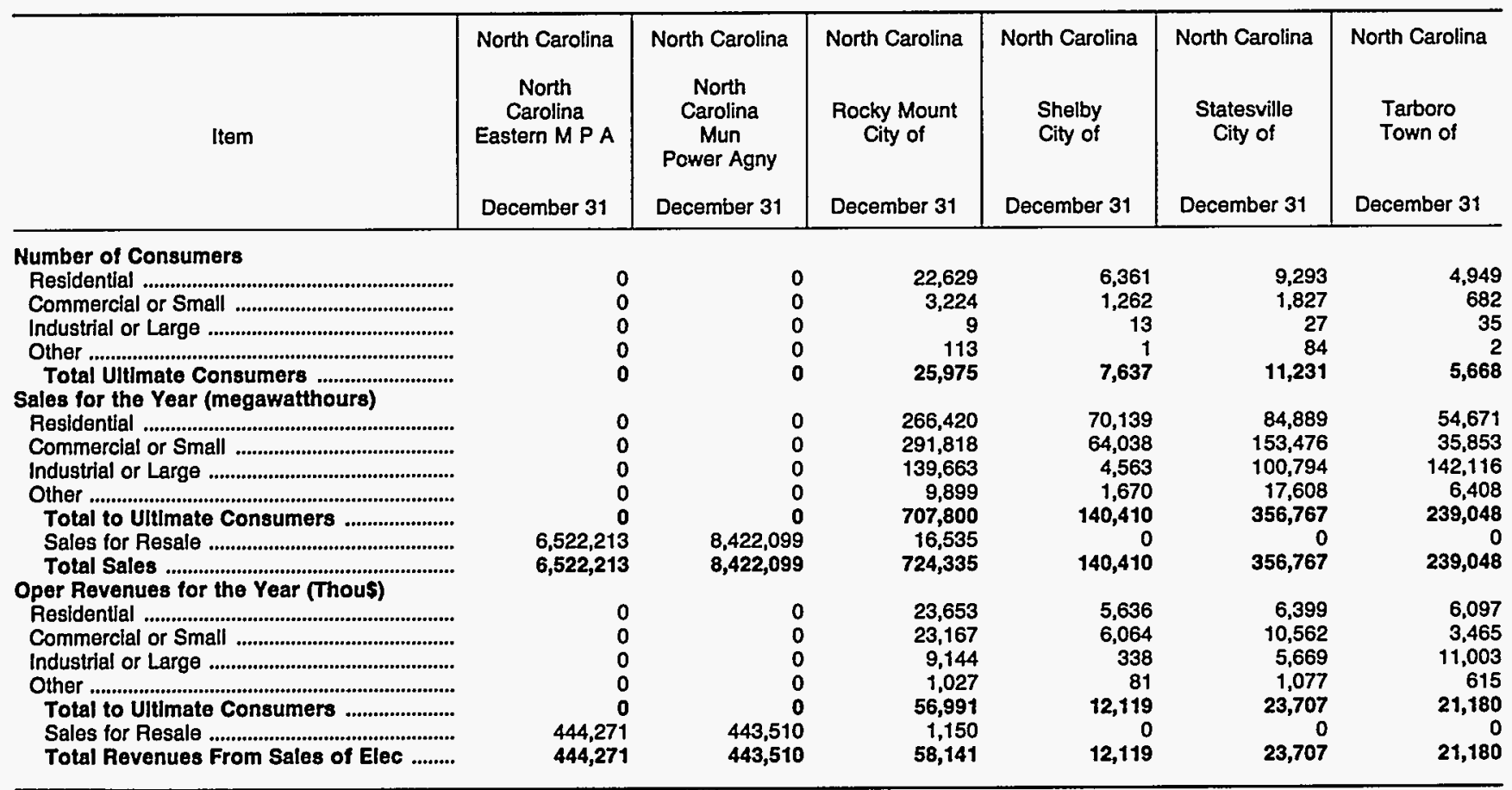

Note: Totals may not equal sum of components because of independentrounding.

Source: Energy Information Administration, Form ElA-861, "Annual Electric Utility Report." Data are submitted on a calendar year. 
Table 25. Number of Consumers, Sales, and Operating Revenue by Major U.S. Publicly Owned Electrlc Utility Within State, 1993 (Continued)

\begin{tabular}{|c|c|c|c|c|c|c|}
\hline Item & $\begin{array}{l}\text { North Carolina } \\
\text { Washington } \\
\text { City of } \\
\text { December } 31\end{array}$ & $\begin{array}{c}\text { North Carolina } \\
\text { Wilson } \\
\text { City of } \\
\text { December } 31\end{array}$ & $\begin{array}{c}\text { Ohio } \\
\text { American } \\
\text { Mun } \\
\text { Power } \\
\text { Ohio Inc } \\
\text { December } 31\end{array}$ & $\begin{array}{c}\text { Ohio } \\
\text { Bowling } \\
\text { Green } \\
\text { City of } \\
\text { December } 31\end{array}$ & $\begin{array}{c}\text { Bryan } \\
\text { City of } \\
\text { December } 31\end{array}$ & $\begin{array}{c}\text { Celina } \\
\text { City of } \\
\text { December } 31\end{array}$ \\
\hline \multicolumn{7}{|l|}{ Number of Consumers } \\
\hline 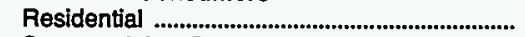 & 9,046 & 27,161 & 0 & 9,279 & 4,379 & 5,904 \\
\hline Commercial or Small & 1,657 & 3,519 & 0 & 1,387 & 524 & 787 \\
\hline 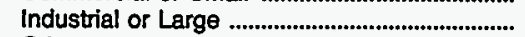 & 39 & 12 & 1 & 67 & 125 & 51 \\
\hline Other & 2 & 0 & 0 & 1 & 0 & 1 \\
\hline \multicolumn{6}{|l|}{ Sales for the Year (megawatthours) } & 6,743 \\
\hline 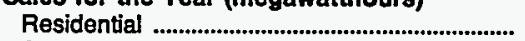 & 98,791 & 312,305 & 0 & 68,643 & 40,326 & 59,985 \\
\hline 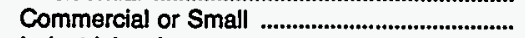 & 50,540 & 245,087 & 0 & 44,053 & 13,481 & 18,594 \\
\hline 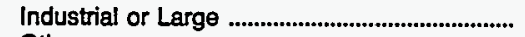 & 76,770 & 351,624 & 492,484 & 163,203 & 142,775 & 71,280 \\
\hline 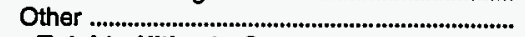 & 2,834 & 0 & 0 & 50 & 0 & 1,164 \\
\hline Total to Ultimate Consumers & 228,935 & 909,016 & 492,484 & 275,949 & 196,582 & 151,023 \\
\hline Sales for Resale ........................................................ & 0 & 61,908 & $4,094,070$ & 3,075 & 0 & \\
\hline \multicolumn{7}{|l|}{ Oper Revenues for the Year (Thous) } \\
\hline 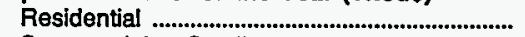 & 10,404 & 29,395 & 0 & 4,450 & 2,203 & 3,263 \\
\hline Commercial or Small & 5,002 & 21,104 & 0 & 2,543 & 915 & 1,124 \\
\hline Industrial or Large & 5,903 & 22,985 & 13,296 & 8,681 & 6,924 & 3,404 \\
\hline \multirow{4}{*}{ 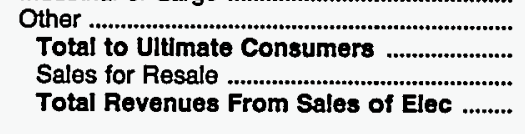 } & 330 & 0 & 0 & 4 & & 53 \\
\hline & 21,639 & 73,484 & 13,296 & 15,678 & 10,042 & 7,844 \\
\hline & $\begin{array}{r}0 \\
21639\end{array}$ & 4,772 & 124,489 & 175 & & \\
\hline & & 78,256 & & 15,853 & 10,042 & 7,844 \\
\hline
\end{tabular}

\begin{tabular}{|c|c|c|c|c|c|c|}
\hline Item & $\begin{array}{c}\text { Ohio } \\
\begin{array}{c}\text { Cleveland } \\
\text { City of }\end{array} \\
\text { December } 31\end{array}$ & $\begin{array}{c}\text { Ohio } \\
\text { Columbus } \\
\text { City of } \\
\text { December } 31\end{array}$ & $\begin{array}{c}\text { Ohio } \\
\text { Cuyahoga } \\
\text { Falls } \\
\text { City of } \\
\text { December } 31\end{array}$ & $\begin{array}{c}\text { Ohio } \\
\text { Dover } \\
\text { City of } \\
\text { December } 31\end{array}$ & $\begin{array}{c}\text { Ohio } \\
\text { Hamilton } \\
\text { City of } \\
\text { December } 31\end{array}$ & $\begin{array}{c}\text { Ohio } \\
\text { Napoleon } \\
\text { City of } \\
\text { December } 31\end{array}$ \\
\hline \multicolumn{7}{|l|}{ Number of Consumers } \\
\hline Residential & 52,688 & 7,335 & 18,855 & 5,200 & 24,100 & 4,662 \\
\hline 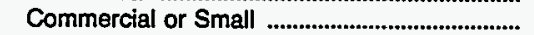 & 6,426 & 2,302 & 1,316 & 760 & 2,785 & 552 \\
\hline Industrial or Large & 16 & 353 & 130 & 80 & 92 & 53 \\
\hline 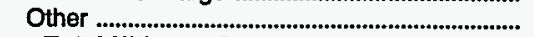 & 3 & 273 & 160 & 10 & 0 & 179 \\
\hline $\begin{array}{l}\text { Total Ultimate Consumers } \\
\text { Sales for the Year (megawatthours) }\end{array}$ & 59,133 & 10,263 & 20,461 & 6,050 & 26,977 & 5,446 \\
\hline 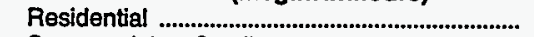 & 252,422 & 43,525 & 123,687 & 46,705 & 205,176 & 40,433 \\
\hline 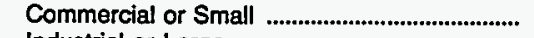 & 306,671 & 62,974 & 39,603 & 26,578 & 171,253 & 18,042 \\
\hline Industrial or Large & 328,522 & 428,203 & 113,253 & 100,806 & 156,271 & 75,022 \\
\hline Other & 48,192 & 49,516 & 8,992 & & 0 & 2,260 \\
\hline Total to Ultimate Consumers ...................... & 935,807 & 584,218 & 285,535 & 174,164 & 532,700 & 135,757 \\
\hline Sales for Resale & & 3,750 & & & 187,380 & \\
\hline \multirow{2}{*}{\multicolumn{7}{|c|}{ Oper Revenues for the Year (Thous) }} \\
\hline 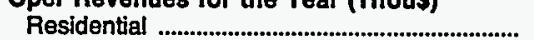 & 20,534 & & & & & \\
\hline Commercial or Small & 23,537 & 4,701 & $\begin{array}{l}0,491 \\
2,899\end{array}$ & $\begin{array}{l}2,9 / 2 \\
1,843\end{array}$ & $\begin{array}{l}15,970 \\
14,485\end{array}$ & $\begin{array}{l}2,512 \\
1,214\end{array}$ \\
\hline 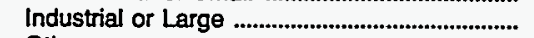 & 18,543 & 21,944 & 6,075 & 4,921 & 8,463 & 3,989 \\
\hline Other & 4,673 & 2,761 & 513 & & 0 & 82 \\
\hline Total to Ultimate Consumers ...................... & 67,287 & 32,471 & 17,978 & 9,739 & 38,918 & 7,797 \\
\hline 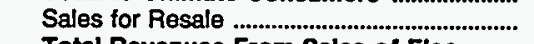 & & 26 & 0 & & 4,457 & \\
\hline Total Revenues From Sales of Elec .......... & 67,287 & 32,497 & 17,978 & 9,739 & 43,375 & 7,797 \\
\hline
\end{tabular}

Note: Totals may not equal sum of components because of independent rounding.

Source: Energy Information Administration, Form EIA-861, "Annual Electric Utility Report." Data are submitted on a calendar year. 
Table 25. Number of Consumers, Sales, and Operating Revenue by Major U.S. Publicly Owned Electric Utility Within State, 1993 (Continued)

\begin{tabular}{|c|c|c|c|c|c|c|}
\hline Item & $\begin{array}{c}\text { Ohio } \\
\text { Niles } \\
\text { City of } \\
\text { December } 31\end{array}$ & $\begin{array}{c}\text { Ohio } \\
\text { Orville } \\
\text { City of } \\
\text { December } 31\end{array}$ & $\begin{array}{c}\text { Ohio } \\
\text { Painesville } \\
\text { City of }\end{array}$ & $\begin{array}{c}\text { Ohio } \\
\text { Piqua } \\
\text { City of } \\
\text { December } 31\end{array}$ & $\begin{array}{c}\text { Ohio } \\
\text { St Marys } \\
\text { City of } \\
\text { December } 31\end{array}$ & $\begin{array}{c}\text { Ohio } \\
\text { Wadsworth } \\
\text { City of } \\
\text { December } 31\end{array}$ \\
\hline \multicolumn{7}{|l|}{ Number of Consumers } \\
\hline 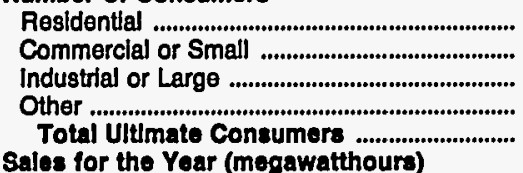 & $\begin{array}{r}10,299 \\
1,021 \\
90 \\
482 \\
11,892\end{array}$ & $\begin{array}{r}5,206 \\
569 \\
15 \\
23 \\
5,813\end{array}$ & $\begin{array}{r}8,387 \\
1,613 \\
1 \\
0 \\
10,001\end{array}$ & $\begin{array}{r}8,527 \\
1,006 \\
20 \\
303 \\
9,856\end{array}$ & $\begin{array}{r}3,345 \\
457 \\
21 \\
13 \\
3,836\end{array}$ & $\begin{array}{r}7,871 \\
1,134 \\
42 \\
1 \\
9,048\end{array}$ \\
\hline 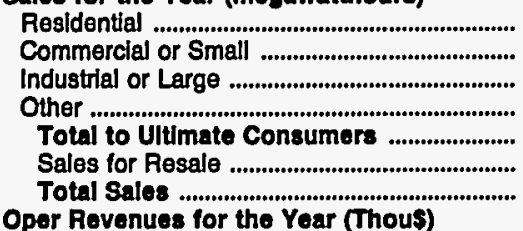 & $\begin{array}{r}76,824 \\
79,863 \\
77,732 \\
1,168 \\
235,587 \\
0 \\
235,587\end{array}$ & $\begin{array}{r}60,409 \\
48,782 \\
124,486 \\
4,416 \\
238,093 \\
89,039 \\
327,132\end{array}$ & $\begin{array}{r}59,110 \\
92,181 \\
31,695 \\
0 \\
182,986 \\
0 \\
182,986\end{array}$ & $\begin{array}{r}71,694 \\
88,523 \\
85,148 \\
1,113 \\
246,478 \\
480 \\
246,958\end{array}$ & $\begin{array}{r}30,157 \\
39,545 \\
73,918 \\
1,786 \\
145,406 \\
6,840 \\
152,246\end{array}$ & $\begin{array}{r}69,766 \\
57,007 \\
61,422 \\
2,590 \\
190,785 \\
0 \\
190,785\end{array}$ \\
\hline 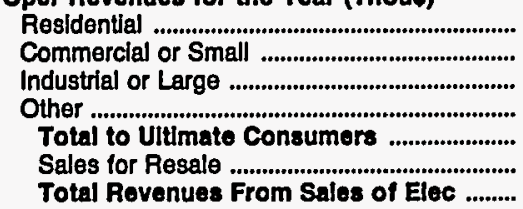 & $\begin{array}{r}5,952 \\
5,231 \\
4,053 \\
136 \\
15,372 \\
0 \\
15,372\end{array}$ & $\begin{array}{r}3,701 \\
3,127 \\
6,382 \\
263 \\
13,473 \\
1,894 \\
15,367\end{array}$ & $\begin{array}{r}4,884 \\
6,938 \\
1,393 \\
0 \\
13,215 \\
0 \\
13,215\end{array}$ & $\begin{array}{r}4,561 \\
5,260 \\
4,474 \\
68 \\
14,363 \\
21 \\
14,384\end{array}$ & $\begin{array}{r}1,806 \\
1,953 \\
2,912 \\
54 \\
6,725 \\
241 \\
6,966\end{array}$ & $\begin{array}{r}4,962 \\
4,040 \\
1,762 \\
98 \\
10,862 \\
0 \\
10,862\end{array}$ \\
\hline
\end{tabular}

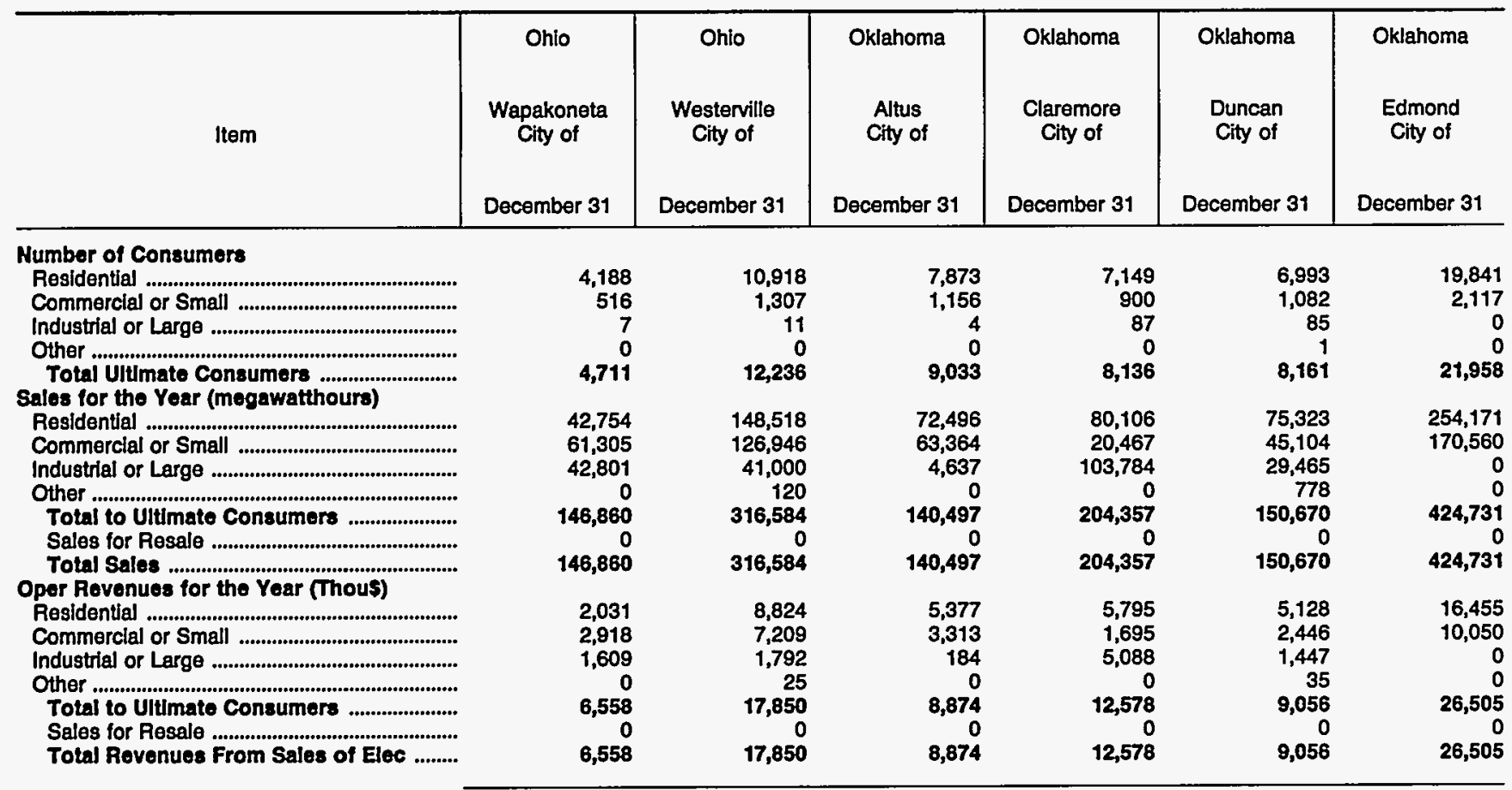

Note: Totals may not equal sum of components because of independent rounding.

Source: Energy Information Admintstration, Form EIA-861, "Annual Electric Utility Report" Data are submitted on a calendar year. 
Table 25. Number of Consumers, Sales, and Operating Revenue by Major U.S. Publicly Owned Electric Utility Within State, 1993 (Continued)

\begin{tabular}{|c|c|c|c|c|c|c|}
\hline Item & $\begin{array}{c}\text { Oklahoma } \\
\text { Grand Fiver } \\
\text { Dam } \\
\text { Authority } \\
\text { December } 31\end{array}$ & $\begin{array}{c}\text { Oklahoma } \\
\text { Miami } \\
\text { City of } \\
\text { December } 31\end{array}$ & $\begin{array}{c}\text { Oklahoma } \\
\text { Oklahoma } \\
\text { Municipal } \\
\text { Power Auth } \\
\text { December } 31\end{array}$ & $\begin{array}{c}\text { Oklahoma } \\
\text { Ponca } \\
\text { City City of } \\
\text { December } 31\end{array}$ & $\begin{array}{c}\text { Oklahoma } \\
\text { Stillwater } \\
\text { Utilities } \\
\text { Authority } \\
\text { December } 31\end{array}$ & $\begin{array}{l}\text { Oregon } \\
\text { Ashland } \\
\text { City of } \\
\text { December } 31\end{array}$ \\
\hline \multicolumn{7}{|l|}{ Number of Consumers } \\
\hline Residential & $\mathbf{0}$ & 5,715 & 0 & 13,837 & 13,480 & 7,210 \\
\hline Commercial or Small & 44 & 781 & 0 & 1,636 & 1,364 & 1,052 \\
\hline Industrial or Large & 17 & 151 & 0 & 40 & 5 & 0 \\
\hline Other & 0 & 2 & 0 & 91 & 0 & 108 \\
\hline $\begin{array}{l}\text { Total UItImate Consumers } \\
\text { Sales for the Year (megawatho.................... }\end{array}$ & 61 & 6,649 & $\mathbf{0}$ & 15,604 & 14,849 & 8,370 \\
\hline 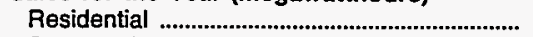 & 0 & 47,357 & 0 & 128,757 & 123,359 & 81,738 \\
\hline Commercial or Small & 29,238 & 10,431 & 0 & 99,466 & 112,412 & 62,401 \\
\hline Industrial or Large & 645,560 & 65,707 & 0 & 36,369 & 136,078 & 0 \\
\hline Other & 0 & 8,944 & 0 & 16,245 & 0 & 19,300 \\
\hline 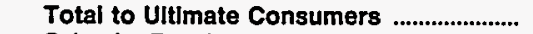 & 674,798 & 132,439 & $\mathbf{0}$ & 280,837 & 371,849 & 163,439 \\
\hline Sales for Resale & $4,848,136$ & 0 & $1,435,856$ & 0 & 0 & \\
\hline Total Sales & $5,522,934$ & 132,439 & $1,435,856$ & 280,837 & 371,849 & 163,439 \\
\hline \multicolumn{7}{|l|}{ Oper Revenues for the Year (Thous) } \\
\hline 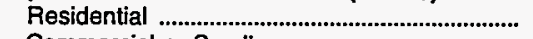 & 0 & 2,700 & 0 & 10,073 & 8,526 & 3,399 \\
\hline Commercial or Small & 1,215 & 595 & 0 & 7,102 & 6,798 & 2,635 \\
\hline Industrial or Large & 19,323 & 3,124 & 0 & 2,064 & 5,679 & 0 \\
\hline Other & 0 & 405 & 0 & 950 & 0 & 944 \\
\hline 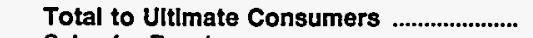 & 20,538 & 6,824 & 0 & 20,189 & 21,003 & 6,978 \\
\hline 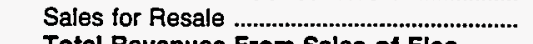 & 140,385 & & 66,846 & 0 & 0 & \\
\hline Total Revenues From Sales of Elec ......... & 160,923 & 6,824 & 66,846 & 20,189 & 21,003 & 6,978 \\
\hline
\end{tabular}

\begin{tabular}{|c|c|c|c|c|c|c|}
\hline Item & $\begin{array}{c}\text { Oregon } \\
\text { Central } \\
\text { Lincoln } \\
\text { Peoples } \\
\text { Utl Dt } \\
\text { December } 31\end{array}$ & $\begin{array}{c}\text { Oregon } \\
\text { Clatskanie } \\
\text { Peoples } \\
\text { Util Dist } \\
\text { December } 31\end{array}$ & $\begin{array}{c}\text { Oregon } \\
\text { Columbia } \\
\text { River } \\
\text { Peoples } \\
\text { Ut Dist } \\
\text { December } 31\end{array}$ & $\begin{array}{l}\text { Oregon } \\
\text { Emerald } \\
\text { Peoples } \\
\text { Utility Dist } \\
\text { December } 31\end{array}$ & $\begin{array}{l}\text { Oregon } \\
\text { Eugene } \\
\text { City of } \\
\text { December } 31\end{array}$ & $\begin{array}{c}\text { Forest Grove } \\
\text { City of }\end{array}$ \\
\hline \multicolumn{7}{|l|}{ Number of Consumers } \\
\hline Residential & 25,750 & 2,840 & 6,624 & 13,030 & 62,327 & 5,934 \\
\hline 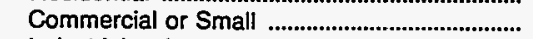 & 4,143 & 386 & 609 & 1,400 & 7,572 & 729 \\
\hline Industrial or Large & 98 & 2 & 8 & 9 & 1 & 80 \\
\hline Other & 2,171 & $\overline{1}$ & 46 & 651 & 11 & 362 \\
\hline \multirow{2}{*}{\multicolumn{7}{|c|}{ Sales for the Year (megawatthours) }} \\
\hline 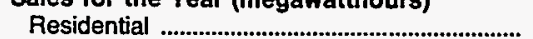 & 376,088 & 54,131 & & & & \\
\hline Commercial or Small & $\begin{array}{l}310,000 \\
195,515\end{array}$ & 23,672 & 21,434 & 70,621 & $\begin{array}{l}1,004,182 \\
951,049\end{array}$ & $\begin{array}{r}101,021 \\
49,938\end{array}$ \\
\hline 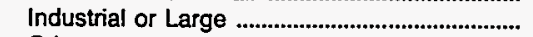 & 739,332 & 818,656 & 149,235 & 88,032 & 504,867 & 62,757 \\
\hline Other & 3,178 & 627 & 1,067 & 7,301 & 19,927 & 1,581 \\
\hline Total to Ultimate Consumers .......................... & $1,314,113$ & 897,086 & 272,346 & 374,777 & $2,480,025$ & 215,797 \\
\hline Sales for Resale & & 0 & 0 & 0 & 328,757 & \\
\hline \multicolumn{7}{|l|}{ Oper Revenues for the Year (Thous) } \\
\hline Residential & 18,189 & 1,830 & 4,627 & 11,448 & 42,041 & 3,852 \\
\hline 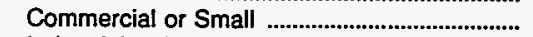 & 8,588 & 1,045 & 1,164 & 4,272 & 34,864 & 1,703 \\
\hline Industrial or Large & 21,384 & 21,284 & 5,991 & 4,060 & 14,515 & 1,944 \\
\hline Other & 576 & 50 & 100 & 339 & 695 & 91 \\
\hline 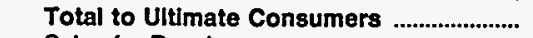 & 48,737 & 24,209 & 11,882 & 20,119 & 92,115 & $\mathbf{7 , 5 9 0}$ \\
\hline 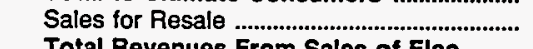 & & & & & 11,310 & \\
\hline Total Revenues From Sales of Elec ......... & 48,737 & 24,209 & 11,882 & 20,119 & 103,425 & 7,590 \\
\hline
\end{tabular}

Note: Totals may not equal sum of components because of independent rounding.

Source: Energy Information Administration, Form EIA-861, "Annual Electric Utility Report." Data are submitted on a calendar year. 
Table 25. Number of Consumers, Sales, and Operating Revenue by Major U.S.

Publicly Owned Electric Utility Within State, 1993 (Continued)

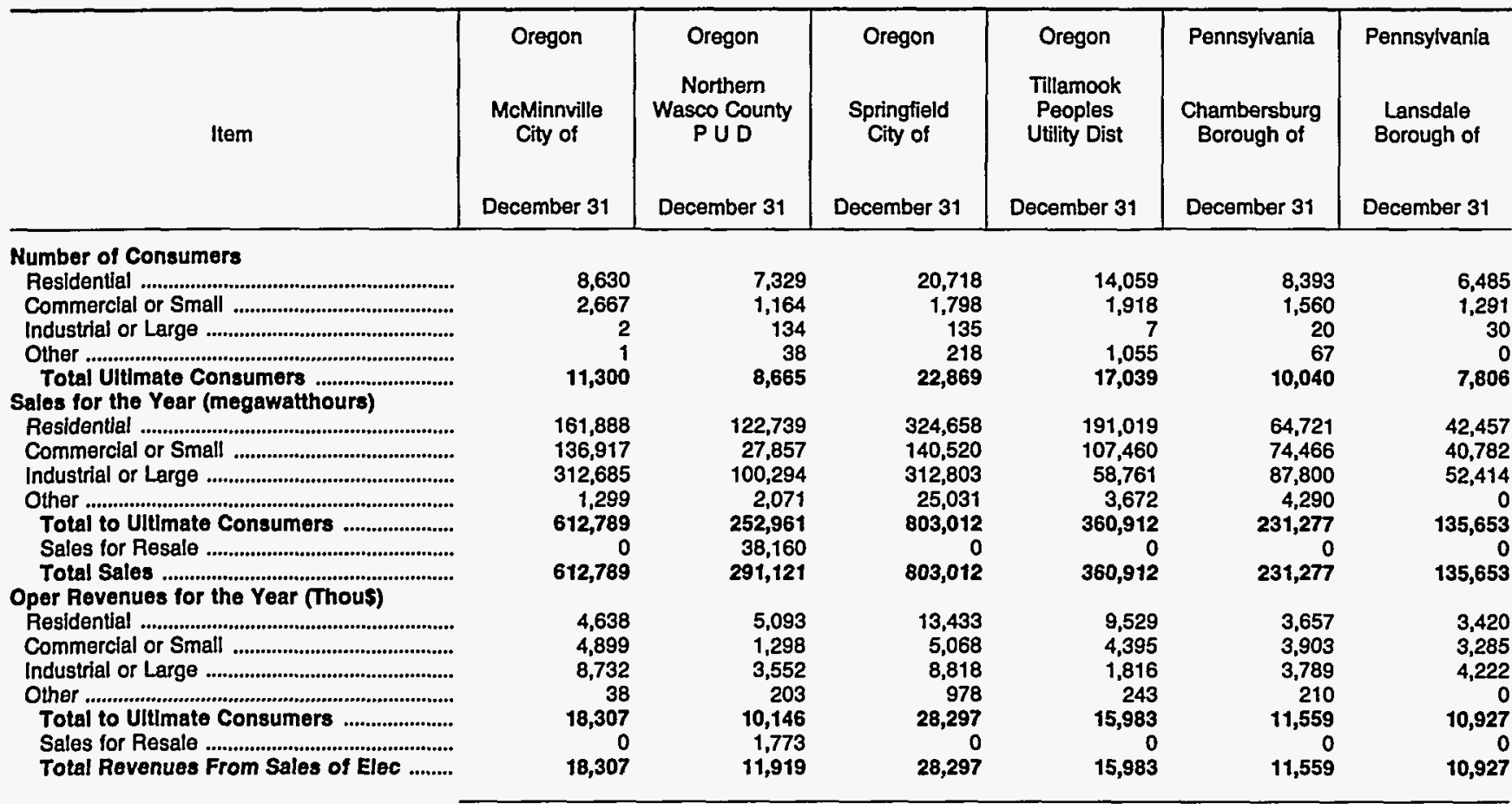

\begin{tabular}{|c|c|c|c|c|c|c|}
\hline Item & $\begin{array}{l}\text { South Carolina } \\
\text { Camden } \\
\text { City of } \\
\text { December } 31\end{array}$ & $\begin{array}{c}\text { South Carolina } \\
\text { Easley } \\
\text { Combined } \\
\text { Utility } \\
\text { System } \\
\text { December } 31\end{array}$ & $\begin{array}{c}\text { South Carolina } \\
\text { Gaffney } \\
\text { City of } \\
\text { December } 31\end{array}$ & $\begin{array}{l}\text { South Carolina } \\
\text { Greenwood } \\
\text { Commissioners } \\
\text { Pub Wk } \\
\text { December } 31\end{array}$ & $\begin{array}{c}\text { South Carolina } \\
\text { Greer } \\
\text { Comm } \\
\text { of } \\
\text { Public Works } \\
\text { December } 31\end{array}$ & $\begin{array}{l}\text { South Carolina } \\
\text { Newberry } \\
\text { City of } \\
\text { December } 31\end{array}$ \\
\hline \multicolumn{7}{|l|}{ Number of Consumers } \\
\hline 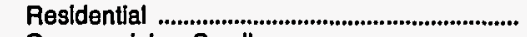 & 8,050 & 8,816 & 6,119 & 10,022 & 6,753 & 3,891 \\
\hline Commercial or Small ......................................... & 1,140 & 1,249 & 865 & 1,561 & 884 & 746 \\
\hline Industrial or Large & 13 & 0 & 23 & 205 & 197 & 13 \\
\hline 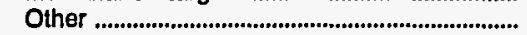 & 0 & 0 & 2,260 & 1 & 1 & 0 \\
\hline $\begin{array}{l}\text { Total Ultlmate Consumers } \\
\text { Sales for the Year (megawatthours) }\end{array}$ & 9,203 & 10,065 & 9,267 & 11,789 & 7,835 & 4,650 \\
\hline 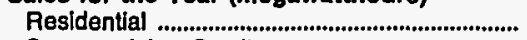 & 84,944 & 119,133 & 69,652 & 101,546 & 85.551 & 40,322 \\
\hline Commercial or Small ....................................... & 53,110 & 80,436 & 61,797 & 26,793 & 18,012 & 47,471 \\
\hline 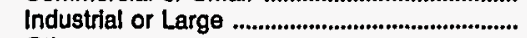 & 3,750 & 0 & 36,228 & 104,824 & 50,129 & 42,870 \\
\hline 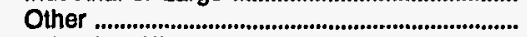 & 0 & 0 & 2,166 & 2,587 & 1,381 & 0 \\
\hline Total to Uitimate Consumers & 141,804 & 199,569 & 169,843 & 235,750 & 155,073 & 130,663 \\
\hline 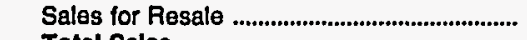 & & 0 & 0 & 0 & $\begin{aligned} 0 \\
0\end{aligned}$ & \\
\hline $\begin{array}{l}\text { Total Sales } \\
\text { Oper Revenues for the Year (Thous) }\end{array}$ & \multicolumn{5}{|c|}{ Oper Revenues for the Year (Thous) } & 130,663 \\
\hline 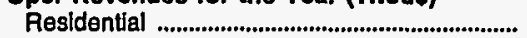 & 7,021 & 8,774 & 5,346 & 6,386 & 6,857 & 3,142 \\
\hline 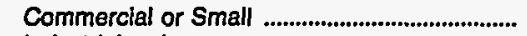 & 4,165 & 5,177 & 4,292 & 1,861 & 1,187 & 3,324 \\
\hline 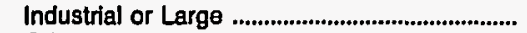 & 341 & 0 & 968 & 5,578 & 2,490 & 2,379 \\
\hline Other & 0 & 0 & 196 & 150 & 89 & \\
\hline 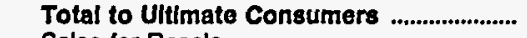 & 11,527 & 13,951 & 10,802 & 13,975 & 10,623 & 8,845 \\
\hline 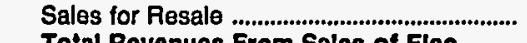 & & & 0 & $\begin{array}{r}0 \\
+2075\end{array}$ & 0 & \\
\hline Total Revenues From Sales of Elec ......... & 11,527 & 13,951 & 10,802 & 13,975 & 10,623 & 8,845 \\
\hline
\end{tabular}

Note: Totals may not equal sum of components because of independent rounding.

Source: Energy Information Administration, Form ElA-861, "Annual Electric Utility Report." Data are submitted on a calendar year. 
Table 25. Number of Consumers, Sales, and Operating Revenue by Major U.S. Publicly Owned Electric Utility Within State, 1993 (Continued)

\begin{tabular}{|c|c|c|c|c|c|c|}
\hline Item & $\begin{array}{c}\text { South Carolina } \\
\text { Orangeburg } \\
\text { City of }\end{array}$ & $\begin{array}{l}\text { South Carolina } \\
\text { Piedmont } \\
\text { Municipal } \\
\text { Power Agny } \\
\text { December } 31\end{array}$ & $\begin{array}{l}\text { South Carolina } \\
\text { Rock Hill } \\
\text { City of } \\
\text { December } 31\end{array}$ & $\begin{array}{l}\text { South Carolina } \\
\text { Seneca } \\
\text { City of } \\
\text { December } 31\end{array}$ & $\begin{array}{c}\text { South Carolina } \\
\text { South } \\
\text { Carolina } \\
\text { Pub } \\
\text { Serv Auth } \\
\text { December } 31\end{array}$ & $\begin{array}{l}\text { South Dakota } \\
\text { Brookings } \\
\text { City of } \\
\text { December } 31\end{array}$ \\
\hline \multicolumn{7}{|l|}{ Number of Consumers } \\
\hline 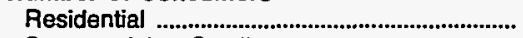 & 18,348 & 0 & 18,509 & 4,391 & 80,267 & 5,915 \\
\hline Commercial or Small & 2,702 & 0 & 2,541 & 766 & 15,373 & 886 \\
\hline 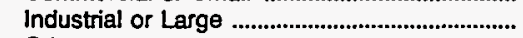 & 93 & 0 & 3 & 3 & 32 & 34 \\
\hline Other & 1 & 0 & 0 & 1 & 303 & 107 \\
\hline $\begin{array}{l}\text { Total Ultimate Consumers } \\
\text { Sales for the Year (megawatthours) }\end{array}$ & \multicolumn{3}{|c|}{ Sales for the Year (megawatthours) } & 5,161 & 95,975 & 6,942 \\
\hline 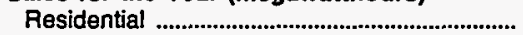 & 254,223 & 0 & 218,460 & 51,008 & $1,024,861$ & 60,033 \\
\hline 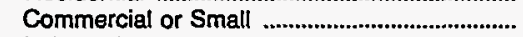 & 120,321 & 0 & 252,808 & 47,857 & $1,152,137$ & 35,800 \\
\hline Industrial or Large & 326,524 & 0 & 22,064 & 34,456 & $5,155,259$ & 66,899 \\
\hline Other & 1,471 & 0 & 0 & 1,388 & 38,481 & 13,811 \\
\hline 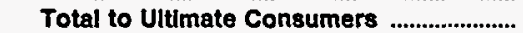 & 702,539 & 0 & 493,332 & 134,709 & $7,370,738$ & 176,643 \\
\hline 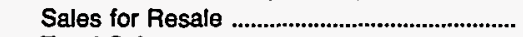 & 0 & $3,048,229$ & 0 & 0 & $7,059,116$ & \\
\hline $\begin{array}{l}\text { Total Sales } \\
\text { Oper Revenues for the Year (Thous) }\end{array}$ & 702,539 & $3,048,229$ & 493,332 & 134,709 & $14,429,854$ & 176,643 \\
\hline 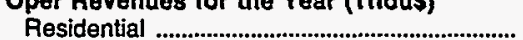 & 13,560 & 0 & 18,587 & 3,516 & \multicolumn{2}{|c|}{ Oper Revenues for the Year (Thous) } \\
\hline Commercial or Small & 7,983 & 0 & 20,111 & 3,769 & 60,802 & $\begin{array}{l}2,400 \\
1,754\end{array}$ \\
\hline Industrial or Large & 14,071 & 0 & 1,506 & 1,735 & 168,339 & 2,739 \\
\hline Other & 131 & 0 & 0 & 104 & 2,032 & 721 \\
\hline Total to Uitimate Consumers & 35,745 & $\mathbf{0}$ & 40,204 & 9,124 & 291,424 & 7,672 \\
\hline 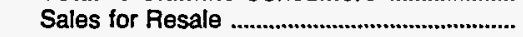 & & 154,533 & 0 & 0 & 292,606 & \\
\hline Total Revenues From Sales of Elec ......... & 35,745 & 154,533 & 40,204 & 9,124 & 584,030 & 7,672 \\
\hline
\end{tabular}

\begin{tabular}{|c|c|c|c|c|c|c|}
\hline Item & $\begin{array}{c}\text { South Dakota } \\
\text { Heartland } \\
\text { Consumers } \\
\text { Power Dist } \\
\text { December } 31\end{array}$ & $\begin{array}{l}\text { South Dakota } \\
\text { Missouri } \\
\text { Basin } \\
\text { Mun } \\
\text { Power Agny } \\
\text { December } 31\end{array}$ & $\begin{array}{c}\text { South Dakota } \\
\text { Pierre } \\
\text { City of } \\
\text { December } 31\end{array}$ & $\begin{array}{l}\text { South Dakota } \\
\text { Watertown } \\
\text { Municipal } \\
\text { Utilities } \\
\text { December } 31\end{array}$ & $\begin{array}{c}\text { Tennessee } \\
\text { Alcoa } \\
\text { Utilities } \\
\text { December } 31\end{array}$ & $\begin{array}{c}\text { Tennessee } \\
\text { Athens } \\
\text { Utility } \\
\text { Board } \\
\text { December } 31\end{array}$ \\
\hline \multicolumn{7}{|l|}{ Number of Consumers } \\
\hline 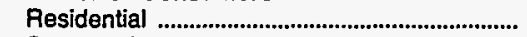 & 0 & 0 & 5,478 & 8,236 & 17,110 & 9,202 \\
\hline Commercial or Small & 0 & 0 & 629 & 1,280 & 2,545 & 1,774 \\
\hline Industrial or Large & 0 & 0 & 73 & 238 & 204 & 221 \\
\hline Other & 0 & 0 & 72 & 896 & 37 & 109 \\
\hline \multicolumn{7}{|l|}{ Sales for the Year (megawatthours) } \\
\hline 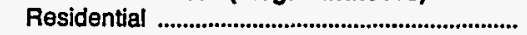 & 0 & 0 & 75,935 & 81,606 & 247,075 & 127,603 \\
\hline Commercial or Small & 0 & 0 & 19,336 & 24,962 & 34,316 & 28,112 \\
\hline Industrial or Large & 0 & 0 & 38,325 & 99,296 & 117,425 & 341,936 \\
\hline Other & 0 & 0 & 9,530 & 3,048 & 6,221 & 5,907 \\
\hline 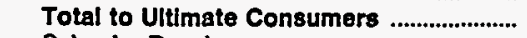 & 0 & $\mathbf{0}$ & 143,126 & 208,912 & 405,037 & 503,558 \\
\hline Sales for Resale & 401,059 & $1,824,685$ & 13,351 & & & \\
\hline \multicolumn{7}{|l|}{ Oper Revenues for the Year (Thous) } \\
\hline 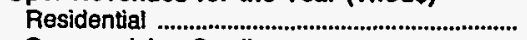 & 0 & 0 & 3,105 & 3,035 & 13,990 & 7,254 \\
\hline 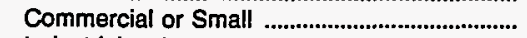 & 0 & 0 & 851 & 1,198 & 2,327 & 1,919 \\
\hline 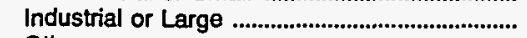 & 0 & 0 & 1,685 & 3,674 & 6,418 & 15,819 \\
\hline Other & 0 & 0 & 362 & 80 & 489 & 476 \\
\hline 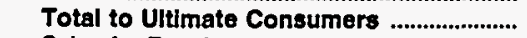 & $\mathbf{0}$ & 0 & 6,003 & 7,987 & 23,224 & 25,468 \\
\hline Sales for Resale & 12,002 & 51,834 & 263 & 0 & & \\
\hline Total Revenues From Sales of Elec ......... & 12,002 & 51,834 & 6,266 & 7,987 & 23,224 & 25,468 \\
\hline
\end{tabular}

Note: Totals may not equal sum of components because of independentrounding.

Source: Energy Information Administration, Form ElA-861, "Annual Electric Utility Report." Data are submitted on a calendar year. 
Table 25. Number of Consumers, Sales, and Operating Revenue by Major U.S. Publicly Owned Electric Utility Within State, 1993 (Continued)

\begin{tabular}{|c|c|c|c|c|c|c|}
\hline Item & $\begin{array}{l}\text { Tennessee } \\
\text { Benton } \\
\text { County } \\
\text { December } 31\end{array}$ & $\begin{array}{c}\text { Tennessee } \\
\text { Bolivar } \\
\text { City of } \\
\text { December } 31\end{array}$ & $\begin{array}{c}\text { Tennessee } \\
\text { Bristol } \\
\text { City of } \\
\text { December } 31\end{array}$ & $\begin{array}{c}\text { Tennessee } \\
\text { Brownsville } \\
\text { City of } \\
\text { December } 31\end{array}$ & $\begin{array}{c}\text { Tennessee } \\
\text { Carroll } \\
\text { County } \\
\text { December } 31\end{array}$ & $\begin{array}{c}\text { Tennessee } \\
\text { Chattanooga } \\
\text { City of }\end{array}$ \\
\hline \multicolumn{7}{|l|}{ Number of Consumers } \\
\hline 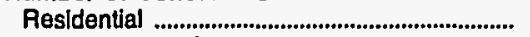 & 7,459 & 8,502 & 24,629 & 3,958 & 11,707 & 126,103 \\
\hline 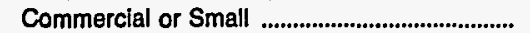 & 1,345 & 1,603 & 2,904 & 695 & 2,373 & 14,616 \\
\hline 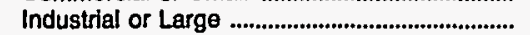 & 79 & 93 & 478 & 83 & 178 & 1,794 \\
\hline Other & 137 & 23 & 164 & 25 & 101 & 149 \\
\hline $\begin{array}{l}\text { Total Ultimate Consumers } \\
\text { Sales for the Year (megawathours) }\end{array}$ & \multicolumn{5}{|c|}{ Sales for the Year (megawatthours) } & 142,662 \\
\hline 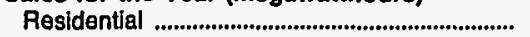 & 92,384 & 115,464 & 386,367 & 51,598 & 166,049 & $2,002,967$ \\
\hline Commercial or Small .......................................... & 15,602 & 19,141 & 48,073 & 11,613 & 26,716 & 411,508 \\
\hline Industrial or Large & 80,759 & 77,730 & 300,352 & 112,984 & 149,488 & $2,790,959$ \\
\hline Other & 4,099 & 3,790 & 7,952 & 1,889 & 7,210 & 56,751 \\
\hline Total to UItImate Consumers ...................... & 192,844 & 216,125 & 742,744 & 178,084 & 349,463 & $5,262,185$ \\
\hline 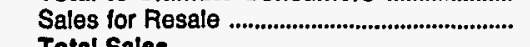 & 0 & 0 & 0 & 0 & 0 & 0 \\
\hline \multicolumn{7}{|l|}{ Oper Revenues for the Year (Thous) } \\
\hline 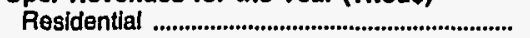 & 5,577 & 6,722 & 21,008 & 2,816 & 9,643 & 111,858 \\
\hline 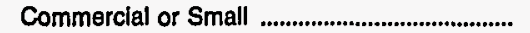 & 1,137 & 1,363 & 3,114 & 700 & 1,953 & 26,205 \\
\hline 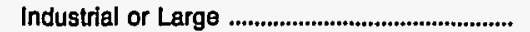 & 4,242 & 4,147 & 15,307 & 5,608 & 7,631 & 135,603 \\
\hline Other & 365 & 383 & 709 & 144 & 529 & 3,913 \\
\hline Total to Ultimate Consumers ......................... & 11,321 & 12,615 & 40,138 & 9,268 & 19,756 & 277,579 \\
\hline Sales for Resale & & & & & & \\
\hline Total Revenues From Sales of Elec ......... & 11,321 & 12,615 & 40,138 & 9,268 & 19,756 & 277,579 \\
\hline
\end{tabular}

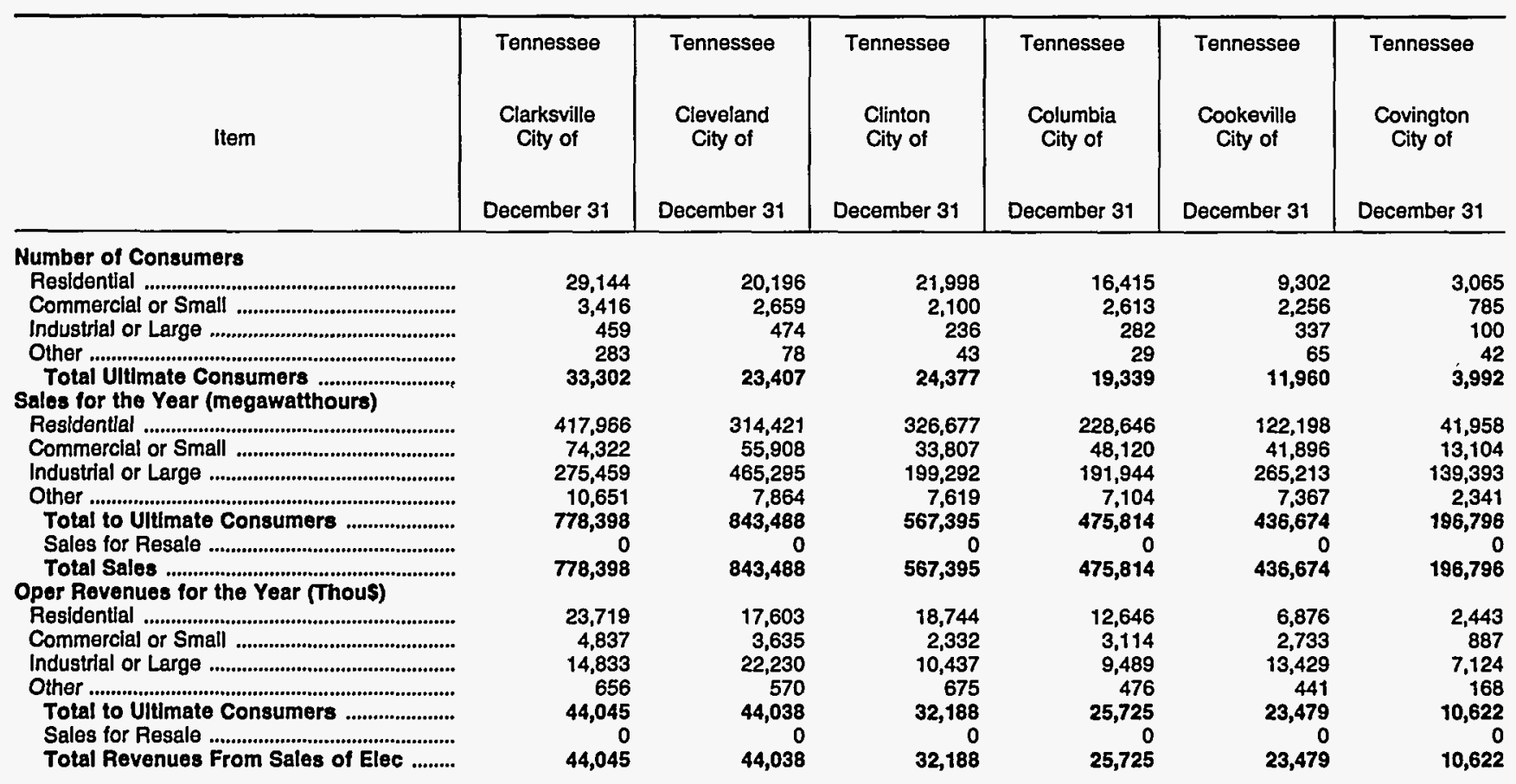

Note: Totals may not equal sum of components because of independent rounding.

Source: Energy Information Administration, Form EIA-861, "Annual Electric Utility Report." Data are submitted on a calendar year. 
Table 25. Number of Consumers, Sales, and Operating Revenue by Major U.S. Publicly Owned Electric Utility Within State, 1993 (Continued)

\begin{tabular}{|c|c|c|c|c|c|c|}
\hline Item & $\begin{array}{c}\text { Tennessee } \\
\text { Dayton } \\
\text { City of } \\
\text { December } 31\end{array}$ & $\begin{array}{c}\text { Tennessee } \\
\text { Dickson } \\
\text { City of } \\
\text { December } 31\end{array}$ & $\begin{array}{c}\text { Tennessee } \\
\text { Dyersburg } \\
\text { City of } \\
\text { December } 31\end{array}$ & $\begin{array}{c}\text { Tennessee } \\
\text { Elizabethton } \\
\text { City of }\end{array}$ & $\begin{array}{c}\text { Tennessee } \\
\text { Enwin } \\
\text { Town of } \\
\text { December } 31\end{array}$ & $\begin{array}{c}\text { Tennessee } \\
\text { Etowah } \\
\text { City of } \\
\text { December } 31\end{array}$ \\
\hline \multicolumn{7}{|l|}{ Number of Consumers } \\
\hline 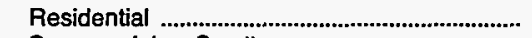 & 6,182 & 19,795 & 9,240 & 19,355 & 6,784 & 4,036 \\
\hline Commercial or Smail & 1,293 & 2,866 & 1,627 & 2,443 & 827 & 498 \\
\hline 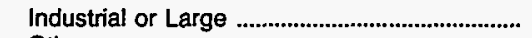 & 94 & 251 & 193 & 226 & 78 & 40 \\
\hline Other & 19 & 60 & 55 & 109 & 20 & 24 \\
\hline $\begin{array}{l}\text { Total Ultimate Consumers } \\
\text { Sales for the Year (megawa................... }\end{array}$ & 7,588 & 22,972 & 11,115 & 22,133 & 7,709 & 4,598 \\
\hline 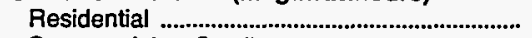 & 74,905 & 294,866 & 114,581 & 273,160 & 85,337 & 54,118 \\
\hline 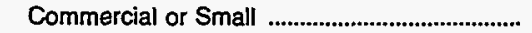 & 16,853 & 39,016 & 30,253 & 33,552 & 12,053 & 7,232 \\
\hline 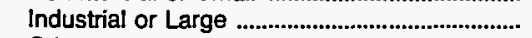 & 89,952 & 201,802 & 414,755 & 156,348 & 100,707 & 77,649 \\
\hline Other & 2,536 & 6,345 & 4,966 & 6,716 & 1,894 & 1,945 \\
\hline Total to Uitimate Consumers ...................... & 184,246 & 542,029 & 564,555 & 469,776 & 199,991 & 140,944 \\
\hline Sales for Resale & 0 & 0 & 0 & 0 & 0 & 0 \\
\hline $\begin{array}{l}\text { Total Sales ........................................... } \\
\text { Oper Revenues for the Year (Thous) }\end{array}$ & 184,246 & 542,029 & 564,555 & 469,776 & 199,991 & 140,944 \\
\hline 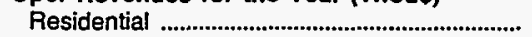 & 4,332 & 17,151 & 6,698 & 15,708 & 4,828 & 3,041 \\
\hline 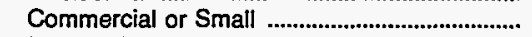 & 1,159 & 2,708 & 2,059 & 2,330 & 800 & 487 \\
\hline Industrial or Large & 4,703 & 10,683 & 18,113 & 8,351 & 4,591 & 3,486 \\
\hline Other & 200 & 388 & 420 & 532 & 183 & 183 \\
\hline 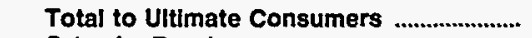 & 10,394 & 30,930 & 27,290 & 26,921 & 10,402 & 7,197 \\
\hline 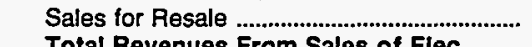 & & $\begin{array}{r}0 \\
3020\end{array}$ & $\begin{array}{r}0 \\
2700\end{array}$ & & & \\
\hline Total Revenues From Sales of Elec ......... & 10,394 & 30,930 & 27,290 & 26,921 & 10,402 & 7,197 \\
\hline
\end{tabular}

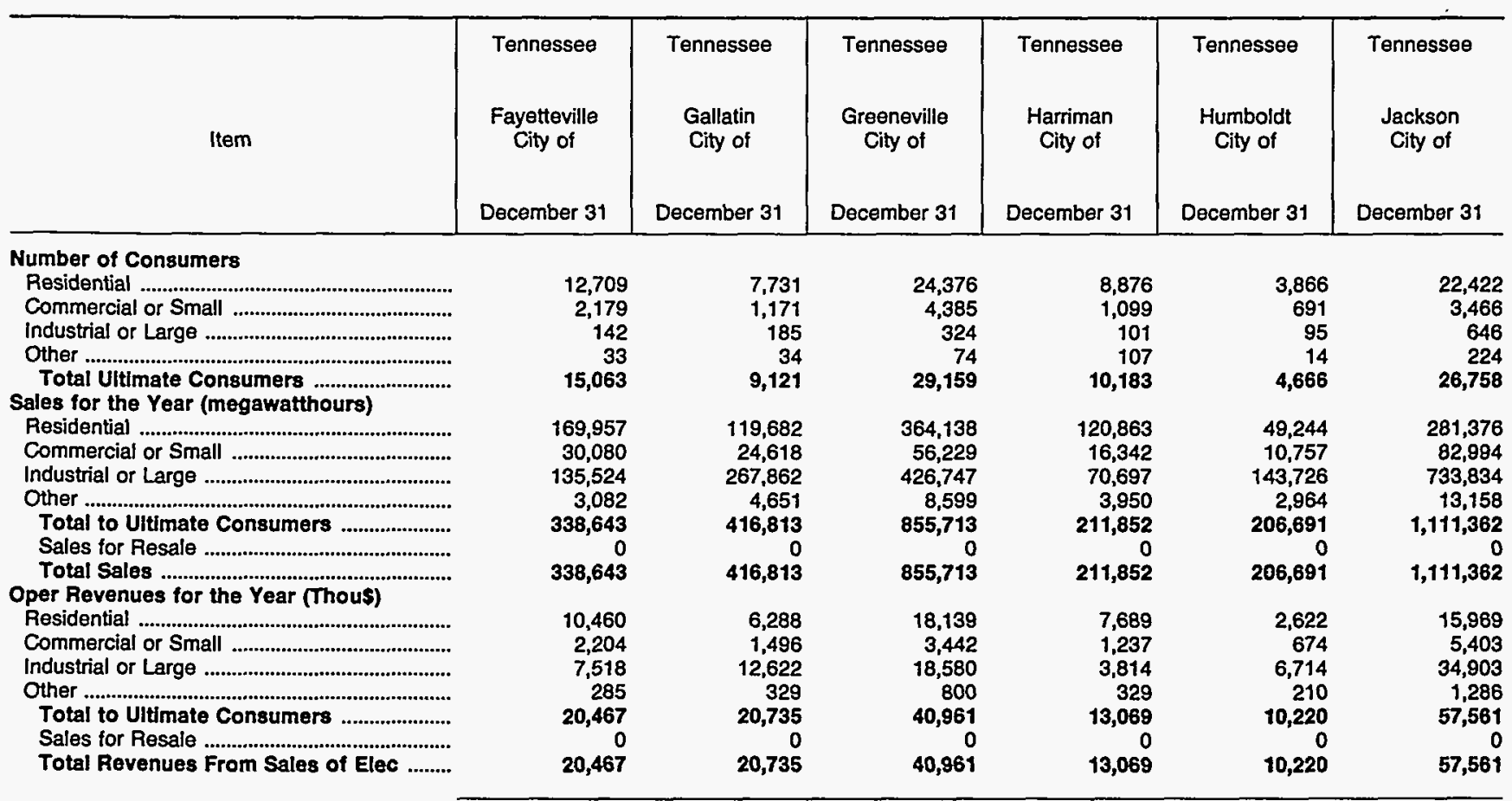

Note: Totals may not equal sum of components because of independent rounding.

Source: Energy Information Administration, Form EIA-861, "Annual Electric Utility Report." Data are submitted on a calendar year. 
Table 25. Number of Consumers, Sales, and Operating Revenue by Major U.S. Publicly Owned Electric Utility Within State, 1993 (Continued)

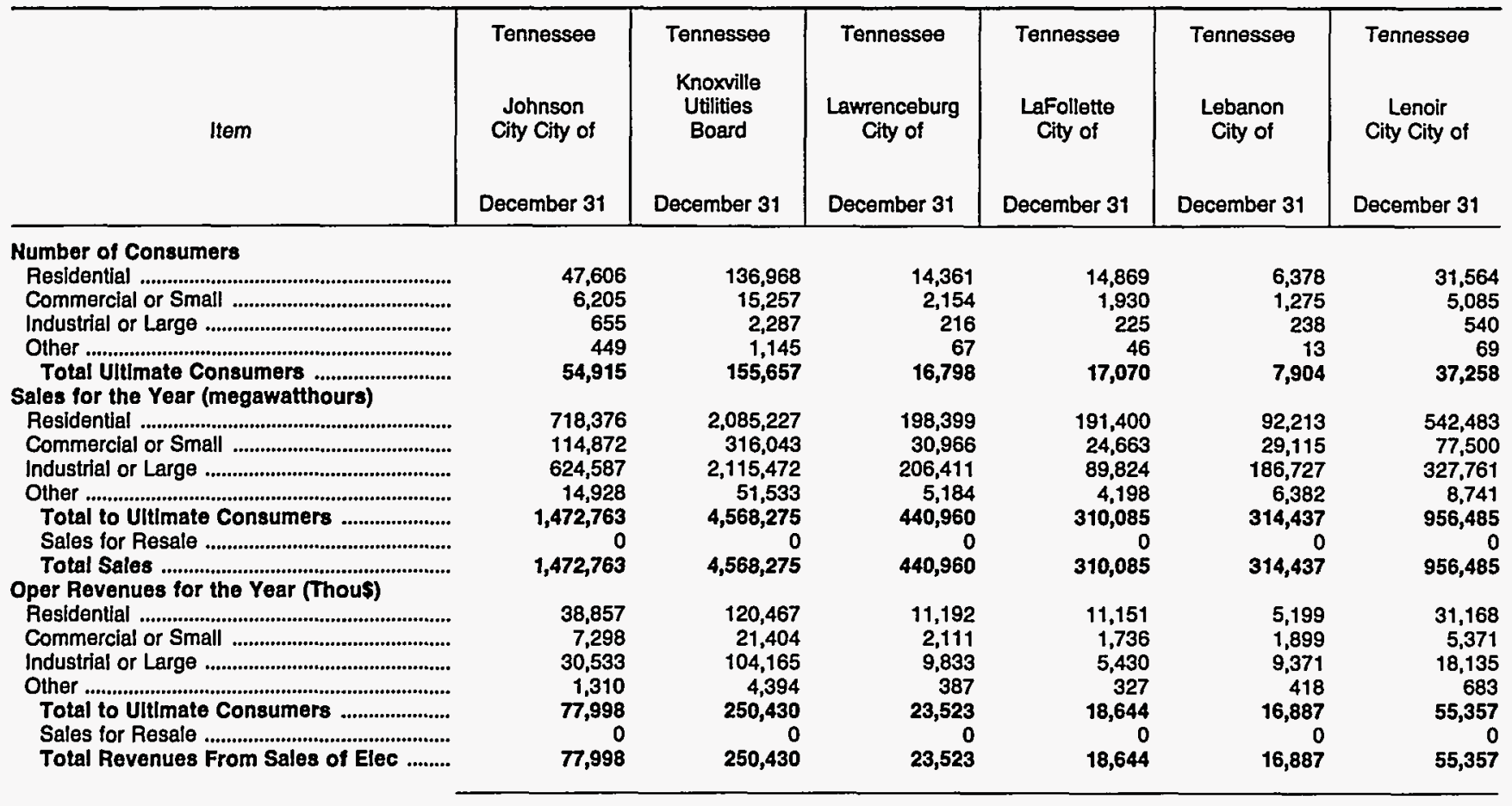

\begin{tabular}{|c|c|c|c|c|c|c|}
\hline Item & $\begin{array}{c}\text { Tennessee } \\
\begin{array}{c}\text { Lewisburg } \\
\text { City of }\end{array} \\
\text { December } 31\end{array}$ & $\begin{array}{c}\text { Tennessee } \\
\text { Lexington } \\
\text { City of } \\
\text { December } 31\end{array}$ & $\begin{array}{c}\text { Tennessee } \\
\text { Loudon } \\
\text { Utilities } \\
\text { Board } \\
\text { December } 31\end{array}$ & $\begin{array}{c}\text { Tennessee } \\
\text { Maryville } \\
\text { Utilities }\end{array}$ & $\begin{array}{c}\text { Tennessee } \\
\text { McMinnville } \\
\text { Electric } \\
\text { System } \\
\text { December } 31\end{array}$ & $\begin{array}{c}\text { Tennessee } \\
\text { Memphis } \\
\text { City of }\end{array}$ \\
\hline \multicolumn{7}{|l|}{ Number of Consumers } \\
\hline 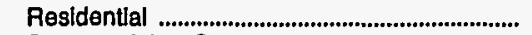 & 4,096 & 14,464 & 5,165 & 14,232 & 5,384 & 320,043 \\
\hline Commercial or Small ........................ & 812 & 2,862 & 765 & 1,873 & 1,221 & 29,927 \\
\hline 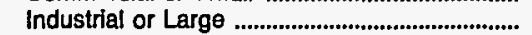 & 130 & 191 & 83 & 211 & 151 & 6,176 \\
\hline Other & 44 & 95 & 20 & & 60 & 188 \\
\hline $\begin{array}{l}\text { Total Uittmate Consumers ......................... } \\
\text { Sales for the Year (megawatthours) }\end{array}$ & Sales for the Year (megawatthours) & 17,612 & 6,033 & 16,402 & 6,816 & 356,334 \\
\hline 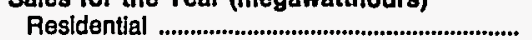 & 57,492 & 172,921 & 72,474 & 188,709 & 67,838 & $4,270,406$ \\
\hline 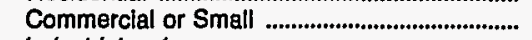 & 14,109 & 28,712 & 9,890 & 40,691 & 21,464 & 671,069 \\
\hline 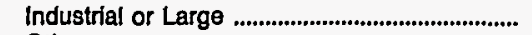 & 184,843 & 142,282 & 183,092 & 258,696 & 111,364 & $6,012,197$ \\
\hline Other & 3,761 & 6,977 & 1,915 & 6,163 & 3,296 & 121,567 \\
\hline Total to Ultimate Consumers ........................... & 260,205 & 350,892 & 267,371 & 494,259 & 203,962 & $11,075,239$ \\
\hline 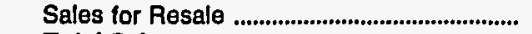 & & & & & & \\
\hline \multicolumn{7}{|l|}{ Oper Revenues for the Year (Thous) } \\
\hline 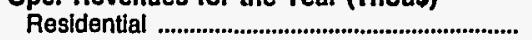 & 3,282 & 10,180 & 4,357 & 10,199 & 3,717 & 251,836 \\
\hline 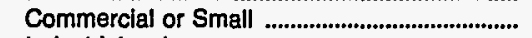 & 944 & 2,090 & 699 & 2,503 & 1,403 & 46,305 \\
\hline Industrial or Large & 9,256 & 7,914 & 8,305 & 11,617 & 5,708 & 317,236 \\
\hline Other & 293 & 595 & 163 & 602 & 247 & 10,587 \\
\hline Total to Ultimate Consumers ............................. & 13,775 & 20,779 & 13,524 & 24,921 & 11,075 & 625,964 \\
\hline Sales for Resale ................................................ & $\begin{array}{r}0 \\
13.775\end{array}$ & $\begin{array}{r}0 \\
20779\end{array}$ & $\begin{array}{r}0 \\
13.524\end{array}$ & $\begin{array}{r}0 \\
24.921\end{array}$ & $\begin{array}{r}0 \\
11.075\end{array}$ & $\begin{array}{r}0 \\
625.964\end{array}$ \\
\hline
\end{tabular}

Note: Totals may not equal sum of components because of independent rounding.

Source: Energy Information Administration, Form EIA-861, "Annual Electric Utility Report." Data are submitted on a calendar year. 


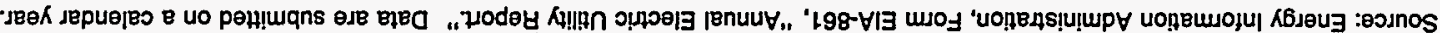

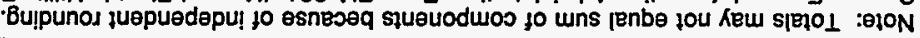

\begin{tabular}{|c|c|c|c|c|c|c|}
\hline 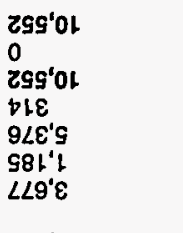 & 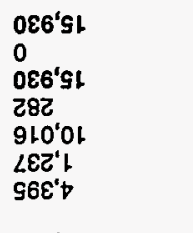 & $\begin{array}{l}0 \angle 9^{\circ} \angle b \\
0 \\
0 \angle 9^{\prime} \angle b \\
\varepsilon \varepsilon 9^{\prime} \\
S \angle 9^{\prime} 0 z \\
68^{\prime} 9 \\
\varepsilon 09^{\prime} 6 \downarrow\end{array}$ & 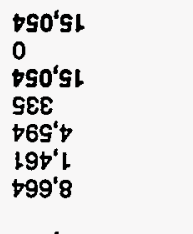 & 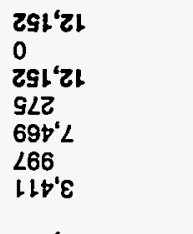 & $\begin{array}{l}10 \varepsilon^{\prime} 6 t \\
0 \\
10 \varepsilon^{\prime} 6 t \\
99 \varepsilon \\
69 L^{\prime} 6 \\
\varepsilon \forall L^{\prime} L \\
\$ 20^{\prime} 8\end{array}$ & 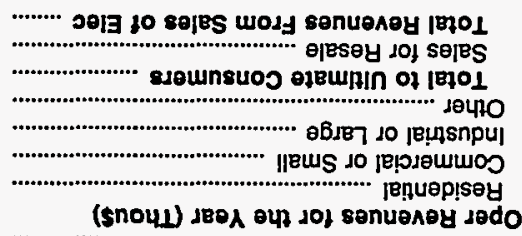 \\
\hline 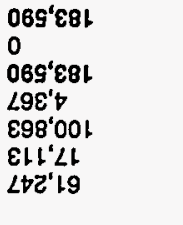 & $\begin{array}{l}809^{\prime} 00 \varepsilon \\
0 \\
\varepsilon 09^{\prime} 00 \varepsilon \\
\text { SLb'\& } \\
0 Z S^{\prime} L O Z \\
666^{\prime} 8 L \\
699^{\prime} 9 L\end{array}$ & $\begin{array}{l}20 S^{\prime} Z 28 \\
0 \\
20 g^{\prime} Z 28 \\
998^{\prime} \angle \\
80 S^{\prime} 9 \angle \varepsilon \\
68 \varepsilon^{\prime} 001 \\
008^{\prime} \angle \varepsilon \varepsilon\end{array}$ & 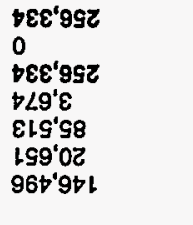 & $\begin{array}{l}100^{\prime} 8 \varepsilon Z \\
0 \\
100^{\prime} 8 \varepsilon Z \\
Z 19^{\prime} \varepsilon \\
81 L^{\prime} \forall S I \\
\forall E t^{\prime} 9 L \\
\angle E Z^{\prime} \varepsilon 9\end{array}$ & 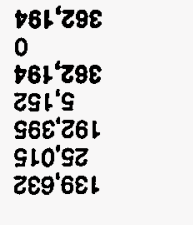 & 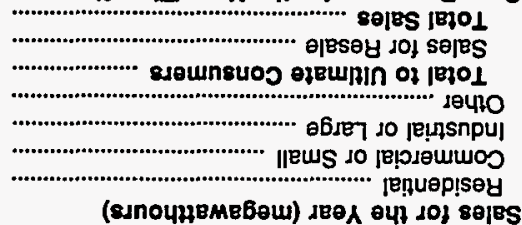 \\
\hline $\begin{array}{l}\text { SEg's } \\
\varepsilon ! \\
6 Z L \\
6 Z L \\
b 99^{\prime} \downarrow\end{array}$ & $\begin{array}{l}\forall 8 \varepsilon^{\prime} L \\
0 \varepsilon \\
2 L 1 \\
888 \\
\forall 6 Z^{\prime} 9\end{array}$ & $\begin{array}{l}010^{\prime} 0 \varepsilon \\
89 Z \\
8 \angle L \\
92 \varepsilon^{\prime} G \\
889^{\prime} \varepsilon Z\end{array}$ & $\begin{array}{l}\text { ISt'LL } \\
9 \varepsilon \\
\text { ZZ! } \\
09 \nabla^{\prime \prime} L \\
\forall \varepsilon 8^{\prime} 6\end{array}$ & $\begin{array}{l}19 b^{\prime} 9 \\
19 \\
86 \\
180^{\prime} \downarrow \\
12 Z^{\prime} 9\end{array}$ & $\begin{array}{l}9 \mapsto 0^{\prime} Z L \\
\downarrow \varepsilon \\
\text { SSL } \\
\text { S†8'L } \\
\text { ¿LO'OL }\end{array}$ & 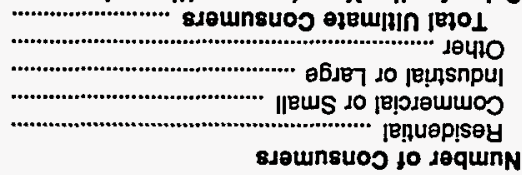 \\
\hline IE dөquөseO & 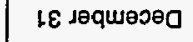 & IE دөqшөэөa & I\& Jөqueseg & IE dөquөsea & IE lequesog & \\
\hline 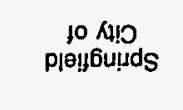 & 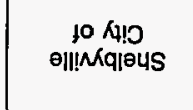 & 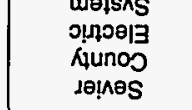 & 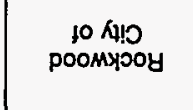 & $\begin{array}{l}\text { to Ry! } \\
\text { Ke|d!! }\end{array}$ & $\begin{array}{l}\text { to k! } 4 \text {. } \\
\text { !ysepind }\end{array}$ & well \\
\hline 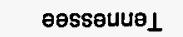 & 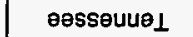 & easseuve $\perp$ & ersseuue 1 & eesseute 1 & eөsseuue $\perp$ & \\
\hline
\end{tabular}

\begin{tabular}{|c|c|c|c|c|c|c|}
\hline $\begin{array}{l}\text { LZG'LZ } \\
0 \\
\text { LZG'LZ } \\
909 \\
Z G 0^{\prime} 8 \\
1 \text { 'L'Z } \\
\text { ZGS'OL }\end{array}$ & $\begin{array}{l}8 Z Z^{\prime} \nleftarrow Z \\
0 \\
8 Z Z^{\prime} \nleftarrow Z \\
8 Z 9 \\
0 \angle L^{\prime} Z L \\
\forall \angle L^{\prime} Z \\
99 Z^{\prime} 6\end{array}$ & $\begin{array}{l}\text { LSE'ZZ } \\
0 \\
\text { ISE'ZZ } \\
\text { O†t } \\
\text { ESZ'6 } \\
8 † L^{\prime} Z \\
\text { OLS'OL }\end{array}$ & 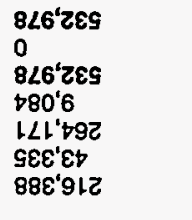 & $\begin{array}{l}9 \varepsilon b^{\prime} Z t \\
0 \\
9 \varepsilon b^{\prime} Z t \\
G L L \\
9 L b^{\prime} Z Z \\
Z E L^{\prime} \varepsilon \\
\varepsilon L G^{\prime} G L\end{array}$ & $\begin{array}{l}1 \oplus 6^{\prime} 1 \varepsilon \\
0 \\
1 \oplus 6^{\prime} L \varepsilon \\
6 Z 9 \\
9 \angle \varepsilon^{\prime} L Z \\
96 t^{\prime} Z \\
0+S^{\prime} L\end{array}$ & 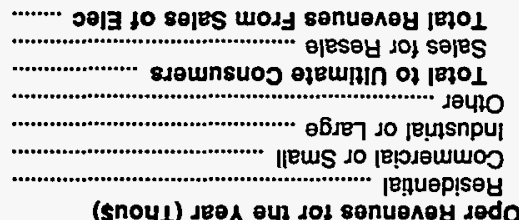 \\
\hline 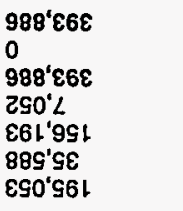 & 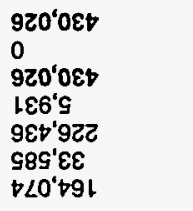 & $\begin{array}{l}1 \angle G^{\prime} \angle 8 \varepsilon \\
0 \\
1 \angle 9^{\prime} \angle 8 \varepsilon \\
619^{\prime} G \\
6 \angle 8^{\prime} \angle L L \\
086^{\prime} 6 Z \\
86 L^{\prime} \square \angle L\end{array}$ & 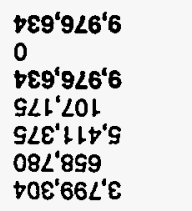 & $\begin{array}{l}\varepsilon \varepsilon L^{\prime} L \text { L8 } \\
0 \\
\varepsilon \varepsilon L^{\prime} L L 8 \\
199^{\prime} 6 \\
+89^{\prime} 09 t \\
8 \varepsilon 6^{\prime} 69 \\
096^{\prime} 08 Z\end{array}$ & 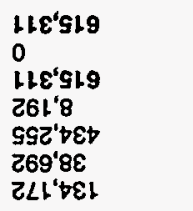 & 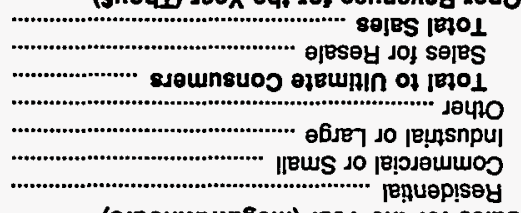 \\
\hline $\begin{array}{l}Z 1 Z^{\prime}<1 \\
t \leftarrow \\
802 \\
196^{\prime} Z \\
t 10^{\prime}+1\end{array}$ & 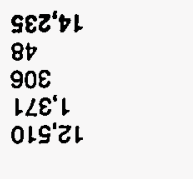 & $\begin{array}{l}88 \varepsilon^{\prime} 91 \\
191 \\
9 L 1 \\
86 t^{\prime} Z \\
8 S S^{\prime} \varepsilon 1\end{array}$ & 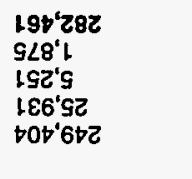 & $\begin{array}{l}Z \angle Z^{\prime} \varepsilon Z \\
16 \\
9 \angle \downarrow \\
Z Z \nabla^{\prime} Z \\
\square 8 Z^{\prime} 0 Z\end{array}$ & 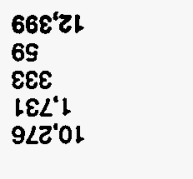 & 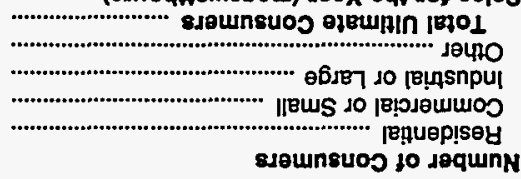 \\
\hline IE səquesəo & IE səquәэә0 & LE Lөquөग्0 & IE JequeseO & IE Jequөग्व & 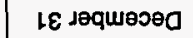 & \\
\hline $\begin{array}{l}\text { fo k } 4 ! 0 \\
\text { s!led }\end{array}$ & 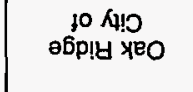 & $\begin{array}{l}10 \times 40 \\
\text { JodMON }\end{array}$ & 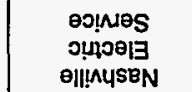 & $\begin{array}{l}104 ! 0 \\
\text { oloqserynw }\end{array}$ & 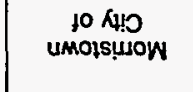 & แอ|| \\
\hline e日sseuue $\perp$ & eอsseuนa 1 & eอsseuน⿰㇒⿻ & e日sseuue & eosseuue 1 & eosseuue 1 & \\
\hline
\end{tabular}


Table 25. Number of Consumers, Sales, and Operating Revenue by Major U.S. Publicly Owned Electric Utility Within State, 1993 (Continued)

\begin{tabular}{|c|c|c|c|c|c|c|}
\hline Item & $\begin{array}{c}\text { Tennessee } \\
\text { Sweetwater } \\
\text { City of } \\
\text { December } 31\end{array}$ & $\begin{array}{c}\text { Tennessee } \\
\text { Tullahoma } \\
\text { Board } \\
\text { of } \\
\text { Pub Utils } \\
\text { December } 31\end{array}$ & $\begin{array}{c}\text { Tennessee } \\
\text { Union } \\
\text { City City of } \\
\text { December } 31\end{array}$ & $\begin{array}{c}\text { Tennessee } \\
\text { Weakley } \\
\text { County } \\
\text { Mun } \\
\text { Elec Sys } \\
\text { December } 31\end{array}$ & $\begin{array}{l}\text { Texas } \\
\text { Austin } \\
\text { City of } \\
\text { December } \mathbf{3 1}\end{array}$ & $\begin{array}{c}\text { Texas } \\
\text { Brenham } \\
\text { City of } \\
\text { December } 31\end{array}$ \\
\hline \multicolumn{7}{|l|}{ Number of Consumers } \\
\hline 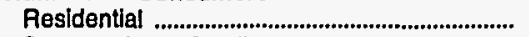 & 5,222 & 7,443 & 4,856 & 14,931 & 253,850 & 4,413 \\
\hline Commercial or Small ............................................. & 1,180 & 1,249 & 783 & 2,661 & 29,752 & 1,054 \\
\hline Industrial or Large & 96 & 159 & 133 & 264 & 8 & 28 \\
\hline 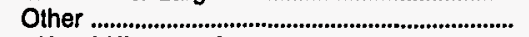 & 22 & 38 & 10 & 90 & 672 & 1 \\
\hline \multicolumn{7}{|l|}{ Sales for the Year (megawatthours) } \\
\hline 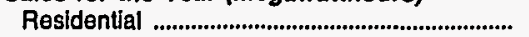 & 74,039 & 105,822 & 56,091 & 231,819 & $2,650,606$ & 60,591 \\
\hline 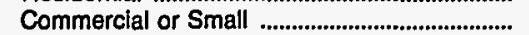 & 15,549 & 26,699 & 15,853 & 33,899 & $3,531,497$ & 62,319 \\
\hline Industrial or Large & 80,493 & 110,983 & 262,137 & 161,123 & 587,704 & 119,063 \\
\hline Other & 3,932 & 4,258 & 2,806 & 6,832 & 256,860 & 1,438 \\
\hline Total to Ultimate Consumers ..................... & 174,013 & 247,762 & 336,887 & 433,673 & $7,026,667$ & 243,411 \\
\hline 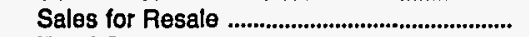 & 0 & 0 & 0 & 0 & 220,651 & 0 \\
\hline \multicolumn{7}{|l|}{ Oper Revenues for the Year (Thous) } \\
\hline 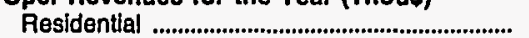 & 4,175 & 5,867 & 2,930 & 12,837 & 194,593 & 3,763 \\
\hline Commercial or Small ............................................. & 1,036 & 1,699 & 934 & 2,251 & 237,140 & 3,187 \\
\hline 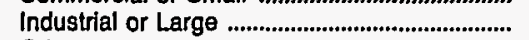 & 4,132 & 5,784 & 10,402 & 8,626 & 31,855 & 4,704 \\
\hline Other & 294 & 374 & 232 & 510 & 18,506 & 91 \\
\hline Total to UitImate Consumers ...................... & 9,637 & 13,724 & 14,498 & 24,224 & 482,094 & 11,745 \\
\hline 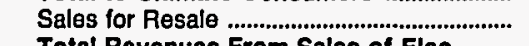 & & & 0 & & 7,291 & \\
\hline Total Revenues From Sales of Elec ........ & 9,637 & 13,724 & 14,498 & 24,224 & 489,385 & 11,745 \\
\hline
\end{tabular}

\begin{tabular}{|c|c|c|c|c|c|c|}
\hline Item & $\begin{array}{c}\text { Texas } \\
\text { Brownsville } \\
\text { Public } \\
\text { Utils Board } \\
\text { December } 31\end{array}$ & $\begin{array}{c}\text { Texas } \\
\text { Bryan } \\
\text { City of } \\
\text { December } 31\end{array}$ & $\begin{array}{c}\text { Texas } \\
\text { College } \\
\text { Station } \\
\text { City of } \\
\text { December } 31\end{array}$ & $\begin{array}{l}\text { Texas } \\
\text { Denton } \\
\text { City of } \\
\text { December } 31\end{array}$ & $\begin{array}{c}\text { Texas } \\
\text { Floresville } \\
\text { City of } \\
\text { December } 31\end{array}$ & $\begin{array}{l}\text { Texas } \\
\text { Garland } \\
\text { City of } \\
\text { December } 31\end{array}$ \\
\hline \multicolumn{7}{|l|}{ Number of Consumers } \\
\hline 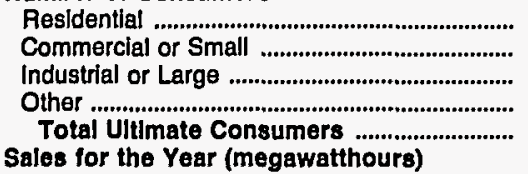 & $\begin{array}{r}26,653 \\
2,425 \\
1,555 \\
0 \\
30,633\end{array}$ & $\begin{array}{r}21,219 \\
2,645 \\
43 \\
247 \\
24,154\end{array}$ & $\begin{array}{r}18,469 \\
1,711 \\
0 \\
0 \\
20,180\end{array}$ & $\begin{array}{r}25,099 \\
3,251 \\
0 \\
254 \\
28,604\end{array}$ & $\begin{array}{r}6,955 \\
1,750 \\
1 \\
1,509 \\
10,215\end{array}$ & $\begin{array}{r}55,860 \\
3,735 \\
1,054 \\
227 \\
60,876\end{array}$ \\
\hline 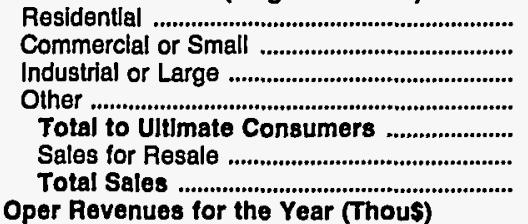 & $\begin{array}{r}271,682 \\
24,896 \\
357,171 \\
0 \\
653,749 \\
0 \\
653,749\end{array}$ & $\begin{array}{r}257,282 \\
155,010 \\
119,086 \\
46,518 \\
577,896 \\
646,037 \\
1,223,933\end{array}$ & $\begin{array}{r}202,468 \\
234,212 \\
0 \\
0 \\
436,680 \\
0 \\
436,680\end{array}$ & $\begin{array}{r}289,150 \\
501,135 \\
0 \\
34,110 \\
824,395 \\
175,223 \\
999,618\end{array}$ & $\begin{array}{r}87,758 \\
44,615 \\
709 \\
1,064 \\
134,146 \\
0 \\
134,146\end{array}$ & $\begin{array}{r}867,856 \\
69,484 \\
749,514 \\
96,261 \\
1,783,115 \\
807,298 \\
2,590,413\end{array}$ \\
\hline 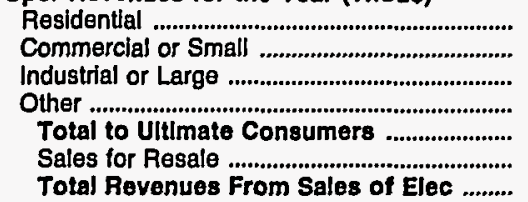 & $\begin{array}{r}18,671 \\
2,265 \\
23,354 \\
0 \\
44,290 \\
0 \\
44,290\end{array}$ & $\begin{array}{r}18,527 \\
11,187 \\
6,124 \\
3,222 \\
39,060 \\
26,466 \\
65,526\end{array}$ & $\begin{array}{r}14,185 \\
14,309 \\
0 \\
0 \\
28,494 \\
0 \\
28,494\end{array}$ & $\begin{array}{r}21,703 \\
30,100 \\
0 \\
2,525 \\
54,328 \\
6,748 \\
61,076\end{array}$ & $\begin{array}{r}6,508 \\
3,358 \\
54 \\
248 \\
10,168 \\
0 \\
10,168\end{array}$ & $\begin{array}{r}67,896 \\
5,724 \\
43,179 \\
7,002 \\
123,801 \\
24,388 \\
148,189\end{array}$ \\
\hline
\end{tabular}

Note: Totals may not equal sum of components because of independentrounding.

Source: Energy Information Administration, Form ElA-861. "Annual Electric Utility Report." Data are submitted on a calendar year. 
Table 25. Number of Consumers, Sales, and Operating Revenue by Major U.S. Publicly Owned Electric Utility Within State, 1993 (Continued)

\begin{tabular}{|c|c|c|c|c|c|c|}
\hline Item & $\begin{array}{c}\text { Texas } \\
\text { Georgetown } \\
\text { City of }\end{array}$ & $\begin{array}{c}\text { Texas } \\
\text { Greenville } \\
\text { Electric } \\
\text { Util Sys } \\
\text { December } 31\end{array}$ & $\begin{array}{c}\text { Texas } \\
\text { Kerville } \\
\text { Public } \\
\text { Utility } \\
\text { Board } \\
\text { December } 31\end{array}$ & $\begin{array}{c}\text { Texas } \\
\text { Lower } \\
\text { Colorado } \\
\text { River } \\
\text { Authority } \\
\text { December } 31\end{array}$ & $\begin{array}{c}\text { Texas } \\
\text { Lubbock } \\
\text { City of } \\
\text { December } 31\end{array}$ & $\begin{array}{c}\text { Texas } \\
\text { New Braunfels } \\
\text { City of } \\
\text { December } 31\end{array}$ \\
\hline \multicolumn{7}{|l|}{ Number of Consumers } \\
\hline 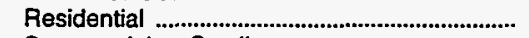 & 7,001 & 9,879 & 13,679 & 6 & 41,356 & 14,063 \\
\hline 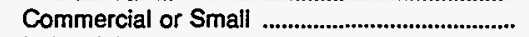 & 937 & 1,770 & 2,722 & 30 & 5,032 & 2,058 \\
\hline Industrial or Large & 35 & 3 & 0 & 14 & 73 & 11 \\
\hline Other & 1 & 12 & 137 & 0 & 855 & 194 \\
\hline \multicolumn{6}{|l|}{ Sales for the Year (megawatthours) } & 16,326 \\
\hline 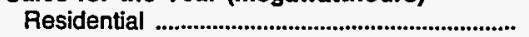 & 95,213 & 105,043 & 183,633 & 113 & 370,875 & 205,189 \\
\hline Commercial or Small ........................................... & 41,890 & 263,477 & 152,971 & 829 & 216,149 & 142,376 \\
\hline Industrial or Large & 26,878 & 50,592 & 0 & 162,399 & 245,917 & 374,866 \\
\hline Other & 5,450 & 2,565 & 5,085 & 0 & 124,813 & 26,239 \\
\hline Total to Ultimate Consumers & 169,431 & 421,677 & 341,689 & 163,341 & 957,754 & 748,670 \\
\hline 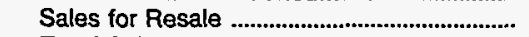 & 0 & 59,695 & & $9,505,719$ & 0 & 0 \\
\hline \multicolumn{7}{|l|}{ Oper Revenues for the Year (Thous) } \\
\hline 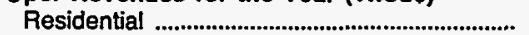 & 6,456 & 8,274 & 11,868 & 7 & 23,328 & 11,807 \\
\hline Commercial or Small & 3,069 & 17,329 & 9,178 & 53 & 12,288 & 8,503 \\
\hline Industrial or Large & 1,425 & 2,733 & 0 & 6,589 & 10,878 & 14,874 \\
\hline Other & 338 & 265 & 306 & 0 & 6,455 & 1,584 \\
\hline Total to Ultimate Consumers ....................... & 11,288 & 28,601 & 21,352 & 6,649 & 52,949 & 36,768 \\
\hline Sales for Resale & & 3,033 & 0 & 361,707 & 0 & \\
\hline Total Revenues From Sales of Elec ......... & 11,288 & 31,634 & 21,352 & 368,356 & 52,949 & 36,768 \\
\hline
\end{tabular}

\begin{tabular}{|c|c|c|c|c|c|c|}
\hline Item & $\begin{array}{c}\text { Texas } \\
\text { Sam Rayburn } \\
\text { Municipal } \\
\text { Pwr } \\
\text { Agny } \\
\text { December } 31\end{array}$ & $\begin{array}{c}\text { San Antonio } \\
\text { City of }\end{array}$ & $\begin{array}{l}\text { San Marcos } \\
\text { City of }\end{array}$ & $\begin{array}{c}\text { Texas } \\
\text { Seguin } \\
\text { City of } \\
\text { December } 31\end{array}$ & $\begin{array}{c}\text { Texas } \\
\text { Texas } \\
\text { Municipal } \\
\text { Power Agency } \\
\text { December } 31\end{array}$ & $\begin{array}{c}\text { Texas } \\
\text { Toledo Bend } \\
\text { Project } \\
\text { Joint } \\
\text { Oper } \\
\text { December } 31\end{array}$ \\
\hline \multicolumn{7}{|l|}{ Number of Consumers } \\
\hline Residential & 0 & 435,660 & 11,447 & 6,428 & 0 & 0 \\
\hline Commercial or Small & $\mathbf{0}$ & 49,201 & 2,407 & 1,024 & 0 & 0 \\
\hline Industrial or Large & 0 & 1,401 & 8 & 7 & 0 & 0 \\
\hline Other & 0 & 4,088 & 112 & 50 & 0 & 0 \\
\hline \multicolumn{5}{|l|}{ Sales for the Year (megawatthours) } & $\mathbf{0}$ & $\mathbf{0}$ \\
\hline 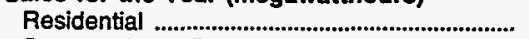 & 0 & $5,010,443$ & 123,867 & 68,977 & 0 & 0 \\
\hline 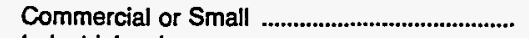 & 0 & $2,066,522$ & 122,405 & 62,307 & 0 & 0 \\
\hline Industrial or Large & 0 & $3,547,221$ & 51,202 & 48,693 & 0 & 0 \\
\hline Other & 0 & $1,745,028$ & 8,369 & 7,290 & 0 & 0 \\
\hline Total to Ultimate Consumers .......................... & $\mathbf{0}$ & $12,369,214$ & 305,843 & 187,267 & 0 & $\mathbf{0}$ \\
\hline Sales for Resale & 641,352 & 356,164 & & & $2,794,865$ & 356,328 \\
\hline \multicolumn{7}{|l|}{ Oper Revenues for the Year (Thous) } \\
\hline 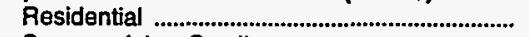 & 0 & 351,274 & 8,164 & 4,843 & 0 & 0 \\
\hline Commercial or Small & 0 & 135,973 & 7,090 & 4,073 & 0 & 0 \\
\hline Industrial or Large & 0 & 180,270 & 3,074 & 2,604 & 0 & 0 \\
\hline Other & 0 & 95,060 & 502 & 437 & 0 & 0 \\
\hline Total to Ultimate Consumers ..................... & & 762,577 & 18,830 & 11,957 & 0 & $\mathbf{0}$ \\
\hline Sales for Resale & 27,531 & 13,569 & & & 145,384 & 7,127 \\
\hline Total Revenues From Sales of Elec ......... & 27,531 & 776,146 & 18,830 & 11,957 & 145,384 & 7,127 \\
\hline
\end{tabular}

Note: Totals may not equal sum of components because of independent rounding.

Source: Energy Information Administration, Form EIA-861, "Annual Electric Utility Report." Data are submitted on a calendar year. 
Table 25. Number of Consumers, Sales, and Operating Revenue by Major U.S. Publicly Owned Electric Utility Within State, 1993 (Continued)

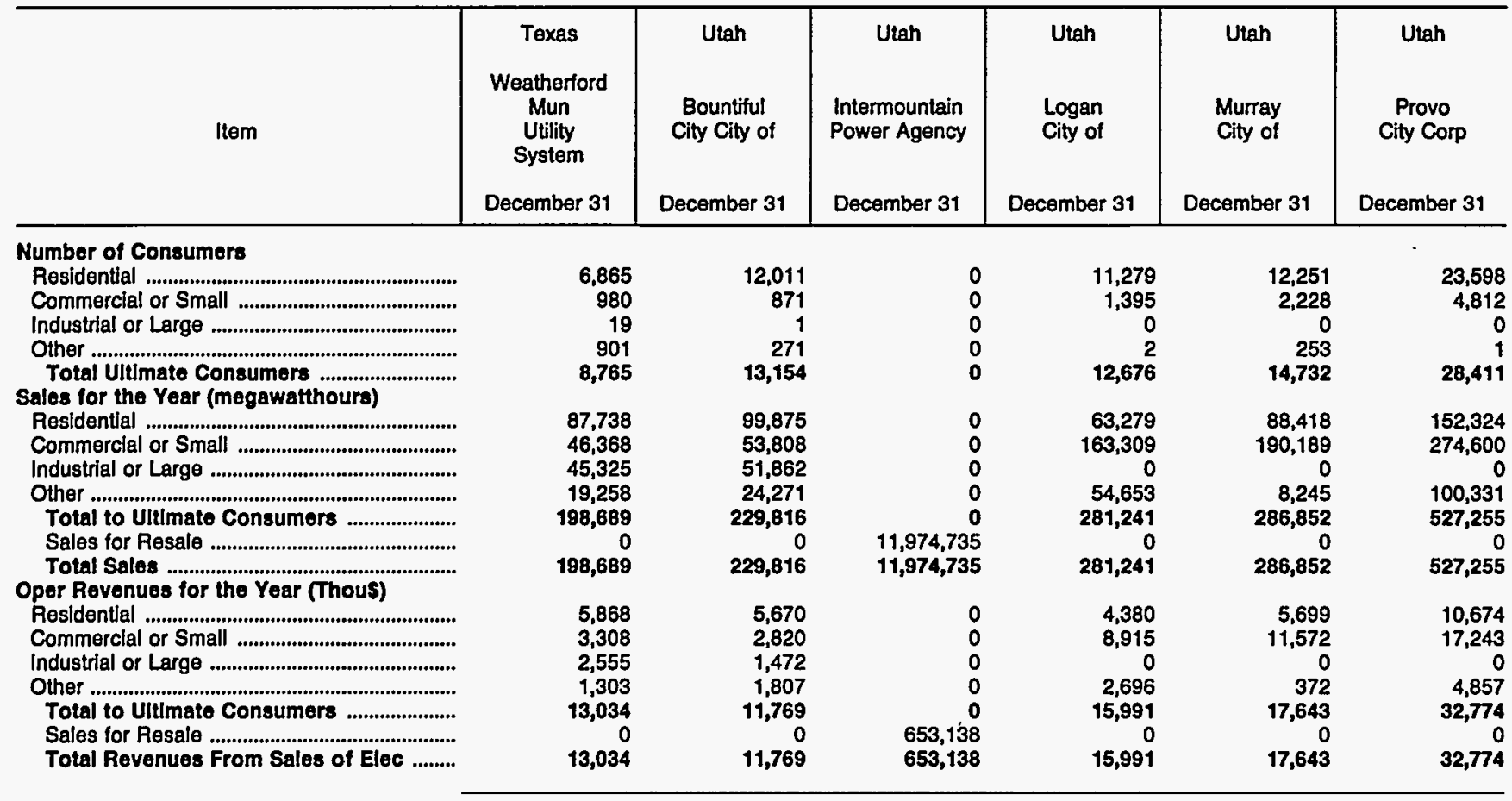

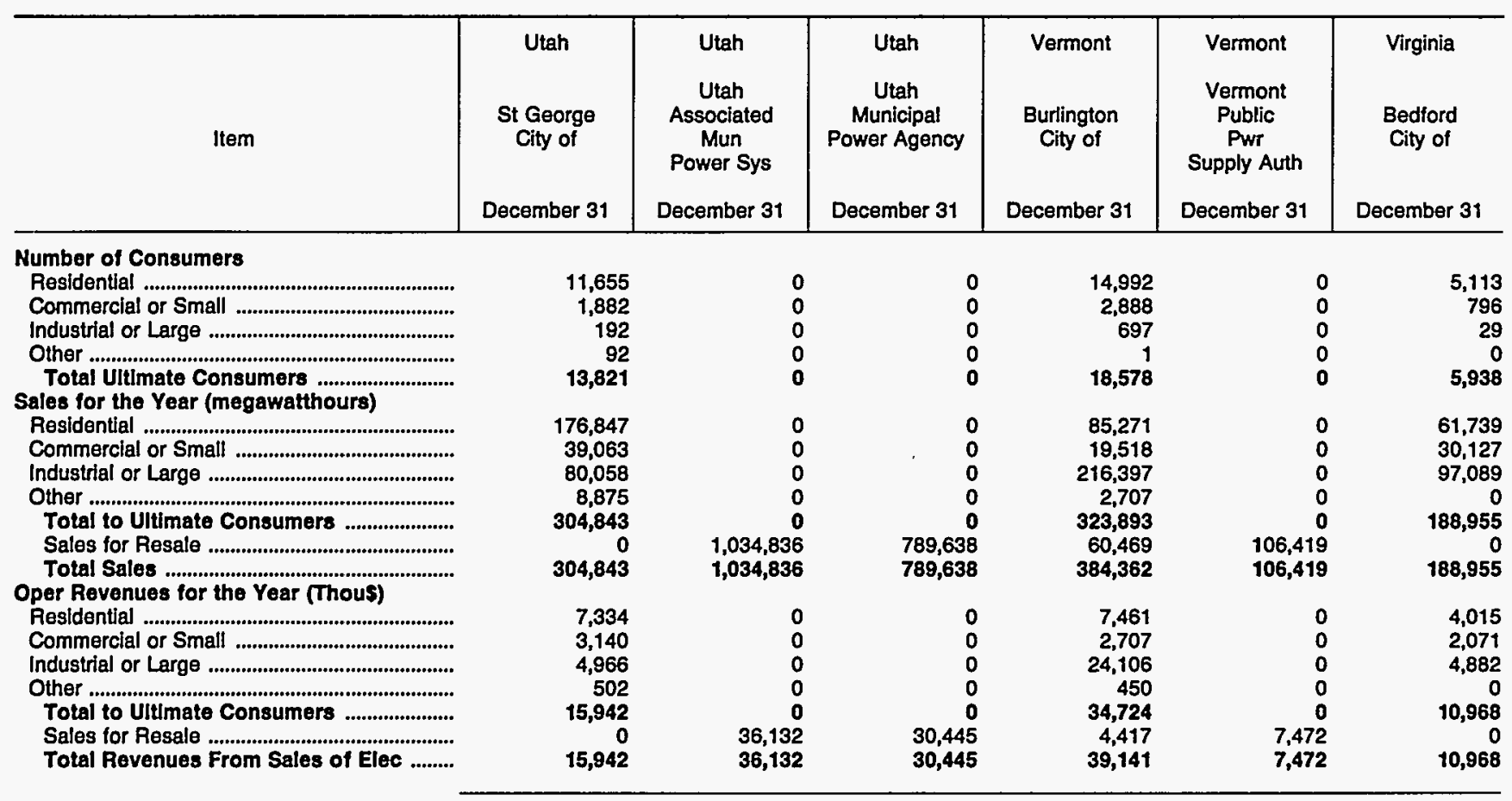

Note: Totals may not equal sum of components because of independent rounding.

Source: Energy Information Administration, Form ElA-861, "Annual Electric Utility Report." Data are submitted on a calendar year. 
Table 25. Number of Consumers, Sales, and Operating Revenue by Major U.S. Publicly Owned Electric Utility Within State, 1993 (Continued)

\begin{tabular}{|c|c|c|c|c|c|c|}
\hline Item & $\begin{array}{c}\text { Virginia } \\
\text { Bristol } \\
\text { Utilities } \\
\text { Board } \\
\text { December } 31\end{array}$ & $\begin{array}{l}\text { Virginia } \\
\text { Danville } \\
\text { City of } \\
\text { December } 31\end{array}$ & $\begin{array}{c}\text { Virginia } \\
\begin{array}{c}\text { Harrisonburg } \\
\text { City of }\end{array} \\
\text { December } 31\end{array}$ & $\begin{array}{c}\text { Virginia } \\
\text { Manassas } \\
\text { City of } \\
\text { December } 31\end{array}$ & $\begin{array}{c}\text { Virginia } \\
\text { Martinsville } \\
\text { City of } \\
\text { December } 31\end{array}$ & $\begin{array}{l}\text { Virginia } \\
\text { Radford } \\
\text { City of } \\
\text { December } 31\end{array}$ \\
\hline \multicolumn{7}{|l|}{ Number of Consumers } \\
\hline Residential & 12,550 & 29,422 & 11,399 & 10,627 & 7,803 & 5,967 \\
\hline 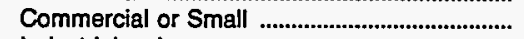 & 1,704 & 3,534 & 2,245 & 1,599 & 212 & 682 \\
\hline Industrial or Large & 260 & 74 & 11 & 115 & 5 & 20 \\
\hline Other & 25 & 4,318 & 138 & 1 & 146 & 12 \\
\hline $\begin{array}{l}\text { Total Ultimate Consumers } \\
\text { Sales for the Year (megawa......................... }\end{array}$ & 14,539 & 37,348 & 13,793 & 12,342 & 8,166 & 6,681 \\
\hline 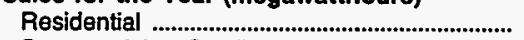 & 182,309 & 436,342 & 119,506 & 141,463 & 92,089 & 63,890 \\
\hline 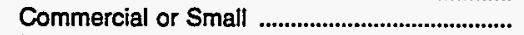 & 32,586 & 228,061 & 199,646 & 35,544 & 71,495 & 30,661 \\
\hline Industrial or Large & 284,138 & 90,487 & 116,035 & 77,462 & 30,992 & 183,918 \\
\hline Other & 6,726 & 48,209 & 59,140 & 1,401 & 11,819 & 5,574 \\
\hline 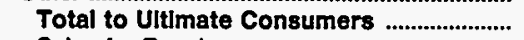 & 505,759 & 803,099 & 494,327 & 255,870 & 206,395 & 284,043 \\
\hline 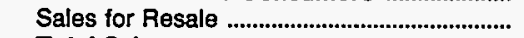 & & 0 & 0 & 0 & 0 & \\
\hline Total Sale8 & 505,759 & 803,099 & 494,327 & 255,870 & 206,395 & 284,043 \\
\hline \multicolumn{7}{|l|}{ Oper Revenues tor the Year (Thous) } \\
\hline 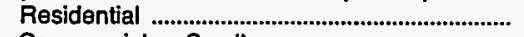 & 10,119 & 24,535 & 7,734 & 9,748 & 5,429 & 3,843 \\
\hline Commercial or Small & 2,066 & 12,268 & 12,869 & 2,753 & 3,395 & 1,441 \\
\hline Industrial or Large & 13,196 & 4,147 & 6,164 & 4,803 & 1,245 & 7,439 \\
\hline Other & 552 & 2,513 & 3,942 & 62 & 604 & 385 \\
\hline 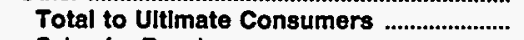 & 25,933 & 43,463 & 30,709 & 17,366 & 10,673 & 13,108 \\
\hline Sales for Resale & & & & & 0 & \\
\hline Total Rovenues From Sales of Elec ......... & 25,933 & 43,463 & 30,709 & 17,366 & 10,673 & 13,108 \\
\hline
\end{tabular}

\begin{tabular}{|c|c|c|c|c|c|c|}
\hline Item & $\begin{array}{c}\text { Virginia } \\
\text { Salem } \\
\text { City of } \\
\text { December } 31\end{array}$ & $\begin{array}{c}\text { Virginia } \\
\text { Virginia } \\
\text { Tech } \\
\text { Electric } \\
\text { Service } \\
\text { December } 31\end{array}$ & $\begin{array}{l}\text { Washington } \\
\text { Centralia } \\
\text { City of } \\
\text { December } 31\end{array}$ & $\begin{array}{l}\text { Washington } \\
\text { Ellensburg } \\
\text { City of }\end{array}$ & $\begin{array}{c}\text { Washington } \\
\begin{array}{c}\text { Port Angeles } \\
\text { City of }\end{array} \\
\text { December } 31\end{array}$ & $\begin{array}{c}\text { Washington } \\
\text { PUD No } 1 \\
\text { of } \\
\text { Benton } \\
\text { County } \\
\text { December } 31\end{array}$ \\
\hline \multicolumn{7}{|l|}{ Number of Consumers } \\
\hline 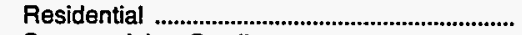 & 9,650 & 4,498 & 7,077 & 4,830 & 7,858 & 29,200 \\
\hline 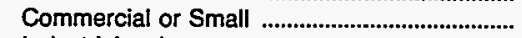 & 1,823 & 532 & 1,140 & 924 & 1,312 & 3,444 \\
\hline 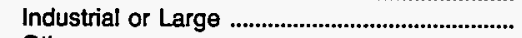 & 97 & 2 & 45 & 1 & 8 & 766 \\
\hline Other & 2 & 310 & 1 & 53 & 165 & 6 \\
\hline Total Ultimate Consumers & 11,572 & 5,342 & 8,263 & 5,808 & 9,343 & 33,416 \\
\hline \multicolumn{7}{|l|}{ Sales for the Year (megawatthours) } \\
\hline 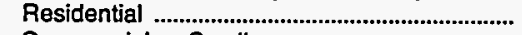 & 113,651 & 47,349 & 113,861 & 55,877 & 136,138 & 619,848 \\
\hline 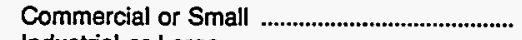 & 58,745 & 30,659 & 80,313 & 51,963 & 84,829 & 413,491 \\
\hline Industrial or Large & 130,716 & 9,649 & 22,908 & 13,824 & 420,098 & 324,126 \\
\hline Other & 17,251 & 129,309 & 1,073 & 43,173 & 3,257 & 2,549 \\
\hline Total to Uitimate Consumers ....................... & 320,363 & 216,966 & 218,155 & 164,837 & 644,322 & $1,360,014$ \\
\hline Sales for Resale ................................................... & & & & & & \\
\hline \multirow{2}{*}{\multicolumn{7}{|c|}{ Oper Revenues for the Year (Thous) }} \\
\hline & & & & & & \\
\hline Commercial or Small & 3,401 & 1,709 & 2,710 & 2,246 & 3,380 & 15,977 \\
\hline 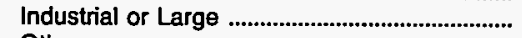 & 5,697 & 427 & 807 & 529 & 10,977 & 9,192 \\
\hline Other & 1,035 & 6,318 & 24 & 1,578 & & 292 \\
\hline Total to Ultimate Consumers & 16,875 & 11,277 & 7,464 & 6,921 & 20,367 & 54,630 \\
\hline Sales for Resale ...................................................... & & & & & & \\
\hline Total Revenues From Sales of Elec ......... & 16,875 & 11,277 & $\mathbf{7 , 4 6 4}$ & 6,921 & 20,367 & 54,630 \\
\hline
\end{tabular}

Note: Totals may not equal sum of components because of independent rounding.

Source: Energy Information Administration, Form ElA-861, "Annual Electric Utility Report." Data are submitted on a calendar year. 
Table 25. Number of Consumers, Sales, and Operating Revenue by Major U.S. Publicly Owned Electric Utility Within State, 1993 (Continued)

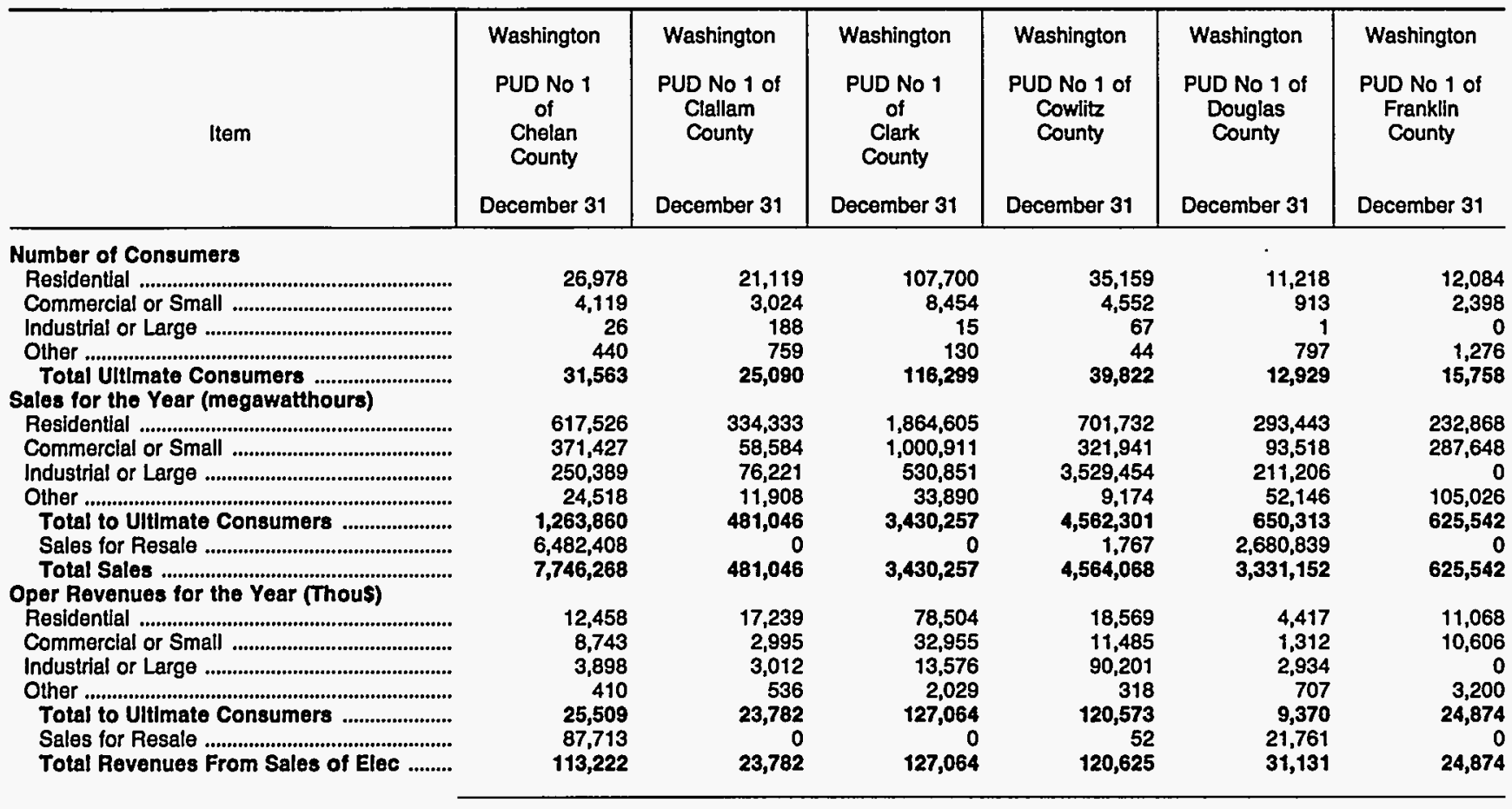

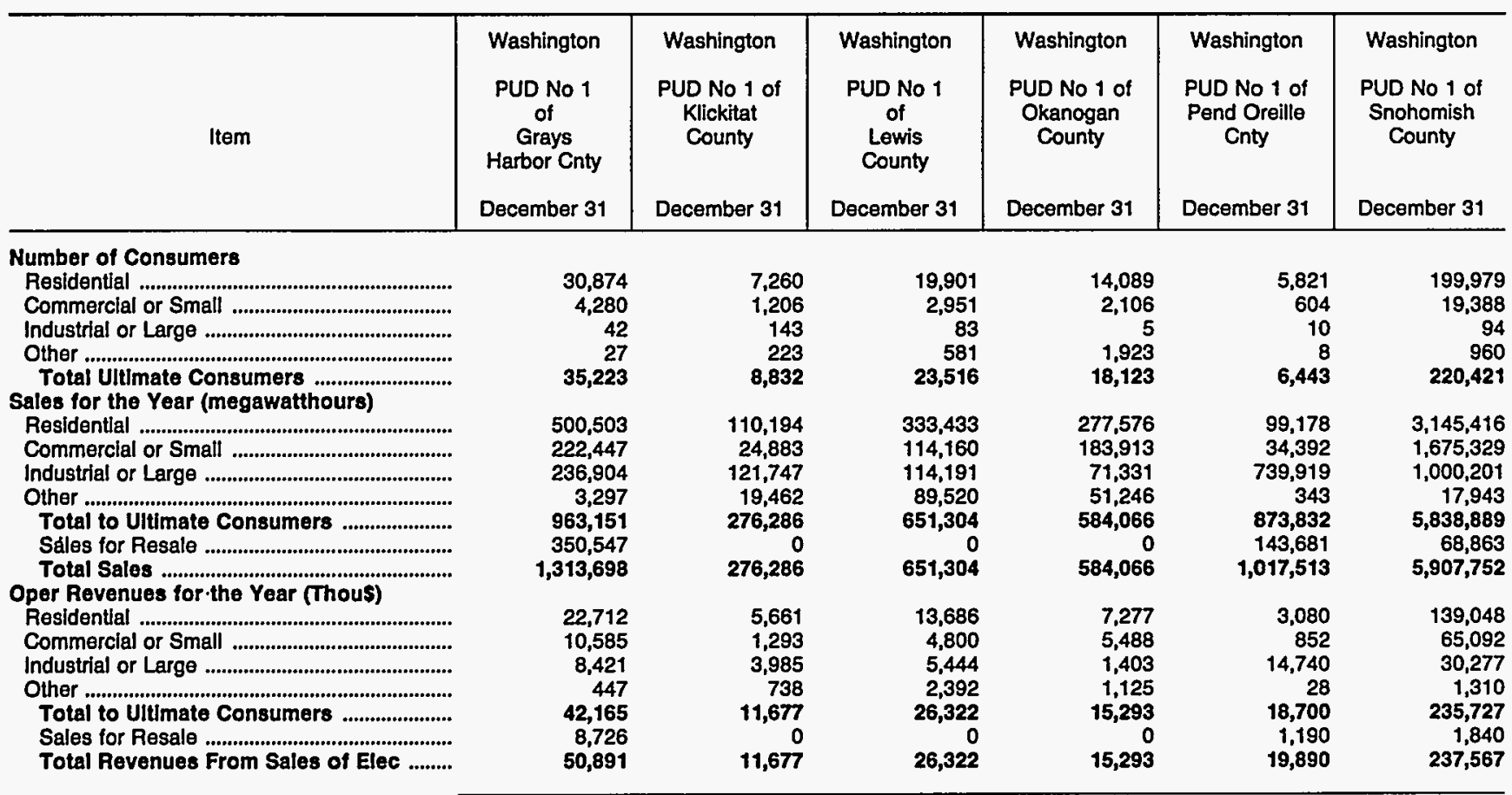

Note: Totals may not equal sum of components because of independent rounding.

Source: Energy Intormation Administration, Form ElA-861, "Annual Electric Utility Report." Data are submitted on a calendar year. 
Table 25. Number of Consumers, Sales, and Operating Revenue by Major U.S. Publicly Owned Electric Utility Within State, 1993 (Continued)

\begin{tabular}{|c|c|c|c|c|c|c|}
\hline Item & $\begin{array}{l}\text { Washington } \\
\text { PUD No } 1 \text { of } \\
\text { Whatcom } \\
\text { County } \\
\text { December } 31\end{array}$ & $\begin{array}{c}\text { Washington } \\
\text { PUD No } 2 \\
\text { of } \\
\text { Grant } \\
\text { County } \\
\text { December } 31\end{array}$ & $\begin{array}{l}\text { Washington } \\
\text { PUD No } 2 \text { of } \\
\text { Pacific } \\
\text { County } \\
\text { December } 31\end{array}$ & $\begin{array}{c}\text { Washington } \\
\text { PUD No } 3 \\
\text { of } \\
\text { Mason } \\
\text { County } \\
\text { December } 31\end{array}$ & $\begin{array}{l}\text { Washington } \\
\text { Richland } \\
\text { City of } \\
\text { December } 31\end{array}$ & $\begin{array}{c}\text { Washington } \\
\text { Seattle } \\
\text { City of } \\
\text { December } 31\end{array}$ \\
\hline \multicolumn{7}{|l|}{ Number of Consumers } \\
\hline 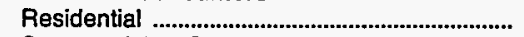 & 0 & 25,096 & 12,428 & 21,687 & 14,106 & 300,099 \\
\hline 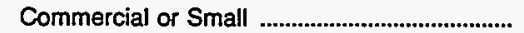 & 0 & 8,503 & 1,327 & 1,747 & 1,010 & 33,506 \\
\hline 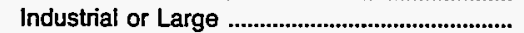 & 1 & 62 & 2 & 1 & 211 & 301 \\
\hline 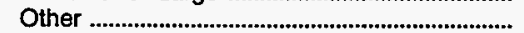 & 0 & 63 & 535 & 65 & 430 & 2,207 \\
\hline & 1 & 33,724 & 14,292 & 23,500 & 15,757 & 336,113 \\
\hline 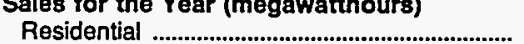 & \multicolumn{6}{|c|}{ Sales for the Year (megawatthours) } \\
\hline Commercial or Small & 0 & 717,039 & $\begin{array}{r}161,387 \\
60,922\end{array}$ & $\begin{array}{l}301,105 \\
125,474\end{array}$ & $\begin{array}{r}284,350 \\
52,993\end{array}$ & $\begin{array}{l}3,260,890 \\
3,360,561\end{array}$ \\
\hline Industrial or Large & 139,229 & $1,327,534$ & 24,811 & 61,684 & 293,200 & $1,420,708$ \\
\hline Other & 0 & 4,265 & 24,990 & 1.716 & 3,539 & 872,729 \\
\hline Total to Uitimate Consumers & 139,229 & $2,666,988$ & 272,110 & 489,979 & 634,082 & $8,914,888$ \\
\hline Sales for Resale & 0 & $5,387,716$ & 0 & 2,084 & 0 & \\
\hline \multicolumn{7}{|l|}{ Oper Revenues for the Year (Thous) } \\
\hline 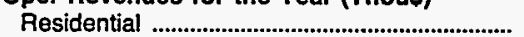 & 0 & 14,647 & 7,439 & 14,329 & 13,699 & 121,446 \\
\hline 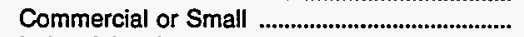 & 0 & 14,908 & 3,129 & 5,666 & 2,081 & 120,247 \\
\hline Industrial or Large & 3,373 & 16,108 & 831 & 1,889 & 9,551 & 44,736 \\
\hline Other & 0 & 422 & 1,342 & 103 & 223 & 33,930 \\
\hline 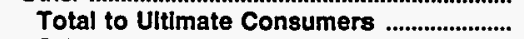 & 3,373 & 46,085 & 12,741 & 21,987 & 25,554 & 320,359 \\
\hline Sales for Resale & 0 & 42,888 & 0 & 65 & 0 & \\
\hline Total Revenues From Sales of Elec ......... & 3,373 & 88,973 & 12,741 & 22,052 & 25,554 & 320,359 \\
\hline
\end{tabular}

\begin{tabular}{|c|c|c|c|c|c|c|}
\hline Item & $\begin{array}{c}\text { Washington } \\
\text { Tacoma } \\
\text { Gity of } \\
\text { December } 31\end{array}$ & $\begin{array}{c}\text { Washington } \\
\text { Vera } \\
\text { Irrigation } \\
\text { District \#5 } \\
\text { December } 31\end{array}$ & $\begin{array}{c}\text { Washington } \\
\text { Washington } \\
\text { Pub } \\
\text { Pwr } \\
\text { Supply Sys } \\
\text { December } 31\end{array}$ & $\begin{array}{l}\text { Wisconsin } \\
\text { Badger Power } \\
\begin{array}{c}\text { Marketing } \\
\text { Auth }\end{array} \\
\text { December } 31\end{array}$ & $\begin{array}{l}\text { Wisconsin } \\
\text { Jefferson } \\
\text { City of } \\
\text { December } 31\end{array}$ & $\begin{array}{l}\text { Wisconsin } \\
\begin{array}{c}\text { Kaukauna } \\
\text { City of }\end{array} \\
\text { December } 31\end{array}$ \\
\hline \multicolumn{7}{|l|}{ Number of Consumers } \\
\hline 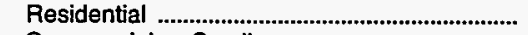 & 121,973 & 6,122 & 0 & 0 & 2,750 & 8,915 \\
\hline 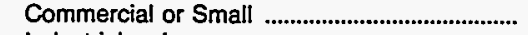 & 10,021 & 475 & 0 & 0 & 396 & 832 \\
\hline Industrial or Large & 1,554 & 0 & 0 & 0 & 34 & 29 \\
\hline Other & 346 & 41 & 0 & $\mathbf{0}$ & 2 & 78 \\
\hline Total Ultimate Consumers & 133,894 & 6,638 & 0 & $\mathbf{0}$ & 3,182 & 9,854 \\
\hline \multicolumn{7}{|l|}{ Sales for the Year (megawatthours) } \\
\hline 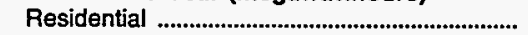 & $1,809,860$ & 124,671 & 0 & 0 & 24,065 & 96,584 \\
\hline Commercial or Small & 320,117 & 42,512 & 0 & 0 & 10,470 & 42,177 \\
\hline Industrial or Large & $2,865,693$ & 0 & 0 & 0 & 98,347 & 419,355 \\
\hline Other & 549,844 & 5,469 & 0 & 0 & 1,498 & 3,283 \\
\hline Total to Ultimate Consumers ............................. & $5,545,514$ & 172,652 & 0 & o & 134,380 & 561,399 \\
\hline 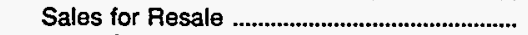 & 440,095 & & $7,195,188$ & 249,304 & & \\
\hline Total Sales & $5,985,609$ & 172,652 & $7,195,188$ & 249,304 & 134,380 & 561,399 \\
\hline \multicolumn{7}{|l|}{ Oper Revenues for the Year (Thou\$) } \\
\hline 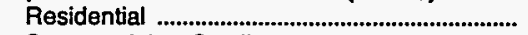 & 71,808 & 4,706 & 0 & 0 & 1,499 & 3,989 \\
\hline 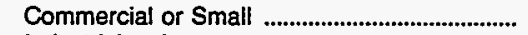 & 12,883 & 1,667 & 0 & 0 & 729 & 1,849 \\
\hline Industrial or Large & 74,031 & 0 & 0 & 0 & 4,230 & 13,818 \\
\hline Other & 14,728 & 225 & 0 & 0 & 111 & 228 \\
\hline Total to Ultimate Consumers ........................ & 173,450 & 6,598 & o & o & 6,569 & 19,884 \\
\hline 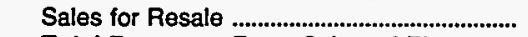 & 23,358 & & 505,237 & 9,451 & & \\
\hline Total Revenues From Sales of Elec ......... & 196,808 & 6,598 & 505,237 & $\mathbf{9 , 4 5 1}$ & 6,569 & 19,884 \\
\hline
\end{tabular}

Note: Totals may not equal sum of components because of independentrounding.

Source: Energy Information Administration, Form EIA-861, "Annual Electric Utility Report." Data are submitted on a calendar year. 
Table 25. Number of Consumers, Sales, and Operating Revenue by Major U.S. Publicly Owned Electric Utility Within State, 1993 (Continued)

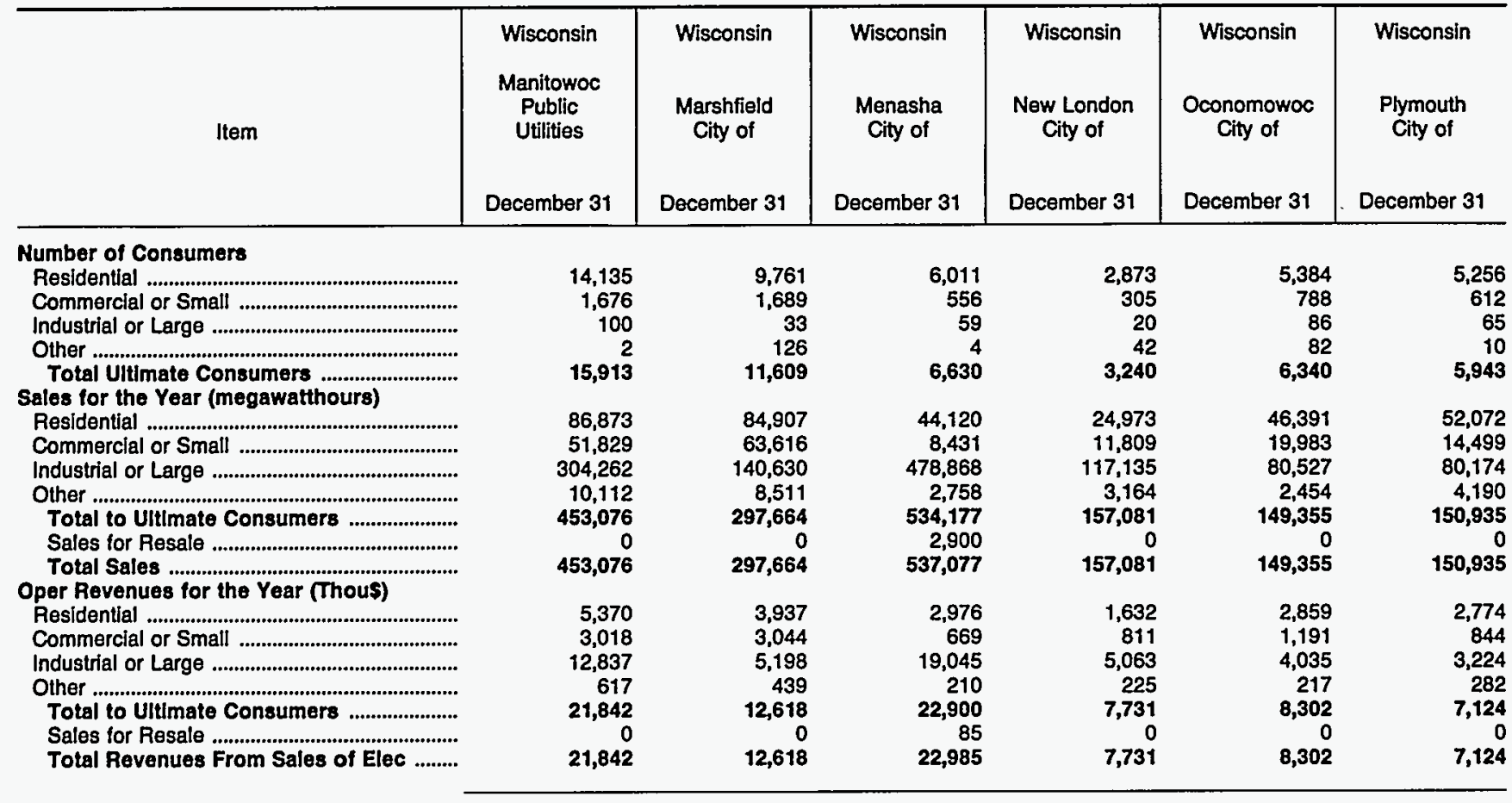

\begin{tabular}{|c|c|c|c|c|c|c|}
\hline Item & $\begin{array}{l}\text { Wisconsin } \\
\text { Reedsburg } \\
\text { Utility Comm } \\
\text { December } 31\end{array}$ & $\begin{array}{c}\text { Wisconsin } \\
\text { Shawano } \\
\text { Municipa! } \\
\text { Utilities } \\
\text { December } 31\end{array}$ & $\begin{array}{c}\text { Wisconsin } \\
\text { Sheboygan } \\
\text { Falls } \\
\text { City of } \\
\text { December } 31\end{array}$ & $\begin{array}{c}\text { Wisconsin } \\
\text { Sturgeon Bay } \\
\text { Combined } \\
\text { Utils }\end{array}$ & $\begin{array}{l}\text { Wisconsin } \\
\text { Sun Prairie } \\
\text { Water \& Light } \\
\text { Comm } \\
\text { December } 31\end{array}$ & $\begin{array}{l}\text { Wisconsin } \\
\text { Wisconsin } \\
\text { Public } \\
\text { Power } \\
\text { Inc Sys } \\
\text { December } 31\end{array}$ \\
\hline \multicolumn{7}{|l|}{ Number of Consumers } \\
\hline 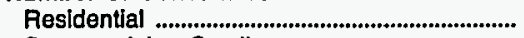 & 2,768 & 3,656 & 2,589 & 6,206 & 5,945 & 0 \\
\hline 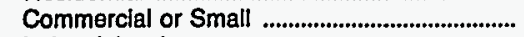 & 553 & 838 & 321 & 1,006 & 770 & 0 \\
\hline 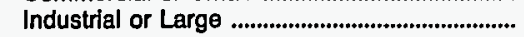 & 32 & 94 & 31 & 42 & 23 & 0 \\
\hline 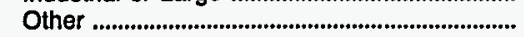 & 45 & 23 & 188 & 48 & 53 & 0 \\
\hline $\begin{array}{l}\text { Total Ultimate Consumers } \\
\text { Sales for the Year (megawathours) }\end{array}$ & \multicolumn{6}{|c|}{ Sales for the Year (megawatthours) } \\
\hline 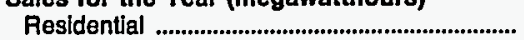 & 24,913 & 29,037 & 19,231 & 45,866 & 51,666 & 0 \\
\hline Commercial or Small & 18,258 & 14,651 & 9,035 & 29,619 & 32,123 & 0 \\
\hline Industrial or Large & 117.786 & 131,381 & 147,805 & 48,171 & 49,216 & 0 \\
\hline Other & 1,512 & 1,935 & 3,338 & 3,135 & 5,394 & 0 \\
\hline Total to Ultimate Consumers ...................... & 162,469 & 177,004 & 179,409 & 126,791 & 138,399 & $\mathbf{0}$ \\
\hline Sales for Resale & & & 0 & & 0 & $2,892,404$ \\
\hline \multicolumn{7}{|l|}{ Oper Revenues for the Year (Thous) } \\
\hline 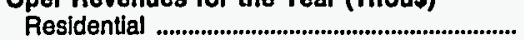 & 1,143 & 1,701 & 873 & 2,935 & 2,655 & 0 \\
\hline 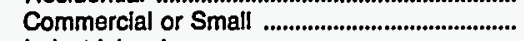 & 946 & 958 & 416 & 1,843 & 1,619 & 0 \\
\hline Industrial or Large ................................................. & 4,443 & 5,331 & 5,525 & 2,483 & 2,070 & 0 \\
\hline Other & 89 & 154 & 191 & 258 & 291 & 0 \\
\hline Total to Ultimate Consumers ...................... & 6,621 & 8,144 & 7,005 & 7,519 & 6,635 & $\mathbf{0}$ \\
\hline Sales for Resale & & & & 0 & & 108,030 \\
\hline Total Revenues From Sales of Elec ......... & 6,621 & 8,144 & 7,005 & 7,519 & 6,635 & 108,030 \\
\hline
\end{tabular}

Note: Totals may not equal sum of components because of independent rounding.

Source: Energy Information Administration, Form ElA-861, "Annual Electric Utility Report." Data are submitted on a calendar year. 
Table 25. Number of Consumers, Sales, and Operating Revenue by Major U.S. Publicly Owned Electric Utility Within State, 1993 (Continued)

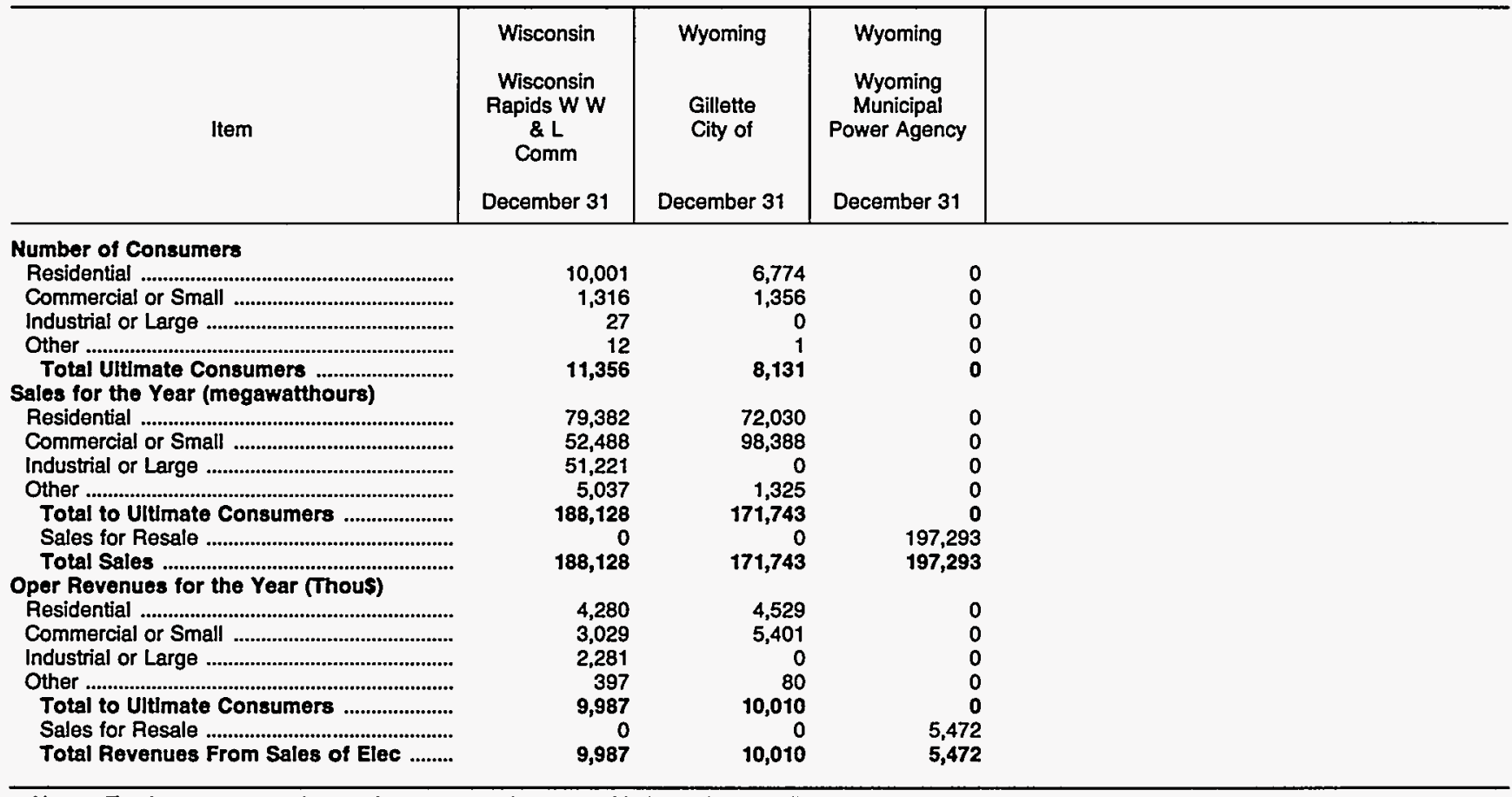

Note: Totals may not equal sum of components because of independentrounding.

Source: Energy Information Administration, Form EIA-861, "Annual Electric Utility Report." Data are submitted on a calendar year. 
Table 26. Electric Energy Account by Major U.S. Publicly Owned Electric Utility Within State, 1993 (Megawatthours)

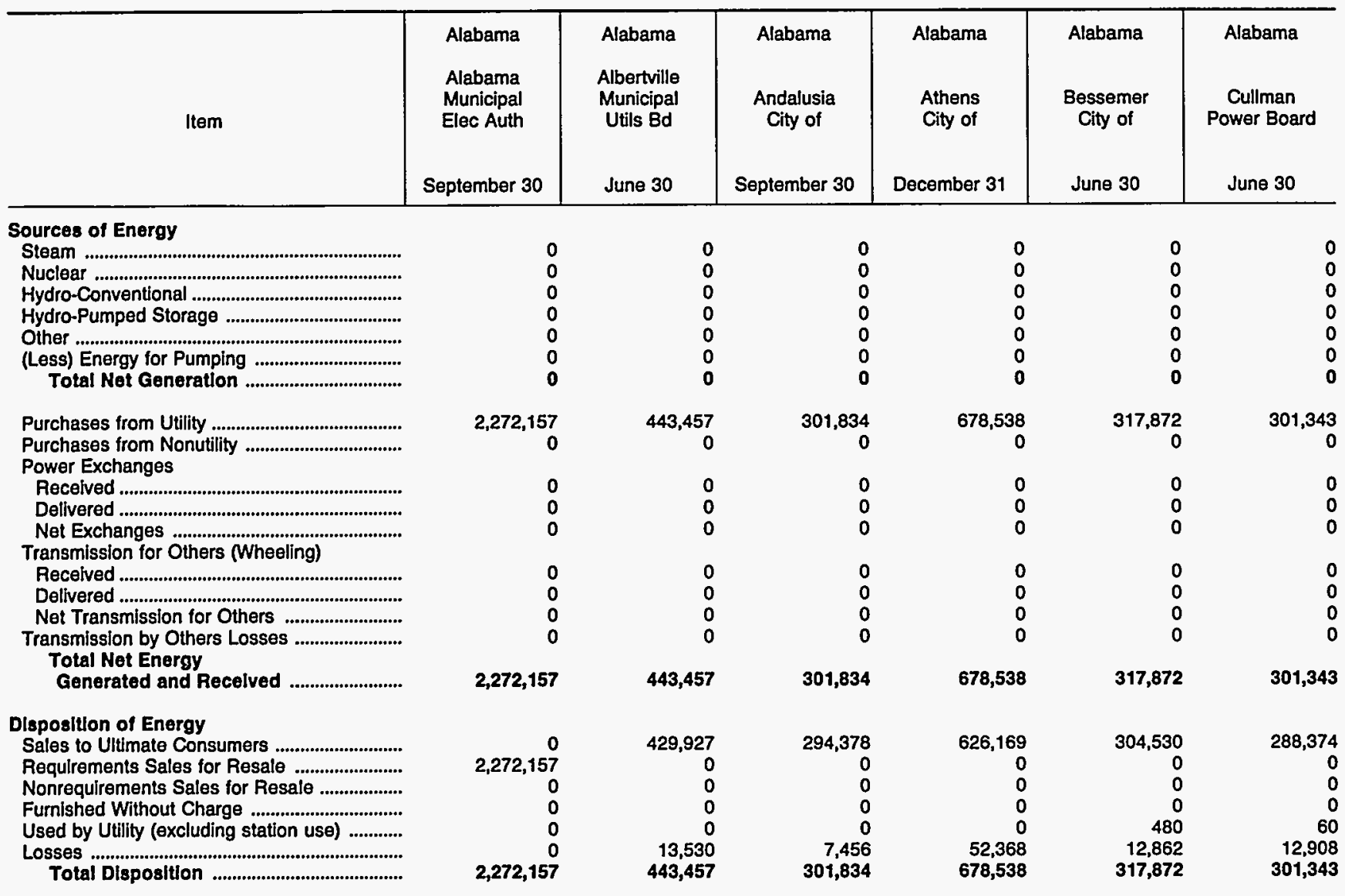

Note: Totals may not equal sum of components because of independent rounding. Double counting occurs in components of both sources and disposition of energy and thus neither provides a true total. Purchases from utilities, net interchanges, and net wheeling (except for imports) are included in net generation. Sales for resale is included in sales to ultimate consumers.

Source: Energy Information Administration, Form EIA-412, "Annual Report of Public Electric Utilities." 
Table 26. Electric Energy Account by Major U.S. Publicly Owned Electric Utility Within State, 1993 (Continued)

(Megawatthours)

\begin{tabular}{|c|c|c|c|c|c|c|}
\hline Item & $\begin{array}{l}\text { Alabama } \\
\text { Decatur } \\
\text { City of } \\
\text { June } 30\end{array}$ & $\begin{array}{l}\text { Alabama } \\
\text { Dothan } \\
\text { City of } \\
\text { September } 30\end{array}$ & $\begin{array}{l}\text { Alabama } \\
\text { Florence } \\
\text { City of } \\
\text { June } 30\end{array}$ & $\begin{array}{c}\text { Alabama } \\
\text { Foley } \\
\text { City of } \\
\text { (Riviera Utils) } \\
\\
\text { December } 31\end{array}$ & $\begin{array}{c}\text { Alabama } \\
\text { Fort Payne } \\
\text { Improvement } \\
\text { Auth } \\
\text { June } 30\end{array}$ & $\begin{array}{l}\text { Alabama } \\
\text { Guntersville } \\
\text { Electric } \\
\text { Board } \\
\text { June } 30\end{array}$ \\
\hline \multicolumn{7}{|l|}{ Sources of Energy } \\
\hline Steam & 0 & 0 & 0 & 0 & 0 & 0 \\
\hline Nuclear & 0 & 0 & 0 & 0 & 0 & 0 \\
\hline 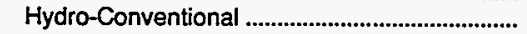 & 0 & 0 & 0 & 0 & 0 & 0 \\
\hline Hydro-Pumped Storage ................................................. & 0 & 0 & 0 & 0 & 0 & 0 \\
\hline 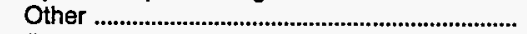 & 0 & 0 & 0 & 0 & 0 & 0 \\
\hline 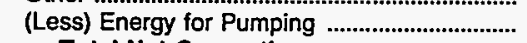 & 0 & 0 & 0 & 0 & 0 & 0 \\
\hline Total Net Generation & 0 & 0 & o & 0 & o & o \\
\hline 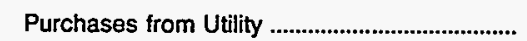 & $1,407,547$ & $1,001,195$ & $1,027,814$ & 506,519 & 299,426 & 226,134 \\
\hline 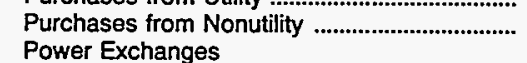 & 0 & 6,603 & $\begin{array}{r}0 \\
0\end{array}$ & 0 & 0 & \\
\hline 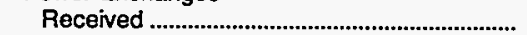 & 0 & 0 & 0 & 0 & 0 & 0 \\
\hline 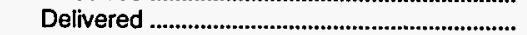 & 0 & 0 & 0 & 0 & 0 & 0 \\
\hline Net Exchanges & 0 & 0 & 0 & 0 & 0 & 0 \\
\hline \multicolumn{7}{|l|}{ Transmission for Others (Wheeling) } \\
\hline 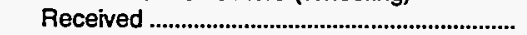 & 0 & 0 & 0 & 0 & 0 & 0 \\
\hline Delivered …………………………………..... & 0 & 0 & 0 & 0 & 0 & 0 \\
\hline 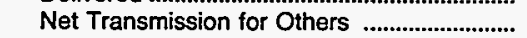 & 0 & 0 & 0 & 0 & 0 & 0 \\
\hline 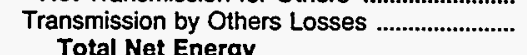 & 0 & 0 & 0 & 0 & 0 & 0 \\
\hline $\begin{array}{l}\text { Total Net Energy } \\
\text { Generated and Recelved .......................... }\end{array}$ & 1407517 & 1007700 & 1027014 & & & \\
\hline 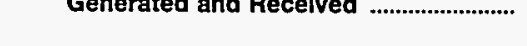 & $3,407,547$ & $1,007,798$ & $1,027,814$ & 506,519 & 299,426 & 226,134 \\
\hline \multicolumn{7}{|l|}{ Disposition of Energy } \\
\hline Sales to Ultimate Consumers ............................... & $1,382,214$ & 930,864 & 944,655 & 472,904 & 281,008 & 213,978 \\
\hline 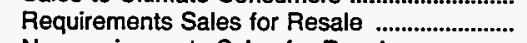 & 0 & 0 & 0 & 0 & 0 & \\
\hline 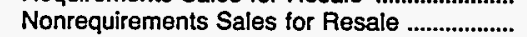 & 0 & 0 & 0 & 0 & 0 & 0 \\
\hline 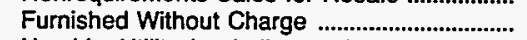 & 0 & 33,614 & 0 & 0 & 0 & 0 \\
\hline Used by Utility (excluding station use) ................ & 0 & 6,864 & 455 & 0 & 224 & 154 \\
\hline Losses & 25,333 & 36,456 & 82,704 & 33,615 & 18,193 & 12,002 \\
\hline Total Disposition & $1,407,547$ & $1,007,798$ & $1,027,814$ & 506,519 & 299,426 & 226,134 \\
\hline
\end{tabular}

Note: Totals may not equal sum of components because of independent rounding. Double counting occurs in components of both sources and disposition of energy and thus neither provides a true total. Purchases from utilities, net interchanges, and net wheeling (except for imports) are included in net generation. Sales for resale is included in sales to ultimate consumers.

Source: Energy Information Administration, Form EIA-412, "Annual Report of Public Electric Utilities." 
Table 26. Electric Energy Account by Major U.S. Publicly Owned Electric Utility Within State, 1993 (Continued)

(Megawatthours)

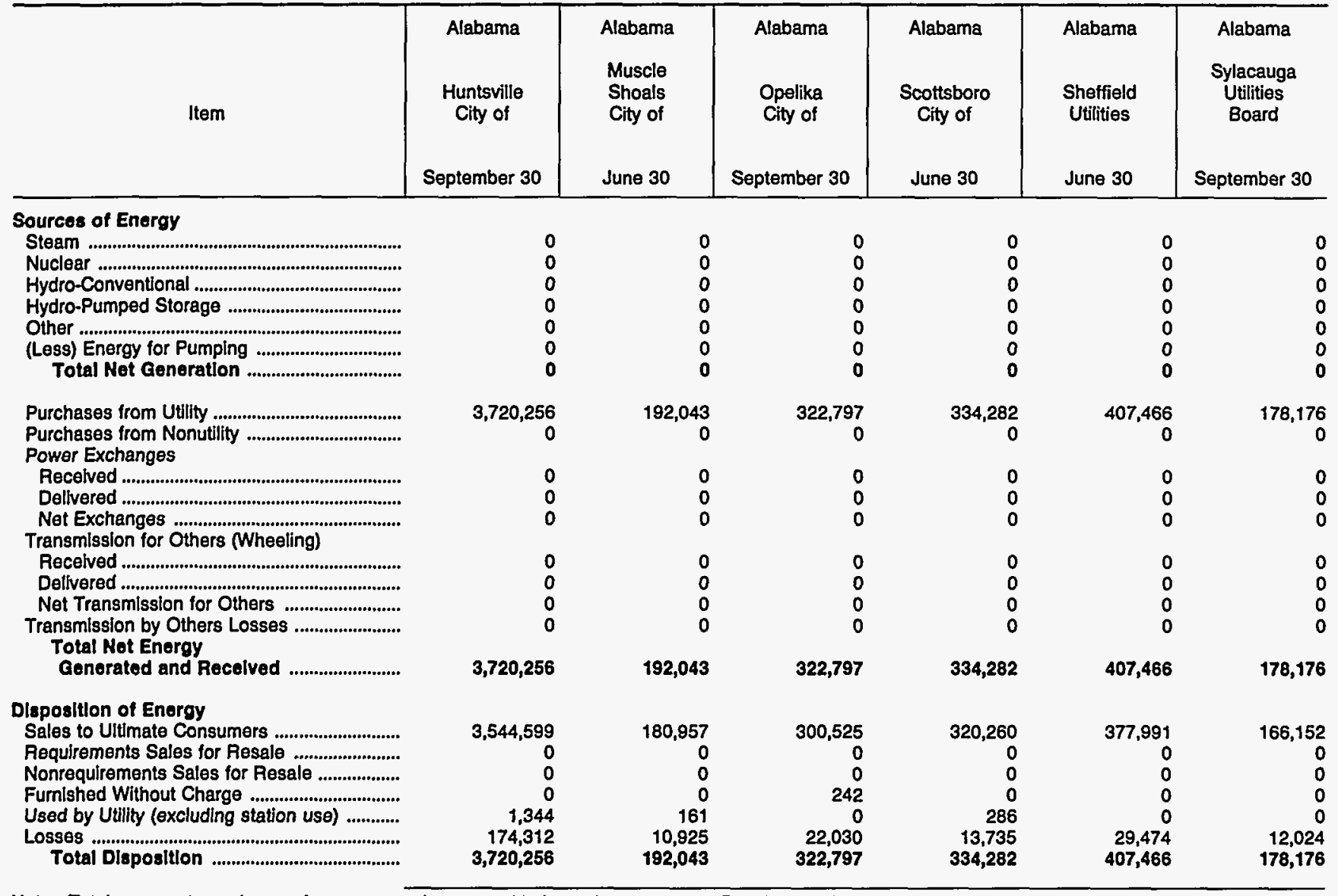

Note: Totals may not equal sum of components because of independent rounding. Double counting occurs in components of both sources and disposition of energy and thus nelther provides a true total. Purchases from utilities, net interchanges, and net wheeling (except for imports) are included in net generation. Sales for resale is included in sales to ultimate consumers.

Source: Energy Information Administration, Form EIA-412, "Annual Report of Public Electric Utilities." 
Table 26. Electric Energy Account by Major U.S. Publicly Owned Electric Utility Within State, 1993 (Continued)

(Megawatthours)

\begin{tabular}{|c|c|c|c|c|c|c|}
\hline Item & $\begin{array}{c}\text { Alabama } \\
\text { Troy } \\
\text { City of } \\
\text { September } 30\end{array}$ & $\begin{array}{l}\text { Alabama } \\
\text { Tuskegee } \\
\text { City of } \\
\text { September } 30\end{array}$ & $\begin{array}{c}\text { Alaska } \\
\text { Alaska } \\
\text { Energy } \\
\text { Authority } \\
\text { June } 30\end{array}$ & $\begin{array}{c}\text { Alaska } \\
\text { Anchorage } \\
\text { City of } \\
\text { December } 31\end{array}$ & $\begin{array}{l}\text { Alaska } \\
\text { Fairbanks } \\
\text { City of } \\
\text { December } 31\end{array}$ & $\begin{array}{c}\text { Alaska } \\
\text { Ketchikan } \\
\text { City of } \\
\text { December } 31\end{array}$ \\
\hline \multicolumn{7}{|l|}{ Sources of Energy } \\
\hline Steam & 0 & $\mathbf{0}$ & 0 & 7,899 & 120,645 & 0 \\
\hline 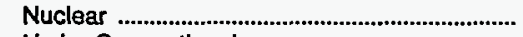 & 0 & 0 & 0 & 0 & 0 & 0 \\
\hline 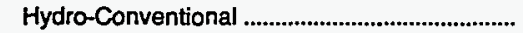 & 0 & 0 & 563,920 & 0 & 0 & 62,280 \\
\hline 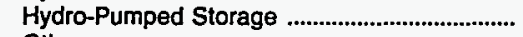 & 0 & $\mathbf{0}$ & 0 & 0 & 0 & \\
\hline Other & 0 & 0 & 0 & 643,685 & 0 & 7,713 \\
\hline 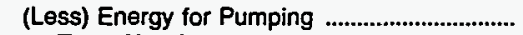 & 0 & 0 & 0 & 0 & $\mathbf{0}$ & \\
\hline Total Net Generation & $\mathbf{0}$ & 0 & 563,920 & 651,584 & 120,645 & 69,993 \\
\hline 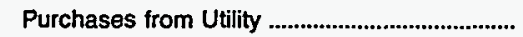 & 229,984 & 153,954 & $\mathbf{0}$ & 199,992 & 37,327 & 71,419 \\
\hline $\begin{array}{l}\text { Purchases from Nonutility ...................................... } \\
\text { Power Exchanges }\end{array}$ & 0 & 0 & 0 & 0 & 0 & 110 \\
\hline 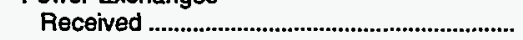 & 0 & 0 & 0 & 0 & 0 & 0 \\
\hline 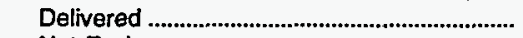 & 0 & 0 & $\mathbf{0}$ & 0 & 0 & 0 \\
\hline Net Exchanges & 0 & 0 & 0 & 0 & 0 & 0 \\
\hline \multicolumn{7}{|l|}{ Transmission for Others (Wheeling) } \\
\hline Received & 0 & 0 & 0 & 0 & 0 & 0 \\
\hline Delivered & 0 & 0 & 0 & 0 & 0 & 0 \\
\hline 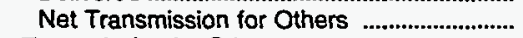 & 0 & 0 & 0 & 0 & 0 & 0 \\
\hline $\begin{array}{l}\text { Transmission by Others Losses ............................ } \\
\text { Total Net Energy }\end{array}$ & 0 & 0 & 0 & 0 & 0 & 0 \\
\hline Generated and Received .......................... & 229,984 & 153,954 & 563,920 & 851,576 & $\{57,972$ & 141,522 \\
\hline \multicolumn{7}{|l|}{ Dispositlon of Energy } \\
\hline 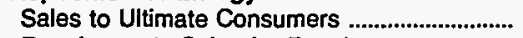 & 207,196 & 137,791 & 0 & 813,204 & 143,073 & 136,271 \\
\hline 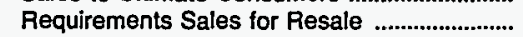 & 0 & 0 & 563,920 & 12,627 & 0 & \\
\hline Nonrequirements Sales for Resale ................... & 0 & 0 & 0 & 0 & 0 & 0 \\
\hline Fumished without Charge & 7,984 & 5,542 & 0 & 0 & 0 & 0 \\
\hline Used by Utility (excluding station use) ............ & 6,478 & 461 & $\mathbf{0}$ & 0 & 0 & 1,067 \\
\hline Losses & 8,326 & 10,160 & 0 & 25,745 & 14,899 & 4,184 \\
\hline Total Dlsposition & 229,984 & 153,954 & 563,920 & 851,576 & 157,972 & 141,522 \\
\hline
\end{tabular}


Table 26. Electric Energy Account by Major U.S. Publicly Owned Electric Utility Within State, 1993 (Continued)

(Megawatthours)

\begin{tabular}{|c|c|c|c|c|c|c|}
\hline Item & $\begin{array}{l}\text { Arizona } \\
\text { Arizona } \\
\text { Power } \\
\text { Authority } \\
\\
\text { June } 30\end{array}$ & $\begin{array}{l}\text { Arizona } \\
\text { Electrical } \\
\text { Dist } \\
\text { No2 } \\
\text { Pinal Cnty } \\
\text { December } 31\end{array}$ & $\begin{array}{l}\text { Arizona } \\
\text { Mesa } \\
\text { City of } \\
\text { June } 30\end{array}$ & $\begin{array}{l}\text { Arizona } \\
\text { Navajo } \\
\text { Tribal } \\
\text { Utility } \\
\text { Auth } \\
\text { December } 31\end{array}$ & $\begin{array}{l}\text { Arizona } \\
\text { Salt River } \\
\text { Proj } \mathrm{Ag} \\
\text { I \& P Dist } \\
\text { April } 30\end{array}$ & $\begin{array}{c}\text { Arizona } \\
\text { Tohono } \\
\text { OOdham } \\
\text { Utility Auth } \\
\text { December } 31\end{array}$ \\
\hline \multicolumn{7}{|l|}{ Sources of Energy } \\
\hline Steam & 0 & 0 & $\mathbf{0}$ & 0 & $12,986,837$ & \\
\hline 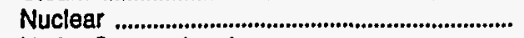 & 0 & 0 & 0 & 0 & $4,762,894$ & 0 \\
\hline 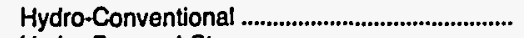 & 0 & 0 & $\mathbf{0}$ & 0 & 796,524 & 0 \\
\hline Hydro-Pumped Storage ....................................... & 0 & 0 & 0 & 0 & 75,222 & 0 \\
\hline Other & 0 & 0 & 0 & 0 & 188,778 & 0 \\
\hline 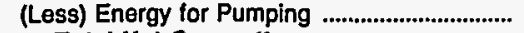 & 0 & 0 & 0 & 0 & 107,281 & 0 \\
\hline 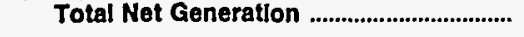 & $\mathbf{0}$ & 0 & $\mathbf{0}$ & 0 & $18,702,974$ & $\mathbf{0}$ \\
\hline 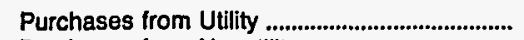 & 635,925 & 135,799 & 325,308 & 547,959 & $1,673,222$ & 161,450 \\
\hline $\begin{array}{l}\text { Purchases from Nonutility ................................... } \\
\text { Power Exchanges }\end{array}$ & $\mathbf{0}$ & 0 & 0 & 0 & 171 & \\
\hline 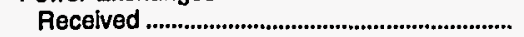 & 0 & 0 & 0 & 0 & 198,418 & 0 \\
\hline Delivered & 0 & 0 & 0 & 0 & 151,172 & 0 \\
\hline Net Exchanges & 0 & 0 & 0 & 0 & 47,246 & 0 \\
\hline \multicolumn{7}{|l|}{ Transmission for Others (Wheeling) } \\
\hline Recelved & 0 & 0 & 0 & 0 & 132,887 & 0 \\
\hline 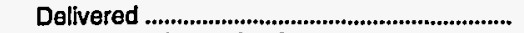 & 0 & 0 & 0 & 0 & 127,753 & 0 \\
\hline Net Transmission for Others ............................. & 0 & 0 & 0 & 0 & 5,134 & 0 \\
\hline Transmission by Others Losses ......................... & 0 & 0 & 0 & 0 & 0 & 0 \\
\hline $\begin{array}{l}\text { Total Net Energy } \\
\text { Generated and Recejved }\end{array}$ & 635,925 & 135,799 & 325,308 & 547,959 & $20,428,747$ & 161,450 \\
\hline \multicolumn{7}{|l|}{ Dispositton of Energy } \\
\hline 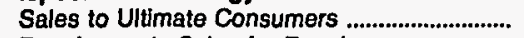 & & 123,845 & 297,191 & 507,074 & $15,575,686$ & 158,806 \\
\hline Requirements Sales for Resale ........................ & 612,863 & 0 & 8,924 & 0 & 777,585 & 0 \\
\hline Nonrequirements Sales for Resale .................. & 0 & 0 & $\mathbf{0}$ & 0 & $2,962,234$ & 0 \\
\hline 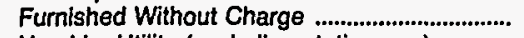 & 0 & 0 & 0 & 0 & 0 & 0 \\
\hline Used by Utility (excluding station use) ............ & 0 & 0 & 0 & 0 & 0 & 157 \\
\hline 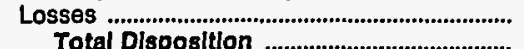 & $\begin{array}{r}23,062 \\
635,925\end{array}$ & $\begin{array}{r}11,954 \\
135,799\end{array}$ & $\begin{array}{r}19,193 \\
325,308\end{array}$ & $\begin{array}{r}40,885 \\
547,959\end{array}$ & $\begin{array}{r}1,113,242 \\
2,198,747\end{array}$ & $\begin{array}{r}2,487 \\
-161,050\end{array}$ \\
\hline 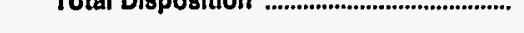 & 030,920 & 135,199 & 520,308 & 547,959 & $20,428,747$ & 161,450 \\
\hline
\end{tabular}

Note: Totals may not equal sum of components because of independent rounding. Double counting occurs in components of both sources and disposition of energy and thus neither provides a true total. Purchases from utilities, net interchanges, and net wheeling (except for imports) are included in net generation. Sales for resale is included in sales to ultimate consumers.

Source: Energy Information Administration, Form EIA-412, "Annual Report of Public Electric Utilities." 
Table 26. Electric Energy Account by Major U.S. Publicly Owned Electric Utility Within State, 1993 (Continued)

(Megawatthours)

\begin{tabular}{|c|c|c|c|c|c|c|}
\hline Item & $\begin{array}{l}\text { Arkansas } \\
\text { Benton } \\
\text { City of } \\
\text { December } 31\end{array}$ & $\begin{array}{l}\text { Arkansas } \\
\text { Bentonville } \\
\text { City of } \\
\text { December } 31\end{array}$ & $\begin{array}{l}\text { Arkansas } \\
\text { Clarksville } \\
\text { Light } \\
\text { \& } \\
\text { Water Co } \\
\text { September } 30\end{array}$ & $\begin{array}{l}\text { Arkansas } \\
\text { Conway } \\
\text { Corp }\end{array}$ & $\begin{array}{l}\text { Arkansas } \\
\text { Hope } \\
\text { City of } \\
\text { December } 31\end{array}$ & $\begin{array}{l}\text { Arkansas } \\
\text { Jonesboro } \\
\text { City of } \\
\text { December } 31\end{array}$ \\
\hline Sources of Energy & & & & & & \\
\hline 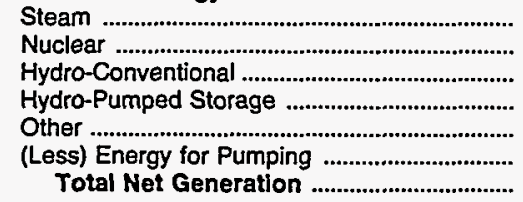 & $\begin{array}{l}0 \\
0 \\
0 \\
0 \\
1 \\
0 \\
1\end{array}$ & $\begin{array}{l}0 \\
0 \\
0 \\
0 \\
0 \\
0 \\
0\end{array}$ & $\begin{array}{l}0 \\
0 \\
0 \\
0 \\
0 \\
0 \\
0\end{array}$ & $\begin{array}{r}350,785 \\
0 \\
0 \\
0 \\
0 \\
0 \\
350,785\end{array}$ & $\begin{array}{l}0 \\
0 \\
0 \\
0 \\
0 \\
0 \\
0\end{array}$ & $\begin{array}{r}127,505 \\
0 \\
0 \\
0 \\
0 \\
0 \\
127,505\end{array}$ \\
\hline $\begin{array}{l}\text { Purchases from Utility } \\
\text { Purchases from Nonutility } \\
\text { Power Exchanges }\end{array}$ & $\begin{array}{r}161,646 \\
0\end{array}$ & $\begin{array}{r}221,732 \\
0\end{array}$ & $\begin{array}{r}167,308 \\
0\end{array}$ & $\begin{array}{r}165,150 \\
0\end{array}$ & $\begin{array}{r}192,238 \\
0\end{array}$ & $\begin{array}{r}720,903 \\
0\end{array}$ \\
\hline 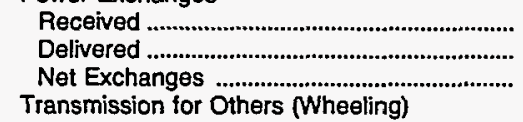 & $\begin{array}{l}0 \\
0 \\
0\end{array}$ & $\begin{array}{l}0 \\
0 \\
0\end{array}$ & $\begin{array}{l}0 \\
0 \\
0\end{array}$ & $\begin{array}{l}0 \\
0 \\
0\end{array}$ & $\begin{array}{l}0 \\
0 \\
0\end{array}$ & $\begin{array}{l}0 \\
0 \\
0\end{array}$ \\
\hline 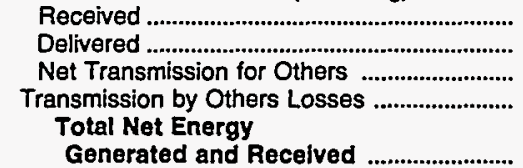 & $\begin{array}{l}0 \\
0 \\
0 \\
0\end{array}$ & $\begin{array}{l}0 \\
0 \\
0 \\
0\end{array}$ & $\begin{array}{l}0 \\
0 \\
0 \\
0\end{array}$ & $\begin{array}{l}0 \\
0 \\
0 \\
0\end{array}$ & $\begin{array}{l}0 \\
0 \\
0 \\
0\end{array}$ & $\begin{array}{l}0 \\
0 \\
0 \\
0\end{array}$ \\
\hline 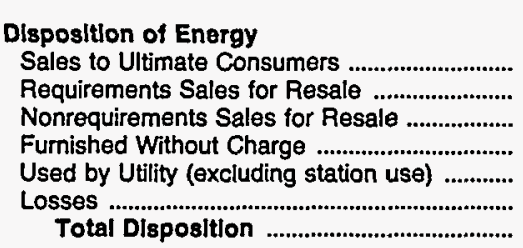 & $\begin{array}{r}143,760 \\
0 \\
0 \\
8,086 \\
45 \\
9,756 \\
161,647\end{array}$ & $\begin{array}{r}212,760 \\
0 \\
0 \\
0 \\
0 \\
8,972 \\
221,732\end{array}$ & $\begin{array}{r}154,703 \\
0 \\
0 \\
1,828 \\
3,124 \\
7,653 \\
167,308\end{array}$ & $\begin{array}{r}474,388 \\
0 \\
0 \\
0 \\
0 \\
41,547 \\
515,935\end{array}$ & $\begin{array}{r}179,356 \\
0 \\
0 \\
3,842 \\
0 \\
9,040 \\
192,238\end{array}$ & $\begin{array}{r}776,211 \\
0 \\
34,350 \\
7,160 \\
0 \\
30,687 \\
848,408\end{array}$ \\
\hline
\end{tabular}

Note: Totals may not equal sum of components because of independent rounding. Double counting occurs in components of both sources and disposition of energy and thus neither provides a true total. Purchases from utilities, net interchanges, and net wheeling (except for imports) are included in net generation. Sales for resale is included in sales to ultimate consumers.

Source: Energy Information Administration, Form ElA-412, "Annual Report of Public Electric Utilities." 
Table 26. Electric Energy Account by Major U.S. Publicly Owned Electric Utility Within State, 1993 (Continued)

(Megawatthours)

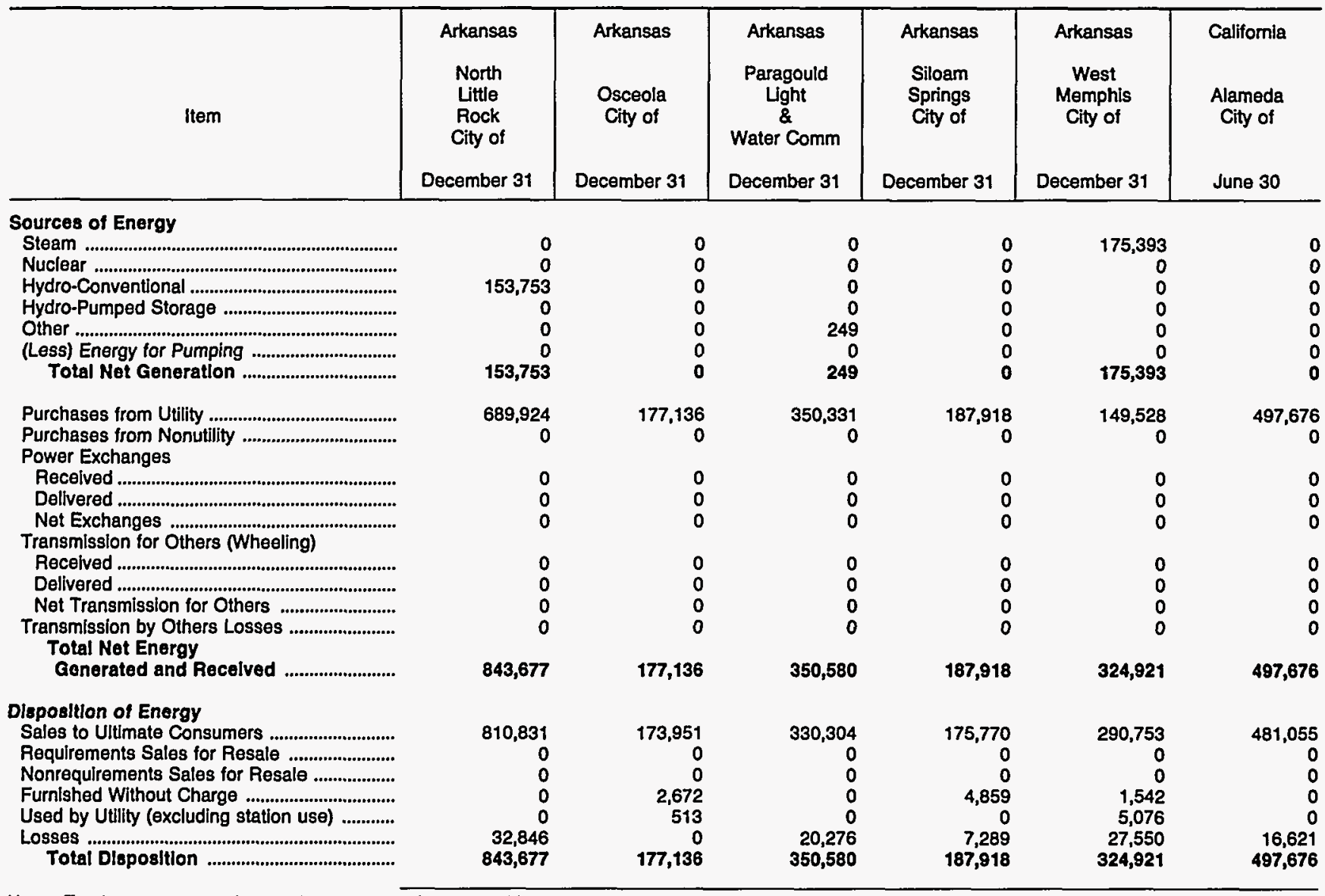

Note: Totals may not equal sum of components because of independent rounding. Double counting occurs in components of both sources and disposition of energy and thus neither provides a true total. Purchases from utilities, net interchanges, and net wheeling (except for imports) are included in net generation. Sales for resale is included in sales to ultimate consumers.

Source: Energy Information Administration, Form EIA-412, "Annual Report of Public Electric Utilities." 
Table 26. Electric Energy Account by Major U.S. Publicly Owned Electric Utility Within State, 1993 (Continued)

(Megawatthours)

\begin{tabular}{|c|c|c|c|c|c|c|}
\hline Item & $\begin{array}{l}\text { California } \\
\text { Anaheim } \\
\text { City of } \\
\text { June } 30\end{array}$ & $\begin{array}{l}\text { California } \\
\text { Azusa } \\
\text { City of } \\
\text { June } 30\end{array}$ & $\begin{array}{l}\text { California } \\
\text { Burbank } \\
\text { City of } \\
\text { June } 30\end{array}$ & $\begin{array}{c}\text { California } \\
\text { California } \\
\text { Dept } \\
\text { Wtr } \\
\text { Resources } \\
\text { June } 30\end{array}$ & $\begin{array}{l}\text { California } \\
\text { Colton } \\
\text { City of } \\
\text { June } 30\end{array}$ & $\begin{array}{l}\text { California } \\
\text { Glendale } \\
\text { City of } \\
\text { June } 30\end{array}$ \\
\hline \multicolumn{7}{|l|}{ Sources of Energy } \\
\hline Steam & 0 & 0 & 160,432 & $1,303,131$ & 0 & 126,632 \\
\hline Nuclear & 564,868 & 0 & 0 & 0 & 0 & \\
\hline 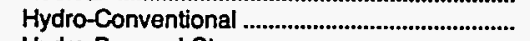 & 0 & 0 & 0 & $2,197,108$ & 0 & 0 \\
\hline Hydro-Pumped Storage ................................................. & 0 & 0 & 0 & $1,444,015$ & 0 & 0 \\
\hline Other & 11,896 & 0 & 1,158 & 0 & 0 & 39,905 \\
\hline 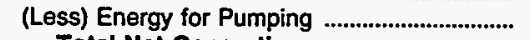 & 0 & 0 & 0 & 0 & 0 & \\
\hline 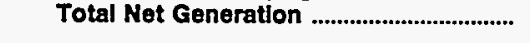 & 576,764 & $\mathbf{0}$ & 161,590 & $4,944,254$ & o & 166,537 \\
\hline 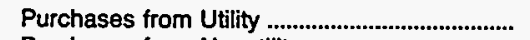 & $2,489,402$ & 204,021 & 917,869 & $1,434,044$ & 220,357 & 995,736 \\
\hline 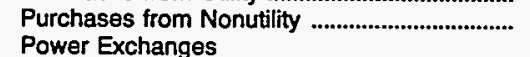 & & 0 & 4,124 & 2,440 & 0 & 0 \\
\hline 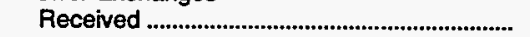 & 21,569 & 0 & 22,442 & $4,159,041$ & 0 & \\
\hline 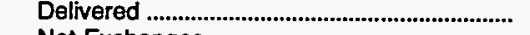 & 65,811 & 0 & 28,049 & $1,889,278$ & 0 & 0 \\
\hline Net Exchanges .......................................................... & $-44,242$ & 0 & $-5,607$ & $2,269,763$ & 0 & 0 \\
\hline \multicolumn{7}{|l|}{ Transmission for Others (Wheeling) } \\
\hline 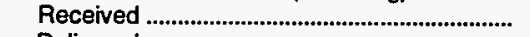 & 0 & 0 & 0 & 0 & 0 & 0 \\
\hline 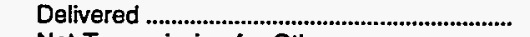 & 0 & 0 & 0 & 0 & 0 & 0 \\
\hline 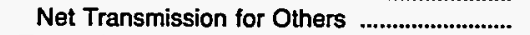 & 0 & 0 & 0 & 0 & 0 & 0 \\
\hline 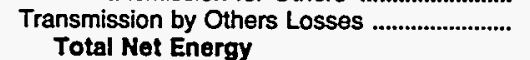 & $-122,647$ & 0 & $-44,562$ & 0 & 0 & 0 \\
\hline 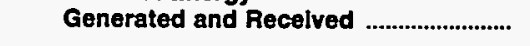 & $2,899,277$ & 204,021 & $1,033,414$ & $8,650,501$ & 220,357 & $1,162,273$ \\
\hline \multicolumn{7}{|l|}{ Disposition of Energy } \\
\hline 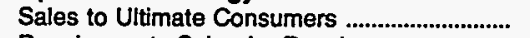 & $2,182,457$ & 186,680 & 990,443 & 0 & 204,526 & 978,635 \\
\hline Requirements Sales for Resale ............................. & & 0 & 225 & $4,174,176$ & 0 & \\
\hline Nonrequirements Sales for Resale ................... & 483,635 & 0 & 0 & 0 & 0 & 0 \\
\hline & 0 & 2,184 & 0 & 0 & 0 & 70,898 \\
\hline Used by Utility (excluding station use) ............. & 0 & 0 & 0 & $4,474,650$ & 0 & 0 \\
\hline 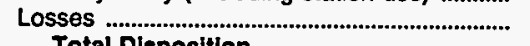 & 233,185 & 15,157 & 42,746 & 1,675 & 15,831 & $\begin{array}{r}112,740 \\
\end{array}$ \\
\hline Total Disposition & $2,899,277$ & 204,021 & $1,033,414$ & $8,650,501$ & 220,357 & $1,162,273$ \\
\hline
\end{tabular}

Note: Totals may not equal sum of components because of independent rounding. Double counting occurs in components of both sources and disposition of energy and thus neither provides a true total. Purchases from utilities, net interchanges, and net wheeling (except for imports) are included in net generation. Sales for resale is included in sales to ultimate consumers.

Source: Energy Information Administration, Form EIA-412, "Annual Report of Public Electric Utilities." 
Table 26. Electric Energy Account by Major U.S. Publicly Owned Electric Utillty Within State, 1993 (Continued)

(Megawatthours)

\begin{tabular}{|c|c|c|c|c|c|c|}
\hline Item & $\begin{array}{c}\text { California } \\
\text { Imperial } \\
\text { Irrigation } \\
\text { District } \\
\text { December } 31\end{array}$ & $\begin{array}{l}\text { Califomia } \\
\text { Lassen } \\
\text { Municipal } \\
\text { Utility Dist } \\
\\
\text { June } 30\end{array}$ & $\begin{array}{l}\text { California } \\
\text { Lodi } \\
\text { City of } \\
\text { June } 30\end{array}$ & $\begin{array}{l}\text { Califomia } \\
\text { Los Angeles } \\
\text { City of } \\
\text { June } 30\end{array}$ & $\begin{array}{l}\text { Califomia } \\
\text { Merced } \\
\text { Irrigation } \\
\text { District } \\
\text { December } 31\end{array}$ & $\begin{array}{c}\text { California } \\
\text { Metropolitan } \\
\text { Water } \\
\text { District } \\
\text { June } 30\end{array}$ \\
\hline \multicolumn{7}{|l|}{ Sources of Energy } \\
\hline 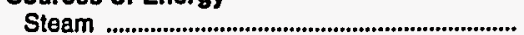 & 640,886 & 0 & 0 & $10,990,592$ & 0 & 0 \\
\hline Nuclear & & 0 & 0 & $1,497,418$ & $\mathbf{0}$ & 0 \\
\hline 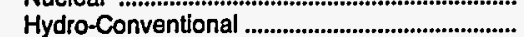 & 261,282 & 0 & 0 & 553,210 & 352,124 & 293,241 \\
\hline 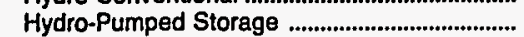 & 0 & 0 & 0 & 803,653 & 0 & 0 \\
\hline Other & 7,983 & 0 & 0 & -744 & 0 & 0 \\
\hline (Less) Energy for Pumping ................................. & $\begin{array}{r}0 \\
910,151\end{array}$ & $\begin{array}{l}0 \\
0\end{array}$ & $\begin{array}{l}0 \\
0\end{array}$ & $\begin{array}{r}937,070 \\
12,907,059\end{array}$ & $\begin{array}{r}0 \\
352,124\end{array}$ & $\begin{array}{r}0 \\
293,241\end{array}$ \\
\hline Purchases from Utility & $1,926,646$ & 136,400 & 385,918 & $11,862,559$ & 0 & 0 \\
\hline $\begin{array}{l}\text { Purchases from Nonutility } \\
\text { Power Exchanges }\end{array}$ & 0 & 0 & 0 & 349,247 & 0 & 0 \\
\hline 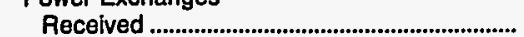 & 0 & 0 & 3,314 & 141,528 & 0 & 0 \\
\hline 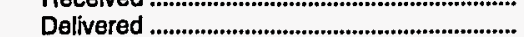 & 0 & 0 & 11,649 & $1,045,492$ & 0 & 0 \\
\hline Net Exchanges & 0 & 0 & $-8,335$ & $-903,964$ & 0 & 0 \\
\hline \multicolumn{7}{|l|}{ Transmission for Others (Wheeling) } \\
\hline 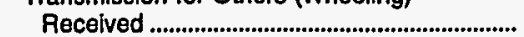 & $3,840,363$ & 304,378 & 0 & $15,844,921$ & 0 & 0 \\
\hline 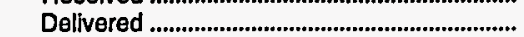 & $3,760,603$ & 300,448 & 0 & $15,791,858$ & 0 & 0 \\
\hline Net Transmission for Others ........................ & 79,760 & 3,930 & 0 & 53,063 & 0 & 0 \\
\hline 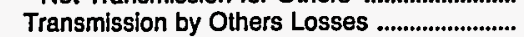 & 0 & $-3,930$ & 0 & 0 & 0 & 0 \\
\hline $\begin{array}{l}\text { Total Net Energy } \\
\text { Generated and Recelved }\end{array}$ & $2,916,557$ & 136,400 & 377,583 & $24,267,964$ & 352,124 & 293,241 \\
\hline \multicolumn{7}{|l|}{ Dlsposition of Energy } \\
\hline Sales to Ultimate Consumers ............................ & $2,135,960$ & 125,687 & 361,165 & $21,769,016$ & 0 & 0 \\
\hline Requirements Sales for Resale ........................ & 458,650 & 0 & $\mathbf{0}$ & 731,719 & 350,312 & 293,241 \\
\hline Nonrequirements Sales for Resale .................. & 0 & 0 & 0 & 0 & 0 & 0 \\
\hline 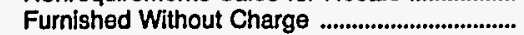 & 0 & 0 & 0 & 0 & 0 & 0 \\
\hline Used by Utility (excluding station use) ............ & 0 & 416 & 0 & 90,000 & 0 & 0 \\
\hline 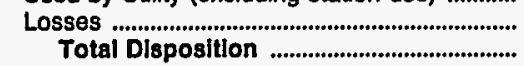 & $\begin{array}{r}321,947 \\
2,916,557\end{array}$ & $\begin{array}{r}10,297 \\
136,400\end{array}$ & $\begin{array}{r}16,418 \\
377,583\end{array}$ & $\begin{array}{r}1,677,229 \\
24,267,964\end{array}$ & $\begin{array}{r}1,812 \\
352,124\end{array}$ & $\begin{array}{r}0 \\
293,241\end{array}$ \\
\hline
\end{tabular}

Note: Totals may not equal sum of components because of independent rounding. Double counting occurs in components of both sources and disposition of energy and thus neither provides a true total. Purchases from utilities, net interchanges, and net wheeling (except for imports) are included in net generation. Sales for resale is included in sales to ultimate consumers.

Source: Energy Intormation Administration, Form ElA-412, "Annual Report of Public Electric Utilities." 
Table 26. Electric Energy Account by Major U.S. Publicly Owned Electric Utility Within State, 1993 (Continued) (Megawatthours)

\begin{tabular}{|c|c|c|c|c|c|c|}
\hline Item & $\begin{array}{l}\text { California } \\
\text { Modesto } \\
\text { Irrigation } \\
\text { District } \\
\text { December } 31\end{array}$ & $\begin{array}{c}\text { California } \\
\text { MSR } \\
\text { Public } \\
\text { Power } \\
\text { Agency } \\
\text { December } 31\end{array}$ & $\begin{array}{l}\text { California } \\
\text { Northern } \\
\text { California } \\
\text { Power Agny } \\
\text { June } 30\end{array}$ & $\begin{array}{c}\text { California } \\
\text { Oakdale \& } \\
\text { South } \\
\text { San Joaquin } \\
\text { December } 31\end{array}$ & $\begin{array}{c}\text { California } \\
\text { Oroville } \\
\text { Wyandotte } \\
\text { Irrig Dist } \\
\text { December } 31\end{array}$ & $\begin{array}{l}\text { California } \\
\text { Palo Alto } \\
\text { City of } \\
\text { June } 30\end{array}$ \\
\hline \multicolumn{7}{|l|}{ Sources of Energy } \\
\hline 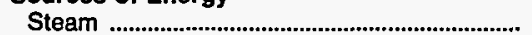 & 0 & 845,695 & $1,193,180$ & 0 & 0 & 0 \\
\hline 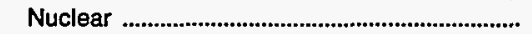 & 0 & 0 & 0 & 0 & 0 & 0 \\
\hline 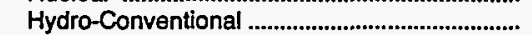 & 145,642 & 0 & 598,104 & 521,369 & 718,946 & 0 \\
\hline 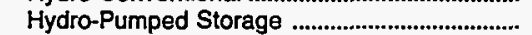 & & 0 & 0 & 0 & 0 & \\
\hline 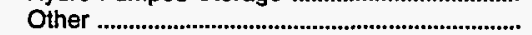 & 17,024 & 0 & 7,344 & 0 & 0 & 0 \\
\hline (Less) Energy for Pumping ............................... & & 0 & 0 & 0 & 0 & \\
\hline 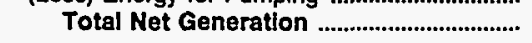 & 162,666 & 845,695 & $1,798,628$ & 521,369 & 718,946 & 0 \\
\hline 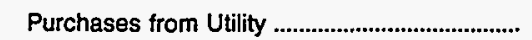 & $1,746,289$ & 359,950 & 332,105 & 0 & 0 & $1,086,522$ \\
\hline 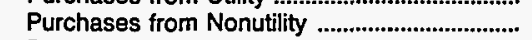 & & 0 & 107,294 & 0 & 0 & 0 \\
\hline Power Exchanges & & & & & & \\
\hline 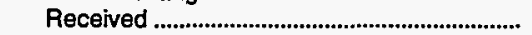 & 0 & 0 & 42,567 & 0 & 0 & 0 \\
\hline Delivered ........................................................ & 3,970 & 0 & 45,490 & 0 & 0 & 0 \\
\hline 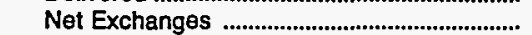 & $-3,970$ & 0 & $-2,923$ & 0 & 0 & 0 \\
\hline \multicolumn{7}{|l|}{ Transmission for Others (Wheeling) } \\
\hline 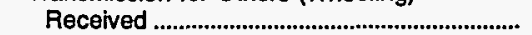 & 0 & 0 & 0 & 0 & 0 & 0 \\
\hline 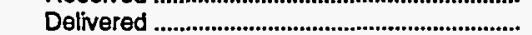 & 0 & 0 & 0 & 0 & 0 & 0 \\
\hline Net Transmission for Others & 0 & 0 & 0 & 0 & 0 & 0 \\
\hline 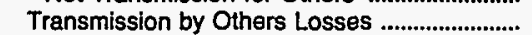 & 0 & 0 & 0 & 0 & 0 & 0 \\
\hline Total Net Energy & & & & & & \\
\hline 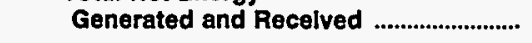 & $1,904,985$ & $1,205,645$ & $2,235,104$ & 521,369 & 718,946 & $1,086,522$ \\
\hline \multicolumn{7}{|l|}{ Disposittion of Energy } \\
\hline 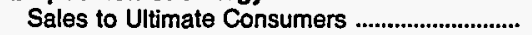 & $1,764,013$ & & 0 & 0 & 0 & $1,041,532$ \\
\hline 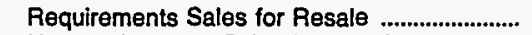 & & $1,205,645$ & $2,154,743$ & 518,645 & 718,946 & \\
\hline Nonrequirements Sales for Resale ................... & 30,910 & 0 & 49,990 & 0 & 0 & \\
\hline Furnished Without Charge ..................................... & 0 & 0 & 0 & 0 & 0 & \\
\hline Used by Utility (excluding station use) ............. & 0 & 0 & 0 & 0 & 0 & 0 \\
\hline 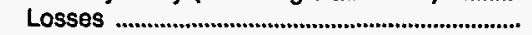 & 110,062 & 0 & 30,371 & 2,724 & & 44,890 \\
\hline Total Dlsposition & $1,904,985$ & $1,205,645$ & $2,235,104$ & 521,369 & 718,946 & $1,086,622$ \\
\hline
\end{tabular}

Note: Totals may not equal sum of components because of independent rounding. Double counting occurs in components of both sources and disposition of energy and thus neither provides a true total. Purchases from utilities, net interchanges, and net wheeling (except for imports) are included in net generation. Sales for resale is included in sales to ultimate consumers.

Source: Energy Information Administration, Form EIA-412, "Annual Report of Public Electric Utilities." 
Table 26. Electric Energy Account by Major U.S. Publicly Owned Electric Utility Within State, 1993 (Continued)

(Megawatthours)

\begin{tabular}{|c|c|c|c|c|c|c|}
\hline Item & $\begin{array}{l}\text { California } \\
\text { Pasadena } \\
\text { City of } \\
\text { June } 30\end{array}$ & $\begin{array}{c}\text { California } \\
\text { Placer } \\
\text { County } \\
\text { Water } \\
\text { Agency } \\
\text { December } 31\end{array}$ & $\begin{array}{l}\text { California } \\
\text { Redding } \\
\text { City of } \\
\text { June } 30\end{array}$ & $\begin{array}{l}\text { California } \\
\text { Riverside } \\
\text { City of } \\
\text { June } 30\end{array}$ & $\begin{array}{l}\text { Califomia } \\
\text { Roseville } \\
\text { City of } \\
\text { June } 30\end{array}$ & $\begin{array}{l}\text { California } \\
\text { Sacramento } \\
\text { Municipal } \\
\text { Util Dist } \\
\text { December } 31\end{array}$ \\
\hline \multicolumn{7}{|l|}{ Sources of Energy } \\
\hline Steam & 289,530 & 0 & 0 & 0 & 0 & 506,084 \\
\hline 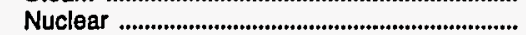 & & 0 & 0 & 319,567 & 0 & \\
\hline 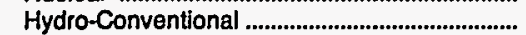 & 10,660 & $1,281,538$ & 0 & 0 & 0 & $2,162,609$ \\
\hline 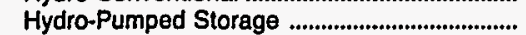 & & 0 & 0 & 0 & 0 & \\
\hline Other & 0 & 0 & 0 & 0 & 0 & 5,759 \\
\hline 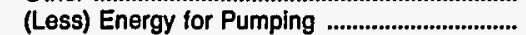 & & 0 & 0 & 0 & 0 & \\
\hline 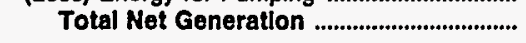 & 300,190 & $1,281,538$ & o & 319,567 & o & $2,674,452$ \\
\hline 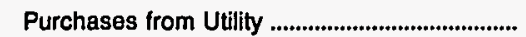 & 979,657 & 0 & 675,701 & $1,445,652$ & 560,227 & $6,609,475$ \\
\hline $\begin{array}{l}\text { Purchases from Nonutility ..................................... } \\
\text { Power Exchanges }\end{array}$ & 1,191 & 0 & 0 & 0 & 0 & \\
\hline Power Exchanges & 0 & 0 & 0 & 0 & 0 & 0 \\
\hline 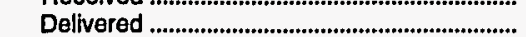 & 0 & 0 & 0 & 0 & 0 & 236,277 \\
\hline 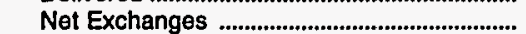 & 0 & 0 & 0 & 0 & 0 & $-236,277$ \\
\hline \multicolumn{7}{|l|}{ Transmission for Others (Wheeling) } \\
\hline 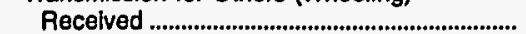 & 0 & 0 & 0 & 0 & 0 & 0 \\
\hline 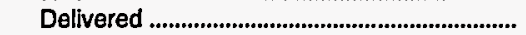 & 0 & 0 & 0 & 0 & 0 & 0 \\
\hline Net Transmission for Others ................................. & 0 & 0 & 0 & 0 & 0 & 0 \\
\hline Transmission by Others Losses ............................. & 0 & 0 & 0 & 0 & 0 & 3,730 \\
\hline $\begin{array}{l}\text { Total Net Energy } \\
\text { Generated and Recelved ........................... }\end{array}$ & $1,281,038$ & $1,281,538$ & 675,701 & $1,765,219$ & 560,227 & $9,051,380$ \\
\hline \multicolumn{7}{|l|}{ Dlsposition of Energy } \\
\hline Sales to Ultimate Consumers ............................... & $1,137,759$ & 0 & 621,517 & $1,556,894$ & 541,369 & $8,446,459$ \\
\hline Requirements Sales for Resale ............................. & 18,373 & 0 & 23,778 & 126,648 & 0 & 98,910 \\
\hline Nonrequirements Sales for Resale ........................ & 25,026 & $1,274,981$ & 0 & 0 & 0 & 0 \\
\hline Furnished Without Charge ...................................... & 7,848 & 0 & 0 & 0 & 0 & 0 \\
\hline Used by Utility (excluding station use) .............. & & 0 & 0 & $\mathbf{0}$ & 0 & 23,262 \\
\hline 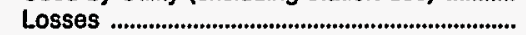 & 92,032 & 6,557 & 30,406 & 81,677 & 18,858 & 482,749 \\
\hline Total Dlsposittlon & $1,281,038$ & $1,281,538$ & 675,701 & $1,765,219$ & 560,227 & $9,051,380$ \\
\hline
\end{tabular}

Note: Totals may not equal sum of components because of independent rounding. Double counting occurs in components of both sources and disposition of energy and thus neither provides a true total. Purchases from utilities, net interchanges, and net wheeling (except for imports) are included in net generation. Sales for resale is included in sales to ultimate consumers.

Source: Energy Information Administration, Form EIA-412, "Annual Report of Public Electric Utilities." 
Table 26. Electric Energy Account by Major U.S. Publicly Owned Electric Utility Within State, 1993 (Continued)

(Megawatthours)

\begin{tabular}{|c|c|c|c|c|c|c|}
\hline Item & $\begin{array}{c}\text { California } \\
\text { San Francisco } \\
\text { City } \\
\& \\
\text { County of } \\
\text { June } 30\end{array}$ & $\begin{array}{l}\text { California } \\
\text { Santa } \\
\text { Clara } \\
\text { City of } \\
\text { June } 30\end{array}$ & $\begin{array}{c}\text { California } \\
\text { Southem } \\
\text { California } \\
\text { P P } \\
\text { A } \\
\text { June } 30\end{array}$ & $\begin{array}{c}\text { California } \\
\text { Turlock } \\
\text { Irrigation } \\
\text { District } \\
\text { December } 31\end{array}$ & $\begin{array}{l}\text { California } \\
\text { Vernon } \\
\text { City of } \\
\text { June } 30\end{array}$ & $\begin{array}{c}\text { California } \\
\text { Yuba } \\
\text { County } \\
\text { Water } \\
\text { Agency } \\
\text { June } 30\end{array}$ \\
\hline \multicolumn{7}{|l|}{ Sources of Energy } \\
\hline Steam & 0 & 0 & 0 & 0 & 0 & 0 \\
\hline 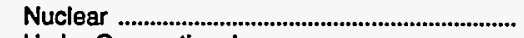 & 0 & 0 & $1,562,606$ & 0 & 0 & 0 \\
\hline Hydro-Conventional & $1,693,122$ & 15,191 & 0 & 344,345 & 0 & $1,589,807$ \\
\hline 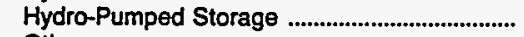 & 0 & 0 & 0 & 0 & 0 & 0 \\
\hline Other & 0 & 46,696 & 0 & 2,335 & 21,039 & 0 \\
\hline 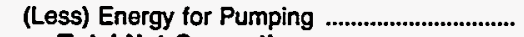 & 0 & 0 & $\mathbf{0}$ & 0 & 0 & 0 \\
\hline 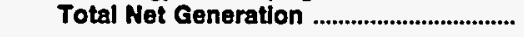 & $1,693,122$ & 61,887 & $1,562,606$ & 346,680 & 21,039 & $1,589,807$ \\
\hline 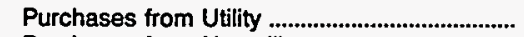 & 346,764 & $2,358,595$ & 0 & 949,815 & 966,484 & 0 \\
\hline $\begin{array}{l}\text { Purchases from Nonutility ...................................... } \\
\text { Power Exchanges }\end{array}$ & & 0 & 0 & 0 & 81,953 & 0 \\
\hline 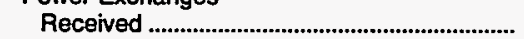 & 0 & 0 & 0 & 1,217 & 23,996 & 0 \\
\hline 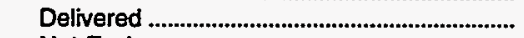 & 0 & 0 & 0 & 1,228 & 13,934 & 0 \\
\hline 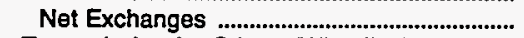 & 0 & 0 & 0 & -11 & 10,062 & 0 \\
\hline \multicolumn{7}{|l|}{ Transmission for Others (Wheeling) } \\
\hline 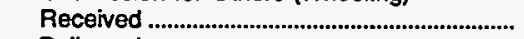 & 0 & 208,107 & 0 & 0 & 15,060 & 0 \\
\hline Delivered & 0 & 205,155 & 0 & 6,350 & 15,060 & 0 \\
\hline Net Transmission for Others .............................. & 0 & 2,952 & 0 & $-6,350$ & 0 & 0 \\
\hline $\begin{array}{l}\text { Transmission by Others Losses .......................... } \\
\text { Total Net Energy }\end{array}$ & 0 & 0 & 0 & $-14,891$ & $\mathbf{0}$ & 0 \\
\hline Generated and Recelved .......................... & $2,039,886$ & $2,423,434$ & $1,562,606$ & $1,275,244$ & $1,079,538$ & $1,589,807$ \\
\hline \multicolumn{7}{|l|}{ Dlspositton of Energy } \\
\hline 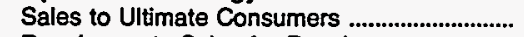 & 563,594 & $2,119,657$ & 0 & $1,170,118$ & $1,029,685$ & 0 \\
\hline Requirements Sales for Resale ........................ & $1,353,168$ & 3,241 & $1,562,606$ & 10,237 & 0 & $1,586,836$ \\
\hline 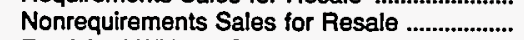 & & 168,179 & 0 & 3,918 & 0 & 0 \\
\hline 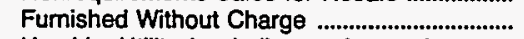 & 2,494 & 8,913 & 0 & 0 & 0 & 0 \\
\hline Used by Utility (excluding station use) ............ & 3,585 & 0 & 0 & 14,648 & 0 & 0 \\
\hline Losses & 117,045 & 123,444 & 0 & 76,323 & 49,853 & 2,971 \\
\hline Total Dlspositton & $2,039,886$ & $2,423,434$ & $1,562,606$ & $1,275,244$ & $1,079,538$ & $1,589,807$ \\
\hline
\end{tabular}

Note: Totals may not equal sum of components because of independent rounding. Double counting occurs in components of both sources and disposition of energy and thus neither provides a true total. Purchases from utilities, net interchanges, and net wheeling (except for imports) are included in net generation. Sales for resale is included in sales to ultimate consumers.

Source: Energy Information Administration, Form ElA-412, "Annual Report of Public Electric Utilities." 
Table 26. Electric Energy Account by Major U.S. Publicly Owned Electric Utility Within State, 1993 (Continued)

(Megawatthours)

\begin{tabular}{|c|c|c|c|c|c|c|}
\hline Item & $\begin{array}{l}\text { Colorado } \\
\text { Arkansas } \\
\text { River } \\
\text { Power } \\
\text { Authority } \\
\text { December } 31\end{array}$ & $\begin{array}{l}\text { Colorado } \\
\text { Colorado } \\
\text { Springs } \\
\text { City of } \\
\text { December } 31\end{array}$ & $\begin{array}{l}\text { Colorado } \\
\text { Fort Collins } \\
\text { City of } \\
\text { December } 31\end{array}$ & $\begin{array}{l}\text { Colorado } \\
\text { Fort Morgan } \\
\text { City of } \\
\text { December } 31\end{array}$ & $\begin{array}{l}\text { Colorado } \\
\text { Longmont } \\
\text { City of } \\
\text { December } 31\end{array}$ & $\begin{array}{l}\text { Colorado } \\
\text { Loveland } \\
\text { City of } \\
\text { December } 31\end{array}$ \\
\hline 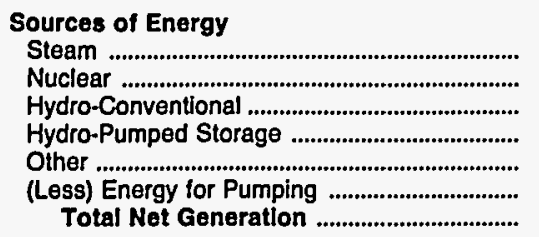 & $\begin{array}{l}0 \\
0 \\
0 \\
0 \\
0 \\
0 \\
0\end{array}$ & $\begin{array}{r}2,857,658 \\
0 \\
8,585 \\
0 \\
0 \\
0 \\
2,866,243\end{array}$ & $\begin{array}{l}0 \\
0 \\
0 \\
0 \\
0 \\
0\end{array}$ & $\begin{array}{l}0 \\
0 \\
0 \\
0 \\
0 \\
0 \\
0\end{array}$ & $\begin{array}{r}0 \\
0 \\
3,624 \\
0 \\
0 \\
0 \\
3,624\end{array}$ & $\begin{array}{r}0 \\
0 \\
3,627 \\
0 \\
0 \\
0 \\
3,627\end{array}$ \\
\hline 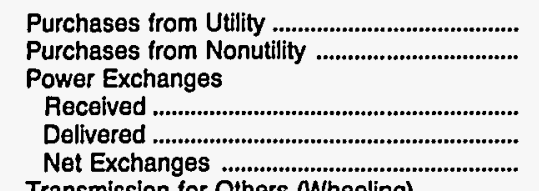 & $\begin{array}{r}297,900 \\
0\end{array}$ & $\begin{array}{r}1,022 \\
84 \\
938\end{array}$ & $\begin{array}{r}890,841 \\
0\end{array}$ & $\begin{array}{r}146,511 \\
0\end{array}$ & $\begin{array}{r}464,589 \\
0\end{array}$ & $\begin{array}{r}384,145 \\
0\end{array}$ \\
\hline 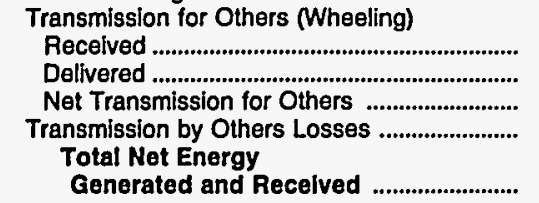 & $\begin{array}{l}0 \\
0 \\
0 \\
0\end{array}$ & $\begin{array}{r}26,805 \\
26,805 \\
0 \\
0\end{array}$ & 890,841 & $\begin{array}{l}0 \\
0 \\
0 \\
0\end{array}$ & $\begin{array}{r}7,001 \\
6,973 \\
28 \\
0\end{array}$ & 387,772 \\
\hline 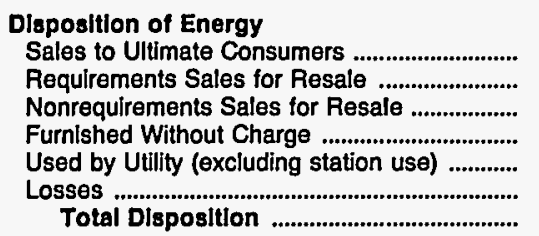 & $\begin{array}{r}0 \\
274,109 \\
0 \\
0 \\
0 \\
23,791 \\
297,900\end{array}$ & $\begin{array}{r}3,031,382 \\
128,360 \\
41,501 \\
0 \\
0 \\
129,745 \\
3,330,988\end{array}$ & $\begin{array}{r}873,919 \\
0 \\
0 \\
6,260 \\
0 \\
10,662 \\
890,841\end{array}$ & $\begin{array}{r}134,685 \\
0 \\
0 \\
0 \\
0 \\
11,826 \\
146,511\end{array}$ & $\begin{array}{r}442,161 \\
0 \\
0 \\
0 \\
10,923 \\
0 \\
15,157 \\
468,241\end{array}$ & $\begin{array}{r}378,542 \\
0 \\
0 \\
5,000 \\
0 \\
4,230 \\
387,772\end{array}$ \\
\hline
\end{tabular}

Note: Totals may not equal sum of components because of independent rounding. Double counting occurs in components of both sources and disposition of energy and thus neither provides a true total. Purchases from utilities, net interchanges, and net wheeling (except for imports) are included in net generation. Sales for resale is included in sales to ultimate consumers.

Source: Energy Information Administration, Form EIA-412, "Annual Report of Public Electric Utilities." 
Table 26. Electric Energy Account by Major U.S. Publicly Owned Electric Utility Within State, 1993 (Continued)

(Megawatthours)

\begin{tabular}{|c|c|c|c|c|c|c|}
\hline Item & $\begin{array}{c}\text { Colorado } \\
\text { Platte River } \\
\text { Power } \\
\text { Authority } \\
\text { December } 31\end{array}$ & $\begin{array}{l}\text { Connecticut } \\
\text { Connecticut } \\
\text { Mun } \\
\text { Elec } \\
\text { Engy Coop } \\
\text { December } 31\end{array}$ & $\begin{array}{l}\text { Connecticut } \\
\text { Groton } \\
\text { City of } \\
\text { June } 30\end{array}$ & $\begin{array}{l}\text { Connecticut } \\
\text { Norwich } \\
\text { City of } \\
\text { June } 30\end{array}$ & $\begin{array}{l}\text { Connecticut } \\
\text { Wallingford } \\
\text { Town of } \\
\text { June } 30\end{array}$ & $\begin{array}{l}\text { Delaware } \\
\text { Dover } \\
\text { City of } \\
\text { June } 30\end{array}$ \\
\hline \multicolumn{7}{|l|}{ Sources of Energy } \\
\hline Steam & $2,920,125$ & 0 & 0 & 0 & 352 & 205,384 \\
\hline 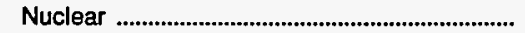 & 0 & 70,877 & 0 & 0 & 0 & 0 \\
\hline 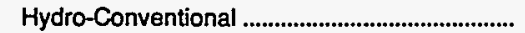 & 0 & 0 & 0 & 11,130 & 0 & 0 \\
\hline 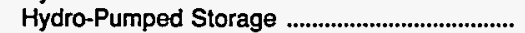 & 0 & 0 & 0 & 0 & 0 & 0 \\
\hline Other & 0 & 0 & 0 & 0 & 0 & 0 \\
\hline 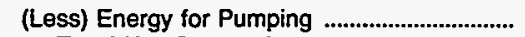 & 0 & 0 & 0 & 0 & 0 & 0 \\
\hline Total Net Generation & $2,920,125$ & 70,877 & $\mathbf{0}$ & 11,130 & 352 & 205,384 \\
\hline 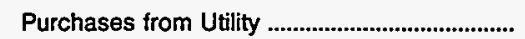 & 730,253 & 803,703 & 639,171 & 274,633 & 548,401 & 315,428 \\
\hline $\begin{array}{l}\text { Purchases from Nonutility ..................................... } \\
\text { Power Exchanges }\end{array}$ & 0 & 0 & 0 & 0 & 0 & 60,288 \\
\hline 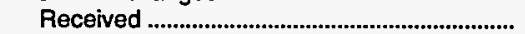 & 24,145 & 245,200 & 0 & 0 & 0 & 0 \\
\hline 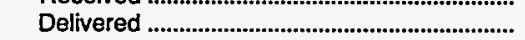 & 30,491 & 27,787 & 0 & 0 & 0 & 0 \\
\hline 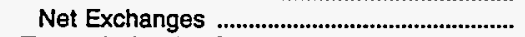 & $-6,346$ & 217,413 & 0 & 0 & 0 & 0 \\
\hline \multicolumn{7}{|l|}{ Transmission for Others (Wheeling) } \\
\hline 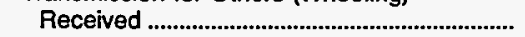 & 0 & $\mathbf{0}$ & 0 & 0 & 0 & 0 \\
\hline 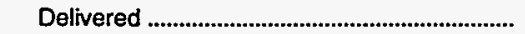 & 0 & 0 & 0 & 0 & 0 & 0 \\
\hline Net Transmission for Others & 0 & 0 & 0 & 0 & 0 & 0 \\
\hline $\begin{array}{l}\text { Transmission by Others Losses ......................... } \\
\text { Total Net Energy }\end{array}$ & 0 & 0 & 0 & 0 & 0 & 0 \\
\hline Generated and Recelved .......................... & $3,644,032$ & $1,091,993$ & 639,171 & 285,763 & 548,753 & 581,100 \\
\hline \multicolumn{7}{|l|}{ Disposition of Energy } \\
\hline 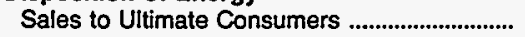 & 0 & $\mathbf{0}$ & 621,720 & 267,040 & 519,205 & 540,405 \\
\hline 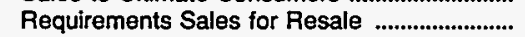 & $1,832,088$ & $1,089,285$ & 5,158 & 0 & 0 & 0 \\
\hline 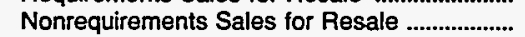 & $1,744,866$ & 0 & 0 & 0 & 0 & 18,212 \\
\hline 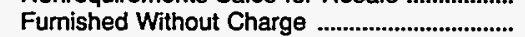 & 0 & 0 & 557 & 0 & 0 & 0 \\
\hline Used by Utility (excluding station use) ............ & 0 & 0 & 846 & 0 & 0 & 0 \\
\hline Losses & 67,078 & 2,708 & 10,890 & 18,723 & 29,548 & 22,483 \\
\hline Total Disposition & $3,644,032$ & $1,091,993$ & 639,171 & 285,763 & 548,753 & 581,100 \\
\hline
\end{tabular}

Note: Totals may not equal sum of components because of independent rounding. Double counting occurs in components of both sources and disposition of energy and thus neither provides a true total. Purchases from utilities, net interchanges, and net wheeling (except for imports) are included in net generation. Sales for resale is included in sales to ultimate consumers.

Source: Energy Information Administration, Form EIA-412, "Annual Report of Public Electric Utilities." 
Table 26. Electric Energy Account by Major U.S. Publicly Owned Electric Utility Within State, 1993 (Continued)

(Megawatthours)

\begin{tabular}{|c|c|c|c|c|c|c|}
\hline Item & $\begin{array}{l}\text { Delaware } \\
\text { Milford } \\
\text { City of } \\
\text { September } 30\end{array}$ & $\begin{array}{l}\text { Delaware } \\
\text { Newark } \\
\text { City of } \\
\text { December } 31\end{array}$ & $\begin{array}{c}\text { Florida } \\
\text { Bartow } \\
\text { City of } \\
\text { September } 30\end{array}$ & $\begin{array}{c}\text { Florida } \\
\text { Florida } \\
\text { Municipal } \\
\text { Power Agency } \\
\text { September } 30\end{array}$ & $\begin{array}{c}\text { Florida } \\
\text { Fort Pierce } \\
\text { Utilities } \\
\text { Auth } \\
\text { September } 30\end{array}$ & $\begin{array}{c}\text { Florida } \\
\text { Gainesville } \\
\text { Regional } \\
\text { Utilities } \\
\text { September } 30\end{array}$ \\
\hline \multicolumn{7}{|l|}{ Sources of Energy } \\
\hline Steam & 0 & 0 & 0 & 750,695 & 197,508 & $1,619,371$ \\
\hline 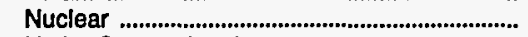 & 0 & 0 & 0 & 437,713 & 0 & 84,346 \\
\hline 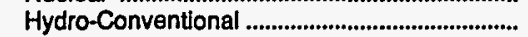 & 0 & 0 & $\mathbf{0}$ & 0 & 0 & \\
\hline 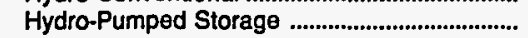 & $\mathbf{0}$ & 0 & 0 & 0 & 0 & 0 \\
\hline Other & 0 & 0 & 0 & 29,185 & 84 & 6,152 \\
\hline 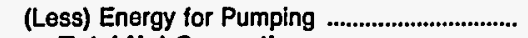 & 0 & 0 & 0 & 0 & 0 & \\
\hline 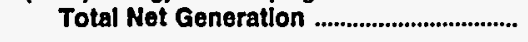 & $\mathbf{0}$ & $\mathbf{0}$ & 0 & $1,217,593$ & 197,592 & $1,709,869$ \\
\hline 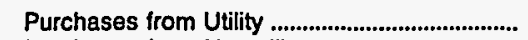 & 136,681 & 300,175 & 251,749 & $1,991,710$ & 341,308 & 114,262 \\
\hline $\begin{array}{l}\text { Purchases from Nonutility ............................... } \\
\text { Power Exchanges }\end{array}$ & 0 & 0 & 0 & 0 & 0 & 0 \\
\hline 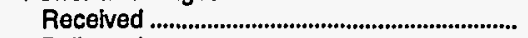 & 0 & 0 & 0 & 0 & 0 & 0 \\
\hline 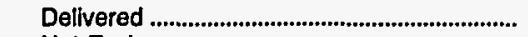 & 0 & 0 & 0 & 0 & 0 & 0 \\
\hline 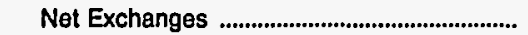 & 0 & 0 & 0 & 0 & 0 & 0 \\
\hline \multicolumn{7}{|l|}{ Transmission for Others (Wheeling) } \\
\hline 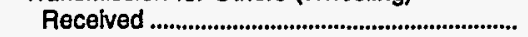 & 0 & 0 & 0 & 0 & 0 & 0 \\
\hline 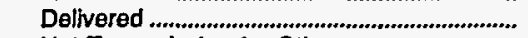 & 0 & 0 & 0 & 0 & 0 & 0 \\
\hline 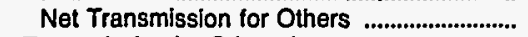 & 0 & 0 & 0 & 0 & 0 & 0 \\
\hline $\begin{array}{l}\text { Transmission by Others Losses ........................ } \\
\text { Total Net Energy }\end{array}$ & 0 & 0 & 0 & 0 & -980 & 0 \\
\hline Generated and Recelved ........................ & 136,681 & 300,175 & 251,749 & $3,209,303$ & 537,920 & $1,824,131$ \\
\hline \multicolumn{7}{|l|}{ Dlspositlon of Energy } \\
\hline Sales to Ultimate Consumers ............................ & 127,423 & 273,248 & 233,170 & $\mathbf{0}$ & 493,904 & $1,290,479$ \\
\hline 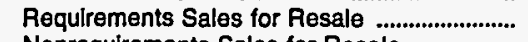 & 0 & 0 & 0 & $3,087,450$ & 0 & 316,569 \\
\hline Nonrequirements Sales for Resale ................... & 0 & 0 & 0 & 0 & 20,004 & 124,630 \\
\hline 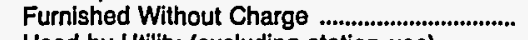 & 0 & 4,187 & 0 & 0 & 0 & $\begin{array}{l}0 \\
0\end{array}$ \\
\hline Used by Utility (excluding station use) ............ & & 2,472 & 0 & 0 & 1,052 & 0 \\
\hline 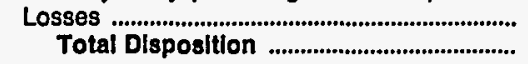 & $\begin{array}{r}9,258 \\
136,681\end{array}$ & $\begin{array}{r}20,268 \\
300,175\end{array}$ & $\begin{array}{r}18,579 \\
251,749\end{array}$ & $\begin{array}{r}121,853 \\
3,209,303\end{array}$ & $\begin{array}{r}22,960 \\
537,920\end{array}$ & $\begin{array}{r}92,453 \\
1,824,131\end{array}$ \\
\hline
\end{tabular}

Note: Totals may not equal sum of components because of independent rounding. Double counting occurs in components of both sources and disposition of energy and thus neither provides a true total. Purchases from utilities, net interchanges, and net wheeling (except for imports) are included in net generation. Sales for resale is included in sales to ultimate consumers.

Source: Energy Information Administration, Form EIA-412, "Annual Report of Public Electric Utilities." 
Table 26. Electric Energy Account by Major U.S. Publicly Owned Electric Utility Within State, 1993 (Continued)

(Megawatthours)

\begin{tabular}{|c|c|c|c|c|c|c|}
\hline Item & $\begin{array}{c}\text { Florida } \\
\begin{array}{c}\text { Homestead } \\
\text { City of }\end{array} \\
\text { September } 30\end{array}$ & $\begin{array}{c}\text { Florida } \\
\text { Jacksonville } \\
\text { Beach } \\
\text { City of } \\
\text { September } 30\end{array}$ & $\begin{array}{c}\text { Florida } \\
\text { Jacksonville } \\
\text { Electric } \\
\text { Auth } \\
\text { September } 30\end{array}$ & $\begin{array}{l}\text { Florida } \\
\text { Key West } \\
\text { City of } \\
\text { September } 30\end{array}$ & $\begin{array}{c}\text { Florida } \\
\text { Kissimmee } \\
\text { Utility } \\
\text { Authority } \\
\text { September } 30\end{array}$ & $\begin{array}{l}\text { Florida } \\
\text { Lake Worth } \\
\text { City of } \\
\text { September } 30\end{array}$ \\
\hline \multirow{2}{*}{\multicolumn{7}{|c|}{ Sources of Energy }} \\
\hline & & & & & & 174,911 \\
\hline Nuclear & 0 & 0 & & & 38,840 & \\
\hline 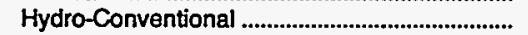 & 0 & 0 & 0 & 0 & 0 & 0 \\
\hline Hydro-Pumped Storage ............................................... & 0 & 0 & 0 & 0 & 0 & 0 \\
\hline Other & 32,245 & 0 & 5,980 & 20,475 & 142,332 & 181 \\
\hline (Less) Energy for Pumping ................................... & & 0 & 0 & 0 & 0 & 0 \\
\hline 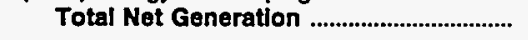 & 32,245 & 0 & $7,844,399$ & 65,296 & 325,850 & 175,091 \\
\hline 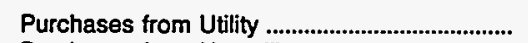 & 184,757 & 489,602 & $1,790,338$ & 492,365 & 458,844 & 182,880 \\
\hline 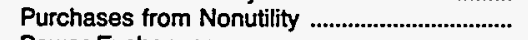 & 0 & & 11,915 & 0 & 0 & \\
\hline \multicolumn{7}{|l|}{ Power Exchanges } \\
\hline 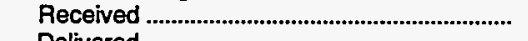 & 0 & 0 & 0 & 0 & 0 & 0 \\
\hline 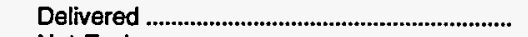 & 0 & 0 & 0 & 0 & 0 & 0 \\
\hline Net Exchanges & 0 & 0 & 0 & 0 & 0 & 0 \\
\hline \multicolumn{7}{|l|}{ Transmission for Others (Wheeling) } \\
\hline 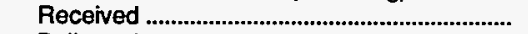 & 0 & 0 & 0 & 0 & 0 & 0 \\
\hline 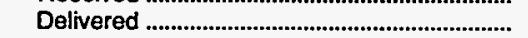 & 0 & 0 & 0 & 0 & 0 & 0 \\
\hline 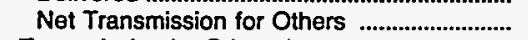 & 0 & 0 & 0 & 0 & 0 & 0 \\
\hline $\begin{array}{l}\text { Transmission by Others Losses ............................. } \\
\text { Total Net Energy }\end{array}$ & 0 & 0 & 0 & 0 & 0 & 0 \\
\hline 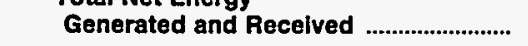 & 217,002 & 489,602 & $9,646,652$ & 557,661 & 784,694 & 357,971 \\
\hline \multicolumn{7}{|l|}{ Dlsposition of Energy } \\
\hline 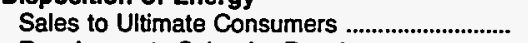 & 191,305 & 457,108 & $8,599,683$ & 518,813 & 744,793 & 325,276 \\
\hline 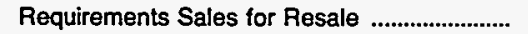 & 14,410 & 0 & 330,847 & 0 & 111 & 10,295 \\
\hline Nonrequirements Sales for Resale .................... & 0 & 0 & 194,968 & 34 & 0 & 0 \\
\hline 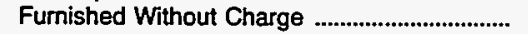 & 0 & 0 & 0 & 995 & 0 & 0 \\
\hline Used by Utility (excluding station use) .............. & 3,340 & 0 & 21,167 & 7,884 & 0 & 1,880 \\
\hline 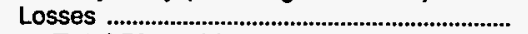 & 7,947 & 32,494 & 499,987 & 29,935 & 39,790 & 20,520 \\
\hline Total Disposition ................................................. & 217,002 & 489,602 & $9,646,652$ & 557,661 & 784,694 & 357,971 \\
\hline
\end{tabular}

Note: Totals may not equal sum of components because of independent rounding. Double counting occurs in components of both sources and disposition of energy and thus neither provides a true total. Purchases from utilities, net interchanges, and net wheeling (except for imports) are included in net generation. Sales for resale is included in sales to ultimate consumers.

Source: Energy Information Administration, Form EIA-412, "Annual Report of Public Electric Utilities." 
Table 26. Electric Energy Account by Major U.S. Publicly Owned Electric Utility Within State, 1993 (Continued)

(Megawatthours)

\begin{tabular}{|c|c|c|c|c|c|c|}
\hline Item & $\begin{array}{l}\text { Florida } \\
\text { Lakeland } \\
\text { City of } \\
\text { September } 30\end{array}$ & $\begin{array}{l}\text { Florida } \\
\text { Leesburg } \\
\text { City of } \\
\text { September } 30\end{array}$ & $\begin{array}{c}\text { Florida } \\
\text { Now Smyrna } \\
\text { Beach } \\
\text { Utils Comm } \\
\text { September } 30\end{array}$ & $\begin{array}{l}\text { Florida } \\
\text { Ocala } \\
\text { City of } \\
\text { September } 30\end{array}$ & $\begin{array}{l}\text { Florida } \\
\text { Orlando } \\
\text { Utilities } \\
\text { Comm } \\
\text { September } 30\end{array}$ & $\begin{array}{l}\text { Florida } \\
\text { Quincy } \\
\text { City of } \\
\text { September } 30\end{array}$ \\
\hline \multicolumn{7}{|l|}{ Sources of Energy } \\
\hline Steam ............................ & $1,476,964$ & 0 & 0 & 0 & $4,374,093$ & \\
\hline Nuclear. & & 49,667 & 32,637 & 95,437 & 398,382 & 0 \\
\hline 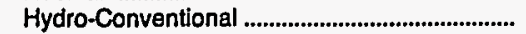 & 0 & 0 & 0 & 0 & 0 & \\
\hline Hydro-Pumped Storage .............................................. & 0 & 0 & 0 & 0 & 0 & c \\
\hline Other & 359,115 & 0 & 68 & 0 & 91,251 & \\
\hline 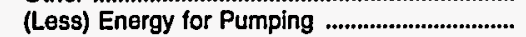 & & 0 & 0 & 0 & & \\
\hline 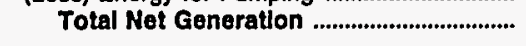 & $1,836,079$ & 49,667 & 32,705 & 95,437 & $4,863,726$ & \\
\hline 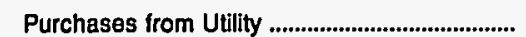 & 391,699 & 316,816 & 262,853 & 944,530 & 247,773 & 143,495 \\
\hline 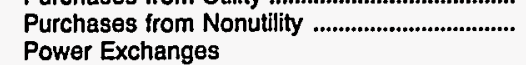 & 0 & 0 & 0 & 0 & 0 & \\
\hline 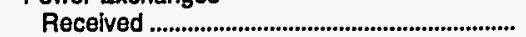 & 0 & 0 & 0 & 0 & 0 & \\
\hline Delivered .................................................................. & 0 & 0 & 0 & 0 & 0 & \\
\hline 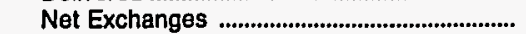 & 0 & 0 & 0 & 0 & 0 & \\
\hline \multicolumn{7}{|l|}{ Transmission for Others (Wheeling) } \\
\hline 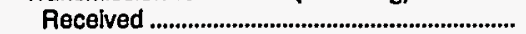 & 0 & 0 & 0 & 30,585 & 359,187 & \\
\hline Delivered.. & 0 & 0 & 0 & 30,585 & 349,742 & \\
\hline Net Transmission for Others .............................. & 0 & 0 & 0 & 0 & 9,445 & 0 \\
\hline 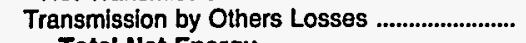 & $\mathbf{0}$ & 0 & $-3,063$ & 0 & $-9,445$ & \\
\hline $\begin{array}{l}\text { Total Net Energy } \\
\text { Generated and Recelved }\end{array}$ & $2,227,778$ & 366,483 & 292,495 & 1039967 & 5111.499 & 143,495 \\
\hline \multirow{2}{*}{\multicolumn{7}{|c|}{ Dlsposittion of Energy }} \\
\hline & & & & & & \\
\hline 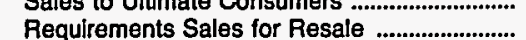 & $\begin{array}{r}2,114,917 \\
68,330\end{array}$ & $\begin{array}{r}352,203 \\
0\end{array}$ & $\begin{array}{r}2 / 2,370 \\
0\end{array}$ & $\begin{array}{r}944,530 \\
0\end{array}$ & $\begin{array}{r}3,009,099 \\
212,387\end{array}$ & $134,1 / 1$ \\
\hline Nonrequirements Sales for Resale ..................... & 4,543 & 0 & 10 & 0 & $1,173,277$ & \\
\hline Furnished Without Charge ....................................... & 0 & 0 & 0 & 0 & 0 & \\
\hline Used by Utility (excluding station use) ............. & 0 & 0 & 0 & 0 & 0 & \\
\hline 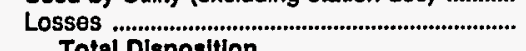 & $\begin{array}{r}39,988 \\
2,7978\end{array}$ & $\begin{array}{r}14,280 \\
\quad-283\end{array}$ & $\begin{array}{r}20,175 \\
202,495\end{array}$ & $\begin{array}{r}95,437 \\
1039067\end{array}$ & $\begin{array}{r}115,936 \\
5,111,499\end{array}$ & $\begin{array}{r}9,324 \\
143,495\end{array}$ \\
\hline Cotal Dlspo & $2,227,778$ & 366,483 & 92,495 & $1,039,967$ & $5,111,499$ & \\
\hline
\end{tabular}

Note: Totals may not equal sum of components because of independent rounding. Double counting occurs in components of both sources and disposition of energy and thus neither provides a true total. Purchases from utilities, net interchanges, and net wheeling (except for imports) are included in net generation. Sales for resale is included in sales to ultimate consumers.

Source: Energy Information Administration, Form ElA-412, "Annual Report of Public Electric Utilities." 
Table 26. Electric Energy Account by Major U.S. Publicly Owned Electric Utility Within State, 1993 (Continued)

(Megawatthours)

\begin{tabular}{|c|c|c|c|c|c|c|}
\hline Item & $\begin{array}{c}\text { Florida } \\
\text { Reedy Creek } \\
\text { Improvement } \\
\text { Dist }\end{array}$ & $\begin{array}{c}\text { St Cloud } \\
\text { City of } \\
\text { September } 30\end{array}$ & $\begin{array}{c}\text { Florida } \\
\text { Tallahassee } \\
\text { City of } \\
\text { September } 30\end{array}$ & $\begin{array}{c}\text { Florida } \\
\text { Vero } \\
\text { Beach } \\
\text { City of } \\
\text { September } 30\end{array}$ & $\begin{array}{l}\text { Georgia } \\
\text { Albany Water } \\
\text { Gas \& Light } \\
\text { Comm } \\
\text { June } 30\end{array}$ & $\begin{array}{l}\text { Georgia } \\
\text { Calhoun } \\
\text { City of } \\
\text { June } 30\end{array}$ \\
\hline \multicolumn{7}{|l|}{ Sources of Energy } \\
\hline 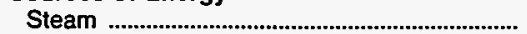 & 46,000 & 0 & $1,318,163$ & 322,403 & 0 & 0 \\
\hline Nuclear & 0 & 0 & 80,135 & 0 & 0 & 0 \\
\hline 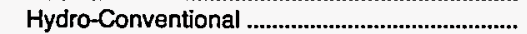 & 0 & 0 & 32,155 & 0 & 0 & 0 \\
\hline 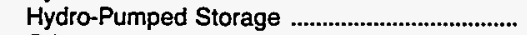 & 0 & 0 & 0 & 0 & 0 & 0 \\
\hline Other & 230,498 & 9,452 & 0 & 0 & 0 & 0 \\
\hline 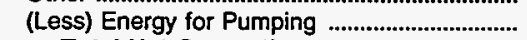 & & & 0 & 0 & 0 & 0 \\
\hline Total Net Generation & 276,498 & 9,452 & $1,430,453$ & 322,403 & 0 & $\mathbf{0}$ \\
\hline 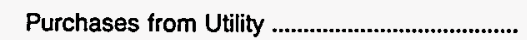 & 594,840 & 219,791 & 723,213 & 262,810 & 886,058 & 300,013 \\
\hline $\begin{array}{l}\text { Purchases from Nonutility ...................................... } \\
\text { Power Exchanges }\end{array}$ & 0 & 0 & 0 & 0 & 0 & 0 \\
\hline 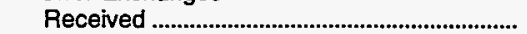 & 0 & 0 & 0 & 0 & 0 & 0 \\
\hline Delivered ............................................................. & 0 & 0 & 0 & 0 & 0 & 0 \\
\hline 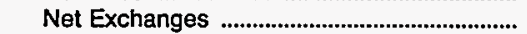 & 0 & 0 & 0 & 0 & 0 & 0 \\
\hline \multicolumn{7}{|l|}{ Transmission for Others (Wheeling) } \\
\hline 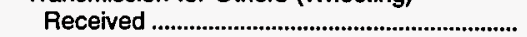 & 0 & 0 & 0 & 0 & 0 & 0 \\
\hline 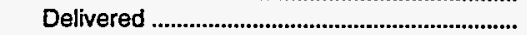 & 0 & 0 & 0 & 0 & 0 & 0 \\
\hline 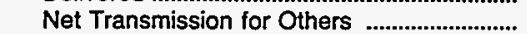 & 0 & 0 & 0 & 0 & 0 & 0 \\
\hline $\begin{array}{l}\text { Transmission by Others Losses .......................................... } \\
\text { Total Net Energy }\end{array}$ & 0 & 0 & 0 & -853 & 0 & 0 \\
\hline Generated and Received & 871,338 & 229,243 & $2,153,666$ & 584,360 & 886,058 & 300,013 \\
\hline \multicolumn{7}{|l|}{ Dlsposition of Energy } \\
\hline 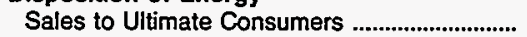 & 803,912 & 206,318 & $1,917,020$ & 500,868 & 840,195 & 294,354 \\
\hline Requirements Sales for Resale .............................. & & 0 & & 0 & 0 & 0 \\
\hline Nonrequirements Sales for Resale ..................... & 0 & 0 & 102,513 & 65,091 & 0 & 0 \\
\hline Furnished Without Charge .......................................... & 0 & 0 & 0 & 0 & 0 & 0 \\
\hline Used by Utility (excluding station use) ............ & 0 & 0 & 0 & 0 & 0 & 0 \\
\hline Losses & 67,426 & 22,925 & 134,133 & 18,401 & 45,863 & 5,659 \\
\hline Total Disposition & 871,338 & 229,243 & $2,153,666$ & 584,360 & 886,058 & 300,013 \\
\hline
\end{tabular}

Note: Totals may not equal sum of components because of independent rounding. Double counting occurs in components of both sources and disposition of energy and thus neither provides a true total. Purchases from utilities, net interchanges, and net wheeling (except for imports) are included in net generation. Sales for resale is included in sales to ultimate consumers.

Source: Energy Information Administration, Form EIA-412, "Annual Report of Public Electric Utilities." 
Table 26. Electric Energy Account by Major U.S. Publicly Owned Electric Utility Within State, 1993 (Continued)

(Megawatthours)

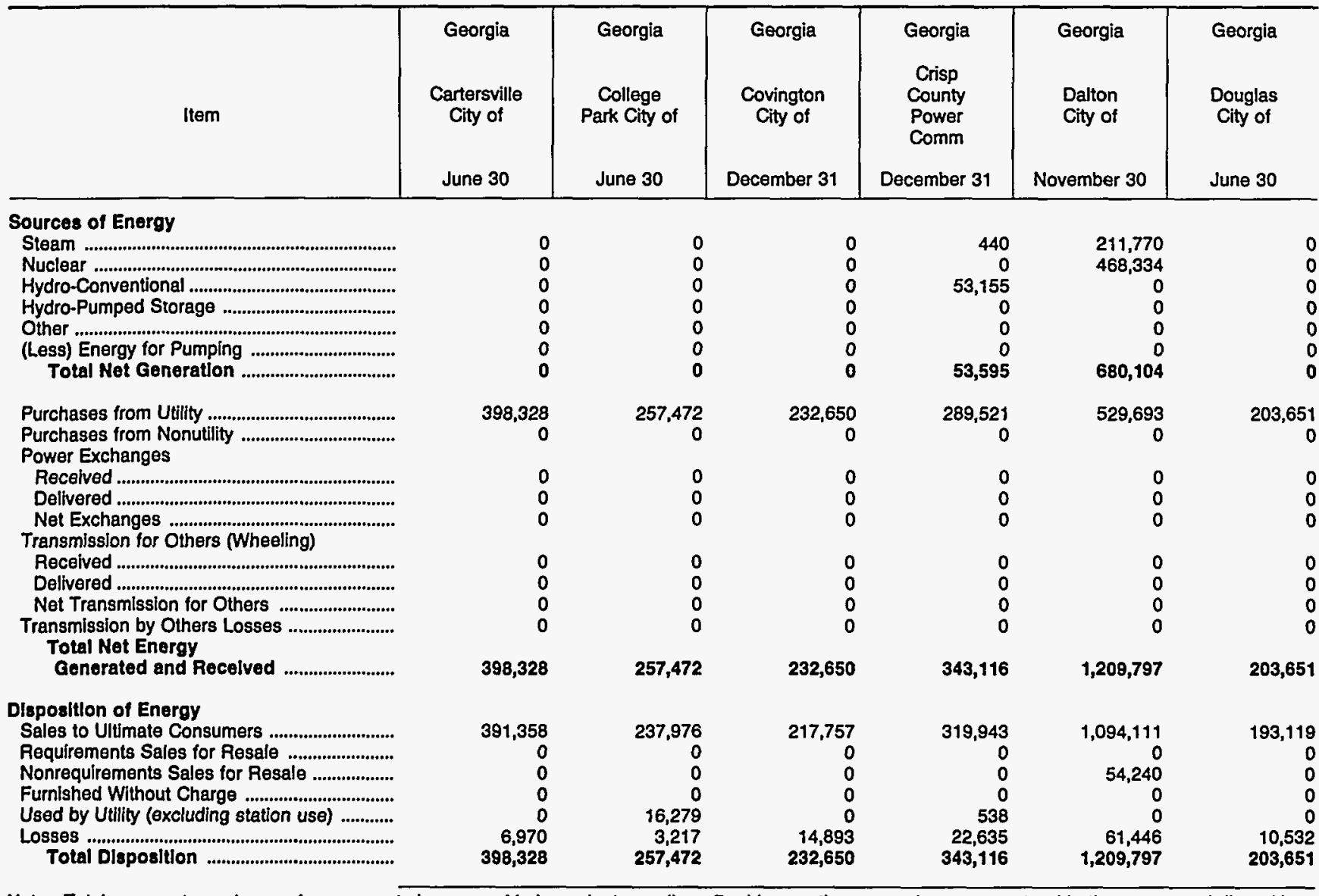

Note: Totals may not equal sum of components because of independent rounding. Double counting occurs in components of both sources and disposition of energy and thus neither provides a true total. Purchases from utilities, net interchanges, and net wheeling (except for imports) are included in net generation, Sales for resale is included in sales to ultimate consumers.

Source: Energy Information Administration, Form EIA-412, "Annual Report of Public Electric Utilities." 
Table 26. Electric Energy Account by Major U.S. Publicly Owned Electric Utility Within State, 1993 (Continued)

(Megawatthours)

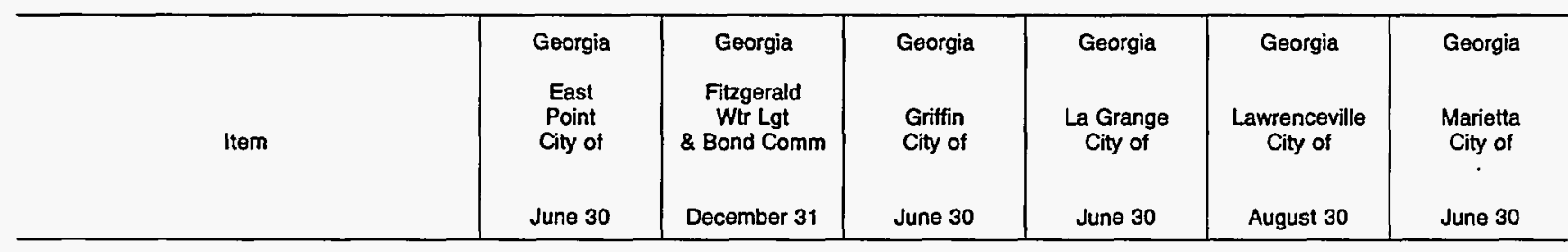

\section{Sources of Energy}

Steam

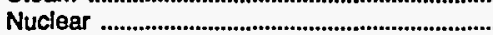

Hydro-Conventional

Hydro-Pumped Storage

Other

(Less) Energy for Pumping

Purchases from Utility

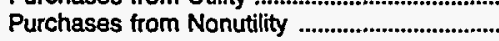

Power Exchanges

Received.

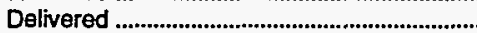

Net Exchanges

Transmission for Others (Wheeling)

Received

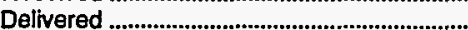

Net Transmission for Others

Transmission by Others Losses

Total Net Energy

Disposition of Energy

Sales to Ultimate Consumers

Requirements Sales for Resale

Sales for Resale

Fumished Without Charge ....

Used by Utility (excluding station use)

Losses

Total Disposition

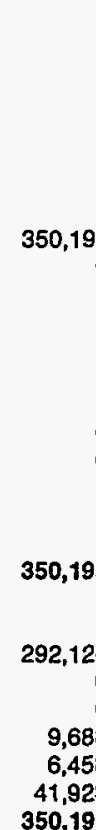

$\begin{array}{ll}0 & 0 \\ 0 & 0 \\ 0 & 0 \\ 0 & 0 \\ 0 & 0 \\ 0 & 0 \\ 0 & 0\end{array}$

0
0
0
0
0
0
0

0
0
0
0
0
0
0

0
0
0
0
0
0
0

178,710

296,546

0

0

0

118
0

798
0

829,656

$\begin{array}{lll}0 & 0 & 0\end{array}$

0 o

0

0
0

$\mathbf{0}$
$\mathbf{0}$

o

$n^{2}$

$\begin{array}{lll}0 & 0\end{array}$

0

0

0
0
0

0
0

0
0
0

0

0
0
0

0

0
0
0

296,546

518,118

196,798

Note: Totals may not equal sum of components because of independent rounding. Double counting occurs in components of both sources and disposition of energy and thus neither provides a true total. Purchases from utilities, net interchanges, and net wheeling (except for imports) are included in net generation. Sales for resale is included in sales to ultimate consumers.

Source: Energy Information Administration, Form EIA-412, "Annual Report of Public Electric Utilities." 
Table 26. Electric Energy Account by Major U.S. Publicly Owned Electric Utility Within State, 1993 (Continued)

(Megawatthours)

\begin{tabular}{|c|c|c|c|c|c|c|}
\hline Item & $\begin{array}{c}\text { Georgia } \\
\text { Moultrie } \\
\text { City of } \\
\text { September } 30\end{array}$ & $\begin{array}{c}\text { Georgia } \\
\text { Municipal } \\
\text { Electric } \\
\text { Authority } \\
\text { December } 31\end{array}$ & $\begin{array}{c}\text { Georgia } \\
\text { Thomasville } \\
\text { City of }\end{array}$ & $\begin{array}{c}\text { Idaho } \\
\text { Idaho } \\
\text { Falls } \\
\text { City of } \\
\text { September } 30\end{array}$ & $\begin{array}{c}\text { Illinois } \\
\text { Batavia } \\
\text { City of } \\
\text { December } 31\end{array}$ & $\begin{array}{l}\text { lllinois } \\
\text { Geneva } \\
\text { City of } \\
\text { April } 30\end{array}$ \\
\hline 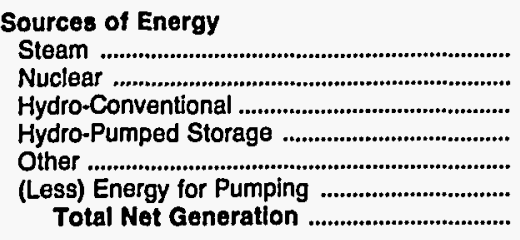 & $\begin{array}{l}0 \\
0 \\
0 \\
0 \\
0 \\
0 \\
0\end{array}$ & $\begin{array}{r}3,221,590 \\
5,684,365 \\
0 \\
0 \\
0 \\
0 \\
8,905,955\end{array}$ & $\begin{array}{l}0 \\
0 \\
0 \\
0 \\
0 \\
0 \\
0\end{array}$ & $\begin{array}{r}0 \\
0 \\
226,938 \\
0 \\
0 \\
0 \\
226,938\end{array}$ & $\begin{array}{l}0 \\
0 \\
0 \\
0 \\
0 \\
0 \\
0\end{array}$ & $\begin{array}{l}0 \\
0 \\
0 \\
0 \\
0 \\
0 \\
0\end{array}$ \\
\hline 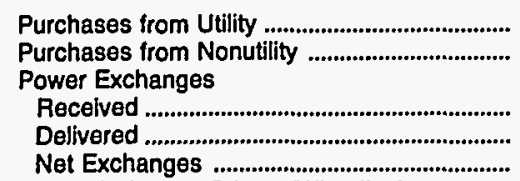 & $\begin{array}{r}170,748 \\
0\end{array}$ & $\begin{array}{r}1,728,081 \\
6,737\end{array}$ & $\begin{array}{r}427,519 \\
0\end{array}$ & $\begin{array}{r}583,712 \\
0\end{array}$ & $\begin{array}{r}213,684 \\
0\end{array}$ & $\begin{array}{r}137,843 \\
21,413\end{array}$ \\
\hline 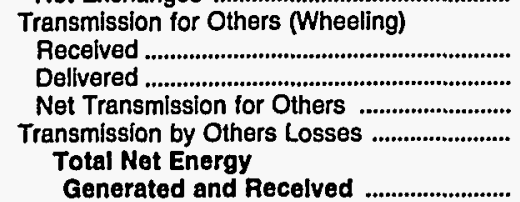 & $\begin{array}{l}0 \\
0 \\
0 \\
0\end{array}$ & $\begin{array}{r}794,328 \\
750,640 \\
43,688 \\
0\end{array}$ & $\begin{array}{l}0 \\
0 \\
0 \\
0\end{array}$ & $\begin{array}{l}0 \\
0 \\
0 \\
0\end{array}$ & $\begin{array}{l}0 \\
0 \\
0 \\
0\end{array}$ & 159,256 \\
\hline 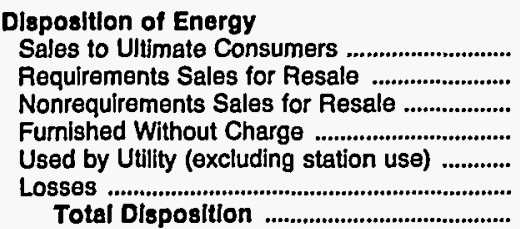 & $\begin{array}{r}148,434 \\
0 \\
0 \\
22,314 \\
0 \\
0 \\
170,748\end{array}$ & $\begin{array}{r}0 \\
10,265,581 \\
0 \\
0 \\
1,294 \\
417,586 \\
10,684,461\end{array}$ & $\begin{array}{r}401,379 \\
0 \\
0 \\
2,449 \\
0 \\
23,691 \\
427,519\end{array}$ & $\begin{array}{r}775,000 \\
0 \\
0 \\
0 \\
0 \\
35,650 \\
810,650\end{array}$ & $\begin{array}{r}203,915 \\
0 \\
0 \\
0 \\
0 \\
9,769 \\
213,684\end{array}$ & $\begin{array}{r}152,651 \\
0 \\
0 \\
3 \\
115 \\
6,487 \\
159,256\end{array}$ \\
\hline
\end{tabular}

Note: Totals may not equal sum of components because of independent rounding. Double counting occurs in components of both sources and disposition of energy and thus neither provides a true total. Purchases from utilities, net interchanges, and net wheeling (except for imports) are included in net generation. Sales for resale is included in sales to ultimate consumers.

Source: Energy Information Administration, Form ElA-412, "Annual Report of Public Electric Utilities." 
Table 26. Electric Energy Account by Major U.S. Publicly Owned Electric Utility Within State, 1993 (Continued)

(Megawatthours)

\begin{tabular}{|c|c|c|c|c|c|c|}
\hline Item & $\begin{array}{c}\text { Illinois } \\
\text { Illinois } \\
\text { Municipal } \\
\text { Elec Agency } \\
\text { April } 30\end{array}$ & $\begin{array}{l}\text { Illinois } \\
\begin{array}{c}\text { Naperville } \\
\text { City of }\end{array} \\
\text { April } 30\end{array}$ & $\begin{array}{l}\text { Illinois } \\
\text { Rochelle } \\
\text { Municipal } \\
\text { Utilities } \\
\text { April } 30\end{array}$ & $\begin{array}{l}\text { Illinois } \\
\begin{array}{c}\text { Springfield } \\
\text { City of }\end{array} \\
\text { February } 28\end{array}$ & $\begin{array}{l}\text { Illinois } \\
\text { St Charles } \\
\text { City of } \\
\text { April } 30\end{array}$ & $\begin{array}{l}\text { Indiana } \\
\text { Anderson } \\
\text { City of } \\
\text { December } 31\end{array}$ \\
\hline \multicolumn{7}{|l|}{ Sources of Energy } \\
\hline Steam & 439,704 & 0 & 5,357 & $1,679,515$ & 0 & 0 \\
\hline 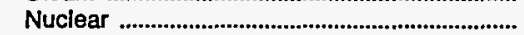 & 0 & 0 & 0 & 0 & 0 & 0 \\
\hline 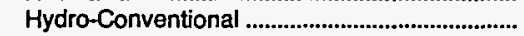 & 0 & 0 & 0 & 0 & 0 & 0 \\
\hline 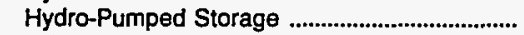 & 0 & 0 & 0 & 0 & 0 & 0 \\
\hline Other & 0 & 0 & 19 & 118 & 0 & 0 \\
\hline (Less) Energy for Pumping ................................... & 0 & 0 & 0 & 0 & 0 & \\
\hline 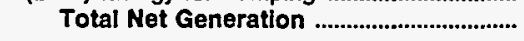 & 439,704 & $\mathbf{0}$ & 5,376 & $1,679,633$ & 0 & 0 \\
\hline Purchases from Utility ................................................. & 936,464 & 626,908 & 155,525 & 16,283 & 343,573 & 655,587 \\
\hline 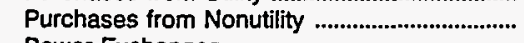 & 0 & 6,692 & 0 & 0 & 0 & \\
\hline Power Exchanges & & & & & & \\
\hline 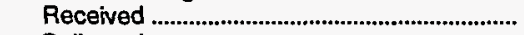 & 0 & 0 & 0 & 0 & 0 & 0 \\
\hline 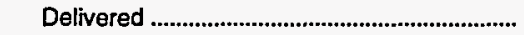 & 0 & 0 & 0 & 0 & 0 & 0 \\
\hline Net Exchanges ......................................................... & 0 & 0 & 0 & 0 & 0 & 0 \\
\hline \multicolumn{7}{|l|}{ Transmission for Others (Wheeling) } \\
\hline 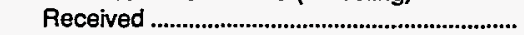 & 0 & 0 & 0 & 0 & 0 & 0 \\
\hline 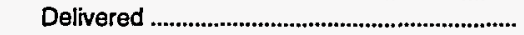 & 0 & 0 & 0 & 0 & 0 & \\
\hline Net Transmission for Others ............................. & 0 & 0 & 0 & 0 & 0 & 0 \\
\hline Transmission by Others Losses .............................. & 0 & 0 & 0 & 0 & 0 & 0 \\
\hline $\begin{array}{l}\text { Total Net Energy } \\
\text { Generated and Received .......................... }\end{array}$ & $1,376,168$ & 633,600 & 160,901 & $1,695,916$ & 343,573 & 655,587 \\
\hline \multicolumn{7}{|l|}{ Disposition of Energy } \\
\hline 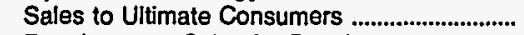 & 0 & 633,600 & 150,626 & $1,447,548$ & 331,787 & 630,092 \\
\hline Requirements Sales for Resale ....................... & $1,300,216$ & 0 & 0 & 136,217 & 0 & \\
\hline Nonrequirements Sales for Resale ..................... & 0 & 0 & 0 & 5,632 & 0 & 0 \\
\hline 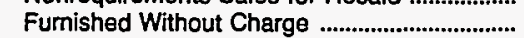 & 0 & 0 & 626 & 17,226 & 0 & 0 \\
\hline Used by Utility (excluding station use) ............ & 0 & 0 & 0 & 3,266 & 0 & 0 \\
\hline 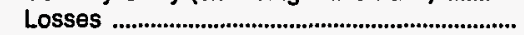 & 75,952 & & 9,649 & 86,027 & 11,786 & 25,495 \\
\hline Total Disposition .................................................. & $1,376,168$ & 633,600 & 160,901 & $1,695,916$ & 343,573 & 655,687 \\
\hline
\end{tabular}

Note: Totals may not equal sum of components because of independent rounding. Double counting occurs in components of both sources and disposition of energy and thus neither provides a true total. Purchases from utilities, net interchanges, and net wheeling (except for imports) are included in net generation. Sales for resale is included in sales to ultimate consumers.

Source: Energy Information Administration, Form EIA-412, "Annual Report of Public Electric Utilities." 
Table 26. Electric Energy Account by Major U.S. Publicly Owned Electric Utility Within State, 1993 (Continued)

(Megawatthours)

\begin{tabular}{|c|c|c|c|c|c|c|}
\hline Item & $\begin{array}{l}\text { Indiana } \\
\text { Auburn } \\
\text { City of } \\
\text { December } 31\end{array}$ & $\begin{array}{l}\text { Indiana } \\
\text { Bluffton } \\
\text { City of } \\
\text { December } 31\end{array}$ & $\begin{array}{c}\text { Indiana } \\
\text { Crawfordsville } \\
\text { Elec } \\
\text { Lgt\&Pwr Co } \\
\text { December } 31\end{array}$ & $\begin{array}{c}\text { Indiana } \\
\text { Frankfort } \\
\text { City of } \\
\text { December } 31\end{array}$ & $\begin{array}{l}\text { Indiana } \\
\text { Greenfield } \\
\text { City of } \\
\text { December } 31\end{array}$ & $\begin{array}{c}\text { Indiana } \\
\text { Indiana } \\
\text { Municipal } \\
\text { Power Agency } \\
\text { December } 31\end{array}$ \\
\hline 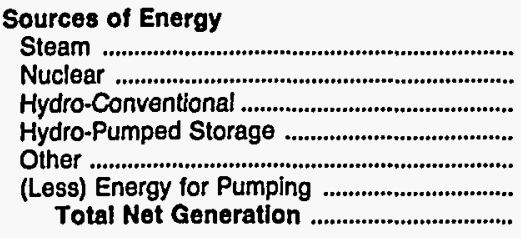 & $\begin{array}{l}0 \\
0 \\
0 \\
0 \\
0 \\
0 \\
0\end{array}$ & $\begin{array}{r}0 \\
0 \\
0 \\
0 \\
5,154 \\
0 \\
5,154\end{array}$ & $\begin{array}{r}14,910 \\
0 \\
0 \\
0 \\
0 \\
0 \\
14,910\end{array}$ & $\begin{array}{l}0 \\
0 \\
0 \\
0 \\
0 \\
0 \\
0\end{array}$ & $\begin{array}{l}0 \\
0 \\
0 \\
0 \\
0 \\
0 \\
0\end{array}$ & $\begin{array}{r}1,296,109 \\
0 \\
0 \\
0 \\
11,727 \\
0 \\
1,307,836\end{array}$ \\
\hline 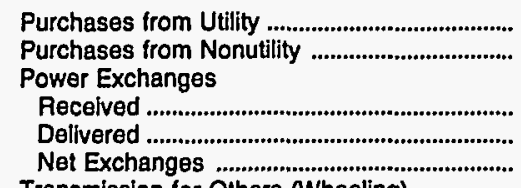 & $\begin{array}{r}346,884 \\
0\end{array}$ & $\begin{array}{r}159,370 \\
0\end{array}$ & $\begin{array}{r}357,918 \\
0 \\
0\end{array}$ & $\begin{array}{r}296,194 \\
0\end{array}$ & $\begin{array}{r}161,695 \\
0\end{array}$ & $\begin{array}{r}2,516,789 \\
0 \\
0\end{array}$ \\
\hline 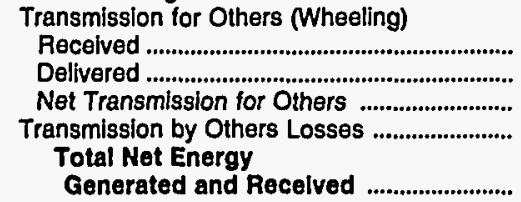 & $\begin{array}{l}0 \\
0 \\
0 \\
0\end{array}$ & $\begin{array}{l}0 \\
0 \\
0 \\
0\end{array}$ & $\begin{array}{l}0 \\
0 \\
0 \\
0\end{array}$ & $\begin{array}{l}0 \\
0 \\
0 \\
0\end{array}$ & $\begin{array}{l}0 \\
0 \\
0 \\
0\end{array}$ & $\begin{array}{r}498,503 \\
498,503 \\
0 \\
0\end{array}$ \\
\hline 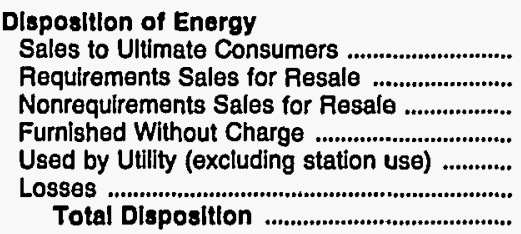 & $\begin{array}{r}337,576 \\
0 \\
0 \\
20 \\
159 \\
9,129 \\
346,884\end{array}$ & $\begin{array}{r}158,548 \\
0 \\
0 \\
0 \\
0 \\
5,976 \\
164,524\end{array}$ & $\begin{array}{r}347,924 \\
14,910 \\
0 \\
0 \\
1,885 \\
8,109 \\
372,828\end{array}$ & $\begin{array}{r}289,101 \\
0 \\
0 \\
0 \\
441 \\
6,651 \\
296,194\end{array}$ & $\begin{array}{r}156,608 \\
0 \\
0 \\
0 \\
0 \\
5,087 \\
161,695\end{array}$ & $\begin{array}{r}0 \\
3,687,880 \\
170 \\
0 \\
2,519 \\
134,056 \\
3,824,625\end{array}$ \\
\hline
\end{tabular}

Note: Totals may not equal sum of components because of independent rounding. Double counting occurs in components of both sources and disposition of energy and thus nelther provides a true total. Purchases from utilities, net interchanges, and net wheeling (except for imports) are included in net generation. Sales for resale is included in sales to ultimate consumers.

Source: Energy Information Administration, Form EIA-412, "Annual Report of Public Electric Utilities." 
Table 26. Electric Energy Account by Major U.S. Publicly Owned Electric Utility Within State, 1993 (Continued)

(Megawatthours)

\begin{tabular}{|c|c|c|c|c|c|c|}
\hline Item & $\begin{array}{l}\text { Indiana } \\
\text { Jasper } \\
\text { City of } \\
\text { December } 31\end{array}$ & $\begin{array}{c}\text { Indiana } \\
\text { Logansport } \\
\text { City of }\end{array}$ & $\begin{array}{c}\text { Indiana } \\
\begin{array}{c}\text { Mishawaka } \\
\text { City of }\end{array} \\
\text { December } 31\end{array}$ & $\begin{array}{c}\text { Indiana } \\
\text { Peru } \\
\text { City of } \\
\text { December } 31\end{array}$ & $\begin{array}{c}\text { Indiana } \\
\text { Richmond } \\
\text { City of } \\
\text { December } 31\end{array}$ & $\begin{array}{c}\text { Indiana } \\
\begin{array}{c}\text { Washington } \\
\text { City of }\end{array} \\
\text { December } 31\end{array}$ \\
\hline \multicolumn{7}{|l|}{ Sources of Energy } \\
\hline Steam ............................. & 52,519 & 127,909 & 0 & 2,211 & 582,081 & \\
\hline 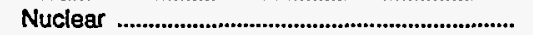 & 0 & 0 & 0 & 0 & 0 & 0 \\
\hline Hydra-Conventional & 0 & 0 & 0 & 0 & 0 & \\
\hline Hydro-Pumped Storage ........................................... & 0 & 0 & 0 & 0 & 0 & 0 \\
\hline Other & 0 & 2,697 & 0 & 0 & 0 & \\
\hline 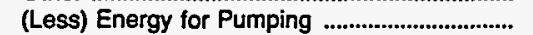 & & & 0 & 0 & 0 & \\
\hline 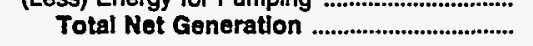 & 52,519 & 130,606 & 0 & 2,211 & 582,081 & \\
\hline Purchases from Utility ............................................... & 215,490 & 195,801 & 455,568 & 197,736 & 200,085 & 164,656 \\
\hline $\begin{array}{l}\text { Purchases from Nonutility .................................. } \\
\text { Power Exchanges }\end{array}$ & 0 & 0 & 0 & 0 & 0 & \\
\hline 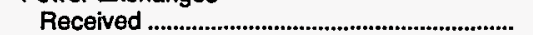 & 0 & 0 & 0 & 0 & 0 & \\
\hline 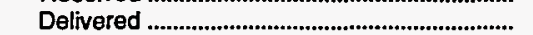 & 0 & 0 & 0 & 0 & 0 & \\
\hline 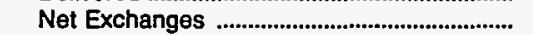 & 0 & 0 & 0 & 0 & 0 & 0 \\
\hline \multicolumn{7}{|l|}{ Transmission for Others (Wheeling) } \\
\hline 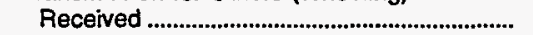 & 0 & 0 & 0 & 0 & 0 & \\
\hline Delivered .......................................... & 0 & 0 & 0 & 0 & 0 & \\
\hline 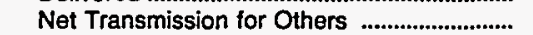 & 0 & 0 & 0 & 0 & 0 & 0 \\
\hline $\begin{array}{c}\text { Transmission by Others Losses ................................. } \\
\text { Total Net Eneray }\end{array}$ & 0 & 0 & 0 & 0 & 0 & 0 \\
\hline 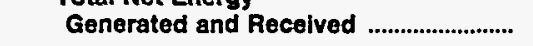 & 268,009 & 326,407 & 455,568 & 199,947 & 782,166 & 164,656 \\
\hline \multicolumn{7}{|l|}{ Disposition of Energy } \\
\hline 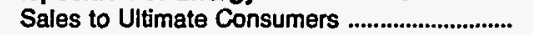 & 255,294 & 308,268 & 425,808 & 187,535 & 749,353 & 144,942 \\
\hline Requirements Sales for Resale ............................. & & & 0 & & 0 & \\
\hline Nonrequirements Sales for Resale .................... & 0 & 0 & 0 & 0 & 0 & 0 \\
\hline 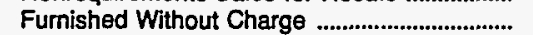 & 71 & 0 & 0 & 0 & 4 & 0 \\
\hline Used by Utility (excluding station use) ............. & 644 & 0 & 0 & 0 & 2,706 & 0 \\
\hline 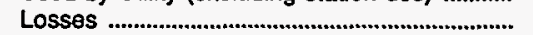 & 12,000 & 18,139 & 29,760 & 12,412 & 30,103 & 19,714 \\
\hline 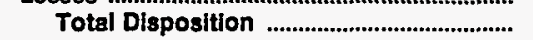 & 268,009 & 326,407 & 455,568 & 199,947 & 782,166 & 164,656 \\
\hline
\end{tabular}

Note: Totals may not equal sum of components because of independent rounding. Double counting occurs in components of both sources and disposition of energy and thus neither provides a true total. Purchases from utilities, net interchanges, and net wheeling (except for imports) are included in net generation. Sales for resale is included in sales to ultimate consumers.

Source: Energy Information Administration, Form ElA-412, "Annual Report of Public Electric Utilities." 
Table 26. Electric Energy Account by Major U.S. Publicly Owned Electric Utility Within State, 1993 (Continued)

(Megawatthours)

\begin{tabular}{|c|c|c|c|c|c|c|}
\hline Item & $\begin{array}{l}\text { lowa } \\
\text { Ames } \\
\text { City of } \\
\text { June } 30\end{array}$ & $\begin{array}{c}\text { lowa } \\
\text { Cedar } \\
\text { Falls } \\
\text { City of } \\
\text { December } 31\end{array}$ & $\begin{array}{c}\text { lowa } \\
\text { Muscatine } \\
\text { City of } \\
\text { December } 31\end{array}$ & $\begin{array}{l}\text { lowa } \\
\text { Pella } \\
\text { City of } \\
\text { June } 30\end{array}$ & $\begin{array}{c}\text { Kansas } \\
\text { Chanute } \\
\text { City of } \\
\text { December } 31\end{array}$ & $\begin{array}{c}\text { Kansas } \\
\text { Coffeyville } \\
\text { City of } \\
\text { December } 31\end{array}$ \\
\hline \multicolumn{7}{|l|}{ Sources of Energy } \\
\hline 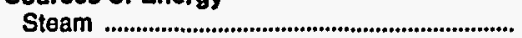 & 280,937 & 243,722 & $1,024,857$ & 64,742 & 0 & 77,276 \\
\hline Nuclear ....................................................................... & 0 & 0 & 0 & 0 & 0 & \\
\hline 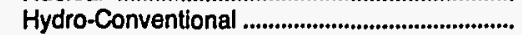 & 0 & 0 & 0 & 0 & 0 & \\
\hline Hydro-Pumped Storage ................................................ & 0 & 0 & 0 & 0 & o & \\
\hline 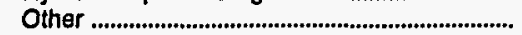 & 0 & 107 & 0 & 0 & 12,167 & \\
\hline 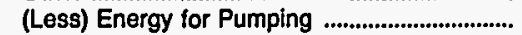 & 0 & & 0 & 0 & 2,161 & \\
\hline 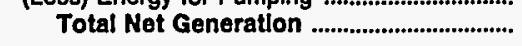 & 280,937 & 243,829 & $1,024,857$ & 64,742 & 10,006 & 77,276 \\
\hline $\begin{array}{l}\text { Purchases from Utility ..................................... } \\
\text { Purchases from Nonutility .............................. } \\
\text { Power Exchanges }\end{array}$ & $\begin{array}{r}115,692 \\
0\end{array}$ & $\begin{array}{r}94,771 \\
2\end{array}$ & $\begin{array}{r}59,323 \\
0\end{array}$ & $\begin{array}{r}72,307 \\
0\end{array}$ & $\begin{array}{r}144,681 \\
0\end{array}$ & $\begin{array}{r}121,259 \\
0\end{array}$ \\
\hline Recelved ................................................................ & 312 & 0 & 0 & 5,587 & 0 & 120,983 \\
\hline Delivered .............................................................. & 225 & 0 & 0 & 5,717 & 0 & 121,259 \\
\hline Net Exchanges ......... & 87 & 0 & 0 & -130 & 0 & -276 \\
\hline \multicolumn{7}{|l|}{ Transmission for Others (Wheeling) } \\
\hline 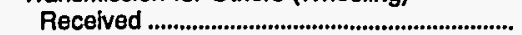 & 0 & 0 & 2,991 & 0 & 0 & \\
\hline 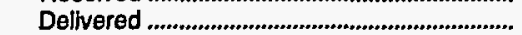 & 0 & 0 & 229 & 0 & 0 & \\
\hline 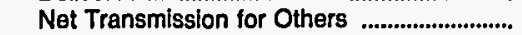 & 0 & 0 & 2,762 & 0 & 0 & \\
\hline 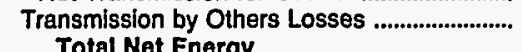 & 0 & 0 & 0 & 0 & 0 & 0 \\
\hline $\begin{array}{l}\text { Total Net Energy } \\
\text { Generated and Recelved .............................. }\end{array}$ & 396,716 & 338,602 & $1,086,942$ & 136,919 & 154,687 & 198,259 \\
\hline \multicolumn{7}{|l|}{ Disposition of Energy } \\
\hline Sales to Ultimate Consumers .............................. & 367,299 & 297,484 & 796,542 & 134,835 & 146,113 & 170,200 \\
\hline Requirements Sales for Resale ........................ & 10,306 & & & & 0 & \\
\hline Nonrequirements Sales for Resale ..................... & & 16,436 & 256,515 & 0 & 0 & \\
\hline 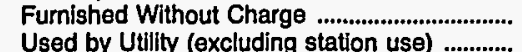 & $\begin{array}{r}0 \\
148\end{array}$ & $\begin{array}{r}0 \\
2,363\end{array}$ & $\begin{array}{r}4,930 \\
2,707\end{array}$ & $\begin{array}{l}0 \\
0\end{array}$ & $\begin{array}{r}0 \\
2,161\end{array}$ & $\begin{array}{l}5,084 \\
1,032\end{array}$ \\
\hline 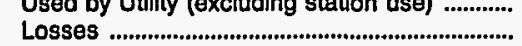 & 18,963 & 22,319 & 26,248 & 2,084 & 6,413 & 21,943 \\
\hline 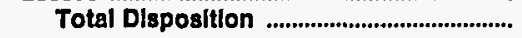 & 396,716 & 338,602 & $1,086,942$ & 136,919 & 154,687 & 198,259 \\
\hline
\end{tabular}

Note: Totals may not equal sum of components because of independent rounding. Double counting occurs in components of both sources and disposition of energy and thus neither provides a true total. Purchases from utilities, net interchanges, and net wheeling (except for imports) are included in net generation. Sales for resale is included in sales to ultimate consumers.

Source: Energy Information Administration, Form EIA-412, "Annual Report of Public Electric Utilities." 
Table 26. Electric Energy Account by Major U.S. Publicly Owned Electric Utility Within State, 1993 (Continued)

(Megawatthours)

\begin{tabular}{|c|c|c|c|c|c|c|}
\hline Item & $\begin{array}{c}\text { Kansas } \\
\text { Garden } \\
\text { City City of } \\
\text { December } 31\end{array}$ & $\begin{array}{l}\text { Kansas } \\
\text { Kansas } \\
\text { City City of } \\
\text { December } 31\end{array}$ & $\begin{array}{c}\text { Kansas } \\
\text { Kansas } \\
\text { Municipal } \\
\text { Energy } \\
\text { Agency } \\
\text { December } 31\end{array}$ & $\begin{array}{l}\text { Kansas } \\
\text { McPherson } \\
\text { City of } \\
\text { December } 31\end{array}$ & $\begin{array}{c}\text { Kansas } \\
\text { Winfield } \\
\text { City of } \\
\text { December } 31\end{array}$ & $\begin{array}{l}\text { Kentucky } \\
\text { Bowling } \\
\text { Green } \\
\text { City of } \\
\text { June } 30\end{array}$ \\
\hline \multicolumn{7}{|l|}{ Sources of Energy } \\
\hline Steam …….............................. & 0 & $2,332,119$ & 0 & 1,297 & 29,878 & \\
\hline Nuclear & 0 & 0 & 0 & 0 & 0 & \\
\hline 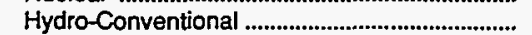 & 0 & 0 & 0 & 0 & $\mathbf{0}$ & \\
\hline 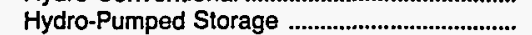 & 0 & 0 & 0 & 0 & 0 & 0 \\
\hline Other & 0 & 492 & 0 & 3,530 & 0 & 0 \\
\hline 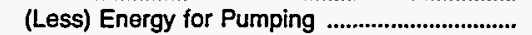 & 0 & 0 & 0 & 0 & 0 & \\
\hline Total Net Generation & 0 & $2,332,611$ & o & 4,827 & 29,878 & 0 \\
\hline Purchases from Utility & 170,768 & 289,672 & 323,038 & 512,107 & 211,217 & 649,794 \\
\hline $\begin{array}{l}\text { Purchases from Nonutility } \\
\text { Power Exchanges }\end{array}$ & 0 & 0 & 0 & 0 & 0 & \\
\hline 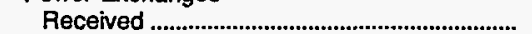 & 0 & 0 & 0 & 0 & 0 & \\
\hline Delivered ....…………………………………….. & 0 & 11,008 & 0 & 0 & 0 & 0 \\
\hline 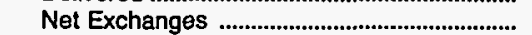 & 0 & $-11,008$ & 0 & 0 & 0 & 0 \\
\hline \multicolumn{7}{|l|}{ Transmission for Others (Wheeling) } \\
\hline 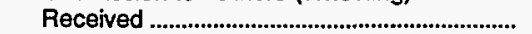 & 0 & 0 & 0 & 0 & 0 & \\
\hline Delivered ................................................................... & 0 & 0 & 0 & 0 & 0 & 0 \\
\hline 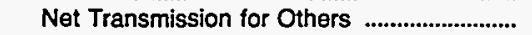 & 0 & 0 & 0 & 0 & 0 & 0 \\
\hline $\begin{array}{l}\text { Transmission by Others Losses ...................................... } \\
\text { Total Net Energy }\end{array}$ & 0 & 0 & 0 & 0 & 0 & 0 \\
\hline 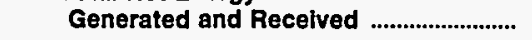 & 170,768 & $2,611,275$ & 323,038 & 516,934 & 241,095 & 649,794 \\
\hline \multicolumn{7}{|l|}{ Disposition of Energy } \\
\hline 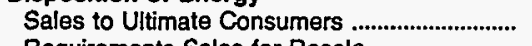 & 146,384 & $1,959,033$ & 0 & 474,743 & 215,650 & 625,499 \\
\hline Requirements Sales for Resale ............................. & 0 & 399,838 & 323,038 & 26,033 & 4,742 & \\
\hline 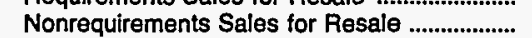 & 0 & 0 & 0 & 0 & 0 & \\
\hline Furnished Without Charge .................................... & 4,813 & 175,548 & 0 & 109 & 0 & 0 \\
\hline Used by Utility (excluding station use) .............. & 9,441 & & 0 & 0 & 4,848 & 937 \\
\hline 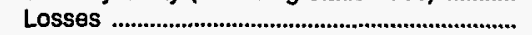 & 10,130 & 76,856 & & 16,049 & 15,855 & 23,356 \\
\hline Total Disposition & 170,768 & $2,611,275$ & 323,038 & 516,934 & 241,095 & 649,794 \\
\hline
\end{tabular}

Note: Totals may not equal sum of components because of independent rounding. Double counting occurs in components of both sources and disposition of energy and thus neither provides a true total. Purchases from utilities, net interchanges, and net wheeling (except for imports) are included in net generation. Sales for resale is included in sales to ultimate consumers.

Source: Energy Information Administration, Form ElA-412, "Annual Report of Public Electric Utilities." 
Table 26. Electric Energy Account by Major U.S. Publicly Owned Electric Utility Within State, 1993 (Continued)

(Megawatthours)

\begin{tabular}{|c|c|c|c|c|c|c|}
\hline Item & $\begin{array}{l}\text { Kentucky } \\
\text { Frankfort } \\
\text { City of } \\
\text { June } 30\end{array}$ & $\begin{array}{l}\text { Kentucky } \\
\text { Franklin } \\
\text { City of } \\
\text { June } 30\end{array}$ & $\begin{array}{l}\text { Kentucky } \\
\text { Glasgow } \\
\text { City of } \\
\text { June } 30\end{array}$ & $\begin{array}{l}\text { Kentucky } \\
\text { Henderson } \\
\text { City } \\
\text { Utility Comm } \\
\text { May } 31\end{array}$ & $\begin{array}{l}\text { Kentucky } \\
\text { Hopkinsville } \\
\text { City of } \\
\text { June } 30\end{array}$ & $\begin{array}{l}\text { Kentucky } \\
\text { Madisonville } \\
\text { Municipal } \\
\text { Utils } \\
\text { June } 30\end{array}$ \\
\hline \multicolumn{7}{|l|}{ Sources of Energy } \\
\hline Steam & 0 & 0 & $\mathbf{0}$ & $1,710,199$ & 0 & 0 \\
\hline Nuclear .......................................................................... & 0 & 0 & 0 & 0 & 0 & 0 \\
\hline 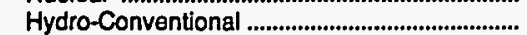 & 0 & 0 & 0 & 0 & 0 & 0 \\
\hline 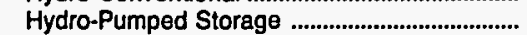 & 0 & 0 & 0 & 0 & 0 & 0 \\
\hline 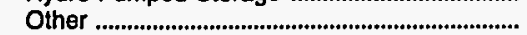 & 0 & 0 & 0 & 0 & 0 & 0 \\
\hline 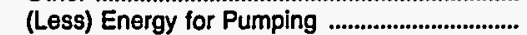 & 0 & 0 & 0 & 0 & 0 & 0 \\
\hline 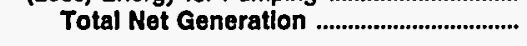 & 0 & 0 & 0 & $1,710,199$ & $\mathbf{0}$ & 0 \\
\hline 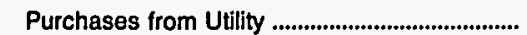 & 587,216 & 193,991 & 288,950 & 21,388 & 401,101 & 262,085 \\
\hline Purchases from Nonutility .................................. & 0 & 0 & 0 & 0 & 0 & 0 \\
\hline Power Exchanges & & & & & & \\
\hline 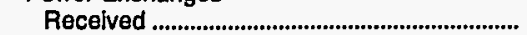 & 0 & 0 & 0 & 0 & 0 & 0 \\
\hline Delivered ............................................................. & 0 & 0 & 0 & 0 & 0 & 0 \\
\hline 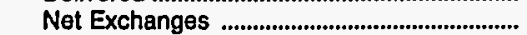 & 0 & 0 & 0 & 0 & 0 & 0 \\
\hline \multicolumn{7}{|l|}{ Transmission for Others (Wheeling) } \\
\hline 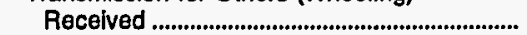 & 0 & 0 & 0 & 0 & 0 & 0 \\
\hline Delivered .............................................................. & 0 & 0 & 0 & 0 & 0 & 0 \\
\hline Net Transmission for Others .............................. & 0 & 0 & 0 & 0 & 0 & 0 \\
\hline \multirow{2}{*}{$\begin{array}{l}\text { Transmission by Others Losses .......................... } \\
\text { Total Net Energy }\end{array}$} & 0 & 0 & 0 & 0 & 0 & 0 \\
\hline & 587,216 & 193,991 & 288,950 & $1,731,587$ & 401,101 & 262,085 \\
\hline \multicolumn{7}{|l|}{ Dlsposittion of Energy } \\
\hline 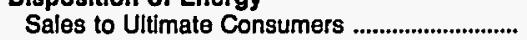 & 548,311 & 188,169 & 274,192 & 366,535 & 385,925 & 254,483 \\
\hline Requirements Sales for Resale ........................... & 0 & 0 & 0 & $1,333,940$ & 0 & 0 \\
\hline Nonrequirements Sales for Resale ..................... & 0 & 0 & 0 & 0 & 0 & 0 \\
\hline Furnished Without Charge .................................. & 0 & 0 & 0 & 6,174 & 0 & 0 \\
\hline Used by Utility (excluding station use) ............. & 0 & 229 & 678 & 398 & 422 & 0 \\
\hline 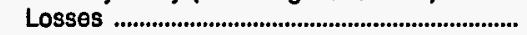 & 38,905 & 5,592 & 14,079 & 24,540 & 14,753 & 7,602 \\
\hline Total Dlsposittlon & 587,216 & 193,991 & 288,950 & $1,731,587$ & 401,101 & 262,085 \\
\hline
\end{tabular}

Note: Totals may not equal sum of components because of independent rounding. Double counting occurs in components of both sources and disposition of energy and thus neither provides a true total. Purchases from utilities, net interchanges, and net wheeling (except for imports) are included in net generation. Sales for resale is included in sales to ultimate consumers.

Source: Energy Information Administration, Form ElA-412, "Annual Report of Public Electric Utilities." 
Table 26. Electric Energy Account by Major U.S. Publicly Owned Electric Utility Within State, 1993 (Continued)

(Megawatthours)

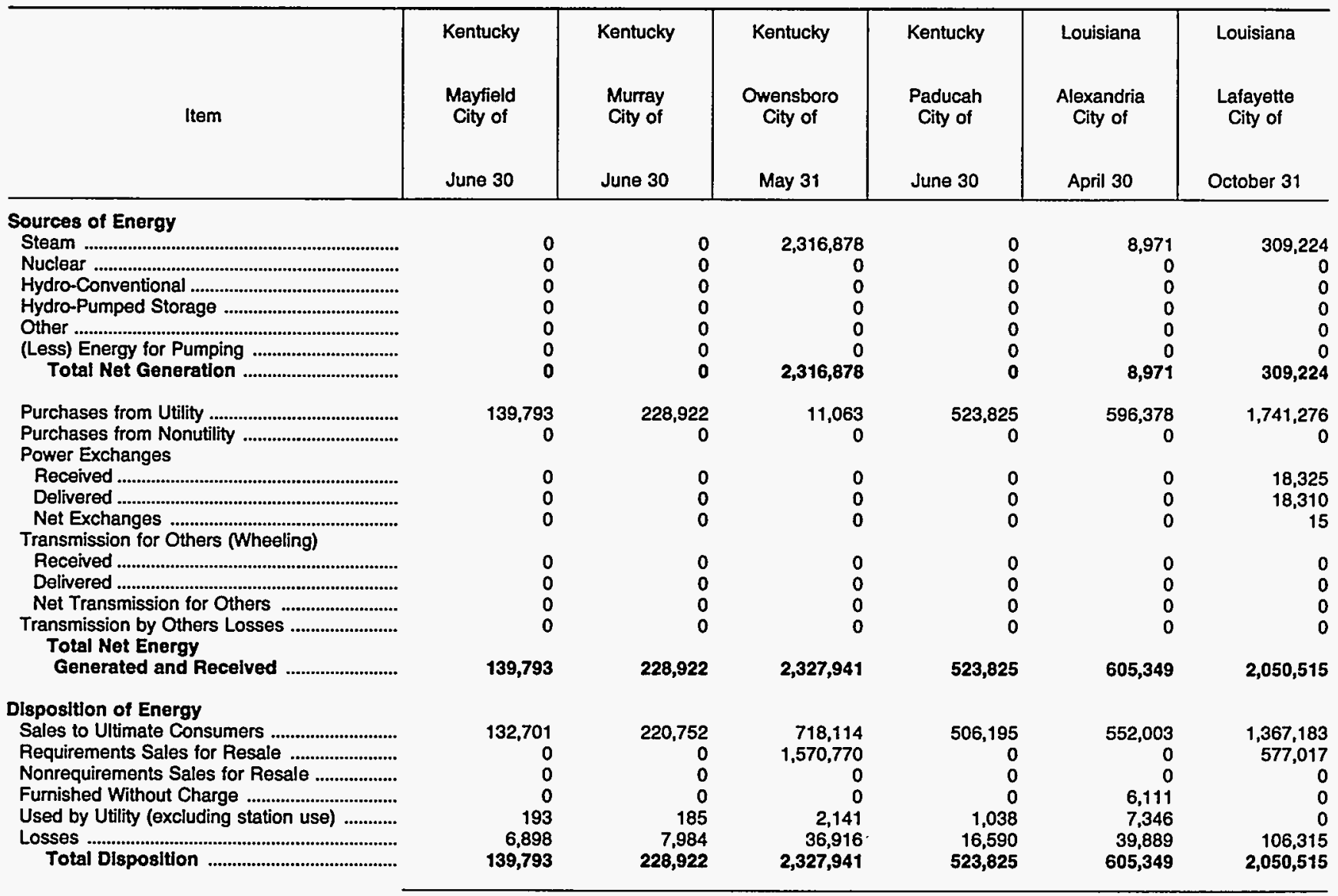

Note: Totals may not equal sum of components because of independent rounding. Double counting occurs in components of both sources and disposition of energy and thus neither provides a true total. Purchases from utilities, net interchanges, and net wheeling (except for imports) are included in net generation. Sales for resale is included in sales to ultimate consumers.

Source: Energy Information Administration, Form EIA-412, "Annual Report of Public Electric Utilities." 
Table 26. Electric Energy Account by Major U.S. Publicly Owned Electric Utility Within State, 1993 (Continued)

(Megawatthours)

\begin{tabular}{|c|c|c|c|c|c|c|}
\hline Item & $\begin{array}{l}\text { Louisiana } \\
\text { Lafayette } \\
\text { Public } \\
\text { Power Auth } \\
\text { October } 31\end{array}$ & $\begin{array}{l}\text { Louisiana } \\
\text { Louisiana } \\
\text { Energy } \\
\text { \& } \\
\text { Power Auth } \\
\text { December } 31\end{array}$ & $\begin{array}{l}\text { Louisiana } \\
\text { Morgan } \\
\text { City City of } \\
\text { December } 31\end{array}$ & $\begin{array}{l}\text { Louisiana } \\
\begin{array}{c}\text { Natchitoches } \\
\text { City of }\end{array} \\
\text { May } 31\end{array}$ & $\begin{array}{l}\text { Louisiana } \\
\text { Ruston } \\
\text { City of } \\
\text { September } 30\end{array}$ & $\begin{array}{c}\text { Louisiana } \\
\text { Terrebonne } \\
\text { Parish } \\
\text { Consol Govt } \\
\text { December } 31\end{array}$ \\
\hline \multicolumn{7}{|l|}{ Sources of Energy } \\
\hline Steam & $1,516,398$ & 735,311 & 1 & 0 & 156,801 & 113,244 \\
\hline 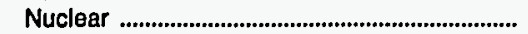 & 0 & 0 & 0 & 0 & & 0 \\
\hline 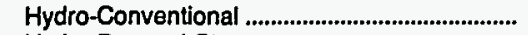 & 0 & 0 & 0 & 0 & 0 & 0 \\
\hline 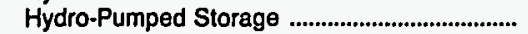 & 0 & $\mathbf{0}$ & 0 & 0 & 0 & 0 \\
\hline Other & 0 & 0 & 0 & 0 & 0 & 0 \\
\hline 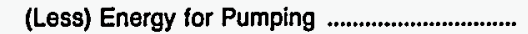 & 0 & $\mathbf{0}$ & $\mathbf{0}$ & 0 & & \\
\hline 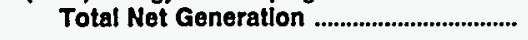 & $1,516,398$ & 735,311 & 1 & 0 & 156,801 & 113,244 \\
\hline 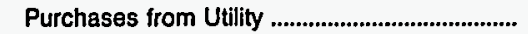 & 0 & 852,519 & 164,730 & 212,005 & 72,358 & 237,360 \\
\hline 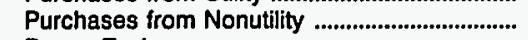 & 0 & 0 & & 0 & 0 & 0 \\
\hline \multicolumn{7}{|l|}{ Power Exchanges } \\
\hline 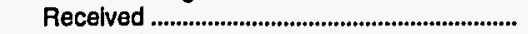 & 0 & 0 & 0 & 0 & 0 & 0 \\
\hline 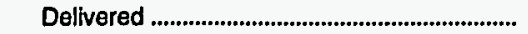 & 0 & $\mathbf{0}$ & $\mathbf{0}$ & 0 & 0 & $\mathbf{0}$ \\
\hline Net Exchanges ............................................................... & 0 & 0 & 0 & 0 & 0 & 0 \\
\hline \multicolumn{7}{|l|}{ Transmission for Others (Wheeling) } \\
\hline 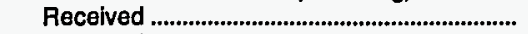 & 0 & 0 & 0 & 0 & 0 & 0 \\
\hline 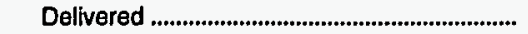 & 0 & 0 & 0 & 0 & 0 & 0 \\
\hline 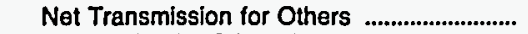 & 0 & 0 & 0 & 0 & 0 & $\mathbf{0}$ \\
\hline \multirow{3}{*}{$\begin{array}{l}\text { Transmission by Others Losses ............................ } \\
\text { Total Net Energy } \\
\text { Generated and Received ............................ }\end{array}$} & 0 & 0 & 0 & 0 & 0 & 0 \\
\hline & & & & & & \\
\hline & $1,516,398$ & $1,587,830$ & 164,731 & 212,005 & 229,159 & 350,604 \\
\hline \multicolumn{7}{|l|}{ Dlspositton of Energy } \\
\hline 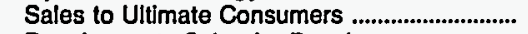 & 0 & $\mathbf{0}$ & 157,892 & 184,284 & 202,003 & 219,956 \\
\hline Requirements Sales for Resale ............................. & $1,480,868$ & $1,537,920$ & 0 & 0 & 0 & 113,244 \\
\hline Nonrequirements Sales for Resale ................... & 0 & 0 & 0 & 0 & 0 & 0 \\
\hline Furnished Without Charge ..................................... & 0 & 0 & 0 & 0 & 8,192 & 0 \\
\hline Used by Utility (excluding station use) ............. & 0 & 0 & 0 & 0 & 0 & 0 \\
\hline 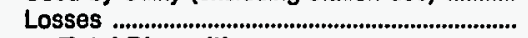 & 35,530 & 49,910 & 6,839 & 27,721 & 18,964 & 17,404 \\
\hline 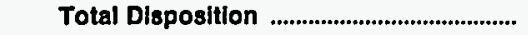 & $1,516,398$ & $1,587,830$ & 164,731 & 212,005 & 229,159 & 350,604 \\
\hline
\end{tabular}

Note: Totals may not equal sum of components because of independent rounding. Double counting occurs in components of both sources and disposition of energy and thus neither provides a true total. Purchases from utilities, net interchanges, and net wheeling (except for imports) are included in net generation. Sales for resale is included in sales to ultimate consumers.

Source: Energy Information Administration, Form ElA-412, "Annual Report of Public Electric Utilities." 
Table 26. Electric Energy Account by Major U.S. Publicly Owned Electric Utility Within State, 1993 (Continued)

(Megawatthours)

\begin{tabular}{|c|c|c|c|c|c|c|}
\hline Item & $\begin{array}{l}\text { Maryland } \\
\text { Easton } \\
\text { Utilities } \\
\text { Comm } \\
\text { June } 30\end{array}$ & $\begin{array}{l}\text { Maryland } \\
\text { Hagerstown } \\
\text { City of } \\
\text { June } 30\end{array}$ & $\begin{array}{c}\text { Massachusetts } \\
\text { Braintree } \\
\text { Town of } \\
\text { December } 31\end{array}$ & $\begin{array}{l}\text { Massachusetts } \\
\text { Chicopee } \\
\text { City of } \\
\text { December } 31\end{array}$ & $\begin{array}{l}\text { Massachusetts } \\
\text { Concord } \\
\text { Town of } \\
\text { December } 31\end{array}$ & $\begin{array}{l}\text { Massachusetts } \\
\text { Danvers } \\
\text { Town of } \\
\text { December } 31\end{array}$ \\
\hline \multicolumn{7}{|l|}{ Sources of Energy } \\
\hline Steam & 0 & 0 & 50,995 & 0 & 0 & 0 \\
\hline 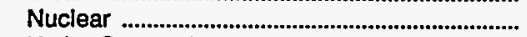 & 0 & 0 & 0 & 88.014 & 0 & 0 \\
\hline 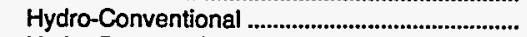 & 0 & 0 & 0 & 0 & 0 & 0 \\
\hline 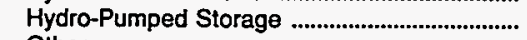 & 0 & 0 & 0 & 0 & 0 & 0 \\
\hline Other & 21,499 & 0 & 111 & 254 & 0 & 0 \\
\hline 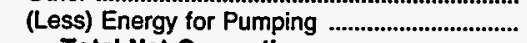 & & 0 & 0 & 0 & 0 & 0 \\
\hline 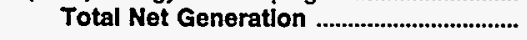 & 21,499 & 0 & 51,106 & 88,268 & 0 & $\mathbf{0}$ \\
\hline 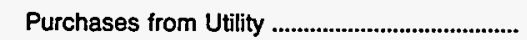 & 0 & 309,264 & 328,615 & 281,687 & 147,291 & 274,406 \\
\hline 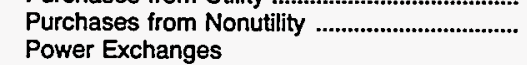 & 0 & 0 & 0 & 0 & 0 & \\
\hline 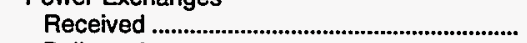 & 181,923 & 0 & 71,117 & 59,627 & 0 & 80,447 \\
\hline Delivered & 789 & 0 & 46,848 & 4,344 & 0 & 42,994 \\
\hline 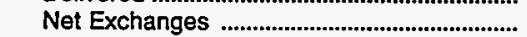 & 181,134 & 0 & 24,269 & 55,284 & 0 & 37,454 \\
\hline \multicolumn{7}{|l|}{ Transmission for Others (Wheeling) } \\
\hline 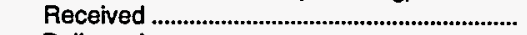 & 0 & 0 & 0 & 0 & 0 & 0 \\
\hline 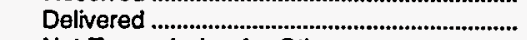 & 0 & 0 & 0 & 0 & 0 & 0 \\
\hline 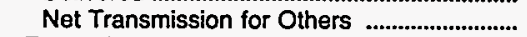 & 0 & 0 & 0 & 0 & 0 & 0 \\
\hline $\begin{array}{l}\text { Transmission by Others Losses ............................ } \\
\text { Total Net Energy }\end{array}$ & 0 & 0 & 0 & 0 & 0 & 0 \\
\hline 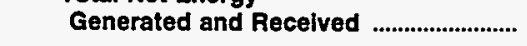 & 202,633 & 309,264 & 403,990 & 425,239 & 147,291 & 311,860 \\
\hline \multicolumn{7}{|l|}{ Dlsposition of Energy } \\
\hline Sales to Ultimate Consumers & 194,264 & 294,760 & 355,474 & 376,697 & 140,467 & 293,813 \\
\hline 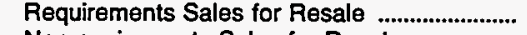 & 1,606 & & 28,251 & 22,468 & 0 & 2,348 \\
\hline Nonrequirements Sales for Resale .................... & 0 & 0 & 0 & 0 & 0 & 0 \\
\hline Furnished Without Charge & 22 & 0 & 0 & 0 & 0 & 155 \\
\hline Used by Utility (excluding station use) .................. & 247 & 711 & 4,190 & 1,250 & 374 & 698 \\
\hline 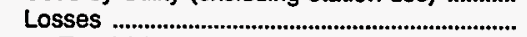 & 6,494 & 13,793 & 16,075 & 24,822 & 6,450 & 14,846 \\
\hline Total Dlsposittion & 202,633 & 309,264 & 403,990 & 425,239 & 147,291 & 311,860 \\
\hline
\end{tabular}

Note: Totals may not equal sum of components because of independent rounding. Double counting occurs in components of both sources and disposition of energy and thus neither provides a true total. Purchases from utilities, net interchariges, and net wheeling (except for imports) are included in net generation. Sales for resale is included in sales to ultimate consumers.

Source: Energy Information Administration, Form EIA-412, "Annual Report of Public Electric Utilities." 
Table 26. Electric Energy Account by Major U.S. Publicly Owned Electric Utility Within State, 1993 (Continued)

(Megawatthours)

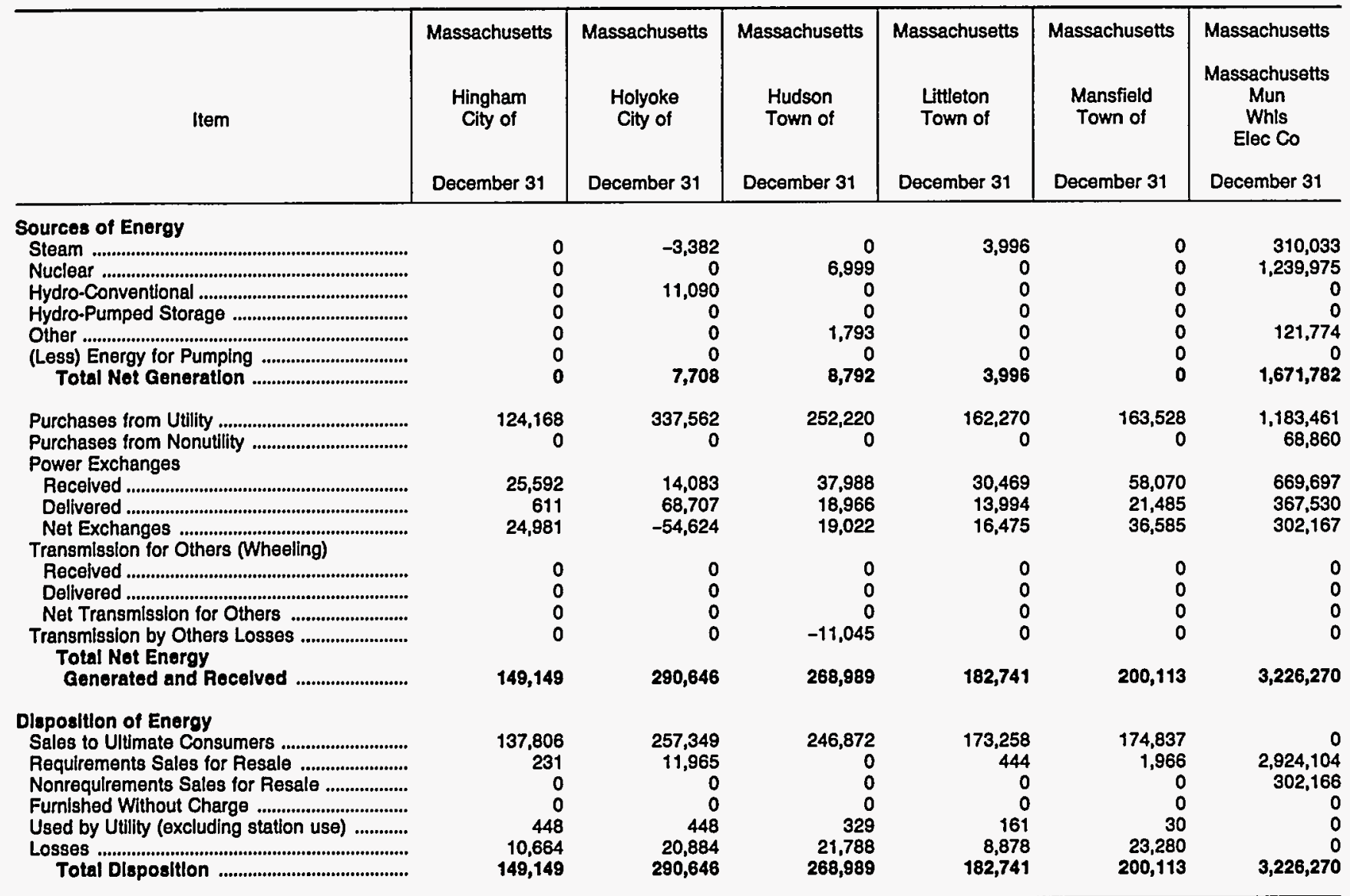

Note: Totals may not equal sum of components because of independent rounding. Double counting occurs in components of both sources and disposition of energy and thus neither provides a true total. Purchases from utilities, net interchanges, and net wheeling (except for imports) are included in net generation. Sales for resale is included in sales to ultimate consumers.

Source: Energy Information Administration, Form EIA-412, "Annual Report of Public Electric Utilities." 
Table 26. Electric Energy Account by Major U.S. Publicly Owned Electric Utility Within State, 1993 (Continued) (Megawatthours)

\begin{tabular}{|c|c|c|c|c|c|c|}
\hline Item & $\begin{array}{l}\text { Massachusetts } \\
\text { Middleborough } \\
\text { Town of } \\
\text { December } 31\end{array}$ & $\begin{array}{l}\text { Massachusetts } \\
\text { North } \\
\text { Attleborough } \\
\text { Town of } \\
\text { December } 31\end{array}$ & $\begin{array}{l}\text { Massachusetts } \\
\text { Norwood } \\
\text { City of } \\
\text { June } 30\end{array}$ & $\begin{array}{l}\text { Massachusetts } \\
\text { Peabody } \\
\text { City of } \\
\text { December } 31\end{array}$ & $\begin{array}{l}\text { Massachusetts } \\
\text { Reading } \\
\text { Town of } \\
\text { December } 31\end{array}$ & $\begin{array}{l}\text { Massachusetts } \\
\text { Shrewsbury } \\
\text { Town of } \\
\text { December } 31\end{array}$ \\
\hline \multicolumn{7}{|l|}{ Sources of Energy } \\
\hline Steam & 0 & 8,056 & 0 & 0 & 0 & \\
\hline 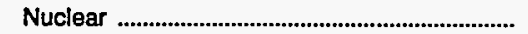 & 0 & 0 & 0 & 0 & 0 & \\
\hline 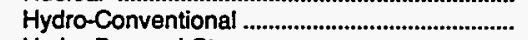 & 0 & 0 & 0 & 0 & 0 & \\
\hline 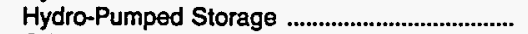 & 0 & 0 & 0 & 0 & 0 & 0 \\
\hline Other & 0 & 0 & 0 & 3,607 & 0 & 462 \\
\hline (Less) Energy for Pumping ...................................... & 0 & 0 & 0 & 0 & 0 & \\
\hline 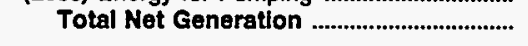 & 0 & 8,056 & 0 & 3,607 & 0 & 462 \\
\hline Purchases from Utility & 176,285 & 119,698 & 322,653 & 339,657 & 490,340 & 220,965 \\
\hline Purchases from Nonutility ....................................... & & & 0 & 621 & 0 & \\
\hline Power Exchanges & & & & & & \\
\hline 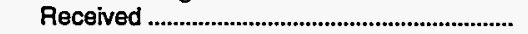 & 0 & 84,415 & 0 & 120,701 & 159,086 & 62,948 \\
\hline 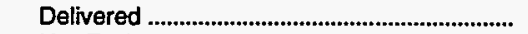 & 2,280 & 14,228 & 0 & 64,634 & 48,591 & 17,207 \\
\hline Net Exchanges & $-2,280$ & 70,187 & 0 & 56,067 & 110,495 & 45,741 \\
\hline \multicolumn{7}{|l|}{ Transmission for Others (Wheeling) } \\
\hline 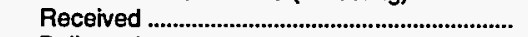 & 0 & 0 & 0 & 0 & 0 & \\
\hline 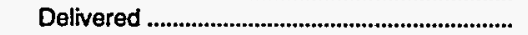 & 0 & 0 & 0 & 0 & 0 & 0 \\
\hline 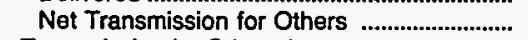 & 0 & 0 & 0 & 0 & 0 & \\
\hline Transmission by Others Losses ............................... & 0 & 0 & 0 & 0 & 0 & \\
\hline $\begin{array}{l}\text { Total Net Energy } \\
\text { Generated and Recelved }\end{array}$ & & & & & & \\
\hline 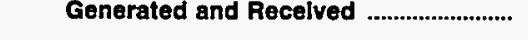 & 174,004 & 197,941 & 322,653 & 399,952 & 600,835 & 267,168 \\
\hline \multicolumn{7}{|l|}{ Disposition of Energy } \\
\hline 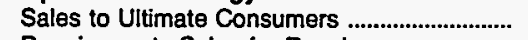 & 165,897 & 184,374 & 310,230 & 379,012 & 554,555 & 242,807 \\
\hline Requirements Sales for Resale & 21 & 0 & 0 & 1,123 & 575 & 1,193 \\
\hline Nonrequirements Sales for Resale ....................... & 0 & 113 & 0 & 0 & 0 & \\
\hline Furnished Without Charge ..................................... & 0 & 0 & 0 & 11 & 0 & \\
\hline Used by Utility (excluding station use) .............. & 0 & 30 & 0 & 1,611 & 803 & 1,270 \\
\hline Losses & 8,085 & 13,434 & 12,423 & 18,194 & 44,902 & 21,898 \\
\hline Total Dlsposition & 174,004 & 197,941 & 322,653 & 399,952 & 600,835 & 267,168 \\
\hline
\end{tabular}


Table 26. Electric Energy Account by Major U.S. Publicly Owned Electric Utility Within State, 1993 (Continued) (Megawatthours)

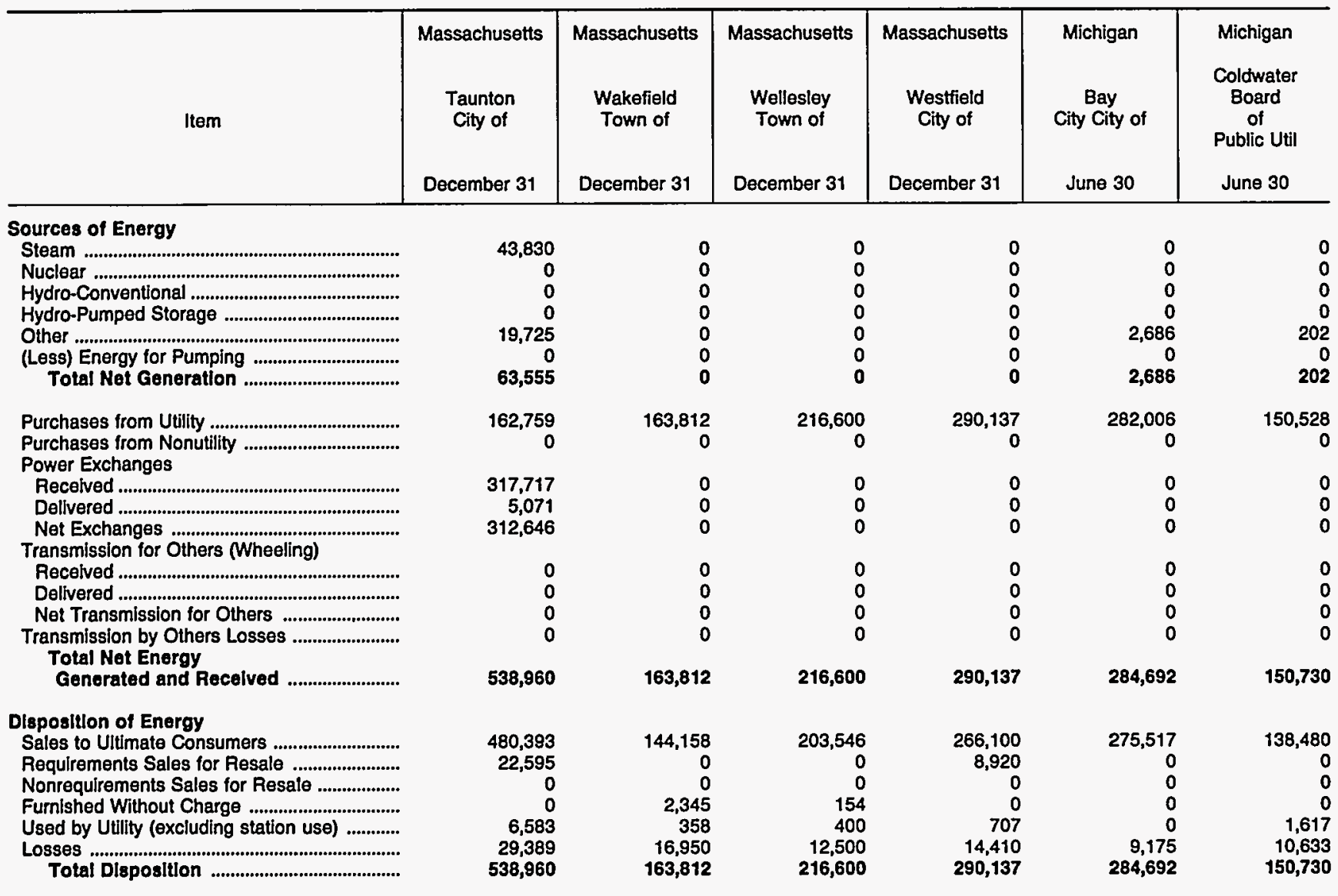

Note: Totals may not equal sum of components because of independent rounding. Double counting occurs in components of both sources and disposition of energy and thus neither provides a true total. Purchases from utilities, net interchanges, and net wheeling (except for imports) are included in net generation. Sales for resale is included in sales to ultimate consumers.

Source: Energy Information Administration, Form ElA-412, "Annual Report of Public Electric Utilities." 
Table 26. Electric Energy Account by Major U.S. Publicly Owned Electric Utility Within State, 1993 (Continued)

(Megawatthours)

\begin{tabular}{|c|c|c|c|c|c|c|}
\hline Item & $\begin{array}{l}\text { Michigan } \\
\text { Detroit } \\
\text { City of } \\
\text { June } 30\end{array}$ & $\begin{array}{l}\text { Michigan } \\
\text { Grand Haven } \\
\text { City of } \\
\text { June } 30\end{array}$ & $\begin{array}{l}\text { Michigan } \\
\text { Hillsdale } \\
\text { Board } \\
\text { of } \\
\text { Public Wks } \\
\text { June } 30\end{array}$ & $\begin{array}{l}\text { Michigan } \\
\text { Holland } \\
\text { City of } \\
\text { June } 30\end{array}$ & $\begin{array}{l}\text { Michigan } \\
\text { Lansing } \\
\text { City of } \\
\text { June } 30\end{array}$ & $\begin{array}{l}\text { Michigan } \\
\text { Marquette } \\
\text { City of } \\
\text { June } 30\end{array}$ \\
\hline \multicolumn{7}{|l|}{ Sources of Energy } \\
\hline Steam & 245,552 & 329,148 & 0 & 323,146 & $1,859,196$ & 222,679 \\
\hline 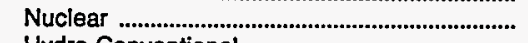 & 0 & 0 & 0 & 0 & & 0 \\
\hline 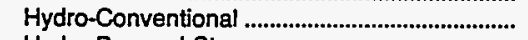 & 0 & 0 & 0 & 0 & 3,790 & 18,713 \\
\hline 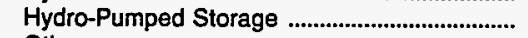 & 0 & 0 & 0 & 0 & 0 & 0 \\
\hline Other & 0 & 21,100 & 589 & 1,921 & 0 & -100 \\
\hline 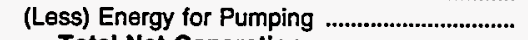 & 0 & & 0 & 0 & 0 & 0 \\
\hline 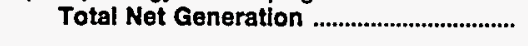 & 245,552 & 350,248 & 589 & 325,067 & $1,862,986$ & 241,292 \\
\hline 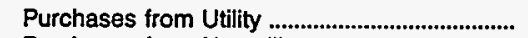 & 445,967 & 34,406 & 137,133 & 355,762 & 539,640 & 13,123 \\
\hline $\begin{array}{l}\text { Purchases from Nonutility ..................................... } \\
\text { Power Exchanges }\end{array}$ & 0 & 0 & 0 & 0 & 0 & 0 \\
\hline 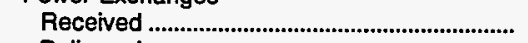 & 0 & 0 & 0 & 0 & 88 & 0 \\
\hline 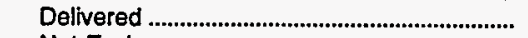 & 0 & 0 & 0 & 0 & 54 & 0 \\
\hline Net Exchanges & 0 & 0 & 0 & 0 & 34 & 0 \\
\hline \multicolumn{7}{|l|}{ Transmission for Others (Wheeling) } \\
\hline 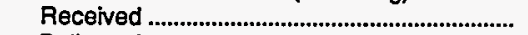 & 0 & 0 & 0 & 0 & 0 & 0 \\
\hline 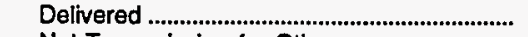 & 0 & 0 & 0 & 0 & 0 & 0 \\
\hline Net Transmission for Others ................................. & 0 & 0 & 0 & 0 & 0 & 0 \\
\hline $\begin{array}{l}\text { Transmission by Others Losses ............................ } \\
\text { Total Net Energy }\end{array}$ & 0 & 0 & 0 & 0 & 0 & 0 \\
\hline 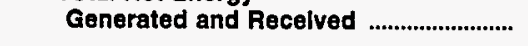 & 691,519 & 384,654 & 137,722 & 680,829 & $2,402,660$ & 254,415 \\
\hline \multicolumn{7}{|l|}{ Disposition of Energy } \\
\hline 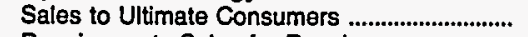 & 521,116 & 236,651 & 129,074 & 650,482 & $2,128,385$ & 229,371 \\
\hline & & & 0 & 0 & 192,264 & 11,152 \\
\hline Nonrequirements Sales for Resale .................... & 0 & 141,459 & 0 & 0 & 0 & 0 \\
\hline 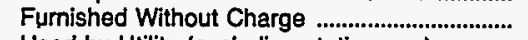 & 128,346 & 0 & 0 & 0 & 0 & 0 \\
\hline Used by Utility (excluding station use) ............. & 4,553 & 397 & 0 & 0 & 0 & 683 \\
\hline 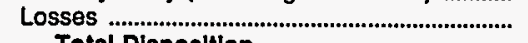 & $\begin{array}{r}37,504 \\
601,510\end{array}$ & $\begin{array}{r}6,147 \\
\end{array}$ & $\begin{array}{r}8,648 \\
\end{array}$ & 30,347 & 82,011 & 13,229 \\
\hline 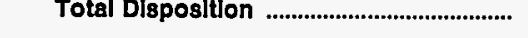 & 691,519 & 384,654 & 137,722 & 680,829 & $2,402,660$ & 254,415 \\
\hline
\end{tabular}

Note: Totals may not equal sum of components because of independent rounding. Double counting occurs in components of both sources and disposition of energy and thus neither provides a true total. Purchases from utilities, net interchanges, and net wheeling (except for imports) are included in net generation. Sales for resale is included in sales to ultimate consumers.

Source: Energy Information Administration, Form EIA-412, "Annual Report of Public Electric Utilities." 
Table 26. Electric Energy Account by Major U.S. Publicly Owned Electric Utility Within State, 1993 (Continued)

(Megawatthours)

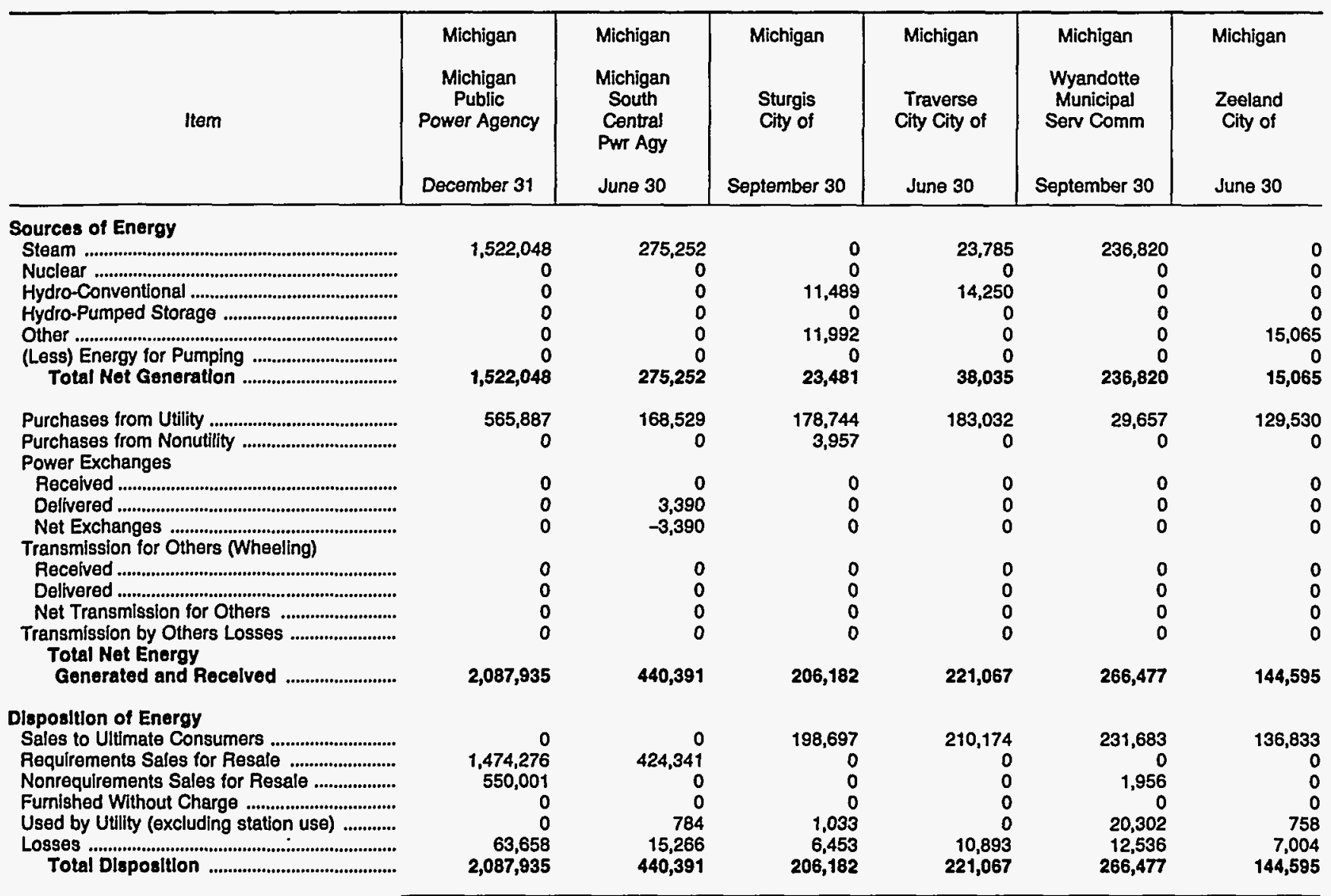

Note: Totals may not equal sum of components because of independent rounding. Double counting occurs in components of both sources and disposition of energy and thus neither provides a true total. Purchases from utilities, net interchanges, and net wheeling (except for imports) are included in net generation. Sales for resale is included in sales to ultimate consumers.

Source: Energy Information Administration, Form ElA-412, "Annual Report of Public Electric Utilities," 
Table 26. Electric Energy Account by Major U.S. Publicly Owned Electric Utility Within State, 1993 (Continued)

(Megawatthours)

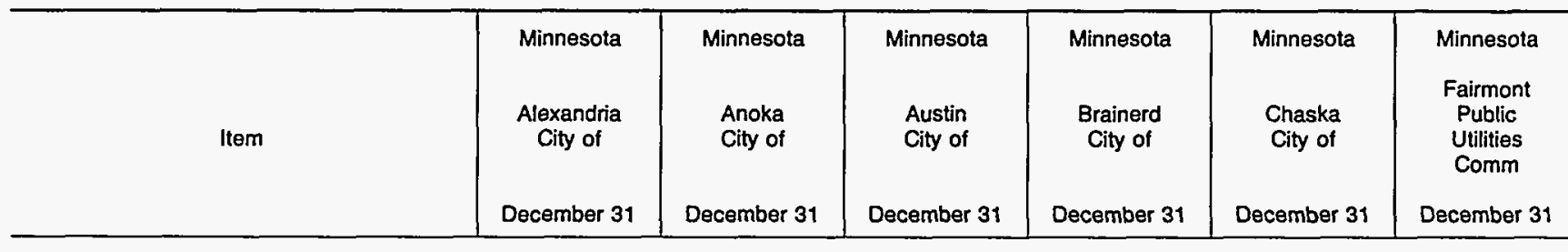

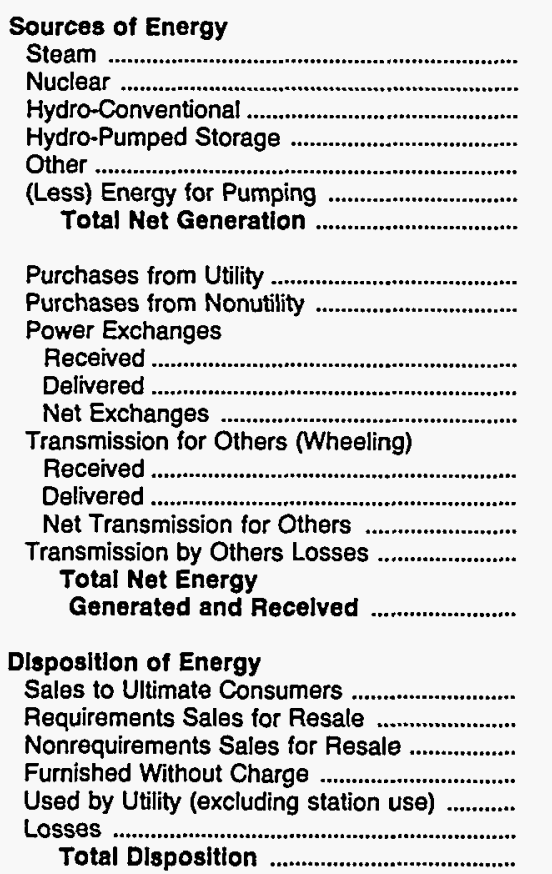

\begin{tabular}{|c|c|}
\hline $\begin{array}{r}0 \\
0 \\
0 \\
0 \\
-167 \\
0 \\
-167\end{array}$ & $\begin{array}{l}0 \\
0 \\
0 \\
0 \\
0 \\
0 \\
0\end{array}$ \\
\hline $\begin{array}{r}180,293 \\
0\end{array}$ & $\begin{array}{r}212,698 \\
0\end{array}$ \\
\hline $\begin{array}{l}0 \\
0 \\
0\end{array}$ & $\begin{array}{l}0 \\
0 \\
0\end{array}$ \\
\hline $\begin{array}{l}0 \\
0 \\
0 \\
0\end{array}$ & $\begin{array}{l}0 \\
0 \\
0 \\
0\end{array}$ \\
\hline 180,126 & 212,698 \\
\hline $\begin{array}{r}167,269 \\
0 \\
0 \\
0 \\
0 \\
12,857 \\
180,126\end{array}$ & $\begin{array}{r}203,746 \\
0 \\
0 \\
0 \\
0 \\
8,952 \\
212,698\end{array}$ \\
\hline
\end{tabular}

80,422
0
0
0
0
0
80,422

$\begin{array}{ll}0 & 0 \\ 0 & 0 \\ 0 & 0 \\ 0 & 0 \\ 0 & 0 \\ 0 & 0 \\ 0 & 0\end{array}$

1,038

Purchases from Utility ..........................................

Purchases from Nonutility

Received

Net Exchanges

smission for Others (Wheeling)

Received

Total Net Energy

osition of Energy

Sales to Ultimate Consumers

Requirements Sales for Resale

Nonrequirements Sales for Resale

Used by Utility (excluding station use) ...........

Total Disposition

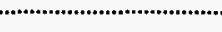

Note: Totals may not equal sum of components because of independent rounding. Double counting occurs in components of both sources and disposition of energy and thus neither provides a true total. Purchases from utilities, net interchanges, and net wheeling (except for imports) are included in net generation. Sales for resale is included in sales to ultimate consumers.

Source: Energy Information Administration, Form EIA-412, "Annual Report of Public Electric Utilities." 
Table 26. Electric Energy Account by Major U.S. Publicly Owned Electric Utility Within State, 1993 (Continued)

(Megawatthours)

\begin{tabular}{|c|c|c|c|c|c|c|}
\hline Item & $\begin{array}{l}\text { Minnesota } \\
\text { Hutchinson } \\
\text { Utilities } \\
\text { Comm } \\
\text { December } 31\end{array}$ & $\begin{array}{c}\text { Minnesota } \\
\text { Marshall } \\
\text { City of } \\
\text { December } 31\end{array}$ & $\begin{array}{c}\text { Minnesota } \\
\text { Moorhead } \\
\text { City of } \\
\text { December } 31\end{array}$ & $\begin{array}{l}\text { Minnesota } \\
\text { New Ulm } \\
\text { Public } \\
\text { Utilities } \\
\text { Comm } \\
\text { December } 31\end{array}$ & $\begin{array}{c}\text { Minnesota } \\
\text { Northem } \\
\text { Municipal } \\
\text { Power Agny } \\
\text { December } 31\end{array}$ & $\begin{array}{c}\text { Minnesota } \\
\text { Owatonna } \\
\text { City of } \\
\text { December } 31\end{array}$ \\
\hline 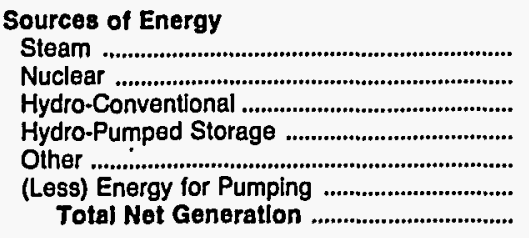 & $\begin{array}{r}0 \\
0 \\
0 \\
0 \\
2,111 \\
0 \\
2,111\end{array}$ & $\begin{array}{r}0 \\
0 \\
0 \\
0 \\
97 \\
0 \\
97\end{array}$ & $\begin{array}{l}0 \\
0 \\
0 \\
0 \\
0 \\
0 \\
0\end{array}$ & $\begin{array}{r}40,714 \\
0 \\
0 \\
0 \\
545 \\
0 \\
41,259\end{array}$ & $\begin{array}{r}798,679 \\
0 \\
0 \\
0 \\
0 \\
0 \\
798,679\end{array}$ & $\begin{array}{l}0 \\
0 \\
0 \\
0 \\
0 \\
0 \\
0\end{array}$ \\
\hline 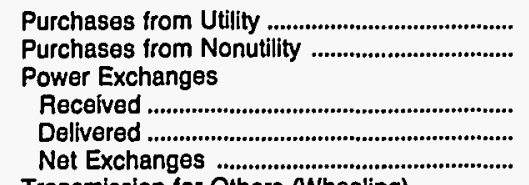 & $\begin{array}{r}263,522 \\
0\end{array}$ & $\begin{array}{r}354,206 \\
0\end{array}$ & $\begin{array}{r}338,468 \\
0\end{array}$ & $\begin{array}{r}126,622 \\
0\end{array}$ & $\begin{array}{l}0 \\
0 \\
0\end{array}$ & $\begin{array}{r}244,033 \\
0\end{array}$ \\
\hline 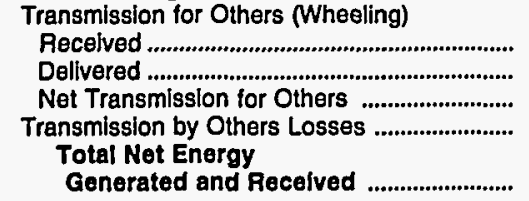 & 265,633 & 354,303 & 338,468 & 167,882 & 798,679 & 244,033 \\
\hline 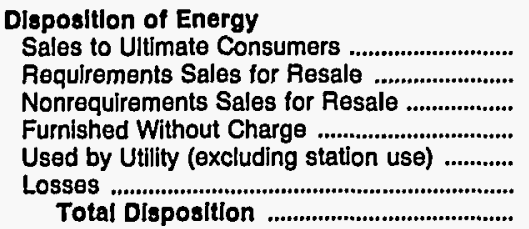 & $\begin{array}{r}252,418 \\
0 \\
26 \\
0 \\
0 \\
13,189 \\
265,633\end{array}$ & $\begin{array}{r}345,850 \\
0 \\
0 \\
0 \\
67 \\
8,386 \\
354,303\end{array}$ & $\begin{array}{r}322,512 \\
0 \\
0 \\
0 \\
1,889 \\
14,067 \\
338,468\end{array}$ & $\begin{array}{r}158,560 \\
0 \\
0 \\
0 \\
0 \\
9,322 \\
167,882\end{array}$ & $\begin{array}{r}0 \\
798,679 \\
0 \\
0 \\
0 \\
0 \\
798,679\end{array}$ & $\begin{array}{r}227,242 \\
0 \\
0 \\
6,798 \\
0 \\
9,993 \\
244,033\end{array}$ \\
\hline
\end{tabular}

Note: Totals may not equal sum of components because of independent rounding. Double counting occurs in components of both sources and disposition of energy and thus neither provides a true total. Purchases from utilities, net interchanges, and net wheeling (except for imports) are included in net generation. Sales for resale is included in sales to ultimate consumers.

Source: Energy Information Administration, Form EIA-412, "Annual Report of Public Electric Utilities." 
Table 26. Electric Energy Account by Major U.S. Publicly Owned Electric Utility Within State, 1993 (Continued) (Megawatthours)

\begin{tabular}{|c|c|c|c|c|c|c|}
\hline Item & $\begin{array}{l}\text { Minnesota } \\
\text { Aochester } \\
\text { Public } \\
\text { Utilities } \\
\text { December } 31\end{array}$ & $\begin{array}{c}\text { Minnesota } \\
\text { Shakopee } \\
\text { Public } \\
\text { Utilities } \\
\text { Comm } \\
\text { December } 31\end{array}$ & $\begin{array}{l}\text { Minnesota } \\
\text { Southern } \\
\text { Minnesota } \\
\text { Mun P } \\
\text { Agny } \\
\text { December } 31\end{array}$ & $\begin{array}{c}\text { Minnesota } \\
\text { Western } \\
\text { Minnesota } \\
\text { Mun } \\
\text { Pwr Agny } \\
\text { December } 31\end{array}$ & $\begin{array}{c}\text { Minnesota } \\
\text { Willmar } \\
\text { Municipal } \\
\text { Utils Comm } \\
\text { December } 31\end{array}$ & $\begin{array}{l}\text { Mississippi } \\
\text { Aberdeen } \\
\text { City of } \\
\text { June } 30\end{array}$ \\
\hline \multicolumn{7}{|l|}{ Sources of Energy } \\
\hline Steam & 124,882 & 0 & $1,948,278$ & $1,665,354$ & 33,294 & 0 \\
\hline 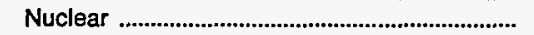 & 0 & 0 & 0 & 0 & 0 & 0 \\
\hline 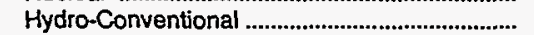 & 16,703 & 0 & 0 & 0 & 0 & 0 \\
\hline 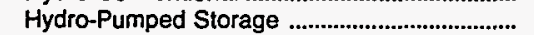 & 0 & 0 & 0 & 0 & 0 & 0 \\
\hline Other & 66 & 0 & 0 & 0 & 0 & 0 \\
\hline 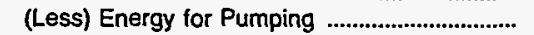 & 0 & 0 & 0 & 0 & 0 & \\
\hline 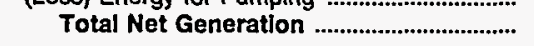 & 141,651 & 0 & $1,948,278$ & $1,665,354$ & 33,294 & 0 \\
\hline 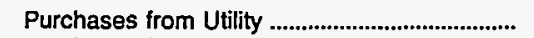 & 910,467 & 132,359 & 499,089 & 0 & 172,859 & 160,266 \\
\hline $\begin{array}{l}\text { Purchases from Nonutility } \\
\text { Power Exchanges }\end{array}$ & 0 & 0 & 9,319 & 0 & 0 & \\
\hline 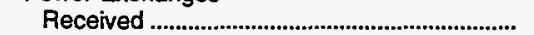 & 0 & 0 & 0 & 0 & 0 & 0 \\
\hline Delivered ................................................................... & 0 & 0 & 0 & 0 & 0 & 0 \\
\hline Net Exchanges .......................................... & 0 & 0 & 0 & 0 & 0 & 0 \\
\hline \multicolumn{7}{|l|}{ Transmission for Others (Wheeling) } \\
\hline Received & 0 & 0 & 0 & 0 & 0 & \\
\hline 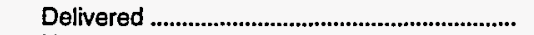 & 0 & 0 & 0 & 0 & 0 & 0 \\
\hline Net Transmission for Others & 0 & 0 & 0 & 0 & 0 & 0 \\
\hline $\begin{array}{l}\text { Transmission by Others Losses ............................ } \\
\text { Total Net Energy }\end{array}$ & 0 & 0 & 0 & 0 & 0 & 0 \\
\hline 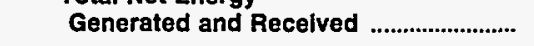 & $1,052,118$ & 132,359 & $2,456,686$ & $1,665,354$ & 206,153 & 160,266 \\
\hline \multicolumn{7}{|l|}{ Disposition of Energy } \\
\hline 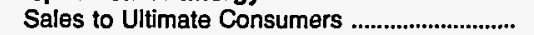 & 890,657 & 126,344 & 0 & 0 & 192,134 & 154,109 \\
\hline Requirements Sales for Resale ............................. & 124,973 & 0 & $2,389,972$ & $1,665,354$ & 0 & \\
\hline Nonrequirements Sales for Resale ................... & 0 & 0 & 0 & 0 & 0 & 0 \\
\hline 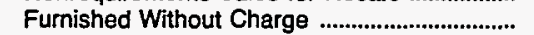 & 0 & 671 & 0 & 0 & 2,427 & 0 \\
\hline Used by Utility (excluding station use) ............. & 4,169 & 262 & 0 & 0 & 2,729 & 79 \\
\hline 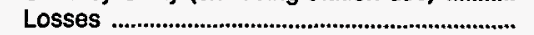 & 32,319 & 5,082 & 66,714 & 0 & 8,863 & 6,077 \\
\hline 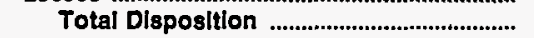 & $1,052,118$ & 132,359 & $2,456,686$ & $1,665,354$ & 206,153 & 160,266 \\
\hline
\end{tabular}

Note: Totals may not equal sum of components because of independent rounding. Double counting occurs in components of both sources and disposition of energy and thus neither provides a true total. Purchases from utilities, net interchanges, and net wheeling (except for imports) are included in net generation. Sales for resale is included in sales to ultimate consumers.

Source: Energy Information Administration, Form EIA-412, "Annual Report of Public Electric Utilities." 
Table 26. Electric Energy Account by Major U.S. Publicly Owned Electric Utility Within State, 1993 (Continued)

(Megawatthours)

\begin{tabular}{|c|c|c|c|c|c|c|}
\hline Item & $\begin{array}{l}\text { Mississippi } \\
\text { Clarksdale } \\
\text { City of } \\
\text { September } 30\end{array}$ & $\begin{array}{l}\text { Mississippi } \\
\text { Columbus } \\
\text { City of } \\
\text { June } 30\end{array}$ & $\begin{array}{l}\text { Mississippi } \\
\text { Greenwood } \\
\text { Utilities } \\
\text { Comm } \\
\text { September } 30\end{array}$ & $\begin{array}{l}\text { Mississippi } \\
\text { Holly } \\
\text { Springs } \\
\text { City of } \\
\\
\text { June } 30\end{array}$ & $\begin{array}{l}\text { Mississippi } \\
\text { Louisville } \\
\text { Electric } \\
\text { System } \\
\text { June } 30\end{array}$ & $\begin{array}{c}\text { Mississippi } \\
\text { Municipal } \\
\text { Energy } \\
\text { Agency } \\
\text { of MS } \\
\text { September } 30\end{array}$ \\
\hline \multicolumn{7}{|l|}{ Sources of Energy } \\
\hline Steam .............................. & 48,751 & 0 & 13,217 & 0 & 0 & \\
\hline 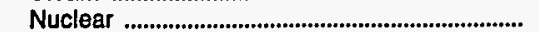 & 0 & 0 & 0 & 0 & 0 & \\
\hline Hydro-Conventional ............................................. & 0 & 0 & 0 & 0 & 0 & \\
\hline Hydro-Pumped Storage ............................................. & 0 & 0 & 0 & 0 & 0 & \\
\hline 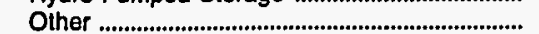 & 0 & 0 & 0 & 0 & 0 & \\
\hline 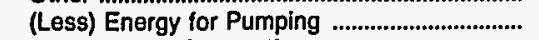 & 0 & 0 & 0 & 0 & 0 & \\
\hline 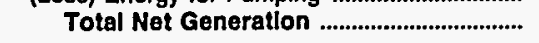 & 48,751 & o & 13,217 & 0 & 0 & \\
\hline 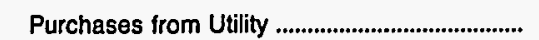 & 182,936 & 454,970 & 278,270 & 208,699 & 155,206 & 818,696 \\
\hline Purchases from Nonutility ...................................... & 0 & 0 & 0 & 0 & 0 & \\
\hline Power Exchanges & & & & & & \\
\hline 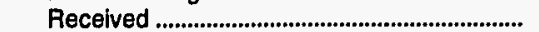 & $\mathbf{0}$ & 0 & 0 & 0 & 0 & \\
\hline Delivered ................................................................. & 0 & 0 & 0 & 0 & 0 & \\
\hline 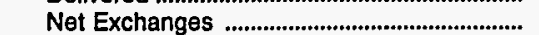 & 0 & 0 & 0 & 0 & 0 & \\
\hline \multicolumn{7}{|l|}{ Transmission for Others (Wheeling) } \\
\hline 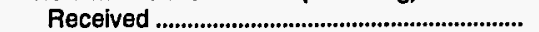 & 0 & 0 & 0 & 0 & 0 & \\
\hline 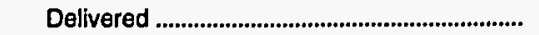 & 0 & 0 & 0 & 0 & 0 & \\
\hline 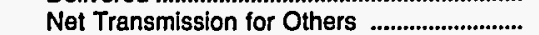 & 0 & 0 & 0 & 0 & 0 & \\
\hline 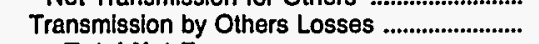 & 0 & 0 & 0 & 0 & 0 & \\
\hline Total Net Energy & & & & & 10500 & \\
\hline Generated and Received ......................... & 231,687 & 454,970 & 291,487 & 208,699 & 155,206 & 818,696 \\
\hline \multicolumn{7}{|l|}{ Disposition of Energy } \\
\hline 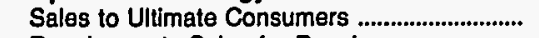 & 166,596 & 433,761 & 267,777 & 192,763 & 147,489 & \\
\hline Requirements Sales for Resale ............................. & 48,751 & 0 & 0 & 0 & 0 & 818,696 \\
\hline Nonrequirements Sales for Resale .................... & 0 & 0 & 0 & 0 & 0 & \\
\hline Furnished Without Charge ...................................... & 0 & 0 & 0 & 0 & 0 & \\
\hline Used by Utility (excluding station use) ............. & 0 & 101 & 2,679 & 334 & 115 & \\
\hline Losses .................................................................. & 16,340 & 21,108 & 21,031 & 15,601 & 7,601 & \\
\hline Total Disposition ........................................... & 231,687 & 454,970 & 291,487 & 208,699 & 155,206 & 818,696 \\
\hline
\end{tabular}

Note: Totals may not equal sum of components because of independent rounding. Double counting occurs in components of both sources and dispos generation. Sales for resale is included in sales to ultimate consumers.

Source: Energy Information Administration, Form ElA-412, "Annual Report of Public Electric Utilities." 
Table 26. Electric Energy Account by Major U.S. Publicly Owned Electric Utility Within State, 1993 (Continued)

(Megawatthours)

\begin{tabular}{|c|c|c|c|c|c|c|}
\hline Item & $\begin{array}{l}\text { Mississippi } \\
\text { New Albany } \\
\text { City of } \\
\text { June } 30\end{array}$ & $\begin{array}{l}\text { Mississippi } \\
\text { Oxford } \\
\text { City of } \\
\text { June } 30\end{array}$ & $\begin{array}{l}\text { Mississippi } \\
\text { Starkville } \\
\text { City of } \\
\text { June } 30\end{array}$ & $\begin{array}{l}\text { Mississippi } \\
\text { Tupelo } \\
\text { City of } \\
\text { June } 30\end{array}$ & $\begin{array}{c}\text { Mississippi } \\
\text { West } \\
\text { Point } \\
\text { City of } \\
\text { June } 30\end{array}$ & $\begin{array}{l}\text { Missouri } \\
\text { Carthage } \\
\text { City of } \\
\text { June } 30\end{array}$ \\
\hline \multirow{2}{*}{\multicolumn{7}{|c|}{ Sources of Energy }} \\
\hline & 0 & 0 & 0 & 0 & 0 & \\
\hline 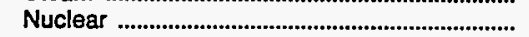 & 0 & 0 & 0 & 0 & 0 & 0 \\
\hline 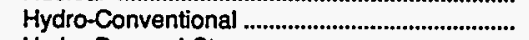 & 0 & 0 & 0 & 0 & 0 & 0 \\
\hline 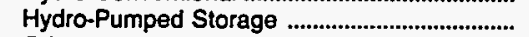 & 0 & 0 & 0 & 0 & 0 & 0 \\
\hline Other & 0 & 0 & 0 & 0 & 0 & 253 \\
\hline 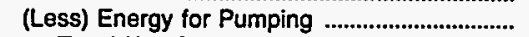 & 0 & 0 & 0 & 0 & 0 & 0 \\
\hline 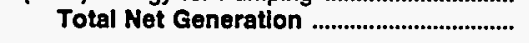 & 0 & $\mathbf{0}$ & $\mathbf{0}$ & 0 & 0 & 253 \\
\hline 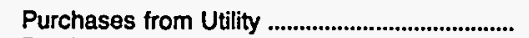 & 235,206 & 146,732 & 319,198 & 620,531 & 183,648 & 190,976 \\
\hline Purchases from Nonutility ................................................ & 0 & 0 & 0 & 0 & 0 & \\
\hline 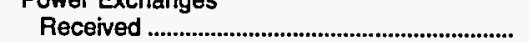 & 0 & 0 & 0 & 0 & 0 & 0 \\
\hline Delivered ........................................................................... & 0 & 0 & 0 & 0 & 0 & 0 \\
\hline Net Exchanges & 0 & 0 & 0 & 0 & 0 & 0 \\
\hline \multicolumn{7}{|l|}{ Transmission for Others (Wheeling) } \\
\hline 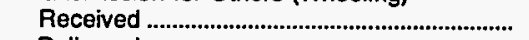 & 0 & 0 & 0 & 0 & 0 & \\
\hline 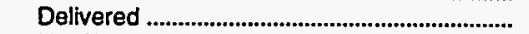 & 0 & 0 & 0 & 0 & 0 & 0 \\
\hline 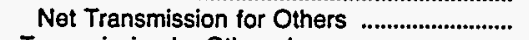 & 0 & 0 & 0 & 0 & 0 & 0 \\
\hline 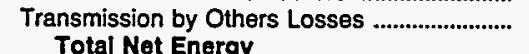 & 0 & 0 & 0 & 0 & 0 & $-7,785$ \\
\hline 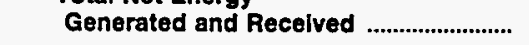 & 235,206 & 146,732 & 319,198 & 620,531 & 183,648 & 183,444 \\
\hline \multicolumn{7}{|l|}{ Disposition of Energy } \\
\hline Sales to Ultimate Consumers ................................... & 214,819 & 138,658 & 304,380 & 596,446 & 178,725 & 173,637 \\
\hline Requirements Sales for Resale .......................... & & 0 & 0 & 0 & 0 & 134 \\
\hline Nonrequirements Sales for Resale ....................... & 0 & 0 & 0 & 0 & 0 & 0 \\
\hline Furnished Without Charge ...................................... & 0 & 0 & 0 & 0 & 0 & 0 \\
\hline Used by Utility (excluding station use) ................. & 206 & 104 & 202 & 373 & 0 & 0 \\
\hline Losses & 20,180 & 7,969 & 14,616 & 23,710 & 4,923 & 9,673 \\
\hline 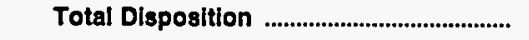 & 235,206 & 146,732 & 319,198 & 620,531 & 183,648 & 183,444 \\
\hline
\end{tabular}

Note: Totals may not equal sum of components because of independent rounding. Double counting occurs in components of both sources and disposition of energy and thus neither provides a true total. Purchases from utilities, net interchanges, and net wheeling (except for imports) are included in net generation. Sales for resale is included in sales to ultimate consumers.

Source: Energy Information Administration, Form ElA-412, "Annual Report of Public Electric Utilities." 
Table 26. Electric Energy Account by Major U.S. Publicly Owned Electric Utility Within State, 1993 (Continued)

(Megawatthours)

\begin{tabular}{|c|c|c|c|c|c|c|}
\hline Item & $\begin{array}{l}\text { Missouri } \\
\text { Columbia } \\
\text { City of } \\
\text { September } 30\end{array}$ & $\begin{array}{l}\text { Missouri } \\
\text { Hannibal } \\
\text { City of } \\
\text { June } 30\end{array}$ & $\begin{array}{c}\text { Missouri } \\
\text { Independence } \\
\text { City of } \\
\text { June } 30\end{array}$ & $\begin{array}{l}\text { Missouri } \\
\text { Kennett } \\
\text { City of } \\
\text { June } 30\end{array}$ & $\begin{array}{l}\text { Missouri } \\
\text { Kirkwood } \\
\text { City of } \\
\text { March } 31\end{array}$ & $\begin{array}{l}\text { Missouri } \\
\text { Lebanon } \\
\text { City of } \\
\text { October } 31\end{array}$ \\
\hline \multirow{2}{*}{\multicolumn{7}{|c|}{ Sources of Energy }} \\
\hline Steam & & & 80,817 & 0 & 0 & 0 \\
\hline Nuclear .... & 0 & 0 & 0 & 0 & 0 & 0 \\
\hline Hydro-Conventional & 0 & 0 & 0 & 0 & 0 & 0 \\
\hline Hydro-Pumped Storage ........................................... & 0 & 0 & 0 & 0 & 0 & 0 \\
\hline 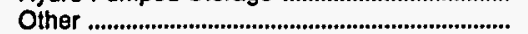 & 0 & 0 & 2,445 & $i$ & 0 & 0 \\
\hline 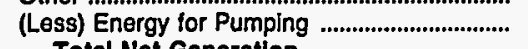 & 0 & 0 & & 0 & 0 & 0 \\
\hline 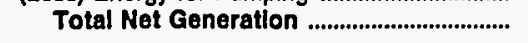 & 72,362 & 0 & 83,262 & 1 & 0 & 0 \\
\hline 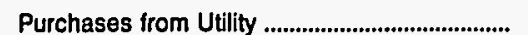 & 698,682 & 187,452 & 780,181 & 145,313 & 175,924 & 168,000 \\
\hline 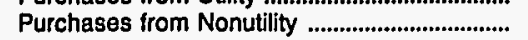 & 0 & 0 & & 0 & 0 & 0 \\
\hline \multicolumn{7}{|l|}{ Power Exchanges } \\
\hline 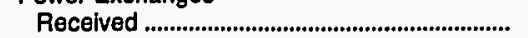 & 0 & 0 & 624,190 & 0 & 0 & 0 \\
\hline 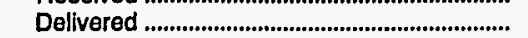 & 0 & 0 & 623,430 & 0 & 0 & 0 \\
\hline Net Exchanges ................................................ & 0 & 0 & 760 & 0 & 0 & 0 \\
\hline \multicolumn{7}{|l|}{ Transmlssion for Others (Wheeling) } \\
\hline 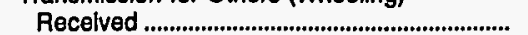 & 0 & 0 & 0 & 0 & 0 & 0 \\
\hline 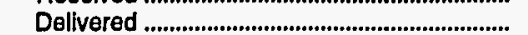 & 0 & 0 & 0 & 0 & 0 & 0 \\
\hline Net Transmission for Others .......................... & 0 & 0 & 0 & 0 & 0 & 0 \\
\hline \multirow{3}{*}{ 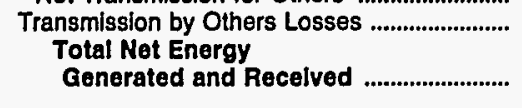 } & 0 & 0 & 0 & 0 & 0 & 0 \\
\hline & 771.044 & 187450 & 864,203 & 105314 & 175001 & 198 nก0 \\
\hline & & & & & & \\
\hline \multicolumn{7}{|l|}{ Disposition of Energy } \\
\hline 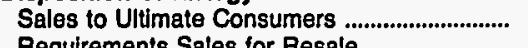 & 735,790 & 168,610 & 774,792 & 139,127 & 164,588 & 137,760 \\
\hline Requirements Sales for Resale ................................ & $\begin{array}{l}0 \\
0\end{array}$ & $\begin{array}{l}0 \\
0\end{array}$ & $\begin{array}{r}1,576 \\
26,966\end{array}$ & $\begin{array}{l}0 \\
0\end{array}$ & $\begin{array}{l}0 \\
0\end{array}$ & (2. \\
\hline 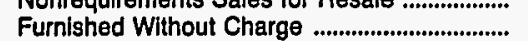 & 0 & 2,952 & 20,50 & 0 & 0 & 10,080 \\
\hline 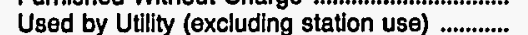 & & 0 & 2,152 & 292 & 0 & 20,160 \\
\hline 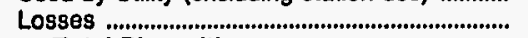 & 35,254 & 15,890 & 58,717 & $\mathbf{5 . 8 9 5}$ & 11,336 & \\
\hline 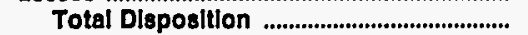 & 771,044 & 187,452 & 864,203 & 145,314 & 175,924 & 168,000 \\
\hline
\end{tabular}

Note: Totals may not equal sum of components because of independent rounding. Double counting occurs in components of both sources and disposition of energy and thus neither provides a true total. Purchases from utilities, net interchanges, and net wheeling (except for imports) are included in net generation. Sales for resale is included in sales to ultimate consumers.

Source: Energy Information Administration, Form EIA-412, "Annual Report of Public Electric Utilities." 
Table 26. Electric Energy Account by Major U.S. Publicly Owned Electric Utility Within State, 1993 (Continued)

(Megawatthours)

\begin{tabular}{|c|c|c|c|c|c|c|}
\hline Item & $\begin{array}{l}\text { Missouri } \\
\text { Marshall } \\
\text { City of } \\
\text { September } 30\end{array}$ & $\begin{array}{l}\text { Missouri } \\
\text { Monett } \\
\text { City of } \\
\text { March } 31\end{array}$ & $\begin{array}{c}\text { Missouri } \\
\text { Poplar } \\
\text { Bluff } \\
\text { City of } \\
\text { December } 31\end{array}$ & $\begin{array}{c}\text { Missouri } \\
\text { Rolla } \\
\text { City of } \\
\text { September } 30\end{array}$ & $\begin{array}{l}\text { Missouri } \\
\text { Sikeston } \\
\text { City of } \\
\text { May } 31\end{array}$ & $\begin{array}{l}\text { Missouri } \\
\text { Springfield } \\
\text { City of } \\
\text { September } 30\end{array}$ \\
\hline \multicolumn{7}{|l|}{ Sources of Energy } \\
\hline Steam & 52,543 & 0 & 0 & 0 & $1,041,344$ & $1,697,506$ \\
\hline 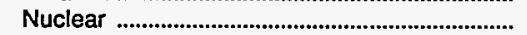 & 0 & 0 & 0 & 0 & 0 & \\
\hline 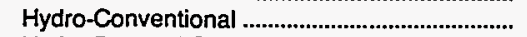 & 0 & 0 & 0 & 0 & 0 & \\
\hline Hydro-Pumped Storage ................................................ & 0 & 0 & 0 & 0 & 0 & \\
\hline Other & 0 & 0 & 317 & 0 & 0 & 56,365 \\
\hline (Less) Energy for Pumping .......................................... & 0 & 0 & 0 & 0 & 0 & \\
\hline Total Net Generation & 52,543 & 0 & 317 & 0 & $1,041,344$ & $1,753,871$ \\
\hline 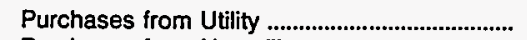 & 93,076 & 149,947 & 265,008 & 226,908 & 146,189 & 512,495 \\
\hline 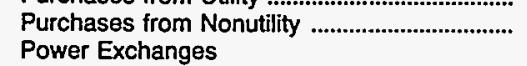 & 0 & 0 & 0 & 0 & 0 & \\
\hline 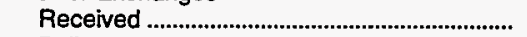 & 0 & 0 & 0 & 0 & 241.132 & 164,068 \\
\hline 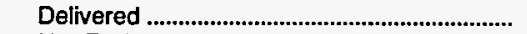 & 0 & 0 & 0 & 0 & 70,689 & 54,861 \\
\hline 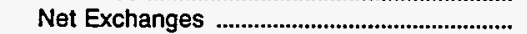 & 0 & 0 & 0 & 0 & 170,443 & 109,207 \\
\hline \multicolumn{7}{|l|}{ Transmission for Others (Wheeling) } \\
\hline 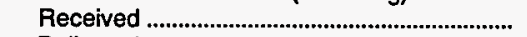 & 0 & 0 & 0 & 0 & 0 & \\
\hline 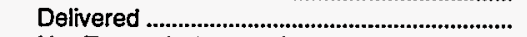 & 0 & 0 & 0 & 0 & 0 & \\
\hline 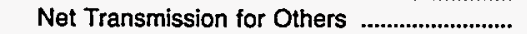 & 0 & 0 & 0 & 0 & 0 & \\
\hline 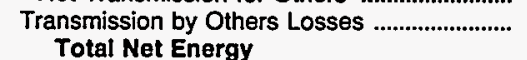 & 0 & 0 & 0 & $\mathbf{0}$ & 0 & $-1,501$ \\
\hline 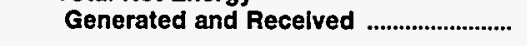 & 145,619 & 149,947 & 265,325 & 226,908 & $1,357,976$ & $2,374,072$ \\
\hline \multicolumn{7}{|l|}{ Disposition of Energy } \\
\hline 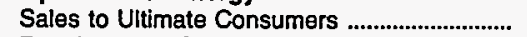 & 138,634 & 139,973 & 242,908 & 212,292 & 225,908 & $2,083,384$ \\
\hline 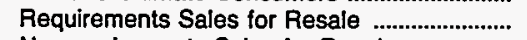 & & 0 & 0 & 0 & 614,251 & 74,053 \\
\hline Nonrequirements Sales for Resale ...................... & 0 & 0 & 0 & 0 & 502,154 & 59,897 \\
\hline Furnished Without Charge ........................................ & 0 & 0 & 5,706 & 1,475 & 3,276 & 57,895 \\
\hline Used by Utility (excluding station use) ............. & 0 & 4,211 & 6 & 3,134 & 0 & 26,162 \\
\hline 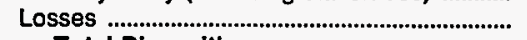 & 6,985 & 5,763 & 16,705 & 10,007 & 12,387 & $\begin{array}{r}72,681 \\
2374,072\end{array}$ \\
\hline Total Dlsposition ............................................... & 145,619 & 149,947 & 265,325 & 226,908 & $1,357,976$ & $2,374,072$ \\
\hline
\end{tabular}

Note: Totals may not equal sum of components because of independent rounding. Double counting occurs in components of both sources and disposition of energy and thus neither provides a true total. Purchases from utilities, net interchanges, and net wheeling (except for imports) are included in net generation. Sales for resale is included in sales to ultimate consumers.

Source: Energy Information Administration, Form EIA-412, "Annual Report of Public Electric Utilities." 
Table 26. Electric Energy Account by Major U.S. Publicly Owned Electric Utility Within State, 1993 (Continued)

(Megawatthours)

\begin{tabular}{|c|c|c|c|c|c|c|}
\hline Item & $\begin{array}{l}\text { Nebraska } \\
\text { Central } \\
\text { Nebraska } \\
\text { Pub } \\
\text { P\&I Dist } \\
\text { December } 31\end{array}$ & $\begin{array}{l}\text { Nebraska } \\
\text { Cornhusker } \\
\text { Public } \\
\text { Power Dist } \\
\text { December } 31\end{array}$ & $\begin{array}{l}\text { Nebraska } \\
\text { Dawson } \\
\text { County } \\
\text { Public } \\
\text { Pwr Dist } \\
\text { December } 31\end{array}$ & $\begin{array}{l}\text { Nebraska } \\
\text { Fremont } \\
\text { City of } \\
\text { July } 31\end{array}$ & $\begin{array}{l}\text { Nebraska } \\
\text { Grand Island } \\
\text { City of } \\
\text { July } 31\end{array}$ & $\begin{array}{l}\text { Nebraska } \\
\text { Hastings } \\
\text { City of } \\
\text { December } 31\end{array}$ \\
\hline 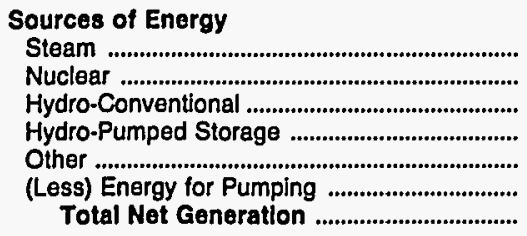 & $\begin{array}{r}0 \\
0 \\
278,782 \\
0 \\
0 \\
0 \\
278,782\end{array}$ & $\begin{array}{l}0 \\
0 \\
0 \\
0 \\
0 \\
0 \\
0\end{array}$ & $\begin{array}{l}0 \\
0 \\
0 \\
0 \\
0 \\
0 \\
0\end{array}$ & $\begin{array}{r}300,741 \\
0 \\
0 \\
0 \\
0 \\
0 \\
300,741\end{array}$ & $\begin{array}{r}409,274 \\
0 \\
0 \\
0 \\
0 \\
0 \\
409,274\end{array}$ & $\begin{array}{r}366,118 \\
0 \\
0 \\
0 \\
448 \\
0 \\
366,566\end{array}$ \\
\hline 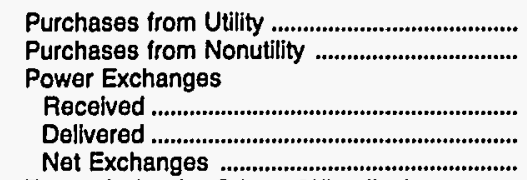 & $\begin{array}{l}0 \\
0 \\
0\end{array}$ & $\begin{array}{r}201,601 \\
0\end{array}$ & $\begin{array}{r}239,936 \\
0\end{array}$ & $\begin{array}{r}29,246 \\
0\end{array}$ & $\begin{array}{r}1,045 \\
593 \\
452\end{array}$ & $\begin{array}{r}71,010 \\
0\end{array}$ \\
\hline 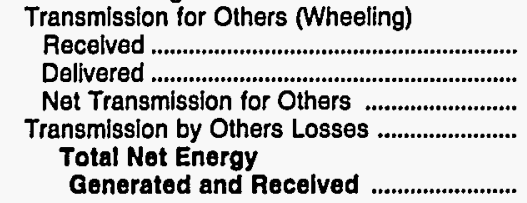 & $\begin{array}{l}0 \\
0 \\
0 \\
0\end{array}$ & $\begin{array}{r}7,476 \\
7,476 \\
0 \\
0\end{array}$ & $\begin{array}{l}0 \\
0 \\
0 \\
0\end{array}$ & $\begin{array}{l}0 \\
0 \\
0 \\
0\end{array}$ & $\begin{array}{l}0 \\
0 \\
0 \\
0\end{array}$ & $\begin{array}{r}5,351 \\
5,351 \\
0 \\
0\end{array}$ \\
\hline 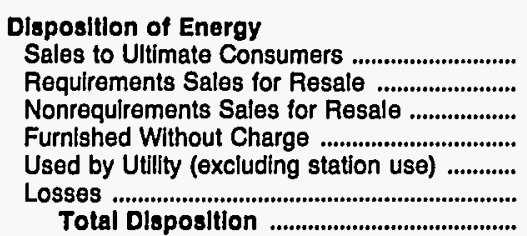 & $\begin{array}{r}0 \\
278,782 \\
0 \\
0 \\
0 \\
0 \\
278,782\end{array}$ & $\begin{array}{r}183,680 \\
2,151 \\
0 \\
0 \\
594 \\
15,176 \\
201,601\end{array}$ & $\begin{array}{r}218,713 \\
4,773 \\
0 \\
0 \\
142 \\
16,308 \\
239,936\end{array}$ & $\begin{array}{r}285,539 \\
0 \\
21,545 \\
5,068 \\
1,495 \\
16,340 \\
329,987\end{array}$ & $\begin{array}{r}467,216 \\
0 \\
50,935 \\
0 \\
0 \\
24,122 \\
542,273\end{array}$ & $\begin{array}{r}262,166 \\
162,513 \\
0 \\
0 \\
0 \\
12,897 \\
437,576\end{array}$ \\
\hline
\end{tabular}

Note: Totals may not equal sum of components because of independent rounding. Double counting occurs in components of both sources and disposition of energy and thus nelther provides a true total. Purchases from utilities, net interchanges, and net wheeling (except for imports) are included in net generation. Sales for resale is included in sales to ultimate consumers.

Source: Energy Information Administration, Form EIA-412, "Annual Report of Public Electric Utilities." 
Table 26. Electric Energy Account by Major U.S. Publicly Owned Electric Utility Within State, 1993 (Continued)

(Megawatthours)

\begin{tabular}{|c|c|c|c|c|c|c|}
\hline Item & $\begin{array}{l}\text { Nebraska } \\
\text { Lincoln } \\
\text { Electric } \\
\text { System } \\
\text { December } 31\end{array}$ & $\begin{array}{c}\text { Nebraska } \\
\text { Loup } \\
\text { River } \\
\text { Public } \\
\text { Power Dist } \\
\text { December } 31\end{array}$ & $\begin{array}{c}\text { Nebraska } \\
\text { Municipal } \\
\text { Energy } \\
\text { Agency } \\
\text { of NE } \\
\text { March } 31\end{array}$ & $\begin{array}{c}\text { Nebraska } \\
\text { Nebraska } \\
\text { Public } \\
\text { Power } \\
\text { District } \\
\text { December } 31\end{array}$ & $\begin{array}{c}\text { Nebraska } \\
\text { Norris } \\
\text { Public } \\
\text { Power } \\
\text { District } \\
\text { December } 31\end{array}$ & $\begin{array}{l}\text { Nebraska } \\
\text { North } \\
\text { Platte } \\
\text { City of } \\
\text { July } 31\end{array}$ \\
\hline \multicolumn{7}{|l|}{ Sources of Energy } \\
\hline 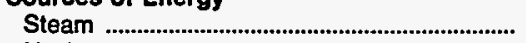 & $1,097,853$ & 0 & 212,123 & $7,976,774$ & 0 & \\
\hline 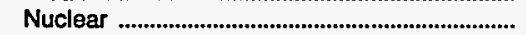 & & 0 & 0 & $3,712,778$ & 0 & \\
\hline Hydro-Conventional ............................................. & 0 & 147,686 & 0 & 97,560 & 0 & \\
\hline 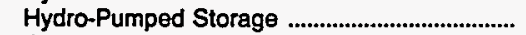 & 0 & 0 & 0 & 0 & 0 & 0 \\
\hline 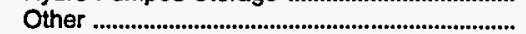 & 11,062 & 0 & 0 & 6,549 & 0 & 0 \\
\hline 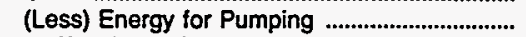 & 0 & 0 & 0 & 0 & 0 & \\
\hline 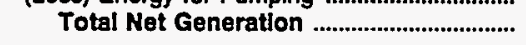 & $1,108,915$ & 147,686 & 212,123 & $11,793,661$ & 0 & \\
\hline Purchases from Utility & $1,892,526$ & 846,421 & 785,354 & $1,672,448$ & 425,339 & 216,586 \\
\hline $\begin{array}{l}\text { Purchases from Nonutility ..................................... } \\
\text { Power Exchanges }\end{array}$ & & 0 & 0 & & 0 & \\
\hline 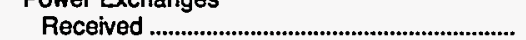 & 2,650 & 0 & 0 & 109.071 & 0 & \\
\hline 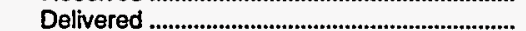 & & 0 & 0 & 43,468 & 0 & \\
\hline Net Exchanges & 2,650 & 0 & 0 & 65,603 & 0 & \\
\hline \multicolumn{7}{|l|}{ Transmission for Others (Wheeling) } \\
\hline 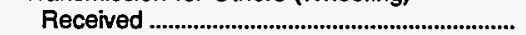 & 108,060 & 0 & 0 & 0 & 0 & \\
\hline 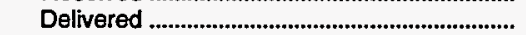 & 108,060 & 0 & 0 & 0 & 0 & \\
\hline Net Transmission for Others & 0 & 0 & 0 & 0 & 0 & 0 \\
\hline \multirow{2}{*}{ 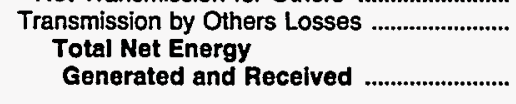 } & 0 & 0 & 0 & 0 & 0 & \\
\hline & $3,004,096$ & 994,107 & 997,477 & $13,531,712$ & 425,339 & 216,586 \\
\hline \multicolumn{7}{|l|}{ Disposition of Energy } \\
\hline Sales to Ultimate Consumers ................................ & $2,138,113$ & 541,781 & 0 & $2,713,221$ & 385,389 & 202,768 \\
\hline 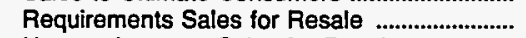 & 71,872 & 427,181 & 823,877 & $4,934,617$ & 14,795 & \\
\hline Nonrequirements Sales for Resale ........................ & 636,069 & 0 & 133,190 & $5,187,694$ & 0 & \\
\hline 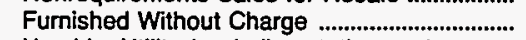 & & 0 & 0 & & 0 & 3,195 \\
\hline Used by Utility (excluding station use) ............. & 4,632 & 1,565 & 0 & 12,884 & 0 & 532 \\
\hline 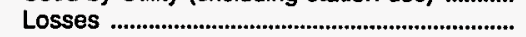 & 153,410 & 23,580 & 40,410 & 683,296 & 25,155 & 10,091 \\
\hline Total Disposition & $3,004,096$ & 994,107 & 997,477 & $13,531,712$ & 425,339 & 216,586 \\
\hline
\end{tabular}

Note: Totals may not equal sum of components because of independent rounding. Double counting occurs in components of both sources and disposition of energy and thus neither provides a true total. Purchases from utilities, net interchanges, and net wheeling (except for imports) are included in net generation. Sales for resale is included in sales to ultimate consumers.

Source: Energy Information Administration, Form EIA-412, "Annual Report of Public Electric Utilities." 
Table 26. Electric Energy Account by Major U.S. Publicly Owned Electric Utility Within State, 1993 (Continued) (Megawatthours)

\begin{tabular}{|c|c|c|c|c|c|c|}
\hline Item & $\begin{array}{c}\text { Nebraska } \\
\text { Omaha Public } \\
\text { Power } \\
\text { District } \\
\text { December } 31\end{array}$ & $\begin{array}{l}\text { Nebraska } \\
\text { Southern } \\
\text { Nebraska Rural } \\
\text { P P D } \\
\text { December } 31\end{array}$ & $\begin{array}{c}\text { Nevada } \\
\text { Colorado } \\
\text { River } \\
\text { Comm } \\
\text { of Nevada } \\
\text { June } 30\end{array}$ & $\begin{array}{l}\text { New Jersey } \\
\text { Vineland } \\
\text { City of } \\
\text { June } 30\end{array}$ & $\begin{array}{l}\text { New Mexico } \\
\text { Farmington } \\
\text { City of } \\
\text { June } 30\end{array}$ & $\begin{array}{l}\text { New Mexico } \\
\text { Gallup } \\
\text { City of } \\
\text { June } 30\end{array}$ \\
\hline \multicolumn{7}{|l|}{ Sources of Energy } \\
\hline Steam & $5,743,312$ & 0 & 0 & 72,580 & 318,241 & \\
\hline 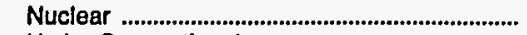 & $3,092,355$ & 0 & 0 & & 0 & 0 \\
\hline 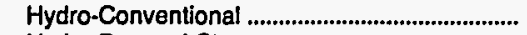 & 0 & 0 & 0 & 0 & 132,906 & 0 \\
\hline 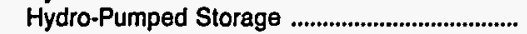 & 0 & 0 & 0 & 0 & 0 & 0 \\
\hline 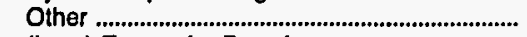 & 10,687 & 0 & 0 & 3,468 & 0 & 0 \\
\hline (Less) Energy for Pumping ......................................... & 0 & 0 & 0 & 0 & 0 & 0 \\
\hline 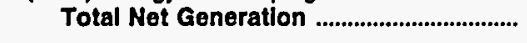 & $8,846,354$ & 0 & $\mathbf{0}$ & 76,048 & 451,147 & 0 \\
\hline 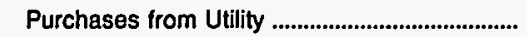 & 407,593 & 364,597 & $1,494,867$ & 396,995 & 117,844 & 178,747 \\
\hline $\begin{array}{l}\text { Purchases from Nonutility ....................................... } \\
\text { Power Exchanges }\end{array}$ & 0 & 0 & 0 & 0 & 0 & \\
\hline 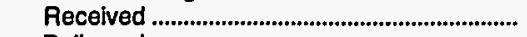 & 229,238 & 0 & 0 & 0 & 14,599 & 0 \\
\hline 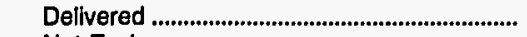 & $2,189,102$ & 0 & 0 & 0 & 15,248 & 0 \\
\hline Net Exchanges & $-1,959,864$ & 0 & 0 & 0 & -649 & 0 \\
\hline \multicolumn{7}{|l|}{ Transmission for Others (Wheeling) } \\
\hline 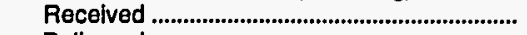 & 135,018 & 0 & 0 & 0 & 9,921 & 0 \\
\hline 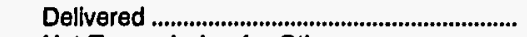 & 126,639 & 0 & 0 & 0 & 9,921 & 0 \\
\hline 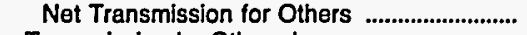 & 8,379 & 0 & 0 & 0 & 0 & 0 \\
\hline $\begin{array}{l}\text { Transmission by Others Losses ........................... } \\
\text { Total Net Energy }\end{array}$ & 0 & 0 & 0 & 0 & 0 & 0 \\
\hline Generated and Recelved ............................. & $7,302,462$ & 364,597 & $1,494,867$ & 473,043 & 568,342 & 178,747 \\
\hline \multicolumn{7}{|l|}{ Disposition of Energy } \\
\hline 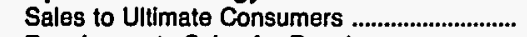 & $6,725,968$ & 331,950 & 726,399 & 442,170 & 516,855 & 167,660 \\
\hline Requirements Sales for Resale ........................... & 153,396 & & 768,468 & 0 & 17,112 & \\
\hline Nonrequirements Sales for Resale ................... & 0 & 0 & 0 & 0 & 2,874 & \\
\hline 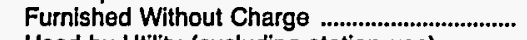 & 0 & 0 & 0 & 45 & 0 & 0 \\
\hline Used by Utility (excluding station use) .............. & $\mathbf{0}$ & 0 & 0 & 1,215 & 0 & 0 \\
\hline Losses & 423,098 & 32,647 & 0 & 29,613 & 31,501 & 11,087 \\
\hline 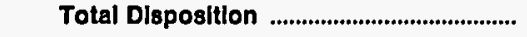 & $7,302,462$ & 364,597 & $1,494,867$ & 473,043 & 568,342 & 178,747 \\
\hline
\end{tabular}

Note: Totals may not equal sum of components because of independent rounding. Double counting occurs in components of both sources and disposition of energy and thus neither provides a true total. Purchases from utilities, net interchanges, and net wheeling (except for imports) are included in net generation. Sales for resale is included in sales to ultimate consumers.

Source: Energy Information Administration, Form EIA-412, "Annual Report of Public Electric Utilities." 
Table 26. Electric Energy Account by Major U.S. Publicly Owned Electric Utility Within State, 1993 (Continued)

(Megawatthours)

\begin{tabular}{|c|c|c|c|c|c|c|}
\hline Item & $\begin{array}{l}\text { New Mexico } \\
\begin{array}{c}\text { Los Alamos } \\
\text { County }\end{array} \\
\text { June } 30\end{array}$ & $\begin{array}{c}\text { New York } \\
\text { Fairport } \\
\text { Village of } \\
\text { May } 31\end{array}$ & $\begin{array}{c}\text { New York } \\
\text { Freeport } \\
\begin{array}{c}\text { Village of } \\
\text { Inc }\end{array} \\
\text { February } 28\end{array}$ & $\begin{array}{c}\text { New York } \\
\text { Jamestown } \\
\text { City of } \\
\text { December } 31\end{array}$ & $\begin{array}{l}\text { New York } \\
\text { Massena } \\
\text { Town of } \\
\text { December } 31\end{array}$ & $\begin{array}{c}\text { New York } \\
\text { Plattsburgh } \\
\text { City of } \\
\text { December } 31\end{array}$ \\
\hline \multicolumn{7}{|l|}{ Sources of Energy } \\
\hline Steam & 203,627 & 0 & 0 & 188,954 & 0 & 0 \\
\hline Nuclear & 0 & 0 & 0 & 0 & 0 & 0 \\
\hline 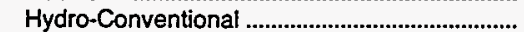 & 77,203 & 0 & 0 & 0 & 0 & 0 \\
\hline 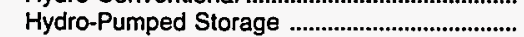 & 0 & 0 & 0 & 0 & 0 & 0 \\
\hline Other & 0 & 0 & 20,444 & 0 & 0 & 0 \\
\hline 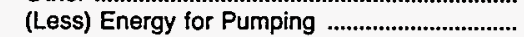 & 0 & 0 & 0 & 0 & 0 & 0 \\
\hline Total Net Generation & 280,830 & 0 & 20,444 & 188,954 & 0 & 0 \\
\hline 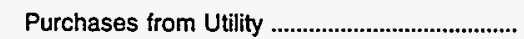 & 185,989 & 354,936 & 226,595 & 461,395 & 164,340 & 533,267 \\
\hline $\begin{array}{l}\text { Purchases from Nonutility ................................................ } \\
\text { Power Exchanges }\end{array}$ & 23,743 & 0 & 0 & 0 & 0 & 0 \\
\hline 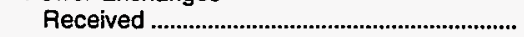 & 63,738 & 0 & 0 & 0 & 0 & 0 \\
\hline Delivered & 43,773 & 0 & 0 & 0 & 0 & 0 \\
\hline 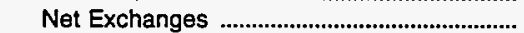 & 19,965 & 0 & 0 & 0 & 0 & 0 \\
\hline \multicolumn{7}{|l|}{ Transmission for Others (Wheeling) } \\
\hline 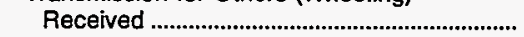 & 0 & 0 & 0 & 0 & 0 & 0 \\
\hline 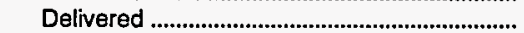 & 0 & 0 & 0 & 0 & 0 & 0 \\
\hline 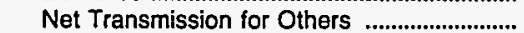 & 0 & 0 & 0 & 0 & 0 & 0 \\
\hline $\begin{array}{l}\text { Transmission by Others Losses ........................ } \\
\text { Total Net Energy }\end{array}$ & 0 & 0 & 0 & $-29,240$ & 0 & 0 \\
\hline 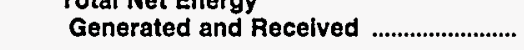 & 510,527 & 354,936 & 247,039 & 621,109 & 164,340 & 533,267 \\
\hline \multicolumn{7}{|l|}{ Disposition of Energy } \\
\hline Sales to Ultimate Consumers ............................ & 454,606 & 340,707 & 233,407 & 449,005 & 149,057 & 512,587 \\
\hline 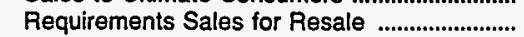 & 0 & 0 & 0 & 148,520 & 0 & \\
\hline Nonrequirements Sales for Resale ................... & 29,878 & 0 & 0 & 0 & 0 & 0 \\
\hline Furnished Without Charge .................................. & 0 & 0 & 0 & 0 & 0 & 0 \\
\hline Used by Utility (excluding station use) ............ & 0 & 205 & 4,079 & 1,320 & 406 & 1,023 \\
\hline 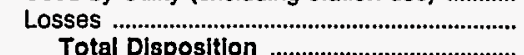 & $\begin{array}{r}26,043 \\
510,527\end{array}$ & $\begin{array}{r}14,024 \\
354,936\end{array}$ & $\begin{array}{r}9,553 \\
247,039\end{array}$ & $\begin{array}{r}22,264 \\
621,109\end{array}$ & $\begin{array}{r}14,877 \\
164,340\end{array}$ & $\begin{array}{r}19,657 \\
533,267\end{array}$ \\
\hline
\end{tabular}

Note: Totals may not equal sum of components because of independent rounding. Double counting occurs in components of both sources and disposition of energy and thus neither provides a true total. Purchases from utilities, net interchanges, and net wheeling (except for imports) are included in net generation. Sales for resale is included in sales to ultimate consumers.

Source: Energy Information Administration, Form EIA-412, "Annual Report of Public Electric Utilities." 
Table 26. Electric Energy Account by Major U.S. Publicly Owned Electric Utility Within State, 1993 (Continued)

(Megawatthours)

\begin{tabular}{|c|c|c|c|c|c|c|}
\hline Item & $\begin{array}{c}\text { New York } \\
\text { Power } \\
\text { Authority } \\
\text { of State of NY } \\
\text { December } 31\end{array}$ & $\begin{array}{l}\text { New York } \\
\text { Rockville } \\
\text { Centre } \\
\text { Village of } \\
\text { May } 31\end{array}$ & $\begin{array}{l}\text { North Carolina } \\
\text { Albemarle } \\
\text { City of } \\
\text { June } 30\end{array}$ & $\begin{array}{l}\text { North Carolina } \\
\text { Concord } \\
\text { City of } \\
\text { June } 30\end{array}$ & $\begin{array}{l}\text { North Carolina } \\
\text { Elizabeth } \\
\text { City City of } \\
\text { June } 30\end{array}$ & $\begin{array}{l}\text { North Carolina } \\
\text { Fayetteville } \\
\text { Public } \\
\text { Works Comm } \\
\\
\text { June } 30\end{array}$ \\
\hline \multicolumn{7}{|l|}{ Sources of Energy } \\
\hline Steam & $2,068,199$ & 0 & $\mathbf{0}$ & 0 & 0 & 0 \\
\hline 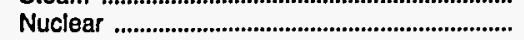 & $5,939,013$ & 0 & 0 & 0 & 0 & 0 \\
\hline 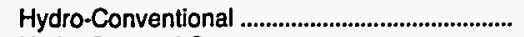 & $24,226,749$ & 0 & 0 & 0 & 0 & 0 \\
\hline Hydro-Pumped Storage ....................................... & $2,014,529$ & 0 & 0 & 0 & 0 & 0 \\
\hline Other & 0 & 19,692 & 0 & 0 & $\mathbf{0}$ & 221,425 \\
\hline (Less) Energy for Pumping .................................... & $3,150,231$ & 0 & 0 & 0 & 0 & \\
\hline 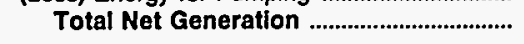 & $31,098,259$ & 19,692 & $\mathbf{0}$ & 0 & $\mathbf{0}$ & 221,425 \\
\hline 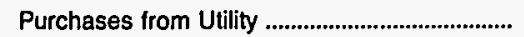 & $7,988,070$ & 156,089 & 270,451 & 392,375 & 242,887 & $1,389,070$ \\
\hline $\begin{array}{l}\text { Purchases from Nonutility ................................... } \\
\text { Power Exchanges }\end{array}$ & 0 & 0 & 0 & 0 & 0 & 0 \\
\hline 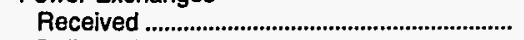 & 570,189 & 0 & 0 & 0 & 0 & 173,830 \\
\hline 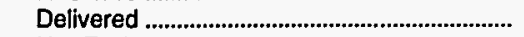 & 368,103 & 0 & 0 & 0 & 0 & 0 \\
\hline 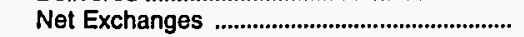 & 202,086 & 0 & 0 & 0 & $\mathbf{0}$ & 173,830 \\
\hline \multicolumn{7}{|l|}{ Transmission for Others (Wheeling) } \\
\hline 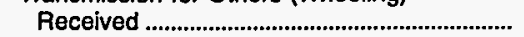 & $2,514,463$ & 0 & 0 & 0 & 0 & 0 \\
\hline 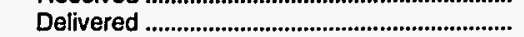 & $2,455,821$ & 0 & 0 & 0 & 0 & 0 \\
\hline Net Transmission for Others & 58,642 & 0 & 0 & 0 & 0 & 0 \\
\hline $\begin{array}{l}\text { Transmission by Others Losses ........................ } \\
\text { Total Net Energy }\end{array}$ & 0 & 0 & 0 & 0 & 0 & 0 \\
\hline 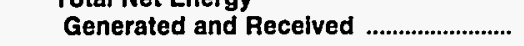 & $39,347,057$ & 175,781 & 270,451 & 392,375 & 242,887 & $1,784,325$ \\
\hline \multicolumn{7}{|l|}{ Disposition of Energy } \\
\hline 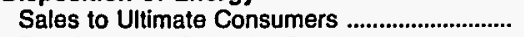 & $13,385,987$ & 164,532 & 242,932 & 358,127 & 219,754 & $1,632,657$ \\
\hline Requirements Sales for Resale ........................ & $4,027,050$ & 0 & 0 & 0 & 0 & 0 \\
\hline Nonrequirements Sales for Resale ................... & $21,107,320$ & 0 & 0 & 0 & 0 & 0 \\
\hline 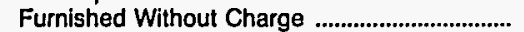 & 8,985 & 0 & 3,892 & 0 & 0 & 0 \\
\hline Used by Utility (excluding station use) ............. & 15,733 & 2,252 & 121 & 3,500 & 0 & 28,550 \\
\hline 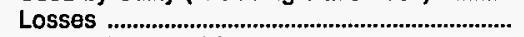 & 801,982 & 8,997 & 23,506 & 30,748 & 23,133 & 123,118 \\
\hline 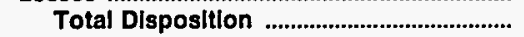 & $39,347,057$ & 175,781 & 270,451 & 392,375 & 242,887 & $1,784,325$ \\
\hline
\end{tabular}

Nole: Totals may not equal sum of components because of independent rounding. Double counting occurs in components of both sources and disposition of energy and thus neither provides a true total. Purchases from utilities, net interchanges, and net wheeling (except for imports) are included in net generation. Sales for resale is included in sales to ultimate consumers.

Source: Energy Information Administration, Form ElA-412, "Annual Report of Public Electric Utilities." 
Table 26. Electric Energy Account by Major U.S. Publicly Owned Electric Utility Within State, 1993 (Continued)

(Megawatthours)

\begin{tabular}{|c|c|c|c|c|c|c|}
\hline Item & $\begin{array}{l}\text { North Carolina } \\
\text { Forest City } \\
\text { Town of } \\
\text { June } 30\end{array}$ & $\begin{array}{l}\text { North Carolina } \\
\text { Gastonia } \\
\text { City of } \\
\text { June } 30\end{array}$ & $\begin{array}{c}\text { North Carolina } \\
\text { Greenville } \\
\text { Utilities } \\
\text { Comm } \\
\text { June } 30\end{array}$ & $\begin{array}{c}\text { North Carolina } \\
\text { High } \\
\text { Point } \\
\text { Town } \\
\text { of } \\
\text { June } 30\end{array}$ & $\begin{array}{l}\text { North Carolina } \\
\text { Kinston } \\
\text { City of } \\
\text { June } 30\end{array}$ & $\begin{array}{l}\text { North Carolina } \\
\text { Lexington } \\
\text { City of } \\
\text { June } 30\end{array}$ \\
\hline \multicolumn{7}{|l|}{ Sources of Energy } \\
\hline 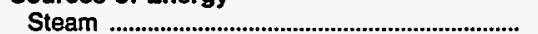 & 0 & 0 & 0 & 0 & 0 & \\
\hline Nuclear ......... & 0 & 0 & 0 & 0 & 0 & 0 \\
\hline 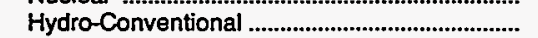 & 0 & 0 & 0 & 0 & 0 & \\
\hline Hydro-Pumped Storage & 0 & 0 & 0 & 0 & 0 & \\
\hline 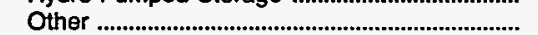 & 0 & 0 & 0 & 0 & 0 & \\
\hline (Less) Energy for Pumping ............................... & 0 & 0 & 0 & 0 & 0 & \\
\hline 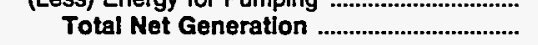 & 0 & 0 & 0 & $\mathbf{0}$ & 0 & \\
\hline 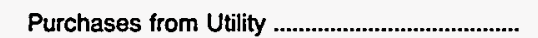 & 144,828 & 609,786 & $1,121,000$ & 833,281 & 444,560 & 446,197 \\
\hline 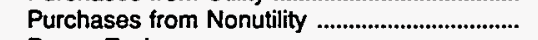 & 0 & 0 & 0 & 0 & 0 & \\
\hline Power Exchanges & & & & & & \\
\hline 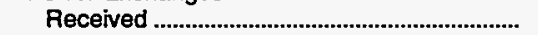 & 0 & 0 & 0 & 0 & 0 & \\
\hline 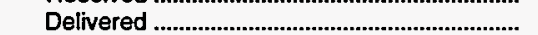 & 0 & 0 & 0 & 0 & 0 & 0 \\
\hline Net Exchanges ................................................ & 0 & 0 & 0 & 0 & 0 & \\
\hline \multicolumn{7}{|l|}{ Transmission for Others (Wheeling) } \\
\hline 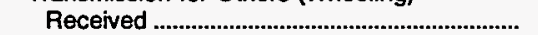 & 0 & 0 & 0 & 0 & 0 & \\
\hline Delivered ............................................................... & 0 & 0 & 0 & 0 & 0 & \\
\hline Net Transmission for Others & 0 & 0 & 0 & 0 & 0 & \\
\hline 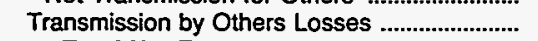 & 0 & 0 & 0 & 0 & 0 & \\
\hline Total Net Energy & & & & & & \\
\hline 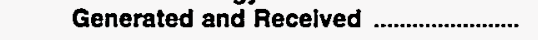 & 144,828 & 609,786 & $1,121,000$ & 833,281 & 444,560 & 446,197 \\
\hline \multicolumn{7}{|l|}{ Disposition of Energy } \\
\hline 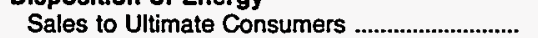 & 126,742 & 550,908 & $1,044,000$ & 770,547 & 408,968 & 423,377 \\
\hline Requirements Sales for Resale ............................. & 0 & 0 & 23,000 & 0 & 0 & \\
\hline 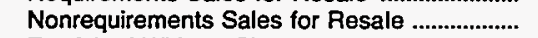 & 0 & 0 & 0 & 0 & 0 & \\
\hline Fumished Without Charge ..................................... & 0 & 0 & 0 & 0 & 0 & \\
\hline Used by Utility (excluding station use) ............. & 8,767 & 0 & 0 & 0 & 0 & \\
\hline 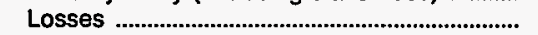 & 9,319 & 58,878 & 54,000 & 62,734 & 35,592 & 22,820 \\
\hline Total Disposition & 144,828 & 609,786 & $1,121,000$ & 833,281 & 444,560 & 446,197 \\
\hline
\end{tabular}

Note: Totals may not equal sum of components because of independent rounding. Double counting occurs in components of both sources and disposition of energy and thus neither provides a true total. Purchases from utilities, net interchanges, and net wheeling (except for imports) are included in net generation. Sales for resale is included in sales to ultimate consumers.

Source: Energy Information Administration, Form ElA-412, "Annual Report of Public Electric Utilities." 
Table 26. Electric Energy Account by Major U.S. Publicly Owned Electric Utility Within State, 1993 (Continued)

(Megawatthours)

\begin{tabular}{|c|c|c|c|c|c|c|}
\hline Item & $\begin{array}{l}\text { North Carolina } \\
\text { Lumberton } \\
\text { City of } \\
\text { June } 30\end{array}$ & $\begin{array}{c}\text { North Carolina } \\
\text { Monroe } \\
\text { City of } \\
\text { June } 30\end{array}$ & $\begin{array}{c}\text { North Carolina } \\
\text { Morganton } \\
\text { City of } \\
\text { June } 30\end{array}$ & $\begin{array}{l}\text { North Carolina } \\
\text { Murphy } \\
\text { City of } \\
\text { June } 30\end{array}$ & $\begin{array}{l}\text { North Carolina } \\
\text { New Bern } \\
\text { City of } \\
\text { June } 30\end{array}$ & $\begin{array}{l}\text { North Carolina } \\
\text { New River } \\
\text { Light } \\
\& \\
\text { Power Co } \\
\text { December } 31\end{array}$ \\
\hline \multicolumn{7}{|l|}{ Sources of Energy } \\
\hline 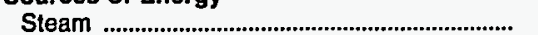 & 0 & 0 & 0 & $\mathbf{0}$ & 0 & 0 \\
\hline 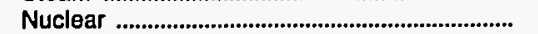 & 0 & 0 & 0 & 0 & 0 & 0 \\
\hline Hydro-Conventional ...................................................... & 0 & 0 & 0 & 0 & 0 & 0 \\
\hline Hydro-Pumped Storage & 0 & 0 & 0 & 0 & 0 & 0 \\
\hline Other & 0 & 0 & 0 & 0 & 0 & $\mathbf{0}$ \\
\hline 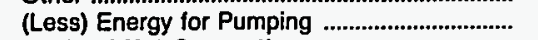 & 0 & 0 & 0 & 0 & 0 & 0 \\
\hline 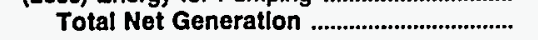 & 0 & 0 & 0 & 0 & 0 & $\mathbf{0}$ \\
\hline 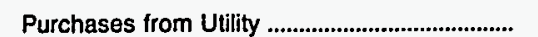 & 274,859 & 413,209 & 284,196 & 129,865 & 371,941 & 172,981 \\
\hline 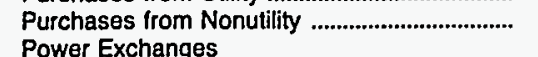 & 0 & 0 & 0 & 0 & 0 & 0 \\
\hline 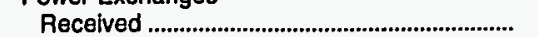 & 0 & 0 & $\mathbf{0}$ & 0 & 0 & $\mathbf{0}$ \\
\hline 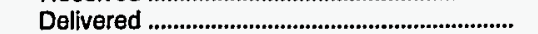 & 0 & 0 & $\mathbf{0}$ & 0 & 0 & 0 \\
\hline 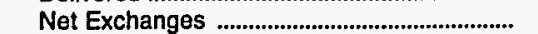 & 0 & 0 & 0 & 0 & 0 & 0 \\
\hline \multicolumn{7}{|l|}{ Transmission for Others (Wheeling) } \\
\hline 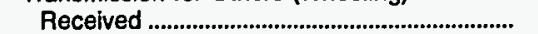 & 0 & 0 & 0 & 0 & 0 & 0 \\
\hline 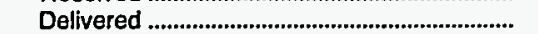 & 0 & 0 & $\mathbf{0}$ & 0 & 0 & $\mathbf{0}$ \\
\hline Net Transmission for Others ................................. & 0 & 0 & 0 & 0 & 0 & 0 \\
\hline 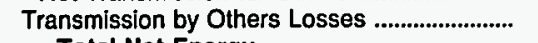 & 0 & 0 & 0 & 0 & 0 & 0 \\
\hline 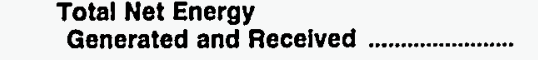 & 274,859 & 413,209 & 284,196 & 129,865 & 371,941 & 172,981 \\
\hline \multicolumn{7}{|l|}{ Dlsposition of Energy } \\
\hline 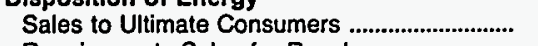 & 257,859 & 388,651 & 263,878 & 124,567 & 348,992 & 166,412 \\
\hline 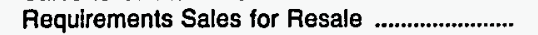 & 0 & 0 & 0 & 0 & 0 & 0 \\
\hline Nonrequirements Sales for Resale ..................... & 0 & $\mathbf{0}$ & 0 & 0 & 0 & 0 \\
\hline Furnished Without Charge .................................... & 3,327 & 0 & 1,389 & 0 & 0 & 0 \\
\hline Used by Utility (excluding station use) ................. & 0 & 0 & 0 & 207 & 2,749 & 0 \\
\hline 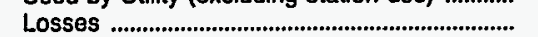 & 13,673 & 24,558 & 18,929 & 5,090 & 20,200 & 6,569 \\
\hline 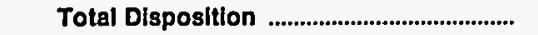 & 274,859 & 413,209 & 284,196 & 129,865 & 371,941 & 172,981 \\
\hline
\end{tabular}

Note: Totals may not equal sum of components because of independent rounding. Double counting occurs in components of both sources and disposition of energy and thus neither provides a true total. Purchases from utilities, net interchanges, and net wheeling (except for imports) are included in net generation. Sales for resale is included in sales to ultimate consumers.

Source: Energy Information Administration, Form EIA-412, "Annual Report of Public Electric Utilities." 
Table 26. Electric Energy Account by Major U.S. Publicly Owned Electric Utility Within State, 1993 (Continued)

(Megawatthours)

\begin{tabular}{|c|c|c|c|c|c|c|}
\hline Item & $\begin{array}{c}\text { North Carolina } \\
\text { North } \\
\text { Carolina } \\
\text { Eastern M P A } \\
\text { December } 31\end{array}$ & $\begin{array}{c}\text { North Carolina } \\
\text { North } \\
\text { Carolina } \\
\text { Mun } \\
\text { Power Agny } \\
\text { December } 31\end{array}$ & $\begin{array}{l}\text { North Carolina } \\
\text { Rocky Mount } \\
\text { City of } \\
\text { June } 30\end{array}$ & $\begin{array}{c}\text { North Carolina } \\
\text { Shelby } \\
\text { City of } \\
\text { June } 30\end{array}$ & $\begin{array}{l}\text { North Carolina } \\
\text { Statesville } \\
\text { City of } \\
\text { June } 30\end{array}$ & $\begin{array}{l}\text { Tarboro } \\
\text { Town of } \\
\text { June } 30\end{array}$ \\
\hline \multicolumn{7}{|l|}{ Sources of Energy } \\
\hline Steam & $1,539,511$ & 0 & 0 & 0 & 0 & 0 \\
\hline 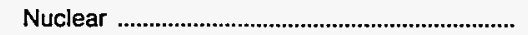 & $1,951,716$ & $5,747,048$ & 0 & 0 & 0 & 0 \\
\hline 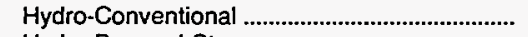 & 0 & 0 & $\mathbf{0}$ & 0 & 0 & 0 \\
\hline 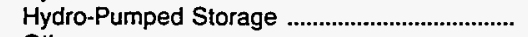 & 0 & 0 & 0 & 0 & 0 & 0 \\
\hline Other & 0 & 0 & $\mathbf{0}$ & 0 & 0 & 0 \\
\hline (Less) Energy for Pumping .................................. & 0 & 0 & 0 & 0 & 0 & 0 \\
\hline 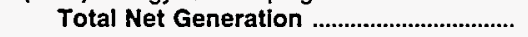 & $3,491,227$ & $5,747,048$ & $\mathbf{0}$ & 0 & 0 & 0 \\
\hline 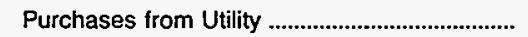 & $3,134,345$ & $2,781,658$ & 775,260 & 180,983 & 379,503 & 243,918 \\
\hline $\begin{array}{l}\text { Purchases from Nonutility ................................ } \\
\text { Power Exchanges }\end{array}$ & 0 & 0 & 0 & 0 & 0 & 0 \\
\hline 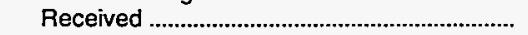 & 0 & 0 & 0 & 0 & 0 & $\mathbf{0}$ \\
\hline 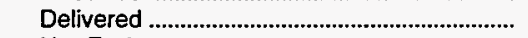 & 0 & 0 & 0 & 0 & 0 & 0 \\
\hline Net Exchanges & 0 & 0 & 0 & 0 & 0 & 0 \\
\hline \multicolumn{7}{|l|}{ Transmission for Others (Wheeling) } \\
\hline Received & 0 & 0 & 0 & 0 & 0 & 0 \\
\hline 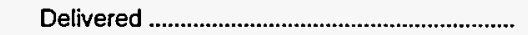 & 0 & 0 & 0 & 0 & 0 & 0 \\
\hline 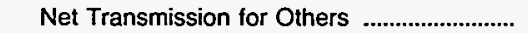 & 0 & 0 & $\mathbf{0}$ & 0 & 0 & 0 \\
\hline $\begin{array}{l}\text { Transmission by Others Losses ......................... } \\
\text { Total Net Energy }\end{array}$ & 0 & 0 & 0 & 0 & 0 & 0 \\
\hline 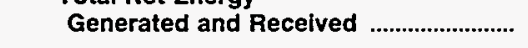 & $6,625,572$ & $8,528,706$ & 775,260 & 180,983 & 379,503 & 243,918 \\
\hline \multicolumn{7}{|l|}{ Disposition of Energy } \\
\hline 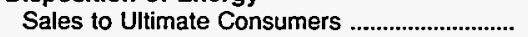 & 0 & 0 & 707,800 & 153,388 & 356,767 & 235,257 \\
\hline 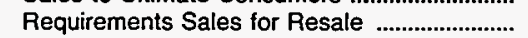 & $6,522,213$ & $8,422,060$ & 16,535 & 0 & 0 & 0 \\
\hline 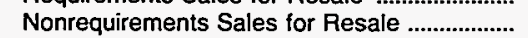 & 0 & 0 & 0 & 0 & 0 & 0 \\
\hline 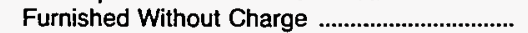 & 0 & 0 & 0 & 0 & 0 & 0 \\
\hline Used by Utility (excluding station use) ............ & 0 & 0 & 0 & 0 & 0 & 0 \\
\hline $\begin{array}{l}\text { Losses } \\
\text { Total Disposition }\end{array}$ & $\begin{array}{r}103,359 \\
6,625,572\end{array}$ & $\begin{array}{r}106,646 \\
8,528,706\end{array}$ & $\begin{array}{r}50,925 \\
775,260\end{array}$ & $\begin{array}{r}27,595 \\
180,983\end{array}$ & $\begin{array}{r}22,736 \\
379,503\end{array}$ & $\begin{array}{r}8,661 \\
243,918\end{array}$ \\
\hline
\end{tabular}

Note: Totals may not equal sum of components because of independent rounding. Double counting occurs in components of both sources and disposition of energy and thus neither provides a true total. Purchases from utilities, net interchanges, and net wheeling (except for imports) are included in net generation. Sales for resale is included in sales to ultimate consumers.

Source: Energy Information Administration, Form EIA-412, "Annual Report of Public Electric Utilities." 
Table 26. Electric Energy Account by Major U.S. Publicly Owned Electric Utility Within State, 1993 (Continued)

(Megawatthours)

\begin{tabular}{|c|c|c|c|c|c|c|}
\hline Item & $\begin{array}{c}\text { North Carolina } \\
\text { Washington } \\
\text { City of } \\
\text { June } 30\end{array}$ & $\begin{array}{l}\text { North Carolina } \\
\text { Wilson } \\
\text { City of } \\
\text { June } 30\end{array}$ & $\begin{array}{c}\text { Ohio } \\
\text { American } \\
\text { Mun } \\
\text { Power } \\
\text { Ohio Inc } \\
\text { December } 31\end{array}$ & $\begin{array}{c}\text { Ohio } \\
\text { Bowling } \\
\text { Green } \\
\text { City of } \\
\text { December } 31\end{array}$ & $\begin{array}{l}\text { Ohio } \\
\text { Bryan } \\
\text { City of } \\
\text { December } 31\end{array}$ & $\begin{array}{c}\text { Ohio } \\
\text { Celina } \\
\text { City of } \\
\text { December } 31\end{array}$ \\
\hline \multicolumn{7}{|l|}{ Sources of Energy } \\
\hline Steam ........................... & 0 & 0 & $1,293,268$ & 0 & 0 & \\
\hline 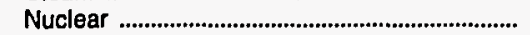 & 0 & 0 & 0 & 0 & 0 & 0 \\
\hline 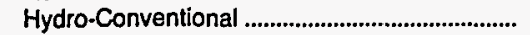 & 0 & 0 & 0 & 0 & 0 & 0 \\
\hline 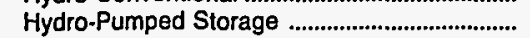 & 0 & 0 & 0 & 0 & 0 & 0 \\
\hline Other & 0 & 0 & 0 & 0 & 860 & 0 \\
\hline 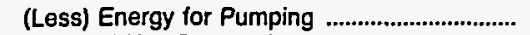 & 0 & 0 & 0 & 0 & 0 & \\
\hline 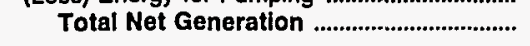 & $\mathbf{0}$ & 0 & $1,293,268$ & 0 & 860 & o \\
\hline 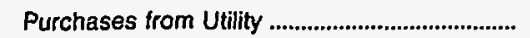 & 236,518 & 992,606 & $3,450,706$ & 294,995 & 196,358 & 163,997 \\
\hline 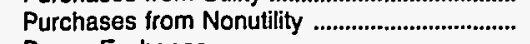 & 0 & 0 & 0 & 0 & 0 & \\
\hline \multicolumn{7}{|l|}{ Power Exchanges } \\
\hline 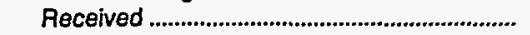 & 0 & 0 & 0 & 0 & 0 & 0 \\
\hline 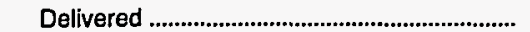 & 0 & 0 & 0 & 0 & 0 & 0 \\
\hline Net Exchanges & 0 & 0 & 0 & 0 & 0 & 0 \\
\hline \multicolumn{7}{|l|}{ Transmission for Others (Wheeling) } \\
\hline 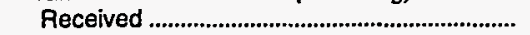 & 0 & 0 & 90,742 & 0 & 0 & \\
\hline 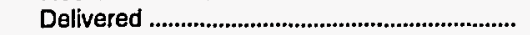 & 0 & 0 & 90.742 & 0 & 0 & 0 \\
\hline Net Transmission for Others .................................. & 0 & 0 & 0 & 0 & 0 & 0 \\
\hline 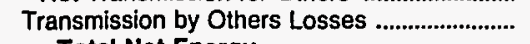 & 0 & 0 & 0 & 0 & 0 & 0 \\
\hline $\begin{array}{l}\text { Total Net Energy } \\
\text { Generated and Recelved }\end{array}$ & 236,518 & 992,606 & $4,743,974$ & 294,995 & 197,218 & 163,997 \\
\hline \multicolumn{7}{|l|}{ Dlsposition of Energy } \\
\hline 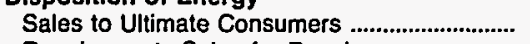 & 220,803 & 878,963 & 492,484 & 275,949 & 187,380 & 151,024 \\
\hline Requirements Sales for Resale ............................. & 0 & 58,814 & $4,094,070$ & 3,075 & 0 & \\
\hline Nonrequirements Sales for Resale .................... & 0 & 0 & 0 & 0 & 0 & 0 \\
\hline 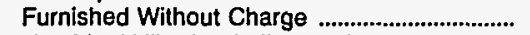 & 0 & 0 & 0 & 3,504 & 1,477 & 2,179 \\
\hline Used by Utility (excluding station use) .............. & 0 & 0 & 0 & 155 & 2,367 & 356 \\
\hline 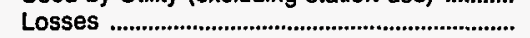 & 15,715 & 54,829 & 157,420 & 12,312 & 5,994 & 10,438 \\
\hline Total Disposition ................................................... & 236,518 & 992,606 & $4,743,974$ & 294,995 & 197,218 & 163,997 \\
\hline
\end{tabular}

Note: Totals may not equal sum of components because of independent rounding. Double counting occurs in components of both sources and disposition of energy and thus neither provides a true total. Purchases from utilities, net interchanges, and net wheeling (except for imports) are included in net generation. Sales for resale is included in sales to ultimate consumers.

Source: Energy Information Administration, Form EIA-412, "Annual Report of Public Electric Utilities." 
Table 26. Electric Energy Account by Major U.S. Publicly Owned Electric Utility Within State, 1993 (Continued)

(Megawatthours)

\begin{tabular}{|c|c|c|c|c|c|c|}
\hline Item & $\begin{array}{c}\text { Ohio } \\
\text { Cleveland } \\
\text { City of } \\
\text { December } 31\end{array}$ & $\begin{array}{c}\text { Ohio } \\
\text { Columbus } \\
\text { City of } \\
\text { December } 31\end{array}$ & $\begin{array}{c}\text { Ohio } \\
\text { Cuyahoga } \\
\text { Falls } \\
\text { City of } \\
\text { December } 31\end{array}$ & $\begin{array}{c}\text { Ohio } \\
\text { Dover } \\
\text { City of } \\
\text { December } 31\end{array}$ & $\begin{array}{c}\text { Ohio } \\
\text { Hamilton } \\
\text { City of } \\
\text { December } 31\end{array}$ & $\begin{array}{c}\text { Ohio } \\
\begin{array}{c}\text { Napoleon } \\
\text { City of }\end{array} \\
\text { December } 31\end{array}$ \\
\hline \multicolumn{7}{|l|}{ Sources of Energy } \\
\hline Steam & 0 & 64,990 & 0 & 61,952 & 314,400 & 0 \\
\hline 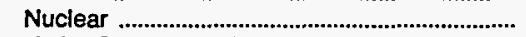 & 0 & 0 & 0 & 0 & 0 & 0 \\
\hline 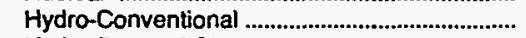 & 0 & 7,716 & 0 & 0 & 281,854 & 0 \\
\hline 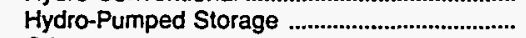 & 0 & 0 & 0 & 0 & 0 & 0 \\
\hline Other & 6,226 & 0 & 0 & 0 & 3,023 & 0 \\
\hline 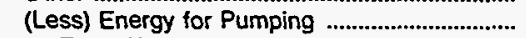 & 0 & 0 & 0 & 0 & 0 & 0 \\
\hline 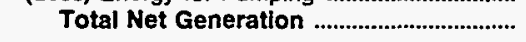 & 6,226 & 72,706 & $\mathbf{0}$ & 61,952 & 599,277 & 0 \\
\hline 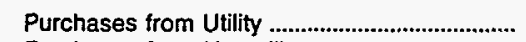 & $1,031,531$ & 584,893 & 317,800 & 124,444 & 181,811 & 143,427 \\
\hline $\begin{array}{l}\text { Purchases from Nonutility } \\
\text { Power Exchanges }\end{array}$ & 0 & 0 & 0 & 0 & 0 & 0 \\
\hline 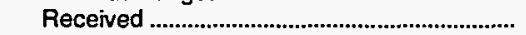 & 0 & 0 & 0 & 0 & 7,271 & 0 \\
\hline Delivered & $\mathbf{0}$ & 0 & 0 & 0 & 11,248 & 0 \\
\hline Net Exchanges & 0 & 0 & 0 & 0 & $-3,977$ & 0 \\
\hline \multicolumn{7}{|l|}{ Transmission for Others (Wheeling) } \\
\hline 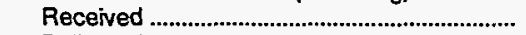 & 0 & 347,565 & 0 & 0 & 0 & 0 \\
\hline 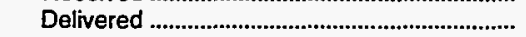 & 0 & 347,565 & 0 & 0 & 0 & 0 \\
\hline 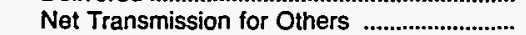 & 0 & 0 & 0 & 0 & 0 & 0 \\
\hline $\begin{array}{l}\text { Transmission by Others Losses ..................................... } \\
\text { Total Net Energy }\end{array}$ & 0 & 0 & 0 & 0 & 0 & 0 \\
\hline 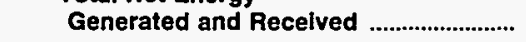 & $1,037,757$ & 657,599 & 317,800 & 186,396 & 777,111 & 143,427 \\
\hline \multicolumn{7}{|l|}{ Disposition of Energy } \\
\hline 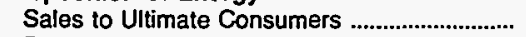 & 935,807 & 584,218 & 285,535 & 176,616 & 532,701 & 135,756 \\
\hline 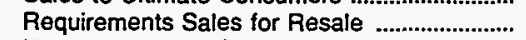 & 0 & 3,750 & 0 & 0 & 168,392 & 0 \\
\hline 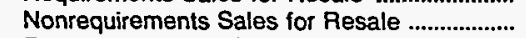 & 0 & 0 & 0 & 0 & 18,988 & 0 \\
\hline 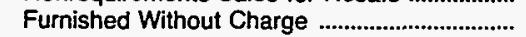 & 0 & 27,594 & 10,302 & 0 & 10,912 & 1,215 \\
\hline 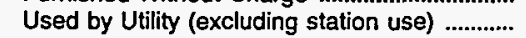 & 1,859 & 1,212 & 136 & 110 & 0 & 0 \\
\hline Losses & 100,091 & 40,825 & 21,827 & 9,670 & 46,118 & 6,456 \\
\hline Total Disposition & $1,037,757$ & 657,599 & 317,800 & 186,396 & 777,111 & 143,427 \\
\hline
\end{tabular}

Note: Totals may not equal sum of components because of independent rounding. Double counting occurs in components of both sources and disposition of energy and thus neither provides a true total. Purchases from utilities, net interchanges, and net wheeling (except for imports) are included in net generation. Sales for resale is included in sales to ultimate consumers.

Source: Energy Information Administration, Form EIA-412, "Annual Report of Public Electric Utilities." 
Table 26. Electric Energy Account by Major U.S. Publicly Owned Electric Utility Within State, 1993 (Continued)

(Megawatthours)

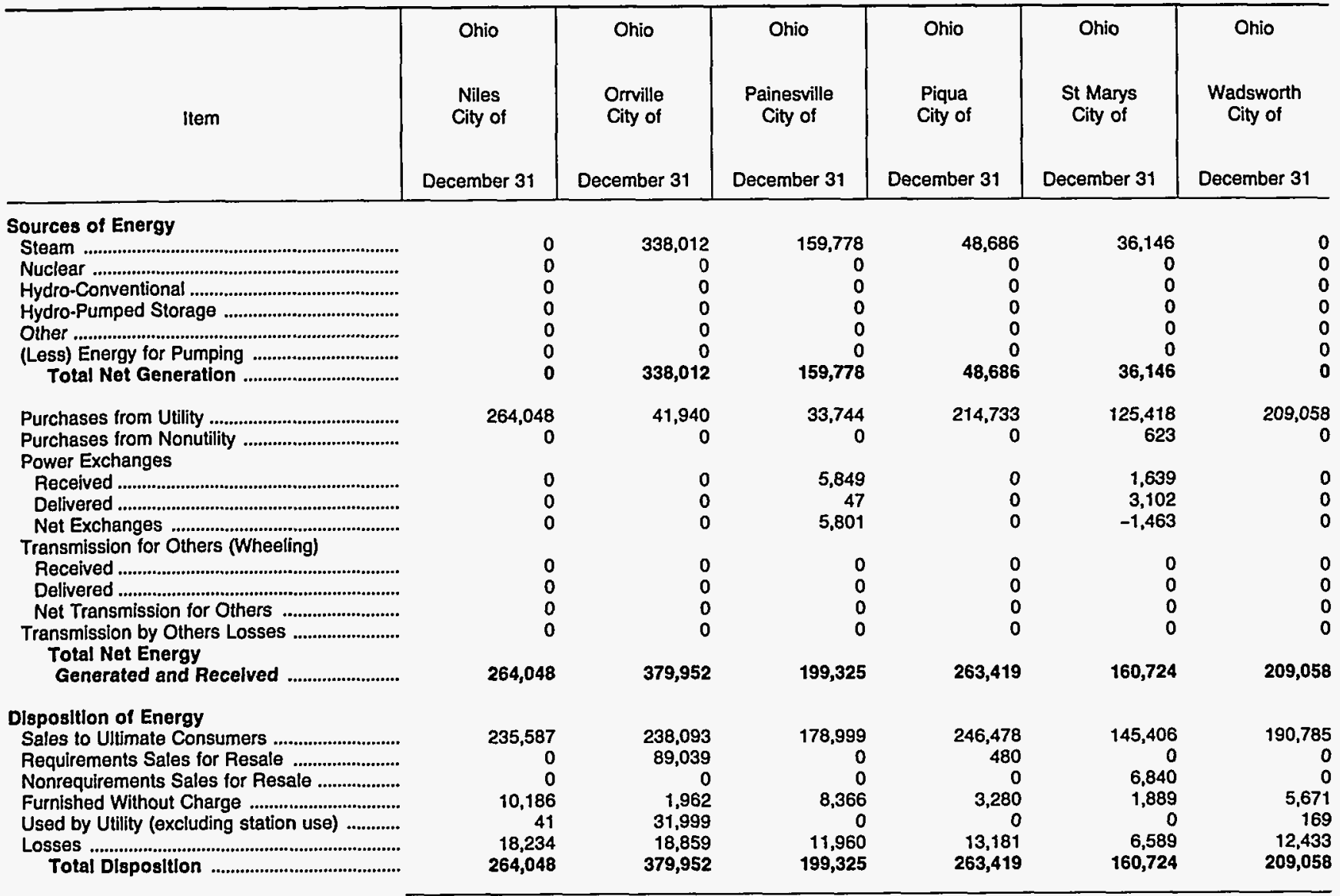

Note: Totals may not equal sum of components because of independent rounding. Double counting occurs in components of both sources and disposition of energy and thus neither provides a true total. Purchases from utilities, net interchanges, and net wheeling (except for imports) are included in net generation. Sales for resale is included in sales to ultimate consumers.

Source: Energy Information Administration, Form EIA-412, "Annual Report of Public Electric Utilities." 
Table 26. Electric Energy Account by Major U.S. Publicly Owned Electric Utility Within State, 1993 (Continued)

(Megawatthours)

\begin{tabular}{|c|c|c|c|c|c|c|}
\hline Item & $\begin{array}{c}\text { Ohio } \\
\text { Wapakoneta } \\
\text { City of }\end{array}$ & $\begin{array}{c}\text { Ohio } \\
\text { Westerville } \\
\text { City of } \\
\text { December } 31\end{array}$ & $\begin{array}{l}\text { Oklahoma } \\
\text { Altus } \\
\text { City of } \\
\text { June } 30\end{array}$ & $\begin{array}{c}\text { Oklahoma } \\
\text { Claremore } \\
\text { City of } \\
\text { June } 30\end{array}$ & $\begin{array}{l}\text { Oklahoma } \\
\text { Duncan } \\
\text { City of } \\
\text { June } 30\end{array}$ & $\begin{array}{l}\text { Oklahoma } \\
\text { Edmond } \\
\text { City of } \\
\text { June } 30\end{array}$ \\
\hline \multicolumn{7}{|l|}{ Sources of Energy } \\
\hline Steam & 0 & 0 & 0 & 0 & 0 & 0 \\
\hline 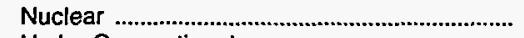 & 0 & 0 & 0 & 0 & 0 & 0 \\
\hline Hydro-Conventional & 0 & 0 & 0 & 0 & 0 & 0 \\
\hline 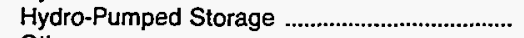 & 0 & 0 & 0 & 0 & 0 & 0 \\
\hline Other & 0 & 0 & 0 & 0 & 0 & 0 \\
\hline 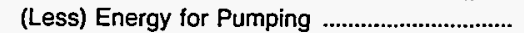 & 0 & 0 & 0 & 0 & 0 & 0 \\
\hline 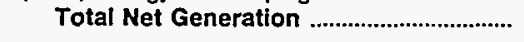 & $\mathbf{0}$ & 0 & 0 & 0 & o & 0 \\
\hline 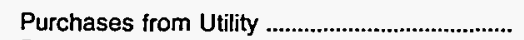 & 156,085 & 338,445 & 142,492 & 205,924 & 152,459 & 448,421 \\
\hline 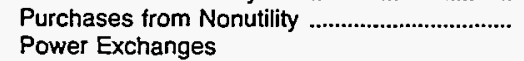 & 0 & 0 & 0 & 0 & 0 & 0 \\
\hline Received & 0 & 0 & 0 & 0 & 0 & 0 \\
\hline 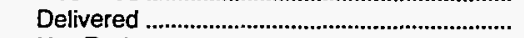 & $\mathbf{0}$ & 0 & 0 & 0 & 0 & 0 \\
\hline Net Exchanges & 0 & 0 & 0 & 0 & 0 & 0 \\
\hline \multicolumn{7}{|l|}{ Transmission for Others (Wheeling) } \\
\hline Received & 0 & 0 & 0 & 0 & 0 & 0 \\
\hline 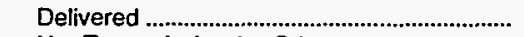 & 0 & 0 & 0 & 0 & 0 & 0 \\
\hline Net Transmission for Others & 0 & 0 & 0 & 0 & 0 & 0 \\
\hline $\begin{array}{l}\text { Transmission by Others Losses ............................ } \\
\text { Total Net Energy }\end{array}$ & 0 & 0 & 0 & 0 & 0 & 0 \\
\hline 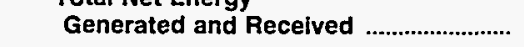 & 156,085 & 338,445 & 142,492 & 205,924 & 152,459 & 448,421 \\
\hline \multicolumn{7}{|l|}{ Disposition of Energy } \\
\hline 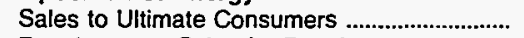 & 146,860 & 316,584 & 129,668 & 192,048 & 144,843 & 393,230 \\
\hline Requirements Sales for Resale ........................... & 0 & 0 & 0 & 0 & 0 & 0 \\
\hline Nonrequirements Sales for Resale .................. & 0 & 0 & 0 & 0 & 0 & 0 \\
\hline 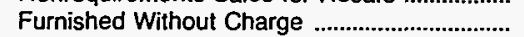 & 9,225 & 13,778 & 0 & 3,618 & 0 & 18,643 \\
\hline 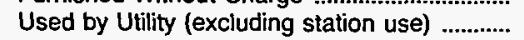 & 0 & 0 & 0 & 49 & 0 & 155 \\
\hline 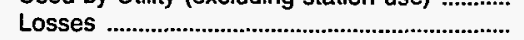 & 0 & 8,083 & 12,824 & 10,209 & 7,616 & 36,393 \\
\hline Total Disposition & 156,085 & 338,445 & 142,492 & 205,924 & 152,459 & 448,421 \\
\hline
\end{tabular}

Note: Totals may not equal sum of components because of independent rounding. Double counting occurs in components of both sources and disposition of energy and thus neither provides a true total. Purchases from utilities, net interchanges, and net wheeling (except for imports) are included in net generation. Sales for resale is included in sales to ultimate consumers.

Source: Energy Information Administration, Form ElA-412, "Annual Report of Public Electric Utilities." 
Table 26. Electric Energy Account by Major U.S. Publicly Owned Electric Utility Within State, 1993 (Continued) (Megawatthours)

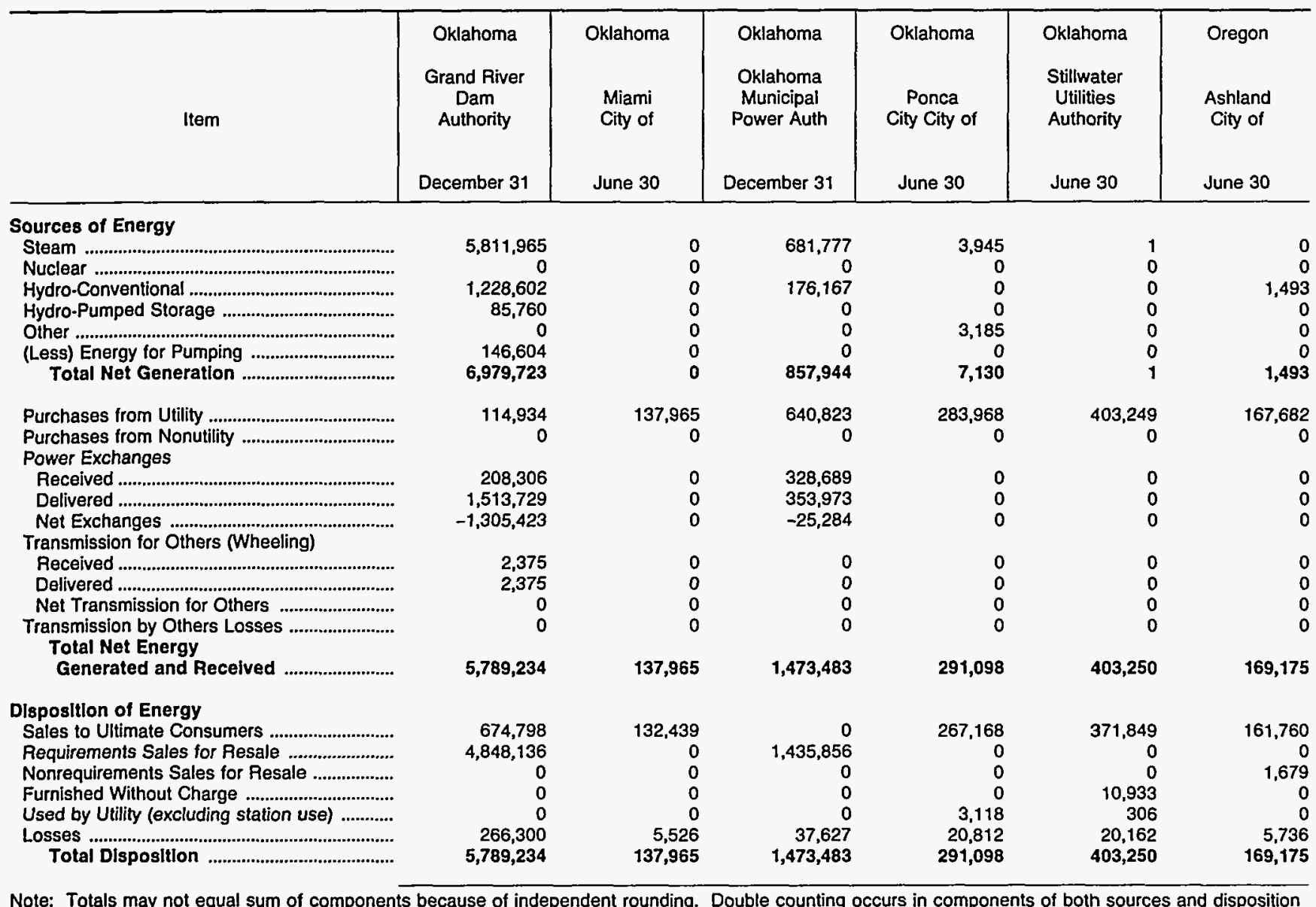
of energy and thus neither provides a true total. Purchases from utilities, net interchanges, and net wheeling (except for imports) are included in net generation. Sales for resale is included in sales to ultimate consumers.

Source: Energy Information Administration, Form EIA-412, "Annual Report of Public Electric Utilities." 
Table 26. Electric Energy Account by Major U.S. Publicly Owned Electric Utility Within State, 1993 (Continued)

(Megawatthours)

\begin{tabular}{|c|c|c|c|c|c|c|}
\hline Item & $\begin{array}{c}\text { Oregon } \\
\text { Central } \\
\text { Lincoln } \\
\text { Peoples } \\
\text { Utt Dt } \\
\text { December } 31\end{array}$ & $\begin{array}{c}\text { Oregon } \\
\text { Clatskanie } \\
\text { Peoples } \\
\text { Util Dist } \\
\text { December } 31\end{array}$ & $\begin{array}{c}\text { Oregon } \\
\text { Columbia } \\
\text { River } \\
\text { Peoples } \\
\text { Ut Dist } \\
\text { December } 31\end{array}$ & $\begin{array}{l}\text { Oregon } \\
\text { Emerald } \\
\text { Peoples } \\
\text { Utility Dist } \\
\text { December } 31\end{array}$ & $\begin{array}{l}\text { Oregon } \\
\text { Eugene } \\
\text { City of } \\
\text { December } 31\end{array}$ & $\begin{array}{c}\text { Oregon } \\
\begin{array}{c}\text { Forest Grove } \\
\text { City of }\end{array} \\
\text { June } 30\end{array}$ \\
\hline \multicolumn{7}{|l|}{ Sources of Energy } \\
\hline Steam & 0 & 0 & 0 & 0 & 127,132 & 0 \\
\hline 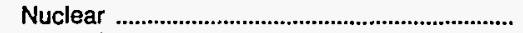 & 0 & 0 & 0 & 0 & 0 & 0 \\
\hline 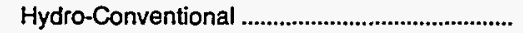 & 0 & 0 & 0 & 0 & 385,848 & 0 \\
\hline 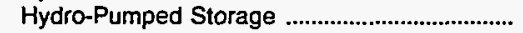 & 0 & 0 & 0 & 0 & 0 & 0 \\
\hline Other & 0 & 0 & 0 & 13,927 & 0 & 0 \\
\hline 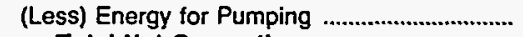 & 0 & 0 & 0 & 0 & 0 & 0 \\
\hline Total Net Generation & 0 & 0 & $\mathbf{0}$ & 13,927 & 512,980 & 0 \\
\hline 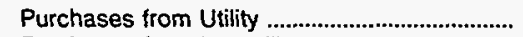 & $1,358,244$ & 901,355 & 280,899 & 387,436 & $2,631,866$ & 217,195 \\
\hline $\begin{array}{l}\text { Purchases from Nonutility ...................................... } \\
\text { Power Exchanges }\end{array}$ & 0 & 0 & 0 & 40 & 58,555 & 0 \\
\hline Received & 0 & 0 & 0 & 0 & 124,839 & 0 \\
\hline 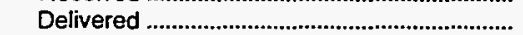 & 0 & 0 & 0 & 0 & 408,852 & 0 \\
\hline Net Exchanges & 0 & 0 & 0 & 0 & $-284,013$ & 0 \\
\hline \multicolumn{7}{|l|}{ Transmission for Others (Wheeling) } \\
\hline Received & 0 & 0 & 0 & 0 & 0 & 0 \\
\hline 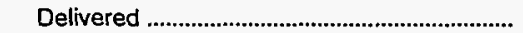 & 0 & 0 & 0 & 0 & 0 & 0 \\
\hline 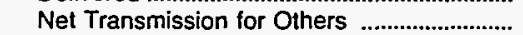 & 0 & 0 & 0 & 0 & 0 & 0 \\
\hline Transmission by Others Losses ........................ & 0 & 0 & 0 & 0 & 0 & 0 \\
\hline $\begin{array}{l}\text { Total Net Energy } \\
\text { Generated and Received }\end{array}$ & $1,358,244$ & 901,355 & 280,899 & 401,403 & $2,919,388$ & 217,195 \\
\hline \multicolumn{7}{|l|}{ Disposition of Energy } \\
\hline 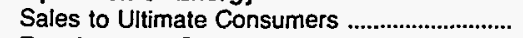 & $1,314,113$ & 897,085 & 272,346 & 374,777 & $2,480,025$ & 208,932 \\
\hline Requirements Sales for Resale .......................... & 0 & 0 & 0 & 0 & 0 & 0 \\
\hline Nonrequirements Sales for Resale .................. & 0 & 0 & 0 & 0 & 328,757 & 0 \\
\hline Furnished Without Charge .................................. & 0 & 0 & 0 & 0 & 0 & 0 \\
\hline Used by Utility (excluding station use) ............ & 1,763 & 164 & 385 & 0 & 0 & 0 \\
\hline Losses & 42,367 & 4,106 & 8,168 & 26,626 & 110,606 & 8,263 \\
\hline 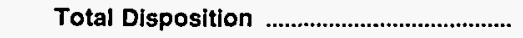 & $1,358,244$ & 901,355 & 280,899 & 401,403 & $2,919,388$ & 217,195 \\
\hline
\end{tabular}

Note: Totals may not equal sum of components because of independent rounding. Double counting occurs in components of both sources and disposition of energy and thus neither provides a true total. Purchases from utilities, net interchanges, and net wheeling (except for imports) are included in net generation. Sales for resale is included in sales to ultimate consumers.

Source: Energy Information Administration, Form EIA-412, "Annual Report of Public Electric Utilities." 
Table 26. Electric Energy Account by Major U.S. Publicly Owned Electric Utility Within State, 1993 (Continued)

(Megawatthours)

\begin{tabular}{|c|c|c|c|c|c|c|}
\hline Item & $\begin{array}{c}\text { Oregon } \\
\begin{array}{c}\text { McMinnville } \\
\text { City of }\end{array} \\
\text { June } 30\end{array}$ & $\begin{array}{c}\text { Oregon } \\
\text { Northern } \\
\text { Wasco County } \\
\text { P U D } \\
\text { December } 31\end{array}$ & $\begin{array}{c}\text { Oregon } \\
\text { Springfield } \\
\text { City of } \\
\text { December } 31\end{array}$ & $\begin{array}{l}\text { Oregon } \\
\text { Tillamook } \\
\text { Peoples } \\
\text { Utility Dist } \\
\text { December } 31\end{array}$ & $\begin{array}{c}\text { Pennsylvania } \\
\text { Chambersburg } \\
\text { Borough of } \\
\text { December } 31\end{array}$ & $\begin{array}{c}\text { Pennsylvania } \\
\text { Lansdale } \\
\text { Borough of } \\
\text { December } 31\end{array}$ \\
\hline \multicolumn{7}{|l|}{ Sources of Energy } \\
\hline Steam & 0 & 0 & 0 & 0 & 0 & 0 \\
\hline 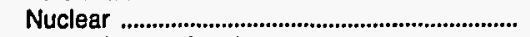 & 0 & 0 & 0 & 0 & 0 & 0 \\
\hline Hydro-Conventional ............................................ & 0 & 38,778 & 0 & 0 & 0 & 0 \\
\hline Hydro-Pumped Storage & 0 & 0 & 0 & 0 & 0 & 0 \\
\hline 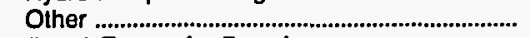 & 0 & 0 & 0 & 0 & 1,182 & 0 \\
\hline 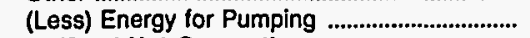 & 0 & 0 & 0 & 0 & 0 & 0 \\
\hline 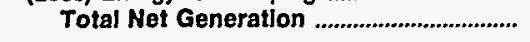 & 0 & 38,778 & $\mathbf{0}$ & 0 & 1,182 & o \\
\hline 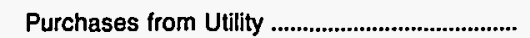 & 627,274 & 259,013 & 831,857 & 380,006 & 241,598 & 139,779 \\
\hline $\begin{array}{l}\text { Purchases from Nonutility ................................... } \\
\text { Power Exchanges }\end{array}$ & 0 & 0 & 0 & 0 & 0 & 0 \\
\hline Received & 0 & 0 & 0 & 0 & 0 & 0 \\
\hline 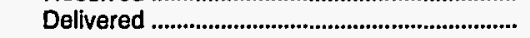 & $\mathbf{0}$ & 0 & 0 & 0 & 0 & 0 \\
\hline Net Exchanges & 0 & 0 & 0 & $\mathbf{0}$ & 0 & 0 \\
\hline \multicolumn{7}{|l|}{ Transmission for Others (Wheeling) } \\
\hline 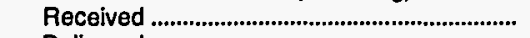 & 0 & 0 & 0 & 0 & 0 & 0 \\
\hline Delivered & 0 & 0 & 0 & 0 & 0 & 0 \\
\hline Net Transmission for Others & 0 & 0 & 0 & 0 & 0 & 0 \\
\hline Transmission by Others Losses ....................... & 0 & 0 & 0 & 0 & 0 & 0 \\
\hline 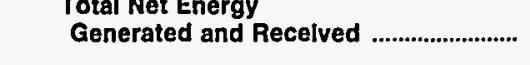 & 627,274 & 297,791 & 831,857 & 380,006 & 242,780 & 139,779 \\
\hline \multicolumn{7}{|l|}{ Disposition of Energy } \\
\hline Sales to Ultimate Consumers .............................. & 612,789 & 252,343 & 803,012 & 360,912 & 231,277 & 135,613 \\
\hline Requirements Sales for Resale ........................ & 0 & 0 & 0 & $\mathbf{0}$ & 0 & \\
\hline Nonrequirements Sales for Resale .................. & 0 & 38,778 & 0 & 0 & 0 & 0 \\
\hline Furnished Without Charge ................................. & 0 & 0 & 0 & 0 & 0 & 0 \\
\hline Used by Utility (excluding station use) ............ & 652 & 222 & 3,844 & 0 & 0 & 1,260 \\
\hline 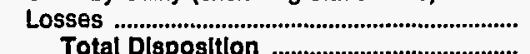 & 13,833 & $\begin{array}{r}6,448 \\
207701\end{array}$ & $\begin{array}{r}25,001 \\
\end{array}$ & 19,094 & $\begin{array}{r}11,503 \\
2,780\end{array}$ & $\begin{array}{r}2,906 \\
139770\end{array}$ \\
\hline 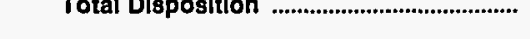 & 627,274 & 297,791 & 837,857 & 380,006 & 242,780 & 139,779 \\
\hline
\end{tabular}


Table 26. Electric Energy Account by Major U.S. Publicly Owned Electric Utility Within State, 1993 (Continued)

(Megawatthours)

\begin{tabular}{|c|c|c|c|c|c|c|}
\hline Item & $\begin{array}{l}\text { South Carolina } \\
\text { Camden } \\
\text { City of } \\
\text { June } 30\end{array}$ & $\begin{array}{l}\text { South Carolina } \\
\text { Easley } \\
\text { Combined } \\
\text { Utility } \\
\text { System } \\
\text { March } 31\end{array}$ & $\begin{array}{l}\text { South Carolina } \\
\begin{array}{c}\text { Gaffney } \\
\text { City of }\end{array} \\
\text { March } 31\end{array}$ & $\begin{array}{l}\text { South Carolina } \\
\text { Greenwood } \\
\text { Commissioners } \\
\text { Pub Wk } \\
\text { December } 31\end{array}$ & $\begin{array}{c}\text { South Carolina } \\
\text { Greer } \\
\text { Comm } \\
\text { of } \\
\text { Public Works } \\
\text { December } 31\end{array}$ & $\begin{array}{l}\text { South Carolina } \\
\text { Newberry } \\
\text { City of } \\
\text { June } 30\end{array}$ \\
\hline \multirow{2}{*}{\multicolumn{7}{|c|}{ Sources of Energy }} \\
\hline & & & 0 & 0 & 0 & 0 \\
\hline 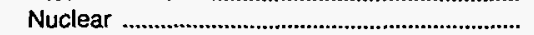 & 0 & 0 & 0 & 0 & 0 & 0 \\
\hline 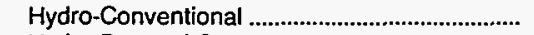 & 0 & 0 & 0 & 0 & 0 & 0 \\
\hline 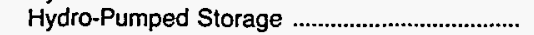 & 0 & 0 & 0 & 0 & 0 & 0 \\
\hline Other & 0 & 0 & 0 & 0 & 0 & 0 \\
\hline 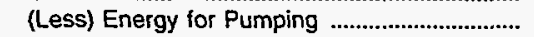 & 0 & 0 & 0 & 0 & 0 & 0 \\
\hline Total Net Generation & 0 & 0 & 0 & $\mathbf{0}$ & 0 & 0 \\
\hline Purchases from Utility ................................................ & 160,042 & 212,906 & 187,051 & 247,842 & 170,470 & 141,512 \\
\hline 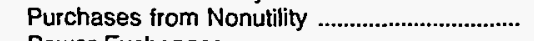 & 2 & 0 & 0 & 0 & 0 & \\
\hline \multicolumn{7}{|l|}{ Power Exchanges } \\
\hline 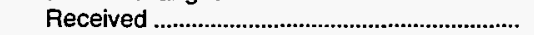 & 0 & 0 & 0 & 0 & 0 & 0 \\
\hline 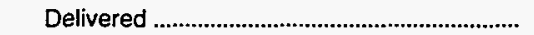 & 0 & 0 & 0 & 0 & 0 & 0 \\
\hline Net Exchanges .................................................... & 0 & 0 & 0 & 0 & 0 & 0 \\
\hline \multicolumn{7}{|l|}{ Transmission for Others (Wheeling) } \\
\hline 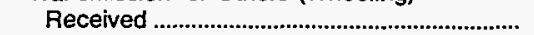 & 0 & 0 & 0 & 0 & 0 & 0 \\
\hline 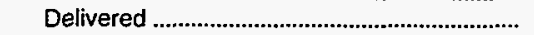 & 0 & 0 & 0 & 0 & 0 & 0 \\
\hline Net Transmission for Others ............................... & 0 & 0 & 0 & 0 & 0 & 0 \\
\hline 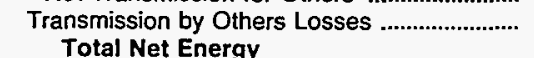 & 0 & 0 & 0 & 0 & 0 & $\mathbf{0}$ \\
\hline Generated and Received & 160,044 & 212,906 & 187,051 & 247,842 & 170,470 & 141,512 \\
\hline \multicolumn{7}{|l|}{ Disposition of Energy } \\
\hline Sales to Ultimate Consumers .............................. & 141,804 & 188,358 & 160,694 & 235,750 & 155,073 & 130,663 \\
\hline Requirements Sales for Resale ............................... & 0 & 0 & 0 & 0 & 0 & 0 \\
\hline Nonrequirements Sales for Resale .................... & 0 & 0 & 0 & 0 & 0 & 0 \\
\hline Furnished Without Charge ................................ & 5,000 & 2,187 & 2,157 & 0 & 4,315 & 1,272 \\
\hline Used by Utility (excluding station use) ............. & 0 & 8,295 & 9,520 & 0 & 2,157 & 0 \\
\hline Losses ...1. & 13,240 & 14,066 & 14,680 & 12,092 & 8,925 & 9.577 \\
\hline Total Disposition & 160,044 & 212,906 & 187,051 & 247,842 & 170,470 & 141,512 \\
\hline
\end{tabular}

Note: Totals may not equal sum of components because of independent rounding. Double counting occurs in components of both sources and disposition of energy and thus neither provides a true total. Purchases from utilities, net interchanges, and net wheeling (except for imports) are included in net generation. Sales for resale is included in sales to ultimate consumers.

Source: Energy Information Administration, Form EIA-412, "Annual Report of Public Electric Utilities." 
Table 26. Electric Energy Account by Major U.S. Publicly Owned Electric Utility Within State, 1993 (Continued)

(Megawatthours)

\begin{tabular}{|c|c|c|c|c|c|c|}
\hline Item & $\begin{array}{l}\text { South Carolina } \\
\text { Orangeburg } \\
\text { City of }\end{array}$ & $\begin{array}{l}\text { South Carolina } \\
\text { Piedmont } \\
\text { Municipal } \\
\text { Power Agny } \\
\text { December } 31\end{array}$ & 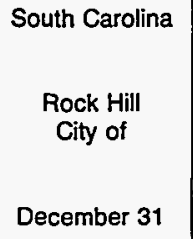 & $\begin{array}{l}\text { South Carolina } \\
\text { Seneca } \\
\text { City of } \\
\text { June } 30\end{array}$ & $\begin{array}{l}\text { South Carolina } \\
\text { South } \\
\text { Carolina } \\
\text { Pub } \\
\text { Serv Auth } \\
\text { December } 31\end{array}$ & $\begin{array}{l}\text { South Dakota } \\
\text { Brookings } \\
\text { City of } \\
\text { December } 31\end{array}$ \\
\hline \multicolumn{7}{|l|}{ Sources of Energy } \\
\hline Steam & 0 & 0 & 0 & 0 & $11,974,224$ & \\
\hline 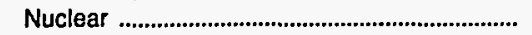 & 0 & $1,974,383$ & 0 & 0 & $2,029,822$ & 0 \\
\hline 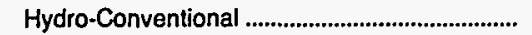 & 0 & 0 & 0 & 0 & 507,748 & 0 \\
\hline Hydro-Pumped Storage ........................................... & 0 & 0 & 0 & 0 & 0 & 0 \\
\hline Other & 5,016 & 0 & 0 & 0 & 4,185 & \\
\hline 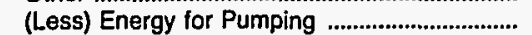 & & 0 & 0 & 0 & 0 & 0 \\
\hline 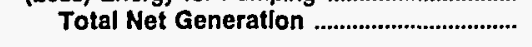 & 5,016 & $1,974,383$ & 0 & 0 & $14,515,979$ & 0 \\
\hline 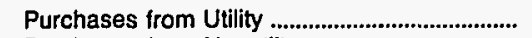 & 737,090 & $1,150,423$ & 519,495 & 140,226 & 315,600 & 185,017 \\
\hline 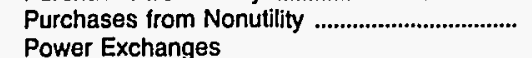 & 0 & & 0 & 0 & 1,875 & \\
\hline 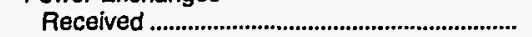 & 0 & 187,487 & 0 & 0 & 56,081 & 0 \\
\hline Delivered ...................................................................... & $\mathbf{0}$ & 246,203 & $\mathbf{0}$ & 0 & 45,560 & \\
\hline 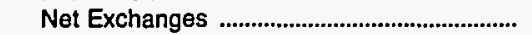 & 0 & $-58,716$ & 0 & 0 & 10,521 & 0 \\
\hline \multicolumn{7}{|l|}{ Transmission for Others (Wheeling) } \\
\hline 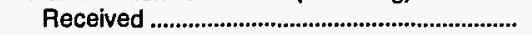 & $\mathbf{0}$ & 0 & 0 & 0 & 479,390 & 0 \\
\hline 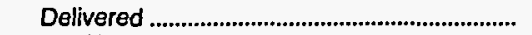 & 0 & 0 & 0 & 0 & 472,387 & \\
\hline 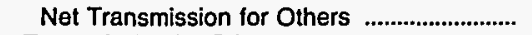 & 0 & 0 & 0 & 0 & 7,003 & 0 \\
\hline 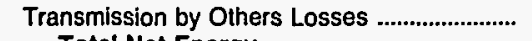 & 0 & 0 & 0 & 0 & 0 & 0 \\
\hline $\begin{array}{l}\text { Total Net Energy } \\
\text { Generated and Recelved }\end{array}$ & 742,106 & $3,066,090$ & 519,495 & 140,226 & $14,850,978$ & 185,017 \\
\hline \multicolumn{7}{|l|}{ Dlsposition of Energy } \\
\hline 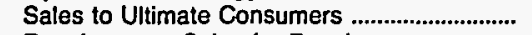 & 702,539 & 0 & 493,332 & 128,845 & $7,370,739$ & 176,643 \\
\hline 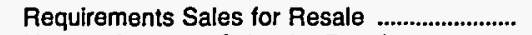 & 0 & $3,048,229$ & 0 & 0 & $7,059,116$ & \\
\hline Nonrequirements Sales for Resale ................... & 0 & 0 & 0 & 0 & 0 & 0 \\
\hline 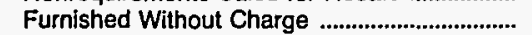 & 0 & 0 & 0 & 0 & 0 & \\
\hline Used by Utility (excluding station use) ............. & 0 & 0 & 0 & 4,324 & 17,135 & 0 \\
\hline Losses & 39,567 & 17,861 & 26,163 & 7,057 & 403,988 & 8,374 \\
\hline Total Dispositlon & 742,106 & $3,066,090$ & 519,495 & 140,226 & $14,850,978$ & 185,017 \\
\hline
\end{tabular}

Note: Totals may not equal sum of components because of independent rounding. Double counting occurs in components of both sources and disposition of energy and thus neither provides a true total. Purchases from utilities, net interchanges, and net wheeling (except for imports) are included in net generation. Sales for resale is included in sales to ultimate consumers.

Source: Energy Information Administration, Form EIA-412, "Annual Report of Public Electric Utilities." 
Table 26. Electric Energy Account by Major U.S. Publicly Owned Electric Utility Within State, 1993 (Continued) (Megawatthours)

\begin{tabular}{|c|c|c|c|c|c|c|}
\hline Item & $\begin{array}{l}\text { South Dakota } \\
\text { Heartland } \\
\text { Consumers } \\
\text { Power Dist } \\
\text { December } 31\end{array}$ & $\begin{array}{l}\text { South Dakota } \\
\text { Missouri } \\
\text { Basin } \\
\text { Mun } \\
\text { Power Agny } \\
\text { December } 31\end{array}$ & $\begin{array}{c}\text { South Dakota } \\
\text { Pierre } \\
\text { City of } \\
\text { December } 31\end{array}$ & $\begin{array}{l}\text { South Dakota } \\
\text { Watertown } \\
\text { Municipal } \\
\text { Utilities } \\
\text { December } 31\end{array}$ & $\begin{array}{c}\text { Tennessee } \\
\text { Alcoa } \\
\text { Utilities } \\
\text { June } 30\end{array}$ & $\begin{array}{l}\text { Tennessee } \\
\text { Athens } \\
\text { Utility } \\
\text { Board } \\
\text { June } 30\end{array}$ \\
\hline \multicolumn{7}{|l|}{ Sources of Energy } \\
\hline Steam & 290,946 & 0 & 0 & 0 & 0 & 0 \\
\hline Nuclear & 0 & 0 & 0 & $\mathbf{0}$ & 0 & 0 \\
\hline 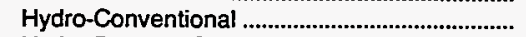 & $\mathbf{0}$ & 0 & 0 & 0 & 0 & 0 \\
\hline 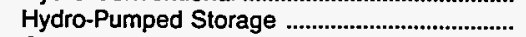 & 0 & 0 & 0 & 0 & 0 & 0 \\
\hline Other & 0 & 0 & 0 & 0 & 0 & 0 \\
\hline 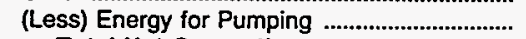 & 0 & 0 & 0 & 0 & 0 & 0 \\
\hline 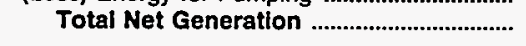 & 290,946 & $\mathbf{0}$ & 0 & 0 & 0 & 0 \\
\hline 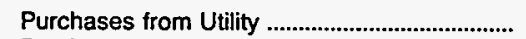 & 134,535 & $1,866,743$ & 163,197 & 218,453 & 433,944 & 526,876 \\
\hline $\begin{array}{l}\text { Purchases from Nonutility } \\
\text { Power Exchanges }\end{array}$ & 0 & 0 & 0 & 0 & 0 & 0 \\
\hline 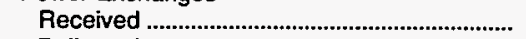 & 10,633 & 1,978 & 0 & 0 & 0 & 0 \\
\hline 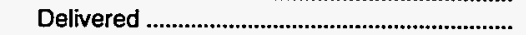 & 3,511 & 287 & 0 & 0 & 0 & 0 \\
\hline Net Exchanges & 7,122 & 1,691 & 0 & 0 & 0 & 0 \\
\hline \multicolumn{7}{|l|}{ Transmission for Others (Wheeling) } \\
\hline 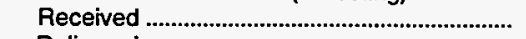 & 0 & 0 & 0 & 0 & 0 & 0 \\
\hline 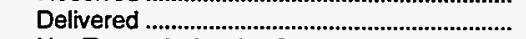 & 0 & 0 & 0 & 0 & 0 & 0 \\
\hline 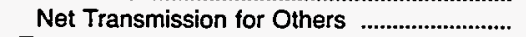 & 0 & 0 & 0 & 0 & 0 & 0 \\
\hline $\begin{array}{l}\text { Transmission by Others Losses ............................ } \\
\text { Total Net Energy }\end{array}$ & 0 & 0 & 0 & 0 & 0 & 0 \\
\hline Generated and Recelved ........................... & 432,603 & $1,868,434$ & 163,197 & 218,453 & 433,944 & 526,876 \\
\hline \multicolumn{7}{|l|}{ Disposition of Energy } \\
\hline 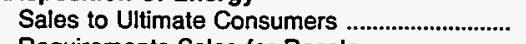 & 0 & 0 & 143,126 & 208,912 & 405,037 & 503,558 \\
\hline 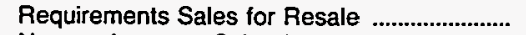 & 401,059 & 905,862 & 13,351 & 0 & 0 & 0 \\
\hline Nonrequirements Sales for Resale .................. & 0 & 918,823 & 0 & 0 & 0 & 0 \\
\hline 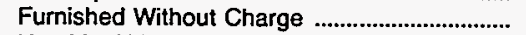 & 0 & 0 & 0 & 0 & 0 & 0 \\
\hline Used by Utility (excluding station use) ............. & 0 & 0 & 2,000 & 0 & 246 & 673 \\
\hline 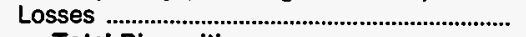 & 31,544 & 43,749 & 4,720 & 9,541 & 28,660 & 22,644 \\
\hline Total Disposition & 432,603 & $1,868,434$ & 163,197 & 218,453 & 433,944 & 526,876 \\
\hline
\end{tabular}

Note: Totals may not equal sum of components because of independent rounding. Double counting occurs in components of both sources and disposition of energy and thus neither provides a true total. Purchases from utilities, net interchanges, and net wheeling (except for imports) are included in net generation. Sales for resale is included in sales to ultimate consumers.

Source: Energy Information Administration, Form EIA-412, "Annual Report of Public Electric Utilities." 
Table 26. Electric Energy Account by Major U.S. Publicly Owned Electric Utility Within State, 1993 (Continued)

(Megawatthours)

\begin{tabular}{|c|c|c|c|c|c|c|}
\hline Item & $\begin{array}{l}\text { Tennessee } \\
\text { Benton } \\
\text { County } \\
\text { June } 30\end{array}$ & $\begin{array}{l}\text { Tennessee } \\
\text { Bolivar } \\
\text { City of } \\
\text { June } 30\end{array}$ & $\begin{array}{l}\text { Tennessee } \\
\text { Bristol } \\
\text { City of } \\
\text { June } 30\end{array}$ & $\begin{array}{l}\text { Tennessee } \\
\text { Brownsville } \\
\text { City of } \\
\text { June } 30\end{array}$ & $\begin{array}{l}\text { Tennessee } \\
\text { Carroll } \\
\text { County } \\
\text { June } 30\end{array}$ & $\begin{array}{l}\text { Tennessee } \\
\text { Chattanooga } \\
\text { City of } \\
\text { June } 30\end{array}$ \\
\hline \multicolumn{7}{|l|}{ Sources of Energy } \\
\hline Steam & 0 & 0 & 0 & 0 & $\mathbf{0}$ & 0 \\
\hline 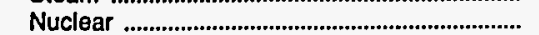 & 0 & 0 & 0 & 0 & 0 & 0 \\
\hline 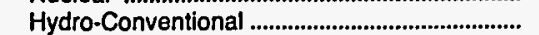 & 0 & 0 & 0 & 0 & 0 & 0 \\
\hline Hydro-Pumped Storage ........................................ & 0 & 0 & 0 & 0 & 0 & 0 \\
\hline 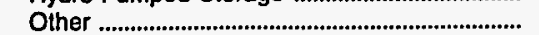 & 0 & 0 & 0 & 0 & 0 & 0 \\
\hline 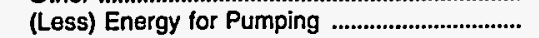 & 0 & 0 & 0 & 0 & 0 & 0 \\
\hline 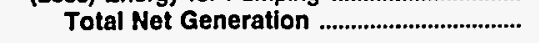 & o & $\mathbf{0}$ & $\mathbf{0}$ & $\mathbf{0}$ & 0 & $\mathbf{0}$ \\
\hline 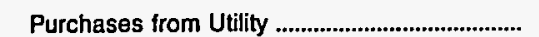 & 208,768 & 232,253 & 779,304 & 184,900 & 373,681 & $5,450,977$ \\
\hline $\begin{array}{l}\text { Purchases from Nonutility } \\
\text { Power Exchanges }\end{array}$ & 0 & 0 & 0 & 0 & 0 & 0 \\
\hline 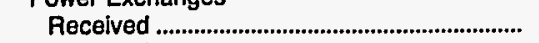 & 0 & 0 & 0 & $\mathbf{0}$ & 0 & 0 \\
\hline 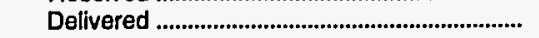 & 0 & 0 & 0 & 0 & 0 & 0 \\
\hline 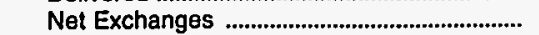 & 0 & 0 & 0 & 0 & 0 & 0 \\
\hline \multicolumn{7}{|l|}{ Transmission for Others (Wheeling) } \\
\hline 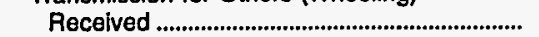 & $\mathbf{0}$ & 0 & 0 & 0 & 0 & 0 \\
\hline 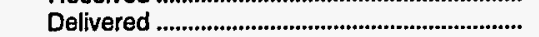 & 0 & 0 & 0 & 0 & 0 & 0 \\
\hline Net Transmission for Others ................................... & 0 & 0 & 0 & 0 & 0 & 0 \\
\hline Transmission by Others Losses .............................. & 0 & 0 & 0 & 0 & 0 & 0 \\
\hline $\begin{array}{l}\text { Total Net Energy } \\
\text { Generated and Recelved }\end{array}$ & 208,768 & 232,253 & 779,304 & 184,900 & 373,681 & $5,450,977$ \\
\hline \multicolumn{7}{|l|}{ Disposition of Energy } \\
\hline 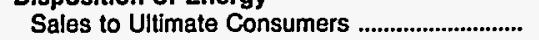 & 192,844 & 216,124 & 742,743 & 178,084 & 349,462 & $5,262,184$ \\
\hline Requirements Sales for Resale ............................. & 0 & 0 & 0 & 0 & 0 & 0 \\
\hline Nonrequirements Sales for Resale .................... & 0 & 0 & 0 & 0 & 0 & 0 \\
\hline 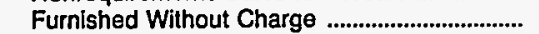 & 0 & 0 & 0 & 0 & 0 & 0 \\
\hline Used by Utility (excluding station use) ............. & 233 & 277 & 877 & 105 & 177 & 8,329 \\
\hline 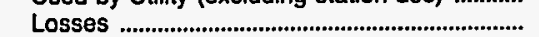 & 15,691 & 15,851 & 35,684 & 6,710 & 24,041 & 180,463 \\
\hline 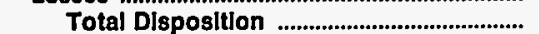 & 208,768 & 232,253 & 779,304 & 184,900 & 373,681 & $5,450,977$ \\
\hline
\end{tabular}

Note: Totals may not equal sum of components because of independent rounding. Double counting occurs in components of both sources and disposition of energy and thus neither provides a true total. Purchases from utilities, net interchanges, and net wheeling (except for imports) are included in net generation. Sales for resale is included in sales to ultimate consumers.

Source: Energy Information Administration, Form EIA-412, "Annual Report of Public Electric Utilities." 
Table 26. Electric Energy Account by Major U.S. Publicly Owned Electric Utility Within State, 1993 (Continued)

(Megawatthours)

\begin{tabular}{|c|c|c|c|c|c|c|}
\hline Item & $\begin{array}{l}\text { Tennessee } \\
\text { Clarksville } \\
\text { City of } \\
\text { June } 30\end{array}$ & $\begin{array}{l}\text { Tennessee } \\
\text { Cleveland } \\
\text { City of } \\
\text { June } 30\end{array}$ & $\begin{array}{l}\text { Tennessee } \\
\text { Clinton } \\
\text { City of } \\
\text { June } 30\end{array}$ & $\begin{array}{l}\text { Tennessee } \\
\text { Columbia } \\
\text { City of } \\
\text { June } 30\end{array}$ & $\begin{array}{c}\text { Tennessee } \\
\text { Cookeville } \\
\text { City of } \\
\text { June } 30\end{array}$ & $\begin{array}{c}\text { Tennessee } \\
\text { Covington } \\
\text { City of } \\
\text { June } 30\end{array}$ \\
\hline \multicolumn{7}{|l|}{ Sources of Energy } \\
\hline Steam & 0 & 0 & 0 & 0 & 0 & 0 \\
\hline Nuclear & 0 & 0 & 0 & 0 & 0 & 0 \\
\hline 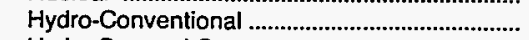 & 0 & 0 & 0 & 0 & 0 & 0 \\
\hline Hydro-Pumped Storage & 0 & 0 & 0 & 0 & 0 & 0 \\
\hline Other & 0 & 0 & 0 & 0 & 0 & 0 \\
\hline 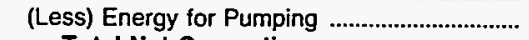 & 0 & 0 & 0 & 0 & 0 & 0 \\
\hline Total Net Generation & 0 & 0 & 0 & $\mathbf{0}$ & $\mathbf{0}$ & 0 \\
\hline 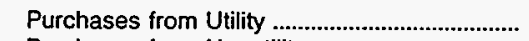 & 811,928 & 878,023 & 601,818 & 502,863 & 454,576 & 194,141 \\
\hline 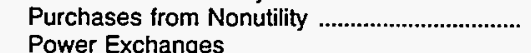 & 0 & 0 & 0 & 0 & 0 & 0 \\
\hline 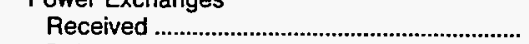 & 0 & 0 & 0 & 0 & 0 & 0 \\
\hline Delivered & 0 & 0 & 0 & 0 & 0 & 0 \\
\hline Net Exchanges & 0 & 0 & 0 & 0 & 0 & 0 \\
\hline \multicolumn{7}{|l|}{ Transmission for Others (Wheeling) } \\
\hline Received & 0 & 0 & 0 & 0 & 0 & 0 \\
\hline 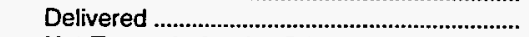 & 0 & 0 & 0 & 0 & 0 & 0 \\
\hline Net Transmission for Others & 0 & 0 & 0 & 0 & 0 & 0 \\
\hline 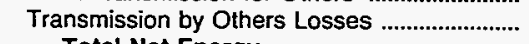 & 0 & 0 & 0 & 0 & 0 & 0 \\
\hline \multicolumn{7}{|l|}{ Total Net Energy } \\
\hline Generated and Received ........................... & 811,928 & 878,023 & 601,818 & 502,863 & 454,576 & 194,141 \\
\hline \multicolumn{7}{|l|}{ Disposition of Energy } \\
\hline Sales to Ultimate Consumers & 778,398 & 843,488 & 567,394 & 475,813 & 436,674 & 188,531 \\
\hline 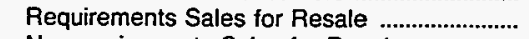 & 0 & 0 & 0 & 0 & 0 & 0 \\
\hline Nonrequirements Sales for Resale .................... & 0 & 0 & 0 & 0 & $\mathbf{0}$ & 0 \\
\hline 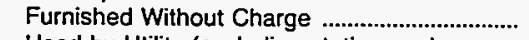 & 0 & 0 & 0 & 0 & 0 & 0 \\
\hline Used by Utility (excluding station use) ............ & 1,027 & 1,333 & 0 & 1,013 & 269 & 165 \\
\hline Losses & 32,502 & 33,201 & 34,423 & 26,035 & 17,632 & 5,445 \\
\hline Total Disposition & 811,928 & 878,023 & 601,818 & 502,863 & 454,576 & 194,141 \\
\hline
\end{tabular}

Note: Totals may not equal sum of components because of independent rounding. Double counting occurs in components of both sources and disposition of energy and thus neither provides a true total. Purchases from utilities, net interchanges, and net wheeling (except for imports) are included in net generation. Sales for resale is included in sales to ultimate consumers.

Source: Energy Information Administration, Form EIA-412, "Annual Report of Public Electric Utilities." 
Table 26. Electric Energy Account by Major U.S. Publicly Owned Electric Utility Within State, 1993 (Continued)

(Megawatthours)

\begin{tabular}{|c|c|c|c|c|c|c|}
\hline Item & $\begin{array}{l}\text { Tennessee } \\
\text { Dayton } \\
\text { City of } \\
\text { June } 30\end{array}$ & $\begin{array}{l}\text { Tennessee } \\
\text { Dickson } \\
\text { City of } \\
\text { June } 30\end{array}$ & $\begin{array}{l}\text { Tennessee } \\
\text { Dyersburg } \\
\text { City of } \\
\text { June } 30\end{array}$ & $\begin{array}{c}\text { Tennessee } \\
\begin{array}{c}\text { Elizabethton } \\
\text { City of }\end{array} \\
\text { June } 30\end{array}$ & $\begin{array}{c}\text { Tennessee } \\
\text { Enwin } \\
\text { Town of } \\
\text { June } 30\end{array}$ & $\begin{array}{l}\text { Tennessee } \\
\text { Etowah } \\
\text { City of } \\
\text { June } 30\end{array}$ \\
\hline \multicolumn{7}{|l|}{ Sources of Energy } \\
\hline 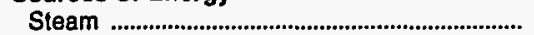 & 0 & 0 & 0 & 0 & 0 & \\
\hline 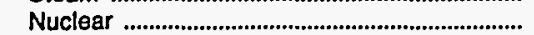 & 0 & 0 & 0 & 0 & 0 & 0 \\
\hline 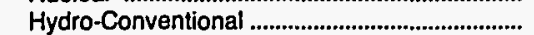 & 0 & 0 & 0 & 0 & 0 & 0 \\
\hline 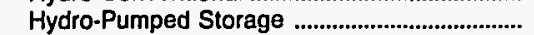 & 0 & 0 & 0 & 0 & 0 & 0 \\
\hline Other & 0 & 0 & 0 & 0 & 0 & 0 \\
\hline 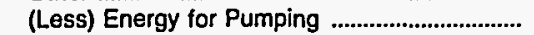 & 0 & 0 & 0 & 0 & 0 & \\
\hline 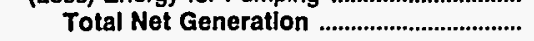 & 0 & $\mathbf{0}$ & 0 & 0 & 0 & o \\
\hline 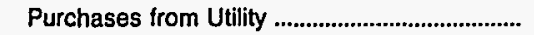 & 196,115 & 574,960 & 582,499 & 497,924 & 209,510 & 146,079 \\
\hline Purchases from Nonutility ..................................... & 0 & 0 & 0 & 0 & 0 & \\
\hline Power Exchanges & & & & & & \\
\hline 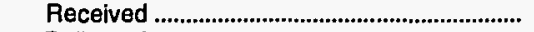 & 0 & 0 & 0 & 0 & 0 & 0 \\
\hline Delivered ................................................................... & 0 & 0 & 0 & 0 & 0 & 0 \\
\hline 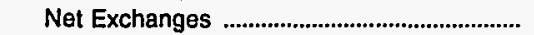 & 0 & 0 & 0 & 0 & 0 & 0 \\
\hline \multicolumn{7}{|l|}{ Transmission for Others (Wheeling) } \\
\hline Received ................................................................. & 0 & 0 & 0 & 0 & 0 & 0 \\
\hline Delivered .............................................................. & 0 & 0 & 0 & 0 & 0 & \\
\hline Net Transmission for Others ............................. & 0 & 0 & 0 & 0 & 0 & 0 \\
\hline 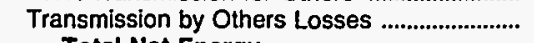 & 0 & 0 & 0 & 0 & 0 & 0 \\
\hline $\begin{array}{l}\text { Total Net Energy } \\
\text { Generated and Received }\end{array}$ & 196,115 & 574,960 & 582,499 & 497,924 & 209,510 & 146,079 \\
\hline \multicolumn{7}{|l|}{ Dlsposition of Energy } \\
\hline 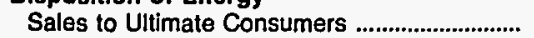 & 184,245 & 542,028 & 564,554 & 469,776 & 199,991 & 140,944 \\
\hline Requirements Sales for Resale .......................... & & 0 & 0 & 0 & 0 & \\
\hline Nonrequirements Sales for Resale .................... & 0 & 0 & 0 & 0 & 0 & 0 \\
\hline 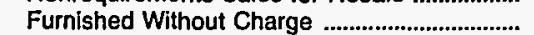 & 0 & 0 & 0 & 0 & 0 & 0 \\
\hline Used by Utility (excluding station use) ............. & 0 & 250 & 308 & 655 & 261 & 0 \\
\hline 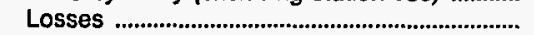 & 11,870 & 32,681 & 17,635 & 27,493 & 9,257 & 5,135 \\
\hline 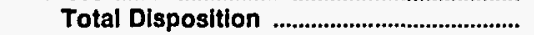 & 196,115 & 574,960 & 582,499 & 497,924 & 209,510 & 146,079 \\
\hline
\end{tabular}

Note: Totals may not equal sum of components because of independent rounding. Double counting occurs in components of both sources and disposition of energy and thus neither provides a true total. Purchases from utilities, net interchanges, and net wheeling (except for imports) are included in net generation. Sales for resale is included in sales to ultimate consumers.

Source: Energy Information Administration, Form EIA-412, "Annual Report of Public Electric Utilities." 
Table 26. Electric Energy Account by Major U.S. Publicly Owned Electric Utility Within State, 1993 (Continued)

(Megawatthours)

\begin{tabular}{|c|c|c|c|c|c|c|}
\hline Item & $\begin{array}{l}\text { Tennessee } \\
\text { Fayetteville } \\
\text { City of } \\
\text { June } 30\end{array}$ & $\begin{array}{l}\text { Tennessee } \\
\text { Gallatin } \\
\text { City of } \\
\text { June } 30\end{array}$ & $\begin{array}{l}\text { Tennessee } \\
\text { Greeneville } \\
\text { City of } \\
\text { June } 30\end{array}$ & $\begin{array}{l}\text { Tennessee } \\
\begin{array}{c}\text { Harriman } \\
\text { City of }\end{array} \\
\text { June } 30\end{array}$ & $\begin{array}{c}\text { Tennessee } \\
\begin{array}{c}\text { Humboldt } \\
\text { City of }\end{array} \\
\text { June } 30\end{array}$ & $\begin{array}{c}\text { Tennessee } \\
\text { Jackson } \\
\text { City of } \\
\text { June } 30\end{array}$ \\
\hline \multicolumn{7}{|l|}{ Sources of Energy } \\
\hline Steam & 0 & 0 & 0 & 0 & 0 & 0 \\
\hline 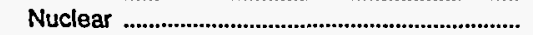 & 0 & 0 & 0 & 0 & 0 & 0 \\
\hline 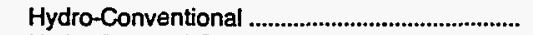 & 0 & 0 & 0 & 0 & 0 & 0 \\
\hline 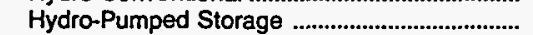 & 0 & 0 & 0 & 0 & 0 & 0 \\
\hline Other & 0 & 0 & 0 & 0 & 0 & 0 \\
\hline 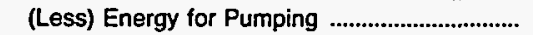 & 0 & 0 & 0 & 0 & 0 & 0 \\
\hline Total Net Generation & 0 & 0 & 0 & 0 & 0 & 0 \\
\hline 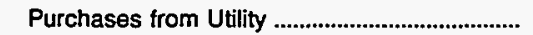 & 361,906 & 430,454 & 896,789 & 231,675 & 216,182 & $1,145,677$ \\
\hline 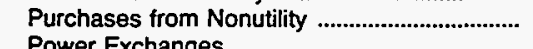 & 0 & 0 & 0 & 0 & 0 & \\
\hline 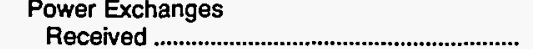 & 0 & 0 & 0 & 0 & 0 & \\
\hline Delivered …………………………………………..... & 0 & 0 & 0 & 0 & 0 & $\begin{array}{l}0 \\
0\end{array}$ \\
\hline Net Exchanges & 0 & 0 & 0 & 0 & 0 & 0 \\
\hline \multicolumn{7}{|l|}{ Transmission for Others (Wheeling) } \\
\hline 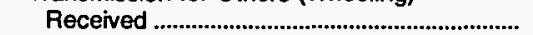 & 0 & 0 & 0 & 0 & 0 & 0 \\
\hline Delivered .................................................................. & 0 & 0 & 0 & 0 & 0 & 0 \\
\hline Net Transmission for Others & 0 & 0 & 0 & 0 & 0 & 0 \\
\hline $\begin{array}{l}\text { Transmission by Others Losses ............................. } \\
\text { Total Net Energy }\end{array}$ & 0 & 0 & 0 & 0 & 0 & 0 \\
\hline 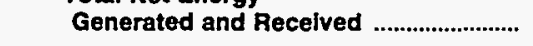 & 361,906 & 430,454 & 896,789 & 231,675 & 216,182 & $1,145,677$ \\
\hline \multicolumn{7}{|l|}{ Dlsposition of Energy } \\
\hline Sales to Ultimate Consumers ................................. & 338,643 & 416,813 & 855,713 & 211,852 & 206,691 & $1,111,362$ \\
\hline 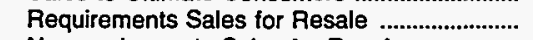 & 0 & 0 & 0 & 0 & 0 & \\
\hline Nonrequirements Sales for Resale ....................... & 0 & 0 & 0 & 0 & 0 & 0 \\
\hline 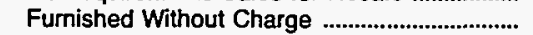 & 0 & 0 & 0 & 0 & 0 & 0 \\
\hline Used by Utility (excluding station use) ............. & 534 & 271 & 800 & 393 & 129 & 0 \\
\hline Losses & 22,728 & 13,369 & 40,275 & 19,429 & 9,361 & 34,315 \\
\hline Total Disposition & 361,906 & 430,454 & 896,789 & 231,675 & 216,182 & $1,145,677$ \\
\hline
\end{tabular}

Note: Totals may not equal sum of components because of independent rounding. Double counting occurs in components of both sources and disposition of energy and thus neither provides a true total. Purchases from utilities, net interchanges, and net wheeling (except for imports) are included in net generation. Sales for resale is included in sales to ultimate consumers.

Source: Energy Information Administration, Form EIA-412, "Annual Report of Public Electric Utilities." 
Table 26. Electric Energy Account by Major U.S. Publicly Owned Electric Utility Within State, 1993 (Continued)

(Megawatthours)

\begin{tabular}{|c|c|c|c|c|c|c|}
\hline Item & $\begin{array}{l}\text { Tennessee } \\
\text { Johnson } \\
\text { City City of } \\
\text { June } 30\end{array}$ & $\begin{array}{c}\text { Tennessee } \\
\text { Knoxville } \\
\text { Utilities } \\
\text { Board } \\
\text { June } 30\end{array}$ & $\begin{array}{l}\text { Tennessee } \\
\begin{array}{c}\text { Lawrenceburg } \\
\text { City of }\end{array} \\
\text { June } 30\end{array}$ & $\begin{array}{l}\text { Tennessee } \\
\text { LaFollette } \\
\text { City of } \\
\text { June } 30\end{array}$ & $\begin{array}{l}\text { Tennessee } \\
\text { Lebanon } \\
\text { City of } \\
\text { June } 30\end{array}$ & $\begin{array}{l}\text { Tennessee } \\
\text { Lenoir } \\
\text { City City of } \\
\text { June } 30\end{array}$ \\
\hline \multicolumn{7}{|l|}{ Sources of Energy } \\
\hline Steam & 0 & 0 & 0 & 0 & 0 & \\
\hline 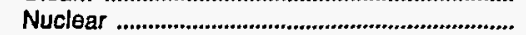 & 0 & 0 & 0 & 0 & 0 & 0 \\
\hline Hydro-Conventional .................................................. & 0 & 0 & 0 & 0 & 0 & 0 \\
\hline Hydro-Pumped Storage .......................................... & 0 & 0 & 0 & 0 & 0 & 0 \\
\hline 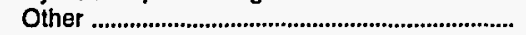 & 0 & 0 & 0 & 0 & 0 & 0 \\
\hline 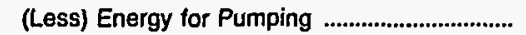 & 0 & $\mathbf{0}$ & 0 & 0 & 0 & 0 \\
\hline 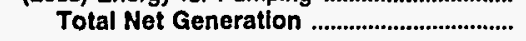 & 0 & 0 & o & 0 & o & 0 \\
\hline 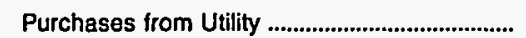 & $1,550,507$ & $4,802,168$ & 465,868 & 335,023 & 328,165 & $1,015,356$ \\
\hline Purchases from Nonutility ......................................... & 0 & 0 & 0 & 0 & 0 & \\
\hline Power Exchanges & & & & & & \\
\hline Received ...................................................................... & 0 & 0 & 0 & 0 & 0 & \\
\hline 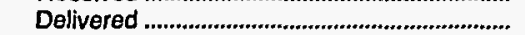 & 0 & 0 & 0 & 0 & 0 & 0 \\
\hline 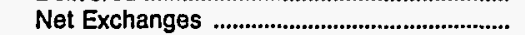 & 0 & 0 & 0 & 0 & 0 & 0 \\
\hline \multicolumn{7}{|l|}{ Transmission for Others (Wheeling) } \\
\hline 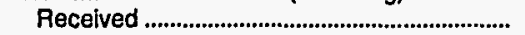 & 0 & 0 & 0 & 0 & 0 & 0 \\
\hline 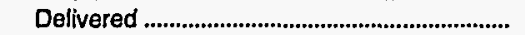 & 0 & 0 & 0 & 0 & 0 & 0 \\
\hline Net Transmission for Others ............................... & 0 & 0 & 0 & 0 & 0 & 0 \\
\hline Transmission by Others Losses .............................. & 0 & 0 & 0 & 0 & 0 & 0 \\
\hline Total Net Energy & & & & & & \\
\hline Generated and Recelved ................................ & $1,550,507$ & $4,802,168$ & 465,868 & 335,023 & 328,165 & $1,015,356$ \\
\hline \multicolumn{7}{|l|}{ Disposition of Energy } \\
\hline 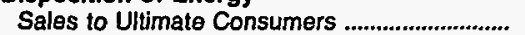 & $1,472,763$ & $4,568,275$ & 440,960 & 310,085 & 314,437 & 956,485 \\
\hline Requirements Sales for Resale .............................. & 0 & 0 & 0 & 0 & 0 & 0 \\
\hline Nonrequirements Sales for Resale ........................ & 0 & 0 & 0 & 0 & 0 & 0 \\
\hline Furnished Without Charge ...................................... & 0 & 0 & 0 & 0 & 0 & 0 \\
\hline Used by Utility (excluding station use) ............. & 853 & 14,579 & 635 & 526 & 3 & 532 \\
\hline 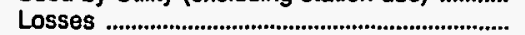 & 76,890 & 219,313 & 24,272 & 24,412 & 13,723 & 58,338 \\
\hline 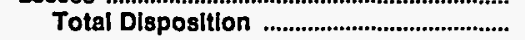 & $1,550,507$ & $4,802,168$ & 465,868 & 335,023 & 328,165 & $1,015,356$ \\
\hline
\end{tabular}

Note: Totals may not equal sum of components because of independent rounding. Double counting occurs in components of both sources and disposition of energy and thus neither provides a true total. Purchases from utilities, net interchanges, and net wheeling (except for imports) are included in net generation. Sales for resale is included in sales to ultimate consumers.

Source: Energy Information Administration, Form EIA-412, "Annual Report of Public Electric Utilities." 
Table 26. Electric Energy Account by Major U.S. Publicly Owned Electric Utility Within State, 1993 (Continued)

(Megawatthours)

\begin{tabular}{|c|c|c|c|c|c|c|}
\hline Item & $\begin{array}{l}\text { Tennessee } \\
\text { Lewisburg } \\
\text { City of } \\
\text { June } 30\end{array}$ & $\begin{array}{l}\text { Tennessee } \\
\text { Lexington } \\
\text { City of } \\
\text { June } 30\end{array}$ & $\begin{array}{l}\text { Tennessee } \\
\text { Loudon } \\
\text { Utilities } \\
\text { Board } \\
\text { June } 30\end{array}$ & $\begin{array}{l}\text { Tennessee } \\
\text { Maryville } \\
\text { Utilities } \\
\text { June } 30\end{array}$ & $\begin{array}{l}\text { Tennessee } \\
\text { McMinnville } \\
\text { Electric } \\
\text { System } \\
\text { June } 30\end{array}$ & $\begin{array}{l}\text { Tennessee } \\
\text { Memphis } \\
\text { City of } \\
\text { June } 30\end{array}$ \\
\hline \multicolumn{7}{|l|}{ Sources of Energy } \\
\hline 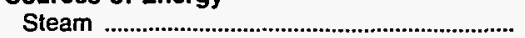 & 0 & 0 & 0 & 0 & 0 & 0 \\
\hline Nuclear & 0 & 0 & 0 & 0 & 0 & 0 \\
\hline 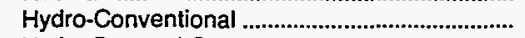 & 0 & 0 & 0 & 0 & 0 & 0 \\
\hline 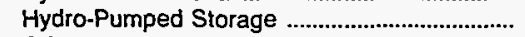 & 0 & 0 & 0 & 0 & 0 & 0 \\
\hline Other & 0 & 0 & 0 & 0 & 0 & 0 \\
\hline (Less) Energy for Pumping & 0 & 0 & 0 & 0 & 0 & 0 \\
\hline Total Net Generation & 0 & 0 & $\mathbf{0}$ & 0 & 0 & 0 \\
\hline 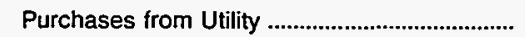 & 271,692 & 374,608 & 279,255 & 523,717 & 212,462 & $11,837,085$ \\
\hline $\begin{array}{l}\text { Purchases from Nonutility } \\
\text { Power Exchanges }\end{array}$ & 0 & 0 & 0 & 0 & 0 & \\
\hline 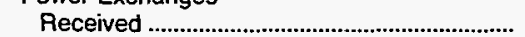 & 0 & 0 & 0 & 0 & 0 & 0 \\
\hline Delivered & 0 & 0 & 0 & 0 & 0 & 0 \\
\hline Net Exchanges & 0 & 0 & 0 & 0 & 0 & 0 \\
\hline \multicolumn{7}{|l|}{ Transmission for Others (Wheeling) } \\
\hline Received & 0 & 0 & 0 & 0 & 0 & 0 \\
\hline 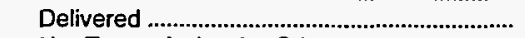 & 0 & 0 & 0 & 0 & 0 & 0 \\
\hline Net Transmission for Others ............................ & 0 & 0 & 0 & 0 & 0 & 0 \\
\hline Transmission by Others Losses ........................ & 0 & 0 & 0 & 0 & 0 & 0 \\
\hline Total Net Energy & & & & & & \\
\hline 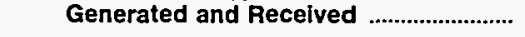 & 271,692 & 374,608 & 279,255 & 523,717 & 212,462 & $11,837,085$ \\
\hline \multicolumn{7}{|l|}{ Disposition of Energy } \\
\hline 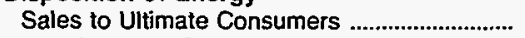 & 260,204 & 350,892 & 267,371 & 494,259 & 203,962 & $11,075,238$ \\
\hline 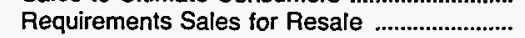 & 0 & 0 & 0 & 0 & 0 & 0 \\
\hline Nonrequirements Sales for Resale ................... & 0 & 0 & 0 & 0 & 0 & 0 \\
\hline Furnished Without Charge ................................ & 0 & 0 & 0 & 0 & 0 & 0 \\
\hline 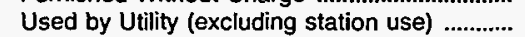 & 479 & 622 & 0 & 0 & 280 & 7,308 \\
\hline 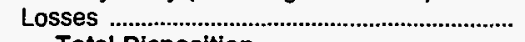 & 11,007 & 23,093 & 11,884 & 29,458 & 8,219 & 754,539 \\
\hline Total Disposition & 271,692 & 374,608 & 279,255 & 523,717 & 212,462 & $11,837,085$ \\
\hline
\end{tabular}

Note: Totals may not equal sum of components because of independent rounding. Double counting occurs in components of both sources and disposition of energy and thus neither provides a true total. Purchases from utilities, net interchanges, and net wheeling (except for imports) are included in net generation. Sales for resale is included in sales to ultimate consumers.

Source: Energy Information Administration, Form ElA-412, "Annual Report of Public Electric Utilities." 
Table 26. Electric Energy Account by Major U.S. Publicly Owned Electric Utility Within State, 1993 (Continued)

(Megawatthours)

\begin{tabular}{|c|c|c|c|c|c|c|}
\hline item & $\begin{array}{l}\text { Tennessee } \\
\text { Morristown } \\
\text { City of } \\
\text { June } 30\end{array}$ & $\begin{array}{l}\text { Tennessee } \\
\text { Murfreesboro } \\
\text { City of } \\
\text { June } 30\end{array}$ & $\begin{array}{c}\text { Tennessee } \\
\text { Nashville } \\
\text { Electric } \\
\text { Service } \\
\text { June } 30\end{array}$ & $\begin{array}{l}\text { Tennessee } \\
\text { Newport } \\
\text { City of } \\
\text { June } 30\end{array}$ & $\begin{array}{l}\text { Tennessee } \\
\text { Oak Ridge } \\
\text { City of } \\
\text { June } 30\end{array}$ & $\begin{array}{c}\text { Tennessee } \\
\text { Paris } \\
\text { City of } \\
\text { June } 30\end{array}$ \\
\hline \multicolumn{7}{|l|}{ Sources of Energy } \\
\hline Steam & 0 & 0 & 0 & 0 & 0 & 0 \\
\hline 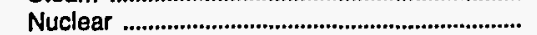 & 0 & 0 & 0 & 0 & 0 & 0 \\
\hline 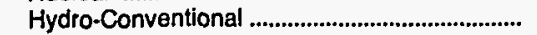 & 0 & 0 & 0 & 0 & 0 & 0 \\
\hline 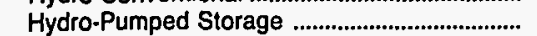 & 0 & 0 & 0 & 0 & 0 & 0 \\
\hline 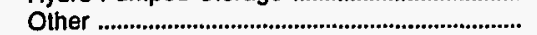 & 0 & 0 & 0 & 0 & 0 & 0 \\
\hline (Less) Energy for Pumping & 0 & 0 & 0 & 0 & 0 & 0 \\
\hline 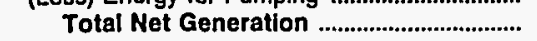 & 0 & 0 & 0 & 0 & 0 & 0 \\
\hline 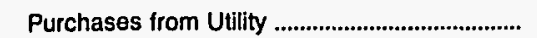 & 640,204 & 836,811 & $10,319,826$ & 415,586 & 459,665 & 421,584 \\
\hline Purchases from Nonutility .......................................... & 0 & 0 & 0 & 0 & 0 & \\
\hline $\begin{array}{l}\text { Power Excnanges } \\
\text { Received ................................................................ }\end{array}$ & 0 & 0 & 0 & 0 & 0 & 0 \\
\hline Delivered ................................................................ & 0 & 0 & 0 & 0 & $\mathbf{0}$ & 0 \\
\hline Net Exchanges ……………………………………......... & 0 & 0 & 0 & 0 & 0 & 0 \\
\hline \multicolumn{7}{|l|}{ Transmission for Others (Wheeling) } \\
\hline 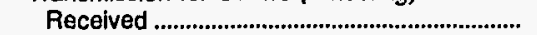 & 0 & 0 & 0 & 0 & 0 & 0 \\
\hline Delivered …………………………………………..... & 0 & 0 & 0 & 0 & 0 & 0 \\
\hline Net Transmission for Others ........................ & 0 & 0 & 0 & 0 & 0 & $\mathbf{0}$ \\
\hline Transmission by Others Losses ....................... & 0 & 0 & 0 & 0 & 0 & 0 \\
\hline $\begin{array}{l}\text { Total Net Energy } \\
\text { Generated and Recelved ......................... }\end{array}$ & 640,204 & 836,811 & $10,319,826$ & 415,586 & 459,665 & 421,584 \\
\hline \multicolumn{7}{|l|}{ Disposition of Energy } \\
\hline 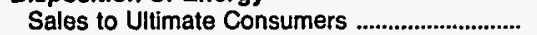 & 615,311 & 811,133 & $9,976,634$ & 387,570 & 430,026 & 393,886 \\
\hline Requirements Sales for Resale ............................. & 0 & 0 & 0 & 0 & 0 & 0 \\
\hline Nonrequirements Sales for Resale .................... & 0 & 0 & 0 & 0 & 0 & 0 \\
\hline Furnished Without Charge .................................... & & 0 & 0 & 0 & 0 & 0 \\
\hline Used by Utility (excluding station use) ............ & 1,202 & 1,104 & 23,276 & 743 & 0 & 225 \\
\hline 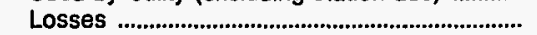 & 23,689 & 24,573 & 319,915 & 27,271 & 29,638 & 27.472 \\
\hline Total DIspositton ................................................... & 640,204 & 836,811 & $10,319,826$ & 415,586 & 459,665 & 421,584 \\
\hline
\end{tabular}

Note: Totals may not equal sum of components because of independent rounding. Double counting occurs in components of both sources and disposition of energy and thus neither provides a true total. Purchases from utilities, net interchanges, and net wheeling (except for imports) are included in net generation. Sales for resale is included in sales to ultimate consumers.

Source: Energy Information Administration, Form ElA-412, "Annual Report of Public Electric Utilities." 
Table 26. Electric Energy Account by Major U.S. Publicly Owned Electric Utility Within State, 1993 (Continued)

(Megawatthours)

\begin{tabular}{|c|c|c|c|c|c|c|}
\hline Item & $\begin{array}{l}\text { Tennessee } \\
\text { Pulaski } \\
\text { City of } \\
\text { June } 30\end{array}$ & $\begin{array}{l}\text { Tennessee } \\
\text { Ripley } \\
\text { City of } \\
\text { June } 30\end{array}$ & $\begin{array}{l}\text { Tennessee } \\
\text { Rockwood } \\
\text { City of } \\
\text { June } 30\end{array}$ & $\begin{array}{c}\text { Tennessee } \\
\text { Sevier } \\
\text { County } \\
\text { Electric } \\
\text { System } \\
\text { June } 30\end{array}$ & $\begin{array}{c}\text { Tennessee } \\
\text { Shelbyville } \\
\text { City of } \\
\text { June } 30\end{array}$ & $\begin{array}{l}\text { Tennessee } \\
\begin{array}{c}\text { Springfield } \\
\text { City of }\end{array} \\
\text { June } 30\end{array}$ \\
\hline \multicolumn{7}{|l|}{ Sources of Energy } \\
\hline Steam & 0 & 0 & 0 & 0 & 0 & $\mathbf{0}$ \\
\hline Nuclear ….............................................................. & 0 & 0 & 0 & 0 & 0 & 0 \\
\hline 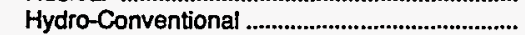 & 0 & 0 & 0 & 0 & 0 & 0 \\
\hline 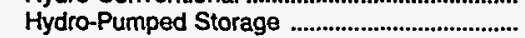 & 0 & 0 & 0 & 0 & 0 & 0 \\
\hline 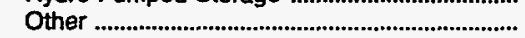 & 0 & 0 & 0 & 0 & 0 & 0 \\
\hline 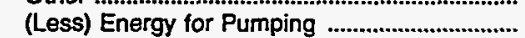 & 0 & 0 & 0 & 0 & 0 & 0 \\
\hline 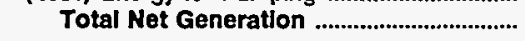 & 0 & 0 & o & 0 & $\mathbf{0}$ & $\mathbf{0}$ \\
\hline 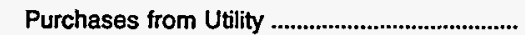 & 385,823 & 246,475 & 276,915 & 871,483 & 312,940 & 195,479 \\
\hline 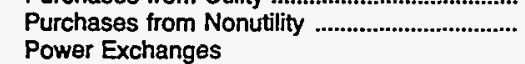 & 0 & 0 & 0 & 0 & 0 & 0 \\
\hline 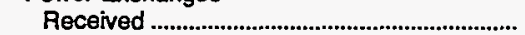 & 0 & 0 & 0 & 0 & 0 & 0 \\
\hline 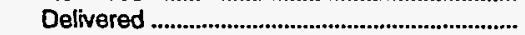 & 0 & 0 & 0 & 0 & 0 & 0 \\
\hline Net Exchanges ....................................................... & 0 & 0 & 0 & 0 & 0 & 0 \\
\hline \multicolumn{7}{|l|}{ Transmission for Others (Wheeling) } \\
\hline 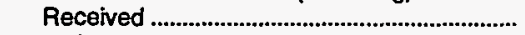 & 0 & 0 & 0 & 0 & 0 & 0 \\
\hline 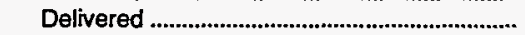 & 0 & 0 & 0 & 0 & 0 & 0 \\
\hline Net Transmission for Others ............................... & 0 & 0 & 0 & 0 & 0 & 0 \\
\hline 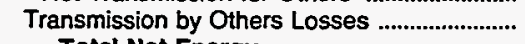 & 0 & 0 & 0 & 0 & 0 & 0 \\
\hline $\begin{array}{l}\text { Total Net Energy } \\
\text { Generated and Recelved ............................... }\end{array}$ & 385,823 & 246,475 & 276,915 & 871,483 & 312,940 & 195,479 \\
\hline \multicolumn{7}{|l|}{ Dlspositton of Energy } \\
\hline Sales to Ultimate Consumers .................................. & 362,193 & 238,000 & 256,333 & 822,502 & 300,603 & 183,590 \\
\hline 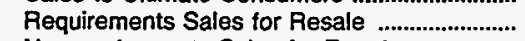 & 0 & 0 & 0 & 0 & 0 & 0 \\
\hline Nonrequirements Sales for Resale .................... & 0 & 0 & 0 & 0 & 0 & 0 \\
\hline Furnished Without Charge .............................. & 0 & 0 & 0 & 0 & 0 & 0 \\
\hline Used by Utility (excluding station use) ............. & 615 & 189 & 207 & 405 & 269 & 0 \\
\hline Losses ..................... & 23,013 & 8,285 & 20,374 & 48,575 & 12,068 & 11,889 \\
\hline Total Dispositton & 385,823 & 246,475 & 276,915 & 871,483 & 312,940 & 195,479 \\
\hline
\end{tabular}

Note: Totals may not equal sum of components because of independent rounding. Double counting occurs in components of both sources and disposition of energy and thus neither provides a true total. Purchases from utilities, net interchanges, and net wheeling (except for imports) are included in net generation. Sales for resale is included in sales to ultimate consumers.

Source: Energy Information Administration, Form ElA-412, "Annual Report of Public Electric Utilities." 
Table 26. Electric Energy Account by Major U.S. Publicly Owned Electric Utility Within State, 1993 (Continued)

(Megawatthours)

\begin{tabular}{|c|c|c|c|c|c|c|}
\hline Item & $\begin{array}{c}\text { Tennessee } \\
\text { Sweetwater } \\
\text { City of } \\
\text { June } 30\end{array}$ & $\begin{array}{c}\text { Tennessee } \\
\text { Tullahoma } \\
\text { Board } \\
\text { of } \\
\text { Pub Utils } \\
\text { June } 30\end{array}$ & $\begin{array}{l}\text { Tennessee } \\
\text { Union } \\
\text { City City of } \\
\text { June } 30\end{array}$ & $\begin{array}{l}\text { Tennessee } \\
\text { Weakley } \\
\text { County } \\
\text { Mun } \\
\text { Elec Sys } \\
\text { June } 30\end{array}$ & $\begin{array}{c}\text { Texas } \\
\text { Austin } \\
\text { City of } \\
\text { September } 30\end{array}$ & $\begin{array}{c}\text { Texas } \\
\text { Brenham } \\
\text { City of } \\
\text { September } 30\end{array}$ \\
\hline 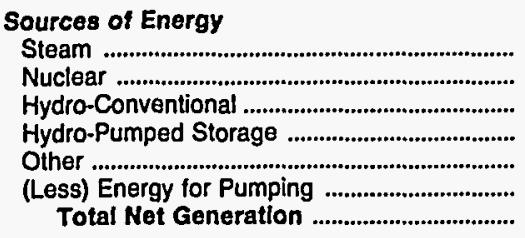 & $\begin{array}{l}0 \\
0 \\
0 \\
0 \\
0 \\
0 \\
0\end{array}$ & $\begin{array}{l}0 \\
0 \\
0 \\
0 \\
0 \\
0 \\
0\end{array}$ & $\begin{array}{l}0 \\
0 \\
0 \\
0 \\
0 \\
0 \\
0\end{array}$ & $\begin{array}{l}0 \\
0 \\
0 \\
0 \\
0 \\
0 \\
0\end{array}$ & $\begin{array}{r}6,597,322 \\
578,999 \\
0 \\
0 \\
36,144 \\
0 \\
7,212,465\end{array}$ & $\begin{array}{l}0 \\
0 \\
0 \\
0 \\
0 \\
0 \\
0\end{array}$ \\
\hline 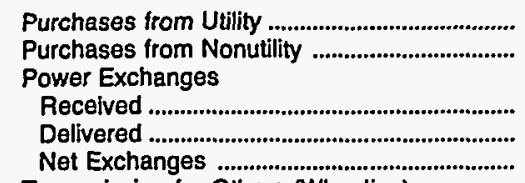 & $\begin{array}{r}182,358 \\
0\end{array}$ & $\begin{array}{r}260,716 \\
0\end{array}$ & $\begin{array}{r}347,931 \\
0\end{array}$ & $\begin{array}{r}467,452 \\
0\end{array}$ & $\begin{array}{r}405,931 \\
2,082 \\
\\
56,886 \\
47,492 \\
9,374\end{array}$ & $\begin{array}{r}250,091 \\
0\end{array}$ \\
\hline 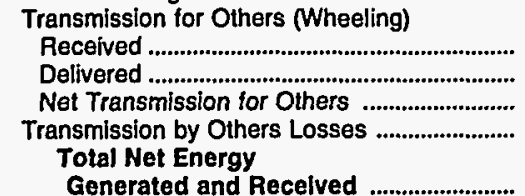 & $\begin{array}{l}0 \\
0 \\
0 \\
0\end{array}$ & $\begin{array}{l}0 \\
0 \\
0 \\
0\end{array}$ & $\begin{array}{l}0 \\
0 \\
0 \\
0\end{array}$ & $\begin{array}{l}0 \\
0 \\
0 \\
0\end{array}$ & $\begin{array}{r}19,673 \\
18,960 \\
713 \\
0\end{array}$ & 250,091 \\
\hline 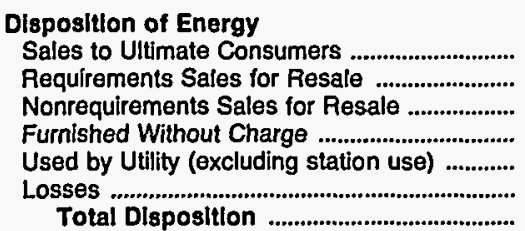 & $\begin{array}{r}174,013 \\
0 \\
0 \\
0 \\
0 \\
8,345 \\
182,358\end{array}$ & $\begin{array}{r}247,761 \\
0 \\
0 \\
0 \\
915 \\
12,039 \\
260,716\end{array}$ & $\begin{array}{r}336,887 \\
0 \\
0 \\
0 \\
214 \\
10,829 \\
347,931\end{array}$ & $\begin{array}{r}433,673 \\
0 \\
0 \\
0 \\
452 \\
33,326 \\
467,452\end{array}$ & $\begin{array}{r}6,967,280 \\
182,372 \\
36,121 \\
0 \\
0 \\
444,792 \\
7,630,565\end{array}$ & $\begin{array}{r}243,411 \\
0 \\
0 \\
0 \\
0 \\
6,680 \\
250,091\end{array}$ \\
\hline
\end{tabular}

Note: Totals may not equal sum of components because of independent rounding. Double counting occurs in components of both sources and disposition of energy and thus neither provides a true total. Purchases from utilities, net interchanges, and net wheeling (except for imports) are included in net generation. Sales for resale is included in sales to ultimate consumers.

Source: Energy Information Administration, Form ElA-412, "Annual Report of Public Electric Utilities." 
Table 26. Electric Energy Account by Major U.S. Publicly Owned Electric Utility Within State, 1993 (Continued)

(Megawatthours)

\begin{tabular}{|c|c|c|c|c|c|c|}
\hline Item & $\begin{array}{c}\text { Texas } \\
\text { Brownsville } \\
\text { Public } \\
\text { Utils Board } \\
\text { September } 30\end{array}$ & $\begin{array}{c}\text { Texas } \\
\text { Bryan } \\
\text { City of } \\
\text { September } 30\end{array}$ & $\begin{array}{c}\text { Texas } \\
\text { College } \\
\text { Station } \\
\text { City of } \\
\text { September } 30\end{array}$ & $\begin{array}{l}\text { Texas } \\
\text { Denton } \\
\text { City of } \\
\text { September } 30\end{array}$ & $\begin{array}{c}\text { Floresville } \\
\text { City of } \\
\text { December } 31\end{array}$ & $\begin{array}{c}\text { Texas } \\
\text { Garland } \\
\text { City of } \\
\text { September } 30\end{array}$ \\
\hline \multicolumn{7}{|l|}{ Sources of Energy } \\
\hline Steam & 609,940 & 436,349 & 0 & 248,881 & 0 & $1,270,641$ \\
\hline Nuclear & 0 & 0 & 0 & 0 & 0 & 0 \\
\hline 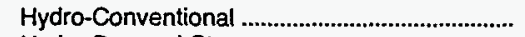 & 0 & 0 & 0 & 4,385 & 0 & 0 \\
\hline 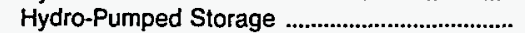 & 0 & 0 & 0 & 0 & 0 & 0 \\
\hline Other & 0 & 194,879 & 0 & 0 & 0 & 0 \\
\hline 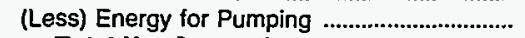 & 0 & 0 & 0 & 0 & 0 & 0 \\
\hline Total Net Generation & 609,940 & 631,228 & $\mathbf{0}$ & 253,266 & 0 & $1,270,641$ \\
\hline 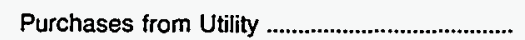 & 165,655 & 614,176 & 424,685 & 740,000 & 147,385 & $1,424,326$ \\
\hline $\begin{array}{l}\text { Purchases from Nonutility ................................. } \\
\text { Power Exchanges }\end{array}$ & 0 & 0 & 0 & 0 & 0 & 0 \\
\hline 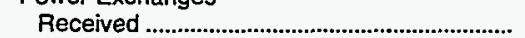 & 0 & 121,489 & 0 & 0 & 0 & 0 \\
\hline 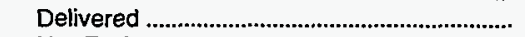 & 0 & 127,405 & 0 & 0 & $\mathbf{0}$ & 0 \\
\hline Net Exchanges & 0 & $-5,915$ & 0 & 0 & 0 & 0 \\
\hline \multicolumn{7}{|l|}{ Transmission for Others (Wheeling) } \\
\hline 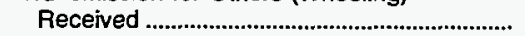 & 0 & 0 & 0 & 0 & 0 & 0 \\
\hline 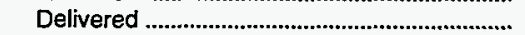 & 0 & 0 & 0 & 0 & 0 & 0 \\
\hline Net Transmission for Others & 0 & 0 & 0 & 0 & 0 & 0 \\
\hline $\begin{array}{l}\text { Transmission by Others Losses ........................... } \\
\text { Total Net Energy }\end{array}$ & $-40,943$ & 0 & 0 & 0 & 0 & 0 \\
\hline Generated and Received .......................... & 734,652 & $1,239,489$ & 424,685 & 993,266 & 147,385 & $2,694,967$ \\
\hline \multicolumn{7}{|l|}{ Disposition of Energy } \\
\hline 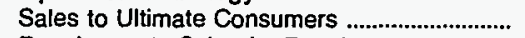 & 642,636 & 754,800 & 409,019 & 818,416 & 134,146 & $1,783,115$ \\
\hline Requirements Sales for Resale ........................... & 0 & 438,681 & 0 & 142,000 & 0 & 283,613 \\
\hline 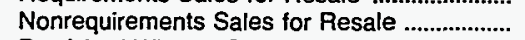 & 0 & 0 & 0 & 0 & 0 & 523,685 \\
\hline 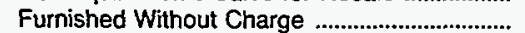 & 21,729 & 3,428 & 1,350 & 0 & 85 & 0 \\
\hline Used by Utility (excluding station use) ............. & 22,039 & 0 & 0 & 0 & 241 & 0 \\
\hline Losses & 48,248 & 42,580 & 14,316 & 32,850 & 12,913 & 104,554 \\
\hline Total Disposition & 734,652 & $1,239,489$ & 424,685 & 993,266 & 147,385 & $2,694,967$ \\
\hline
\end{tabular}

Note: Totals may not equal sum of components because of independent rounding. Double counting occurs in components of both sources and disposition of energy and thus neither provides a true total. Purchases from utilities, net interchanges, and net wheeling (except for imports) are included in net generation. Sales for resale is included in sales to ultimate consumers.

Source: Energy Information Administration, Form ElA-412, "Annual Report of Public Electric Utilities." 
Table 26. Electric Energy Account by Major U.S. Publicly Owned Electric Utility Within State, 1993 (Continued)

(Megawatthours)

\begin{tabular}{|c|c|c|c|c|c|c|}
\hline Item & $\begin{array}{l}\text { Texas } \\
\text { Georgetown } \\
\text { City of } \\
\text { September } 30\end{array}$ & $\begin{array}{c}\text { Texas } \\
\text { Greenville } \\
\text { Electric } \\
\text { Util Sys } \\
\text { September } 30\end{array}$ & $\begin{array}{c}\text { Texas } \\
\text { Kerrville } \\
\text { Public } \\
\text { Utility } \\
\text { Board } \\
\text { September } 30\end{array}$ & $\begin{array}{l}\text { Texas } \\
\text { Lower } \\
\text { Colorado } \\
\text { River } \\
\text { Authority } \\
\text { June } 30\end{array}$ & $\begin{array}{l}\text { Texas } \\
\text { Lubbock } \\
\text { City of } \\
\text { September } 30\end{array}$ & $\begin{array}{c}\text { Texas } \\
\begin{array}{c}\text { New Braunfels } \\
\text { City of }\end{array} \\
\text { July } 31\end{array}$ \\
\hline \multicolumn{7}{|l|}{ Sources of Energy } \\
\hline 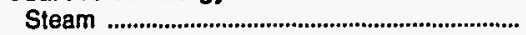 & 0 & 70,301 & 0 & $8,963,589$ & 466,169 & \\
\hline Nuclear ............................................................ & 0 & 0 & 0 & 0 & 0 & 0 \\
\hline 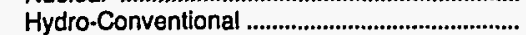 & 0 & 0 & 0 & 295,990 & 0 & \\
\hline Hydro-Pumped Storage ……………………......... & 0 & 0 & 0 & 0 & 0 & 0 \\
\hline 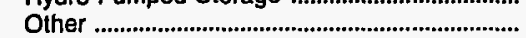 & 0 & -191 & 0 & 0 & 162,464 & 0 \\
\hline (Less) Energy for Pumping ................................. & 0 & 0 & 0 & 0 & 0 & \\
\hline 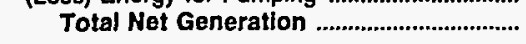 & 0 & 70,110 & 0 & $9,259,579$ & 628,633 & 0 \\
\hline 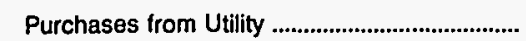 & 176,491 & 437,490 & 354,165 & 47,138 & 379,534 & 766,922 \\
\hline $\begin{array}{l}\text { Purchases from Nonutility .................................... } \\
\text { Power Exchanges }\end{array}$ & 0 & 0 & 0 & 0 & 0 & \\
\hline 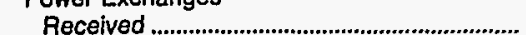 & 0 & 0 & 0 & 0 & 0 & \\
\hline 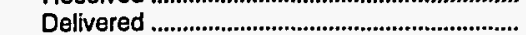 & 0 & 0 & 0 & 0 & 0 & \\
\hline Net Exchanges ............................................................ & 0 & 0 & 0 & 0 & 0 & 0 \\
\hline \multicolumn{7}{|l|}{ Transmission for Others (Wheeling) } \\
\hline 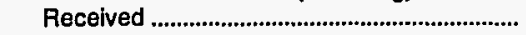 & 0 & 0 & 0 & 0 & 0 & \\
\hline Delivered .................................................................... & 0 & 0 & 0 & 0 & 0 & \\
\hline 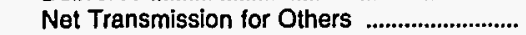 & 0 & 0 & 0 & 0 & 0 & 0 \\
\hline 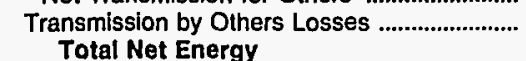 & 0 & 0 & 0 & 0 & 0 & 0 \\
\hline Generated and Received & 176,491 & 507,600 & 354,165 & $9,306,717$ & $1,008,167$ & 766,922 \\
\hline \multicolumn{7}{|l|}{ Dlspositlon of Energy } \\
\hline 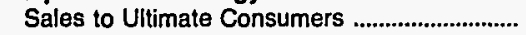 & 169,432 & 421,677 & 334,815 & 153,326 & 951,297 & 743,231 \\
\hline Requirements Sales for Resale ........................ & 0 & 58,230 & 0 & $8,799,456$ & 0 & \\
\hline Nonrequirements Sales for Resale .................... & 0 & 1,465 & 0 & 0 & 0 & 0 \\
\hline Furnished Without Charge ................................... & 0 & 0 & 0 & 0 & 0 & 1,987 \\
\hline Used by Utility (excluding station use) .............. & 0 & 0 & 0 & 10,056 & 0 & 0 \\
\hline Losses ...................................................... & 7,059 & 26,228 & 19,350 & 343,879 & 56,870 & 21,704 \\
\hline Total Dlsposition & 176,491 & 507,600 & 354,165 & $9,306,717$ & $1,008,167$ & 766,922 \\
\hline
\end{tabular}

Note: Totals may not equal sum of components because of independent rounding. Double counting occurs in components of both sources and disposition of energy and thus neither provides a true total. Purchases from utilities, net interchanges, and net wheeling (except for imports) are included in net generation. Sales for resale is included in sales to ultimate consumers.

Source: Energy Information Administration, Form EIA-412, "Annual Report of Public Electric Utilities." 
Table 26. Electric Energy Account by Major U.S. Publicly Owned Electric Utility Within State, 1993 (Continued) (Megawatthours)

\begin{tabular}{|c|c|c|c|c|c|c|}
\hline Item & $\begin{array}{c}\text { Texas } \\
\text { Sam Rayburn } \\
\text { Municipal } \\
\text { Pwr } \\
\text { Agny } \\
\text { September } 30\end{array}$ & $\begin{array}{l}\text { Texas } \\
\text { San Antonio } \\
\text { City of } \\
\text { January } 31\end{array}$ & $\begin{array}{c}\text { Texas } \\
\text { San Marcos } \\
\text { City of } \\
\text { September } 30\end{array}$ & $\begin{array}{l}\text { Texas } \\
\text { Seguin } \\
\text { City of } \\
\text { September } 30\end{array}$ & $\begin{array}{c}\text { Texas } \\
\text { Texas } \\
\text { Municipal } \\
\text { Power Agency } \\
\text { September } 30\end{array}$ & $\begin{array}{l}\text { Texas } \\
\text { Toledo Bend } \\
\text { Project } \\
\text { Joint } \\
\text { Oper } \\
\text { August } 30\end{array}$ \\
\hline \multicolumn{7}{|l|}{ Sources of Energy } \\
\hline Steam & 567,589 & $13,490,471$ & 0 & 0 & $2,943,848$ & \\
\hline 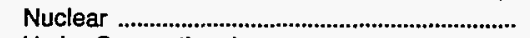 & 0 & $-58,525$ & 0 & 0 & 0 & 0 \\
\hline 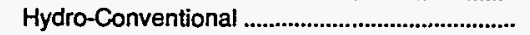 & 0 & 0 & 0 & 1,579 & 0 & 354,797 \\
\hline Hydro-Pumped Storage ............................................... & 0 & 0 & 0 & 0 & 0 & 0 \\
\hline Other & 0 & 0 & 0 & 0 & 0 & 0 \\
\hline 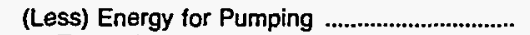 & 0 & 0 & 0 & 0 & 0 & 0 \\
\hline 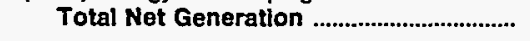 & 567,589 & $13,431,946$ & 0 & 1,579 & $2,943,848$ & 354,797 \\
\hline 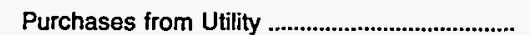 & 80,190 & 70,977 & 313,076 & 211,089 & 0 & 0 \\
\hline $\begin{array}{l}\text { Purchases from Nonutility .......................................... } \\
\text { Power Exchanges }\end{array}$ & 0 & 0 & 0 & 0 & 0 & 0 \\
\hline 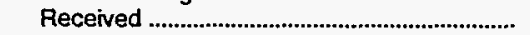 & 0 & $2,398,378$ & 0 & 0 & 0 & 0 \\
\hline 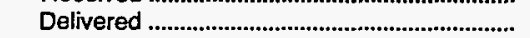 & 0 & $2,380,264$ & 0 & 0 & 0 & 0 \\
\hline 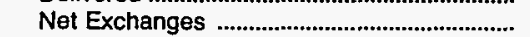 & 0 & 18,114 & 0 & 0 & 0 & 0 \\
\hline \multicolumn{7}{|l|}{ Transmission for Others (Wheeling) } \\
\hline 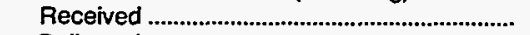 & 0 & 0 & 0 & 0 & 0 & 636 \\
\hline 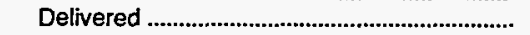 & 0 & 0 & 0 & 0 & 0 & 636 \\
\hline 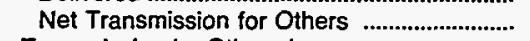 & 0 & 0 & 0 & 0 & 0 & 0 \\
\hline 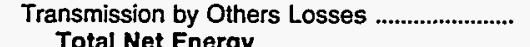 & 0 & 0 & 0 & 0 & 0 & 0 \\
\hline $\begin{array}{l}\text { Total Net Energy } \\
\text { Generated and Recelved }\end{array}$ & 647,779 & $13,521,037$ & 313,076 & 212,668 & $2,943,848$ & 354,797 \\
\hline \multicolumn{7}{|l|}{ Dlspositton of Energy } \\
\hline Sales to Ultimate Consumers .................................. & 0 & $12,369,214$ & 299,035 & 201,838 & 0 & 0 \\
\hline 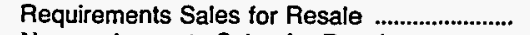 & 324,105 & 213,765 & 0 & 0 & $2,836,234$ & 0 \\
\hline Nonrequirements Sales for Resale .................... & 317,247 & 142,399 & 0 & 0 & 0 & 354,161 \\
\hline 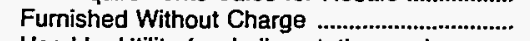 & 0 & 0 & 0 & 10,830 & 43,925 & $\mathbf{0}$ \\
\hline Used by Utility (excluding station use) ................. & 0 & 56,385 & 0 & 0 & 0 & 344 \\
\hline 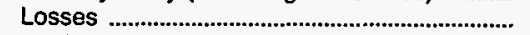 & 6,427 & 739,284 & 14,041 & 0 & 63,689 & 292 \\
\hline Total Disposition & 647,779 & $13,521,037$ & 313,076 & 212,668 & $2,943,848$ & 354,797 \\
\hline
\end{tabular}

Note: Totals may not equal sum of components because of independent rounding. Double counting occurs in components of both sources and disposition of energy and thus neither provides a true total. Purchases from utilities, net interchanges, and net wheeling (except for imports) are included in net generation. Sales for resale is included in sales to ultimate consumers.

Source: Energy Information Administration, Form EIA-412, "Annual Report of Public Electric Utilities." 
Table 26. Electric Energy Account by Major U.S. Publicly Owned Electric Utility Within State, 1993 (Continued)

(Megawatthours)

\begin{tabular}{|c|c|c|c|c|c|c|}
\hline Item & $\begin{array}{c}\text { Texas } \\
\text { Weatherford } \\
\text { Mun } \\
\text { Utility } \\
\text { System } \\
\text { September } 30\end{array}$ & $\begin{array}{c}\text { Utah } \\
\text { Bountiful } \\
\text { City City of } \\
\text { June } 30\end{array}$ & $\begin{array}{c}\text { Intermountain } \\
\text { Power Agency } \\
\text { June } 30\end{array}$ & $\begin{array}{l}\text { Utah } \\
\text { Logan } \\
\text { City of } \\
\text { June } 30\end{array}$ & $\begin{array}{l}\text { Utah } \\
\text { Murray } \\
\text { City of } \\
\text { June } 30\end{array}$ & $\begin{array}{l}\text { Utah } \\
\text { Provo } \\
\text { City Corp } \\
\text { June } 30\end{array}$ \\
\hline \multicolumn{7}{|l|}{ Sources of Energy } \\
\hline Steam & 0 & 0 & $11,974,500$ & 0 & 0 & 0 \\
\hline 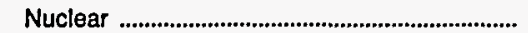 & 0 & 0 & 0 & 0 & 0 & 0 \\
\hline 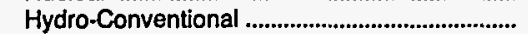 & 0 & 11,800 & 0 & 18,417 & 8,735 & 0 \\
\hline Hydro-Pumped Storage ....................................... & 0 & 0 & 0 & 0 & 0 & 0 \\
\hline Other & 927 & 20,874 & 0 & -357 & 327 & 0 \\
\hline (Less) Energy for Pumping .................................... & 0 & 0 & 0 & 0 & 0 & 0 \\
\hline Total Net Generation & 927 & 32,674 & $11,974,500$ & 18,059 & 9,062 & 0 \\
\hline 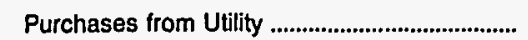 & 214,414 & 211,861 & 235 & 270,877 & 295,795 & 557,362 \\
\hline $\begin{array}{l}\text { Purchases from Nonutility ................................... } \\
\text { Power Exchanges }\end{array}$ & 0 & 0 & 0 & 0 & 0 & 0 \\
\hline 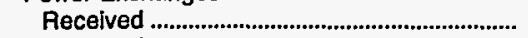 & 0 & 0 & 0 & 0 & 0 & 0 \\
\hline 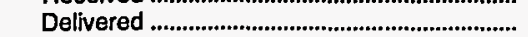 & 0 & 0 & 0 & 0 & 0 & 0 \\
\hline Net Exchanges & 0 & 0 & 0 & 0 & 0 & 0 \\
\hline \multicolumn{7}{|l|}{ Transmission for Others (Wheeling) } \\
\hline 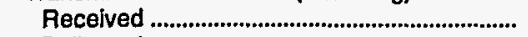 & 0 & 0 & 0 & 0 & 0 & 0 \\
\hline 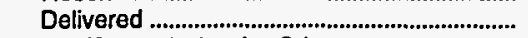 & 0 & 0 & 0 & 0 & 0 & 0 \\
\hline 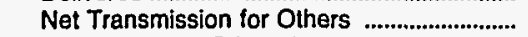 & 0 & 0 & 0 & 0 & 0 & 0 \\
\hline $\begin{array}{l}\text { Transmission by Others Losses ......................... } \\
\text { Total Net Energy }\end{array}$ & 0 & 0 & 0 & 0 & 0 & 0 \\
\hline 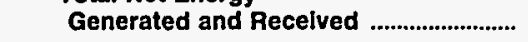 & 215,341 & 244,535 & $11,974,735$ & 288,937 & 304,857 & 557,362 \\
\hline \multicolumn{7}{|l|}{ Disposition of Energy } \\
\hline 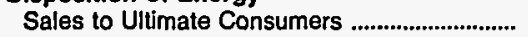 & 198,689 & 230,983 & 0 & 278,241 & 286,852 & 527,255 \\
\hline Requirements Sales for Resale ......................... & 0 & 0 & $11,974,735$ & 0 & 0 & 0 \\
\hline Nonrequirements Sales for Resale .................. & 0 & 0 & 0 & 0 & 0 & 0 \\
\hline 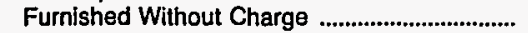 & 0 & 0 & 0 & 0 & 1,824 & 12,417 \\
\hline Used by Utility (excluding station use) ............ & 0 & 1,712 & 0 & 680 & 0 & 0 \\
\hline Losses & $\begin{array}{r}16,652 \\
215,341\end{array}$ & $\begin{array}{r}11,840 \\
244,535\end{array}$ & $\begin{array}{r}0 \\
11,974,735\end{array}$ & $\begin{array}{r}10,016 \\
288,937\end{array}$ & $\begin{array}{r}16,181 \\
304,857\end{array}$ & $\begin{array}{r}17,689 \\
557,362\end{array}$ \\
\hline
\end{tabular}

Note: Totals may not equal sum of components because of independent rounding. Double counting occurs in components of both sources and disposition of energy and thus neither provides a true total. Purchases from utilities, net interchanges, and net wheeling (except for imports) are included in net generation. Sales for resale is included in sales to ultimate consumers.

Source: Energy Information Administration, Form EIA-412, "Annual Report of Public Electric Utilities." 
Table 26. Electric Energy Account by Major U.S. Publicly Owned Electric Utility Within State, 1993 (Continued)

(Megawatthours)

\begin{tabular}{|c|c|c|c|c|c|c|}
\hline Item & $\begin{array}{c}\text { Utah } \\
\text { St George } \\
\text { City of } \\
\text { June } 30\end{array}$ & $\begin{array}{c}\text { Utah } \\
\text { Utah } \\
\text { Associated } \\
\text { Mun } \\
\text { Power Sys } \\
\text { March } 31\end{array}$ & $\begin{array}{c}\text { Utah } \\
\text { Utah } \\
\text { Municipal } \\
\text { Power Agency } \\
\text { June } 30\end{array}$ & $\begin{array}{c}\text { Vermont } \\
\text { Burlington } \\
\text { City of } \\
\text { December } 31\end{array}$ & $\begin{array}{l}\text { Vermont } \\
\text { Vermont } \\
\text { Public } \\
\text { Pwr } \\
\text { Supply Auth } \\
\text { December } 31\end{array}$ & $\begin{array}{l}\text { Virginia } \\
\text { Bedford } \\
\text { City of } \\
\text { June } 30\end{array}$ \\
\hline \multicolumn{7}{|l|}{ Sources of Energy } \\
\hline Steam & 0 & 387,043 & 384,422 & 42,697 & 16,229 & 0 \\
\hline Nuclear & 0 & 0 & 0 & 0 & 0 & 0 \\
\hline 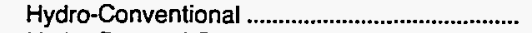 & 0 & 0 & 0 & 0 & 0 & 19,626 \\
\hline 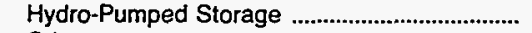 & 0 & 0 & 0 & 0 & 0 & 0 \\
\hline Other & 2,104 & 0 & 48,410 & 553 & 0 & 0 \\
\hline 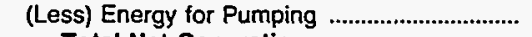 & 0 & 0 & 0 & 0 & 0 & 0 \\
\hline Total Net Generation & 2,104 & 387,043 & 432,832 & 43,250 & 16,229 & 19,626 \\
\hline 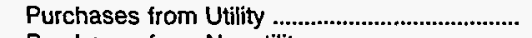 & 315,550 & 636,455 & 378,839 & 363,975 & 90,190 & 187,284 \\
\hline $\begin{array}{l}\text { Purchases from Nonutility .................................... } \\
\text { Power Exchanges }\end{array}$ & 0 & 0 & 0 & 0 & 0 & 0 \\
\hline 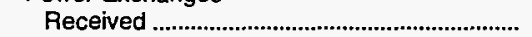 & 0 & 1,676 & 0 & 0 & 0 & 0 \\
\hline 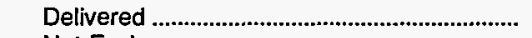 & 0 & 572 & $\mathbf{0}$ & 0 & 0 & 0 \\
\hline Net Exchanges & 0 & 1,104 & 0 & 0 & 0 & 0 \\
\hline \multicolumn{7}{|l|}{ Transmission for Others (Wheeling) } \\
\hline Received & 0 & 0 & 0 & 4,928 & 0 & 0 \\
\hline Delivered & 0 & 0 & 0 & 4,928 & 0 & 0 \\
\hline Net Transmission for Others ............................ & 0 & 0 & 0 & 0 & 0 & 0 \\
\hline Transmission by Others Losses ............................. & 0 & 0 & 0 & 0 & 0 & 0 \\
\hline \multicolumn{7}{|l|}{ Total Net Energy } \\
\hline 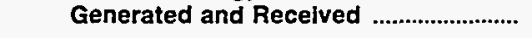 & 317,654 & $1,024,602$ & 811,671 & 407,225 & 106,419 & 206,910 \\
\hline \multicolumn{7}{|l|}{ Disposition of Energy } \\
\hline 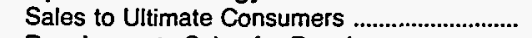 & 304,843 & 0 & $\mathbf{0}$ & 323,893 & $\mathbf{0}$ & 188,955 \\
\hline 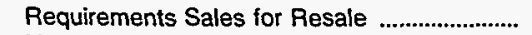 & 0 & 0 & 789,638 & 0 & 106,419 & 0 \\
\hline Nonrequirements Sales for Resale .................. & 0 & $1,024,602$ & $\mathbf{0}$ & 60,469 & 0 & 0 \\
\hline 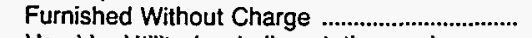 & 2,811 & 0 & 0 & 859 & 0 & 0 \\
\hline Used by Utility (excluding station use) ............ & 0 & 0 & $\mathbf{0}$ & 1,397 & 0 & 6,213 \\
\hline 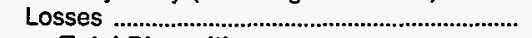 & 10,000 & 0 & 22,033 & 20,607 & 0 & 11,742 \\
\hline 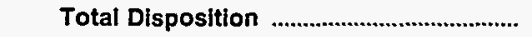 & 317,654 & $1,024,602$ & 811,671 & 407,225 & 106,419 & 206,910 \\
\hline
\end{tabular}

Note: Totals may not equal sum of components because of independent rounding. Double counting occurs in components of both sources and disposition of energy and thus neither provides a true total. Purchases from utilities, net interchanges, and net wheeling (except for imports) are included in net generation. Sales for resale is included in sales to ultimate consumers.

Source: Energy Information Administration, Form EIA-412, "Annual Report of Public Electric Utilities." 
Table 26. Electric Energy Account by Major U.S. Publicly Owned Electric Utility Within State, 1993 (Continued)

(Megawatthours)

\begin{tabular}{|c|c|c|c|c|c|c|}
\hline Item & $\begin{array}{l}\text { Virginia } \\
\text { Bristol } \\
\text { Utilities } \\
\text { Board } \\
\\
\text { June } 30\end{array}$ & $\begin{array}{l}\text { Virginia } \\
\text { Danville } \\
\text { City of } \\
\text { June } 30\end{array}$ & $\begin{array}{c}\text { Virginia } \\
\begin{array}{c}\text { Harrisonburg } \\
\text { City of }\end{array} \\
\text { June } 30\end{array}$ & $\begin{array}{l}\text { Virginia } \\
\text { Manassas } \\
\text { City of } \\
\text { June } 30\end{array}$ & $\begin{array}{c}\text { Virginia } \\
\begin{array}{c}\text { Martinsville } \\
\text { City of }\end{array} \\
\text { June } 30\end{array}$ & $\begin{array}{l}\text { Virginia } \\
\text { Radford } \\
\text { City of } \\
\text { June } 30\end{array}$ \\
\hline \multicolumn{7}{|l|}{ Sources of Energy } \\
\hline 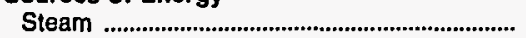 & 0 & 0 & 0 & 0 & 0 & 0 \\
\hline 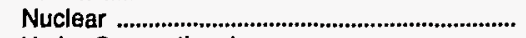 & 0 & 0 & 0 & 0 & 0 & 0 \\
\hline Hydro-Conventional ............................................... & 0 & 38,039 & 0 & 0 & 6,615 & 5,781 \\
\hline Hydro-Pumped Storage & 0 & 0 & 0 & 0 & 0 & 0 \\
\hline Other & 0 & 0 & 0 & 4,268 & 0 & $\mathbf{0}$ \\
\hline 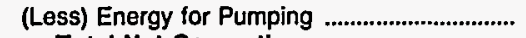 & 0 & 0 & 0 & 0 & 0 & 0 \\
\hline Total Net Generation & $\mathbf{0}$ & 38,039 & $\mathbf{0}$ & 4,268 & 6,615 & 5,781 \\
\hline 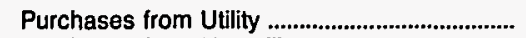 & 529,372 & 780,307 & 503,298 & 269,599 & 205,024 & 288,297 \\
\hline $\begin{array}{l}\text { Purchases from Nonutility ................................... } \\
\text { Power Exchanges }\end{array}$ & 0 & 0 & 0 & 0 & 0 & 0 \\
\hline 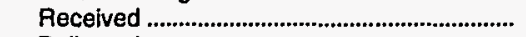 & 0 & 0 & 0 & 0 & 0 & 0 \\
\hline 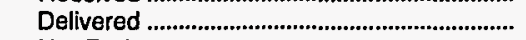 & 0 & 0 & 0 & 0 & 0 & 0 \\
\hline Net Exchanges & 0 & 0 & 0 & 0 & 0 & 0 \\
\hline \multicolumn{7}{|l|}{ Transmission for Others (Wheeling) } \\
\hline 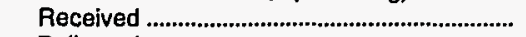 & 0 & 0 & 0 & 0 & 0 & 0 \\
\hline 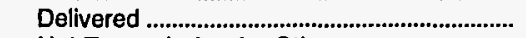 & 0 & 0 & 0 & 0 & 0 & 0 \\
\hline 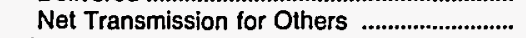 & 0 & 0 & 0 & 0 & 0 & 0 \\
\hline $\begin{array}{l}\text { Transmission by Others Losses ............................ } \\
\text { Total Net Energy }\end{array}$ & $\mathbf{0}$ & 0 & 0 & 0 & 0 & 0 \\
\hline Generated and Recelved ............................ & 529,372 & 818,346 & 503,298 & 273,867 & 211,639 & 294,078 \\
\hline \multicolumn{7}{|l|}{ Disposition of Energy } \\
\hline 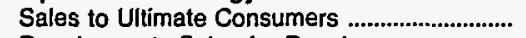 & 505,758 & 752,811 & 483,477 & 255,870 & 196,794 & 284,043 \\
\hline Requirements Sales for Resale ........................... & 0 & 0 & 0 & 0 & 0 & 0 \\
\hline Nonrequirements Sales for Resale ................. & 0 & 0 & 0 & 0 & $\mathbf{0}$ & 0 \\
\hline 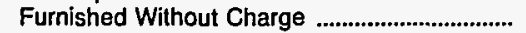 & 0 & 0 & 0 & 0 & 1,721 & 11 \\
\hline Used by Utility (excluding station use) ............ & o & 0 & 0 & 0 & 180 & 13 \\
\hline Losses & 23,613 & 65,535 & 19,821 & 17,997 & 12,944 & 10,011 \\
\hline 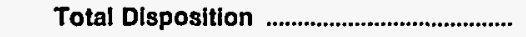 & 529,372 & 818,346 & 503,298 & 273,867 & 211,639 & 294,078 \\
\hline
\end{tabular}

Note: Totals may not equal sum of components because of independent rounding. Double counting occurs in components of both sources and disposition of energy and thus neither provides a true total. Purchases from utilities, net interchanges, and net wheeling (except for imports) are included in net generation. Sales for resale is included in sales to ultimate consumers.

Source: Energy Information Administration, Form EIA-412, "Annual Report of Public Electric Utilities." 
Table 26. Electric Energy Account by Major U.S. Publicly Owned Electric Utility Within State, 1993 (Continued)

(Megawatthours)

\begin{tabular}{|c|c|c|c|c|c|c|}
\hline Item & $\begin{array}{l}\text { Virginia } \\
\text { Salem } \\
\text { City of } \\
\text { June } 30\end{array}$ & $\begin{array}{c}\text { Virginia } \\
\text { Virginia } \\
\text { Tech } \\
\text { Electric } \\
\text { Service } \\
\text { June } 30\end{array}$ & $\begin{array}{l}\text { Washington } \\
\text { Centralia } \\
\text { City of } \\
\text { December } 31\end{array}$ & $\begin{array}{l}\text { Washington } \\
\text { Ellensburg } \\
\text { City of }\end{array}$ & $\begin{array}{l}\text { Washington } \\
\begin{array}{c}\text { Port Angeles } \\
\text { City of }\end{array} \\
\text { December } 31\end{array}$ & $\begin{array}{c}\text { Washington } \\
\text { PUD No } 1 \\
\text { of } \\
\text { Benton } \\
\text { County } \\
\text { December } 31\end{array}$ \\
\hline \multicolumn{7}{|l|}{ Sources of Energy } \\
\hline 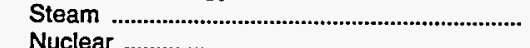 & 0 & 14,159 & 0 & 0 & 0 & \\
\hline 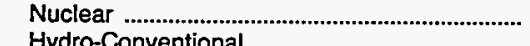 & 0 & 0 & 0 & 0 & 0 & 0 \\
\hline & 0 & 0 & 48,517 & 0 & 2,274 & \\
\hline Hydro-Pumped Storage .............................................. & 0 & 0 & 0 & 0 & 0 & 0 \\
\hline Other & 0 & 0 & 0 & 0 & 0 & \\
\hline 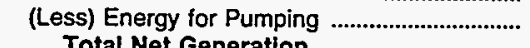 & 0 & $\begin{array}{r}0 \\
0\end{array}$ & 0 & 0 & 0 & 0 \\
\hline 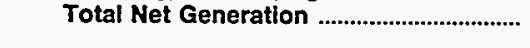 & & 14,159 & 48,517 & 0 & 2,274 & 0 \\
\hline 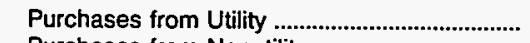 & 335,118 & 210,139 & 182,240 & 169,205 & 652,317 & $1,411,957$ \\
\hline $\begin{array}{l}\text { Purchases from Nonutility } \\
\text { Power Exchanges }\end{array}$ & 0 & 0 & 0 & 0 & 0 & \\
\hline 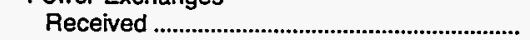 & 0 & 0 & 0 & 0 & 0 & \\
\hline Delivered ………………………………………... & 0 & 0 & 0 & 0 & 0 & 0 \\
\hline Net Exchanges & 0 & 0 & 0 & 0 & 0 & 0 \\
\hline \multicolumn{7}{|l|}{ Transmission for Others (Wheeling) } \\
\hline 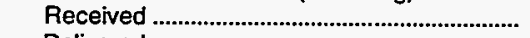 & 0 & 0 & 0 & 0 & 0 & \\
\hline - & 0 & 0 & 0 & 0 & 0 & \\
\hline Net Transmission for Others ................................ & 0 & 0 & 0 & $\mathbf{0}$ & 0 & 0 \\
\hline 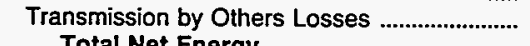 & 0 & 0 & 0 & 0 & 0 & 0 \\
\hline $\begin{array}{l}\text { Total Net Energy } \\
\text { Generated and Received }\end{array}$ & 335,118 & 224,298 & 230,757 & 169,205 & 654,591 & $1,411,957$ \\
\hline \multicolumn{7}{|l|}{ Disposition of Energy } \\
\hline 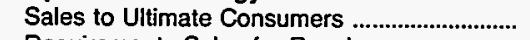 & 314,924 & 214,902 & 218,155 & 164,837 & 644,322 & $1,360,014$ \\
\hline Requirements Sales for Resale & 0 & 0 & 0 & 0 & 0 & \\
\hline Nonrequirements Sales for Resale .................. & 0 & 0 & 0 & 0 & 0 & 0 \\
\hline 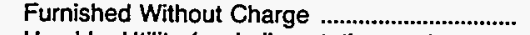 & 0 & 0 & 0 & 0 & 855 & 0 \\
\hline Used by Utility (excluding station use) .............. & 0 & 0 & 361 & 0 & 512 & 1,441 \\
\hline 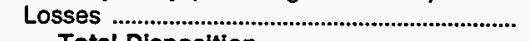 & 20,194 & 9,396 & 12,241 & 4,368 & 8,902 & 50,502 \\
\hline Total Disposition & 335,118 & 224,298 & 230,757 & 169,205 & 654,591 & $1,411,957$ \\
\hline
\end{tabular}

Note: Totals may not equal sum of components because of independent rounding. Double counting occurs in components of both sources and disposition of energy and thus neither provides a true total. Purchases from utilities, net interchanges, and net wheeling (except for imports) are included in net generation. Sales for resale is included in sales to ultimate consumers.

Source: Energy Information Administration, Form ElA-412, "Annual Report of Public Electric Utilities." 
Table 26. Electric Energy Account by Major U.S. Publicly Owned Electric Utility Within State, 1993 (Continued)

(Megawatthours)

\begin{tabular}{|c|c|c|c|c|c|c|}
\hline flem & $\begin{array}{c}\text { Washington } \\
\text { PUD No } 1 \\
\text { of } \\
\text { Chelan } \\
\text { County } \\
\text { December } 31\end{array}$ & $\begin{array}{l}\text { Washington } \\
\text { PUD No } 1 \text { of } \\
\text { Clallam } \\
\text { County } \\
\text { December } 31\end{array}$ & $\begin{array}{c}\text { Washington } \\
\text { PUD No } 1 \\
\text { of } \\
\text { Clark } \\
\text { County } \\
\text { December } 31\end{array}$ & $\begin{array}{l}\text { Washington } \\
\text { PUD No } 1 \text { of } \\
\text { Cowlitz } \\
\text { County } \\
\text { December } 31\end{array}$ & $\begin{array}{l}\text { Washington } \\
\text { PUD No } 1 \text { of } \\
\text { Douglas } \\
\text { County } \\
\text { December } 31\end{array}$ & $\begin{array}{l}\text { Washington } \\
\text { PUD No } 1 \text { of } \\
\text { Franklin } \\
\text { County } \\
\text { December } 31\end{array}$ \\
\hline \multicolumn{7}{|l|}{ Sources of Energy } \\
\hline 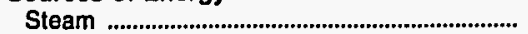 & 0 & 0 & 0 & 0 & 0 & \\
\hline 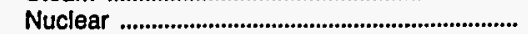 & 0 & 0 & 0 & 0 & 0 & 0 \\
\hline 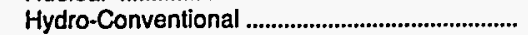 & $7,402,591$ & 0 & 0 & 160,457 & $3,621,438$ & \\
\hline 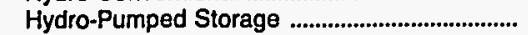 & 0 & 0 & 0 & 0 & 0 & 0 \\
\hline 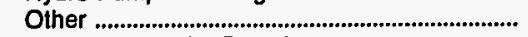 & 0 & 0 & 0 & 0 & $\mathbf{0}$ & 0 \\
\hline 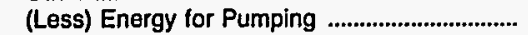 & 0 & 0 & 0 & 0 & 0 & \\
\hline 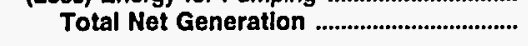 & $7,402,591$ & 0 & 0 & 160,457 & $3,621,438$ & 0 \\
\hline Purchases from Utility .......... & 279,357 & 510,183 & $3,436,754$ & $4,419,825$ & 145,893 & 661,971 \\
\hline Purchases from Nonutility ...................................... & & 262 & 155,138 & 0 & 0 & \\
\hline \multicolumn{7}{|l|}{ Power Exchanges } \\
\hline 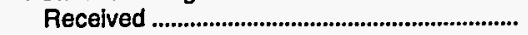 & $1,096,913$ & 0 & 0 & 41,683 & 394,270 & \\
\hline 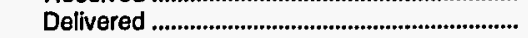 & 575,892 & 0 & 0 & 1,685 & 404,849 & \\
\hline 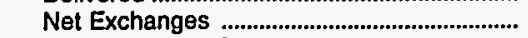 & 521,021 & 0 & 0 & 39,998 & $-10,579$ & \\
\hline \multicolumn{7}{|l|}{ Transmission for Others (Wheeling) } \\
\hline 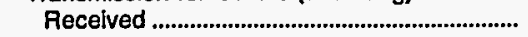 & 85,224 & 0 & 0 & 0 & 0 & \\
\hline 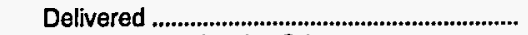 & 83,260 & 0 & 0 & 0 & 0 & 0 \\
\hline 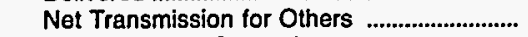 & 1,964 & 0 & 0 & 0 & 0 & 0 \\
\hline Transmission by Others Losses .......................... & 876 & 0 & 0 & 0 & 0 & 0 \\
\hline $\begin{array}{l}\text { Total Net Energy } \\
\text { Generated and Recelved }\end{array}$ & & & & & & \\
\hline Generated and Recelved & $8,205,809$ & 510,445 & $3,591,892$ & $4,620,280$ & $\mathbf{3 , 7 5 6 , 7 5 2}$ & 661,971 \\
\hline \multicolumn{7}{|l|}{ Disposition of Energy } \\
\hline 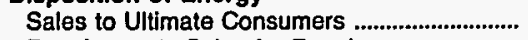 & $1,263,860$ & 481,046 & $3,430,257$ & $4,562,301$ & 650,313 & 625,542 \\
\hline Requirements Sales for Resale ............................ & $6,186,485$ & 0 & 0 & 1.767 & $2,505,651$ & \\
\hline Nonrequirements Sales for Resale ................... & 295,923 & 0 & 0 & 0 & 175,188 & \\
\hline Furnished Without Charge ........................................ & 22 & 0 & 0 & 0 & 355,841 & \\
\hline Used by Utility (excluding station use) ............. & 252 & 1,313 & 12,673 & 3,333 & 1,938 & 1,380 \\
\hline 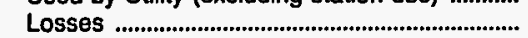 & 459,267 & 28,086 & 148,962 & 52,879 & 67,821 & 35,049 \\
\hline 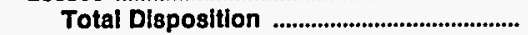 & $8,205,809$ & 510,445 & $3,591,892$ & $4,620,280$ & $3,756,752$ & 661,971 \\
\hline
\end{tabular}

Note: Totals may not equal sum of components because of independent rounding. Double counting occurs in components of both sources and disposition of energy and thus neither provides a true total. Purchases from utilities, net interchanges, and net wheeling (except for imports) are included in net generation. Sales for resale is included in sales to ultimate consumers.

Source: Energy Information Administration, Form ElA-412, "Annual Report of Public Electric Utilities." 
Table 26. Electric Energy Account by Major U.S. Publicly Owned Electric Utility Within State, 1993 (Continued)

(Megawatthours)

\begin{tabular}{|c|c|c|c|c|c|c|}
\hline Item & $\begin{array}{l}\text { Washington } \\
\text { PUD No } 1 \\
\text { of } \\
\text { Grays } \\
\text { Harbor Cnty } \\
\text { December } 31\end{array}$ & $\begin{array}{l}\text { Washington } \\
\text { PUD No } 1 \text { of } \\
\text { Klickitat } \\
\text { County } \\
\text { December } 31\end{array}$ & $\begin{array}{l}\text { Washington } \\
\text { PUD No } 1 \\
\text { of } \\
\text { Lewis } \\
\text { County } \\
\text { December } 31\end{array}$ & $\begin{array}{l}\text { Washington } \\
\text { PUD No } 1 \text { of } \\
\text { Okanogan } \\
\text { County }\end{array}$ & $\begin{array}{l}\text { Washington } \\
\text { PUD No } 1 \text { of } \\
\text { Pend Oreille } \\
\text { Cnty } \\
\text { December } 31\end{array}$ & $\begin{array}{l}\text { Washington } \\
\text { PUD No } 1 \text { of } \\
\text { Snohomish } \\
\text { County } \\
\text { December } 31\end{array}$ \\
\hline \multicolumn{7}{|l|}{ Sources of Energy } \\
\hline Steam & 350,546 & 0 & 0 & 0 & 0 & 717,907 \\
\hline 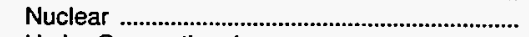 & 0 & 0 & 0 & 0 & 0 & \\
\hline 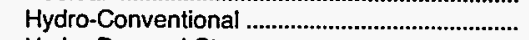 & 0 & 0 & 903 & 0 & 482,522 & 306,890 \\
\hline Hydro-Pumped Storage ............................................. & 0 & 0 & 0 & 0 & 0 & \\
\hline Other & 0 & 0 & 0 & 0 & 0 & \\
\hline (Less) Energy for Pumping ........................................ & 0 & 0 & 0 & 0 & 0 & \\
\hline 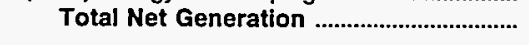 & 350,546 & o & 903 & 0 & 482,522 & $1,024,797$ \\
\hline Purchases from Utility. & $1,028,748$ & 296,070 & 693,488 & 617,118 & 562,819 & $5,177,800$ \\
\hline Purchases from Nonutility ............ & 0 & 58 & 0 & 624 & 0 & 604 \\
\hline $\begin{array}{l}\text { Power Exchanges } \\
\text { Received }\end{array}$ & & & & & & \\
\hline 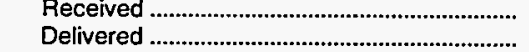 & $\begin{array}{l}0 \\
0\end{array}$ & $\begin{array}{l}0 \\
0\end{array}$ & 0 & 0 & 22,203 & 123,188 \\
\hline Net Exchanges & 0 & 0 & $\begin{array}{l}0 \\
0\end{array}$ & $\begin{array}{l}0 \\
0\end{array}$ & 17,589 & 136,889 \\
\hline \multicolumn{7}{|l|}{ Transmission for Others (Wheeling) } \\
\hline 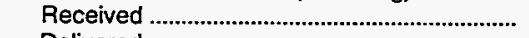 & 0 & 0 & 0 & 0 & 0 & 11,005 \\
\hline Delivered & 0 & 0 & 0 & 0 & 0 & 11,005 \\
\hline Net Transmission for Others .................................. & 0 & 0 & 0 & 0 & 0 & 0 \\
\hline Transmission by Others Losses ............................ & 0 & 0 & 0 & 0 & 0 & 0 \\
\hline $\begin{array}{l}\text { Total Net Energy } \\
\text { Generated and Received }\end{array}$ & & & & & & \\
\hline Generated and Received ........................... & $1,379,294$ & 296,128 & 694,391 & 617,742 & $1,049,955$ & $6,189,500$ \\
\hline \multicolumn{7}{|l|}{ Disposition of Energy } \\
\hline Sales to Ultimate Consumers ....... & 963,151 & 276,286 & 651,304 & 584,066 & 873,832 & $5,838,889$ \\
\hline Requirements Sales for Resale ........................ & 350,548 & 0 & 0 & 0 & 143,681 & 68,863 \\
\hline Nonrequirements Sales for Resale ..................... & & 0 & 0 & 0 & 0 & \\
\hline 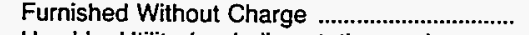 & 3,115 & 0 & 0 & 0 & 0 & \\
\hline Used by Utility (excluding station use) ............. & 0 & 873 & 872 & 1,490 & 2,280 & 14,773 \\
\hline Losses & 62,480 & 18,969 & 42,215 & 32,186 & 30,162 & 266,975 \\
\hline 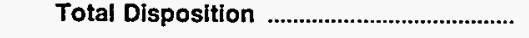 & $1,379,294$ & 296,128 & 694,391 & 617,742 & $1,049,955$ & $6,189,500$ \\
\hline
\end{tabular}

Note: Totals may not equal sum of components because of independent rounding. Double counting occurs in components of both sources and disposition of energy and thus neither provides a true total. Purchases from utilities, net interchanges, and net wheeling (except for imports) are included in net generation. Sales for resale is included in sales to ultimate consumers.

Source: Energy Information Administration, Form ElA-412, "Annual Report of Public Electric Utilities." 
Table 26. Electric Energy Account by Major U.S. Publicly Owned Electric Utility Within State, 1993 (Continued)

(Megawatthours)

\begin{tabular}{|c|c|c|c|c|c|c|}
\hline Item & $\begin{array}{l}\text { Washington } \\
\text { PUD No } 1 \text { of } \\
\text { Whatcom } \\
\text { County }\end{array}$ & $\begin{array}{c}\text { Washington } \\
\text { PUD No } 2 \\
\text { of } \\
\text { Grant } \\
\text { County } \\
\text { December } 31\end{array}$ & $\begin{array}{l}\text { Washington } \\
\text { PUD No } 2 \text { of } \\
\text { Pacific } \\
\text { County } \\
\text { December } 31\end{array}$ & $\begin{array}{l}\text { Washington } \\
\text { PUD No } 3 \\
\text { of } \\
\text { Mason } \\
\text { County } \\
\text { December } 31\end{array}$ & $\begin{array}{l}\text { Washington } \\
\text { Richland } \\
\text { City of } \\
\text { December } 31\end{array}$ & $\begin{array}{c}\text { Washington } \\
\text { Seattle } \\
\text { City of } \\
\text { December } 31\end{array}$ \\
\hline \multicolumn{7}{|l|}{ Sources of Energy } \\
\hline Steam .............................. & 0 & 0 & 0 & 0 & 0 & 696,933 \\
\hline 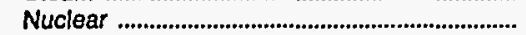 & 0 & 0 & 0 & 0 & 0 & \\
\hline 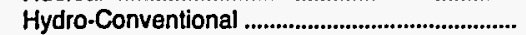 & 0 & $8,491,615$ & 0 & 0 & 0 & $5,347,899$ \\
\hline Hydro-Pumped Storage ............................................... & 0 & 0 & 0 & 0 & 0 & \\
\hline 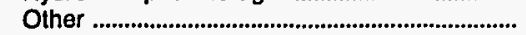 & 0 & 0 & 0 & 0 & 0 & 0 \\
\hline (Less) Energy for Pumping ................................... & 0 & 0 & 0 & 0 & 0 & 10,886 \\
\hline 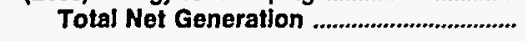 & 0 & $8,491,615$ & 0 & o & 0 & $6,033,946$ \\
\hline 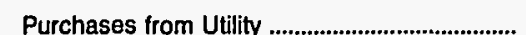 & 139,229 & 363,186 & 275,743 & 517,682 & 656,949 & $3,443,011$ \\
\hline 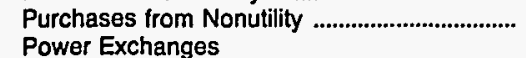 & 0 & 0 & 0 & 0 & 0 & 11,236 \\
\hline 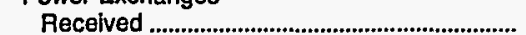 & 0 & 665,990 & 0 & 0 & 0 & $6,353,854$ \\
\hline 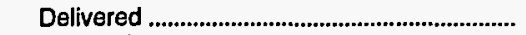 & 0 & 650,362 & 0 & 0 & 0 & $6,366,850$ \\
\hline 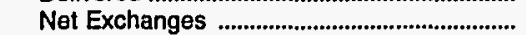 & 0 & 15,628 & 0 & 0 & 0 & $-12,996$ \\
\hline \multicolumn{7}{|l|}{ Transmission for Others (Wheeling) } \\
\hline 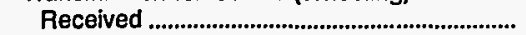 & 0 & 0 & 0 & 0 & 0 & 49,898 \\
\hline Delivered ................................................................ & 0 & 0 & $\mathbf{0}$ & 0 & 0 & 49,898 \\
\hline Net Transmission for Others ............................... & 0 & 0 & 0 & 0 & 0 & 0 \\
\hline Transmission by Others Losses ................................... & 0 & 0 & 0 & 0 & 0 & 0 \\
\hline 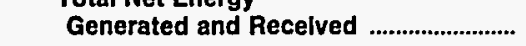 & 139,229 & $8,870,429$ & 275,743 & 517,682 & 656,949 & $9,475,197$ \\
\hline \multicolumn{7}{|l|}{ Dispositton of Energy } \\
\hline 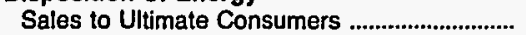 & 139,229 & $2,666,988$ & 272,100 & 489,979 & 634,082 & $8,914,889$ \\
\hline 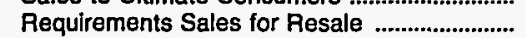 & 0 & $5,387,716$ & 0 & 2,084 & 0 & \\
\hline Nonrequirements Sales for Resale ...................... & 0 & 0 & 0 & 0 & 0 & 0 \\
\hline Furnished Without Charge ..................................... & 0 & 654,339 & 0 & 0 & 0 & 0 \\
\hline Used by Utility (excluding station use) ............. & 0 & 9,764 & 570 & 912 & 0 & 29,881 \\
\hline 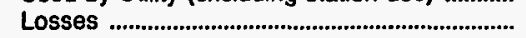 & 0 & 151,622 & 3,073 & 24,707 & 22,867 & 530,427 \\
\hline Total Disposition & 139,229 & $8,870,429$ & 275,743 & 517,682 & 656,949 & $9,475,197$ \\
\hline
\end{tabular}

Note: Totals may not equal sum of components because of independent rounding. Double counting occurs in components of both sources and disposition of energy and thus neither provides a true total. Purchases from utilities, net interchanges, and net wheeling (except for imports) are included in net generation. Sales for resale is included in sales to ultimate consumers.

Source: Energy Information Administration, Form EIA-412, "Annual Report of Public Electric Utilities." 
Table 26. Electric Energy Account by Major U.S. Publicly Owned Electric Utility Within State, 1993 (Continued)

(Megawatthours)

\begin{tabular}{|c|c|c|c|c|c|c|}
\hline Item & $\begin{array}{c}\text { Washington } \\
\text { Tacoma } \\
\text { City of } \\
\text { December } 31\end{array}$ & $\begin{array}{c}\text { Washington } \\
\text { Vera } \\
\text { Irrigation } \\
\text { District \#15 } \\
\text { December } 31\end{array}$ & $\begin{array}{l}\text { Washington } \\
\text { Washington } \\
\text { Pub } \\
\text { Pwr } \\
\text { Supply Sys } \\
\text { June } 30\end{array}$ & $\begin{array}{l}\text { Wisconsin } \\
\begin{array}{c}\text { Badger Power } \\
\text { Marketing } \\
\text { Auth }\end{array} \\
\text { December } 31\end{array}$ & $\begin{array}{l}\text { Wisconsin } \\
\text { Jefferson } \\
\text { City of } \\
\text { December } 31\end{array}$ & $\begin{array}{l}\text { Wisconsin } \\
\text { Kaukauna } \\
\text { City of } \\
\text { December } 31\end{array}$ \\
\hline \multicolumn{7}{|l|}{ Sources of Energy } \\
\hline Steam ............................ & 828,843 & 0 & 0 & 0 & 0 & 0 \\
\hline 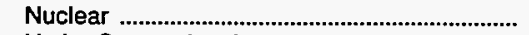 & 0 & 0 & $6,129,742$ & 0 & 0 & 0 \\
\hline Hydro-Conventional ................................................. & $1,920,046$ & 0 & 65,800 & 0 & 0 & 179,122 \\
\hline Hydro-Pumped Storage ............................................ & 0 & 0 & 0 & 0 & 0 & 0 \\
\hline Other & 0 & 0 & 0 & 0 & 0 & $\mathbf{0}$ \\
\hline (Less) Energy for Pumping ......................................... & 0 & 0 & 0 & 0 & 0 & 0 \\
\hline 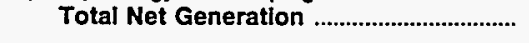 & $2,748,889$ & 0 & $6,195,542$ & 0 & 0 & 179,122 \\
\hline Purchases from Utility .............................................. & $2,826,056$ & 177,630 & 0 & 250,800 & 139,000 & 403,812 \\
\hline 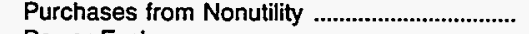 & 546,030 & 0 & 0 & 0 & 0 & 0 \\
\hline \multicolumn{7}{|l|}{ Power Exchanges } \\
\hline 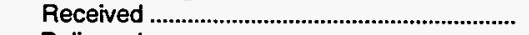 & 68,504 & 0 & $\mathbf{0}$ & 0 & 0 & 0 \\
\hline 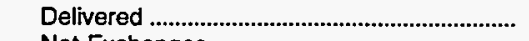 & 6,285 & 0 & 0 & 0 & 0 & 0 \\
\hline Net Exchanges & 62,219 & 0 & 0 & 0 & 0 & 0 \\
\hline \multicolumn{7}{|l|}{ Transmission for Others (Wheeling) } \\
\hline 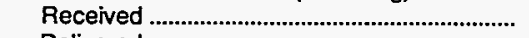 & $1,296,899$ & 0 & 0 & 0 & 0 & 0 \\
\hline 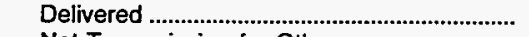 & $1,296,899$ & 0 & 0 & 0 & 0 & 0 \\
\hline Net Transmission for Others ................................. & 0 & 0 & 0 & 0 & 0 & 0 \\
\hline $\begin{array}{l}\text { Transmission by Others Losses ............................. } \\
\text { Total Net Energy }\end{array}$ & 0 & 0 & 0 & 0 & 0 & 0 \\
\hline 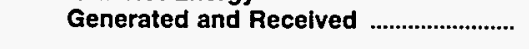 & $6,183,194$ & 177,630 & $6,195,542$ & 250,800 & 139,000 & 582,934 \\
\hline \multicolumn{7}{|l|}{ Disposition of Energy } \\
\hline 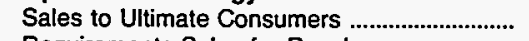 & $5,545,514$ & 172,652 & 0 & 0 & 134,000 & 561,399 \\
\hline Requirements Sales for Resale ........................... & 375,008 & 0 & $6,188,829$ & 249,200 & 0 & 0 \\
\hline Nonrequirements Sales for Resale ...................... & 65,087 & 0 & 0 & 0 & 0 & 0 \\
\hline Furnished Without Charge & 0 & 0 & 0 & 0 & 0 & 0 \\
\hline Used by Utility (excluding station use) ............. & 6,059 & 0 & 0 & 0 & 0 & 583 \\
\hline Losses & 191,526 & 4,978 & 6,713 & 1,600 & 5,000 & 20,952 \\
\hline Total Disposition ................................................. & $6,183,194$ & 177,630 & $6,195,542$ & 250,800 & 139,000 & 582,934 \\
\hline
\end{tabular}

Note: Totals may not equal sum of components because of independent rounding. Double counting occurs in components of both sources and disposition of energy and thus neither provides a true total. Purchases from utilities, net interchanges, and net wheeling (except for imports) are included in net generation. Sales for resale is included in sales to ultimate consumers.

Source: Energy Information Administration, Form ElA-412, "Annual Report of Public Electric Utilities." 
Table 26. Electric Energy Account by Major U.S. Publicly Owned Electric Utility Within State, 1993 (Continued)

(Megawatthours)

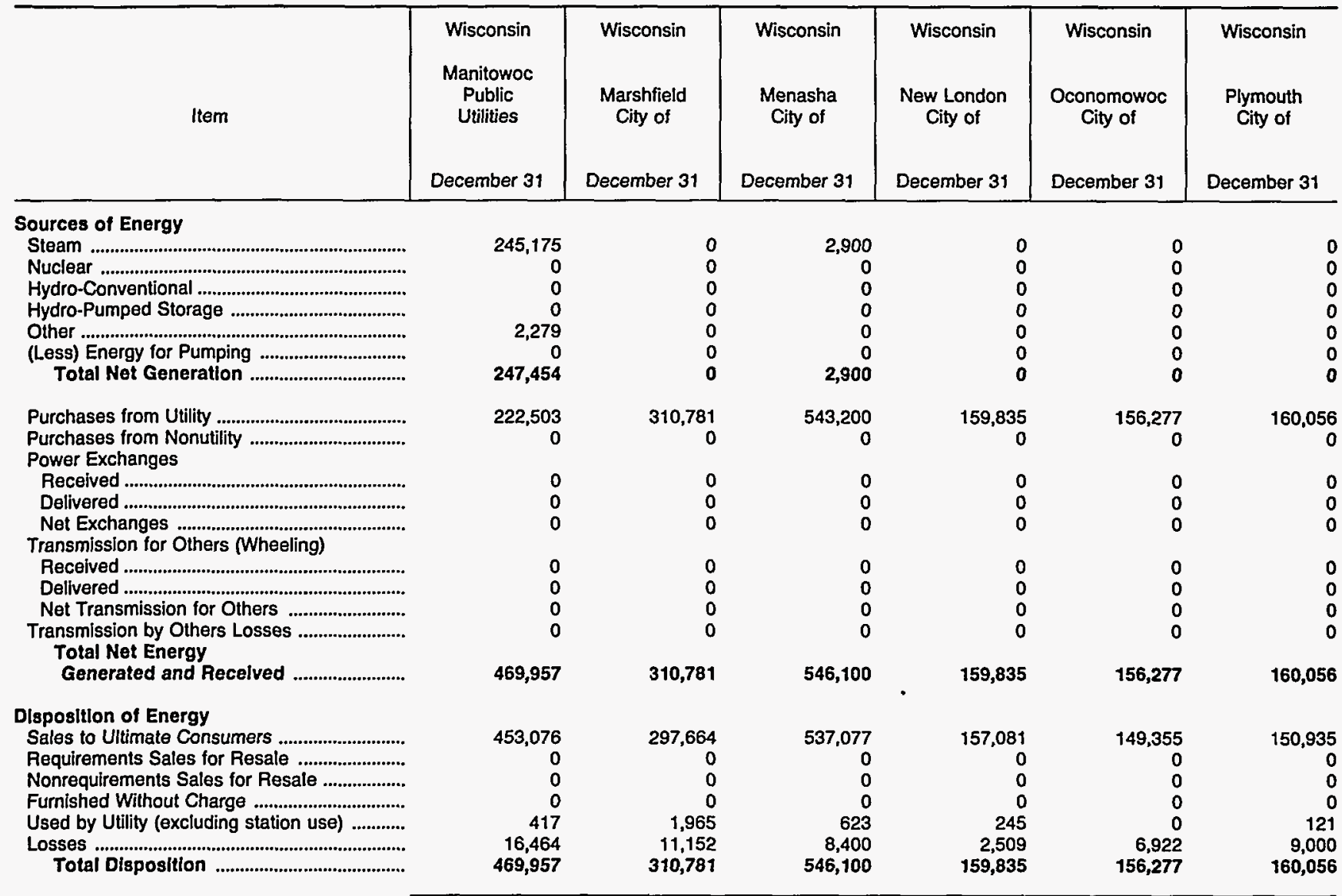

Note: Totals may not equal sum of components because of independent rounding. Double counting occurs in components of both sources and disposition of energy and thus neither provides a true total. Purchases from utilities, net interchanges, and net wheeling (except for imports) are included in nat generation. Sales for resale is included in sales to ultimate consumers.

Source: Energy Information Administration, Form EIA-412, "Annual Report of Public Electric Utilities." 
Table 26. Electric Energy Account by Major U.S. Publicly Owned Electric Utility Within State, 1993 (Continued)

(Megawatthours)

\begin{tabular}{|c|c|c|c|c|c|c|}
\hline Item & $\begin{array}{l}\text { Wisconsin } \\
\text { Reedsburg } \\
\text { Utility Comm } \\
\text { December } 31\end{array}$ & $\begin{array}{c}\text { Wisconsin } \\
\text { Shawano } \\
\text { Municipal } \\
\text { Utilities } \\
\text { December } 31\end{array}$ & $\begin{array}{c}\text { Wisconsin } \\
\text { Sheboygan } \\
\text { Falls } \\
\text { City of } \\
\text { December } 31\end{array}$ & $\begin{array}{c}\text { Wisconsin } \\
\text { Sturgeon Bay } \\
\text { Combined } \\
\text { Utils }\end{array}$ & $\begin{array}{l}\text { Wisconsin } \\
\text { Sun Prairie } \\
\text { Water \& Light } \\
\text { Comm } \\
\text { December } 31\end{array}$ & $\begin{array}{l}\text { Wisconsin } \\
\text { Wisconsin } \\
\text { Public } \\
\text { Power } \\
\text { Inc Sys } \\
\text { December } 31\end{array}$ \\
\hline \multicolumn{7}{|l|}{ Sources of Energy } \\
\hline Steam & 0 & 0 & 0 & 0 & 0 & 602,351 \\
\hline 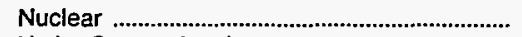 & 0 & 0 & 0 & 0 & 0 & 0 \\
\hline 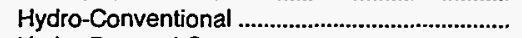 & 0 & 0 & 0 & 0 & 0 & 0 \\
\hline Hydro-Pumped Storage ...................................... & 0 & 0 & 0 & 0 & 0 & 0 \\
\hline Other & 0 & 0 & 0 & 0 & 0 & 817 \\
\hline 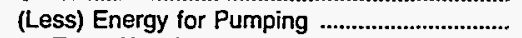 & 0 & 0 & 0 & 0 & 0 & 0 \\
\hline 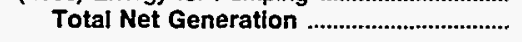 & $\mathbf{0}$ & 0 & 0 & 0 & 0 & 603,168 \\
\hline 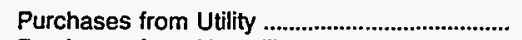 & 168,574 & 180,525 & 186,036 & 134,620 & 144,827 & $2,323,300$ \\
\hline $\begin{array}{l}\text { Purchases from Nonutility ................................. } \\
\text { Power Exchanges }\end{array}$ & 0 & 1 & 0 & 0 & 0 & 0 \\
\hline 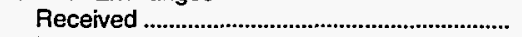 & $\mathbf{0}$ & 0 & 0 & 0 & 0 & 0 \\
\hline Delivered & 0 & 0 & 0 & 0 & 0 & 0 \\
\hline Net Exchanges & 0 & 0 & 0 & 0 & 0 & 0 \\
\hline \multicolumn{7}{|l|}{ Transmission for Others (Wheeling) } \\
\hline 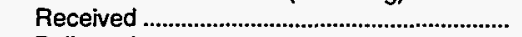 & 0 & $\mathbf{0}$ & 0 & 0 & 0 & 0 \\
\hline 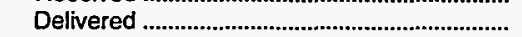 & 0 & 0 & 0 & 0 & 0 & 0 \\
\hline 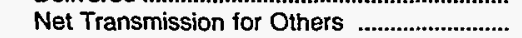 & 0 & 0 & 0 & 0 & 0 & 0 \\
\hline $\begin{array}{l}\text { Transmission by Others Losses ......................... } \\
\text { Total Net Energy }\end{array}$ & 0 & 0 & 0 & 0 & 0 & 0 \\
\hline 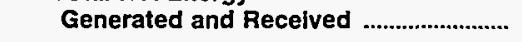 & 168,574 & 180,526 & 186,036 & 134,620 & 144,827 & $2,926,468$ \\
\hline \multicolumn{7}{|l|}{ Disposition of Energy } \\
\hline 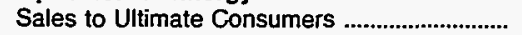 & 162,469 & 177,004 & 179,409 & 126,791 & 138,399 & 0 \\
\hline Requirements Sales for Resale .......................... & 0 & 0 & 0 & 0 & 0 & $2,892,404$ \\
\hline Nonrequirements Sales for Resale ................... & 0 & 0 & 0 & 0 & 0 & 0 \\
\hline Furnished Without Charge ............................... & 0 & 0 & 0 & 0 & 0 & 0 \\
\hline Used by Utility (excluding station use) ............. & 0 & 0 & 65 & $\mathbf{0}$ & 162 & 0 \\
\hline Losses & 6,105 & 3,522 & 6,562 & 7,829 & 6,266 & 34,064 \\
\hline 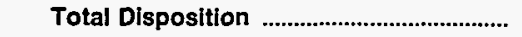 & 168,574 & 180,526 & 186,036 & 134,620 & 144,827 & $2,926,468$ \\
\hline
\end{tabular}

Note: Totals may not equal sum of components because of independent rounding. Double counting occurs in components of both sources and disposition of energy and thus neither provides a true total. Purchases from utilities, net interchanges, and net wheeling (except for imports) are included in net generation. Sales for resale is included in sales to ultimate consumers.

Source: Energy information Administration, Form EIA-412, "Annual Report of Public Electric Utilities." 
Table 26. Electric Energy Account by Major U.S. Publicly Owned Electric Utility Within State, 1993 (Continued)

(Megawatthours)

\begin{tabular}{l|c|c|c|c}
\hline & Wisconsin & Wyoming & Wyoming \\
Wisconsin & & Wyoming \\
Rapids WW & Gillette & $\begin{array}{c}\text { Municipal } \\
\& L\end{array}$ & City of & Power Agency \\
Comm & & \\
& December 31 & June 30 & December 31 & \\
\hline
\end{tabular}

\section{Sources of Energy}

Steam

Nuclear

Hydro-Conventional

Hydro-Pumped Storage ......................................

Other

(Less) Energy for Pumping

Total Net Generation

Purchases from Utility ...

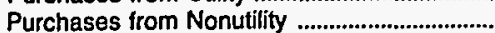

Power Exchanges

Received.

Delivered...

Transmission for Others (Wheeling)

Received

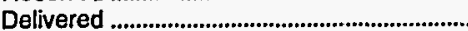

Net Transmission for Others

Transmission by Others Losses .......................

\section{Total Net Energy}

Generated and Recelved

ind

sposition of Energy

Sales to Ultimate Consumers

Requirements Sales for Resale

Nonrequirements Sales for Resale

Furnished Without Charge

Used by Utility (excluding station use) .............

Losses

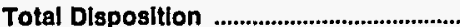

\section{7,530}

0

0

o

0

0

0

0

197,530

188,128

0
0
0
0
9,402
97,530
$0 \quad 160,162$

0

0

0

160,162

56,472

2,190

3,319

$-1,122$

$$
\begin{aligned}
& 0 \\
& 0 \\
& 0 \\
& 0
\end{aligned}
$$

180,883

215,512

$\begin{array}{rr}169,110 & 0 \\ 0 & 175,088 \\ 0 & 22,205 \\ 0 & 0 \\ 0 & 0 \\ 11,773 & 18,219 \\ 180,883 & 215,512\end{array}$

Note: Totals may not equal sum of components because of independent rounding. Double counting occurs in components of both sources and disposition of energy and thus neither provides a true total. Purchases from utilities, net interchanges, and net wheeling (except for imports) are included in net generation. Sales for resale is included in sales to ultimate consumers.

Source: Energy Information Administration, Form EIA-412, "Annual Report of Public Electric Utilities." 


\section{Summary Statistics of U.S. Federal Electric Utilities}

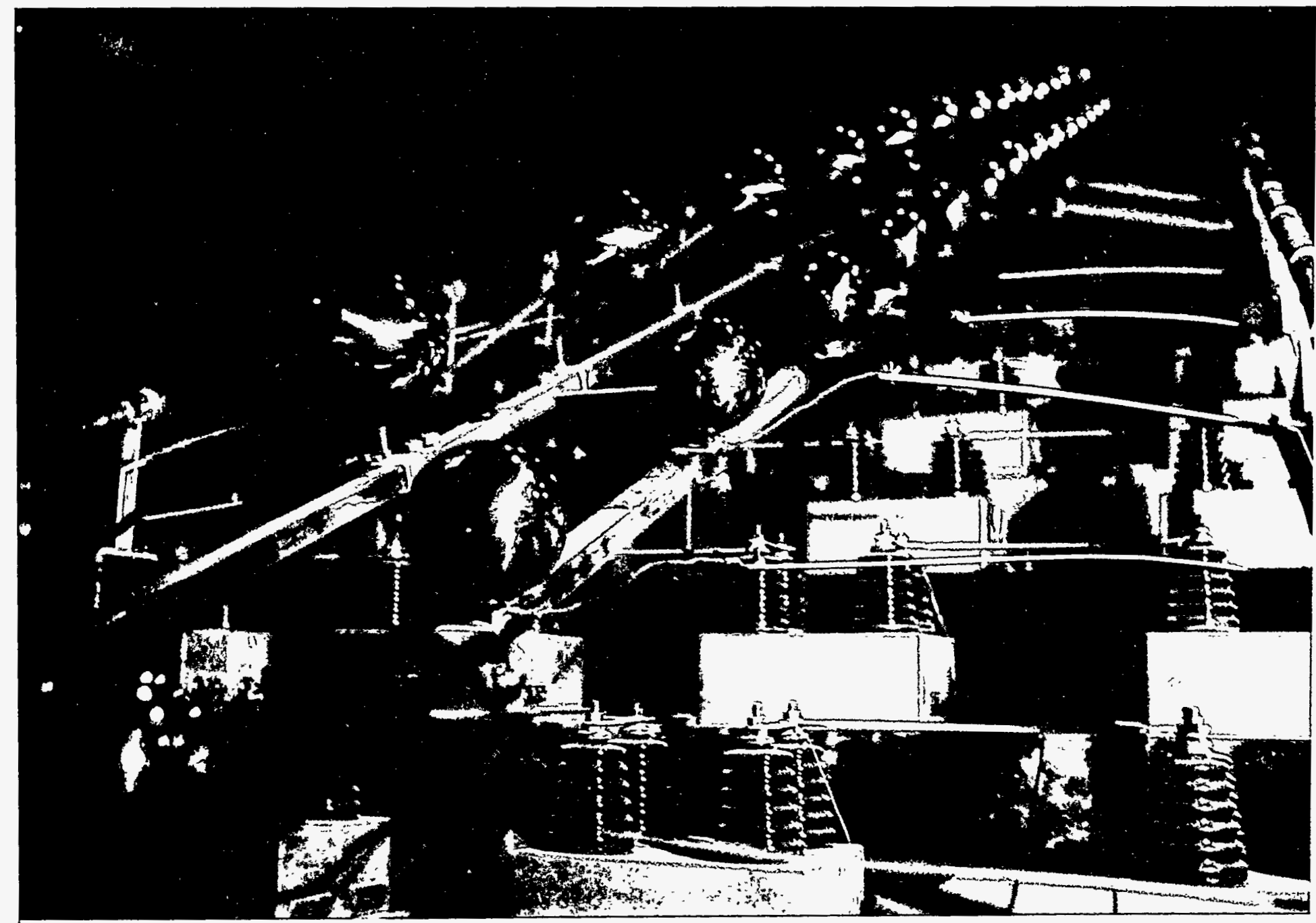

Ultra high voltage transmission lines near Vancouver, Washington, owned by Bonneville Power Administration. 


\section{Financial Performance}

\section{Background}

There are 10 Federal electric utilities in the United States. They are the Department of Defense - U.S. Army Corps of Engineers; the Department of Energy - the Alaska, Bonneville, Southeastern, Southwestern, and Western Area Power Administrations; the Department of Interior - U.S. Bureau of Indian Affairs and the U.S. Bureau of Reclamation; the Department of State - International Water and Boundary Commission; and, the Tennessee Valley Authority. The Federal electric utilities are primarily generators and wholesalers of electricity rather than distributors to ultimate consumers. Federal electric utilities operate over 150 power plants and produce approximately 8 percent of the electricity generated in the United States. Most of the power plants are Federal hydroelectric projects initially designed for flood control and irrigation purposes. Federal power is not sold for profit, but to recover the cost of operations. Most Federal generation is sold for resale to municipals, cooperative electric utilities, and other nonprofit preference customers, as required by law. There are three major producers of electricity : the Tennessee Valley Authority (TVA), the largest Federal producer; the U.S. Army Corps of Engineers (USCE); and the U.S. Bureau of Reclamation (USBR). The TVA markets its own power while the generation by the USCE, except for the North Central Division (Saint Mary's Falls at Sault St. Marie, Michigan), and the USBR is marketed by four of the Federal power marketing administrations - Bonneville, Southeastern, Southwestern, and Western Area. These four power marketing administrations also purchase energy for resale from other electric utilities in the United States and Canada. Alaska, the fifth power marketing administration, operates its own power plants and distributes power to ultimate consumers.

The Tennessee Valley Authority (TVA) was the first of the wholesale marketing organizations to be formed. It was authorized under the Tennessee Valley Authority Act in 1933 "for the purposes of maintaining and operating the properties now owned by the United States in the vicinity of Muscle Shoals, Alabama, in the interest of national defense and for agricultural and industrial development, and to improve navigation in the Tennessee River and to control the destructive flood waters in the Tennessee River and Mississippi River Basins." It was given the authority to both own and operate dams, transmission lines, and power plants along the Tennessee River and its tributaries. By the beginning of World War II, the TVA had developed most of its water resources, but growing war demands and domestic needs required new capacity. In 1949, Congress approved con- struction of a steam plant, opening the way for construction of other nonhydroelectric facilities. The TVA's fossil-fueled capacity and nuclear capacity now each exceed its hydroelectric capacity (run of river and pumped storage). In 1993, total net generation was 125.1 million megawatthours. The TVA sold 100.0 million megawathours to its wholesale customers in 1993.

During the depression in the early 1930's, New Deal legislation was passed that authorized construction of a number of Federal dams, including Grand Coulee and Bonneville dams in the Pacific Northwest. In 1937, the Government decided that the U.S. Bureau of Reclamation would be responsible for building and operating the dams in the Northwest, and a new marketing administration, the Bonneville Power Administration (BPA), was created by the Bonneville Project Act of 1937 to build and operate transmission facilities and to market the power. The BPA grew, but in the late 1960 's, like the TVA, the BPA faced a potential shortage of hydroelectric capacity to meet their load. In 1980, the Pacific Northwest Electric Power Planning and Conservation Act gave the BPA the authority to plan for and acquire additional power to meet its growing load requirements. The BPA's responsibilities were also extended from only marketing Federal power to supplying the power. Its authority to supply power, however, was restricted to obtaining it from plants built by others. The BPA cannot build its own power plants. Only the BPA and the TVA are responsible for meeting their customers loads. Under the 1980 Act, the BPA also must protect and enhance the fish and wildlife of the Columbia River and its tributaries. In 1993, the BPA sold 57.2 million megawatthours of energy to its wholesale customers from over 30 Federally owned dams operated by either the U.S. Bureau of Reclamation or the U.S. Army Corps of Engineers and from non-Federal system generators. In 1993, total net generation amounted to 77.9 million megawatthours.

In 1943, the Southwestern Power Administration (SWPA) was created using the Executive Branch's emergency war powers authority to meet the growing power demands from weapons development and domestic needs. Later, the SWPA's authority to continue to operate after World War II came from the Flood Control Act of 1944. Initially, the SWPA was assigned to market power from dams in Arkansas, Oklahoma, and Texas that were operated by the U.S. Department of Army to serve munitions plants. In 1945, the SWPA was designated as the agent for marketing power generated by the U.S. Army Corps of Engineers in the States of Arkansas, Kansas, Louisiana, Missouri, Oklahoma, and Texas. Today, the SWPA sells power from 24 hydroelectric facilities in these States that total 2,158 megawatts of installed capacity. In 1993, total net generation amounted to 9.3 million megawatthours. The SWPA sold 8.1 million megawatthours to its wholesale customers in 1993. 
The third power marketing administration, Southeastern Power Administration (SEPA), was established in 1950 under the authority of the Flood Control Act of 1944 to sell power produced by the U.S. Army Corps of Engineers in the Southeast. The SEPA currently markets power in West Virginia, Virginia, North Carolina, South Carolina, Georgia, Florida, Alabama, Mississippi, Tennessee, and Kentucky. The SEPA is unique from the other marketing authorities in that it owns no transmission lines. It must rely on private firms to transmit the power it sells. In its role to market the energy generated by the Southeastern Federal reservoir projects, it participated in the establishment of the Southeastern Federal Power Alliance, which consists of SEPA, the South Atlantic Division of the U.S. Army Corps of Engineers, and SEPA's preference customers. The purpose of this organization is to improve communication and establish a strategy by which the three groups can better implement the Federal Power Program in the southeast. In 1993, total net generation amounted to 9.2 million megawatthours. The SEPA sold 9.0 million megawatthours to its wholesale customers in 1993.

The Alaska Power Marketing Administration (APA) was formed in 1967 under the Flood Control Act of 1944 to both operate and market the power from two hydroelectric plants in Alaska: the Eklutna Project (30 megawatts) and the Snettisham Project (78 megawatts). In 1993, total net generation amounted to 0.4 million megawatthours. The TVA and the APA are the only two Federal marketing organizations to operate their own plants.

The last Federal marketing administration to be created was the Western Area Power Administration (WAPA), which was formed in 1977 when the Congress created the U.S. Department of Energy and assigned the other Federal marketing administrations to be a part of the new energy department. The territory that the WAPA serves covers the 15 Central and Western States of Arizona, California, Colorado, Iowa, Kansas, Minnesota, Montana, Nebraska, Nevada, New Mexico, North Dakota, South Dakota, Texas, Utah, and Wyoming. Its mission is to market Federally-owned hydroelectric resources "...in such a manner as to encourage the most widespread use thereof at the lowest possible rates to consumers consistent with sound business principles ..." The WAPA's authority was extended through the Hoover Power Plant Act of 1984 to require customer utilities to undertake certain conservation activities and to withhold a part of customer's power allocation if they did not comply. The WAPA markets hydroelectric power from 51 plants operated by the U.S. Bureau of Reclamation, the U.S. Army Corps of Engineers, and the International Boundary and Water Commission. In addition, the WAPA markets the Federal Government's 547 megawatt entitlement from the coal-fired Navajo Generating Station in Arizona. In 1993, total net generation amounted to 25.1 million megawatthours. The WAPA was responsible for selling 27.7 million megawatthours to its wholesale customers in 1993. 


\section{The Largest Federal Producer}

The Tennessee Valley Authority provides power to approximately 110 municipal and 50 cooperative electric systems for distribution to over 3.3 million customers. The four largest municipalities are the Tennessee cities of Memphis, Nashville, Chattanooga, and Knoxville. Of the 125.1 million megawatthours of electricity generated in 1993 by TVA, the four largest municipals distributed 30.9 million megawatthours or 24.7 percent of TVA's total generation to their customers. The 160 locally owned distributors serve an 80,000 -square-mile area in parts of seven States. In 1993, the TVA accounted for approximately half of the total net generation by the Federal electric utilities.

\section{Composite Income Statement}

As of the end of the fiscal year (September 31, 1993), operating revenues for the federal electric utilities totaled $\$ 8,141.1$ million. Total electric utility operating expenses were $\$ 6,055.8$ million in 1993 . A major portion of these total electric utility operating expenses include production expenses that totaled $\$ 4,272.3$ million. Production expenses for the Federal electric utilities were 70.5 percent of total electric utility operating expenses. Total electric operation and maintenance expenses were $\$ 5,207.6$ million, 86.0 percent of total electric utility operating expenses for the Federal electric utilities.

Total electric utility income for the Federal electric utilities was $\$ 2,215.4$ million. Income deductions totaled $\$ 2,119.2$ million. Of the income deductions, $\$ 1,840.6$ million came from interest on long-term debt, which represented 86.9 percent of total income deductions. Net income for the Federal electric utilities as of the end of September 1993 was $\$ 1,486.7$ million compared with -\$54.9 million in 1992.

\section{Balance Sheet}

As of September 30, 1993, net investment in electric utility plant for the Federal electric utilities was $\$ 33,554.1$ million, including construction work in progress, which increased to $\$ 15,660.6$ million, compared with $\$ 14,200.5$ million in 1992 .

Total proprietary capital was $\$ 11,128.8$ million in 1993 , a slight increase from $\$ 10,925.3$ million in 1992 , 23.1 percent of total liabilities and other credits. The amount of long-term debt and current and accrued liabilities was $\$ 36,968.4$ million, 76.6 percent of total liabilities and other credits of the Federal electric utilities.
Sales of Electric Power

In 1993, the Federal electric utilities had sales of electric energy to ultimate consumers of 45.3 million megawatthours and electricity sold for resale of 202.8 million megawatthours. Total disposition of energy was 266.6 million megawatthours of which the Federal electric utilities had a net generation of 247.2 million megawatthours (Table 32). 
Table 27. Statement of Income by U.S. Federal Electric Utility, 1993 (Thousand Dollars)

\begin{tabular}{|c|c|c|c|c|c|}
\hline Item & $\begin{array}{c}\text { Alaska } \\
\text { Power } \\
\text { Admin }\end{array}$ & $\begin{array}{c}\text { Bonneville } \\
\text { Power } \\
\text { Admin } \\
\text { September } 30\end{array}$ & $\begin{array}{l}\text { Southeastem } \\
\text { Power } \\
\text { Admin } \\
\text { September } 30\end{array}$ & $\begin{array}{c}\text { Southwestern } \\
\text { Power } \\
\text { Admin } \\
\text { September } 30\end{array}$ & $\begin{array}{c}\text { Western Area } \\
\text { Power } \\
\text { Admin } \\
\text { September } 30\end{array}$ \\
\hline Electrlc Utilty Operating Revenues ............................................... & 10,249 & $1,934,773$ & 164,858 & 115,547 & 606,319 \\
\hline 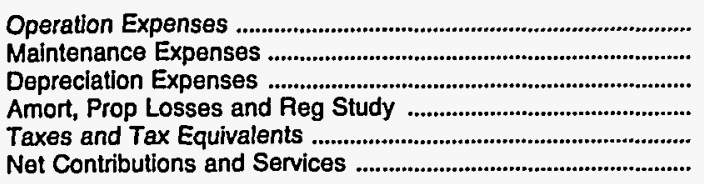 & $\begin{array}{r}3,070 \\
591 \\
2,873 \\
0 \\
0 \\
0\end{array}$ & $\begin{array}{r}1,756,668 \\
77,155 \\
101,454 \\
49,538 \\
0 \\
0\end{array}$ & $\begin{array}{r}32,778 \\
0 \\
30 \\
0 \\
59 \\
0\end{array}$ & $\begin{array}{r}96,457 \\
10,236 \\
2,776 \\
0 \\
0 \\
0\end{array}$ & $\begin{array}{r}629,137 \\
0 \\
0 \\
0 \\
0 \\
0\end{array}$ \\
\hline $\begin{array}{l}\text { Total Electric Utllity Operating } \\
\text { Expenses }\end{array}$ & 6,534 & $1,984,815$ & 32,867 & 109,469 & 629,137 \\
\hline $\begin{array}{l}\text { Net Electric Utility Operating Income } \\
\text { income from Electric Plant Leased } \\
\text { to Others }\end{array}$ & 3,715 & $\begin{array}{r}-50,042 \\
241\end{array}$ & 131,991 & 6,079 & $\begin{array}{r}-22,818 \\
0\end{array}$ \\
\hline 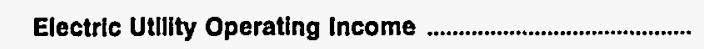 & 3,715 & $-49,801$ & 131,991 & 6,079 & $-22,818$ \\
\hline Other Electric Income & 0 & $-3,274$ & 12 & 0 & 130,934 \\
\hline $\begin{array}{l}\text { Other Electric Deductions } \\
\text { Allowance for Other Funds Used }\end{array}$ & 277 & 0 & 0 & 0 & 0 \\
\hline During Construction & $\begin{array}{l}0 \\
0\end{array}$ & $\begin{array}{l}0 \\
0\end{array}$ & $\begin{array}{l}0 \\
0\end{array}$ & $\begin{array}{l}0 \\
0\end{array}$ & $\begin{array}{r}-17,843 \\
0\end{array}$ \\
\hline Electric Utllity Income & 3,438 & $-53,075$ & 132,003 & 6,079 & 90,273 \\
\hline 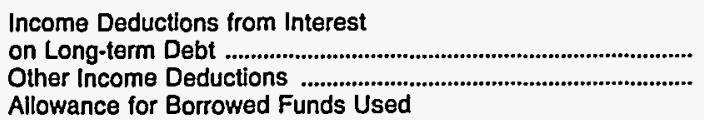 & $\begin{array}{r}4,817 \\
0\end{array}$ & $\begin{array}{r}216,941 \\
1,381\end{array}$ & $\begin{array}{r}55 \\
131,948\end{array}$ & $\begin{array}{r}611 \\
0\end{array}$ & $\begin{array}{r}0 \\
63,391\end{array}$ \\
\hline 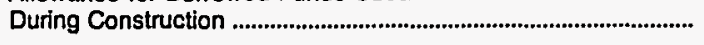 & 0 & $-18,369$ & 0 & 0 & 0 \\
\hline 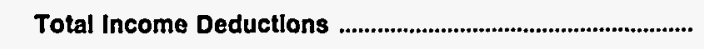 & 4,817 & 199,953 & 132,003 & 611 & 63,391 \\
\hline 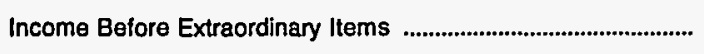 & $-1,379$ & $-253,028$ & 0 & 5,468 & 26,882 \\
\hline Extraordinary Income & 0 & 0 & 0 & 0 & $1,388,892$ \\
\hline 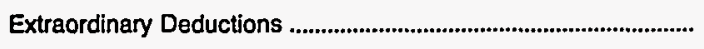 & 0 & 0 & 0 & 0 & 0 \\
\hline Net Income & $-1,379$ & $-253,028$ & 0 & 5,468 & $1,415,774$ \\
\hline
\end{tabular}

See endnotes at end of this table. 
Table 27. Statement of Income by U.S. Federal Electric Utility, 1993 (Continued) (Thousand Dollars)

\begin{tabular}{|c|c|c|c|c|c|}
\hline \multirow[b]{2}{*}{ Item } & \multirow[b]{2}{*}{$\begin{array}{c}\text { Tennessee } \\
\text { Valley } \\
\text { Authority } \\
\text { September } 30\end{array}$} & \multicolumn{2}{|c|}{ U.S. Bureau of Indian Affairs } & \multirow[b]{2}{*}{$\begin{array}{l}\text { USCE- } \\
\text { North Central } \\
\text { Division }{ }^{1} \\
\text { September } 30\end{array}$} & \multirow[b]{2}{*}{$\begin{array}{c}\text { Total } \\
\text { September } 30\end{array}$} \\
\hline & & $\begin{array}{c}\text { Mission } \\
\text { Valley Power } \\
\text { September } 30\end{array}$ & $\begin{array}{c}\text { San Carlos } \\
\text { September } 30\end{array}$ & & \\
\hline 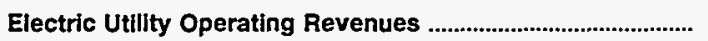 & $5,275,728$ & 13,826 & 17,872 & 1,914 & $8,141,087$ \\
\hline 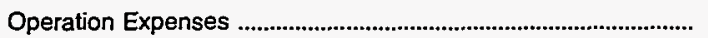 & $2,283,809$ & 8,763 & 15,315 & 558 & $4,826,555$ \\
\hline 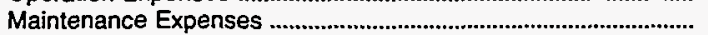 & 291,476 & 690 & 656 & 272 & 381,075 \\
\hline 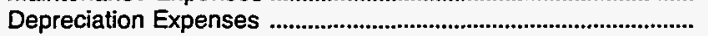 & 453,107 & 1 & 799 & 147 & 561,187 \\
\hline Amort, Prop Losses and Reg Study ...................................... & 0 & 0 & 0 & 212 & 49,750 \\
\hline 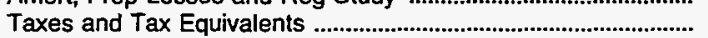 & 236,999 & 209 & 0 & 0 & 237,267 \\
\hline 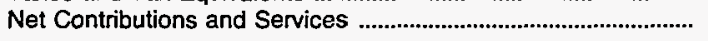 & 0 & 0 & 0 & 0 & \\
\hline \multicolumn{6}{|l|}{ Total Electric Utility Operating } \\
\hline 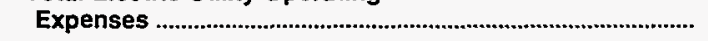 & $3,265,391$ & 9,663 & 16,769 & 1,188 & $6,055,833$ \\
\hline $\begin{array}{l}\text { Net Electric Utility Operating Income } \\
\text { Income from Electric Plant Leased }\end{array}$ & $2,010,337$ & 4,164 & 1,103 & 726 & $2,085,254$ \\
\hline to Others & $-3,394$ & 0 & 0 & 0 & $-3,153$ \\
\hline Electric Utilty Operating Income & $2,006,943$ & 4,164 & 1,103 & 726 & $2,082,101$ \\
\hline Other Electric Income & 22,974 & 323 & 583 & 0 & 151,552 \\
\hline $\begin{array}{l}\text { Other Electric Deductions } \\
\text { Allowance for Other Funds Used }\end{array}$ & 0 & 0 & 0 & 168 & 446 \\
\hline During Construction & 0 & 0 & 0 & 0 & $-17,843$ \\
\hline Taxes on Other income and Deduct & 0 & 0 & 0 & 0 & 0 \\
\hline Electric Utility Income & $2,029,917$ & 4,486 & 1,686 & 557 & $2,215,364$ \\
\hline Income Deductions from Interest & & & & & \\
\hline 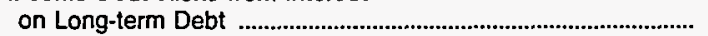 & $1,618,198$ & 0 & $\mathbf{0}$ & 0 & $1,840,621$ \\
\hline 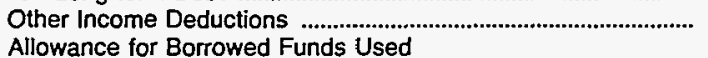 & 158,186 & 0 & 0 & 0 & 354,906 \\
\hline 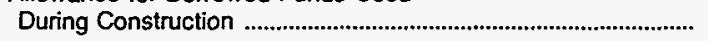 & $-57,915$ & 0 & 0 & 0 & $-76,284$ \\
\hline Total Income Deductions & $1,718,468$ & 0 & $\mathbf{0}$ & 0 & $2,119,243$ \\
\hline 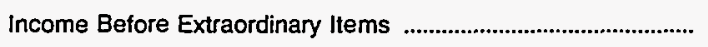 & 311,449 & 4,486 & 1,686 & 557 & 96,121 \\
\hline Extraordinary Income & 0 & 0 & 1,694 & 0 & $1,390,586$ \\
\hline 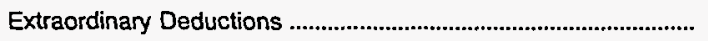 & 0 & 0 & 0 & 0 & 0 \\
\hline Net Income & 311,449 & 4,486 & $\mathbf{3 , 3 8 0}$ & 557 & $1,486,707$ \\
\hline
\end{tabular}

' Includes data only for Saint Mary's Falls at Sault St. Marie, Michigan. The rest of the generation produced by the U.S. Army Corps of Engineers (USCE) is sold by the Department of Energy-Bonneville, Southeastern, Southwestern, and Western Area Power Administrations.

Note: Totals may not equal sum of components because of independent rounding.

Source: Energy Information Administration, Form EIA-412, "Annual Report of Public Electric Utilities." 
Table 28. Balance Sheet by U.S. Federal Electric Utility

on September 30, 1993

(Thousand Dollars)

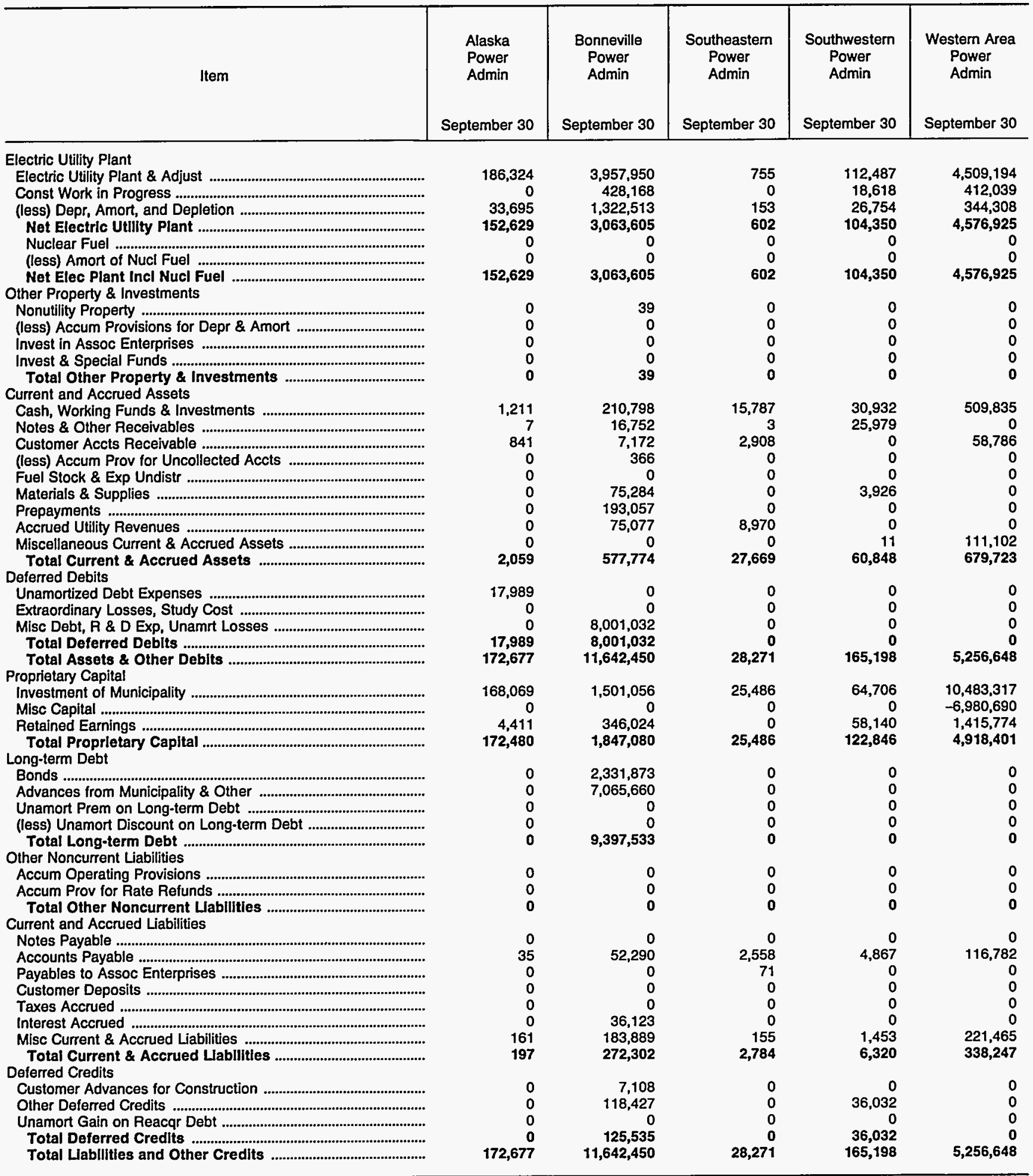

See endnotes at end of this table. 
Table 28. Balance Sheet by U.S. Federal Electric Utility on September 30, 1993 (Continued) (Thousand Dollars)

\begin{tabular}{|c|c|c|c|c|c|}
\hline \multirow[b]{2}{*}{ Item } & \multirow[b]{2}{*}{$\begin{array}{c}\text { Tennessee } \\
\text { Valley } \\
\text { Authority } \\
\text { September } 30\end{array}$} & \multicolumn{2}{|c|}{ U.S. Bureau of Indian Affairs } & \multirow[b]{2}{*}{ 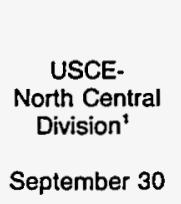 } & \multirow[b]{2}{*}{$\begin{array}{c}\text { Total } \\
\text { September } 30\end{array}$} \\
\hline & & $\begin{array}{c}\text { Mission } \\
\text { Valley Power } \\
\text { September } 30\end{array}$ & September 30 & & \\
\hline \multicolumn{6}{|l|}{ Electric Utility Plant } \\
\hline Electric Utility Plant \& Adjust & $15,978,517$ & 22,213 & 24,064 & 12,343 & $24,803,848$ \\
\hline Const Work in Progress & $14,800,152$ & 1,598 & & 0 & $15,660,575$ \\
\hline 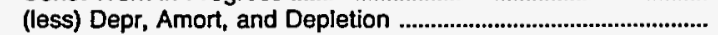 & $5,160,569$ & 9,366 & 9,539 & 3,438 & $6,910,335$ \\
\hline Net Electric Utillty Plant & $25,618,101$ & 14,446 & 14,525 & 8,905 & $33,554,088$ \\
\hline 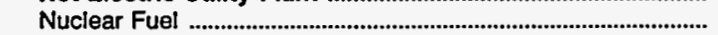 & $3,595,428$ & 0 & 0 & 0 & $3,595,428$ \\
\hline (less) Amort of Nuel Fuel & $1,326,941$ & 0 & 0 & 0 & $1,326,941$ \\
\hline Net Elec Plant Incl Nucl Fuel & $27,886,588$ & 14,446 & 14,525 & 8,905 & $35,822,575$ \\
\hline \multicolumn{6}{|l|}{ Other Property \& Investments } \\
\hline 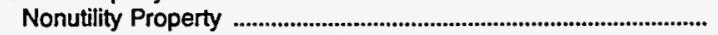 & 4,099 & 0 & 0 & 0 & 4,138 \\
\hline 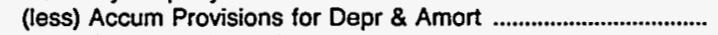 & 2,998 & $\mathbf{0}$ & 0 & 0 & 2,998 \\
\hline 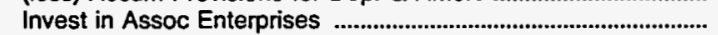 & 0 & 0 & 0 & 0 & 0 \\
\hline 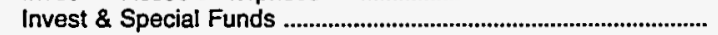 & 0 & 0 & 0 & 0 & 0 \\
\hline 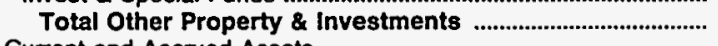 & 1,101 & 0 & 0 & 0 & 1,140 \\
\hline \multicolumn{6}{|l|}{ Current and Accrued Assets } \\
\hline Cash, Working Funds \& Investments & 236,514 & 4,931 & 18,670 & 27 & $1,028,705$ \\
\hline 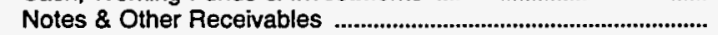 & 28,978 & 0 & 1,495 & 0 & 73,213 \\
\hline Customer Accts Receivable & 250,381 & 377 & 1,959 & 0 & 322,425 \\
\hline (less) Accum Prov for Uncollected Accts ........................................ & & 84 & 223 & 0 & 673 \\
\hline 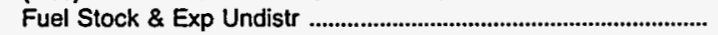 & 175,246 & 0 & 0 & 0 & 175,246 \\
\hline 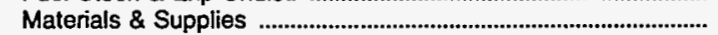 & 270,689 & 1,276 & 1,936 & 0 & 353,111 \\
\hline 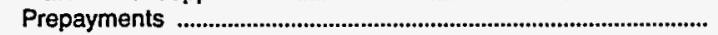 & 0 & 0 & 0 & 0 & 193,057 \\
\hline 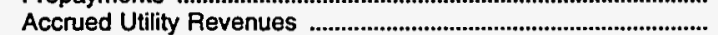 & 472,660 & 0 & 433 & 0 & 557,140 \\
\hline Miscellaneous Current \& Accrued Assets ........................................ & & 0 & 2,085 & 0 & 113,198 \\
\hline 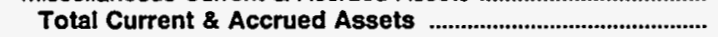 & $1,434,467$ & 6,500 & 26,355 & 27 & $2,815,422$ \\
\hline \multicolumn{6}{|l|}{ Deferred Debits } \\
\hline 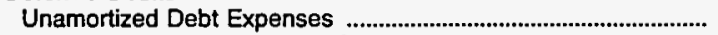 & $1,254,658$ & 0 & 0 & 0 & $1,272,646$ \\
\hline Extraordinary Losses, Study Cost & & 0 & 0 & 0 & 0 \\
\hline 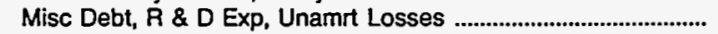 & 346,613 & 0 & 0 & 0 & $8,347,645$ \\
\hline 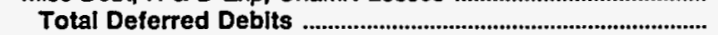 & $1,601,270$ & $\mathbf{0}$ & $\mathbf{0}$ & o & $9,620,291$ \\
\hline 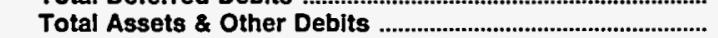 & $30,923,426$ & 20,946 & 40,880 & 8,932 & $48,259,428$ \\
\hline \multicolumn{6}{|l|}{ Proprietary Capital } \\
\hline Investment of Municipality & 668,315 & 0 & 0 & 0 & $12,910,949$ \\
\hline 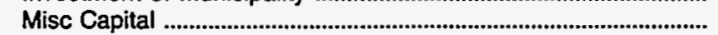 & & 0 & 0 & 0 & $-6,980,690$ \\
\hline 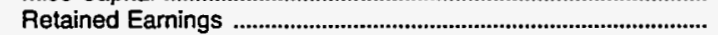 & $3,325,434$ & 11,353 & 28,461 & 8,932 & $5,198,529$ \\
\hline 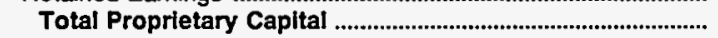 & $3,993,749$ & 11,353 & 28,461 & 8,932 & $11,128,788$ \\
\hline \multicolumn{6}{|l|}{ Long-term Debt } \\
\hline Bonds & $21,259,340$ & 0 & 0 & 0 & $23,591,213$ \\
\hline 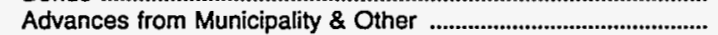 & 0 & 6,140 & 8,083 & 0 & $7,079,882$ \\
\hline 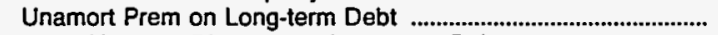 & 0 & 0 & 0 & 0 & 0 \\
\hline 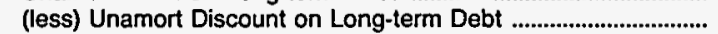 & 304,976 & 0 & 0 & 0 & 304,976 \\
\hline 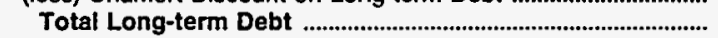 & $20,954,364$ & 6,140 & 8,083 & 0 & $30,366,119$ \\
\hline \multicolumn{6}{|l|}{ Other Noncurrent Liabilities } \\
\hline 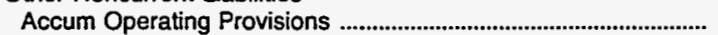 & 0 & 0 & 246 & 0 & 246 \\
\hline 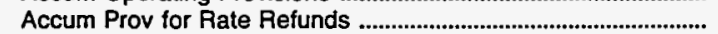 & 0 & 0 & 0 & 0 & 0 \\
\hline 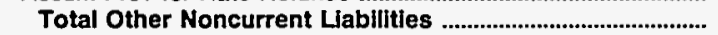 & $\mathbf{0}$ & o & 246 & 0 & 246 \\
\hline \multicolumn{6}{|l|}{ Current and Accrued Liabilities } \\
\hline 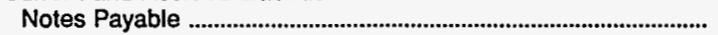 & $3,632,017$ & 0 & 479 & 0 & $3,632,496$ \\
\hline 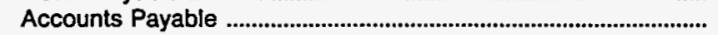 & 655,804 & 2,871 & 1,879 & 0 & 837,086 \\
\hline 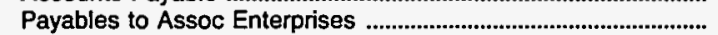 & 0 & 0 & 0 & 0 & 71 \\
\hline 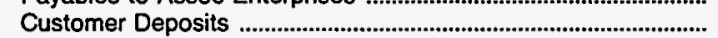 & 0 & 278 & 1,207 & 0 & 1,485 \\
\hline 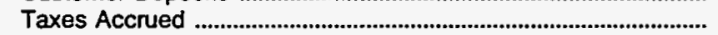 & 0 & 1 & 0 & 0 & 1 \\
\hline 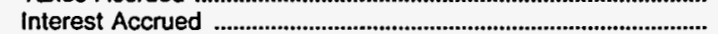 & 444,196 & 0 & 0 & 0 & 480,319 \\
\hline 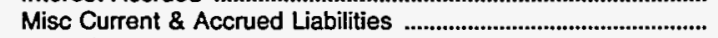 & $1,243,297$ & -112 & 505 & 0 & $1,650,814$ \\
\hline Total Current \& Accrued Liabilities ........................................... & $5,975,314$ & 3,038 & 4,070 & 0 & $6,602,272$ \\
\hline \multicolumn{6}{|l|}{ Deferred Credits } \\
\hline 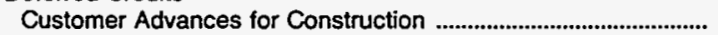 & 0 & 415 & 21 & 0 & 7,544 \\
\hline 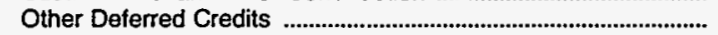 & 0 & 0 & 0 & 0 & 154,459 \\
\hline 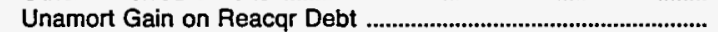 & 0 & 0 & 0 & 0 & \\
\hline Total Deferred Credits & & 415 & & & 162,003 \\
\hline Total Liabillties and Other Credits ......................................... & $30,923,426$ & 20,946 & 40,880 & 8,932 & $48,259,428$ \\
\hline
\end{tabular}

' Includes data only for Saint Mary's Falls at Sault St. Marie, Michigan. The rest of the generation produced by the U.S. Army Corps of Engineers (USCE) is sold by the Department of Energy-Bonneville, Southeastern, Southwestern, and Western Area Power Administrations.

Note: Totals may not equal sum of components because of independent rounding.

Source: Energy Information Administration, Form ElA-412, "Annual Report of Public Electric Utilities." 
Table 29. Electric Operation and Maintenance Expenses

by U.S. Federal Electric Utility, 1993

(Thousand Dollars)

\begin{tabular}{|c|c|c|c|c|c|}
\hline Item & $\begin{array}{l}\text { Alaska } \\
\text { Power } \\
\text { Admin }\end{array}$ & $\begin{array}{l}\text { Bonneville } \\
\text { Power } \\
\text { Admin }\end{array}$ & $\begin{array}{l}\text { Southeastern } \\
\text { Power } \\
\text { Admin }\end{array}$ & $\begin{array}{l}\text { Southwestern } \\
\text { Power } \\
\text { Admin }\end{array}$ & $\begin{array}{l}\text { Western Area } \\
\text { Power } \\
\text { Admin }\end{array}$ \\
\hline & September 30 & September 30 & September 30 & September 30 & September 30 \\
\hline
\end{tabular}

Production Expenses

Steam Power Generation

Nuclear Power Generation

Hydraulic Power Generat

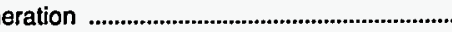

Other Power Generation

Purchased Power

Other Production Expenses

Total Production Expenses

Transmission Expenses

Distribution Expenses ...........................................................................

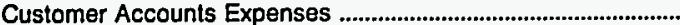

Customer Service and Information

Expenses...

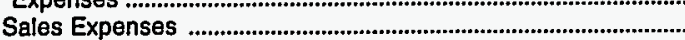

Administrative and General

Expenses

Total Electric Operation and

Malntenance Expenses

Number of Elec Dept Employees

Regular Full-time ........................................................................

Part-time \& Temporary

Total Elec Dept Employees

$\begin{array}{rr}0 & 0 \\ 0 & 0 \\ 795 & 1,272 \\ 0 & 0 \\ 0 & 221,918 \\ 0 & 1,382,484\end{array}$

795

921

0

0

0

1,944

3,661

$1,605,674$

162,167

2,331

0

0

63,651

$1,833,823$

3,532

123

3,655

29

4

33
0
0
2,336

$$
\begin{array}{r}
4,139 \\
0
\end{array}
$$

6,475

23,471

23,471
0

49

0

2,782

32,778

106,693

629,137

40

192

1,464

1

18

41

0

1,482

See endnotes at end of this table. 
Table 29. Electric Operation and Maintenance Expenses by U.S. Federal Electric Utility, 1993 (Continued) (Thousand Dollars)

\begin{tabular}{|c|c|c|c|c|c|}
\hline \multirow[b]{2}{*}{ Item } & \multirow[b]{2}{*}{$\begin{array}{c}\text { Tennessee } \\
\text { Valley } \\
\text { Authority } \\
\text { September } 30\end{array}$} & \multicolumn{2}{|c|}{ U.S. Bureau of Indian Affairs } & \multirow[b]{2}{*}{$\begin{array}{l}\text { USCE- } \\
\text { North Central } \\
\text { Division' } \\
\text { September } 30\end{array}$} & \multirow[b]{2}{*}{$\begin{array}{c}\text { Total } \\
\text { September } 30\end{array}$} \\
\hline & & $\begin{array}{c}\text { Mission } \\
\text { Valley Power }\end{array}$ & $\begin{array}{c}\text { San Carlos } \\
\text { September } 30\end{array}$ & & \\
\hline \multicolumn{6}{|l|}{ Production Expenses } \\
\hline Steam Power Generation & $1,505,617$ & 0 & 0 & 0 & $1,505,617$ \\
\hline 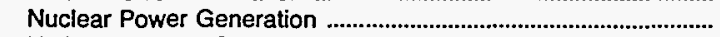 & 390,795 & 0 & 0 & 0 & 390,795 \\
\hline Hydraulic Power Generation & 56,086 & 0 & 0 & 830 & 388,113 \\
\hline Other Power Generation & 19,359 & $\mathbf{0}$ & 0 & 0 & 19,359 \\
\hline Purchased Power & $-3,569$ & 6,115 & 8,852 & 0 & 495,531 \\
\hline Other Production Expenses & 48,786 & 0 & 0 & 0 & $1,472,894$ \\
\hline 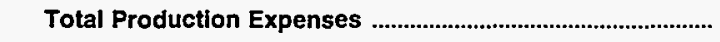 & $2,017,074$ & 6,115 & 8,852 & 830 & $4,272,309$ \\
\hline 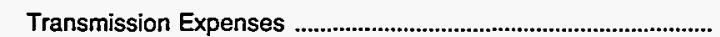 & 73,242 & 54 & 907 & 0 & 318,699 \\
\hline 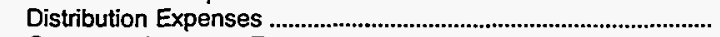 & 0 & 944 & 1,318 & 0 & 2,263 \\
\hline $\begin{array}{l}\text { Customer Accounts Expenses } \\
\text { Customer Service and Information }\end{array}$ & 1,084 & 369 & 111 & 0 & 3,944 \\
\hline 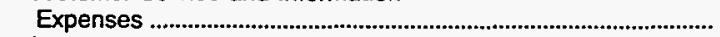 & 26,595 & 526 & 76 & 0 & 27,197 \\
\hline $\begin{array}{l}\text { Sales Expenses } \\
\text { Administrative and General }\end{array}$ & 0 & 0 & 0 & 0 & 5,588 \\
\hline 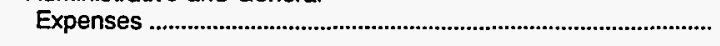 & 457,290 & 1,445 & 4,706 & 0 & 577,632 \\
\hline \multicolumn{6}{|l|}{ Total Electric Operation and } \\
\hline 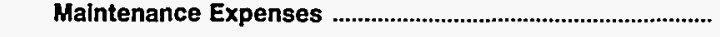 & $2,575,285$ & 9,453 & 15,971 & 830 & $5,207,630$ \\
\hline \multicolumn{6}{|l|}{ Number of Elec Dept Employees } \\
\hline 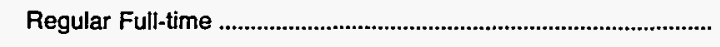 & 18,974 & 77 & 60 & 9 & 24,377 \\
\hline 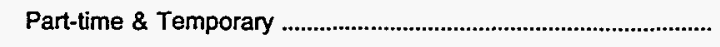 & 0 & 0 & 0 & 1 & 147 \\
\hline Total Elec Dept Employees & 18,974 & 77 & 60 & 10 & 24,524 \\
\hline
\end{tabular}

1 Includes data only for Saint Mary's Falls at Sault St. Marie, Michigan. The rest of the generation produced by the U.S. Army Corps of Engineers (USCE) is sold by the Department of Energy-Bonneville, Southeastern, Southwestern, and Western Area Power Administrations.

Note: Totals may not equal sum of components because of independent rounding.

Source: Energy Information Administration, Form EIA-412, "Annual Report of Public Electric Utilities." 
Table 30. Electric Utility Plant by U.S. Federal Electric Utility

on September 30, 1993

(Thousand Dollars)

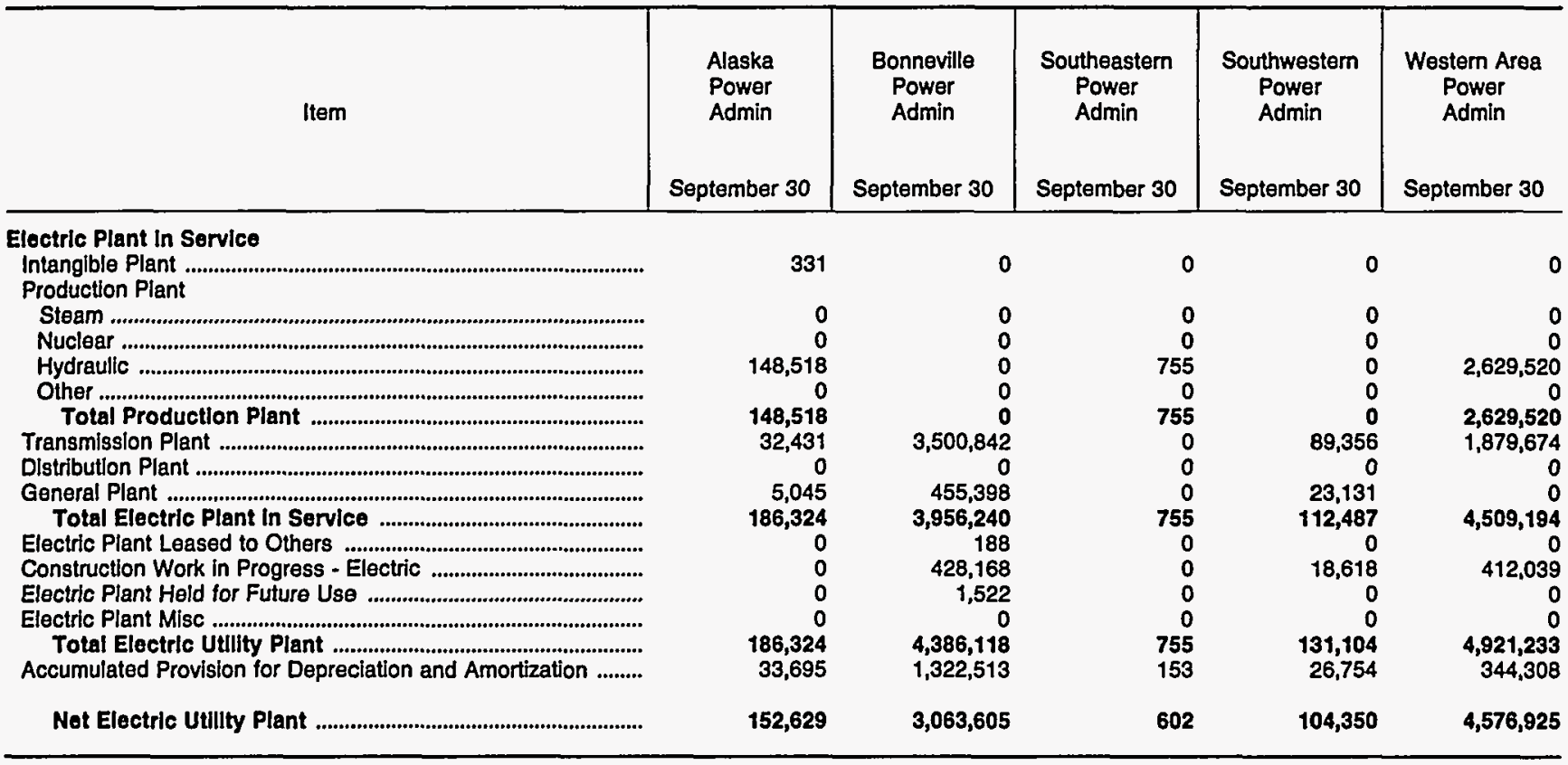

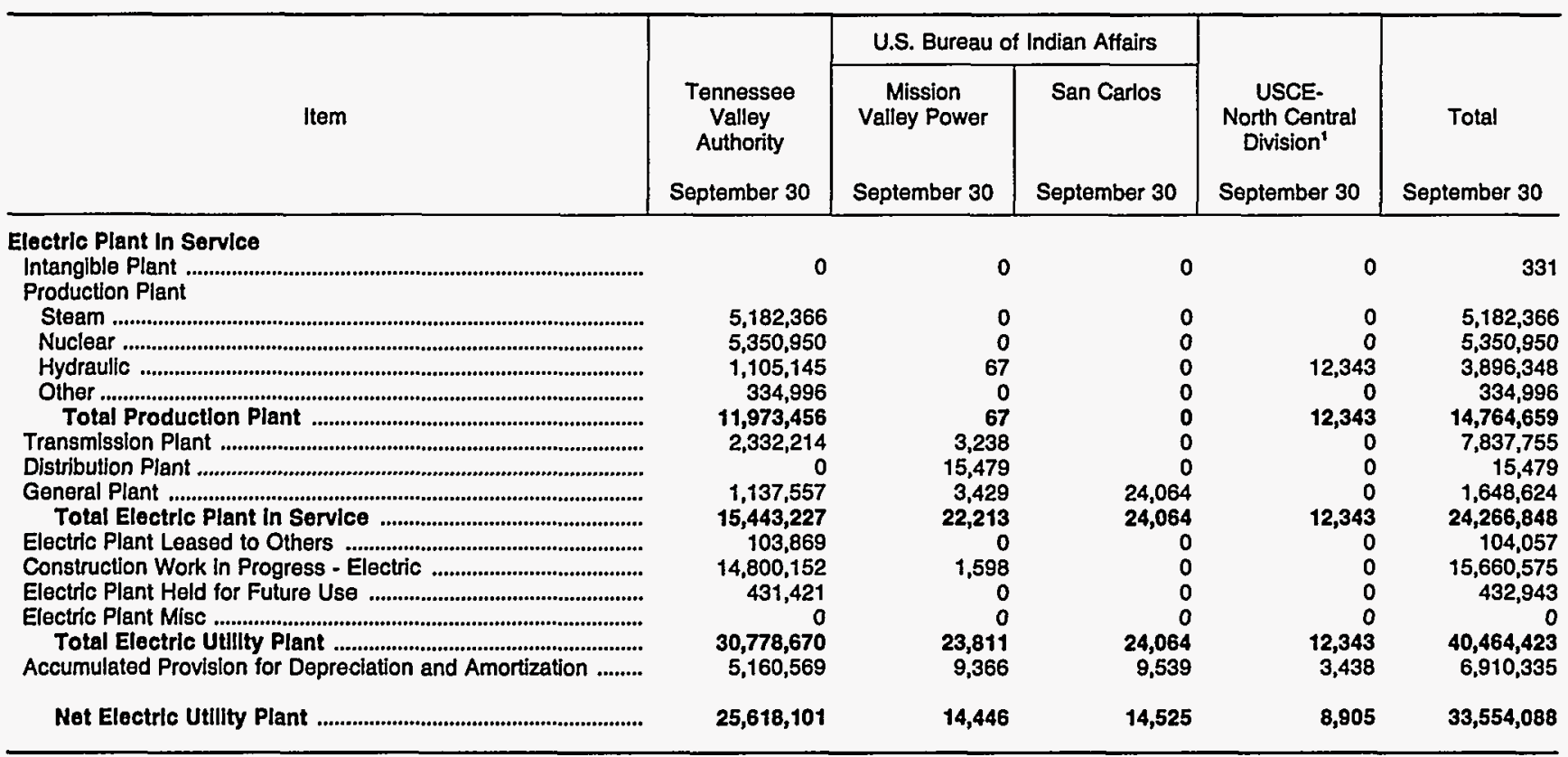

Includes data only for Saint Mary's Falls at Sault St. Marie, Michigan. The rest of the generation produced by the U.S. Army Corps of Engineers (USCE) is sold by the Department of Energy-Bonneville, Southeastem, Southwestern, and Western Area Power Administrations.

Note: Totals may not equal sum of components because of independent rounding.

Source: Energy Information Administration, Form EIA-412, "Annual Report of Public Electric Utilities." 
Table 31. Number of Consumers, Sales, and Operating Revenue by U.S. Federal Electric Utility, 1993

\begin{tabular}{|c|c|c|c|c|c|}
\hline Item & $\begin{array}{l}\text { Alaska } \\
\text { Power } \\
\text { Admin }\end{array}$ & $\begin{array}{l}\text { Bonneville } \\
\text { Power } \\
\text { Admin } \\
\text { December } 31\end{array}$ & $\begin{array}{c}\text { Southeastern } \\
\text { Power } \\
\text { Admin }\end{array}$ & $\begin{array}{l}\text { Southwestern } \\
\text { Power } \\
\text { Admin } \\
\text { December } 31\end{array}$ & $\begin{array}{c}\text { Western Area } \\
\text { Power } \\
\text { Admin } \\
\text { December } 31\end{array}$ \\
\hline \multicolumn{6}{|l|}{ Number of Consumers } \\
\hline 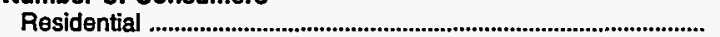 & 0 & 0 & 0 & 0 & 0 \\
\hline Commercial or Small & $\mathbf{0}$ & 0 & 0 & 0 & 1 \\
\hline Industrial or Large & 0 & 17 & 0 & 0 & 0 \\
\hline Other & 2 & 9 & 0 & 0 & 244 \\
\hline Total UItlmate Consumers & 2 & 26 & $\mathbf{0}$ & 0 & 245 \\
\hline \multicolumn{6}{|l|}{ Sales for the Year (megawatthours) } \\
\hline 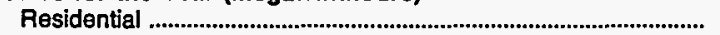 & 0 & 0 & 0 & 0 & 0 \\
\hline Commercial or Small & 0 & 0 & 0 & 0 & 43 \\
\hline Industrial or Large & 0 & $20,729,382$ & 0 & 0 & 0 \\
\hline Other & 3,294 & $1,013,383$ & 0 & 0 & $5,450,234$ \\
\hline 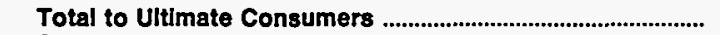 & 3,294 & $21,742,765$ & 0 & $\mathbf{0}$ & $5,450,277$ \\
\hline Sales for Resale & 399,193 & $53,814,018$ & $9,014,114$ & $8,310,189$ & $27,907,360$ \\
\hline 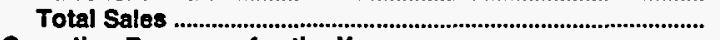 & 402,487 & $75,556,783$ & $9,014,114$ & $8,310,189$ & $33,357,637$ \\
\hline \multicolumn{6}{|l|}{ Operating Revenues for the Year } \\
\hline 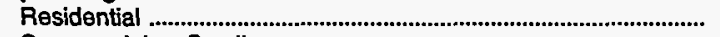 & 0 & 0 & 0 & 0 & 0 \\
\hline Commercial or Small & 0 & 0 & 0 & 0 & 1 \\
\hline Industrial or Large & $\mathbf{0}$ & 396,651 & 0 & 0 & 0 \\
\hline Other & 60 & 25,403 & 0 & 0 & 90,852 \\
\hline 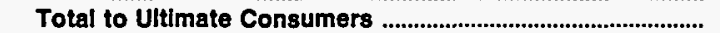 & 60 & 422,054 & $\mathbf{0}$ & 0 & 90,853 \\
\hline Sales for Resale & 9,278 & $1,321,805$ & 164,858 & 102,181 & 511,689 \\
\hline 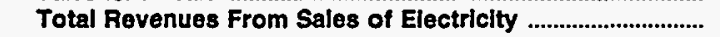 & 9,338 & $1,743,859$ & 164,858 & 102,181 & 602,542 \\
\hline
\end{tabular}

\begin{tabular}{|c|c|c|c|c|c|}
\hline \multirow[b]{2}{*}{ Item } & \multirow[b]{2}{*}{$\begin{array}{c}\text { Tennessee } \\
\text { Valley } \\
\text { Authority } \\
\text { December } 31\end{array}$} & \multicolumn{2}{|c|}{ U.S. Bureau of Indian Affairs } & \multirow[b]{2}{*}{$\begin{array}{c}\text { USCE- } \\
\text { North Central } \\
\text { Division' }\end{array}$} & \multirow[b]{2}{*}{$\begin{array}{c}\text { Total } \\
\text { December } 31\end{array}$} \\
\hline & & $\begin{array}{c}\text { Mission } \\
\text { Valley Power } \\
\text { December } 31\end{array}$ & December 31 & & \\
\hline \multicolumn{6}{|l|}{ Number of Consumers } \\
\hline 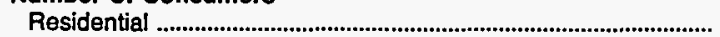 & 0 & 10,528 & 12,390 & 0 & 22,918 \\
\hline Commercial or Smalt & 0 & 2,081 & 1,512 & 0 & 3,594 \\
\hline Industrial or Large & 62 & 1 & 86 & 0 & 166 \\
\hline Other & 37 & 1,061 & 380 & 0 & 1,733 \\
\hline $\begin{array}{l}\text { Total Ultimate Consumers } \\
\text { Sales for the Year (megawatthours) }\end{array}$ & 99 & 13,671 & 14,368 & $\mathbf{0}$ & 28,411 \\
\hline 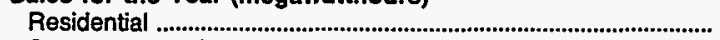 & 0 & 155,741 & 82,000 & 0 & 237,741 \\
\hline Commercial or Small & 0 & 74,457 & 98,399 & 0 & 172,898 \\
\hline Industrial or Large & $18,462,839$ & 17,491 & 49,199 & 0 & $39,258,911$ \\
\hline Other & 176,529 & 13,165 & 43,732 & 0 & $6,700,337$ \\
\hline Total to UltImate Consumers & $18,639,368$ & 260,854 & 273,330 & $\mathbf{0}$ & $46,369,888$ \\
\hline Sales for Resale & $101,111,513$ & 0 & 0 & 152,080 & $200,708,467$ \\
\hline \multicolumn{6}{|l|}{ Operating Revenues for the Year } \\
\hline 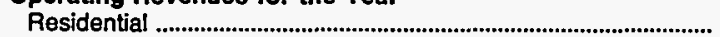 & 0 & 7,647 & 6,076 & 0 & 13,723 \\
\hline Commercial or Small & 0 & 4,240 & 6,434 & $\mathbf{0}$ & 10,675 \\
\hline 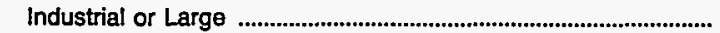 & 730,285 & 702 & 2,377 & 0 & $1,130,015$ \\
\hline Other & 8,343 & 803 & 2,984 & 0 & 128,445 \\
\hline Total to Ultimate Consumers & 738,628 & 13,392 & 17,871 & 0 & $1,282,858$ \\
\hline $\begin{array}{l}\text { Sales for Resale } \\
\text { Total Revenues From Sales of Electriclty }\end{array}$ & $\begin{array}{l}4,537,617 \\
5,276,245\end{array}$ & $\begin{array}{r}0 \\
13,392\end{array}$ & $\begin{array}{r}0 \\
17,871\end{array}$ & $\begin{array}{l}1,914 \\
1,914\end{array}$ & $\begin{array}{l}6,649,342 \\
7,932,200\end{array}$ \\
\hline
\end{tabular}

1 Includes data only for Saint Mary's Falls at Sault St. Marie, Michigan. The rest of the generation produced by the U.S. Army Corps of Engineers (USCE) is sold by the Department of Energy-Bonneville, Southeastern, Southwestern, and Western Area Power Administrations.

Note: Totals may not equal sum of components because of independent rounding. Data are submitted on a calendar year.

Source: Energy Information Administration, Form EIA-861, "Annual Electric Utility Report." Data are submitted on a calendar year. 
Table 32. Electric Energy Account by U.S. Federal Electric Utility, 1993 (Megawatthours)

\begin{tabular}{|c|c|c|c|c|c|}
\hline Item & $\begin{array}{l}\text { Alaska } \\
\text { Power } \\
\text { Admin } \\
\text { September } 30\end{array}$ & $\begin{array}{c}\text { Bonneville } \\
\text { Power } \\
\text { Admin } \\
\text { September } 30\end{array}$ & $\begin{array}{l}\text { Southeastern } \\
\text { Power } \\
\text { Admin } \\
\text { September } 30\end{array}$ & $\begin{array}{c}\text { Southwestern } \\
\text { Power } \\
\text { Admin } \\
\text { September } 30\end{array}$ & $\begin{array}{c}\text { Western Area } \\
\text { Power } \\
\text { Admin } \\
\text { September } 30\end{array}$ \\
\hline 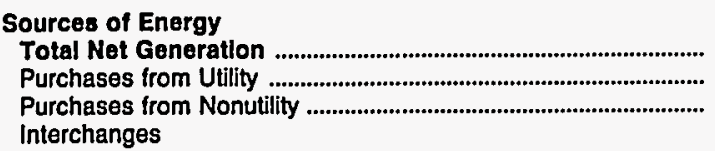 & $\begin{array}{r}411,230 \\
0 \\
0\end{array}$ & $\begin{array}{r}77,868,808 \\
8,677,318 \\
0\end{array}$ & $\begin{array}{r}9,210,836 \\
275,207 \\
0\end{array}$ & $\begin{array}{r}9,316,857 \\
19,228 \\
0\end{array}$ & $\begin{array}{r}25,090,310 \\
11,348,000 \\
379,000\end{array}$ \\
\hline $\begin{array}{l}\text { In (gross) } \\
\text { Out (gross) } \\
\text { Net Interchanges } \\
\text { Transmission for/by Others (Wheeling) }\end{array}$ & $\begin{array}{l}0 \\
0 \\
0\end{array}$ & $\begin{array}{l}14,432,799 \\
21,355,410 \\
-6,922,611\end{array}$ & $\begin{array}{r}588 \\
0 \\
588\end{array}$ & $\begin{array}{r}388,745 \\
907,767 \\
-519,022\end{array}$ & $\begin{array}{r}1,486,000 \\
894,000 \\
592,000\end{array}$ \\
\hline 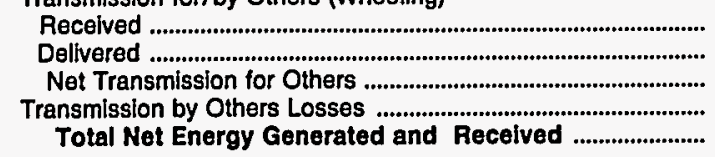 & $\begin{array}{r}295,939 \\
295,939 \\
0 \\
0 \\
411,230\end{array}$ & $\begin{array}{r}34,977,416 \\
32,312,660 \\
2,664,756 \\
0 \\
82,288,271\end{array}$ & $\begin{array}{r}5,723,233 \\
5,723,233 \\
0 \\
0 \\
9,486,631\end{array}$ & $\begin{array}{r}0 \\
0 \\
0 \\
0 \\
8,817,063\end{array}$ & $\begin{array}{r}5,553,586 \\
5,553,586 \\
0 \\
0 \\
37,409,310\end{array}$ \\
\hline 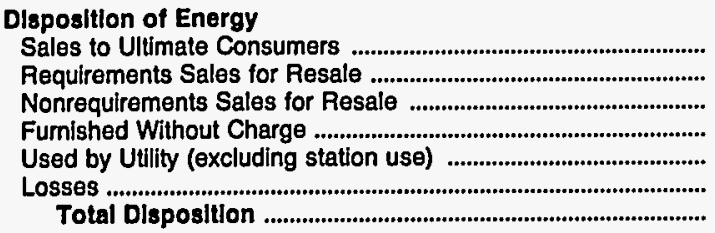 & $\begin{array}{r}3,571 \\
397,561 \\
0 \\
199 \\
0 \\
9,899 \\
411,230\end{array}$ & $\begin{array}{r}20,925,091 \\
57,245,116 \\
0 \\
0 \\
65,635 \\
4,052,429 \\
82,288,271\end{array}$ & $\begin{array}{r}0 \\
9,014,114 \\
0 \\
0 \\
180,000 \\
7,363 \\
285,154 \\
9,486,631\end{array}$ & $\begin{array}{r}0 \\
8,135,233 \\
0 \\
555,305 \\
0 \\
126,525 \\
8,817,063\end{array}$ & $\begin{array}{r}5,468,093 \\
27,710,057 \\
179,487 \\
0 \\
2,104,000 \\
1,947,673 \\
37,409,310\end{array}$ \\
\hline
\end{tabular}

\begin{tabular}{|c|c|c|c|c|c|}
\hline \multirow[b]{2}{*}{ Item } & \multirow[b]{2}{*}{$\begin{array}{c}\text { Tennessee } \\
\text { Valley } \\
\text { Authority } \\
\text { September } 30\end{array}$} & \multicolumn{2}{|c|}{ U.S. Bureau of Indian Affairs } & \multirow[b]{2}{*}{$\begin{array}{l}\text { USCE- } \\
\text { North Central } \\
\text { Division' } \\
\text { September } 30\end{array}$} & \multirow[b]{2}{*}{$\begin{array}{c}\text { Total } \\
\text { September } 30\end{array}$} \\
\hline & & $\begin{array}{c}\text { Mission } \\
\text { Valley Power } \\
\text { September } 30\end{array}$ & $\begin{array}{l}\text { San Carlos } \\
\text { September } 30\end{array}$ & & \\
\hline 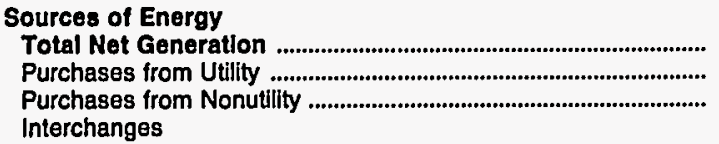 & $\begin{array}{r}125,119,788 \\
0 \\
98,415\end{array}$ & $\begin{array}{r}1,985 \\
284,183 \\
956\end{array}$ & $\begin{array}{r}0 \\
273,330 \\
0\end{array}$ & $\begin{array}{r}162,452 \\
0 \\
0\end{array}$ & $\begin{array}{r}247,182,266 \\
20,877,266 \\
478,371\end{array}$ \\
\hline 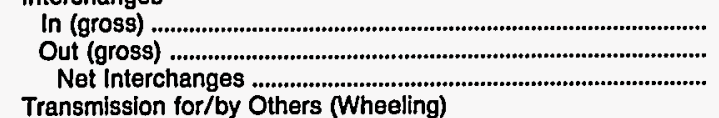 & $\begin{array}{r}27,916,034 \\
25,704,590 \\
2,211,444\end{array}$ & $\begin{array}{l}0 \\
0 \\
0\end{array}$ & $\begin{array}{l}0 \\
0 \\
0\end{array}$ & $\begin{array}{l}0 \\
0 \\
0\end{array}$ & $\begin{array}{l}44,224,166 \\
48,861,767 \\
-4,637,601\end{array}$ \\
\hline 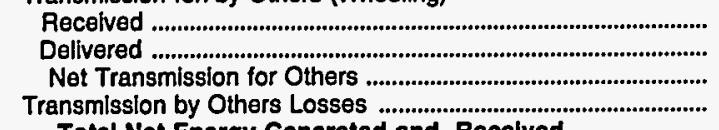 & $\begin{array}{r}1,566,174 \\
1,528,680 \\
37,494 \\
0\end{array}$ & $\begin{array}{l}0 \\
0 \\
0 \\
0\end{array}$ & $\begin{array}{r}0 \\
0 \\
0 \\
0\end{array}$ & $\begin{array}{l}0 \\
0 \\
0 \\
0\end{array}$ & $\begin{array}{r}48,116,348 \\
45,414,098 \\
2,702,250 \\
0\end{array}$ \\
\hline Total Net Energy Generated and Recelved ...................... & $127,467,141$ & 287,124 & 273,330 & 162,452 & $266,602,552$ \\
\hline 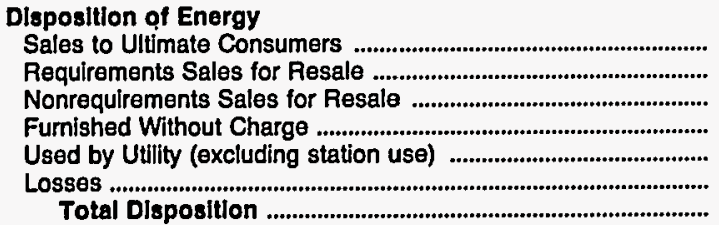 & $\begin{array}{r}18,398,577 \\
99,981,798 \\
0 \\
0 \\
9,830 \\
9,076,936 \\
127,467,141\end{array}$ & $\begin{array}{r}241,153 \\
0 \\
0 \\
0 \\
1,466 \\
44,505 \\
287,124\end{array}$ & $\begin{array}{r}263,763 \\
0 \\
0 \\
0 \\
0 \\
9,567 \\
273,330\end{array}$ & $\begin{array}{r}0 \\
155,272 \\
0 \\
0 \\
4,513 \\
671 \\
1,996 \\
162,452\end{array}$ & $\begin{array}{r}45,300,248 \\
202,639,151 \\
179,487 \\
740,017 \\
2,188,965 \\
15,554,684 \\
266,602,552\end{array}$ \\
\hline
\end{tabular}

1 Includes data only for Saint Mary's Falls at Sault St. Marie, Michigan. The rest of the generation produced by the U.S. Army Corps of Engineers (USCE) is sold by the Department of Energy-Bonneville, Southeastern, Southwestern, and Western Area Power Administrations.

Note: Totals may not equal sum of components because of independent rounding.

Source: Energy Information Administration, Form EIA-412, "Annual Report of Public Electric Utilities." 


\title{
Appendix A
}

\author{
Summary \\ Statistics of \\ U.S. Rural \\ Electric \\ Cooperative \\ Borrowers
}





\section{Summary Statistics of U.S. Rural Electric Cooperative Borrowers}

\section{Background}

The Rural Electrification Administration (REA), U.S. Department of Agriculture, was established under the Rural Electrification Act of 1936. The purpose was to extend electric service to small rural communities (usually under 1,500 customers) and farms where it was more expensive to provide service. Through the REA, electric cooperatives (customer-owned, nonprofit entities) were formed and provided with low interest rate government-guaranteed loans to allow them to build power lines to transmit and distribute wholesale electricity purchased from other electric utilities. By the early 1960's, the REA began to make large loans to cooperatives for the construction of generating plants and transmission facilities to "protect the security and effectiveness of REA-financed systems."

The latest statistics taken from the 1993 Statistical Report, Rural Electric Borrowers ${ }^{1}$ publication show that 855 of the 909 cooperative borrowers were distribution borrowers. The remaining 54 were power supply borrowers. By the end of 1993, the REA-financed electric utilities were serving more than 11 million consumers in 46 States. When the REA was formed, less than 10 percent of the rural areas in the United States had electric service. Today, about 99 percent of U.S. farmers have electric power.

\section{Composite Income Account}

Operating revenues for the cooperative borrowers were $\$ 24.9$ billion in 1993 , compared with $\$ 23.3$ billion in 1992, and $\$ 22.8$ billion in 1991 .

Total electric utility operating expenses for the cooperative borrowers were $\$ 21.7$ billion in 1993. Operation and maintenance expenses represented $\$ 19.3$ billion or 89.0 percent of the total operating expenses.
Purchased power, a major portion of operation and maintenance expenses, was $\$ 13.0$ billion. Taxes were $\$ 0.6$ billion or 2.8 percent of total electric operating expenses.

Utility operating income for the cooperative borrowers was $\$ 3.2$ billion in 1993 . Utility operating income, as a proportion of net utility plant, was 7.1 percent. Net income was $\$ 1.0$ billion.

Interest expense on long-term debt was $\$ 2.7$ billion in 1993 , a slight decrease from $\$ 2.8$ million in 1992 . Interest expenses as a percentage of long-term debt was 6.3 percent in 1993, compared with 6.6 percent in 1992.

\section{Balance Sheet}

The net investment in electric utility plant for the cooperative borrowers was $\$ 44.7$ billion at the end of 1993, which includes $\$ 1.7$ billion for construction work in progress (CWIP). The CWIP was $\$ 1.6$ billion in 1992. As a percentage of net investment in electric utility plant, CWIP was about 8.9 percent higher in 1993, compared with 1989. The investment and funds accounts were $\$ 5.4$ billion and the long-term debt was $\$ 42.7$ billion at the end of 1993 .

\section{Electric Utility Operating Revenues}

The number of residential consumers served by the cooperative borrowers was 10.5 million in 1993, up slightly from 10.3 million in 1992 . Revenues from residential consumers were $\$ 10.0$ billion or 66.5 percent of the total revenues from all ultimate consumers. In 1993, consumption of electricity by each residential customer averaged 12.2 megawatthours at an average annual cost of $\$ 946.42$, an increase from 1992 when each residential customer averaged 11.5 megawatthours at an average annual cost of $\$ 888.76$. 
Table A1. Composite Statement of Income for the U.S. Cooperative Borrowers, 1989-1993

(Thousand Dollars)

\begin{tabular}{|c|c|c|c|c|c|}
\hline Item & 1993 & 1992 & 1991 & 1990 & 1989 \\
\hline $\begin{array}{l}\text { Electric Utllity Operating Revenues ................... } \\
\text { Utility Operating Expenses }\end{array}$ & $24,872,684$ & $23,325,191$ & $22,784,208$ & $22,226,008$ & $21,986,690$ \\
\hline Operation and Maintenance Expenses ................ & $19,291,776$ & $18,038,115$ & $17,654,756$ & $17,036,873$ & $16,800,017$ \\
\hline 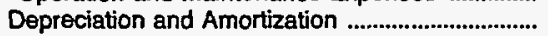 & $1,767,525$ & $1,709,293$ & $1,639,148$ & $1,616,945$ & $1,549,685$ \\
\hline Taxes & 615,890 & 605,275 & 592,850 & 515,486 & 555,146 \\
\hline $\begin{array}{c}\text { Total Electric Utility Operating } \\
\text { Expenses }\end{array}$ & $21,675,191$ & $20,352,683$ & $19,886,754$ & $19,169,304$ & $18,904,848$ \\
\hline Utility Operating Income & $3,197,493$ & $2,972,507$ & $2,897,454$ & $3,056,704$ & $3,081,842$ \\
\hline 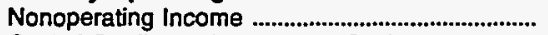 & 399,378 & 433,518 & 506,859 & 539,204 & 526,654 \\
\hline Capital Credits and Patronage Capital ................... & 323,345 & 248,996 & 234,137 & 178,520 & 157,501 \\
\hline Allowance for Funds Used During Construction. & 50,906 & 55,440 & 52,481 & 69,056 & 103,476 \\
\hline 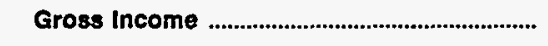 & $3,971,122$ & $3,710,461$ & $3,690,931$ & $3,843,484$ & $3,869,473$ \\
\hline Income Deductions from & & & & & \\
\hline 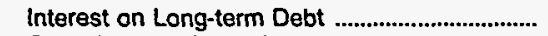 & $2,718,249$ & $2,833,653$ & $2,883,852$ & $2,875,063$ & $2,771,605$ \\
\hline Other Income Deductions ........................................... & 218,024 & 165,921 & 67,847 & 264,197 & 358,795 \\
\hline Total Income Deductions ...................................... & $2,936,273$ & $2,999,574$ & $2,951,699$ & $3,139,260$ & $3,130,400$ \\
\hline Net Income and Patronage Capltal ............ & $1,034,849$ & 710,887 & 739,232 & 704,224 & 739,073 \\
\hline
\end{tabular}

Notes: Totals may not equal sum of components because of independent rounding. Data for 1993 represent 855 Distribution Borrowers and 54 Power Supply Borrowers; data for 1992 represent 862 Distribution Borrowers and 54 Power Supply Borrowers; data for 1991 represent 832 Distribution Borrowers and 55 Power Supply Borrowers; data for 1990 represent 838 Distribution Borrowers and 56 Power Supply Borrowers; and data for 1989 represent 839 Distribution Borrowers and 58 Power Supply Borrowers.

Source: U.S. Department of Agriculture, Rural Electrification Administration, Statistical Report, Rural Electric Borrowers publications for the years $1989,1990,1991,1992$, and 1993.

Table A2. Composite Balance Sheet for the U.S. Cooperative Borrowers on December 31, 1989-1993

(Thousand Dollars)

\begin{tabular}{|c|c|c|c|c|c|}
\hline Item & 1993 & 1992 & 1991 & 1990 & 1989 \\
\hline \multicolumn{6}{|l|}{ Assets and Other Debits } \\
\hline 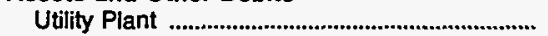 & $60,946,122$ & $59,043,411$ & $56,752,533$ & $56,211,882$ & $55,102,550$ \\
\hline $\begin{array}{l}\text { Construction Work in Progress ............................. } \\
\text { (Less) Accumulated Provisions for }\end{array}$ & $1,708,168$ & $1,626,552$ & $1,511,459$ & $1,326,488$ & $1,534,253$ \\
\hline 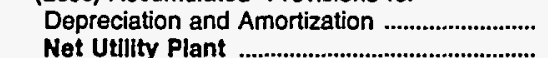 & $\begin{array}{l}17,907.939 \\
44,746,351\end{array}$ & $\begin{array}{l}16,594,358 \\
44,075,606\end{array}$ & $\begin{array}{l}15,093,304 \\
43,170,688\end{array}$ & $\begin{array}{l}14,108,095 \\
43,430,275\end{array}$ & $\begin{array}{l}12,867,844 \\
43,768,959\end{array}$ \\
\hline 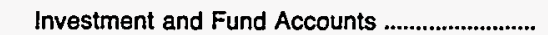 & $5,379,236$ & $5,379,400$ & $5,017,772$ & $4,675,202$ & $4,204,565$ \\
\hline 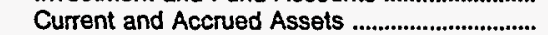 & $7,986,359$ & $7,810,050$ & $8,002,973$ & $7,966,885$ & $8,132,679$ \\
\hline 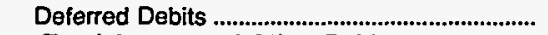 & $3,970,658$ & $2,287,018$ & $1,811,064$ & $2,028,760$ & $2,604,551$ \\
\hline Total Assets and Other Deblts ........................... & $62,430,395$ & $59,552,073$ & $58,002,497$ & $58,101,121$ & $58,710,754$ \\
\hline \multicolumn{6}{|l|}{ Llablittes and Other Credits } \\
\hline 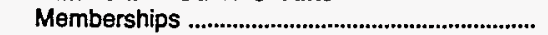 & 97,081 & 96,146 & 91,664 & 91,122 & 88,373 \\
\hline Patronage Capital and Other Equities ............... & $12,230,419$ & $11,372,465$ & $10,470,168$ & $9,944,290$ & $9,391,401$ \\
\hline Total Equlty & $12,327,500$ & $11,468,611$ & $10,561,832$ & $10,035,412$ & $9,479,774$ \\
\hline 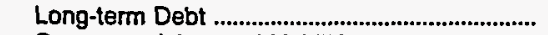 & $42,719,188$ & $42,691,944$ & $42,273,766$ & $42,887,350$ & $40,220,703$ \\
\hline Current and Accrued Liabilities ................................ & $3,852,903$ & $3,381,957$ & $3,194,377$ & $3,221,216$ & $6,955,326$ \\
\hline 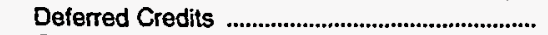 & $1,555,059$ & $1,469,722$ & $1,442,849$ & $1,546,174$ & $1,662,396$ \\
\hline 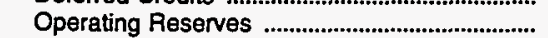 & $1,975,745$ & 539,839 & 529,673 & 410,971 & 392,555 \\
\hline Total Llabillties and Other Credits .............. & $62,430,395$ & $59,552,073$ & $58,002,497$ & $58,101,121$ & $58,710,754$ \\
\hline
\end{tabular}

Notes: Totals may not equal sum of components because of independent rounding. Data for 1993 represent 855 Distribution Borrowers and 54 Power Supply Borrowers; data for 1992 represent 862 Distribution Borrowers and 54 Power Supply Borrowers; data for 1991 represent 832 Distribution Borrowers and 55 Power Supply Borrowers; data for 1990 represent 838 Distribution Borrowers and 56 Power Supply Borrowers; and data for 1989 represent 839 Distribution Borrowers and 58 Power Supply Borrowers.

Source: U.S. Department of Agriculture, Rural Electrification Administration, Statlstical Report, Rural Electric Borrowers publications for the years $1989,1990,1991,1992$ and 1993. 
Table A3. Electric Operation and Maintenance Expenses for the U.S. Cooperative Borrowers, 1989-1993

(Thousand Dollars)

\begin{tabular}{|c|c|c|c|c|c|}
\hline Item & 1993 & 1992 & 1991 & 1990 & 1989 \\
\hline $\begin{array}{l}\text { Production Expenses } \\
\text { Power Production Expenses .................................. } \\
\text { Purchased Power .............................................. } \\
\text { Total Production Expenses ............................. }\end{array}$ & $\begin{array}{r}3,083,578 \\
13,017,485 \\
16,101,063\end{array}$ & $\begin{array}{r}2,998,260 \\
12,061,066 \\
15,059,326\end{array}$ & $\begin{array}{r}2,978,362 \\
11,857,765 \\
14,836,127\end{array}$ & $\begin{array}{r}3,100,268 \\
11,246,600 \\
14,346,868\end{array}$ & $\begin{array}{r}3,020,715 \\
11,250,727 \\
14,271,442\end{array}$ \\
\hline 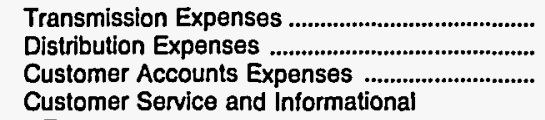 & $\begin{array}{r}336,401 \\
1,044,359 \\
386,310\end{array}$ & $\begin{array}{l}323,527 \\
980,017 \\
368,563\end{array}$ & $\begin{array}{l}312,982 \\
916,569 \\
348,605\end{array}$ & $\begin{array}{l}318,117 \\
873,947 \\
334,288\end{array}$ & $\begin{array}{l}294,591 \\
821,151 \\
321,013\end{array}$ \\
\hline 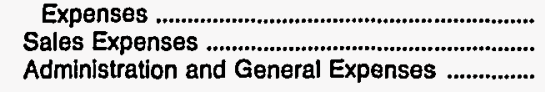 & $\begin{array}{r}100,991 \\
57,438 \\
1,265,214\end{array}$ & $\begin{array}{r}94,907 \\
52,235 \\
1,159,540\end{array}$ & $\begin{array}{r}89,029 \\
47,153 \\
1,104,291\end{array}$ & $\begin{array}{r}82,714 \\
41,619 \\
1,039,319\end{array}$ & $\begin{array}{r}75,569 \\
35,144 \\
981,109\end{array}$ \\
\hline $\begin{array}{l}\text { Total Electric Operation and } \\
\text { Malntenance Expenses }\end{array}$ & $19,291,776$ & $18,038,115$ & $17,654,756$ & $17,036,872$ & $16,800,017$ \\
\hline
\end{tabular}

Notes: Totals may not equal sum of components because of independent rounding. Data for 1993 represent 855 Distribution Borrowers and 54 Power Supply Borrowers; data for 1992 represent 862 Distribution Borrowers and 54 Power Supply Borrowers; data for 1991 represent 832 Distribution Borrowers and 55 Power Supply Borrowers; data for 1990 represent 838 Distribution Borrowers and 56 Power Supply Borrowers; and data for 1989 represent 839 Distribution Borrowers and 58 Power Supply Borrowers.

Source: U.S. Department of Agriculture, Rural Electrification Administration, Statistical Report, Rural Electric Borrowers publications for the years 1989, 1990, 1991, 1992 and 1993.

Table A4. Number of Consumers, Sales, and Operating Revenue for the U.S. Cooperative Distributor Borrowers, 1989-1993

\begin{tabular}{|c|c|c|c|c|c|}
\hline Item & 1993 & 1992 & 1991 & 1990 & 1989 \\
\hline \multicolumn{6}{|l|}{ Number of Consumers on December 31} \\
\hline 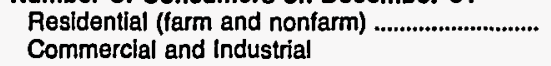 & $10,533,502$ & $10,320,348$ & $9,865,739$ & $9,732,694$ & $9,555,287$ \\
\hline 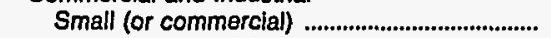 & $1,007,028$ & 987,261 & 928,085 & 909,111 & 862,904 \\
\hline Large (or industrial) & 6,922 & 6,499 & 6,238 & 6,252 & 6,009 \\
\hline \multirow{4}{*}{ 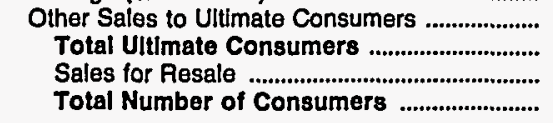 } & 176,307 & 172,995 & 157,506 & 153,324 & 148,764 \\
\hline & $11,723,759$ & $11,487,103$ & $10,957,568$ & $10,801,381$ & $10,572,964$ \\
\hline & 274 & 251 & & & \\
\hline & $11,723,973$ & $11,487,354$ & $10,957,765$ & $10,801,584$ & $10,573,172$ \\
\hline \multicolumn{6}{|l|}{ Sales for the Year (Megawatthours) } \\
\hline \multicolumn{6}{|l|}{ 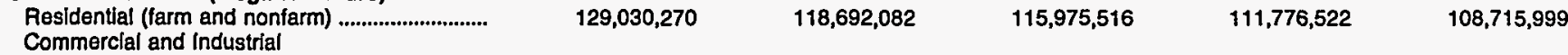 } \\
\hline \multirow{2}{*}{ Small (or commercial) } & $38,747,491$ & $37,109,870$ & $34,862,307$ & $34,055,526$ & $32,750,344$ \\
\hline & $39,237,790$ & $36,852,497$ & $33,619,491$ & $31,739,197$ & $29,297,743$ \\
\hline Other Sales to Ultimate Consumers ......................... & $5,581,171$ & $5,633,095$ & $5,603,651$ & $5,814,007$ & $4,615,639$ \\
\hline Total Sales to Ultimate Consumers ............... & $212,596,722$ & $198,287,544$ & $190,060,965$ & $183,385,252$ & $175,379,725$ \\
\hline \multirow{2}{*}{ Sales for Resale } & $2,645,738$ & $2,741,863$ & $1,934,117$ & $3,095,647$ & $3,107,445$ \\
\hline & $215,242,460$ & $201,029,407$ & $191,995,082$ & $186,480,899$ & $178,487,170$ \\
\hline \multicolumn{6}{|l|}{$\begin{array}{l}\text { Operating Revenues for the Year (thousand } \\
\text { dollars) }\end{array}$} \\
\hline 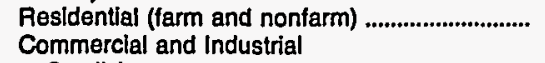 & $9,969,111$ & $9,172,348$ & $8,806,081$ & $8,403,275$ & $8,077,510$ \\
\hline \multirow{2}{*}{ 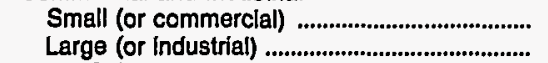 } & $2,823,106$ & $2,719,063$ & $2,543,472$ & $2,467,830$ & $2,355,380$ \\
\hline & $1,717,394$ & $1,617,928$ & $1,502,148$ & $1,438,675$ & $1,437,407$ \\
\hline \multirow{2}{*}{$\begin{array}{l}\text { Other Sales to Ultimate Consumers .......................... } \\
\text { Total Sales to Ultimate Consumers ........... }\end{array}$} & 384,628 & $\mathbf{3 7 1 , 4 0 5}$ & 365,037 & 374,504 & 351,157 \\
\hline & $14,894,239$ & $13,880,744$ & $13,216,738$ & $12,684,284$ & $12,221,454$ \\
\hline \multirow{2}{*}{ Sales for Resale } & 95,737 & 94,602 & 84,548 & 121,008 & 116,255 \\
\hline & $14,989,976$ & $13,975,346$ & $13,301,286$ & $12,805,290$ & $12,337,709$ \\
\hline \multirow{2}{*}{ 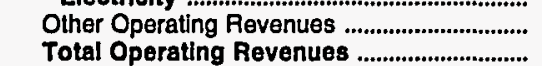 } & 210,831 & 214,504 & 198,943 & 196,248 & 160,293 \\
\hline & $15,200,807$ & $14,189,850$ & $13,500,229$ & $13,001,538$ & $12,498,002$ \\
\hline
\end{tabular}

Notes: Totals may not equal sum of components because of independent rounding. This table does not include in 1993 the 54 Power Supply Borrowers, In 1992 the 54 Power Supply Borrowers, in 1991 the 55 Power Supply Borrowers, in 1990 the 56 Power Supply Borrowers, and in 1989 the 58 Power Supply Borrowers included in Tables A1, A2, and A3. Data for 1993 represent 855 Distribution Borrowers; data for 1992 represent 862 Distribution Borrowers; data for 1991 represent 832 Distribution Borrowers; data for 1990 represent 838 Distribution Borrowers; and data for 1989 represent 839 Dlstribution Borrowers.

Source: U.S. Department of Agriculture, Rural Electrification Administration, Statistical Report, Rural Electric Borrowers publications for the years $1989,1990,1991,1992$ and 1993. 



\title{
Appendix B
}

\author{
Major U.S. \\ Publicly \\ Owned \\ Electric Utility \\ Respondents
}




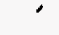




\section{Major U.S. Publicly Owned Electric Utility Respondents}

Table B1. Major U.S. Publicly Owned Electric Utilities Added to and Deleted from the Form ElA-412, 1989-1993

\begin{tabular}{|c|c|c|c|c|c|}
\hline \multirow{2}{*}{ Year } & \multicolumn{2}{|r|}{ Added } & \multicolumn{2}{|r|}{ Deleted } & \multirow{2}{*}{$\begin{array}{l}\text { Total Number } \\
\text { Available }^{1}\end{array}$} \\
\hline & No. & Name & No. & Name & \\
\hline $1989^{2} \ldots$ & 4 & $\begin{array}{l}\text { Illinois Muni Elec Agency (Illinois) } \\
\text { Kerrville Public Utility Board (Texas) } \\
\text { Southern Calif Pub Serv Auth (Calif) } \\
\text { Terrebone Paris Consol Govt (Louisiana) }\end{array}$ & 40 & $\begin{array}{l}\text { Amory City of (Mississippi) } \\
\text { Arcade Village of (New York) } \\
\text { Benton City of (Arkansas) } \\
\text { Brainerd City of (Minnesota) } \\
\text { Denison City of (lowa) } \\
\text { Duncan City of (Oklahoma) } \\
\text { Electrical Dist No } 4 \text { Pinal Cnty (Ariz) } \\
\text { Elkhorn Rural Public Pwr Dist (Neb) } \\
\text { Geneva City of (Illinois) } \\
\text { Georgetown City of (South Carolina) } \\
\text { Hartselle City of (Alabama) } \\
\text { Hillsdale City of (Michigan) } \\
\text { Houma City of (Louisiana) } \\
\text { Jasper City of (Texas) } \\
\text { Kennett City of (Missouri) } \\
\text { Lansdale Borough of (Pennsylvania) } \\
\text { Lawrenceville City of (Georgia) } \\
\text { Lebanon City of (Indiana) } \\
\text { Lebanon City of (Missouri) } \\
\text { McCook Public Power District (Nebraska) } \\
\text { Miami City of (Oklahoma) } \\
\text { Milton-Freewater City of (Oregon) } \\
\text { Minden City of (Louisiana) } \\
\text { Monett City of (Missouri) } \\
\text { Napoleon City of (Ohio) } \\
\text { Niles City of (Michigan) } \\
\text { Oxford City of (Mississippi) } \\
\text { Paris City of (Tennessee) } \\
\text { Piedmont City of (Alabama) } \\
\text { Pierre City of (South Dakota) } \\
\text { Plymouth City of Wisconsin) } \\
\text { PUD No } 1 \text { of Skamania County (Washington) } \\
\text { Rochelle Municipal Utilities (Illinois) } \\
\text { Russellville City of (Alabama) } \\
\text { Seneca City of (South Carolina) } \\
\text { South Hadley Town of (Massachusetts) } \\
\text { St Marys City of (Ohio) } \\
\text { Sturgeon Bay City of (Wisconsin) } \\
\text { Vanceburg City of (Kentucky) } \\
\text { Wapakoneta City of (Ohio) }\end{array}$ & 454 \\
\hline
\end{tabular}

See endnotes at end of this table. 
Table B1. Publicly Owned Electric Utilities Added to and Deleted from the Form ElA-412, 1989-1993 (Continued)

\begin{tabular}{|c|c|c|c|c|c|}
\hline \multirow{2}{*}{ Year } & \multicolumn{2}{|r|}{ Added } & \multicolumn{2}{|r|}{ Deleted } & \multirow{2}{*}{$\begin{array}{l}\text { Total Number } \\
\text { Available' }\end{array}$} \\
\hline & No. & Name & No. & Name & \\
\hline $1990 \ldots . . . .$. & 13 & $\begin{array}{l}\text { Alabama Municipal Elec Auth (Alabama) } \\
\text { Geneva City of (Illinois) } \\
\text { Jefferson City of (Wisconsin) } \\
\text { Ketchikan City of (Alaska) } \\
\text { Lawrenceville City of (Georgia) } \\
\text { McCook Public Power Dist (Nebraska) } \\
\text { Oxford City of (Mississippi) } \\
\text { Paris City of (Tennessee) } \\
\text { Pierre City of (South Dakota) } \\
\text { Plymouth City of (Wisconsin) } \\
\text { Rochelle Municipal Utilities (lllinois) } \\
\text { San Marcos City of (Texas) } \\
\text { Wapakoneta City of (Ohio) }\end{array}$ & - & & 467 \\
\hline $1991 \ldots . . . .$. & 08 & $\begin{array}{l}\text { Benton City of (Arkansas) } \\
\text { Hillsdale Board of Pub Works (Michigan) } \\
\text { Kennett City of (Missouri) } \\
\text { Lebanon City of (Missouri) } \\
\text { Monett City of (Missouri) } \\
\text { Reedsburg Util Commission (Wisconsin) } \\
\text { St Marys City of (Ohio) } \\
\text { Sturgeon Bay Combined Utils(Wisconsin) }\end{array}$ & 05 & $\begin{array}{l}\text { Kings River Conserv Dist (California) } \\
\text { McCook Public Power Dist (Nebraska) } \\
\text { Merced Irrigation District (California) } \\
\text { Sebring Utilities Commission (Florida) } \\
\text { Solvay Village of (New York) } \\
\end{array}$ & 470 \\
\hline $1992 \ldots . . . .$. & 14 & $\begin{array}{l}\text { Badger Power Marketing Auth (Wisconsin) } \\
\text { Brainerd City of (Minnesota) } \\
\text { Chanute City of (Kansas) } \\
\text { Duncan City of (Oklahoma) } \\
\text { Electrical Dist No2 Pinal Cnty (Arizona) } \\
\text { Floresville City of (Texas) } \\
\text { Greenfield City of (Indiana) } \\
\text { Lafayette Public Power Auth (Louisiana) } \\
\text { Massena Town of (New York) } \\
\text { Milford City of (Delaware) } \\
\text { Pella City of (lowa) } \\
\text { Reedy Creek Improvement Dist (Florida) } \\
\text { Sebring Utilities Commission (Florida) } \\
\text { Tohono O dham Utility Auth (Arizona) }\end{array}$ & 01 & Milan City of (Tennessee) & 483 \\
\hline $1993 \ldots . . . .$. & 13 & $\begin{array}{l}\text { Chaska City of (Minnesota) } \\
\text { Clarksville Light \& Water Co (Arkansas) } \\
\text { Forest City Town of (North Carolina) } \\
\text { Fort Morgan City of (Colorado) } \\
\text { Lansdale Borough of (Pennyslvannia) } \\
\text { Lassen Municipal Utility Dist (California) } \\
\text { Merced Irrigation Dist (California) } \\
\text { Miami City of (Oklahoma) } \\
\text { Napoleon City of (Ohio) } \\
\text { Seneca City of (South Carolina) } \\
\text { Shakopee Public Utilities Comm (Minnesota) } \\
\text { Sun Prairie Water \& Light Comm (Wisconsin) } \\
\text { Zeeland City of (Michigan) }\end{array}$ & 01 & Sebring Utilities Commission (Florida) & 495 \\
\hline
\end{tabular}

1 Excluded are the Federal electric utilities.

2 The threshold for reporting requirements changed from 100,000 megawatthours to 120,000 megawatthours. Source: Energy Information Administration, Form ElA-412, "Annual Report of Public Electric Utilities."

Table B2. Major U.S. Publicly Owned Electric Utilities by Fiscal Year and Generator/Nongenerator Status from the Form EIA-412, 1993

\begin{tabular}{|c|c|c|c|}
\hline Fiscal Year & All Respondents & Generator Respondents & Nongenerator Respondents \\
\hline June 30 & 198 & 56 & 142 \\
\hline December 31 & 206 & 113 & 93 \\
\hline Other & 91 & 57 & 34 \\
\hline Total & 495 & 226 & 269 \\
\hline
\end{tabular}

Source: Energy Information Administration, Form EIA-412, "Annual Report of Public Electric Utilities." 
Table B3. Publicly Owned Electric Utilities That Submitted the Form EIA-412, 1993

\begin{tabular}{|c|c|c|c|}
\hline Publicly Owned Electric Utllitles & State & Reporting Date & Generating Status \\
\hline 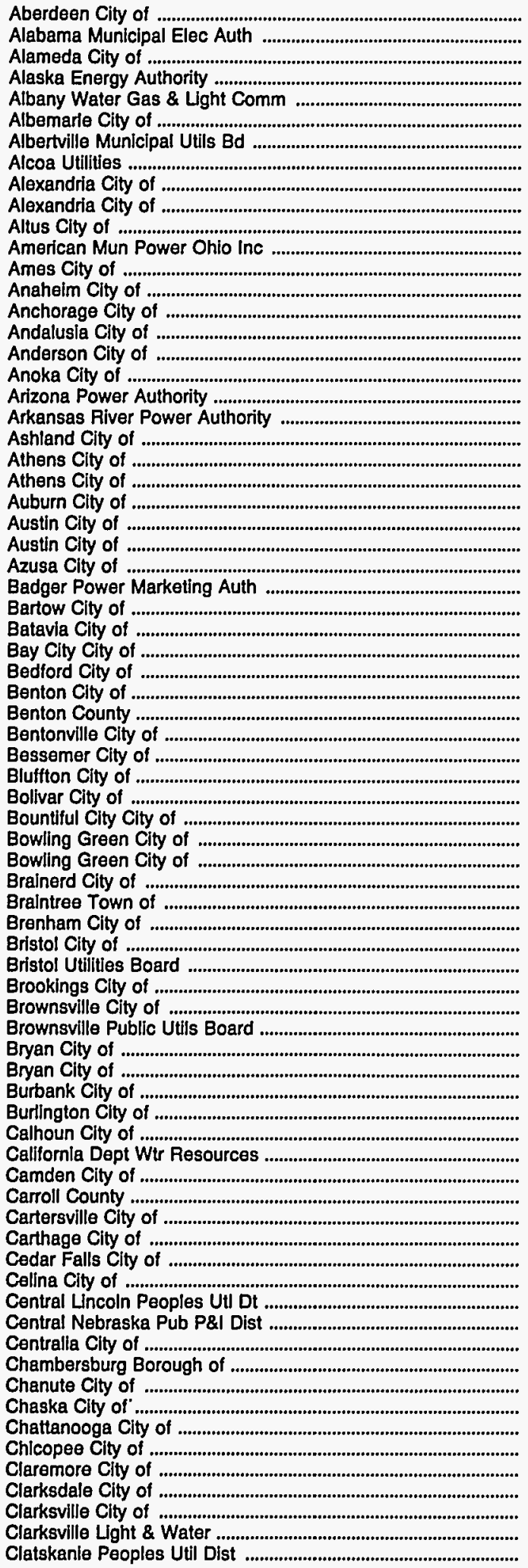 & 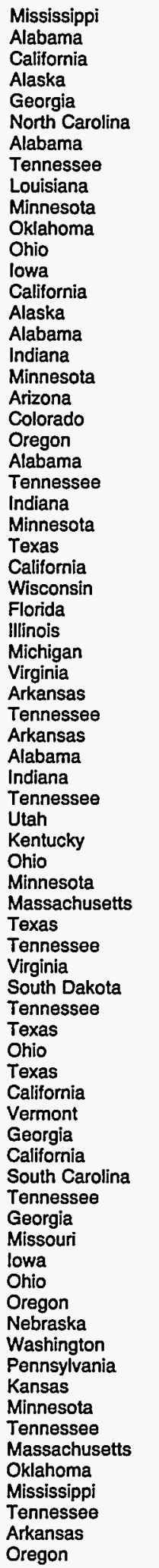 & 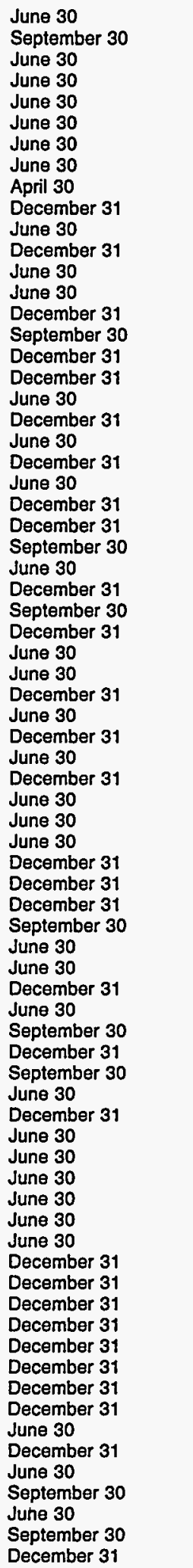 & 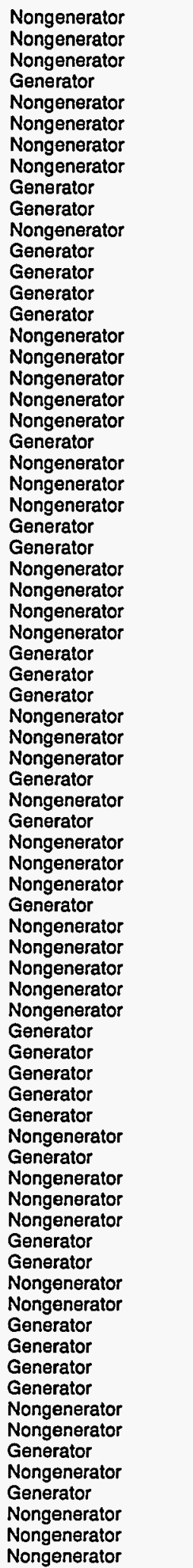 \\
\hline
\end{tabular}

See endnotes at end of this table. 
Table B3. Publicly Owned Electric Utilities That Submitted the Form EIA-412, 1993 (Continued)

\begin{tabular}{|c|c|c|c|}
\hline Publicly Owned Electric Utilitles & State & Reporting Date & Generating Status \\
\hline 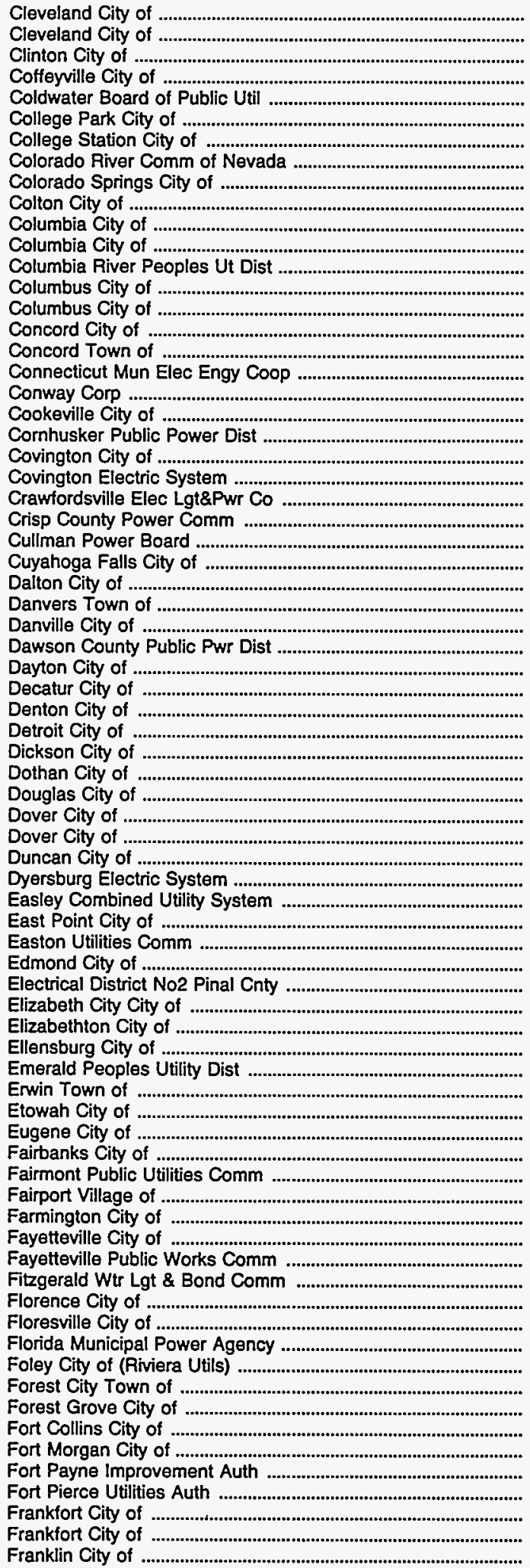 & 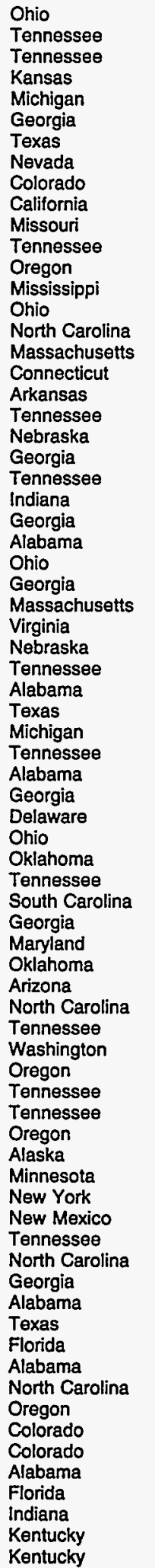 & 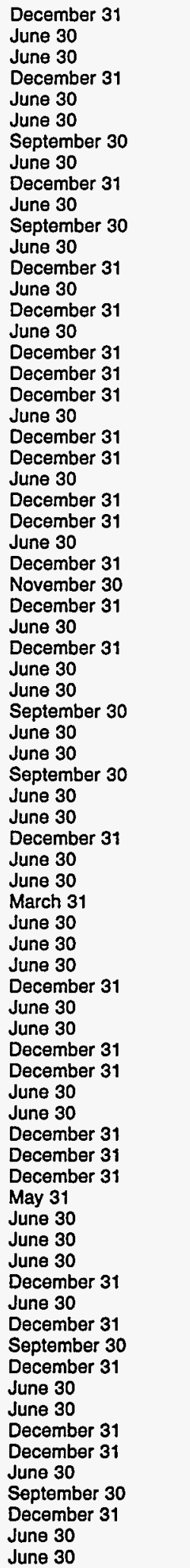 & 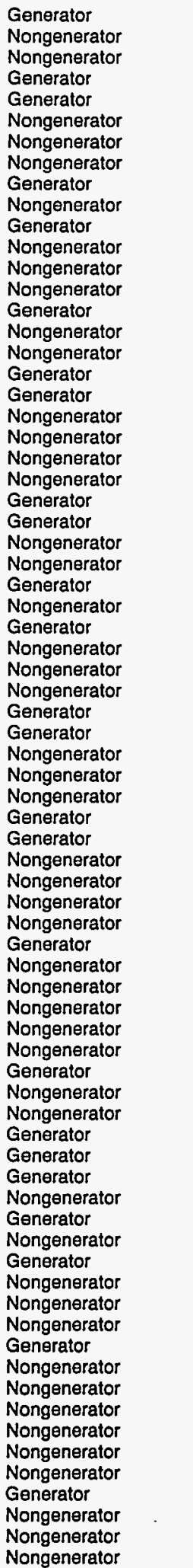 \\
\hline
\end{tabular}

See endnotes at end of this table. 
Table B3. Publicly Owned Electric Utilities That Submitted the Form EIA-412, 1993 (Continued)

\begin{tabular}{|c|c|c|c|}
\hline Publicly Owned Electric Utilities & State & Reporting Date & Generating Status \\
\hline 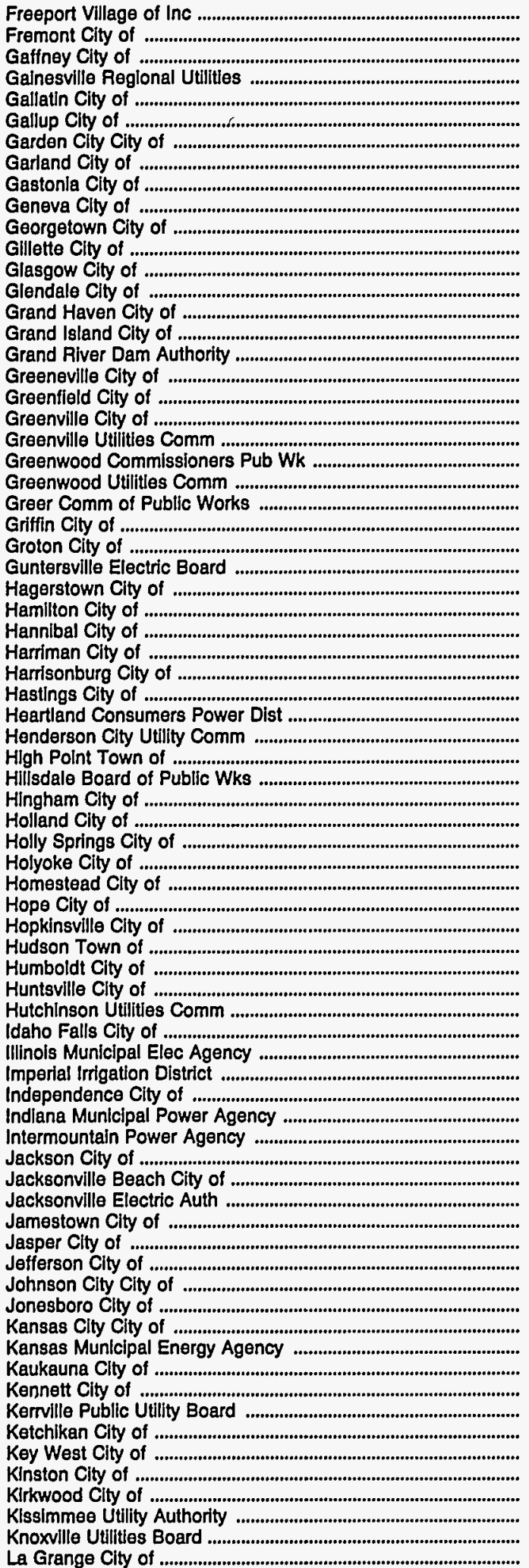 & 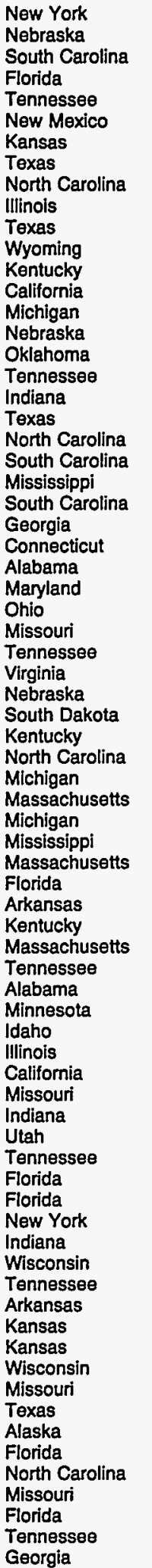 & 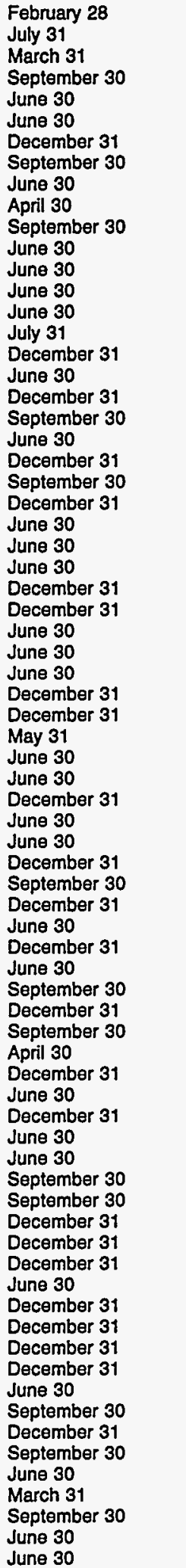 & 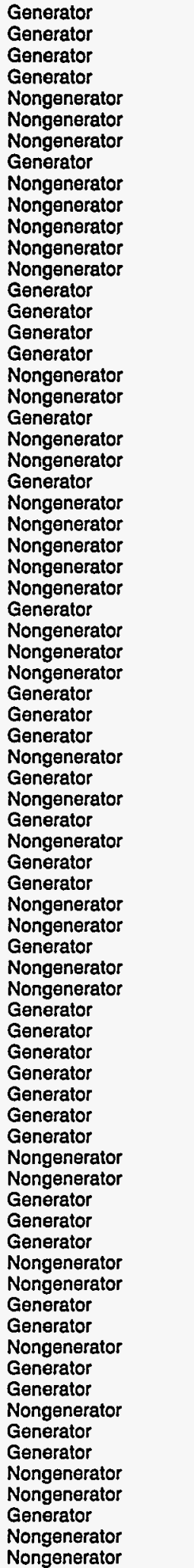 \\
\hline
\end{tabular}

See endnotes at end of this table. 
Table B3. Publicly Owned Electric Utilities That Submitted the Form EIA-412, 1993 (Continued)

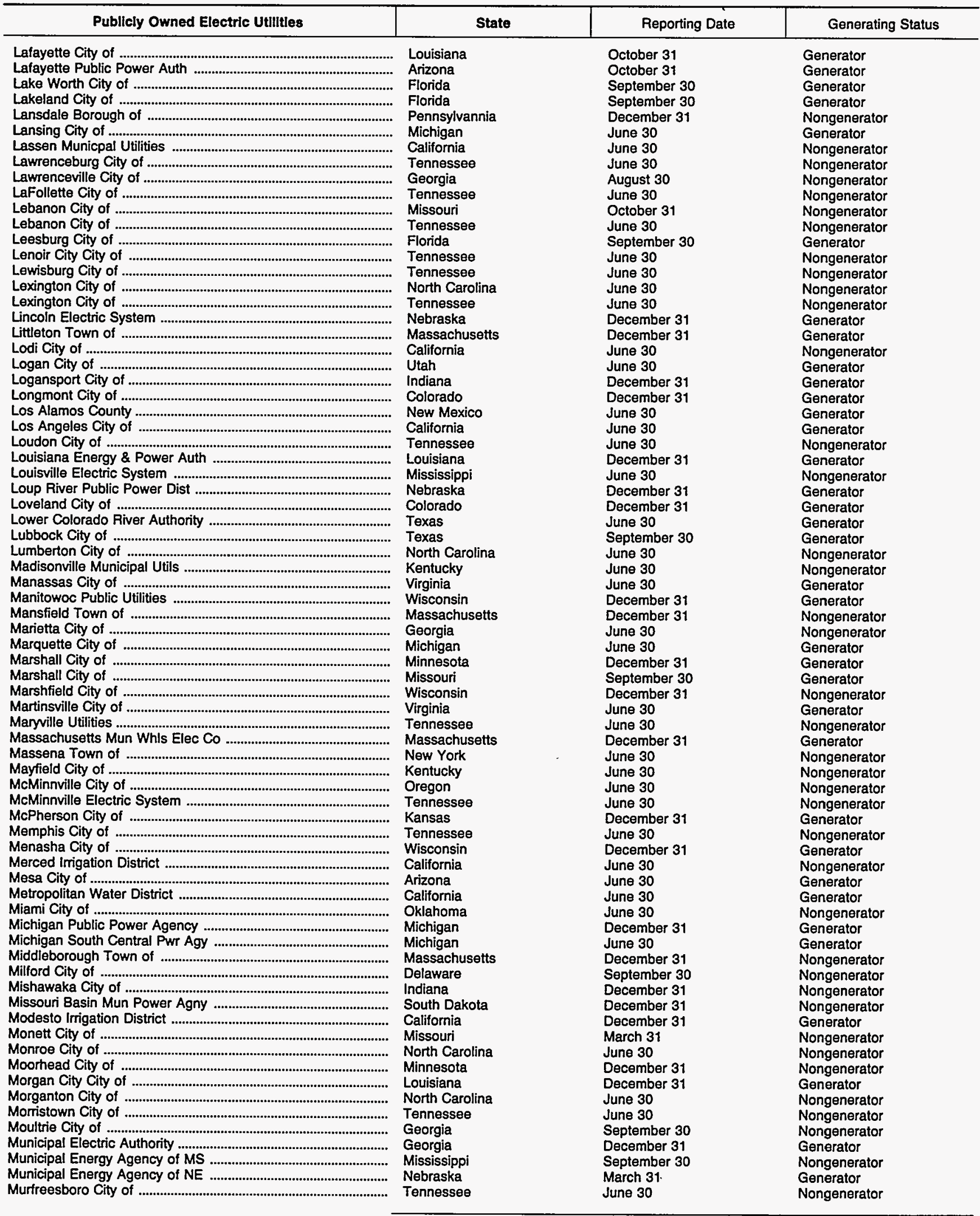

See endnotes at end of this table. 
Table B3. Publicly Owned Electric Utilities That Submitted the Form EIA-412, 1993 (Continued)

\begin{tabular}{|c|c|c|c|}
\hline Publlcly Owned Electric Utllities & State & Reporting Date & Generating Status \\
\hline 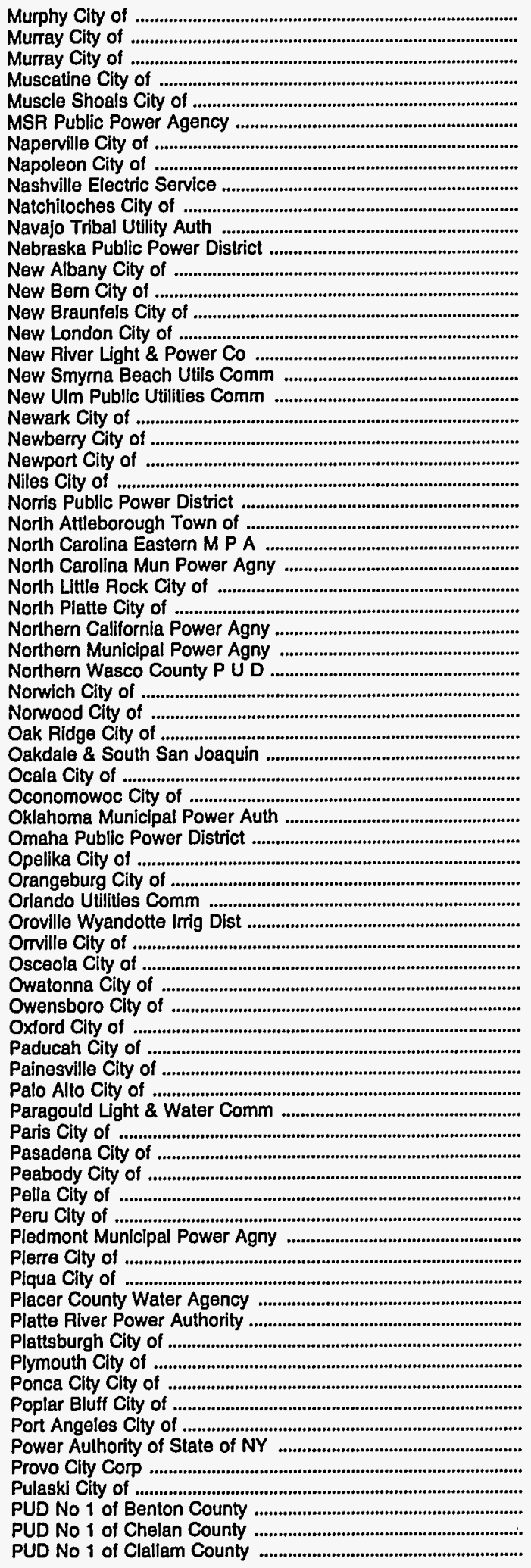 & 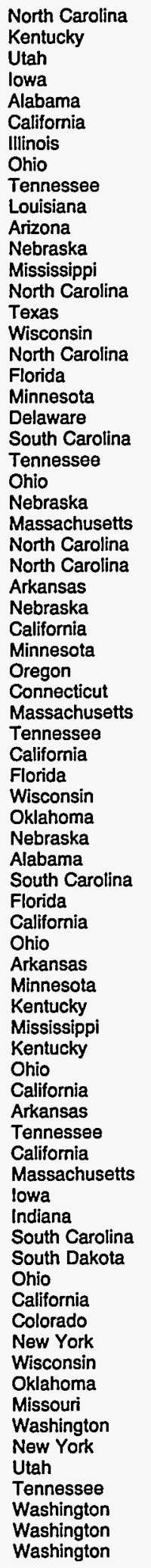 & 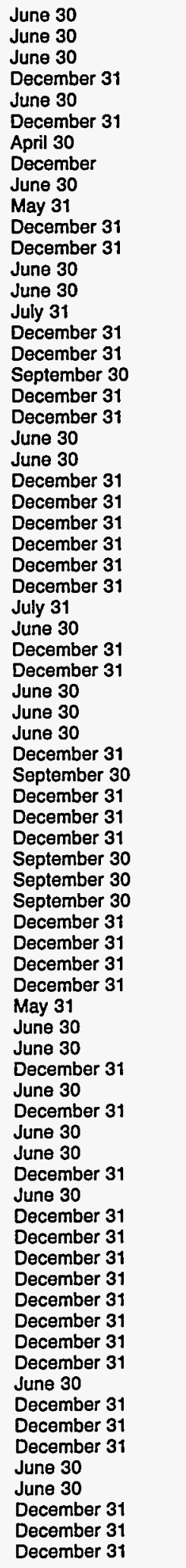 & 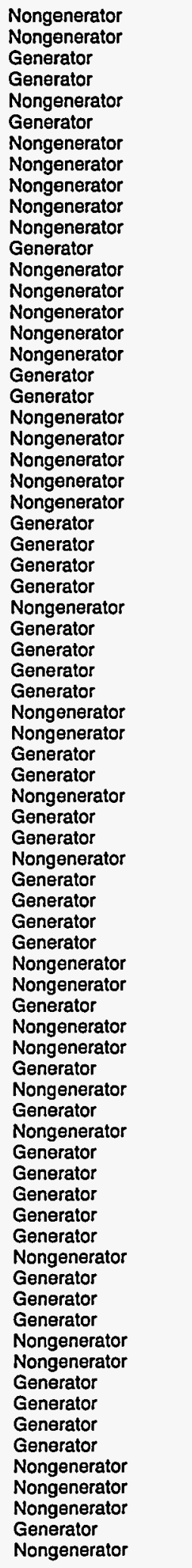 \\
\hline
\end{tabular}

See endnotes at end of this table. 
Table B3. Publicly Owned Electric Utilities That Submitted the Form EIA-412, 1993 (Continued)

\begin{tabular}{|c|c|c|c|}
\hline Publlcly Owned Electric Utilities & State & Reporting Date & Generating Status \\
\hline 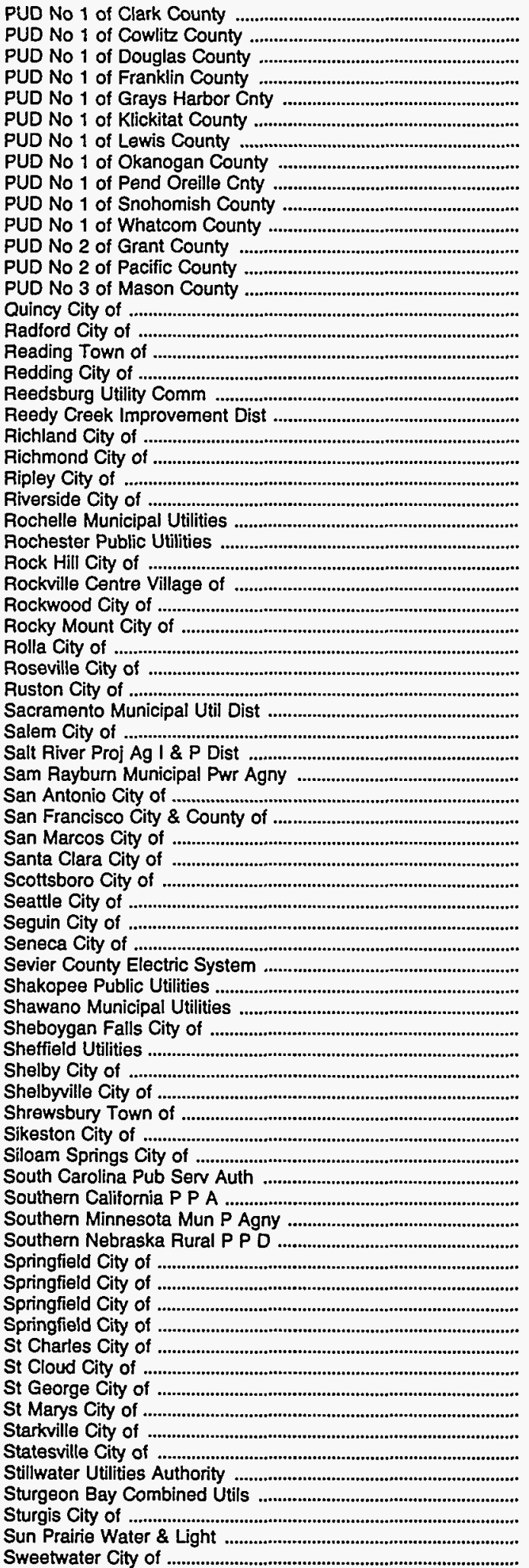 & 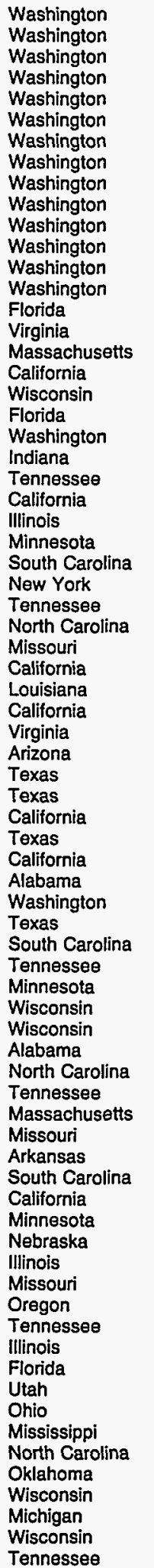 & 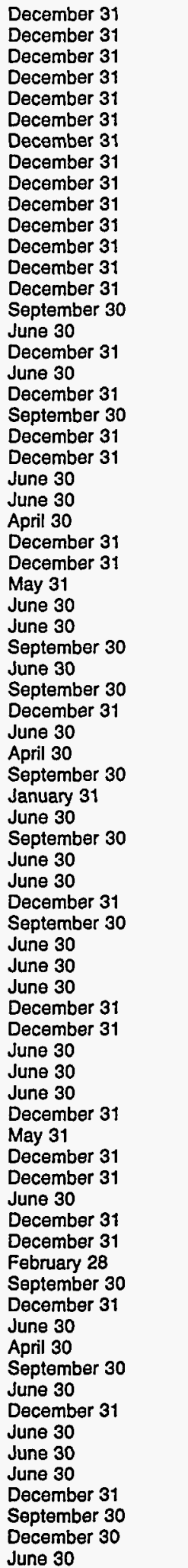 & 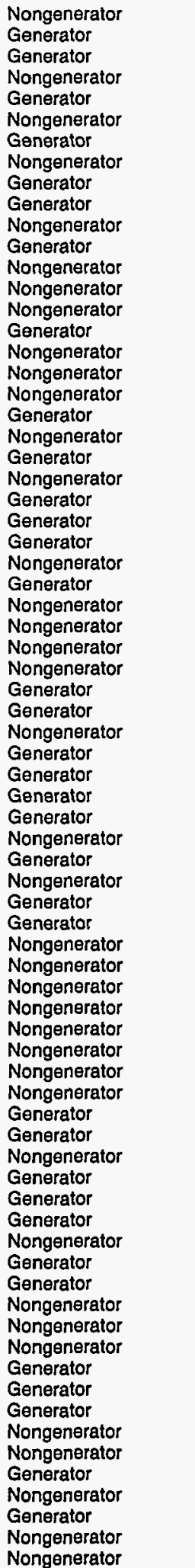 \\
\hline
\end{tabular}

See endnotes at end of this table. 
Table B3. Publicly Owned Electric Utilities That Submitted the Form EIA-412, 1993 (Continued)

\begin{tabular}{|c|c|c|c|}
\hline Publicly Owned Electric Utilltes & State & Reporting Date & Generating Status \\
\hline 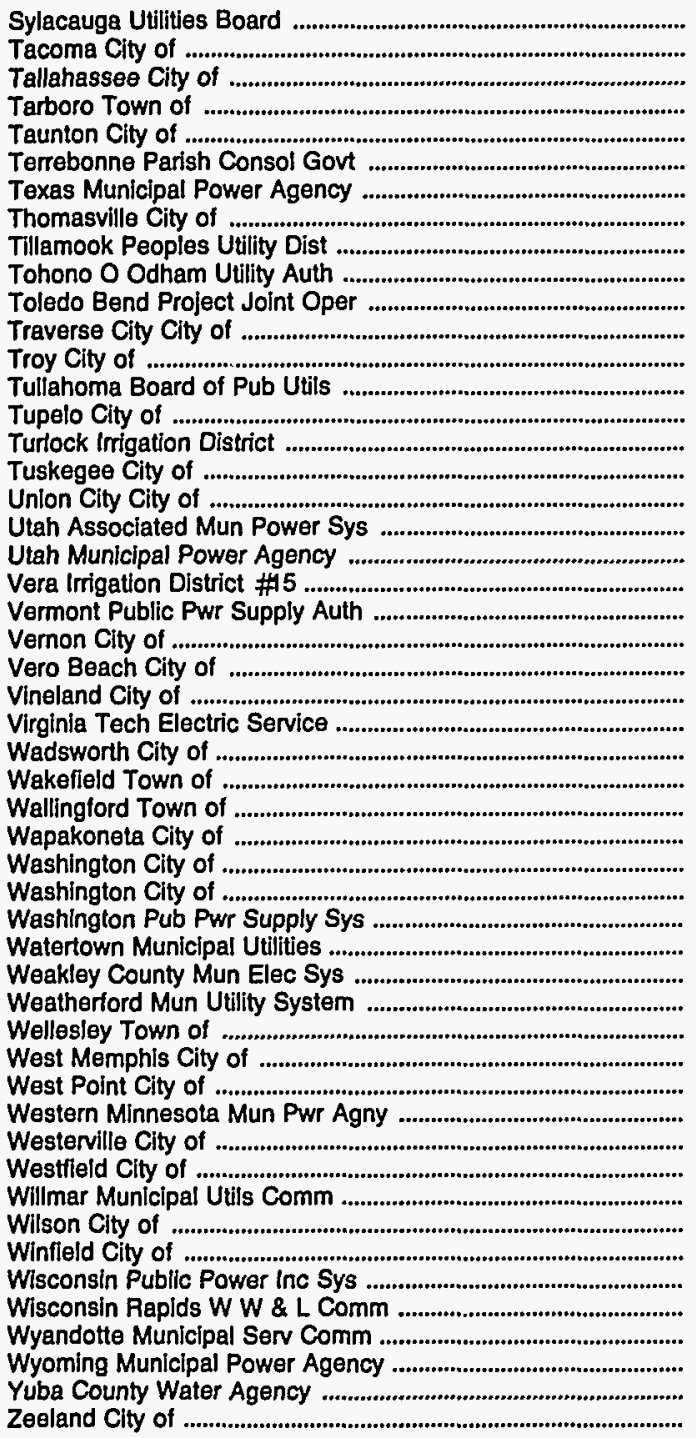 & $\begin{array}{l}\text { Alabama } \\
\text { Washington } \\
\text { Florida } \\
\text { North Carolina } \\
\text { Massachusetts } \\
\text { Louisiana } \\
\text { Texas } \\
\text { Georgia } \\
\text { Oregon } \\
\text { Arizona } \\
\text { Texas } \\
\text { Michigan } \\
\text { Alabama } \\
\text { Tennessee } \\
\text { Mississippi } \\
\text { California } \\
\text { Alabama } \\
\text { Tennessee } \\
\text { Utah } \\
\text { Utah } \\
\text { Washington } \\
\text { Vermont } \\
\text { California } \\
\text { Florida } \\
\text { New Jersey } \\
\text { Virginia } \\
\text { Ohio } \\
\text { Massachusetts } \\
\text { Connecticut } \\
\text { Ohio } \\
\text { Indiana } \\
\text { North Carolina } \\
\text { Washington } \\
\text { South Dakota } \\
\text { Tennessee } \\
\text { Texas } \\
\text { Massachusetts } \\
\text { Arkansas } \\
\text { Mississippi } \\
\text { Minnesota } \\
\text { Ohio } \\
\text { Massachusetts } \\
\text { Minnesota } \\
\text { North Carolina } \\
\text { Kansas } \\
\text { Wisconsin } \\
\text { Wisconsin } \\
\text { Michigan } \\
\text { Wyoming } \\
\text { California } \\
\text { Michigan } \\
\text { Mang }\end{array}$ & $\begin{array}{l}\text { September } 30 \\
\text { December } 31 \\
\text { September } 30 \\
\text { June } 30 \\
\text { December } 31 \\
\text { December } 31 \\
\text { September } 30 \\
\text { December } 31 \\
\text { December } 31 \\
\text { December } 31 \\
\text { August } 30 \\
\text { June } 30 \\
\text { September } 30 \\
\text { June } 30 \\
\text { June } 30 \\
\text { December } 31 \\
\text { September } 30 \\
\text { June } 30 \\
\text { March } 31 \\
\text { June } 30 \\
\text { December } 31 \\
\text { December } 31 \\
\text { June } 30 \\
\text { September } 30 \\
\text { June } 30 \\
\text { June } 30 \\
\text { December } 31 \\
\text { December } 31 \\
\text { June } 30 \\
\text { December } 31 \\
\text { December } 31 \\
\text { June } 30 \\
\text { June } 30 \\
\text { December } 31 \\
\text { June } 30 \\
\text { September } 30 \\
\text { December } 31 \\
\text { December } 31 \\
\text { June } 30 \\
\text { December } 31 \\
\text { December } 31 \\
\text { December } 31 \\
\text { December } 31 \\
\text { June } 30 \\
\text { December } 31 \\
\text { June } 30 \\
\text { December } 31 \\
\text { September } 30 \\
\text { December } 31 \\
\text { June } 30 \\
\text { June } 30 \\
\text { J } 30\end{array}$ & $\begin{array}{l}\text { Nongenerator } \\
\text { Generator } \\
\text { Generator } \\
\text { Nongenerator } \\
\text { Generator } \\
\text { Generator } \\
\text { Generator } \\
\text { Nongenerator } \\
\text { Nongenerator } \\
\text { Nongenerator } \\
\text { Generator } \\
\text { Generator } \\
\text { Nongenerator } \\
\text { Nongenerator } \\
\text { Nongenerator } \\
\text { Generator } \\
\text { Nongenerator } \\
\text { Nongenerator } \\
\text { Generator } \\
\text { Generator } \\
\text { Nongenerator } \\
\text { Generator } \\
\text { Generator } \\
\text { Generator } \\
\text { Generator } \\
\text { Generator } \\
\text { Nongenerator } \\
\text { Nongenerator } \\
\text { Generator } \\
\text { Nongenerator } \\
\text { Nongenerator } \\
\text { Nongenerator } \\
\text { Generator } \\
\text { Nongenerator } \\
\text { Nongenerator } \\
\text { Generator } \\
\text { Nongenerator } \\
\text { Generator } \\
\text { Nongenerator } \\
\text { Generator } \\
\text { Nongenerator } \\
\text { Nongenerator } \\
\text { Generator } \\
\text { Nongenerator } \\
\text { Generator } \\
\text { Generator } \\
\text { Nongenerator } \\
\text { Generator } \\
\text { Generator } \\
\text { Generator } \\
\text { Generator }\end{array}$ \\
\hline
\end{tabular}

Source: Energy Information Administration, Form EIA-412, "Annual Report of Public Electric Utilities." 
Figure B1. Principal Business Office of the Major U.S. Publicly Owned Electric Utilities, 1993

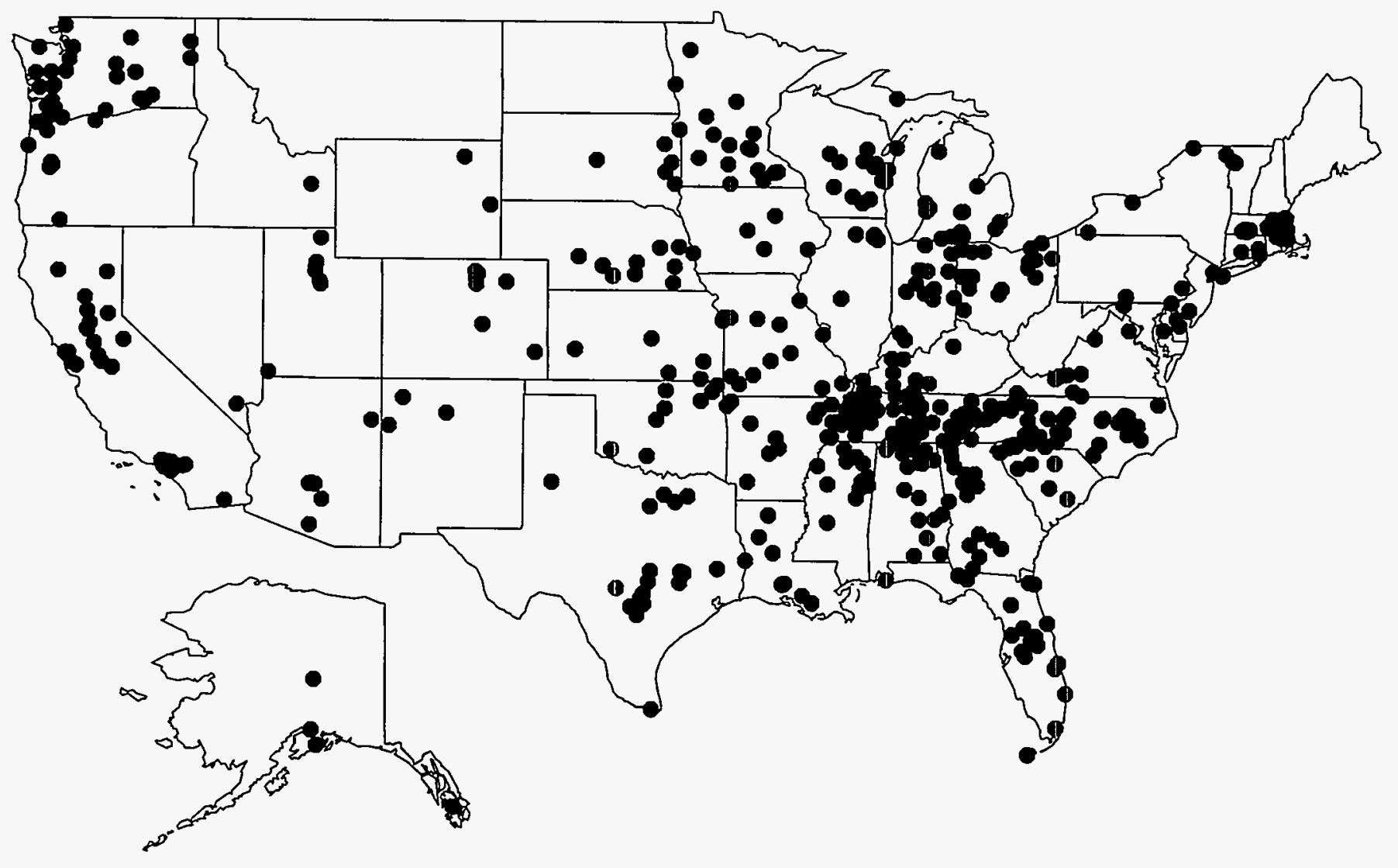

Source: Energy Information Administration, Form ElA-412, Annual Report of Public Electric Utilities. 


\title{
Appendix C
}

\author{
Major U.S. \\ Generator/ \\ Nongenerator \\ Respondents \\ by June 30 \\ and December \\ 31 Fiscal \\ Years and by \\ All \\ Respondents, \\ 1989-1993
}





\section{Major U.S. Generator/Nongenerator Respondents by June 30 and December 31 Fiscal Years and by All Respondents, 1989-1993}


Table C1. Ten Largest U.S. Publicly Owned Generator Electric Utilities Ranked by Megawatthour Sales to Uitimate Consumers with Financial Year Ending on June 30, 1993

\begin{tabular}{|c|c|c|c|}
\hline Publlcly Owned Electric Utillties & State & Amount & Percent \\
\hline Los Angeles City of & Califomia & $21,769,016$ & 46.23 \\
\hline 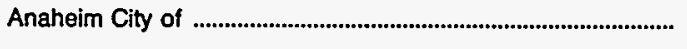 & California & $2,182,457$ & 4.63 \\
\hline Lansing City of & Michigan & $2,128,385$ & 4.52 \\
\hline Santa Clara City of & California & $2,119,657$ & 4.50 \\
\hline Fayetteville Public Works Comm & North Carolina & $1,632,657$ & 3.47 \\
\hline Riverside City of & California & $1,556,894$ & 3.31 \\
\hline Pasadena City of & California & $1,137,759$ & 2.42 \\
\hline 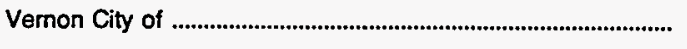 & California & $1,029,685$ & 2.19 \\
\hline Burbank City of & California & 990,443 & 2.10 \\
\hline Glendale City of & California & 978,635 & 2.08 \\
\hline Subtotal & & $35,525,588$ & 75.44 \\
\hline
\end{tabular}

Source: Energy Information Administration, Form EIA-412, "Annual Report of Public Electric Utilities."

Table C2. Ten Largest U.S. Publicly Owned Generator Electric Utilities Ranked by Megawatthour Sales for Resale with Financial Year Ending on June 30, 1993

\begin{tabular}{|c|c|c|c|}
\hline Publlcly Owned Electric Utilitles & State & Amount & Percent \\
\hline Intermountain Power Agency & Utah & $11,974,735$ & 28.56 \\
\hline 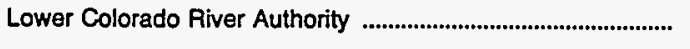 & Texas & $8,799,456$ & 20.99 \\
\hline Washington Pub Pwr Supply Sys & Washington & $6,188,829$ & 14.76 \\
\hline California Dept-Wtr Resources & California & $4,174,176$ & 9.96 \\
\hline 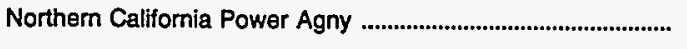 & California & $2,204,733$ & 5.26 \\
\hline Yuba County Water Agency & California & $1,586,836$ & 3.78 \\
\hline 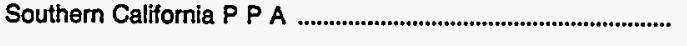 & California & $1,562,606$ & 3.73 \\
\hline 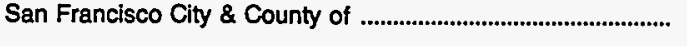 & California & $1,353,168$ & 3.23 \\
\hline 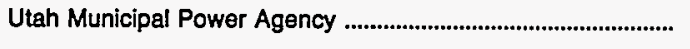 & Utah & 789,638 & 1.88 \\
\hline Los Angeles City of & California & 731,719 & 1.75 \\
\hline Subtotal & & $39,365,896$ & 93.89 \\
\hline
\end{tabular}

Source: Energy Information Administration, Form EIA-412, "Annual Report of Public Electric Utilities." 
Table C3. Composite Statement of Income for Major U.S. Publicly Owned

Generator Electric Utilities with Financial Year Ending on

June 30, 1989-1993

(Thousand Dollars)

\begin{tabular}{|c|c|c|c|c|c|}
\hline Item & 1993 & 1992 & 1991 & 1990 & 1989 \\
\hline Electric Utllity Operating Revenues .................... & $6,056,616$ & $5,873,621$ & $5,583,983$ & $5,522,510$ & $5,580,095$ \\
\hline 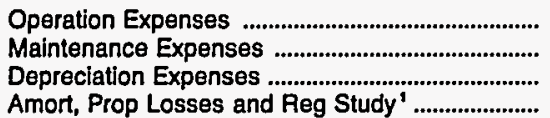 & $\begin{array}{r}3,607,659 \\
376,031 \\
665,941 \\
46,572\end{array}$ & $\begin{array}{r}3,525,928 \\
368,959 \\
627,770 \\
36,028\end{array}$ & $\begin{array}{r}3,389,558 \\
350,956 \\
623,168 \\
-\end{array}$ & $\begin{array}{r}3,243,473 \\
404,302 \\
562,284 \\
-\end{array}$ & $\begin{array}{r}3,167,210 \\
519,534 \\
641,313 \\
-\end{array}$ \\
\hline 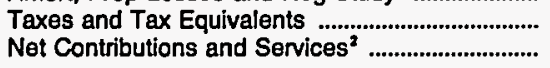 & $\begin{array}{r}126,376 \\
-\end{array}$ & $\begin{array}{r}109,783 \\
-\end{array}$ & $\begin{array}{r}107,916 \\
66,809\end{array}$ & $\begin{array}{r}101,236 \\
72,042\end{array}$ & $\begin{array}{l}91,193 \\
91,112\end{array}$ \\
\hline $\begin{array}{l}\text { Total Electrlc Utillty Operating } \\
\text { Expenses }\end{array}$ & $4,822,580$ & $4,668,469$ & $4,538,407$ & $4,383,337$ & $4,510,362$ \\
\hline $\begin{array}{l}\text { Net Electric Utility Operating Income } \\
\text { Income from Electric Plant Leased }\end{array}$ & $1,234,036$ & $1,205,152$ & $1,045,576$ & $1,139,173$ & $1,069,733$ \\
\hline to Others & 791 & 2,474 & 719 & 448 & 252 \\
\hline Electric Utllity Operating Income ........................ & $1,234,827$ & $1,207,627$ & $1,046,295$ & $1,139,621$ & $1,069,985$ \\
\hline Other Electric Income & 336,677 & 391,113 & 355,740 & 348,547 & 386,804 \\
\hline 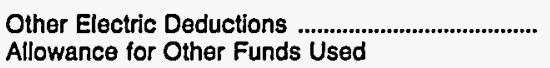 & 109,123 & 122,334 & 1,824 & - & - \\
\hline 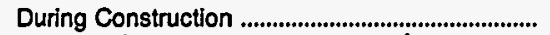 & - & - & 6,143 & 3,188 & 9,454 \\
\hline Taxes on Other Income and Deduct '........................ & 64 & 885 & - & - & - \\
\hline Electric Utllity Income & $1,462,317$ & $1,475,521$ & $1,406,354$ & $1,491,356$ & $1,466,243$ \\
\hline $\begin{array}{l}\text { Income Deductions from Interest } \\
\text { on Long-term Debt } \\
\text { Other.................................................. } \\
\text { Allowance for Boductions ...................................... }\end{array}$ & $\begin{array}{r}1,219,759 \\
-73,744\end{array}$ & $\begin{array}{r}1,298,247 \\
-12,878\end{array}$ & $\begin{array}{r}1,182,775 \\
-87,632\end{array}$ & $\begin{array}{r}1,172,787 \\
57,623\end{array}$ & $\begin{array}{r}1,131,305 \\
-2,108\end{array}$ \\
\hline 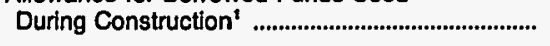 & $-15,152$ & $-10,592$ & - & - & - \\
\hline 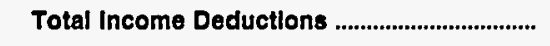 & $1,130,863$ & $1,274,778$ & $1,095,143$ & $1,230,409$ & $1,129,196$ \\
\hline Income Before Extraordinary Items ............................. & 331,453 & 200,744 & 311,212 & 260,947 & 337,046 \\
\hline Extraordinary Income & 7,174 & 6,593 & 5,763 & 82,133 & 3,388 \\
\hline 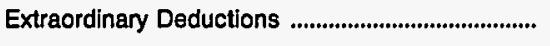 & 112,481 & 73,027 & 132,571 & 126,517 & 30,368 \\
\hline 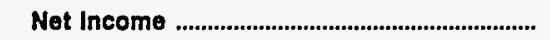 & 226,146 & 134,310 & 184,403 & 216,563 & 310,066 \\
\hline
\end{tabular}

Data reporting initiated in 1992.

2 Data reporting discontinued in 1992.

- Data not available.

Note: Totals may not equal sum of components because of independent rounding. The number of generating publicly owned electric utilities for end of period is 56 for June 30, 1993; 56 for June 30, 1992; 53 for June 30, 1991; 52 for June 30, 1990; and 50 for June 30, 1989. The City of Vineland (NJ) changed fiscal year from June 30 to December 31 in 1991; the California Department of Water Resources (CA) changed fiscal year from December 31 to June 30 in 1992; and the Wisconsin Power Inc Sys (WI) changed fiscal year from June 30 to December 31 in 1993. Emerald Peoples Utility District (OR), City of Bryan (OH), and Northern Wasco County PUD (OR) were nongenerators for 1989 through 1991, but became generators in 1992. The South Carolina Public Service Authority (SC) changed fiscal year from June 30 to December 31 in 1990. The Utah Associated Municipal Power System (UT) changed fiscal year from June 30 to March 31 in 1991. The City of Marshfield (WI) was a generator in 1989 and 1990, but became a nongenerator in 1991. The Wisconsin Public Power incorporated System (WI) was a nongenerator in 1989 and 1990, but became a generator in 1991.

Source: Energy Information Administration, Form ElA-412, "Annual Report of Public Electric Utilities." 
Table C4. Composite Balance Sheet for Major U.S. Publicly Owned Generator Electric Utilities with Financial Year Ending on June 30 at End of Period, 1989-1993

(Thousand Dollars)

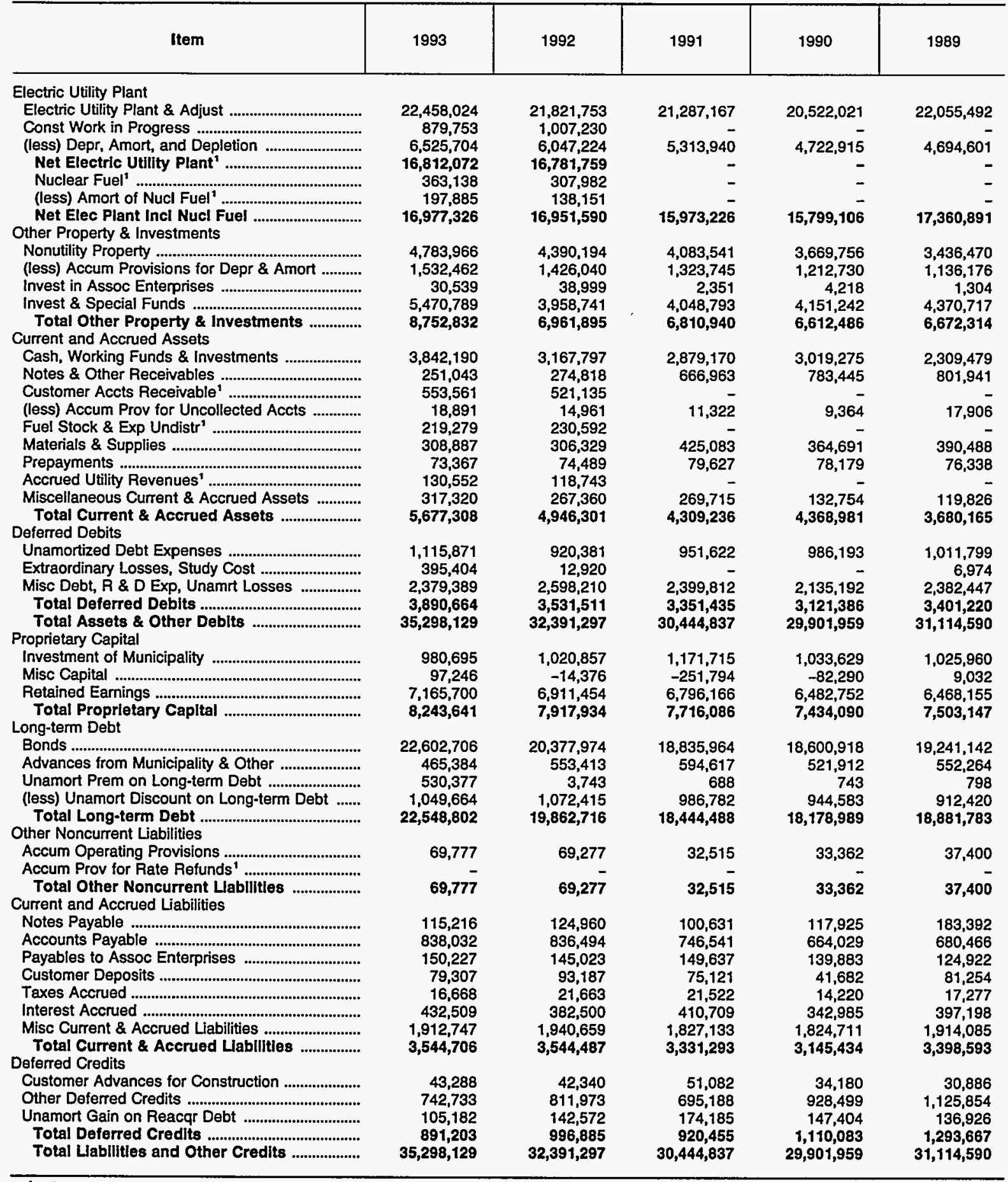

Data reporting initiated in 1992

Note: Totals may not equal sum of components because of independent rounding. The number of generating publicly owned electric utilities for end of period is 56 for June 1993; 56 for June 30, 1992; 53 for June 30, 1991; 52 for June 30, 1990; and 50 for June 30, 1989. The City of Vineland (NJ) changed fiscal year from June 30 to December 31 in 1991; the California Department of Water Resources (CA) changed fiscal year from December 31 to June 30 in 1992; and the Wisconsin Public Power Inc SYs (WI) changed fiscal year from December 31 to June 30 in 1993. Emerald Peoples Utility District (OR), City of Bryan (OH), and Northern Wasco County PUD (OR) were nongenerators for 1989 through 1991, but became generators in 1992. The South Carolina Public Service Authority (SC) changed fiscal year from June 30 to December 31 in 1990. The Utah Associated Municipal Power System (UT) changed fiscal year from June 30 to March 31 in 1991. The City of Marshfield (WI) was a generator in 1989 and 1990, but became a nongenerator in 1991. The Wisconsin Public Power incorporated System (WI) was a nongenerator in 1989 and 1990, but became a generator in 1991.

Source: Energy Information Administration, Form EIA-412, "Annual Report of Public Electric Utilities." 
Table C5. Composite Financial Indicators for Major U.S. Publicly Owned

Generator Electric Utilities with Financial Year Ending on

June 30, 1989-1993

\begin{tabular}{|c|c|c|c|c|c|}
\hline Item & 1993 & 1992 & 1991 & 1990 & 1989 \\
\hline Total Electric Utillity Plant per Dollar of Revenue & 3.9 & 3.9 & 3.8 & 3.7 & 4.0 \\
\hline Current Assets to Current Liabilities ........................... & 1.6 & 1.4 & 1.3 & 1.4 & 1.1 \\
\hline $\begin{array}{l}\text { Total Electric Utility Plant as a Percent of Total } \\
\text { Assets }\end{array}$ & 67.1 & 71.4 & 69.9 & 68.6 & 70.9 \\
\hline 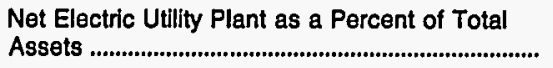 & 48.1 & 52.3 & 52.5 & 52.8 & 55.8 \\
\hline Debt as a Percent of Total Liabilities ...................... & 73.9 & 72.3 & 71.5 & 71.3 & 71.6 \\
\hline $\begin{array}{l}\text { Depreciation, Amortization and Depletion } \\
\text { as a Percent of Total Electric Utility Plant ........... }\end{array}$ & 28.4 & 26.7 & 25.0 & 23.0 & 21.3 \\
\hline $\begin{array}{l}\text { Electric Operation and Maintenance Expenses } \\
\text { as a Percent of } \\
\text { Electric Utillty Operating Revenues ......................... }\end{array}$ & 65.8 & 66.3 & 67.0 & 66.1 & 66.1 \\
\hline $\begin{array}{l}\text { Electric Depreciation and Amortization } \\
\text { as a Percent of } \\
\text { Electric Utility Operating Revenues ........................ }\end{array}$ & 11.0 & 10.7 & 11.2 & 10.2 & 11.5 \\
\hline $\begin{array}{l}\text { Taxes and Tax Equivalents } \\
\text { as a Percent of } \\
\text { Electric Utility Operating Revenues ........................ }\end{array}$ & 2.1 & 1.9 & 1.9 & 1.8 & 1.6 \\
\hline $\begin{array}{l}\text { Interest on Long-term Debt } \\
\text { as a Percent of } \\
\text { Electric Utility Operating Revenues ........................ }\end{array}$ & 20.1 & 22.1 & 21.2 & 21.2 & 20.3 \\
\hline 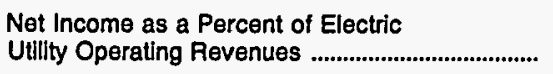 & 3.7 & 2.3 & 3.3 & 3.9 & 5.6 \\
\hline Purchased Power Cents Per Kilowatthour ........... & 4.3 & 4.3 & 4.5 & 4.7 & 5.9 \\
\hline Generated Cents Per Kilowatthour ........................ & 2.3 & 2.3 & 2.3 & 2.3 & 1.9 \\
\hline $\begin{array}{l}\text { Total Power Supply Per } \\
\text { Kilowatthour Sold .................................................... }\end{array}$ & 3.4 & 3.5 & 3.5 & 3.5 & 3.1 \\
\hline
\end{tabular}

Note: Totals may not equal sum of components because of independent rounding. The number of generating publicly owned electric utilitles for end of period is 56 for June 30, 1993; 56 for June 30, 1992; 53 for June 30, 1991; 52 for June 30, 1990; and 50 for June 30 , 1989. The City of Vineland (NJ) changed fiscal year from June 30 to December 31 in 1991; the California Department of Water Resources (CA) changed fiscal year from December 31 to June 30 in 1992; and the Wisconsin Public Power Inc Sys (WI) changed fiscal year from De. cember 31 to June 30 in 1993. Emerald Peoples Utility District (OR), City of Bryan (OH), and Northern Wasco County PUD (OR) were nongenerators for 1989 through 1991, but became generators in 1992. The South Carolina Public Service Authority (SC) changed fiscal year from June 30 to December 31 in 1990. The Utah Associated Municipal Power System (UT) changed fiscal year from June 30 to March 31 In 1991. The City of Marshfleid (WI) was a generator in 1989 and 1990, but became a nongenerator in 1991. The Wisconsin Public Power Incorporated System (WI) was a nongenerator in 1989 and 1990, but became a generator in 1991.

Source: Energy Information Administration, Form ElA-412, "Annual Report of Public Electric Utillties." 
Table C6. Electric Operation and Maintenance Expenses for Major U.S.

Publicly Owned Generator Electric Utilities with Financial

Year Ending on June 30, 1989-1993

(Thousand Dollars)

\begin{tabular}{|c|c|c|c|c|c|}
\hline Item & 1993 & 1992 & 1991 & 1990 & 1989 \\
\hline \multicolumn{6}{|l|}{ Production Expenses } \\
\hline 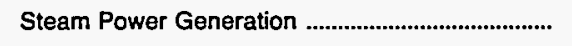 & $1,078,045$ & 952,188 & 920,777 & 991,183 & $1,179,944$ \\
\hline 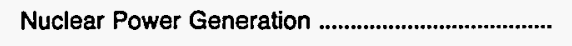 & 211,994 & 195,820 & 208,094 & 197,714 & 221,487 \\
\hline 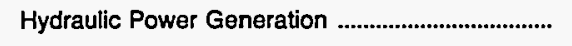 & 51,177 & 51,216 & 49,211 & 45,352 & 48,750 \\
\hline 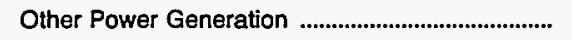 & 41,629 & 38,213 & 24,478 & 34,899 & 21,741 \\
\hline 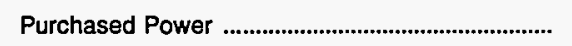 & $1,618,260$ & $1,696,102$ & $1,634,208$ & $1,542,275$ & $1,415,978$ \\
\hline 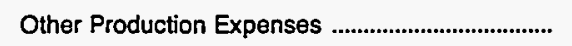 & 15,753 & 25,393 & 26,376 & 12,417 & 11,976 \\
\hline Total Production Expenses & $3,016,859$ & $2,958,932$ & $2,863,145$ & $2,823,839$ & $2,899,876$ \\
\hline 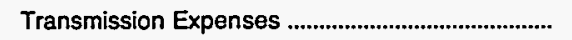 & 128,866 & 122,955 & 114,691 & 113,483 & 92,302 \\
\hline 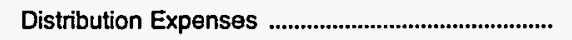 & 267,820 & 249,276 & 232,287 & 212,305 & 210,443 \\
\hline 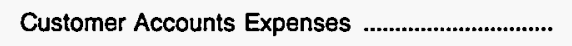 & 92,470 & 85,956 & 77,482 & 75,973 & 66,122 \\
\hline Customer Service and Information Expenses ..... & 29,378 & 23,888 & 19,756 & 14,472 & 15,878 \\
\hline Sales Expenses & 813 & 1,507 & 3,126 & 4,155 & 3,703 \\
\hline Administrative and General Expenses ....................... & 447,484 & 452,373 & 430,027 & 403,548 & 398,420 \\
\hline $\begin{array}{l}\text { Total Electric Operation } \\
\text { and Maintenance Expenses }\end{array}$ & $3,983,691$ & $3,894,887$ & $3,740,513$ & $3,647,775$ & $3,686,744$ \\
\hline \multicolumn{6}{|l|}{ Fuel Expenses in Operation } \\
\hline 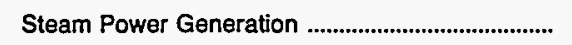 & 799,613 & 702,909 & 651,050 & 729,064 & 918,618 \\
\hline 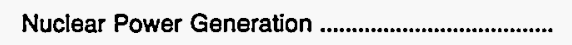 & 54,438 & 38,524 & 56,309 & 42,634 & 59,049 \\
\hline 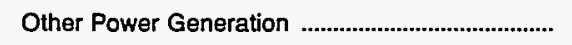 & 19,689 & 17,832 & 16,092 & 11,879 & 14,297 \\
\hline \multicolumn{6}{|l|}{ Number of Elec Dept Employees } \\
\hline Regular Full-time ${ }^{1}$ & 15,442 & 16,894 & - & - & - \\
\hline 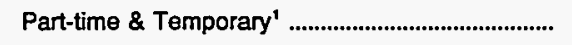 & 967 & 1,217 & - & - & - \\
\hline 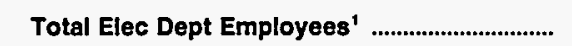 & 16,409 & 18,111 & - & - & - \\
\hline
\end{tabular}

1 Data reporting initiated in 1992.

Note: Totals may not equal sum of components because of independent rounding. The number of generating publicly owned electric utilities for end of period is 56 for June 30, 1993; 56 for June 30, 1992; 53 for June 30, 1991; 52 for June 30,$1990 ;$ and 50 for June 30 , 1989. The City of Vineland (NJ) changed fiscal year from June 30 to December 31 in 1991; the California Department of Water Resources (CA) changed fiscal year trom December 31 to June 30 in 1992; and the Wisconsin Public Power Inc Sys (WI) changed fiscal year from December 31 to June 30 in 1993. Emerald Peoples Utility District (OR), City of Bryan (OH), and Northern Wasco County PUD (OR) were nongenerators for 1989 through 1991, but became generators in 1992. The South Carolina Public Service Authority (SC) changed fiscal year from June 30 to December 31 in 1990 . The Utah Associated Municipal Power System (UT) changed fiscal year from June 30 to March 31 in 1991. The City of Marshfield (WI) was a generator in 1989 and 1990, but became a nongenerator in 1991. The Wisconsin Public Power incorporated System (WI) was a nongenerator in 1989 and 1990, but became a generator in 1991.

Source: Energy Information Administration, Form EIA-412, "Annual Report of Public Electric Utilities." 
Table C7. Electric Utility Plant for Major U.S. Publicly Owned Generator

Electric Utilities with Financial Year Ending

on June 30 at End of Period, 1989-1993

(Thousand Dollars)

\begin{tabular}{|c|c|c|c|c|c|}
\hline Item & 1993 & 1992 & 1991 & 1990 & 1989 \\
\hline \multicolumn{6}{|l|}{ Electric Plant In Service } \\
\hline 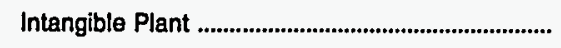 & 88,231 & 103,370 & 141,436 & 83,134 & 172,036 \\
\hline \multicolumn{6}{|l|}{ Production Plant } \\
\hline Steam & $6,381,047$ & $6,074,387$ & $5,849,534$ & $5,789,039$ & $6,485,865$ \\
\hline Nuclear & $4,580,460$ & $4,584,312$ & $4,859,875$ & $4,857,227$ & $5,274,101$ \\
\hline 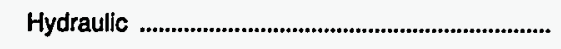 & $2,627,882$ & $2,618,895$ & $1,794,146$ & $1,793,520$ & $1,457,555$ \\
\hline Other & 435,135 & 590,691 & 248,642 & 217,512 & 236,807 \\
\hline Total Production Plant .............................................. & $14,024,524$ & $13,868,285$ & $12,752,197$ & $12,657,299$ & $13,454,328$ \\
\hline 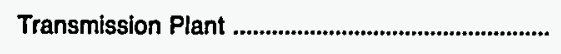 & $2,443,364$ & $2,372,536$ & $2,257,636$ & $2,211,441$ & $2,450,653$ \\
\hline 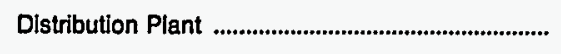 & $4,237,454$ & $4,056,844$ & $3,757,918$ & $3,443,680$ & $3,486,859$ \\
\hline 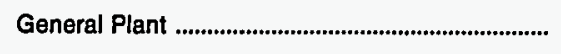 & $1,373,699$ & $1,189,667$ & $1,123,472$ & $1,037,843$ & $1,099,187$ \\
\hline Total Electric Plant in Service ............................ & $22,167,272$ & $21,590,702$ & $20,032,658$ & $19,433,397$ & $20,663,064$ \\
\hline 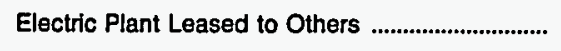 & 1 & 1 & 655 & 1,920 & 1 \\
\hline Construction Work in Progress - Electric ............... & 879,753 & $1,007,230$ & $1,002,642$ & 840,947 & $1,366,413$ \\
\hline 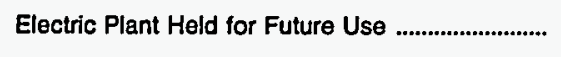 & 9,487 & 17 & 264,295 & 268,278 & 52,523 \\
\hline 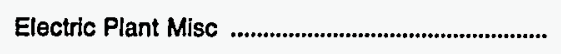 & 281,264 & 231,033 & $-13,083$ & $-22,522$ & $-26,509$ \\
\hline 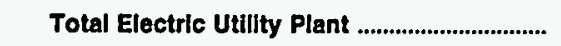 & $23,337,776$ & $22,828,983$ & $21,287,167$ & $20,522,021$ & $22,055,492$ \\
\hline 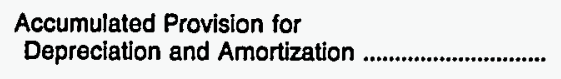 & $6,525,704$ & $6,047,224$ & $5,313,940$ & $4,722,915$ & $4,694,601$ \\
\hline 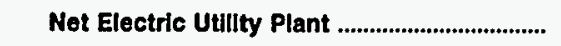 & $16,812,072$ & $16,781,759$ & $15,973,226$ & $15,799,106$ & $17,360,891$ \\
\hline
\end{tabular}

Note: Totals may not equal sum of components because of independent rounding. The number of generating publicly owned electric utilities for end of period is 56 for June 30, 1993; 56 for June 30, 1992; 53 for June 30, 1991; 52 for June 30 , 1990; and 50 for June 30 , 1989. The City of Vineland (NJ) changed fiscal year from June 30 to December 31 in 1991; the California Department of Water Resources (CA) changed fiscal year from December 31 to June 30 in 1992; and the Wisconsin Public Power inc Sys (WI) changed fiscal year from December 31 to June 30 in 1993. Emerald Peoples Utility District (OR), City of Bryan (OH), and Northem Wasco County PUD (OR) were nongenerators for 1989 through 1991, but became generators in 1992. The South Carolina Public Service Authority (SC) changed fiscal year from June 30 to December 31 in 1990. The Utah Associated Municipal Power System (UT) changed fiscal year from June 30 to March 31 in 1991. The City of Marshfield (WI) was a generator in 1989 and 1990, but became a nongenerator in 1991. The Wisconsin Public Power Incorporated System (WI) was a nongenerator in 1989 and 1990, but became a generator in 1991.

Source: Energy Information Administration, Form ElA-412, "Annual Report of Public Electric Utilities." 
Table C8. Number of Consumers, Sales, and Operating Revenue for Major U.S. Publicly Owned Generator Electric Utilities with Financial Year Ending on June 30, 1989-1993

\begin{tabular}{|c|c|c|c|c|c|}
\hline Item & 1993 & 1992 & 1991 & 1990 & 1989 \\
\hline \multicolumn{6}{|l|}{ Number of Consumers } \\
\hline 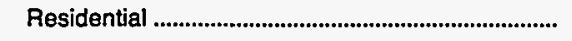 & $2,068,364$ & $2,051,709$ & $2,099,789$ & $2,004,831$ & $2,045,125$ \\
\hline Commercial or Small & 299,862 & 298,130 & 234,033 & 237,665 & 303,841 \\
\hline Industrial or Large & 23,482 & 23,782 & 20,265 & 23,732 & 24,026 \\
\hline Other & 16,039 & 19,858 & 20,055 & 24,462 & 19,326 \\
\hline 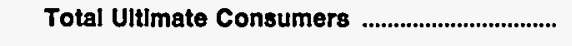 & $2,407,747$ & $2,393,479$ & $2,374,142$ & $2,290,690$ & $2,392,318$ \\
\hline \multicolumn{6}{|l|}{ Sales for the Year (megawatthours) } \\
\hline 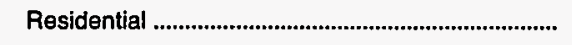 & $12,646,336$ & $12,802,964$ & $12,232,289$ & $12,283,575$ & $12,797,465$ \\
\hline Commercial or Small & $19,091,042$ & $18,772,290$ & $18,643,257$ & $19,535,853$ & $19,477,643$ \\
\hline Industrial or Large & $12,437,301$ & $12,741,755$ & $12,451,053$ & $11,657,126$ & $17,450,359$ \\
\hline Other & $2,180,702$ & $2,628,594$ & $2,299,173$ & $2,234,449$ & $2,220,118$ \\
\hline Total Sales to Ultimate Consumers ...................... & $46,355,381$ & $46,945,603$ & $45,625,772$ & $45,711,003$ & $51,945,585$ \\
\hline Sales for Resale & $44,312,299$ & $39,068,959$ & $33,831,354$ & $35,636,950$ & $40,700,200$ \\
\hline Total Sales & $90,667,680$ & $86,014,562$ & $79,457,126$ & $81,347,953$ & $92,645,785$ \\
\hline \multicolumn{6}{|l|}{$\begin{array}{l}\text { Operating Revenues for the Year } \\
\text { (thousand dollars) }\end{array}$} \\
\hline 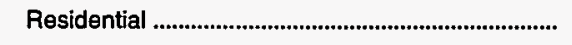 & $1,109,153$ & $1,073,325$ & $1,002,074$ & 998,394 & 993,414 \\
\hline Commercial or Small & $1,618,563$ & $1,535,038$ & $1,469,595$ & $1,576,384$ & $1,478,254$ \\
\hline Industrial or Large & 905,778 & 881,541 & 838,360 & 775,832 & 994,231 \\
\hline Other & 143,731 & 177,005 & 145,979 & 162,520 & 149,472 \\
\hline $\begin{array}{l}\text { Total Revenues from Sales to } \\
\text { UItImate Consumers }\end{array}$ & $3,777,225$ & $3,666,909$ & $3,456,008$ & $3,513,130$ & $3,615,371$ \\
\hline Sales for Resale & $2,131,533$ & $2,065,351$ & $1,858,972$ & $1,945,902$ & $1,982,161$ \\
\hline $\begin{array}{l}\text { Total Revenues From Sales of } \\
\text { Electriclty }\end{array}$ & $5,908,758$ & $5,732,260$ & $5,314,980$ & $5,459,032$ & $5,597,532$ \\
\hline
\end{tabular}

Note: Totals may not equal sum of components because of independent rounding. The number of generating publicly owned electric utilities for end of period is 56 for June 30, 1993; 56 for June 30, 1992; 53 for June 30, 1991; 52 for June 30, 1990; and 50 for June 30 , 1989. The City of Vineland (NJ) changed fiscal year from June 30 to December 31 in 1991; the California Department of Water Resources (CA) changed fiscal year from December 31 to June 30 in 1992; and the Wisconsin Public Power Inc Sys (WI) changed fiscal year from December 31 to June 30 in 1993. Emerald Peoples Utility District (OR), City of Bryan (OH), and Northern Wasco County PUD (OR) were nongenerators for 1989 through 1991, but became generators in 1992. The City of Foley (AL) and the South Carolina Public Service Authority (SC) changed fiscal year from June 30 to December 31 in 1990. The Utah Associated Municipal Power System (UT) changed fiscal year from June 30 to March 31 in 1991. The City of Marshfield (WI) was a generator in 1989 and 1990, but became a nongenerator in 1991. The Wisconsin Public Power Incorporated System (WI) was a nongenerator in 1989 and 1990, but became a generator in 1991. sions.

Source: Energy Information Administration, Form ElA-861, "Annual Electric Utility Report." Data are based on calendar year submis- 
Table C9. Electric Energy Account for Major U.S. Publicly Owned Generator Electric Utilities with Financial Year Ending on June 30, 1989-1993

(Megawatthours)

\begin{tabular}{|c|c|c|c|c|c|}
\hline Item & 1993 & 1992 & 1991 & 1990 & 1989 \\
\hline \multicolumn{6}{|l|}{ Sources of Energy } \\
\hline Steam & $39,909,551$ & $38,133,584$ & $35,805,972$ & $38,852,538$ & $56,925,918$ \\
\hline Nuclear & $10,074,201$ & $7,253,503$ & $9,571,421$ & $8,156,114$ & $10,739,246$ \\
\hline 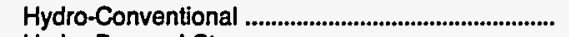 & $8,244,651$ & $7,347,109$ & $5,277,435$ & $6,663,865$ & $7,572,745$ \\
\hline Hydro-Pumped Storage & $2,247,668$ & $2,414,851$ & $1,247,928$ & $1,158,727$ & $1,010,187$ \\
\hline Other & 496,659 & 580,196 & 777,690 & 819,236 & 609,282 \\
\hline (Less) Energy for Pumping & 937,070 & $1,161,213$ & 720,925 & 494,296 & 608,410 \\
\hline 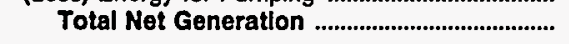 & $60,035,659$ & $54,568,030$ & $51,959,522$ & $55,156,184$ & $76,248,968$ \\
\hline 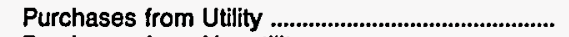 & $35,417,196$ & $37,654,330$ & $36,465,229$ & $33,376,728$ & $23,484,457$ \\
\hline $\begin{array}{l}\text { Purchases from Nonutility } \\
\text { Power Exchanges }\end{array}$ & 630,280 & 153,015 & 60,371 & 54,689 & 4,188 \\
\hline 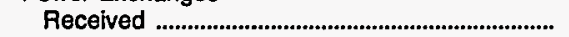 & $5,475,410$ & $5,699,468$ & $1,748,125$ & $18,533,919$ & $2,518,889$ \\
\hline 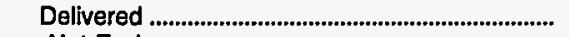 & $3,780,680$ & $3,637,592$ & $1,807,581$ & $18,905,883$ & $2,103,502$ \\
\hline Net Exchanges & $1,694,730$ & $2,061,876$ & $-59,456$ & $-371,964$ & 415,387 \\
\hline \multicolumn{6}{|l|}{ Transmission for Others (Wheeling) } \\
\hline 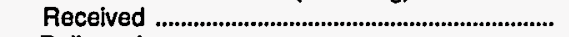 & $16,078,009$ & $14,009,909$ & $17,569,869$ & $16,146,595$ & $22,123,228$ \\
\hline Delivered & $16,021,994$ & $13,959,201$ & $17,509,416$ & $16,005,354$ & $21,842,800$ \\
\hline 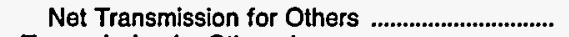 & 56,015 & 50.708 & 60,453 & 141,241 & 280,428 \\
\hline Transmission by Others Losses ............................... & $-174,994$ & $-141,770$ & $-130,869$ & $-49,401$ & - \\
\hline \multicolumn{6}{|l|}{ Total Net Energy Generated and } \\
\hline 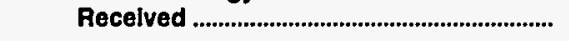 & $97,658,887$ & $94,346,189$ & $88,355,250$ & $88,307,477$ & $100,433,427$ \\
\hline \multicolumn{6}{|l|}{ Disposition of Energy } \\
\hline 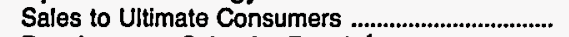 & $47,089,512$ & $46,312,232$ & $45,847,782$ & $45,230,998$ & $51,859,155$ \\
\hline 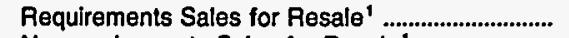 & $40,980,045$ & $36,745,586$ & $34,776,080$ & $34,269,664$ & $40,284,496$ \\
\hline Nonrequirements Sales for Resale ${ }^{1}$...................... & 947,898 & 453,567 & 759,838 & $1,695,756$ & - \\
\hline Furnished Without Charge & 235,866 & 200,424 & 180,152 & 65,996 & 170,627 \\
\hline Used by Utility (excluding station use) ................... & $4,631,889$ & $6,179,980$ & $2,590,094$ & $2,555,266$ & $3,104,156$ \\
\hline 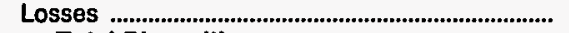 & $3,773,677$ & $4,454,398$ & $4,201,299$ & $4,489,797$ & $5,014,997$ \\
\hline Total Disposition & $97,658,887$ & $94,346,189$ & $88,355,250$ & $88,307,477$ & $100,433,427$ \\
\hline
\end{tabular}

1 The 1989 data were reported as Sales for Resale (one entry) which is shown as Requirements Sales for Resale.

Note: Totals may not equal sum of components because of independent rounding. The number of generating publicly owned electric utilities for end of period is 56 for June 30, 1993; 56 for June 30, 1992; 53 for June 30, 1991; 52 for June 30, $1990 ;$ and 50 for June 30 , 1989. The City of Vineland (NJ) changed fiscal year from June 30 to December 31 in 1991; the California Department of Water Resources (CA) changed fiscal year from December 31 to June 30 in 1992; and the Wisconsin Public Power Inc Sys (WI) changed fiscal year from De. cember 31 to June 30 in 1993. Emerald Peoples Utility District (OR), City of Bryan (OH), and Northern Wasco County PUD (OR) were nongenerators for 1989 through 1991, but became generators in 1992. The South Carolina Public Service Authority (SC) changed fiscal year from June 30 to December 31 in 1990. The Utah Associated Municipal Power System (UT) changed fiscal year from June 30 to March 31 in 1991. The City of Marshfield (WI) was a generator in 1989 and 1990, but became a nongenerator in 1991 . The Wisconsin Public Power Incorporated System (WI) was a nongenerator in 1989 and 1990, but became a generator in 1991.

Source: Energy Information Administration, Form ElA-412, "Annual Report of Public Electric Utilities." 
Table C10. Ten Largest U.S. Publicly Owned Generator Electric Utllitles Ranked by Megawatthour Sales to Ultimate Consumers with Financial Year Ending on December 31, 1993

\begin{tabular}{|c|c|c|c|}
\hline Publicly Owned Electric Utilities & State & Amount & Percent \\
\hline Power Authority of State of NY & New York & $13,385,987$ & 12.24 \\
\hline 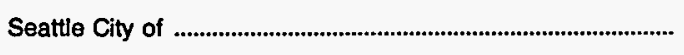 & Washington & $8,914,889$ & 8.15 \\
\hline 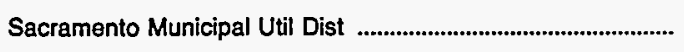 & California & $8,446,459$ & 7.72 \\
\hline 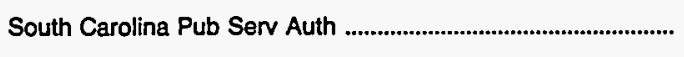 & South Carolina & $7,370,739$ & 6.74 \\
\hline 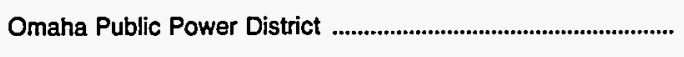 & Nebraska & $6,725,968$ & 6.15 \\
\hline 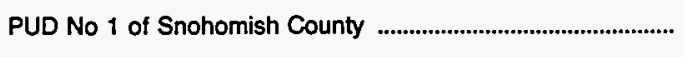 & Washington & $5,838,889$ & 5.34 \\
\hline Tacoma City of & Washington & $5,545,514$ & 5.07 \\
\hline PUD No 1 of Cowlitz County & Washington & $4,562,301$ & 4.17 \\
\hline Colorado Springs City of & Colorado & $3,031,382$ & 2.77 \\
\hline 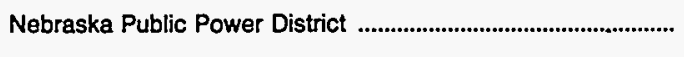 & Nebraska & $2,713,221$ & 2.48 \\
\hline Subtotal & & $66,535,349$ & 60.84 \\
\hline
\end{tabular}

Source: Energy Information Administration, Form ElA-412, "Annual Report of Public Electric Utilities."

Table C11. Ten Largest U.S. Publicly Owned Generator Electric Utilities Ranked by Megawatthour Sales for Resale with Financial Year Ending on December 31, 1993

\begin{tabular}{|c|c|c|c|}
\hline Publicly Owned Electric Utilltes & State & Amount & Percent \\
\hline Power Authority of State of NY & New York & $25,134,370$ & 19.53 \\
\hline 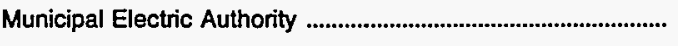 & Georgia & $10,265,581$ & 7.98 \\
\hline 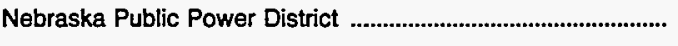 & Nebraska & $10,122,311$ & 7.86 \\
\hline 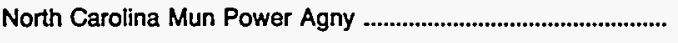 & North Carolina & $8,422,060$ & 6.54 \\
\hline South Carolina Pub Serv Auth & South Carolina & $7,059,116$ & 5.48 \\
\hline 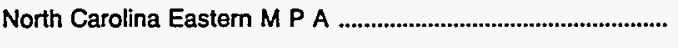 & North Carolina & $6,522,213$ & 5.07 \\
\hline PUD No 1 of Chelan County & Washington & $6,482,408$ & 5.04 \\
\hline 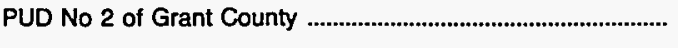 & Washington & $5,387,716$ & 4.19 \\
\hline 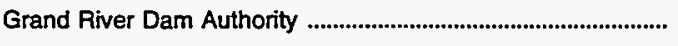 & Oklahoma & $4,848,136$ & 3.77 \\
\hline 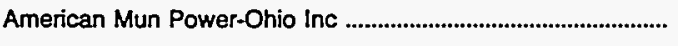 & Ohio & $4,094,070$ & 3.18 \\
\hline Subtotal & & $88,337,981$ & 68.63 \\
\hline
\end{tabular}

Source: Energy Information Administration, Form EIA-412, "Annual Report of Public Electric Utilities." 
Table C12. Composite Statement of Income for Major U.S. Publicly Owned Generator Electric Utilities with Financial Year Ending on December 31, 1989-1993 (Thousand Dollars)

\begin{tabular}{|c|c|c|c|c|c|}
\hline Item & 1993 & 1992 & 1991 & 1990 & 1989 \\
\hline Electric UtIlity Operating Revenues ................... & $10,265,144$ & $9,978,727$ & $9,945,735$ & $9,563,698$ & $8,488,030$ \\
\hline 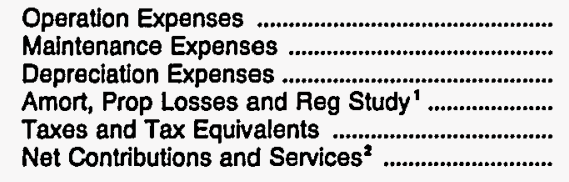 & $\begin{array}{r}6,271,036 \\
726,808 \\
1,082,958 \\
99,467 \\
261,135 \\
-\end{array}$ & $\begin{array}{r}5,929,885 \\
785,806 \\
1,042,213 \\
93,501 \\
236,234 \\
-\end{array}$ & $\begin{array}{r}5,834,899 \\
691,105 \\
1,096,953 \\
- \\
237,006 \\
32,237\end{array}$ & $\begin{array}{r}5,860,117 \\
650,551 \\
964,558 \\
- \\
230,400 \\
34,621\end{array}$ & $\begin{array}{r}5,287,937 \\
610,525 \\
892,359 \\
212,213 \\
25,754\end{array}$ \\
\hline Total Electric Utility Operating & $8,441,404$ & $8,087,639$ & $7,892,200$ & $7,740,246$ & $7,028,789$ \\
\hline $\begin{array}{l}\text { Net Electric Utility Operating Income } \\
\text { Income from Electric Plant Leased }\end{array}$ & $1,823,740$ & $1,891,088$ & $2,053,535$ & $1,823,451$ & $1,459,241$ \\
\hline 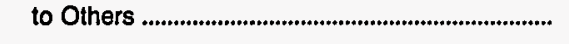 & 10,131 & 1,865 & 2,272 & 1,605 & 1,893 \\
\hline Electrlc Utility Operating Income ................... & $1,833,871$ & $1,892,953$ & $2,055,807$ & $1,825,057$ & $1,461,134$ \\
\hline 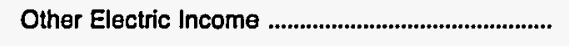 & 720,647 & $1,021,872$ & 947,124 & 929,862 & $1,017,293$ \\
\hline $\begin{array}{l}\text { Other Electric Deductions ................................... } \\
\text { Allowance for Other Funds Used }\end{array}$ & 34,484 & 31,702 & 24,235 & - & - \\
\hline $\begin{array}{l}\text { During Construction } \\
\text { Taxes on Other Income and Deduct ' }\end{array}$ & $\begin{array}{l}5,721 \\
2,952\end{array}$ & $\begin{array}{l}6,151 \\
2,755\end{array}$ & $\begin{array}{r}15,842 \\
-\end{array}$ & $\begin{array}{r}54,305 \\
-\end{array}$ & $\begin{array}{r}133,125 \\
-\end{array}$ \\
\hline Electric UtIIty Income & $2,522,803$ & $2,886,519$ & $2,994,538$ & $2,809,223$ & $2,611,552$ \\
\hline 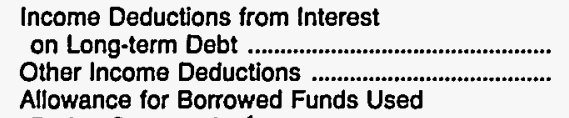 & $\begin{array}{r}2,088,036 \\
173,302\end{array}$ & $\begin{array}{r}2,258,140 \\
136,087\end{array}$ & $\begin{array}{r}2,405,347 \\
119,052\end{array}$ & $\begin{array}{r}2,299,233 \\
184,417\end{array}$ & $\begin{array}{r}2,183,136 \\
202,297\end{array}$ \\
\hline During Construction' & $-10,057$ & $-10,843$ & - & - & - \\
\hline Total Income Deductions ................................. & $2,251,282$ & $2,383,383$ & $2,524,399$ & $2,483,649$ & $2,385,434$ \\
\hline Income Before Extraordinary Items ........................ & 271,521 & 503,136 & 470,139 & 325,574 & 226,119 \\
\hline 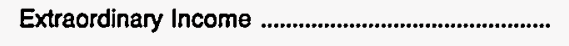 & 54,810 & 72,686 & 84,099 & 31,676 & 21,748 \\
\hline Extraordinary Deductions .......................................... & 137,312 & 126,373 & 26,113 & 106,814 & 644,093 \\
\hline 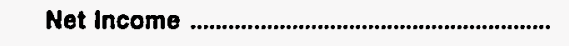 & 189,020 & 449,449 & 528,125 & 250,436 & $3-396,227$ \\
\hline $\begin{array}{l}\text { Data reporting initiated in } 1992 \text {. } \\
\text { Data reporting discontinued in } 1992 \text {. } \\
\text { Net income reflects } \$ 584 \text { million of extraordi } \\
\text { ported by the Sacramento Municipal Utility District. } \\
\text { - Data not available. } \\
\text { Note: Totals may not equal sum of componer } \\
\text { utilities for end of period is } 113 \text { for December } 31 \text {, } \\
1990 ; \text { and } 108 \text { for December } 31,1989 \text {. The City o } \\
\text { Department of Water Resources (CA) changed fisc } \\
\text { WI) changed fiscal year from December } 31 \text { to Ju } \\
\text { Wasco County PUD (OR) were nongenerators for } \\
\text { Authority (SC) changed fiscal year from June } 30 \text { to } \\
\text { cal year from June } 30 \text { to March } 31 \text { in 1991. The } \\
1991 \text {. The Wisconsin Public Power Incorporated Sy } \\
\text { Source: Energy Information Administration, Fo }\end{array}$ & $\begin{array}{l}\text { deduction a } \\
\text { because of in } \\
33 \text {; } 111 \text { for } \\
\text { רeland (NJ) } \\
\text { ear from Ded } \\
30 \text { in } 1993 \text {. } \\
9 \text { through } 19 \\
\text { cember } 31 \text { in } \\
\text { of Marshfield } \\
m \text { (WI) was a } \\
=1 A-41 ?\end{array}$ & $\begin{array}{l}\text { Ited with the } \\
\text { ndent roundif } \\
\text { ber } 31,1992 \\
\text { d fiscal year } \\
31 \text { to June } \\
\text { ald Peoples } \\
\text { it became g } \\
\text { The Utah } \\
\text { was a gener } \\
\text { enerator in } 1\end{array}$ & $\begin{array}{l}\text { Indonment of } \\
\text { The number } \\
0 \text { for Decemb } \\
n \text { June } 30 \text { to } \\
\text { in 1992; and } \\
\text { y District (OR } \\
\text { ators in } 1992 \text {. } \\
\text { ciated Munici } \\
\text { in } 1989 \text { and } 1 \\
\text { and } 1990 \text {, but }\end{array}$ & $\begin{array}{l}\text { ancho Seco } \\
\text { erating public } \\
1991 ; 110 \\
\text { iber } 31 \text { in } 19 \\
\text { isconsin Pub } \\
\text { of Bryan (O } \\
\text { South Caroli } \\
\text { wer System } \\
\text { ut became } \\
\text { ne a generat }\end{array}$ & $\begin{array}{l}\text { gar Plant re- } \\
\text { uned electric } \\
\text { ecember } 31 \text {, } \\
\text { he California } \\
\text { wer Inc Sys } \\
\text { ind Northern } \\
\text { ublic Service } \\
\text { changed fis- } \\
\text { generator in } \\
\text { 1991. }\end{array}$ \\
\hline
\end{tabular}


Table C13. Composite Balance Sheet for Major U.S. Publicly Owned Generator Electric Utilities with Financial Year Ending on December 31 at End of Period, 1989-1993

(Thousand Dollars)

\begin{tabular}{|c|c|c|c|c|c|}
\hline Item & 1993 & 1992 & 1991 & 1990 & 1989 \\
\hline \multicolumn{6}{|l|}{ Electric Utility Plant } \\
\hline 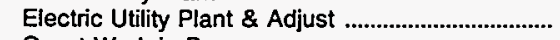 & $36,270,042$ & $35,222,457$ & $37,479,683$ & $35,754,753$ & $32,508,145$ \\
\hline 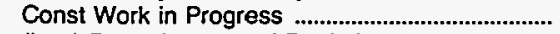 & $1,950,440$ & $1,523,008$ & - & & - \\
\hline (less) Depr, Amort, and Depletion .............................. & $11,345,511$ & $10,493,142$ & $10,075,535$ & $9,044,556$ & $7,623,800$ \\
\hline Net Electric Utllity Plant' & $26,874,970$ & $26,252,323$ & - & - & - \\
\hline 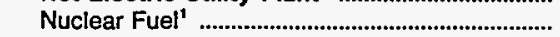 & $1,705,807$ & $1,653,317$ & - & - & - \\
\hline 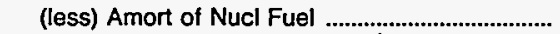 & $1,150,437$ & $1,042,691$ & - & - & - \\
\hline Net Elec Plant Incl Nucl Fuel ${ }^{1}$ & $27,430,340$ & $26,862,950$ & $27,404,148$ & $26,710,198$ & $24,884,345$ \\
\hline \multicolumn{6}{|l|}{ Other Property \& Investments } \\
\hline 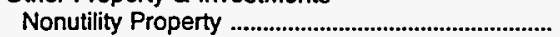 & 430,836 & 370,608 & 403,811 & 371,810 & 431,129 \\
\hline (less) Accum Provisions for Depr \& Amort ........... & 182,708 & 172,216 & 163,570 & 160,561 & 179,516 \\
\hline Invest in Assoc Enterprises & 295,967 & 188,979 & 60,343 & 58,539 & 58,537 \\
\hline Invest \& Special Funds ................................................ & $7,101,773$ & $6,994,760$ & $6,462,983$ & $5,413,412$ & $5,158,118$ \\
\hline Total Other Property \& Investments & $7,645,868$ & $7,399,131$ & $6,763,567$ & $5,683,199$ & $5,468,268$ \\
\hline \multicolumn{6}{|l|}{ Current and Accrued Assets } \\
\hline Cash, Working Funds \& Investments .......................... & $4,303,347$ & $4,546,678$ & $5,266,571$ & $5,294,535$ & $5,264,132$ \\
\hline 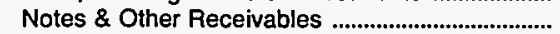 & 375,331 & 281,987 & 963,205 & 966,485 & 949,036 \\
\hline 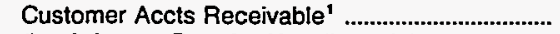 & 872,478 & 770,319 & - & - & - \\
\hline (less) Accum Prov for Uncollected Accts ............ & 20,667 & 20,575 & 19,880 & 19,066 & 16.539 \\
\hline 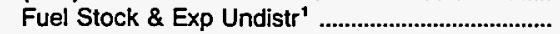 & 122,831 & 183,952 & - & - & \\
\hline Materials \& Supplies & 457,540 & 436,404 & 700,104 & 623,849 & 534,578 \\
\hline 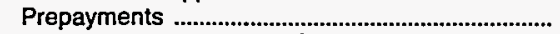 & 151,661 & 148,608 & 148,138 & 74,488 & 77,638 \\
\hline 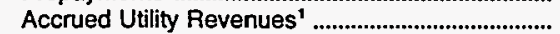 & 97,627 & 88,636 & - & - & - \\
\hline Miscellaneous Current \& Accrued Assets .............. & 614,489 & 640,721 & 250,407 & 240,850 & 254,643 \\
\hline Total Current \& Accrued Assets ..................... & $6,974,638$ & $7,076,731$ & $7,308,543$ & $7,181,141$ & $7,063,488$ \\
\hline \multicolumn{6}{|l|}{ Deferred Debits } \\
\hline 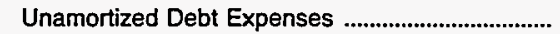 & $1,083,853$ & 942,727 & 736,895 & 643,102 & 650,285 \\
\hline Extraordinary Losses, Study Cost ............................. & 443,321 & 384,193 & 34,360 & 29,846 & 26,172 \\
\hline Misc Debt, R \& D Exp, Unamrt Losses ................... & $6,112,902$ & $5,228,559$ & $5,075,383$ & $4,542,172$ & $3,415,442$ \\
\hline 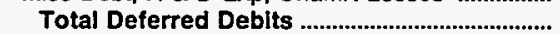 & $7,640,077$ & $6,555,478$ & $5,846,637$ & $5,215,120$ & $4,091,899$ \\
\hline Total Assets \& Other Debits ..................................... & $49,690,923$ & $47,894,290$ & $47,322,895$ & $44,789,657$ & $41,508,000$ \\
\hline \multicolumn{6}{|l|}{ Proprietary Capital } \\
\hline Investment of Municipality & 382,728 & 394,516 & 308,846 & 256,885 & 343,767 \\
\hline 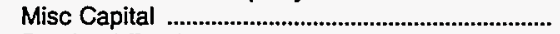 & 54,912 & 50,262 & 66,098 & 68,299 & 62,308 \\
\hline 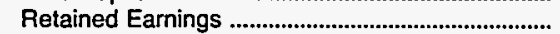 & $7,607,441$ & $7,443,810$ & $7,426,859$ & $7,288,802$ & $6,390,869$ \\
\hline Total Proprietary Capital & $8,045,082$ & $7,888,588$ & $7,801,802$ & $7,613,986$ & $6,796,944$ \\
\hline \multicolumn{6}{|l|}{ Long-term Debt } \\
\hline 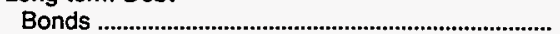 & $34,703,101$ & $34,287,344$ & $33,165,999$ & $30,950,035$ & $29,105,207$ \\
\hline Advances from Municipality \& Other ........................... & $1,762,850$ & $1,223,179$ & $1,883,188$ & $2,316,299$ & $2,202,953$ \\
\hline Unamort Prem on Long-term Debt ......................... & 68,644 & 35,176 & 8,141 & 855 & 487 \\
\hline (less) Unamort Discount on Long-term Debt ....... & 916,321 & $1,012,260$ & 984,342 & 917,760 & 879,102 \\
\hline Total Long-term Debt ............................................. & $35,618,275$ & $34,533,438$ & $34,072,986$ & $32,349,429$ & $30,429,545$ \\
\hline \multicolumn{6}{|l|}{ Other Noncurrent Liabilities } \\
\hline Accum Operating Provisions ....... & 109,206 & 409,800 & 414,731 & 254,309 & 298,729 \\
\hline 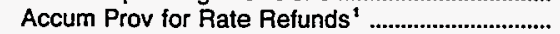 & 109,290 & 4,277 & - & - & \\
\hline Total Other Noncurrent Llabillties .................... & 218,495 & 414,077 & 414,731 & 254,309 & 298,729 \\
\hline \multicolumn{6}{|l|}{ Current and Accrued Liabilities } \\
\hline 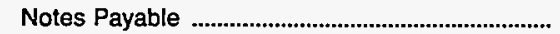 & $1,089,125$ & 861,989 & 761,201 & 709,310 & 452,701 \\
\hline Accounts Payable ....................................................... & 733,766 & 690,877 & 646,324 & 778,237 & 726,594 \\
\hline Payables to Assoc Enterprises ............................... & 55,730 & 38,023 & 46,715 & 35,375 & 37,210 \\
\hline 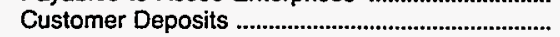 & 44,848 & 44,205 & 46,508 & 45,534 & 38,290 \\
\hline 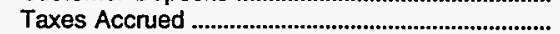 & 108,973 & 89,751 & 90,009 & 88,738 & 75,552 \\
\hline 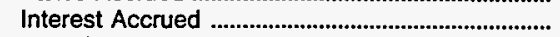 & 700,474 & 716,138 & 755,391 & 740,148 & 675,577 \\
\hline Misc Current \& Accrued Liabilities ................................ & 826.121 & 550,077 & 506,597 & 357,230 & 321,843 \\
\hline 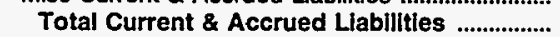 & $3,559,037$ & $2,991,060$ & $2,852,744$ & $2,754,571$ & $2,327,767$ \\
\hline \multicolumn{6}{|l|}{ Deferred Credits } \\
\hline Customer Advances for Construction ........................ & 37,909 & 37,120 & 27,116 & 30,138 & 28,297 \\
\hline Other Deferred Credits ............................................... & $2,021,905$ & $1,813,190$ & $1,914,443$ & $1,680,486$ & $1,513,951$ \\
\hline Unamort Gain on Reacqr Debt ................................. & 190,221 & 216,817 & 239,073 & 106,738 & 112,767 \\
\hline Total Deferred Credits .............................................. & $2,250,035$ & $2,067,127$ & $2,180,632$ & $1,817,362$ & $1,655,015$ \\
\hline Total Llablilities and Other Credits ....................... & $49,690,923$ & $47,894,290$ & $47,322,895$ & $44,789,657$ & $41,508,000$ \\
\hline
\end{tabular}

Data reporting initiated in 1992.

Note: Totals may not equal sum of components because of independent rounding. The number of generating publicly owned electric utilities for end of period is 113 for December 31, 1993; 111 for December 31, 1992; 110 for December 31, 1991; 110 for December 31, 1990; and 108 for December 31, 1989. The City of Vineland (NJ) changed fiscal year from June 30 to December $3 i$ in 1991; the California Department of Water Resources (CA) changed fiscal year from December 31 to June 30 in 1992; and the Wisconsin Public Power Inc Sys (WI) changed fiscal year from December 31 to June 30 in 1993. Emerald Peoples Utility District (OR), City of Bryan (OH), and Northern Wasco County PUD (OR) were nongenerators for 1989 through 1991, but became generators in 1992. The South Carolina Public Service Authority (SC) changed fiscal year from June 30 to December 31 in 1990. The Utah Associated Municipal Power System (UT) changed fiscal year from June 30 to March 31 in 1991. The City of Marshfield (WI) was a generator in 1989 and 1990, but became a nongenerator in 1991. The Wisconsin Public Power Incorporated System (WI) was a nongenerator in 1989 and 1990, but became a generator in 1991.

Source: Energy Information Administration, Form ElA-412, "Annual Report of Public Electric Utilities." 
Table C14. Composite Financial Indicators for Major U.S. Publicly Owned Generator Electric Utilities with Financial Year Ending on

December 31, 1989-1993

\begin{tabular}{|c|c|c|c|c|c|}
\hline Item & 1993 & 1992 & 1991 & 1990 & 1989 \\
\hline Total Electric Utility Plant per Dollar of Revenue & 3.9 & 3.8 & 3.8 & 3.7 & 3.8 \\
\hline 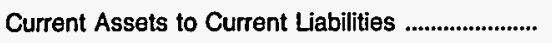 & 2.0 & 2.4 & 2.6 & 2.6 & 3.0 \\
\hline $\begin{array}{l}\text { Total Electric Utility Plant as a Percent of Total } \\
\text { Assets }\end{array}$ & 80.3 & 80.2 & 79.2 & 79.8 & 78.3 \\
\hline $\begin{array}{l}\text { Net Electric Utility Plant as a Percent of Total } \\
\text { Assets }\end{array}$ & 55.2 & 56.1 & 57.9 & 59.6 & 60.0 \\
\hline Debt as a Percent of Total Liabilities ....................... & 78.8 & 78.3 & 78.0 & 78.4 & 78.9 \\
\hline $\begin{array}{l}\text { Depreciation, Amortization and Depletion } \\
\text { as a Percent of Total Electric Utility Plant ........... }\end{array}$ & 31.3 & 30.0 & 26.9 & 25.3 & 23.5 \\
\hline $\begin{array}{l}\text { Electric Operation and Maintenance Expenses } \\
\text { as a Percent of } \\
\text { Electric Utility Operating Revenues ......................... }\end{array}$ & 68.2 & 67.3 & 65.6 & 68.1 & 69.5 \\
\hline $\begin{array}{l}\text { Electric Depreciation and Amortization } \\
\text { as a Percent of } \\
\text { Electric Utility Operating Revenues ....................... }\end{array}$ & 10.5 & 10.4 & 11.0 & 10.1 & 10.5 \\
\hline $\begin{array}{l}\text { Taxes and Tax Equivalents } \\
\text { as a Percent of } \\
\text { Electric Utility Operating Revenues ........................ }\end{array}$ & 2.5 & 2.4 & 2.4 & 2.4 & 2.5 \\
\hline $\begin{array}{l}\text { Interest on Long-term Debt } \\
\text { as a Percent of } \\
\text { Electric Utility Operating Revenues ........................ }\end{array}$ & 20.3 & 22.6 & 24.2 & 24.0 & 25.7 \\
\hline $\begin{array}{l}\text { Net Income as a Percent of Electric } \\
\text { Electric Operating Revenues }\end{array}$ & 1.8 & 4.5 & 5.3 & 2.6 & -4.7 \\
\hline Purchased Power Cents Per Kilowatthour ............ & 3.2 & 3.4 & 3.4 & 3.6 & 3.5 \\
\hline 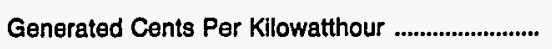 & 1.5 & 1.6 & 1.4 & 1.3 & 1.3 \\
\hline 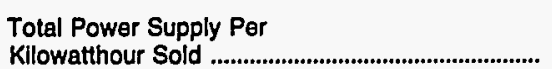 & 2.2 & 2.3 & 2.1 & 2.2 & 2.1 \\
\hline
\end{tabular}

Note: Totals may not equal sum of components because of independent rounding. The number of generating publicly owned electric utilities for end of period is 113 for December 31, 1993; 111 for December 31, 1992; 110 for December 31, 1991 ; 110 for December 31, 1990; and 108 for December 31, 1989 . The City of Vineland (NJ) changed fiscal year from June 30 to December 31 in 1991; the California Department of Water Resources (CA) changed fiscal year from December 31 to June 30 in 1992; and the Wisconsin Public Power Inc Sys (Wi) changed fiscal year from December 31 to June 30 in 1993. Emerald Peoples Utility District (OR), City of Bryan (OH), and Northern Wasco County PUD (OR) were nongenerators for 1989 through 1991, but became generators in 1992. The South Carolina Public Service Authority (SC) changed fiscal year from June 30 to December 31 in 1990. The Utah Associated Municipal Power System (UT) changed fiscal year from June 30 to March 31 in 1891. The City of Marshfield (WI) was a generator in 1989 and 1990, but became a nongenerator in 1891. The Wisconsin Public Power Incorporated System (Wi) was a nongenerator in 1989 and 1990, but became a generator in 1991.

Source: Energy Information Administration, Form EIA-412, "Annual Report of Public Electric Utilities." 
Table C15. Electric Operation and Maintenance Expenses for Major U.S.

Publicly Owned Generator Electric Utilities with Financial

Year Ending on December 31, 1989-1993

(Thousand Dollars)

\begin{tabular}{|c|c|c|c|c|c|}
\hline Item & 1993 & 1992 & 1991 & 1990 & 1989 \\
\hline \multicolumn{6}{|l|}{ Production Expenses } \\
\hline 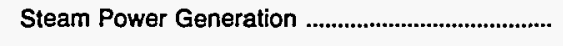 & $1,338,540$ & $1,282,834$ & $1,300,701$ & $1,261,277$ & 927,117 \\
\hline 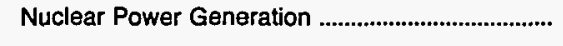 & 833,951 & 874,038 & 775,240 & 722,829 & 763,421 \\
\hline 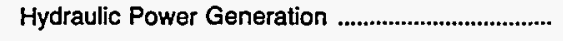 & 176,149 & 179,079 & 169,004 & 148,086 & 127,805 \\
\hline Other Power Generation & 56,429 & 73,927 & 83,339 & 80,600 & 95,481 \\
\hline 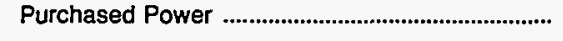 & $2,794,807$ & $2,659,016$ & $2,569,367$ & $2,770,259$ & $2,567,040$ \\
\hline 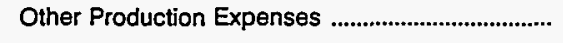 & 94,807 & 31,459 & 46,277 & 73,468 & 31,020 \\
\hline 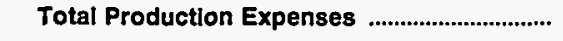 & $5,294,683$ & $5,100,351$ & $4,943,929$ & $5,056,518$ & $4,511,885$ \\
\hline Transmission Expenses & 482,984 & 439,935 & 429,942 & 397,977 & 374,843 \\
\hline 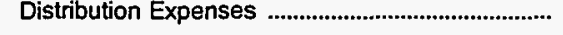 & 330,158 & 308,399 & 286,590 & 261,495 & 240.911 \\
\hline Customer Accounts Expenses ....................................... & 124,537 & 116,469 & 115,765 & 107,563 & 94,427 \\
\hline Customer Service and Information Expenses ..... & 38,145 & 40,755 & 36,664 & 31,340 & 39,103 \\
\hline Sales Expenses & 7,990 & 8,274 & 7,617 & 7,067 & 5,445 \\
\hline Administrative and General Expenses .................... & 719,348 & 701,509 & 705,496 & 648,707 & 631,848 \\
\hline $\begin{array}{l}\text { Total Electric Operation } \\
\text { and Malntenance Expenses }\end{array}$ & $6,997,844$ & $6,715,691$ & $6,526,004$ & $6,510,667$ & $5,898,463$ \\
\hline \multicolumn{6}{|l|}{ Fuel Expenses in Operation } \\
\hline 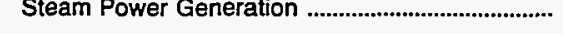 & 951,608 & 899,205 & 893,191 & 637,365 & 649,864 \\
\hline Nuclear Power Generation ............................................ & 205,222 & ' 183,294 & 215,353 & 156,136 & 228,260 \\
\hline 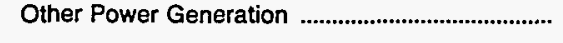 & 32,663 & R 32,799 & 42,796 & 46,938 & 65,933 \\
\hline \multicolumn{6}{|l|}{ Number of Elec Dept Employees } \\
\hline 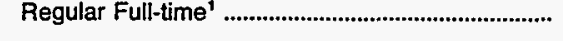 & 26,313 & 26,379 & - & - & - \\
\hline Part-time \& Temporary & 973 & 1,127 & - & - & - \\
\hline 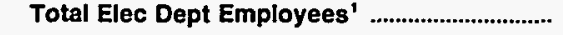 & 27,285 & 27,503 & - & - & - \\
\hline
\end{tabular}

1 Data reporting initiated in 1992.

$\mathbf{R}=$ Revised data.

Note: Totals may not equal sum of components because of independent rounding. The number of generating publicly owned electric utilities for end of period is 113 for December 31, 1993; 111 for December 31, 1992; 110 for December 31 , 1991 ; 110 for December 31 , 1990; and 108 for December 31, 1989. The City of Vineland (NJ) changed fiscal year from June 30 to December 31 in 1991 ; the California Department of Water Resources (CA) changed fiscal year from December 31 to June 30 in 1992; and the Wisonsin Public Power Inc Sys (Wi) changed fiscal year from December 31 to June 30 in 1993. Emerald Peoples Utility District (OR), City of Bryan (OH), and Northern Wasco County PUD (OR) were nongenerators for 1989 through 1991, but became generators in 1992 . The South Carolina Public Service Authority (SG) changed fiscal year from June 30 to December 31 in 1990 . The Utah Associated Municipal Power System (UT) changed fis. cal year from June 30 to March 31 in 1991. The City of Marshfield (WI) was a generator in 1989 and 1990, but became a nongenerator in 1991. The Wisconsin Public Power Incorporated System (WI) was a nongenerator in 1989 and 1990, but became a generator in 1991. Source: Energy Information Administration, Form ElA-412, "Annual Report of Public Electric Utilities." 
Table C16. Electric Utility Plant for Major U.S. Publicly Owned Generator Electric Utilities with Financial Year Ending on December 31 at End of Period, 1989-1993 (Thousand Dollars)

\begin{tabular}{|c|c|c|c|c|c|}
\hline Item & 1993 & 1992 & 1991 & 1990 & 1989 \\
\hline \multicolumn{6}{|l|}{ Electric Plant In Servlce } \\
\hline Intangible Plant & 187.454 & 147,119 & 166,530 & 193,723 & 157,599 \\
\hline \multicolumn{6}{|l|}{ Production Plant } \\
\hline Steam & $8,922,654$ & $8,631,927$ & $8,826,802$ & $7,965,718$ & $6,622,860$ \\
\hline 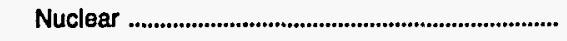 & $9,156,237$ & $9,134,357$ & $9,494,275$ & $8,966,077$ & $8,028,487$ \\
\hline 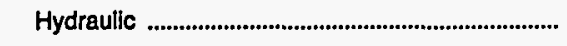 & $4,742,634$ & $4,615,920$ & $4,940,668$ & $4,799,518$ & $4,643,098$ \\
\hline Other & 744,582 & 653,883 & 896,234 & 921,650 & 804,293 \\
\hline 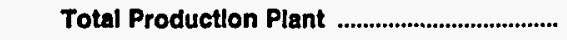 & $23,566,107$ & $23,036,088$ & $24,157,980$ & $22,652,963$ & $20,098,738$ \\
\hline 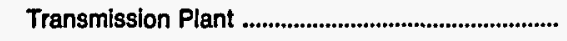 & $4,415,887$ & $4,391,256$ & $4,332,303$ & $3,860,130$ & $3,314,733$ \\
\hline 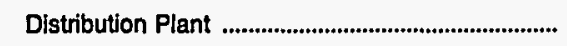 & $5,391,646$ & $5,099,992$ & $4,908,645$ & $4,567,340$ & $4,153,899$ \\
\hline 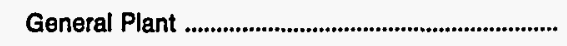 & $1,885,786$ & $1,761,568$ & $1,928,771$ & $1,801,420$ & $1,491,094$ \\
\hline 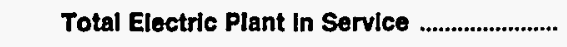 & $35,446,880$ & $34,436,024$ & $35,494,228$ & $33,075,576$ & $29,216,062$ \\
\hline 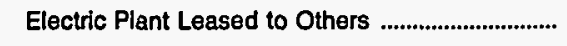 & 16,297 & 17,376 & 18,558 & 19,533 & 16,549 \\
\hline Construction Work in Progress - Electric ............... & $1,950,440$ & $1,523,008$ & $1,524,793$ & $1,984,117$ & $2,609,383$ \\
\hline 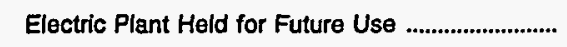 & 34,897 & 35,048 & 96,163 & 85,069 & 235,480 \\
\hline 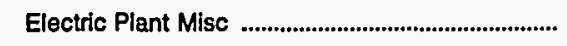 & 771,967 & 734,009 & 345,941 & 590,458 & 430,670 \\
\hline 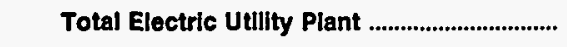 & $38,220,481$ & $36,745,465$ & $37,479,683$ & $35,754,753$ & $32,508,145$ \\
\hline $\begin{array}{l}\text { Accumulated Provision for } \\
\text { Depreciation and Amortization ............................... }\end{array}$ & $11,345,511$ & $10,493,142$ & $10,075,535$ & $9,044,556$ & $7,623,800$ \\
\hline 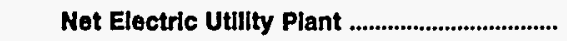 & $26,874,970$ & $26,252,323$ & $27,404,148$ & $26,710,198$ & $24,884,345$ \\
\hline
\end{tabular}

Note: Totals may not equal sum of components because of independent rounding. The number of generating publicly owned electric utilities for end of period is 113 for December 31, 1993; 111 for December 31, 1992; 110 for December 31, 1991; 110 for December 31 , 1990; and 108 for December 31, 1989. The City of Vineland (NJ) changed fiscal year from June 30 to December 31 in 1991; the California Department of Water Resources (CA) changed fiscal year from December 31 to June 30 in 1992; and the Wisconsin Public Power Inc Sys Wi) changed fiscal year from December 31 to June 30 in 1993. Emerald Peoples Utility District (OR), City of Bryan (OH), and Northern Wasco County PUD (OR) were nongenerators for 1989 through 1991, but became generators in 1992. The South Carolina Public Service Authority (SC) changed fiscal year from June 30 to December 31 in 1990. The Utah Associated Municipal Power System (UT) changed fiscal year from June 30 to March 31 in 1991. The City of Marshfield (WI) was a generator in 1989 and 1990, but became a nongenerator in 1991. The Wisconsin Public Power Incorporated System (WI) was a nongenerator in 1989 and 1990, but became a generator in 1991.

Source: Energy Information Administration, Form EIA-412, "Annual Report of Public Electric Utilities." 
Table C17. Number of Consumers, Sales, and Operating Revenue for Major

U.S. Publicly Owned Generator Electric Utilities with

Financial Year Ending on December 31, 1989-1993

\begin{tabular}{|c|c|c|c|c|c|}
\hline Item & 1993 & 1992 & 1991 & 1990 & 1989 \\
\hline \multicolumn{6}{|l|}{ Number of Consumers } \\
\hline 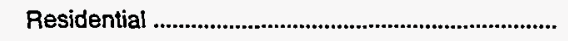 & $2,837,306$ & $2,814,249$ & $2,764,821$ & $2,715,134$ & $2,582,601$ \\
\hline Commercial or Small & 373,262 & 374,138 & 364,247 & 359,959 & 336,873 \\
\hline Industrial or Large & 19,018 & 17,308 & 17,030 & 18,626 & 16,447 \\
\hline Other & 32,448 & 31,715 & 38,909 & 35,493 & 30,932 \\
\hline 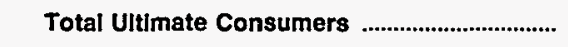 & $3,262,034$ & $3,237,410$ & $3,185,007$ & $3,129,212$ & $2,966,853$ \\
\hline \multicolumn{6}{|l|}{ Sales for the Year (megawatthours) } \\
\hline 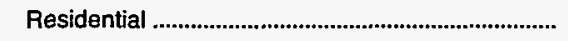 & $30,738,679$ & $28,973,686$ & $30,255,280$ & $29,060,284$ & $27,672,270$ \\
\hline Commercial or Small & $23,278,772$ & $22,588,007$ & $22,393,283$ & $21,894,020$ & $20,215,328$ \\
\hline Industrial or Large & $43,255,235$ & $43,005,294$ & $41,800,834$ & $41,714,889$ & $32,954,353$ \\
\hline Other & $11,831,805$ & $11,573,845$ & $11,674,348$ & $11,358,773$ & $11,080,275$ \\
\hline Total Sales to Ultimate Consumers .................... & $109,104,491$ & $106,140,832$ & $106,123,745$ & $104,027,966$ & $91,922,226$ \\
\hline Sales for Resale & $132,927,109$ & $119,936,732$ & $127,090,088$ & $128,453,278$ & $118,654,857$ \\
\hline Total Sales & $242,031,600$ & $226,077,564$ & $233,213,833$ & $232,481,244$ & $210,577,083$ \\
\hline \multicolumn{6}{|l|}{$\begin{array}{l}\text { Operating Revenues for the Year } \\
\text { (thousand dollars) }\end{array}$} \\
\hline 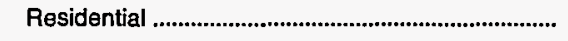 & $1,731,915$ & $1,643,062$ & $1,662,361$ & $1,595,478$ & $1,476,648$ \\
\hline Commercial or Small & $1,266,188$ & $1,207,356$ & $1,182,160$ & $1,136,745$ & $1,044,373$ \\
\hline Industrial or Large & $1,635,998$ & $1,606,898$ & $1,571,144$ & $1,550,851$ & $1,227,393$ \\
\hline Other & 891,751 & 829,977 & 739,838 & 745,745 & 711,863 \\
\hline 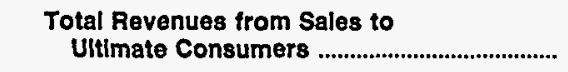 & $5,525,852$ & $5,287,293$ & $5,155,503$ & $5,028,819$ & $4,460,277$ \\
\hline Sales for Resale & $4,677,071$ & $4,266,138$ & $4,317,957$ & $4,373,787$ & $4,008,169$ \\
\hline $\begin{array}{l}\text { Total Revenues From Sales of } \\
\text { Electrlelty }\end{array}$ & $10,202,923$ & $9,553,431$ & $9,473,460$ & $9,402,608$ & $8,468,446$ \\
\hline
\end{tabular}

Note: Totals may not equal sum of components because of independent rounding. The number of generating publicly owned electric utilities for end of period is 113 for December 31, 1993; 111 for December 31, 1992; 110 for December 31, 1991; 110 for December 31, 1990; and 108 for December 31, 1989. The City of Vineland (NJ) changed fiscal year from June 30 to December 31 in 1991; the Callfornia Department of Water Resources (CA) changed fiscal year from December 31 to June 30 in 1992; and the Wisconsin Public Power Inc Sys (WI) changed fiscal year from December 31 to June 30 in 1993. Emerald Peoples Utility District (OR), City of Bryan (OH), and Northern Wasco County PUD (OR) were nongenerators for 1989 through 1991, but became generators in 1992. The City of Foley (AL) and the South Carolina Public Service Authority (SC) changed fiscal year from June 30 to December 31 in 1990. The Utah Associated Municipal Power System (UT) changed fiscal year from June 30 to March 31 in 1991. The City of Marshfield (WI) was a generator in 1989 and 1990, but became a nongenerator in 1991. The Wisconsin Public Power Incorporated System (WI) was a nongenerator in 1989 and 1990, but became a generator in 1991. sions.

Source: Energy Information Administration, Form ElA-861, "Annual Electric Utility Report." Data are based on calendar year submis- 
Table C18. Electric Energy Account for Major U.S. Publicly Owned

Generator Electric Utilities with Financial Year

Ending on December 31, 1989-1993

(Megawatthours)

\begin{tabular}{|c|c|c|c|c|c|}
\hline Item & 1993 & 1992 & 1991 & 1990 & 1989 \\
\hline \multicolumn{6}{|l|}{ Sources of Energy } \\
\hline 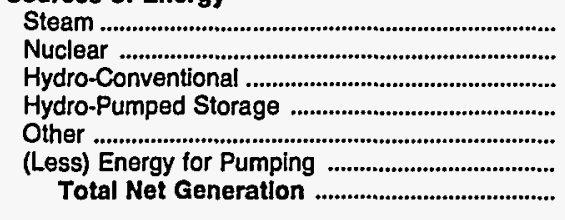 & $\begin{array}{r}68,884,126 \\
31,537,345 \\
61,442,436 \\
2,100,289 \\
933,116 \\
3,309,882 \\
161,587,430\end{array}$ & $\begin{array}{r}65,609,210 \\
31,849,000 \\
57,178,818 \\
2,170,285 \\
1,203,274 \\
2,897,644 \\
155,112,932\end{array}$ & $\begin{array}{r}66,891,679 \\
36,462,063 \\
67,268,340 \\
2,364,088 \\
1,302,950 \\
2,942,457 \\
171,346,662\end{array}$ & $\begin{array}{r}68,121,001 \\
34,561,351 \\
67,433,345 \\
3,537,783 \\
1,316,570 \\
2,983,818 \\
171,986,234\end{array}$ & $\begin{array}{r}53,992,803 \\
36,125,796 \\
60,581,382 \\
3,048,854 \\
1,374,343 \\
2,995,236 \\
152,127,942\end{array}$ \\
\hline 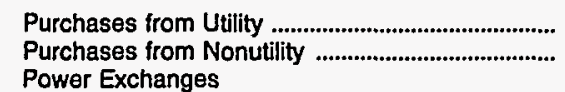 & $\begin{array}{r}87,548,082 \\
704,617\end{array}$ & $\begin{array}{r}79,898,277 \\
711,796\end{array}$ & $\begin{array}{r}76,660,807 \\
925,307\end{array}$ & $\begin{array}{r}78,428,609 \\
864,340\end{array}$ & $\begin{array}{r}73,986,902 \\
779,593\end{array}$ \\
\hline 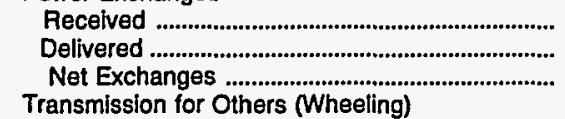 & $\begin{array}{r}12,472,066 \\
14,404,251 \\
-1,932,178\end{array}$ & $\begin{array}{l}11,060,566 \\
12,420,396 \\
-1,359,823\end{array}$ & $\begin{array}{l}15,364,045 \\
18,418,514 \\
-3,054,468\end{array}$ & $\begin{array}{l}14,622,676 \\
16,409,072 \\
-1,786,397\end{array}$ & $\begin{array}{r}16,049,716 \\
16,700,782 \\
-651,067\end{array}$ \\
\hline 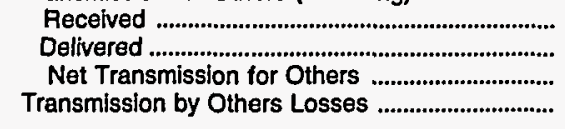 & $\begin{array}{r}10,300,909 \\
10,105,033 \\
195,876 \\
-50,570\end{array}$ & $\begin{array}{r}7,563,741 \\
7,426,968 \\
136,773 \\
-42,446\end{array}$ & $\begin{array}{r}6,457,352 \\
6,321,064 \\
136,287 \\
-12,108\end{array}$ & $\begin{array}{r}12,322,641 \\
12,203,547 \\
119,093 \\
-16,107\end{array}$ & $\begin{array}{r}5,160,664 \\
5,074,696 \\
85,968\end{array}$ \\
\hline $\begin{array}{l}\text { Total Net Energy Generated and } \\
\text { Recelved }\end{array}$ & $248,053,261$ & $234,457,495$ & $246,002,489$ & $249,595,771$ & $226,329,339$ \\
\hline 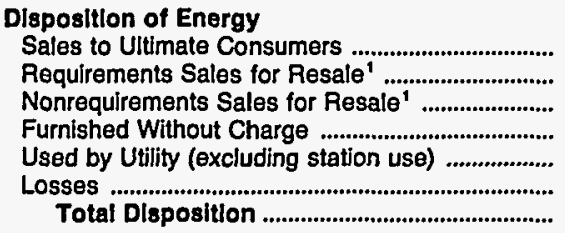 & $\begin{array}{r}109,361,116 \\
96,509,633 \\
32,199,271 \\
1,306,097 \\
254,107 \\
8,423,044 \\
248,053,261\end{array}$ & $\begin{array}{r}106,146,840 \\
92,606,439 \\
27,422,443 \\
1,250,309 \\
258,375 \\
6,773,090 \\
234,457,495\end{array}$ & $\begin{array}{r}106,253,382 \\
102,726,112 \\
24,241,019 \\
1,299,635 \\
4,793,554 \\
6,688,779 \\
246,002,489\end{array}$ & $\begin{array}{r}104,050,549 \\
101,969,005 \\
26,484,486 \\
1,474,860 \\
8,867,221 \\
6,749,649 \\
249,595,771\end{array}$ & $\begin{array}{r}91,842,235 \\
118,681,859 \\
- \\
1,395,340 \\
7,954,930 \\
6,454,962 \\
226,329,339\end{array}$ \\
\hline
\end{tabular}

1 The 1989 data were reported as Sales for Resale (one entry) which is shown as Requirements Sales for Resale.

Note: Totals may not equal sum of components because of independent rounding. The number of generating publicly owned electric utilities for end of period is 113 for December 31, 1993; 111 for December 31, 1992; 110 tor December 31, $1991 ; 110$ for December 31, 1990; and 108 for December 31, 1989. The City of Vineland (NJ) changed fiscal year from June 30 to December 31 in 1991 ; the California Department of Water Resources (CA) changed fiscal year from December 31 to June 30 in 1992; and the Wissonsin Public Power Inc Sys (WI) changed fiscal year from December 31 to June 30 in 1993. Emerald Peoples Utility District (OR), City of Bryan (OH), and Northern Wasco County PUD (OR) were nongenerators for 1989 through 1991, but became generators in 1992 . The South Carolina Public Service Authority (SC) changed fiscal year from June 30 to December 31 in 1990. The Utah Associated Municipal Power System (UT) changed fiscal year from June 30 to March 31 in 1991. The City of Marshfield (WI) was a generator in 1989 and 1990, but became a nongenerator in 1991. The Wisconsin Public Power Incorporated System (WI) was a nongenerator in 1989 and 1990, but became a generator in 1991. Source: Energy Information Administration, Form ElA-412, "Annual Report of Public Electric Utilities." 
Table C19. Ten Largest U.S. Publicly Owned Nongenerator Electric Utilities Ranked by Megawatthour Sales to Uitimate Consumers with Financlal Year Ending on June 30, 1993

\begin{tabular}{|c|c|c|c|}
\hline Publicly Owned Electric Utilities & State & Amount & Percent \\
\hline Memphis City of & Tennessee & $11,075,238$ & 12.95 \\
\hline 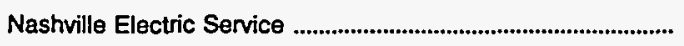 & Tennessee & $9,976,634$ & 11.66 \\
\hline Chattanooga City of & Tennessee & $5,262,184$ & 6.15 \\
\hline 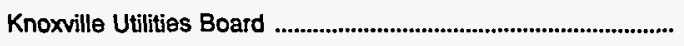 & Tennessee & $4,568,275$ & 5.34 \\
\hline 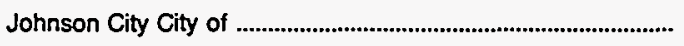 & Tennessee & $1,472,763$ & 1.72 \\
\hline Decatur City of & Alabama & $1,382,214$ & 1.62 \\
\hline Jackson City of & Tennessee & $1,111,362$ & 1.30 \\
\hline Greenville Utilities Comm & North Carolina & $1,044,000$ & 1.22 \\
\hline Palo Alto City of & California & $1,041,532$ & 1.22 \\
\hline Lenoir City City of & Tennessee & 956,485 & 1.12 \\
\hline Subtotal & & $37,890,687$ & 44.30 \\
\hline
\end{tabular}

Source: Energy Information Administration, Form EIA-412, "Annual Report of Public Electric Utilities."

Table C20. U.S. Publicly Owned Nongenerator Electric Utilities Ranked by Megawatthour Sales for Resale with Financial Year Ending on June 30, 1993

\begin{tabular}{|c|c|c|c|}
\hline Publicly Owned Electric Utilities & State & Amount & Percent \\
\hline 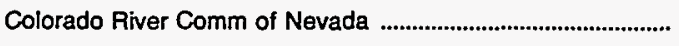 & Nevada & 768,468 & 50.64 \\
\hline Arizona Power Authority & Arizona & 612,863 & 40.39 \\
\hline Wilson City of & North Carolina & 58,814 & 3.88 \\
\hline Redding City of & California & 23,778 & 1.57 \\
\hline 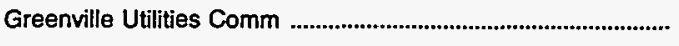 & North Carolina & 23,000 & 1.52 \\
\hline Rocky Mount City of & North Carolina & 16,535 & 1.09 \\
\hline Mesa City of & Arizona & 8,924 & .59 \\
\hline 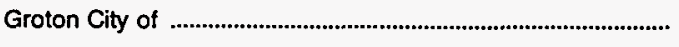 & Connecticut & 5,158 & .34 \\
\hline 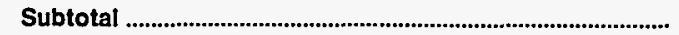 & & $1,517,540$ & 100.00 \\
\hline
\end{tabular}

Source: Energy Information Administration, Form ElA-412, "Annual Report of Public Electric Utilities." 
Table C21. Composite Statement of Income for Major U.S. Publicly Owned Nongenerator Electric Utilities with Financial Year Ending on June 30, 1989-1993

(Thousand Dollars)

\begin{tabular}{|c|c|c|c|c|c|}
\hline Item & 1993 & 1992 & 1991 & 1990 & 1989 \\
\hline 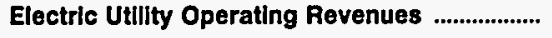 & $5,046,608$ & $4,265,830$ & $4,167,470$ & $4,143,051$ & $4,002,283$ \\
\hline 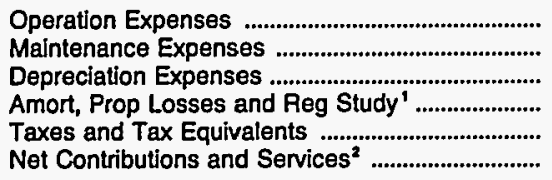 & $\begin{array}{r}4,390,415 \\
143,949 \\
153,256 \\
1,492 \\
108,434 \\
-\end{array}$ & $\begin{array}{r}3,735,743 \\
109,346 \\
126,288 \\
476 \\
85,310 \\
-\end{array}$ & $\begin{array}{r}3,646,906 \\
104,862 \\
121,975 \\
- \\
69,589 \\
106,005\end{array}$ & $\begin{array}{r}3,645,672 \\
111,773 \\
116,224 \\
64,919 \\
88,261\end{array}$ & $\begin{array}{r}3,514,644 \\
108,284 \\
107,743 \\
- \\
61,090 \\
103,436\end{array}$ \\
\hline $\begin{array}{l}\text { Total Electric Utillty Operating } \\
\text { Expenses }\end{array}$ & $4,797,546$ & $4,057,164$ & $4,049,336$ & $4,026,850$ & $3,895,197$ \\
\hline 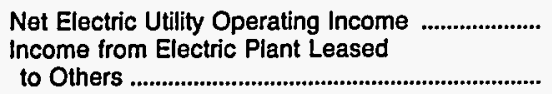 & 249,062 & 208,666 & 118,134 & 116,201 & 107,086 \\
\hline Electrlc Utillty Operating Income ........................ & 249,062 & 208,748 & 119,293 & 116,896 & 107,685 \\
\hline Other Electric Income & 117,290 & 80,578 & 73,710 & 76,072 & 84,288 \\
\hline $\begin{array}{l}\text { Other Electric Deductions ........................................... } \\
\text { Allowance for Other Funds Used }\end{array}$ & 44,866 & 44,944 & 8,220 & - & - \\
\hline 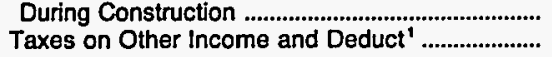 & $\overline{-}$ & $\overline{5}$ & $\begin{array}{r}1,229 \\
-\end{array}$ & $\begin{array}{r}130 \\
-\end{array}$ & $\begin{array}{r}170 \\
-\end{array}$ \\
\hline Electric Utillty Income & 321,486 & 244,329 & 186,012 & 193,098 & 192,143 \\
\hline 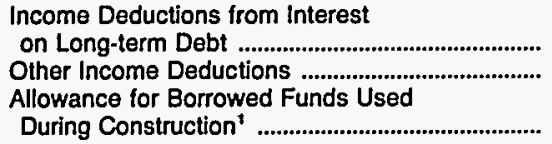 & $\begin{array}{l}60,302 \\
32,697\end{array}$ & $\begin{array}{l}42,612 \\
18,618\end{array}$ & $\begin{array}{l}43,191 \\
16,967\end{array}$ & $\begin{array}{l}44,711 \\
14,892\end{array}$ & $\begin{array}{l}45,145 \\
11,356\end{array}$ \\
\hline 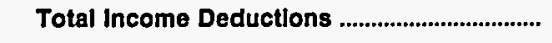 & 92,999 & 61,230 & 60,157 & 59,602 & 56,500 \\
\hline 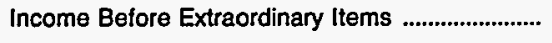 & 228,486 & 183,099 & 125,855 & 133,496 & 135,643 \\
\hline Extraordinary Income & 16,698 & 18,338 & 21,330 & 2,541 & 2,033 \\
\hline 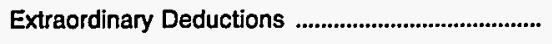 & 29,130 & 11,979 & 19,747 & 13,024 & 4,226 \\
\hline 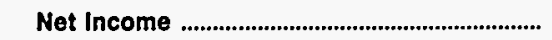 & 216,054 & 189,459 & 127,438 & 123,012 & 133,451 \\
\hline
\end{tabular}

1 Data reporting initiated in 1992.

Data reporting discontinued in 1992.

- Data not available.

Note: Totals may not equal sum of components because of independent rounding. The number of nongenerating publicly owned electric utilities for end of period is 142 for June 30, 1993; 137 for June 30, 1992; 135 for June 30, 1991; 136 for June 30, 1990; and 135 for June 30, 1989. The City of Hagerstown (MD) changed fiscal year from December 31 to June 30 in 1993; and the City of Memphis (TN) and the City of LaFollette (TN) changed fiscal years from December 31 to June 30 in 1992. Emerald Peoples Utility District (OR), City of Bryan $(\mathrm{OH})$, and Northern Wasco County PUD (OR) were nongenerators for 1989 through 1991, but became generators in 1992 . The City of Foley (AL) changed fiscal year from June 30 to December 31 in 1990. The Wisconsin Public Power Incorporated System (WI) was a nongenerator in 1989 and 1990, but became a generator in 1991. The City of Marshfield (WI) was a generator in 1989 and 1990 , but became a nongenerator in 1991.

Source: Energy Information Administration, Form ElA-412, "Annual Report of Public Electric Utilities." 
Table C22. Composite Balance Sheet for Major U.S. Publicly Owned Nongenerator Electric Utilities with Financial Year Ending on June 30 at End of Period, 1989-1993 (Thousand Dollars)

\begin{tabular}{|c|c|c|c|c|c|}
\hline Item & 1993 & 1992 & 1991 & 1990 & 1989 \\
\hline \multicolumn{6}{|l|}{ Electric Utility Plant } \\
\hline $\begin{array}{l}\text { Electric Utility Plant \& Adjust } \\
\text { Const Work in Progress }\end{array}$ & $4,931,174$ & $\begin{array}{r}3,876,053 \\
131,760\end{array}$ & $\begin{array}{r}3,793,405 \\
-\end{array}$ & $3,563,010$ & $3,364,686$ \\
\hline & $1,866,469$ & $1,457,939$ & $1,356,953$ & $1,257,905$ & $1,175,271$ \\
\hline 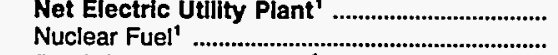 & $3,215,769$ & $2,549,875$ & - & - & - \\
\hline 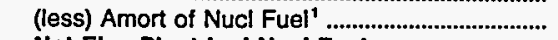 & - & - & - & - & \\
\hline $\begin{array}{l}\text { Net Elec Plant Inci Nucl Fuel ........................................... } \\
\text { Other Property \& Investments }\end{array}$ & $3,215,769$ & $2,549,875$ & $2,436,453$ & 2,305,105 & $2,189,415$ \\
\hline 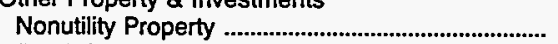 & $1,119,736$ & \multicolumn{4}{|c|}{ Other Property \& investments } \\
\hline (less) Accum Provisions for Depr \& Amort ........... & 277,219 & 246,838 & 224,761 & 223,212 & 197,865 \\
\hline 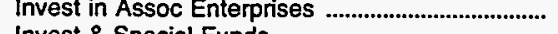 & 11,010 & 8,808 & 9,821 & 9,969 & 6,018 \\
\hline Invest \& Special Funds & 467,481 & 373,447 & 342,179 & 326,036 & 339,994 \\
\hline \multicolumn{6}{|l|}{ Current and Accrued Assets } \\
\hline 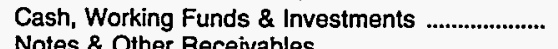 & 759,413 & 645,610 & 606,203 & 588,851 & 568,326 \\
\hline $\begin{array}{l}\text { Notes \& Other Receivables } \\
\text { Customer Accts Receivable }\end{array}$ & $\begin{array}{l}330,984 \\
145,997\end{array}$ & $\begin{array}{l}220,262 \\
173,544\end{array}$ & $\begin{array}{r}431,451 \\
-\end{array}$ & 466,338 & 443,934 \\
\hline & 8,418 & 10,382 & 10,519 & 8,962 & 9,480 \\
\hline $\begin{array}{l}\text { Fuel Stock \& Exp Undistr } \\
\text { Materials \& Supplies }\end{array}$ & & $\begin{array}{r}680 \\
81.063\end{array}$ & & $830 \overline{5}$ & \\
\hline & $\begin{array}{l}9 b, 304 \\
23,649\end{array}$ & $\begin{array}{l}81,063 \\
21,100\end{array}$ & $\begin{array}{l}82,498 \\
20,390\end{array}$ & $\begin{array}{l}83,405 \\
44,432\end{array}$ & 86,000 \\
\hline 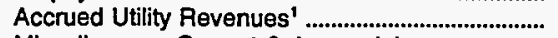 & 14,928 & $\begin{array}{l}21,700 \\
14,061\end{array}$ & & $\begin{array}{r}44,432 \\
-\end{array}$ & $\begin{array}{r}39,564 \\
-\end{array}$ \\
\hline $\begin{array}{l}\text { Miscellaneous Current \& Accrued Assets .............. } \\
\text { Total Current \& Accrued Assets ....................... }\end{array}$ & 63,745 & 42,405 & $\begin{array}{r}33,666 \\
\end{array}$ & 16,127 & $\begin{array}{r}30,200 \\
\end{array}$ \\
\hline \multicolumn{6}{|l|}{ Deferred Debits } \\
\hline $\begin{array}{l}\text { Unamortized Debt Expenses ......................................... } \\
\text { Extraordinary Losses, Study Cost }\end{array}$ & 67,342 & 54,266 & 40,495 & 34,697 & 33,037 \\
\hline & $\begin{array}{r}283 \\
231,823\end{array}$ & $\begin{array}{r}380 \\
207,957\end{array}$ & 171,031 & $130.72 \vec{g}$ & 130,405 \\
\hline Total Deferred Debits ......................................... & 299,449 & 262,602 & 211,527 & 165,426 & 163,442 \\
\hline \multicolumn{6}{|l|}{ Proprietary Capital } \\
\hline 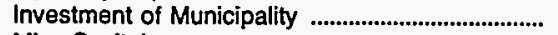 & 140,533 & 130,155 & 181,752 & 189,661 & 165,533 \\
\hline 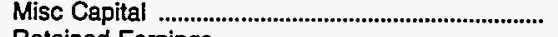 & 322,812 & 321,883 & 309,795 & 264,116 & 273,808 \\
\hline 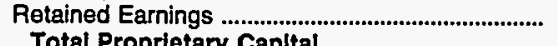 & $3,182,217$ & $2,655,556$ & $2,464,326$ & $2,400,616$ & $2,262,249$ \\
\hline \multicolumn{6}{|l|}{ Long-term Debt } \\
\hline Bonds & $1,499,796$ & $1,121,996$ & $1,021,581$ & $1,014,631$ & $1,044,629$ \\
\hline Advances from Municipality \& Other ....................... & 367,687 & 350,771 & 306,400 & 307,645 & 309,444 \\
\hline Unamort Prem on Long-term Debt ........................ & $-1,857$ & 6,144 & 1,317 & 994 & 1,076 \\
\hline (less) Unamort Discount on Long-term Debt ....... & 7,964 & 8,254 & 14,948 & 15,471 & 16,393 \\
\hline $\begin{array}{l}\text { Total Long-term Debt ..................................................... } \\
\text { Other Noncurrent Liabilities }\end{array}$ & $1,857,662$ & $1,470,657$ & $1,314,349$ & $1,307,799$ & $1,338,756$ \\
\hline Accum Operating Provisions ................................... & \multicolumn{5}{|c|}{ Other Noncurrent Liabilities } \\
\hline 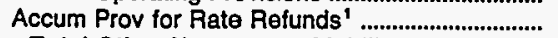 & & $\begin{array}{r}0,401 \\
206\end{array}$ & 10,410 & 0,031 & 10,204 \\
\hline \multirow{2}{*}{\multicolumn{6}{|c|}{ Current and Accrued Liabilities }} \\
\hline & & & & & \\
\hline Notes Payable & 22,173 & 24,735 & 23,134 & 27,149 & 22,272 \\
\hline Accounts Payable & 450,921 & 353,395 & 358,975 & 359,439 & 335,341 \\
\hline Payables to Assoc Enterprises ................................. & 5,786 & 10,252 & 24,142 & 17,759 & 24,095 \\
\hline 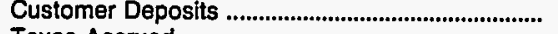 & 95,561 & 87,252 & 79,605 & 71,803 & 66,386 \\
\hline Taxes Accrued & 10,564 & 9,891 & 25,935 & 8,172 & 8,375 \\
\hline Interest Accrued & 24,215 & 46,566 & 27,387 & 38,542 & 26,363 \\
\hline 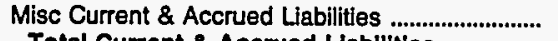 & 62,787 & 50,848 & 40,828 & 45,490 & 40,422 \\
\hline $\begin{array}{l}\text { Total Current \& Accrued Llabllities ................ } \\
\text { Deferred Credits }\end{array}$ & 672,006 & 582,938 & 580,007 & 568,354 & 523,253 \\
\hline Customer Advances for Construction ......................... & 5,712 & 3,614 & 3,597 & & 3,268 \\
\hline 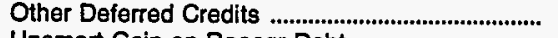 & 79,194 & 49,733 & 91,505 & 90,243 & 93,671 \\
\hline Unamort Gain on Reacqr Debt ..................................... & & & 666 & 13 & 52 \\
\hline 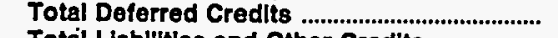 & 84,906 & 53,346 & 95,769 & 93,778 & 96,992 \\
\hline 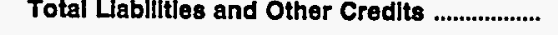 & $6,261,830$ & $5,218,177$ & $4,964,477$ & $4,830,856$ & $4,670,855$ \\
\hline
\end{tabular}

1 Data reporting initiated in 1992.

Note: Totals may not equal sum of components because of independent rounding. The number of nongenerating publicly owned electric utilities for end of period is 142 for June 30, 1993; 137 for June 30, 1992; 135 for June 30, 1991; 136 for June 30, 1990; and 135 for June 30, 1989. The City of Hagerstown (MD) changed fiscal year from December 31 to June 30 in 1993; and the City of Memphis (TN) and the City of LaFollette (TN) changed fiscal years from December 31 to June 30 in 1992. Emerald Peoples Utility District (OR), City of Bryan $(\mathrm{OH})$, and Northern Wasco County PUD (OR) were nongenerators for 1989 through 1991, but became generators in 1992. The City of Foley (AL) changed fiscal year from June 30 to December 31 in 1990 . The Wisconsin Public Power Incorporated System (WI) was a nongenerator in 1989 and 1990, but became a generator in 1991. The City of Marshfield (WI) was a generator in 1989 and 1990, but became a nongenerator in 1991.

Source: Energy Information Administration, Form ElA-412, "Annual Report of Public Electric Utilities." 
Table C23. Composite Financial Indicators for Major U.S. Publicly Owned Nongenerator Electric Utilities with Financial Year Ending on June 30, 1989-1993

\begin{tabular}{|c|c|c|c|c|c|}
\hline Item & 1993 & 1992 & 1991 & 1990 & 1989 \\
\hline Total Electric Utility Plant per Dollar of Revenue & 1.0 & 0.9 & 0.9 & 0.9 & 0.8 \\
\hline Current Assets to Current Liabilities ....................... & 2.1 & 2.0 & 2.0 & 2.1 & 2.2 \\
\hline $\begin{array}{l}\text { Total Electric Utility Plant as a Percent of Total } \\
\text { Assets }\end{array}$ & 81.2 & 76.8 & 76.4 & 73.8 & 72.0 \\
\hline $\begin{array}{l}\text { Net Electric Utility Plant as a Percent of Total } \\
\text { Assets }\end{array}$ & 51.4 & 48.9 & 49.1 & 47.7 & 46.9 \\
\hline Debt as a Percent of Total Liabilities ..................... & 40.4 & 39.4 & 38.2 & 38.8 & 39.9 \\
\hline $\begin{array}{l}\text { Depreciation, Amortization and Depletion } \\
\text { as a Percent of Total Electric Utility Plant ........... }\end{array}$ & 36.7 & 36.4 & 35.8 & 35.3 & 34.9 \\
\hline $\begin{array}{l}\text { Electric Operation and Maintenance Expenses } \\
\text { as a Percent of } \\
\text { Electric Utility Operating Revenues ........................ }\end{array}$ & 89.8 & 90.1 & 90.0 & 90.7 & 90.5 \\
\hline $\begin{array}{l}\text { Electric Depreciation and Amortization } \\
\text { as a Percent of } \\
\text { Electric Utility Operating Revenues ............................ }\end{array}$ & 3.0 & 3.0 & 2.9 & 2.8 & 2.7 \\
\hline $\begin{array}{l}\text { Taxes and Tax Equivalents } \\
\text { as a Percent of } \\
\text { Electric Utility Operating Revenues }\end{array}$ & 2.1 & 2.0 & 1.7 & 1.6 & 1.5 \\
\hline $\begin{array}{l}\text { Interest on Long-term Debt } \\
\text { as a Percent of } \\
\text { Electric Utility Operating Revenues ....................... }\end{array}$ & 1.2 & 1.0 & 1.0 & 1.1 & 1.1 \\
\hline $\begin{array}{l}\text { Net Income as a Percent of Electric } \\
\text { Utility Operating Revenues ......................................... }\end{array}$ & 4.3 & 4.4 & 3.1 & 3.0 & 3.3 \\
\hline Purchased Power Cents Per Kilowatthour ............ & 4.3 & 4.4 & 4.4 & 4.4 & 4.2 \\
\hline
\end{tabular}

Note: Totals may not equal sum of components because of independent rounding. The number of nongenerating publicly owned electric utilities for end of period is 142 for June 30, 1993; 137 for June 30, 1992; 135 for June 30, 1991; 136 for June 30,1993 ; and 135 for June 30, 1989. The City of Hagerstowm (MD) changed fiscal year from December 31 to June 30 in 1993; and the City of Memphis (TN) and the City of LaFollette (TN) changed fiscal years from December 31 to June 30 in 1992 . Emerald Peoples Utility District (OR), City of Bryan (OH), and Northern Wasco County PUD (OR) were nongenerators for 1989 through 1991, but became generators in 1992 . The City of Foley (AL) changed fiscal year from June 30 to December 31 in 1990. The Wisconsin Public Power Incorporated System (WI) was a nongenerator in 1989 and 1990, but became a generator in 1991. The City of Marshfield (WI) was a generator in 1989 and 1990, but became a nongenerator in 1991.

Source: Energy Information Administration, Form ElA-412, "Annual Report of Public Electric Utilities." 
Table C24. Electric Operation and Maintenance Expenses for Major U.S. Publicly Owned Nongenerator Electric Utilities with Financial Year Ending on June 30, 1989-1993

(Thousand Dollars)

\begin{tabular}{|c|c|c|c|c|c|}
\hline Item & 1993 & 1992 & 1991 & 1990 & 1989 \\
\hline \multicolumn{6}{|l|}{ Production Expenses } \\
\hline 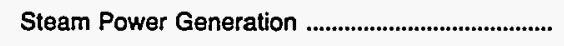 & - & - & - & - & - \\
\hline 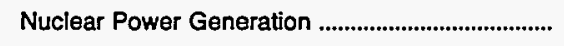 & - & - & - & - & - \\
\hline 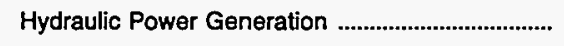 & - & - & - & - & - \\
\hline Other Power Generation & - & - & - & - & 1,802 \\
\hline 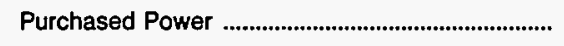 & $3,981,725$ & $3,410,265$ & $3,339,710$ & $3,352,355$ & $3,118,544$ \\
\hline Other Production Expenses & 2,789 & 2,565 & 6,949 & 12,356 & 4,817 \\
\hline 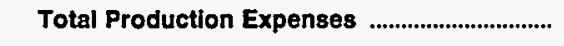 & $3,984,514$ & $3,412,829$ & $3,346,659$ & $3,364,711$ & $3,125,163$ \\
\hline 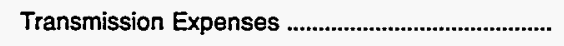 & 18,336 & 17,158 & 13,330 & 11,290 & 10,515 \\
\hline 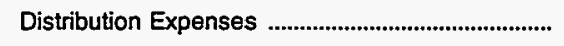 & 253,320 & 194,782 & 167,664 & 159,815 & 241,118 \\
\hline 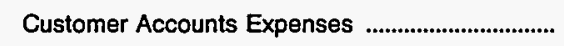 & 77,485 & 64,164 & 60,355 & 59.192 & 55,808 \\
\hline Customer Service and Information Expenses ..... & 9,559 & 7,703 & 9,006 & 8,043 & 8,011 \\
\hline Sales Expenses & 6,386 & 8,597 & 9,731 & 9,635 & 3,690 \\
\hline 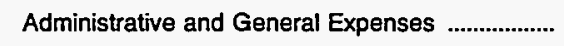 & 184,764 & 139,857 & 145,023 & 144,759 & 178,624 \\
\hline $\begin{array}{l}\text { Total Electric Operation } \\
\text { and Malntenance Expenses }\end{array}$ & $4,534,363$ & $3,845,089$ & $3,751,767$ & $3,757,445$ & $3,622,929$ \\
\hline \multicolumn{6}{|l|}{ Fuel Expenses In Operation } \\
\hline 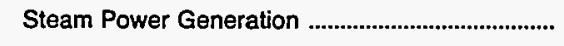 & - & - & - & - & - \\
\hline 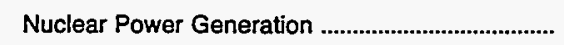 & - & - & - & - & - \\
\hline Other Power Generation & - & - & - & - & - \\
\hline \multicolumn{6}{|l|}{ Number of Elec Dept Employees } \\
\hline 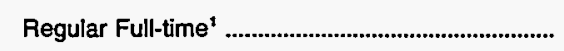 & 9,749 & 7,772 & - & - & - \\
\hline Part-time \& Temporary' & 101 & 165 & - & - & - \\
\hline 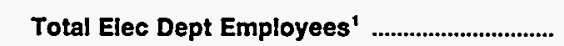 & 9,850 & 7,937 & - & - & - \\
\hline
\end{tabular}

1 Data reporting initiated in 1992.

Note: Totals may not equal sum of components because of independent rounding. The number of nongenerating publicly owned electric utilities for end of period is 142 for June 30,$1993 ; 137$ for June 30, 1992; 135 for June 30, 1991; 136 for June 30, 1990 ; and 135 for June 30, 1989. The City of Hagerstown (MD) changed fiscal year from December 31 to June 30 in 1993; and the City of Memphis (TN) and the City of LaFollette (TN) changed fiscal years from December 31 to June 30 in 1992. Emerald Peoples Utility District (OR), City of Bryan $(\mathrm{OH})$, and Northern Wasco County PUD (OR) were nongenerators for 1989 through 1991, but became generators in 1992. The City of Foley (AL) changed fiscal year from June 30 to December 31 in 1990. The Wisconsin Public Power Incorporated System (WI) was a nongenerator in 1989 and 1990, but became a generator in 1991. The City of Marshfield (WI) was a generator in 1989 and 1990 , but became a nongenerator in 1991.

Source: Energy Information Administration, Form EIA-412, “Annual Report of Public Electric Utilities." 
Table C25. Electric Utility Plant for Major U.S. Publicly Owned Nongenerator

Electric Utilities with Financlal Year Ending on

June 30 at End of Perlod, 1989-1993

(Thousand Dollars)

\begin{tabular}{|c|c|c|c|c|c|}
\hline Jtem & 1993 & 1992 & 1991 & 1990 & 1989 \\
\hline \multicolumn{6}{|l|}{ Electric Plant In Service } \\
\hline 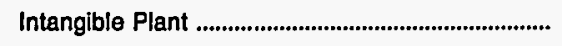 & 102 & 102 & 1 & 1 & 1 \\
\hline \multicolumn{6}{|l|}{ Production Plant } \\
\hline Steam & 53,463 & 41,649 & 40,412 & 286 & 39,768 \\
\hline 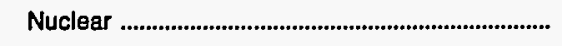 & - & - & - & - & - \\
\hline 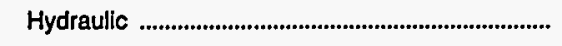 & - & - & - & - & - \\
\hline Other & 13.151 & 12,615 & 12,622 & 46,445 & 12,796 \\
\hline Total Production Plant .......................................... & 66,613 & 54,264 & 53,034 & 46,731 & 52,564 \\
\hline 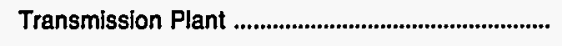 & 409,023 & 264,009 & 303,770 & 225,936 & 213,418 \\
\hline 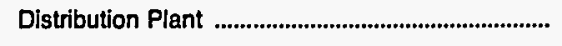 & $3,595,158$ & $2,793,942$ & $2,665,391$ & $2,534,520$ & $2,393,745$ \\
\hline 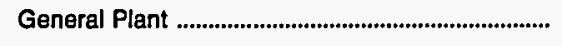 & 813,520 & 719,782 & 657,870 & 624,449 & 579,758 \\
\hline Total Electric Plant in Service ............................ & $4,884,416$ & $3,832,099$ & $3,680,067$ & $3,431,637$ & $3,239,487$ \\
\hline 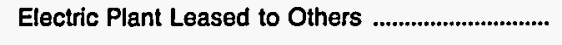 & 0 & - & - & - & - \\
\hline Construction Work in Progress - Electric ................. & 151,064 & 131,760 & 91,741 & 107,001 & 98,906 \\
\hline 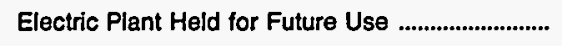 & 14,976 & 14,765 & 3,207 & 1,195 & 592 \\
\hline 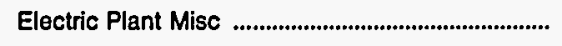 & 31,782 & 29,189 & 18,391 & 23,178 & 25,702 \\
\hline 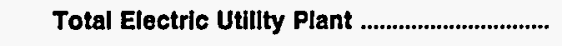 & $5,082,237$ & $4,007,814$ & $3,793,405$ & $3,563,010$ & $3,364,686$ \\
\hline 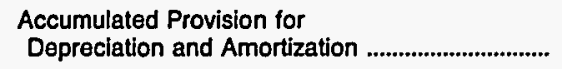 & $1,866,469$ & $1,457,939$ & $1,356,953$ & $1,257,905$ & $1,175,271$ \\
\hline 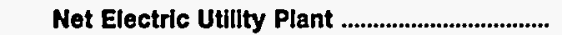 & $3,215,769$ & $2,549,875$ & $2,436,453$ & $2,305,105$ & $2,189,415$ \\
\hline
\end{tabular}

Note: Totals may not equal sum of components because of independent rounding. The number of nongenerating publicly owned electric utilities for end of period is 142 for June 30, 1993; 137 for June 30, 1992; 135 for June 30, 1991; 136 for June 30, 1990; and 135 for June 30, 1989. The City of Hagerstown (MD) changed fiscal year from December 31 to June 30 in 1993; and the City of Memphis (TN) and the City of LaFollette (TN) changed fiscal years from December 31 to June 30 in 1992. Emerald Peoples Utility District (OR), City of Bryan $(\mathrm{OH})$, and Northern Wasco County PUD (OR) were nongenerators for 1989 through 1991, but became generators in 1992. The City of Foley (AL) changed fiscal year from June 30 to December 31 in 1990. The Wisconsin Public Power Incorporated System (WI) was a nongenerator in 1989 and 1990, but became a generator in 1991. The City of Marshfield (WI) was a generator in 1989 and 1990, but became a nongenerator in 1991.

Source: Energy Information Administration, Form ElA-412, "Annual Report of Public Electric Utilities." 
Table C26. Number of Consumers, Sales, and Operating Revenue for Major

U.S. Publicly Owned Nongenerator Electric Utilities with Financial Year Ending on June 30, 1989-1993

\begin{tabular}{|c|c|c|c|c|c|}
\hline Item & 1993 & 1992 & 1991 & 1990 & 1989 \\
\hline \multicolumn{6}{|l|}{ Number of Consumers } \\
\hline 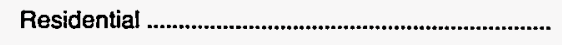 & $2,501,499$ & $2,076,553$ & $2,043,331$ & $2,014,320$ & $1,994,831$ \\
\hline Commercial or Small & 346,644 & 302,966 & 304,983 & 299,578 & 274,657 \\
\hline Industrial or Large & 36,848 & 28,125 & 21,272 & 22,680 & 26,849 \\
\hline Other & 28,713 & 29,744 & 37,337 & 39,318 & 37,806 \\
\hline Total Ultimate Consumers & $2,913,704$ & $2,437,388$ & $2,406,923$ & $2,375,896$ & $2,334,143$ \\
\hline \multicolumn{6}{|l|}{ Sales for the Year (megawatthours) } \\
\hline 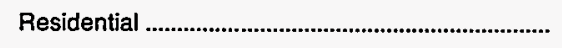 & $32,294,944$ & $26,477,707$ & $26,467,624$ & $25,874,718$ & $25,712,773$ \\
\hline Commercial or Small & $12,443,868$ & $11,831,242$ & $12,926,802$ & $12,284,981$ & $10,997,593$ \\
\hline Industrial or Large & $40,318,799$ & $31,979,721$ & $30,010,647$ & $29,889,490$ & $29,509,416$ \\
\hline Other & $1,501,485$ & $1,304,399$ & $1,335,152$ & $1,319,707$ & $1,401,838$ \\
\hline Total Sales to Ultimate Consumers ................... & $86,559,096$ & $71,593,069$ & $70,740,225$ & $69,368,896$ & $67,621,620$ \\
\hline 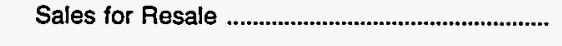 & $1,611,743$ & $1,601,017$ & $1,729,566$ & $4,488,088$ & $4,318,625$ \\
\hline 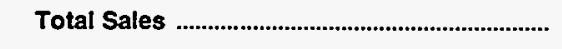 & $88,170,839$ & $73,194,086$ & $72,469,791$ & $73,856,984$ & $71,940,245$ \\
\hline \multicolumn{6}{|l|}{$\begin{array}{l}\text { Operating Revenues for the Year } \\
\text { (thousand dollars) }\end{array}$} \\
\hline Residential & $2,006,083$ & $1,638,723$ & $1,607,450$ & $1,569,090$ & $1,539,650$ \\
\hline Commercial or Small & 886,381 & 830,365 & 874,603 & 825,242 & 740,813 \\
\hline 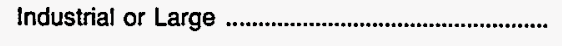 & $2,034,544$ & $1,634,958$ & $1,539,511$ & $1,532,962$ & $1,509,668$ \\
\hline Other & 113,894 & 98,564 & 100,996 & 98,548 & 95,847 \\
\hline $\begin{array}{l}\text { Total Revenues from Sales to } \\
\text { Ultimate Consumers }\end{array}$ & $5,040,902$ & $4,202,610$ & $4,122,560$ & $4,025,842$ & $3,885,978$ \\
\hline Sales for Resale & 43,755 & 37,832 & 34,291 & 128,216 & 116,892 \\
\hline $\begin{array}{l}\text { Total Revenues From Sales of } \\
\text { Electricity }\end{array}$ & $5,084,657$ & $4,240,442$ & $4,156,851$ & $4,154,058$ & $4,002,870$ \\
\hline
\end{tabular}

Note: Totals may not equal sum of components because of independent rounding. The number of nongenerating publicly owned electric utilities for end of period is 142 for June 30, 1993; 137 for June 30,1992; 135 for June 30, 1991; 136 for June 30, 1990; and 135 for June 30, 1989. The City of Hagerstown (MD) changed fiscal year from December 31 to June 30 in 1993; and the City of Memphis (TN) and the City of LaFollette (TN) changed fiscal years from December 31 to June 30 in 1992. Emerald Peoples Utility District (OR), City of Bryan (OH), and Northern Wasco County PUD (OR) were nongenerators for 1989 through 1991, but became generators in 1992. The City of Foley (AL) changed fiscal year from June 30 to December 31 in 1990. The Wisconsin Public Power incorporated System (WI) was a nongenerator in 1989 and 1990, but became a generator in 1991. The City of Marshfield (WI) was a generator in 1989 and 1990, but became a nongenerator in 1991 . sions.

Source: Energy Information Administration, Form EIA-861, "Annual Electric Utility Report." Data are based on calendar year submis- 
Table C27. Electric Energy Account for Major U.S. Publicly Owned Nongenerator Electric Utilitles with Financial Year Ending on

June 30, 1989-1993

(Megawatthours)

\begin{tabular}{|c|c|c|c|c|c|}
\hline Item & 1993 & 1992 & 1991 & 1990 & 1989 \\
\hline \multicolumn{6}{|l|}{ Sources of Energy } \\
\hline Steam & - & - & - & - & - \\
\hline 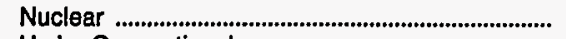 & - & - & - & - & - \\
\hline 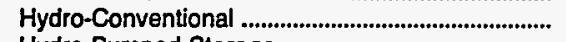 & - & - & - & - & - \\
\hline 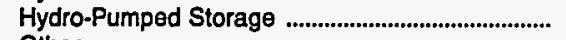 & - & - & - & - & - \\
\hline Other & - & - & - & - & - \\
\hline 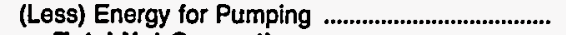 & - & - & - & - & - \\
\hline 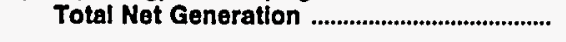 & - & - & - & - & - \\
\hline 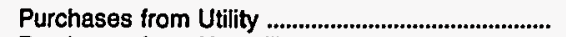 & $91,646,505$ & $76,788,784$ & $75,437,318$ & $76,601,551$ & $74,896,969$ \\
\hline 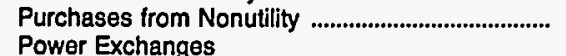 & 2 & 2 & 2,040 & 2,000 & - \\
\hline 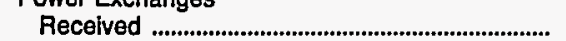 & 3,314 & - & - & 17 & 30 \\
\hline 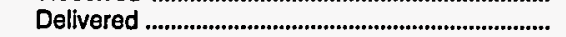 & 11,649 & - & - & - & - \\
\hline 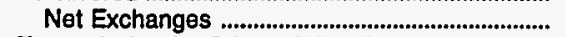 & $-8,335$ & - & - & 17 & 30 \\
\hline \multicolumn{6}{|l|}{ Transmission for Others (Wheeling) } \\
\hline 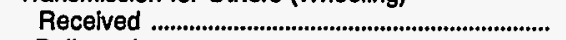 & 304,378 & - & - & - & - \\
\hline 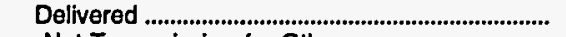 & 300,448 & - & - & - & - \\
\hline Net Transmission for Others & 3,930 & - & - & - & - \\
\hline Transmission by Others Losses ................................... & $-3,930$ & - & - & - & - \\
\hline \multicolumn{6}{|l|}{ Total Net Energy Generated and } \\
\hline 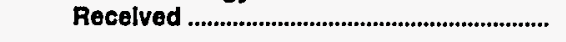 & $91,638,172$ & $76,788,786$ & $75,439,358$ & $76,603,568$ & $74,896,999$ \\
\hline \multicolumn{6}{|l|}{ Disposition of Energy } \\
\hline $\begin{array}{l}\text { Sales to Ultimate Consumers } \\
\text { Requirements Sales for Resale }{ }^{1}\end{array}$ & $\begin{array}{r}85,534,702 \\
1,517,540\end{array}$ & $\begin{array}{r}71,571,297 \\
1,668,178\end{array}$ & $\begin{array}{r}70,032,792 \\
1,860,185\end{array}$ & $\begin{array}{r}69,035,099 \\
4,228,709\end{array}$ & $\begin{array}{r}67,340,630 \\
4,016,600\end{array}$ \\
\hline 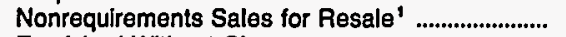 & - & 6,542 & - & - & - \\
\hline Furnished Without Charge & 78,854 & 51,491 & 67,296 & 44,395 & 87,318 \\
\hline Used by Utility (excluding station use) ................... & 126,866 & 112,766 & 128,449 & 129,036 & 116,177 \\
\hline Losses & $\begin{array}{r}4,380,140 \\
91,638,172\end{array}$ & $\begin{array}{r}3,378,453 \\
76,788,786\end{array}$ & $\begin{array}{r}3,350,648 \\
75,439,358\end{array}$ & $\begin{array}{r}3,166,319 \\
76,603,568\end{array}$ & $\begin{array}{r}3,336,278 \\
74,896,999\end{array}$ \\
\hline
\end{tabular}

1 The 1989 data were reported as Sales for Resale (one entry) which is shown as Requirements Sales for Resale.

Note: Totals may not equal sum of components because of independent rounding. The number of nongenerating publicly owned electric utilities for end of period is 142 for June 30, 1993; 137 for June 30, 1992; 135 for June 30, 1991; 136 for June 30,$1990 ;$ and 135 for June 30, 1989. The City of Hagerstown (MD) changed fiscal year from December 31 to June 30 in 1993; and the City of Memphis (TN) and the City of LaFollette (TN) changed fiscal years from December 31 to June 30 in 1992. Emerald Peoples Utility District (OR), City of Bryan $(\mathrm{OH})$, and Northern Wasco County PUD (OR) were nongenerators for 1989 through 1991, but became generators in 1992. The City of Foley (AL) changed fiscal year from June 30 to December 31 in 1990 . The Wisconsin Public Power Incorporated System (WI) was a nongenerator in 1989 and 1990, but became a generator in 1991. The City of Marshfield (WI) was a generator in 1989 and 1990, but became a nongenerator in 1991.

Source: Energy Information Administration, Form ElA-412, "Annual Report of Public Electric Utilities." 
Table C28. Ten Largest U.S. Publicly Owned Nongenerator Electric Utilities

Ranked by Megawatthour Sales to Ultimate Consumers with

Financial Year Ending on December 31, 1993

\begin{tabular}{|c|c|c|c|}
\hline Publicly Owned Electric Utilities & State & Amount & Porcent \\
\hline PUD No 1 of Clark County & Washington & $3,430,257$ & 11.52 \\
\hline PUD No 1 of Benton County & Washington & $1,360,014$ & 4.57 \\
\hline Central Lincoln Peoples UtI Dt & Oregon & $1,314,113$ & 4.41 \\
\hline 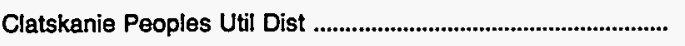 & Oregon & 897,085 & 3.01 \\
\hline Fort Collins City of & Colorado & 873,919 & 2.94 \\
\hline Springfield City of & Oregon & 803,012 & 2.70 \\
\hline 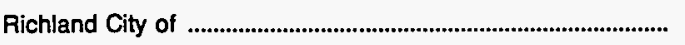 & Washington & 634,082 & 2.13 \\
\hline 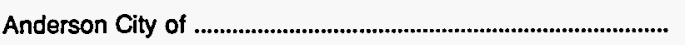 & Indiana & 630,092 & 2.12 \\
\hline Athens City of & Alabama & 626,169 & 2.10 \\
\hline 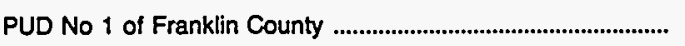 & Washington & 625,542 & 2.10 \\
\hline Subtotal & & $11,194,285$ & 37.60 \\
\hline
\end{tabular}

Source: Energy Information Administration, Form EIA-412, "Annual Report of Public Electric Utilities."

Table C29. Ten Largest U.S. Publicly Owned Nongenerator Electric Utllities Ranked by Megawatthour Sales for Resale with Financial Year Ending on December 31, 1993

\begin{tabular}{|c|c|c|c|}
\hline Publicly Owned Electric Utilltles & State & Amount & Percent \\
\hline 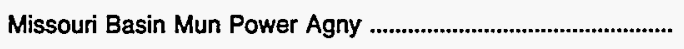 & South Dakota & $1,824,685$ & 66.95 \\
\hline Kansas Municipal Energy Agency & Kansas & 323,038 & 11.85 \\
\hline 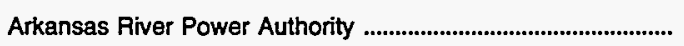 & Colorado & 274,109 & 10.06 \\
\hline Badger Power Marketing Auth & Wisconsin & 249,200 & 9.14 \\
\hline Norris Public Power District & Nebraska & 14,795 & .54 \\
\hline Pierre City of & South Dakota & 13,351 & .49 \\
\hline Westfield City of & Massachusetts & 8,920 & .33 \\
\hline Dawson County Public Pwr Dist & Nebraska & 4,773 & .18 \\
\hline 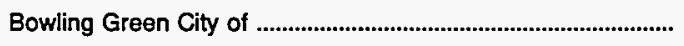 & Ohio & 3,075 & .11 \\
\hline Danvers Town of & Massachusetts & 2,348 & .09 \\
\hline Subtotal & & $2,718,294$ & 99.74 \\
\hline
\end{tabular}

Source: Energy Information Administration, Form EIA-412, "Annual Report of Public Electric Utilities." 
Table C30. Composite Statement of Income for Major U.S. Publicly Owned Nongenerator Electric Utilities with Financial Year Ending on December 31, 1989-1993

(Thousand Dollars)

\begin{tabular}{|c|c|c|c|c|c|}
\hline Item & 1993 & 1992 & 1991 & 1990 & 1989 \\
\hline Electric Utility Operating Revenues ..................... & $1,629,821$ & $2,158,597$ & $2,251,181$ & $2,128,674$ & $1,901,801$ \\
\hline 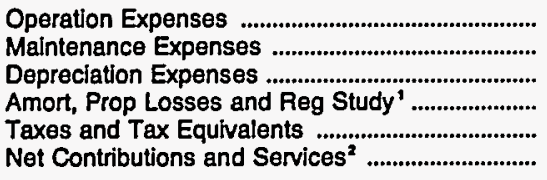 & $\begin{array}{r}1,343,821 \\
46,241 \\
74,479 \\
2,168 \\
48,592 \\
-\end{array}$ & $\begin{array}{r}1,833,153 \\
68,719 \\
87,335 \\
2,340 \\
56,344 \\
-\end{array}$ & $\begin{array}{r}1,894,483 \\
63,243 \\
93,189 \\
- \\
54,151 \\
35,714\end{array}$ & $\begin{array}{r}1,794,945 \\
63,287 \\
89,010 \\
- \\
52,609 \\
35,693\end{array}$ & $\begin{array}{r}1,640,446 \\
59,486 \\
72,264 \\
- \\
49,263 \\
30,132\end{array}$ \\
\hline $\begin{array}{l}\text { Total Electric Utility Operating } \\
\text { Expenses }\end{array}$ & $1,515,301$ & $2,047,891$ & $2,140,780$ & $2,035,543$ & $1,851,591$ \\
\hline $\begin{array}{l}\text { Net Electric Utility Operating Income } \\
\text { Income from Electric Plant Leased }\end{array}$ & 114,520 & 110,707 & 110,401 & 93,131 & 50,210 \\
\hline 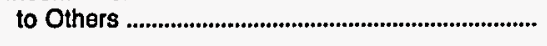 & 1,440 & 750 & 360 & 424 & 140 \\
\hline Electric Utility Operating Income ..................... & 115,960 & 111,456 & 110,761 & 93,555 & 50,350 \\
\hline 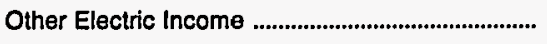 & 34,556 & 65,687 & 51,653 & 54,390 & 60,863 \\
\hline $\begin{array}{l}\text { Other Electric Deductions } \\
\text { Allowance for Other Funds Used }\end{array}$ & 8,155 & 23,319 & 4,873 & - & - \\
\hline 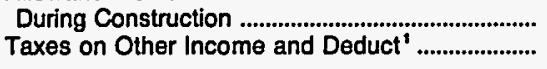 & $\begin{array}{r}87 \\
1,838\end{array}$ & $\begin{array}{r}21 \\
1,374\end{array}$ & $\begin{array}{r}361 \\
-\end{array}$ & 562 & 289 \\
\hline 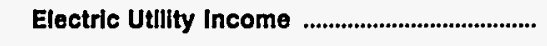 & 140,610 & 152,471 & 157,902 & 148,506 & 111,502 \\
\hline 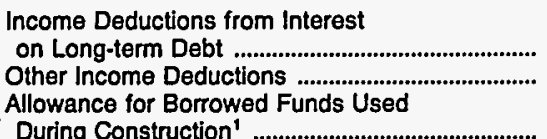 & $\begin{array}{l}30,060 \\
14,211\end{array}$ & $\begin{array}{r}46,371 \\
4,172\end{array}$ & $\begin{array}{r}61,140 \\
4,724\end{array}$ & $\begin{array}{r}57,925 \\
5,953\end{array}$ & $\begin{array}{r}47,579 \\
3,970\end{array}$ \\
\hline 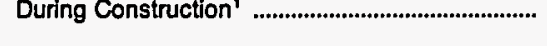 & -270 & -78 & - & - & - \\
\hline 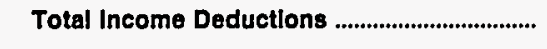 & 44,002 & 50,465 & 65,864 & 63,878 & 51,549 \\
\hline Income Before Extraordinary Items ........................ & 96,609 & 102,006 & 92,038 & 84,628 & 59,953 \\
\hline Extraordinary Income & 1,284 & 13,557 & 1,973 & 2,558 & 24,423 \\
\hline 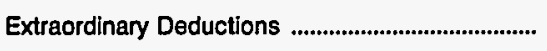 & 1,900 & 14,209 & 5,426 & 240 & 4,916 \\
\hline Net Income & 95,993 & 101,354 & 88,585 & 86,947 & 79,461 \\
\hline
\end{tabular}

1 Data reporting initiated in 1992.

2 Data reporting discontinued in 1992.

- Data not available.

Note: Totals may not equal sum of components because of independent rounding. The number of nongenerating publicly owned electric utilities for end of period is 93 for December 31, 1993; 88 for December 31, 1992; 86 for December 31, 1991; 84 for December 31, 1990; and 77 for December 31, 1989. The City of Hagerstown (MD) changed fiscal year from December 31 to June 30 in 1993; and the City of Memphis (TN) and the City of LaFollette (TN) changed fiscal years from December 31 to June 30 in 1992. Emerald Peoples Utility District (OR), City of Bryan (OH), and Northern Wasco County PUD (OR) were nongenerators for 1989 through 1991, but became generators in 1992. The City of Foley (AL) changed fiscal year from June 30 to December 31 in 1990. The Wisconsin Public Power Incorporated System (WI) was a nongenerator in 1989 and 1990, but became a generator in 1991 . The City of Marshfield (WI) was a generator in 1989 and 1990, but became a nongenerator in 1991.

Source: Energy Information Administration, Form ElA-412, "Annual Report of Public Electric Utilities." 
Table C31. Composite Balance Sheet for Major U.S. Publicly Owned Nongenerator Electric Utilities with Financial Year Ending on

December 31 at End of Period, 1989-1993

(Thousand Dollars)

\begin{tabular}{|c|c|c|c|c|c|}
\hline Item & 1993 & 1992 & 1991 & 1990 & 1989 \\
\hline \multicolumn{6}{|l|}{ Electric Utility Plant } \\
\hline Electric Utility Plant \& Adjust ........................................ & $2,354,689$ & $2,882,052$ & $2,852,226$ & $2,670,370$ & $2,432,306$ \\
\hline Const Work in Progress & 85,520 & 115,017 & - & - & \\
\hline (less) Depr, Amort, and Depletion ............................ & 907,475 & $1,096,972$ & $1,035,792$ & 960,118 & 858,220 \\
\hline Net Electric Utllity Plant' ....................................... & $1,532,734$ & $1,900,097$ & - & - & - \\
\hline 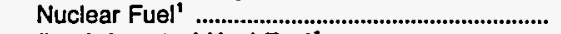 & - & - & - & - & - \\
\hline 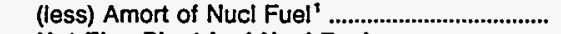 & - & - & - & - & - \\
\hline $\begin{array}{l}\text { Net Elec Plant Incl Nucl Fuel } \\
\text { Other Property \& Investments }\end{array}$ & $1,532,734$ & $1,900,097$ & $1,816,434$ & $1,710,253$ & $1,574,086$ \\
\hline 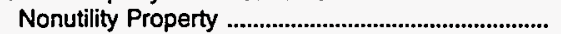 & 227,813 & 203,618 & 198,098 & 159,993 & 159,012 \\
\hline (less) Accum Provisions for Depr \& Amort ............ & 54,766 & 48,346 & 45,858 & 35,068 & 39,158 \\
\hline Invest in Assoc Enterprises & 9,550 & 7,762 & & 525 & 788 \\
\hline 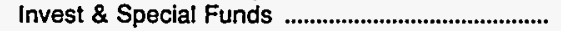 & 207,033 & 304,054 & 370,683 & 306,116 & 274,650 \\
\hline Total Other Property \& Investments ............... & 389,631 & 467,088 & 523,021 & 431,566 & 395,283 \\
\hline \multicolumn{6}{|l|}{ Current and Accrued Assets } \\
\hline Cash, Working Funds \& Investments ..................... & 357,472 & 339,322 & 362,180 & 271,648 & 280,657 \\
\hline 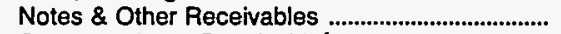 & 26,934 & 71,293 & 235,845 & 215,712 & 198,098 \\
\hline 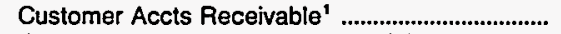 & 162,190 & 147,247 & & - & \\
\hline (less) Accum Prov for Uncollected Accts ............. & 7,801 & 8,016 & 7,590 & 6,807 & 6,626 \\
\hline 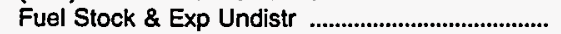 & 264 & 500 & & - & \\
\hline 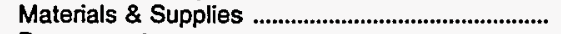 & 61,358 & 69,972 & 67,872 & 67,040 & 62,867 \\
\hline 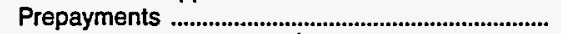 & 23,490 & 21,237 & 83,368 & 85,744 & 10,138 \\
\hline 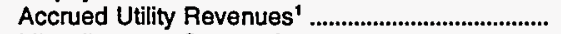 & 12,311 & 11,517 & - & - & - \\
\hline Miscellaneous Current \& Accrued Assets ............ & 9,526 & 15,415 & 27,160 & 24,173 & 33,421 \\
\hline Total Current \& Accrued Assets .......................... & 645,745 & 668,487 & 768,834 & 657,510 & 578,555 \\
\hline \multicolumn{6}{|l|}{ Deferred Debits } \\
\hline 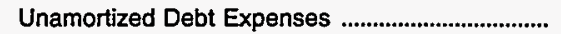 & 22,259 & 18,917 & 25,875 & 26,614 & 15,817 \\
\hline Extraordinary Losses, Study Cost ................................. & 6,434 & 3,980 & & & \\
\hline Misc Debt, R \& D Exp, Unamrt Losses ................. & 24,497 & 39,228 & 80,645 & 74,893 & 65,708 \\
\hline Total Deferred Debits ..................................................... & 53,190 & 62,125 & 106,520 & 101,508 & 81,524 \\
\hline Total Assets \& Other Debits .................................. & $2,621,300$ & $3,097,797$ & $3,214,809$ & $2,900,836$ & $2,629,458$ \\
\hline \multicolumn{6}{|l|}{ Proprietary Capital } \\
\hline 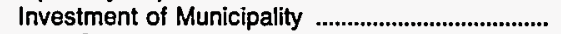 & 135,447 & 91,968 & 95,426 & 93,420 & 85,966 \\
\hline 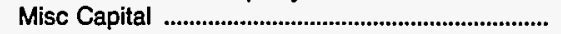 & 81,107 & 88,736 & 136,711 & 126,335 & 114,893 \\
\hline Retained Earnings …........................................................ & $1,471,780$ & $1,702,946$ & $1,512,670$ & $1,410,735$ & $1,305,678$ \\
\hline \multirow{2}{*}{\multicolumn{6}{|c|}{ Long-term Debt }} \\
\hline & & & & & \\
\hline 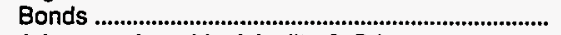 & 547,884 & 759,756 & $1,011,891$ & 838,541 & 698,437 \\
\hline Advances from Municipality \& Other ........................... & 55,206 & 70,241 & 58,600 & 50,983 & 56,589 \\
\hline Unamort Prem on Long-term Debt ............................ & 2,398 & 2,791 & & & \\
\hline (less) Unamort Discount on Long-term Debt ....... & 2,151 & 1,481 & 1,283 & 1,464 & 5,312 \\
\hline 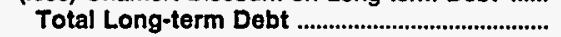 & 603,337 & 831,307 & $1,069,215$ & 888,064 & 749,730 \\
\hline \multicolumn{6}{|l|}{ Other Noncurrent Liabilities } \\
\hline 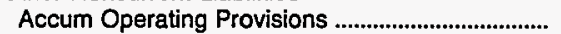 & 8,712 & 6,035 & 36,590 & 31,001 & 29,484 \\
\hline Accum Prov for Rate Refunds ${ }^{1}$..................................... & 224 & - & - & & \\
\hline Total Other Noncurrent Llabilities .................... & 8,936 & 6,035 & 36,590 & 31,001 & 29,484 \\
\hline \multicolumn{6}{|l|}{ Current and Accrued Liabilities } \\
\hline 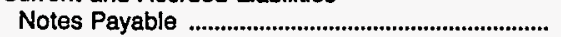 & 29,567 & 22,041 & 24,474 & 18,660 & 13,814 \\
\hline Accounts Payable & 149,460 & 190,881 & 192,092 & 192,249 & 188,613 \\
\hline Payables to Assoc Enterprises …….............................. & 2,700 & 2,998 & 1,898 & 1,914 & 2,043 \\
\hline 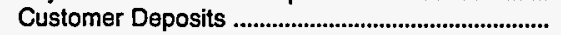 & 17,498 & 16,811 & 15,768 & 15,059 & 12,557 \\
\hline 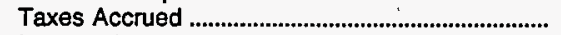 & 12,960 & 11,124 & 10,501 & 9,238 & 9,044 \\
\hline 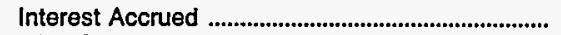 & 7,859 & 8,666 & 10,514 & 9,736 & 8,719 \\
\hline 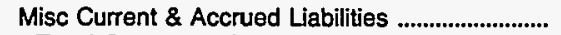 & 35,012 & 40,286 & 34,968 & 34,715 & 35,723 \\
\hline \multirow{2}{*}{\multicolumn{6}{|c|}{ Deferred Credits }} \\
\hline & & & & & \\
\hline Customer Advances for Construction ..................... & 43,169 & 35,813 & 35,394 & 30,221 & 25,316 \\
\hline Other Deferred Credits ............................................... & 20,959 & 43,212 & 37,365 & 39,404 & 43,032 \\
\hline 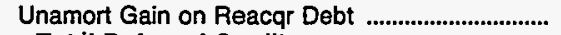 & 1,508 & 4,973 & 1,224 & 85 & 4,748 \\
\hline Total Deferred Credits ................................................. & 65,637 & 83,998 & 73,982 & 69,710 & 73,096 \\
\hline Total Llabilities and Other Credits ................... & $2,621,300$ & $3,097,797$ & $3,214,809$ & $2,900,836$ & $2,629,458$ \\
\hline
\end{tabular}

1 Data reporting initiated in 1992.

Note: Totals may not equal sum of components because of independent rounding. The number of nongenerating publicly owned electric utilities for end of period is 93 for December 31, 1993; 88 for December 31, 1992; 86 for December 31, 1991; 84 for December 31, 1990; and 77 for December 31, 1989. The City of Hagerstown (MD) changed fiscal year from December 31 to June 30 in 1993; and the City of Memphis (TN) and the City of LaFollette (TN) changed fiscal years from December 31 to June 30 in 1992. Emerald Peoples Utility District (OR), City of Bryan (OH), and Northern Wasco County PUD (OR) were nongenerators for 1989 through 1991, but became generators in 1992. The City of Foley (AL) changed fiscal year from June 30 to December 31 in 1990. The Wisconsin Public Power Incorporated System (WI) was a nongenerator in 1989 and 1990, but became a generator in 1991. The City of Marshfield (WI) was a generator in 1989 and 1990, but became a nongenerator in 1991.

Source: Energy Information Administration, Form EIA-412, "Annual Report of Public Electric Utilities." 
Table C32. Composite Financial Indicators for Major U.S. Publicly Owned Nongenerator Electric Utilities with Financial Year Ending on December 31, 1989-1993

\begin{tabular}{|c|c|c|c|c|c|}
\hline Item & 1993 & 1992 & 1991 & 1990 & 1989 \\
\hline Total Electric Utility Plant per Dollar of Revenue & 1.5 & 1.4 & 1.3 & 1.3 & 1.3 \\
\hline Current Assets to Current Liabilities .......................... & 2.5 & 2.3 & 2.6 & 2.3 & 2.1 \\
\hline $\begin{array}{l}\text { Total Electric Utility Plant as a Percent of Total } \\
\text { Assets }\end{array}$ & 93.1 & 96.7 & 88.7 & 92.1 & 92.5 \\
\hline $\begin{array}{l}\text { Net Electric Utility Plant as a Percent of Total } \\
\text { Assets }\end{array}$ & 58.5 & 61.3 & 56.5 & 59.0 & 59.9 \\
\hline 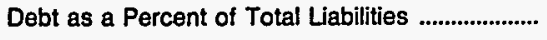 & 32.7 & 36.2 & 42.3 & 40.3 & 38.8 \\
\hline $\begin{array}{l}\text { Depreciation, Amortization and Depletion } \\
\text { as a Percent of Total Electric Utility Plant ........... }\end{array}$ & 37.2 & 36.6 & 36.3 & 36.0 & 35.3 \\
\hline $\begin{array}{l}\text { Electric Operation and Maintenance Expenses } \\
\text { as a Percent of } \\
\text { Electric Utility Operating Pevenues ........................ }\end{array}$ & 85.3 & 88.1 & 87.0 & 87.3 & 89.4 \\
\hline $\begin{array}{l}\text { Electric Depreciation and Amortization } \\
\text { as a Percent of } \\
\text { Electric Utility Operating Revenues ........................ }\end{array}$ & 4.6 & 4.0 & 4.1 & 4.2 & 3.8 \\
\hline $\begin{array}{l}\text { Taxes and Tax Equivalents } \\
\text { as a Percent of } \\
\text { Electric Utility Operating Revenues .......................... }\end{array}$ & 3.0 & 2.6 & 2.4 & 2.5 & 2.6 \\
\hline $\begin{array}{l}\text { Interest on Long-term Debt } \\
\text { as a Percent of } \\
\text { Electric Utility Operating Revenues }\end{array}$ & 1.8 & 2.1 & 2.7 & 2.7 & 2.5 \\
\hline 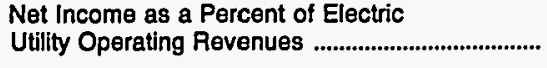 & 5.9 & 4.7 & 3.9 & 4.1 & 4.2 \\
\hline Purchased Power Cents Per Kilowatthour ............ & 3.3 & 3.6 & 3.6 & 3.5 & 3.6 \\
\hline
\end{tabular}

Note: Totals may not equal sum of components because of independent rounding. The number of nongenerating publicly owned electric utilities for end of period is 93 for December 31, 1993; 88 for December 31, 1992; 86 for December 31, 1991; 84 for December 31, 1880; and 77 for December 31, 1989. The City of Hagerstown (MD) changed fiscal year from December 31 to June 30 in 1993; and the City of Memphis (TN) and the City of LaFollette (TN) changed fiscal years from December 31 to June 30 in 1992 . Emerald Peoples Utility District (OR), City of Bryan (OH), and Northern Wasco County PUD (OR) were nongenerators for 1989 through 1991, but became generators in 1992. The City of Foley (AL) changed fiscal year from June 30 to December 31 in 1990. The Wisconsin Public Power Incorporated System (WI) was a nongenerator in 1989 and 1990, but became a generator in 1991. The City of Marshfield (WI) was a generator in 1989 and 1990, but became a nongenerator in 1991.

Source: Energy Information Administration, Form EIA-412, "Annual Report of Public Electric Utilities." 
Table C33. Electric Operation and Maintenance Expenses for Major U.S.

Publicly Owned Nongenerator Electric Utilities with

Financial Year Ending on December 31, 1989-1993

(Thousand Dollars)

\begin{tabular}{|c|c|c|c|c|c|}
\hline Item & 1993 & 1992 & 1991 & 1990 & 1989 \\
\hline \multicolumn{6}{|l|}{ Production Expenses } \\
\hline 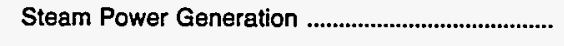 & 362 & 416 & 544 & 230 & 263 \\
\hline 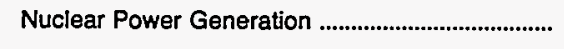 & - & - & - & - & - \\
\hline 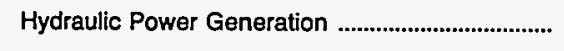 & 9 & 1 & - & - & - \\
\hline Other Power Generation & 1,249 & 622 & 97 & 105 & - \\
\hline Purchased Power & $1,140,781$ & $1,579,889$ & $1,648,190$ & $1,538,236$ & $1,414,003$ \\
\hline 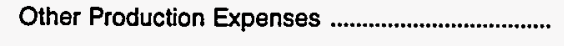 & 8,113 & 4,576 & 7,326 & 36,240 & 31,211 \\
\hline 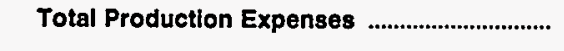 & $1,150,514$ & $1,585,505$ & $1,656,156$ & $1,574,811$ & $1,445,478$ \\
\hline 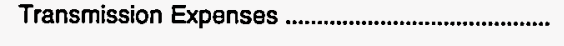 & 19,145 & 22,387 & 20,321 & 22,677 & 17,736 \\
\hline 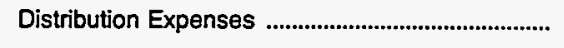 & 97,151 & 134,814 & 125,756 & 114,903 & 103,496 \\
\hline 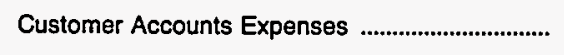 & 33,441 & 38,622 & 37,058 & 36,105 & 33,759 \\
\hline Customer Service and Information Expenses ..... & 5,753 & 6,113 & 5,280 & 4,879 & 4,695 \\
\hline Sales Expenses & 2,167 & 2,495 & 1,582 & 1,483 & 1,743 \\
\hline Administrative and General Expenses ................... & 81,871 & 111,937 & 111,572 & 103,374 & 93,025 \\
\hline $\begin{array}{l}\text { Total Electric Operation } \\
\text { and Maintenance Expenses }\end{array}$ & $1,390,042$ & $1,901,872$ & $1,957,726$ & $1,858,231$ & $1,699,932$ \\
\hline
\end{tabular}

Fuel Expenses in Operation

Steam Power Generation

Nuclear Power Generation

Other Power Generation

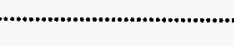

13

2

13

2

$-3$

$-$

5

3,714

5,493

Regular Full-time'

911

870

Total Elec Dept Employees

4,625

6,365

1 Data reporting initiated in 1992.

Note: Totals may not equal sum of components because of independent rounding. The number of nongenerating publicly owned electric utilities for end of period is 93 for December 31, 1993; 88 for December 31, 1992; 86 for December 31, 1991; 84 for December 31 , 1990; and 77 for December 31, 1989. The City of Hagerstown (MD) changed fiscal year from December 31 to June 30 in 1993; and the City of Memphis (TN) and the City of LaFollette (TN) changed fiscal years from December 31 to June 30 in 1992 . Emerald Peoples Utility District (OR), City of Bryan (OH), and Northern Wasco County PUD (OR) were nongenerators for 1989 through 1991, but became generators in 1992. The City of Foley (AL) changed fiscal year from June 30 to December 31 in 1990. The Wisconsin Public Power Incorporated System (WI) was a nongenerator in 1989 and 1990, but became a generator in 1991. The City of Marshfield (WI) was a generator in 1989 and 1990 , but became a nongenerator in 1991.

Source: Energy Information Administration, Form ElA-412, "Annual Report of Public Electric Utilities." 
Table C34. Electric Utillty Plant for Major U.S. Publicly Owned Nongenerator

Electric Utilitles with Financial Year Ending on

December 31 at End of Period, 1989-1993

(Thousand Dollars)

\begin{tabular}{|c|c|c|c|c|c|}
\hline Item & 1993 & 1992 & 1991 & 1990 & 1989 \\
\hline \multicolumn{6}{|l|}{ Electric Plant In Service } \\
\hline 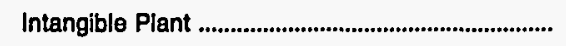 & 10,181 & 10,091 & 7,860 & 7,015 & 6,854 \\
\hline \multicolumn{6}{|l|}{ Production Plant } \\
\hline Steam & 16,298 & 28,078 & 27,651 & 26,928 & 31,281 \\
\hline 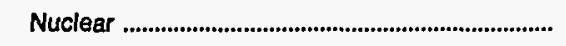 & - & - & - & - & - \\
\hline 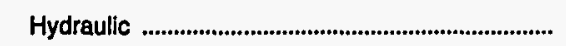 & 582 & 582 & 582 & 582 & 582 \\
\hline Other & 13,931 & 6,369 & 6,541 & 2,162 & 2,158 \\
\hline 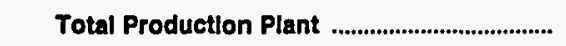 & 30,811 & 35,029 & 34,774 & 29,673 & 34,021 \\
\hline 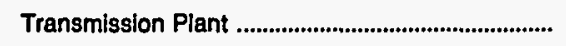 & 157,091 & 287,707 & 251,496 & 242,341 & 214,584 \\
\hline 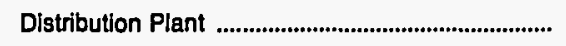 & $1,752,874$ & $2,129,995$ & $2,060,843$ & $1,924,956$ & $1,753,797$ \\
\hline 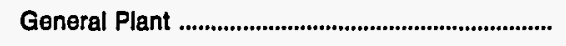 & 359,138 & 376,397 & 346,682 & 332,205 & 298,721 \\
\hline Total Electric Plant In Service ............................. & $2,310,095$ & $2,839,219$ & $2,701,656$ & $2,536,190$ & $2,307,977$ \\
\hline 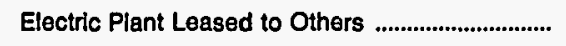 & 704 & 615 & 662 & 708 & 640 \\
\hline Construction Work in Progress - Electric ............... & 85,520 & 115,017 & 103,296 & 89,870 & 75,729 \\
\hline 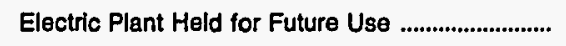 & 1,292 & 1,309 & 10,653 & 10,197 & 10,046 \\
\hline Electric Plant Misc & 42,599 & 40,909 & 35,960 & 33,407 & 37,914 \\
\hline 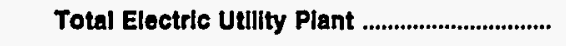 & $2,440,209$ & $2,997,069$ & $2,852,226$ & $2,670,370$ & $2,432,306$ \\
\hline $\begin{array}{l}\text { Accumulated Provision for } \\
\text { Depreciation and Amortization ................................ }\end{array}$ & 907,475 & $1,096,972$ & $1,035,792$ & 960,118 & 858,220 \\
\hline Net Electric Utility Plant ....................................... & $1,532,734$ & $1,900,097$ & $1,816,434$ & $1,710,253$ & $1,574,086$ \\
\hline
\end{tabular}

Note: Totals may not equal sum of components because of independent rounding. The number of nongenerating publicly owned electric utilities for end of period is 93 for December 31, 1993; 88 for December 31, 1992; 86 for December 31, 1991; 84 for December 31, 1990; and 77 for December 31, 1989. The City of Hagerstown (MD) changed fiscal year from December 31 to June 30 in 1993; and the City of Memphis (TN) and the City of LaFollette (TN) changed fiscal years from December 31 to June 30 in 1992 . Emerald Peoples Utility District (OR), City of Bryan (OH), and Northern Wasco County PUD (OR) were nongenerators for 1989 through 1991, but became generators in 1992. The City of Foley (AL) changed fiscal year from June 30 to December 31 in 1990. The Wisconsin Public Power Incorporated System (WI) was a nongenerator in 1989 and 1890, but became a generator in 1991. The City of Marshfield (WI) was a generator in 1989 and 1990 , but became a nongenerator in 1991.

Source: Energy Information Administration, Form EIA-412, "Annual Report of Public Electric Utilities." 
Table C35. Number of Consumers, Sales, and Operating Revenue for Major

U.S. Publicly Owned Nongenerator Electric Utilities with

Financial Year Ending on December 31, 1989-1993

\begin{tabular}{|c|c|c|c|c|c|}
\hline Item & 1993 & 1992 & 1991 & 1990 & 1989 \\
\hline \multicolumn{6}{|l|}{ Number of Consumers } \\
\hline 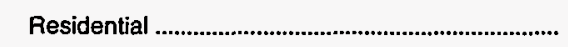 & 972,174 & $1,252,787$ & $1,215,874$ & $1,187,590$ & $1,131,699$ \\
\hline Commercial or Small & 121,116 & 143,672 & 146,187 & 143,435 & 131,239 \\
\hline Industrial or Large & 8,702 & 14,306 & 6,913 & 6,824 & 6,583 \\
\hline Other & 35,169 & 49,680 & 58,258 & 54,952 & 51,921 \\
\hline 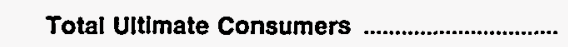 & $1,137,161$ & $1,460,445$ & $1,427,232$ & $1,392,801$ & $1,321,442$ \\
\hline \multicolumn{6}{|l|}{ Sales for the Year (megawatthours) } \\
\hline Residential & $11,886,299$ & $15,090,546$ & $15,659,505$ & $14,897,373$ & $14,093,218$ \\
\hline Commercial or Small & $7,048,676$ & $7,259,565$ & $11,332,825$ & $10,868,836$ & $10,243,430$ \\
\hline Industrial or Large & $10,347,973$ & $15,685,347$ & $11,090,867$ & $10,624,836$ & $10,064,758$ \\
\hline Other & 783,628 & $1,250,985$ & $1,432,510$ & $1,400,762$ & $1,312,076$ \\
\hline Total Sales to Ultimate Consumers ................... & $30,066,576$ & $39,286,443$ & $39,515,707$ & $37,791,807$ & $35,713,482$ \\
\hline Sales for Resale & $2,725,475$ & $2,881,020$ & $4,786,485$ & $4,517,100$ & $2,070,272$ \\
\hline Total Sales & $32,792,051$ & $42,167,463$ & $44,302,192$ & $42,308,907$ & $37,783,754$ \\
\hline \multicolumn{6}{|l|}{$\begin{array}{l}\text { Operating Revenues for the Year } \\
\text { (thousand dollars) }\end{array}$} \\
\hline Residential & 667,634 & 851,333 & 859,173 & 814,217 & 761,718 \\
\hline Commercial or Small & 383,543 & 399,907 & 625,575 & 596,333 & 560,246 \\
\hline Industrial or Large & 452,305 & 726,419 & 464,741 & 444,333 & 423,850 \\
\hline Other & 49,644 & 71,459 & 79,256 & 75,527 & 70,472 \\
\hline 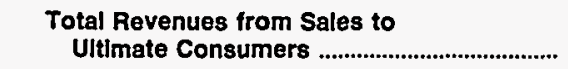 & $1,553,126$ & $2,049,118$ & $2,028,745$ & $1,930,410$ & $1,816,286$ \\
\hline Sales for Resale & 84,259 & 79,291 & 164,736 & 152,081 & 76,877 \\
\hline $\begin{array}{l}\text { Total Revenues From Sales of } \\
\text { Electricity }\end{array}$ & $1,637,385$ & $2,128,409$ & $2,193,481$ & $2,082,491$ & $1,893,163$ \\
\hline
\end{tabular}

Note: Totals may not equal sum of components because of independent rounding. The number of nongenerating publicly owned electric utilities for end of period is 93 for December 31, 1993; 88 for December 31, 1992; 86 for December 31, 1991; 84 for December 31, 1990; and 77 for December 31, 1989. The City of Hagerstown (MD) changed fiscal year from December 31 to June 30 in 1993; and the City of Memphis (TN) and the City of LaFollette (TN) changed fiscal years from December 31 to June 30 in 1992. Emerald Peoples Utility District (OR), City of Bryan (OH), and Northern Wasco County PUD (OR) were nongenerators for 1989 through 1991, but became generators in 1992. The City of Foley (AL) changed fiscal year from June 30 to December 31 in 1990. The Wisconsin Public Power Incorporated System (Wi) was a nongenerator in 1989 and 1990, but became a generator in 1991. The City of Marshfield (WI) was a generator in 1989 and 1990, but became a nongenerator in 1991. sions.

Source: Energy Information Administration, Form ElA-861, "Annual Electric Utility Report." Data are based on calendar year submis- 
Table C36. Electric Energy Account for Major U.S. Publicly Owned Nongenerator Electric Utilities with Financial Year Ending on December 31, 1989-1993 (Megawatthours)

\begin{tabular}{|c|c|c|c|c|c|}
\hline Item & 1993 & 1992 & 1991 & 1990 & 1989 \\
\hline \multicolumn{6}{|l|}{ Sources of Energy } \\
\hline Steam & - & - & - & - & - \\
\hline 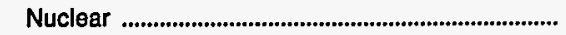 & - & - & - & - & - \\
\hline 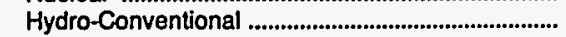 & - & - & - & - & - \\
\hline 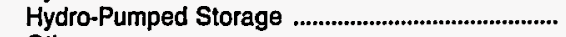 & - & - & - & - & - \\
\hline Other & - & - & - & - & - \\
\hline (Less) Energy for Pumping ........................................ & - & - & - & - & - \\
\hline Total Net Generation ........................................ & - & - & - & - & - \\
\hline 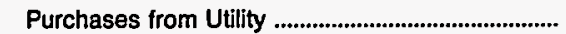 & $33,801,100$ & $43,971,877$ & $45,754,785$ & $44,246,921$ & $39,792,406$ \\
\hline $\begin{array}{l}\text { Purchases from Nonutility ........................................ } \\
\text { Power Exchanges }\end{array}$ & 156,083 & 160,421 & 318,282 & 5,865 & 2,345 \\
\hline 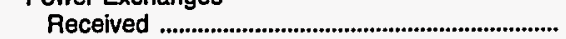 & 325,173 & 363,092 & 289,014 & 67,326 & 274,542 \\
\hline Delivered & 116,248 & 158,997 & 202,905 & 22,994 & 268,065 \\
\hline Net Exchanges & 208,926 & 204,095 & 86,109 & 44,332 & 6,476 \\
\hline \multicolumn{6}{|l|}{ Transmission for Others (Wheeling) } \\
\hline 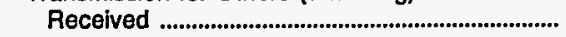 & 7,476 & 1,986 & 7,164 & 8,071 & 14.484 \\
\hline 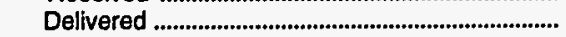 & 7,476 & 1,986 & 7,164 & 8,825 & 6,681 \\
\hline Net Transmission for Others .............................. & - & - & - & -754 & 7,803 \\
\hline Transmission by Others Losses ............................... & - & -220 & - & - & - \\
\hline \multicolumn{6}{|l|}{ Total Net Energy Generated and } \\
\hline 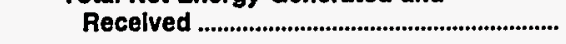 & $34,166,108$ & $44,336,172$ & $46,159,176$ & $44,296,364$ & $39,809,034$ \\
\hline \multicolumn{6}{|l|}{ Disposition of Energy } \\
\hline 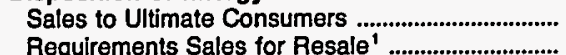 & $\begin{array}{r}29,773,216 \\
1,806,499\end{array}$ & $\begin{array}{r}39,282,927 \\
1,459,980\end{array}$ & $\begin{array}{r}39,512,479 \\
3,775,557\end{array}$ & $\begin{array}{r}37,790,731 \\
\mathbf{3}, 517,537\end{array}$ & $\begin{array}{r}35,735,573 \\
2,051,847\end{array}$ \\
\hline 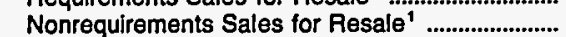 & 918,823 & $1,420,967$ & $1,010,926$ & 999,561 & \\
\hline Furnished Without Charge ........................................ & 106,278 & 77,698 & 78,966 & 86,114 & 83,438 \\
\hline Used by Utility (excluding station use) ................... & 58,697 & 57,199 & 54,114 & 67,227 & 67,065 \\
\hline Losses & $1,502,590$ & $2,037,395$ & $1,727,132$ & $1,835,182$ & $1,871,106$ \\
\hline Total Disposition & $34,166,108$ & $44,336,172$ & $46,159,176$ & $44,296,364$ & $39,809,034$ \\
\hline
\end{tabular}

1 The 1989 data were reported as Sales for Resale (one entry) which is shown as Requirements Sales for Resale.

Note: Totals may not equal sum of components because of independent rounding. The number of nongenerating publicly owned electric utilities for end of period is 93 for December 31, 1993; 88 for December 31, 1992; 86 for December 31, 1991 ; 84 for December 31. 1990; and 77 for December 31, 1989. The City of Hagerstown (MD) changed fiscal year from December 31 to June 30 in 1993 ; and the City of Memphis (TN) and the City of LaFollette (TN) changed fiscal years from December 31 to June 30 in 1992. Emerald Peoples Utility District (OR). City of Bryan (OH), and Northern Wasco County PUD (OR) were nongenerators for 1989 through 1991, but became generators in 1992. The City of Foley (AL) changed fiscal year from June $\mathbf{3 0}$ to December $\mathbf{3 1}$ in 1990 . The Wisconsin Public Power Incorporated System (WI) was a nongenerator in 1989 and 1990, but became a generator in 1991. The City of Marshfield (WI) was a generator in 1989 and 1990 , but became a nongenerator in 1991 .

Source: Energy Information Administration, Form ElA-412, "Annual Report of Public Electric Utilities." 
Table C37. Twenty Largest U.S. Publicly Owned Electric Utilities Ranked by Megawatthour Sales to Ultimate Consumers for All Respondents, 1993

\begin{tabular}{|c|c|c|c|}
\hline Publicly Owned Electric Utilities & State & Amount & Reporting Date \\
\hline $\begin{array}{l}\text { Los Angeles City of } \\
\text { Salt River Proj Ag I \& P Dist } \\
\text { Power Authority of State of NY } \\
\text { San Antonio City of } \\
\text { Memphis City of }\end{array}$ & $\begin{array}{l}\text { California } \\
\text { Arizona } \\
\text { New York } \\
\text { Texas } \\
\text { Tennessee }\end{array}$ & $\begin{array}{l}21,769,016 \\
15,575,686 \\
13,385,987 \\
12,369,214 \\
11,075,238\end{array}$ & $\begin{array}{l}\text { June } 30 \\
\text { April } 30 \\
\text { December } 31 \\
\text { January } 31 \\
\text { June } 30\end{array}$ \\
\hline 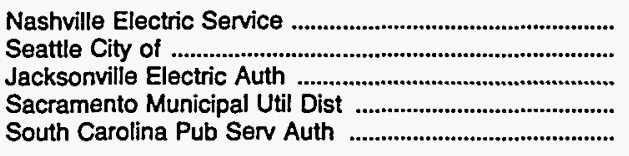 & $\begin{array}{l}\text { Tennessee } \\
\text { Washington } \\
\text { Florida } \\
\text { California } \\
\text { South Carolina }\end{array}$ & $\begin{array}{l}9,976,634 \\
8,914,889 \\
8,599,683 \\
8,446,459 \\
7,370,739\end{array}$ & $\begin{array}{l}\text { June } 30 \\
\text { December } 31 \\
\text { September } 30 \\
\text { December } 31 \\
\text { December } 31\end{array}$ \\
\hline 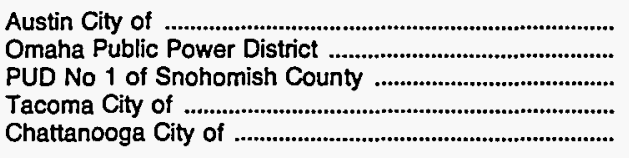 & $\begin{array}{l}\text { Texas } \\
\text { Nebraska } \\
\text { Washington } \\
\text { Washington } \\
\text { Tennessee }\end{array}$ & $\begin{array}{l}6,967,280 \\
6,725,968 \\
5,838,889 \\
5,545,514 \\
5,262,184\end{array}$ & $\begin{array}{l}\text { September } 30 \\
\text { December } 31 \\
\text { December } 31 \\
\text { December } 31 \\
\text { June } 30\end{array}$ \\
\hline 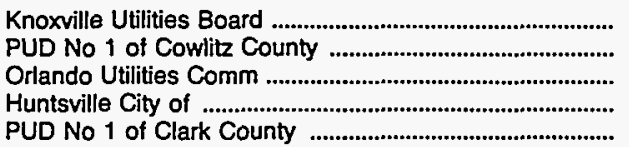 & $\begin{array}{l}\text { Tennessee } \\
\text { Washington } \\
\text { Florida } \\
\text { Alabama } \\
\text { Washington }\end{array}$ & $\begin{array}{l}4,568,275 \\
4,562,301 \\
3,609,899 \\
3,544,599 \\
3,430,257\end{array}$ & $\begin{array}{l}\text { June } 30 \\
\text { December } 31 \\
\text { September } 30 \\
\text { September } 30 \\
\text { December } 31\end{array}$ \\
\hline
\end{tabular}

Source: Energy Information Administration, Form ElA-412, "Annual Report of Public Electric Utilities." Individual electric utilities report fiscal year data. Appendix $B$ shows the fiscal year for each electric utility.

Table C38. Twenty Largest U.S. Publicly Owned Electric Utilities Ranked by Megawatthour Sales for Resale for All Respondents, 1993

\begin{tabular}{|c|c|c|c|}
\hline Publicly Owned Electric Utilities & State & Amount & Reporting Date \\
\hline 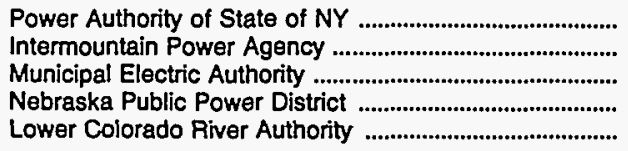 & $\begin{array}{l}\text { New York } \\
\text { Utah } \\
\text { Georgia } \\
\text { Nebraska } \\
\text { Texas }\end{array}$ & $\begin{array}{r}25,134,370 \\
11,974,735 \\
10,265,581 \\
10,122,311 \\
8,799,456\end{array}$ & $\begin{array}{l}\text { December } 31 \\
\text { June } 30 \\
\text { December } 31 \\
\text { December } 31 \\
\text { June } 30\end{array}$ \\
\hline $\begin{array}{l}\text { North Carolina Mun Power Agny } \\
\text { South Carolina Pub Sen Auth } \\
\text { North Carolina Eastern M P A } \\
\text { PUD No } 1 \text { of Chelan County } \\
\text { Washington Pub Pwr Supply Sys }\end{array}$ & $\begin{array}{l}\text { North Carolina } \\
\text { South Carolina } \\
\text { North Carolina } \\
\text { Washington } \\
\text { Washington }\end{array}$ & $\begin{array}{l}8,422,060 \\
7,059,116 \\
6,522,213 \\
6,482,408 \\
6,188,829\end{array}$ & $\begin{array}{l}\text { December } 31 \\
\text { December } 31 \\
\text { December } 31 \\
\text { December } 31 \\
\text { June } 30\end{array}$ \\
\hline 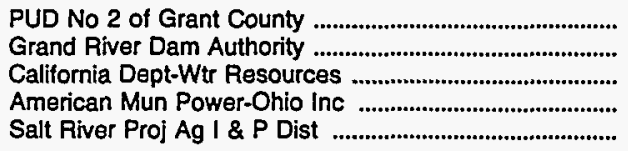 & $\begin{array}{l}\text { Washington } \\
\text { Oklahoma } \\
\text { California } \\
\text { Ohio } \\
\text { Arizona }\end{array}$ & $\begin{array}{l}5,387,716 \\
4,848,136 \\
4,174,176 \\
4,094,070 \\
3,739,819\end{array}$ & $\begin{array}{l}\text { December } 31 \\
\text { December } 31 \\
\text { June } 30 \\
\text { December } 31 \\
\text { April } 30\end{array}$ \\
\hline
\end{tabular}

Source: Energy Information Administration, Form EIA-412, "Annual Report of Public Electric Utilities." Individual electric utilities report fiscal year data. Appendix $B$ shows the fiscal year for each electric utility. 
Table C39. Twenty Largest U.S. Publicly Owned Electric Utilities Ranked by Electric Utility Revenues for All Respondents, 1993

(Thousand Dollars)

\begin{tabular}{|c|c|c|c|}
\hline Publicly Owned Electric Utilitles & State & Amount & Reporting Date \\
\hline $\begin{array}{l}\text { Los Angeles City of } \\
\text { Power Authority of State of NY } \\
\text { Salt Piver Pro] Ag I \& P Dist } \\
\text { San Antonio City of } \\
\text { Jacksonville Electric Auth }\end{array}$ & $\begin{array}{l}\text { California } \\
\text { New York } \\
\text { Arizona } \\
\text { Texas } \\
\text { Florida }\end{array}$ & $\begin{array}{r}2,037,698,748 \\
1,429,791,000 \\
1,295,670,723 \\
779,929,324 \\
681,877,869\end{array}$ & $\begin{array}{l}\text { June } 30 \\
\text { December } 31 \\
\text { April } 30 \\
\text { January } 31 \\
\text { September } 30\end{array}$ \\
\hline $\begin{array}{l}\text { Intermountaln Power Agency } \\
\text { Memphis City of } \\
\text { Sacramento Municipal Util Dist } \\
\text { South Carollina Pub Serv Auth } \\
\text { Municipal Electric Authority }\end{array}$ & $\begin{array}{l}\text { Utah } \\
\text { Tennessee } \\
\text { California } \\
\text { South Carolina } \\
\text { Georgia }\end{array}$ & $\begin{array}{l}653,312,000 \\
626,724,399 \\
617,117,469 \\
589,483,000 \\
537,785,000\end{array}$ & $\begin{array}{l}\text { June } 30 \\
\text { June } 30 \\
\text { December } 31 \\
\text { December } 31 \\
\text { December } 31\end{array}$ \\
\hline 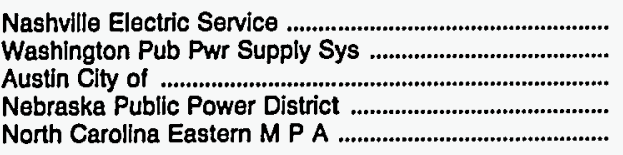 & $\begin{array}{l}\text { Tennessee } \\
\text { Washington } \\
\text { Texas } \\
\text { Nebraska } \\
\text { North Carolina }\end{array}$ & $\begin{array}{l}537,111,411 \\
510,943,580 \\
488,844,474 \\
467,101,000 \\
444,271,000\end{array}$ & $\begin{array}{l}\text { June } 30 \\
\text { June } 30 \\
\text { September } 30 \\
\text { December } 31 \\
\text { December } 31\end{array}$ \\
\hline $\begin{array}{l}\text { North Carolina Mun Power Agny } \\
\text { Omaha Public Power District } \\
\text { Lower Colorado River Authority } \\
\text { Seattle City of } \\
\text { Orlando Utilities Comm }\end{array}$ & $\begin{array}{l}\text { North Carolina } \\
\text { Nebraska } \\
\text { Texas } \\
\text { Washington } \\
\text { Florida }\end{array}$ & $\begin{array}{l}443,511,000 \\
402,360,015 \\
349,567,683 \\
320,359,379 \\
303,150,255\end{array}$ & $\begin{array}{l}\text { December } 31 \\
\text { December } 31 \\
\text { June } 30 \\
\text { December } 31 \\
\text { September } 30\end{array}$ \\
\hline
\end{tabular}

Source: Energy Information Administration, Form EIA-412, "Annual Report of Public Electric Utilities." Individual electric utilities report fiscal year data. Appendix B shows the fiscal year for each electric utility.

Table C40. Twenty Largest U.S. Publicly Owned Electric Utilities Ranked by Purchase Power Expenses for All Respondents, 1993 (Thousand Dollars)

\begin{tabular}{|c|c|c|c|}
\hline Publlcly Owned Electrlc Utllities & State & Amount & Reportlng Date \\
\hline 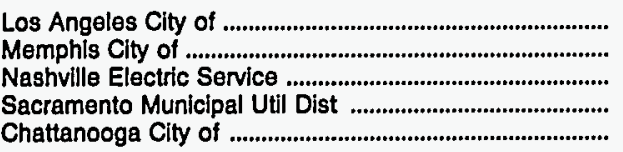 & $\begin{array}{l}\text { California } \\
\text { Tennessee } \\
\text { Tennessee } \\
\text { California } \\
\text { Tennessee }\end{array}$ & $\begin{array}{l}648,156,544 \\
494,151,778 \\
440,542,797 \\
275,753,684 \\
226,889,305\end{array}$ & $\begin{array}{l}\text { June } 30 \\
\text { June } 30 \\
\text { June } 30 \\
\text { December } 31 \\
\text { June } 30\end{array}$ \\
\hline 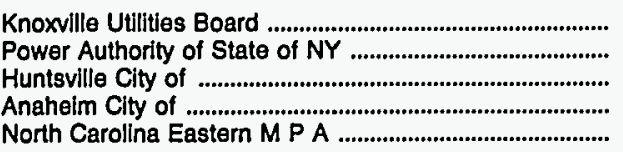 & $\begin{array}{l}\text { Tennessee } \\
\text { New York } \\
\text { Alabama } \\
\text { California } \\
\text { North Carolina }\end{array}$ & $\begin{array}{l}203,510,635 \\
187,397,000 \\
161,720,953 \\
138,228,000 \\
131,117,000\end{array}$ & $\begin{array}{l}\text { June } 30 \\
\text { December } 31 \\
\text { September } 30 \\
\text { June } 30 \\
\text { December } 31\end{array}$ \\
\hline 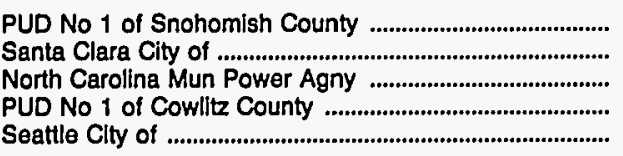 & $\begin{array}{l}\text { Washington } \\
\text { California } \\
\text { North Carolina } \\
\text { Washington } \\
\text { Washington }\end{array}$ & $\begin{array}{l}128,638,391 \\
119,322,910 \\
115,660,000 \\
103,005,053 \\
102,598,643\end{array}$ & $\begin{array}{l}\text { December } 31 \\
\text { June } 30 \\
\text { December } 31 \\
\text { December } 31 \\
\text { December } 31\end{array}$ \\
\hline 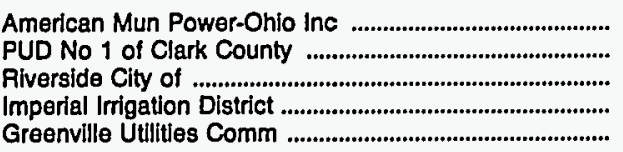 & $\begin{array}{l}\text { Ohio } \\
\text { Washington } \\
\text { California } \\
\text { California } \\
\text { North Carolina }\end{array}$ & $\begin{array}{l}98,926,863 \\
93,177,334 \\
84,031,329 \\
81,372,050 \\
74,462,227\end{array}$ & $\begin{array}{l}\text { December } 31 \\
\text { December } 31 \\
\text { June } 30 \\
\text { December } 31 \\
\text { June } 30\end{array}$ \\
\hline
\end{tabular}

Source: Energy Information Administration, Form EIA-412, "Annual Report of Public Electric Utilities." Individual electric utilities report fiscal year data. Appendix B shows the fiscal year for each electric utility. 
Table C41. Twenty Largest U.S. Publicly Owned Electric Utilities Ranked by Electric Utility Plant for All Respondents, 1993

(Thousand Dollars)

\begin{tabular}{|c|c|c|c|}
\hline Publicly Owned Electric Utillties & State & Amount & Reporting Date \\
\hline 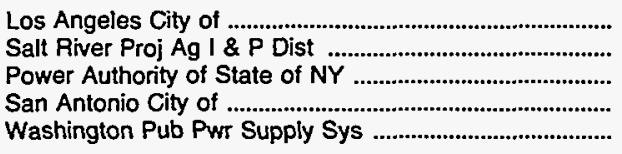 & $\begin{array}{l}\text { California } \\
\text { Arizona } \\
\text { New York } \\
\text { Texas } \\
\text { Washington }\end{array}$ & $\begin{array}{l}6,177,608,472 \\
5,480,152,438 \\
4,913,044,000 \\
4,414,735,182 \\
3,296,697,624\end{array}$ & $\begin{array}{l}\text { June } 30 \\
\text { April } 30 \\
\text { December } 31 \\
\text { January } 31 \\
\text { June } 30\end{array}$ \\
\hline 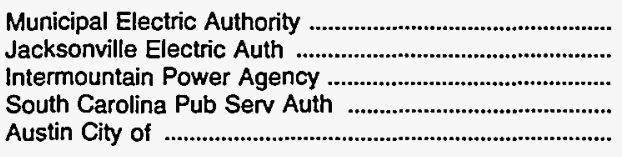 & $\begin{array}{l}\text { Georgia } \\
\text { Florida } \\
\text { Utah } \\
\text { South Carolina } \\
\text { Texas }\end{array}$ & $\begin{array}{l}3,136,809,000 \\
2,806,372,566 \\
2,801,094,000 \\
2,540,433,000 \\
2,090,944,531\end{array}$ & $\begin{array}{l}\text { December } 31 \\
\text { September } 30 \\
\text { June } 30 \\
\text { December } 31 \\
\text { September } 30\end{array}$ \\
\hline 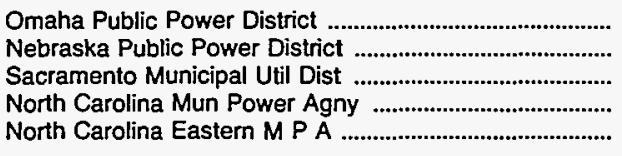 & $\begin{array}{l}\text { Nebraska } \\
\text { Nebraska } \\
\text { California } \\
\text { North Carolina } \\
\text { North Carolina }\end{array}$ & $\begin{array}{l}1,907,812,725 \\
1,796,429,534 \\
1,429,922,284 \\
1,402,387,000 \\
1,385,857,000\end{array}$ & $\begin{array}{l}\text { December } 31 \\
\text { December } 31 \\
\text { December } 31 \\
\text { December } 31 \\
\text { December } 31\end{array}$ \\
\hline 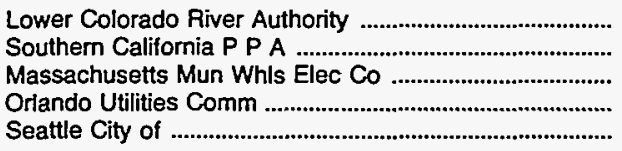 & $\begin{array}{l}\text { Texas } \\
\text { California } \\
\text { Massachusetts } \\
\text { Florida } \\
\text { Washington }\end{array}$ & $\begin{array}{l}1,375,585,288 \\
1,316,926,004 \\
1,231,649,864 \\
1,221,203,962 \\
1,134,629,844\end{array}$ & $\begin{array}{l}\text { June } 30 \\
\text { June } 30 \\
\text { December } 31 \\
\text { September } 30 \\
\text { December } 31\end{array}$ \\
\hline
\end{tabular}

Source: Energy Information Administration, Form ElA-412, "Annual Report of Public Electric Utilities." Individual electric utilities report fiscal year data. Appendix B shows the fiscal year for each electric utility.

Table C42. Twenty Largest U.S. Publicly Owned Electric Utilities Ranked by Construction Work in Progress for All Respondents, 1993 (Thousand Dollars)

\begin{tabular}{|c|c|c|c|}
\hline Publicly Owned Electric Utilities & State & Amount & Reporting Date \\
\hline 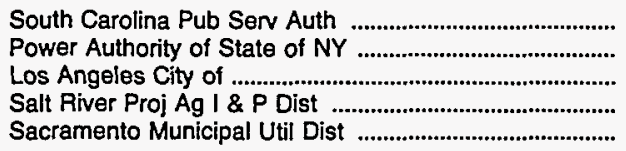 & $\begin{array}{l}\text { South Carolina } \\
\text { New York } \\
\text { California } \\
\text { Arizona } \\
\text { California }\end{array}$ & $\begin{array}{l}423,317,000 \\
290,993,000 \\
271,252,925 \\
199,193,029 \\
166,244,638\end{array}$ & $\begin{array}{l}\text { December } 31 \\
\text { December } 31 \\
\text { June } 30 \\
\text { April } 30 \\
\text { December } 31\end{array}$ \\
\hline 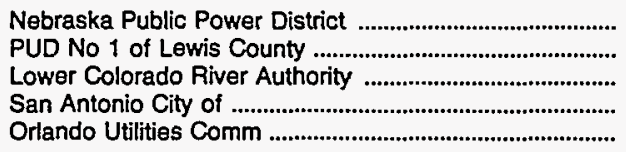 & $\begin{array}{l}\text { Nebraska } \\
\text { Washington } \\
\text { Texas } \\
\text { Texas } \\
\text { Florida }\end{array}$ & $\begin{array}{l}164,406,942 \\
141,887,739 \\
136,985,123 \\
112,719,472 \\
108,956,916\end{array}$ & $\begin{array}{l}\text { December } 31 \\
\text { December } 31 \\
\text { June } 30 \\
\text { January } 31 \\
\text { September } 30\end{array}$ \\
\hline 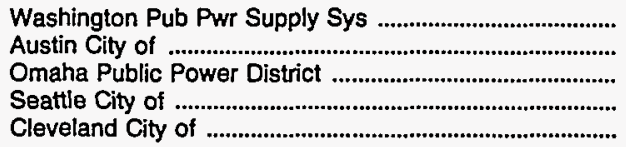 & $\begin{array}{l}\text { Washington } \\
\text { Texas } \\
\text { Nebraska } \\
\text { Washington } \\
\text { Ohio }\end{array}$ & $\begin{array}{r}106,946,893 \\
101,387,411 \\
95,497,793 \\
85,676,238 \\
69,309,047\end{array}$ & $\begin{array}{l}\text { June } 30 \\
\text { September } 30 \\
\text { December } 31 \\
\text { December } 31 \\
\text { December } 31\end{array}$ \\
\hline
\end{tabular}

Source: Energy Information Administration, Form EIA-412, "Annual Report of Public Electric Utilities." Individual electric utilities report fiscal year data. Appendix $B$ shows the fiscal year for each electric utility. 
Table C43. Composite Statement of Income for Major U.S. Publicly Owned Electric Utilities for All Respondents, 1989-1993 (Thousand Dollars)

\begin{tabular}{|c|c|c|c|c|c|}
\hline Item & 1993 & 1992 & 1991 & 1990 & 1989 \\
\hline Electric Utility Operating Revenues ................... & $30,045,300$ & $28,933,756$ & $28,202,745$ & $27,449,123$ & $25,814,544$ \\
\hline 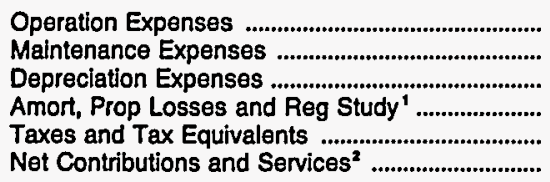 & $\begin{array}{r}19,666,365 \\
1,772,339 \\
2,694,777 \\
158,059 \\
933,886 \\
-\end{array}$ & $\begin{array}{r}18,772,266 \\
1,757,427 \\
2,533,847 \\
134,511 \\
836,134 \\
-\end{array}$ & $\begin{array}{r}18,274,460 \\
1,632,563 \\
2,547,126 \\
- \\
734,209 \\
558,182\end{array}$ & $\begin{array}{r}17,978,112 \\
1,647,407 \\
2,306,792 \\
- \\
683,167 \\
586,148\end{array}$ & $\begin{array}{r}17,003,962 \\
1,668,932 \\
2,251,638 \\
- \\
624,584 \\
526,596\end{array}$ \\
\hline 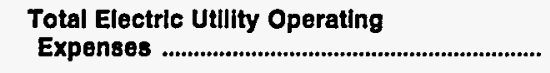 & $25,225,425$ & $24,034,185$ & $23,746,541$ & $23,201,626$ & $22,075,712$ \\
\hline 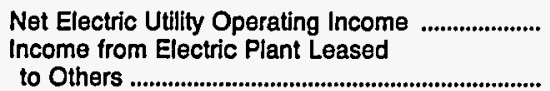 & $4,819,876$ & $4,899,571$ & $4,456,204$ & $\begin{array}{r}4,247,497 \\
13,452\end{array}$ & $\begin{array}{r}3,738,832 \\
7,052\end{array}$ \\
\hline Electric Utility Operating Income ................... & $4,845,856$ & $4,916,473$ & $4,465,411$ & $4,260,949$ & $3,745,884$ \\
\hline Other Electric Income & $1,628,552$ & $2,012,422$ & $2,037,255$ & $1,889,347$ & $1,909,736$ \\
\hline $\begin{array}{l}\text { Other Electric Deductions .......................................... } \\
\text { Allowance for Other Funds Used }\end{array}$ & 336,659 & 324,310 & 137,294 & - & - \\
\hline 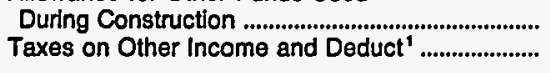 & $\begin{array}{l}28,582 \\
27,925\end{array}$ & $\begin{array}{l}24,222 \\
25,807\end{array}$ & $\begin{array}{r}72,632 \\
-\end{array}$ & $\begin{array}{r}123,069 \\
-\end{array}$ & 231,694 \\
\hline Electric UtIlity Income & $6,138,407$ & $6,603,001$ & $6,438,004$ & $6,273,365$ & $5,887,314$ \\
\hline $\begin{array}{l}\text { Income Deductions from Interest } \\
\text { on Long-term Debt ................................................ } \\
\text { Other Income Deductions ...................................... } \\
\text { Allowance for Borrowed Funds Used }\end{array}$ & $\begin{array}{r}4,547,594 \\
350,500\end{array}$ & $\begin{array}{r}4,866,961 \\
345,454\end{array}$ & $\begin{array}{r}4,887,034 \\
458,570\end{array}$ & $\begin{array}{r}4,773,086 \\
429,161\end{array}$ & $\begin{array}{r}4,439,431 \\
423,163\end{array}$ \\
\hline During Construction' ................................................ & $-43,279$ & $-45,797$ & - & - & - \\
\hline Total Income Deductlons .................................... & $4,854,815$ & $5,166,618$ & $5,345,605$ & $5,202,247$ & $4,862,594$ \\
\hline Income Before Extraordinary Items ...................... & $1,283,592$ & $1,436,382$ & $1,092,399$ & $1,071,118$ & $1,024,721$ \\
\hline Extreordinary Income .............................................. & 87,738 & 146,747 & 123,504 & 141,966 & 87,059 \\
\hline 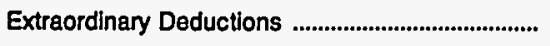 & 327,565 & 264,178 & 198,300 & 262,239 & 725,970 \\
\hline Net Income & $1,043,766$ & $1,318,951$ & $1,017,603$ & 950,845 & 385,809 \\
\hline
\end{tabular}

Data reporting initiated in 1992.

2 Data reporting discontinued in 1992.

- Net income reflects $\$ 584$ million of extraordinary deduction associated with the abandonment of the Rancho Seco Nuclear Plant reported by the Sacramento Municipal Utility District.

- Data not available.

Note: Totals may not equal sum of components because of independent rounding. The number of publicly owned electric utilities for end of period is 495 for 1993,483 for 1992,470 for 1981,467 for 1990 , and 454 for 1989 .

Source: Energy Information Administration, Form EIA-412, "Annual Report of Public Electric Utilities." Individual electric utilities report fiscal year data. Appendix B shows the fiscal year for each electric utility. 
Table C44. Composite Balance Sheet for Major U.S. Publicly Owned Electric Utilities for All Respondents at End of Period, 1989-1993

(Thousand Dollars)

\begin{tabular}{|c|c|c|c|c|c|}
\hline Item & 1993 & 1992 & 1991 & 1990 & 1989 \\
\hline \multicolumn{6}{|l|}{ Electric Utility Plant } \\
\hline 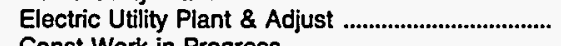 & $90,051,059$ & $87,030,170$ & $88,854,231$ & $85,106,027$ & $81,009,708$ \\
\hline 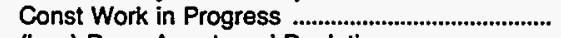 & $4,038,613$ & $3,790,826$ & & & \\
\hline 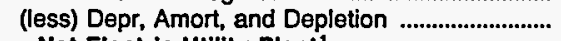 & $27,273,454$ & $25,153,126$ & $23,454,394$ & $21,101,995$ & $18,572,145$ \\
\hline 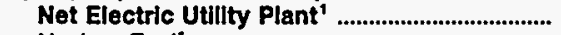 & $66,816,218$ & $65,667,870$ & - & - & - \\
\hline 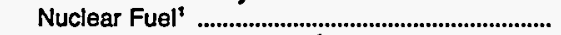 & $2,580,570$ & $2,271,919$ & - & - & - \\
\hline (less) Amort of Nucl Fuel' & $1,650,975$ & $1,348,032$ & - & - & - \\
\hline $\begin{array}{l}\text { Net Elec Plant Incl Nucl Fuel } \\
\text { Other Property \& Investments }\end{array}$ & $67,745,814$ & $66,591,756$ & $65,399,837$ & $64,004,032$ & $62,437,563$ \\
\hline \multicolumn{6}{|l|}{ Other Property \& Investments } \\
\hline (less) Accum Provisions for Depr \& Amort .......... & $2,138,049$ & $\begin{array}{l}6,407,886 \\
1,977,104\end{array}$ & $1,840,621$ & $\begin{array}{l}0,5 / 8,250 \\
1,712,103\end{array}$ & $\begin{array}{l}5,335,165 \\
1,624,556\end{array}$ \\
\hline Invest in Assoc Enterprises & 371,792 & 255,261 & 87,717 & 81,471 & 70,790 \\
\hline 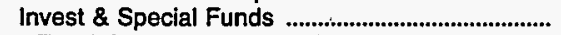 & $17,207,623$ & $15,416,345$ & $14,865,256$ & $13,624,271$ & $12,965,817$ \\
\hline $\begin{array}{l}\text { Total Other Property \& Investments } \\
\text { Current and Accrued Assets }\end{array}$ & $22,399,126$ & $20,119,388$ & $19,182,188$ & $17,571,894$ & $16,747,815$ \\
\hline 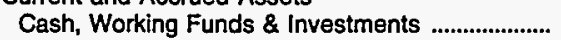 & $10,890,858$ & $10,521,181$ & $10,428,543$ & $10,315,631$ & $9,478,855$ \\
\hline Notes \& Other Receivables ..................................... & $1,102,841$ & $1,047,920$ & $3,065,407$ & $3,254,072$ & $3,113,724$ \\
\hline 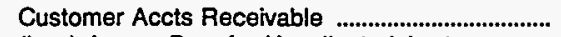 & $2,374,004$ & $2,141,086$ & & & \\
\hline (less) Accum Prov for Uncollected Accts ............. & 125,658 & 121,384 & 114,245 & 104,326 & 100,219 \\
\hline 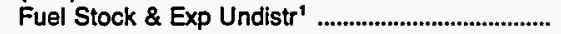 & 496,413 & 545,311 & & & \\
\hline 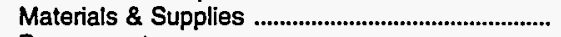 & $1,283,844$ & $1,331,630$ & $1,796,964$ & $1,620,700$ & $1,555,731$ \\
\hline 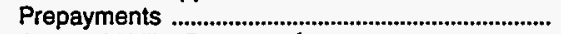 & 393,267 & 405,601 & 377,684 & 321,876 & 240,698 \\
\hline 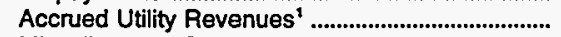 & 334,841 & 287,479 & - & - & - \\
\hline Miscellaneous Current \& Accrued Assets ............ & $1,102,461$ & $1,058,968$ & 692,469 & 523,141 & 610,942 \\
\hline $\begin{array}{l}\text { Total Current \& Accrued Assets ........................ } \\
\text { Deferred Debits }\end{array}$ & $17,852,872$ & $17,217,791$ & $16,246,822$ & $15,931,093$ & $14,899,730$ \\
\hline Unamortized Debt Expenses ........................................... & $2,536,132$ & $2,291,314$ & $1,909,159$ & $1,830,959$ & $1,857,147$ \\
\hline Extraordinary Losses, Study Cost ................................ & 918,432 & 469,651 & 34,360 & 31,911 & 33,146 \\
\hline 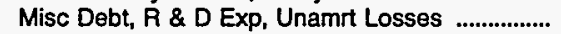 & $10,956,667$ & $9,642,339$ & $9,271,082$ & $8,335,276$ & $7,088,547$ \\
\hline 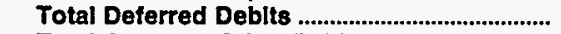 & $14,411,230$ & $12,403,304$ & $11,214,601$ & $10,198,147$ & $8,978,840$ \\
\hline Total Assets \& Other Debits .................................... & $122,409,042$ & $116,332,239$ & $112,043,449$ & $107,705,166$ & $103,063,948$ \\
\hline \multicolumn{6}{|l|}{ Proprietary Capital } \\
\hline Investment of Municipality ............................................... & $1,891,224$ & $1,865,553$ & $2,089,179$ & $1,901,842$ & $1,946,296$ \\
\hline 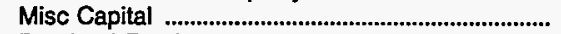 & 656,589 & 522,116 & 452,305 & 445,306 & 657,259 \\
\hline 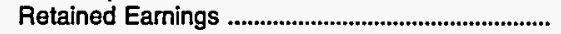 & $26,963,161$ & $25,957,799$ & $24,925,509$ & $24,328,102$ & $23,121,259$ \\
\hline \multicolumn{2}{|l|}{ Long-term Debt } & $28,345,468$ & $27,466,993$ & $26,675,251$ & $25,724,815$ \\
\hline 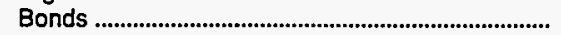 & $77,624,677$ & $74,650,183$ & $70,415,936$ & $67,432,594$ & $63,852,226$ \\
\hline 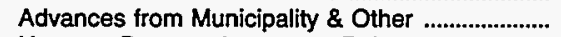 & $3,667,150$ & $2,972,620$ & $3,581,623$ & $3,879,978$ & $3,700,743$ \\
\hline $\begin{array}{l}\text { Unamort Prem on Long-term Debt ............... } \\
\text { (less) Unamort Discount on Long-term Debt }\end{array}$ & $\begin{array}{r}619,822 \\
2,844,050\end{array}$ & $\begin{array}{r}70,350 \\
2,975041\end{array}$ & $\begin{array}{r}15,850 \\
2599,459\end{array}$ & $\begin{array}{r}1,468 \\
2,455,142\end{array}$ & $\begin{array}{r}3,134 \\
2,237,748\end{array}$ \\
\hline 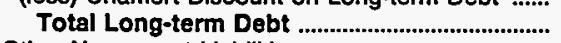 & $79,067,600$ & $74,718,112$ & $71,413,951$ & $68,858,898$ & $65,318,356$ \\
\hline \multicolumn{6}{|l|}{ Other Noncurrent Liabilities } \\
\hline Accum Operating Provisions ........................................ & 486,149 & 704,151 & 677,995 & 473,827 & 442,239 \\
\hline Accum Prov for Rate Refunds ${ }^{\prime}$...................................... & 115,389 & 4,483 & & & \\
\hline \multicolumn{6}{|l|}{ Current and Accrued Liabilities } \\
\hline Notes Payable ................................ & $1,364,779$ & $1,167,670$ & $1,234,282$ & $1,041,608$ & $1,132,035$ \\
\hline Accounts Payable ........................................................... & $2,723,943$ & $2,627,626$ & $2,437,591$ & $2,505,401$ & $2,329,922$ \\
\hline Payables to Assoc Enterprises & 314,445 & 300,678 & 269,323 & 252,383 & 224,494 \\
\hline 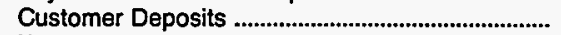 & 422,191 & 423,866 & 384,587 & 326,546 & 342,498 \\
\hline 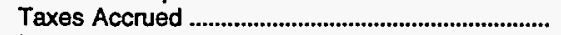 & 226,289 & 213,220 & 295,651 & 249,297 & 227,780 \\
\hline 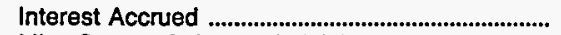 & $1,508,730$ & $1,524,242$ & $1,549,877$ & $1,472,067$ & $1,353,716$ \\
\hline Misc Current \& Accrued Liabilities ................................. & $3,073,542$ & $2,807,340$ & $2,642,284$ & $2,385,522$ & $2,489,779$ \\
\hline $\begin{array}{l}\text { Total Current \& Accrued Llabilities .................. } \\
\text { Deferred Credits }\end{array}$ & $9,633,919$ & $9,063,364$ & $8,813,594$ & $8,232,824$ & $8,100,225$ \\
\hline 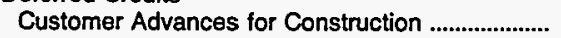 & 228,397 & 216,947 & 189,349 & 171,257 & 132,016 \\
\hline 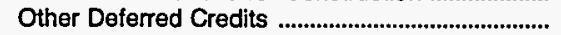 & $3,055,314$ & $2,888,796$ & $2,912,524$ & $2,868,551$ & $2,895,655$ \\
\hline 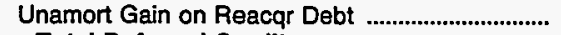 & 311,302 & 389,640 & 569,043 & 424,557 & 450,641 \\
\hline Total Deferred Credits ............................................ & $3,595,012$ & $3,495,383$ & $3,670,916$ & $3,464,365$ & $3,478,312$ \\
\hline Total Llabillities and Other Credits ..................... & $122,409,042$ & $116,332,239$ & $112,043,449$ & $107,705,166$ & $103,063,948$ \\
\hline
\end{tabular}

Data reporting initiated in 1992.

Note: Totals may not equal sum of components because of independent rounding. The number of publicly owned electric utilities for end of period is 495 for 1993,483 for 1992,470 for 1991,467 for 1990, and 454 for 1989.

Source: Energy Information Administration, Form ElA-412, "Annual Report of Public Electric Utilities." Individual electric utilities report fiscal year data. Appendix B shows the fiscal year for each electric utility. 
Table C45. Composite Financial Indicators for Major U.S. Publicly Owned Electric Utilities for All Respondents, 1989-1993

\begin{tabular}{|c|c|c|c|c|c|}
\hline Item & 1993 & 1992 & 1991 & 1990 & 1989 \\
\hline Total Electric Utility Plant per Dollar of Revenue & 3.2 & 3.2 & 3.2 & 3.1 & 3.1 \\
\hline Current Assets to Current Liabilities ...................... & 1.9 & 1.9 & 1.8 & 1.9 & 1.8 \\
\hline $\begin{array}{l}\text { Total Electric Utility Plant as a Percent of Total } \\
\text { Assets }\end{array}$ & 79.0 & 80.0 & 79.3 & 79.0 & 78.6 \\
\hline $\begin{array}{l}\text { Net Electric Utility Plant as a Percent of Total } \\
\text { Assets }\end{array}$ & 55.3 & 57.2 & 58.4 & 59.4 & 60.6 \\
\hline Debt as a Percent of Total Liabilities ...................... & 72.5 & 72.0 & 71.6 & 71.6 & 71.2 \\
\hline $\begin{array}{l}\text { Depreciation, Amortization and Depletion } \\
\text { as a Percent of Total Electric Utility Plant .......... }\end{array}$ & 29.9 & 28.5 & 26.4 & 24.8 & 22.9 \\
\hline $\begin{array}{l}\text { Electric Operation and Maintenance Expenses } \\
\text { as a Percent of } \\
\text { Electric Utility Operating Revenues ....................... }\end{array}$ & 71.4 & 71.0 & 70.6 & 71.5 & 72.3 \\
\hline $\begin{array}{l}\text { Electric Depreciation and Amortization } \\
\text { as a Percent of } \\
\text { Electric Utility Operating Revenues ...................... }\end{array}$ & 9.0 & 8.8 & 9.0 & 8.4 & 8.7 \\
\hline $\begin{array}{l}\text { Taxes and Tax Equivalents } \\
\text { as a Percent of } \\
\text { Electric Utility Operating Revenues ....................... }\end{array}$ & 3.1 & 2.9 & 2.6 & 2.5 & 2.4 \\
\hline $\begin{array}{l}\text { Interest on Long-term Debt } \\
\text { as a Percent of } \\
\text { Electric Utility Operating Revenues ...................... }\end{array}$ & 15.1 & 16.8 & 17.3 & 17.4 & 17.2 \\
\hline 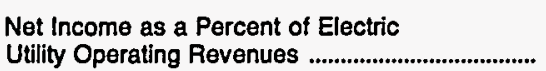 & 3.5 & 4.6 & 3.6 & 3.5 & 1.5 \\
\hline Purchased Power Cents Per Kilowatthour ............ & 3.8 & 3.9 & 3.9 & 3.9 & 4.1 \\
\hline Generated Cents Per Kilowatthour ........................ & 1.9 & 1.9 & 1.8 & 1.8 & 1.6 \\
\hline $\begin{array}{l}\text { Total Power Supply Per } \\
\text { Kilowatthour Sold }\end{array}$ & 3.0 & 3.1 & 3.0 & 3.0 & 2.9 \\
\hline
\end{tabular}

Note: Totals may not equal sum of components because of independent rounding. The number of publicly owned electric utilities for end of period is 495 for 1993,483 for 1992, 470 for 1991, 467 for 1990, and 454 for 1989.

Source: Energy Information Administration, Form EIA-412, "Annual Report of Public Electric Utilities." Individual electric utilities report fiscal year data. Appendix B shows the fiscal year for each electric utility. 
Table C46. Electric Operation and Maintenance Expenses for Major U.S. Publicly Owned Electric Utilities for All Respondents, 1989-1993 (Thousand Dollars)

\begin{tabular}{|c|c|c|c|c|c|}
\hline Item & 1993 & 1992 & 1991 & 1990 & 1989 \\
\hline \multicolumn{6}{|l|}{ Production Expenses } \\
\hline Steam Power Generation & $4,105,022$ & $3,762,399$ & $3,688,872$ & $3,741,569$ & $3,437,966$ \\
\hline 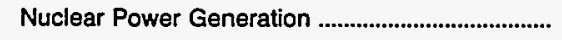 & $1,304,604$ & $1,318,443$ & $1,217,567$ & $1,133,495$ & $1,179,125$ \\
\hline 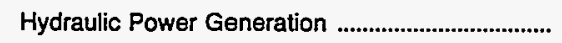 & 241,549 & 244,158 & 225,699 & 204,512 & 187,182 \\
\hline Other Power Generation & 179,738 & 175,873 & 167,230 & 196,419 & 171,871 \\
\hline 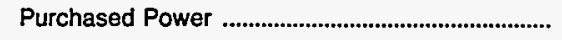 & $11,097,082$ & $10,834,814$ & $10,571,167$ & $10,541,975$ & $10,000,080$ \\
\hline 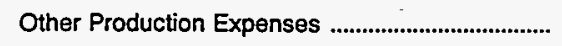 & 140,863 & 80,582 & 102,572 & 154,970 & 99,149 \\
\hline Total Production Expenses ..................................... & $17,068,858$ & $16,416,269$ & $15,973,107$ & $15,972,941$ & $15,075,473$ \\
\hline Transmission Expenses & 729,745 & 677,711 & 645,169 & 604,017 & 552,316 \\
\hline Distribution Expenses & $1,199,411$ & $1,125,391$ & $1,027,679$ & 950,271 & 988,374 \\
\hline 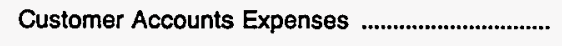 & 432,345 & 408,405 & 393,462 & 374,729 & 344,197 \\
\hline Customer Service and Information Expenses ...... & 111,255 & 98,360 & 89,656 & 74,710 & 77,971 \\
\hline Sales Expenses & 25,914 & 29,191 & 29,665 & 29,350 & 17,615 \\
\hline Administrative and General Expenses ........................ & $1,871,156$ & $1,774,365$ & $1,748,285$ & $1,619,500$ & $1,616,947$ \\
\hline $\begin{array}{l}\text { Total Electric Operation } \\
\text { and Maintenance Expenses }\end{array}$ & $21,438,683$ & $20,529,693$ & $19,907,023$ & $19,625,519$ & $18,672,894$ \\
\hline \multicolumn{6}{|l|}{ Fuel Expenses in Operation } \\
\hline 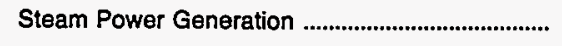 & $3,036,077$ & R $2,733,581$ & $2,634,842$ & $2,394,566$ & $2,142,836$ \\
\hline 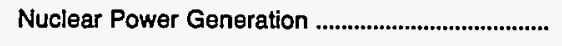 & 299,445 & ${ }^{8} 303,042$ & 345,206 & 242,283 & 351,899 \\
\hline Other Power Generation & 102,414 & R 82,828 & 92,113 & 113,041 & 92,268 \\
\hline \multicolumn{6}{|l|}{ Number of Elec Dept Employees } \\
\hline Regular Full-time $\theta^{t}$ & 73,315 & 74,893 & - & - & - \\
\hline 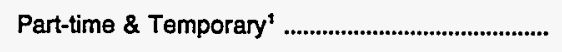 & 3,641 & 3,866 & - & - & - \\
\hline 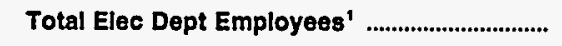 & 76,954 & 78,758 & - & - & - \\
\hline
\end{tabular}

1. Data reporting initiated in 1992.

$\mathbf{R}=$ Revised data.

Note: Totals may not equal sum of components because of independent rounding. The number of publicly owned electric utilities for end of period is 495 for 1993, 483 for 1992, 470 for 1991, 467 for 1990, and 454 for 1989 .

Source: Energy Information Administration, Form EIA-412, "Annual Report of Public Electric Utilities." Individual electric utilities report fiscal year data. Appendix 8 shows the fiscal year for each electric utility. 
Table C47. Electric Utility Plant for Major U.S. Publicly Owned Electric Utilities for All Respondents at End of Period, 1989-1993 (Thousand Dollars)

\begin{tabular}{|c|c|c|c|c|c|}
\hline Item & 1993 & 1992 & 1991 & 1990 & 1989 \\
\hline \multicolumn{6}{|l|}{ Electric Plant In Service } \\
\hline 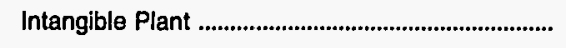 & 351,952 & 294,715 & 373,212 & 325,985 & 390,809 \\
\hline \multicolumn{6}{|l|}{ Production Plant } \\
\hline Steam & $24,239,169$ & $23,415,826$ & $22,556,413$ & $21,246,646$ & $19,191,316$ \\
\hline Nuclear & $18,814,910$ & $18,743,463$ & $19,440,482$ & $18,992,687$ & $18,313,109$ \\
\hline 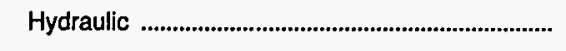 & $7,648,279$ & $7,506,785$ & $6,991,010$ & $6,852,874$ & $6,348,174$ \\
\hline Other & $1,843,331$ & $1,887,069$ & $1,576,299$ & $1,639,697$ & $1,485,027$ \\
\hline Total Production Plant ............................................. & $52,545,689$ & $51,553,142$ & $50,564,203$ & $48,731,905$ & $45,337,626$ \\
\hline 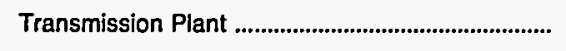 & $9,548,867$ & $9,345,935$ & $9,079,912$ & $8,348,613$ & $7,936,162$ \\
\hline 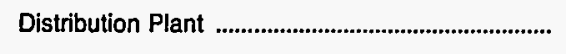 & $20,145,751$ & $18,846,975$ & $17,779,290$ & $16,579,615$ & $15,686,298$ \\
\hline 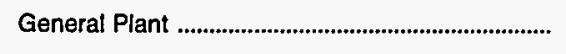 & $5,860,450$ & $5,455,979$ & $5,221,061$ & $4,867,426$ & $4,227,270$ \\
\hline 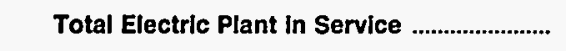 & $88,452,709$ & $85,496,746$ & $83,017,677$ & $78,853,544$ & $73,578,165$ \\
\hline Electric Plant Leased to Others ................................... & 17,404 & 68,195 & 566,610 & 483,654 & 478,683 \\
\hline Construction Work in Progress - Electric ............... & $4,038,613$ & $3,790,826$ & $4,119,184$ & $4,151,170$ & $5,559,795$ \\
\hline Electric Plant Held for Future Use .............................. & 337,975 & 321,639 & 640,637 & 830,399 & 754,445 \\
\hline Electric Plant Misc .......................................................... & $1,242,970$ & $1,143,590$ & 510,123 & 787,260 & 638,620 \\
\hline Total Electric Utility Plant ..................................... & $94,089,672$ & $90,820,996$ & $88,854,231$ & $85,106,027$ & $81,009,708$ \\
\hline 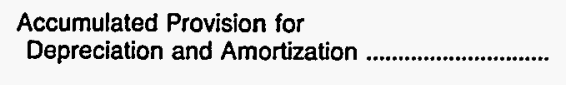 & $27,273,454$ & $25,153,126$ & $23,454,394$ & $21,101,995$ & $18,572,145$ \\
\hline 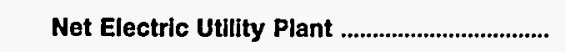 & $66,816,218$ & $65,667,870$ & $65,399,837$ & $64,004,032$ & $62,437,563$ \\
\hline
\end{tabular}

Note: Totals may not equal sum of components because of independent rounding. The number of publicly owned electric utilities for end of period is 495 for 1993,483 for 1992, 470 for 1991, 467 for 1990, and 454 for 1989 .

Source: Energy Information Administration, Form ElA-412, "Annual Report of Public Electric Utilities." Individual electric utilities report fiscal year data. Appendix B shows the fiscal year for each electric utility. 
Table C48. Number of Consumers, Sales, and Operating Revenue

for Major U.S. Publicly Owned Electric Utillities

for All Respondents, 1989-1993

\begin{tabular}{|c|c|c|c|c|c|}
\hline Item & 1993 & 1992 & 1991 & 1990 & \\
\hline \multicolumn{6}{|l|}{ Number of Consumers } \\
\hline 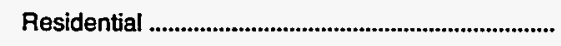 & $11,319,257$ & $11,105,178$ & $10,944,056$ & $10,712,154$ & $10,481,349$ \\
\hline Commercial or Small & $1,502,772$ & $1,477,033$ & $1,398,521$ & $1,386,959$ & $1,381,849$ \\
\hline Industrial or Large & 100,639 & 96,002 & 75,831 & 82,683 & 85,548 \\
\hline Other & 160,934 & 245,135 & 266,248 & 264,000 & 232,389 \\
\hline Total UItimate Consumers & $13,083,602$ & $12,923,348$ & $12,684,656$ & $12,445,796$ & $12,181,135$ \\
\hline \multicolumn{6}{|l|}{ Sales for the Year (megawatthours) } \\
\hline 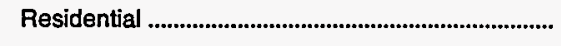 & $123,054,125$ & $\$ 17,620,115$ & $118,476,942$ & $115,426,617$ & $112,306,344$ \\
\hline Commercial or Small & $90,526,004$ & $88,617,000$ & $92,271,342$ & $91,071,107$ & $86,439,072$ \\
\hline Industrial or Large & $125,969,030$ & $122,151,852$ & $113,244,276$ & $111,325,058$ & $107,626,843$ \\
\hline Other & $20,473,499$ & $20,914,175$ & $20,790,016$ & $20,433,764$ & $18,405,584$ \\
\hline 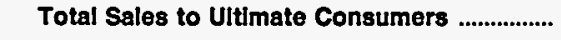 & $360,022,658$ & $349,303,142$ & $344,782,576$ & $338,256,546$ & $324,777,843$ \\
\hline Sales for Resale & $206,072,262$ & $191,766,731$ & $190,797,303$ & $195,603,526$ & $189,649,740$ \\
\hline Total Sales & $566,094,920$ & $541,069,873$ & $535,579,879$ & $533,860,072$ & $514,427,583$ \\
\hline \multicolumn{6}{|l|}{$\begin{array}{l}\text { Operatlng Revenues for the Year } \\
\text { (thousand dollars) }\end{array}$} \\
\hline Residential & $8,125,789$ & $7,671,053$ & $7,512,382$ & $7,333,324$ & $7,014,301$ \\
\hline Commercial or Small & $6,107,757$ & $5,846,417$ & $5,924,545$ & $5,893,278$ & $5,469,714$ \\
\hline Industrial or Large & $6,040,719$ & $5,797,866$ & $5,305,256$ & $5,165,253$ & $5,044,231$ \\
\hline Other & $1,462,066$ & $1,431,809$ & $1,303,801$ & $1,333,963$ & $1,192,012$ \\
\hline $\begin{array}{l}\text { Total Revenues from Sales to } \\
\text { Ultimate Consumers }\end{array}$ & $21,736,331$ & $20,747,145$ & $20,045,984$ & $19,725,818$ & $18,720,258$ \\
\hline Sales for Resale & $7,838,707$ & $7,479,049$ & $7,221,545$ & $7,397,548$ & $7,075,131$ \\
\hline $\begin{array}{l}\text { Total Revenues From Sales of } \\
\text { Electricity }\end{array}$ & $29,575,038$ & $28,226,194$ & $27,267,529$ & $27,123,366$ & $25,795,389$ \\
\hline
\end{tabular}

Note: Totals may not equal sum of components because of independent rounding. The number of publicly owned electric utilities for end of period is 495 for 1993, 4831992,470 for 1991, 467 for 1990, and 454 for 1989.

Source: Energy Information Administration, Form EIA-861, "Annual Electric Utility Report." Data are based on calender year submis- 
Table C49. Electric Energy Account for Major U.S. Publicly Owned Electric Utilities for All Respondents, 1989-1993

(Megawatthours)

\begin{tabular}{|c|c|c|c|c|c|}
\hline Item & 1993 & 1992 & 1991 & 1990 & 1989 \\
\hline \multicolumn{6}{|l|}{ Sources of Energy } \\
\hline 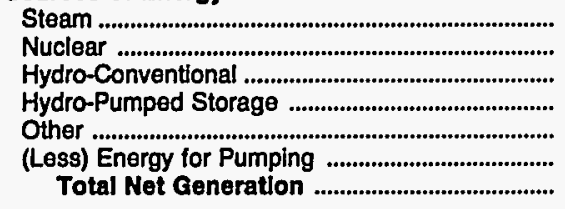 & $\begin{array}{r}179,616,592 \\
48,580,405 \\
71,114,954 \\
4,423,179 \\
3,053,440 \\
4,354,233 \\
302,434,335\end{array}$ & $\begin{array}{r}169,087,041 \\
52,565,245 \\
65,807,396 \\
4,722,771 \\
2,940,656 \\
4,255,476 \\
290,867,622\end{array}$ & $\begin{array}{r}164,401,739 \\
57,756,871 \\
73,348,633 \\
3,789,638 \\
3,137,344 \\
3,904,547 \\
298,529,666\end{array}$ & $\begin{array}{r}168,806,546 \\
50,740,159 \\
75,007,682 \\
4,741,854 \\
3,990,503 \\
3,551,799 \\
299,734,947\end{array}$ & $\begin{array}{r}177,940,856 \\
53,149,705 \\
68,743,015 \\
4,059,041 \\
2,371,953 \\
3,603,646 \\
302,660,924\end{array}$ \\
\hline $\begin{array}{l}\text { Purchases from Utility } \\
\text { Purchases from Nonutility } \\
\text { Power Exchanges }\end{array}$ & $\begin{array}{r}289,691,688 \\
1,543,815\end{array}$ & $\begin{array}{r}276,321,959 \\
1,085,377\end{array}$ & $\begin{array}{r}269,663,812 \\
1,380,739\end{array}$ & $\begin{array}{r}268,249,437 \\
1,006,129\end{array}$ & $\begin{array}{r}244,431,395 \\
1,026,297\end{array}$ \\
\hline 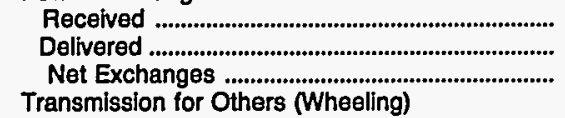 & $\begin{array}{r}21,477,360 \\
21,164,186 \\
313,183\end{array}$ & $\begin{array}{r}18,993,247 \\
18,641,568 \\
351,686\end{array}$ & $\begin{array}{l}19,788,332 \\
22,835,269 \\
-3,046,936\end{array}$ & $\begin{array}{l}35,464,128 \\
37,525,397 \\
-2,061,270\end{array}$ & $\begin{array}{r}21,257,570 \\
21,995,791 \\
-738,223\end{array}$ \\
\hline 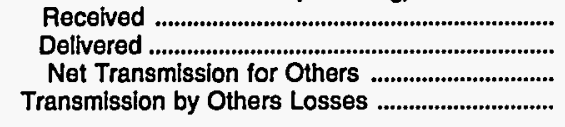 & $\begin{array}{r}27,233,740 \\
26,962,627 \\
271,113 \\
-286,279\end{array}$ & $\begin{array}{r}22,142,579 \\
21,938,318 \\
204,261 \\
-243,202\end{array}$ & $\begin{array}{r}27,661,154 \\
27,454,743 \\
206,410 \\
-169,733\end{array}$ & $\begin{array}{r}30,857,303 \\
30,584,606 \\
272,696 \\
-81,436\end{array}$ & $\begin{array}{r}30,259,971 \\
29,732,194 \\
527,777 \\
-\end{array}$ \\
\hline \multicolumn{4}{|l|}{ Total Net Energy Generated and } & $567,120,501$ & $547,908,177$ \\
\hline 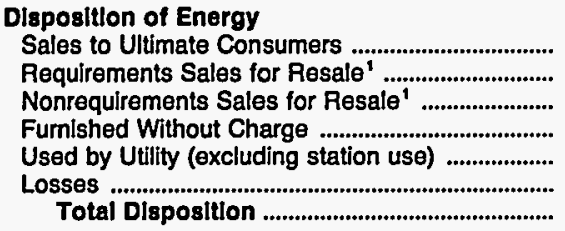 & $\begin{array}{r}359,971,921 \\
161,161,514 \\
41,942,525 \\
2,008,578 \\
5,333,241 \\
23,550,022 \\
593,967,859\end{array}$ & $\begin{array}{r}347,801,781 \\
152,099,605 \\
37,818,022 \\
1,851,080 \\
6,877,310 \\
22,139,822 \\
568,587,689\end{array}$ & $\begin{array}{r}343,531,980 \\
161,294,421 \\
31,087,612 \\
1,881,389 \\
7,865,267 \\
20,903,280 \\
566,563,961\end{array}$ & $\begin{array}{r}336,588,347 \\
160,452,347 \\
34,819,786 \\
1,957,491 \\
11,843,735 \\
21,458,772 \\
567,120,501\end{array}$ & $\begin{array}{r}324,252,064 \\
188,376,475 \\
- \\
2,006,568 \\
11,633,694 \\
21,639,359 \\
547,908,177\end{array}$ \\
\hline
\end{tabular}

1 The 1989 data were reported as Sales for Resale (one entry) which is shown as Requirements Sales for Resale.

Note: Totals may not equal sum of components because of independent rounding. The number of publicly owned electric utilities for end of period is 495 for 1993,483 for 1992, 470 for 1991, 467 for 1990 , and 454 for 1989 . Double counting occurs in components of both sources and disposition of energy and thus neither provides a true total. Purchases from utilities, net exchanges, and net wheeling (except for imports) are included in net generation. Sales for resale is included in sales to ultimate consumers.

Source: Energy Information Administration, Form ElA-412, "Annual Report of Public Electric Utilities." Individual electric utilities report fiscal year data. Appendix B shows the fiscal year for each electric utility. 



\section{Appendix D}

Regulation of

U.S. Publicly

Owned

Electric

Utilities 
, 


\section{Regulation of U.S. Publicly Owned Electric Utilities}

\section{Table D1. State Agency Authority to Regulate Rates of}

Public Owned Electric Utilities, 1993

\begin{tabular}{|c|c|c|c|c|c|c|}
\hline \multirow{2}{*}{ State } & \multirow{2}{*}{ State Agency Authority } & \multirow{2}{*}{$\begin{array}{c}\text { Authority } \\
\text { To Regulate } \\
\text { Rates }\end{array}$} & \multirow[b]{2}{*}{ Boundaries } & \multicolumn{3}{|c|}{ Sales Regulated } \\
\hline & & & & $\begin{array}{c}\text { Ultimate } \\
\text { Consumer }\end{array}$ & $\begin{array}{c}\text { Public } \\
\text { Authority }\end{array}$ & $\begin{array}{c}\text { Sales for } \\
\text { Resale }\end{array}$ \\
\hline AL & Alabama Public Service Commission & NO & & & & \\
\hline AK & Alaska Public Utilities Commission & YES & inside \& outside & $x$ & $x$ & $x$ \\
\hline$A Z$ & Arizona Corporation Commission & NO & & & & \\
\hline AR & Arkansas Public Service Commission & NO & & & & \\
\hline CA & Callfornia Public Utilities Commission & NO & & & & \\
\hline co & Colorado Public Utilities Commission & LTD & outside & & & \\
\hline CT & Connecticut Department of Public Utility Control & LTD & & & & $x$ \\
\hline $\mathrm{DE}$ & Delaware Public Service Commission & No & & & & \\
\hline $\mathrm{FL}$ & Florida Public Service Commision & LTD & inside \& outside' & $x$ & $x$ & \\
\hline GA & Georgia Public Service Commission & NO & outside home cty & & & \\
\hline $\mathrm{HI}$ & Hawaii Public Utilities Commission & NO & & & & \\
\hline ID & Idaho Public Utilities Commission & NO & & & & \\
\hline IL & Illinols Commerce Commission & NO & inside \& outside & & & \\
\hline IN & Indiana Utility Regulatory Commision & LTD & inside \& outside ${ }^{2}$ & $x$ & $x$ & $x$ \\
\hline IA & lowa Utilities Board & NO & inside \& outside & $\mathbf{x}$ & $x$ & \\
\hline KS & Kansas State Corporation Commission & YES & outside & $x$ & $x$ & $x$ \\
\hline KY & Kentucky Public Service Commission & NO & & & & \\
\hline LA & Lousiana Public Service Commission & NO & & & & \\
\hline ME & Maine Public Utilities Commission & YES & outside & $x$ & $\mathbf{x}$ & \\
\hline MD & Maryland Public Service Commission & YES & inside \& outside & $\mathbf{x}$ & $x$ & \\
\hline MA & Massachusetts Department of Public Utilities & YES & inside \& outside & $x$ & $x$ & $x$ \\
\hline MI & Michigan Public Service Commission & NO & & & & \\
\hline MN & Minnesota Public Service Commission & NO & & & & \\
\hline MS & Mississippi Public Service Commission & LTD & safety inside, full outside & $x$ & $x$ & \\
\hline MO & Missouri Public Service Commission & No & & $x$ & $x$ & $x$ \\
\hline MT & Montana Public Service Commission & YES & inside \& outsidea & & & \\
\hline
\end{tabular}


Table D1. State Agency Authority to Regulate Rates of

Public Owned Electric Utilities, 1993

\begin{tabular}{|c|c|c|c|c|c|c|}
\hline \multirow[b]{2}{*}{ State } & \multirow[b]{2}{*}{ State Agency Authority } & \multirow{2}{*}{$\begin{array}{l}\text { Authority } \\
\text { To Regulate } \\
\text { Rates }\end{array}$} & \multirow[b]{2}{*}{ Boundaries } & \multicolumn{3}{|c|}{ Sales Regulated } \\
\hline & & & & $\begin{array}{c}\text { Ultimate } \\
\text { Consumer }\end{array}$ & $\begin{array}{l}\text { Public } \\
\text { Authority }\end{array}$ & $\begin{array}{l}\text { Sales for } \\
\text { Resale }\end{array}$ \\
\hline NE & Nebraska Public Service Commission & No & inside \& outside & & & \\
\hline NV & Nevada Public Service Commission & NO & & & & \\
\hline $\mathrm{NH}$ & New Hampshire Public Utilities Commission & YES & outside & $x$ & $x$ & $x$ \\
\hline NJ & New Jersey Board of Public Utilities & YES & outside & $x$ & & \\
\hline NM & New Mexico Public Service Commission & NO & & & & \\
\hline NY & New York Public Service Commission & YES & outside & $x$ & $x$ & $x$ \\
\hline NC & North Carolina Utilities Commission & NO & & & & \\
\hline ND & North Dakota Public Service Commission & NO & & & & \\
\hline $\mathrm{OH}$ & Ohio Public Utilities Commission & NO & & & & \\
\hline OK & Oklahoma Corporation Commission & NO & & & & \\
\hline OR & Oregon Public Utility Commission & LTD & & & & \\
\hline PA & Pennsysivania Public Utility Commission & YES & outside & $x$ & & \\
\hline $\mathbf{R} \mathbf{l}$ & Rhode Island Public Utilities Commission & NO & inside \& outside & $x$ & $x$ & \\
\hline SC & South Carolina Public Service Commission & LTD & inside \& outside & & & \\
\hline SD & South Dakota Public Utilities Commission & LTD & & & & \\
\hline TN & Tennessee Public Service Commission & NO & outside & & & \\
\hline$T X$ & Texas Public Utility Commission & YES & outside & $x$ & $x$ & $x$ \\
\hline UT & Utah Public Service Commission & NO & & & & \\
\hline VT & Vermont Public Service Board & YES & inside \& outside & $x$ & $x$ & $x$ \\
\hline VA & Virginia State Corporation Commission & NO & & & & \\
\hline WA & Washington Utilities \& Transportation Commission & NO & inside \& outside & & & \\
\hline wv & West Virginia Public Service Commission & LTD & & & & \\
\hline W! & Wisconsin Public Service Commission & YES & inside \& outside & $x$ & $x$ & $x$ \\
\hline WY & Wyoming Public Service Commission & YES & outside & $x$ & & \\
\hline
\end{tabular}

1 Rate Schedule.

2 Rates Only.

- Annual revenue increase greater than 12 percent.

Note: There are no publicly owned electric utilities in the District of Columbia. The District of Columbia Public Service Commission does regulate invester-owned electric utilities.

Source: National Association of Regulatory Utility Commissioners, 1990 Annual Report on Utillty and Carrier Regulation, publication. 


\section{Appendix E}

\section{Technical Notes}


, 


\section{Appendix E}

\section{Technical Notes}

\section{Sources of Data}

\begin{abstract}
The Financial Statistics of Major U.S. Publicly Owned Electric Utilities (FSMPO) publication is prepared by the Management Survey Division; Office of Coal, Nuclear, Electric and Alternate Fuels; Energy Information Administration (EIA); U.S. Department of Energy (DOE). Detailed financial data published in this publication are from the Form EIA-412, "Annual Report of Public Electric Utilities. " Other summary data are provided from the Form EIA-861, "Annual Electric Utility Report," and the Rural Electrification Administration statistics taken from the Statistical Report, Rural Electric Borrowers publication for the years 1987 through 1993. A brief summary of surveys in this publication is presented below.
\end{abstract}

\section{Form EIA-412}

The Form EIA-412 is used annually to collect accounting, financial, and operating data from major publicly owned electric utilities in the United States. For the fiscal or calendar year that ended December 31,1993 , the criteria used to select the respondents for this survey resulted in submissions by 483 publicly owned and 8 Federal electric utilities. Those publicly owned electric utilities engaged in the generation, transmission, or distribution of electricity which had 120,000 megawatthours of sales to ultimate consumers and/or 120,000 megawatthours of sales for resale for the 2 previous years, as reported on the Form EIA-861, "Annual Electric Utility Report," must submit the Form EIA-412. Summary data are also published in the Electric Power Annual .

Federally owned electric utilities are required to file the Form EIA-412. The financial data for the U.S. Army Corps of Engineers (except for Saint Mary's Falls at Sault St. Marie, Michigan), the U.S. International Boundary and Water Commission, and the U.S. Department of Interior Bureau of Reclamation were collected on the Form EIA-412 from the Federal power marketing administrations.

Instrument and Design History. The FPC created the Form 1M in 1961 as a mandatory survey. It became the responsibility of the EIA in October 1977 when the FPC was merged with DOE. Since 1979, the FPC Form $1 \mathrm{M}$ has been superseded by the Economic Reg- ulatory Administration (ERA) Form ERA-412, and in January 1980 by the Form EIA-412.

Data Processing. The processing of data reported on this survey is the responsibility of the Management Survey Division, Office of Coal, Nuclear, Electric and Alternate Fuels. The completed surveys are due on or before the last day of the third month following the close of the fiscal year. Nonresponse follow-up procedures are used to attain 100 percent response. Automated systems are used to edit data from the surveys using deterministic and statistical checks. When all data have passed the edit process, the data are aggregated into a master file used as input to the publication.

\section{Form EIA-861}

The Form EIA-861 is a mandatory census of electric utilities in the United States, its territories, and Puerto Rico. The survey is used to collect information on power production and sales data from 3,235 electric utilities in the United States. (3,239 electric utilities if U.S. territories are included.) These data collected are used to maintain and update the electric utility frame data base for the EIA. This data base supports queries from the Executive Branch, Congress, other public agencies, and the general public. Summary data from the Form EIA-861 are also contained in the Electric Power Monthly, the Electric Power Annual, the Electric Sales and Revenue, the Annual Outlook for U.S. Electric Power, the Financial Statistics of Major U.S. Investor-Owned Electric Utilities and the Financial Statistics of Major U.S. Publicly Owned Electric Utilities. These reports present aggregate totals for electric utilities on a national level by State and by ownership type.

Instrument and Design History. The Form EIA-861 was implemented in January 1985 to collect data as of year-end 1984. The Federal Administration Act of 1974 (Public Law 93-275) defines the legislative authority to collect these data.

Data Processing. The Form EIA-861 is mailed to the respondents in February to collect data for the preceding calendar year. The completed surveys are returned to the EIA by May 1 . These data are manually edited before being entered into the interactive on-line system. Internal edit checks are performed to verify that current data total across and between schedules, and are comparable to data reported the 
previous year. Edit checks are also performed to compare data reported on the Form EIA-861 and similar data reported on the Form EIA-826, "Monthly Electric Utility Sales and Revenue Report with State Distributions," the FERC Form 1, "Annual Report of Major Electric Utilities, Licensees and Others," and the Form EIA-412, "Annual Report of Public Electric Utilities." These are utility-level checks. Respondents are called to clarify reported data and to obtain missing data.

\section{Rural Electrification Administration}

The Rural Electrification Administration (REA) in the U.S. Department of Agriculture is authorized to provide long-term financing and guarantee long-term loans for utilities supplying power to rural America. Borrowing electric utilities file the REA Form 7, "Financial and Statistical Report" and the REA Form 12a through 12i, "Electric Power Supply Borrowers" or the REA Form 12c through 12g, "Electric Distribution Borrowers with Generating Facilities." Data are provided on a yearly basis. Other revenue and expense statistics show the year's financial operations. For 1993, borrowers' operations data are based on the financial and operating statements of 909 active borrowers, of which 855 were distribution borrowers and 54 were power supply borrowers. Operations of cooperative borrowers systems are based on reports submitted by borrowers. The reports are subject to possible revisions from audits and adjustments. No attempt has been made to consolidate (in the technical accounting sense) the borrowers' accounts in the summary statement appearing in this publication. The combined totals represent the sum of all accounts as reported by the individual borrowers.

\section{Quality of Data}

The Office of Coal, Nuclear, Electric, and Alternate Fuels (CNEAF) is responsible for routine data improvement and quality assurance. All operations at CNEAF are done in accordance with formal standards established by EIA. Data improvement efforts include verification of data-keyed input by automatic computerized methods, editing by subject matter specialists, and follow-up on nonrespondents. CNEAF reviews the structure of information requirements and proposed designs for new and revised data collection surveys and systems. Once started, the performance of working data collection systems is also validated. Computerized respondent data files are checked to identify those respondents which fail to respond to the survey. EIA tries to obtain required information by encouraging the cooperation of nonrespondents. By law, nonrespondents may be fined or penalized for not filing a mandatory EIA data survey.

CNEAF screens submitted surveys for completeness, and keys the data onto computer tapes for storage. These data are transferred to random access databases for computer processing. The information coded on the computer tapes is manually spot-checked against the surveys to certify accuracy of the tapes. To ensure EIA quality standards, formulas using the past history of data values in the data base have been designed and implemented to automatically check data input for errors. Data values falling outside the ranges prescribed in the formulas are verified by telephoning respondents to resolve any discrepancies.

Conceptual problems affecting the quality of data are discussed in the report, An Assessment of the Quality of Selected EIA Data Series : Electric Power Data. This report is published by the Office of Statistical Standards in EIA.

\section{Data Entry System}

Manual editing of the reported data is completed prior to data entry. Additional edit checks of the data are performed through computer programs. The program edits include both deterministic checks, in which records are checked for the presence of data in required fields, and statistical checks, in which data are checked against a range of values based on historical data values and for logical or mathematical consistency with data elements reported in the survey. Discrepancies found in the data, as a result of these checks, are resolved either by the processing office or by further information obtained from a telephone call to the respondent.

\section{Confidentiality of the Data}

Data collected on the surveys for this publication are not confidential.

\section{Rounding Rules for Data}

Given a number with $r$ digits to the left of the decimal and $d+t$ digits in the fraction part, with $d$ being the place to which the number is to be rounded and $t$ being the remaining digits which will be truncated. This number is then rounded to $\mathrm{r}+\mathrm{d}$ digits by adding five to the $(r+d+1)$ th digit when the number is positive or by subtracting five when the number is negative. The $t$ digits are then truncated at the $(r+d+1)$ th digit. The symbol for a rounded number truncated to zero is $\left(^{*}\right)$.

\section{Data Correction and Revision Procedures}

The CNEAF has adopted the following policy with respect to the revision and correction of recurrent data in energy publications :

- Annual survey data collected by this office are published either as preliminary or final when first appearing in a data report. Data initially released as preliminary will be so noted in the report. These data will be revised, if necessary, and declared final in the next publication of the data.

- All monthly and quarterly survey data collected by this office are published as preliminary. These data are revised only after the completion of the 12 -month cycle of the data. No revisions are made to the published data before this. 
- The magnitudes of changes due to revisions experienced in the past will be included in the data reports, so that the reader can assess the accuracy of the data.

- After data are published as final, corrections will be made only in the event of a greater than one percent difference at the national level. Corrections for differences that are less than the before-mentioned threshold are left to the discretion of the Office Director.

In accordance with this policy, the CNEAF has not revised any prior year summary data in this publication.

\section{Formulas and Calculations}

\section{Composite Financial Indicators for Selected Publicly Owned Electric Utilities}

Total Electric Utility Plant per Dollar of Revenue =

$$
\frac{\sum_{i}\left(T E U P_{i}\right)}{\sum_{i}\left(E U O R_{i}\right)}
$$

where TEUP is the Total Electric Utility Plant for the $i^{\text {th }}$ public utility; and, $E U O R$ is the Electric Utility Operating Revenue for the $i^{\text {th }}$ public utility.

Current Assets to Current Liabilities =

$$
\frac{\sum_{i}\left(C A_{i}\right)}{\sum_{i}\left(C L_{i}\right)}
$$

where $C A_{i}$ are the Current and Accrued Assets for the $i^{\text {th }}$ public utility; and, $C L_{i}$ are the Current and Accrued Liabilities for the $i^{\text {th }}$ public utility.

Total Electric Utility Plant as a Percent of Total Assets $=$

$$
\frac{\sum_{l}\left(T E U P_{i}\right)}{\sum_{i}\left(T A_{i}\right)} \times 100
$$

where $T E U P_{i}$ is the Total Electric Utility Plant for the $i^{t h}$ public utility; and, $T A_{i}$ are the Total Assets for the $i^{\text {th }}$ public utility.

Net Electric Utility Plant as a Percent of Total Assets =
$\frac{\sum_{i}\left(N E U P_{i}\right)}{\sum_{i}\left(T A_{i}\right)} \times 100$,

where $N E U P_{i}$ is the Net Electric Utility Plant for the $i^{\text {th }}$ public utility; and, $T A_{i}$ is the Total Assets for the $i^{t h}$ public utility.

Debt as a percent of Total Liabilities =

$\frac{\sum_{i}\left(D_{i}\right)}{\sum_{i}\left(T L_{i}\right)} \times 100$

where $D_{i}$ is the Debt for the $i^{\text {th }}$ public utility; and, $T L_{i}$ is the Total Liabilities for the $i^{t h}$ public utility.

Depreciation, Amortization and Depletion as a Percent of Total Electric Utility Plant =

$$
\frac{\sum_{i}\left(D A D_{i}\right)}{\sum_{i}\left(T E U P_{i}\right)} \times 100,
$$

where $D A D_{i}$ is the Depreciation, Amortization and Depletion for the $i^{\text {th }}$ public utility; and, TEUP is the Total Electric Plant for the $i^{\text {th }}$ public utility.

Electric Operation and Maintenance Expenses as a Percent of Electric Utility Operating Revenues =

$$
\frac{\sum_{i}\left(E O M E_{i}\right)}{\sum_{i}\left(E U O R_{i}\right)} \times 100
$$

where $E O M E_{i}$ is the Electric Operation and Maintenance Expenses for the $i^{t h}$ public utility; and, $E U O R_{i}$ is the Electric Utility Operating Revenues for the $i^{\text {th }}$ public utility.

Electric Depreciation and Amortization as a Percent of Electric Utility Operating Revenues =

$$
\frac{\sum_{i}\left(E D A_{i}\right)}{\sum_{i}\left(E U O R_{i}\right)} \times 100,
$$

where $E D A_{i}$ is Electric Depreciation and Amortization for the $i^{\text {th }}$ public utility; and, EUOR ${ }_{i}$ is the Electric Utility Operating Revenues for the $i^{t h}$ public utility.

Taxes and Tax Equivalents as a Percent of Electric Utility Operating Revenues = 


$$
\frac{\sum_{i}\left(T T E_{i}\right)}{\sum_{i}\left(E U O R_{i}\right)} \times 100
$$

where $T T E_{i}$ are the Taxes and Tax Equivalents for the $i^{\text {th }}$ public utility; and, $E U O R_{i}$ is the Electric Utility Operating Revenues for the $i^{\text {th }}$ public utility.

Interest on Long-term Debt as a Percent of Electric Utility Operating Revenues =

$$
\frac{\sum_{i}\left(I L T D_{i}\right)}{\sum_{i}\left(E U O R_{i}\right)} \times 100,
$$

where $I L T D_{i}$ is the Interest on Long-term Debt for the $i^{t h}$ public utility; and, $E U O R_{i}$ is the Electric Utility Operating Revenues for the $i^{\text {th }}$ public utility.

Net Income as a Percent of Electric Utility Operating Revenues $=$

$$
\frac{\sum_{i}\left(N I_{i}\right)}{\sum_{i}\left(E U O R_{i}\right)} \times 100,
$$

where $N I_{i}$ is the Net Income for the $i^{\text {th }}$ public utility; and, $E U O R_{i}$ is the Electric Utility Operating Revenues for the $i^{\text {th }}$ public utility.

Purchase Power Cents Per Kilowatthour =

$$
\frac{\sum_{i}\left(P P C_{i}\right)}{\sum_{i}\left(P P K_{i}\right)} \times 10,
$$

where $P P C_{i}$ is the Purchase Power Costs (in cents) for the $i^{\text {th }}$ public utility; and, $P P K_{i}$ is the Purchased Power Kilowatthours for the $i^{\text {th }}$ public utility.

Generated Cents Per Kilowatthour =

$$
\frac{\sum_{i}\left(T G C_{i}\right)}{\sum_{i}\left(T G K_{i}\right)} \times 10,
$$

where $T G C_{i}$ is the Total Generation Costs (in cents) for the $i^{t h}$ public utility; and, $T G K_{i}$ is the Total Generated Kilowatthours for the $i^{\text {th }}$ public utility.

Total Power Suppiy Per Kilowatthour Sold =

$$
\frac{\sum_{i}\left(T P C_{i}\right)}{\sum_{i}\left(T P K_{i}\right)} \times 10,
$$

where $T P C_{i}$ is the Total Generation and Purchase Power Cost for the $i^{\text {th }}$ public utility; and, $T P K_{i}$ is the Total Generated and Purchased Power Kilowatthours Sold for the $i^{\text {th }}$ public utility.

\section{General Information}

\section{Use of the Glossary}

The terms in the glossary have been defined for general use. Restrictions on the definitions, as used in these data collection systems, are included in each definition when necessary to define the terms as they are used in this report.

\section{Obtaining Copies of Data}

Upon EIA approval of the Financial Statistics of Major U.S. Publicly Owned Electric Utilities, these data are available for public use.

Computer listings are obtained by submitting a written request to :

Energy Information Administration

Survey Management Division, EI-523

U. S. Department of Energy

1000 Independence Avenue, S.W.

Washington, DC 20585

(202) 254-5440

FAX (202) 254-5765

Magnetic tapes may be purchased by using Visa, Master Card, or American Express cards, as well as money orders or checks payable to the National Technical Information Service (NTIS). Purchasers may also use NTIS and Government Printing Office deposit accounts. To place an order, contact :

National Technical Information Service (NTIS)

Office of Data Base Services

U.S. Department of Commerce

5285 Port Royal Road

Springfield, Virginia 22161

(703) $487-4650$

FAX (703) 321-8547

Personal computer diskettes $\left(31 / 2^{\prime \prime}\right.$ or $\left.51 / 4^{\prime \prime}\right)$ may be purchased by using Visa or Master Card, as well as money orders or checks payable to the Superintendent of Documents. Purchasers may also use Government Printing Office deposit accounts. To place an order, contact :

Superintendent of Documents

U.S. Government Printing Office

Attn : Electronic Products Sales Coordinator

P.O. Box 37080

Washington, DC 20013-7082

(202) $512-1530$

FAX (202) 512-1262 


\section{Glossary}

Accounting System. A method of recording accounting data for a utility or company or a method of supplying accounting information for controlling, evaluating, planning and decisionmaking.

Administrative and General Expenses. Expenses of an electric utility relating to the overall directions of its corporate offices and administrative affairs, as contrasted with expenses incurred for specialized functions. Examples include office salaries, office supplies, advertising, and other general expenses.

\begin{abstract}
Allowance for Funds Used During Construction (AFUDC). A noncash item representing the estimated composite interest costs of debt and a return on equity funds used to finance construction. The allowance is capitalized in the property accounts and included in income.

Amortization. The gradual write-off of an amount in an account by distributing such amount over a fixed period, over the life of the asset or liability to which it applies, or over the period during which it is anticipated the benefit will be realized.
\end{abstract}

Asset. An economic resource, tangible or intangible, which is expected to provide benefits to a business.

Average Stream Flow. The rate, usually expressed in cubic feet per second, at which water passes a given point in a stream over a set period of time.

Capacity. The amount of electric power delivered or required for which a generator, turbine, transformer, transmission circuit, station, or system is rated by the manufacturer.

Capacity (Purchased). The amount of energy and capacity available for purchase from outside the system.

Capital. The equity interest of the owners consisting of common stock, preferred stock, and retained earnings in the entity, that is the difference between assets and liabilities.

Capital (Financial). The line items on the right side of a balance sheet, that include debt, preferred stock, and common equity. A net increase in assets must be financed by an increase in one or more forms of capital.

Capital Intensive. A condition in which investment in plant and equipment is relatively large compared to labor and to operation and maintenance expenses.

Capitalization. The long-term sources of funds comprising an entity's total capitalization; that is, the long- term debt, preferred stock, and common equity. The short-term sources of capital are not included.

Capitalization Ratio. The percentage of debt, or preferred stock, or common stock, or other equity to the total capital structure of an entity.

Circuit. A conductor or a system of conductors through which electric current flows.

Circuit-Mile. The total length in miles of separate circuits regardless of the number of conductors used per circuit.

Classes of Service. Consumers grouped by similar characteristics in order to be identified for the purpose of setting a common rate for electric service. Usually classified into groups identified as residential, commercial, industrial and other.

Commercial. The commercial sector is generally defined as nonmanufacturing business establishments, including hotels, motels, restaurants, wholesale businesses, retail stores, and health, social, and educational institutions. The utility may classify commercial service as all consumers whose demand or annual use exceeds some specified limit. The limit may be set by the utility based on the rate schedule of the utility.

Commercial and Industrial. Classes of service supplied to a similar grouping of consumers. These customer groupings are usually subdivided into smaller segments by classifying such consumers as commercial or industrial using the Federal Government's Office Of Management and Budget's Standard Industrial Classification Guide and/or a scale of energy usage as yardsticks; other consumers are reclassified as commercial or industrial when their demands or annual use exceeds some specified limit. These limits are generally based on a utility's rate schedules, except for those consumers who are supplied under special contracts or agreements calling for particular services.

Common Equity (Book Value). The retained earnings and common stock earnings plus the balances in common equity reserves and all other common stock accounts. This also includes the capital surplus, the paid-in surplus, the premium on common stocks, except those balances specifically related to preferred or preference stocks; less any common stocks held in the treasury.

Condenser Cooling Water. A source of water external to a boiler's feed system is passed through the steam leaving the turbine in order to cool and condense the steam. This reduces the steam's exit pressure and recaptures its heat, which is then used to preheat fluid entering the boiler, thereby increasing the plant's thermodynamic efficiency. 
Conditionally Effective Rates. An electric rate schedule that has been put into effect by the FERC subject to refund pending final disposition or refiling.

Construction Costs (of the electric power industry). All direct and indirect costs incurred in acquiring and constructing electric utility plant and equipment and proportionate shares of common utility plant. Included are the cost of land and improvements, nuclear fuel and spare parts, allowance for funds used during construction, general overheads capitalized, less the cost of acquiring plant and equipment previously operated in utility service.

Construction Expenditures (of the electric power industry). The gross expenditures for construction costs, including the cost of replacing worn-out plants, and electric construction costs and land held for future use.

Construction Work In Progress (CWIP). The balance shown on a utility's balance sheet for construction work not yet completed but in process. This balance line item may or may not be included in the rate base.

Conventional Hydroelectric Plant. A plant in which all of the power is produced from natural streamflow as regulated by available storage.

Cooperative Electric Utility. An electric utility legally established to be owned by and operated for the benefit of those using its service. The utility company will generate, transmit, and/or distribute supplies of electric energy to a specified area not being serviced by another utility. Such ventures are generally exempt from Federal income tax laws. Most electric cooperatives have been initially financed by the Rural Electrification Administration, U.S. Department of Agriculture.

Cost. The amount paid to acquire resources, such as plant and equipment, fuel, or labor services.

Cost of Capital. The rate of return a utility must offer to obtain additional funds. The cost of capital varies with the leverage ratio, the effective income tax rate, conditions in the bond and stock markets, growth rate of the utility, its dividend strategy, stability of net income, the amount of new capital required, and other factors dealing with business and financial risks. It is a composite of the cost for debt interest, preferred stock dividends, and common stockholders' earnings that provide the facilities used in supplying utility service.

Cost of Debt. The interest rate paid on new increments of debt capital multiplied by 1 minus the tax rate.

Cost of Preferred Stock. The preferred dividend divided by the net price of preferred stock.

Cost of Retained Earnings. The residual of a utility's earnings over expenditures, including taxes and dividends, that are reinvested in its business. The cost of these funds is always lower than the cost of new equity capital, due to taxes and transactions costs. Therefore, the cost of retained earnings is the yield that retained earnings accrue upon reinvestment.

Cost of Service. A ratemaking concept used for the design and development of rate schedules to ensure that the filed rate schedules recover only the cost of providing the electric service at issue. These costs include operating and maintenance expenses, depreciation and amortization expenses, and income and other taxes found just and reasonable by the regulatory agency for ratemaking purposes plus, in the case of privately owned electric utilities, an allowance for a return on capital (usually computed by applying a rate of return to the rate base). This concept attempts to equate the cost incurred by the utility to the revenue received for the service provided to each of the consumer classes.

Current Assets. Cash and other assets that are expected to be turned into cash, sold, or exchanged within the normal operating cycle of the utility, usually one year. Current assets include cash, marketable securities, receivables, inventory and current prepayments.

Current Liabilities. A debt or other obligation that must be discharged within one year or the normal operating cycle of the utility by expending a current asset or the incurrence of another short-term obligation. Current liabilities included account payable, short-term notes payable, and accrued expenses payable such as taxes and salaries payable.

Current Ratio. The ratio of current assets divided by current liabilities that shows the ability of a utility to pay its current obligations from its current assets. A measure of liquidity, the higher the current ratio, the more assurance that current liabilities can be paid.

Debt. Money or services owed through a legal obligation to an outside party. Debt may be classified short-term which is one year or less or long-term which is more than one year.

Deferred Cost. An expenditure not recognized as a cost of operation of the period in which incurred, but carried forward to be written off in future periods.

Deferred Fuel Costs. An expenditure for fuel that is not recognized for bookkeeping practices as a cost in the operating period incurred, but carried forward to be written off in future periods.

Deferred Income Tax (Liability). A liability in the balance sheet representing the additional Federal income taxes that would have been due if a utility had not been allowed to compute tax expenses differently for income tax reporting purposes than for ratemaking purposes.

Depreciation. Charges made against income for distributing the cost of a tangible asset, so as to allocate it systematically across the period in which the asset is used. 
Design Head. The achieved river, pondage, or reservoir surface height (forebay elevation) that provides the water level to produce the full flow at the gate of the turbine in order to attain the manufacturer's installed nameplate rating for generation capacity.

Diesel-Electric Plant. A generating station that uses diesel engines to drive its electric generators.

Distribution System. The portion of an electric system that is dedicated to delivering electric energy to an end user.

Docket. A formal record of a Federal Energy Regulatory Commission proceeding. These records are available for inspection and copying by the public. Each individual case proceeding is identified by an assigned number.

Economy of Scale. The principle that larger production facilities have lower unit costs than smaller facilities.

Electric Expenses. The cost of labor, material, and expenses incurred in operating a facility's prime movers, generators, auxiliary apparatus, switching gear, and other electric equipment for each of the points where electricity enters the transmission or distribution grid.

Electric Operating Expenses. Summation of electric operation-related expenses, such as operation expenses, maintenance expenses, depreciation expenses, amortization, taxes other than income taxes, Federal income taxes, other income taxes, provision for deferred income taxes, provision for deferred income-credit, and investment tax credit adjustment.

Electric Plant (Financial). Assets comprising land, building, and equipment permanently employed.

Electric Power Industry. The privately, publicly, federally and cooperatively owned electric utilities of the United States taken as a whole. This includes all electric systems serving the public: regulated investorowned electric utility companies; Federal power projects; State, municipal, and other governmentowned systems, including electric public utility districts; electric cooperatives, including generation and transmission entities. Excluded from this definition are the special purpose electric facilities or systems that do not offer service to the public.

Electric Power System. An individual electric power entity -- a company, an electric cooperative, a public electric supply corporation as the Tennessee Valley Authority, a similar Federal department or agency as the Bonneville Power Administration, the Bureau of Reclamation or the Corps of Engineers, a municipally owned, electric department offering service to the public, or an electric public utility district (a "PUD "); also a jointly owned electric supply project such as the Keystone.

Electric Rate Schedule. A statement of the electric rate and the terms and conditions governing its appli- cation, including attendant contract terms and conditions that have been accepted by a regulatory body with appropriate oversite authority.

Electric Utility. A corporation, person, agency, authority, or other legal entity or instrumentality that owns and/or operates facilities within the United States, its territories, or Puerto Rico for the generation, transmission, distribution, or sale of electric energy primarily for use by the public and files forms listed in the Code of Federal Regulations, Title 18, Part 141. Facilities that qualify as cogenerators or small power producers under the Public Utility Regulatory Policies Act (PURPA) are not considered electric utilities.

Electrical System Energy Losses. The amount of energy lost during generation, transmission, and distribution of electricity, including plant and unaccounted for use.

End User. The final consumer of electricity.

Energy. The capacity for doing work as measured by the capability of doing work (potential energy) or the conversion of this capability to motion (kinetic energy). Energy has several forms, some of which are easily convertible and can be changed to another form useful for work. Most of the world's convertible energy comes from fossil fuels that are burned to produce heat that is then used as a transfer medium to mechanical or other means in order to accomplish tasks. Electrical energy is usually measured in kilowatthours, while heat energy is usually measured in British thermal units.

Energy Deliveries. Energy generated by one electric utility system and delivered to another system through one or more transmission lines.

Energy Information Administration (EIA). An independent agency within the U.S. Department of Energy that develops surveys, collects energy data, and does analytical and modeling analyses of energy issues. The Agency must satisfy the requests of Congress, other elements within the Department of Energy, Federal Energy Regulatory Commission, the Executive Branch, its own independent needs, and assist the general public, or other interest groups, without taking a policy position.

Energy Loss. The difference between energy input and output as a result of transfer of energy between two points.

Energy Receipts. Energy generated by one electric utility system and received by another system through one or more transmission lines.

Equity (Financial). Ownership of shareholders in a corporation represented by stock.

Equity Capital. The sum of capital from retained earnings and the issuance of stocks. 
Expenditure. The incurrence of a liability to obtain an asset or service.

Federal Electric Utility. A utility that is either owned or financed by the Federal Government.

Federal Energy Regulatory Commission (FERC). A quasi-independent regulatory agency within the Department of Energy having jurisdiction over interstate electricity sales, wholesale electric rates, hydroelectric licensing, natural gas pricing, oil pipeline rates, and gas pipeline certification.

Federal Power Act. Enacted in 1920, and amended in 1935, the Act consists of three parts. The first part incorporated the Federal Water Power Act administered by the former Federal Power Commission, whose activities were confined almost entirely to licensing non-Federal hydroelectric projects. Parts II and III were added with the passage of the Public Utility Act. These parts extended the Act's jurisdiction to include regulating the interstate transmission of electrical energy and rates for its sale as wholesale in interstate commerce. The Federal Energy Regulatory Commission is now charged with the administration of this law.

Federal Power Commission. The predecessor agency of the Federal Energy Regulatory Commission. The Federal Power Commission (FPC) was created by an Act of Congress under the Federal Water Power Act on June 10, 1920. It was charged originally with regulating the electric power and natural gas industries. The FPC was abolished on September 20, 1977, when the Department of Energy was created. The functions of the FPC were divided between the Department of Energy and the Federal Energy Regulatory Commission.

FERC. The Federal Energy Regulatory Commission.

FERC Guidelines. A compilation of the Federal Energy Regulatory Commission's enabling statutes, procedural and program regulations, and orders, opinions and decisions.

Financial Accounting Standards Board (FASB). An independent board responsible, since 1973, for establishing generally accepted accounting principles. Its official pronouncement are called "Statements of Financial Accounting Standards" and "Interpretations of Financial Accounting Standards."

Fiscal Year. A financial year based on a predetermined starting date. The Federal Government's financial year runs from October 1 through September 30.

Fixed Asset Turnover. A ratio of revenue to fixed assets which is a measure of the productivity and efficiency of property, plant, and equipment in generating revenue. A higher turnover reflects positively on the entity's ability to utilize properly its fixed assets in business operations.
Fixed Assets. Tangible property used in the operations of an entity, but not expected to be consumed or converted into cash in the ordinary course of events. With a life in excess of one year, not intended for resale to customers, and subject to depreciation (with the exception of land), they are usually referred to as property, plant, and equipment.

Fixed Charge Coverage. The ratio of earnings available to pay so-called fixed charges to such fixed charges. Fixed charges include interest on funded debt, including leases, plus the related amortization of debt discount, premium and expense. Earnings available for fixed charges may be computed before or after deducting income taxes. Occasionally credits for the "allowance for fund used during construction " are excluded from the earnings figures. The precise procedures followed in calculating fixed charge or interest coverages vary widely.

Fixed Cost (expense). An expenditure or expense that does not vary with volume level of activity.

Fixed Operating Costs. Costs other than those associated with capital investment that do not vary with the operation, such as maintenance and payroll.

Fossil Fuel. Any naturally occurring organic fuel, such as petroleum, coal, and natural gas.

Fossil-Fuel Plant. A plant using coal, petroleum, or gas as its source of energy.

Fuel Expenses. These costs include the fuel used in the production of steam or driving another prime mover for the generation of electricity. Other associated expenses include unloading the shipped fuel and all handling of the fuel up to the point where it enters the first bunker, hopper, bucket, tank, or holder in the boiler-house structure.

Gas Turbine Plant. A plant in which the prime mover is a gas turbine. A gas turbine consists typically of an axial-flow air compressor, one or more combustion chambers, where liquid or gaseous fuel is burned and the hot gases are passed to the turbine and where the hot gases expand to drive the generator and are then used to run the compressor.

Generally Accepted Accounting Principles (GAAP). Defined by the FASB as the conventions, rules, and procedures necessary to define accepted accounting practice at a particular time; includes both broad guidelines and relatively detailed practices and procedures.

Generating Unit. Any combination of physically connected generator(s), reactor(s), boiler(s), combustion turbine(s), or other prime mover(s) operated together to produce electric power.

Generator Nameplate Capacity. The full-load continuous rating of a generator, prime mover, or other electric power production equipment under specific conditions as designated by the manufacturer. Installed generator nameplate rating is usually indi- 
cated on a nameplate physically attached to the generator.

Geothermal Plant. A plant in which the prime mover is a steam turbine. The turbine is driven either by steam produced from hot water or by natural steam that derives its energy from heat found in rocks or fluids at various depths beneath the surface of the earth. The energy is extracted by drilling and/or pumping.

Grid. The layout of an electrical distribution system.

Gross Generation. The total amount of electric energy produced by a generating facility, as measured at the generator terminals.

Head. The product of the water's weight and a usable difference in elevation gives a measurement of the potential energy possessed by water.

Historical Plant Cost of Equipment. The charges for equipment assigned to power production include: the net purchased price thereof; sales taxes; investigation and inspection expenses necessary for such purchases, any expenses of transportation when borne by the utility; labor employed charges; materials and supplies consumed; and expenses incurred by the utility in unloading and placing the equipment in readiness to operate.

Historical Plant Cost of Land and Land Rights. The cost of land purchased or the fees paid by the utility for rights, interests, and privileges to be held by the utility in land owned by others. The types of rights acquired include leaseholds, easements, water and water power rights, rights-of-way, and other like interests.

Historical Plant Cost of Structures and Improvements (Expenses). The cost of all buildings and facilities to house, support, or safeguard property or persons, including all fixtures permanently attached to and made a part of building. Also includes the cost incurred in connection with the first clearing and grading of land and rights-of-ways.

Holding Company. A company that confines its activities to owning stock in, and supervising management of, other companies. The Securities and Exchange Commission, as administrator of the Public Utility Holding Company Act of 1935, defines a holding company as "a company which directly or indirectly owns, controls or holds 10 percent or more of the outstanding vóting securities of a holding company" (15 USC 79b, par. a (7)).

Hydroelectric Energy. The production of electricity from kinetic energy in flowing water.

Hydroelectric Plant. A plant in which the turbine generators are driven by falling water.

Hydroelectric Plant Capacity. This capacity figure is a function of fluid flow losses, hydraulic turbines, head, and water flow. The minimum net head limits the firm capacity of the plant.

Hydroelectric Power. The harnessing of flowing water to produce mechanical or electrical energy.

Independent Power Producer. A corporation, person, agency, authority, or other legal entity or instrumentality that owns electric generating capacity and is a wholesale electric producer without a designated franchised service area. The entity is not a qualifying facility as defined in the Public Utility Regulatory Policies Act of 1978.

Industrial. The industrial sector is generally defined as manufacturing, construction, mining, agriculture, fishing and forestry establishments Standard Industrial Classification (SIC) codes 01-39. The utility may classify industrial service using the SIC codes, or based on demand or annual usage exceeding some specified limit. The limit may be set by the utility based on the rate schedule of the utility.

Instantaneous Peak Demand. The maximum demand at the instant of greatest load.

Interchange Energy. Kilowatthours delivered to or received by one electric utility or pooling system from another. Settlement may be by payment, returned in kind at a later time or accumulated as energy balances until the end of the stated period.

Interconnection. Two or more electric systems having a common transmission line that permits a flow of energy between them. The physical connection of the electric power transmission facilities allows for the sale or exchange of energy.

Interdepartmental Service (Electric). Interdepartmental service includes amounts charged by the electric department at tariff or other specified rates for electricity supplied by it to other utility departments.

Interest Coverage Ratio. The number of times that fixed interest charges were earned. It indicates the margin of safety of interest on fixed debt. The timesinterest-earned ratio is calculated using net income before and after income taxes; and the credits of interest charged to construction being treated as other income. The interest charges include interest on longterm debt, interest on debt of associated companies, and other interest expense.

Interlocking Directorates. The holding of a significant position in management or a position on the corporate board of a utility, while simultaneously holding a comparable position with another utility, or with a firm doing business with the utility.

Internal Combustion Plant. A plant in which the prime mover is an internal combustion engine. An internal combustion engine has one or more cylinders in which the process of combustion takes place, converting energy released from the rapid burning of a fuel-air mixture into mechanical energy. Diesel or gasfired engines are the principal types used in electric 
plants. The plant is usually operated during periods of high demand for electricity.

Investor-Owned Electric Utility. A class of utility that is investor owned and organized as a tax paying business, usually financed by the sales of securities in the capital market.

Kilowatt $(\mathrm{kW})$. One thousand watts.

Kilowatthour (kWh). One thousand watthours.

Leverage Ratio. A measure that indicates the financial ability to meet debt service requirements and increase the value of the investment to the stockholders. (i.e. the ratio of total debt to total assets).

Liability. An amount payable in dollars or by future services to be rendered.

Licensees. Entity that has been granted permission to engage in an activity otherwise unlawful (i.e. hydropower project).

Line Loss. Energy kilowatthours lost in transmission and distribution lines.

Load (Electric). The amount of electric power delivered or required at any specific point or points on a system. The requirement originates at the energyconsuming equipment of the consumers.

Long-term Debt. Debt securities or borrowings having a maturity of more than one yeâr.

Maintenance Expenses. That portion of operating expenses consisting of labor, materials, and other direct and indirect expenses incurred for preserving the operating efficiency and/or physical condition of utility plants used for power production, transmission, and distribution of energy.

Maximum Demand. The greatest of all demands of the load that has occurred within a specified period of time.

Mcf. One thousand cubic feet.

Megawatt (MW). One million watts.

Megawatthour (MWh). One million watthours.

Mill. A monetary cost and billing unit used by utilities; it is equal to $1 / 1000$ of the U.S. dollar (equivalent to $1 / 10$ of $I$ cent).

Multiple Purpose Reservoir. Stored water and its usage governed by advanced water resource conservation practices to achieve more than one water control objective. Some of the objectives include flood control, hydro- electric power development, irrigation, recreation usage, and wilderness protection.

Municipality. (As defined in section 3, paragraph (7) of the Federal Power Act, P.L. 66-280 as amended) A city, county, irrigation district, drainage district, or other political subdivision or agency of a State competent under the laws thereof to carry on the business of developing, transmitting, utilizing, or distributing power (41 Stat. 1064; 49 Stat. 838; 16 U.S.C. 796(7)).

Net Generation. Gross generation minus plant use from all electric utility owned plants. The energy required for pumping at a pumped-storage plant is regarded as plant use and must be deducted from the gross generation.

Net Income. The excess of all revenues and gains for a period over all expenses and losses of the period.

Nonutility Power Producer. A corporation, person, agency, authority, or other legal entity or instrumentality that owns electric generating capacity and is not an electric utility. Nonutility power producers include qualifying cogenerators, qualifying small power producers, and other nonutility generators (including independent power producers) without a designated franchised service area, and which do not file forms listed in the Code of Federal Regulations, Title 18, Part 141.

Nuclear Fuel. Fissionable materials that have been enriched to such a composition that, when placed in a nuclear reactor, will support a self-sustaining fission chain reaction, producing heat in a controlled manner for process use.

Nuclear Power Plant. A facility in which heat produced in a reactor by the fissioning of nuclear fuel is used to drive a steam turbine.

Nuclear Reactor. An apparatus in which the nuclear fission chain can be initiated, maintained, and controlled so that energy is released at a specific rate. The reactor includes fissionable material (fuel), such as uranium or plutonium; fertile material; moderating material (unless it is a fast reactor); a heavy-walled pressure vessel; shielding to protect personnel; provision for heat removal; and control elements and instrumentation.

Ohm. The unit of measurement of electrical resistance. The resistance of a circuit in which a potential difference of 1 volt produces a current of 1 ampere.

Operating Expenses. Expenses related to utility operations, which include operation and maintenance expenses, provisions for depreciation and amortization, taxes other than income taxes, income taxes, provision for deferred income taxes, income taxes deferred in prior years-- credit and investment tax credit adjustments--net.

Operating Income. Operating revenues less operating expenses.

Operation Expenses. The components of power production expenses that incur cost for operations that are directly related to producing electricity. The major item is almost always fuel that has to be burned to generate the electricity. 
Operation Supervision and Engineering (Expenses). These expenses include the cost of labor and expenses incurred in the general supervision and direction of the operation of power generation stations. The supervision and engineering costs consist of the pay and expenses of staff and consultants engaged in supervising and directing the operation of each utility function. Direct supervision and engineering of activities, such as fuel handling, boiler room operations, and generator operations, are charged to the appropriate accounts.

Original Cost. The initial amount of money spent to acquire an asset. It is equal to the price paid, or present value of the liability incurred, or fair value of stock issued, plus normal incidental costs necessary to put the asset into its initial use.

Other Generation. Electricity originating from these sources: biomass, fuel cells, geothermal heat, solar power, waste, wind, and wood.

Owner's Equity. Interest of the owners in the assets of the business represented by capital contributions and retained earnings.

Parent Company. Company owning more than 50 percent of the voting shares of another company, called the subsidiary.

Plant. A facility at which are located prime movers, electric generators, and auxiliary equipment for converting mechanical, chemical, and/or nuclear energy into electric energy. A plant may contain more than one type of prime mover. Electric utility plants exclude facilities that satisfy the definition of a qualifying facility under the Public Utility Regulatory Policies Act of 1978.

Plant-Use Electricity. The electric energy used in the operation of a plant. This energy total is subtracted from the gross energy production of the plant; for reporting purposes the plant energy production is then reported as a net figure. The energy required for pumping at pumped-storage plants is, by definition, subtracted, and the energy production for these plants is then reported as a net figure.

Pole-Mile. A unit of measuring the simple length of a transmission line carrying electric conductors, without regard to the number of conductors carried.

Power. The rate at which energy is transferred. Electrical energy is usually measured in watts. Also used for a measurement of capacity.

Power (Electrical). An electric measurement unit of power called a voltampere is equal to the product of 1 volt and 1 ampere. This is equivalent to 1 Watt for a direct current system and a unit of apparent power is separated into real and reactive power. Real power is the work- producing part of apparent power that measures the rate of supply of energy and is denoted as Kilowatts $(\mathrm{KW})$. Reactive power is the portion of apparent power that does no work and is referred to as kilovars; this type of power must be supplied to most types of magnetic equipment, such as motors, and is supplied by generator or by electrostatic equipment. Voltamperes are usually divided by 1,000 and called kilovoltamperes (kVA). Energy is denoted by the product of real power and the length of time utilized; this product is expressed as kilowatthours.

Power Production Plant. All the land and land rights, structures and improvements, boiler or reactor vessel equipment, engines and engine-driven generator, turbogenerator units, accessory electric equipment, and miscellaneous power plant equipment are grouped together for each individual facility.

Preferred Stock. Ownership interests in a corporation which have been granted a preference, usually in the distribution of dividends before payment of dividends to common stockholders and assets in dissolution. It is usually nonvoting.

Price. The amount of money or consideration-in-kind for which a service is bought, sold, or offered for sale.

Prime Mover. The motive force that drives an electric generator (e.g., steam engine, turbine, or water wheel).

Production (Electric). Act or process of producing electric energy from other forms of energy; also, the amount of electric energy expressed in watthours (Wh).

Production Expenses. Costs incurred in the production of electric power that conform to the accounting requirements of the Operation and Maintenance Expense Accounts of the FERC Uniform System of Accounts.

Profit. The income remaining after all business expenses are paid.

Public Authority Service to Public Authorities. Public authority service includes electricity supplied and services rendered to municipalities or divisions or agencies of State or Federal governments, under special contracts or agreements or service classifications applicable only to public authorities.

Public Street and Highway Lighting. Public street and highway lighting includes electricity supplied and services rendered for the purposes of lighting streets, highways, parks, and other public places; or for traffic or other signal system service, for municipalities, or other divisions or agencies of State or Federal governments.

Public Utility District. Municipal corporations organized to provide electric service to both incorporated cities and towns and unincorporated rural areas. Public utility districts, sometimes called "People's Utility Districts" or "Public Power Districts," operate in six States.

Pumped-Storage Hydroelectric Plant. A plant that usually generates electric energy during peak-load periods by using water previously pumped into an ele- 
vated storage reservoir during off-peak periods when excess generating capacity is available to do so. When additional generating capacity is needed, the water can be released from the reservoir through a conduit to turbine generators located in a power plant at a lower level.

Purchased Power. Power purchased or available for purchase from a source outside the system.

Railroad and Railway Services. Railroad and railway services include electricity supplied and services rendered to railroads and interurban and street railways, for general railroad use, including the propulsion of cars or locomotives, where such electricity is supplied under separate and distinct rate schedules.

Rate Base. The value of property upon which a utility is permitted to earn a specified rate of return as established by a regulatory authority. The rate base generally represents the value of property used by the utility in providing service and may be calculated by any one or a combination of the following accounting methods: fair value, prudent investment, reproduction cost, or original cost. Depending on which method is used, the rate base includes cash, working capital, materials and supplies, and deductions for accumulated provisions for depreciation, contributions in aid of construction, customer advances for construction, accumulated deferred income taxes, and accumulated deferred investment tax credits.

Ratemaking Authority. A utility comimission's legal authority to fix, modify, approve, or disapprove rates, as determined by the powers given the commission by a State or Federal legislature.

Rate of Return. The ratio of net operating income earned by a utility is calculated as a percentage of its rate base.

Rate of Return on Rate Base. The ratio of net operating income earned by a utility calculated as a percentage of its rate base.

Refunding. Retirement of one security issue with proceeds received from selling another. Refunding provides for retiring maturing debt by taking advantage of favorable money market conditions.

Regulation. The governmental function of controlling or directing economic entities through the process of rulemaking and adjudication.

Residential. The residential sector is defined as private household establishments which consume energy primarily for space heating, water heating, air conditioning, lighting, refrigeration, cooking and clothes drying. The classification of an individual consumer's account, where the use is both residential and commercial, is based on principal use. For the residential class, do not duplicate consumer accounts due to multiple metering for special services (water, heating, etc.). Apartment houses are also included.
Retail. Sales covering electrical energy supplied for residential, commercial, and industrial end-use purposes. Other small classes, such as agriculture and street lighting, also are included in this category.

Retail Wheeling. An arrangement in which a utility transmits electricity from outside its service territory to a retail customer within its customer service territory.

Retained Earnings. The balance, either debit or credit, of appropriated or unappropriated earnings of an entity that are retained in the business.

Return on Common Equity. The net income less preferred stock dividends divided by the average common stock equity.

Return on Common Stock Equity. An entity's earnings available for 'common stockholders calculated as a percentage of its common equity capital.

Revenue. The total amount of money received by a firm from sales of its products and/or services, gains from the sales or exchange of assets, interest and dividends earned on investments, and other increases in the owner's equity except those arising from capital adjustments.

Revenue Requirement. The total revenue that the utility is authorized an opportunity to recover, which includes operating expenses and a reasonable return on rate base.

Rural Electrification Administration (REA). A lending agency of the U.S. Department of Agriculture, the REA makes self-liquidation loans to qualified borrowers to finance electric and telephone service to rural areas. The REA also finances the construction and operation of generating plants, electric transmission and distribution lines, or systems for the furnishing of initial and continued adequate electric services to persons in rural areas not receiving central station service.

Sales. The amount of kilowatthours sold in a given period of time; usually grouped by classes of service, such as residential, commercial, industrial, and other. Other sales include public street and highway lighting, other sales to public authorities and railways, and interdepartmental sales.

Sales for Resale. Energy supplied to other electric utilities, cooperatives, municipalities, and Federal and State electric agencies for resale to ultimate consumers.

Short-term Debt or Borrowings. Debt securities or borrowings having a maturity of less than one year.

Solar Energy. Energy produced from the sun's radiation.

Steam-Electric Plant (Conventional). A plant in which the prime mover is a steam turbine. The steam used to 
drive the turbine is produced in a boiler where fossil fuels are burned.

Steam Expenses. The cost of labor, materials, fuel, and other expenses incurred in production of steam for electric generation.

Steam from other Sources. Steam purchased, transferred from another department of the utility, or acquired from others under a joint-facility operating agreement.

1.

Steam Transferred-Credit., , The expenses of producing steam charged to others or to other utility departments under a joint operating arrangement.

Substation. Facility equipment that switches, changes, or regulates electric voltage.

Switching Station. Facility equipment used to tie together two or more electric circuits through switches. The switches are selectively arranged to permit a circuit to be disconnected, or to change the electric connection between the circuits.

System (Electric). Physically connected generation, transmission, and distribution facilities operated as an integrated unit under one central management, or operating supervision.

Transformer. An electrical device for changing the voltage of alternating current.

Transmission. The movement or transfer of electric energy over an interconnected group of lines and associated equipment between points of supply and points at which it is transformed for delivery to consumers, or is delivered to other electric systems. Transmission is considered to end when the energy is transformed for distribution to the consumer.
Transmission System (Electric). An interconnected group of electric transmission lines and associated equipment for moving or transferring electric energy in bulk between points of supply and points at which it is transformed for delivery over the distribution system lines to consumers, or is delivered to other electric systems.

Turbine. A machine for generating rotary mechanical power from the energy of a stream of fluid (such as water, steam, or hot gas). Turbines convert the kinetic energy of fluids to mechanical energy through the principles of impulse and reaction, or a mixture of the two.

Ultimate Consumer. A consumer that purchases electricity for its own use and not for resale.

Uniform System of Accounts. Prescribed financial rules and regulations established by the Federal Energy Regulatory Commission for utilities subject to its jurisdiction under the authority granted by the Federal Power Act.

Utility Generation. Generation by electric systems engaged in selling electric energy to the public.

Watt. The electrical unit of power. The rate of energy transfer equivalent to 1 ampere flowing under a pressure of 1 volt at unity power factor.

Watthour (Wh). An electrical energy unit of measure equal to 1 watt of power supplied to, or taken from, an electric circuit steadily for 1 hour.

Wheeling Service. The movement of electricity from one system to another over transmission facilities of intervening systems. Wheeling service contracts can be established between two or more systems. 